Prepared for the U.S. Department of Energy

under Contract DE-AC05-76RL01830

\title{
Methods and Models of the Hanford Internal Dosimetry Program, PNNL-MA-860
}

\author{
EH Carbaugh \\ DE Bihl \\ JA MacLellan \\ CL Antonio \\ RL Hill
}

\section{September 2009}




\title{
Methods and Models of the Hanford Internal Dosimetry Program, PNNL-MA-860
}

\author{
EH Carbaugh \\ DE Bihl \\ JA MacLellan \\ CL Antonio \\ RL Hill
}

September 2009

Prepared for

the U.S. Department of Energy under Contract DE-AC05-76RL01830

Pacific Northwest National Laboratory

Richland, Washington 99352 

Radiation and Health Technology

\section{Methods and Models of the Hanford Internal Dosimetry Program}

Approved for Use and Application by:

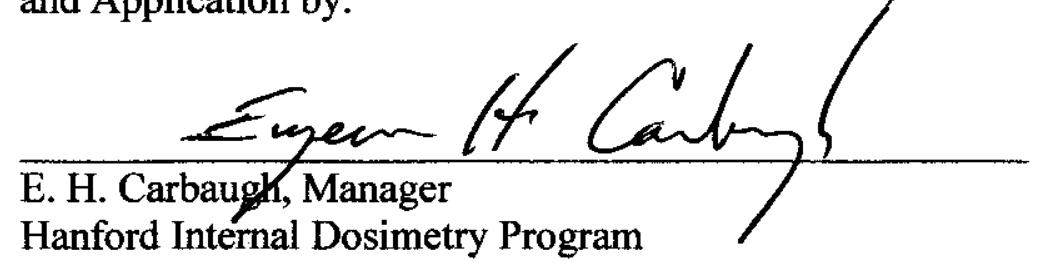

Pacific Northwest National Laboratory

Richland, Washington 99352 



\section{Preface}

This manual provides the scientific and technical foundation of the Hanford Internal Dosimetry Program (HIDP) for bioassay program design and interpretation, and for the assessment of occupational intakes and internal doses. The Hanford Internal Dosimetry Program Manual (PNL-MA-552) ${ }^{1}$ applies this foundation to define the recommended worker bioassay monitoring programs and internal dose assessment efforts at the Hanford Site.

According to the U.S. Department of Energy Internal Dosimetry Program Guide (DOE G 441.1C, 0519-08), a technical basis document should record the approach to evaluating internal doses from bioassay data, and where appropriate, from workplace monitoring data. The document should also describe the physical and chemical characteristics of radioactive materials encountered in the workplace; methods for calculating internal doses and dose equivalents and the methods for documenting those calculations; dose evaluation quality assurance; recording and reporting practices for internal dosimetry; selection of workers for monitoring; and establishment of the type and frequency of measurements to be used. Furthermore, statistical methods for evaluating bioassay data, identifying bioassay results above environmental background values, using appropriate blanks, and analyzing trends should be described.

This manual describes the basic methods and biokinetic models used for bioassay program design, interpretation, and internal dose assessment. These methods and models are combined with good practices and professional judgment to give the operational recommendations for routine and special bioassay monitoring contained in the Hanford Internal Dosimetry Program Manual (PNL-MA-552). The actual selection of workers for monitoring and the characterization of the physical, chemical, and radiological properties of contaminants in the many Hanford facilities are the domain of the individual Hanford contractors.

The recommendations in this manual are provided as guidance, not requirements, to personnel responsible for designing and operating bioassay monitoring programs and evaluating bioassay results. Commitments by contractors to use these recommendations may be found in the contractor radiation protection plans. This manual is on a 3-year revision schedule; however, individual sections are revised as necessary, and upon revision, commence their own 3-year revision cycle.

This manual is maintained by the HIDP, operated by the Pacific Northwest National Laboratory's (PNNL's) Radiation and Health Technology group. The contact person for questions or comments regarding the content of this manual is the HIDP Manager, Eugene H. Carbaugh at 376-6632 or gene.carbaugh@pnl.gov.

\footnotetext{
${ }^{1}$ Hanford Internal Dosimetry Program Manual. PNL-MA-552, PNNL-15613, Pacific Northwest National Laboratory, Richland, Washington. (Internal manual.) A copy of this manual is maintained in the HIDP files and available from the HIDP Manager or online by searching, PNNL-15613 @ http://www.pnl.gov/publications/.
} 



\section{Acronyms and Abbreviations}

ACGIH

ALI

AMAD

AMTD

ANSI

BEIR

$\mathrm{Bq}$

$\mu \mathrm{Ci}$

$\mathrm{Ci}$

$\mathrm{Ci} / \mathrm{g}$

CF

CFR

CL

$\mathrm{cm}^{2}$

Cpm

CSU

d

DAC

DALI

DCL

DCF

D\&D

DIL

DL

DOE

dpm

DRL

DSL

DTPA

DU
American Conference on Governmental Industrial Hygienists

annual limit on intake

activity median aerodynamic diameter

activity median thermodynamic diameter

American National Standards Institute

Biological Effects of Ionizing Radiation

becquerel(s)

microcurie(s)

curie(s)

curie(s) per gram

commercial fuel

Code of Federal Regulations

contract limit

square centimeter(s)

counts per minute

combined standard uncertainty

day(s)

derived air concentration

deterministic annual limit on intake

derived compliance level

dose conversion factor

decontamination and decommissioning

derived investigation level

decision level

U.S. Department of Energy

disintegrations per minute

dose reporting level

derived screening level

diethylene triamine pentaacetic acid

depleted uranium 
$E(50)$

$e(50)$

EDTA

EPA

ET

$f_{1}$

fCi

FAO

FFTF

$\mu g$

g

GI

$H_{\mathrm{T}}(50)$

hT(50)

$\mathrm{h}$

HEU

HIDP

HPS

HRTM

HTO

I

IAEA

ICPMS

ICRP

IG

IL

IMBA

IRF

ITP

IVRRF

$\mathrm{keV}$

$\mathrm{kg}$ 50-year committed effective dose

50-year committed effective dose coefficient

ethylene diamine tetraacetic acid

U.S. Environmental Protection Agency

extrathoracic

fractional absorption in the gastrointestinal tract

femtocuries

Food and Agriculture Organization

Fast Flux Test Facility

microgram(s)

$\operatorname{gram}(\mathrm{s})$

gastrointestinal

50-year committed organ or tissue equivalent dose

hour(s)

highly enriched uranium

Hanford Internal Dosimetry Program

Health Physics Society

Human Respiratory Tract Model

tritiated water vapor or liquid

iodine

International Atomic Energy Agency

inductively coupled plasma mass spectrometry

International Commission on Radiological Protection

intrinsic germanium

investigation level

Integrated Modules for Bioassay $\underline{\text { Analysis (Computer Code) }}$

intake retention function or fraction (depending on context)

insoluble tritiated particulates

In Vivo Radioassay and Research Facility

kilo electron volt(s)

kilogram(s) 


\begin{tabular}{|c|c|}
\hline $\mathrm{L}$ & liter(s) \\
\hline $\mathrm{lb}$ & pound(s) \\
\hline $\mathrm{L}_{\mathrm{c}}$ & critical level of detection \\
\hline $\mathrm{L}_{\mathrm{d}}$ & detection level \\
\hline LLD & lower limit of detection \\
\hline$\mu \mathrm{m}$ & micron(s); micrometers \\
\hline $\mathrm{m}$ & meter(s) \\
\hline MDA & minimum detectable activity or amount \\
\hline MDD & minimum detectable dose \\
\hline MDI & minimum detectable intake \\
\hline $\mathrm{MeV}$ & million electron volts \\
\hline mg & milligram(s) \\
\hline $\min$ & minute(s) \\
\hline $\mathrm{ml}$ & milliliter(s) \\
\hline MKIV & Mark IV \\
\hline MPBB & maximum permissible body burden \\
\hline mrem & millirem(s) \\
\hline $\mathrm{m}(\mathrm{t})$ & measurement expectation value \\
\hline NaI & sodium iodide \\
\hline NBS & National Bureau of Standards \\
\hline $\mathrm{nCi}$ & nanocurie(s) \\
\hline NCRP & National Council on Radiation Protection and Measurements \\
\hline NIOSH & National Institute for Occupational Safety and Health \\
\hline NU & natural uranium \\
\hline NWVP & Nuclear Waste Vitrification Project \\
\hline OBT & organically bound tritium \\
\hline ORNL & Oak Ridge National Laboratory \\
\hline OSHA & Occupational Safety and Health Administration \\
\hline PC & personal computer \\
\hline $\mathrm{pCi}$ & picoCurie(s) \\
\hline PEL & permissible exposure limit \\
\hline PFP & Plutonium Finishing Plant \\
\hline
\end{tabular}




\begin{tabular}{|c|c|}
\hline PHS & Public Health Services \\
\hline PNL & Pacific Northwest Laboratory \\
\hline PNNL & Pacific Northwest National Laboratory \\
\hline ppb & parts per billion \\
\hline ppm & parts per million \\
\hline PUREX & Plutonium-Uranium Extraction Plant (or process) \\
\hline $\mathrm{RBM}$ & red bone marrow \\
\hline REDOX & Reduction-Oxidation Plant \\
\hline REX & Radiation Exposure System \\
\hline RL & (DOE) Richland Operations Office \\
\hline RU & recycled uranium \\
\hline s & second(s) \\
\hline SALI & stochastic annual limit on intake \\
\hline SEE & specific effective energy \\
\hline SL & screening level \\
\hline SR & solubility or reactivity class of deposition \\
\hline SRS & Savannah River Site \\
\hline STC & special tritium compounds \\
\hline STP & soluble tritiated particulates \\
\hline STEL & short-term exposure limit \\
\hline Sv & sievert(s) \\
\hline TLV & threshold limit valve \\
\hline TPU & total propagated uncertainty \\
\hline ULI & upper large intestine \\
\hline UNSCEAR & United Nations Scientific Committee on the Effects of Atomic Radiation \\
\hline USTUR & United States Transuranium and Uranium Registries \\
\hline UO3 & Uranium Oxide (Plant) \\
\hline VL & verification level \\
\hline WESF & Waste Encapsulation and Storage Facility \\
\hline WHO & World Health Organization \\
\hline
\end{tabular}





\section{Contents}

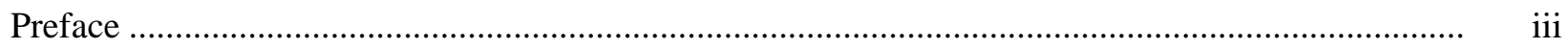

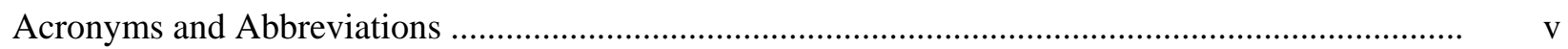

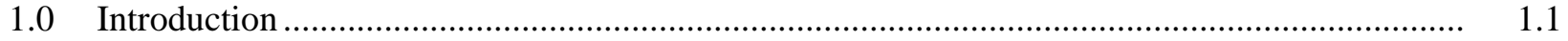

$2.0 \quad$ General Methods for Internal Dosimetry ................................................................ 2.1

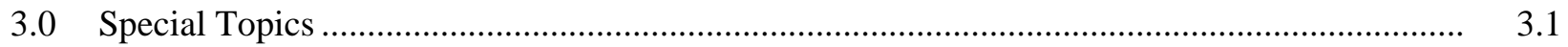

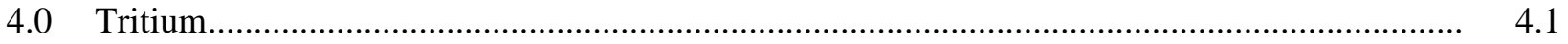

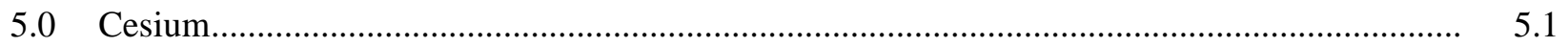

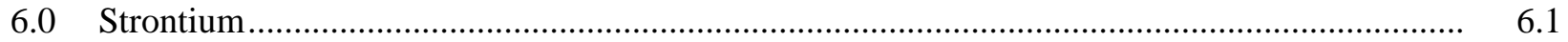

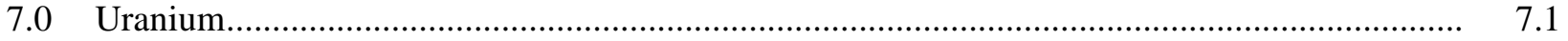

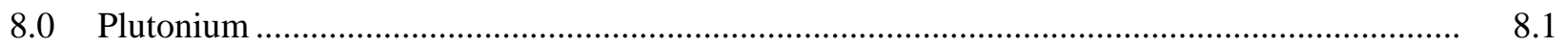

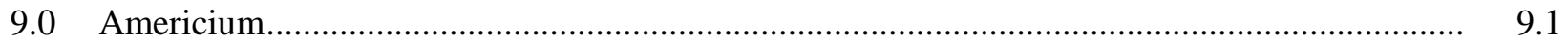

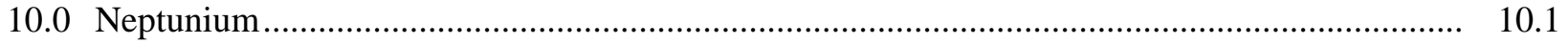

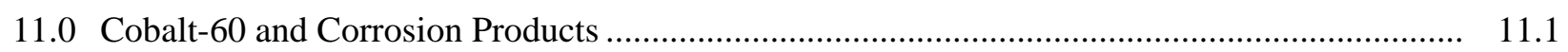

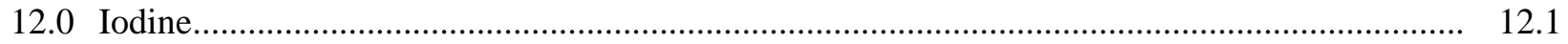

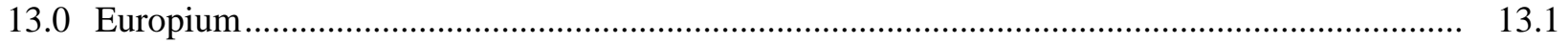

Appendix A - Glossary ........................................................................................................ A

Appendix B - Statistical Methods for Internal Dosimetry .............................................................. B.1

Appendix C - Biokinetic Models................................................................................................ C.1

Appendix D - Computer Codes ................................................................................... D. 1

Appendix E - Mixture and Tracer Radionuclides............................................................................ E.1 


\section{Methods and Models of the Hanford Internal Dosimetry Program \\ PNNL-MA-860}

\subsection{Introduction}

Issued for implementation effective 01/01/2010

Supersedes: January 31, 2003

\section{Use Category: Not applicable}

\section{Approval Signatures:}

Prepared by:

EH Carbaugh, Internal Dosimetry Program Manager

Approved by:

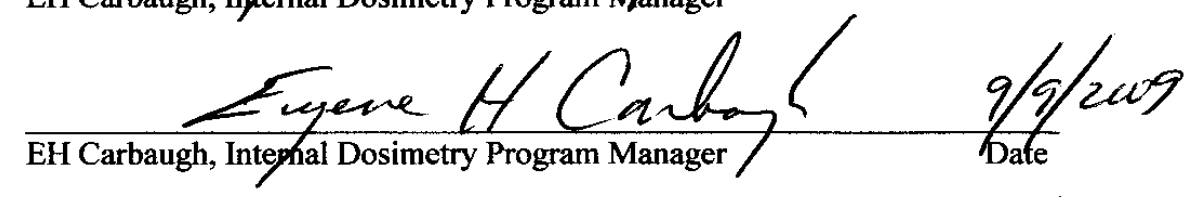

Reviewer Signatures:

Reviewed by:

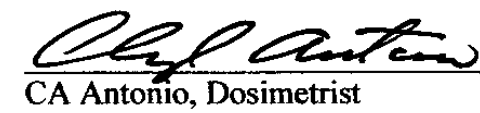

Approved by the Hanford Personnel Dosimetry Advisory Committee as recorded in the meeting minutes of February 10, 2009. 


\section{Contents}

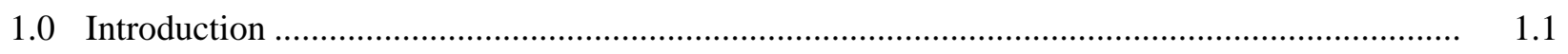

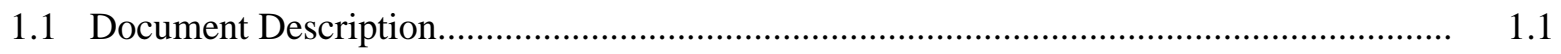

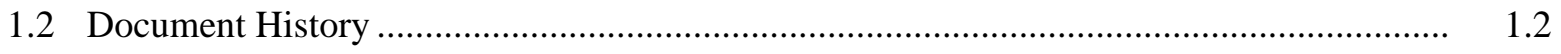

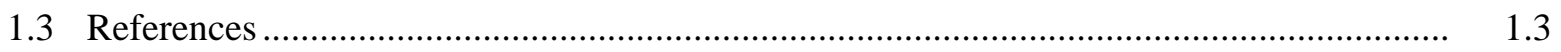





\subsection{Introduction}

The Hanford Internal Dosimetry Program (HIDP) provides internal dosimetry support services for operations at the Hanford Site. The HIDP is staffed and managed by the Radiation and Health Technology group, within the Pacific Northwest National Laboratory (PNNL). Operations supported by the HIDP include research and development, the decontamination and decommissioning of facilities formerly used to produce and purify plutonium, and waste management activities. Radioelements of particular interest are plutonium, uranium, americium, tritium, and the fission and activation product radionuclides ${ }^{137} \mathrm{Cs},{ }^{90} \mathrm{Sr}$, and ${ }^{60} \mathrm{Co}$.

This manual describes the technical basis for the design of the routine bioassay monitoring program and for assessment of internal dose. The purposes of the manual are as follows:

- Provide assurance that the HIDP derives from a sound technical base.

- Promote the consistency and continuity of routine program activities.

- Provide a historical record.

- Serve as a technical reference for radiation protection personnel.

- Aid in identifying and planning for future needs.

The internal dosimetry philosophy documented in this manual is based on the concepts of equivalent dose and effective dose described in Publication 60 of the International Commission on Radiological Protection (ICRP 1991) and Title 10 of the Code of Federal Regulations Part 835 (10 CFR 835). The committed doses (doses integrated over a period of 50 years following intake) are the basis for evaluating compliance with regard to the 10 CFR 835.202 dose limits of $5 \mathrm{rem} / \mathrm{y}$ for effective dose and $50 \mathrm{rem} / \mathrm{y}$ equivalent dose for any organ or tissue.

\subsection{Document Description}

This manual describes the science underlying internal dosimetry as practiced by the HIDP. The general methods chapter describes the fundamental principles used for internal dose calculations, and subsequent chapters deal with specific radioelements or a related group of radionuclides. The appendixes provide information that is general to all of the chapters: Glossary (Appendix A), Statistical Methods (Appendix B), Biokinetic Models (Appendix C), Computer Codes (Appendix D), and Mixtures and Tracer Nuclides (Appendix E). Radionuclides not specifically mentioned are rarely encountered at levels of dosimetric concern at Hanford. The basis for dosimetry for additional radionuclides will be added to this manual as the need arises. A "special topics” chapter provides for a documented record of technical issues that do not fit under other specific chapters, or that will subsequently be incorporated into other chapters upon major revisions of chapters. The recommendations for specific bioassay programs and capabilities of such programs for demonstrating compliance with regulations are presented in the companion Hanford Internal Dosimetry Program Manual (PNL-MA-552; PNNL 2009).

The tables, figures, and appendixes included in this manual (PNNL-MA-860) reflect the current information at the time of the revision of this manual. Revisions are completed chapter by chapter, as 
needed, to reflect changes and improvements in technical aspects (models and methods), and in total (cover to cover) on a three-year revision cycle. Any revision is reflected in the revision number associated with the PNNL document number on the cover and title page of the report and in the revised chapter(s) only. The HIDP Program Manager should be contacted if there are questions or concerns about the manual contents.

\subsection{Document History}

The first version of this manual was the Technical Basis for Internal Dosimetry at Hanford, issued in April 1989 as a technical document (PNL-6866; Sula et al. 1989). During its first 2 years of publication, the document found a wide audience throughout the U.S. Department of Energy (DOE), its contractors, and other organizations involved in internal dosimetry. It not only served well as the intended reference for data, but also became a template for other sites in developing their own technical basis documents.

The “Technical Basis” was always intended to be a "living” document, responsive to the needs of the HIDP. The first revision of the document (Sula et al. 1991) was prompted by the desire to have additional information readily available for routine use in dose assessment and bioassay program design. Also, changes were made in the presentation of information to make the document easier to use. Throughout the next 8 years, no revisions were made to the document proper, although some updates and additions were made by supplemental letter reports addressing specific issues. The document itself remained unchanged due to program priorities and the fact that the essence of the material in the document was still current.

In January 2000, the Hanford technical basis changed its format from a document (PNL-6866) to a manual (PNNL-MA-860). Although the content and layout remained similar to previous versions, the manual format was adopted to allow future changes to be accomplished without republishing the entire document. The name change to Methods and Models of the Hanford Internal Dosimetry Program was made to more accurately reflect the manual's purpose and content, and avoid confusion that one document constituted the entire "technical basis."

Major revisions were issued in 2009 to implement 10 CFR 835 regulatory changes that incorporated ICRP 60 (1991) dosimetry concepts and methods. Those revisions also marked a change to the advanced biokinetic models summarized and referenced in ICRP 78 (1997). The IMBA Professional Plus (IMBA) internal dosimetry computer code (v. 4.043; James et al. 2004) ${ }^{1}$ was adopted as the primary dose assessment code to support those revisions.

Shutdown and cleanup of Hanford facilities have continued since the last revision. Plutonium production and fuel reprocessing have ceased, and facilities are in the midst of decontamination and decommissioning. Relatively short-lived fission and activation products have decayed to the point where the need for their dosimetry is substantially reduced, and the additional time since the end of reprocessing has changed the expected isotopic ratios in reference plutonium mixtures. As new missions are added or existing site programs are modified, further modification of this manual may be required.

\footnotetext{
${ }^{1}$ IMBA Professional Plus, which includes the current version of the user manual, is available from Health Protection Agency (HPA), Radiation Protection Division, Chilton, Didicot, Oxon., OX11 0RQ UK and from http://www.imbaprofessional.com/
} 
The HIDP seeks to implement technically appropriate and cost-effective methods and tools to carry out its functions. The HIDP will continue to evaluate new models and tools for internal dosimetry, as they become available and incorporate cost-effective improvements that are consistent with regulatory and contractual requirements. Changes affecting the technical basis nature of this manual require review and concurrence by the Hanford Personnel Dosimetry Advisory Committee prior to their implementation.

\subsection{References}

10 CFR 835. 2007. “Occupational Radiation Protection.” Code of Federal Regulations.

U.S. Department of Energy. Available at: http://www.access.gpo.gov

International Commission on Radiological Protection (ICRP). 1991. "1990 Recommendations of the International Commission on Radiological Protection.” ICRP Publication 60, Annals of the ICRP, 21:1-3, Pergamon Press, New York.

International Commission on Radiological Protection (ICRP). 1997. "Individual Monitoring for Internal Exposure of Workers.” ICRP Publication 78, Annals of the ICRP, 27:3/4, Pergamon Press, New York.

Carbaugh, EH, DE Bihl, JA MacLellan. 2009. Hanford Internal Dosimetry Program Manual. PNL-MA-552, PNNL-15613, Pacific Northwest National Laboratory Richland, Washington. Available at: http://www.pnl.gov/main/publications/external/technical_reports/PNNL-15613.pdf

James, AC, A Birchall, JW Marsh, and M Puncher. 2004 (or current version). User Manual for IMBA Expert USDOE Edition (Phase II). ACJ \& Associates, Richland, Washington. (Current version is available electronically as part of the IMBA Professional Plus software package.)

Sula, MJ, EH Carbaugh, and DE Bihl. 1989. Technical Basis for Internal Dosimetry at Hanford. PNL-6866, Pacific Northwest Laboratory, Richland, Washington.

Sula, MJ, EH Carbaugh, and DE Bihl. 1991. Technical Basis for Internal Dosimetry at Hanford. PNL-6866, Rev. 1, Pacific Northwest Laboratory, Richland, Washington. 
PNNL-15614, Rev. 1

\title{
Methods and Models of the Hanford Internal Dosimetry Program \\ PNNL-MA-860
}

\subsection{General Methods for Internal Dosimetry}

\author{
Issued for implementation effective 01/01/2010
}

Supersedes: January 31, 2003

Use Category: Not applicable

\section{Approval Signatures:}

Prepared by:

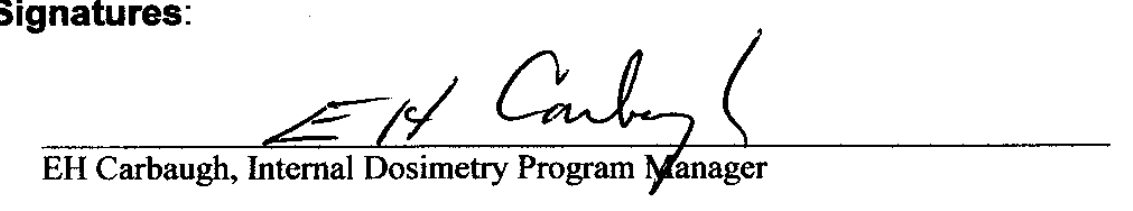

Approved by:
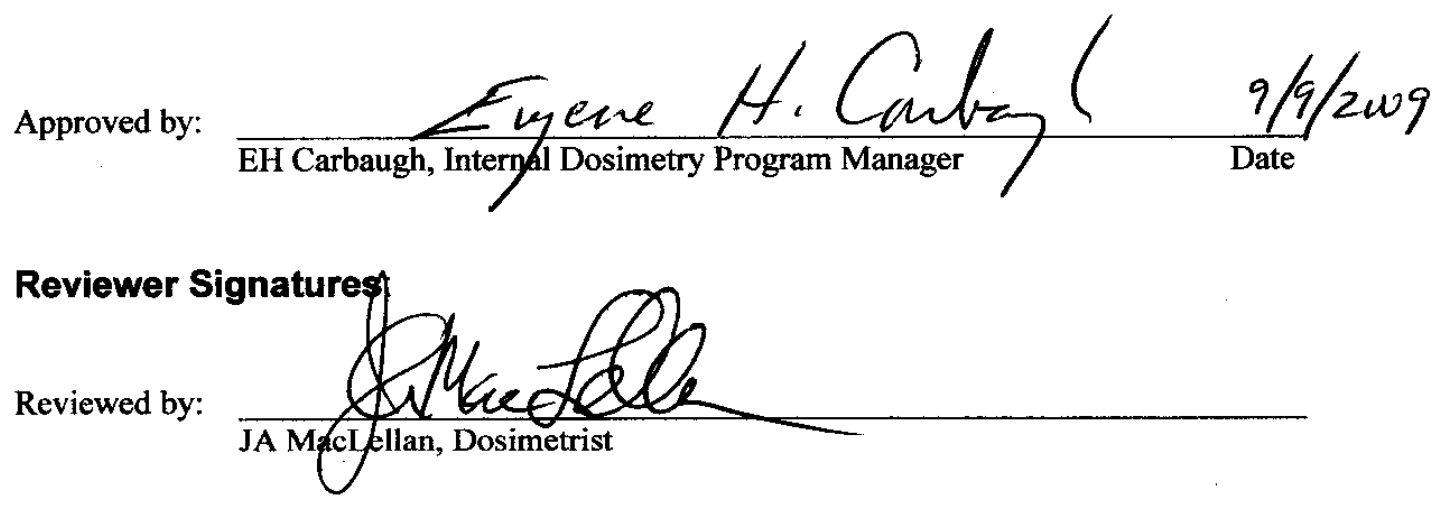

Approved by the Hanford Personnel Dosimetry Advisory Committee as recorded in the meeting minutes of March 10, 2009. 


\section{Contents}

2.0 General Methods for Internal Dosimetry ........................................................................ 2.1

2.1 Radiation and Tissue Weighting Factors .................................................................... 2.1

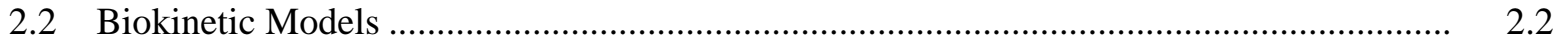

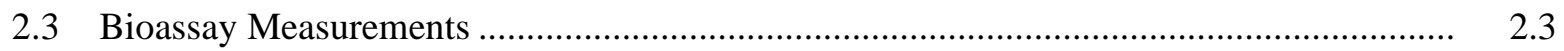

2.4 Internal Dosimetry Assessments .......................................................................... 2.3

2.5 Organs or Tissues of Concern ….............................................................................. 2.4

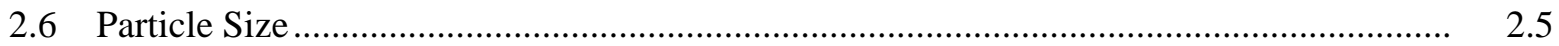

2.7 Assumed Date of Intake ........................................................................................ 2.5

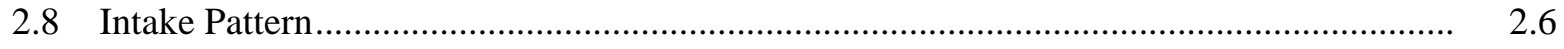

2.9 Interpretation of Bioassay Program Capability ........................................................... 2.6

2.10 Normalizing Bioassay Data ...................................................................................... 2.6

2.11 Fitting Bioassay Data to Biokinetic Models .................................................................... 2.7

2.12 Reference Levels and Derived Reference Levels ..................................................... 2.8

2.13 Fundamental Relationships ............................................................................ 2.8

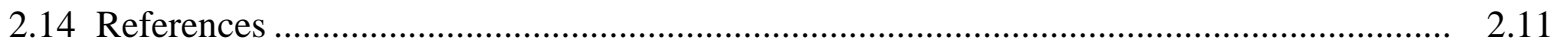

\section{Tables}

2.1 Comparison of Radiation Weighting Factors........................................................................ 2.1

2.2 Comparison of Organ/Tissue Weighting Factors............................................................... 2.2 


\subsection{General Methods for Internal Dosimetry}

The Hanford Internal Dosimetry Program (HIDP) uses the fundamental concepts described by the International Commission on Radiological Protection (ICRP) for calculations of intake, deposition, and dose. The basic concepts and techniques are those described in ICRP Publication 68 (1994a), including specific effective energy factors and Reference Man parameters, with annual limits on intake and derived air concentrations, radiation weighting factors, and organ/tissue weighting factors as defined by Title 10 of the Code of Federal Regulations Part 835 (10 CFR 835). The biokinetic models used to describe distribution, retention, and excretion for various radionuclides are described in the pertinent chapters of this manual. Generally, preference is given to well-documented and peer-reviewed models; particularly those published by the ICRP. This chapter summarizes the calculational methods and factors most commonly used for intake assessment and internal dosimetry. In some cases, discussion is included concerning scientific recommendations that are currently incompatible with regulatory requirements. Such discussion is intended to provide guidance for alternate assessments appropriate for purposes other than regulatory compliance. This chapter also describes the various reference levels and derived reference levels used by the HIDP.

Though nomenclature and terms may vary slightly, the methods and assumptions described in this manual are generally consistent with guidance and methods for internal dosimetry described in International Atomic Energy Agency (IAEA) Safety Series Report No. 37 (IAEA 2004) and IAEA Safety Guide RS-G-1.2 (1999), U.S. Department of Energy (DOE) Guide G 441.1-1C (DOE 2008a), DOE Standard 1121-2008 (DOE 2008b), and the American National Standards Institute/Health Physics Society Standard ANSI/HPS N13.39 (HPS 2001).

\subsection{Radiation and Tissue Weighting Factors}

The radiation weighting factors and tissue weighting factors of 10 CFR 835 are used for routine calculations. These factors are consistent with those of ICRP 60 (1990) and have been incorporated into the computer codes and dose coefficients used in the calculations. Table 2.1 provides a comparison of the radiation weighting factors pertinent to the HIDP, and Table 2.2 compares the tissue weighting factors. Factors from ICRP 26 (1977) and ICRP 103 (2007) are shown for comparison with historical values and as an indication of the most recent scientific guidance.

Table 2.1. Comparison of Radiation Weighting Factors

\begin{tabular}{ccccc}
\hline Radiation & $\begin{array}{c}\text { 10 CFR 835 } \\
(2007)\end{array}$ & $\begin{array}{c}\text { ICRP 60 } \\
(1990)\end{array}$ & $\begin{array}{c}\text { ICRP 30 } \\
(1977)\end{array}$ & $\begin{array}{c}\text { ICRP 103 } \\
(2007)\end{array}$ \\
\hline Alpha & 20 & 20 & 20 & 20 \\
Proton & 5 & 5 & 10 & 2 \\
Beta & 1 & 1 & 1 & 1 \\
Gamma, X & 1 & 1 & 1 & 1 \\
\hline
\end{tabular}


Table 2.2. Comparison of Organ/Tissue Weighting Factors

\begin{tabular}{lcccc}
\hline Tissue or Organ & $\begin{array}{c}\text { 10 CFR 835 } \\
(2007)\end{array}$ & $\begin{array}{c}\text { ICRP 60 } \\
(1990)\end{array}$ & $\begin{array}{c}\text { ICRP 30 } \\
(1977)\end{array}$ & $\begin{array}{c}\text { ICRP 103 } \\
(2007)\end{array}$ \\
\hline Gonads & 0.20 & 0.20 & 0.25 & 0.08 \\
Breasts & 0.05 & 0.05 & 0.15 & 0.12 \\
Red Bone Marrow & 0.12 & 0.12 & 0.12 & 0.12 \\
Lungs & 0.12 & 0.12 & 0.12 & 0.12 \\
Thyroid & 0.05 & 0.05 & 0.03 & 0.04 \\
Bone Surfaces & 0.01 & 0.01 & 0.03 & 0.01 \\
Colon & 0.12 & 0.12 & -- & 0.12 \\
Stomach & 0.12 & 0.12 & -- & 0.12 \\
Bladder & 0.05 & 0.05 & -- & 0.04 \\
Liver & 0.05 & 0.05 & -- & 0.04 \\
Esophagus & 0.05 & 0.05 & -- & 0.04 \\
Brain & -- & -- & -- & 0.01 \\
Salivary Glands & -- & -- & -- & 0.01 \\
Skin & 0.01 & 0.01 & -- & 0.01 \\
Remainder & 0.05 applied to & 0.05 applied to & 0.06 for each of & 0.12 applied to the \\
& 10 specified organs & 10 specified organs & 5 other organs & arithmetic mean dose \\
& and tissues & and tissues & with highest dose & of 13 additional \\
& & & & organs and tissues \\
\hline
\end{tabular}

\subsection{Biokinetic Models}

Biokinetic models are used to describe the deposition and movement of material throughout the body. The models listed in ICRP 68 (1994a) for the respiratory tract, gastrointestinal (GI) tract, and metabolic distribution are used for most assessments. Specific metabolic retention and excretion models for various elements are described in the corresponding chapters of this manual. If adjustments are made to the parameter values of these models, those adjustments are explained in the documentation associated with the assessment.

Intake retention functions (IRFs) or measurement expectation values [m(t)] combine various biokinetic models to provide an expression of the amount of a radionuclide retained in a compartment of the body (or excreted by a particular pathway) as a fractional value of the amount of the intake. These values for various times post intake are tabulated in this manual for intake circumstances of greatest interest to the HIDP. Other common sources of measurement expectation values that may be used include the IMBA Professional Plus (IMBA) internal dosimetry computer code (James et al. 2004), ${ }^{1}$ ICRP 78 (1997), and peer-reviewed literature or hand calculations.

The IMBA computer code is the preferred code used for internal dosimetry by the HIDP. This code incorporates the ICRP 66 human respiratory tract model (ICRP 1994b), and the ICRP 30 GI tract model

\footnotetext{
${ }^{1}$ IMBA Professional Plus, which includes the current version of the user manual, is available from Health Protection Agency (HPA), Radiation Protection Division, Chilton, Didicot, Oxon., OX11 0RQ UK and from http://www.imbaprofessional.com/
} 
(ICRP 1979), along with the metabolic distribution models to give bioassay projections, intake assessments based on bioassay data, and estimates of dose equivalent.

Committed dose coefficients, $h_{\mathrm{T}}(50)$ and $e(50)$, sometimes referred to as dose conversion factors, are the factors that express the committed tissue or effective dose, respectively, for a unit intake. They are derived based on a specified set of conditions. The dose coefficients tabulated in this manual are for circumstances most commonly encountered at Hanford. Typically, these are transportable injection (instant uptake) and inhalation of Type $\mathrm{F}$ (for fast rate of solubilization), M (for moderate), and S (for slow) materials, assuming a 5- $\mu$ m activity median aerodynamic diameter (AMAD) particle size. Other tabulations of dose coefficients that might be useful include ICRP 68, 72, and 78 (ICRP 1994a; 1996; 1997). In addition, coefficients for differing conditions can be calculated using the IMBA computer code.

\subsection{Bioassay Measurements}

Bioassay is defined as the direct measurement of radioactivity in the body or the indirect measurement of radioactivity in the body by analyzing material excreted or otherwise removed from the body. Direct measurements, also called in vivo measurements, use detector systems such as whole body counters, lung counters, and wound counters. Indirect measurements, also called in vitro measurements, involve the laboratory analysis of material excreted or removed from the body. In vitro measurements may include urine, feces, tissue samples, blood, or sputum. As a practical matter, most in vitro bioassays are made using urine or feces, and these measurements are generically referred to at Hanford as excreta bioassay.

\subsection{Internal Dosimetry Assessments}

The HIDP uses intake assessment as the principal means for most dose evaluations, with internal doses calculated based on estimated intake. The intake is estimated using available data, preferably bioassay measurements, but exposure time to air concentrations may also be used. The 50-year committed effective dose, $E(50)$, and any appropriate 50-year committed organ or tissue equivalent doses, $H_{\mathrm{T}}(50)$, are calculated based on the intake. In some cases (notably tritium), dose may be directly calculated from bioassay measurements, with intake subsequently estimated based on the assessed dose. The 50-year committed doses, assigned to the year of intake, are used as the basis for compliance monitoring.

The concept of deposition assessment was often used by the HIDP through 1993, particularly for the assessment of plutonium, and is described here primarily for historical reference to archived evaluations. Rather than calculating an intake, this method used bioassay data to estimate the amount of material initially deposited in the intake compartments of interest. For example, instead of calculating a total inhalation intake, the bioassay data would be used to estimate the quantity initially retained in long-term compartments of the lung. In addition, a "presystemic deposition” was estimated to be the amount initially deposited in a compartment that would eventually translocate to the systemic circulation. The term "presystemic deposition" was coined for use in the Technical Basis for Internal Dosimetry at Hanford (Sula et al. 1989). Prior to that document the term "deposition” had been used, often very imprecisely. Clearance rates were estimated for both nonsystemic and presystemic depositions. Compliance with regulatory requirements was demonstrated either by calculating annual (not committed) 
dose equivalents to critical organs for comparison with the radiation protection standards in effect at the time, or, prior to 1989, by comparing the presystemic deposition with the maximum permissible body burden (MPBB). Tabulations of MPBBs in ICRP 2 (1959) or earlier National Bureau of Standards (NBS) handbooks (NBS 1953, 1959) were used as the radiation protection standards. In 1989, the ICRP 26 (1977) system was implemented for calculating effective dose equivalent using tissue weighting factors applied to organ and tissue dose equivalents, and calculated annual doses (not committed doses) were used as the basis for compliance. With the 1994 implementation of the DOE Radiological Control Manual (DOE 1994), compliance monitoring became based on assigning the committed dose equivalent to the year of intake.

\subsection{Organs or Tissues of Concern}

The DOE has established limiting values for occupational exposure to radiation in 10 CFR 835.202. These values include a limit on dose to individual organs or tissues to prevent deleterious deterministic effects, and a limit on the effective dose based on the risk of stochastic effects. Requirements for recording committed equivalent doses to organs and tissues of concern as well as the committed effective dose are given in 10 CFR 835.702(c)(4). However, neither the rule nor its implementation guide (DOE 2008a) specifically defines "organs and tissues of concern." Practices for recording doses to "organs and tissues of concern” are defined in the Hanford Internal Dosimetry Program Manual (PNL-MA-552; EH Carbaugh, et al. 2009). In cases involving relatively small effective doses, there may be no single organ that meets the recording criteria, whereas for a very significant exposure, several organs may qualify. Candidate organs and tissues used by the HIDP are those identified by the tissue weighting factors of 10 CFR 835, however the element-specific chapters of this manual (PNNL-MA-860) narrow those candidates to the appropriate organs and tissues. As noted below, doses received by localized tissues are not included in either the assessment of effective dose or in the assessment of equivalent dose to organs and tissues of concern.

Intakes of radionuclides via wounds may result in the irradiation of local tissues at the wound site, as well as regional lymph nodes that drain the wound region. Because of their small mass, the absorbed dose to the regional lymph nodes may greatly exceed that to other tissues. Evidence from studies of experimental animals suggests that the lymph nodes are not primary sites for development of radiationinduced malignant disease (Nenot and Stather 1979), and National Council on Radiation Protection and Measurements Report 156 (NCRP 2006) notes that lymph nodes are generally not considered to be at radiogenic risk. Similarly, the irradiation of local tissues at the wound site is not considered to carry significant risk of carcinogenesis.

Concentrated activity in such localized sources can be expected to result in relatively high doses and cell death or tissue fibrosis (e.g., scar tissue) within a limited area, but unless this area comprises more than a minor fraction of the organ/tissue, there will likely be no observable deterministic effect at any dose. Assessment of organ or tissue equivalent dose from highly localized sources, made by averaging the energy deposited in the organ over the organ mass, is not a relevant measure for comparison with the limiting values for assessed dose based on deterministic effects. Furthermore, in most situations, it is not possible to determine the actual mass of affected tissue for computing the absorbed dose. Because the absorbed dose is highly nonuniform over the tissue and only a limited number of cells within the organ/tissue are affected, the use of equivalent dose for assessing this localized exposure is not valid. 
For these situations, the HIDP will estimate the quantity of radionuclide(s) locally deposited and the projected retention half-time. These estimates become part of the individual's radiation protection record, but are not used for determining compliance with either the stochastic or deterministic limits. This approach is analogous to the approach described in 10 CFR 835.205(b)(3) for irradiation of limited areas of the skin.

\subsection{Particle Size}

The ICRP 66 lung model (ICRP 1994b) provided two particle size recommendations for radiological protection purposes, in the absence of more specific information. For occupational exposure circumstances, a reference AMAD of $5 \mu \mathrm{m}$ was recommended, and a 1- $\mu \mathrm{m}$ AMAD was recommended for exposures in the general environment, e.g., members of the general public. It is the intent of the HIDP to follow the particle size recommendations of ICRP 66 and assume occupational exposure to radioactive aerosols of a 5 - $\mu \mathrm{m}$ particle size, unless exposure information suggests otherwise.

Dorrian and Bailey (1995) reported on a survey of 52 publications addressing radioactive aerosol particle size distributions in the workplace. Reported values ranged from $0.12 \mu \mathrm{m}$ to $25 \mu \mathrm{m}$, and were well fitted by a lognormal distribution with a median value of $4.4 \mu \mathrm{m}$. They noted that nuclear power and nuclear fuel handling facilities gave median values of about $4 \mu \mathrm{m}$. Uranium mills gave a median value of $6.8 \mu \mathrm{m}$, with AMADs frequently above $10 \mu \mathrm{m}$. High temperature and arc saw cutting operations generated submicron particles. They concluded that a 5- $\mu \mathrm{m}$ AMAD was a realistic default value for occupational exposure to unknown aerosols. They also cautioned that, where possible, particle sizes should be measured for individual work practices to provide realistic parameters for dose assessment, because the 5- $\mu \mathrm{m}$ value of the ICRP 66 lung model was chosen to be deliberately realistic rather than conservative.

Kelso and Wraight (1996) reported on 50 AMAD measurements associated with reactor fuel reprocessing in several buildings at Sellafield in Cumbria, England. They found a mean value of 3.7- $\mu \mathrm{m}$ AMAD over the six buildings examined, with results consistently larger than the $1-\mu \mathrm{m}$ value. They also concluded that the use of $5 \mu \mathrm{m}$ as a default particle size was reasonable as a realistic rather than conservative assumption for occupational aerosols.

Heid and Jech (1972) reported that measurements in the majority of Hanford incidents indicated a mean particle size of $4 \mu \mathrm{m}$ for plutonium oxide particles. Palmer et al. (1964) reported submicron particle sizes for radon in mines. These two reports provide some older historical data in support of the ICRP 66 lung model recommendations.

\subsection{Assumed Date of Intake}

The actual intake time or period, when that time is known, is used for assessment of intake and dose.

When the actual intake time or period is not known, it is necessary to identify the probable intake date(s). This may be done by considering available evidence, such as air monitoring results, contamination surveys, operating periods, specific tasks performed, and previous bioassay measurement results. After the intake time is narrowed to a probable time period, it is assumed that an acute intake occurred at 
the midpoint of that period. This approach is consistent with recommendations of the ICRP $(1988,1997)$ and the National Council on Radiation Protection and Measurements (NCRP 1987).

If the evidence suggests that a chronic intake is more reasonable, it is assumed that the chronic intake occurred uniformly throughout the probable exposure period.

For describing the capability of a bioassay program (i.e., the minimum detectable intake or dose associated with a bioassay measurement protocol), the intake is assumed to be on a worst-case date (i.e., the minimum IRF value for the interval is used). Typically, that date is the longest elapsed time between measurements.

\subsection{Intake Pattern}

Occupational intakes in a well-engineered and -operated facility usually occur as acute inhalations due to unplanned or unanticipated events. Thus, acute inhalations are used for most bioassay program designs and as default intake patterns for assessment of high routine bioassay samples. Exceptions to this may include tritium exposures, which can be expected to occur as acute or chronic uptake events combining both inhalation and absorption. Historically at Hanford, there has also been planned chronic exposure to uncontained uranium in several facilities, however the work associated with such patterns is now quite rare. Very low-level chronic exposure, below the sensitivity of normal air sampling and bioassay monitoring, may be present in areas of uncontained radioactivity.

\subsection{Interpretation of Bioassay Program Capability}

Bioassay program capability (i.e., sensitivity) is described by the minimum detectable intake (MDI) and its associated minimum detectable dose (MDD), based on an assumed bioassay measurement equal to the minimum detectable activity or amount (MDA) and an assumed time between measurements (Carbaugh 2003).

Occasionally, it is desirable to make a statement, based on an actual bioassay measurement showing no detectable result, about what might be the potentially undetected dose associated with the measurement. When a bioassay measurement has been made with a result showing no detection, the MDA value, rather than the critical level of detection $\left(\mathrm{L}_{c}\right)$ should be used as a basis for determining a potentially undetected dose. The MDA and critical level for detection concepts are discussed in Appendix B of this manual.

\subsection{Normalizing Bioassay Data}

Indirect bioassay data may be normalized differently based on the sampling protocol. Generally, Hanford urine data are automatically normalized to a total 24-hour excretion by use of the standard “approximate 24-hour” sampling protocol of collecting all urine voided between 30 minutes before retiring at night and 30 minutes after rising in the morning for two consecutive nights (NCRP 1987). This protocol was originated at Hanford in the mid-1940s, based on unpublished work by JW Healy (Carbaugh 2008). Medley et al. (1994) identified a potential bias of up to a factor of 2 for this protocol. 
If the sample is collected properly, a total or approximate 24-hour urine sample result is used as is; no further normalization is done. A proper 12-hour sample result is normalized by doubling the result. If it is suspected that a sample has not been provided according to instructions, several approaches are considered for normalization. A sample that is supposed to contain 24-hour excretion may not be analyzed if the volume is less than $500 \mathrm{ml}$ because the volume is too small to represent a true 24-hour collection, and the worker may be asked to provide another sample. Alternatively, the result may be 1) normalized to 24-hour excretion based on information from the provider, 2) ignored, or 3) normalized by volume to 24-hour excretion. To normalize by volume, $1600 \mathrm{ml}$ for males and $1200 \mathrm{ml}$ for females (ICRP 2002) should be used for 24-hour excretion unless the person-specific daily excretion rate is known.

Normalization by creatinine or specific gravity has been suggested (NCRP 1987; NIOSH 1974; Anderson et al. 1995; Karpas et al. 1998; Duke 1998). However, various studies suggest that normalization by these methods does not provide any improved confidence in the result over normalization by time or volume (Jackson 1966; Kim 1995; Boeniger et al. 1993; and Graul and Stanley 1982). The best way to ascertain if the sample represents 24-hour excretion may be to simply ask the worker providing the sample (Harris et al. 2000).

The one exception to the above discussion concerns the analysis for tritium in urine. Because tritium is usually considered to be in equilibrium with body water, dosimetry can be accomplished using urine concentration rather than a daily excretion rate.

The fecal excretion for adults depends on the fiber content of their diet. It can range from 50 to $500 \mathrm{~g} /$ day, with a recommended reference value of $150 \mathrm{~g} /$ day for an adult male and $120 \mathrm{~g} / \mathrm{day}$ for an adult female (ICRP 2002). Note that these values represent excretion "per day," not excretion "per bowel movement." When a single bowel movement is collected, it is generally interpreted as representing excretion for 1 day. If the sample is greater than $50 \mathrm{~g}$, no normalization is used. If the sample is less than $50 \mathrm{~g}$, normalizing to $150 \mathrm{~g}$ for males and $120 \mathrm{~g}$ for females may be appropriate, if it is considered likely that a total day's fecal excretion was not obtained.

If total accumulated fecal excretion over a time period was requested and there is no apparent reason to suspect that total excretion was not provided, then all sample results should be used as they are, without regard for the mass of individual samples. If excretions were missed during the time period, then normalization of the total mass to the total mass expected based on the reference values given above should be used.

\subsection{Fitting Bioassay Data to Biokinetic Models}

The assessment of intakes or internal dose requires fitting bioassay data to an appropriate biokinetic model to assess the IRF (i.e., the cumulative activity or the number of radionuclide transformations over the time period of interest). Normally the HIDP uses the IMBA computer code (James et al. 2004) to make these assessments. Curve-fitting routines within the code are addressed in Appendix D. 


\subsection{Reference Levels and Derived Reference Levels}

A reference level is a predetermined value of a quantity that triggers a specified course of action when exceeded or expected to be exceeded. Reference levels at Hanford are expressed as dose-based or intakebased. Derived reference levels are the measurement values for particular bioassay or air sampling results that correspond to a more general reference level under specifically defined circumstances. The reference and derived reference levels used in this document are as follows:

- screening level (SL) - The level below which a bioassay measurement need not be considered for investigation of intake and assignment of dose. The Hanford SL is based on a committed effective dose of 10 mrem.

- derived screening level (DSL) - The value of a bioassay measurement or airborne exposure estimate corresponding to a committed effective dose of 10 mrem for the referenced conditions or an estimated normal environmental level.

- verification level (VL) - The level above which an attempt should be made to confirm the intake as real (i.e., special measurements should be made in follow-up to a high routine measurement). The Hanford VL is 100-mrem committed effective dose.

- investigation level (IL) - The level above which a bioassay or air monitoring result shall be investigated, to the extent reasonable, to determine actual conditions and parameters for dose evaluation. An investigation may involve special measurements, work history review, determination of material form, and modification of biokinetic parameters. The Hanford IL is 100-mrem committed effective dose. In practice, Hanford does not discriminate between the VL and the IL.

- derived investigation level (DIL) - The bioassay measurement or airborne exposure measurement corresponding to a committed effective dose of 100 mrem for the referenced conditions.

- derived compliance level (DCL) - The bioassay measurement level corresponding to the 10 CFR 835 dose limit, i.e., 5-rem committed effective dose or 50-rem committed organ/tissue equivalent dose.

Values of DCLs, DILs, and DSLs are tabulated in the various chapters of this document.

\subsection{Fundamental Relationships}

The first principles equation for equivalent dose rate to an organ or tissue is described as

$$
\dot{H}_{T}=1.6 \times 10^{-10} \times \operatorname{SEE}(T \leftarrow S) \times A_{S}
$$

\footnotetext{
where $\quad \dot{H}_{\mathrm{T}}=$ equivalent dose rate in the target organ or tissue $(\mathrm{T})$ from radioactive transformations in a source organ or tissue, in units of sieverts per second (Sv/s),

$\mathrm{SEE}(\mathrm{T} \leftarrow \mathrm{S})=$ specific effective energy deposited in the target organ or tissue from a radionuclide transformation in a source organ or tissue in units of $\mathrm{MeV}$ per gram - transformation (MeV/g-trans), and $A_{s}=$ radioactivity present in the source organ or tissue in becquerels $(B q)$.
} 
Integrating Equation (2.1) with respect to retention time gives the following equivalent dose:

$$
H_{T}=1.6 \times 10^{-10} \times \operatorname{SEE}(T \leftarrow S) \times A_{s} \int R(t) d t
$$

where $\quad \mathrm{H}_{\mathrm{T}}=$ equivalent dose in sieverts $(\mathrm{Sv})$, $\mathrm{R}(\mathrm{t})$ = retention function in the source organ or tissue, and

$A_{S} \int R(t) d t=$ total number of transformations in the source organ over the time interval of interest. This latter term is also known as cumulative activity. For most internal dosimetry calculations, the integral is solved for $\mathrm{t}=50$ years (or $1.58 \times$ 109 seconds). ICRP 30 (1979) nomenclature identifies this term as $U_{s}$.

In conventional health physics units, Equation (2.2) is expressed as

$$
H_{T}=51.2 \times \operatorname{SEE}(T \leftarrow S) \times A_{s} \int R(t) d t
$$

where $\quad \mathrm{H}_{\mathrm{T}}=$ rems,

$$
\mathrm{A}_{\mathrm{s}}=\text { microcuries }(\mu \mathrm{Ci}) \text {, and }
$$

$\mathrm{t}=$ the time interval in days.

A few fundamental relationships are repetitively used for most internal dosimetry calculations. Some of these relationships are described conceptually in the following equations. Because these are intended to be conceptual relationships, no units or unit conversion factors are shown. It is understood that consistency in units will be addressed by the specific application of the relationship.

Bioassay Result from an Intake and Intake Retention (or Excretion) Fraction

$$
\mathrm{M}(\mathrm{t})=\mathrm{I} \times \operatorname{IRF}(\mathrm{t})
$$

Intake Estimate from a Single Bioassay Measurement

$$
\mathrm{I}=\frac{\mathrm{M}(\mathrm{t})}{\operatorname{IRF}(\mathrm{t})}
$$

Intake Estimate from Air Concentration Data

$$
\mathrm{I}=\frac{\mathrm{C}_{\text {air }} \times \text { Breathing Rate } \times \text { Exposure Duration }}{\text { Respiratory Protection Factor }}
$$

Calculation of Airborne Exposure (DAC-hours)

$$
\text { DAC }- \text { hours }=\sum_{\mathrm{i}=1}^{\mathrm{n}} \frac{\mathrm{C}_{\mathrm{air}, \mathrm{i}}}{\mathrm{DAC}_{\mathrm{i}}} \times \text { Duration of Exposure (hours) }
$$


Annual Limit on Intake (ALI), the most limiting from dose limits and dose coefficients, stochastic and deterministic, respectively.

$$
A L I=\frac{\text { Dose Limit }}{\text { Dose Coefficient }}=\frac{5 \text { rem }}{e(50)}, \text { or } \frac{50 \text { rem }}{h_{T}(50)}
$$

Intake Estimate from Airborne Exposure (DAC-hours) and Annual Limit on Intake

$$
I=\frac{\text { ALI }}{2000 \text { DAC }- \text { hours }} \times \text { DAC }- \text { hours }
$$

Committed Effective Dose based on Intake and Dose Coefficient

$$
E(50)=I \times e(50)
$$

Committed Organ/Tissue Equivalent Dose based on Intake and Dose Coefficient

$$
H(50)=I \times h_{T}(50)
$$

Committed Dose from DAC-hours

$$
E(50)=D A C-\text { hours } \times \frac{5 \text { rem }}{2000 \text { DAC }- \text { hours }}
$$

(for stochastically based DACs)

$$
H_{T}(50)=D A C-\text { hours } \times \frac{50 \text { rem }}{2000 D A C-\text { hours }}
$$

(for deterministically based DACs)

Minimum Detectable Intake (MDI)

$$
\mathrm{MDI}=\frac{\mathrm{MDA}}{\operatorname{IRF}(\mathrm{t})}
$$

Minimum Detectable Dose (MDD)

$$
M D D=M D I \times h_{T}(50) \text { or } e(50)
$$




\subsection{References}

10 CFR 835. 2007. “Occupational Radiation Protection.” Code of Federal Regulations.

U.S. Department of Energy. Available at: http://www.access.gpo.gov

Anderson J, B Kahn, R Rosson, E Kim, and TR La Bone. 1995. "Use of creatinine measurement to confirm the time interval of a urine sample.” Rad. Prot. Management, 12(5):51-65.

Boeniger MF, LK Lowry, and J Rosenberg. 1993. "Interpretation of urine results used to assess chemical exposure with emphasis on creatinine adjustments: A review.” Am. Ind. Hyg. Assoc. J. 54(10):615-627.

Carbaugh EH. 2003. "Minimum detectable dose as a measure of bioassay programme capability.” Rad Prot. Dosim. 105(1-4):391-394.

Carbaugh EH. 2008. "Jack Healy remembers: Anecdotal evidence for the origin of the simulated 24-hour urine sampling protocol used for worker bioassay monitoring.” Health Physics News, XXXVI, No. 10, Health Physics Society, McLean, Virginia.

Carbaugh EH, DE Bihl, JA MacLellan. 2009. Hanford Internal Dosimetry Program Manual. PNL-MA552, PNNL-15613, Pacific Northwest National Laboratory, Richland, Washington. (Internal manual.) A copy of this manual is maintained in the HIDP files and available from the HIDP Manager or online by searching, PNNL-15613 @ http://www.pnl.gov/publications/.

Duke K. 1998. "Use of the urinary excretion of creatinine in plutonium in urine bioassay.” Rad. Prot. Dosim. 79(1-4):125-128.

Dorrian MD and MR Bailey. 1995. "Particle size distributions of radioactive aerosols measured in workplaces.” Rad. Prot. Dosim. 60(2):119-133.

Graul RJ and RL Stanley. 1982. "Specific gravity adjustment of urine analysis results." Am. Ind. Hyg. Assoc. J. 43(11):863.

Harris SA, JT Purdham, RN Covey, and AM Sass-Kortask. 2000. “An evaluation of 24-hour urinary creatinine excretion for use in identification of incomplete urine collections and adjustment of absorbed dose of pesticides.” Am. Ind. Hyg. Assoc. J.61:649-657.

Health Physics Society (HPS). American National Standard - Design for Internal Dosimetry Programs. ANSI/HPS N13.39-2001, Health Physics Society, McLean, Virginia.

Heid KR and JJ Jech. 1972. "Prompt handling of cases involving accidental exposure to plutonium.” In Health Physics Operational Monitoring, Vol. 3, Proceedings of the Third Annual Health Physics Society Midyear Symposium, January, 29-31, 1969, CA Willis and JS Handloser, eds., Gordon and Breach Science Publishers, New York.

International Atomic Energy Agency (IAEA). 1999. Assessment of Occupational Exposure Due to Intakes of Radionuclides. Safety Standards Series No. RS-G-1.2. International Atomic Energy Agency, Vienna, Austria.

Issued for implementation effective 01/01/2010 
International Atomic Energy Agency (IAEA). 2004. Methods for Assessing Occupational Radiation Doses Due to Intakes of Radionuclides. Safety Reports Series No. 37. International Atomic Energy Agency, Vienna, Austria.

International Commission on Radiological Protection (ICRP). 1959. Report of Committee II on Permissible Dose for Internal Radiation. ICRP Publication 2, Pergamon Press, New York.

International Commission on Radiological Protection (ICRP). 1974. Report of the Task Group on Reference Man. ICRP Publication 23, Pergamon Press, New York.

International Commission on Radiological Protection (ICRP). 1977. "Recommendations of the International Commission on Radiological Protection.” ICRP Publication 26, Annals of the ICRP, 1:3, Pergamon Press, New York.

International Commission on Radiological Protection (ICRP). 1979. "Limits for Intakes of Radionuclides by Workers.” ICRP Publication 30, Part 1, Annals of the ICRP, 2:3-4, Pergamon Press, New York.

International Commission on Radiological Protection (ICRP). 1988. "Individual Monitoring for Intakes of Radionuclides by Workers: Design and Interpretation.” ICRP Publication 54, Annals of the ICRP, 19:1-3, Pergamon Press, New York.

International Commission on Radiological Protection (ICRP). 1990. "1990 Recommendations of the International Commission on Radiological Protection.” ICRP Publication 60, Annals of the ICRP, 21:1-3, Pergamon Press, New York.

International Commission on Radiological Protection (ICRP). 1994a. "Dose Coefficients for Intakes of Radionuclides by Workers.” ICRP Publication 68, Annals of the ICRP, 24:4, Pergamon Press, New York.

International Commission on Radiological Protection (ICRP). 1994b. "Human Respiratory Tract Model for Radiological Protection.” ICRP Publication 66, Annals of the ICRP, 24:1-3, Pergamon Press, New York.

International Commission on Radiological Protection (ICRP). 1996. “Age-dependent Doses to Members of the Public from Intakes of Radionuclides: Part 5 Compilation of Ingestion and Inhalation Dose Coefficients.” ICRP Publication 72, Annals of the ICRP, 26:1, Pergamon Press, New York.

International Commission on Radiological Protection (ICRP). 1997. "Individual Monitoring for Internal Exposure of Workers.” ICRP Publication 78, Annals of the ICRP, 27:3-4, Pergamon Press, New York.

International Commission on Radiological Protection (ICRP). 2002. "Basic Anatomical and Physiological Data for Use in Radiological Protection: Reference Values.” ICRP Publication 89. Annals of the ICRP, 32:3-4. Pergamon Press, New York.

International Commission on Radiological Protection (ICRP). 2007. "The 2007 Recommendations of the international Commission on Radiological Protection.” ICRP Publication 103, Annals of the ICRP, 37:2-4, Pergamon Press, New York 
Jackson S. 1966. “Creatinine in urine as an index of urinary excretion rate.” Health Phys. 12:843.

James AC, A Birchall, JW Marsh, and M Puncher. 2004 (or current version). User Manual for IMBA Expert, USDOE-Edition (Phase II). ACJ \& Associates, Richland, Washington. (Current version is available electronically as part of the IMBA Professional Plus software package.)

Karpas Z, A Lorber, E Elish, P Marcus, Y Roiz, R Marko, R Kol, D Brikner, and L Halicz. 1998. "Uranium in urine-normalization to creatinine.” Health Phys. 74(1):86-90.

Kelso SM and JC Wraight. 1996. "The measurement of aerosol size distributions (AMAD) in buildings on BNFL’s Sellafield Site.” Rad. Prot. Dosim. 63(2):1127-131.

Kim EM. 1995. Determination of Time Interval of Urine Sample by Measuring Creatinine in Urine. ESH-HPT-95007, Westinghouse Savannah River Company, Savannah River Site, Aiken, South Carolina.

Medley DW, RL Kathren, and AG Miller. 1994. "Diurnal urinary volume and uranium output in uranium workers and unexposed controls.” Health Phys. 67(2):122-130.

National Bureau of Standards (NBS). 1953. Maximum Permissible Amounts of Radioisotopes in the Human Body and Maximum Permissible Concentrations in Air and Water. Handbook 52, U.S. Department of Commerce, Washington, D.C.

National Bureau of Standards (NBS). 1959. Maximum Permissible Body Burdens and Maximum Permissible Concentrations of Radionuclides in Air and Water for Occupational Exposure.

Handbook 69, U.S. Department of Commerce, Washington, D.C.

National Council on Radiation Protection and Measurements (NCRP). 1987. Use of Bioassay Procedures for Assessment of Internal Radionuclide Deposition. NCRP Report No. 87, Bethesda, Maryland.

National Council on Radiation Protection and Measurements (NCRP). 2006. Development of a Biokinetic Model for Radionuclide-Contaminated Wounds and Procedures for Their Assessment, Dosimetry, and Treatment. NCRP Report No. 156, Bethesda, Maryland.

National Institute for Occupational Safety and Health (NIOSH). 1974. Criteria for a Recommended Standard - Occupational Exposure to Benzene. Health, Education, and Welfare (HEW) publication (NIOSH) 74-137, U.S. Government Printing Office, Washington, D.C.

National Research Council. 1988. Health Risks of Radon and Other Internally Deposited AlphaEmitters. Biological Effects of Ionizing Radiation (BEIR) IV, National Academy Press, Washington, D.C.

Nenot JE and JW Stather. 1979. The Toxicity of Plutonium, Americium, and Curium. Commission of the European Communities, Pergamon Press, Oxford, England.

Palmer HE, RW Perkins, and BO Stuart. 1964. "The distribution and deposition of radon daughters attached to dust particles in the respiratory system of humans exposed to uranium mine atmospheres.” Health Phys. 10:1129-1135.

Issued for implementation effective 01/01/2010

PNNL-MA-860 Chapter 2.0

Supersedes: January 31, 2003

Page 2.13 
Sula MJ, EH Carbaugh, and DE Bihl. 1989. Technical Basis for Internal Dosimetry at Hanford. PNL-6866, Pacific Northwest Laboratory, Richland, Washington.

U.S. Department of Energy (DOE). 1994. Radiological Control Manual. DOE/EH-0256T, Rev. 1, Washington, D.C.

U.S. Department of Energy (DOE). 2008a. Radiation Protection Program Guide for Use with Title 10, Code of Federal Regulations, Part 835, Occupational Radiation Protection. DOE G 441.1-1C, Washington, D.C. Available at: http://www.directives.doe.gov

U.S. Department of Energy (DOE). 2008b. Internal Dosimetry. DOE-STD-1121-2008, Washington, D.C. Available at: http://www.hss.energy.gov/nuclearsafety/techstds/ 


\subsection{Special Topics}

This chapter provides a subject area for technical basis discussions of special issues that arise and do not fit neatly in other chapters or appendices of this manual. These topics may be of short-term application, limited scope, or simultaneously deal with multiple chapters of this manual. This chapter will include sequentially numbered sections as topics are issued. 


\section{Methods and Models of the Hanford Internal Dosimetry Program \\ PNNL-MA-860}

\subsection{Tritium}

Issued for implementation effective 01/01/2010

Supersedes: September 12, 2000

\section{Use Category: Not applicable}

\section{Approval Signatures:}

Prepared by:
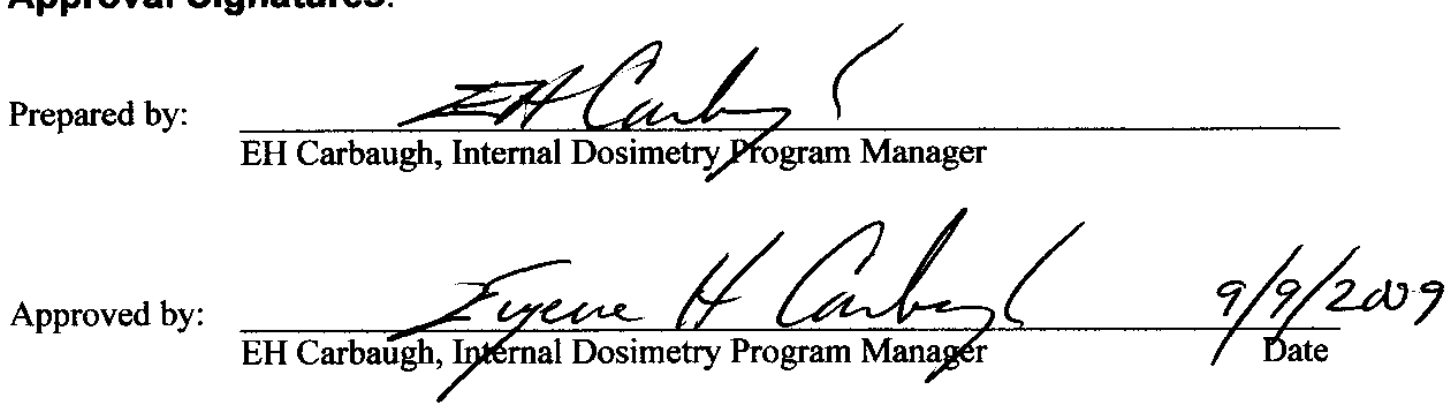

\section{Reviewer Signatures:}

Reviewed by:

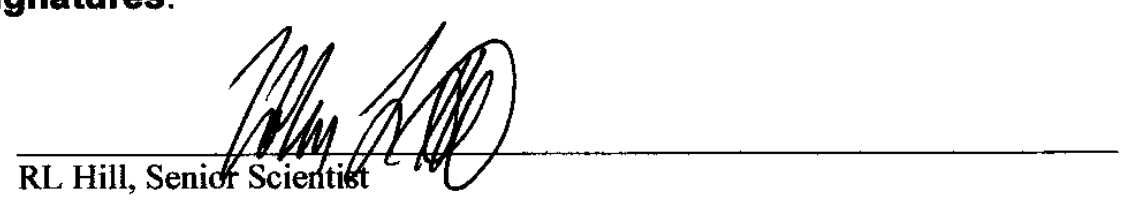

Approved by the Hanford Personnel Dosimetry Advisory Committee as recorded in the meeting minutes of March 10, 2009. 


\section{Contents}

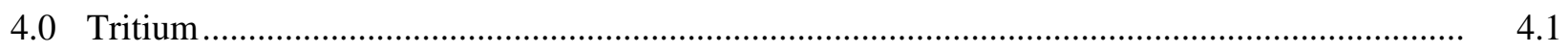

4.1 Sources and Environmental Levels of Tritium...............................................................

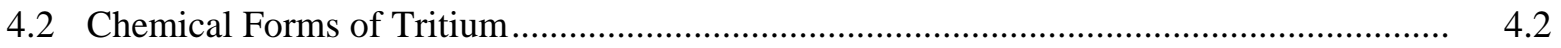

4.3 Internal Dosimetry for Tritiated Water ....................................................................... 4.2

4.3.1 Dose Calculation for an Acute Exposure to Tritiated Water..................................... 4.4

4.3.2 Dose Calculation for a Chronic Exposure to Tritiated Water .................................... 4.5

4.3.3 Tritiated Water Dosimetry Based on Multiple Sample Results .............................. 4.6

4.3.4 Bioassay for Intakes of Tritiated Water ............................................................... 4.6

4.3.5 Derived Reference Levels for Tritiated Water Bioassay....................................... 4.7

4.3.6 Bioassay Measurements Capability for Acute Tritiated Water Exposures ............... 4.8

4.3.7 Bioassay Measurement Capability for Chronic Tritiated Water Exposures.............. 4.10

4.3.8 Optimum Bioassay Sampling Intervals for Tritiated Water Exposures .................... 4.10

4.3.9 Special Monitoring for Tritiated Water............................................................... 4.10

4.4 Internal Dose Assessment Protocols for Tritiated Water ................................................... 4.11

4.4.1 Dose Assessment for a Single Acute Exposure......................................................... 4.11

4.4.2 Dose Assessment for Chronic Exposure ….......................................................... 4.11

4.4.3 Dose Assessment for Periodic Samples ................................................................. 4.11

4.5 Management of Internal Contamination Cases ............................................................... 4.12

4.6 Tritium Monitoring Program for the 400 Area ............................................................... 4.12

4.7 Special Tritium Compounds......................................................................................... 4.13

4.7.1 Organically Bound Tritium …............................................................................... 4.13

4.7.2 Tritiated Particulate Aerosols ..................................................................... 4.14

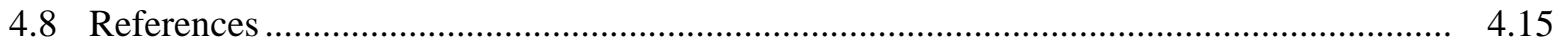

\section{Figures}

4.1 Tritiated Water Metabolic Model from ICRP 67 and ICRP 78 .............................................. 4.4

4.2 Tritium Bioassay Monitoring Program Detection Capability for Analytical Sensitivity of $20 \mathrm{dpm} / \mathrm{ml}$ using the ICRP 78 Retention Model........................................................................ 4.9

4.3 Tritium Urine Concentration in Occupationally Unexposed FFTF Workers ............................. 4.13

4.4 Organically Bound Tritium Metabolic Model from ICRP 78 ...................................................... 4.15 


\section{Tables}

4.1 Hanford Tritiated Water Dosimetry Factors ....................................................................

4.2 Comparison of Tritium Dose Factors ……...........................................................................

4.3 Single Acute Intake Derived Reference Levels for Tritium Urine Excretion .............................. 4.8

4.4 Multiple Acute Intake Derived Reference Levels for Tritium Urine Excretion.......................... 4.8

4.5 Minimum Detectable Intakes and Doses for Acute Tritium Intakes, Assuming the ICRP 78 Two-Component Body Water Retention Model and an Analytical Sensitivity of $20 \mathrm{dpm} / \mathrm{ml}$ in Body Water. 



\subsection{Tritium}

This chapter provides information about the sources and biokinetics of tritium and summarizes the technical basis used for the internal dosimetry of tritium $\left({ }^{3} \mathrm{H}\right)$ at Hanford. This chapter is not intended to be an all-encompassing technical basis for any type of tritium exposure, rather it is intended to provide the approach to be used for routinely encountered exposures at Hanford. A detailed review of tritium metabolism and dosimetry was published by Hill and Johnson (1993). There is broad consensus on the internal dosimetry for tritiated water vapor. However, organic forms and stable tritium particulates (notably metal tritides) have undergone substantial technical evaluation within the U.S. Department of Energy (DOE) complex in the last few years, and the dosimetry for such materials is subject to change with emerging knowledge. Therefore, this chapter addresses such special tritium compounds in only a cursory manner at this time. For any concerns about these materials, contact the Internal Dosimetry staff.

\subsection{Sources and Environmental Levels of Tritium}

Tritium exists as part of the natural background of environmental radiation (NCRP 1979a) originating from cosmic ray interactions. It is also a man-made nuclide that has been widely dispersed in the environment from nuclear weapons tests, nuclear power programs, and radioisotope applications.

Tritium work at Hanford has included tritium production, research associated with tritium production, the decontamination and decommissioning of former tritium production facilities and laboratories associated with such facilities, radioluminescent lights developed by Pacific Northwest National Laboratory (PNNL), and as a tracer or labeling compound for biological research projects. Tritium waste is also received at Hanford from other sites. Predominant forms of tritium have been tritium oxide (tritiated water), tritium gas, and at least one project involving stable metal tritides (notably, zirconium tritide).

Tritium oxide in the human body can be routinely detected at levels well below those of any dosimetric concern. Therefore, in addition to its use for dosimetry, tritium bioassay can be readily used as a workplace monitoring technique supplemental to air sampling or contamination surveys.

It can be assumed that the tritium concentration of the body water of non-occupationally exposed persons should be reasonably close to that of their drinking water. The U.S. Environmental Protection Agency (EPA) has reported that background tritium concentrations in U.S. drinking water range from 100 to $400 \mathrm{pCi} / \mathrm{L}$ (EPA 1985), which corresponds to about 0.2 to $1 \mathrm{dpm} / \mathrm{ml}$. In addition, the EPA has promulgated a limit for tritium in drinking water of $20 \mathrm{nCi} / \mathrm{L}$, based on $4 \mathrm{mrem} / \mathrm{y}$ (65 FR 76708-76753), although an upward revision of this limit seems technically justifiable (Moghissi and Cothern 1986).

Tritium has been widely distributed in the public domain as a source of luminosity for various "glowin-the-dark" applications, such as the faces of watches, clocks, instruments, and exit signs. Breakage or other loss of containment in such devices could result in tritium levels in urine being substantially above background without occupational exposure. Normal diffusion of tritium through watch cases can account for detectable urinary excretion of tritium. Brunner et al. (1996) reported urine concentrations of 197 to $1133 \mathrm{~Bq} / \mathrm{L}$ (12 to $68 \mathrm{dpm} / \mathrm{ml}$ ) in 108 persons wearing plastic case watches containing tritium. 


\subsection{Chemical Forms of Tritium}

Tritium occurs in several chemical forms that significantly affect the internal dosimetry associated with it. These forms include tritium gas (which is an external dose hazard posing little internal dosimetry impact, and thus is not addressed here), tritiated water vapor or liquid, and special tritium compounds including organically bound tritium and soluble or insoluble tritiated particulates. Tritiated water is the typical form encountered at Hanford, and routine Hanford dosimetry is based on this form. Organically bound tritium may be associated with things such as contaminated oils or experiments using tritium as a tracer. Tritiated particulates are often linked to metal tritides associated with tritium storage devices or tritium rust (tritiated iron oxide). Limited activities involving stable metal tritides have been identified by PNNL. The U.S. Department of Energy has collectively referred to organically bound tritium and stable metal tritides as "special tritium compounds" and has addressed them in a handbook (DOE 2004). Organically bound tritium and stable metal particulates of tritium can deliver substantially more dose per unit intake than tritiated water.

Internal dosimetry for each of the three tritium forms of greatest concern is discussed in the following sections.

\subsection{Internal Dosimetry for Tritiated Water}

Determining the dose from tritium exposures involves calculating the dose to soft tissue from tritium that is assumed to be uniformly distributed throughout the body water. The body water concentration can be determined by first sampling the body fluids (typically urine), then by directly measuring tritium using liquid scintillation techniques. For acute exposure situations, the initial body water concentration can be estimated from the retention function, and a total tritium uptake can be calculated using the Reference Man body water mass from International Commission on Radiological Protection Publication 23 (ICRP 1974). From this uptake, the soft tissue equivalent dose can be calculated for any pertinent time period. For chronic exposure situations, an equilibrium body burden of tritium can be estimated from the body water concentration, and an equivalent dose can be calculated for any pertinent time period using a dose rate factor. A summary of selected Hanford internal dosimetry factors for tritiated water (HTO) is shown in Table 4.1. Their derivation is described in the following paragraphs.

Table 4.1. Hanford Tritiated Water (HTO) Dosimetry Factors

\begin{tabular}{ll}
\hline Radiological half-life & $12.35 \mathrm{y}$ \\
Hanford HTO dose coefficient & $1.80 \mathrm{E}-11 \mathrm{~Sv} / \mathrm{Bq}$, or $0.0666 \mathrm{mrem} / \mu \mathrm{Ci}$ \\
Water absorption rate through skin & $0.065 \mathrm{mg} / \mathrm{cm}^{2}$ per minute \\
Equivalent dose per unit concentration & $1.26 \mathrm{E}-03 \mathrm{mrem}$ per $\mathrm{dpm} / \mathrm{ml}$ \\
factor & $2.79 \mathrm{mrem}$ per $\mu \mathrm{Ci} / \mathrm{l}$ \\
Dose rate per unit body water & $0.19 \mathrm{mrem} /$ day per $\mu \mathrm{Ci} / \mathrm{l}$ \\
concentration factor & $8.7 \mathrm{E}-5 \mathrm{mrem} /$ day per dpm $/ \mathrm{ml}$ \\
Derived air concentration (10 CFR 835 & $2 \mathrm{E}-05 \mu \mathrm{Ci} / \mathrm{ml}$ or \\
Appendix A) & $7 \mathrm{E}+05 \mathrm{~Bq} / \mathrm{m}^{3}$ \\
\hline
\end{tabular}

Historically, the approach to tritium dosimetry used in ICRP 2 and 10 and the American National Standards Institute Standard N13.14-1983 (ANSI 1983) was to calculate the dose to body water as the 
critical organ (ICRP 1959, 1969; ANSI 1983). A body water mass of 42,000 g was assumed for ICRP 23 Reference Man (1974). It was assumed that the dose to body water was essentially the same as the dose to soft tissue. In ICRP 30 (1979), a more realistic approach to tritium dosimetry was defined. The body water mass of ICRP 23 Reference Man (42,000 g) was recognized to be essentially uniformly distributed throughout the body mass of soft tissue (63,000 g). ICRP 67 (1993) used a body mass of $68.831 \mathrm{~kg}$, representing the total body mass minus the contents of the gastrointestinal (GI) tract and urinary and gall bladders. Thus the resulting ICRP 67 specific effective energy factor was slightly lower than the ICRP 30 value, which offset the increase in retention time resulting from use of a two-component model described below. The net effect was a very slight increase in the dose coefficient from the ICRP 30 value of 1.7E-11 Sv/Bq to the ICRP 67 value of $1.8 \mathrm{E}-11 \mathrm{~Sv} / \mathrm{Bq}$. In other words, the tritium dosimetry factors did not significantly change, although their derivation did. Tritiated water is readily absorbed through intact skin. Pinson and Laugham (1980) reported a skin absorption rate for water of $0.065 \mathrm{mg} / \mathrm{cm}^{2}$ per minute.

Tritium as HTO is assumed to be instantaneously and uniformly mixed with body water immediately following intake. The $f_{1}$ factor is assumed to be 1.0 for all ages. This makes HTO a special case where total intake and systemic uptake are identical. Although the National Council on Radiation Protection and Measurements (NCRP 1976) suggests that 2 or more hours may be required for this distribution and mixing to occur, from a practical standpoint the process is quite rapid and an approximate equilibrium condition will probably be reached by the time a sample can be collected. The collection of overnight urine samples provides good assurance that an equilibrium condition in the body has been achieved; however, adequate dosimetry can be done using single void samples.

The metabolic model used for HTO is summarized in ICRP 78 (1997) and illustrated in Figure 4.1. Tritiated water is assumed to be uniformly distributed among all soft tissues at any time following intake. Its retention, $R(t)$, is described as a two-component exponential with $97 \%$ of the uptake having a clearance half-time of 10 days, and the remaining 3\% having a clearance half-time of 40 days. Thus, the fraction of tritium taken into the body as HTO, which is retained in the body at time t days later, is given by

$$
R(t)=0.97 e^{\frac{-0.693}{10} \times t}+0.03 e^{\frac{-0.693}{40} \times t}
$$

Radioactive decay is insignificant in this determination because the biological clearance far surpasses the physical decay half-time of 12 years as a mode of clearance from the body. This retention function supersedes that of ICRP 30 (1979) and Health Physics Society American National Standard HPS N13.14 (HPS 1994) which used only the 10-day half-time component. It can be expected that the retention of HTO in individuals will vary from this, and if sufficient data are available to establish an alternate model for an individual worker's exposure, they should be used. 


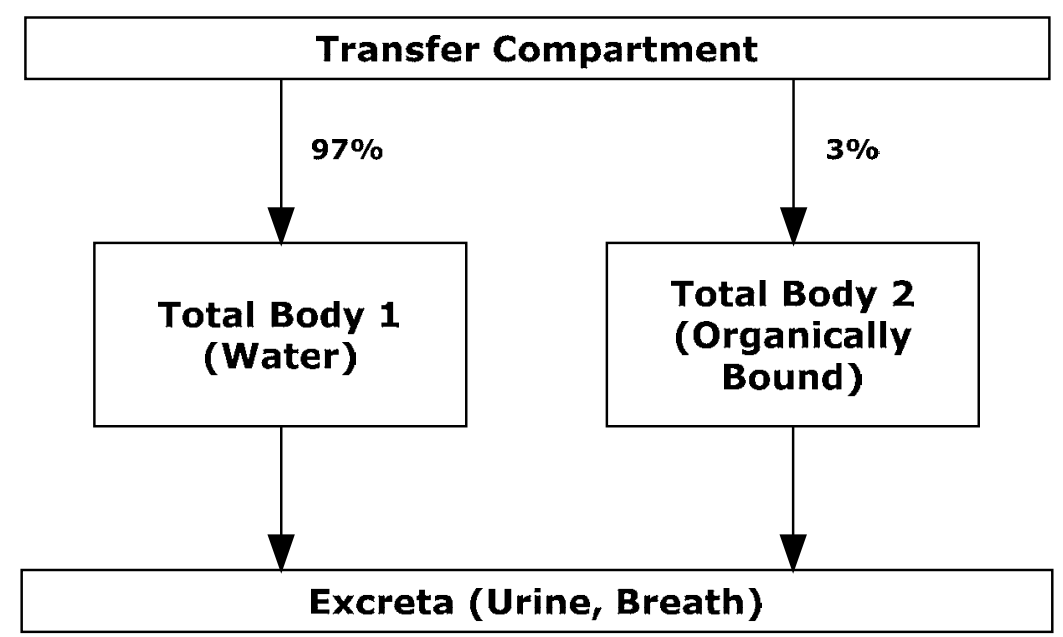

Figure 4.1. Tritiated Water Metabolic Model from ICRP 67 and ICRP 78 (adapted from James et al. 2004)

The number of transformations $\left(\mathrm{U}_{\mathrm{s}}\right)$ resulting from an intake of $1 \mathrm{~Bq}$ can be calculated by integrating the retention function over the appropriate time interval. This calculation is shown below for the 50-year committed dose period:

$$
\begin{aligned}
U_{s} & =\int_{0}^{18,250} 0.97 e^{\frac{-0.693}{10} \times t}+0.03 e^{\frac{-0.693}{40} \times t} d t \\
& =15.73 \mathrm{~Bq} d \times 24 h d^{-1} \times 3,600 s h^{-1} \\
& =1.36 \times 10^{6} \text { transformations }
\end{aligned}
$$

\subsubsection{Dose Calculation for an Acute Exposure to Tritiated Water}

The uniform concentration of tritium in body water and its relatively simple biokinetic model allow for the estimation of uptake based on concentration rather than total daily excretion. The retention function (Equation [4.1]) can be used to directly estimate the body water concentration as follows:

$$
C_{t}=C_{0} \times R(t)
$$

where $\quad C_{t}=$ body water concentration on day $t$

$$
\begin{aligned}
R(t) & =\text { the retention function value for day } t \\
C_{0} & =\text { initial body water concentration } \\
t & =\text { elapsed time (days) post intake. }
\end{aligned}
$$

$C_{0}$ can be determined from $C_{t}$ and $t$ by simple algebraic manipulation of this equation.

$$
C_{0}=\frac{C_{t}}{R(t)}
$$


Once $C_{0}$ has been determined, the intake $\mathrm{I}_{0}$ (same as uptake for HTO) for an acute exposure can be estimated by multiplying $C_{0}$ by the source organ (body water) mass as shown in Equation (4.5):

$$
\mathrm{I}_{0}=\mathrm{C}_{0} \times \text { Body Water Mass or Volume }
$$

where concentration and body water mass or volume units are consistent. The ICRP Reference Man body water mass of $42 \mathrm{~kg}$ or volume of $42,000 \mathrm{ml}$ is used for normal internal dose calculations.

The effective dose coefficient, $e(50)$, from ICRP 78 is $1.80 \mathrm{E}-11 \mathrm{~Sv} \mathrm{~Bq}{ }^{-1}$. This dose coefficient and its conventional units conversion $(0.0666 \mathrm{mrem} / \mu \mathrm{Ci})$ are the factors used for HTO for Hanford internal dosimetry.

Using conventional units of mrem for $E(50)$ and $\mu \mathrm{Ci}$ for $I_{0}$, as is customary for the Hanford Internal Dosimetry Program (HIDP), the committed effective dose from an intake of tritium is calculated as

$$
E(50)(\text { mrem })=0.0666 \times I_{0}(\mu C i)
$$

Substituting concentration $C_{0}$ (in $\mu \mathrm{Ci} / \mathrm{L}$ ) times the Reference Man body water volume of $42 \mathrm{~L}$ for $I_{0}$ (i.e., $0.0666 \times 42=2.79$ ), gives the following relationship, as described in American National Standard HPS N13.14 (1983):

$$
E(50)(\text { mrem })=2.79 \times C_{0}(\mu C i / L)
$$

which, when converted to the Hanford reporting units for concentration of dpm/ml, becomes

$$
E(50)(\text { mrem })=0.00126 \times C_{0}(\mathrm{dpm} / \mathrm{ml})
$$

It should be noted that the IMBA Professional Plus (IMBA) internal dosimetry computer code, v. 4.0.43 (James et al. 2004) ${ }^{1}$ may also be used for dose evaluations for tritium. However, while IMBA includes methods for looking at both inorganic and organic tritium, it does not currently include tritiated gases or vapors. In addition, the bioassay calculations section in IMBA indicates activity per day when it is actually units of activity per liter (OCAS 2003). Using IMBA for tritium dose calculations is somewhat more labor intensive, so a simple method described in Section 4.4 is the preferred method used at Hanford.

\subsubsection{Dose Calculation for a Chronic Exposure to Tritiated Water}

For chronic exposure to HTO, or a series of continuing acute exposures, an equilibrium concentration in body water is assumed. The effective dose rate during the period when the concentration is maintained

\footnotetext{
${ }^{1}$ IMBA Professional Plus, which includes the current version of the user manual, is available from Health Protection Agency (HPA), Radiation Protection Division, Chilton, Didicot, Oxon., OX11 0RQ UK and from http://www.imbaprofessional.com/
} 
can be calculated by substituting the equilibrium body water concentration $\left(\mathrm{C}_{\mathrm{eq}}(\mu \mathrm{Ci} / \mathrm{l}) \times 42\right)$ for $\mathrm{A}_{\mathrm{s}}$ in Equation (2.1) and addressing units conversion, which gives

$$
\dot{E}(50)(\mathrm{mrem} / \mathrm{d})=0.19 \times C_{e q}(\mu \mathrm{Ci} / \mathrm{L})
$$

and in units typically reported by the Hanford radiochemistry bioassay laboratory:

$$
\dot{E}(50)(\mathrm{mrem} / \mathrm{d})=8.7 \times 10^{-5} \times C_{e q}(\mathrm{dpm} / \mathrm{ml})
$$

The effective dose for the time period during which the equilibrium body water concentration is maintained can then be calculated by

$$
E(50)(\text { mrem })=\dot{E}(50) \times t
$$

where $t$ is the duration of exposure in days.

The total committed dose resulting from a chronic exposure interval consists of the dose incurred during the interval, as calculated by Equation (4.11), and the dose incurred after the termination of intake. This latter component can be calculated using the equation for an acute exposure (e.g., Equation [4.7]) where $C_{0}$ is equal to $C_{e q}$ ) in $\mu \mathrm{Ci} / \mathrm{L}$ as follows:

$$
E(50)(\text { mrem })=(\dot{E}(50) \times t)+\left(2.79 \times C_{0}\right)
$$

\subsubsection{Tritiated Water Dosimetry Based on Multiple Sample Results}

When data from routine monitoring indicate that multiple acute intakes or combinations of acute and chronic exposure conditions may exist, dosimetry may be performed by integrating the body water concentration over time and multiplying by the dose rate per unit concentration factor listed in Table 4.2 (as shown in Equation [4.13]). This method is particularly useful if samples are obtained frequently enough to provide an accurate estimate of the integral value.

$$
E(50)=0.19 \int C_{t} d t
$$

where $E(50)$ is in mrem and $C_{t}$ is in $\mu \mathrm{Ci} / \mathrm{L}$.

\subsubsection{Bioassay for Intakes of Tritiated Water}

Bioassay monitoring for intakes of HTO is relatively simple and involves sampling a representative body fluid. Any body fluid can be used, but from a practical standpoint urine is the medium of choice. Because dosimetry can be readily performed using concentration data and because the models are quite simple, a single voiding (spot) urine sample is sufficient to obtain an adequate volume for analysis. Only a few milliliters are actually used in the liquid scintillation analysis procedure. Sufficient time should 
pass following exposure to allow for uniform distribution throughout body fluids. The NCRP suggests that 2 or more hours may be required for this (NCRP 1976). For this reason, it is usually recommended that tritium samples be collected at home using a multiple voiding sampling protocol to obtain an average concentration.

Table 4.2. Comparison of Tritium Dose Factors

\begin{tabular}{|c|c|}
\hline Dose Factor & Reference \\
\hline \multicolumn{2}{|c|}{ Tritiated Water (HTO) } \\
\hline \multicolumn{2}{|l|}{ Effective Dose Coefficients } \\
\hline 1.8E-11 Sv/Bq (0.0666 mrem/ $\mu \mathrm{Ci})$ & ICRP 67 (1993), 68 (1994), 71 (1995) and 78 (1997) \\
\hline \multicolumn{2}{|l|}{ Derived Air Concentration (DAC) } \\
\hline $2 \mathrm{E}-05 \mu \mathrm{Ci} / \mathrm{ml}\left(7 \mathrm{E}+05 \mathrm{~Bq} / \mathrm{m}^{3}\right)$ & 10 CFR 835 Appendix A \\
\hline \multicolumn{2}{|l|}{ Annual Limit on Intake (ALI) } \\
\hline 75,000 $\mu \mathrm{Ci}(2.8 \mathrm{E}+09 \mathrm{~Bq})$ & Derived from Eq. 2.8, (this manual) \\
\hline \multicolumn{2}{|c|}{ Organically Bound Tritium (OBT) } \\
\hline \multicolumn{2}{|l|}{ Effective Dose Coefficients } \\
\hline 4.2E-11 Sv/Bq (0.16 mrem/ $\mu \mathrm{Ci})$ & ICRP 67 (1993), 68 [1994]), 78 (1997) \\
\hline 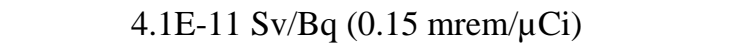 & Inhalation $\quad$ ICRP 71 (1995), 78 (1997); DOE (2004) \\
\hline \multicolumn{2}{|l|}{ Derive Air Concentration Value (DAC) } \\
\hline $1 \mathrm{E}-05 \mu \mathrm{Ci} / \mathrm{ml}\left(5 \mathrm{E}+05 \mathrm{~Bq} / \mathrm{m}^{3}\right)$ & 10 CFR 835 Appendix A (Soluble STCs) \\
\hline \multicolumn{2}{|c|}{ Soluble and Insoluble Tritiated Particulates (STP, ITP) } \\
\hline Effective Dose Coefficients for 5 - $\mu \mathrm{m}$ particles & DOE (2004) Appendix A \\
\hline \multicolumn{2}{|l|}{$\begin{array}{l}\text { Type F insoluble STP and all soluble STP: } \\
5.5 \mathrm{E}-11 \mathrm{~Sv} / \mathrm{Bq}(0.20 \mathrm{mrem} / \mu \mathrm{Ci})\end{array}$} \\
\hline \multicolumn{2}{|l|}{ Type M: 8.6E-11 Sv/Bq (0.31 mrem/ $\mu \mathrm{Ci})$} \\
\hline \multicolumn{2}{|l|}{ 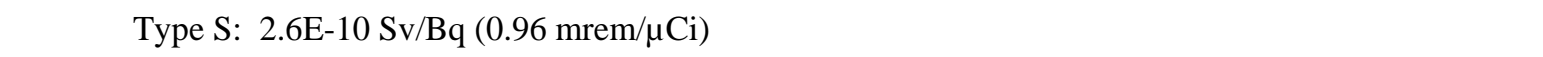 } \\
\hline \multicolumn{2}{|l|}{ Derived Air Concentration Values (DAC) } \\
\hline Type F: $1 \mathrm{E}-05 \mu \mathrm{Ci} / \mathrm{ml}\left(3 \mathrm{E}+05 \mathrm{~Bq} / \mathrm{m}^{3}\right)$ & 10 CFR 835 Appendix A (Insoluble STC) \\
\hline Type M: $6 \mathrm{E}-06 \mu \mathrm{Ci} / \mathrm{ml}\left(2 \mathrm{E}+05 \mathrm{~Bq} / \mathrm{m}^{3}\right)$ & 10 CFR 835 Appendix A (Insoluble STC) \\
\hline Type S: $2 \mathrm{E}-06 \mu \mathrm{Ci} / \mathrm{ml}\left(8 \mathrm{E}+04 \mathrm{~Bq} / \mathrm{m}^{3}\right)$ & 10 CFR 835 Appendix A (Insoluble STC) \\
\hline STC = special tritium compounds & \\
\hline
\end{tabular}

The Hanford bioassay laboratory's liquid scintillation procedure involves direct mixing of a small quantity (e.g., 1 or $2 \mathrm{ml}$ ) of the urine sample with the scintillation cocktail solution. The sample is then counted in a liquid scintillation analyzer.

\subsubsection{Derived Reference Levels for Tritiated Water Bioassay}

Derived screening levels, investigation levels, and compliance levels, based on committed effective doses of 10 mrem, 100 mrem, and 5,000 mrem, respectively, are shown in Table 4.3 for a single acute intake, and Table 4.4 for multiple intakes. 


\subsubsection{Bioassay Measurements Capability for Acute Tritiated Water Exposures}

The detection capability of a routine tritium bioassay monitoring program for acute exposures has been considered in terms of minimum detectable dose (committed effective dose) per intake and year, using an analytical procedure sensitivity of $20 \mathrm{dpm} / \mathrm{ml}$. In making these calculations, it was assumed that an acute intake occurred on the day immediately following a sample; thus, the time post intake was considered equal to the length of the sample interval. It was also assumed that the pattern of one intake at the start of each interval might be maintained for a year. The results of these calculations are listed in Table 4.5 and plotted as the acute intake curve in Figure 4.1.

Table 4.3. Single Acute Intake Derived Reference Levels for Tritium Urine Excretion

\begin{tabular}{|c|c|c|c|c|}
\hline Days Post Intake & $\begin{array}{c}\text { Body Water Intake } \\
\text { Retention Fraction } \\
\text { ICRP } 78 \text { HTO } \\
\end{array}$ & $\begin{array}{c}\text { 10-mrem E }(50) \\
\text { Derived Screening } \\
\text { Level }^{(\text {a) }}(\mathrm{dpm} / \mathrm{ml}) \\
\end{array}$ & $\begin{array}{c}\text { 100-mrem E(50) Derived } \\
\text { Investigation Level }^{(\mathrm{b})} \\
(\mathrm{dpm} / \mathrm{ml})\end{array}$ & $\begin{array}{c}\text { 5-rem } E(50) \\
\text { Derived Compliance }^{(\mathrm{c})}(\mathrm{dpm} / \mathrm{ml}) \\
\text { Level }^{(\mathrm{c})}\end{array}$ \\
\hline 0 & $1.00 \mathrm{E}+00$ & $7.93 \mathrm{E}+03$ & 7.93E+04 & $3.96 \mathrm{E}+06$ \\
\hline 1 & 9.35E-01 & $7.41 \mathrm{E}+03$ & $7.41 \mathrm{E}+04$ & $3.70 \mathrm{E}+06$ \\
\hline 2 & 8.73E-01 & $6.93 E+03$ & $6.93 E+04$ & $3.46 \mathrm{E}+06$ \\
\hline 3 & 8.16E-01 & $6.47 \mathrm{E}+03$ & $6.47 \mathrm{E}+04$ & $3.24 \mathrm{E}+06$ \\
\hline 7 & $6.24 \mathrm{E}-01$ & $4.95 \mathrm{E}+03$ & $4.95 \mathrm{E}+04$ & $2.47 \mathrm{E}+06$ \\
\hline 14 & 3.91E-01 & $3.10 \mathrm{E}+03$ & $3.10 \mathrm{E}+04$ & $1.55 \mathrm{E}+06$ \\
\hline 30 & 1.39E-01 & $1.10 \mathrm{E}+03$ & $1.10 \mathrm{E}+04$ & $5.52 \mathrm{E}+05$ \\
\hline 60 & 2.58E-02 & $2.04 \mathrm{E}+02$ & $2.04 \mathrm{E}+03$ & $1.02 \mathrm{E}+05$ \\
\hline 90 & $8.21 \mathrm{E}-03$ & $6.51 \mathrm{E}+01$ & $6.51 \mathrm{E}+02$ & $3.25 E+04$ \\
\hline 180 & 1.33E-03 & $1.05 \mathrm{E}+01$ & $1.05 \mathrm{E}+02$ & $5.27 \mathrm{E}+03$ \\
\hline 365 & 5.38E-05 & 4.27E-01 & $4.27 \mathrm{E}+00$ & $2.13 \mathrm{E}+02$ \\
\hline
\end{tabular}

(a) Based on a $150-\mu C i$ intake.

(b) Based on a $1,500-\mu \mathrm{Ci}$ intake.

(c) Based on a 75,000- $\mu \mathrm{Ci}$ intake.

Table 4.4. Multiple Acute Intake Derived Reference Levels for Tritium Urine Excretion

\begin{tabular}{|c|c|c|c|c|}
\hline Days Post Intake & $\begin{array}{c}\text { Body Water Intake } \\
\text { Retention Fraction } \\
\text { ICRP } 78 \text { HTO }\end{array}$ & $\begin{array}{l}\text { Monitoring } \\
\text { Intervals } \\
\text { per Year }\end{array}$ & $\begin{array}{c}\text { 10-mrem } E(50) \\
\text { Derived Screening } \\
\text { Level }^{(a)}(\mathrm{dpm} / \mathrm{ml})\end{array}$ & $\begin{array}{l}\text { 100-mrem E(50) Derived } \\
\text { Investigation Level }^{(\mathrm{b})} \\
(\mathrm{dpm} / \mathrm{ml})\end{array}$ \\
\hline 1 & 9.35E-01 & 365 & 20 & 203 \\
\hline 2 & 8.73E-01 & 182 & 38 & 381 \\
\hline 3 & 8.16E-01 & 122 & 53 & 531 \\
\hline 7 & $6.24 \mathrm{E}-01$ & 52 & 95 & 951 \\
\hline 14 & 3.91E-01 & 26 & 119 & 1193 \\
\hline 30 & 1.39E-01 & 12 & 92 & 919 \\
\hline 60 & 2.58E-02 & 6 & 34 & 341 \\
\hline 90 & $8.21 \mathrm{E}-03$ & 4 & 16 & 163 \\
\hline 180 & 1.33E-03 & 2 & 5.3 & 53 \\
\hline 365 & 5.38E-05 & 1 & 0.4 & 4.3 \\
\hline
\end{tabular}

(a) Assumes one intake per monitoring interval and ignores residual from previous intakes.

(b) Based on 10-mrem screening level intake of $150 \mu \mathrm{Ci}$ cumulative for 1 year.

(c) Based on 100-mrem investigation level intake of $1500 \mu \mathrm{Ci}$ cumulative for 1 year.

PNNL-MA-860 Chapter 4.0

Page 4.8
Issued for implementation effective 01/01/2010

Superseded: January 2002 
Table 4.5. Minimum Detectable Intakes (MDIs) and Doses (MDDs) ${ }^{(a)}$ for Acute Tritium Intakes, Assuming the ICRP 78 Two-Component Body Water Retention Model and an Analytical Sensitivity of $20 \mathrm{dpm} / \mathrm{ml}$ in Body Water

\begin{tabular}{cccccc}
\hline $\begin{array}{c}\text { Days Post } \\
\text { Intake }\end{array}$ & $\begin{array}{c}\text { ICRP 78 Retention } \\
\text { Fraction }\end{array}$ & $\begin{array}{c}\text { MDI for } \\
\text { Interval }(\mu \mathrm{Ci})\end{array}$ & $\begin{array}{c}\text { Interval } \\
\text { MDD }(\mathrm{mrem})\end{array}$ & $\begin{array}{c}\text { Monitoring } \\
\text { Intervals per Year }\end{array}$ & $\begin{array}{c}\text { Maximum Annual } \\
\text { MDD }^{(\mathrm{b})}(\mathrm{mrem})\end{array}$ \\
\hline 1 & $9.35 \mathrm{E}-01$ & $4.05 \mathrm{E}-01$ & $2.70 \mathrm{E}-02$ & NA & NA \\
2 & $8.73 \mathrm{E}-01$ & $4.33 \mathrm{E}-01$ & $2.89 \mathrm{E}-02$ & $\mathrm{NA}$ & $\mathrm{NA}$ \\
3 & $8.16 \mathrm{E}-01$ & $4.63 \mathrm{E}-01$ & $3.09 \mathrm{E}-02$ & NA & NA \\
7 & $6.24 \mathrm{E}-01$ & $6.07 \mathrm{E}-01$ & $4.04 \mathrm{E}-02$ & 52 & 2.1 \\
14 & $3.91 \mathrm{E}-01$ & $9.67 \mathrm{E}-01$ & $6.44 \mathrm{E}-02$ & 26 & 1.7 \\
30 & $1.39 \mathrm{E}-01$ & $2.72 \mathrm{E}+00$ & $1.81 \mathrm{E}-01$ & 12 & 2.2 \\
60 & $2.58 \mathrm{E}-02$ & $1.47 \mathrm{E}+01$ & $9.78 \mathrm{E}-01$ & 6 & 12 \\
90 & $8.21 \mathrm{E}-03$ & $4.61 \mathrm{E}+01$ & $3.07 \mathrm{E}+00$ & 4 & 19 \\
120 & $3.99 \mathrm{E}-03$ & $9.49 \mathrm{E}+01$ & $6.32 \mathrm{E}+00$ & 3 & 38 \\
180 & $1.33 \mathrm{E}-03$ & $2.84 \mathrm{E}+02$ & $1.89 \mathrm{E}+01$ & 2 & 468 \\
365 & $5.38 \mathrm{E}-05$ & $7.03 \mathrm{E}+03$ & $4.68 \mathrm{E}+02$ & 1 & \\
\hline
\end{tabular}

(a) Committed effective dose.

(b) Assumes 1 intake per interval and no buildup from multiple intakes.

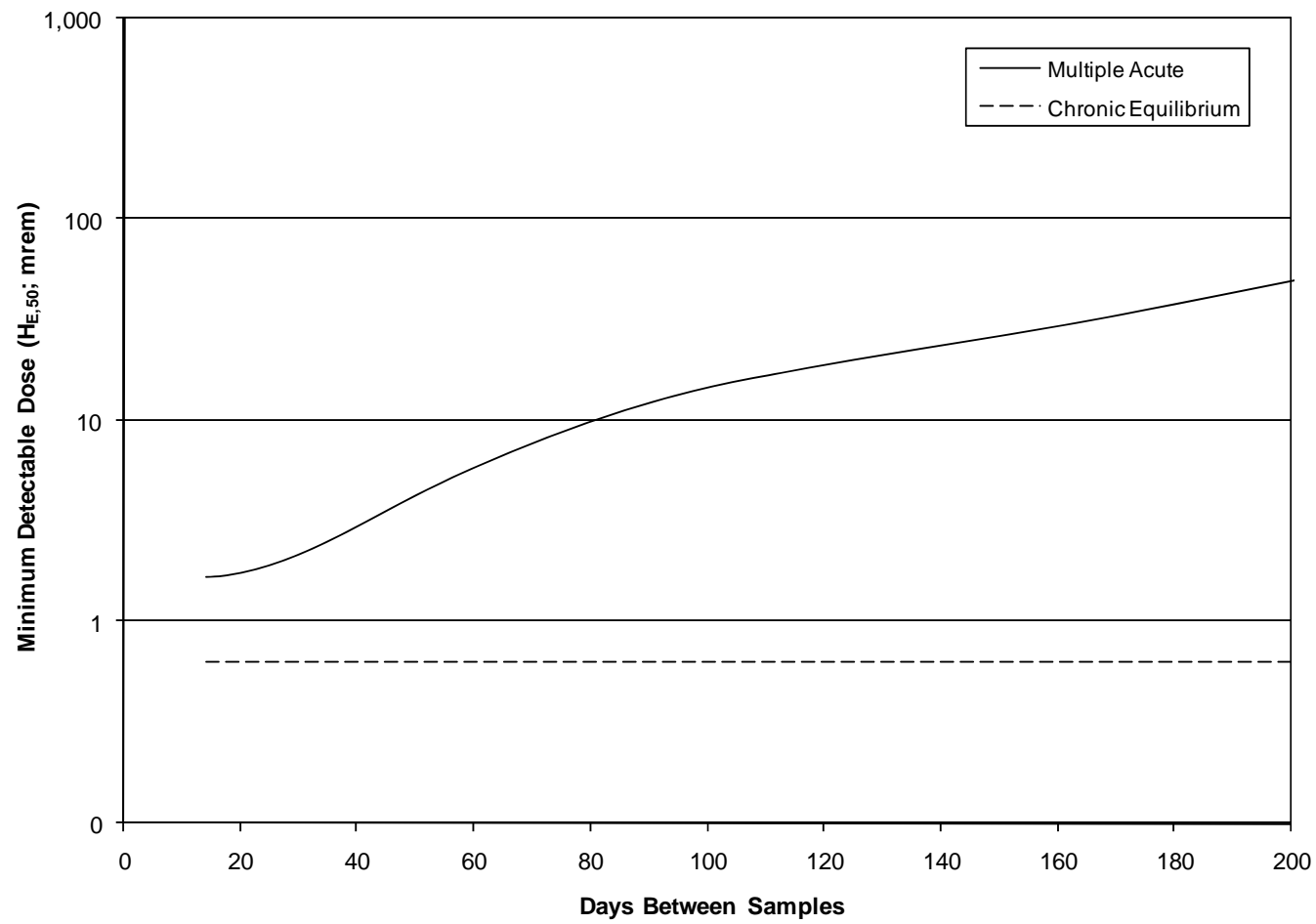

Figure 4.2. Tritium Bioassay Monitoring Program Detection Capability for Analytical Sensitivity of $20 \mathrm{dpm} / \mathrm{ml}$ using the ICRP 78 Retention Model

As previously noted, there is evidence for an organically bound component of a tritium oxide intake that can affect bioassay data interpretation at long times (e.g., >90 days) post intake. 


\subsubsection{Bioassay Measurement Capability for Chronic Tritiated Water Exposures}

If the exposure condition is chronic and an equilibrium body water concentration of $20 \mathrm{dpm} / \mathrm{ml}$ is assumed (equal to the sensitivity of the analytical procedure and implying a daily intake rate of $26 \mathrm{nCi}$ ), then the resulting committed effective dose from 365 days of intake would be 0.64 mrem. Because of the assumption of chronic equilibrium conditions, this estimate is independent of sample frequency, and is thus shown as a flat line in Figure 4.2.

\subsubsection{Optimum Bioassay Sampling Intervals for Tritiated Water Exposures}

From Figure 4.2, it is apparent that the optimum routine bioassay sampling frequency for tritium is once every 2 weeks (biweekly) for periodic acute intakes of tritium. Where exposure conditions are well established and anticipated tritium doses are low (e.g., $<100$ mrem for the year), less frequent intervals (e.g., monthly to quarterly) are adequate. However, the uncertainties with dose estimates associated with longer sampling intervals become much higher. Because of the approximate 10-day effective half-life, sampling intervals for HTO greater than 90 days are specifically not recommended. If the potential exposure to tritium is anticipated only for a very limited interval, starting and ending bioassay samples might be more suitable than participation in a continuing monitoring program.

Based on Table 4.4, a worker monitoring program using screening levels of $120 \mathrm{dpm} / \mathrm{ml}$ for biweekly samples or $90 \mathrm{dpm} / \mathrm{ml}$ for monthly samples is capable of detecting a 10-mrem committed effective dose in a year based on a series of acute or chronic HTO intakes. These screening levels are conservative because they ignore the buildup of excretion of tritium in urine as the number of periodic intakes increases during the year. At these screening levels, sampling schedules should be reviewed to ensure that workers are on an adequate routine monitoring program that is consistent with their work. If indications are that annual doses may exceed 100 mrem from ongoing work, then a biweekly sampling program is recommended.

\subsubsection{Special Monitoring for Tritiated Water}

Special monitoring may be required after unplanned or unusual exposures. When an unusual exposure has been suspected or reported, arrangements should be made to collect a urine specimen within a reasonably short period of time following the exposure, allowing for the achievement of body water equilibrium. For potentially high exposures, this sample might be a single voiding sample collected at the workplace. For less serious exposures, an overnight (simulated 12-hour) or simulated 24-hour sample provides confidence that body equilibrium has been achieved and may be more convenient.

Follow-up sampling should be performed to confirm the initial sample results if implied doses might exceed 100 mrem. Additional follow-up samples may be warranted to verify the applicability of the 10-day retention half-time in the individual, or to assess a more suitable half-time. To adequately determine the degree of agreement between observed and anticipated retention may require only two or three samples over a period of about 3 weeks, or it may involve a more extended sampling program. The evaluator must exercise judgment in determining the number of samples warranted. If the exposed worker is already on a routine (e.g., biweekly) monitoring frequency, additional special sampling for follow-up may not be required. 
Once an exposure has been evaluated, elevated urine samples might be expected for some time (several months). If the worker returns to work that involves potential tritium exposure, a more frequent sampling program may be required until normal baselines are re-established. During this time period, consideration may need to be given to the possibility that additional low-level uptakes of tritium might occur, which could be undetectable due to variability in the excretion pattern of tritium retained from the earlier intake.

\subsection{Internal Dose Assessment Protocols for Tritiated Water}

This section provides summary protocols for the assessment of occupational internal dose for HTO. As such, it applies the concepts described in the foregoing Section 4.3.

\subsubsection{Dose Assessment for a Single Acute Exposure}

To calculate the committed effective dose from an acute intake of tritium based on a single urine sample result, proceed as follows:

1. Calculate the initial body water concentration, $C_{0}$, in $\mathrm{dpm} / \mathrm{ml}$.

$$
C_{0}=\frac{C_{t}}{0.97 e^{\frac{-0.693}{10} \times t}+0.03 e^{\frac{-0.693}{40} \times t}}
$$

where $t$ is the time in days between the intake and the collection of the urine sample.

2. Calculate the committed effective dose, $E(50)$, in mrem.

$$
E(50)=0.00126 \times C_{0}
$$

\subsubsection{Dose Assessment for Chronic Exposure}

The committed effective dose from a chronic exposure to tritium (assuming the equilibrium condition) can be calculated as follows $\mathrm{C}_{\mathrm{eq}}$ in $\mathrm{dpm} / \mathrm{ml}$ :

$$
E(50)=\left[\left(8.7 \times 10^{-5} \times t\right)+0.00126\right] \times C_{e q}
$$

\subsubsection{Dose Assessment for Periodic Samples}

In situations where periodic samples are obtained, not associated with specifically identified intakes but rather with ongoing work practices, an average concentration and dose associated with a sampling interval can be calculated. The choice of an arithmetic mean versus a logarithmic mean has little impact on the dose estimates for intervals of 1 month or less (La Bone 1992). The dose for each sampling interval can be calculated using Equations (4.10) and (4.11), and the total dose for multiple intervals (e.g., 
for a year) can be calculated by summing the interval doses for the total period. This approach lends itself well to a simple computer spreadsheet application software, which the HIDP typically uses for these cases.

\subsection{Management of Internal Contamination Cases}

The primary treatment for reducing internal dose from a tritium uptake is to accelerate the turnover of body water. This can be done by substantially increasing the fluid intake rate of an individual through oral or intravenous means, and/or using diuretics (Bhattacharyya et al. 1992; NCRP 1980; IAEA 1978). A case study by Lloyd et al. (1986) of therapy for two HTO intakes indicated that diuresis therapy for workers while hospitalized resulted in a 2.7-day clearance half-time, compared with a 10-day normal clearance half-time, and a sustained drinking regime gave a clearance half-time of about 6 days. Such dose-mitigating actions should only be done under the oversight of Occupational Medicine or a competent medical authority in consultation with HIDP.

\subsection{Tritium Monitoring Program for the 400 Area}

The 400 Area of the Hanford Site, which includes the Fast Flux Test Facility (FFTF), obtains its drinking water from groundwater wells. Some of these wells contain low levels of tritium (below the EPA drinking water standards) originating from aquifer contamination by the past operation of 200 Area fuel processing and waste management facilities (Jaquish and Bryce 1989). Planned operations supporting fusion materials research were expected to produce large quantities of tritium, resulting in the need for a routine tritium bioassay program. In FFTF workers, the existence of potentially detectable tritium, which could be attributable to environmental sources rather than occupational exposure, warranted establishing a screening level to use as a basis for initiating investigations and dose assessments of potential occupational exposure.

A baseline bioassay monitoring program was undertaken for FFTF workers prior to the commencement of the tritium operations (Carbaugh, et al. 1990). Forty-seven urine samples were collected from FFTF operations personnel over a 5-month period in early 1989. The sample data are plotted in Figure 4.3.

Based on the curve fit, it was estimated that the geometric mean was $3 \mathrm{dpm} / \mathrm{ml}$ and the tritium concentration corresponding to the 99.9 percentile for environmental exposure at FFTF was $40 \mathrm{dpm} / \mathrm{ml}$. This concentration is similar to the $20,000 \mathrm{pCi} / \mathrm{L}(44 \mathrm{dpm} / \mathrm{ml})$ EPA Drinking Water Standard for tritium (EPA 2000).

The minimum detectable committed effective dose associated with a 40-dpm/ml tritium screening level was estimated to be 1.3 mrem for chronic equilibrium exposure conditions, 2 mrem for acute intakes with weekly to monthly sampling intervals (the anticipated range of sampling intervals), and 50 mrem for quarterly intervals. 


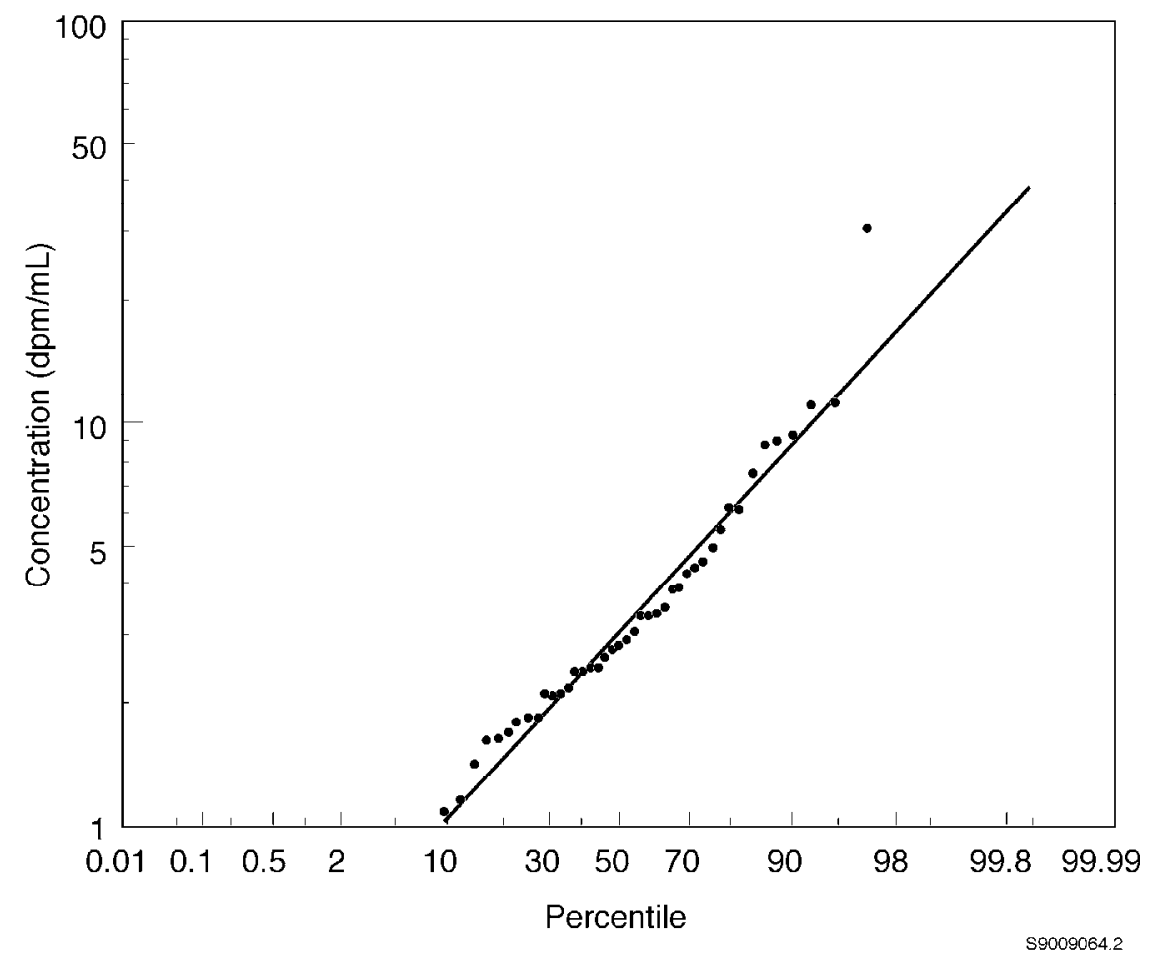

Figure 4.3. Tritium Urine Concentration in Occupationally Unexposed FFTF Workers

Because of the low dose potentially associated with chronic exposure or anticipated sampling intervals, use of the 99.9 percentile is justifiable on a cost-benefit basis. Thus, $40 \mathrm{dpm} / \mathrm{ml}$ was selected as a baseline level for tritium in 400 Area workers. Results below $40 \mathrm{dpm} / \mathrm{ml}$ are considered normal for persons working in the 400 Area. Results in excess of $40 \mathrm{dpm} / \mathrm{ml}$ indicate potential occupational exposure.

\subsection{Special Tritium Compounds}

The term "special tritium compounds" (STC) has been established by DOE to describe any compounds, other than HTO, that contain tritium either intentionally (e.g., by synthesis) or inadvertently (e.g., by contamination). These tritiated materials include organically bound tritium (OBT), soluble tritiated particulates (STP), and insoluble tritiated particulates (ITP). Hanford has had no need for routine biossay or dosimetry for STC, so no standard guidance or assumptions are adopted for default Hanford use in this manual. The HIDP should be consulted for specific needs. The DOE Handbook Radiological Control Programs for Special Tritium Compounds (DOE 2004) contains substantial guidance on the assumptions and factors to be considered for use with STC. IMBA includes capabilities for organic and inorganic tritium compounds for absorption Types $\mathrm{F}$ (for fast rate of solubilization), $\mathrm{M}$ (for moderate), and S (for slow).

\subsubsection{Organically Bound Tritium}

Organically bound tritium is not a typical form of tritium found in Hanford facilities. It is usually anticipated that OBT can be found in ingested foods, machinery oil used in tritium facilities, in laboratory 
compounds labeled for research purposes, or in wastes received from other DOE facilities. The NCRP has also addressed the issue of dosimetry for tritium-labeled organic compounds incorporated into genetic material in NCRP 63 (NCRP 1979b). The following paragraphs provide a current summary of work in progress.

In its Publication 56 (1989), the ICRP recommended a $f_{1}$ factor of 1.0 for GI tract absorption to blood for OBT, and proposed a two-component retention model for OBT. The OBT model suggested that 50\% of the OBT would be associated with body water and demonstrate the HTO half-time of 10 days. The remaining 50\% would be associated with carbon-hydrogen bonding in tissues and would demonstrate a metabolic turnover rate similar to carbon (biological half-time of 40 days). The formulation of the retention function is as follows:

$$
R(t)=0.5 e^{\frac{-0.693 t}{10}}+0.5 e^{\frac{-0.693 t}{40}}
$$

with $t$ in days.

Equilibrium between body water (e.g., urine) and OBT is not an appropriate assumption because of the substantial fraction bound to organic molecules, as shown in Figure 4.4. Thus, daily urinary excretion of OBT must be considered for bioassay interpretation.

The effective dose coefficients, $e(50)$, for OBT, as tabulated in ICRP Publications 67, 68, 71, and 78 (1993, 1994, 1995, and 1997) are as follows:

- Inhalation $e(50)$

- Ingestion $e(50)$
4.1E-11 Sv/Bq

4.2E-11 Sv/Bq.

\subsubsection{Tritiated Particulate Aerosols}

Tritiated particulate aerosols result from tritium being absorbed and retained on metal surfaces such as getters for tritium collection and storage devices (typically these are in the form of metal tritides) and as a residual contaminant in tritium production facilities. An additional possibility for tritiated particulates is tritiated metal oxides (e.g., rust and dust). At Hanford, a limited source of zirconium tritide metal filings was identified in the 325 Building.

The ICRP 71 adult effective dose coefficients are considered appropriate for calculation of committed effective dose. Table 4.2 lists the effective dose coefficients and the derived air concentration values.

Bioassay protocols for tritiated particles are not well established, and the basic tool for monitoring STP and ITP intake (and associated dose calculations) is personal air sampling. The DACs for soluble and insoluble tritated particulates have been promulgated by 10 CFR 835 to aid in monitoring of workers and the workplace, and are included in the Table 4.2 tabulation of tritium dosimetry factors. 


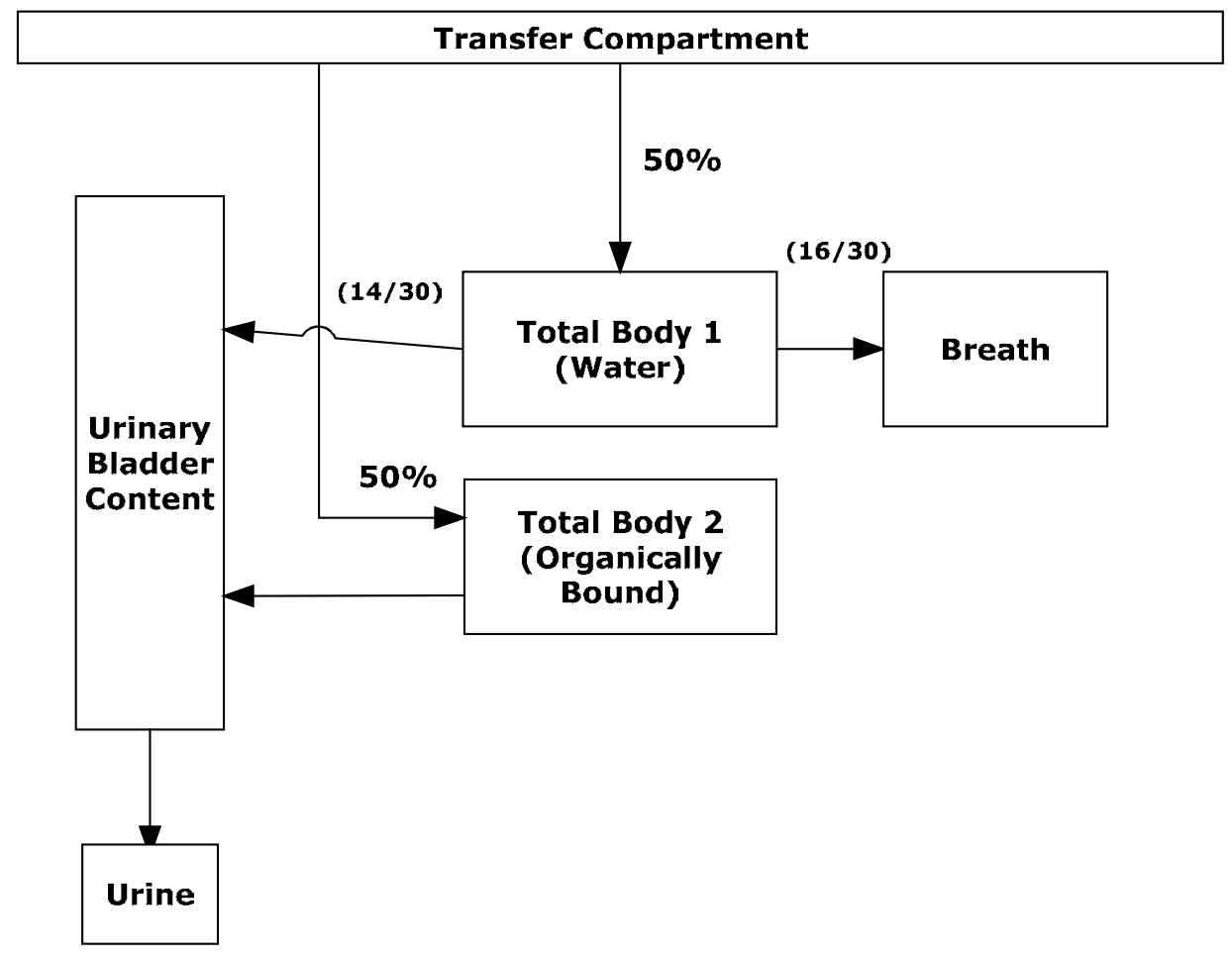

Figure 4.4. Organically Bound Tritium Metabolic Model from ICRP 78 (adapted from James et al. 2004)

\subsection{References}

10 CFR 835. 2007. “Occupation Radiation Protection.” Code of Federal Regulations. U.S. Department of Energy. Available at: http://www.access.gpo.gov

65 FR 76708-76753. December 7, 2000. “National Primary Drinking Water Regulations; Radionuclides; Final Rule.” Federal Register, U.S. Environmental Protection Agency.

American National Standard Institute (ANSI). 1983. Internal Dosimetry Standards for Tritium. ANSI Standard N13.14-1983, New York.

Bhattacharyya MH, BD Breitenstein, H Metivier, BA Muggenburg, GN Stradling, and V Volf. 1992. "Guidebook for the treatment of accidental internal radionuclide contamination of workers." Eds. GB Gerber and RG Thomas, Rad. Prot. Dosim. 41:1

Brunner P, P Schneider, H Scheicher, G Seyerl, P Kurnick, O Ennemoser, and W Ambach. 1996. “Tritium intake by exposure to plastic case watches.” Health Phys. 70(4):484-487.

Carbaugh EH, MJ Sula, and KM McFadden. 1990. Use of Probability Analysis to Establish Routine Bioassay Screening Levels. PNL-SA-17716, Pacific Northwest Laboratory, Richland, Washington. 
Health Physics Society (HPS). 1994. Internal Dosimetry Programs for Tritium Exposure-Minimum Requirements. ANSI/HPS N13.14-1994, Health Physics Society, McLean, Virginia.

Hill RL and JR Johnson. 1993. “Metabolism and dosimetry of tritium.” Health Phys. 65(6):628-647.

International Atomic Energy Agency (IAEA). 1978. Manual on Early Medical Treatment of Possible Radiation Injury. Safety Series No. 47, Vienna, Austria.

International Commission on Radiological Protection (ICRP). 1959. Report of Committee II on Permissible Dose for Internal Radiation. ICRP Publication 2, Pergamon Press, New York.

International Commission on Radiological Protection (ICRP). 1969. Evaluation of Radiation Doses to Body Tissues from Internal Contamination due to Occupational Exposure. ICRP Publication 10, Pergamon Press, New York.

International Commission on Radiological Protection (ICRP). 1974. Report of the Task Group on Reference Man. ICRP Publication 23, Pergamon Press, New York.

International Commission on Radiological Protection (ICRP). 1979. "Limits for Intakes of Radionuclides by Workers.” ICRP Publication 30, Part 1 and Supplements, Annals of the ICRP, 2:3-4, Pergamon Press, New York.

International Commission on Radiological Protection (ICRP). 1989. “Age-dependent Doses to Members of the Public from Intakes of Radionuclides: Part 1.” ICRP Publication 56, Annals of the ICRP, 20:2, Pergamon Press, New York.

International Commission on Radiological Protection (ICRP). 1993. “Age-dependent Doses to Members of the Public from Intakes of Radionuclides: Part 2 Ingestion Dose Coefficients.” ICRP Publication 67, Annals of the ICRP, 23:3-4, Pergamon Press, New York.

International Commission on Radiological Protection (ICRP). 1994. "Dose Coefficients for Intakes of Radionuclides by Workers.” ICRP Publication 68, Annals of the ICRP, 24:4, Pergamon Press, New York.

International Commission on Radiological Protection (ICRP). 1995. “Age-dependent Doses to Members of the Public from Intakes of Radionuclides: Part 4 Inhalation Dose Coefficients.” ICRP Publication 71, Annals of the ICRP, 25:3-4, Pergamon Press, New York.

International Commission on Radiological Protection (ICRP). 1997. “Individual Monitoring for Internal Exposure of Workers.” ICRP Publication 78, Annals of the ICRP, 27:3-4, Pergamon Press, New York.

James AC, JW March, A Burchall, NS Jarvis, M Puncher, K Davis, and D King. 2004. User Manual for IMBA Expert USDOE-Edition, “Appendix A: Technical Basis.” ACJ \& Associates, Richland, Washington.

Jaquish RE and RW Bryce, eds. 1989. Hanford Site Environmental Report for Calendar Year 1988. PNL-6825, Pacific Northwest Laboratory, Richland, Washington. 
Johnson JR. 1982. “The estimation of effective dose equivalent from tritiated water exposures using tritium concentrations in urine.” Rad. Prot. Dosim. 2(4):245-247.

La Bone TR. 1992. Internal Dosimetry of Tritium. WSRC-MS-92-072, Westinghouse Savannah River Company, Aiken, South Carolina.

Lloyd DC, AA Edwards, JS Prosser, A Auf der Maur, A Etzweiler, U Weickhardt, U Gossi, L Geiger, U Noelpp, and H Rosler. 1986. “Accidental intake of tritiated water: a report of two cases.” Rad. Prot. Dosim. 15:3(191-196).

Moghissi AA and CR Cothern. 1986. "Background information for the development of a standard for tritium in drinking water.” Rad. Prot. Dosim. 16(1-2):175-179.

National Council on Radiation Protection and Measurements (NCRP). 1976. Tritium Measurement Techniques. NCRP Report No. 47, Bethesda, Maryland.

National Council on Radiation Protection and Measurements (NCRP). 1979a. Tritium in the Environment. NCRP Report No. 62, Bethesda, Maryland.

National Council on Radiation Protection and Measurements (NCRP). 1979b. Tritium and Other Radionuclide Labeled Organic Compounds Incorporated in Genetic Material. NCRP Report No. 63, Bethesda, Maryland.

National Council on Radiation Protection and Measurements (NCRP). 1980. Management of Persons Accidentally Contaminated with Radionuclides. NCRP Report No. 65, Bethesda, Maryland.

Office of Compensation Analysis and Support (OCAS). 2003. "Tritium Calculations with IMBA.” Technical Bulletin OCAS-OTIB-002, National Institute for Occupational Safety and Health. Available at: www.cdc.gov/niosh/ocas/pdfs/tibs/oc-t2-ro.pdf (Accessed 09/09/2009).

Pinson EA and WH Langham. 1980. "Physiology and Toxicology of Tritium in Man.” Health Phys. 38 (1087-1110).

U.S. Department of Energy (DOE). 2004. DOE Handbook Radiological Control Program for Special Tritium Compounds. DOE-HDBK-1184-2004, Washington, D.C. Available at: www.standards.doe.gov (Accessed 12/23/2008).

U.S. Environmental Protection Agency (EPA). 1985. Environmental Radiation Data-Report 42. EPA 520/5-85-031, Eastern Environmental Radiation Facility, Montgomery, Alabama. 


\title{
Methods and Models of the Hanford Internal Dosimetry Program
}

\author{
PNL-MA-860
}

\subsection{Cesium}

Issued for implementation effective 01/01/2010

Supersedes: January 2003

\section{Use Category: Not applicable}

\section{Approval Signatures:}

Prepared by:

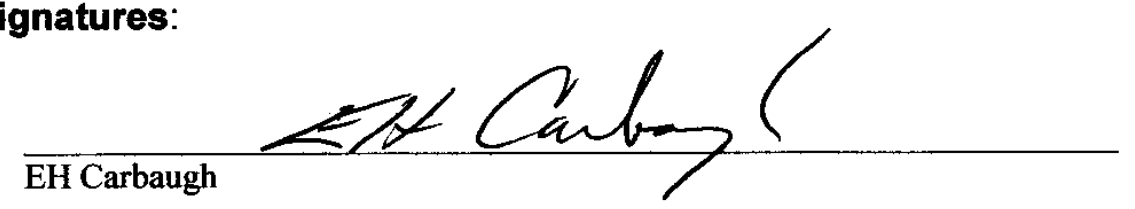

Approved by:

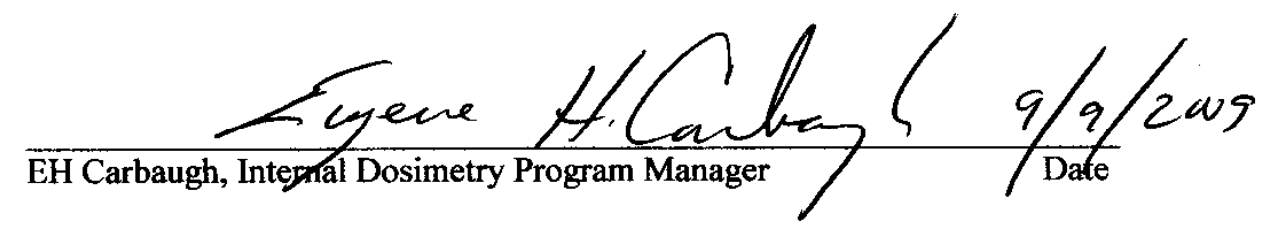

\section{Reviewer Signatures:}

Reviewed by:

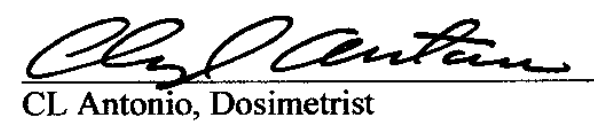

Approved by the Hanford Personnel Dosimetry Advisory Committee as recorded in the meeting minutes of October 14, 2008. 


\section{Contents}

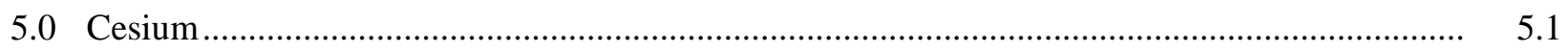

5.1 Sources and Characteristics of Radiocesium................................................................. 5.1

5.2 Environmental Levels of ${ }^{137} \mathrm{Cs}$................................................................................... 5.2

5.3 Biokinetic Behavior of Radiocesium ..................................................................... 5.3

5.4 Internal Dosimetry for Radiocesium .......................................................................... 5.4

5.4.1 Intake-Based Dosimetry Using the ICRP System and the IMBA Computer

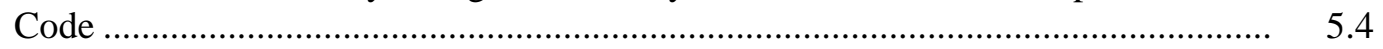

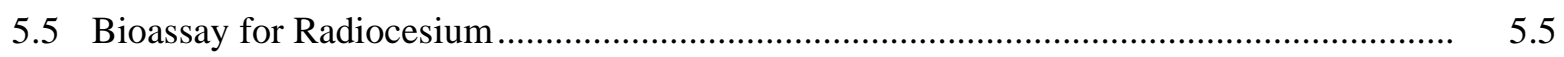

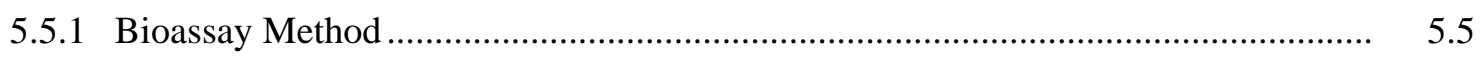

5.5 .2 In Vivo Measurements ................................................................................. 5.6

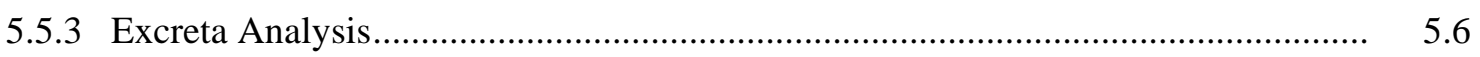

5.5.4 Routine Bioassay Monitoring Protocol ............................................................. 5.8

5.5.5 Bioassay Measurements Following an Acute Intake............................................ 5.8

5.6 Assessment of Internal Dose .................................................................................. 5.9

5.7 Management of Internal Contamination Cases ................................................................. 5.9

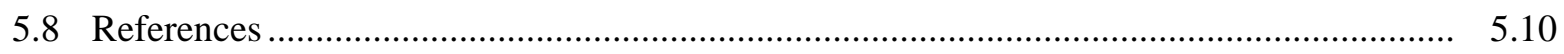

\section{Tables}

5.1 Summary of ${ }^{137}$ Cs Hanford Dosimetric Data .....................................................................

$5.2{ }^{137}$ Cs Retention and Excretion Fractions Following Acute Exposure .......................................... 5.4

$5.3{ }^{137}$ Cs Whole Body Reference Levels for 5- $\mu$ m-AMAD Type F Inhalation ................................. 5.5

$5.4{ }^{137}$ Cs Urine Excretion Reference Levels for 5- $\mu$ m-AMAD Type F Inhalation............................ 5.6

5.5 Minimum Detectable Intakes and E(50) Doses for 5- $\mu m$ AMAD Type F Acute Inhalation Using Direct In Vivo Whole Body Counting........................................................................ 5.7

5.6 Minimum Detectable Intakes and E(50) Doses for 5- $\mu$ m AMAD Type F Inhalation Using Gamma Analysis of Indirect Urine Sample with MDA of 15 dpm/L Assuming 1.6 L/d Reference Man Urine Excretion .... 


\subsection{Cesium}

This chapter provides technical information about the sources, characteristics, and biokinetics of radiocesium and summarizes the technical basis used for its internal dosimetry at Hanford. Dosimetry methods used for radiocesium are based on the concepts summarized in Publications 30 and 68 of the International Commission on Radiation Protection (ICRP 1979a, 1994), as implemented using the Integrated Modules for Bioassay Analysis (IMBA) Professional Plus internal dosimetry computer code (James et al. 2004). ${ }^{1}$ A summary of ${ }^{137}$ Cs dosimetric data is tabulated in Table 5.1. Details are provided in the following sections.

Table 5.1. Summary of ${ }^{137}$ Cs Hanford Dosimetric Data

\begin{tabular}{|c|c|c|c|}
\hline Radiological Half-Life & \multicolumn{3}{|l|}{30.0 years } \\
\hline Absorption Type & \multicolumn{3}{|l|}{ Type F - all compounds } \\
\hline Gastrointestinal Absorption $\left(f_{1}\right)$ & 0.99 for all compounds & \multicolumn{2}{|c|}{$\left(\mathrm{IMBA}, \mathrm{ICRP} f_{1}=1\right)$} \\
\hline \multirow[t]{4}{*}{ Systemic Biokinetic Model } & \multicolumn{3}{|c|}{$\begin{array}{l}\text { Uniform distribution in all body organs and tissues. } \\
\text { Two component exponential compartment retention. }\end{array}$} \\
\hline & Component & $\underline{\text { Fraction }}$ & $\underline{\text { Half-Time }}$ \\
\hline & A & 0.1 & $2 \mathrm{~d}$ \\
\hline & $\mathrm{B}$ & 0.9 & $110 \mathrm{~d}$ \\
\hline \multirow[t]{2}{*}{ Excretion Fractions } & Urine & & \\
\hline & Feces & & \\
\hline \multicolumn{4}{|l|}{ Dose Coefficients $^{(a)}, e(50)$} \\
\hline 5- $\mu$ m-AMAD Inhalation & \multirow{2}{*}{\multicolumn{3}{|c|}{$\begin{array}{l}0.0247 \mathrm{mrem} / \mathrm{nCi}(6.68 \mathrm{E}-09 \mathrm{~Sv} / \mathrm{Bq}) \\
0.0497 \mathrm{mrem} / \mathrm{nCi}(1.35 \mathrm{E}-08 \mathrm{~Sv} / \mathrm{Bq})\end{array}$}} \\
\hline Soluble Ingestion & & & \\
\hline Derived Air Concentration ${ }^{(\mathrm{b})}$ & \multicolumn{3}{|c|}{$8 \mathrm{E}-08 \mu \mathrm{Ci} / \mathrm{ml}\left(3 \mathrm{E}+03 \mathrm{~Bq} / \mathrm{m}^{3}\right)$} \\
\hline \multicolumn{4}{|l|}{ Annual Limit on Intake } \\
\hline Inhalation $^{(\mathrm{c})}$ & \multicolumn{3}{|l|}{$200 \mu \mathrm{Ci}(7.4 \mathrm{MBq})$} \\
\hline Soluble Ingestion $^{(c)}$ & \multicolumn{3}{|l|}{$100 \mu \mathrm{Ci}(3.7 \mathrm{MBq})$} \\
\hline \\
\hline \multirow{2}{*}{\multicolumn{4}{|c|}{$\begin{array}{l}\text { (b) From } 10 \text { CFR } 835 \text { Appendix B, stochastic limit-based, Type F, 5- } \mu \mathrm{m} \text { AMAD. } \\
\text { (c) Calculated as } 5 \mathrm{rem} / e(50) \text {. }\end{array}$}} \\
\hline & & & \\
\hline \multicolumn{4}{|c|}{ AMAD = activity median aerodynamic diameter. } \\
\hline
\end{tabular}

\subsection{Sources and Characteristics of Radiocesium}

The most important radionuclide of cesium at Hanford from an internal exposure standpoint is the fission product ${ }^{137} \mathrm{Cs}\left(\mathrm{T}_{1 / 2}=30.0 \mathrm{y}\right)$. Historically, ${ }^{134} \mathrm{Cs}\left(\mathrm{T}_{1 / 2}=2.1 \mathrm{y}\right.$, produced by neutron activation of stable ${ }^{133} \mathrm{Cs}$ ) was observed at activities on the order of less than $5 \%$ of the ${ }^{137} \mathrm{Cs}$ activity during Hanford production operations. However, with the lack of production of new sources at Hanford and the normal

\footnotetext{
${ }^{1}$ IMBA Professional Plus, which includes the current version of the user manual, is available from Health Protection Agency (HPA), Radiation Protection Division, Chilton, Didicot, Oxon., OX11 ORQ UK and from http://www.imbaprofessional.com/
} 
radiological decay process, ${ }^{134} \mathrm{Cs}$ is no longer a significant nuclide in Hanford fission product or waste mixtures. Further discussion for this technical basis is limited to ${ }^{137} \mathrm{Cs}$.

Because of its relatively high fission yield and its long half-life, ${ }^{137} \mathrm{Cs}$, along with ${ }^{90} \mathrm{Sr}$, is one of the most abundant radionuclides in aged fission product mixtures. More volatile than most of the longerlived fission product radionuclides, cesium is more apt to escape containment or confinement and is commonly the most abundant radionuclide found in fission product releases within a facility. As discussed later, ${ }^{137} \mathrm{Cs}$ is easily detected using in vivo bioassay techniques and can serve as a good indicator radionuclide for intakes of fission products, waste mixtures, and spent fuel.

In addition to its presence in mixtures, ${ }^{137} \mathrm{Cs}$ has existed in relatively pure form at the Waste Fractionation Facility (B Plant, 221-B Building) and the Waste Encapsulation and Storage Facility (WESF, 225-B Building). Encapsulation programs at WESF have been terminated; however, cesiumbearing capsules and cesium-contaminated equipment are stored in the facility.

Cesium has been found to be more dispersible than strontium, and therefore in most intake situations involving ${ }^{137} \mathrm{Cs}$ and ${ }^{90} \mathrm{Sr},{ }^{137} \mathrm{Cs}$ will likely constitute the major component of intake. In cases where it is suspected that ${ }^{90} \mathrm{Sr}$ or other radionuclides may be present along with ${ }^{137} \mathrm{Cs}$ but no radionuclide ratio information exists, it is prudent to consider additional bioassay appropriate for the other radionuclides of concern.

\subsection{Environmental Levels of ${ }^{137} \mathrm{Cs}$}

Cesium-137 is environmentally present worldwide as a result of atmospheric testing of nuclear weapons and releases from the 1986 Chornobyl nuclear accident in Ukraine. Elevated levels of ${ }^{137} \mathrm{Cs}$ in caribou and reindeer have long been recognized as contributing to detectable levels in people who consume such meats, and fish have also been identified as concentrators of environmental cesium (NCRP 1977). After the Chornobyl accident, whole body activity levels of ${ }^{137} \mathrm{Cs}$ in humans were widely reported in the literature (e.g., Tarroni et al. 1990; Strand et al. 1989; Lloyd 1990; and Kang 1989). Generally these levels were in the range of a few nanocuries, although Strand et al. indicated microcurie quantities in Lapps who breed and consume reindeer.

Potential transfer of radioactivity through the food chain received world-wide attention following the Chornobyl accident. In 1989, the joint World Health Organization (WHO)/Food and Agriculture Organization established a guideline level of $1000 \mathrm{~Bq} / \mathrm{kg}$ for cesium contamination in foods moving in international trade (WHO 1989); the guidance level has been incorporated in the Codex Alimentarius general standard (WHO 1995). As summarized by Woodman and Nisbet (1999), the European Union has established additional intervention levels for cesium marketed in human foodstuffs and animal feeds.

Mushrooms can also be a potentially significant source of radiocesium intake. The radiocesium content of mushrooms depends on the species, locality of growth, and radiocesium in the local soil. Nakajima et al. (1998) reported levels of 3 to $18 \mathrm{nCi} / \mathrm{g}$ in mushrooms grown in the contaminated areas near Chornobyl. Mushrooms imported to France from Austria were removed from the retail market in 1998 after levels as high as $135 \mathrm{nCi} / \mathrm{kg}$ were discovered. 
The possible existence of ${ }^{137} \mathrm{Cs}$ at the foregoing levels complicates interpretation of the source of lowlevel cesium that might be detected in routine whole body examinations. An attempt should be made to ascertain whether the detected levels are most likely of occupational or environmental origin: if occupational, then dose assessment may be warranted; if environmental, then occupational dose assessment is not warranted.

For workers who regularly consume large wild game, it might be reasonable to conclude that a few nanocuries of ${ }^{137} \mathrm{Cs}$ may represent nonoccupational intake. This can be further investigated if samples of the meat can be obtained for direct assessment. However, even then conclusions may be tenuous because only limited data are available regarding expected variation throughout the Pacific Northwest. These data, obtained by counting meat samples provided by Hanford workers showing detectable levels of ${ }^{137} \mathrm{Cs}$ in their periodic whole body exams, indicate over 3 orders of magnitude of variability (MacLellan et al. 1993).

Likewise, for a worker who has spent time in a location known to be potentially affected by elevated cesium levels (e.g., Ukraine, Europe, Scandinavian countries, or Russia), it may also be reasonable to assume environmental exposure. Such exposure would probably result from consumption of locally obtained meat, dairy products, or produce. Consideration should be given to the location where one was exposed, length of time there, food consumption, and elapsed time since exposure in determining the likelihood that environmental sources were responsible for cesium intake.

\subsection{Biokinetic Behavior of Radiocesium}

ICRP 78 (1997) classifies all isotopes of cesium as absorption Type F, indicating that inhaled material will be absorbed rapidly from the respiratory tract into the circulatory system. This is consistent with observations at Hanford. From the blood, cesium is distributed uniformly in the body with no organ or tissues showing a higher concentration than muscle. For dose assessment purposes, cesium is assumed to be completely and rapidly absorbed into systemic circulation from both the respiratory tract and the gastrointestinal $(\mathrm{GI})$ tract $\left(f_{1}\right.$ factor $\left.=0.99\right)$. The retention of stable cesium is described as two compartments, with $10 \%$ exhibiting a clearance half-time of 2 days and $90 \%$ exhibiting a clearance half-time of 110 days. Mathematically, the systemic compartment biokinetic model for stable cesium is depicted as follows:

$$
R(t)=0.1 \exp \left[-\frac{0.693 \times t}{2}\right]+0.9 \exp \left[-\frac{0.693 \times t}{110}\right]
$$

where $R(t)$ is the fraction of the initial uptake that is present in the body at $t$ days post uptake. This systemic retention function is used for Hanford dosimetry unless there are sufficient data on an individual to identify an alternate function. For systemic excretion, the ICRP 54 (1988) split of 80\% to urine and $20 \%$ to feces is used as the normal assumption.

The ICRP 30 (1979) systemic model continues to be used in the more recent ICRP 68 (1994) and ICRP 78 (1997). Publication 78 notes that the biological clearance half-time from the transfer compartment to the systemic compartment (i.e., the translocation to body tissues) is 0.25 days. That publication also notes that females may exhibit significantly shorter retention half-times in the long-term compartment than males. 
The whole body retention fractions, urine excretion fractions, and feces excretion fractions for an acute inhalation of Type $\mathrm{F}$ particles of 5 - $\mu \mathrm{m}$ activity median aerodynamic diameter (AMAD), and for an acute soluble ingestion intake are shown in Table 5.2.

Table 5.2. ${ }^{137}$ Cs Retention and Excretion Fractions Following Acute Exposure

\begin{tabular}{rcccccc}
\hline & \multicolumn{2}{c}{ Type F 5- $\mu \mathrm{m}$ Acute Inhalation } & \multicolumn{3}{c}{ Acute Soluble Ingestion } \\
\cline { 2 - 7 } $\begin{array}{c}\text { Days Post } \\
\text { Intake }\end{array}$ & $\begin{array}{c}\text { Whole Body } \\
\text { Retention }\end{array}$ & $\begin{array}{c}\text { Urine } \\
\text { Excretion }\end{array}$ & $\begin{array}{c}\text { Fecal } \\
\text { Excretion }\end{array}$ & $\begin{array}{c}\text { Whole Body } \\
\text { Retention }\end{array}$ & $\begin{array}{c}\text { Urine } \\
\text { Excretion }\end{array}$ & $\begin{array}{c}\text { Fecal } \\
\text { Excretion }\end{array}$ \\
\hline 1 & $5.97 \mathrm{E}-01$ & $7.87 \mathrm{E}-03$ & $9.65 \mathrm{E}-04$ & $9.80 \mathrm{E}-01$ & $1.58 \mathrm{E}-02$ & $4.08 \mathrm{E}-03$ \\
2 & $5.05 \mathrm{E}-01$ & $1.11 \mathrm{E}-02$ & $2.11 \mathrm{E}-03$ & $9.51 \mathrm{E}-01$ & $2.29 \mathrm{E}-02$ & $6.42 \mathrm{E}-03$ \\
3 & $4.65 \mathrm{E}-01$ & $8.77 \mathrm{E}-03$ & $2.42 \mathrm{E}-03$ & $9.26 \mathrm{E}-01$ & $1.82 \mathrm{E}-02$ & $5.99 \mathrm{E}-03$ \\
5 & $4.34 \mathrm{E}-01$ & $5.45 \mathrm{E}-03$ & $1.89 \mathrm{E}-03$ & $8.92 \mathrm{E}-01$ & $1.13 \mathrm{E}-02$ & $4.07 \mathrm{E}-03$ \\
7 & $4.21 \mathrm{E}-01$ & $3.76 \mathrm{E}-03$ & $1.27 \mathrm{E}-03$ & $8.69 \mathrm{E}-01$ & $7.79 \mathrm{E}-03$ & $2.65 \mathrm{E}-03$ \\
14 & $3.97 \mathrm{E}-01$ & $2.15 \mathrm{E}-03$ & $5.72 \mathrm{E}-04$ & $8.20 \mathrm{E}-01$ & $4.44 \mathrm{E}-03$ & $1.18 \mathrm{E}-03$ \\
30 & $3.58 \mathrm{E}-01$ & $1.81 \mathrm{E}-03$ & $4.56 \mathrm{E}-04$ & $7.40 \mathrm{E}-01$ & $3.74 \mathrm{E}-03$ & $9.43 \mathrm{E}-04$ \\
60 & $2.96 \mathrm{E}-01$ & $1.49 \mathrm{E}-03$ & $3.77 \mathrm{E}-04$ & $6.11 \mathrm{E}-01$ & $3.09 \mathrm{E}-03$ & $7.78 \mathrm{E}-04$ \\
90 & $2.44 \mathrm{E}-01$ & $1.23 \mathrm{E}-03$ & $3.11 \mathrm{E}-04$ & $5.05 \mathrm{E}-01$ & $2.55 \mathrm{E}-03$ & $6.43 \mathrm{E}-04$ \\
180 & $1.38 \mathrm{E}-01$ & $6.95 \mathrm{E}-04$ & $1.75 \mathrm{E}-04$ & $2.85 \mathrm{E}-01$ & $1.44 \mathrm{E}-03$ & $3.63 \mathrm{E}-04$ \\
365 & $4.24 \mathrm{E}-02$ & $2.14 \mathrm{E}-04$ & $5.41 \mathrm{E}-05$ & $8.77 \mathrm{E}-02$ & $4.43 \mathrm{E}-04$ & $1.12 \mathrm{E}-04$ \\
730 & $4.16 \mathrm{E}-03$ & $2.10 \mathrm{E}-05$ & $5.30 \mathrm{E}-06$ & $8.59 \mathrm{E}-03$ & $4.34 \mathrm{E}-05$ & $1.09 \mathrm{E}-05$ \\
1825 & $3.91 \mathrm{E}-06$ & $1.97 \mathrm{E}-08$ & $4.98 \mathrm{E}-09$ & $8.08 \mathrm{E}-06$ & $4.08 \mathrm{E}-08$ & $1.03 \mathrm{E}-08$ \\
\hline
\end{tabular}

\subsection{Internal Dosimetry for Radiocesium}

Internal dosimetry for ${ }^{137} \mathrm{Cs}$ is routinely performed using hand calculations based on the fundamental principles or by using IMBA as an implementation of the ICRP 60/68 methodology. Similar approaches can be used for ${ }^{134} \mathrm{Cs}$, if dosimetry for that radionuclide is required.

\subsubsection{Intake-Based Dosimetry Using the ICRP System and the IMBA Computer Code}

IMBA is used for most internal dose calculations at Hanford. The code uses ICRP 60/68 methods, biokinetic models, and specific effective energies (SEEs) for radiocesiums. When bioassay data are available, IMBA calculates intake based on the bioassay data and the biokinetic models specified. To obtain internal doses, IMBA calculates the integrated retention for the interval of interest (e.g., 50 years), and then applies the SEE factors to give committed equivalent doses for organs and tissues. The weighted organ and tissue doses are summed to give effective dose. For ${ }^{137} \mathrm{Cs}$, IMBA calculates the following dose coefficients:

Type F inhalation 5- $\mu \mathrm{m}-\mathrm{AMAD}$ particles: $\quad 0.0247 \mathrm{mrem} / \mathrm{nCi}$

Soluble ingestion: $\quad 0.0497 \mathrm{mrem} / \mathrm{nCi}$. 
These values are comparable to the ICRP 68 (1994) and ICRP 78 (1997) values.

Derived reporting, investigation, and compliance levels (based on committed effective doses of 10 mrem, 100 mrem, and 5,000 mrem, respectively) have been calculated for inhalation of 5- $\mu \mathrm{m}$-AMAD particles. The derived levels for whole body retention (as might be measured by whole body counting) are shown in Table 5.3 and the derived levels for daily urine excretion are shown in Table 5.4.

Table 5.3. ${ }^{137}$ Cs Whole Body Reference Levels for 5- $\mu$ m-AMAD Type F Inhalation

\begin{tabular}{cccc}
\hline & $\begin{array}{c}\text { 10-mrem Derived } \\
\text { Reporting Level }\end{array}$ & $\begin{array}{c}\text { 100-mrem Derived } \\
\text { Investigation Level }\end{array}$ & $\begin{array}{c}\text { 5-rem Derived } \\
\text { Compliance Level }\end{array}$ \\
\hline Inhalation Intake (nCi): & 4.05E+02 & $4.05 \mathrm{E}+03$ & $2.02 \mathrm{E}+05$ \\
\hline $\begin{array}{c}\text { Days Post } \\
\text { Intake }\end{array}$ & $\begin{array}{c}\text { Derived Reporting } \\
\text { Level (nCi) }\end{array}$ & $\begin{array}{c}\text { Derived Investigation } \\
\text { Level (nCi) }\end{array}$ & $\begin{array}{c}\text { Derived Compliance } \\
\text { Level (nCi) }\end{array}$ \\
\hline 1 & $2.42 \mathrm{E}+02$ & $2.42 \mathrm{E}+03$ & $1.21 \mathrm{E}+05$ \\
2 & $2.04 \mathrm{E}+02$ & $2.04 \mathrm{E}+03$ & $1.02 \mathrm{E}+05$ \\
3 & $1.88 \mathrm{E}+02$ & $1.88 \mathrm{E}+03$ & $9.41 \mathrm{E}+04$ \\
5 & $1.76 \mathrm{E}+02$ & $1.76 \mathrm{E}+03$ & $8.78 \mathrm{E}+04$ \\
7 & $1.70 \mathrm{E}+02$ & $1.70 \mathrm{E}+03$ & $8.51 \mathrm{E}+04$ \\
14 & $1.61 \mathrm{E}+02$ & $1.61 \mathrm{E}+03$ & $8.03 \mathrm{E}+04$ \\
30 & $1.45 \mathrm{E}+02$ & $1.45 \mathrm{E}+03$ & $7.25 \mathrm{E}+04$ \\
60 & $1.20 \mathrm{E}+02$ & $1.20 \mathrm{E}+03$ & $5.99 \mathrm{E}+04$ \\
90 & $9.89 \mathrm{E}+01$ & $9.89 \mathrm{E}+02$ & $4.95 \mathrm{E}+04$ \\
180 & $5.58 \mathrm{E}+01$ & $5.58 \mathrm{E}+02$ & $2.79 \mathrm{E}+04$ \\
365 & $1.72 \mathrm{E}+01$ & $1.72 \mathrm{E}+02$ & $8.59 \mathrm{E}+03$ \\
730 & $1.68 \mathrm{E}+00$ & $1.68 \mathrm{E}+01$ & $8.42 \mathrm{E}+02$ \\
1825 & $1.58 \mathrm{E}-03$ & $1.58 \mathrm{E}-02$ & $7.92 \mathrm{E}-01$ \\
\hline
\end{tabular}

\subsection{Bioassay for Radiocesium}

The bioassay techniques, the recommended routine program, and the measurements required for monitoring radiocesium after an acute intake are discussed in the following sections.

\subsubsection{Bioassay Method}

The presence of ${ }^{137} \mathrm{Cs}$ is detected by gamma spectroscopy using the $0.661-\mathrm{MeV}$ photon of ${ }^{137 \mathrm{~m}} \mathrm{Ba}$, which is the short half-life $\left(\mathrm{T}_{1 / 2}=2.5 \mathrm{~min}\right)$ progeny that exists in secular equilibrium with ${ }^{137} \mathrm{Cs}$. Gamma spectroscopy can be used for either in vivo measurements or for excreta analysis. In vivo whole body counting is the preferred method for ${ }^{137} \mathrm{Cs}$ bioassay, due to its simplicity. Urine sample gamma spectroscopy can also be highly effective if in vivo measurements cannot be readily obtained. Fecal sampling is not normally recommended due to the high absorption (theoretically, 100\%) in the GI tract. (An exception might occur if a person was being treated with Prussian blue, whereby fecal results would aid in determining the efficacy of the treatment.) 
Table 5.4. ${ }^{137} \mathrm{Cs}$ Urine Excretion Reference Levels for 5- $\mu \mathrm{m}$-AMAD Type F Inhalation

\begin{tabular}{cccc}
\hline & $\begin{array}{c}\text { 10-mrem Derived } \\
\text { Reporting Level }\end{array}$ & $\begin{array}{c}\text { 100-mrem Derived } \\
\text { Investigation Level }\end{array}$ & $\begin{array}{c}\text { 5-rem Medical } \\
\text { Referral Level }\end{array}$ \\
\hline Inhalation Intake (nCi): & $4.05 \mathrm{E}+02$ & $4.05 \mathrm{E}+03$ & $2.02 \mathrm{E}+05$ \\
\hline $\begin{array}{c}\text { Days Post } \\
\text { Intake }\end{array}$ & $\begin{array}{c}\text { Derived Reporting } \\
\text { Level (dpm/d) }\end{array}$ & $\begin{array}{c}\text { Derived Investigation } \\
\text { Level (dpm/d) }\end{array}$ & $\begin{array}{c}\text { Derived Compliance } \\
\text { Level (dpm/d) }\end{array}$ \\
\hline 1 & $7.07 \mathrm{E}+03$ & $7.07 \mathrm{E}+04$ & $3.54 \mathrm{E}+06$ \\
2 & $9.95 \mathrm{E}+03$ & $9.95 \mathrm{E}+04$ & $4.97 \mathrm{E}+06$ \\
3 & $7.88 \mathrm{E}+03$ & $7.88 \mathrm{E}+04$ & $3.94 \mathrm{E}+06$ \\
5 & $4.90 \mathrm{E}+03$ & $4.90 \mathrm{E}+04$ & $2.45 \mathrm{E}+06$ \\
7 & $3.38 \mathrm{E}+03$ & $3.38 \mathrm{E}+04$ & $1.69 \mathrm{E}+06$ \\
14 & $1.93 \mathrm{E}+03$ & $1.93 \mathrm{E}+04$ & $9.65 \mathrm{E}+05$ \\
30 & $1.62 \mathrm{E}+03$ & $1.62 \mathrm{E}+04$ & $8.12 \mathrm{E}+05$ \\
60 & $1.34 \mathrm{E}+03$ & $1.34 \mathrm{E}+04$ & $6.71 \mathrm{E}+05$ \\
90 & $1.11 \mathrm{E}+03$ & $1.11 \mathrm{E}+04$ & $5.54 \mathrm{E}+05$ \\
180 & $6.25 \mathrm{E}+02$ & $6.25 \mathrm{E}+03$ & $3.13 \mathrm{E}+05$ \\
365 & $1.93 \mathrm{E}+02$ & $1.93 \mathrm{E}+03$ & $9.63 \mathrm{E}+04$ \\
730 & $1.89 \mathrm{E}+01$ & $1.89 \mathrm{E}+02$ & $9.43 \mathrm{E}+03$ \\
1825 & $1.77 \mathrm{E}-02$ & $1.77 \mathrm{E}-01$ & $8.87 \mathrm{E}+00$ \\
\hline
\end{tabular}

\subsubsection{In Vivo Measurements}

Hanford whole body counting using a 3-minute count on the sodium iodide (NaI) detector preview counter currently provides a minimum detectable activity (MDA) of $1.3 \mathrm{nCi}{ }^{137} \mathrm{Cs}$ in the body of a male subject of average size. A 10-minute count using the coaxial germanium scanning detector system gives an MDA of about $1 \mathrm{nCi}$. The associated minimum detectable doses for Type $\mathrm{F}$ inhalation of $5-\mu \mathrm{m}$ particles are shown in Table 5.5. Comparing this table with the derived reference levels of Table 5.3 shows that whole body counting provides excellent sensitivity for pure ${ }^{137} \mathrm{Cs}$. For the pure nuclide, an annual whole body count using either system is appropriate bioassay monitoring.

Cesium-137 is also often used as an indicator for other nuclides because of its isotopic abundance in Hanford waste mixtures. For such circumstances, ${ }^{137} \mathrm{Cs}$ whole body counting can be used as an effective monitor for other nuclides (notably ${ }^{90} \mathrm{Sr}$ and plutonium). The dosimetric significance of ${ }^{137} \mathrm{Cs}$ compared with the other nuclides is highly variable, depending on the mixture ratios. Statements of minimum detectable dose for mixtures are beyond the scope of this chapter, and are treated elsewhere in the technical basis documentation (see Appendix E of this manual and the exhibits in Chapter 5.0 of PNL-MA-552, EH Carbaugh, et al. 2009).

\subsubsection{Excreta Analysis}

Urine sample gamma spectroscopy can also be used to detect internal radiocesium; however, because of the ease and sensitivity of in vivo detection methods, it is not commonly used for Hanford monitoring. As shown in compilations of the minimum detectable dose in Table 5.6, urinalysis gamma spectrometry 
can provide excellent bioassay monitoring sensitivity. This sensitivity makes offsite urine sample collection a viable alternative for follow-up measurement of former workers who left the area without obtaining a termination whole body count.

Table 5.5. Minimum Detectable Intakes and $E(50)$ Doses for $5-\mu m$ AMAD Type F Acute Inhalation Using Direct In Vivo Whole Body Counting

\begin{tabular}{rcccc}
\hline \multicolumn{2}{c}{ NaI Detector Standup System } & \multicolumn{2}{c}{ Coaxial Germanium Detector System } \\
\hline $\begin{array}{c}\text { Whole Body } \\
\text { Count MDA: }\end{array}$ & \multicolumn{2}{c}{$1.3 \mathrm{nCi}$} & \multicolumn{2}{c}{$1 \mathrm{nCi}$} \\
\hline $\begin{array}{c}\text { Minimum } \\
\text { Intake }\end{array}$ & $\begin{array}{c}\text { Minimum } \\
\text { Detectable } \\
\text { Intake (nCi) }\end{array}$ & $\begin{array}{c}\text { Detectable } \\
\text { Dose (mrem) }\end{array}$ & $\begin{array}{c}\text { Minimum Detectable } \\
\text { Intake (nCi) }\end{array}$ & $\begin{array}{c}\text { Minimum } \\
\text { Detectable } \\
\text { Dose (mrem) }\end{array}$ \\
\hline 1 & 2.2 & 0.05 & 1.7 & 0.04 \\
2 & 2.6 & 0.06 & 2.0 & 0.05 \\
3 & 2.8 & 0.07 & 2.2 & 0.05 \\
5 & 3.0 & 0.07 & 2.3 & 0.06 \\
7 & 3.1 & 0.08 & 2.4 & 0.06 \\
14 & 3.3 & 0.08 & 2.5 & 0.06 \\
30 & 3.6 & 0.09 & 2.8 & 0.07 \\
60 & 4.4 & 0.11 & 3.4 & 0.08 \\
90 & 5.3 & 0.13 & 4.1 & 0.10 \\
180 & 9.4 & 0.23 & 7.3 & 0.18 \\
365 & 31 & 0.76 & 24 & 0.58 \\
730 & 310 & 7.7 & 240 & 5.9 \\
1825 & $3.3 \mathrm{E}-05$ & $8.2 \mathrm{E}+03$ & $2.6 \mathrm{E}+05$ & $6.3 \mathrm{E}+03$ \\
\hline
\end{tabular}

Table 5.6. Minimum Detectable Intakes and $E(50)$ Doses for 5- $\mu$ m AMAD Type F Inhalation Using Gamma Analysis of Indirect Urine Sample with MDA of 15 dpm/L Assuming 1.6 L/d Reference Man Urine Excretion

\begin{tabular}{rcc}
\hline $\begin{array}{c}\text { Days Post } \\
\text { Intake }\end{array}$ & $\begin{array}{c}\text { Minimum Detectable } \\
\text { Intake (nCi) }\end{array}$ & $\begin{array}{c}\text { Minimum Detectable } \\
\text { Dose (mrem) }\end{array}$ \\
\hline 1 & 1.4 & 0.03 \\
2 & 0.98 & 0.02 \\
3 & 1.2 & 0.03 \\
5 & 2.0 & 0.05 \\
7 & 2.9 & 0.07 \\
14 & 5.0 & 0.12 \\
30 & 6.0 & 0.15 \\
60 & 7.2 & 0.18 \\
90 & 8.8 & 0.22 \\
180 & 16 & 0.38 \\
365 & 50 & 1.2 \\
730 & 520 & 13 \\
1825 & $5.5 \mathrm{E}+05$ & $1.4 \mathrm{E}+04$ \\
\hline
\end{tabular}




\subsubsection{Routine Bioassay Monitoring Protocol}

Annual in vivo measurements are recommended for periodic retrospective bioassay monitoring of workers who are potentially exposed to mixtures of radionuclides containing radiocesium. In vivo measurement capabilities are sufficiently sensitive for a biennial frequency for pure ${ }^{137} \mathrm{Cs}$ exposures, however, the longer time between measurements makes investigation of potential exposures more difficult, and thus a minimum annual frequency is recommended.

If radiocesium is detected through a routine measurement, then follow-up measurements to confirm the initial indication should generally be performed. Follow-up measurements can usually be most conveniently performed immediately following the initial measurement, while the subject is at the In Vivo Radioassay and Research Facility. Follow-up measurements should be performed as promptly as practical following an indication of an intake in order to facilitate any health physics investigation associated with the potential exposures. However, because of the high sensitivity of the in vivo measurement, verification measurements for cesium are not appreciably affected by delays of a few days to a month in obtaining them.

Follow-up in vivo measurements using high-resolution germanium detectors are preferred for identifying other radionuclides possibly associated with the exposure, to discriminate against interference from radon progeny, and because the germanium detectors provide a more precise and accurate measurement. In addition to follow-up in vivo measurements, special bioassay should be considered for other significant nuclides (e.g., ${ }^{90} \mathrm{Sr}$ or plutonium urinalysis, plutonium fecal analysis), if ${ }^{137} \mathrm{Cs}$ is a mixture indicator nuclide.

\subsubsection{Bioassay Measurements Following an Acute Intake}

An in vivo examination should be performed after any indication of an intake of radiocesium. Unless the exposure appears to be of such magnitude that medical treatment to aid its removal is considered, the exam may be scheduled as convenient within several days of the intake, without significantly compromising the dosimetric sensitivity of the measurement. Appropriate bioassay for all significant radionuclides potentially involved in the exposure should be considered in the follow-up investigation. Because of the wide range of waste mixtures in Hanford facilities, a standard default mixture is no longer used for general internal dosimetry. In the event of an exposure, the composition of the source mixture should be determined by appropriate analysis of a representative sample of the material, special bioassay for the appropriate specific nuclides, or use of facility characterization data.

The interpretation of in vivo measurements performed shortly after intake may be complicated by early transport of material through the lung and GI tract. Measurements performed after about 5 days post intake are more appropriate for dose evaluation. For intakes potentially above a 100-mrem committed effective dose (considering all radionuclides contributing), long-term follow-up bioassay measurements should be considered to monitor internal radioactivity levels and establish individual retention characteristics. 


\subsection{Assessment of Internal Dose}

The assessment of the internal dose from ${ }^{137} \mathrm{Cs}$ is normally accomplished by evaluation of in vivo measurement results. Committed effective dose is assessed for any confirmed intake not attributed to environmental or other nonoccupational sources.

Assessed committed effective doses below 100 mrem may be based on a single bioassay measurement and the standard biokinetic models described in this chapter. Assessments of internal dose that would potentially exceed a committed effective dose of 100 mrem should be based on observed retention to the extent practicable. The ICRP 30/68 model for uptake and retention of cesium was described previously. Default biokinetic assumptions about internal deposition and retention of cesium can be modified to obtain a better fit between the observed retention data and the model. The modified model can then be used to calculate dose. IMBA can be used for this intake and dose assessment, or if based on limited bioassay data, the tabulated values of this chapter can be used in conjunction with the basic formulas of Chapter 2.0.

Because cesium distributes relatively uniformly in the body, the dose received by individual organs and tissues is about the same as the effective dose. To simplify the recording of doses to specific organs and tissues, the dose to uniformly distributed radionuclides is ascribed to a single organ category called "total body." That is, assessments of exposure to radiocesium will include the committed effective dose, which is equivalent to the total body equivalent dose, which, in turn, is equivalent to the dose received by any organ. The "total body" designation thus serves as a surrogate for any specific organ or tissue in the body.

\subsection{Management of Internal Contamination Cases}

Although one of the most abundant radionuclides at Hanford, ${ }^{137} \mathrm{Cs}$ has not historically contributed significantly to internal doses. Cesium-137 is easily detected by whole body counting and therefore early measurements can result in fairly rapid intake and dose assessments. Primary considerations that might cause some difficulty for interpretation of initial in vivo measurements are possible external contamination on the subject, the rapid translocation and elimination that occurs shortly after intake, and the possibility of a nonoccupational source.

Being a major fission product radionuclide, ${ }^{137} \mathrm{Cs}$ is often accompanied by other fission product radionuclides. Thus, investigation of internal exposures involving ${ }^{137} \mathrm{Cs}$ should also consider that other radionuclides may be involved.

The most effective measure for removal of cesium from the body is by oral administration of Prussian blue. Prussian blue is a drug that must be administered by competent medical authorities. Prussian blue is not absorbed from the intestine and it binds the cesium ions that are enterically cycled into the GI tract, so that the cesium is not reabsorbed. The treatment can reduce the biological half-life to about one-third of its usual value. The effectiveness of the treatment depends on how soon after exposure it is started (NCRP 1980). Bhattacharyya et al. (1992) recommended administrations of 3 to $4 \mathrm{~g}$ of Prussian blue in water orally divided over three doses per day, continued for as long as effective. Significant human experience with Prussian blue therapy resulted from the Goiania, Brazil accident in which several members of the public incurred very high ${ }^{137} \mathrm{Cs}$ intakes when a medical therapy machine was stolen for 
salvage and the source was unknowingly opened (IAEA 1988). Dunstana et al. (1994) reported dose reductions of $51 \%$ to $84 \%$ based on orally administered dosages of Prussian blue from 3 to $10 \mathrm{~g} / \mathrm{d}$. An excellent case study of this accident, the associated dosimetry, and the medical case management is described by the International Atomic Energy Agency (IAEA 1998). The IAEA report includes a large citation of references appropriate for case management.

\subsection{References}

10 CFR 835. 2007. “Occupational Radiation Protection.” Code of Federal Regulations.

U.S. Department of Energy. Available at: http://www.access.gpo.gov

Bhattacharyya MH, BD Breitenstein, H Metivier, BA Muggenburg, GN Stradling, and V Volf. 1992. "Guidebook for the Treatment of Accidental Internal Radionuclide Contamination of Workers." Eds. GB Gerber and RG Thomas. Rad. Prot. Dosim. 41:1.

Carbaugh, EH, DE Bihl, JA MacLellan. 2007. Hanford Internal Dosimetry Program Manual. PNLMA-552, PNNL-15614, Pacific Northwest National Laboratory, Richland, Washington. (Internal manual.) Available at: http://www.pnl.gov/main/publications/external/technical_reports/PNNL15614.pdf

Dunstana RM, JL Lipsztein, AN de Oliveira Carlos, and L Bertelli. 1994. “Cs-137 internal contamination involving a Brazilian accident, and the efficacy of Prussian blue treatment." Health Phys. 66(3):245-252.

International Atomic Energy Agency (IAEA). 1988. The Radiological Accident in Goiana. Vienna, Austria.

International Atomic Energy Agency (IAEA). 1998. Dosimetric and Medical Aspects of the Radiological Accident in Goiana in 1987. IAEA-TECDOC-1009, Vienna, Austria.

International Commission on Radiological Protection and Measurements (ICRP). 1979. "Limits for Intakes of Radionuclides by Workers.” ICRP Publication 30, Part 1, Annals of the ICRP, 2:3-4, Pergamon Press, New York.

International Commission on Radiological Protection and Measurements (ICRP). 1988. "Individual Monitoring for Intakes of Radionuclides by Workers: Design and Interpretation.” ICRP Publication 54, Annals of the ICRP, 19:1-3, Pergamon Press, New York.

International Commission on Radiological Protection (ICRP). 1990. "1990 Recommendations of the International Commission on Radiological Protection.” ICRP Publication 60, Annals of the ICRP, 21:1-3, Pergamon Press, New York.

International Commission on Radiological Protection and Measurements (ICRP). 1994. "Dose Coefficients for Intakes of Radionuclides by Workers.” ICRP Publication 68, Annals of the ICRP, 24:4, Pergamon Press, New York. 
International Commission on Radiological Protection and Measurements (ICRP). 1997. "Individual Monitoring for Internal Exposure of Workers.” ICRP Publication 78, Annals of the ICRP, 27:3-4, Pergamon Press, New York.

James AC, A Birchall, JW Marsh, and M Puncher. 2004 (or current version). User Manual for IMBA Expert, USDOE Edition (PhaseII). ACJ \& Associates, Richland, Washington. (Current version is available electronically as part of the IMBA Professional Plus Software code.)

Kang C. 1989. "Measurements of whole body radiocesium at the Harwell Laboratory, 1976-1988." Health Phys. 57:995-1001.

Lloyd RD. 1990. “Chernobyl fallout radionuclides in Utah residents.” Health Phys. 58:533-534.

MacLellan JA, TP Lynch, GA Rieksts, and RL Brodzinski. 1993. "Identification of environmentally derived cesium-137 burdens in a worker population." In Environmental Health Physics: Proceeding of the $26^{\text {th }}$ Midyear Topical Meeting of the Health Physics Society, eds. RL Kathren, DH Denham, and K Salmon. Columbia Chapter, Health Physics Society, Richland, Washington.

Nakajima H, H Ryo, T Nomura, T Saito, Y Yamaguchi, and KG Yeliseeva. 1998. "Radionuclides carved on the annual rings of a tree near Chernobyl.” Health Phys. 74(2):265-267.

National Council on Radiation Protection and Measurements (NCRP). 1977. Cesium-137 from the Environment to Man: Metabolism and Dose. NCRP Report No. 52, Washington, D.C.

National Council on Radiation Protection and Measurements (NCRP). 1980. Management of Persons Accidentally Contaminated with Radionuclides. NCRP Report No. 65, Bethesda, Maryland.

Strand P, E Bøe, L Berteig, T Berthelsen, T Strand, K Trygg, and O Harbit. 1989. "Whole body counting and dietary surveys in Norway during the first year after the Chernobyl accident.” Rad. Prot. Dosim. 27(3):163-171.

Tarroni G, C Melandri, P Battisti, CM Castellani, M Formignani, and E Rampa. 1990. “ ${ }^{137}$ Cs and ${ }^{134}$ Cs human internal contamination in Italy following the 1986 Chernobyl event.” Rad. Prot. Dosim. 32(4):259-271.

Woodman RFM and AF Nisbet. 1999. "Derivation of working levels for radionuclides in animal feedstuffs for use following a nuclear accident.” Health Phys. 77(4):383-391.

World Health Organization (WHO). 1989. "WHO-FAO Coden Alimentarius Commission agrees activity levels in foods." Health Phys. 57:1048. 


\title{
Methods and Models of the Hanford Internal Dosimetry Program
}

\author{
PNNL-MA-860
}

\subsection{Strontium}

Issued for implementation effective 01/01/2010

Supersedes: January 2003

\section{Use Category: Not applicable}

\section{Approval Signatures:}

Prepared by:

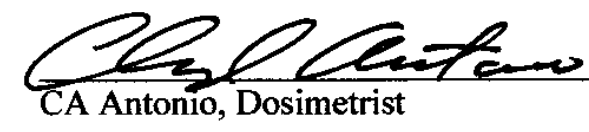

Approved by:

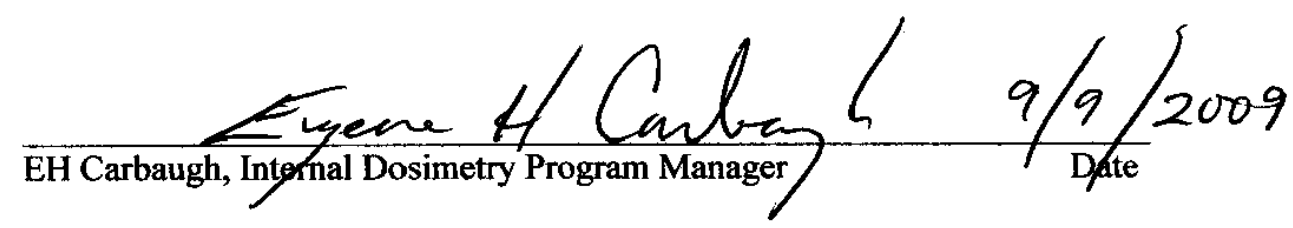

Reviewer Signatures:

Reviewed by:

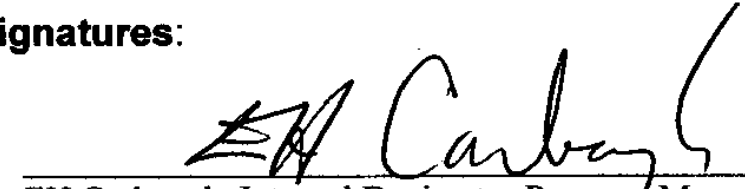

EH Carbaugh, Internal Dosimetry Progran Manager

Approved by the Hanford Personnel Dosimetry Advisory Committee as recorded in the meeting minutes of October 14, 2008. 


\section{Contents}

6.0 Strontium

6.1 Sources and Characteristics of Strontium at Hanford .....................................................

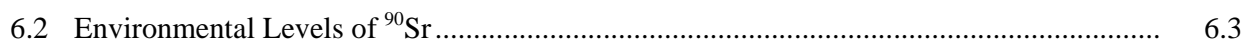

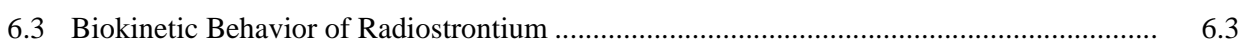

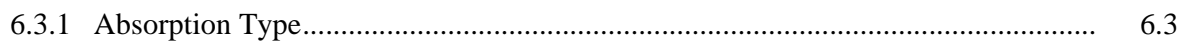

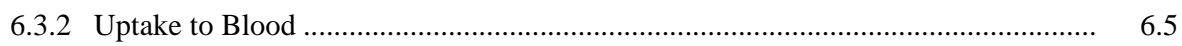

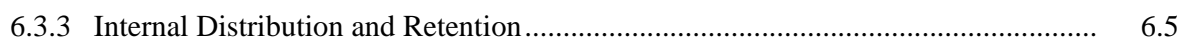

6.3.4 Excretion of Strontium ...................................................................................... 6.5

6.4 Internal Dosimetry Factors for Radiostrontium ............................................................. 6.7

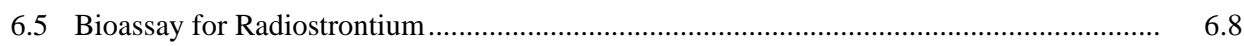

6.5.1 Excreta Bioassay Techniques for ${ }^{90} \mathrm{Sr}$............................................................... 6.8

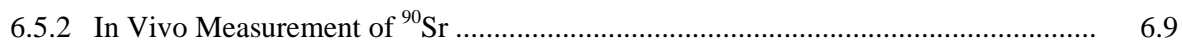

6.5.3 Recommended Periodic Bioassay Monitoring Protocol........................................... 6.11

6.5.4 Special Monitoring for Suspected Exposures ...................................................... 6.11

6.6 Assessment of Internal Dose ................................................................................. 6.12

6.7 Management of Internal Contamination Cases ............................................................. 6.12

6.7.1 Diagnostic Procedures ............................................................................... 6.12

6.7.2 Therapeutic Actions ................................................................................... 6.13

6.7.3 Long-Term Bioassay Follow-Up Monitoring After an Intake ................................ 6.13

6.8 Historical ${ }^{90} \mathrm{Sr}$ Internal Dosimetry Practices at Hanford .................................................. 6.13

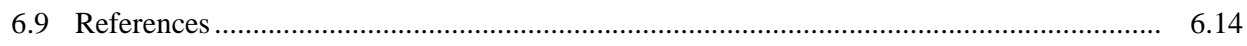

\section{Figure}

$6.1{ }^{90} \mathrm{Sr}$ Urine Excretion After an Acute Inhalation Intake ............................................................ 6.7

\section{Tables}

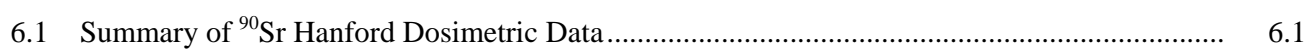

$6.2{ }^{90} \mathrm{Sr}$ Fission Product Mass Yields ................................................................................ 6.2

6.3 Decay Data for Strontium Isotopes............................................................................... 6.2

6.4 Transfer Rates Between Compartments in the Strontium Systemic Model.............................. 6.4

$6.5{ }^{90} \mathrm{Sr}$ Urine Excretion Fractions ......................................................................................... 


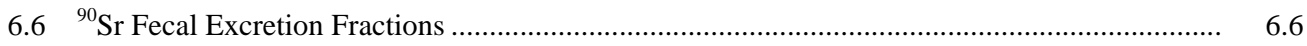

6.7 Hanford ${ }^{90} \mathrm{Sr}$ Dose Coefficients for Significant Organs....................................................... 6.7

$6.8{ }^{90} \mathrm{Sr}$ Daily Urine Excretion Reference Levels for 5- $\mu \mathrm{m}$-AMAD Inhalations ............................ 6.8

$6.9{ }^{90} \mathrm{Sr}$ Daily Urine Excretion Reference Levels for Soluble Ingestion and Transportable

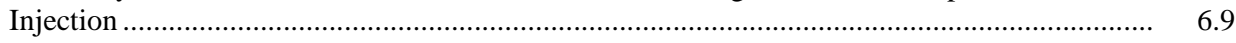

6.10 Hanford Bioassay Program Capability for ${ }^{90} \mathrm{Sr}$ in Urine for 5- $\mu \mathrm{m}$ AMAD Acute Inhalation ..... $\quad 6.10$

6.11 Hanford Bioassay Program Capability for ${ }^{90} \mathrm{Sr}$ in Urine for Transportable Injection and Soluble Ingestion Intakes........................................................................................... 6.10

PNNL-MA-860 Chapter 6.0

Page 6.iii
Issued for implementation effective 01/01/2010

Supersedes: January 31, 2003 



\subsection{Strontium}

This chapter provides technical information about the sources of radiostrontium and its characteristics, and summarizes the technical basis used for its internal dosimetry at Hanford. The dosimetry methods used are based on the concepts summarized in Publications 68 and 78 of the International Commission on Radiological Protection (ICRP 1994a, 1997), as implemented using the IMBA Professional Plus (IMBA) internal internal dosimetry computer code (James et al. 2004). ${ }^{1}$ Because of its long radiological half-life, ${ }^{90} \mathrm{Sr}$ (with its secular equilibrium progeny ${ }^{90} \mathrm{Y}$ ) is now the strontium isotope of significance at Hanford. Some information for the short-lived ${ }^{89} \mathrm{Sr}$ is also included here for historical purposes. A summary of the ${ }^{90} \mathrm{Sr}$ dosimetric data is tabulated in Table 6.1. A brief history of the strontium evaluation methods used at Hanford is also provided. Details are provided in the following sections.

Table 6.1. Summary of ${ }^{90} \mathrm{Sr}$ Hanford Dosimetric Data

\begin{tabular}{lcc}
\hline & \multicolumn{2}{c}{ Chemical Form } \\
\cline { 2 - 3 } & All Forms Except & Sr-Titanate $\left(\mathrm{SrTiO}_{3}\right)$ \\
\hline Absorption Type ${ }^{(\mathrm{a})}$ & & \\
Inhalation model & Type $\mathrm{F}\left(f_{1}=0.3\right)$ & Type $\mathrm{S}\left(f_{1}=0.01\right)$ \\
${\text { Gastrointestinal absorption }\left(f_{1}\right)}$ & Soluble $\left(f_{1}=0.3\right)$ & Insoluble $\left(f_{1}=0.01\right)$ \\
Dose Coefficients ${ }^{(\mathrm{b})}, e(50)$ & & \\
5-mm-AMAD inhalation & $0.112 \mathrm{mrem} / \mathrm{nCi}$ & $0.285 \mathrm{mrem} / \mathrm{nCi}$ \\
& $(3.03 \mathrm{E}-08 \mathrm{~Sv} / \mathrm{Bq})$ & $(7.70 \mathrm{E}-08 \mathrm{~Sv} / \mathrm{Bq})$ \\
Ingestion & $($ soluble $)$ & $($ insoluble $)$ \\
& $0.102 \mathrm{mrem} / \mathrm{nCi}$ & $9.92 \mathrm{E}-03 \mathrm{mrem} / \mathrm{nCi}$ \\
Transportable injection & $(2.76 \mathrm{E}-08 \mathrm{~Sv} / \mathrm{Bq})$ & $(2.68 \mathrm{E}-09 \mathrm{~Sv} / \mathrm{Bq})$ \\
& $0.325 \mathrm{mrem} / \mathrm{nCi}$ & \\
& $(8.78 \mathrm{E}-08 \mathrm{~Sv} / \mathrm{Bq})$ & Not applicable \\
\hline
\end{tabular}

(a) Type F = fast; Type $\mathrm{S}$ = slow.

(b) Calculated using IMBA.

AMAD = activity median aerodynamic diameter.

\subsection{Sources and Characteristics of Strontium at Hanford}

The isotopes of dominant concern for strontium internal dosimetry are ${ }^{90} \mathrm{Sr}$ and its decay product ${ }^{90} \mathrm{Y}$. These nuclides may be found in almost any Hanford facility that deals with fission products or fission product waste mixtures. Most facilities that have strontium may also be expected to have other fission products present, notably ${ }^{137} \mathrm{Cs}$, and it is a common practice to use ${ }^{137} \mathrm{Cs}$ as an indicator of potential ${ }^{90} \mathrm{Sr}$. This can be a valid assumption, because both nuclides have comparable yields from the fissioning of ${ }^{235} \mathrm{U}$

\footnotetext{
${ }^{1}$ IMBA Professional Plus, which includes the current version of the user manual, is available from Health Protection Agency (HPA), Radiation Protection Division, Chilton, Didicot, Oxon., OX11 0RQ UK and from http://www.imbaprofessional.com/
} 
(see Table 6.2). However, it must be noted that some Hanford chemical processes have separated cesium from strontium, and relatively pure ${ }^{90} \mathrm{Sr}$ may be associated with laboratories, waste separation facilities (notably B Plant, [221-B Building]) and the Waste Encapsulation and Storage Facility (WESF, [225-B Building]), and waste storage tank sludge.

Table 6.2. ${ }^{90} \mathrm{Sr}$ Fission Product Mass Yields ${ }^{(\mathrm{a})}$

\begin{tabular}{|c|c|c|}
\hline Fissionable Nuclide & $\begin{array}{c}\text { FP Mass No. } 90 \\
(\%)\end{array}$ & $\begin{array}{c}\text { FP Mass No. } 137 \\
(\%)\end{array}$ \\
\hline${ }^{233} \mathrm{U}$ & 6.9 & 6.81 \\
\hline${ }^{235} \mathrm{U}$ & 5.91 & 6.22 \\
\hline${ }^{239} \mathrm{Pu}$ & 2.11 & 6.7 \\
\hline
\end{tabular}

Thus, caution must be exercised because the ${ }^{90} \mathrm{Sr} /{ }^{137} \mathrm{Cs}$ ratio is highly variable between and within facilities. This use of a ratio can be valid if the nature of facility contamination is known.

When Hanford reactors were operating, the potential existed for ${ }^{89} \mathrm{Sr}$ to also be a concern, most likely at N Reactor, the fuel storage basins, the Fast Flux Test Facility, or the Plutonium-Uranium Extraction Plant. However, the short radiological half-life of ${ }^{89} \mathrm{Sr}$ (50 days) and the long time that has elapsed since reactors operated indicates that ${ }^{89} \mathrm{Sr}$ is no longer a concern at Hanford, unless a new source (e.g., material received from offsite) is established. The ORIGEN computer code (Hedengren 1985) indicated that, for $\mathrm{N}$ Reactor, 6\%, Mark IV (MKIV) fuel at discharge, there might have been about 90 times as much ${ }^{89} \mathrm{Sr}$ as ${ }^{90} \mathrm{Sr}$. Exposure to such material would have been more limiting in terms of internal dose than exposure to just ${ }^{90} \mathrm{Sr}$. But because of the rapid decay of ${ }^{89} \mathrm{Sr}$, within about 6 months ${ }^{90} \mathrm{Sr}$ became the dominant isotope of concern. Less than $1 \%$ of the ${ }^{89} \mathrm{Sr}$ produced in fuel remained at 1 year after exposure, and, for practical purposes, that nuclide ceased to be a dosimetric concern by that time.

Selected decay data for ${ }^{90} \mathrm{Sr},{ }^{90} \mathrm{Y}$, and ${ }^{89} \mathrm{Sr}$ are shown in Table 6.3.

Table 6.3. Decay Data for Strontium Isotopes

\begin{tabular}{lccc}
\hline \multicolumn{1}{c}{ Parameter } & ${ }^{90} \mathrm{Sr}$ & ${ }^{90} \mathrm{Y}$ & ${ }^{89} \mathrm{Sr}$ \\
\hline Half-life & $29.12 \mathrm{y}$ & $64.0 \mathrm{~h}$ & $50.5 \mathrm{~d}$ \\
Decay constant & $6.5 \mathrm{E}-05 \mathrm{~d}^{-1}$ & $0.26 \mathrm{~d}^{-1}$ & $0.014 \mathrm{~d}^{-1}$ \\
& Beta & Beta & Beta \\
Decay mode & (no gamma) & (no gamma) & (no gamma) \\
\hline
\end{tabular}

For most internal dosimetry purposes, ${ }^{90} \mathrm{Sr}$ and ${ }^{90} \mathrm{Y}$ are the nuclides of concern. These nuclides are found in equilibrium in virtually all circumstances under which exposure is likely. Although strontium separation operations have been performed in which pure ${ }^{90} \mathrm{Sr}$ might be obtained, the rapid ingrowth of the ${ }^{90} \mathrm{Y}$ decay product results in the secular equilibrium condition being achieved within about 2 weeks

PNNL-MA-860 Chapter 6.0

Page 6.2
Issued for implementation effective 01/01/2010

Supersedes: January 31, 2003 
after separation. Thus, even if an exposure to pure ${ }^{90} \mathrm{Sr}$ occurred, within about 2 weeks of exposure equal quantities of both nuclides would be present in the body. Pure ${ }^{90} \mathrm{Y}$ was produced and packaged in the 325 Building during the 1990s (through 1999).

\subsection{Environmental Levels of ${ }^{90} \mathrm{Sr}$}

Daily dietary intake of ${ }^{90} \mathrm{Sr}$ is estimated to range from 0.1 to $0.4 \mathrm{~Bq} / \mathrm{d}$ (3 to $11 \mathrm{pCi} / \mathrm{d}$ ) from San Francisco to New York, according to the United Nations Scientific Committee on the Effects of Atomic Radiation (UNSCEAR 1982, p. 231). Intakes of about 8 to $11 \mathrm{pCi} / \mathrm{d}$ were reported by Stroube et al. (1985). The concentration in milk may run from 0.04 to $0.2 \mathrm{~Bq} / \mathrm{L}$. A brief note by Irlweck and Streit (1979) indicated that normal background ${ }^{90} \mathrm{Sr}$ in urine levels for the population of Austria ranged from 0.2 to $2 \mathrm{pCi} / \mathrm{L}$, which would correspond to 0.7 to $7 \mathrm{dpm} / \mathrm{d}$ for an ICRP Reference Man excretion rate of $1.6 \mathrm{~L} / \mathrm{d}$. These levels were attributed to worldwide fallout and natural variability. They suggested a screening level of $5 \mathrm{pCi} / \mathrm{L}(18 \mathrm{dpm} / \mathrm{d})$ as a basis for assuming intake from sources other than worldwide fallout.

A detailed study of the environmental background levels of ${ }^{90} \mathrm{Sr}$ in the urine of unexposed Hanford workers was performed in 2008 (Antonio and Rivard 2008). The study found that an environmental screening level of $1 \mathrm{dpm} / \mathrm{d}$ would imply that about 1 out of 100 workers not occupationally exposed might exceed it. For routine ${ }^{90} \mathrm{Sr}$ urinalyses, the Hanford Internal Dosimetry Program (HIDP) uses a 10-mrem investigation screening level of $4 \mathrm{dpm} / \mathrm{d}$, consistent with guidance in the Health Physics Society American National Standard HPS N13.39 (HPS 2001). However, for incident follow-up samples, better sensitivity may be desired. Establishing an incident screening level of $1 \mathrm{dpm} / \mathrm{d}$ would be consistent with previous studies of environmental ${ }^{90} \mathrm{Sr}$ levels in urine as well as result in a $1 \%$ probability of assuming an occupational intake when the source was environmental.

\subsection{Biokinetic Behavior of Radiostrontium}

The biokinetic behavior of strontium is a composite of the intake mode, the chemical form, the absorption type, the internal distribution and retention, the excretion, and the radiological half-life of the strontium isotope. The ICRP systemic models presented in Publications 67 (1993) and 78 (1997) are used for calculating the distribution and retention of strontium in the body. The recycling model for strontium is described in Appendix A of ICRP 67. The main sites of deposition and retention are on the trabecular and cortical bone, and consideration is also given to the retention in liver and other soft tissues. The recycling model accounts for the initial uptake of strontium onto bone surfaces, transfer from surface to bone volume, and recycling from bone and other tissues to plasma. The transfer rates are listed in Table 6.4.

\subsubsection{Absorption Type}

All inhalation and ingestion intakes of strontium at Hanford are considered to be absorption Type F (for fast rate of solubilization) with an $f_{1}=0.3$, in accordance with the recommendations of ICRP 78 (1997). It is noted that strontium titanate $\left(\mathrm{SrTiO}_{3}\right)$ is the only compound identified by the ICRP as belonging to absorption Type $S$ (for slow) with an $f_{1}=0.01$. However, that compound of strontium has not been used at Hanford and might only be associated with laboratory work.

Issued for implementation effective 01/01/2010

Supersedes: January 31, 2003

PNNL-MA-860 Chapter 6.0

Page 6.3 
Table 6.4. Transfer Rates Between Compartments in the Strontium Systemic Model

\begin{tabular}{lc}
\hline \multicolumn{1}{c}{ Route } & $\begin{array}{c}\text { Transfer Rate } \\
\left(\mathrm{d}^{-1}\right)\end{array}$ \\
\hline ST0 to plasma ${ }^{(a)}$ & $2.50 \mathrm{E}+00$ \\
ST1 to plasma & $1.16 \mathrm{E}-01$ \\
ST2 to plasma & $3.80 \mathrm{E}-04$ \\
Cortical surface to plasma & $5.78 \mathrm{E}-01$ \\
Non-exchangeable cortical volume to plasma & $8.21 \mathrm{E}-05$ \\
Trabecular surface to plasma & $5.78 \mathrm{E}-01$ \\
Non-exchangeable trabecular volume to plasma & $4.93 \mathrm{E}-04$ \\
Plasma to ST0 & $7.50 \mathrm{E}+00$ \\
Plasma to ST1 & $1.50 \mathrm{E}+00$ \\
Plasma to ST2 & $3.00 \mathrm{E}-03$ \\
Plasma to cortical surface & $1.67 \mathrm{E}+00$ \\
Exchangeable cortical volume to cortical surface & $4.30 \mathrm{E}-03$ \\
Cortical surface to exchangeable cortical volume & $1.16 \mathrm{E}-01$ \\
Exchangeable cortical volume to non-exchangeable cortical volume & $4.30 \mathrm{E}-03$ \\
Plasma to trabecular surface & $2.08 \mathrm{E}+00$ \\
Exchangeable trabecular volume to trabecular surface & $4.30 \mathrm{E}-03$ \\
Trabecular surface to exchangeable trabecular volume & $1.16 \mathrm{E}-01$ \\
Exchangeable trabecular volume to non-exchangeable trabecular volume & $4.30 \mathrm{E}-03$ \\
Plasma to urinary bladder & $1.73 \mathrm{E}+00$ \\
Plasma to upper large intestine & $5.25 \mathrm{E}-01$ \\
\hline (a) ST = soft tissue (numbers indicate compartment numbers). \\
\hline
\end{tabular}

Waste management practices involving strontium fluoride $\left(\mathrm{SrF}_{2}\right)$ are of particular interest from an internal dosimetry perspective, because $\mathrm{SrF}_{2}$ was not specifically included in the ICRP lung model descriptions of strontium compounds. The waste fractionation process separated and purified ${ }^{90} \mathrm{Sr}$ at B Plant, and then converted it into $\mathrm{SrF}_{2}$ powder, which was encapsulated into welded cylinders at WESF. The cylinders remain stored in a water pool at WESF. The $\mathrm{SrF}_{2}$ powder was selected as the chemical form because of its chemical stability and only moderate solubility (i.e., its relative insolubility). This relative insolubility and lack of specific discussion in the ICRP lung model might be cause for considering $\mathrm{SrF}_{2}$ to be a Type $\mathrm{S}$ material. However, this is not thought to be the case. While solubility studies for $\mathrm{SrF}_{2}$ in simulated lung fluid have not been identified, $\mathrm{SrF}_{2}$ is only moderately soluble on a large scale, having a solubility product of $3.5 \times 10^{-4} \mathrm{mg} / \mathrm{L}$. A different picture emerges upon consideration of the microscopic scale, as might be encountered in human intakes. Because of the very high specific activity of ${ }^{90} \mathrm{Sr}$, dosimetrically significant quantities of $\mathrm{SrF}_{2}$ powder have extremely small masses that come nowhere near the solubility product and thus are very quickly dissolved in a small volume of fluid as might be found in the lung or gastrointestinal (GI) tract. Hence, ${ }^{90} \mathrm{SrF}_{2}$ would be expected to exhibit Type $\mathrm{F}$ behavior upon intake.

PNNL-MA-860 Chapter 6.0

Page 6.4
Issued for implementation effective 01/01/2010

Supersedes: January 31, 2003 


\subsubsection{Uptake to Blood}

The absorption coefficient $\left(f_{1}\right)$ used for the GI tract absorption of readily transportable (Type F) forms of strontium is 0.3, which is consistent with the recommendations of ICRP Publications 30 (1979), 56 (1989), 67 (1993), and 78 (1997). These ICRP publications note that the normal range of the absorption coefficient is 0.15 to 0.45 , and fasting for 24 hours can elevate it to 0.25 to 0.55 . Suggested values for infants and children (age 1 to 15 ) are 0.6 and 0.4 , respectively.

Where evaluation of poorly transportable (Type S) forms may be required, the ICRP 78 value of 0.01 will be used.

\subsubsection{Internal Distribution and Retention}

The biokinetic model used for the distribution, retention, and excretion of stable strontium is the ICRP 67 (1993) methodology as implemented by IMBA.

For dosimetry purposes, it is assumed that the intake is the pure isotope of ${ }^{90} \mathrm{Sr}$. The dose contribution from any ${ }^{90} \mathrm{Y}$ present at the time of intake due to equilibrium with the ${ }^{90} \mathrm{Sr}$ parent makes no significant difference in the total dose.

\subsubsection{Excretion of Strontium}

Urine sample analysis is the easiest and most common bioassay method for both ${ }^{89} \mathrm{Sr}$ and ${ }^{90} \mathrm{Sr}$, and therefore the urinary excretion function becomes the key for internal dosimetry evaluations of strontium. The IMBA ${ }^{90} \mathrm{Sr}$ urinary excretion function is used in this technical basis for strontium evaluations.

Urine and feces excretion fractions, respectively, are shown in Tables 6.5 and 6.6 for Type $\mathrm{F}$ and $\mathrm{S}$ inhalations, soluble ingestion, and transportable injection (wound) intakes. For inhalations, a 5- $\mu \mathrm{m}$ AMAD was established as the default particle size per the recommendations set forth in ICRP 66 (1994b), which concluded that a 5 - $\mu$ m AMAD (activity median aerodynamic diameter) was more representative of workplace aerosols than the 1- $\mu$ m-AMAD default value recommended in ICRP 30. For readily transportable injection intakes (i.e., wounds), the total uptake to blood occurs very quickly. In these cases, the calculated intake and uptake are essentially synonymous. Figure 6.1 illustrates the urine excretion fractions for inhalation of 5- $\mu$ m Type $F$ and Type S particles. 
Table 6.5. ${ }^{90} \mathrm{Sr}$ Urine Excretion Fractions

\begin{tabular}{|c|c|c|c|c|c|}
\hline $\begin{array}{l}\text { Days Post } \\
\text { Intake }\end{array}$ & $\begin{array}{c}5-\mu m-A M A D \\
\text { Type F } \\
\text { Inhalation } \\
\left(f_{1}=0.3\right)\end{array}$ & $\begin{array}{c}\text { Soluble } \\
\text { Ingestion } \\
\left(f_{1}=0.3\right)\end{array}$ & $\begin{array}{l}\text { Insoluble } \\
\text { Ingestion } \\
\left(f_{1}=0.01\right)\end{array}$ & $\begin{array}{l}\text { Transportable } \\
\text { Injection }\end{array}$ & $\begin{array}{c}5-\mu \mathrm{m}- \\
\text { AMAD Type } \\
\text { S Inhalation } \\
\left(f_{1}=0.01\right)\end{array}$ \\
\hline 1 & $6.8 \mathrm{E}-02$ & $5.6 \mathrm{E}-02$ & $1.8 \mathrm{E}-03$ & $2.0 \mathrm{E}-01$ & $8.1 \mathrm{E}-04$ \\
\hline 2 & 2.3E-02 & $2.2 \mathrm{E}-02$ & 7.6E-04 & $6.7 \mathrm{E}-02$ & $3.4 \mathrm{E}-04$ \\
\hline 3 & $1.6 \mathrm{E}-02$ & $1.4 \mathrm{E}-02$ & $4.9 \mathrm{E}-04$ & 4.5E-02 & $2.2 \mathrm{E}-04$ \\
\hline 5 & $9.2 \mathrm{E}-03$ & 8.3E-03 & $2.8 \mathrm{E}-04$ & 2.7E-02 & $1.3 \mathrm{E}-04$ \\
\hline 7 & $6.3 \mathrm{E}-03$ & 5.7E-03 & $1.9 \mathrm{E}-04$ & $1.8 \mathrm{E}-02$ & $9.0 \mathrm{E}-05$ \\
\hline 14 & $2.8 \mathrm{E}-03$ & 2.5E-03 & $8.4 \mathrm{E}-05$ & $8.2 \mathrm{E}-03$ & 4.3E-05 \\
\hline 30 & $9.5 \mathrm{E}-04$ & 8.5E-04 & $2.8 \mathrm{E}-05$ & $2.8 \mathrm{E}-03$ & $1.8 \mathrm{E}-05$ \\
\hline 60 & $2.2 \mathrm{E}-04$ & $1.9 \mathrm{E}-04$ & $6.4 \mathrm{E}-06$ & $6.4 \mathrm{E}-04$ & $6.9 \mathrm{E}-06$ \\
\hline 90 & $1.1 \mathrm{E}-04$ & $9.8 \mathrm{E}-05$ & 3.3E-06 & $3.2 \mathrm{E}-04$ & 4.7E-06 \\
\hline 180 & 5.6E-05 & $4.9 \mathrm{E}-05$ & $1.6 \mathrm{E}-06$ & $1.6 \mathrm{E}-04$ & $3.1 \mathrm{E}-06$ \\
\hline 365 & $2.1 \mathrm{E}-05$ & $1.8 \mathrm{E}-05$ & $6.1 \mathrm{E}-07$ & $6.1 \mathrm{E}-05$ & $2.2 \mathrm{E}-06$ \\
\hline 730 & $8.0 \mathrm{E}-06$ & 7.1E-06 & $2.4 \mathrm{E}-07$ & 2.4E-05 & $1.5 \mathrm{E}-06$ \\
\hline 1,825 & $4.4 \mathrm{E}-06$ & $3.9 \mathrm{E}-06$ & $1.3 \mathrm{E}-07$ & $1.3 \mathrm{E}-05$ & $6.5 \mathrm{E}-07$ \\
\hline 3,650 & $2.1 \mathrm{E}-06$ & $1.8 \mathrm{E}-06$ & $6.1 \mathrm{E}-08$ & $6.1 \mathrm{E}-06$ & $2.6 \mathrm{E}-07$ \\
\hline 7,300 & $6.7 \mathrm{E}-07$ & $5.9 \mathrm{E}-07$ & $2.0 \mathrm{E}-08$ & $2.0 \mathrm{E}-06$ & $9.2 \mathrm{E}-08$ \\
\hline 18,250 & $1.0 \mathrm{E}-07$ & $8.8 \mathrm{E}-08$ & $2.9 \mathrm{E}-09$ & $2.9 \mathrm{E}-07$ & $1.0 \mathrm{E}-08$ \\
\hline
\end{tabular}

Comment [ske1]: FORMAT: Globally, get rid of excess white space at top across columns here. Same in ensuing tables.

Table 6.6. ${ }^{90} \mathrm{Sr}$ Fecal Excretion Fractions

\begin{tabular}{rccccc}
\hline $\begin{array}{r}\text { Days } \\
\text { Post } \\
\text { Intake }\end{array}$ & $\begin{array}{c}5 \text { - } \mu \text { Am AMAD } \\
\text { Type F } \\
\text { Inhalation } \\
\left(f_{1}=0.3\right)\end{array}$ & $\begin{array}{c}\text { Soluble } \\
\text { Ingestion } \\
\left(f_{1}=0.3\right)\end{array}$ & $\begin{array}{c}\text { Insoluble } \\
\text { Ingestion } \\
\left(f_{1}=0.01\right)\end{array}$ & $\begin{array}{c}\text { Transportable } \\
\text { Injection }\end{array}$ & $\begin{array}{c}\text { Type } S \\
\text { Inhalation } \\
\left(f_{1}=0.01\right)\end{array}$ \\
\hline 1 & $4.8 \mathrm{E}-02$ & $2.2 \mathrm{E}-01$ & $2.8 \mathrm{E}-01$ & $1.6 \mathrm{E}-02$ & $1.1 \mathrm{E}-01$ \\
2 & $6.3 \mathrm{E}-02$ & $2.8 \mathrm{E}-01$ & $3.9 \mathrm{E}-01$ & $2.8 \mathrm{E}-02$ & $1.6 \mathrm{E}-01$ \\
3 & $3.5 \mathrm{E}-02$ & $1.4 \mathrm{E}-01$ & $1.9 \mathrm{E}-01$ & $2.4 \mathrm{E}-02$ & $8.3 \mathrm{E}-02$ \\
5 & $8.7 \mathrm{E}-03$ & $2.5 \mathrm{E}-02$ & $3.1 \mathrm{E}-02$ & $1.3 \mathrm{E}-02$ & $1.4 \mathrm{E}-02$ \\
7 & $3.3 \mathrm{E}-03$ & $5.3 \mathrm{E}-03$ & $4.4 \mathrm{E}-03$ & $7.8 \mathrm{E}-03$ & $2.5 \mathrm{E}-03$ \\
14 & $9.8 \mathrm{E}-04$ & $8.8 \mathrm{E}-04$ & $3.3 \mathrm{E}-05$ & $2.9 \mathrm{E}-03$ & $5.2 \mathrm{E}-04$ \\
30 & $3.2 \mathrm{E}-04$ & $2.8 \mathrm{E}-04$ & $9.4 \mathrm{E}-06$ & $9.3 \mathrm{E}-04$ & $3.5 \mathrm{E}-04$ \\
60 & $7.0 \mathrm{E}-05$ & $6.2 \mathrm{E}-05$ & $2.1 \mathrm{E}-06$ & $2.1 \mathrm{E}-04$ & $1.9 \mathrm{E}-04$ \\
90 & $3.4 \mathrm{E}-05$ & $3.0 \mathrm{E}-05$ & $1.0 \mathrm{E}-06$ & $1.0 \mathrm{E}-04$ & $1.1 \mathrm{E}-04$ \\
180 & $1.7 \mathrm{E}-05$ & $1.5 \mathrm{E}-05$ & $5.0 \mathrm{E}-07$ & $5.0 \mathrm{E}-05$ & $3.7 \mathrm{E}-05$ \\
365 & $6.4 \mathrm{E}-06$ & $5.6 \mathrm{E}-06$ & $1.9 \mathrm{E}-07$ & $1.9 \mathrm{E}-05$ & $2.2 \mathrm{E}-05$ \\
730 & $2.4 \mathrm{E}-06$ & $2.2 \mathrm{E}-06$ & $7.2 \mathrm{E}-08$ & $7.2 \mathrm{E}-06$ & $1.4 \mathrm{E}-05$ \\
1,825 & $1.3 \mathrm{E}-06$ & $1.2 \mathrm{E}-06$ & $3.9 \mathrm{E}-08$ & $3.9 \mathrm{E}-06$ & $4.3 \mathrm{E}-06$ \\
3,650 & $6.4 \mathrm{E}-07$ & $5.6 \mathrm{E}-07$ & $1.9 \mathrm{E}-08$ & $1.9 \mathrm{E}-06$ & $7.1 \mathrm{E}-07$ \\
7,300 & $2.0 \mathrm{E}-07$ & $1.8 \mathrm{E}-07$ & $6.0 \mathrm{E}-09$ & $6.0 \mathrm{E}-07$ & $1.0 \mathrm{E}-07$ \\
18,250 & $3.0 \mathrm{E}-08$ & $2.7 \mathrm{E}-08$ & $8.9 \mathrm{E}-10$ & $8.9 \mathrm{E}-08$ & $6.0 \mathrm{E}-09$ \\
\hline
\end{tabular}

PNNL-MA-860 Chapter 6.0 Page 6.6
Issued for implementation effective 01/01/2010

Supersedes: January 31, 2003
Comment [ske2]: FORMAT: Globally, fix number alignment across 1 rows. 


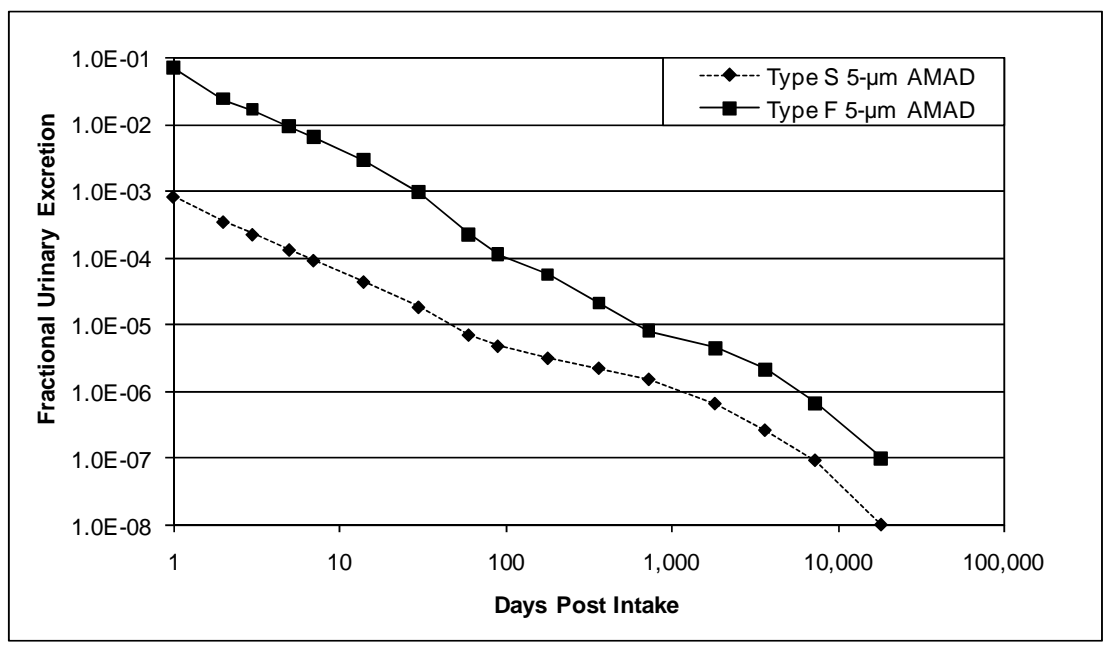

Figure 6.1. ${ }^{90} \mathrm{Sr}$ Urine Excretion After an Acute Inhalation Intake

\subsection{Internal Dosimetry Factors for Radiostrontium}

IMBA is used for ${ }^{90} \mathrm{Sr}$ intake and dose assessments use the ICRP 60/68 methods, biokinetic models, and specific effective energies. Committed dose coefficients for organs and tissues of significance for several different intake conditions are tabulated in Table 6.7.

Table 6.7. Hanford ${ }^{90} \mathrm{Sr}$ Dose Coefficients for Significant Organs $\left(e(50) h_{\mathrm{T}}(50)\right.$ in mrem/nCi Intake $\left.{ }^{[\mathrm{a}, \mathrm{b}]}\right)$

\begin{tabular}{lccccc}
\hline & $\begin{array}{c}\text { Type F - } \\
\text { Inhalation } \\
5-\mu \text { AMAD } \\
\left(f_{1}=0.3\right)\end{array}$ & $\begin{array}{c}\text { Type S - } \\
\text { Inhalation } \\
5-\mu \text { AMAD } \\
\left(f_{1}=0.01\right)\end{array}$ & $\begin{array}{c}\text { Soluble } \\
\text { Ingestion } \\
\left(f_{1}=0.3\right)\end{array}$ & $\begin{array}{c}\text { Insoluble } \\
\text { Ingestion } \\
\left(f_{1}=0.01\right)\end{array}$ & $\begin{array}{c}\text { Transportable } \\
\text { Injection }\end{array}$ \\
\hline Effective $e(50)$ & 0.112 & 0.285 & 0.102 & 0.00992 & 0.325 \\
Bone surfaces & 1.710 & 0.0502 & 1.51 & 0.0503 & 5.03 \\
Red bone marrow & 0.751 & 0.0223 & 0.661 & 0.0220 & 2.20 \\
Lung & {$[0.00286]$} & 2.32 & {$[0.00245]$} & {$[8.17 \mathrm{E}-05]$} & {$[0.00812]$} \\
\hline
\end{tabular}

(a) Bracketed values are considered insignificant contributors to effective dose and are shown for information only.

(b) The values for ${ }^{90} \mathrm{Sr}$ and ${ }^{90} \mathrm{Sr}+{ }^{90} \mathrm{Y}$ are not significantly different at the precision shown.

Committed dose coefficients for ${ }^{90} \mathrm{Y}$ are approximately 2 to 4 orders of magnitude lower than those for ${ }^{90} \mathrm{Sr}$, hence the existence of ${ }^{90} \mathrm{Y}$ in secular equilibrium to ${ }^{90} \mathrm{Sr}$ at the time of intake does not add any significant dose to the intake beyond that resulting from the ${ }^{90} \mathrm{Sr}$.

Derived reporting, investigation, and dose limit compliance levels (based on committed effective doses of 10 mrem, 100 mrem, and 5,000 mrem, respectively) have been calculated for 5- $\mu \mathrm{m}$ particle sizes. The derived levels for daily urine excretion are shown in Table 6.8 for inhalation of Type $\mathrm{F}$ and Type $\mathrm{S}$ 
materials, and in Table 6.9 for soluble ingestion and transportable injection. Although there is no reason to suspect Type $\mathrm{S}^{90} \mathrm{Sr}$ at Hanford, the dose coefficients and derived levels are provided for information purposes.

Table 6.8. ${ }^{90} \mathrm{Sr}$ Daily Urine Excretion Reference Levels for 5 - $\mu \mathrm{m}$-AMAD Inhalations

\begin{tabular}{|c|c|c|c|c|c|c|}
\hline & \multicolumn{3}{|c|}{ Type F Inhalation } & \multicolumn{3}{|c|}{ Type S Inhalation } \\
\hline & $\begin{array}{l}\text { 10-mrem } \\
\text { E(50) } \\
\text { Reporting } \\
\text { Level }\end{array}$ & $\begin{array}{c}100 \text {-mrem E(50) } \\
\text { Investigation Level }\end{array}$ & $\begin{array}{l}\text { 50-rem } \mathrm{H}_{\mathrm{T}}(50) \\
\text { Compliance } \\
\text { Level }\end{array}$ & $\begin{array}{l}\text { 10-mrem } \\
\text { E(50) } \\
\text { Reporting } \\
\text { Level }\end{array}$ & $\begin{array}{c}\text { 100-mrem } \\
\text { E(50) } \\
\text { Investigation } \\
\text { Level }\end{array}$ & $\begin{array}{c}\text { 5-rem E(50) } \\
\text { Compliance } \\
\text { Level }\end{array}$ \\
\hline $\begin{array}{l}\text { Inhalation } \\
\text { Intake: }\end{array}$ & $89.3 \mathrm{nCi}$ & $893 n C i$ & $29,200 n C i$ & $35.1 \mathrm{nCi}$ & $351 \mathrm{nCi}$ & $17,500 \mathrm{nCi}$ \\
\hline $\begin{array}{l}\text { Days Post } \\
\text { Intake }\end{array}$ & $\begin{array}{l}\text { Derived } \\
\text { Reporting } \\
\text { Level } \\
(\mathrm{dpm} / \mathrm{d})\end{array}$ & $\begin{array}{c}\text { Derived Investigation } \\
\text { Level } \\
(\mathrm{dpm} / \mathrm{d})\end{array}$ & $\begin{array}{c}\text { Derived } \\
\text { Compliance } \\
\text { Level } \\
(\mathrm{dpm} / \mathrm{d})\end{array}$ & $\begin{array}{l}\text { Derived } \\
\text { Reporting } \\
\text { Level } \\
(\mathrm{dpm} / \mathrm{d})\end{array}$ & $\begin{array}{c}\text { Derived } \\
\text { Investigation } \\
\text { Level } \\
\text { (dpm/d) }\end{array}$ & $\begin{array}{c}\text { Derived } \\
\text { Compliance } \\
\text { Level } \\
\text { (dpm/d) }\end{array}$ \\
\hline 1 & $1.4 \mathrm{E}+04$ & $1.4 \mathrm{E}+05$ & $4.4 \mathrm{E}+06$ & $6.3 \mathrm{E}+01$ & $6.3 \mathrm{E}+02$ & $3.1 \mathrm{E}+04$ \\
\hline 2 & $4.6 \mathrm{E}+03$ & $4.6 \mathrm{E}+04$ & $1.5 E+06$ & $2.7 \mathrm{E}+01$ & $2.7 \mathrm{E}+02$ & $1.3 \mathrm{E}+04$ \\
\hline 3 & $3.1 \mathrm{E}+03$ & $3.1 \mathrm{E}+04$ & $1.0 \mathrm{E}+06$ & $1.7 \mathrm{E}+01$ & $1.7 \mathrm{E}+02$ & $8.6 \mathrm{E}+03$ \\
\hline 5 & $1.8 \mathrm{E}+03$ & $1.8 \mathrm{E}+04$ & $6.0 \mathrm{E}+05$ & $1.0 \mathrm{E}+01$ & $1.0 \mathrm{E}+02$ & $5.0 \mathrm{E}+03$ \\
\hline 7 & $1.3 \mathrm{E}+03$ & $1.3 \mathrm{E}+04$ & $4.1 \mathrm{E}+05$ & $7.0 \mathrm{E}+00$ & $7.0 \mathrm{E}+01$ & $3.5 \mathrm{E}+03$ \\
\hline 14 & $5.6 \mathrm{E}+02$ & $5.6 \mathrm{E}+03$ & $1.8 \mathrm{E}+05$ & $3.3 E+00$ & $3.3 \mathrm{E}+01$ & $1.7 \mathrm{E}+03$ \\
\hline 30 & $1.9 \mathrm{E}+02$ & $1.9 \mathrm{E}+03$ & $6.2 \mathrm{E}+04$ & $1.4 \mathrm{E}+00$ & $1.4 \mathrm{E}+01$ & $6.9 \mathrm{E}+02$ \\
\hline 60 & $4.3 \mathrm{E}+01$ & $4.3 \mathrm{E}+02$ & $1.4 \mathrm{E}+04$ & $5.4 \mathrm{E}-01$ & $5.4 \mathrm{E}+00$ & $2.7 \mathrm{E}+02$ \\
\hline 90 & $2.2 \mathrm{E}+01$ & $2.2 \mathrm{E}+02$ & $7.2 \mathrm{E}+03$ & 3.7E-01 & $3.7 \mathrm{E}+00$ & $1.8 \mathrm{E}+02$ \\
\hline 180 & $1.1 \mathrm{E}+01$ & $1.1 \mathrm{E}+02$ & $3.6 E+03$ & $2.4 \mathrm{E}-01$ & $2.4 \mathrm{E}+00$ & $1.2 \mathrm{E}+02$ \\
\hline 365 & $4.1 \mathrm{E}+00$ & $4.1 \mathrm{E}+01$ & $1.4 \mathrm{E}+03$ & 1.7E-01 & $1.7 \mathrm{E}+00$ & $8.6 \mathrm{E}+01$ \\
\hline 730 & $1.6 \mathrm{E}+00$ & $1.6 \mathrm{E}+01$ & $5.2 \mathrm{E}+02$ & $1.2 \mathrm{E}-01$ & $1.2 \mathrm{E}+00$ & $5.8 \mathrm{E}+01$ \\
\hline 1,825 & 8.7E-01 & $8.7 \mathrm{E}+00$ & $2.8 \mathrm{E}+02$ & $5.0 \mathrm{E}-02$ & $5.0 \mathrm{E}-01$ & $2.5 \mathrm{E}+01$ \\
\hline 3,650 & 4.2E-01 & $4.2 \mathrm{E}+00$ & $1.4 \mathrm{E}+02$ & $2.0 \mathrm{E}-02$ & $2.0 \mathrm{E}-01$ & $1.0 \mathrm{E}+01$ \\
\hline 7,300 & 1.3E-01 & $1.3 \mathrm{E}+00$ & $4.3 E+01$ & 7.2E-03 & 7.2E-02 & $3.6 \mathrm{E}+00$ \\
\hline 18,250 & 2.0E-02 & $2.0 \mathrm{E}-01$ & $6.5 \mathrm{E}+00$ & 8.1E-04 & 8.1E-03 & 4.0E-01 \\
\hline
\end{tabular}

\subsection{Bioassay for Radiostrontium}

The general techniques and applicability of bioassay for strontium, urine and fecal sample bioassay, in vivo measurement of ${ }^{90} \mathrm{Sr}$, bioassay monitoring program capability, a recommended program, and special monitoring needs are discussed in the following sections.

\subsubsection{Excreta Bioassay Techniques for ${ }^{90} \mathrm{Sr}$}

The standard method of bioassay for strontium is by analysis of urine excreta samples. Because strontium at Hanford is a Type F material, its rapid transport to the systemic compartment makes urine sampling an accurate, reliable, and convenient means for bioassay monitoring. In addition, the lack of any readily detectable gamma emissions makes in vivo detection somewhat ineffective, although if

PNNL-MA-860 Chapter 6.0

Page 6.8
Issued for implementation effective 01/01/2010

Supersedes: January 31, 2003 
sufficient strontium is present, the bremsstrahlung can be detected by in vivo counting. Fecal samples can also be analyzed; however, their collection is more difficult, and analysis of fecal samples is more costly than analysis of urine samples.

Table 6.9. ${ }^{90}$ Sr Daily Urine Excretion Reference Levels for Soluble Ingestion and Transportable Injection

\begin{tabular}{|c|c|c|c|c|c|c|}
\hline & \multicolumn{3}{|c|}{ Soluble Ingestion } & \multicolumn{3}{|c|}{ Transportable Injection } \\
\hline & $\begin{array}{l}\text { 10-mrem E(50) } \\
\text { Reporting } \\
\text { Level }\end{array}$ & $\begin{array}{c}\text { 100-mrem E(50) } \\
\text { Investigation } \\
\text { Level }\end{array}$ & $\begin{array}{c}\text { 50-rem } \\
\mathrm{H}_{\mathrm{T}}(50) \\
\text { Compliance } \\
\text { Level }\end{array}$ & $\begin{array}{l}\text { 10-mrem E(50) } \\
\text { Reporting } \\
\text { Level }\end{array}$ & $\begin{array}{c}\text { 100-mrem E(50) } \\
\text { Investigation } \\
\text { Level }\end{array}$ & $\begin{array}{c}\text { 50-rem } \mathrm{H}_{\mathrm{T}}(50) \\
\text { Compliance } \\
\text { Level }\end{array}$ \\
\hline $\begin{array}{l}\text { Inhalation } \\
\text { Intake: }\end{array}$ & $98.0 \mathrm{nCi}$ & $980 \mathrm{nCi}$ & $33,100 \mathrm{nCi}$ & $30.8 \mathrm{nCi}$ & $308 n C i$ & $9,940 n C i$ \\
\hline $\begin{array}{l}\text { Days Post } \\
\text { Intake }\end{array}$ & $\begin{array}{l}\text { Derived } \\
\text { Reporting } \\
\text { Level } \\
(\mathrm{dpm} / \mathrm{d}) \\
\end{array}$ & $\begin{array}{c}\text { Derived } \\
\text { Investigation } \\
\text { Level } \\
(\mathrm{dpm} / \mathrm{d}) \\
\end{array}$ & $\begin{array}{c}\text { Derived } \\
\text { Compliance } \\
\text { Level } \\
(\mathrm{dpm} / \mathrm{d}) \\
\end{array}$ & $\begin{array}{l}\text { Derived } \\
\text { Reporting } \\
\text { Level } \\
(\mathrm{dpm} / \mathrm{d}) \\
\end{array}$ & $\begin{array}{c}\text { Derived } \\
\text { Investigation } \\
\text { Level } \\
(\mathrm{dpm} / \mathrm{d}) \\
\end{array}$ & $\begin{array}{c}\text { Derived } \\
\text { Compliance } \\
\text { Level } \\
(\mathrm{dpm} / \mathrm{d}) \\
\end{array}$ \\
\hline 1 & $1.2 \mathrm{E}+04$ & $1.2 \mathrm{E}+05$ & $4.2 \mathrm{E}+06$ & $1.4 \mathrm{E}+04$ & $1.4 \mathrm{E}+05$ & $4.5 \mathrm{E}+06$ \\
\hline 2 & $4.8 \mathrm{E}+03$ & $4.8 \mathrm{E}+04$ & $1.6 \mathrm{E}+06$ & $4.6 \mathrm{E}+03$ & $4.6 \mathrm{E}+04$ & $1.5 \mathrm{E}+06$ \\
\hline 3 & $3.1 \mathrm{E}+03$ & $3.1 \mathrm{E}+04$ & $1.1 \mathrm{E}+06$ & $3.1 \mathrm{E}+03$ & $3.1 \mathrm{E}+04$ & $1.0 \mathrm{E}+06$ \\
\hline 5 & $1.8 \mathrm{E}+03$ & $1.8 \mathrm{E}+04$ & $6.1 \mathrm{E}+05$ & $1.8 \mathrm{E}+03$ & $1.8 \mathrm{E}+04$ & $5.9 \mathrm{E}+05$ \\
\hline 7 & $1.2 \mathrm{E}+03$ & $1.2 \mathrm{E}+04$ & $4.2 \mathrm{E}+05$ & $1.3 \mathrm{E}+03$ & $1.3 \mathrm{E}+04$ & $4.1 \mathrm{E}+05$ \\
\hline 14 & $5.4 \mathrm{E}+02$ & $5.4 \mathrm{E}+03$ & $1.8 \mathrm{E}+05$ & $5.6 \mathrm{E}+02$ & $5.6 \mathrm{E}+03$ & $1.8 \mathrm{E}+05$ \\
\hline 30 & $1.8 \mathrm{E}+02$ & $1.8 \mathrm{E}+03$ & $6.2 \mathrm{E}+04$ & $1.9 \mathrm{E}+02$ & $1.9 \mathrm{E}+03$ & $6.2 \mathrm{E}+04$ \\
\hline 60 & $4.2 \mathrm{E}+01$ & $4.2 \mathrm{E}+02$ & $1.4 \mathrm{E}+04$ & $4.4 \mathrm{E}+01$ & $4.4 \mathrm{E}+02$ & $1.4 \mathrm{E}+04$ \\
\hline 90 & $2.1 \mathrm{E}+01$ & $2.1 \mathrm{E}+02$ & $7.2 \mathrm{E}+03$ & $2.2 \mathrm{E}+01$ & $2.2 \mathrm{E}+02$ & $7.2 \mathrm{E}+03$ \\
\hline 180 & $1.1 \mathrm{E}+01$ & $1.1 \mathrm{E}+02$ & $3.6 \mathrm{E}+03$ & $1.1 \mathrm{E}+01$ & $1.1 \mathrm{E}+02$ & $3.6 \mathrm{E}+03$ \\
\hline 365 & $4.0 \mathrm{E}+00$ & $4.0 \mathrm{E}+01$ & $1.4 \mathrm{E}+03$ & $4.2 \mathrm{E}+00$ & $4.2 \mathrm{E}+01$ & $1.4 \mathrm{E}+03$ \\
\hline 730 & $1.5 \mathrm{E}+00$ & $1.5 \mathrm{E}+01$ & $5.5 \mathrm{E}+02$ & $1.6 \mathrm{E}+00$ & $1.6 \mathrm{E}+01$ & $5.2 \mathrm{E}+02$ \\
\hline 1,825 & $8.4 \mathrm{E}-01$ & $8.4 \mathrm{E}+00$ & $2.8 \mathrm{E}+02$ & 8.8E-01 & $8.8 \mathrm{E}+00$ & $2.8 \mathrm{E}+02$ \\
\hline 3,650 & $4.0 \mathrm{E}-01$ & $4.0 \mathrm{E}+00$ & $1.4 \mathrm{E}+02$ & 4.2E-01 & $4.2 \mathrm{E}+00$ & $1.4 \mathrm{E}+02$ \\
\hline 7,300 & $1.3 \mathrm{E}-01$ & $1.3 \mathrm{E}+00$ & $4.3 \mathrm{E}+01$ & $1.3 \mathrm{E}-01$ & $1.3 \mathrm{E}+00$ & $4.3 \mathrm{E}+01$ \\
\hline 18,250 & 1.9E-02 & 1.9E-01 & $6.5 \mathrm{E}+00$ & 2.0E-02 & 2.0E-01 & $6.5 \mathrm{E}+00$ \\
\hline
\end{tabular}

The minimum detectable intakes and committed effective doses associated with various urinalysis sampling times post intake, based on a 10-dpm/d minimum detectable activity (MDA) for ${ }^{90} \mathrm{Sr}$ in urine for 5- $\mu \mathrm{m}$-AMAD particle sizes are shown for inhalation intakes of Type $\mathrm{F}$ and Type $\mathrm{S}$ material in Table 6.10. Corresponding values for transportable injection intakes and ingestion of soluble material are shown in Table 6.11.

\subsubsection{In Vivo Measurement of ${ }^{90} \mathrm{Sr}$}

Direct in vivo measurement of ${ }^{90} \mathrm{Sr}$ in the skeleton is possible by counting the bremsstrahlung from its decay. This procedure is subject to substantial interference by any other gamma- and beta-emitting nuclides that might be present. Indications are that a retained quantity in the skeleton of about $100 \mathrm{nCi}$ might be detectable by head counting; however, there is no calibration for this measurement. 
Table 6.10. Hanford Bioassay Program Capability for ${ }^{90} \mathrm{Sr}$ in Urine for $5-\mu \mathrm{m}$ AMAD Acute Inhalation $(\mathrm{MDA}=10 \mathrm{dpm} / \mathrm{d})$

\begin{tabular}{rcccc}
\hline & \multicolumn{2}{c}{$\begin{array}{c}\text { Inhalation Type F Inhalation } \\
\left(f_{1}=0.3\right)\end{array}$} & \multicolumn{2}{c}{$\begin{array}{c}\text { Inhalation Type S Inhalation } \\
\left(f_{1}=0.01\right)\end{array}$} \\
\cline { 2 - 5 } $\begin{array}{c}\text { Pass } \\
\text { Intake }\end{array}$ & $\begin{array}{c}\text { Minimum Detectable } \\
\text { Intake (nCi) }\end{array}$ & $\begin{array}{c}\text { Minimum Detectable } \\
\text { Dose (mrem) }\end{array}$ & $\begin{array}{c}\text { Minimum Detectable } \\
\text { Intake }(n C i)\end{array}$ & $\begin{array}{c}\text { Minimum Detectable } \\
\text { Dose (mrem) }\end{array}$ \\
\hline 1 & $6.6 \mathrm{E}-02$ & $7.4 \mathrm{E}-03$ & $5.6 \mathrm{E}+00$ & $1.6 \mathrm{E}+00$ \\
2 & $1.9 \mathrm{E}-01$ & $2.2 \mathrm{E}-02$ & $1.3 \mathrm{E}+01$ & $3.7 \mathrm{E}+00$ \\
3 & $2.9 \mathrm{E}-01$ & $3.2 \mathrm{E}-02$ & $2.0 \mathrm{E}+01$ & $5.8 \mathrm{E}+00$ \\
5 & $4.9 \mathrm{E}-01$ & $5.5 \mathrm{E}-02$ & $3.5 \mathrm{E}+01$ & $9.9 \mathrm{E}+00$ \\
7 & $7.1 \mathrm{E}-01$ & $8.0 \mathrm{E}-02$ & $5.0 \mathrm{E}+01$ & $1.4 \mathrm{E}+01$ \\
14 & $1.6 \mathrm{E}+00$ & $1.8 \mathrm{E}-01$ & $1.1 \mathrm{E}+02$ & $3.0 \mathrm{E}+01$ \\
30 & $4.7 \mathrm{E}+00$ & $5.3 \mathrm{E}-01$ & $2.5 \mathrm{E}+02$ & $7.2 \mathrm{E}+01$ \\
60 & $2.1 \mathrm{E}+01$ & $2.3 \mathrm{E}+00$ & $6.5 \mathrm{E}+02$ & $1.9 \mathrm{E}+02$ \\
90 & $4.1 \mathrm{E}+01$ & $4.6 \mathrm{E}+00$ & $9.6 \mathrm{E}+02$ & $2.7 \mathrm{E}+02$ \\
180 & $8.0 \mathrm{E}+01$ & $9.0 \mathrm{E}+00$ & $1.4 \mathrm{E}+03$ & $4.1 \mathrm{E}+02$ \\
365 & $2.2 \mathrm{E}+02$ & $2.4 \mathrm{E}+01$ & $2.0 \mathrm{E}+03$ & $5.8 \mathrm{E}+02$ \\
730 & $5.6 \mathrm{E}+02$ & $6.3 \mathrm{E}+01$ & $3.0 \mathrm{E}+03$ & $8.6 \mathrm{E}+02$ \\
1,825 & $1.0 \mathrm{E}+03$ & $1.2 \mathrm{E}+02$ & $7.0 \mathrm{E}+03$ & $2.0 \mathrm{E}+03$ \\
3,650 & $2.1 \mathrm{E}+03$ & $2.4 \mathrm{E}+02$ & $1.7 \mathrm{E}+04$ & $5.0 \mathrm{E}+03$ \\
7,300 & $6.7 \mathrm{E}+03$ & $7.5 \mathrm{E}+02$ & $4.9 \mathrm{E}+04$ & $1.4 \mathrm{E}+04$ \\
18,250 & $4.5 \mathrm{E}+04$ & $5.0 \mathrm{E}+03$ & $4.3 \mathrm{E}+05$ & $1.2 \mathrm{E}+05$ \\
\hline
\end{tabular}

Table 6.11. Hanford Bioassay Program Capability for ${ }^{90} \mathrm{Sr}$ in Urine for Transportable Injection and Soluble Ingestion Intakes (MDA = $10 \mathrm{dpm} /$ sample)

\begin{tabular}{|c|c|c|c|c|}
\hline \multirow{2}{*}{$\begin{array}{c}\text { Days } \\
\text { Post } \\
\text { Intake }\end{array}$} & \multicolumn{2}{|c|}{ Transportable Injection Intake } & \multicolumn{2}{|c|}{ Soluble Ingestion Intake $\left(f_{1}=0.01\right)$} \\
\hline & $\begin{array}{l}\text { Minimum Detectable } \\
\text { Intake (nCi) }\end{array}$ & $\begin{array}{c}\text { Minimum Detectable } \\
\text { Effective Dose (mrem) }\end{array}$ & $\begin{array}{l}\text { Minimum Detectable } \\
\text { Intake (nCi) }\end{array}$ & $\begin{array}{c}\text { Minimum Detectable } \\
\text { Effective Dose (mrem) }\end{array}$ \\
\hline 1 & $2.2 \mathrm{E}-02$ & 7.2E-03 & 8.0E-02 & $8.1 \mathrm{E}-03$ \\
\hline 2 & $6.7 E-02$ & $2.2 \mathrm{E}-02$ & $2.0 \mathrm{E}-01$ & $2.1 \mathrm{E}-02$ \\
\hline 3 & $1.0 \mathrm{E}-01$ & $3.2 \mathrm{E}-02$ & $3.1 \mathrm{E}-01$ & $3.2 \mathrm{E}-02$ \\
\hline 5 & $1.7 \mathrm{E}-01$ & 5.5E-02 & $5.4 \mathrm{E}-01$ & 5.5E-02 \\
\hline 7 & $2.4 \mathrm{E}-01$ & 8.0E-02 & 7.9E-01 & 8.1E-02 \\
\hline 14 & 5.5E-01 & $1.8 \mathrm{E}-01$ & $1.8 \mathrm{E}+00$ & $1.8 \mathrm{E}-01$ \\
\hline 30 & $1.6 \mathrm{E}+00$ & $5.2 \mathrm{E}-01$ & $5.3 \mathrm{E}+00$ & 5.4E-01 \\
\hline 60 & $7.0 \mathrm{E}+00$ & $2.3 \mathrm{E}+00$ & $2.3 \mathrm{E}+01$ & $2.4 \mathrm{E}+00$ \\
\hline 90 & $1.4 \mathrm{E}+01$ & $4.5 \mathrm{E}+00$ & $4.6 \mathrm{E}+01$ & $4.7 \mathrm{E}+00$ \\
\hline 180 & $2.7 \mathrm{E}+01$ & $8.9 \mathrm{E}+00$ & $9.1 \mathrm{E}+01$ & $9.3 \mathrm{E}+00$ \\
\hline 365 & $7.3 \mathrm{E}+01$ & $2.4 \mathrm{E}+01$ & $2.4 \mathrm{E}+02$ & $2.5 \mathrm{E}+01$ \\
\hline 730 & $1.9 \mathrm{E}+02$ & $6.2 \mathrm{E}+01$ & $6.4 \mathrm{E}+02$ & $6.5 \mathrm{E}+01$ \\
\hline 1,825 & $3.5 E+02$ & $1.1 \mathrm{E}+02$ & $1.2 \mathrm{E}+03$ & $1.2 \mathrm{E}+02$ \\
\hline 3,650 & $7.3 \mathrm{E}+02$ & $2.4 \mathrm{E}+02$ & $2.4 \mathrm{E}+03$ & $2.5 \mathrm{E}+02$ \\
\hline 7,300 & $2.3 E+03$ & $7.5 \mathrm{E}+02$ & $7.7 \mathrm{E}+03$ & $7.8 \mathrm{E}+02$ \\
\hline 18,250 & $1.5 E+04$ & $5.0 \mathrm{E}+03$ & $5.1 \mathrm{E}+04$ & $5.2 \mathrm{E}+03$ \\
\hline
\end{tabular}


If isotope activity relationships are known, in vivo whole body counting can be an effective indicator for the potential presence of strontium. Cesium-137 is frequently used as the indicator, because its fission product yield is comparable to that of ${ }^{90} \mathrm{Sr}$. However, this method is not conclusive and caution must be exercised because there are processes at Hanford where strontium and cesium have undergone chemical separation from each other. Use of ${ }^{137} \mathrm{Cs}$ as an indicator of ${ }^{90} \mathrm{Sr}$ is more fully described in Chapter 5.0. Radiochemistry analyses for ${ }^{137} \mathrm{Cs}$ and ${ }^{90} \mathrm{Sr}$ in media representative of an intake may be used in lieu of supplemental bioassay measurements. This method is most appropriate when dealing with intakes of small dosimetric consequence.

It is generally recommended that in vivo measurements be used only as indicators of the potential for strontium being present, and that evaluations of any strontium intake be based on urine samples.

\subsubsection{Recommended Periodic Bioassay Monitoring Protocol}

Workers potentially exposed to ${ }^{90} \mathrm{Sr}$ should be on an annual or biennial urinalysis bioassay program. Such programs should be easily capable of detecting Type F intakes resulting in committed effective doses of less than 100 mrem. Similar monitoring programs applied to Type S inhalation are capable of detecting committed effective doses between 600 and 900 mrem. For most Hanford applications, a whole body exam for high-energy gamma-emitting nuclides can also be used as a screening measurement for potential intake of mixed fission products. A worker scheduled only for a whole body exam may not be recognized as having potential exposure to radiostrontium.

If gamma-emitting nuclides such as ${ }^{137} \mathrm{Cs}$ are also of potential concern, the impact of mixtures on potentially undetected effective dose must also be addressed. If other means (e.g., in vivo measurements) are used to monitor for other nuclides, then annual or biennial urine samples should be sufficient to monitor the ${ }^{90} \mathrm{Sr}$ contribution to dose.

\subsubsection{Special Monitoring for Suspected Exposures}

If exposure to ${ }^{90} \mathrm{Sr}$ has occurred or is suspected to have occurred, one or more urine samples should be scheduled for investigation purposes. Because of the high sensitivity of the urine sample analysis, even slight intakes of ${ }^{90} \mathrm{Sr}$ resulting in small fractions of a millirem committed effective dose can be detected if prompt sampling is performed. This also permits the use of less sensitive but faster turnaround analytical procedures (i.e., expedite or emergency processing analyses) for reasonably accurate dose estimates.

As is apparent from Table 6.8 for Type $\mathrm{F}$ inhalation, a urine sample result of $10 \mathrm{dpm} / \mathrm{d}$ obtained within 30 days following the intake would imply a committed effective dose of less than 1 mrem.

Isotopic strontium analyses should be considered for any potential exposures to ${ }^{89} \mathrm{Sr}$. However, if more than 1 year has elapsed since the production of ${ }^{89} \mathrm{Sr}$, that isotope is unlikely to be a dosimetric concern due to its short radiological half-life.

In vivo measurements should also be considered following potential ${ }^{90} \mathrm{Sr}$ exposures, because generally ${ }^{90} \mathrm{Sr}$ is likely to be mixed with other nuclides. 
For relatively small intakes, fecal samples for strontium are not likely to be warranted because of the high degree of systemic uptake and the ease of detection by urine sampling. If major intakes are suspected, fecal samples combined with urine samples may provide more accurate estimates of intake, particularly if the intake is thought to contain some nontransportable strontium.

\subsection{Assessment of Internal Dose}

Internal dosimetry for radiostrontium is performed at Hanford using an intake assessment methodology and urine bioassay data. The method may use either tabulated values for the excretion fractions or IMBA for curve fitting or determining excretion fractions at specific times post intake. Doses may be calculated using either an intake value and tabulated dose coefficients or by using IMBA. For Hanford sources, ${ }^{90} \mathrm{Sr}$ and its ${ }^{90} \mathrm{Y}$ decay product have generally been the isotopes of greatest concern for strontium dosimetry. As noted in the previous sections, ${ }^{89} \mathrm{Sr}$ may also be a concern under some conditions.

The general protocol for strontium dosimetry is as follows:

- Estimate the intake based on urine excreta analyses and the appropriate intake excretion function using IMBA or the tabulated values. The contractor has the option to determine intakes from air sample data rather than obtain urine data.

- Estimate doses using IMBA or tabulated dose coefficients. This includes committed effective doses, as well as equivalent dose to specific organs of concern based on criteria presented in the Hanford Internal Dosimetry Program Manual (PNL-MA-552; EH Carbaugh, et al. 2009).

When estimated intakes and associated doses are a relatively small fraction of the applicable radiation protection limit, direct application of the biokinetic models and dosimetry factors without modification for individual-specific considerations is appropriate. As intakes and doses become more significant, it is appropriate to give correspondingly greater attention to those individual-specific details. Urine data normalization is the factor most likely to be adjusted for an individual-specific modification.

Dose assessments use the techniques and biokinetic models described previously and assume ICRP 23 (1974) and ICRP 89 (2002) basic anatomical and physiological data, usually without correction for individual-specific characteristics. These assessments provide a basis for prospective bioassay program design and retrospective evaluation of doses that are small relative to the occupational exposure limits.

\subsection{Management of Internal Contamination Cases}

The diagnostic procedures, therapeutic actions, and long-term monitoring following an intake of ${ }^{90} \mathrm{Sr}$ are discussed in the following sections on the management of potential internal contamination cases.

\subsubsection{Diagnostic Procedures}

A worker who may have received an intake of strontium should be scheduled for a urine sample and also a whole body count if the mixture contained other fission products. These initial measurements can be used to confirm an intake and provide preliminary estimates of the magnitude of potential doses.

PNNL-MA-860 Chapter 6.0

Page 6.12
Issued for implementation effective 01/01/2010

Supersedes: January 31, 2003 
Suitable urine samples can include a single voiding, overnight sample, or a total or simulated 24-hour sample, depending on the potential severity of the intake (the higher the severity, the more important prompt information becomes). However, as noted in previous sections, the in vivo measurements are for the detection of gamma-emitting nuclides, which may or may not be indicative of ${ }^{90} \mathrm{Sr}$.

A potential intake of ${ }^{90} \mathrm{Sr}$ is best indicated by the results of the urine sample. Where the indicated dose is small (e.g., less than tens of millirem), a single urine sample is adequate for dosimetry. For more significant intakes, getting two or more urine samples (representing actual or approximate 24-hour periods) collected over several days or weeks following the intake is preferred. In general, less credence for dosimetry is placed on a sample taken within the first couple of days after an intake compared with one taken several days or more after the intake.

\subsubsection{Therapeutic Actions}

Therapeutic actions to prevent the uptake of strontium are based primarily on reducing GI tract absorption and accelerating the passage of material through the GI tract. These measures require administration of drugs under medical supervision and are addressed in NCRP 65 (1980) and the "Guidebook for treatment of accidental internal radionuclide contamination of workers” (Bhattacharyya et al. 1992). Aluminum phosphate gel and sodium alginate are the drugs identified as being potentially effective in reducing the GI tract uptake of strontium. Accelerating the passage of material through the GI tract can be accomplished by use of laxatives and enemas. These measures can only be taken under the supervision of the Hanford Site Occupational Medicine organization. Frequent sampling should be used during treatment to provide information about treatment efficiencies. However, standard models should not be used on these samples for dosimetry.

\subsubsection{Long-Term Bioassay Follow-Up Monitoring After an Intake}

Long-term monitoring of urinary excretion after a ${ }^{90} \mathrm{Sr}$ intake may be required to validate the excretion model or to ensure that potential additional intakes do not go undetected. The establishment of a sampling frequency for such monitoring is dependent upon the nature of the exposure, magnitude of deposition, and likelihood for additional exposure. Appropriate long-term follow-up monitoring should be determined as part of the exposure evaluation.

\subsection{Historical ${ }^{90}$ Sr Internal Dosimetry Practices at Hanford}

Historically, Hanford internal dosimetry for strontium was based on estimating the long-term systemic deposition, using urine data and Dolphin’s excretion model (Dolphin and Eve 1963a; 1963b), and comparing it with the 2- $\mu$ Ci ICRP 2 Maximum Permissible Body Burden (ICRP 1959). The longterm (formerly referred to as "permanent") deposition was defined as the amount remaining in the body at 1 year post intake, which was calculated to be $15 \%$ of the initial systemic uptake. This evaluation technique was described in several short explanations, the most recent being Appendix $\mathrm{G}$ of the Hanford Dosimetry Evaluation Manual (PNL-MA-575). ${ }^{2}$ Earlier versions are listed by Sula et al. (1991).

\footnotetext{
${ }^{2}$ Pacific Northwest National Laboratory. 1982. Hanford Dosimetry Evaluation Manual. PNL-MA-575, Richland, Washington. (Internal manual.) 
In April 1985, the practice of investigating all positive ${ }^{90} \mathrm{Sr}$ results regardless of their dose implication was discontinued to be replaced by the practice whereby only results potentially indicating long-term systemic depositions in excess of $1 \%$ of the above-described level were investigated. This change in practice was made due to increased sensitivity of the analytical procedure and the indication of potential background levels in the range of the minimum detection level for the analytical procedure. Using the above method, derived investigation levels were calculated for various times post intake, and these were documented by letter to the Hanford Radiation Protection Historical Files as cited by Sula et al. (1991).

With the issuance of Technical Basis for Internal Dosimetry at Hanford (Sula et al. 1989), the ICRP 30 (1979) dosimetry concepts of committed organ and tissue dose equivalents, and committed effective dose equivalent were adopted, along with the ICRP 20 (1973) alkaline earth model.

\subsection{References}

Antonio C and J Rivard. 2008. "Determination of an environmental background level of strontium in urine for the Hanford bioassay program”. PNNL-SA-62071, Pacific Northwest National Laboratory, Richland, Washington. (Journal Publication Pending)

Bhattacharyya MH, BD Breitenstein, H Metivier, BA Muggenburg, GN Stradling, and V Volf. 1992. "Guidebook for the Treatment of Accidental Internal Radionuclide Contamination of Workers.” Eds. GB Gerber and RG Thomas. Rad. Prot. Dosim. 41:1.

Carbaugh, EH, DE Bihl, and JA MacLellan. 2007. Hanford Internal Dosimetry Program Manual. PNLMA-552, PNNL-15614, Pacific Northwest National Laboratory, Richland, Washington. (Internal manual.) Available at: http://www.pnl.gov/main/publications/external/technical_reports/PNNL15614.pdf

Dolphin GW and IS Eve. 1963a. "The metabolism of strontium in humans.” Phys. in Med. and Biol. 8(2):193-203.

Dolphin GW and IS Eve. 1963b. "Some aspects of radiostrontium dosimetry." Phys. in Med. and Biol. 8(2):205-214.

General Electric Company. 1983. Chart of the Nuclides. 13th Edition, San Jose, California.

Health Physics Society (HPS). 2001. Design of Internal Dosimetry Programs. ANSI/HPS N13.39, American National Standards Institute, Inc., McLean Virginia.

Hedengren DC. 1985. ORIGEN2 Predictions of N-Reactor Fuel Fission Product Composition. SD-CP-I-077, Rockwell Hanford Operations, Richland, Washington.

International Commission on Radiological Protection (ICRP). 1959. Report of Committee II on Permissible Dose for Internal Radiation. ICRP Publication 2, Pergamon Press, New York.

International Commission on Radiological Protection (ICRP). 1973. Alkaline Earth Metabolism in Adult Man. ICRP Publication 20, Pergamon Press, New York.

PNNL-MA-860 Chapter 6.0

Page 6.14
Issued for implementation effective 01/01/2010

Supersedes: January 31, 2003 
International Commission on Radiological Protection (ICRP). 1974. Report of Task Group on Reference Man. ICRP Publication 23, Pergamon Press, New York.

International Commission on Radiological Protection (ICRP). 1979. "Limits for Intakes of Radionuclides by Workers.” ICRP Publication 30, Part 1, Annals of the ICRP, 2:3-4, Pergamon Press, New York.

International Commission on Radiological Protection (ICRP). 1989. “Age-dependent Doses to Members of the Public from Intake of Radionuclides.” ICRP Publication 56, Part 1, Annals of the ICRP, 20:2, Pergamon Press, New York.

International Commission on Radiological Protection (ICRP). 1990. "1990 Recommendations of the International Commission on Radiological Protection.” ICRP Publication 60, Annals of the ICRP, 21:1-3, Pergamon Press, New York.

International Commission on Radiological Protection and Measurements (ICRP). 1994b. "Human

Respiratory Tract Model for Radiological Protection.” ICRP Publication 66, Annals of the ICRP, 24:1-3, Pergamon Press, New York.

International Commission on Radiological Protection (ICRP). 1993. “Age-dependent Doses to Members of the Public from Intake of Radionuclides: Part 2 Ingestion Dose Coefficients.” ICRP Publication 67, Annals of the ICRP, 23:3-4, Pergamon Press, New York.

International Commission on Radiological Protection (ICRP). 1994a. "Dose Coefficients for Intakes of Radionuclides by Workers.” ICRP Publication 68, Annals of the ICRP, 24:4, Pergamon Press, New York.

International Commission on Radiological Protection (ICRP). 1994b. "Human Respiratory Tract Model for Radiological Protection.” ICRP Publication 66, Annals of the ICRP, 24:1-3, Pergamon Press, New York.

International Commission on Radiological Protection (ICRP). 2002. "Basic Anatomical and Physiological Data for Use in Radiological Protection: Reference Values.” ICRP Publication 89, Annals of the ICRP, 32:3-4, Pergamon Press, New York.

International Commission on Radiological Protection (ICRP). 1997. "Individual Monitoring for Internal Exposure of Workers.” ICRP Publication 78, Annals of the ICRP, 27:3-4, Pergamon Press, New York.

Irlweck K and S Streit. 1979. "Urinary ${ }^{90} \mathrm{Sr}$ concentration in occupationally exposed and nonexposed persons in Austria.” Health Phys. 37(1):163-165.

National Council on Radiation Protection and Measurements (NCRP). 1980. Management of Persons Accidentally Contaminated with Radionuclides. NCRP Report No. 65, Bethesda, Maryland.

Stroube Jr. WB, CF Jeline, and EJ Baratta. 1985. "Survey of radionuclides in foods, 1978-1982.”

Health Phys. 49(5):731-735.

Sula MJ, EH Carbaugh, and DE Bihl. 1989. Technical Basis for Internal Dosimetry at Hanford. PNL-6866, Pacific Northwest Laboratory, Richland, Washington. 
Sula MJ, EH Carbaugh, and DE Bihl. 1991. Technical Basis for Internal Dosimetry at Hanford.

PNL-6866, Rev. 1, Pacific Northwest Laboratory, Richland, Washington.

United Nations Scientific Committee on the Effects of Atomic Radiation (UNSCEAR). 1982. Ionizing

Radiation: Sources and Biological Effects. Report 82.IX.8, United Nations, New York.

PNNL-MA-860 Chapter 6.0

Page 6.16
Issued for implementation effective 01/01/2010

Supersedes: January 31, 2003 


\section{Methods and Models of the Hanford Internal Dosimetry Program \\ PNNL-MA-860}

\subsection{Uranium}

Issued for implementation effective 01/01/2010

Supersedes: January 2003

Use Category: Not applicable

\section{Approval Signatures:}

Prepared by: Oonald Bihl

DE Bihl, Scientist

Approved by:

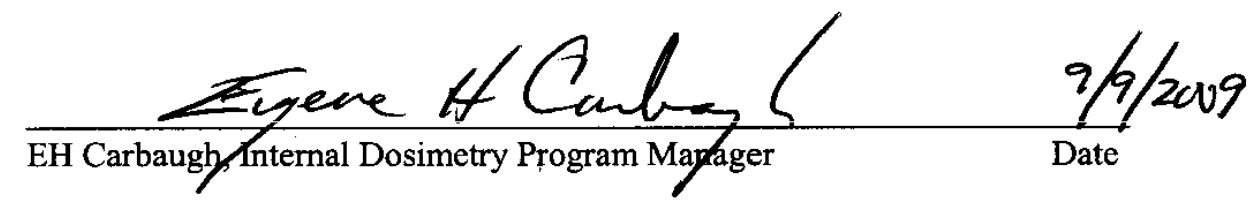

Reviewer Signatures:

Reviewed by:

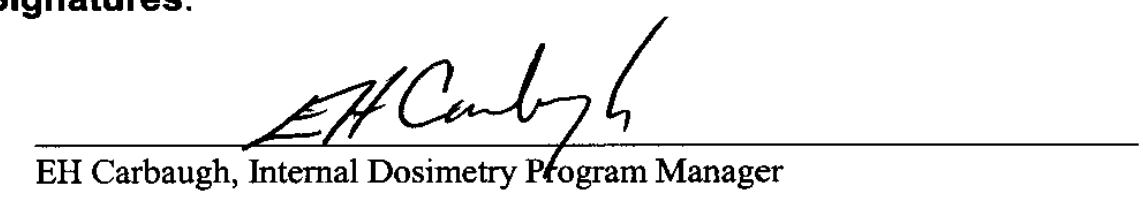

Approved by the Hanford Personnel Dosimetry Advisory Committee as recorded in the meeting minutes of March 10, 2009. 



\section{Contents}

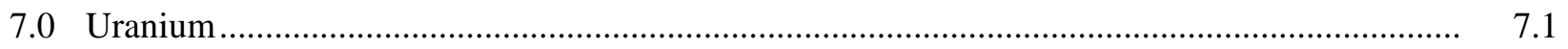

7.1 Sources and Characteristics........................................................................................... 7.1

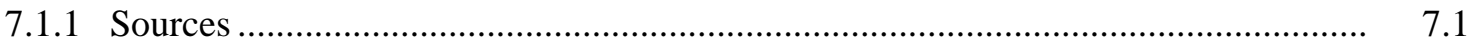

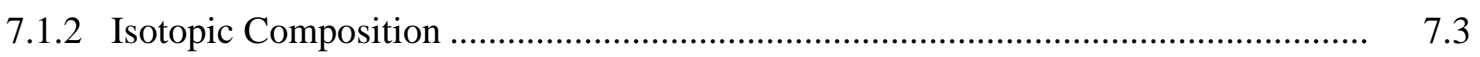

7.1.3 Environmental Background............................................................................. 7.8

7.2 Biokinetic Behavior............................................................................................ 7.11

7.2.1 Absorption Type and Lung Retention ............................................................. 7.11

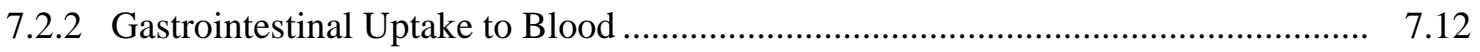

7.2.3 Distribution and Retention in Systemic Organs and Tissues .................................. 7.14

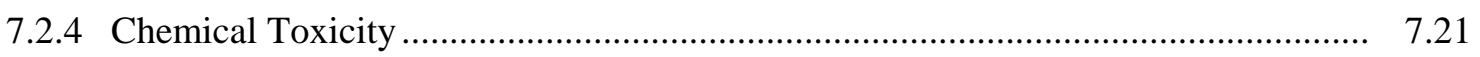

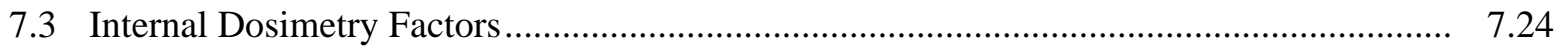

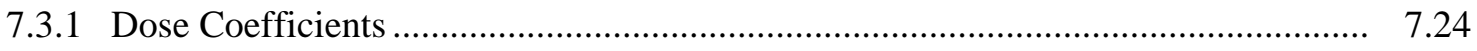

7.3.2 Comparison with Published Dose Coefficients .................................................. 7.27

7.3.3 Annual Limits on Intake and Derived Air Concentrations...................................... 7.29

7.3.4 Derived Reference Levels ..................................................................................... 7.30

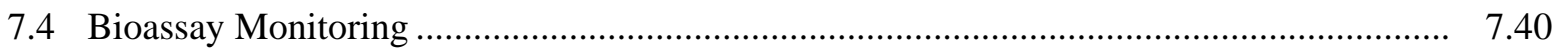

7.4.1 Urine Sampling and Analysis............................................................................ 7.40

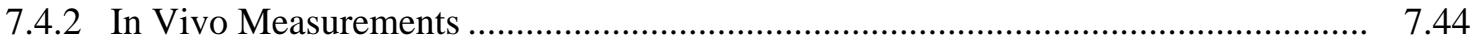

7.4.3 Fecal Sample Measurements ..................................................................... 7.48

7.4.4 Routine Bioassay Monitoring Program ............................................................... 7.51

7.4.5 Type F Routine Monitoring ................................................................................. 7.51

7.4.6 Type M Routine Monitoring....................................................................... 7.51

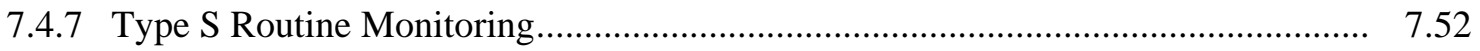

7.4.8 Special Monitoring for Suspected Intakes............................................................. 7.52

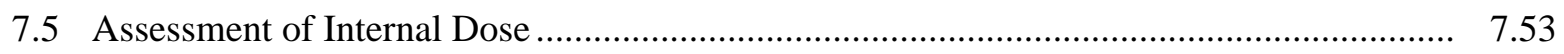

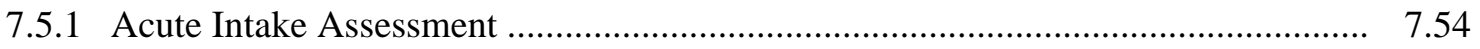

7.5.2 Chronic Intake Assessment ................................................................................. 7.54

7.5.3 Assessment of Kidney Burden and Potential Chemical Toxicity........................... 7.55

7.6 Management of Internal Contamination Cases ................................................................

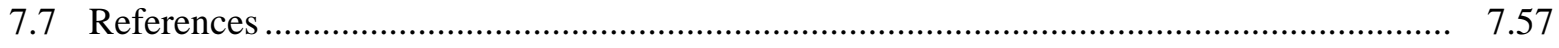




\section{Figures}

7.1 Urinary Excretion of Uranium in Unexposed Hanford Workers ...............................................

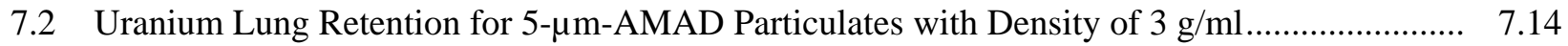

7.3 Uranium Urinary Excretion, Fraction of Intake..................................................................... 7.17

7.4 Uranium Fecal Excretion, Fraction of Intake ...............................................................

7.5 Uranium Fecal-to-Urine Ratios ........................................................................................ 7.19

7.6 Kidney Retention, Mass Fraction of Intake ........................................................................ 7.21

7.7 Daily Variability in Instantaneous Urinary Excretion from Chronic Dayshift Inhalation of $1 \mathrm{mg}$ /workday of Type F Uranium ...............................................................................

7.8 Minimum Detectable Committed Effective Dose for Recycled Uranium Based on $0.18 \mu \mathrm{g} / \mathrm{d}$ Net Urine Excretion........................................................................................ 7.46

7.9 Minimum Detectable Committed Effective Dose for Recycled Uranium Based on $1.5 \mathrm{nCi}^{234} \mathrm{Th}$ or $0.09 \mathrm{nCi}^{235} \mathrm{U}$ in a Chest Count ................................................................ 7.47

7.10 Minimum Detectable Committed Effective Doses of Recycled Uranium Based on $2 \mu \mathrm{g} / \mathrm{d}$ Above Background in Feces.................................................................................. 7.50

7.11 Urinary Uranium Concentration Resulting from a Kidney Burden at the Threshold for Permanent Kidney Damage as a Function of Time Shortly After an Acute Intake... 7.56

\section{Tables}

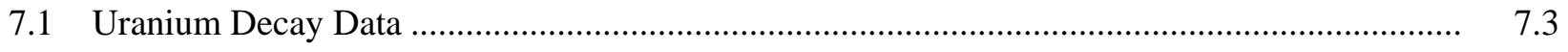

7.2 Variation in Radiological Characteristics of Natural Uranium Mixtures .................................. 7.4

7.3 Variation in Reference Compositions of Depleted Uranium .................................................... 7.5

7.4 Default Radiological Characteristics of Hanford Recycled Uranium....................................... 7.6

7.5 Impurities in Slightly Enriched, Recycled Uranium at Hanford............................................. 7.7

7.1 Environmental Levels of Uranium................................................................................... 7.8

7.7 Absorption Type and $f_{1}$ Factors for Occupational Exposure to Uranium Compounds ................ 7.12

7.2 Lung Retention for 5- $\mu$ m-AMAD Uranium Particles Acute Inhalation Intake .......................... 7.13

7.9 Transfer Rates Between Compartments in the Uranium Systemic Model ................................ 7.15

$7.3{ }^{238} \mathrm{U}$ Urine Excretion Fractions for Instantaneous Uptake, Inhalation, and Ingestion Intakes ..... $\quad 7.16$

$7.11{ }^{238} \mathrm{U}$ Fecal Excretion Fractions for Instantaneous Uptake, Inhalation, and Ingestion Intakes ..... 7.17

7.12 Fecal-to-Urine Ratios for Uranium Intakes .................................................................... 7.19

7.13 Kidney Retention Fractions Following Uranium Intake........................................................ 7.20

7.14 Risk Characterization - Chemical Risk to the Kidney ......................................................... 7.23

7.15 Committed Dose Coefficients for Acute Intakes of ${ }^{238} \mathrm{U}$...................................................... 7.25

7.16 Committed Dose Coefficients for Acute Intakes of ${ }^{236} \mathrm{U}$..................................................... 7.25 
7.17 Committed Dose Coefficients for Acute Intakes of ${ }^{235} \mathrm{U}$................................................... 7.26

7.18 Committed Dose Coefficients for Acute Intakes of ${ }^{234} \mathrm{U}$...................................................... 7.26

7.4 Dose Coefficients for Slightly Enriched Recycled Uranium with Impurities............................. 7.27

7.20 Committed Dose Coefficients for Acute Intakes of Uranium Mixtures ..................................... 7.28

7.21 Comparison of Committed Effective Dose Coefficients ........................................................ 7.29

7.22 Derived Air Concentrations and Annual Limits on Intake for Uranium Isotopes ...................... 7.30

7.5 Reference Level Intakes and Urinary Excretion Derived Reference Levels for Instantaneous Uptake of Recycled Uranium....................................................................... 7.31

7.24 Reference Level Intakes and Urinary Excretion Derived Reference Levels for Type F Inhalation of Recycled Uranium.

7.25 Reference Level Intakes and Urinary Excretion Derived Reference Levels for Type M Inhalation of Recycled Uranium.

7.26 Reference Level Intakes and Urinary Excretion Derived Reference Levels for Type S Inhalation of Recycled Uranium....

7.27 Reference Levels and Urinary Excretion Derived Reference Levels for Ingestion of Soluble Recycled Uranium

7.28 Reference Levels and Urinary Excretion Derived Reference Levels for Ingestion of Insoluble Recycled Uranium

7.29 Reference Level Intakes of ${ }^{238} \mathrm{U}$ in the Recycled Uranium Mixture and ${ }^{234} \mathrm{Th}$ Lung Retention Derived Reference Levels for Type M Inhalation Intakes

7.30 Reference Level Intakes of ${ }^{238} \mathrm{U}$ in the Recycled Uranium Mixture and ${ }^{234}$ Th Lung Retention Derived Reference Levels for Type S Inhalation Intakes.

7.31 Reference Level Intakes of ${ }^{235} \mathrm{U}$ in the Recycled Uranium Mixture and ${ }^{235} \mathrm{U}$ Lung Retention Derived Reference Levels for Type M Inhalation Intakes.

7.32 Reference Level Intakes of ${ }^{235} \mathrm{U}$ in the Recycled Uranium Mixture and ${ }^{235} \mathrm{U}$ Lung Retention Derived Reference Levels for Type S Inhalation Intakes.

7.6 Natural Uranium Background Levels for Hanford Bioassay Urinalysis ................................... 7.42

7.34 Minimum Detectable Intakes of Uranium Based on $0.18 \mu \mathrm{g} / \mathrm{d}$ in Urine

7.35 Minimum Detectable Committed Effective Doses for Recycled Uranium Based on $0.18 \mu \mathrm{g} / \mathrm{d}$ in Urine

7.36 Minimum Detectable Committed Equivalent Doses to Critical Organs for Recycled Uranium Based on $0.18 \mu \mathrm{g} / \mathrm{d}$ in Urine.

7.37 Minimum Detectable Intakes of Recycled Uranium Based on $1.5 \mathrm{nCi}^{234} \mathrm{Th}$ in Chest Count.

7.38 Minimum Detectable Committed Doses for Recycled Uranium Based on $1.5 \mathrm{nCi}{ }^{234} \mathrm{Th}$ in Chest Count

7.39 Minimum Detectable Intakes of Recycled Uranium Based on 0.09 nCi

7.40 Minimum Detectable Committed Doses for Recycled Uranium Based on $0.09 \mathrm{nCi}^{235} \mathrm{U}$ in Chest Count

7.41 Minimum Detectable Intakes of Uranium Based on $2 \mu \mathrm{g} / \mathrm{d}$ in Feces

7.42 Minimum Detectable Committed Doses for Recycled Uranium Based on $2 \mu \mathrm{g} / \mathrm{d}$ in Feces........ 



\subsection{Uranium}

This chapter provides technical information about uranium sources, characteristics, biokinetics, and internal dosimetry for general application at Hanford. Also included are some discussions of historical assessment practices for exposures in specific facilities where uncontained uranium was routinely handled.

Bioassay monitoring and internal dosimetry for uranium at Hanford posed relatively unique problems, primarily because, except for highly enriched uranium, total containment was not provided. Thus, lowlevel chronic airborne contamination levels were assumed to exist in facilities in which uncontained uranium was routinely handled. Such facilities associated with Hanford's former plutonium production mission are no longer in operation, and have either been stabilized or undergone decontamination and decommissioning. Potential exposures in these facilities are now very rare, due to infrequent entry. Thus, the chronic exposure scenario is no longer considered routine and single acute exposures are considered the most likely. Chronic exposure to low-level uranium-contaminated soil is possible during excavation operations. Typically the exposure period for these operations is days or weeks and intakes are monitored through air sampling. The Hanford Internal Dosimetry Program (HIDP) is then notified if the total derived air concentration (DAC)-hours exceeds the notification level established in the Hanford Internal Dosimetry Program Manual (EH Carbaugh, et al. 2009).

Additional difficulties with uranium dosimetry are caused by the relatively low sensitivity of direct (in vivo) measurement capabilities for depleted and low-enrichment uranium and the presence of environmental uranium in urine as background interference.

\subsection{Sources and Characteristics}

The sources, isotopic composition, transportability, particle size, environmental background, chemical toxicity, and biokinetic characteristics of uranium at Hanford are discussed in the following sections.

\subsubsection{Sources}

Uranium at Hanford may be present from a number of possible sources, including residual slightly enriched recycled uranium (RU) from the fuel cycle of the production reactors, depleted uranium (DU) from a recent research and development project, and various individual isotopes or mixtures associated with short-term, research-scale projects. Highly enriched uranium (HEU) and natural uranium were used at Hanford in its early history, so the cleanup operations might encounter some residual contamination or buried waste with HEU or natural uranium. In addition, natural uranium is ubiquitous in the environment and can interfere with bioassay measurements.

Uranium compounds encountered during historical production operations at Hanford ranged from the highly soluble uranyl nitrate, $\mathrm{UO}_{2}\left(\mathrm{NO}_{3}\right)_{2}$, to somewhat less soluble uranium trioxide, $\mathrm{UO}_{3}$, to relatively insoluble uranium oxides, $\mathrm{UO}_{2}$ and $\mathrm{U}_{3} \mathrm{O}_{8}$. The highly reactive uranium hexafluoride, $\mathrm{UF}_{6}$, and uranyl fluoride, $\mathrm{UO}_{2} \mathrm{~F}_{2}$, were not handled at Hanford. 
Historically at Hanford, uranium was used primarily as feed material in the plutonium production process. The uranium was received as natural uranium until 1952 and slightly enriched metallic uranium after that in the form of large billets. It was extruded into fuel elements at the 300 Area Fuel Production Facilities, originally in the 313 and 314 buildings and later in the 333 Building (also 303-M and some ancillary buildings). After irradiation in production reactors, the elements were shipped to the fuel dissolution facilities (T Plant, B Plant, Reduction-Oxidation Plant [REDOX], and Plutonium-Uranium Extraction Plant [PUREX]) for processing. During T Plant and B Plant operations, uranium was sent as waste to the underground waste tanks, then later was pumped from the tanks for recovery at U Plant (from 1952-1958). At REDOX and PUREX, the uranium was separated, as uranyl nitrate-hexahydrate. Uranium from U Plant, REDOX, and PUREX was shipped to the Uranium Oxide $\left(\mathrm{UO}_{3}\right)$ Plant in 200 West Area for conversion to uranium trioxide. The final operating plutonium production reactor (N Reactor) and its associated fuels production facility were shut down in 1987, and the extraction of plutonium and uranium from the irradiated fuels ended at PUREX in 1990. The $\mathrm{UO}_{3}$ Plant operated intermittently from 1952 to 1994 . A more detailed explanation and history of uranium processing at Hanford is contained in Volume II Part 1 of Recycled Uranium (DOE-RL 2000).

Uranium was also used in fuel elements for the Fast Flux Test Facility (FFTF) reactor. The FFTF fuel consisted of a mixture of plutonium and natural uranium oxide, with plutonium being the primary concern. The fuel elements were not fabricated at Hanford, but were received as sealed units. FFTF fuel was not dissolved at Hanford.

Depleted uranium metal was machined in shops in the 306-W Building in support of a long-term research and development program until fairly recently, but the 306-W Building has since been decontaminated and removed.

Uranium isotopes (both as separated isotopes and mixtures of isotopes) are stored and handled in several laboratories in the 200 and 300 Areas.

Highly enriched uranium was used historically (from 1949 through 1958) in some fuel elements in the single-pass reactors. These were called $\mathrm{C}$ and J slugs. They consisted of a uranium-aluminum alloy in which the uranium was $93.2 \%$ enriched in ${ }^{235} \mathrm{U}$ (Lane 1961). The slugs were manufactured at Oak Ridge National Laboratory, canned at Hanford in the 313 Building, irradiated in the Hanford single-pass reactors, and sent to the Idaho Chemical Processing Plant at Idaho National Engineering Laboratory for processing (Burley 1956). Uranium-aluminum alloy (also called uranium aluminide) has unique lung adsorption characteristics (see Boice et al. [2006]). Supposedly all of these special slugs were removed from Hanford years ago, but regular fuel slugs have been unexpectedly found in burial areas, so encountering one of these special slugs cannot be ruled out.

Uranium-233 was made by irradiation of ${ }^{232}$ Th wafers and separated at PUREX in distinct campaigns in 1965, 1966, and 1970 (Isochem 1967; Jackson and Walser 1977).

There is also evidence of work with 37\% enriched uranium for a short time in the 306 Building from 1970 through 1971 (Jech 1970).

These historical source terms of ${ }^{233} \mathrm{U}$ and HEU should not be currently relevant however, there is a possibility they could be reencountered during decontamination of buildings or digging in old burial grounds. 


\subsubsection{Isotopic Composition}

Table 7.1 gives radiological data for uranium isotopes from International Commission on Radiological Protection Publication 38 (ICRP 1983). Half-lives and specific activities used by the Integrated Modules for Bioassay Analysis (IMBA) Professional Plus internal dosimetry computer code (James et al. 2004) ${ }^{1}$ are different from those in Table 7.1 by less than $1 \%$.

Table 7.1. Uranium Decay Data

\begin{tabular}{cccc}
\hline & \multicolumn{2}{c}{ Half-Life } & $\begin{array}{c}\text { Specific Activity } \\
\text { (Ci/g) }\end{array}$ \\
\cline { 2 - 3 } Isotope & Years $^{(\text {a) }}$ & Days & $2.14 \mathrm{E}+01$ \\
\hline${ }^{232} \mathrm{U}$ & 72 & $2.63 \mathrm{E}+04$ & $9.68 \mathrm{E}-03$ \\
${ }^{233} \mathrm{U}$ & $1.585 \mathrm{E}+05$ & $5.79 \mathrm{E}+07$ & $6.25 \mathrm{E}-03$ \\
${ }^{234} \mathrm{U}$ & $2.445 \mathrm{E}+05$ & $8.92 \mathrm{E}+07$ & $2.16 \mathrm{E}-06$ \\
${ }^{235} \mathrm{U}$ & $7.038 \mathrm{E}+08$ & $2.57 \mathrm{E}+11$ & $6.47 \mathrm{E}-05$ \\
${ }^{236} \mathrm{U}$ & $2.3415 \mathrm{E}+07$ & $8.55 \mathrm{E}+09$ & $3.36 \mathrm{E}-07$ \\
${ }^{238} \mathrm{U}$ & $4.468 \mathrm{E}+09$ & $1.63 \mathrm{E}+12$ &
\end{tabular}

(a) From ICRP 38 (1983).

Residual uranium contamination at Hanford generally represents the composition of the bulk of the processing over the years, which ranged from depleted to slightly enriched, based on the weight percent of ${ }^{235} \mathrm{U}$. However, other enrichments might be encountered during cleanup of old facilities; for instance, a nondestructive analysis of gloveboxes in the 231-Z Building in 2008 found some gloveboxes with enrichments ranging from $1 \%$ to $18 \%$ (Hilliard 2008). These gloveboxes were originally used in the 308 Building. Some irradiated fuel from the FFTF is stored in the 200 Area but is well contained and should not be a source of contamination. FFTF fuel had various mixtures of natural uranium and plutonium so if a contamination event were to occur, it would be necessary to get ratios of uranium and plutonium isotopes from the contamination itself. As mentioned in the preceding section, ${ }^{233} \mathrm{U}$ was separated and handled for a short time and HEU slugs were used from 1949 to 1958 so these compositions might also be encountered during cleanup operations. There are a number of ${ }^{233} \mathrm{U}$ bioassay in the Radiation Exposure database (REX) obtained in 1969 and 1970, which might be encountered by a dosimetrist if re-evaluation of an old case were needed.

Isotopic composition of uranium mixtures can vary from sample to sample or batch to batch. Even for natural uranium, different default compositions can be found. Table 7.2 shows three default compositions for natural uranium, one used at Hanford from the mid-1980s to present, one used in IMBA, and one used by the international standards organization, International Union of Pure and Applied Chemistry. ${ }^{2}$ For natural uranium, the differences are small, generally a few percent and always $<10 \%$.

\footnotetext{
${ }^{1}$ IMBA Professional Plus, which includes the current version of the user manual, is available from Health Protection Agency (HPA), Radiation Protection Division, Chilton, Didicot, Oxon., OX11 0RQ UK and from http://www.imbaprofessional.com/

${ }^{2}$ Personal electronic mail correspondence between Steven A. Goldberg, Director, Mass Spectrometry \& Spectroscopy Division, U.S. Department of Energy - New Brunswick Laboratory, and EH Carbaugh, Hanford Internal Dosimetry Program Manager, Pacific Northwest National Laboratory, March 28, 2003.
} 
The IMBA default values are acceptable. Knowledge of the isotopic composition of natural uranium is important to help discriminate potential occupational exposure from normal environmental exposure.

Table 7.2. Variation in Radiological Characteristics of Natural Uranium Mixtures

\begin{tabular}{|c|c|c|c|}
\hline \multirow[b]{2}{*}{ Radionuclide } & \multicolumn{3}{|c|}{ Natural Uranium Mixture } \\
\hline & $\begin{array}{l}\text { Previous Hanford } \\
\text { Technical Basis } \\
\text { Documents }^{(a)}\end{array}$ & $\operatorname{IMBA}^{(b)}$ & $\begin{array}{c}\text { International Union of } \\
\text { Pure and Applied } \\
\text { Chemistry }{ }^{(\mathrm{c})}\end{array}$ \\
\hline \multicolumn{4}{|c|}{ Weight Percentage } \\
\hline${ }^{234} \mathrm{U}$ & 0.0057 & 0.005367 & 0.005388 \\
\hline${ }^{235} \mathrm{U}$ & 0.7204 & 0.7204 & 0.7110 \\
\hline${ }^{236} \mathrm{U}$ & negligible & 0 & 0 \\
\hline${ }^{238} \mathrm{U}$ & 99.2739 & 99.2742 & 99.2836 \\
\hline \multicolumn{4}{|c|}{ 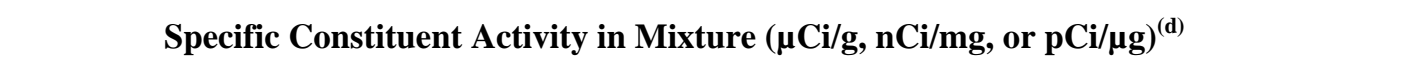 } \\
\hline${ }^{234} \mathrm{U}$ & 0.3563 & 0.3337 & 0.3368 \\
\hline${ }^{235} \mathrm{U}$ & 0.01556 & 0.01557 & 0.01536 \\
\hline${ }^{238} \mathrm{U}$ & 0.3336 & 0.3337 & 0.3336 \\
\hline Total $^{(\mathrm{e})}$ & 0.7054 & 0.6830 & 0.6857 \\
\hline \multicolumn{4}{|c|}{ Specific Constituent Activity in Mixture (dpm/ $/ \mu g)^{(\mathrm{e})}$} \\
\hline${ }^{234} \mathrm{U}$ & 0.7909 & 0.7408 & 0.7477 \\
\hline${ }^{235} \mathrm{U}$ & 0.0345 & 0.0346 & 0.0341 \\
\hline${ }^{238} \mathrm{U}$ & 0.7405 & 0.7408 & 0.7406 \\
\hline Total $^{(\mathrm{e})}$ & 1.566 & 1.5162 & 1.5223 \\
\hline \multicolumn{4}{|c|}{ Activity Percentage of Total Uranium } \\
\hline${ }^{234} \mathrm{U}$ & 50.51 & 48.87 & 49.11 \\
\hline${ }^{235} \mathrm{U}$ & 2.21 & 2.25 & 2.24 \\
\hline${ }^{236} \mathrm{U}$ & 0 & 0 & 0 \\
\hline${ }^{238} \mathrm{U}$ & 47.29 & 48.87 & 48.65 \\
\hline
\end{tabular}

(a) From Sula et al. (1989, 1991).

(b) IMBA v. 4.0.43 (James et al. 2004).

(c) From Rosman and Taylor (1998).

(d) For this technical basis document and International Union of Pure and Applied Chemistry values, the specific activities in Table 7.1 were used. IMBA uses slightly different specific activities.

(e) Can be used to represent specific alpha activity in the mixture as well, ignoring progeny. True specific activity of the mixture depends on degree of equilibrium with progeny.

For DU, more variability is noted. One important fact discovered recently is that virtually all DU is contaminated with ${ }^{236} \mathrm{U}$ similar to slightly enriched uranium. Depleted uranium was created in the same processes from the same feedstock as was slightly to highly enriched uranium. From 1952 on, the feedstock was generally recycled uranium from the Hanford Site and Savannah River Site production reactors, which had small amounts of ${ }^{236} U$. Having a mass between ${ }^{238} U$ and ${ }^{235} U$, in the processes in the enrichment facilities to send the lighter isotopes one way and the ${ }^{238} U$ the other, ${ }^{236} U$ was caught in between and went both ways. Three default compositions of DU are shown in Table 7.3. The overall specific activities of DU are within $10 \%$ between the three compositions, but the specific amounts and 
activities of the rarer isotopes vary considerably. Dosimetrically, the differences are not significant enough to cause one composition to be preferred over another and the IMBA composition is acceptable as a default. However, in any given intake of DU the relative activities of the rarer isotopes might vary considerably from the IMBA default.

Table 7.3. Variation in Reference Compositions of Depleted Uranium

\begin{tabular}{|c|c|c|c|}
\hline \multirow[b]{2}{*}{ Radionuclide } & \multicolumn{3}{|c|}{ Depleted Uranium Mixture } \\
\hline & $\begin{array}{l}\text { Previous Hanford } \\
\text { Technical Basis } \\
\text { Documents }\end{array}$ & IMBA $^{(\mathrm{b})}$ & Military Standard ${ }^{(\mathrm{c})}$ \\
\hline \multicolumn{4}{|c|}{ Weight Percentage } \\
\hline${ }^{234} \mathrm{U}$ & 0.0005 & 0.0010 & 0.0006 \\
\hline${ }^{235} \mathrm{U}$ & 0.2500 & 0.1991 & 0.2 \\
\hline${ }^{236} \mathrm{U}$ & negligible & 0.00031 & 0.003 \\
\hline${ }^{238} \mathrm{U}$ & 99.7500 & 99.800 & 99.8 \\
\hline \multicolumn{4}{|c|}{ Specific Constituent Activity in Mixture ( $\mu \mathrm{Ci} / \mathrm{g}, \mathbf{n C i} / \mathbf{m g}$, or pCi/pg) ${ }^{(\mathrm{d})}$} \\
\hline${ }^{234} \mathrm{U}$ & 0.0313 & 0.06218 & 0.038 \\
\hline${ }^{235} \mathrm{U}$ & 0.00540 & 0.004303 & 0.0043 \\
\hline${ }^{236} \mathrm{U}$ & negligible & 0.000201 & 0.0019 \\
\hline${ }^{238} \mathrm{U}$ & 0.3352 & 0.3356 & 0.34 \\
\hline $\operatorname{Total}^{(\mathrm{e})}$ & 0.3718 & 0.4021 & 0.38 \\
\hline \multicolumn{4}{|c|}{ Specific Constituent Activity in Mixture (dpm/ $/ \mu g)^{(e)}$} \\
\hline${ }^{234} \mathrm{U}$ & 0.0694 & 0.1380 & 0.083 \\
\hline${ }^{235} \mathrm{U}$ & 0.0120 & 0.00955 & 0.0096 \\
\hline${ }^{236} \mathrm{U}$ & negligible & 0.000466 & 0.0043 \\
\hline${ }^{238} \mathrm{U}$ & 0.7441 & 0.7450 & 0.74 \\
\hline $\operatorname{Total}^{(\mathrm{e})}$ & 0.8254 & 0.8927 & 0.842 \\
\hline \multicolumn{4}{|c|}{ Activity Percentage of Total Uranium } \\
\hline${ }^{234} \mathrm{U}$ & 8.40 & 15.46 & 9.9 \\
\hline${ }^{235} \mathrm{U}$ & 1.46 & 1.07 & 1.1 \\
\hline${ }^{236} \mathrm{U}$ & negligible & 0.05 & 0.51 \\
\hline${ }^{238} \mathrm{U}$ & 90.14 & 83.42 & 88.5 \\
\hline
\end{tabular}

(a) From Sula et al. 1989, 1991. In fact, all DU made after 1952 has some ${ }^{236} U$.

(b) From IMBA v. 4.0.43 (James et al. 2004).

(c) From Parkhurst et al. (2005).

(d) For this technical basis document and military values, the specific activities in Table 7.1 were used. IMBA uses slightly different specific activities.

(e) Can be used to represent specific alpha activity in the mixture as well, assuming insignificant ingrowth of alpha-emitting progeny.

Most of the uranium fabricated into fuel elements, irradiated in the production reactors, and recovered in the dissolution and concentration facilities was slightly enriched, typically $0.8 \%$ to $1.2 \%$. Over time this type of uranium has been referred to as enriched uranium, recycled uranium, E metal, Ike metal, or Eisenhower metal (Lane 1961). Slightly enriched, recycled uranium was especially present in the Fuel 
Production Facilities, REDOX, PUREX, $\mathrm{UO}_{3}$ Plant, in sludge in 100 Area fuel storage basins, and in waste tanks. Table 7.4 shows a reference mixture for recycled uranium. The atom ratios used to calculate specific activity in Table 7.4 are based on operational data obtained from facility operating records and represent a reference mixture rather than any specific batch. IMBA has a default for slightly enriched uranium based on 3.4 weight percent ${ }^{235} \mathrm{U}$ that does not well represent Hanford recycled uranium and should not be used for that purpose. Table 7.4 shows that the specific alpha activity of the recycled uranium exceeds that of virgin uranium for corresponding ${ }^{235} \mathrm{U}$ weight percentages. This increase is due primarily to higher levels of ${ }^{234} \mathrm{U}$ and ${ }^{236} \mathrm{U}$ in the recycled uranium.

Table 7.4. Default Radiological Characteristics of Hanford Recycled Uranium

\begin{tabular}{|c|c|c|}
\hline \multirow[b]{2}{*}{ Radionculide } & \multicolumn{2}{|c|}{ Uranium Mixture } \\
\hline & $\begin{array}{l}\text { Slightly Enriched, } \\
\text { Recycled (RU) }^{(a)}\end{array}$ & Commercial Fuel $^{(\mathrm{b})}$ \\
\hline \multicolumn{3}{|c|}{ Weight Percentage } \\
\hline${ }^{234} \mathrm{U}$ & 0.0082 & 0.0300 \\
\hline${ }^{235} \mathrm{U}$ & 0.970 & 2.96 \\
\hline${ }^{236} \mathrm{U}$ & 0.0680 & negligible \\
\hline${ }^{238} \mathrm{U}$ & 98.95 & 97.01 \\
\hline \multicolumn{3}{|c|}{ Specific Constituent Activity in Mixture ( $\mu \mathrm{Ci} / \mathrm{g}, \mathrm{nCi} / \mathrm{mg}$, or $\mathrm{pCi} / \mu \mathrm{g})$} \\
\hline${ }^{234} \mathrm{U}$ & 0.5125 & 1.875 \\
\hline${ }^{235} \mathrm{U}$ & 0.0210 & 0.0639 \\
\hline${ }^{236} \mathrm{U}$ & 0.0440 & negligible \\
\hline${ }^{238} \mathrm{U}$ & 0.3325 & 0.3260 \\
\hline Total $^{(\mathrm{c})}$ & 0.910 & 2.265 \\
\hline \multicolumn{3}{|c|}{ Specific Constituent Activity in Mixture (dpm/pg) } \\
\hline${ }^{234} \mathrm{U}$ & 1.14 & 4.16 \\
\hline${ }^{235} \mathrm{U}$ & 0.0465 & 0.142 \\
\hline${ }^{236} \mathrm{U}$ & 0.0977 & negligible \\
\hline${ }^{238} \mathrm{U}$ & 0.738 & 0.7236 \\
\hline Total $^{(\mathrm{c})}$ & 2.02 & 5.03 \\
\hline \multicolumn{3}{|c|}{ Activity Percentage of Total Uranium } \\
\hline${ }^{234} \mathrm{U}$ & 56.3 & 82.8 \\
\hline${ }^{235} \mathrm{U}$ & 2.30 & 2.82 \\
\hline${ }^{236} \mathrm{U}$ & 4.84 & negligible \\
\hline${ }^{238} \mathrm{U}$ & 36.5 & 14.4 \\
\hline
\end{tabular}

(a) RU data based on average of data presented by Sula et al. (1991).

(b) From Rich et al. (1988).

(c) Can be used to represent specific alpha activity in the mixture as well, assuming insignificant ingrowth of alpha-emitting progeny.

Most uranium used in the plutonium production process was recycled uranium and incurred ingrowth of impurities during the irradiation phase of the fuel cycle (Rich et al. 1988 and DOE-RL 2000). These impurities were not completely removed during the reprocessing and plutonium extraction phases of the 
production cycle and thus their presence in residual uranium contributes to internal dose along with uranium. The impurities included ${ }^{236} \mathrm{U},{ }^{239} \mathrm{Pu},{ }^{99} \mathrm{Tc},{ }^{237} \mathrm{~Np}$, thorium, and some short-lived fission products which have now decayed away. Table 7.5 gives maximum allowed levels of these impurities in uranium that was handled at the $\mathrm{UO}_{3}$ Plant circa the 1980s (Thompson 1986) and typical values observed in 1988 and 1993. However, higher levels of impurities were observed for plutonium and neptunium in some batches in the past (DOE-RL 2000). The default reference levels for these impurities shown in the table are generally higher than the observed values in the 1980s and 1990s and account to some extent for higher levels in earlier times. The presence of ${ }^{236} \mathrm{U}$ is an indicator of recycled as opposed to natural uranium.

Data compiled by Wittekind and Morey (1985) suggest that ${ }^{236} \mathrm{U}$ concentration in cast uranium ingots could range from 0.03 to 0.08 weight percent for Hanford uranium fuel.

The ${ }^{234} \mathrm{U}:{ }^{238} \mathrm{U}$ activity ratio can help in differentiating types of uranium. Goldstein et al. (1997) reported that depleted uranium $\left({ }^{234} U:{ }^{238} U<0.18\right)$ and highly enriched uranium $\left({ }^{234} \mathrm{U}:{ }^{238} \mathrm{U}>100\right)$ are compositions only rarely found in natural samples, that typical water samples show ${ }^{234} \mathrm{U}:{ }^{238} \mathrm{U}$ activity ratios of 0.8 to 10 , and that soil sample activity ratios ranged from 0.5 to 1.2 . They suggested that activity ratios outside of these natural limits could be indicative of exposure to anthropogenic sources of uranium. Fleisher (2008) suggested caution in using this approach because of the high variability in the ratio in groundwater, which he suggested ranged from 0.5 to 12 or maybe even 14 (and hence might be nearly as variable in urine).

Table 7.5. Impurities in Slightly Enriched, Recycled Uranium at Hanford

\begin{tabular}{|c|c|c|c|}
\hline Constituent & $\begin{array}{l}\text { Maximum } \\
\text { Allowed }^{(a)}\end{array}$ & $\begin{array}{l}\text { Observed } \\
\text { Range }^{(b)}\end{array}$ & $\begin{array}{l}\text { Reference } \\
\text { Level }^{(c)}\end{array}$ \\
\hline Plutonium & $10 \mathrm{ppb} \mathrm{U}$ & $<1-2$ ppb U & 0.4 nCi Pu-alpha/g-U $\mathrm{U}^{(\mathrm{d})}$ \\
\hline Neptunium & Not established & $0.04-0.16$ ppm U & $0.4 \mathrm{nCi}{ }^{237} \mathrm{~Np} / \mathrm{g}-\mathrm{U}^{(\mathrm{e})}$ \\
\hline Thorium & 750 ppm U & 8-10 ppm U & 5 pCi ${ }^{232} \mathrm{Th} / \mathrm{g}-\mathrm{U}^{(\mathrm{f})}$ \\
\hline${ }^{99} \mathrm{Tc}$ & Not established & 3-4 ppm U & $0.2 \mu \mathrm{Ci}{ }^{99} \mathrm{Tc} / \mathrm{g}-\mathrm{U}^{(\mathrm{g})}$ \\
\hline${ }^{103,106} \mathrm{Ru}$ & $<20 \mu \mathrm{Ci} / \mathrm{lb}-\mathrm{U}$ & $<6 \mu \mathrm{Ci} / \mathrm{lb}-\mathrm{U}$ & No longer present \\
\hline${ }^{95} \mathrm{ZrNb}$ & $<10 \mu \mathrm{Ci} / \mathrm{lb}-\mathrm{U}$ & $<4 \mu \mathrm{Ci} / \mathrm{lb}-\mathrm{U}$ & No longer present \\
\hline $\begin{array}{l}\text { Other gamma emitters excluding } \\
{ }^{99} \mathrm{Tc}\end{array}$ & $<2 \mu \mathrm{Ci} / \mathrm{lb}-\mathrm{U}$ & $0.09-0.75 \mu \mathrm{Ci} / \mathrm{lb}-\mathrm{U}$ & No longer present \\
\hline
\end{tabular}

(a) From $\mathrm{UO}_{3}$ Plant operating specifications, OSD-U-185-0001 (Thompson 1986).

(b) From analysis of uranium lots 88-1, 88-2, and 88-3 that were processed in 1988, and lots 93-01, 93-02, 93-03, 93-04, and 93.05 that were processed in 1993.

(c) A reference level is chosen for determining bioassay monitoring needs and for use as an initial assumption in evaluating intakes. The use of the reference levels is expected to result in a slight overestimate of dose compared to levels actually observed in 1988.

(d) Based on $5 \mathrm{ppb}$ and assuming plutonium is represented by aged $6 \%{ }^{240} \mathrm{Pu}$ (weapons grade) material.

(e) Based on $0.5 \mathrm{ppm}$ of ${ }^{237} \mathrm{~Np}$.

(f) Based on $50 \mathrm{ppm}$ of ${ }^{232} \mathrm{Th}$.

(g) Based on $10 \mathrm{ppm}$ of ${ }^{99} \mathrm{Tc}$. 


\subsubsection{Environmental Background}

Uranium is ubiquitous to the natural environmental background. It is found in trace quantities in rocks, soil, surface water, groundwater, air, plants, and animals. Some of the routine concentrations that might be naturally encountered are shown in Table 7.6.

Table 7.6. Environmental Levels of Uranium

\begin{tabular}{|c|c|c|}
\hline Medium & Level & Reference $^{(a)}$ \\
\hline \multirow[t]{5}{*}{ Soil (typical) } & $3 \mathrm{ppm}$ & PHS (1997) \\
\hline & $1 \mathrm{pCi} / \mathrm{g}$ & PHS (1997) \\
\hline & $0.5-4.7 \mathrm{ppm}$ & NCRP 94 (1988) \\
\hline & $\left(7-60 \mathrm{~Bq}^{238} \mathrm{U} / \mathrm{kg}\right)$ & \\
\hline & $\begin{array}{c}25 \mathrm{~Bq}^{238} \mathrm{U} / \mathrm{kg} \\
\left(10-50 \mathrm{~Bq}{ }^{238} \mathrm{U} / \mathrm{kg}\right)\end{array}$ & UNSCEAR (1988) \\
\hline Soil (phosphate rich) & 4.5-83.4 pCi/g & PHS (1997) \\
\hline \multirow[t]{3}{*}{ Air } & $0.011-3 \mathrm{fCi} / \mathrm{m}^{3}$ & PHS (1997) \\
\hline & $0.3 \mu \mathrm{Bq} / \mathrm{m}^{3}$ & Golchert et al. (1985) \\
\hline & $0.7 \mu \mathrm{Bq} / \mathrm{m}^{3}$ (New York City) & Fisenne et al. (1987) \\
\hline Water & $<1 \mathrm{pCi} / \mathrm{L}$ & PHS (1997) \\
\hline Surface water & $\begin{array}{c}37 \mathrm{mBq} / \mathrm{L} \\
(0.37-25,000 \mathrm{mBq} / \mathrm{L})\end{array}$ & Drury et al. 1983 \\
\hline Groundwater & $\begin{array}{c}111 \mathrm{mBq} / \mathrm{L} \\
(0.037-24,000 \mathrm{mBq} / \mathrm{L})\end{array}$ & Drury et al. 1983 \\
\hline Drinking water standard & $30 \mu \mathrm{g} / \mathrm{L}$ & EPA (2006) \\
\hline \multicolumn{3}{|l|}{ Human Consumption } \\
\hline \multirow[t]{2}{*}{ Food } & $0.6-1.0 \mathrm{pCi} / \mathrm{d}$ & PHS (1997) \\
\hline & $1.3-1.4 \mu \mathrm{g} / \mathrm{d}$ & Welford and Baird (1967) \\
\hline Water & $0.8 \mathrm{pCi} / \mathrm{L}$ & PHS (1997) \\
\hline \multicolumn{3}{|l|}{ Human Excretion } \\
\hline \multirow[t]{2}{*}{ Urine } & $0.05-0.5 \mu \mathrm{g} / \mathrm{d}$ & ICRP Publication 23 (1974) \\
\hline & $0.2 \mu \mathrm{g} / \mathrm{d}$ & $\begin{array}{l}\text { Hanford Environmental } \\
\text { Screening Level (this document) }\end{array}$ \\
\hline Feces & $1.4-1.8 \mu \mathrm{g} / \mathrm{d}$ & ICRP Publication 23 (1974) \\
\hline \multicolumn{3}{|c|}{$\begin{array}{l}\text { ntal Protection Agency. } \\
\text { Scientific Committee on the }\end{array}$} \\
\hline
\end{tabular}

The presence of uranium as part of the natural environment results in its presence in urine. The sensitivity of urine sampling as a uranium bioassay tool is limited by the presence of environmental levels of uranium. The sensitivity is subject to some uncertainty in interpretation. In ICRP 30 (1979) the average daily ingestion intake of natural uranium in food and water was estimated to be $1.9 \mu \mathrm{g}$. Assuming that the gastrointestinal (GI) tract absorption of uranium at environmental levels is about $1 \%$ 
(Wrenn et al. 1985) at equilibrium, about $0.02 \mu \mathrm{g} / \mathrm{d}$ could be expected in the urine of occupationally unexposed workers. The ICRP Reference Man report (1974) lists urinary excretion from 0.05 to $0.5 \mu \mathrm{g} / \mathrm{d}$ and fecal excretion from 1.4 to $1.8 \mu \mathrm{g} / \mathrm{d}$, although the range reported in its cited literature is much greater. Studies at Hanford, performed in 1985, 1990, and 1995, indicated that the concentrations of uranium in urine in the Hanford area are similar or slightly higher than the foregoing estimates (Carbaugh et al. 1990; Long et al. 1994; and Long and Carbaugh 1995).

Urine samples were collected in mid-1985 from 21 occupationally unexposed Hanford workers who resided in various locations around Hanford, including Yakima, Benton City, Kennewick, and Richland. Both municipal drinking water and individual well-water systems were represented by the sampling. The results ranged from below detectable levels $(0.03 \mu \mathrm{g} / \mathrm{d})$ to $0.12 \mu \mathrm{g} / \mathrm{d}$. For seven of the individuals, three samples were collected over a 2-week period, and the daily excretion remained fairly constant for each individual over the period. Data for this group are shown as the 1985 curve in Figure 7.1. The median daily uranium output for the 1985 study group was $0.06 \mu \mathrm{g}$ and $0.2 \mu \mathrm{g} / \mathrm{d}$ was estimated to be the 99.9 percentile (one in a thousand samples collected from unexposed workers would be expected to exceed that value). Based on this study, samples containing less than $0.2 \mu \mathrm{g} / \mathrm{d}$ of uranium were considered to be within the expected environmental range, and results above $0.2 \mu \mathrm{g} / \mathrm{d}$ were considered to contain occupationally derived uranium. The net amount attributed to occupational sources was calculated as the total observed amount minus the average expected environmental level of $0.06 \mu \mathrm{g} / \mathrm{d}$.

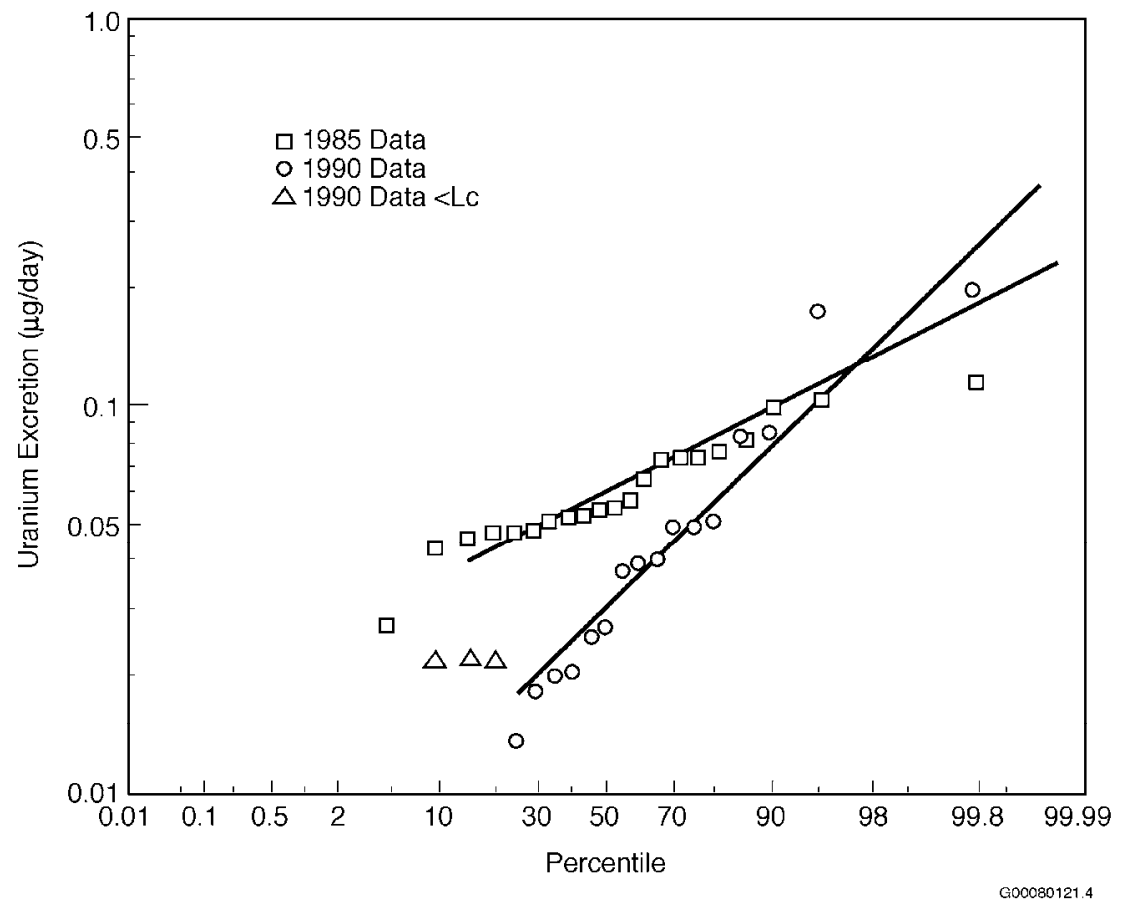

Figure 7.1. Urinary Excretion of Uranium in Unexposed Hanford Workers

A second study of background uranium levels in urine commenced in 1990. Urine samples were collected from 20 nonoccupationally exposed workers in early 1990 with the intent of collecting quarterly samples from each worker throughout the year, as well as samples of their drinking water. The workers were selected to provide an indication of the possible correlation between drinking water sources and urinary excretion. Due to the cancellation of the analytical support services laboratory contract, this study 
was terminated after collection of the first samples. However, the data are useful as a comparison with the 1985 data and, as can be seen in Figure 7.1, show some very interesting variations. The geometric mean of this sample group was $0.024 \mu \mathrm{g} / \mathrm{d}$ with a 99.9 percentile of $0.28 \mu \mathrm{g} / \mathrm{d}$. The $0.2-\mu \mathrm{g} / \mathrm{d}$ value used as the 99.9 percentile for the 1985 data corresponds more closely to a 99 percentile for the 1990 data, implying that one in a hundred (rather than one in a thousand) samples from occupationally unexposed workers might exceed it. At least two factors contribute to these apparent differences. First, the workers sampled were a substantially different subset than the first group; whereas the 1985 subjects were primarily from two large municipal water systems, the 1990 subjects were carefully selected to provide an indication of possible impact from water consumption in numerous outlying communities around Hanford. Second, a significant change in the analytical process occurred during the time that elapsed between the two sets of samples-namely, the practice of subtracting reagent blanks from sample results was initiated. Interpretation of the 1990 data was considered preliminary and led to the 1995 study.

The 1995 study involved sampling 20 nonoccupationally exposed male Hanford workers, 8 of whom were resampled at 3-month intervals for a year. Concurrent drinking water samples were obtained from each worker and also analyzed for uranium. The workers included residents of Richland, Pasco, and Kennewick, as well as outlying areas, and included drinking water sources from surface water and groundwater wells. The study made the following conclusions important to the interpretation of worker uranium urinalyses:

- The urinary screening level of $0.2 \mu \mathrm{g} \mathrm{U} / \mathrm{d}$ established by the 1985 study was appropriate for most individuals; however, $2 \%$ to $5 \%$ of the workers could be expected to be above that value due to unknown nonoccupational sources. The study indicated the possibility that home drinking water might be the primary source of the unusually high excretion of uranium; however, the study was not extensive enough to make that a definitive conclusion. Complicating factors include how much home water is consumed, the source of the water (wells or surface, i.e., Columbia River water), and water treatment (e.g., water softener systems).

- The geometric mean urinary excretion for the group was $0.021 \mu \mathrm{g} / \mathrm{d}$.

- The use of the ${ }^{238} \mathrm{U}-\mathrm{to}^{-234} \mathrm{U}$ ratio as a co-indicator for Hanford occupational exposure to recycled uranium is not feasible because the isotopic ratio in the slightly enriched Hanford recycled uranium may not be significantly different from that of natural environmental sources. The ratio can be of value if highly enriched or depleted uranium is the potential occupational concern. However, in natural groundwater (and hence, potentially in urine) disequilibrium between ${ }^{238} U$ and ${ }^{234} U$ exists and the ratio of ${ }^{234} \mathrm{U}$ to ${ }^{238} \mathrm{U}$ can vary considerably (from 0.5 to 12 , as suggested by Fleischer 2008) so knowledge of the range of the ratio in local waters is essential.

- Correlation analyses between the amount of uranium in the urine sample and the amount of uranium in the drinking water samples showed no significant correlation. There was a weak correlation when the concentration of uranium in water was high.

- A water source effect was observed for uranium in water. Private well water typically exhibited higher uranium concentrations than large municipal drinking water sources.

- There did not appear to be a correlation between geographic location of residence within the Yakima River Valley and daily excretion of uranium.

- There did not appear to be a seasonal effect on the concentration of uranium in urine or water when the overall data were tested, nor when specific mid-Columbia regions were examined. 
Fecal excretion of uranium from ingestion of nonoccupational sources of uranium in the Hanford environs has not been studied in a manner similar to that of urine excretion. Lacking Hanford-specific information, it is assumed that the ICRP Reference Man (ICRP 1974) values of 1.4 to $1.8 \mu \mathrm{g} / \mathrm{d}$ are reasonable.

\subsection{Biokinetic Behavior}

This section discusses uranium inhalation absorption types, internal distribution and retention, urinary and fecal excretion, and chemical toxicity. The intake retention (or excretion) fraction expresses the fraction of intake retained in a particular compartment or excreted by a particular pathway (urine or feces) at a given time after intake. Although excretion implies elimination rather than retention, conventional models include excretion compartments under the general term retention and use the term "intake retention fraction" (IRF) to describe both. The IRFs for various times post intake are tabulated as described below for ${ }^{238} \mathrm{U}$. These values are also suitable for other isotopes of uranium and mixtures of isotopes, with the exception of ${ }^{232} U$ for long times (years) after the intake because of its 72-year half-life.

The term "instantaneous uptake" is used in this technical basis to refer to the material that is essentially immediately taken up by the transfer compartment upon intake, and is typically applied to wound scenarios. (This mode of uptake is called “injection” in IMBA.)

\subsubsection{Absorption Type and Lung Retention}

In the ICRP 66 (1994b) respiratory tract model, deposition of particles into the respiratory tract and particle transport from various regions of the respiratory tract are assumed to be the same for all materials. Absorption of deposited material into the blood depends on the physical and chemical form of the material, but default values are given only for chemical forms. Absorption types are identified for particulates as Types F (for fast), M (for moderate), and S (for slow). Details and additional discussion of the respiratory tract model are provided in Appendix C.

Table 7.7 provides absorption types for uranium compounds as recommended in ICRP 68 (1994a). Unless special dissolution analysis is performed or data suggest otherwise, these assigned classifications are used for Hanford internal dosimetry. Special dissolution studies were performed in the mid-1980s for uranium handled in the $\mathrm{UO}_{3}$ Plant, the Fuel Production Facilities, and the 306-W Building, for which the resulting data are summarized in Table 7.7. The Fuel Production Facilities and 306-W Building no longer exist, but residual contamination from the processes in these buildings might still be encountered in the 300 Areas or burial grounds. The results of the original studies were expressed in ICRP 30 inhalation classes. As a rough approximation, the $\mathrm{D}, \mathrm{W}$, and $\mathrm{Y}$ designations can be considered similar to $\mathrm{F}$, $\mathrm{M}$, and S absorption types, respectively.

Lung retention fractions for absorption Types $M$ and $S$ acute inhalations of 5- $\mu \mathrm{m}$-AMAD particles of ${ }^{238} \mathrm{U}$ with a $3 \mathrm{~g} / \mathrm{ml}$ density are tabulated in Table 7.8 and plotted in Figure 7.2. Table 7.8 also shows the effect of density on fractional lung retention, using the extreme case of $19 \mathrm{~g} / \mathrm{ml}$, which is appropriate for pure metal. In general, the extremely dense particles only change the deposition/retention in the lung by $10 \%$ or less. Oxides of uranium are less dense than metal and for dosimetry purposes the density effect is small enough to be ignorable. (Even for metal the density effect on urine excretion is even less than for lung retention and can be ignored for dosimetry purposes.)

Issued for implementation effective 01/01/2010 
Table 7.7. Absorption Type and $f_{1}$ Factors for Occupational Exposure to Uranium Compounds

\begin{tabular}{|c|c|c|}
\hline \multicolumn{3}{|c|}{ ICRP 68 Absorption } \\
\hline Most hexavalent compounds, e.g., $\mathrm{UF}_{6}, \mathrm{UO}_{2} \mathrm{~F}_{2}, \mathrm{UO}_{2}\left(\mathrm{NO}_{3}\right)_{2}$ & $\begin{array}{c}F \\
0.02\end{array}$ & NA \\
\hline $\begin{array}{l}\text { Less soluble forms, e.g., } \mathrm{UO}_{3}, \mathrm{UF}_{4}, \mathrm{UCl}_{4} \text {, and most other } \\
\text { hexavalent compounds }\end{array}$ & $\begin{array}{c}\mathrm{M} \\
0.02\end{array}$ & $\begin{array}{l}\text { NA, except see } \mathrm{UO}_{3} \\
\text { Plant study below }\end{array}$ \\
\hline Highly insoluble forms, e.g., $\mathrm{UO}_{2}, \mathrm{U}_{3} \mathrm{O}_{8}$ & $\begin{array}{c}S \\
0.002\end{array}$ & NA \\
\hline $\begin{array}{l}\text { Hanford } \mathrm{UO}_{3} \text { Plant smear sample dissolution study in } 1984,{ }^{\text {(a) }} \\
\left(\mathrm{UO}_{3} \text { powder) }\right.\end{array}$ & mostly F & $\begin{array}{l}80 \% \mathrm{D} \\
20 \% \mathrm{~W}\end{array}$ \\
\hline $\begin{array}{l}\text { Hanford 303-M Building air sample dissolution study }{ }^{(b)} \\
\text { (300 Area Uranium Fuel Production Facilities) }\end{array}$ & $\begin{array}{l}\text { mostly S but some M } \\
\text { characteristics }\end{array}$ & $\begin{array}{l}90 \% \mathrm{Y} \\
10 \% \mathrm{D}\end{array}$ \\
\hline $\begin{array}{l}\text { Hanford } 333 \text { Building air sample dissolution study }{ }^{(\mathrm{b})} \\
\text { (300 Area Uranium Fuel Production Facilities) }\end{array}$ & $\begin{array}{l}\text { some combination of } \mathrm{M} \\
\text { and } \mathrm{S}\end{array}$ & $\begin{array}{l}71 \% \mathrm{Y} \\
29 \% \mathrm{D}\end{array}$ \\
\hline $\begin{array}{l}\text { Hanford 306-W Building Machine Shop air sample } \\
\text { dissolution study }^{(\mathrm{b})}\end{array}$ & $\begin{array}{l}\text { some combination of } \mathrm{M} \\
\text { and } \mathrm{S}\end{array}$ & $\begin{array}{l}80 \% \mathrm{Y} \\
20 \% \mathrm{D}\end{array}$ \\
\hline $\begin{array}{l}\text { Uranium-aluminum alloy, uranium aluminide (Hanford } \mathrm{C} \text { and } \\
\text { J slugs) }\end{array}$ & delayed Type $\mathbf{M}^{(\mathrm{c})}$ & NA \\
\hline $\begin{array}{l}\text { (a) Sula et al. (1989). } \\
\text { (b) Letter Report to Monte J. Sula from Darrell R. Fisher, Janu } \\
\text { Solubility of Uranium Aerosols in } 333 \text { and 303M Building } \\
\text { available in Hanford Radiological Records Historical File). } \\
\text { (c) See Boice et al. (2006) for description of absorption charac }\end{array}$ & $\begin{array}{l}\text { ary 20, 1986, "Particle Siz } \\
\text { at UNC, and PNL’s } 306 \mathrm{~V} \\
\text { eristics of this material. }\end{array}$ & $\begin{array}{l}\text { istribution and } \\
\text { uilding. (Copy }\end{array}$ \\
\hline
\end{tabular}

\subsubsection{Gastrointestinal Uptake to Blood}

The latest GI tract model was issued by the ICRP in 2006, but it is not incorporated into IMBA so it is not used by the HIDP at present. Table 7.7 includes the recommendations of the ICRP in Publication 68 (1994a) for the fractional absorption of uranium to blood from the GI tract $\left(f_{1}\right)$. The ICRP $30 f_{1}$ value of 0.05 for inorganic forms of uranium was established based mainly on human data for uranyl nitrate ingestion reported by Hursh et al. (1969). More recent data reviewed by Wrenn et al. (1985), Harrison (1991), and Leggett and Harrison (1995) resulted in ICRP adopting 0.02 for adults as more realistic for dietary forms of uranium (ICRP 1995), while retaining 0.002 for insoluble forms. It was noted that this value actually summarizes a range of 1 to 2 orders of magnitude, with the more soluble compounds being more readily absorbed. Leggett and Harrison noted that the range was from $<0.001$ to 0.06 , with a central range of 0.003 to 0.032 , and their choice of a value was 0.01 to 0.015 . They also noted that uranium may be more readily absorbed from water than food such as fresh vegetables and shellfish, because the latter may have more insoluble forms of uranium. Fasting may result in enhanced absorption. 
Table 7.8. Lung Retention for $5-\mu m-A M A D$ Uranium Particles Acute Inhalation Intake (fraction of intake) ${ }^{(\mathrm{a})}$

\begin{tabular}{ccccc}
\hline \multirow{2}{*}{$\begin{array}{c}\text { Days Post } \\
\text { Intake }\end{array}$} & \multicolumn{2}{c}{ Type M } & \multicolumn{2}{c}{ Type S } \\
\cline { 2 - 5 } & Density 3 g/ml & Density $19 \mathrm{~g} / \mathrm{ml}^{(\mathrm{b})}$ & Density 3 g/ml & Density $19 \mathrm{~g} / \mathrm{ml}^{(\mathrm{b})}$ \\
\hline 0 & $8.20 \mathrm{E}-02$ & $8.59 \mathrm{E}-02$ & $8.20 \mathrm{E}-02$ & $8.59 \mathrm{E}-02$ \\
1 & $5.76 \mathrm{E}-02$ & $6.39 \mathrm{E}-02$ & $6.43 \mathrm{E}-02$ & $7.12 \mathrm{E}-02$ \\
2 & $5.59 \mathrm{E}-02$ & $6.21 \mathrm{E}-02$ & $6.27 \mathrm{E}-02$ & $6.96 \mathrm{E}-02$ \\
3 & $5.50 \mathrm{E}-02$ & $6.10 \mathrm{E}-02$ & $6.19 \mathrm{E}-02$ & $6.87 \mathrm{E}-02$ \\
4 & $5.42 \mathrm{E}-02$ & $6.00 \mathrm{E}-02$ & $6.13 \mathrm{E}-02$ & $6.80 \mathrm{E}-02$ \\
5 & $5.34 \mathrm{E}-02$ & $5.91 \mathrm{E}-02$ & $6.07 \mathrm{E}-02$ & $6.72 \mathrm{E}-02$ \\
6 & $5.26 \mathrm{E}-02$ & $5.82 \mathrm{E}-02$ & $6.01 \mathrm{E}-02$ & $6.65 \mathrm{E}-02$ \\
7 & $5.18 \mathrm{E}-02$ & $5.73 \mathrm{E}-02$ & $5.95 \mathrm{E}-02$ & $6.58 \mathrm{E}-02$ \\
8 & $5.11 \mathrm{E}-02$ & $5.64 \mathrm{E}-02$ & $5.90 \mathrm{E}-02$ & $6.51 \mathrm{E}-02$ \\
9 & $5.04 \mathrm{E}-02$ & $5.56 \mathrm{E}-02$ & $5.84 \mathrm{E}-02$ & $6.45 \mathrm{E}-02$ \\
10 & $4.97 \mathrm{E}-02$ & $5.47 \mathrm{E}-02$ & $5.79 \mathrm{E}-02$ & $6.38 \mathrm{E}-02$ \\
12 & $4.83 \mathrm{E}-02$ & $5.31 \mathrm{E}-02$ & $5.68 \mathrm{E}-02$ & $6.26 \mathrm{E}-02$ \\
14 & $4.70 \mathrm{E}-02$ & $5.16 \mathrm{E}-02$ & $5.59 \mathrm{E}-02$ & $6.14 \mathrm{E}-02$ \\
30 & $3.84 \mathrm{E}-02$ & $4.17 \mathrm{E}-02$ & $4.94 \mathrm{E}-02$ & $5.36 \mathrm{E}-02$ \\
60 & $2.81 \mathrm{E}-02$ & $3.00 \mathrm{E}-02$ & $4.18 \mathrm{E}-02$ & $4.48 \mathrm{E}-02$ \\
90 & $2.18 \mathrm{E}-02$ & $2.32 \mathrm{E}-02$ & $3.76 \mathrm{E}-02$ & $4.00 \mathrm{E}-02$ \\
180 & $1.19 \mathrm{E}-02$ & $1.26 \mathrm{E}-02$ & $3.20 \mathrm{E}-02$ & $3.38 \mathrm{E}-02$ \\
365 & $3.99 \mathrm{E}-03$ & $4.21 \mathrm{E}-03$ & $2.65 \mathrm{E}-02$ & $2.80 \mathrm{E}-02$ \\
$2 \mathrm{y}$ & $4.80 \mathrm{E}-04$ & $5.07 \mathrm{E}-04$ & $1.91 \mathrm{E}-02$ & $2.01 \mathrm{E}-02$ \\
$3 \mathrm{y}$ & $5.91 \mathrm{E}-05$ & $6.23 \mathrm{E}-05$ & $1.40 \mathrm{E}-02$ & $1.48 \mathrm{E}-02$ \\
$5 \mathrm{y}$ & $9.55 \mathrm{E}-07$ & $1.01 \mathrm{E}-06$ & $8.15 \mathrm{E}-03$ & $8.60 \mathrm{E}-03$ \\
$10 \mathrm{y}$ & $5.05 \mathrm{E}-11$ & $5.32 \mathrm{E}-11$ & $3.31 \mathrm{E}-03$ & $3.49 \mathrm{E}-03$ \\
$20 \mathrm{y}$ & $3.65 \mathrm{E}-19$ & $3.84 \mathrm{E}-19$ & $1.42 \mathrm{E}-03$ & $1.50 \mathrm{E}-03$ \\
8,000 & $1.07 \mathrm{E}-20$ & $1.13 \mathrm{E}-20$ & $1.26 \mathrm{E}-03$ & $1.32 \mathrm{E}-03$ \\
9,000 & $6.69 \mathrm{E}-23$ & $7.05 \mathrm{E}-23$ & $1.06 \mathrm{E}-03$ & $1.11 \mathrm{E}-03$ \\
10,000 & $4.21 \mathrm{E}-25$ & $4.43 \mathrm{E}-25$ & $8.91 \mathrm{E}-04$ & $9.39 \mathrm{E}-04$ \\
$50 \mathrm{y}$ & $3.15 \mathrm{E}-43$ & $3.32 \mathrm{E}-43$ & $2.55 \mathrm{E}-04$ & $2.68 \mathrm{E}-04$ \\
\hline
\end{tabular}

(a) Factors are applicable to ${ }^{234} \mathrm{U},{ }^{235} \mathrm{U},{ }^{236} \mathrm{U},{ }^{238} \mathrm{U},{ }^{233} \mathrm{U}$, natural uranium, depleted uranium, enriched uranium, or any combination of these isotopes. These factors can be applied to ${ }^{232} \mathrm{U}$ out to about 10 years within $10 \%$ accuracy.

(b) Typical densities of pure compounds are $19 \mathrm{~g} / \mathrm{ml}$ for metal, $8.3 \mathrm{~g} / \mathrm{ml}$ for $\mathrm{U}_{3} \mathrm{O}_{8}$, and 7.3 for $\mathrm{UO}_{3}$ (Weast 1985). 


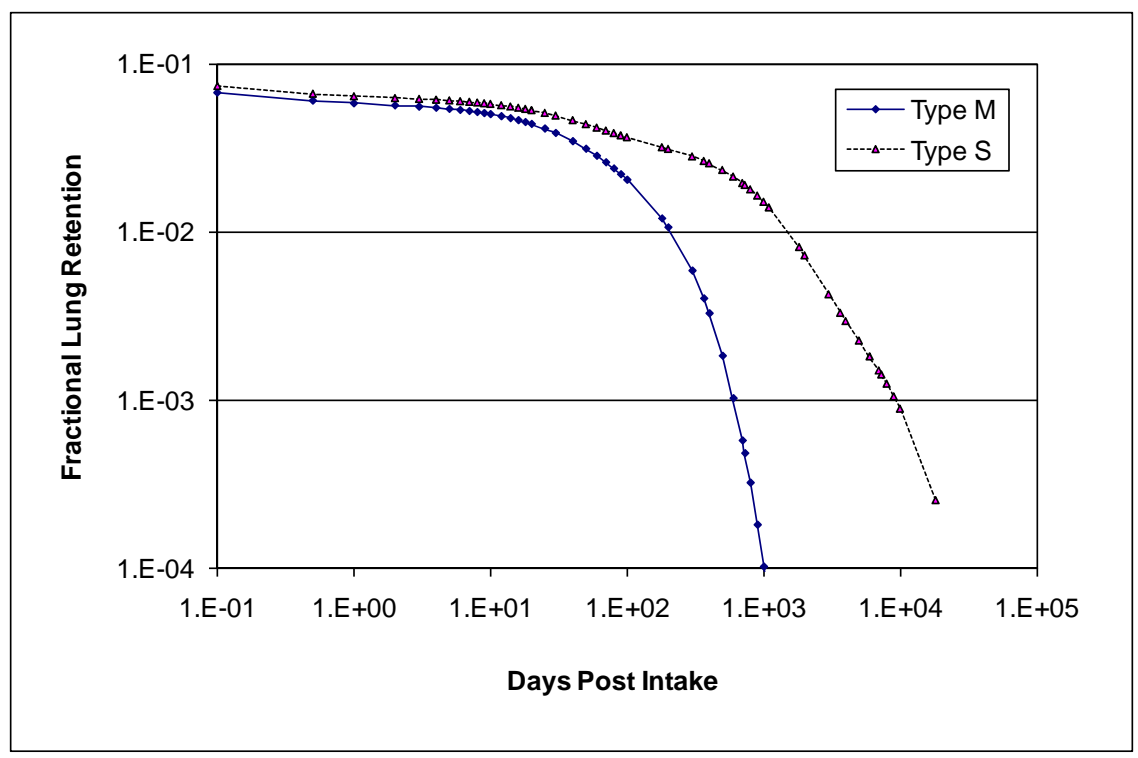

Figure 7.2. Uranium Lung Retention for 5- $\mu \mathrm{m}$-AMAD Particulates with Density of $3 \mathrm{~g} / \mathrm{ml}$

\subsubsection{Distribution and Retention in Systemic Organs and Tissues}

The systemic model presented in ICRP 69 (1995) and ICRP 78 (1997) is used to calculate the distribution and retention of uranium in the body. The basic model is described in Appendix C. The main sites of retention are the skeleton, kidneys, and all other soft tissue. Most, approximately 63\%, of uranium reaching the blood is removed via urine and most of that is excreted within 24 hours. Whereas the ICRP 30 (1979) model had essentially no uranium leaving the systemic organs or blood via the GI tract, the new model has $0.5 \%$ of systemic uranium going to feces. Flow of uranium from blood to organs, within organ compartments, and back to blood and to excretion is determined entirely by transfer rates, which are listed in Table 7.9.

The urinary excretion as a fraction of intake per day for uranium instantaneously taken up by blood, for acute inhalation of 5- $\mu \mathrm{m}$-AMAD particles, and for ingestion of soluble and insoluble material is listed in Table 7.10 and plotted in Figure 7.3. The data show the large rate of excretion in the first 24 hours followed by an approximate 10-fold reduction in daily excretion between day 1 and day 2, and then another 10-to-100-fold reduction in the next 6 months. Fecal excretion as a function of time for instantaneous uptake, acute inhalation of $5-\mu \mathrm{m}$ particles, and soluble and insoluble ingestion is listed in Table 7.11 and plotted in Figure 7.4. The instantaneous uptake (referred to as "injection" in IMBA) data show the smallest percentage of systemic uranium excreted in feces. The fecal excretion curves for soluble and insoluble ingestion are nearly identical for the first 2 weeks. Also the shapes of curves for Type F (for fast rate of solubilization), $\mathrm{M}$ (for moderate), and S (for slow) inhalations for both urine and fecal excretion are similar enough during the first 2 weeks and first year for Types $\mathrm{M}$ and $\mathrm{S}$ that determination of the absorption type from either urine or fecal data alone might not be possible. Table 7.12 and Figure 7.5 provide the fecal-to-urine ratios as a function of time after an acute intake, which might be helpful in determining the absorption type or to separate components if both inhalation and ingestion may have occurred. Note that by 20 days after an intake, there is no practical difference in the fecal to urine ratio between instantaneous uptake, ingestion, or Type $\mathrm{F}$ inhalation because all of the uranium excreted from that time on has a systemic origin. 
Table 7.9. Transfer Rates Between Compartments in the Uranium Systemic Model ${ }^{(\mathrm{a})}$

\begin{tabular}{|c|c|}
\hline Route & Transfer Rate $\left(\mathrm{d}^{-1}\right)$ \\
\hline Plasma to $\mathrm{ST} 0^{(\mathrm{b})}$ & $1.05 \mathrm{E}+01$ \\
\hline Plasma to red blood cells & 2.45E-01 \\
\hline Plasma to urinary bladder content & $1.543 \mathrm{E}+01$ \\
\hline Plasma to kidneys (urinary path) & $2.94 \mathrm{E}+00$ \\
\hline Plasma to kidney tissue & 1.22E-02 \\
\hline Plasma to upper large intestine contents & 1.22E-01 \\
\hline Plasma to liver 1 & 3.67E-01 \\
\hline Plasma to ST1 & $1.63 \mathrm{E}+00$ \\
\hline Plasma to ST2 & 7.35E-02 \\
\hline Plasma to trabecular surfaces & $2.04 \mathrm{E}+00$ \\
\hline Plasma to cortical surfaces & $1.63 \mathrm{E}+00$ \\
\hline ST0 to plasma & $8.32 \mathrm{E}+00$ \\
\hline ST1 to plasma & 3.47E-02 \\
\hline ST2 to plasma & $1.90 \mathrm{E}-05$ \\
\hline Red blood cells to plasma & 3.47E-01 \\
\hline Kidney tissue to plasma & 3.8E-04 \\
\hline Liver1 to plasma & $9.20 \mathrm{E}-02$ \\
\hline Liver2 to plasma & 1.90E-04 \\
\hline Bone surfaces to plasma & 6.93E-02 \\
\hline Non-exchangeable trabecular volume to plasma & 4.93E-04 \\
\hline Non-exchangeable cortical volume to plasma & $8.21 \mathrm{E}-05$ \\
\hline Kidneys (urinary path) to urinary bladder content & $9.90 \mathrm{E}-02$ \\
\hline Liver1 to Liver2 & 6.93E-03 \\
\hline Bone surfaces to exchangeable bone volume & 6.93E-02 \\
\hline Exchangeable bone volume to bone surfaces & 1.73E-02 \\
\hline $\begin{array}{l}\text { Exchangeable bone volume to non-exchangeable } \\
\text { volume }\end{array}$ & 5.78E-03 \\
\hline
\end{tabular}

(a) From ICRP 69 (adult) (1995).

(b) $\mathrm{ST}=$ soft tissue (the numbers are compartment numbers). 
Table 7.10. ${ }^{238} \mathrm{U}$ Urine Excretion Fractions for Instantaneous Uptake, Inhalation (5 $\left.\mu \mathrm{m}\right)$, and Ingestion Intakes $^{(a)}$

\begin{tabular}{ccccccc}
\hline Days & & & & & \multicolumn{2}{c}{ Ingestion } \\
\cline { 6 - 7 } $\begin{array}{c}\text { Post } \\
\text { Intake }\end{array}$ & Instantaneous & Type F & Type M & Type $S$ & \\
\cline { 6 - 7 } & Uptake & Inhalation & Inhalation & Inhalation & $f_{1}=2 \mathrm{E}-02$ & $f_{1}=2 \mathrm{E}-03$ \\
\hline 0.5 & $6.04 \mathrm{E}-01$ & $1.71 \mathrm{E}-01$ & $2.07 \mathrm{E}-02$ & $5.56 \mathrm{E}-04$ & $9.60 \mathrm{E}-03$ & $9.55 \mathrm{E}-04$ \\
1 & $6.45 \mathrm{E}-01$ & $1.84 \mathrm{E}-01$ & $2.32 \mathrm{E}-02$ & $7.04 \mathrm{E}-04$ & $1.26 \mathrm{E}-02$ & $1.26 \mathrm{E}-03$ \\
2 & $2.21 \mathrm{E}-02$ & $6.38 \mathrm{E}-03$ & $1.12 \mathrm{E}-03$ & $4.41 \mathrm{E}-05$ & $6.92 \mathrm{E}-04$ & $7.04 \mathrm{E}-05$ \\
3 & $1.80 \mathrm{E}-02$ & $5.14 \mathrm{E}-03$ & $8.53 \mathrm{E}-04$ & $2.60 \mathrm{E}-05$ & $3.69 \mathrm{E}-04$ & $3.69 \mathrm{E}-05$ \\
4 & $1.63 \mathrm{E}-02$ & $4.64 \mathrm{E}-03$ & $7.89 \mathrm{E}-04$ & $2.37 \mathrm{E}-05$ & $3.32 \mathrm{E}-04$ & $3.32 \mathrm{E}-05$ \\
5 & $1.48 \mathrm{E}-02$ & $4.21 \mathrm{E}-03$ & $7.35 \mathrm{E}-04$ & $2.20 \mathrm{E}-05$ & $3.01 \mathrm{E}-04$ & $3.01 \mathrm{E}-05$ \\
6 & $1.34 \mathrm{E}-02$ & $3.83 \mathrm{E}-03$ & $6.88 \mathrm{E}-04$ & $2.05 \mathrm{E}-05$ & $2.74 \mathrm{E}-04$ & $2.74 \mathrm{E}-05$ \\
7 & $1.23 \mathrm{E}-02$ & $3.50 \mathrm{E}-03$ & $6.46 \mathrm{E}-04$ & $1.92 \mathrm{E}-05$ & $2.50 \mathrm{E}-04$ & $2.50 \mathrm{E}-05$ \\
8 & $1.12 \mathrm{E}-02$ & $3.20 \mathrm{E}-03$ & $6.08 \mathrm{E}-04$ & $1.80 \mathrm{E}-05$ & $2.28 \mathrm{E}-04$ & $2.28 \mathrm{E}-05$ \\
9 & $1.03 \mathrm{E}-02$ & $2.93 \mathrm{E}-03$ & $5.74 \mathrm{E}-04$ & $1.70 \mathrm{E}-05$ & $2.09 \mathrm{E}-04$ & $2.09 \mathrm{E}-05$ \\
10 & $9.42 \mathrm{E}-03$ & $2.69 \mathrm{E}-03$ & $5.44 \mathrm{E}-04$ & $1.60 \mathrm{E}-05$ & $1.92 \mathrm{E}-04$ & $1.92 \mathrm{E}-05$ \\
12 & $7.98 \mathrm{E}-03$ & $2.28 \mathrm{E}-03$ & $4.91 \mathrm{E}-04$ & $1.44 \mathrm{E}-05$ & $1.62 \mathrm{E}-04$ & $1.62 \mathrm{E}-05$ \\
14 & $6.81 \mathrm{E}-03$ & $1.94 \mathrm{E}-03$ & $4.47 \mathrm{E}-04$ & $1.31 \mathrm{E}-05$ & $1.38 \mathrm{E}-04$ & $1.38 \mathrm{E}-05$ \\
30 & $2.39 \mathrm{E}-03$ & $6.81 \mathrm{E}-04$ & $2.66 \mathrm{E}-04$ & $7.72 \mathrm{E}-06$ & $4.83 \mathrm{E}-05$ & $4.83 \mathrm{E}-06$ \\
60 & $7.95 \mathrm{E}-04$ & $2.27 \mathrm{E}-04$ & $1.67 \mathrm{E}-04$ & $5.18 \mathrm{E}-06$ & $1.60 \mathrm{E}-05$ & $1.60 \mathrm{E}-06$ \\
90 & $4.20 \mathrm{E}-04$ & $1.20 \mathrm{E}-04$ & $1.25 \mathrm{E}-04$ & $4.28 \mathrm{E}-06$ & $8.44 \mathrm{E}-06$ & $8.44 \mathrm{E}-07$ \\
180 & $1.09 \mathrm{E}-04$ & $3.12 \mathrm{E}-05$ & $6.53 \mathrm{E}-05$ & $3.29 \mathrm{E}-06$ & $2.19 \mathrm{E}-06$ & $2.19 \mathrm{E}-07$ \\
365 & $1.94 \mathrm{E}-05$ & $5.53 \mathrm{E}-06$ & $2.18 \mathrm{E}-05$ & $2.64 \mathrm{E}-06$ & $3.89 \mathrm{E}-07$ & $3.89 \mathrm{E}-08$ \\
$2 \mathrm{y}$ & $9.11 \mathrm{E}-06$ & $2.60 \mathrm{E}-06$ & $3.17 \mathrm{E}-06$ & $1.91 \mathrm{E}-06$ & $1.82 \mathrm{E}-07$ & $1.82 \mathrm{E}-08$ \\
$3 \mathrm{y}$ & $7.77 \mathrm{E}-06$ & $2.22 \mathrm{E}-06$ & $8.70 \mathrm{E}-07$ & $1.41 \mathrm{E}-06$ & $1.55 \mathrm{E}-07$ & $1.55 \mathrm{E}-08$ \\
$5 \mathrm{y}$ & $5.83 \mathrm{E}-06$ & $1.67 \mathrm{E}-06$ & $4.25 \mathrm{E}-07$ & $8.38 \mathrm{E}-07$ & $1.17 \mathrm{E}-07$ & $1.17 \mathrm{E}-08$ \\
$10 \mathrm{y}$ & $3.07 \mathrm{E}-06$ & $8.75 \mathrm{E}-07$ & $2.20 \mathrm{E}-07$ & $3.55 \mathrm{E}-07$ & $6.14 \mathrm{E}-08$ & $6.14 \mathrm{E}-09$ \\
$20 \mathrm{y}$ & $1.23 \mathrm{E}-06$ & $3.50 \mathrm{E}-07$ & $8.68 \mathrm{E}-08$ & $1.58 \mathrm{E}-07$ & $2.45 \mathrm{E}-08$ & $2.45 \mathrm{E}-09$ \\
$50 \mathrm{y}$ & $3.83 \mathrm{E}-07$ & $1.10 \mathrm{E}-07$ & $2.70 \mathrm{E}-08$ & $3.17 \mathrm{E}-08$ & $7.67 \mathrm{E}-09$ & $7.67 \mathrm{E}-10$ \\
\hline
\end{tabular}

(a) Factors are applicable to ${ }^{234} \mathrm{U},{ }^{235} \mathrm{U},{ }^{236} \mathrm{U},{ }^{238} \mathrm{U},{ }^{233} \mathrm{U}$, natural uranium, depleted uranium, enriched uranium, or any combination of these isotopes. These factors can be applied to ${ }^{232} \mathrm{U}$ out to about 10 years within $10 \%$ accuracy. 


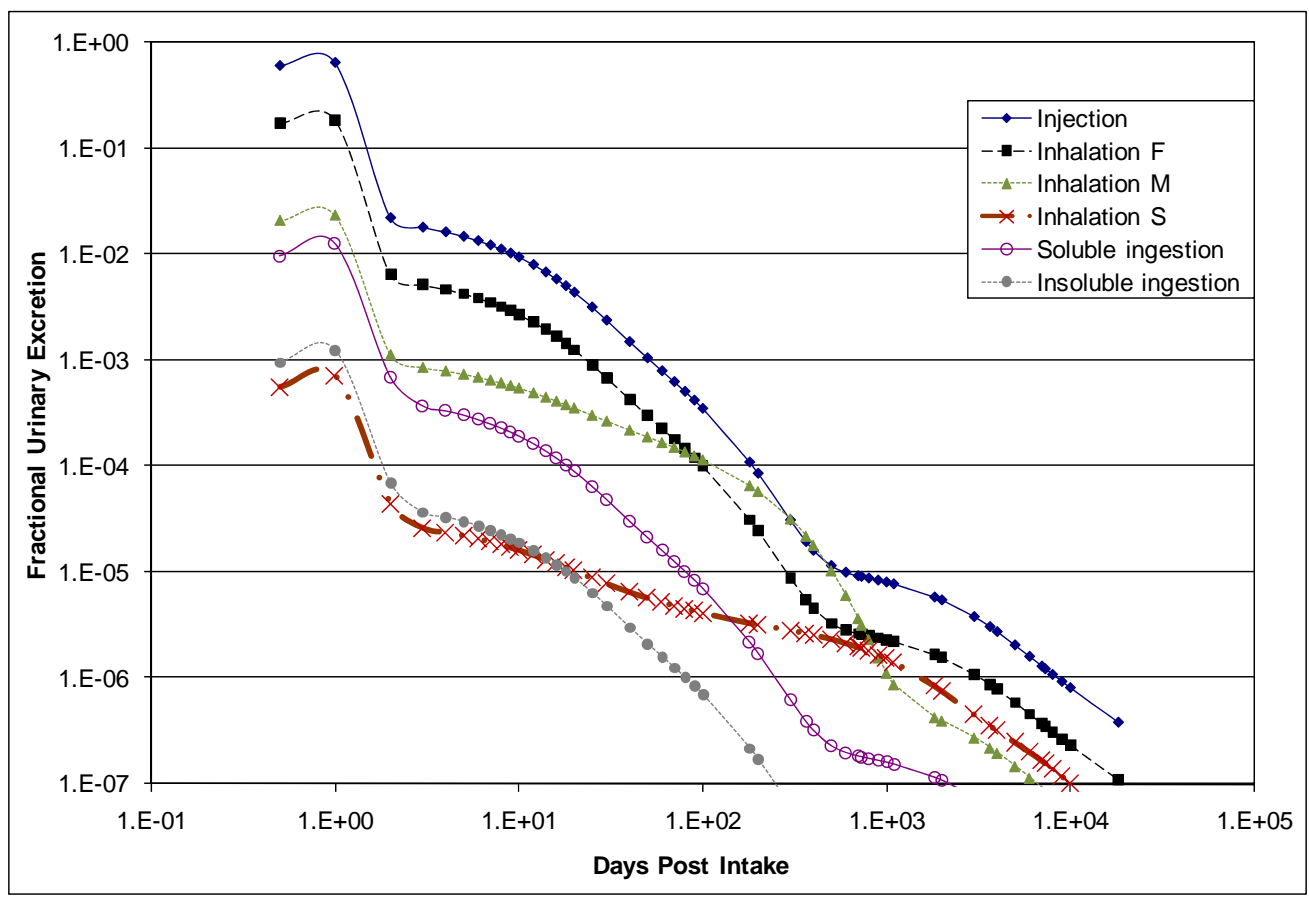

Figure 7.3. Uranium Urinary Excretion, Fraction of Intake

Table 7.11. ${ }^{238} \mathrm{U}$ Fecal Excretion Fractions for Instantaneous Uptake, Inhalation (5 $\left.\mu \mathrm{m}\right)$, and Ingestion Intakes $^{(a)}$

\begin{tabular}{ccccccc}
\hline \multirow{2}{*}{$\begin{array}{c}\text { Days Post } \\
\text { Intake }\end{array}$} & Instantaneous & Type $F$ & \multirow{2}{*}{ Type M } & \multirow{2}{*}{ Type $S$} & \multicolumn{2}{c}{ Ingestion } \\
\cline { 6 - 7 } & Uptake & Inhalation & Inhalation & Inhalation & $f_{1}=2 \mathrm{E}-02$ & $f_{1}=2 \mathrm{E}-03$ \\
\hline 0.5 & $5.50 \mathrm{E}-04$ & $1.38 \mathrm{E}-02$ & $2.57 \mathrm{E}-02$ & $2.73 \mathrm{E}-02$ & $6.97 \mathrm{E}-02$ & $7.03 \mathrm{E}-02$ \\
1 & $1.69 \mathrm{E}-03$ & $5.56 \mathrm{E}-02$ & $1.07 \mathrm{E}-01$ & $1.14 \mathrm{E}-01$ & $2.78 \mathrm{E}-01$ & $2.82 \mathrm{E}-01$ \\
2 & $1.87 \mathrm{E}-03$ & $7.69 \mathrm{E}-02$ & $1.52 \mathrm{E}-01$ & $1.63 \mathrm{E}-01$ & $3.81 \mathrm{E}-01$ & $3.88 \mathrm{E}-01$ \\
3 & $9.46 \mathrm{E}-04$ & $3.89 \mathrm{E}-02$ & $7.79 \mathrm{E}-02$ & $8.39 \mathrm{E}-02$ & $1.93 \mathrm{E}-01$ & $1.97 \mathrm{E}-01$ \\
4 & $4.24 \mathrm{E}-04$ & $1.61 \mathrm{E}-02$ & $3.27 \mathrm{E}-02$ & $3.53 \mathrm{E}-02$ & $7.95 \mathrm{E}-02$ & $8.12 \mathrm{E}-02$ \\
5 & $1.98 \mathrm{E}-04$ & $6.22 \mathrm{E}-03$ & $1.30 \mathrm{E}-02$ & $1.40 \mathrm{E}-02$ & $3.07 \mathrm{E}-02$ & $3.13 \mathrm{E}-02$ \\
6 & $1.06 \mathrm{E}-04$ & $2.35 \mathrm{E}-03$ & $5.21 \mathrm{E}-03$ & $5.65 \mathrm{E}-03$ & $1.15 \mathrm{E}-02$ & $1.18 \mathrm{E}-02$ \\
7 & $6.78 \mathrm{E}-05$ & $8.79 \mathrm{E}-04$ & $2.25 \mathrm{E}-03$ & $2.47 \mathrm{E}-03$ & $4.28 \mathrm{E}-03$ & $4.37 \mathrm{E}-03$ \\
8 & $5.09 \mathrm{E}-05$ & $3.32 \mathrm{E}-04$ & $1.14 \mathrm{E}-03$ & $1.27 \mathrm{E}-03$ & $1.58 \mathrm{E}-03$ & $1.61 \mathrm{E}-03$ \\
9 & $4.24 \mathrm{E}-05$ & $1.29 \mathrm{E}-04$ & $7.24 \mathrm{E}-04$ & $8.21 \mathrm{E}-04$ & $5.83 \mathrm{E}-04$ & $5.95 \mathrm{E}-04$ \\
10 & $3.72 \mathrm{E}-05$ & $5.37 \mathrm{E}-05$ & $5.61 \mathrm{E}-04$ & $6.47 \mathrm{E}-04$ & $2.15 \mathrm{E}-04$ & $2.19 \mathrm{E}-04$ \\
12 & $3.07 \mathrm{E}-05$ & $1.46 \mathrm{E}-05$ & $4.59 \mathrm{E}-04$ & $5.40 \mathrm{E}-04$ & $2.97 \mathrm{E}-05$ & $2.97 \mathrm{E}-05$ \\
14 & $2.62 \mathrm{E}-05$ & $8.27 \mathrm{E}-06$ & $4.25 \mathrm{E}-04$ & $5.05 \mathrm{E}-04$ & $4.46 \mathrm{E}-06$ & $4.07 \mathrm{E}-06$ \\
30 & $1.11 \mathrm{E}-05$ & $3.16 \mathrm{E}-06$ & $2.72 \mathrm{E}-04$ & $3.50 \mathrm{E}-04$ & $2.23 \mathrm{E}-07$ & $2.23 \mathrm{E}-08$ \\
60 & $4.96 \mathrm{E}-06$ & $1.41 \mathrm{E}-06$ & $1.25 \mathrm{E}-04$ & $1.86 \mathrm{E}-04$ & $9.96 \mathrm{E}-08$ & $9.96 \mathrm{E}-09$ \\
90 & $2.74 \mathrm{E}-06$ & $7.82 \mathrm{E}-07$ & $6.22 \mathrm{E}-05$ & $1.07 \mathrm{E}-04$ & $5.51 \mathrm{E}-08$ & $5.51 \mathrm{E}-09$
\end{tabular}


Table 7.11. (contd)

\begin{tabular}{ccccccc}
\hline \multirow{2}{*}{$\begin{array}{c}\text { Days Post } \\
\text { Intake }\end{array}$} & Instantaneous & Type $\mathrm{F}$ & Type $\mathrm{M}$ & \multirow{2}{*}{ Type $S$} & \multicolumn{2}{c}{ Ingestion } \\
\cline { 6 - 7 } & Uptake & Inhalation & Inhalation & Inhalation & $f_{1}=2 \mathrm{E}-02$ & $f_{1}=2 \mathrm{E}-03$ \\
\hline 180 & $7.23 \mathrm{E}-07$ & $2.06 \mathrm{E}-07$ & $1.42 \mathrm{E}-05$ & $3.72 \mathrm{E}-05$ & $1.45 \mathrm{E}-08$ & $1.45 \mathrm{E}-09$ \\
365 & $1.29 \mathrm{E}-07$ & $3.67 \mathrm{E}-08$ & $3.45 \mathrm{E}-06$ & $2.21 \mathrm{E}-05$ & $2.57 \mathrm{E}-09$ & $2.57 \mathrm{E}-10$ \\
$2 \mathrm{y}$ & $6.05 \mathrm{E}-08$ & $1.73 \mathrm{E}-08$ & $3.90 \mathrm{E}-07$ & $1.48 \mathrm{E}-05$ & $1.21 \mathrm{E}-09$ & $1.21 \mathrm{E}-10$ \\
$3 \mathrm{y}$ & $5.16 \mathrm{E}-08$ & $1.47 \mathrm{E}-08$ & $4.63 \mathrm{E}-08$ & $9.94 \mathrm{E}-06$ & $1.03 \mathrm{E}-09$ & $1.03 \mathrm{E}-10$ \\
$5 \mathrm{y}$ & $3.88 \mathrm{E}-08$ & $1.10 \mathrm{E}-08$ & $3.35 \mathrm{E}-09$ & $4.62 \mathrm{E}-06$ & $7.75 \mathrm{E}-10$ & $7.75 \mathrm{E}-11$ \\
$10 \mathrm{y}$ & $2.04 \mathrm{E}-08$ & $5.81 \mathrm{E}-09$ & $1.46 \mathrm{E}-09$ & $8.16 \mathrm{E}-07$ & $4.08 \mathrm{E}-10$ & $4.08 \mathrm{E}-11$ \\
$20 \mathrm{y}$ & $8.14 \mathrm{E}-09$ & $2.32 \mathrm{E}-09$ & $5.76 \mathrm{E}-10$ & $1.18 \mathrm{E}-07$ & $1.63 \mathrm{E}-10$ & $1.63 \mathrm{E}-11$ \\
$50 \mathrm{y}$ & $2.55 \mathrm{E}-09$ & $7.26 \mathrm{E}-10$ & $1.79 \mathrm{E}-10$ & $9.68 \mathrm{E}-09$ & $5.09 \mathrm{E}-11$ & $5.09 \mathrm{E}-12$ \\
\hline
\end{tabular}

(a) Factors are applicable to ${ }^{234} \mathrm{U},{ }^{235} \mathrm{U},{ }^{236} \mathrm{U},{ }^{238} \mathrm{U},{ }^{233} \mathrm{U}$, natural uranium, depleted uranium, enriched uranium, or any combination of these isotopes. These factors can be applied to ${ }^{232} \mathrm{U}$ out to about 10 years within $10 \%$ accuracy.

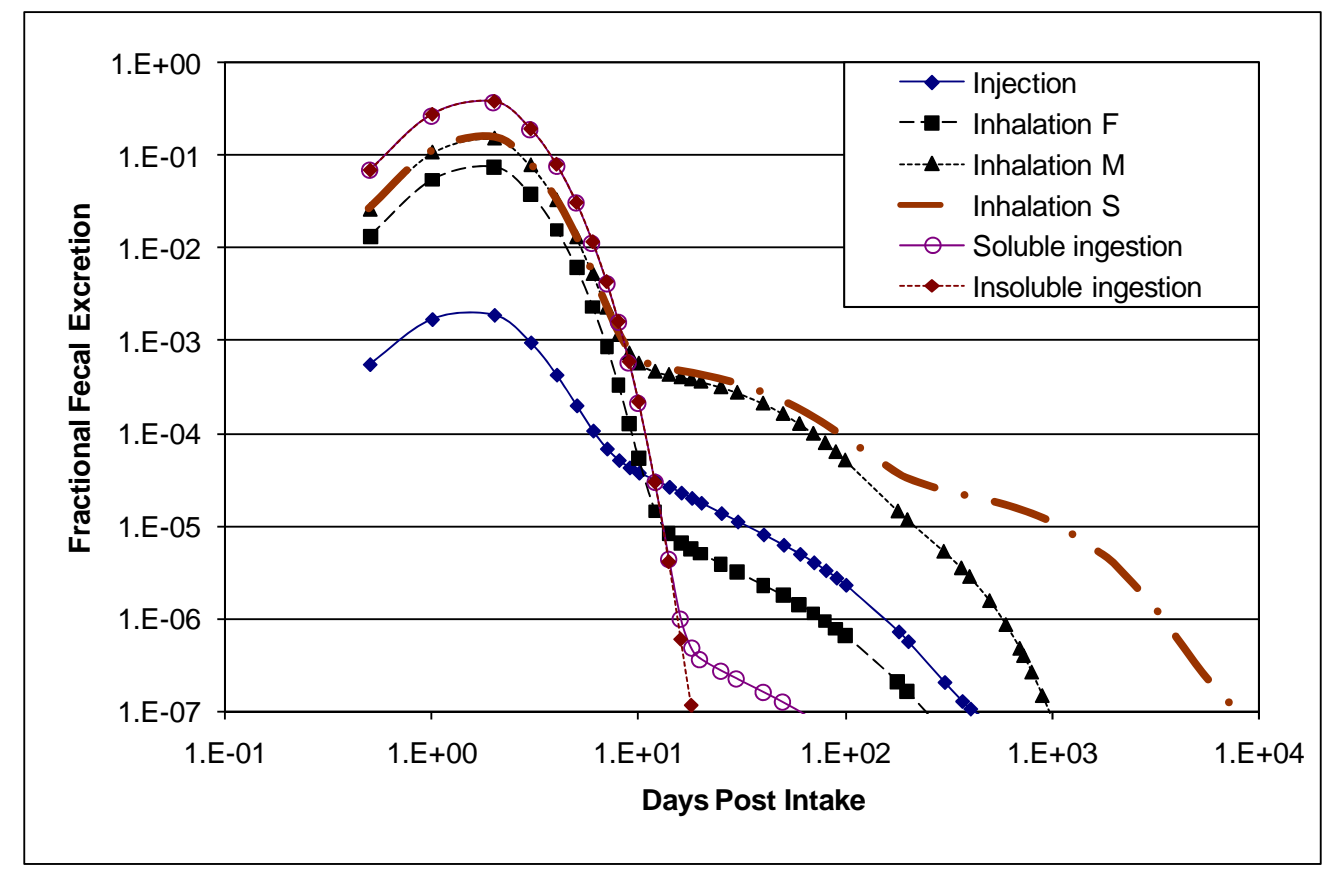

Figure 7.4. Uranium Fecal Excretion, Fraction of Intake 
Table 7.12. Fecal-to-Urine Ratios for Uranium Intakes ${ }^{(a)}$

\begin{tabular}{ccccccc}
\hline & & Type $F$ & Type M & Type $S$ & \multicolumn{2}{c}{ Ingestion } \\
\cline { 5 - 7 } $\begin{array}{c}\text { Days Post } \\
\text { Intake }\end{array}$ & $\begin{array}{c}\text { Instantaneous } \\
\text { Uptake }\end{array}$ & $\begin{array}{c}\text { Inhalation } \\
(5 \mu \mathrm{m})\end{array}$ & $\begin{array}{c}\text { Inhalation } \\
(5 \mu \mathrm{m})\end{array}$ & $\begin{array}{c}\text { Inhalation } \\
(5 \mu \mathrm{m})\end{array}$ & $f_{1}=2 \mathrm{E}-2$ & $f_{1}=2 \mathrm{E}-3$ \\
\hline 1 & $2.61 \mathrm{E}-03$ & $3.03 \mathrm{E}-01$ & $4.60 \mathrm{E}+00$ & $1.62 \mathrm{E}+02$ & $2.21 \mathrm{E}+01$ & $2.25 \mathrm{E}+02$ \\
2 & $8.47 \mathrm{E}-02$ & $1.21 \mathrm{E}+01$ & $1.35 \mathrm{E}+02$ & $3.69 \mathrm{E}+03$ & $5.51 \mathrm{E}+02$ & $5.52 \mathrm{E}+03$ \\
3 & $5.26 \mathrm{E}-02$ & $7.58 \mathrm{E}+00$ & $9.13 \mathrm{E}+01$ & $3.23 \mathrm{E}+03$ & $5.21 \mathrm{E}+02$ & $5.32 \mathrm{E}+03$ \\
4 & $2.61 \mathrm{E}-02$ & $3.47 \mathrm{E}+00$ & $4.14 \mathrm{E}+01$ & $1.49 \mathrm{E}+03$ & $2.39 \mathrm{E}+02$ & $2.44 \mathrm{E}+03$ \\
5 & $1.34 \mathrm{E}-02$ & $1.48 \mathrm{E}+00$ & $1.77 \mathrm{E}+01$ & $6.39 \mathrm{E}+02$ & $1.02 \mathrm{E}+02$ & $1.04 \mathrm{E}+03$ \\
7 & $5.53 \mathrm{E}-03$ & $2.51 \mathrm{E}-01$ & $3.49 \mathrm{E}+00$ & $1.29 \mathrm{E}+02$ & $1.71 \mathrm{E}+01$ & $1.75 \mathrm{E}+02$ \\
8 & $4.54 \mathrm{E}-03$ & $1.04 \mathrm{E}-01$ & $1.88 \mathrm{E}+00$ & $7.06 \mathrm{E}+01$ & $6.93 \mathrm{E}+00$ & $7.07 \mathrm{E}+01$ \\
10 & $3.95 \mathrm{E}-03$ & $2.00 \mathrm{E}-02$ & $1.03 \mathrm{E}+00$ & $4.04 \mathrm{E}+01$ & $1.12 \mathrm{E}+00$ & $1.14 \mathrm{E}+01$ \\
12 & $3.85 \mathrm{E}-03$ & $6.41 \mathrm{E}-03$ & $9.36 \mathrm{E}-01$ & $3.75 \mathrm{E}+01$ & $1.83 \mathrm{E}-01$ & $1.83 \mathrm{E}+00$ \\
14 & $3.85 \mathrm{E}-03$ & $4.25 \mathrm{E}-03$ & $9.50 \mathrm{E}-01$ & $3.87 \mathrm{E}+01$ & $3.22 \mathrm{E}-02$ & $2.94 \mathrm{E}-01$ \\
30 & $4.64 \mathrm{E}-03$ & $4.64 \mathrm{E}-03$ & $1.02 \mathrm{E}+00$ & $4.53 \mathrm{E}+01$ & $4.63 \mathrm{E}-03$ & $4.63 \mathrm{E}-03$ \\
60 & $6.23 \mathrm{E}-03$ & $6.23 \mathrm{E}-03$ & $7.49 \mathrm{E}-01$ & $3.59 \mathrm{E}+01$ & $6.23 \mathrm{E}-03$ & $6.23 \mathrm{E}-03$ \\
90 & $6.53 \mathrm{E}-03$ & $6.53 \mathrm{E}-03$ & $5.00 \mathrm{E}-01$ & $2.49 \mathrm{E}+01$ & $6.53 \mathrm{E}-03$ & $6.53 \mathrm{E}-03$ \\
180 & $6.61 \mathrm{E}-03$ & $6.61 \mathrm{E}-03$ & $2.18 \mathrm{E}-01$ & $1.13 \mathrm{E}+01$ & $6.61 \mathrm{E}-03$ & $6.61 \mathrm{E}-03$ \\
365 & $6.62 \mathrm{E}-03$ & $6.62 \mathrm{E}-03$ & $1.58 \mathrm{E}-01$ & $8.38 \mathrm{E}+00$ & $6.62 \mathrm{E}-03$ & $6.62 \mathrm{E}-03$ \\
$2 \mathrm{y}$ & $6.64 \mathrm{E}-03$ & $6.64 \mathrm{E}-03$ & $1.23 \mathrm{E}-01$ & $7.75 \mathrm{E}+00$ & $6.64 \mathrm{E}-03$ & $6.64 \mathrm{E}-03$ \\
$5 \mathrm{y}$ & $6.64 \mathrm{E}-03$ & $6.64 \mathrm{E}-03$ & $7.87 \mathrm{E}-03$ & $5.52 \mathrm{E}+00$ & $6.64 \mathrm{E}-03$ & $6.64 \mathrm{E}-03$ \\
$10 \mathrm{y}$ & $6.64 \mathrm{E}-03$ & $6.64 \mathrm{E}-03$ & $6.64 \mathrm{E}-03$ & $2.30 \mathrm{E}+00$ & $6.64 \mathrm{E}-03$ & $6.64 \mathrm{E}-03$ \\
$20 \mathrm{y}$ & $6.64 \mathrm{E}-03$ & $6.64 \mathrm{E}-03$ & $6.64 \mathrm{E}-03$ & $7.44 \mathrm{E}-01$ & $6.64 \mathrm{E}-03$ & $6.64 \mathrm{E}-03$ \\
$50 \mathrm{y}$ & $6.64 \mathrm{E}-03$ & $6.62 \mathrm{E}-03$ & $6.62 \mathrm{E}-03$ & $3.05 \mathrm{E}-01$ & $6.64 \mathrm{E}-03$ & $6.64 \mathrm{E}-03$ \\
\hline
\end{tabular}

(a) Factors apply to ratio of individual isotopes or like mixtures of uranium.

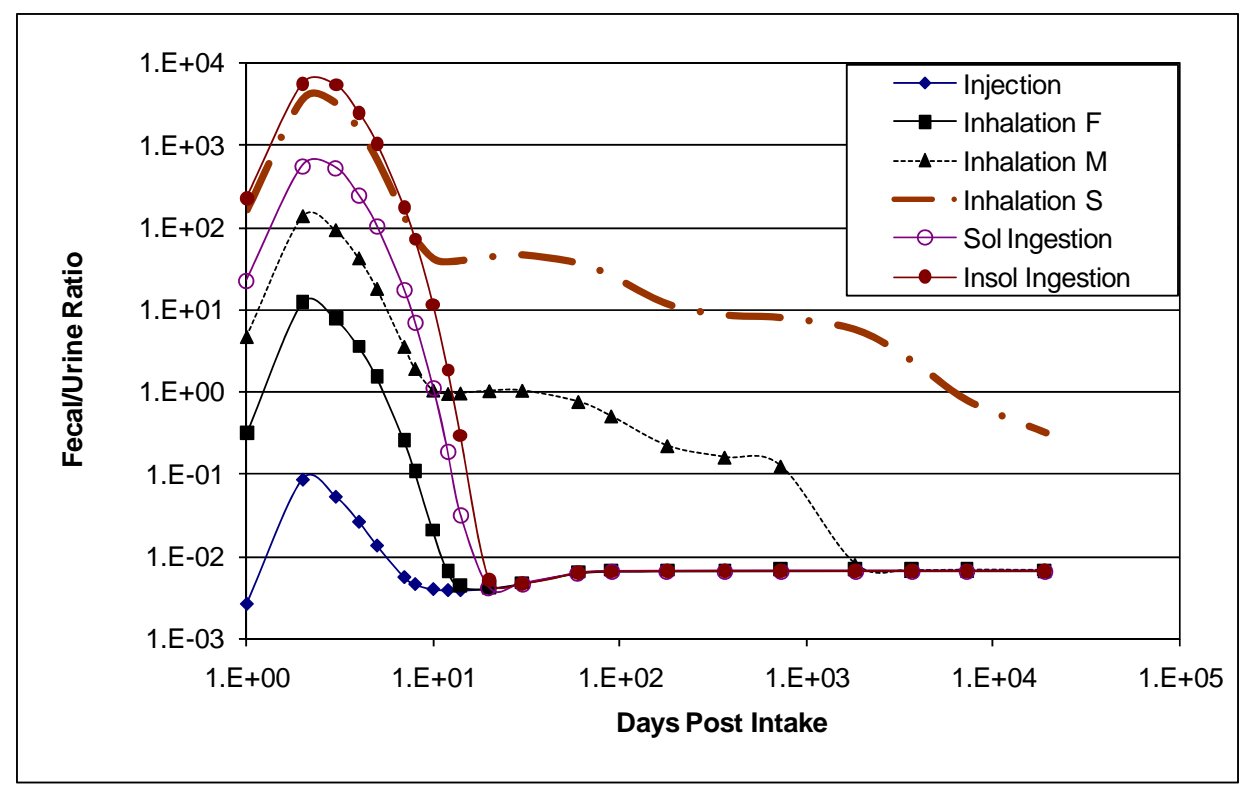

Figure 7.5. Uranium Fecal-to-Urine Ratios 
Uranium has chemical toxicity independent from its radiological characteristics with the kidney being the affected organ (see discussion in the next section). Therefore, it may be important to determine the uranium concentration in the kidney after an intake. This is especially relevant for depleted to slightly enriched uranium in readily absorbed forms or for a contaminated wound. The retention of uranium in the kidneys as a fraction of the mass of intake is listed in Table 7.13 and plotted in Figure 7.6 as a function of time after intake. Note that fractions of the first day are shown in this table and plot. The peak concentration in the kidney occurs between 12 and 24 hours after an intake (at 18 hours for instantaneous uptake and inhalation of Types $\mathrm{F}$ and $\mathrm{M}$ ). If chemical toxicity is a concern, a series of spot urine samples collected from about 12 to 30 hours after the intake would provide the best data for determining peak kidney concentration.

Table 7.13. Kidney Retention Fractions Following Uranium Intake ${ }^{(a)}$

\begin{tabular}{|c|c|c|c|c|c|c|}
\hline \multirow{2}{*}{$\begin{array}{l}\text { Days Post } \\
\text { Intake }\end{array}$} & \multirow{2}{*}{$\begin{array}{c}\text { Instantaneous } \\
\text { Uptake }\end{array}$} & \multirow{2}{*}{$\begin{array}{c}\text { Type F } \\
\text { Inhalation } \\
(5 \mu \mathrm{m})\end{array}$} & \multirow{2}{*}{$\begin{array}{c}\text { Type } \mathrm{M} \\
\text { Inhalation } \\
(5 \mu \mathrm{m})\end{array}$} & \multirow{2}{*}{$\begin{array}{c}\text { Type S } \\
\text { Inhalation } \\
(5 \mu \mathrm{m})\end{array}$} & \multicolumn{2}{|c|}{ Ingestion } \\
\hline & & & & & $f_{1}=2 \mathrm{E}-2$ & $f_{1}=2 \mathrm{E}-3$ \\
\hline 0.1 & 8.93E-02 & 2.47E-02 & $2.58 \mathrm{E}-03$ & 3.63E-05 & 3.53E-04 & $3.48 \mathrm{E}-05$ \\
\hline 0.3 & $1.08 \mathrm{E}-01$ & 3.06E-02 & $3.59 \mathrm{E}-03$ & 8.80E-05 & $1.47 \mathrm{E}-03$ & $1.45 \mathrm{E}-04$ \\
\hline 0.5 & 1.13E-01 & 3.22E-02 & 3.97E-03 & 1.13E-04 & 1.99E-03 & $1.98 \mathrm{E}-04$ \\
\hline 0.75 & $1.14 \mathrm{E}-01$ & 3.25E-02 & 4.09E-03 & $1.24 \mathrm{E}-04$ & 2.21E-03 & 2.21E-04 \\
\hline 1 & 1.12E-01 & $3.20 \mathrm{E}-02$ & $4.08 \mathrm{E}-03$ & $1.26 \mathrm{E}-04$ & $2.25 \mathrm{E}-03$ & $2.25 \mathrm{E}-04$ \\
\hline 2 & 1.03E-01 & 2.95E-02 & 3.81E-03 & 1.19E-04 & $2.10 \mathrm{E}-03$ & 2.10E-04 \\
\hline 3 & $9.48 \mathrm{E}-02$ & 2.71E-02 & 3.53E-03 & 1.10E-04 & 1.93E-03 & 1.93E-04 \\
\hline 4 & 8.70E-02 & 2.48E-02 & 3.27E-03 & $1.01 \mathrm{E}-04$ & 1.77E-03 & 1.77E-04 \\
\hline 5 & 7.98E-02 & $2.28 \mathrm{E}-02$ & 3.03E-03 & $9.40 \mathrm{E}-05$ & $1.62 \mathrm{E}-03$ & 1.63E-04 \\
\hline 6 & 7.33E-02 & 2.09E-02 & 2.81E-03 & 8.71E-05 & 1.49E-03 & 1.49E-04 \\
\hline 7 & 6.73E-02 & $1.92 \mathrm{E}-02$ & $2.62 \mathrm{E}-03$ & 8.08E-05 & $1.37 \mathrm{E}-03$ & 1.37E-04 \\
\hline 8 & $6.18 \mathrm{E}-02$ & $1.76 \mathrm{E}-02$ & 2.43E-03 & $7.50 \mathrm{E}-05$ & $1.26 \mathrm{E}-03$ & $1.26 \mathrm{E}-04$ \\
\hline 9 & $5.68 \mathrm{E}-02$ & 1.62E-02 & 2.27E-03 & 6.97E-05 & $1.16 \mathrm{E}-03$ & 1.16E-04 \\
\hline 10 & $5.22 \mathrm{E}-02$ & 1.49E-02 & $2.11 \mathrm{E}-03$ & $6.49 \mathrm{E}-05$ & $1.06 \mathrm{E}-03$ & 1.06E-04 \\
\hline 12 & 4.41E-02 & $1.26 \mathrm{E}-02$ & $1.84 \mathrm{E}-03$ & $5.64 \mathrm{E}-05$ & 8.98E-04 & 8.98E-05 \\
\hline 14 & $3.74 \mathrm{E}-02$ & 1.07E-02 & $1.62 \mathrm{E}-03$ & 4.92E-05 & $7.60 \mathrm{E}-04$ & 7.61E-05 \\
\hline 30 & 1.09E-02 & 3.11E-03 & 6.93E-04 & 2.05E-05 & 2.21E-04 & $2.21 \mathrm{E}-05$ \\
\hline 60 & $2.45 \mathrm{E}-03$ & $6.98 \mathrm{E}-04$ & 3.34E-04 & $1.01 \mathrm{E}-05$ & 4.93E-05 & 4.93E-06 \\
\hline 90 & $1.41 \mathrm{E}-03$ & 4.02E-04 & $2.48 \mathrm{E}-04$ & 8.18E-06 & 2.83E-05 & 2.83E-06 \\
\hline
\end{tabular}

(a) Mass fraction of total uranium. 


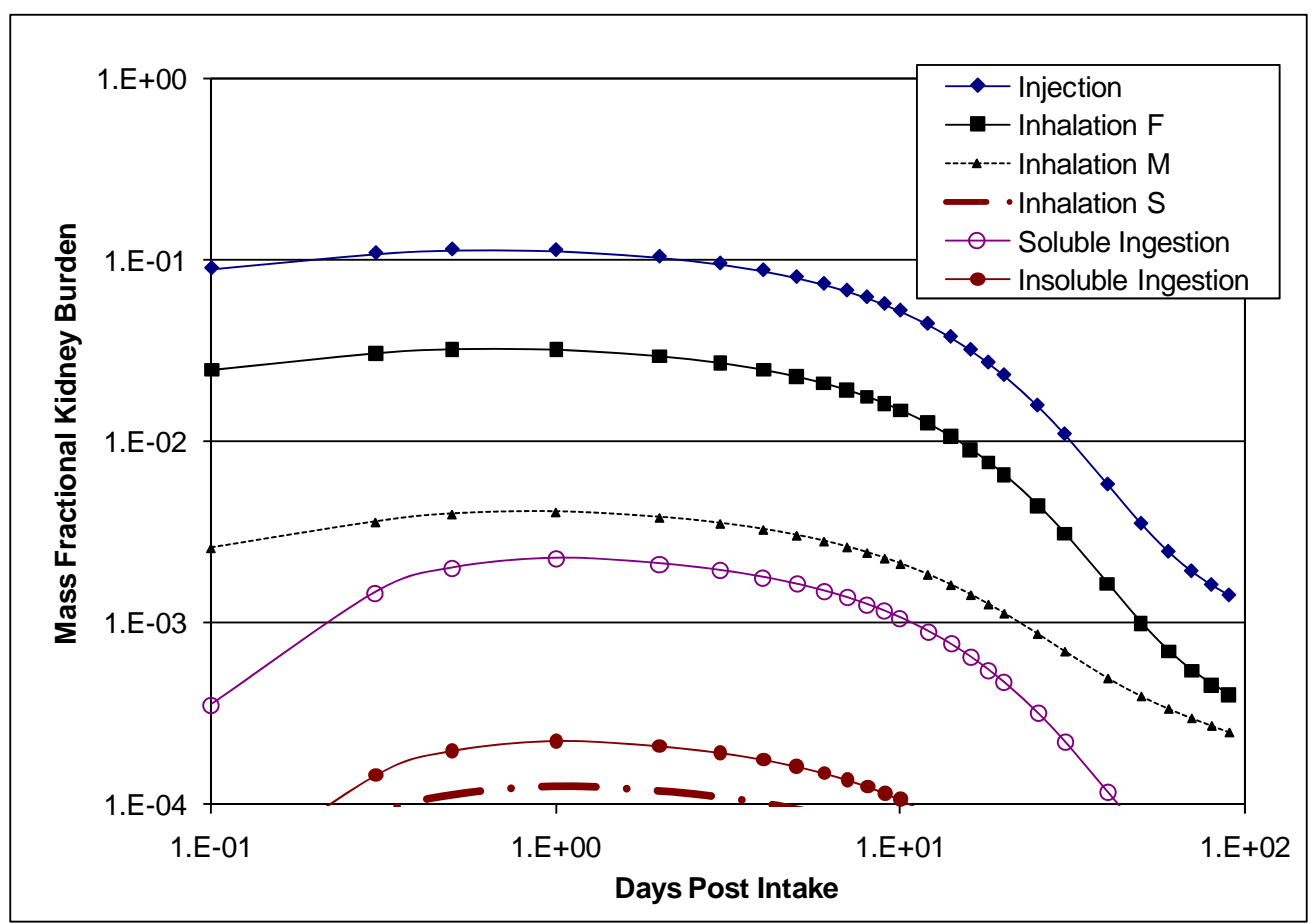

Figure 7.6. Kidney Retention, Mass Fraction of Intake

\subsubsection{Chemical Toxicity}

Chemical toxicity is a potential concern for intakes of low-enrichment uranium $\left(<10 \%{ }^{235} \mathrm{U}\right.$, by weight) in a readily transportable form (wounds, inhalation absorption Types $\mathrm{F}$ and $\mathrm{M}$, and soluble ingestion). Such concerns can make chemical toxicity a more limiting intake condition than equivalent dose. Chemical toxicity is not the predominant concern for ingestions or inhalation absorption Type S. (Even for insoluble ingestions, the reference intake for chemical toxicity for recycled uranium is smaller than the reference dose compliance intake [see Table 7.28], but the intake is so large that it is not significant in practice.)

The Hanford basis for chemical toxicity is a peak kidney concentration of $1.1 \mu \mathrm{g}-\mathrm{U} / \mathrm{g}-\mathrm{kidney}$ resulting from either acute or chronic exposure. This approach is conservative in that a larger acute kidney concentration can be tolerated without significant effect than might result from a long-term chronic concentration. The 1.1- $\mu \mathrm{g} / \mathrm{g}$ value was chosen based on acute or chronic intake scenarios, even though indications are that a 2 to $3-\mu \mathrm{g} / \mathrm{g}$ chronic value can be tolerated without significant effect (see the following paragraphs for more detailed discussion). Multiplying the 1.1- $\mu \mathrm{g} / \mathrm{g}$ value by the kidney mass of $310 \mathrm{~g}$ (adult male) gives a total kidney burden of $341 \mu \mathrm{g}$ as a Reference Man value for a "no effect" threshold. Acute intakes can be calculated that would result in such a kidney burden by dividing the kidney burden by the kidney retention fraction. This analysis is included for several intake scenarios in Section 7.3.4. Chronic intake rates can be similarly calculated; however, such levels have not been included in this manual because chronic intake is not currently a routine Hanford condition.

A chronic kidney burden of $3 \mu \mathrm{g}$-U/g-kidney has historically been the basis for development of action levels for bioassay monitoring of workers who are chronically exposed to uranium (Hursh and Spoor 
1973). Studies by Morrow et al. (1982) with the highly transportable and toxic form of uranium, $\mathrm{UO}_{2} \mathrm{~F}_{2}$, indicated that steady-state kidney concentrations of $3 \mu \mathrm{g} / \mathrm{g}$ in dogs were sufficient to produce indications of uranium poisoning. Although $\mathrm{UO}_{2} \mathrm{~F}_{2}$ is not handled at Hanford, it is prudent for bioassay monitoring purposes to assume a renal toxicity threshold of less than $3 \mu \mathrm{g} / \mathrm{g}$ of kidney. Based on recent studies by a number of investigators, Rich et al. (1988) suggested that the "no effect" threshold for uranium in kidney is $1.1 \mu \mathrm{g} / \mathrm{g}$. Hanford adopted a "no effect" threshold of $0.4 \mu \mathrm{g} / \mathrm{g}$ as a sustained kidney burden value, based on one-third of the Rich value, rounded to one significant figure (Sula et al. 1989). This sustained kidney burden approach was replaced in 2000 for Hanford applications by a peak kidney concentration approach, using the 1.1- $\mu \mathrm{g} / \mathrm{g}$ value for both chronic and acute exposure scenarios.

Additional publications have raised some question about the appropriate magnitude for an assumed "no effects threshold level" of uranium intake, uptake, or kidney burden. In an extensive review article, Leggett (1989) noted that results and conclusions of studies have varied widely and that "apparent discrepancies may be due largely to differences in 1) perceptions and/or definitions of toxicity, 2) sensitivity of the measurements of kidney damage or dysfunction, 3) patterns of exposure (for example, acute versus chronic), and 4) sensitivity to renal uranium in different species." Leggett concluded "it may be prudent to lower this long-standing guidance level [of $3 \mu \mathrm{gU} / \mathrm{g}$ ] by roughly an order of magnitude until more is known about subtle physiological effects of small quantities of uranium in the kidneys.” Similar sentiment was expressed by Zhao and Zhao (1990) in recommending a maximum safe uranium burden in the kidney of $0.26 \mu \mathrm{g} / \mathrm{g}$, based on a 10-fold safety factor below mild kidney impairment observed in one human case at $2.6 \mu \mathrm{gU} / \mathrm{g}$. Considering that Leggett noted that the early researchers cited ranges of "much less than $5 \mu \mathrm{g} / \mathrm{g}$, probably 2 to $3 \mu \mathrm{g} / \mathrm{g}$ ” rather than absolute values, the question of a 1.1- $\mu \mathrm{g} / \mathrm{g}$ versus a $0.3-\mu \mathrm{g} / \mathrm{g}$ "no effects" threshold relates more to a matter of an assumed factor for conservativeness rather than actual linkage to significant identifiable effects.

The ICRP provided a brief overview of chemical toxicity in ICRP 78 (1997). Guidance for a maximum single acute intake of 2.5-mg uranium in any 1 day was provided in ICRP 6 (1964), based on work by Eve (1964). However, Eve's analysis was derived from the assumption that a daily intake of $2.5 \mathrm{mg}$ of uranium could be tolerated without harm (i.e., chronic exposure of $2.5 \mathrm{mg} / \mathrm{d}$ ). Of more relevance for acute intakes are the results of human injection studies that have shown an uptake of $0.07 \mathrm{mg}$ of hexavalent uranium per kilogram of body weight produced transient injury and $0.1 \mathrm{mgU} / \mathrm{kg}$ of body weight produced catalasuria and proteinuria (Hursh and Spoor 1973). A renal toxicity threshold of $0.1 \mathrm{mg}$ of acute uptake to blood per kilogram of body weight or a 7-mg acute uptake for Reference Man was used at Hanford during the 1980s and 1990s as a basis for action levels for highly soluble uranium bioassay monitoring. This corresponded to an acute inhalation of $15 \mathrm{mg}$ of Class $\mathrm{D}$ uranium as a threshold for renal toxicity.

The Occupational Safety and Health Administration (OSHA) regulations (29 CFR 1910.1000 Table Z-1) set airborne permissible exposure limits (PELs) for natural uranium of $0.05 \mathrm{mg} / \mathrm{m}^{3}$ for soluble compounds and $0.25 \mathrm{mg} / \mathrm{m}^{3}$ for insoluble compounds, implying daily intake limits of $0.48 \mathrm{mg}(0.5 \mathrm{mg})$ and $2.4 \mathrm{mg}$, respectively. The American Conference on Governmental Industrial Hygienists (ACGIH 1968,1983 ) recommended a threshold limit value (TLV) for air concentration of uranium as $0.2 \mathrm{mg} / \mathrm{m}^{3}$. In addition, ACGIH set a short-term exposure limit (STEL) of $0.6 \mathrm{mg} / \mathrm{m}^{3}$ as an average concentration over a 15-minute period. The OSHA PELs and ACGIH TLVs are time-weighted-average values that apply over an 8-hour workday for a 40-hour workweek and a working lifetime; i.e., they represent a chronic occupational exposure condition. 
Studies of the highly soluble uranyl fluoride $\left(\mathrm{UO}_{2} \mathrm{~F}_{2}\right)$ showed that intravenous doses of $0.01 \mathrm{mg}-\mathrm{U} / \mathrm{kg}$ of body weight for dogs and $0.1 \mathrm{mg}-\mathrm{U} / \mathrm{kg}$ of body weight for rats were nephrotoxic, and that the threshold for injury in man was thought to be about $0.07 \mathrm{mg}-\mathrm{U} / \mathrm{kg}$ of body weight (Morrow et al. 1982). The renal toxicity of uranium varies with the compound form, with toxicity increasing with chemical solubility (Morrow et al. 1982). Based on work by Just (1984), Just and Emler (1984), and Fisher et al. (1990), McGuire (1991) concluded that an acute intake of soluble uranium of $10 \mathrm{mg}$ or less is unlikely to have any detectable (even transient) effects, and that a 40-mg intake (possibly as high as $100 \mathrm{mg}$ ) is likely to be below the level of any permanent effects. McGuire cited as levels corresponding to a threshold for transient renal injury or effect, the values of $0.058 \mathrm{mg}-\mathrm{U} / \mathrm{kg}$ of body weight, $4 \mathrm{mg}$ in total body of 70-kg person (Reference Man), and an acute intake of $8.3 \mathrm{mg}$. The Health Physics Society Standard American National Standard HPS N13.22-1995, Bioassay Programs for Uranium (HPS 1995), repeated McGuire’s tabulations in its appendix.

Recently, Hahn and Roszell reviewed uranium toxicity studies (in Guilmette et al. 2005). Their conclusion was summarized in a table repeated here as Table 7.14.

Table 7.14. Risk Characterization - Chemical Risk to the Kidney ${ }^{(a)}$

\begin{tabular}{ccll}
\hline REG $^{(\text {b) }}$ & $\begin{array}{c}\text { Kidney Uranium Concentration } \\
(\mu \mathrm{g}-U / \mathrm{g}-\mathrm{kidney} \mathrm{tissue)}\end{array}$ & \multicolumn{1}{c}{ Acute Renal Effect } & \multicolumn{1}{c}{ Predicted Outcome } \\
\hline 0 & $\leq 2.2$ & No Detectable Effects & No Detectable Effects \\
1 & $>2.2$ to $\leq 6.4$ & $\begin{array}{l}\text { Possible Transient Indicators of } \\
\text { Renal Dysfunction }\end{array}$ & Not Likely to Become Ill \\
& $>6.4$ to $\leq 18$ & $\begin{array}{l}\text { Possible Protracted Indicators of } \\
\text { Renal Dysfunction }\end{array}$ & May Become Ill \\
& $>18$ & $\begin{array}{l}\text { Possible Severe Clinical } \\
\text { Symptoms of Renal Dysfunction }\end{array}$ & Likely to Become Ill \\
& & & \\
\hline
\end{tabular}

(a) From Guilmette et al. (2005, Table 6.22, p. 163).

(b) REG = Renal Effects Groups.

More recently Kathren and Burklin (2008a) reviewed all of the above studies and others, including human diabetes medical treatment cases involving administration of uranyl nitrate by mouth. They concluded, "Review of the high level acute intake cases described above and especially Table 1 indicates peak kidney burdens of tens of milligrams of uranium, and peak concentrations an order of magnitude or more greater than the 3- $\mu \mathrm{g} \mathrm{U} \mathrm{g}{ }^{-1}$ kidney considered to be the threshold for permanent kidney damage, apparently incurred without significant or long lasting ill effects. This suggests that the $3-\mu \mathrm{g} \mathrm{U} \mathrm{g}{ }^{-1}$ kidney concentration is adequate and quite likely has a safety factor of 10 to 100, as has been suggested by its framers." Kathren and Burklin continued their study in a follow-up article (2008b) in which they recommended the following toxicological action levels for acute intake of soluble low enrichment uranium: 2500-mg, 1400-mg, and 410-mg acute ingestion for life endangerment, irreversible or serious long lasting health effects, and mild transient health effects, respectively, and 500-mg, 100-mg, and 30-mg acute inhalation for the same categories.

When converted to peak concentrations in the kidney, the Kathren and Burklin action levels (18-52, 10, and 3, $\mu$ g U/g kidney) align well with Hahn and Roszell's Renal Effects Groups 3, 2, and 1. Both articles imply that the $1.1 \mu \mathrm{g}-\mathrm{U} / \mathrm{g}$-kidney in use at Hanford should be adequately conservative. The latter 
value is also somewhat consistent with Leggett's recommendation for prudence by using a value well below $3 \mu \mathrm{g}-\mathrm{U} / \mathrm{g}$-kidney. Hence, the HIDP will continue to use $1.1 \mu \mathrm{g}-\mathrm{U} / \mathrm{g}$-kidney in program design as the prudent value to trigger involvement by Occupational Medicine.

\subsection{Internal Dosimetry Factors}

This section contains factors that are useful in making internal dosimetry calculations. The factors included in this section were derived from IMBA and incorporate the models and assumptions described in the preceding section. Their application is intended for those circumstances where such assumptions are appropriate or more specific information is lacking. Variation from these factors is appropriate if sufficient data are available.

\subsubsection{Dose Coefficients}

Dose coefficients, expressed as committed equivalent dose per unit activity of intake (rem per nanocurie of acute intake or rem per nanocurie per day of chronic intake) are a convenient shortcut to estimating doses based on standard assumptions when the magnitude of an intake is known or assumed. The dose coefficients can be converted to rem per mass of intake using the pure isotopic specific activity of Table 7.1 or the isotopic mixture specific activities of Tables 7.2 through 7.4. Acute intake dose coefficients are tabulated in Tables 7.15 through 7.18 for the uranium isotopes ${ }^{238} \mathrm{U},{ }^{236} \mathrm{U}$, ${ }^{235} \mathrm{U}$, and ${ }^{234} \mathrm{U}$ for instantaneous uptake, Type F, M, and S inhalations (5- $\mu \mathrm{m}$-AMAD particle size), and for soluble and insoluble ingestion. The dose from ${ }^{238} \mathrm{U}$ includes contributions from ${ }^{234} \mathrm{Th},{ }^{234 \mathrm{~m}} \mathrm{~Pa}$, and ${ }^{234} \mathrm{~Pa}$ assuming that the progeny are in equilibrium at intake and at all times after intake. The dose from ${ }^{235} \mathrm{U}$ includes contributions from ${ }^{231} \mathrm{Th}$ also assuming equilibrium. The biokinetics of the progeny are assumed to be the same as uranium. These calculations were made using the "merge" or "speed" option in IMBA.

NOTE: The default option in IMBA for ${ }^{238} U$ and ${ }^{235} U$ is the "super-merge" or "accuracy" calculation, so using the default setting will not give the same doses per unit intake as in the following tables. The differences in doses between the merge and super-merge calculations are small (except for GI organs under some conditions) with the merge doses always being equal or greater than the super-merge doses.

Impurity radionuclides present in recycled uranium must be considered in dose assessments. Table 7.19 includes a summary of the contributions to the 50 -year committed effective dose and committed equivalent dose to bone surface and lungs from the presence of reference levels of impurities in recycled uranium. Table 7.19 also shows the percent contribution of all of the impurities relative to dose total, which generally is small compared to other uncertainties in internal dose estimation. However, from wounds, and to a lesser extent inhalation of Type F uranium, the bone surface dose is sufficiently influenced by the impurities such that if a worker's bone surface dose is approaching limits the contribution from impurities should be included in the dose estimate. Contributions to total dose from nonuranium impurity radionuclides may be estimated by multiplying the committed dose from uranium isotopes by 1+ the fractional contribution of the impurities (e.g., 1.15 for effective dose from instantaneous uptake). Alternatively, each impurity can be entered into IMBA as an associated radionuclide in which case IMBA will calculate the total dose from all isotopes of uranium and all impurities. A note of caution if the latter method is used: the associated radionuclides have to be entered in IMBA as a percent of the indicator nuclide, not as a percent or fraction of total uranium mass or activity which 
is how the impurities are listed in Table 7.5. This represents a reasonable assessment of the total dose when impurities are within the historical specifications. If intakes are sufficiently large that depositions of impurity radionuclides may be observable via bioassay measurements, then such measurements should be performed and resulting measurements factored into dose estimates.

Table 7.15. Committed Dose Coefficients for Acute Intakes of ${ }^{238} \mathrm{U}(\mathrm{rem} / \mathrm{nCi})^{(\mathrm{a}, \mathrm{b})}$

\begin{tabular}{|c|c|c|c|c|c|c|}
\hline \multirow[b]{2}{*}{ Organ or Tissue } & \multirow[b]{2}{*}{$\begin{array}{c}\text { Instantaneous } \\
\text { Uptake }\end{array}$} & \multirow{2}{*}{$\begin{array}{c}\text { Type F } \\
\text { Inhalation } \\
(5 \mu \mathrm{m})\end{array}$} & \multirow{2}{*}{$\begin{array}{c}\text { Type M } \\
\text { Inhalation } \\
(5 \mu \mathrm{m})\end{array}$} & \multirow{2}{*}{$\begin{array}{l}\text { Type } S \\
\text { Inhalation } \\
(5 \mu \mathrm{m})\end{array}$} & \multicolumn{2}{|c|}{ Ingestion } \\
\hline & & & & & $f_{1}=2 \mathrm{E}-02$ & $f_{1}=2 \mathrm{E}-03$ \\
\hline Effective & $7.56 \mathrm{E}-03$ & 2.16E-03 & $6.14 \mathrm{E}-03$ & 2.12E-02 & $1.76 \mathrm{E}-04$ & 4.07E-05 \\
\hline Bone Surface & $1.29 \mathrm{E}-01$ & 3.68E-02 & 8.99E-03 & 8.96E-04 & 2.58E-03 & 2.58E-04 \\
\hline Red Marrow & 1.38E-02 & 3.92E-03 & 9.59E-04 & 9.63E-05 & 2.75E-04 & 2.75E-05 \\
\hline Kidneys & 4.72E-02 & $1.34 \mathrm{E}-02$ & 3.29E-03 & $3.41 \mathrm{E}-04$ & 9.43E-04 & 9.43E-05 \\
\hline Lungs & 4.53E-03 & 1.32E-03 & 4.70E-02 & $1.26 \mathrm{E}-01$ & 9.05E-05 & $9.05 \mathrm{E}-06$ \\
\hline ET & 4.53E-03 & $1.31 \mathrm{E}-03$ & 3.99E-02 & $2.40 \mathrm{E}-01$ & 9.05E-05 & $9.05 \mathrm{E}-06$ \\
\hline Liver & $1.77 \mathrm{E}-02$ & 5.04E-03 & 1.23E-03 & $1.24 \mathrm{E}-04$ & 3.53E-04 & 3.54E-05 \\
\hline Lower Large Intestine & 4.53E-03 & 1.36E-03 & 4.50E-04 & $1.85 \mathrm{E}-04$ & 4.12E-04 & 3.36E-04 \\
\hline Colon & 4.53E-03 & 1.33E-03 & 3.99E-04 & $1.26 \mathrm{E}-04$ & 2.92E-04 & $2.14 \mathrm{E}-04$ \\
\hline Upper Large Intestine & 4.53E-03 & $1.31 \mathrm{E}-03$ & 3.61E-04 & 8.22E-05 & 2.00E-04 & $1.21 \mathrm{E}-04$ \\
\hline Small Intestine & 4.53E-03 & $1.29 \mathrm{E}-03$ & 3.22E-04 & 3.80E-05 & 1.09E-04 & 2.76E-05 \\
\hline Stomach & 4.52E-03 & $1.29 \mathrm{E}-03$ & 3.18E-04 & 3.32E-05 & 9.79E-05 & $1.65 \mathrm{E}-05$ \\
\hline Others & 4.53E-03 & $1.29 \mathrm{E}-03$ & 3.15E-04 & 3.02E-05 & 9.05E-05 & $9.06 \mathrm{E}-06$ \\
\hline $\begin{array}{l}\text { (a) Includes contribut } \\
\text { (b) To convert to rem } \\
\text { ET = extrathoracic. }\end{array}$ & $\begin{array}{l}\text { from }{ }^{234} \mathrm{Th},{ }^{234} \\
\text { multiply by sp }\end{array}$ & $\begin{array}{l}\text { and }{ }^{234} \mathrm{~Pa} \text { as } \\
\text { activity of }\end{array}$ & $\begin{array}{l}\text { to always } \\
\text { nCi/mg. }\end{array}$ & quilibrium & se option in & \\
\hline
\end{tabular}

Table 7.16. Committed Dose Coefficients for Acute Intakes of ${ }^{236} \mathrm{U}(\mathrm{rem} / \mathrm{nCi})^{(\mathrm{a})}$

\begin{tabular}{|c|c|c|c|c|c|c|}
\hline \multirow[b]{2}{*}{ Organ or Tissue } & \multirow[b]{2}{*}{$\begin{array}{c}\text { Instantaneous } \\
\text { Uptake }\end{array}$} & \multirow{2}{*}{$\begin{array}{c}\text { Type F } \\
\text { Inhalation } \\
(5 \mu \mathrm{m})\end{array}$} & \multirow{2}{*}{$\begin{array}{c}\text { Type M } \\
\text { Inhalation } \\
(5 \mu \mathrm{m})\end{array}$} & \multirow{2}{*}{$\begin{array}{c}\text { Type S } \\
\text { Inhalation } \\
(5 \mu \mathrm{m})\end{array}$} & \multicolumn{2}{|c|}{ Ingestion } \\
\hline & & & & & $f_{1}=2 \mathrm{E}-02$ & $f_{1}=2 \mathrm{E}-03$ \\
\hline Effective & 7.97E-03 & $2.28 \mathrm{E}-03$ & 7.04E-03 & 2.34E-02 & 1.73E-04 & 2.94E-05 \\
\hline Bone Surface & 1.37E-01 & 3.90E-02 & $9.54 \mathrm{E}-03$ & $9.51 \mathrm{E}-04$ & 2.74E-03 & 2.74E-04 \\
\hline Red Marrow & 1.42E-02 & 4.04E-03 & $9.87 \mathrm{E}-04$ & $9.85 \mathrm{E}-05$ & 2.83E-04 & 2.83E-05 \\
\hline Kidneys & 5.01E-02 & 1.43E-02 & $3.50 \mathrm{E}-03$ & 3.62E-04 & $1.00 \mathrm{E}-03$ & $1.00 \mathrm{E}-04$ \\
\hline Lungs & 4.81E-03 & $1.41 \mathrm{E}-03$ & 5.43E-02 & 1.39E-01 & $9.62 \mathrm{E}-05$ & 9.62E-06 \\
\hline $\mathrm{ET}$ & 4.81E-03 & 1.37E-03 & 4.38E-02 & 2.64E-01 & $9.62 \mathrm{E}-05$ & $9.62 \mathrm{E}-06$ \\
\hline Liver & $1.88 \mathrm{E}-02$ & 5.36E-03 & $1.31 \mathrm{E}-03$ & $1.31 \mathrm{E}-04$ & 3.76E-04 & 3.76E-05 \\
\hline Lower Large Intestine & 4.81E-03 & $1.41 \mathrm{E}-03$ & 4.06E-04 & 1.13E-04 & 2.65E-04 & $1.82 \mathrm{E}-04$ \\
\hline Colon & 4.81E-03 & 1.39E-03 & 3.79E-04 & $8.21 \mathrm{E}-05$ & $2.02 \mathrm{E}-04$ & 1.17E-04 \\
\hline Upper Large Intestine & 4.81E-03 & $1.38 \mathrm{E}-03$ & 3.59E-04 & 5.88E-05 & $1.54 \mathrm{E}-04$ & $6.84 \mathrm{E}-05$ \\
\hline Small Intestine & 4.81E-03 & 1.37E-03 & 3.38E-04 & 3.56E-05 & $1.06 \mathrm{E}-04$ & $1.93 \mathrm{E}-05$ \\
\hline Stomach & 4.81E-03 & $1.37 \mathrm{E}-03$ & 3.36E-04 & 3.28E-05 & $1.00 \mathrm{E}-04$ & 1.35E-05 \\
\hline Others & 4.81E-03 & $1.37 \mathrm{E}-03$ & 3.34E-04 & 3.10E-05 & 9.62E-05 & $9.62 \mathrm{E}-06$ \\
\hline
\end{tabular}

(a) To convert to rem/mg, multiply by specific activity of $64.7 \mathrm{nCi} / \mathrm{mg}$.

ET = extrathoracic. 
Table 7.17. Committed Dose Coefficients for Acute Intakes of ${ }^{235} \mathrm{U}(\mathrm{rem} / \mathrm{nCi})^{(a)}$

\begin{tabular}{|c|c|c|c|c|c|c|}
\hline \multirow[b]{2}{*}{ Organ or Tissue } & \multirow[b]{2}{*}{$\begin{array}{c}\text { Instantaneous } \\
\text { Uptake }\end{array}$} & \multirow{2}{*}{$\begin{array}{c}\text { Type F } \\
\text { Inhalation } \\
(5 \mu \mathrm{m})\end{array}$} & \multirow{2}{*}{$\begin{array}{c}\text { Type } \mathrm{M} \\
\text { Inhalation } \\
(5 \mu \mathrm{m})\end{array}$} & \multirow{2}{*}{$\begin{array}{c}\text { Type S } \\
\text { Inhalation } \\
(5 \mu \mathrm{m})\end{array}$} & \multicolumn{2}{|c|}{ Ingestion } \\
\hline & & & & & $f_{1}=2 \mathrm{E}-02$ & $f_{1}=2 \mathrm{E}-03$ \\
\hline Effective & 7.83E-03 & $2.24 \mathrm{E}-03$ & 6.73E-03 & $2.26 \mathrm{E}-02$ & 1.73E-04 & 3.22E-05 \\
\hline Bone Surface & $1.34 \mathrm{E}-01$ & 3.82E-02 & $9.34 \mathrm{E}-03$ & 9.35E-04 & $2.68 \mathrm{E}-03$ & $2.68 \mathrm{E}-04$ \\
\hline Red Marrow & $1.40 \mathrm{E}-02$ & 3.98E-03 & $9.75 E-04$ & $1.00 \mathrm{E}-04$ & $2.80 \mathrm{E}-04$ & 2.81E-05 \\
\hline Kidneys & 4.91E-02 & $1.40 \mathrm{E}-02$ & 3.42E-03 & $3.56 \mathrm{E}-04$ & $9.81 \mathrm{E}-04$ & 9.82E-05 \\
\hline Lungs & 4.72E-03 & $1.38 \mathrm{E}-03$ & 5.18E-02 & $1.35 \mathrm{E}-01$ & 9.43E-05 & $9.44 \mathrm{E}-06$ \\
\hline ET & 4.72E-03 & 1.37E-03 & 4.26E-02 & $2.56 \mathrm{E}-01$ & $9.43 E-05$ & $9.43 E-06$ \\
\hline Liver & $1.84 \mathrm{E}-02$ & $5.24 \mathrm{E}-03$ & $1.28 \mathrm{E}-03$ & $1.34 \mathrm{E}-04$ & $3.68 \mathrm{E}-04$ & 3.68E-05 \\
\hline Lower Large Intestine & 4.72E-03 & 1.39E-03 & 4.14E-04 & $1.30 \mathrm{E}-04$ & $3.00 \mathrm{E}-04$ & 2.19E-04 \\
\hline Colon & 4.72E-03 & 1.37E-03 & $3.82 \mathrm{E}-04$ & 9.29E-05 & 2.23E-04 & $1.41 \mathrm{E}-04$ \\
\hline Upper Large Intestine & 4.72E-03 & $1.36 \mathrm{E}-03$ & 3.58E-04 & 6.49E-05 & 1.65E-04 & 8.12E-05 \\
\hline Small Intestine & 4.72E-03 & 1.35E-03 & 3.33E-04 & 3.66E-05 & 1.07E-04 & 2.18E-05 \\
\hline Stomach & 4.71E-03 & $1.34 \mathrm{E}-03$ & 3.30E-04 & $3.56 \mathrm{E}-05$ & 9.92E-05 & $1.43 \mathrm{E}-05$ \\
\hline Others & 4.72E-03 & $1.35 \mathrm{E}-03$ & 3.29E-04 & 3.63E-05 & $9.45 \mathrm{E}-05$ & $9.49 \mathrm{E}-06$ \\
\hline
\end{tabular}

(a) To convert to rem/mg, multiply by specific activity of $2.16 \mathrm{nCi} / \mathrm{mg}$.

ET = extrathoracic.

Table 7.18. Committed Dose Coefficients for Acute Intakes of ${ }^{234} \mathrm{U}(\mathrm{rem} / \mathrm{nCi})^{(\mathrm{a})}$

\begin{tabular}{|c|c|c|c|c|c|c|}
\hline \multirow[b]{2}{*}{ Organ or Tissue } & \multirow[b]{2}{*}{$\begin{array}{c}\text { Instantaneous } \\
\text { Uptake }\end{array}$} & \multirow{2}{*}{$\begin{array}{c}\text { Type } \mathrm{F} \\
\text { Inhalation } \\
(5 \mu \mathrm{m})\end{array}$} & \multirow{2}{*}{$\begin{array}{c}\text { Type M } \\
\text { Inhalation } \\
(5 \mu \mathrm{m})\end{array}$} & \multirow{2}{*}{$\begin{array}{c}\text { Type } S \\
\text { Inhalation } \\
(5 \mu \mathrm{m})\end{array}$} & \multicolumn{2}{|c|}{ Ingestion } \\
\hline & & & & & $f_{1}=2 \mathrm{E}-02$ & $f_{1}=2 \mathrm{E}-03$ \\
\hline Effective & $8.42 \mathrm{E}-03$ & $2.41 \mathrm{E}-03$ & $7.80 \mathrm{E}-03$ & $2.53 \mathrm{E}-02$ & $1.82 \mathrm{E}-04$ & $3.10 \mathrm{E}-05$ \\
\hline Bone Surface & $1.45 \mathrm{E}-01$ & 4.12E-02 & $1.01 \mathrm{E}-02$ & $1.00 \mathrm{E}-03$ & 2.89E-03 & 2.89E-04 \\
\hline Red Marrow & $1.49 \mathrm{E}-02$ & 4.26E-03 & $1.04 \mathrm{E}-03$ & $1.04 \mathrm{E}-04$ & 2.99E-04 & 2.99E-05 \\
\hline Kidneys & 5.30E-02 & $1.51 \mathrm{E}-02$ & 3.69E-03 & 3.83E-04 & $1.06 \mathrm{E}-03$ & $1.06 \mathrm{E}-04$ \\
\hline Lungs & 5.08E-03 & 1.49E-03 & 6.04E-02 & $1.52 \mathrm{E}-01$ & 1.02E-04 & $1.02 \mathrm{E}-05$ \\
\hline ET & $5.08 \mathrm{E}-03$ & $1.45 \mathrm{E}-03$ & 4.62E-02 & $2.78 \mathrm{E}-01$ & $1.02 \mathrm{E}-04$ & $1.02 \mathrm{E}-05$ \\
\hline Liver & $1.98 \mathrm{E}-02$ & $5.66 \mathrm{E}-03$ & $1.38 \mathrm{E}-03$ & 1.39E-04 & 3.97E-04 & 3.97E-05 \\
\hline Lower Large Intestine & $5.08 \mathrm{E}-03$ & $1.48 \mathrm{E}-03$ & 4.28E-04 & 1.19E-04 & 2.81E-04 & $1.92 \mathrm{E}-04$ \\
\hline Colon & $5.08 \mathrm{E}-03$ & $1.47 \mathrm{E}-03$ & $4.00 \mathrm{E}-04$ & 8.68E-05 & 2.14E-04 & $1.24 \mathrm{E}-04$ \\
\hline Upper Large Intestine & 5.08E-03 & $1.46 \mathrm{E}-03$ & 3.79E-04 & $6.22 \mathrm{E}-05$ & $1.63 \mathrm{E}-04$ & 7.23E-05 \\
\hline Small Intestine & 5.08E-03 & 1.45E-03 & 3.57E-04 & $3.76 \mathrm{E}-05$ & $1.12 \mathrm{E}-04$ & $2.04 \mathrm{E}-05$ \\
\hline Stomach & $5.08 \mathrm{E}-03$ & $1.45 \mathrm{E}-03$ & 3.55E-04 & 3.47E-05 & $1.06 \mathrm{E}-04$ & $1.43 \mathrm{E}-05$ \\
\hline Others & 5.08E-03 & $1.45 \mathrm{E}-03$ & 3.53E-04 & 3.27E-05 & $1.02 \mathrm{E}-04$ & $1.02 \mathrm{E}-05$ \\
\hline
\end{tabular}

(a) To convert to rem/mg, multiply by specific activity of $6,250 \mathrm{nCi} / \mathrm{mg}$.

$\mathrm{ET}=$ extrathoracic.

Table 7.20 summarizes dose coefficients for natural uranium, depleted uranium, and recycled uranium mixtures, and it tabulates dose coefficients for acute intakes of uranium mixtures in terms of committed effective or equivalent dose per unit mass of uranium intake. These units were selected because the monitoring for such mixtures has historically been performed using elemental uranium mass bioassay measurements. 
Table 7.19. Dose Coefficients for Slightly Enriched Recycled Uranium with Impurities

\begin{tabular}{|c|c|c|c|c|c|c|}
\hline & \multirow[b]{2}{*}{$\begin{array}{l}\text { Instantaneous } \\
\text { Uptake }\end{array}$} & \multirow{2}{*}{$\begin{array}{c}\text { Type F } \\
\text { Inhalation } \\
(5 \mu \mathrm{m})\end{array}$} & \multirow{2}{*}{$\begin{array}{c}\text { Type M } \\
\text { Inhalation } \\
(5 \mu \mathrm{m})\end{array}$} & \multirow{2}{*}{$\begin{array}{c}\text { Type S } \\
\text { Inhalation } \\
(5 \mu \mathrm{m})\end{array}$} & \multicolumn{2}{|c|}{ Ingestion } \\
\hline & & & & & $f_{1}=2 \mathrm{E}-02$ & $f_{1}=2 \mathrm{E}-03$ \\
\hline \multicolumn{7}{|c|}{ Committed Effective Dose Coefficients (rem/nCi U) } \\
\hline U only & 8.07E-03 & $2.31 \mathrm{E}-03$ & 7.13E-03 & 2.36E-02 & 1.79E-04 & $3.45 \mathrm{E}-05$ \\
\hline \multicolumn{7}{|l|}{ Impurities } \\
\hline $\mathrm{Pu}$ alpha ${ }^{(\mathrm{a})}$ & 8.48E-04 & $5.41 \mathrm{E}-05$ & $5.41 \mathrm{E}-05$ & $1.44 \mathrm{E}-05$ & 8.88E-08 & $1.51 \mathrm{E}-08$ \\
\hline${ }^{237} \mathrm{~Np}^{(\mathrm{b})}$ & 3.33E-04 & 2.37E-05 & 2.37E-05 & $1.31 \mathrm{E}-05$ & 1.73E-07 & 1.73E-07 \\
\hline Thorium $^{(\mathrm{c})}$ & 4.80E-05 & 1.35E-05 & 2.99E-06 & 5.03E-07 & 2.41E-08 & 9.67E-09 \\
\hline${ }^{99} \mathrm{Tc}$ & 7.03E-07 & 3.27E-07 & 2.51E-06 & 6.31E-06 & 6.37E-07 & 3.32E-07 \\
\hline Total with impurities & 9.30E-03 & 2.40E-03 & 7.21E-03 & 2.36E-02 & 1.80E-04 & 3.53E-05 \\
\hline$\%$ contribution of impurities & 15 & 4 & 1 & 0.1 & 0.5 & 2 \\
\hline \multicolumn{7}{|c|}{ Committed Bone Surface Dose Coefficients (rem/nCi U) } \\
\hline U only & 1.38E-01 & 3.94E-02 & & & & \\
\hline \multicolumn{7}{|l|}{ Impurities } \\
\hline Pu alpha ${ }^{(a)}$ & 2.84E-02 & $1.76 \mathrm{E}-03$ & & & & \\
\hline${ }^{237} \mathrm{~Np}^{(\mathrm{b})}$ & $1.76 \mathrm{E}-02$ & 1.09E-03 & & & & \\
\hline Thorium $^{(\mathrm{c})}$ & 2.93E-03 & 8.24E-04 & & & & \\
\hline${ }^{99} \mathrm{Tc}$ & 6.29E-08 & 2.77E-08 & & & & \\
\hline Total with impurities & $1.85 \mathrm{E}-01$ & 4.31E-02 & & & & \\
\hline$\%$ contribution of impurities & 36 & 9 & & & & \\
\hline \multicolumn{7}{|c|}{ Committed Lung Dose Coefficients (rem/nCi U) } \\
\hline U only & & & & $1.42 \mathrm{E}-01$ & & \\
\hline \multicolumn{7}{|l|}{ Impurities } \\
\hline $\mathrm{Pu}$ alpha ${ }^{\text {(a) }}$ & & & & 7.96E-05 & & \\
\hline${ }^{237} \mathrm{~Np}$ & & & & $6.73 \mathrm{E}-05$ & & \\
\hline Thorium $^{(\mathrm{c})}$ & & & & 7.8E-06 & & \\
\hline${ }^{99} \mathrm{Tc}$ & & & & 5.12E-05 & & \\
\hline Total with impurities & & & & $1.42 \mathrm{E}-01$ & & \\
\hline$\%$ contribution of impurities & & & & 0.1 & & \\
\hline \multicolumn{7}{|c|}{$\begin{array}{l}\text { (a) Based on 20-year-aged weapons-grade mixture. See Table 8.19. Type M plutonium used for Type F and Type M uranium. } \\
\text { (b) Type M neptunium used for Type F and Type M uranium. } \\
\text { (c) Assumed to be }{ }^{232} \mathrm{Th} \text {. Dose coefficients from IMBA v. } 4.0 .43 \text {, which are known to be biased high. }\end{array}$} \\
\hline
\end{tabular}

\subsubsection{Comparison with Published Dose Coefficients}

A comparison of committed effective dose coefficients between IMBA-derived coefficients and those published in ICRP 68 (ICRP 1994a) is provided in Table 7.21. IMBA provides dose coefficients with three figures, whereas the ICRP 68 values are listed with only two figures. Taking the rounding of numbers into account, most of the differences are minor. Noticeable differences occur for ingestion intakes for the two isotopes where the merge option was used in IMBA, ${ }^{235} \mathrm{U}$ and ${ }^{238} \mathrm{U}$, with the IMBA coefficients being higher than the ICRP 68 coefficients. The merge option in IMBA assumes that the intermediate half-lived progeny are in equilibrium at intake, a better assumption for old uranium found at Hanford. 
Table 7.20. Committed Dose Coefficients for Acute Intakes of Uranium Mixtures (rem/mg-U)

\begin{tabular}{|c|c|c|c|c|c|c|}
\hline \multirow[b]{2}{*}{ Organ or Tissue } & \multirow[b]{2}{*}{$\begin{array}{l}\text { Instantaneous } \\
\text { Uptake }\end{array}$} & \multirow{2}{*}{$\begin{array}{c}\text { Type F } \\
\text { Inhalation } \\
(5 \mu \mathrm{m})\end{array}$} & \multirow{2}{*}{$\begin{array}{c}\text { Type M } \\
\text { Inhalation } \\
(5 \mu \mathrm{m})\end{array}$} & \multirow{2}{*}{$\begin{array}{c}\text { Type S } \\
\text { Inhalation } \\
(5 \mu \mathrm{m})\end{array}$} & \multicolumn{2}{|c|}{ Ingestion } \\
\hline & & & & & $f_{1}=2 \mathrm{E}-02$ & $f_{1}=2 \mathrm{E}-03$ \\
\hline \multicolumn{7}{|c|}{ Natural Uranium } \\
\hline Effective & $5.45 \mathrm{E}-03$ & $1.56 \mathrm{E}-03$ & 4.75E-03 & 1.59E-02 & $1.18 \mathrm{E}-04$ & 2.02E-05 \\
\hline Bone Surface & 9.33E-02 & $2.66 \mathrm{E}-02$ & $6.51 \mathrm{E}-03$ & 6.49E-04 & 1.87E-03 & $1.87 \mathrm{E}-04$ \\
\hline Red Marrow & 9.79E-03 & 2.79E-03 & $6.82 \mathrm{E}-04$ & $6.84 \mathrm{E}-05$ & $1.96 \mathrm{E}-04$ & $1.96 \mathrm{E}-05$ \\
\hline Kidneys & 3.41E-02 & 9.73E-03 & 2.38E-03 & $2.47 \mathrm{E}-04$ & $6.82 \mathrm{E}-04$ & $6.82 \mathrm{E}-05$ \\
\hline Lungs & $3.28 \mathrm{E}-03$ & 9.59E-04 & 3.66E-02 & $9.49 \mathrm{E}-02$ & $6.56 \mathrm{E}-05$ & 6.56E-06 \\
\hline ET & $3.28 \mathrm{E}-03$ & 9.37E-04 & 2.94E-02 & 1.77E-01 & $6.56 \mathrm{E}-05$ & $6.56 \mathrm{E}-06$ \\
\hline Liver & $1.28 \mathrm{E}-02$ & $3.65 E-03$ & 8.93E-04 & 8.98E-05 & $2.56 \mathrm{E}-04$ & $2.56 \mathrm{E}-05$ \\
\hline Lower Large Intestine & $3.28 \mathrm{E}-03$ & $9.58 \mathrm{E}-04$ & $2.78 \mathrm{E}-04$ & 8.05E-05 & $1.84 \mathrm{E}-04$ & 1.27E-04 \\
\hline Colon & $3.28 \mathrm{E}-03$ & $9.49 \mathrm{E}-04$ & 2.59E-04 & $5.82 \mathrm{E}-05$ & $1.39 \mathrm{E}-04$ & $8.14 \mathrm{E}-05$ \\
\hline Upper Large Intestine & $3.28 \mathrm{E}-03$ & $9.43 \mathrm{E}-04$ & 2.45E-04 & 4.12E-05 & 1.05E-04 & 4.70E-05 \\
\hline Small Intestine & $3.28 \mathrm{E}-03$ & $9.36 \mathrm{E}-04$ & 2.31E-04 & $2.44 \mathrm{E}-05$ & 7.21E-05 & $1.32 \mathrm{E}-05$ \\
\hline Stomach & 3.28E-03 & 9.35E-04 & 2.29E-04 & $2.26 \mathrm{E}-05$ & 6.82E-05 & $9.21 \mathrm{E}-06$ \\
\hline Others & $3.28 \mathrm{E}-03$ & 9.35E-04 & $2.28 \mathrm{E}-04$ & 2.15E-05 & $6.56 \mathrm{E}-05$ & 6.56E-06 \\
\hline \multicolumn{7}{|c|}{ Depleted Uranium } \\
\hline Effective & 3.09E-03 & 8.84E-04 & 2.57E-03 & 8.78E-03 & $6.71 \mathrm{E}-05$ & 1.15E-05 \\
\hline Bone Surface & 5.28E-02 & $1.51 \mathrm{E}-02$ & $3.68 \mathrm{E}-03$ & 3.67E-04 & $1.06 \mathrm{E}-03$ & $1.06 \mathrm{E}-04$ \\
\hline Red Marrow & 5.60E-03 & $1.60 \mathrm{E}-03$ & $3.90 \mathrm{E}-04$ & 3.92E-05 & 1.12E-04 & 1.12E-05 \\
\hline Kidneys & 1.93E-02 & $5.50 \mathrm{E}-03$ & $1.35 \mathrm{E}-03$ & $1.40 \mathrm{E}-04$ & $3.86 \mathrm{E}-04$ & $3.86 \mathrm{E}-05$ \\
\hline Lungs & 1.85E-03 & $5.41 \mathrm{E}-04$ & 1.97E-02 & $5.24 \mathrm{E}-02$ & 3.71E-05 & 3.71E-06 \\
\hline ET & $1.85 \mathrm{E}-03$ & 5.30E-04 & $1.64 \mathrm{E}-02$ & $9.90 \mathrm{E}-02$ & 3.71E-05 & 3.71E-06 \\
\hline Liver & 7.24E-03 & 2.06E-03 & 5.05E-04 & 5.09E-05 & 1.45E-04 & $1.45 \mathrm{E}-05$ \\
\hline Lower Large Intestine & $1.86 \mathrm{E}-03$ & $5.42 \mathrm{E}-04$ & $1.58 \mathrm{E}-04$ & 4.70E-05 & $1.05 \mathrm{E}-04$ & 7.25E-05 \\
\hline Colon & 1.85E-03 & 5.37E-04 & 1.47E-04 & 3.38E-05 & 7.91E-05 & 4.65E-05 \\
\hline Upper Large Intestine & $1.85 \mathrm{E}-03$ & 5.33E-04 & 1.39E-04 & 2.37E-05 & $5.96 \mathrm{E}-05$ & 2.66E-05 \\
\hline Small Intestine & $1.85 \mathrm{E}-03$ & 5.29E-04 & $1.31 \mathrm{E}-04$ & 1.39E-05 & $4.08 \mathrm{E}-05$ & 7.45E-06 \\
\hline Stomach & $1.85 \mathrm{E}-03$ & 5.29E-04 & 1.30E-04 & 1.29E-05 & 3.86E-05 & 5.20E-06 \\
\hline Others & 1.85E-03 & $5.29 \mathrm{E}-04$ & $1.29 \mathrm{E}-04$ & $1.23 \mathrm{E}-05$ & $3.71 \mathrm{E}-05$ & $3.71 \mathrm{E}-06$ \\
\hline \multicolumn{7}{|c|}{$\begin{array}{l}\text { Slightly Enriched Recycled Uranium (Instantaneous uptake and Type F inhalation values include impurity contributions. } \\
\text { Impurity contributions to Type M, Type S, and ingestion values are insignificant.) }\end{array}$} \\
\hline Effective & 8.44E-03 & 2.18E-03 & $6.50 \mathrm{E}-03$ & 2.15E-02 & $1.63 \mathrm{E}-04$ & $3.14 \mathrm{E}-05$ \\
\hline Bone Surface & 1.69E-01 & 3.92E-02 & 8.77E-03 & 8.75E-04 & $2.52 \mathrm{E}-03$ & $2.52 \mathrm{E}-04$ \\
\hline Red Marrow & 1.55E-02 & 4.10E-03 & 9.17E-04 & 9.19E-05 & 2.63E-04 & 2.63E-05 \\
\hline Kidneys & 4.74E-02 & 1.32E-02 & $3.22 \mathrm{E}-03$ & 3.33E-04 & $9.22 \mathrm{E}-04$ & $9.22 \mathrm{E}-05$ \\
\hline Lungs & 4.49E-03 & $1.35 \mathrm{E}-03$ & 5.01E-02 & $1.29 \mathrm{E}-01$ & 8.84E-05 & 8.84E-06 \\
\hline $\mathrm{ET}$ & 4.49E-03 & $1.31 \mathrm{E}-03$ & 3.98E-02 & 2.39E-01 & 8.84E-05 & 8.84E-06 \\
\hline Liver & 1.77E-02 & 4.95E-03 & $1.20 \mathrm{E}-03$ & $1.21 \mathrm{E}-04$ & 3.45E-04 & $3.45 \mathrm{E}-05$ \\
\hline Lower Large Intestine & 4.49E-03 & $1.31 \mathrm{E}-03$ & $3.96 \mathrm{E}-04$ & $1.30 \mathrm{E}-04$ & 2.99E-04 & $2.23 \mathrm{E}-04$ \\
\hline Colon & 4.49E-03 & 1.30E-03 & 3.63E-04 & $9.22 \mathrm{E}-05$ & $2.21 \mathrm{E}-04$ & $1.43 \mathrm{E}-04$ \\
\hline Upper Large Intestine & 4.49E-03 & 1.29E-03 & 3.38E-04 & $6.32 \mathrm{E}-05$ & $1.60 \mathrm{E}-04$ & 8.20E-05 \\
\hline Small Intestine & 4.49E-03 & $1.26 \mathrm{E}-03$ & 3.13E-04 & 3.43E-05 & $1.00 \mathrm{E}-04$ & 2.10E-05 \\
\hline Stomach & 4.49E-03 & $1.27 \mathrm{E}-03$ & $3.10 \mathrm{E}-04$ & 3.10E-05 & 9.33E-05 & 1.37E-05 \\
\hline Others & 4.49E-03 & $1.26 \mathrm{E}-03$ & $3.08 \mathrm{E}-04$ & 2.89E-05 & 8.85E-05 & 8.85E-06 \\
\hline
\end{tabular}

PNNL-MA-860 Chapter 7.0

Page 7.28
Issued for implementation effective 01/01/2010

Supersedes: January 2003 
Table 7.21. Comparison of Committed Effective Dose Coefficients (Sv/Bq) $)^{(a)}$

\begin{tabular}{|c|c|c|}
\hline Radionuclide/Intake Mode & $\begin{array}{l}\text { IMBA Effective } \\
\text { Dose Coefficient }\end{array}$ & $\begin{array}{l}\text { ICRP } 68 \text { Effective } \\
\text { Dose Coefficient }\end{array}$ \\
\hline${ }^{234} \mathrm{U}$, Type F & $6.51 \mathrm{E}-07$ & $6.4 \mathrm{E}-07$ \\
\hline${ }^{234} \mathrm{U}$, Type $\mathrm{M}$ & 2.11E-06 & $2.1 \mathrm{E}-06$ \\
\hline${ }^{234} \mathrm{U}$, Type S & 6.83E-06 & $6.8 \mathrm{E}-06$ \\
\hline${ }^{234} \mathrm{U}$, soluble ingestion & 4.93E-08 & $4.9 \mathrm{E}-08$ \\
\hline${ }^{234} \mathrm{U}$, insoluble ingestion & 8.39E-09 & 8.3E-09 \\
\hline${ }^{235} \mathrm{U},{ }^{(\mathrm{b})}$ Type $\mathrm{F}$ & 6.05E-07 & $6.0 \mathrm{E}-07$ \\
\hline${ }^{235} \mathrm{U},{ }^{(\mathrm{b})}$ Type $\mathrm{M}$ & $1.82 \mathrm{E}-06$ & $1.8 \mathrm{E}-06$ \\
\hline${ }^{235} \mathrm{U},{ }^{(\mathrm{b})}$ Type $\mathrm{S}$ & 6.11E-06 & $6.1 \mathrm{E}-06$ \\
\hline${ }^{235} \mathrm{U},{ }^{(b)}$ soluble ingestion & 4.67E-08 & 4.6E-08 \\
\hline${ }^{235} \mathrm{U},{ }^{(\mathrm{b})}$ insoluble ingestion & 8.70E-09 & 8.3E-09 \\
\hline${ }^{236} \mathrm{U}$, Type F & 6.16E-07 & $6.1 \mathrm{E}-07$ \\
\hline${ }^{236} \mathrm{U}$, Type $\mathrm{M}$ & $1.90 \mathrm{E}-06$ & $1.9 \mathrm{E}-06$ \\
\hline${ }^{236} \mathrm{U}$, Type S & 6.32E-06 & 6.3E-06 \\
\hline${ }^{236} \mathrm{U}$, soluble ingestion & 4.67E-08 & 4.6E-08 \\
\hline${ }^{236} \mathrm{U}$, insoluble ingestion & 7.94E-09 & 7.9E-09 \\
\hline${ }^{238} \mathrm{U},{ }^{(\mathrm{b})}$ Type $\mathrm{F}$ & 5.85E-07 & $5.8 \mathrm{E}-07$ \\
\hline${ }^{238} \mathrm{U},{ }^{(\mathrm{b})}$ Type $\mathrm{M}$ & $1.66 \mathrm{E}-06$ & $1.6 \mathrm{E}-06$ \\
\hline${ }^{238} \mathrm{U},{ }^{(\mathrm{b})}$ Type $\mathrm{S}$ & 5.73E-06 & 5.7E-06 \\
\hline${ }^{238} \mathrm{U}$,(b) soluble ingestion & 4.78E-08 & $4.4 \mathrm{E}-08$ \\
\hline${ }^{238} \mathrm{U}{ }^{(\mathrm{b})}$ insoluble ingestion & $1.10 \mathrm{E}-08$ & 7.6E-09 \\
\hline
\end{tabular}

(a) 5- $\mu$ m-AMAD particle size for inhalations.

(b) Merge option.

\subsubsection{Annual Limits on Intake and Derived Air Concentrations}

Derived air concentrations (DACs) from Title 10 of the Code of Federal Regulations Part 835 (10 CFR 835) Appendix A (2007) are shown in Table 7.22 for pure radionuclides. Annual limits on intake (ALIs) for the same radionuclides are also listed in Table 7.22. The inhalation ALIs were calculated from

$$
\mathrm{ALI}=\frac{\text { Dose Limit }}{\text { Dose Coefficient }}
$$

where the ALI is in $\mu \mathrm{Ci}$. The instantaneous uptake and ingestion ALIs were determined using IMBA to find the intake that produced the limiting dose of 5,000 mrem committed effective dose or 50,000 mrem committed organ equivalent dose, rounded to two figures. 
Table 7.22. Derived Air Concentrations and Annual Limits on Intake for Uranium Isotopes

\begin{tabular}{|c|c|c|c|c|}
\hline & ${ }^{234} \mathrm{U}$ & ${ }^{235} \mathrm{U}$ & $\mathrm{U}-236$ & $\mathrm{U}-238$ \\
\hline \multicolumn{5}{|c|}{ Derived Air Concentrations $(\mu \mathrm{Ci} / \mathrm{ml})$ and Limiting Organ or Tissue ${ }^{(a)}$} \\
\hline Type F (bone surface) & $5 \mathrm{E}-10$ & 5E-10 & $5 \mathrm{E}-10$ & $5 \mathrm{E}-10$ \\
\hline Type M (whole body) & $2 \mathrm{E}-10$ & $3 \mathrm{E}-10$ & $2 \mathrm{E}-10$ & $3 \mathrm{E}-10$ \\
\hline Type S (ET) & 7E-11 & 8E-11 & $7 \mathrm{E}-11$ & $8 E-11$ \\
\hline \multicolumn{5}{|c|}{ Annual Limits on Intake $(\mu \mathrm{Ci})$} \\
\hline $\begin{array}{l}\text { Instantaneous uptake (bone } \\
\text { surface) })^{(\mathrm{b})}\end{array}$ & 0.35 & $0.37^{(\mathrm{c})}$ & 0.36 & $0.39^{(c)}$ \\
\hline Type F Inhalation (bone surface) & 1.2 & $1.3^{(\mathrm{c})}$ & $1.3^{(\mathrm{c})}$ & $1.4^{(\mathrm{c})}$ \\
\hline Type M Inhalation (effective) & 0.64 & $0.74^{(\mathrm{c})}$ & 0.71 & $0.81^{(\mathrm{c})}$ \\
\hline Type S Inhalation (ET) & 0.18 & 0.20 & 0.19 & 0.21 \\
\hline Soluble ingestion (bone surface) & 17 & 19 & 18 & 19 \\
\hline Insoluble ingestion (whole body) & 160 & 160 & 170 & 120 \\
\hline \multicolumn{5}{|c|}{$\begin{array}{l}\text { (a) From } 10 \text { CFR } 835 \text { Appendix A (2007). } \\
\text { (b) Assumes single acute intake. } \\
\text { (c) Chemical toxicity based on } 1.1 \mu \text { g-U/g-kidney would be more limiting for the pure isotope. } \\
\text { ET = extrathoracic. }\end{array}$} \\
\hline
\end{tabular}

\subsubsection{Derived Reference Levels}

Hanford reference and derived reference levels have been tabulated for recycled uranium. Screening and investigation levels have been calculated based on committed effective doses of 10 mrem and 100 mrem, respectively. A dose compliance level has been calculated based on 50 rem to the bone surfaces for instantaneous uptake and Type F inhalation, on 5-rem committed effective dose for Type M inhalation, and 50 rem to the extrathoracic tissue (ET) for Type S inhalations. The chemical toxicity threshold was calculated based on a peak kidney concentration of $1.1 \mu \mathrm{g}-\mathrm{U} / \mathrm{g}$-kidney, giving a total kidney burden of $341 \mu \mathrm{g}$ (adult male kidney mass) and applying the most limiting kidney retention fraction, which occurs at about 18 hours after an instantaneous uptake or acute Type F or M inhalation. The peak kidney concentration occurs at about 24 hours for an acute Type S inhalation or either of the ingestions. The Hanford chemical toxicity threshold intake is more limiting than the radiological compliance intake for instantaneous uptake, for Type F and M inhalations, and both of the ingestions. Stated another way, the radiological compliance intake is more limiting only for Type $\mathrm{S}$ inhalation.

Reference level inhalation intakes and associated daily urinary excretion values are tabulated for instantaneous uptake, Type F, M, and S inhalations, and soluble and insoluble ingestions of slightly enriched recycled uranium in Tables 7.23 through 7.28, respectively. The derived urine excretion levels shown in Tables 7.23 through 7.28 represent the excess urinary excretion associated with the indicated intake above the natural background. To account for the anticipated natural uranium background at Hanford, $0.021 \mu \mathrm{g} / \mathrm{d}$ (rounding to 0.02 is appropriate) should be added to the tabulated values. For an instantaneous uptake (e.g., a wound with soluble uranium) and inhalation of Type F material, the screening level can be detected up to at least 90 days after intake and the chemical toxicity threshold level can be detected for at least 180 days after intake; beyond those periods anything detected should be investigated. For a Type M inhalation, the screening level can be detected up to a few days short of 90 days after intake, but the chemical toxicity threshold can be detected for up to 2 years after intake, and 
the radiological compliance level can be detected for up to 5 years after intake. For Type $S$ inhalation, for practical purposes the screening level can not be detected except for very shortly after an intake so anything detected essentially exceeds the screening level, but the radiological compliance level can be detected for up to 4 years after intake. For an ingestion of soluble material, the screening level can be detected for 150 days after intake and the chemical toxicity threshold can be detected for 220 days after intake. For an ingestion of insoluble material, the screening level can be detected for about 90 days after intake and the chemical toxicity threshold can be detected for about 220 days after intake.

Table 7.23. Reference Level Intakes and Urinary Excretion ${ }^{(a)}$ Derived Reference Levels for Instantaneous Uptake of Recycled Uranium

\begin{tabular}{|c|c|c|c|c|}
\hline \multicolumn{5}{|c|}{ Instantaneous Uptake (mg) } \\
\hline & $\begin{array}{c}\text { Screening Level, } \\
10 \text {-mrem } \\
\text { Committed } \\
\text { Effective Dose } \\
\end{array}$ & $\begin{array}{c}\text { Investigation } \\
\text { Level, 100-mrem } \\
\text { Committed } \\
\text { Effective Dose } \\
\end{array}$ & $\begin{array}{l}\text { Compliance Level, } \\
\text { 50-rem Committed } \\
\text { Equivalent Dose to } \\
\text { Bone Surface }\end{array}$ & $\begin{array}{l}\text { Chemical Toxicity } \\
\text { Threshold Level }^{(\mathrm{b})}\end{array}$ \\
\hline & $1.18 \mathrm{E}+00$ & $1.18 \mathrm{E}+01$ & $2.96 \mathrm{E}+02$ & $2.99 \mathrm{E}+00$ \\
\hline \multicolumn{5}{|c|}{ Derived Urine Excretion Levels $(\mu \mathrm{g} / \mathrm{d})$} \\
\hline $\begin{array}{l}\text { Days Post } \\
\text { Intake }\end{array}$ & $\begin{array}{c}\text { Derived Screening } \\
\text { Level }\end{array}$ & $\begin{array}{c}\text { Derived } \\
\text { Investigation Level }\end{array}$ & $\begin{array}{c}\text { Derived } \\
\text { Compliance Level }\end{array}$ & $\begin{array}{l}\text { Derived Chemical } \\
\text { Toxicity Level }\end{array}$ \\
\hline 1 & $7.64 \mathrm{E}+02$ & $7.64 \mathrm{E}+03$ & $1.91 \mathrm{E}+05$ & $1.93 \mathrm{E}+03$ \\
\hline 2 & $2.62 \mathrm{E}+01$ & $2.62 \mathrm{E}+02$ & $6.54 \mathrm{E}+03$ & $6.61 \mathrm{E}+01$ \\
\hline 3 & $2.13 \mathrm{E}+01$ & $2.13 \mathrm{E}+02$ & $5.33 \mathrm{E}+03$ & $5.38 \mathrm{E}+01$ \\
\hline 4 & $1.93 \mathrm{E}+01$ & $1.93 \mathrm{E}+02$ & $4.82 \mathrm{E}+03$ & $4.87 \mathrm{E}+01$ \\
\hline 5 & $1.75 \mathrm{E}+01$ & $1.75 \mathrm{E}+02$ & $4.37 \mathrm{E}+03$ & $4.42 \mathrm{E}+01$ \\
\hline 6 & $1.59 \mathrm{E}+01$ & $1.59 \mathrm{E}+02$ & $3.98 \mathrm{E}+03$ & $4.02 \mathrm{E}+01$ \\
\hline 7 & $1.45 \mathrm{E}+01$ & $1.45 \mathrm{E}+02$ & $3.63 \mathrm{E}+03$ & $3.67 \mathrm{E}+01$ \\
\hline 14 & $8.07 \mathrm{E}+00$ & $8.07 \mathrm{E}+01$ & $2.02 E+03$ & $2.04 \mathrm{E}+01$ \\
\hline 30 & $2.83 \mathrm{E}+00$ & $2.83 \mathrm{E}+01$ & $7.07 \mathrm{E}+02$ & $7.14 \mathrm{E}+00$ \\
\hline 60 & 9.42E-01 & $9.42 \mathrm{E}+00$ & $2.35 \mathrm{E}+02$ & $2.38 \mathrm{E}+00$ \\
\hline 90 & $4.98 \mathrm{E}-01$ & $4.98 \mathrm{E}+00$ & $1.24 \mathrm{E}+02$ & $1.26 \mathrm{E}+00$ \\
\hline 180 & 1.30E-01 & $1.30 \mathrm{E}+00$ & $3.24 \mathrm{E}+01$ & 3.27E-01 \\
\hline $1 \mathrm{y}$ & 2.30E-02 & 2.30E-01 & $5.75 \mathrm{E}+00$ & 5.81E-02 \\
\hline $2 y$ & $1.08 \mathrm{E}-02$ & $1.08 \mathrm{E}-01$ & $2.70 \mathrm{E}+00$ & 2.73E-02 \\
\hline $3 y$ & 9.22E-03 & 9.22E-02 & $2.30 \mathrm{E}+00$ & 2.33E-02 \\
\hline $5 y$ & $6.92 \mathrm{E}-03$ & 6.92E-02 & $1.73 \mathrm{E}+00$ & 1.75E-02 \\
\hline $10 \mathrm{y}$ & 3.63E-03 & 3.63E-02 & $9.08 \mathrm{E}-01$ & 9.18E-03 \\
\hline
\end{tabular}

(a) Excess excretion above background.

(b) Based on maximum kidney burden of $1.1 \mu \mathrm{g}$-U/g-kidneys at approximately 18 hours post intake $(\mathrm{Rt}=0.114)$. 
Table 7.24. Reference Level Intakes and Urinary Excretion ${ }^{(a)}$ Derived Reference Levels for Type F Inhalation of Recycled Uranium

\begin{tabular}{ccccc}
\hline \multicolumn{5}{c}{ Inhalation Intake, mg } \\
\hline & $\begin{array}{c}\text { Screening Level, } \\
\text { 10-mrem Committed } \\
\text { Effective Dose }\end{array}$ & $\begin{array}{c}\text { Investigation Level, } \\
\text { 100-mrem Committed } \\
\text { Effective Dose }\end{array}$ & $\begin{array}{c}\text { Compliance Level, } \\
\text { 50-rem Committed } \\
\text { Equivalent Dose to } \\
\text { Bone Surface }\end{array}$ & $\begin{array}{c}\text { Chemical Toxicity } \\
\text { Threshold Level }{ }^{(b)}\end{array}$ \\
\cline { 2 - 5 } & $4.59 \mathrm{E}+00$ & $4.59 \mathrm{E}+01$ & $1.28 \mathrm{E}+03$ & $1.05 \mathrm{E}+01$ \\
\hline \multicolumn{5}{c}{ Derived Urine Excretion Levels $(\boldsymbol{\mu g}$ /d) } \\
\hline Days Post & Derived Screening & Derived Investigation & Derived Compliance & Derived Chemical \\
Intake & Level & Level & Level & Toxicity Level \\
\hline 1 & $8.42 \mathrm{E}+02$ & $8.42 \mathrm{E}+03$ & $2.34 \mathrm{E}+05$ & $1.93 \mathrm{E}+03$ \\
2 & $2.92 \mathrm{E}+01$ & $2.92 \mathrm{E}+02$ & $8.13 \mathrm{E}+03$ & $6.69 \mathrm{E}+01$ \\
3 & $2.35 \mathrm{E}+01$ & $2.35 \mathrm{E}+02$ & $6.54 \mathrm{E}+03$ & $5.39 \mathrm{E}+01$ \\
4 & $2.13 \mathrm{E}+01$ & $2.13 \mathrm{E}+02$ & $5.92 \mathrm{E}+03$ & $4.87 \mathrm{E}+01$ \\
5 & $1.93 \mathrm{E}+01$ & $1.93 \mathrm{E}+02$ & $5.37 \mathrm{E}+03$ & $4.42 \mathrm{E}+01$ \\
6 & $1.76 \mathrm{E}+01$ & $1.76 \mathrm{E}+02$ & $4.88 \mathrm{E}+03$ & $4.02 \mathrm{E}+01$ \\
7 & $1.60 \mathrm{E}+01$ & $1.60 \mathrm{E}+02$ & $4.46 \mathrm{E}+03$ & $3.67 \mathrm{E}+01$ \\
14 & $8.90 \mathrm{E}+00$ & $8.90 \mathrm{E}+01$ & $2.48 \mathrm{E}+03$ & $2.04 \mathrm{E}+01$ \\
30 & $3.12 \mathrm{E}+00$ & $3.12 \mathrm{E}+01$ & $8.68 \mathrm{E}+02$ & $7.15 \mathrm{E}+00$ \\
60 & $1.04 \mathrm{E}+00$ & $1.04 \mathrm{E}+01$ & $2.89 \mathrm{E}+02$ & $2.38 \mathrm{E}+00$ \\
90 & $5.49 \mathrm{E}-01$ & $5.49 \mathrm{E}+00$ & $1.53 \mathrm{E}+02$ & $1.26 \mathrm{E}+00$ \\
180 & $1.43 \mathrm{E}-01$ & $1.43 \mathrm{E}+00$ & $3.97 \mathrm{E}+01$ & $3.27 \mathrm{E}-01$ \\
$1 \mathrm{y}$ & $2.53 \mathrm{E}-02$ & $2.53 \mathrm{E}-01$ & $7.05 \mathrm{E}+00$ & $5.81 \mathrm{E}-02$ \\
$2 \mathrm{y}$ & $1.19 \mathrm{E}-02$ & $1.19 \mathrm{E}-01$ & $3.31 \mathrm{E}+00$ & $2.73 \mathrm{E}-02$ \\
$3 \mathrm{y}$ & $1.02 \mathrm{E}-02$ & $1.02 \mathrm{E}-01$ & $2.83 \mathrm{E}+00$ & $2.33 \mathrm{E}-02$ \\
$5 \mathrm{y}$ & $7.63 \mathrm{E}-03$ & $7.63 \mathrm{E}-02$ & $2.12 \mathrm{E}+00$ & $1.75 \mathrm{E}-02$ \\
$10 \mathrm{y}$ & $4.01 \mathrm{E}-03$ & $4.01 \mathrm{E}-02$ & $1.11 \mathrm{E}+00$ & $9.18 \mathrm{E}-03$ \\
\hline
\end{tabular}

(a) Excess excretion above background.

(b) Based on maximum kidney burden of $1.1 \mu \mathrm{g}-\mathrm{U} / \mathrm{g}$-kidneys at approximately 18 hours post intake $(\mathrm{Rt}=$ 0.0325). 
Table 7.25. Reference Level Intakes and Urinary Excretion ${ }^{(a)}$ Derived Reference Levels for Type M Inhalation of Recycled Uranium

\begin{tabular}{|c|c|c|c|c|}
\hline \multicolumn{5}{|c|}{ Inhalation Intake (mg) } \\
\hline & $\begin{array}{l}\text { Screening Level, } \\
\text { 10-mrem Committed } \\
\text { Effective Dose }\end{array}$ & $\begin{array}{l}\text { Investigation Level, } \\
\text { 100-mrem Committed } \\
\text { Effective Dose }\end{array}$ & $\begin{array}{l}\text { Compliance Level, } \\
\text { 5-rem Committed } \\
\text { Effective Dose }\end{array}$ & $\begin{array}{l}\text { Chemical Toxicity } \\
\text { Threshold Level }^{(b)}\end{array}$ \\
\hline & $1.54 \mathrm{E}+00$ & $1.54 \mathrm{E}+01$ & $7.69 \mathrm{E}+02$ & $8.34 \mathrm{E}+01$ \\
\hline \multicolumn{5}{|c|}{ Derived Urine Excretion Levels $(\mu \mathrm{g} / \mathrm{d})$} \\
\hline $\begin{array}{l}\text { Days Post } \\
\text { Intake }\end{array}$ & $\begin{array}{c}\text { Derived Screening } \\
\text { Level }\end{array}$ & $\begin{array}{c}\text { Derived Investigation } \\
\text { Level }\end{array}$ & $\begin{array}{c}\text { Derived } \\
\text { Compliance Level }\end{array}$ & $\begin{array}{l}\text { Derived Chemical } \\
\text { Toxicity Level }\end{array}$ \\
\hline 1 & $3.57 \mathrm{E}+01$ & $3.57 \mathrm{E}+02$ & $1.79 \mathrm{E}+04$ & $1.94 \mathrm{E}+03$ \\
\hline 2 & $1.73 \mathrm{E}+00$ & $1.73 \mathrm{E}+01$ & $8.65 \mathrm{E}+02$ & $9.37 \mathrm{E}+01$ \\
\hline 3 & $1.31 \mathrm{E}+00$ & $1.31 \mathrm{E}+01$ & $6.56 \mathrm{E}+02$ & $7.11 \mathrm{E}+01$ \\
\hline 4 & $1.21 \mathrm{E}+00$ & $1.21 \mathrm{E}+01$ & $6.07 \mathrm{E}+02$ & $6.57 \mathrm{E}+01$ \\
\hline 5 & $1.13 \mathrm{E}+00$ & $1.13 \mathrm{E}+01$ & $5.65 \mathrm{E}+02$ & $6.13 \mathrm{E}+01$ \\
\hline 6 & $1.06 \mathrm{E}+00$ & $1.06 \mathrm{E}+01$ & $5.29 \mathrm{E}+02$ & $5.73 \mathrm{E}+01$ \\
\hline 7 & $9.94 \mathrm{E}-01$ & $9.94 \mathrm{E}+00$ & $4.97 \mathrm{E}+02$ & $5.38 \mathrm{E}+01$ \\
\hline 14 & 6.88E-01 & $6.88 \mathrm{E}+00$ & $3.44 \mathrm{E}+02$ & $3.73 \mathrm{E}+01$ \\
\hline 30 & 4.09E-01 & $4.09 \mathrm{E}+00$ & $2.04 \mathrm{E}+02$ & $2.21 \mathrm{E}+01$ \\
\hline 60 & 2.57E-01 & $2.57 \mathrm{E}+00$ & $1.28 \mathrm{E}+02$ & $1.39 \mathrm{E}+01$ \\
\hline 90 & 1.92E-01 & $1.92 \mathrm{E}+00$ & $9.58 \mathrm{E}+01$ & $1.04 \mathrm{E}+01$ \\
\hline 180 & $1.00 \mathrm{E}-01$ & $1.00 \mathrm{E}+00$ & $5.02 \mathrm{E}+01$ & $5.45 \mathrm{E}+00$ \\
\hline $1 \mathrm{y}$ & 3.36E-02 & 3.36E-01 & $1.68 \mathrm{E}+01$ & $1.82 \mathrm{E}+00$ \\
\hline $2 y$ & 4.88E-03 & 4.88E-02 & $2.44 \mathrm{E}+00$ & 2.64E-01 \\
\hline $3 y$ & $1.34 \mathrm{E}-03$ & $1.34 \mathrm{E}-02$ & 6.70E-01 & 7.26E-02 \\
\hline $5 y$ & $6.54 \mathrm{E}-04$ & $6.54 \mathrm{E}-03$ & 3.27E-01 & 3.55E-02 \\
\hline $10 \mathrm{y}$ & 3.38E-04 & 3.38E-03 & 1.69E-01 & 1.83E-02 \\
\hline
\end{tabular}

(a) Excess excretion above background.

(b) Based on maximum kidney burden of $1.1 \mu \mathrm{g}-\mathrm{U} / \mathrm{g}$-kidneys at approximately 18 hours post intake (Rt $=$ 0.00409). 
Table 7.26. Reference Level Intakes and Urinary Excretion ${ }^{(a)}$ Derived Reference Levels for Type S Inhalation of Recycled Uranium

\begin{tabular}{|c|c|c|c|c|}
\hline \multicolumn{5}{|c|}{ Inhalation Intake (mg) } \\
\hline & $\begin{array}{l}\text { Screening Level, } \\
\text { 10-mrem Committed } \\
\text { Effective Dose }\end{array}$ & $\begin{array}{c}\text { Investigation Level, } \\
\text { 100-mrem } \\
\text { Committed Effective } \\
\text { Dose } \\
\end{array}$ & $\begin{array}{l}\text { Compliance Level, } \\
\text { 50-rem Committed } \\
\text { Equivalent Dose to } \\
\text { Extrathoracic Tissue }\end{array}$ & $\begin{array}{l}\text { Chemical Toxicity } \\
\text { Threshold Level }^{(b)}\end{array}$ \\
\hline & 4.65E-01 & $4.65 \mathrm{E}+00$ & $2.09 \mathrm{E}+02$ & $2.71 \mathrm{E}+03$ \\
\hline \multicolumn{5}{|c|}{ Derived Urine Excretion Levels $(\mu \mathrm{g} / \mathrm{d})$} \\
\hline $\begin{array}{l}\text { Days Post } \\
\text { Intake }\end{array}$ & $\begin{array}{c}\text { Derived Screening } \\
\text { Level }\end{array}$ & $\begin{array}{c}\text { Derived } \\
\text { Investigation Level }\end{array}$ & $\begin{array}{c}\text { Derived Compliance } \\
\text { Level }\end{array}$ & $\begin{array}{l}\text { Derived Chemical } \\
\text { Toxicity Level }\end{array}$ \\
\hline 1 & $3.28 \mathrm{E}-01$ & $3.28 \mathrm{E}+00$ & $1.47 \mathrm{E}+02$ & $1.91 \mathrm{E}+03$ \\
\hline 2 & 2.05E-02 & 2.05E-01 & $9.22 \mathrm{E}+00$ & $1.19 \mathrm{E}+02$ \\
\hline 3 & $1.21 \mathrm{E}-02$ & $1.21 \mathrm{E}-01$ & $5.44 \mathrm{E}+00$ & $7.04 \mathrm{E}+01$ \\
\hline 4 & 1.10E-02 & $1.10 \mathrm{E}-01$ & $4.95 \mathrm{E}+00$ & $6.41 \mathrm{E}+01$ \\
\hline 5 & 1.02E-02 & $1.02 \mathrm{E}-01$ & $4.59 \mathrm{E}+00$ & $5.94 \mathrm{E}+01$ \\
\hline 6 & 9.53E-03 & 9.53E-02 & $4.29 \mathrm{E}+00$ & $5.54 \mathrm{E}+01$ \\
\hline 7 & 8.92E-03 & 8.92E-02 & $4.01 \mathrm{E}+00$ & $5.19 \mathrm{E}+01$ \\
\hline 14 & $6.08 \mathrm{E}-03$ & $6.08 \mathrm{E}-02$ & $2.73 \mathrm{E}+00$ & $3.54 \mathrm{E}+01$ \\
\hline 30 & 3.59E-03 & 3.59E-02 & $1.61 \mathrm{E}+00$ & $2.09 \mathrm{E}+01$ \\
\hline 60 & 2.41E-03 & 2.41E-02 & $1.08 \mathrm{E}+00$ & $1.40 \mathrm{E}+01$ \\
\hline 90 & $1.99 \mathrm{E}-03$ & 1.99E-02 & 8.96E-01 & $1.16 \mathrm{E}+01$ \\
\hline 180 & $1.53 \mathrm{E}-03$ & $1.53 \mathrm{E}-02$ & 6.88E-01 & $8.91 \mathrm{E}+00$ \\
\hline $1 \mathrm{y}$ & $1.23 \mathrm{E}-03$ & $1.23 \mathrm{E}-02$ & 5.52E-01 & $7.14 \mathrm{E}+00$ \\
\hline $2 \mathrm{y}$ & 8.86E-04 & 8.86E-03 & 3.99E-01 & $5.16 \mathrm{E}+00$ \\
\hline $3 y$ & $6.57 \mathrm{E}-04$ & $6.57 \mathrm{E}-03$ & 2.96E-01 & $3.83 \mathrm{E}+00$ \\
\hline $5 y$ & $3.90 \mathrm{E}-04$ & $3.90 \mathrm{E}-03$ & 1.75E-01 & $2.27 \mathrm{E}+00$ \\
\hline $10 y$ & 1.65E-04 & 1.65E-03 & 7.44E-02 & $9.62 \mathrm{E}-01$ \\
\hline
\end{tabular}

(a) Excess excretion above background.

(b) Based on maximum kidney burden of $1.1 \mu \mathrm{g}$-U/g-kidneys at approximately 24 hours post intake $(\mathrm{Rt}=1.26 \times$ $10^{-4}$. For Type $\mathrm{S}$ material, radiological overexposure is the primary concern. 
Table 7.27. Reference Levels and Urinary Excretion ${ }^{(a)}$ Derived Reference Levels for Ingestion of Soluble Recycled Uranium

\begin{tabular}{|c|c|c|c|c|}
\hline \multicolumn{5}{|c|}{ Ingestion Intake (mg) } \\
\hline & $\begin{array}{l}\text { Screening Level, } \\
\text { 10-mrem Committed } \\
\text { Effective Dose }\end{array}$ & $\begin{array}{c}\text { Investigation Level, } \\
100 \text {-mrem } \\
\text { Committed Effective } \\
\text { Dose } \\
\end{array}$ & $\begin{array}{l}\text { Compliance Level, } \\
\text { 50-rem Committed } \\
\text { Equivalent Dose to } \\
\text { Bone Surface }\end{array}$ & $\begin{array}{l}\text { Chemical Toxicity } \\
\text { Threshold Level }^{(b)}\end{array}$ \\
\hline & $6.13 \mathrm{E}+01$ & $6.13 \mathrm{E}+02$ & $1.98 \mathrm{E}+04$ & $1.51 \mathrm{E}+02$ \\
\hline \multicolumn{5}{|c|}{ Derived Urine Excretion Levels $(\mu \mathrm{g} / \mathrm{d})$} \\
\hline $\begin{array}{l}\text { Days Post } \\
\text { Intake }\end{array}$ & $\begin{array}{c}\text { Derived Screening } \\
\text { Level }\end{array}$ & $\begin{array}{c}\text { Derived Investigation } \\
\text { Level }\end{array}$ & $\begin{array}{c}\text { Derived Compliance } \\
\text { Level }\end{array}$ & $\begin{array}{l}\text { Derived Chemical } \\
\text { Toxicity Level }\end{array}$ \\
\hline 1 & $7.71 \mathrm{E}+02$ & $7.71 \mathrm{E}+03$ & $2.49 \mathrm{E}+05$ & $1.90 \mathrm{E}+03$ \\
\hline 2 & 4.24E+01 & $4.24 \mathrm{E}+02$ & $1.37 \mathrm{E}+04$ & $1.05 \mathrm{E}+02$ \\
\hline 3 & $2.27 \mathrm{E}+01$ & $2.27 \mathrm{E}+02$ & $7.33 \mathrm{E}+03$ & $5.59 \mathrm{E}+01$ \\
\hline 4 & $2.04 \mathrm{E}+01$ & $2.04 \mathrm{E}+02$ & $6.59 \mathrm{E}+03$ & $5.03 \mathrm{E}+01$ \\
\hline 5 & $1.85 \mathrm{E}+01$ & $1.85 \mathrm{E}+02$ & $5.98 \mathrm{E}+03$ & $4.56 \mathrm{E}+01$ \\
\hline 6 & $1.68 \mathrm{E}+01$ & $1.68 \mathrm{E}+02$ & $5.44 \mathrm{E}+03$ & $4.14 \mathrm{E}+01$ \\
\hline 7 & $1.53 \mathrm{E}+01$ & $1.53 \mathrm{E}+02$ & $4.96 \mathrm{E}+03$ & $3.78 \mathrm{E}+01$ \\
\hline 14 & $8.49 \mathrm{E}+00$ & $8.49 \mathrm{E}+01$ & $2.75 \mathrm{E}+03$ & $2.09 \mathrm{E}+01$ \\
\hline 30 & $2.96 \mathrm{E}+00$ & $2.96 \mathrm{E}+01$ & $9.58 \mathrm{E}+02$ & $7.31 \mathrm{E}+00$ \\
\hline 60 & $9.81 \mathrm{E}-01$ & $9.81 \mathrm{E}+00$ & $3.17 \mathrm{E}+02$ & $2.42 \mathrm{E}+00$ \\
\hline 90 & 5.18E-01 & $5.18 \mathrm{E}+00$ & $1.67 \mathrm{E}+02$ & $1.28 \mathrm{E}+00$ \\
\hline 180 & 1.35E-01 & $1.35 \mathrm{E}+00$ & $4.35 \mathrm{E}+01$ & 3.32E-01 \\
\hline $1 \mathrm{y}$ & 2.38E-02 & 2.38E-01 & $7.71 \mathrm{E}+00$ & $5.88 \mathrm{E}-02$ \\
\hline $2 y$ & 1.12E-02 & 1.12E-01 & $3.62 \mathrm{E}+00$ & 2.76E-02 \\
\hline $3 y$ & $9.55 \mathrm{E}-03$ & $9.55 \mathrm{E}-02$ & $3.09 \mathrm{E}+00$ & 2.35E-02 \\
\hline $5 y$ & 7.17E-03 & 7.17E-02 & $2.32 \mathrm{E}+00$ & 1.77E-02 \\
\hline $10 \mathrm{y}$ & 3.77E-03 & 3.77E-02 & $1.22 \mathrm{E}+00$ & $9.29 \mathrm{E}-03$ \\
\hline
\end{tabular}

(a) Excess excretion above background.

(b) Based on maximum kidney burden of $1.1 \mu \mathrm{g}-\mathrm{U} / \mathrm{g}$-kidneys at approximately 24 hours post intake (Rt $=2.25 \times$ $10^{-3}$. 
Table 7.28. Reference Levels and Urinary Excretion ${ }^{(a)}$ Derived Reference Levels for Ingestion of Insoluble Recycled Uranium

\begin{tabular}{|c|c|c|c|c|}
\hline \multicolumn{5}{|c|}{ Ingestion Intake (mg) } \\
\hline & $\begin{array}{l}\text { Screening Level, } \\
\text { 10-mrem Committed } \\
\text { Effective Dose }\end{array}$ & $\begin{array}{c}\text { Investigation Level, } \\
\text { 100-mrem } \\
\text { Committed Effective } \\
\text { Dose } \\
\end{array}$ & $\begin{array}{l}\text { Compliance Level, } \\
\text { 5-rem Committed } \\
\text { Effective Dose }\end{array}$ & $\begin{array}{l}\text { Chemical Toxicity } \\
\text { Threshold Level }^{(b)}\end{array}$ \\
\hline & $3.18 \mathrm{E}+02$ & $3.18 \mathrm{E}+03$ & $1.59 \mathrm{E}+05$ & $1.51 \mathrm{E}+03$ \\
\hline \multicolumn{5}{|c|}{ Derived Urine Excretion Levels $(\mu \mathrm{g} / \mathrm{d})$} \\
\hline $\begin{array}{l}\text { Days Post } \\
\text { Intake }\end{array}$ & $\begin{array}{c}\text { Derived Screening } \\
\text { Level }\end{array}$ & $\begin{array}{c}\text { Derived } \\
\text { Investigation Level }\end{array}$ & $\begin{array}{c}\text { Derived Compliance } \\
\text { Level }\end{array}$ & $\begin{array}{l}\text { Derived Chemical } \\
\text { Toxicity Level }\end{array}$ \\
\hline 1 & $4.00 \mathrm{E}+02$ & $4.00 \mathrm{E}+03$ & $2.00 \mathrm{E}+05$ & $1.90 \mathrm{E}+03$ \\
\hline 2 & $2.24 \mathrm{E}+01$ & $2.24 \mathrm{E}+02$ & $1.12 \mathrm{E}+04$ & $1.06 \mathrm{E}+02$ \\
\hline 3 & $1.18 \mathrm{E}+01$ & $1.18 \mathrm{E}+02$ & $5.88 \mathrm{E}+03$ & $5.59 \mathrm{E}+01$ \\
\hline 4 & $1.06 \mathrm{E}+01$ & $1.06 \mathrm{E}+02$ & $5.29 \mathrm{E}+03$ & $5.03 \mathrm{E}+01$ \\
\hline 5 & $9.60 \mathrm{E}+00$ & $9.60 \mathrm{E}+01$ & $4.80 \mathrm{E}+03$ & $4.56 \mathrm{E}+01$ \\
\hline 6 & 8.73E+00 & 8.73E+01 & $4.36 \mathrm{E}+03$ & $4.15 \mathrm{E}+01$ \\
\hline 7 & $7.96 \mathrm{E}+00$ & $7.96 \mathrm{E}+01$ & $3.98 \mathrm{E}+03$ & $3.78 \mathrm{E}+01$ \\
\hline 14 & $4.41 \mathrm{E}+00$ & $4.41 \mathrm{E}+01$ & $2.20 \mathrm{E}+03$ & $2.10 \mathrm{E}+01$ \\
\hline 30 & $1.54 \mathrm{E}+00$ & $1.54 \mathrm{E}+01$ & $7.69 \mathrm{E}+02$ & $7.31 \mathrm{E}+00$ \\
\hline 60 & 5.09E-01 & $5.09 \mathrm{E}+00$ & $2.55 \mathrm{E}+02$ & $2.42 \mathrm{E}+00$ \\
\hline 90 & 2.69E-01 & $2.69 \mathrm{E}+00$ & $1.34 \mathrm{E}+02$ & $1.28 \mathrm{E}+00$ \\
\hline 180 & $6.98 \mathrm{E}-02$ & $6.98 \mathrm{E}-01$ & $3.49 \mathrm{E}+01$ & 3.32E-01 \\
\hline $1 \mathrm{y}$ & $1.24 \mathrm{E}-02$ & $1.24 \mathrm{E}-01$ & $6.19 \mathrm{E}+00$ & 5.88E-02 \\
\hline $2 y$ & $5.81 \mathrm{E}-03$ & $5.81 \mathrm{E}-02$ & $2.90 \mathrm{E}+00$ & $2.76 \mathrm{E}-02$ \\
\hline $3 y$ & 4.96E-03 & 4.96E-02 & $2.48 \mathrm{E}+00$ & 2.36E-02 \\
\hline $5 y$ & 3.72E-03 & 3.72E-02 & $1.86 \mathrm{E}+00$ & $1.77 \mathrm{E}-02$ \\
\hline $10 \mathrm{y}$ & $1.96 \mathrm{E}-03$ & 1.96E-02 & $9.78 \mathrm{E}-01$ & $9.29 \mathrm{E}-03$ \\
\hline
\end{tabular}

(a) Excess excretion above background.

(b) Based on maximum kidney burden of $1.1 \mu \mathrm{g}$-U/g-kidneys at approximately 24 hours post intake $(\mathrm{Rt}=2.25 \times$ $10^{-4}$.

Derived reference levels for chest counting for Type $\mathrm{M}$ and $\mathrm{S}$ intakes, based on recycled uranium, are shown in Tables 7.29 and 7.30 for measurement of ${ }^{234} \mathrm{Th}$ (assumed to be in equilibrium with ${ }^{238} \mathrm{U}$ ), and in Tables 7.31 and 7.32 for measurement of ${ }^{235} \mathrm{U}$. 
Table 7.29. Reference Level Intakes of ${ }^{238} \mathrm{U}$ in the Recycled Uranium Mixture and ${ }^{234} \mathrm{Th}^{(\mathrm{a})} \mathrm{Lung}$ Retention Derived Reference Levels for Type M Inhalation Intakes

\begin{tabular}{|c|c|c|c|c|}
\hline \multicolumn{5}{|c|}{ Inhalation Intake (nCi of $\left.{ }^{238} \mathrm{U}\right)$} \\
\hline & $\begin{array}{l}\text { Screening Level, } \\
\text { 10-mrem Committed } \\
\text { Effective Dose }\end{array}$ & $\begin{array}{l}\text { Investigation Level, } \\
\text { 100-mrem Committed } \\
\text { Effective Dose }\end{array}$ & $\begin{array}{c}\text { Compliance Level, } \\
\text { 5-rem Committed } \\
\text { Effective Dose }\end{array}$ & $\begin{array}{l}\text { Chemical Toxicity } \\
\text { Threshold Level }^{(b)}\end{array}$ \\
\hline & $5.12 \mathrm{E}-01$ & $5.12 \mathrm{E}+00$ & $2.56 \mathrm{E}+02$ & $2.77 \mathrm{E}+01$ \\
\hline \multicolumn{5}{|c|}{ Derived Lung Retention (nCi of $\left.{ }^{234} \mathrm{Th}\right)$} \\
\hline $\begin{array}{l}\text { Days Post } \\
\text { Intake }\end{array}$ & $\begin{array}{c}\text { Derived Screening } \\
\text { Level }\end{array}$ & $\begin{array}{c}\text { Derived Investigation } \\
\text { Level }\end{array}$ & $\begin{array}{c}\text { Derived Compliance } \\
\text { Level }\end{array}$ & $\begin{array}{l}\text { Derived Chemical } \\
\text { Toxicity Level }\end{array}$ \\
\hline 1 & 2.95E-02 & 2.95E-01 & $1.47 \mathrm{E}+01$ & $1.60 \mathrm{E}+00$ \\
\hline 2 & 2.86E-02 & 2.86E-01 & $1.43 \mathrm{E}+01$ & $1.55 \mathrm{E}+00$ \\
\hline 3 & 2.81E-02 & $2.81 \mathrm{E}-01$ & $1.41 \mathrm{E}+01$ & $1.52 \mathrm{E}+00$ \\
\hline 4 & 2.77E-02 & 2.77E-01 & $1.39 \mathrm{E}+01$ & $1.50 \mathrm{E}+00$ \\
\hline 5 & 2.73E-02 & 2.73E-01 & $1.36 \mathrm{E}+01$ & $1.48 \mathrm{E}+00$ \\
\hline 6 & 2.69E-02 & 2.69E-01 & $1.34 \mathrm{E}+01$ & $1.46 \mathrm{E}+00$ \\
\hline 7 & 2.65E-02 & 2.65E-01 & $1.33 \mathrm{E}+01$ & $1.44 \mathrm{E}+00$ \\
\hline 14 & 2.40E-02 & 2.40E-01 & $1.20 \mathrm{E}+01$ & $1.30 \mathrm{E}+00$ \\
\hline 30 & $1.96 \mathrm{E}-02$ & $1.96 \mathrm{E}-01$ & $9.82 \mathrm{E}+00$ & $1.06 \mathrm{E}+00$ \\
\hline 60 & $1.44 \mathrm{E}-02$ & $1.44 \mathrm{E}-01$ & $7.19 \mathrm{E}+00$ & 7.79E-01 \\
\hline 90 & 1.12E-02 & 1.12E-01 & $5.58 \mathrm{E}+00$ & $6.05 \mathrm{E}-01$ \\
\hline 180 & 6.10E-03 & 6.10E-02 & $3.05 E+00$ & 3.31E-01 \\
\hline $1 \mathrm{y}$ & 2.04E-03 & 2.04E-02 & $1.02 \mathrm{E}+00$ & $1.11 \mathrm{E}-01$ \\
\hline $2 y$ & $2.46 \mathrm{E}-04$ & $2.46 \mathrm{E}-03$ & $1.23 \mathrm{E}-01$ & 1.33E-02 \\
\hline $3 y$ & 3.02E-05 & 3.02E-04 & $1.51 \mathrm{E}-02$ & 1.64E-03 \\
\hline $5 y$ & 4.89E-07 & 4.89E-06 & $2.44 \mathrm{E}-04$ & 2.65E-05 \\
\hline $10 \mathrm{y}$ & $2.58 \mathrm{E}-11$ & $2.58 \mathrm{E}-10$ & 1.29E-08 & 1.40E-09 \\
\hline
\end{tabular}

(a) Assumed to be in equilibrium with ${ }^{238} \mathrm{U}$.

(b) Based on maximum kidney burden of $1.1 \mu \mathrm{g}-\mathrm{U} / \mathrm{g}$-kidneys at approximately 18 hours post intake (Rt $=$ 0.00409 . 
Table 7.30. Reference Level Intakes of ${ }^{238} \mathrm{U}$ in the Recycled Uranium Mixture and ${ }^{234} \mathrm{Th}^{(\mathrm{a})}$ Lung Retention Derived Reference Levels for Type S Inhalation Intakes

\begin{tabular}{|c|c|c|c|c|}
\hline \multicolumn{5}{|c|}{ Inhalation Intake (nCi of ${ }^{238} \mathrm{U}$ ) } \\
\hline & $\begin{array}{l}\text { Screening Level, } \\
\text { 10-mrem Committed } \\
\text { Effective Dose }\end{array}$ & $\begin{array}{l}\text { Investigation Level, } \\
\text { 100-mrem Committed } \\
\text { Effective Dose }\end{array}$ & $\begin{array}{l}\text { Compliance Level, } \\
\text { 50-rem Committed } \\
\text { Equivalent Dose to } \\
\text { Extra Thoracic Tissue }\end{array}$ & $\begin{array}{l}\text { Chemical Toxicity } \\
\text { Threshold Level }^{(b)}\end{array}$ \\
\hline & $1.55 \mathrm{E}-01$ & $1.55 \mathrm{E}+00$ & $6.96+01$ & $9.00 \mathrm{E}+02$ \\
\hline \multicolumn{5}{|c|}{ Derived Lung Retention (nCi of $\left.{ }^{234} \mathrm{Th}\right)$} \\
\hline $\begin{array}{l}\text { Days Post } \\
\text { Intake }\end{array}$ & $\begin{array}{c}\text { Derived Screening } \\
\text { Level }\end{array}$ & $\begin{array}{c}\text { Derived Investigation } \\
\text { Level }\end{array}$ & $\begin{array}{c}\text { Derived Compliance } \\
\text { Level }\end{array}$ & $\begin{array}{l}\text { Derived Chemical } \\
\text { Toxicity Level }\end{array}$ \\
\hline 1 & 9.94E-03 & $9.94 \mathrm{E}-02$ & $4.47 \mathrm{E}+00$ & $5.78 \mathrm{E}+01$ \\
\hline 2 & $9.70 \mathrm{E}-03$ & $9.70 \mathrm{E}-02$ & $4.36 \mathrm{E}+00$ & $5.64 \mathrm{E}+01$ \\
\hline 3 & $9.58 \mathrm{E}-03$ & $9.58 \mathrm{E}-02$ & $4.31 \mathrm{E}+00$ & $5.57 \mathrm{E}+01$ \\
\hline 4 & $9.48 \mathrm{E}-03$ & $9.48 \mathrm{E}-02$ & $4.26 \mathrm{E}+00$ & $5.52 \mathrm{E}+01$ \\
\hline 5 & 9.39E-03 & 9.39E-02 & $4.22 \mathrm{E}+00$ & $5.46 \mathrm{E}+01$ \\
\hline 6 & $9.30 \mathrm{E}-03$ & $9.30 \mathrm{E}-02$ & $4.18 \mathrm{E}+00$ & $5.41 \mathrm{E}+01$ \\
\hline 7 & $9.21 \mathrm{E}-03$ & $9.21 \mathrm{E}-02$ & $4.14 \mathrm{E}+00$ & $5.36 \mathrm{E}+01$ \\
\hline 14 & 8.64E-03 & 8.64E-02 & $3.89 \mathrm{E}+00$ & $5.03 \mathrm{E}+01$ \\
\hline 30 & 7.63E-03 & 7.63E-02 & $3.43 \mathrm{E}+00$ & $4.44 \mathrm{E}+01$ \\
\hline 60 & 6.47E-03 & 6.47E-02 & $2.91 \mathrm{E}+00$ & $3.77 \mathrm{E}+01$ \\
\hline 90 & 5.82E-03 & 5.82E-02 & $2.62 \mathrm{E}+00$ & $3.39 \mathrm{E}+01$ \\
\hline 180 & 4.94E-03 & 4.94E-02 & $2.22 \mathrm{E}+00$ & $2.88 \mathrm{E}+01$ \\
\hline $1 \mathrm{y}$ & 4.10E-03 & 4.10E-02 & $1.84 \mathrm{E}+00$ & $2.38 \mathrm{E}+01$ \\
\hline $2 \mathrm{y}$ & $2.95 \mathrm{E}-03$ & 2.95E-02 & $1.33 \mathrm{E}+00$ & $1.72 \mathrm{E}+01$ \\
\hline $3 y$ & 2.17E-03 & 2.17E-02 & $9.75 E-01$ & $1.26 \mathrm{E}+01$ \\
\hline $5 y$ & $1.26 \mathrm{E}-03$ & $1.26 \mathrm{E}-02$ & 5.67E-01 & $7.33 \mathrm{E}+00$ \\
\hline $10 y$ & 5.12E-04 & 5.12E-03 & 2.30E-01 & $2.98 \mathrm{E}+00$ \\
\hline
\end{tabular}

(a) Assumed to be in equilibrium with ${ }^{238} \mathrm{U}$.

(b) Based on maximum kidney burden of $1.1 \mu \mathrm{g}$-U/g-kidneys at approximately 24 hours post intake $(\mathrm{Rt}=1.26 \times$ $10^{-4}$. 
Table 7.31. Reference Level Intakes of ${ }^{235} U$ in the Recycled Uranium Mixture and ${ }^{235} U$ Lung Retention Derived Reference Levels for Type M Inhalation Intakes

\begin{tabular}{|c|c|c|c|c|}
\hline \multicolumn{5}{|c|}{ Inhalation Intake (nCi of ${ }^{235} \mathrm{U}$ ) } \\
\hline & $\begin{array}{l}\text { Screening Level, } \\
\text { 10-mrem Committed } \\
\text { Effective Dose }\end{array}$ & $\begin{array}{l}\text { Investigation Level, } \\
\text { 100-mrem Committed } \\
\text { Effective Dose }\end{array}$ & $\begin{array}{l}\text { Compliance Level, } \\
\text { 5-rem Committed } \\
\text { Effective Dose }\end{array}$ & $\begin{array}{l}\text { Chemical Toxicity } \\
\text { Threshold Level }^{(a)}\end{array}$ \\
\hline & 3.23E-02 & 3.23E-01 & $1.62 \mathrm{E}+01$ & $1.75 \mathrm{E}+00$ \\
\hline \multicolumn{5}{|c|}{ Derived Lung Retention $\left(\mathrm{nCi}^{235} \mathrm{U}\right)$} \\
\hline $\begin{array}{l}\text { Days Post } \\
\text { Intake }\end{array}$ & $\begin{array}{c}\text { Derived Screening } \\
\text { Level }\end{array}$ & $\begin{array}{c}\text { Derived Investigation } \\
\text { Level }\end{array}$ & $\begin{array}{c}\text { Derived Compliance } \\
\text { Level }\end{array}$ & $\begin{array}{l}\text { Derived Chemical } \\
\text { Toxicity Level }\end{array}$ \\
\hline 1 & 1.93E-03 & 1.93E-02 & $9.66 \mathrm{E}-01$ & $1.05 \mathrm{E}-01$ \\
\hline 2 & $1.86 \mathrm{E}-03$ & 1.86E-02 & 9.31E-01 & $1.01 \mathrm{E}-01$ \\
\hline 3 & $1.81 \mathrm{E}-03$ & $1.81 \mathrm{E}-02$ & $9.04 \mathrm{E}-01$ & 9.79E-02 \\
\hline 4 & $1.78 \mathrm{E}-03$ & $1.78 \mathrm{E}-02$ & 8.88E-01 & 9.63E-02 \\
\hline 5 & $1.75 \mathrm{E}-03$ & 1.75E-02 & 8.75E-01 & $9.48 \mathrm{E}-02$ \\
\hline 6 & $1.72 \mathrm{E}-03$ & $1.72 \mathrm{E}-02$ & 8.62E-01 & $9.34 \mathrm{E}-02$ \\
\hline 7 & $1.70 \mathrm{E}-03$ & $1.70 \mathrm{E}-02$ & 8.49E-01 & $9.21 \mathrm{E}-02$ \\
\hline 14 & $1.60 \mathrm{E}-03$ & $1.60 \mathrm{E}-02$ & 8.02E-01 & 8.69E-02 \\
\hline 30 & $1.52 \mathrm{E}-03$ & $1.52 \mathrm{E}-02$ & 7.59E-01 & 8.23E-02 \\
\hline 60 & $1.24 \mathrm{E}-03$ & $1.24 \mathrm{E}-02$ & $6.20 \mathrm{E}-01$ & 6.72E-02 \\
\hline 90 & $9.08 \mathrm{E}-04$ & $9.08 \mathrm{E}-03$ & 4.54E-01 & 4.92E-02 \\
\hline 180 & 7.05E-04 & 7.05E-03 & 3.52E-01 & 3.82E-02 \\
\hline $1 \mathrm{y}$ & 3.85E-04 & $3.85 \mathrm{E}-03$ & 1.93E-01 & 2.09E-02 \\
\hline $2 y$ & $1.29 \mathrm{E}-04$ & $1.29 \mathrm{E}-03$ & 6.45E-02 & 6.99E-03 \\
\hline $3 y$ & 1.55E-05 & $1.55 \mathrm{E}-04$ & 7.76E-03 & 8.41E-04 \\
\hline $5 y$ & 2.39E-07 & 2.39E-06 & 1.19E-04 & $1.29 \mathrm{E}-05$ \\
\hline $10 \mathrm{y}$ & 3.09E-08 & 3.09E-07 & $1.54 \mathrm{E}-05$ & 1.67E-06 \\
\hline
\end{tabular}

(a) Based on maximum kidney burden of $1.1 \mu \mathrm{g}$-U/g-kidneys at approximately 18 hours post intake $(\mathrm{Rt}=$ 0.00409 . 
Table 7.32. Reference Level Intakes of ${ }^{235} \mathrm{U}$ in the Recycled Uranium Mixture and ${ }^{235} \mathrm{U}$ Lung Retention Derived Reference Levels for Type S Inhalation Intakes

\begin{tabular}{|c|c|c|c|c|}
\hline \multicolumn{5}{|c|}{ Inhalation Intake ( $\mathrm{nCi}$ of ${ }^{235} \mathrm{U}$ ) } \\
\hline & $\begin{array}{l}\text { Screening Level, } \\
\text { 10-mrem Committed } \\
\text { Effective Dose }\end{array}$ & $\begin{array}{c}\text { Investigation Level, } \\
\text { 100-mrem } \\
\text { Committed Effective } \\
\text { Dose }\end{array}$ & $\begin{array}{l}\text { Compliance Level, } \\
\text { 50-rem Committed } \\
\text { Equivalent Dose to } \\
\text { Extrathoracic Tissue }\end{array}$ & $\begin{array}{l}\text { Chemical Toxicity } \\
\text { Threshold Level }^{(\mathrm{a})}\end{array}$ \\
\hline & $9.77 \mathrm{E}-03$ & $9.77 \mathrm{E}-02$ & $4.39 \mathrm{E}+00$ & $5.68 \mathrm{E}+01$ \\
\hline \multicolumn{5}{|c|}{ Derived Lung Retention (nCi of ${ }^{235} \mathrm{U}$ ) } \\
\hline $\begin{array}{l}\text { Days Post } \\
\text { Intake }\end{array}$ & $\begin{array}{c}\text { Derived Screening } \\
\text { Level }\end{array}$ & $\begin{array}{c}\text { Derived } \\
\text { Investigation Level }\end{array}$ & $\begin{array}{c}\text { Derived Compliance } \\
\text { Level }\end{array}$ & $\begin{array}{l}\text { Derived Chemical } \\
\text { Toxicity Level }\end{array}$ \\
\hline 1 & $6.28 \mathrm{E}-04$ & $6.28 \mathrm{E}-03$ & $2.82 \mathrm{E}-01$ & $3.65 \mathrm{E}+00$ \\
\hline 2 & 6.12E-04 & $6.12 \mathrm{E}-03$ & 2.75E-01 & $3.56 \mathrm{E}+00$ \\
\hline 3 & 6.05E-04 & 6.05E-03 & 2.72E-01 & $3.52 \mathrm{E}+00$ \\
\hline 4 & 5.99E-04 & 5.99E-03 & 2.69E-01 & $3.48 \mathrm{E}+00$ \\
\hline 5 & 5.93E-04 & 5.93E-03 & 2.67E-01 & $3.45 \mathrm{E}+00$ \\
\hline 6 & 5.87E-04 & 5.87E-03 & 2.64E-01 & $3.42 \mathrm{E}+00$ \\
\hline 7 & 5.81E-04 & $5.81 \mathrm{E}-03$ & 2.62E-01 & $3.38 \mathrm{E}+00$ \\
\hline 14 & $5.46 \mathrm{E}-04$ & 5.46E-03 & 2.45E-01 & $3.17 \mathrm{E}+00$ \\
\hline 30 & 4.82E-04 & 4.82E-03 & 2.17E-01 & $2.81 \mathrm{E}+00$ \\
\hline 60 & 4.09E-04 & 4.09E-03 & 1.84E-01 & $2.38 \mathrm{E}+00$ \\
\hline 90 & 3.68E-04 & $3.68 \mathrm{E}-03$ & 1.65E-01 & $2.14 \mathrm{E}+00$ \\
\hline 180 & 3.12E-04 & 3.12E-03 & $1.40 \mathrm{E}-01$ & $1.82 \mathrm{E}+00$ \\
\hline $1 \mathrm{y}$ & 2.59E-04 & 2.59E-03 & 1.16E-01 & $1.51 \mathrm{E}+00$ \\
\hline $2 y$ & $1.86 \mathrm{E}-04$ & 1.86E-03 & 8.38E-02 & $1.08 \mathrm{E}+00$ \\
\hline $3 y$ & 1.37E-04 & 1.37E-03 & 6.16E-02 & 7.97E-01 \\
\hline $5 y$ & 7.96E-05 & 7.96E-04 & 3.58E-02 & 4.63E-01 \\
\hline $10 \mathrm{y}$ & 3.23E-05 & 3.23E-04 & $1.46 \mathrm{E}-02$ & $1.88 \mathrm{E}-01$ \\
\hline
\end{tabular}

(a) Based on maximum kidney burden of $1.1 \mu \mathrm{g}$-U/g-kidneys at approximately 24 hours post intake $(\mathrm{Rt}=1.26 \times$ $10^{-4}$.

\subsection{Bioassay Monitoring}

Bioassay monitoring procedures for uranium include excreta analysis and in vivo measurements. Urinalysis is an indicator of systemically deposited uranium; prompt fecal analysis provides an indication of the amount of uranium that is being cleared from the lung; and in vivo counting provides a direct measurement of the quantity of uranium in the lung. The following sections discuss urine sampling, in vivo measurement, fecal excretion, the routine bioassay monitoring program, and special bioassay measurements following a potential acute intake.

\subsubsection{Urine Sampling and Analysis}

The interpretation of urinalysis measurements is highly dependent on knowledge of the time and duration of the intake and on assumptions regarding the biokinetic transport and excretion of systemically 
absorbed uranium. Standard biokinetic models provide estimated uranium excretion rates in terms of daily output (e. g., micrograms per day). The influence of diurnal variations in urination frequency and volume may be lessened if a full 24-hour collection is obtained rather than a single grab sample.

According to the ICRP 69 model (and the predecessor ICRP 30 model), a significant amount of uranium entering the circulatory system (about 60\%) is not deposited in body tissue or is retained only briefly in the kidneys and therefore passes quickly to excretion. The excretion of this essentially unabsorbed fraction can result in highly variable urinary levels under conditions of ongoing repeated or chronic exposure as depicted in Figure 7.7. This effect is equally important for urine samples collected shortly after an acute intake as indicated by the greater-than-factor-of-ten change in excretion rate from 24 to 48 hours after the intake for all intake modes and inhalation types, as shown in Table 7.10 and Figure 7.3.

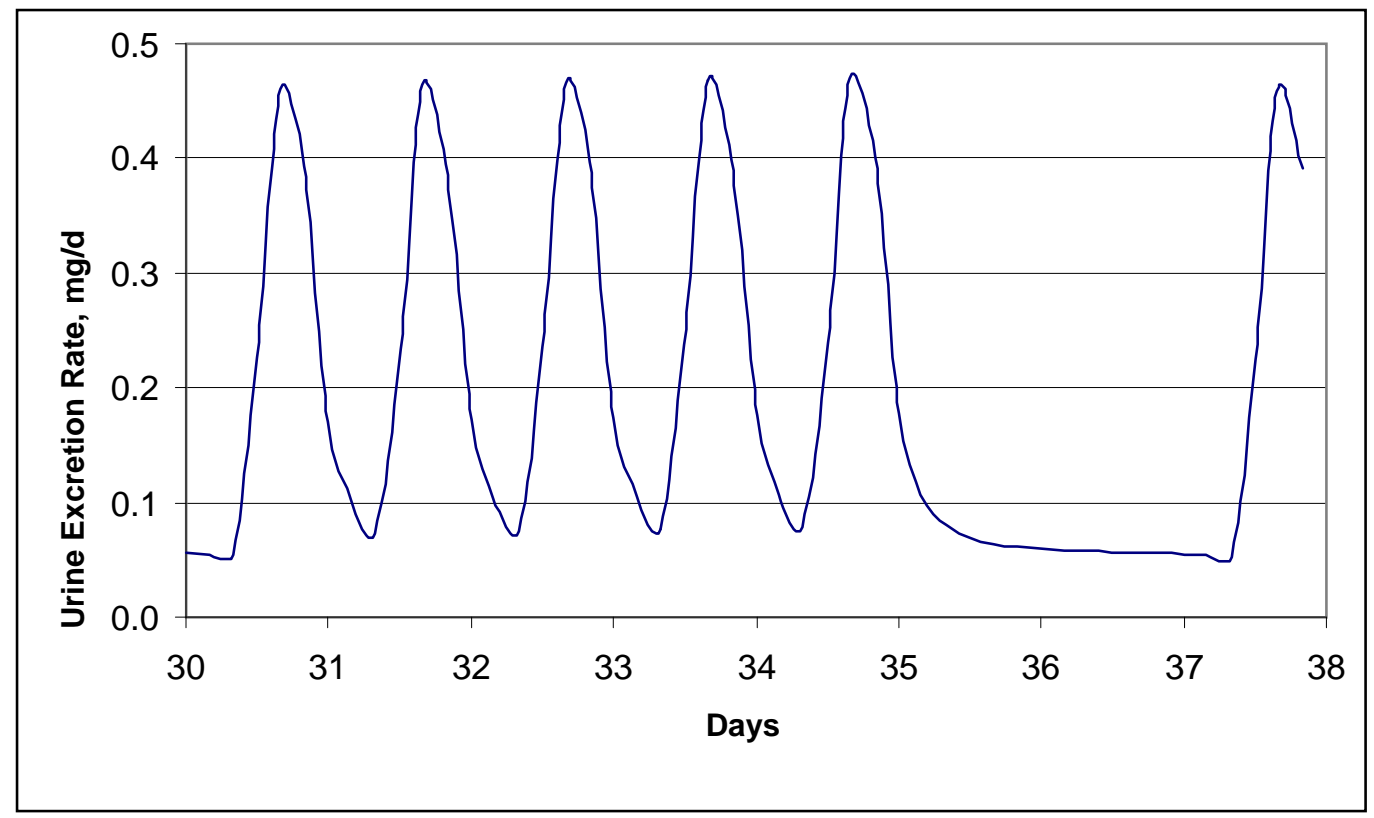

Figure 7.7. Daily Variability in Instantaneous Urinary Excretion from Chronic Dayshift Inhalation of $1 \mathrm{mg}$ /workday of Type F Uranium (Curve shown is for fifth week of exposure.)

Because of the large variability in uranium excretion rates in a short time due to this unabsorbed fraction, quantitative interpretation of bioassay data is best accomplished by either collecting all of the unabsorbed fraction (i.e., that voided during the first several days after exposure) or by collecting samples after the unabsorbed fraction has been eliminated. For routine sampling of potentially chronically exposed workers, it is desirable to collect the urine sample several days after any possible exposure. For the initial evaluation of potentially significant uptakes of uranium, a single void sample within 3 to 4 hours of the exposure is appropriate.

For the reasons stated above, the optimum urine sample for a routine uranium bioassay sampling program is a 24-hour total urine collection after several days' absence from any source of intake. Because this is not always practicable to implement on a large scale, an approximate 24-hour sample is commonly used, which consists of urine voided between one-half hour prior to retiring to bed in the evening and 
one-half hour after rising for two consecutive nights. Alternatively, the evaluation of bioassay measurement results may be normalized to a single day's excretion using reference volumes of $1600 \mathrm{ml} / \mathrm{d}$ for males and $1200 \mathrm{ml} / \mathrm{d}$ for females (ICRP 2002) if only a partial day's sample (e.g., single void) is obtained.

The sensitivity of urine sampling is limited by the presence of environmental levels of uranium. As discussed in Section 7.1.3, it is estimated that environmental levels in urine locally average $0.021 \mu \mathrm{g} / \mathrm{d}$ and range from non-detection to over $0.2 \mu \mathrm{g} / \mathrm{d}$. The net occupationally derived uranium in urine can be approximated by subtracting $0.02 \mu \mathrm{g} / \mathrm{d}$ (rounded) from the observed total daily excretion. Samples containing less than $0.2 \mu \mathrm{g} / \mathrm{d}$ of uranium are generally considered to be within the expected environmental range. As such, any result above $0.2 \mu \mathrm{g} / \mathrm{d}$ is initially considered to possibly contain occupationally derived uranium and the net amount attributed to occupational sources is generally calculated as the total observed amount minus the average expected environmental level of $0.02 \mu \mathrm{g} / \mathrm{d}$. Thus, $0.18 \mu \mathrm{g} / \mathrm{d}$ becomes the de facto minimum detectable occupational urine excretion rate.

Urine samples can be analyzed using either elemental mass or alpha radioactivity measurements. The above discussion of background uranium levels in urine can be converted from elemental uranium mass units to isotopic alpha activity units by multiplying by the specific activity for each constituent of natural uranium. Results are shown in Table 7.33. The minimum detectable uranium intakes based on the $0.18 \mu \mathrm{g} / \mathrm{d}$ net occupational excretions described above are shown in Table 7.34. The associated minimum detectable doses for Table 7.34 values of recycled uranium intakes are shown in Table 7.35 for committed effective doses and in Table 7.36 for committed equivalent doses to the critical organs. Committed effective doses are limiting for Type $S$ inhalation and insoluble ingestion so those intake modes are not included in Table 7.36. The committed effective doses are depicted graphically in Figure 7.8. The detection goal of 100 mrem is met out to one year after intake for instantaneous uptake, inhalation of Types $\mathrm{F}$ and $\mathrm{M}$, and soluble ingestion and is nearly met at 1 year for insoluble ingestion. Urinalysis for inhalations of Type S material should be complemented by in vivo counting, but the compliance 50-rem dose limit to the ET can be met for several years after an intake. The doses for natural uranium and depleted uranium are lower by ratios that can be determined from Table 7.20.

Table 7.33. Natural Uranium Background Levels for Hanford Bioassay Urinalysis

\begin{tabular}{ccc}
\hline & $\begin{array}{c}\text { Geometric } \\
\text { Mean Excretion }\end{array}$ & $\begin{array}{c}\text { Normal Upper Bound } \\
\text { Screening Level }\end{array}$ \\
\hline Elemental U(mass) & $0.021 \mu \mathrm{g} / \mathrm{d}$ & $0.2 \mu \mathrm{g} / \mathrm{d}$ \\
${ }^{238} \mathrm{U}$ & $0.0070 \mathrm{dpm} / \mathrm{d}$ & $0.15 \mathrm{dpm} / \mathrm{d}$ \\
${ }^{236} \mathrm{U}$ & negligible & negligible \\
${ }^{235} \mathrm{U}$ & $0.0003 \mathrm{dpm} / \mathrm{d}$ & $0.003 \mathrm{dpm} / \mathrm{d}$ \\
${ }^{234} \mathrm{U}$ & $0.0075 \mathrm{dpm} / \mathrm{d}$ & $0.16 \mathrm{dpm} / \mathrm{d}$ \\
\hline
\end{tabular}


Table 7.34. Minimum Detectable Intakes (mg) of Uranium Based on $0.18 \mu \mathrm{g} / \mathrm{d}$ in Urine ${ }^{(a)}$

\begin{tabular}{ccccccc}
\hline $\begin{array}{c}\text { Days Post } \\
\text { Intake }\end{array}$ & $\begin{array}{c}\text { Instantaneous } \\
\text { Uptake }\end{array}$ & $\begin{array}{c}\text { Type F } \\
\text { Inhalation }\end{array}$ & $\begin{array}{c}\text { Type M } \\
\text { Inhalation }\end{array}$ & $\begin{array}{c}\text { Type } S \\
\text { Inhalation }\end{array}$ & $\begin{array}{c}\text { Soluble } \\
\text { Ingestion }\end{array}$ & $\begin{array}{c}\text { Insoluble } \\
\text { Ingestion }\end{array}$ \\
\hline 1 & $2.79 \mathrm{E}-04$ & $9.80 \mathrm{E}-04$ & $7.75 \mathrm{E}-03$ & $2.56 \mathrm{E}-01$ & $1.43 \mathrm{E}-02$ & $1.43 \mathrm{E}-01$ \\
2 & $8.14 \mathrm{E}-03$ & $2.82 \mathrm{E}-02$ & $1.60 \mathrm{E}-01$ & $4.08 \mathrm{E}+00$ & $2.60 \mathrm{E}-01$ & $2.56 \mathrm{E}+00$ \\
3 & $1.00 \mathrm{E}-02$ & $3.50 \mathrm{E}-02$ & $2.11 \mathrm{E}-01$ & $6.92 \mathrm{E}+00$ & $4.88 \mathrm{E}-01$ & $4.87 \mathrm{E}+00$ \\
4 & $1.11 \mathrm{E}-02$ & $3.88 \mathrm{E}-02$ & $2.28 \mathrm{E}-01$ & $7.60 \mathrm{E}+00$ & $5.42 \mathrm{E}-01$ & $5.42 \mathrm{E}+00$ \\
5 & $1.22 \mathrm{E}-02$ & $4.27 \mathrm{E}-02$ & $2.45 \mathrm{E}-01$ & $8.20 \mathrm{E}+00$ & $5.98 \mathrm{E}-01$ & $5.97 \mathrm{E}+00$ \\
6 & $1.34 \mathrm{E}-02$ & $4.70 \mathrm{E}-02$ & $2.62 \mathrm{E}-01$ & $8.79 \mathrm{E}+00$ & $6.57 \mathrm{E}-01$ & $6.57 \mathrm{E}+00$ \\
7 & $1.47 \mathrm{E}-02$ & $5.15 \mathrm{E}-02$ & $2.79 \mathrm{E}-01$ & $9.39 \mathrm{E}+00$ & $7.21 \mathrm{E}-01$ & $7.20 \mathrm{E}+00$ \\
8 & $1.61 \mathrm{E}-02$ & $5.63 \mathrm{E}-02$ & $2.96 \mathrm{E}-01$ & $9.99 \mathrm{E}+00$ & $7.89 \mathrm{E}-01$ & $7.88 \mathrm{E}+00$ \\
9 & $1.75 \mathrm{E}-02$ & $6.15 \mathrm{E}-02$ & $3.13 \mathrm{E}-01$ & $1.06 \mathrm{E}+01$ & $8.61 \mathrm{E}-01$ & $8.61 \mathrm{E}+00$ \\
10 & $1.91 \mathrm{E}-02$ & $6.69 \mathrm{E}-02$ & $3.31 \mathrm{E}-01$ & $1.12 \mathrm{E}+01$ & $9.38 \mathrm{E}-01$ & $9.38 \mathrm{E}+00$ \\
14 & $2.64 \mathrm{E}-02$ & $9.26 \mathrm{E}-02$ & $4.03 \mathrm{E}-01$ & $1.38 \mathrm{E}+01$ & $1.30 \mathrm{E}+00$ & $1.30 \mathrm{E}+01$ \\
30 & $7.54 \mathrm{E}-02$ & $2.64 \mathrm{E}-01$ & $6.78 \mathrm{E}-01$ & $2.33 \mathrm{E}+01$ & $3.73 \mathrm{E}+00$ & $3.73 \mathrm{E}+01$ \\
60 & $2.26 \mathrm{E}-01$ & $7.94 \mathrm{E}-01$ & $1.08 \mathrm{E}+00$ & $3.48 \mathrm{E}+01$ & $1.13 \mathrm{E}+01$ & $1.13 \mathrm{E}+02$ \\
90 & $4.28 \mathrm{E}-01$ & $1.50 \mathrm{E}+00$ & $1.44 \mathrm{E}+00$ & $4.20 \mathrm{E}+01$ & $2.13 \mathrm{E}+01$ & $2.13 \mathrm{E}+02$ \\
180 & $1.65 \mathrm{E}+00$ & $5.77 \mathrm{E}+00$ & $2.76 \mathrm{E}+00$ & $5.47 \mathrm{E}+01$ & $8.21 \mathrm{E}+01$ & $8.21 \mathrm{E}+02$ \\
365 & $9.27 \mathrm{E}+00$ & $3.25 \mathrm{E}+01$ & $8.24 \mathrm{E}+00$ & $6.82 \mathrm{E}+01$ & $4.63 \mathrm{E}+02$ & $4.63 \mathrm{E}+03$ \\
$2 \mathrm{y}$ & $1.98 \mathrm{E}+01$ & $6.93 \mathrm{E}+01$ & $5.68 \mathrm{E}+01$ & $9.44 \mathrm{E}+01$ & $9.87 \mathrm{E}+02$ & $9.87 \mathrm{E}+03$ \\
$3 \mathrm{y}$ & $2.31 \mathrm{E}+01$ & $8.11 \mathrm{E}+01$ & $2.07 \mathrm{E}+02$ & $1.27 \mathrm{E}+02$ & $1.16 \mathrm{E}+03$ & $1.16 \mathrm{E}+04$ \\
$5 \mathrm{y}$ & $3.08 \mathrm{E}+01$ & $1.08 \mathrm{E}+02$ & $4.23 \mathrm{E}+02$ & $2.15 \mathrm{E}+02$ & $1.54 \mathrm{E}+03$ & $1.54 \mathrm{E}+04$ \\
$10 \mathrm{y}$ & $5.86 \mathrm{E}+01$ & $2.06 \mathrm{E}+02$ & $8.19 \mathrm{E}+02$ & $5.06 \mathrm{E}+02$ & $2.93 \mathrm{E}+03$ & $2.93 \mathrm{E}+04$ \\
$20 \mathrm{y}$ & $1.47 \mathrm{E}+02$ & $5.15 \mathrm{E}+02$ & $2.07 \mathrm{E}+03$ & $1.14 \mathrm{E}+03$ & $7.34 \mathrm{E}+03$ & $7.34 \mathrm{E}+04$ \\
$50 \mathrm{y}$ & $4.68 \mathrm{E}+02$ & $1.64 \mathrm{E}+03$ & $6.67 \mathrm{E}+03$ & $5.67 \mathrm{E}+03$ & $2.34 \mathrm{E}+04$ & $2.34 \mathrm{E}+05$ \\
\hline
\end{tabular}

(a) Assumes a $0.2-\mu \mathrm{g} / \mathrm{d}$ screening level with $0.02-\mu \mathrm{g} / \mathrm{d}$ mean background excretion subtracted.

In addition to the routine elemental mass and alpha spectroscopy analytical methods, inductively coupled plasma mass spectrometry (ICPMS) is capable of detecting the very small levels of ${ }^{236} \mathrm{U}$ associated with Hanford recycled uranium (Wyse et al. 1995). This procedure is not part of the routine monitoring program but is occasionally used as an investigational tool for high routine analyses (MacLellan et al. 1998).

Of special importance in the evaluation of uranium bioassay measurement capability is the potential for chronic intakes. Any chronic exposure subsequent to an acute intake could significantly affect the interpretation of the urinalysis measurement. In facilities where uncontained uranium is handled, urinalysis as a means for monitoring for acute intakes is acceptable, but quantitative assessment of intake or dose based on the results of routine urine samples can be subject to large uncertainties. At present, it is assumed that chronic occupational exposure of uranium at Hanford is not occurring. Assessment of inhalation intakes of Type $\mathrm{M}$ or S uranium using urinalysis should be cautiously performed and should consider available in vivo measurement results and other information regarding the exposure. 
Table 7.35. Minimum Detectable Committed Effective Doses (rem) for Recycled Uranium Based on $0.18 \mu \mathrm{g} / \mathrm{d}$ in Urine ${ }^{(a)}$

\begin{tabular}{ccccccc}
\hline $\begin{array}{c}\text { Days Post } \\
\text { Intake }\end{array}$ & $\begin{array}{c}\text { Instantaneous } \\
\text { Uptake }\end{array}$ & $\begin{array}{c}\text { Type F } \\
\text { Inhalation }\end{array}$ & $\begin{array}{c}\text { Type M } \\
\text { Inhalation }\end{array}$ & $\begin{array}{c}\text { Type S } \\
\text { Inhalation }\end{array}$ & $\begin{array}{c}\text { Soluble } \\
\text { Ingestion }\end{array}$ & $\begin{array}{c}\text { Insoluble } \\
\text { Ingestion }\end{array}$ \\
\hline 1 & $2.36 \mathrm{E}-06$ & $2.14 \mathrm{E}-06$ & $5.04 \mathrm{E}-05$ & $5.49 \mathrm{E}-03$ & $2.33 \mathrm{E}-06$ & $4.50 \mathrm{E}-06$ \\
2 & $6.88 \mathrm{E}-05$ & $6.16 \mathrm{E}-05$ & $1.04 \mathrm{E}-03$ & $8.78 \mathrm{E}-02$ & $4.24 \mathrm{E}-05$ & $8.03 \mathrm{E}-05$ \\
3 & $8.45 \mathrm{E}-05$ & $7.65 \mathrm{E}-05$ & $1.37 \mathrm{E}-03$ & $1.49 \mathrm{E}-01$ & $7.95 \mathrm{E}-05$ & $1.53 \mathrm{E}-04$ \\
4 & $9.34 \mathrm{E}-05$ & $8.46 \mathrm{E}-05$ & $1.48 \mathrm{E}-03$ & $1.63 \mathrm{E}-01$ & $8.83 \mathrm{E}-05$ & $1.70 \mathrm{E}-04$ \\
5 & $1.03 \mathrm{E}-04$ & $9.33 \mathrm{E}-05$ & $1.59 \mathrm{E}-03$ & $1.76 \mathrm{E}-01$ & $9.74 \mathrm{E}-05$ & $1.88 \mathrm{E}-04$ \\
6 & $1.13 \mathrm{E}-04$ & $1.03 \mathrm{E}-04$ & $1.70 \mathrm{E}-03$ & $1.89 \mathrm{E}-01$ & $1.07 \mathrm{E}-04$ & $2.06 \mathrm{E}-04$ \\
7 & $1.24 \mathrm{E}-04$ & $1.12 \mathrm{E}-04$ & $1.81 \mathrm{E}-03$ & $2.02 \mathrm{E}-01$ & $1.17 \mathrm{E}-04$ & $2.26 \mathrm{E}-04$ \\
8 & $1.36 \mathrm{E}-04$ & $1.23 \mathrm{E}-04$ & $1.92 \mathrm{E}-03$ & $2.15 \mathrm{E}-01$ & $1.29 \mathrm{E}-04$ & $2.48 \mathrm{E}-04$ \\
9 & $1.48 \mathrm{E}-04$ & $1.34 \mathrm{E}-04$ & $2.04 \mathrm{E}-03$ & $2.28 \mathrm{E}-01$ & $1.40 \mathrm{E}-04$ & $2.70 \mathrm{E}-04$ \\
10 & $1.61 \mathrm{E}-04$ & $1.46 \mathrm{E}-04$ & $2.15 \mathrm{E}-03$ & $2.42 \mathrm{E}-01$ & $1.53 \mathrm{E}-04$ & $2.95 \mathrm{E}-04$ \\
14 & $2.23 \mathrm{E}-04$ & $2.02 \mathrm{E}-04$ & $2.62 \mathrm{E}-03$ & $2.96 \mathrm{E}-01$ & $2.12 \mathrm{E}-04$ & $4.08 \mathrm{E}-04$ \\
30 & $6.36 \mathrm{E}-04$ & $5.77 \mathrm{E}-04$ & $4.41 \mathrm{E}-03$ & $5.01 \mathrm{E}-01$ & $6.07 \mathrm{E}-04$ & $1.17 \mathrm{E}-03$ \\
60 & $1.91 \mathrm{E}-03$ & $1.73 \mathrm{E}-03$ & $7.02 \mathrm{E}-03$ & $7.47 \mathrm{E}-01$ & $1.84 \mathrm{E}-03$ & $3.54 \mathrm{E}-03$ \\
90 & $3.62 \mathrm{E}-03$ & $3.28 \mathrm{E}-03$ & $9.39 \mathrm{E}-03$ & $9.04 \mathrm{E}-01$ & $3.48 \mathrm{E}-03$ & $6.70 \mathrm{E}-03$ \\
180 & $1.39 \mathrm{E}-02$ & $1.26 \mathrm{E}-02$ & $1.79 \mathrm{E}-02$ & $1.18 \mathrm{E}+00$ & $1.34 \mathrm{E}-02$ & $2.58 \mathrm{E}-02$ \\
365 & $7.83 \mathrm{E}-02$ & $7.10 \mathrm{E}-02$ & $5.36 \mathrm{E}-02$ & $1.47 \mathrm{E}+00$ & $7.55 \mathrm{E}-02$ & $1.45 \mathrm{E}-01$ \\
$2 \mathrm{y}$ & $1.67 \mathrm{E}-01$ & $1.51 \mathrm{E}-01$ & $3.69 \mathrm{E}-01$ & $2.03 \mathrm{E}+00$ & $1.61 \mathrm{E}-01$ & $3.10 \mathrm{E}-01$ \\
$3 \mathrm{y}$ & $1.95 \mathrm{E}-01$ & $1.77 \mathrm{E}-01$ & $1.34 \mathrm{E}+00$ & $2.74 \mathrm{E}+00$ & $1.88 \mathrm{E}-01$ & $3.63 \mathrm{E}-01$ \\
$5 \mathrm{y}$ & $2.60 \mathrm{E}-01$ & $2.36 \mathrm{E}-01$ & $2.75 \mathrm{E}+00$ & $4.62 \mathrm{E}+00$ & $2.51 \mathrm{E}-01$ & $4.84 \mathrm{E}-01$ \\
$10 \mathrm{y}$ & $4.95 \mathrm{E}-01$ & $4.49 \mathrm{E}-01$ & $5.33 \mathrm{E}+00$ & $1.09 \mathrm{E}+01$ & $4.78 \mathrm{E}-01$ & $9.21 \mathrm{E}-01$ \\
$20 \mathrm{y}$ & $1.24 \mathrm{E}+00$ & $1.12 \mathrm{E}+00$ & $1.35 \mathrm{E}+01$ & $2.45 \mathrm{E}+01$ & $1.20 \mathrm{E}+00$ & $2.30 \mathrm{E}+00$ \\
$50 \mathrm{y}$ & $3.95 \mathrm{E}+00$ & $3.59 \mathrm{E}+00$ & $4.34 \mathrm{E}+01$ & $1.22 \mathrm{E}+02$ & $3.82 \mathrm{E}+00$ & $7.35 \mathrm{E}+00$ \\
\hline
\end{tabular}

(a) Assumes a 0.2- $\mu \mathrm{g} / \mathrm{d}$ screening level with $0.02-\mu \mathrm{g} / \mathrm{d}$ mean background excretion subtracted.

\subsubsection{In Vivo Measurements}

Uranium is detectable in the lung using in vivo techniques. Detection is achieved by measuring photon emissions from ${ }^{235} \mathrm{U}$ and ${ }^{234} \mathrm{Th}$. Thorium-234 is a decay product of ${ }^{238} \mathrm{U}$ (half-life about 24 days) assumed to be in secular equilibrium for uranium contamination at Hanford. It is important to remember that this assumption will not be true if the uranium source material has been separated from its progeny elements within about 6 months. The Hanford method for in vivo measurement of uranium is chest counting using the low-energy planar germanium detectors, as described in the In Vivo Monitoring Program Manual (PNL-MA-574, TP Lynch. 2007). Current measurement protocols provide a nominal minimum detectable activity of $1.5 \mathrm{nCi}$ for ${ }^{234} \mathrm{Th}$ and $0.09 \mathrm{nCi}$ for ${ }^{235} \mathrm{U}$ for average chest wall thicknesses.

Table 7.37 shows the minimum detectable intakes of recycled uranium implied by the detection of $1.5 \mathrm{nCi}$ of ${ }^{234} \mathrm{Th}$ in the lung. The associated minimum detectable committed doses are listed in Table 7.38 and plotted in Figure 7.9. Tables 7.39, 7.40, and Figure 7.9 provide similar information based on the detection of $0.09 \mathrm{nCi}$ of ${ }^{235} \mathrm{U}$ in the lung. Collectively, these presentations show that routine in vivo measurements do not meet the bioassay monitoring goal of 100-mrem committed effective dose as a minimum detectable dose. Annual in vivo measurements can demonstrate compliance with dose limits for Type S inhalations and nearly so for Type $\mathrm{M}$ inhalations. In vivo measurements are especially valuable as a tool for measurements shortly following suspected inhalations of Type $\mathrm{M}$ or S material. 
Table 7.36. Minimum Detectable Committed Equivalent Doses (rem) to Critical Organs for Recycled Uranium Based on $0.18 \mu \mathrm{g} / \mathrm{d}$ in Urine ${ }^{(a)}$

\begin{tabular}{ccccc}
\hline $\begin{array}{c}\text { Days Post } \\
\text { Intake }\end{array}$ & $\begin{array}{c}\text { Instantaneous } \\
\text { Uptake, Dose to } \\
\text { Bone Surface }\end{array}$ & $\begin{array}{c}\text { Type F Inhalation, } \\
\text { Dose to Bone } \\
\text { Surface }\end{array}$ & $\begin{array}{c}\text { Type S Inhalation, } \\
\text { Dose to Extra- } \\
\text { Thoracic Tissue }\end{array}$ & $\begin{array}{c}\text { Soluble Ingestion, } \\
\text { Dose to Bone } \\
\text { Surface }\end{array}$ \\
\hline 1 & $4.71 \mathrm{E}-05$ & $3.84 \mathrm{E}-05$ & $6.11 \mathrm{E}-02$ & $3.61 \mathrm{E}-05$ \\
2 & $1.38 \mathrm{E}-03$ & $1.11 \mathrm{E}-03$ & $9.76 \mathrm{E}-01$ & $6.56 \mathrm{E}-04$ \\
3 & $1.69 \mathrm{E}-03$ & $1.38 \mathrm{E}-03$ & $1.65 \mathrm{E}+00$ & $1.23 \mathrm{E}-03$ \\
4 & $1.87 \mathrm{E}-03$ & $1.52 \mathrm{E}-03$ & $1.82 \mathrm{E}+00$ & $1.37 \mathrm{E}-03$ \\
5 & $2.06 \mathrm{E}-03$ & $1.68 \mathrm{E}-03$ & $1.96 \mathrm{E}+00$ & $1.51 \mathrm{E}-03$ \\
6 & $2.26 \mathrm{E}-03$ & $1.84 \mathrm{E}-03$ & $2.10 \mathrm{E}+00$ & $1.66 \mathrm{E}-03$ \\
7 & $2.48 \mathrm{E}-03$ & $2.02 \mathrm{E}-03$ & $2.24 \mathrm{E}+00$ & $1.82 \mathrm{E}-03$ \\
8 & $2.71 \mathrm{E}-03$ & $2.21 \mathrm{E}-03$ & $2.39 \mathrm{E}+00$ & $1.99 \mathrm{E}-03$ \\
9 & $2.96 \mathrm{E}-03$ & $2.41 \mathrm{E}-03$ & $2.54 \mathrm{E}+00$ & $2.17 \mathrm{E}-03$ \\
10 & $3.23 \mathrm{E}-03$ & $2.63 \mathrm{E}-03$ & $2.69 \mathrm{E}+00$ & $2.36 \mathrm{E}-03$ \\
14 & $4.46 \mathrm{E}-03$ & $3.64 \mathrm{E}-03$ & $3.29 \mathrm{E}+00$ & $3.28 \mathrm{E}-03$ \\
30 & $1.27 \mathrm{E}-02$ & $1.04 \mathrm{E}-02$ & $5.57 \mathrm{E}+00$ & $9.39 \mathrm{E}-03$ \\
60 & $3.82 \mathrm{E}-02$ & $3.12 \mathrm{E}-02$ & $8.31 \mathrm{E}+00$ & $2.84 \mathrm{E}-02$ \\
90 & $7.24 \mathrm{E}-02$ & $5.89 \mathrm{E}-02$ & $1.00 \mathrm{E}+01$ & $5.38 \mathrm{E}-02$ \\
180 & $2.78 \mathrm{E}-01$ & $2.27 \mathrm{E}-01$ & $1.31 \mathrm{E}+01$ & $2.07 \mathrm{E}-01$ \\
365 & $1.57 \mathrm{E}+00$ & $1.28 \mathrm{E}+00$ & $1.63 \mathrm{E}+01$ & $1.17 \mathrm{E}+00$ \\
$2 \mathrm{y}$ & $3.34 \mathrm{E}+00$ & $2.72 \mathrm{E}+00$ & $2.26 \mathrm{E}+01$ & $2.49 \mathrm{E}+00$ \\
$3 \mathrm{y}$ & $3.91 \mathrm{E}+00$ & $3.18 \mathrm{E}+00$ & $3.04 \mathrm{E}+01$ & $2.91 \mathrm{E}+00$ \\
$5 \mathrm{y}$ & $5.20 \mathrm{E}+00$ & $4.24 \mathrm{E}+00$ & $5.13 \mathrm{E}+01$ & $3.88 \mathrm{E}+00$ \\
$10 \mathrm{y}$ & $9.91 \mathrm{E}+00$ & $8.07 \mathrm{E}+00$ & $1.21 \mathrm{E}+02$ & $7.39 \mathrm{E}+00$ \\
$20 \mathrm{y}$ & $2.48 \mathrm{E}+01$ & $2.02 \mathrm{E}+01$ & $2.72 \mathrm{E}+02$ & $1.85 \mathrm{E}+01$ \\
$50 \mathrm{y}$ & $7.91 \mathrm{E}+01$ & $6.44 \mathrm{E}+010$ & $1.36 \mathrm{E}+03$ & $5.90 \mathrm{E}+01$ \\
\hline
\end{tabular}

(a) Assumes a $0.2-\mu \mathrm{g} / \mathrm{d}$ screening level with $0.02-\mu \mathrm{g} / \mathrm{d}$ mean background excretion subtracted.

In vivo measurements of ${ }^{235} \mathrm{U}$ and ${ }^{234} \mathrm{Th}$ are used as co-indicators of natural and recycled uranium based on the isotopic compositions shown in Tables 7.2 and 7.4. These compositions and the minimum detectable doses (MDDs) of Tables 7.38 and 7.40 show that ${ }^{234} \mathrm{Th}$ and ${ }^{235} \mathrm{U}$ are roughly comparable indicators of recycled uranium. This is readily apparent in Figure 7.9. For depleted and natural uranium mixtures, the ${ }^{234} \mathrm{Th}$ measurement will be more sensitive. These two results, i.e., for ${ }^{234} \mathrm{Th}$ and ${ }^{235} \mathrm{U}$, obtained from a single in vivo chest measurement, can be used as independent verification of the presence of slightly enriched uranium, or alternatively as a method of identifying potential false-positive detections. For example, the relative isotopic activity abundance of ${ }^{238} U$ to ${ }^{235} U$ for a mixture can be multiplied by the detected amount of ${ }^{235} \mathrm{U}$. This result (the ${ }^{238} \mathrm{U}$ implied by the ${ }^{235} \mathrm{U}$ measurement) can then be compared with the measured activity of ${ }^{234} \mathrm{Th}$ (assumed to be in equilibrium with the ${ }^{238} \mathrm{U}$ ) to determine if the measurements reasonably agree. 


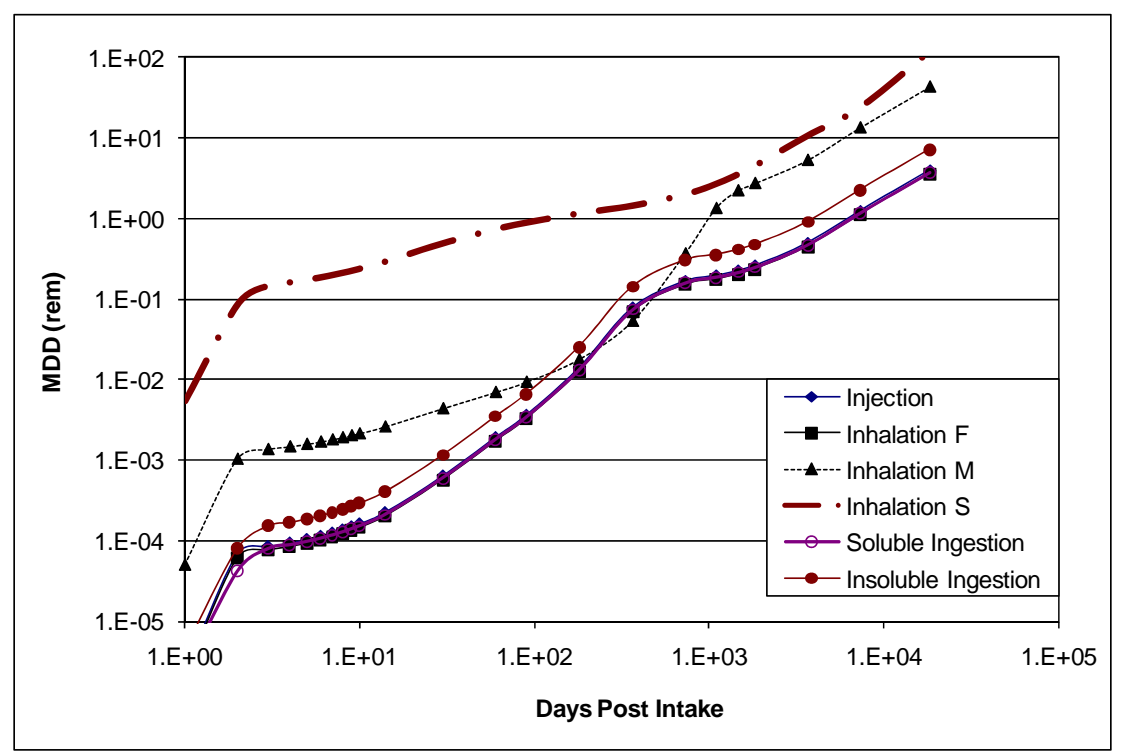

Figure 7.8. Minimum Detectable Committed Effective Dose for Recycled Uranium Based on $0.18 \mu \mathrm{g} / \mathrm{d}$ Net Urine Excretion (Curves for injection, Type F inhalation, and soluble ingestion are indistinguishable.)

Table 7.37. Minimum Detectable Intakes (mg) of Recycled Uranium Based on $1.5 \mathrm{nCi}^{234} \mathrm{Th}$ in Chest Count $^{(a, b)}$

\begin{tabular}{ccc}
\hline Days Post Intake & Type M Inhalation & Type S Inhalation \\
\hline 0.5 & $7.54 \mathrm{E}+01$ & $6.78 \mathrm{E}+01$ \\
1 & $7.83 \mathrm{E}+01$ & $7.02 \mathrm{E}+01$ \\
2 & $8.06 \mathrm{E}+01$ & $7.19 \mathrm{E}+01$ \\
3 & $8.20 \mathrm{E}+01$ & $7.28 \mathrm{E}+01$ \\
4 & $8.33 \mathrm{E}+01$ & $7.36 \mathrm{E}+01$ \\
5 & $8.45 \mathrm{E}+01$ & $7.43 \mathrm{E}+01$ \\
6 & $8.58 \mathrm{E}+01$ & $7.50 \mathrm{E}+01$ \\
7 & $8.70 \mathrm{E}+01$ & $7.58 \mathrm{E}+01$ \\
8 & $8.83 \mathrm{E}+01$ & $7.65 \mathrm{E}+01$ \\
9 & $8.95 \mathrm{E}+01$ & $7.72 \mathrm{E}+01$ \\
10 & $9.08 \mathrm{E}+01$ & $7.79 \mathrm{E}+01$ \\
14 & $9.60 \mathrm{E}+01$ & $8.07 \mathrm{E}+01$ \\
30 & $1.17 \mathrm{E}+02$ & $9.14 \mathrm{E}+01$ \\
60 & $1.61 \mathrm{E}+02$ & $1.08 \mathrm{E}+02$ \\
90 & $2.07 \mathrm{E}+02$ & $1.20 \mathrm{E}+02$ \\
180 & $3.78 \mathrm{E}+02$ & $1.41 \mathrm{E}+02$ \\
365 & $1.13 \mathrm{E}+03$ & $1.70 \mathrm{E}+02$ \\
$2 \mathrm{y}$ & NA & $2.36 \mathrm{E}+02$ \\
$3 \mathrm{y}$ & NA & $3.22 \mathrm{E}+02$ \\
$5 \mathrm{y}$ & NA & $5.53 \mathrm{E}+02$ \\
\hline
\end{tabular}

(a) Assumes secular equilibrium with ${ }^{238} U$.

(b) Implies a minimum detectable amount of $4.5 \mathrm{mg}$ recycled uranium, based on Table 7.3 isotopic composition.

$\mathrm{NA}=$ not applicable. 
Table 7.38. Minimum Detectable Committed Doses for Recycled Uranium Based on $1.5 \mathrm{nCi}^{234} \mathrm{Th}$ in Chest Count ${ }^{(a, b)}$

\begin{tabular}{cccc}
\hline $\begin{array}{c}\text { Days Post } \\
\text { Intake }\end{array}$ & $\begin{array}{c}\text { Inhalation Type M, } \\
\text { Effective Dose (rem) }\end{array}$ & $\begin{array}{c}\text { Inhalation Type S, } \\
\text { Effective Dose (rem) }\end{array}$ & $\begin{array}{c}\text { Inhalation Type S, } \\
\text { Equivalent Dose to } \\
\text { Extrathoracic Tissues (rem) }\end{array}$ \\
\hline 0.5 & $4.90 \mathrm{E}-01$ & $1.46 \mathrm{E}+00$ & $1.62 \mathrm{E}+01$ \\
1 & $5.09 \mathrm{E}-01$ & $1.51 \mathrm{E}+00$ & $1.68 \mathrm{E}+01$ \\
2 & $5.24 \mathrm{E}-01$ & $1.55 \mathrm{E}+00$ & $1.72 \mathrm{E}+01$ \\
3 & $5.33 \mathrm{E}-01$ & $1.57 \mathrm{E}+00$ & $1.74 \mathrm{E}+01$ \\
4 & $5.41 \mathrm{E}-01$ & $1.58 \mathrm{E}+00$ & $1.76 \mathrm{E}+01$ \\
5 & $5.49 \mathrm{E}-01$ & $1.60 \mathrm{E}+00$ & $1.78 \mathrm{E}+01$ \\
6 & $5.57 \mathrm{E}-01$ & $1.61 \mathrm{E}+00$ & $1.79 \mathrm{E}+01$ \\
7 & $5.66 \mathrm{E}-01$ & $1.63 \mathrm{E}+00$ & $1.81 \mathrm{E}+01$ \\
8 & $5.74 \mathrm{E}-01$ & $1.64 \mathrm{E}+00$ & $1.83 \mathrm{E}+01$ \\
9 & $5.82 \mathrm{E}-01$ & $1.66 \mathrm{E}+00$ & $1.85 \mathrm{E}+01$ \\
10 & $5.90 \mathrm{E}-01$ & $1.68 \mathrm{E}+00$ & $1.86 \mathrm{E}+01$ \\
14 & $6.24 \mathrm{E}-01$ & $1.74 \mathrm{E}+00$ & $1.93 \mathrm{E}+01$ \\
30 & $7.64 \mathrm{E}-01$ & $1.96 \mathrm{E}+00$ & $2.18 \mathrm{E}+01$ \\
60 & $1.04 \mathrm{E}+00$ & $2.32 \mathrm{E}+00$ & $2.58 \mathrm{E}+01$ \\
90 & $1.34 \mathrm{E}+00$ & $2.58 \mathrm{E}+00$ & $2.86 \mathrm{E}+01$ \\
180 & $2.46 \mathrm{E}+00$ & $3.03 \mathrm{E}+00$ & $3.37 \mathrm{E}+01$ \\
365 & $7.34 \mathrm{E}+00$ & $3.66 \mathrm{E}+00$ & $4.07 \mathrm{E}+01$ \\
$2 \mathrm{y}$ & NA & $5.08 \mathrm{E}+00$ & $5.65 \mathrm{E}+01$ \\
$3 \mathrm{y}$ & NA & $6.92 \mathrm{E}+00$ & $7.69 \mathrm{E}+01$ \\
\hline
\end{tabular}

(a) Assumes secular equilibrium with ${ }^{238} \mathrm{U}$.

(b) Implies a minimum detectable amount of $4.5 \mathrm{mg}$ recycled uranium, based on Table 7.3 isotopic composition.

NA = not applicable.

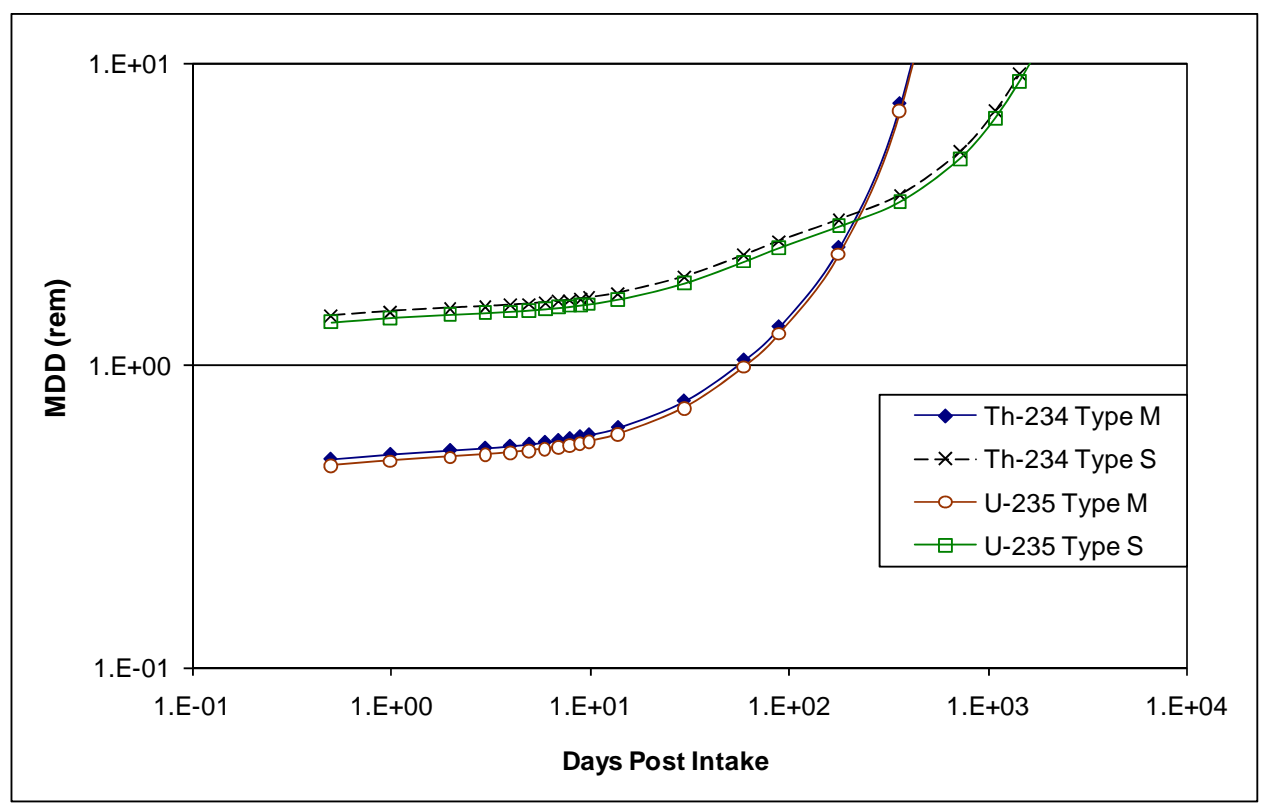

Figure 7.9. Minimum Detectable Committed Effective Dose for Recycled Uranium Based on $1.5 \mathrm{nCi}$ ${ }^{234} \mathrm{Th}$ or $0.09 \mathrm{nCi}^{235} \mathrm{U}$ in a Chest Count 
Table 7.39. Minimum Detectable Intakes (mg) of Recycled Uranium Based on $0.09 \mathrm{nCi}$

\begin{tabular}{|c|c|c|}
\hline Days Post Intake & Type M Inhalation & Type S Inhalation \\
\hline 0.5 & 7.17E+01 & $6.44 \mathrm{E}+01$ \\
\hline 1 & $7.44 \mathrm{E}+01$ & $6.67 \mathrm{E}+01$ \\
\hline 2 & $7.66 \mathrm{E}+01$ & $6.84 \mathrm{E}+01$ \\
\hline 3 & $7.79 \mathrm{E}+01$ & $6.92 \mathrm{E}+01$ \\
\hline 4 & $7.91 \mathrm{E}+01$ & $6.99 \mathrm{E}+01$ \\
\hline 5 & $8.03 \mathrm{E}+01$ & $7.06 \mathrm{E}+01$ \\
\hline 6 & $8.15 \mathrm{E}+01$ & $7.13 \mathrm{E}+01$ \\
\hline 7 & $8.27 \mathrm{E}+01$ & $7.20 \mathrm{E}+01$ \\
\hline 8 & $8.39 \mathrm{E}+01$ & $7.27 \mathrm{E}+01$ \\
\hline 9 & $8.51 \mathrm{E}+01$ & $7.34 \mathrm{E}+01$ \\
\hline 10 & $8.63 \mathrm{E}+01$ & $7.40 \mathrm{E}+01$ \\
\hline 14 & $9.12 \mathrm{E}+01$ & $7.67 \mathrm{E}+01$ \\
\hline 30 & $1.12 \mathrm{E}+02$ & $8.68 \mathrm{E}+01$ \\
\hline 60 & $1.53 \mathrm{E}+02$ & $1.02 \mathrm{E}+02$ \\
\hline 90 & $1.96 \mathrm{E}+02$ & $1.14 \mathrm{E}+02$ \\
\hline 180 & $3.59 \mathrm{E}+02$ & $1.34 \mathrm{E}+02$ \\
\hline 365 & $1.07 \mathrm{E}+03$ & $1.62 \mathrm{E}+02$ \\
\hline $2 \mathrm{y}$ & NA & $2.25 \mathrm{E}+02$ \\
\hline $3 \mathrm{y}$ & NA & $3.06 \mathrm{E}+02$ \\
\hline $5 \mathrm{y}$ & NA & $5.26 \mathrm{E}+02$ \\
\hline $\begin{array}{l}\text { (a) Implies a min } \\
\text { based on Tabl } \\
\text { NA = not applicab }\end{array}$ & $\begin{array}{l}\text { detectable amount } \\
\text { isotopic compositio }\end{array}$ & ng recycled uranium \\
\hline
\end{tabular}

\subsubsection{Fecal Sample Measurements}

Fecal samples are useful for confirming and evaluating suspected Type $\mathrm{M}$ and $\mathrm{S}$ inhalation and ingestion exposures, especially at times shortly after the suspected intake. The sample results can be used with the models to estimate the magnitudes of intakes and initial lung depositions as a basis for lung dose assessment. They can also be used as checks on urine- or in vivo-based estimates of intake. In addition, fecal samples can provide radionuclide identification data and isotope ratios. In this regard, they are preferred to urine samples. Fecal samples are of primary value immediately after a suspected intake when material is rapidly clearing the respiratory and GI tracts. Long-term sampling after intake can be useful for differentiating ingestion from inhalation and Type $\mathrm{M}$ from Type $\mathrm{S}$ inhalation provided there is no chance of new ingestion intakes and the contribution from the occupational intake is much larger than excretion from natural background sources, assumed to be about $2 \mu \mathrm{g} / \mathrm{d}$. Fecal sampling after incidents can be used effectively for isotopic mixtures considerably different from natural uranium, as for depleted uranium or highly enriched uranium. It is usually not of much value at long times post intake, because of the level and variability of excretion from intakes of natural background sources. Table 7.41 lists minimum detectable intakes of uranium based on the detection of a net excretion of 2- $\mu \mathrm{g} / \mathrm{d}$ uranium above the background level. Table 7.42 and Figure 7.10 show the minimum detectable doses associated with the Table 7.41 intakes for recycled uranium. The table and figure show that fecal sampling can meet the 100-mrem effective dose goal within the first 2 months after an intake for Type $M$ and within the first 21 days for Type $\mathrm{S}$ inhalations. The associated doses for natural and depleted uranium are lower. 
Table 7.40. Minimum Detectable Committed Doses for Recycled Uranium Based on $0.09 \mathrm{nCi}^{235} \mathrm{U}$ in Chest Count ${ }^{(a)}$

\begin{tabular}{cccc}
\hline $\begin{array}{c}\text { Days Post } \\
\text { Intake }\end{array}$ & $\begin{array}{c}\text { Inhalation Type M, } \\
\text { Effective Dose (rem) }\end{array}$ & $\begin{array}{c}\text { Inhalation Type S, } \\
\text { Effective Dose (rem) }\end{array}$ & $\begin{array}{c}\text { Inhalation Type S, } \\
\text { Equivalent Dose to } \\
\text { Extrathoracic Tissues (rem) }\end{array}$ \\
\hline 0.5 & $4.66 \mathrm{E}-01$ & $1.38 \mathrm{E}+00$ & $1.54 \mathrm{E}+01$ \\
1 & $4.83 \mathrm{E}-01$ & $1.43 \mathrm{E}+00$ & $1.59 \mathrm{E}+01$ \\
2 & $4.98 \mathrm{E}-01$ & $1.47 \mathrm{E}+00$ & $1.63 \mathrm{E}+01$ \\
3 & $5.07 \mathrm{E}-01$ & $1.49 \mathrm{E}+00$ & $1.65 \mathrm{E}+01$ \\
4 & $5.14 \mathrm{E}-01$ & $1.50 \mathrm{E}+00$ & $1.67 \mathrm{E}+01$ \\
5 & $5.22 \mathrm{E}-01$ & $1.52 \mathrm{E}+00$ & $1.69 \mathrm{E}+01$ \\
6 & $5.30 \mathrm{E}-01$ & $1.53 \mathrm{E}+00$ & $1.70 \mathrm{E}+01$ \\
7 & $5.37 \mathrm{E}-01$ & $1.55 \mathrm{E}+00$ & $1.72 \mathrm{E}+01$ \\
8 & $5.45 \mathrm{E}-01$ & $1.56 \mathrm{E}+00$ & $1.74 \mathrm{E}+01$ \\
9 & $5.53 \mathrm{E}-01$ & $1.58 \mathrm{E}+00$ & $1.75 \mathrm{E}+01$ \\
10 & $5.61 \mathrm{E}-01$ & $1.59 \mathrm{E}+00$ & $1.77 \mathrm{E}+01$ \\
14 & $5.93 \mathrm{E}-01$ & $1.65 \mathrm{E}+00$ & $1.83 \mathrm{E}+01$ \\
30 & $7.26 \mathrm{E}-01$ & $1.87 \mathrm{E}+00$ & $2.08 \mathrm{E}+01$ \\
60 & $9.92 \mathrm{E}-01$ & $2.20 \mathrm{E}+00$ & $2.45 \mathrm{E}+01$ \\
90 & $1.28 \mathrm{E}+00$ & $2.45 \mathrm{E}+00$ & $2.72 \mathrm{E}+01$ \\
180 & $2.34 \mathrm{E}+00$ & $2.88 \mathrm{E}+00$ & $3.20 \mathrm{E}+01$ \\
365 & $6.98 \mathrm{E}+00$ & $3.48 \mathrm{E}+00$ & $3.87 \mathrm{E}+01$ \\
$2 \mathrm{y}$ & NA & $4.83 \mathrm{E}+00$ & $5.37 \mathrm{E}+01$ \\
$3 \mathrm{y}$ & NA & $6.57 \mathrm{E}+00$ & $7.31 \mathrm{E}+01$ \\
\hline
\end{tabular}

(a) Implies a minimum detectable amount of $4.3 \mathrm{mg}$ recycled uranium, based on Table 7.3 isotopic composition.

NA = not applicable.

Table 7.41. Minimum Detectable Intakes (mg) of Uranium Based on $2 \mu \mathrm{g} / \mathrm{d}$ in Feces ${ }^{(\mathrm{a})}$

\begin{tabular}{rcccc}
\hline Days Post Intake & Inhalation Type M & Inhalation Type S & Soluble Ingestion & Insoluble Ingestion \\
\hline 1 & $1.87 \mathrm{E}-02$ & $1.76 \mathrm{E}-02$ & $7.19 \mathrm{E}-03$ & $7.09 \mathrm{E}-03$ \\
2 & $1.32 \mathrm{E}-02$ & $1.23 \mathrm{E}-02$ & $5.25 \mathrm{E}-03$ & $5.15 \mathrm{E}-03$ \\
3 & $2.57 \mathrm{E}-02$ & $2.38 \mathrm{E}-02$ & $1.04 \mathrm{E}-02$ & $1.02 \mathrm{E}-02$ \\
4 & $6.12 \mathrm{E}-02$ & $5.67 \mathrm{E}-02$ & $2.52 \mathrm{E}-02$ & $2.46 \mathrm{E}-02$ \\
5 & $1.54 \mathrm{E}-01$ & $1.43 \mathrm{E}-01$ & $6.52 \mathrm{E}-02$ & $6.38 \mathrm{E}-02$ \\
6 & $3.84 \mathrm{E}-01$ & $3.54 \mathrm{E}-01$ & $1.74 \mathrm{E}-01$ & $1.70 \mathrm{E}-01$ \\
7 & $8.87 \mathrm{E}-01$ & $8.10 \mathrm{E}-01$ & $4.67 \mathrm{E}-01$ & $4.58 \mathrm{E}-01$ \\
8 & $1.75 \mathrm{E}+00$ & $1.57 \mathrm{E}+00$ & $1.27 \mathrm{E}+00$ & $1.24 \mathrm{E}+00$ \\
9 & $2.76 \mathrm{E}+00$ & $2.43 \mathrm{E}+00$ & $3.43 \mathrm{E}+00$ & $3.36 \mathrm{E}+00$ \\
10 & $3.57 \mathrm{E}+00$ & $3.09 \mathrm{E}+00$ & $9.30 \mathrm{E}+00$ & $9.12 \mathrm{E}+00$ \\
11 & $4.06 \mathrm{E}+00$ & $3.48 \mathrm{E}+00$ & $2.51 \mathrm{E}+01$ & $2.48 \mathrm{E}+01$ \\
12 & $4.35 \mathrm{E}+00$ & $3.70 \mathrm{E}+00$ & $6.74 \mathrm{E}+01$ & $6.73 \mathrm{E}+01$ \\
13 & $4.55 \mathrm{E}+00$ & $3.85 \mathrm{E}+00$ & $1.78 \mathrm{E}+02$ & $1.82 \mathrm{E}+02$ \\
14 & $4.71 \mathrm{E}+00$ & $3.96 \mathrm{E}+00$ & $4.48 \mathrm{E}+02$ & $4.92 \mathrm{E}+02$ \\
30 & $7.36 \mathrm{E}+00$ & $5.71 \mathrm{E}+00$ & $8.95 \mathrm{E}+03$ & NA \\
60 & $1.60 \mathrm{E}+01$ & $1.08 \mathrm{E}+01$ & NA & NA \\
90 & $3.21 \mathrm{E}+01$ & $1.87 \mathrm{E}+01$ & NA & NA \\
180 & $1.41 \mathrm{E}+02$ & $5.37 \mathrm{E}+01$ & NA & NA \\
\hline
\end{tabular}

(a) Assumes net excretion when corrected for nominal background 1.4 to $1.8 \mu \mathrm{g} / \mathrm{d}$.

NA = not applicable. 
Table 7.42. Minimum Detectable Committed Doses (rem) for Recycled Uranium Based on $2 \mu \mathrm{g} / \mathrm{d}$ in Feces $^{(a)}$

\begin{tabular}{rcccccc}
\hline $\begin{array}{c}\text { Days Post } \\
\text { Intake }\end{array}$ & $\begin{array}{c}\text { Inhalation } \\
\text { Type M, } \\
\text { Effective Dose }\end{array}$ & $\begin{array}{c}\text { Inhalation } \\
\text { Type S, } \\
\text { Effective Dose }\end{array}$ & $\begin{array}{c}\text { Inhalation } \\
\text { Type S, Dose to } \\
\text { Extrathoracic } \\
\text { Tissue }\end{array}$ & $\begin{array}{c}\text { Soluble } \\
\text { Ingestion, } \\
\text { Effective } \\
\text { Dose }\end{array}$ & $\begin{array}{c}\text { Soluble } \\
\text { Ingestion, } \\
\text { Dose to Bone } \\
\text { Surface }\end{array}$ & $\begin{array}{c}\text { Insoluble } \\
\text { Ingestion, } \\
\text { Effective } \\
\text { Dose }\end{array}$ \\
\hline 1 & $1.22 \mathrm{E}-04$ & $3.77 \mathrm{E}-04$ & $4.20 \mathrm{E}-03$ & $1.17 \mathrm{E}-06$ & $1.81 \mathrm{E}-05$ & $2.23 \mathrm{E}-07$ \\
2 & $8.58 \mathrm{E}-05$ & $2.64 \mathrm{E}-04$ & $2.94 \mathrm{E}-03$ & $8.56 \mathrm{E}-07$ & $1.32 \mathrm{E}-05$ & $1.62 \mathrm{E}-07$ \\
3 & $1.67 \mathrm{E}-04$ & $5.13 \mathrm{E}-04$ & $5.70 \mathrm{E}-03$ & $1.69 \mathrm{E}-06$ & $2.62 \mathrm{E}-05$ & $3.20 \mathrm{E}-07$ \\
4 & $3.98 \mathrm{E}-04$ & $1.22 \mathrm{E}-03$ & $1.36 \mathrm{E}-02$ & $4.10 \mathrm{E}-06$ & $6.34 \mathrm{E}-05$ & $7.73 \mathrm{E}-07$ \\
5 & $1.00 \mathrm{E}-03$ & $3.06 \mathrm{E}-03$ & $3.41 \mathrm{E}-02$ & $1.06 \mathrm{E}-05$ & $1.64 \mathrm{E}-04$ & $2.00 \mathrm{E}-06$ \\
6 & $2.50 \mathrm{E}-03$ & $7.61 \mathrm{E}-03$ & $8.45 \mathrm{E}-02$ & $2.83 \mathrm{E}-05$ & $4.37 \mathrm{E}-04$ & $5.33 \mathrm{E}-06$ \\
7 & $5.77 \mathrm{E}-03$ & $1.74 \mathrm{E}-02$ & $1.94 \mathrm{E}-01$ & $7.62 \mathrm{E}-05$ & $1.18 \mathrm{E}-03$ & $1.44 \mathrm{E}-05$ \\
8 & $1.14 \mathrm{E}-02$ & $3.38 \mathrm{E}-02$ & $3.76 \mathrm{E}-01$ & $2.06 \mathrm{E}-04$ & $3.19 \mathrm{E}-03$ & $3.89 \mathrm{E}-05$ \\
9 & $1.80 \mathrm{E}-02$ & $5.24 \mathrm{E}-02$ & $5.82 \mathrm{E}-01$ & $5.59 \mathrm{E}-04$ & $8.64 \mathrm{E}-03$ & $1.06 \mathrm{E}-04$ \\
10 & $2.32 \mathrm{E}-02$ & $6.65 \mathrm{E}-02$ & $7.39 \mathrm{E}-01$ & $1.52 \mathrm{E}-03$ & $2.34 \mathrm{E}-02$ & $2.87 \mathrm{E}-04$ \\
11 & $2.64 \mathrm{E}-02$ & $7.48 \mathrm{E}-02$ & $8.32 \mathrm{E}-01$ & $4.10 \mathrm{E}-03$ & $6.33 \mathrm{E}-02$ & $7.78 \mathrm{E}-04$ \\
12 & $2.83 \mathrm{E}-02$ & $7.96 \mathrm{E}-02$ & $8.85 \mathrm{E}-01$ & $1.10 \mathrm{E}-02$ & $1.70 \mathrm{E}-01$ & $2.11 \mathrm{E}-03$ \\
13 & $2.96 \mathrm{E}-02$ & $8.27 \mathrm{E}-02$ & $9.19 \mathrm{E}-01$ & $2.90 \mathrm{E}-02$ & $4.48 \mathrm{E}-01$ & $5.72 \mathrm{E}-03$ \\
14 & $3.06 \mathrm{E}-02$ & $8.51 \mathrm{E}-02$ & $9.46 \mathrm{E}-01$ & $7.31 \mathrm{E}-02$ & $1.13 \mathrm{E}+00$ & $1.54 \mathrm{E}-02$ \\
30 & $4.78 \mathrm{E}-02$ & $1.23 \mathrm{E}-01$ & $1.37 \mathrm{E}+00$ & $1.46 \mathrm{E}+00$ & $2.26 \mathrm{E}+01$ & $2.81 \mathrm{E}+00$ \\
60 & $1.04 \mathrm{E}-01$ & $2.32 \mathrm{E}-01$ & $2.57 \mathrm{E}+00$ & $3.27 \mathrm{E}+00$ & $5.06 \mathrm{E}+01$ & $6.31 \mathrm{E}+00$ \\
90 & $2.09 \mathrm{E}-01$ & $4.03 \mathrm{E}-01$ & $4.48 \mathrm{E}+00$ & $5.92 \mathrm{E}+00$ & $9.15 \mathrm{E}+01$ & $1.14 \mathrm{E}+01$ \\
180 & $9.15 \mathrm{E}-01$ & $1.15 \mathrm{E}+00$ & $1.28 \mathrm{E}+01$ & $2.25 \mathrm{E}+01$ & $3.48 \mathrm{E}+02$ & NA \\
\hline
\end{tabular}

(a) Assumes net excretion when corrected for nominal background of 1.4 to $1.8 \mu \mathrm{g} / \mathrm{d}$.

NA = not applicable.

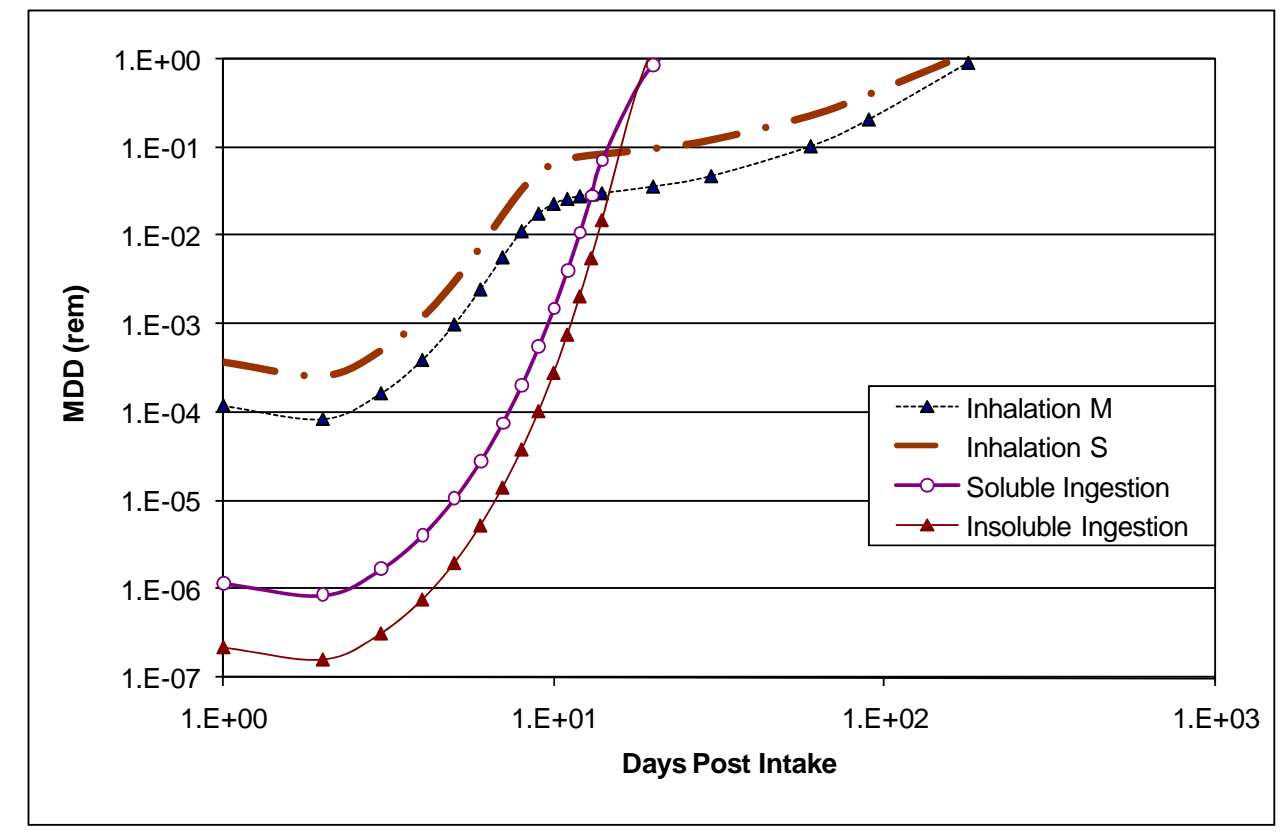

Figure 7.10. Minimum Detectable Committed Effective Doses (rem) of Recycled Uranium Based on $2 \mu \mathrm{g} / \mathrm{d}$ Above Background in Feces 


\subsubsection{Routine Bioassay Monitoring Program}

Because of the high variability in background uranium excretion in urine, all workers involved in uranium bioassay should have a baseline bioassay prior to commencing uranium work. In addition, significant changes in geographic location (e.g., moving from a private groundwater well to a surface water supply or vice versa) may warrant reestablishing a baseline excretion.

A contractor request urinalysis may be obtained as a non-periodic measurement after completion of a specific task involving potential uranium exposure. This approach may provide a cost-effective monitoring program for workers with infrequent potential for occupational uranium intakes, and may permit higher supplemental screening levels based on the time following the potential for intake.

The interpretation of routine urinalysis measurements is highly dependent on the nature of the intake, i.e., low-level chronic exposure conditions significantly affect the interpretation of bioassay measurements. Chronic exposures to uranium have occurred in the $\mathrm{UO}_{3}$ Plant, 300 Area Fuel Production Facilities, and the 306-W Building, but are no longer normal conditions, and thus bioassay protocols for chronic exposure have been terminated. Chronic exposure bioassay programs for these facilities were most recently described in Technical Basis for Internal Dosimetry at Hanford (Sula et al. 1991). If such exposure conditions return, the current bioassay program recommendations will be reconsidered. The discussion below addresses bioassay monitoring for acute intakes, which are now considered to be the most likely intake scenarios.

\subsubsection{Type F Routine Monitoring}

Routine bioassay monitoring for acute inhalations of highly soluble uranium (Type F) should consist of a minimum of quarterly urinalyses using a dose assessment screening level of $0.5-\mu \mathrm{g} / \mathrm{d}$, based on Table 7.24. Such a program provides adequate assurance that potentially significant doses do not go undetected and that the chemical toxicity threshold level has not been exceeded. Results between the upper bound of normal background $(0.2-\mu \mathrm{g} / \mathrm{d})$ and $0.5-\mu \mathrm{g} / \mathrm{d}$ may indicate that slight intakes have occurred but may not require individual dose assessment. Results above $0.5-\mu \mathrm{g} / \mathrm{d}$ should be investigated. Results above $1 \mu \mathrm{g} / \mathrm{d}$ suggest that the transient chemical toxicity level might have been exceeded; however, a more recent intake or chronic low-level nonoccupational ingestion could significantly affect interpretation. More frequent sampling (e.g., monthly) allows for the use of substantially higher screening levels (e.g., $30 \mu \mathrm{g} / \mathrm{d}$ as a screening level for investigation and dose assessment, and $7 \mu \mathrm{g} / \mathrm{d}$ as a screening level for transient chemical toxicity).

Chest counting is not warranted as periodic bioassay for acute Type F uranium monitoring.

\subsubsection{Type M Routine Monitoring}

Annual urinalysis for Type $\mathrm{M}$ recycled uranium meets the bioassay goal of 100-mrem committed effective dose. Any result exceeding the $0.2-\mu \mathrm{g} / \mathrm{d}$ environmental screening level should be investigated for potential occupational intake resulting in a committed effective dose exceeding 10 mrem.

Annual chest counting is appropriate for highly enriched, Type $\mathrm{M}$ or S uranium, which are rarely encountered at Hanford. For Type M slightly enriched to depleted uranium, urinalysis is far more 
sensitive, but chest counting should be included in an investigation of an intake discovered through urinalysis to help determine the absorption type of the material and to account for individual variance in lung retention. Annual chest counting is capable of independently demonstrating compliance with dose limits.

\subsubsection{Type S Routine Monitoring}

Routine bioassay monitoring programs are inherently not capable of meeting the 100-mrem committed effective dose bioassay goal due to the normal presence of uranium in the environment. Thus, reliance must be placed on good workplace surveillance practices to detect potential intake conditions in a timely manner so that special bioassay may be initiated. Annual urinalysis and annual chest counting can meet the compliance limits of 5-rem effective dose and 50-rem equivalent dose to any organ/tissue, ET being the critical tissue.

The recommended routine monitoring program for Type S inhalations of uranium is an annual urinalysis combined with an annual chest count. This protocol provides the capability of demonstrating compliance with the annual dose limits and adequately covers intakes that are slightly different than the models, e.g., variations in particle size, lung absorption parameters, or ${ }^{235} \mathrm{U}$ enrichment.

As shown in Table 7.35, quarterly urinalysis would improve sensitivity by about $38 \%$ over annual urinalysis, but the sensitivity would still not be close to the 100-mrem goal. Prompt detection of intakes through workplace monitoring and prompt special bioassay is the best approach for Type $S$ uranium.

\subsubsection{Special Monitoring for Suspected Intakes}

Bioassay monitoring should be initiated promptly upon indication that a potential acute intake has occurred. The primary consideration in determining the appropriate measurements is the mode of intake and the clearance rate of the material from the initial deposition site.

For readily absorbed materials, urine sampling to determine kidney burden is required. For slowly absorbed material, in vivo measurements and collection of early fecal excretion are necessary.

For unknown forms or mixtures with a range of absorption characteristics or if mixed modes of intake are involved, both urine and fecal samples are recommended in addition to lung counts.

For intakes of readily absorbed forms of uranium where workplace indicators raise concern about approaching the threshold for chemical toxicity (intakes of 3, 10, and $83 \mathrm{mg}$ for a wound, inhalation Type F, and inhalation Type M, respectively; see Tables 7.23, 7.24, and 7.25), a urine sample should be collected and analyzed within 12 hours of the intake with a follow-up at about 24 hours after the intake (which should be indicative of the peak kidney concentration). If preliminary information indicates that a significant intake was likely, the contractor should be advised to contact Occupational Medicine promptly for medical support. (See also Section 7.6.)

Investigations of high routine uranium urinalysis measurements are often problematic due to the potential for elevated background from natural environmental sources. Verification and confirmation of the initial measurement is important. If the worker is potentially exposed to recycled uranium (including depleted uranium), analysis for ${ }^{236} \mathrm{U}$ by the special ICPMS method can be an effective tool to discriminate 
occupational intake from environmental exposure. Comparison of isotopic ratios in a urine sample (or possibly a fecal sample if the intake was either very large or recent) with the potential workplace source can be useful, provided that the workplace source is significantly different from natural environmental uranium. In some cases, investigation of potential nonoccupational sources (e.g., drinking water or comparison with a family member) can be beneficial to the investigation.

\subsection{Assessment of Internal Dose}

Internal dose assessment can be performed using the methods described in Section 7.5.1 for acute intakes and Section 7.5.2 for chronic intakes. The kidney burden and potential chemical toxicity associated with uranium intakes are discussed in Section 7.5.3.

Assessment of internal dose from intakes of uranium is preferably based on evaluation of bioassay measurements. The choice of bioassay measurement depends on consideration of the likely mode of intake and degree of solubility or rate of absorption of the material. Generally, urinalysis measurements are most indicative of systemically deposited uranium, and in vivo measurements provide a measure of lung burden. The potential for mixed chronic and acute intakes (i.e., acute occupational exposure on top of a low-level chronic natural background exposure) complicates the interpretation of available data and must be carefully considered during the evaluation process.

Experience has shown that actual uranium exposures may involve varying mixtures of absorption types and particle sizes that may not be adequately represented by a single classification. If there is no basis for establishing the absorption type and particle size characteristics of the intake, then it is prudent to assume a Type $\mathrm{S}$ material with a particle AMAD of $5 \mu \mathrm{m}$ for evaluation of dose. Evaluations of potential for renal damage, based on urinalysis, are relatively insensitive to solubility and particle size variations. If either the threshold for toxicity or a committed effective dose of 100 mrem is exceeded, simplifying assumptions should be reviewed for their appropriateness and additional bioassay and other measurements should be performed, as necessary, to improve the quality of the assessment.

Special care should be taken to account for the isotopic composition of the uranium. For example, the equivalent dose for an intake of slightly enriched recycled uranium will exceed the equivalent dose from an equal mass of natural uranium or depleted uranium because of the higher specific alpha activity. Impurity radionuclides present in the recycled uranium can also increase the magnitude of the internal dose received relative to natural or depleted uranium, particularly for wounds and to a slight extent for Type $\mathrm{F}$ forms of uranium. Consequently, the default assumption of recycled uranium used for bioassay program design may not be appropriate for a given dose assessment.

Tables and graphs provided in this chapter have been constructed using the ICRP 69 (1995) model for uranium biokinetics and thus can be used to convert bioassay measurement results to intake and committed effective dose or committed equivalent organ dose. Although the tables and figures are sufficient for evaluating lower-level intakes and those that are relatively straightforward, additional computing capability may be necessary for more complex evaluations, particularly when bioassay data indicate that distribution and retention patterns deviate from the standard model. In this case, evaluations are performed using IMBA (see Appendix D). IMBA parameters are set up to produce the same results 
as the ICRP 69 biokinetic model for uranium; however, the code provides the capability to change model parameters based on bioassay measurement results. Deviations from the standard ICRP model are documented in the assessment.

\subsubsection{Acute Intake Assessment}

Acute intakes are best assessed through the performance of bioassay measurements beginning shortly after the intake. It is important that any additional exposure to uranium, even low-level chronic intakes, be avoided to the extent practicable during the period of bioassay monitoring following an acute intake. Interpretation of excreta data is highly susceptible to errors introduced by even minor subsequent intakes and thus, if the possibility of continued exposure cannot be ruled out, all excreta sample data collected following an acute intake must be considered to be potentially biased.

Wounds or acute intakes of readily absorbed forms of uranium are best evaluated through collection and analysis of follow-up urine samples (plus, for wounds, an in vivo count of the wound area). Samples collected after the unabsorbed fraction is eliminated from the body (i.e., after the first day post intake) provide the best estimate of systemically deposited material. Table 7.10 lists urine excretion fractions that may be used as default values for selected times following an acute intake.

In vivo measurements of lung activity provide the most direct basis for the assessment of internal equivalent dose for moderately or poorly absorbed forms of uranium, however they are insensitive to small intakes. They do provide a useful tool for estimating the upper bound of an intake immediately following exposure. Multiple measurements of internal activity can provide a measure of the pulmonary retention for the specific exposure case; however, the initial assessment of intake, based on a single in vivo measurement, can be made using the retention factors of Table 7.8.

Although intakes of poorly absorbed uranium are preferably assessed using direct (in vivo) bioassay measurements, most acute intakes of such material will be below the sensitivity of in vivo measurement techniques. The collection and analysis of fecal samples within the first week provides an alternative, and the most sensitive, indicator of activity deposited in the respiratory tract. It is difficult to obtain all fecal matter representing the rapidly clearing component from the lung to the GI tract, and normalizing available fecal sample data to account for partial collection may be required. Table 7.11 provides fecal excretion rates at various times post intakes, and Table 7.12 provides feces-to-urine ratios that should be helpful in determining the mode of intake or absorption type, especially if there is a chance of combined intake modes. Additional information about the collection and evaluation of fecal samples is provided in Appendix C.

\subsubsection{Chronic Intake Assessment}

Urinalysis is the preferred bioassay measurement technique for monitoring chronic exposures to readily absorbed forms of uranium. Because "chronic” exposure is often in practice not actually "every day" and because of the sharp decrease in excretion rate during the first couple of days after cessation of intake, care must be taken when using urine or fecal data to calculate chronic intake. The time from last intake to the excretion period can be critical. After 365 days of chronic intake of Type F uranium, the urinary excretion rate decreases 55\% in the first 24 hours and $69 \%$ in the first 48 hours. In the past at Hanford urine samples were collected Sunday night through Monday morning to avoid collection of the 
unabsorbed fraction from the last day's (presumably Friday’s) intake. This or a similar pattern of collection would be recommended again if monitoring of chronic intake became necessary.

For poorly absorbed forms of uranium, the lung is the primary contributor to effective dose and in vivo chest measurements are the most direct indicator of internal dose. Because of the relatively poor sensitivity of in vivo techniques for low-enrichment uranium, the results of periodic urinalysis measurements may provide a means for estimating the magnitude of dose from chronic exposures below the sensitivity of the in vivo measurements. After 365 days of chronic intake of Type S slightly enriched uranium, urinalysis is about four times more sensitive than chest counting. The urinary excretion rate decreases more slowly after cessation of chronic intake of Type S uranium, so if the nature of the uranium is uncertain, collection of several urine samples over several days after cessation of intake can be used to characterize the absorption type of uranium. However, if the activity in the lung is detectable, direct chest counting is preferred. IMBA can be adjusted to incorporate the exact length of chronic intake to produce worker-specific fractional excretion or lung retention curves or to calculate the daily intake rate from the bioassay data.

Alternatively, if multiple small, intermittent intakes are assumed throughout the year, each can be entered into IMBA as a separate intake for up to 10 intakes in a year (or any specified exposure period). Previously, another method was used where each sample can be assumed to be independent of (i.e., unaffected by) the others. Under this scenario, an effective chronic intake rate can be approximated using the geometric mean $\left(\mu_{\mathrm{g}}\right)$ of the daily urinary excretion rate $\left[\mathrm{M}_{\mathrm{u}}(\mathrm{t})\right]$ based on analysis of urine samples $(\mathrm{n})$ collected during the period of exposure, as follows:

$$
\mu_{\mathrm{g}}=\operatorname{Anti} \log \left[\frac{\sum \log \mathrm{M}_{\mathrm{u}}(\mathrm{t})}{\mathrm{n}}\right]
$$

This effective daily excretion rate can then be used to calculate an effective daily intake rate for the period of exposure. Multiplying the effective daily intake rate by the duration of the exposure will give the total intake, from which committed doses can be calculated using the appropriate dose coefficient.

The historical use of the above method for evaluating routine bioassay program data for the $\mathrm{UO}_{3}$ Plant, the 300 Area Fuel Production Facilities, and 306-W Building was described more fully in Technical Basis for Internal Dosimetry at Hanford (Sula et al. 1991).

\subsubsection{Assessment of Kidney Burden and Potential Chemical Toxicity}

The maximum kidney burden from an acute exposure can be assessed from urinalysis data in the following manner. First calculate the total uranium intake using one of the methods described above. Then multiply the intake by the maximum kidney retention fraction from Table 7.13 (or as calculated for a specific intake scenario using the User Defined option in IMBA). As long as the total maximum kidney retention does not exceed $341 \mu \mathrm{g}$, the threshold for chemical toxicity (based on $1.1 \mu \mathrm{g}-\mathrm{U} / \mathrm{g}$-kidney, as described in Section 7.2.4) has not been exceeded and the uranium intake is below that considered potentially harmful, even for short-term effects.

The average daily urinary excretion for continuous intake is related to the kidney burden. This ratio varies with time, but is independent of inhalation absorption type and particle size. For continuous exposures lasting 1 to 5 years, the ratio of the kidney burden to the average daily excretion varies from 
1.8 to 2.5. A ratio of 2 can be used as a rough approximation. Thus, assuming a kidney burden of $341 \mu g$ (i.e., $1.1 \mu \mathrm{g}$-U/g-kidney; the assumed threshold level at which a chronic kidney burden may result in temporary renal dysfunction), the average daily excretion would be about $341 / 2=170 \mu \mathrm{g} / \mathrm{d}$. If exposure were halted for 2 days (such as during a weekend), the ratio would climb to 7 so, as previously mentioned, for urine (or fecal) results for Type F uranium knowing the time since last intake is crucial. For Type F uranium, the 341- $\mu$ g kidney burden would result from prolonged intakes of about $500 \mu \mathrm{g} / \mathrm{d}$.

If preliminary information indicates that an intake at the threshold for chemical toxicity was possible, investigation of the potential intake should be performed. If evidence suggests that a significant intake was likely, follow-up samples should be promptly collected and analyzed, and Occupational Medicine should be notified. Because acute damage of the kidneys is the primary consideration, kidney function tests provide the most direct and useful means of assessing the impact of the exposure. Sensitive tests for kidney damage include beta-2-microglobulin and catalase relative to creatinine (Fisher 1985). Albuminuria is also an indicator of kidney damage. Leggett (1989) and Fisher et al. (1990) have identified a number of other potentially useful tests. The decision to perform such tests is made by Occupational Medicine.

According to the HPS Standard, Bioassay Programs for Uranium (HPS 1995), permanent renal damage may occur if the total body content of soluble uranium reaches $0.3 \mathrm{mgU} / \mathrm{kg}$ body weight. For a 70-kg person, that whole body content is $21 \mathrm{mg}$. For an inhalation of Type F uranium, that whole body content would result in a peak kidney burden at about 18 hours after intake of $1.5 \mathrm{mg}$, which compares well with the lower part of the range for protracted renal dysfunction by Hahn and Roszell (Table 7.14) $(6.4 \mu \mathrm{g} / \mathrm{g}$ kidney $\times 310 \mathrm{~g}$ kidney $=2.0 \mathrm{mg})$. This kidney burden would result from an inhalation of $47 \mathrm{mg}$ Type F uranium. For an instantaneous uptake, the same kidney burden would result from an intake of only $13 \mathrm{mg}$. Figure 7.11 shows the urinary excretion concentration from an acute intake that might produce protracted renal damage.

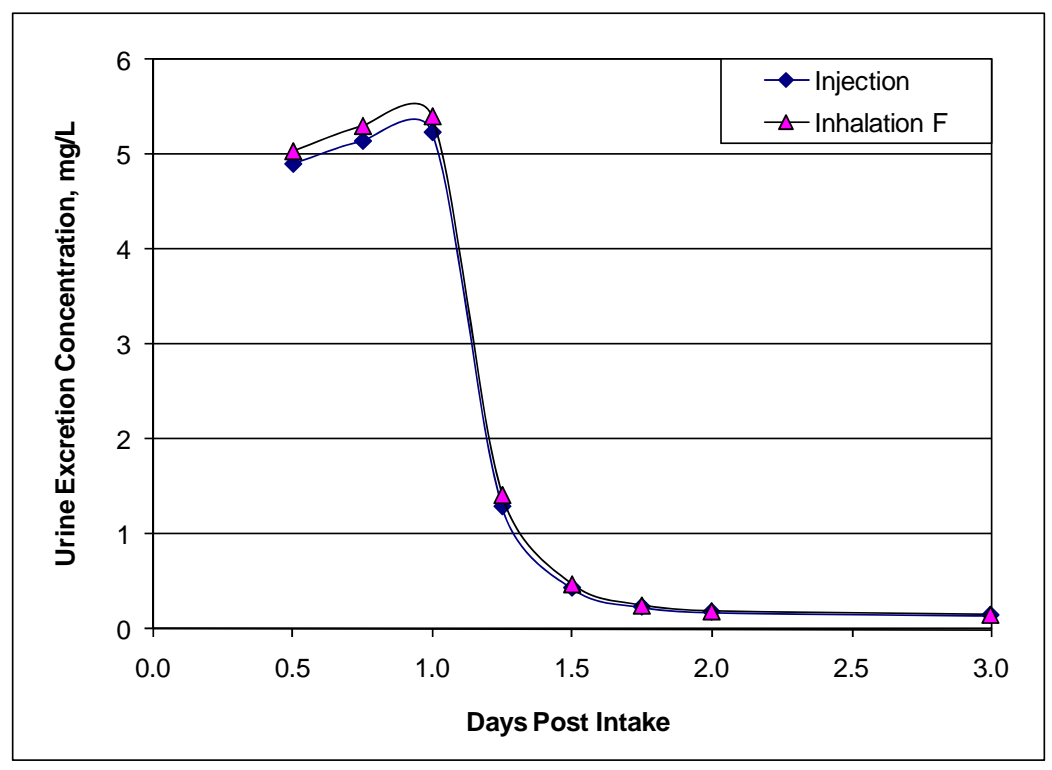

Figure 7.11. Urinary Uranium Concentration Resulting from a Kidney Burden at the Threshold for Permanent Kidney Damage as a Function of Time Shortly After an Acute Intake 


\subsection{Management of Internal Contamination Cases}

Acute intakes of uranium pose both radiological and nephrotoxicity concerns. Renal damage results in failure of the proximal tubules to reabsorb constituents filtered from the blood. Laboratory abnormalities include proteinuria, glucosuria, and increased urine output. Clinical symptoms of severe uranium poisoning may include nausea, vomiting, abdominal cramps, and diarrhea.

Urine samples should be collected within several hours following any uranium uptake with potential chemical toxicity concerns to be scheduled for immediate processing. A follow-up sample should be collected at about 24 hours after the intake to provide an indication of the peak kidney burden. If only one sample can be reasonably obtained, then a 12-hour sample starting at about 14 hours after intake and ending about 26 hours after intake is preferred. As a general rule, biological indicators of kidney damage should be checked if urine concentrations exceed $2 \mathrm{mg} / \mathrm{l}$ for the first-day samples. Clinical indicators of kidney damage include albuminuria, glucose, catalase, and beta-2 microglobulin. Urine concentrations in the first 24 hours exceeding $6 \mathrm{mg} / \mathrm{l}$ indicate serious exposure and concentrations much above that might be life-threatening and are cause for immediate medical attention. Note from Figure 7.11 the steep decrease in urine concentrations in the next 24 hours such that a urine concentration after the first day exceeding $1 \mathrm{mg} / \mathrm{l}$ would be cause for immediate attention.

Antidotal therapy for uranium poisoning includes oral administration of GI tract adsorbents and oral or intravenous infusion of sodium bicarbonate (Bhattacharyya et al. 1992; NCRP 1980). The bicarbonate promotes formation of the uranyl-bicarbonate complex, which is more rapidly excreted in urine (Fisher 1985). Ethylene diamine tetraacetic acid (EDTA) and diethylene triamine pentaacetic acid (DTPA) have been used in experimental animals to increase the excretion of uranium; however, chelation therapy appears to have no beneficial effect more than 4 hours after exposure (NCRP 1980). Therapeutic actions such as described above require prescription by the appropriate medical authority (e.g., Occupational Medicine).

\subsection{References}

10 CFR 835. 2007. “Occupational Radiation Protection” (Appendix A, pp. 31927-31939). Code of Federal Regulations. U.S. Department of Energy.

29 CFR 1910.1000 Table Z-1. 2000. "Limits for Air Contaminants.” Code of Federal Regulations. Occupational Safety and Health Administration (OSHA). Available at: http://www.osha.gov/pls/oshaweb/owadisp.show document?p table=STANDARDS\&p id=9992

American Conference on Governmental Industrial Hygienists (ACGIH). 1968. Threshold Limit Values in Airborne Contaminants for 1968, Recommended and Intended Values. St. Louis, Missouri.

American Conference on Governmental Industrial Hygienists (ACGIH). 1983. Threshold Limit Values for Chemical Substances and Physical Agents in the Work Environment with Intended Changes for 1983-84. Cincinnati, Ohio.

Bhattacharyya MH, BD Breitenstein, H Metivier, BA Muggenburg, GN Stradling, and V Volf. 1992. "Guidebook for the treatment of accidental internal radionuclide contamination of workers." Eds. GB Gerber and RG Thomas. Rad. Prot. Dosim. 41:1. 
Boice JD, RW Leggett, ED Ellis, PW Wallace, M Mumma, SS Cohen, AB Brill, B Chadda, BB Boecker, RC Yoder, and KF Eckerman. 2006. “A comprehensive dose reconstruction methodology for former Rocketdyne/Atomics International radiation workers.” Health Phys. 90(5):409-430.

Burley HH. 1956. Fuel Element Technical Manual. HW-40000, General Electric Hanford Atomic Products Operation, Richland, Washington.

Carbaugh EH, MJ Sula, and KM McFadden. 1990. Use of Probability Analysis to Establish Routine Bioassay Screening Levels. PNL-SA-17716, Pacific Northwest Laboratory, Richland, Washington.

Drury JS, MF Baldauf, EW Daniel, CS Fore, and MS Uziel. 1983. Radioactivity in Food Crops. ORNL-5963, Oak Ridge National Laboratory, Oak Ridge, Tennessee.

Eve IS. 1964. "Some suggested maximum permissible single intakes of uranium.” Health Phys. 10:773-776.

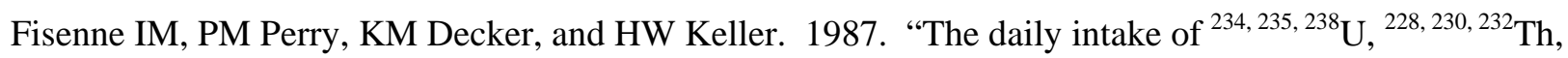
and ${ }^{226,228}$ Ra by New York City residents.” Health Phys. 53(4):357-363.

Fisher DR. 1985. “Uranium.” In Handbook on the Toxicity of Inorganic Compounds. Eds. HG Seiler and H Sigel. Marcel Dekker, Inc., New York.

Fisher DR, MJ Swint, and RL Kathren. 1990. Evaluation of Health Effects in Sequoyah Fuels Corporation (SFC) Workers from Accidental Exposure to Uranium Hexafluoride. NRC Report NUREG/CR-5566 (PNL-7328), U.S. Nuclear Regulatory Commission, Washington, D.C.

Fleischer RL. 2008. "Difficulties in using ${ }^{234} \mathrm{U} /{ }^{238} \mathrm{U}$ ratios to detect enriched or depleted uranium." Health Phys. 94(3):292-293.

Golchert NW, TL Duffy, and J Sedlet. 1985. Environmental Monitoring at Argonne National Laboratory. Report ANL-85-17, 1984 data, Argonne National Laboratory, Argonne, Illinois.

Goldstein SJ, JM Rodriguez, and N Lujan. 1997. "Measurement and application of uranium isotopes for human and environmental monitoring.” Health Phys. 72(1):10-18.

Guilmette RA, MA Parkhurst, G Miller, FF Hahn, LE Roszell, EG Daxon, TT Little, JJ Whicker, YS Cheng, RJ Traub, GM Lodde, F Szom, DE Bihl, KL Creek, and CB Mckee. 2005. Human Health Risk Assessment of Capstone Depleted Uranium Aerosols, Attachment 3 of Depleted Uranium Aerosol Doses and Risk: Summary of U.S. Assessments. Battelle Press, Columbus, Ohio.

Harrison JD. 1991. “The gastrointestinal absorption of the actinide elements.” Sci. Total Environ. 100:43-60.

Hilliard JR. 2008. "Determination of the Radioactive and Plutonium Holdup in Selection 231-Z Building Components.” Prepared by Pacific Northwest National Laboratory, Richland, Washington. Available from Fluor Hanford Company, Central Plateau Surveillance and Maintenance Project. 
Health Physics Society (HPS). 1995. Bioassay Programs for Uranium. ANSI/HPS N13.22-1995, Health Physics Society, McLean, Virginia.

Hursh JB, WR Neuman, T Toribara, H Wilson, and C Waterhouse. 1969. “Oral ingestion of uranium by man.” Health Phys. 17:619-621.

Hursh JB and NL Spoor. 1973. "Protection Criteria.” In Uranium, Plutonium, and Transplutonium Elements. Eds. HC Hodge, JN Stannard, and JB Hursh, pp. 197-239, Springer-Verlag, Berlin, West Germany.

International Commission on Radiological Protection (ICRP). 1964. Recommendations of the Internal Commission on Radiological Protection. ICRP Publication 6, Pergamon Press, Oxford, England.

International Commission on Radiological Protection (ICRP). 1974. Report of Task Group on Reference Man. ICRP Publication 23, Pergamon Press, New York.

International Commission on Radiological Protection (ICRP). 1979. "Limits for intakes of radionuclides by workers.” ICRP Publication 30, Part 1, Annals of the ICRP, 2:3-4, Pergamon Press, New York.

International Commission on Radiological Protection (ICRP). 1983. "Radionuclide Transformations, Energy and Intensity of Emissions.” ICRP Publication 38, Annals of the ICRP, 11-13, Pergamon Press, New York.

International Commission on Radiological Protection (ICRP). 1994a. "Dose Coefficients for Intakes of Radionuclides by Workers.” ICRP Publication 68, Annals of the ICRP, 24:4, Pergamon Press, New York.

International Commission on Radiological Protection (ICRP). 1994b. "Human Respiratory Tract Model for Radiological Protection.” ICRP Publication 66, Annals of the ICRP, 24:1-3, Pergamon Press, New York.

International Commission on Radiological Protection (ICRP). 1995. “Age-dependent Doses to Members of the Public from Intakes of Radionuclides: Part 3 Ingestion Dose Coefficients.” ICRP Publication 69, Annals of the ICRP, 25:1, Pergamon Press, New York.

International Commission on Radiological Protection (ICRP). 1997. "Individual Monitoring for Internal Exposure of Workers.” ICRP Publication 78, Annals of the ICRP, 27:3-4, Pergamon Press, New York.

International Commission on Radiological Protection (ICRP). 2002. "Basic Anatomical and Physiological Data for Use in Radiological Protection: Reference Values.” ICRP Publication 89, Ed. J Valentin, Annals of the ICRP, 32:3-4, Pergamon Press, New York.

International Commission on Radiological Protection (ICRP). 2006. "Human Alimentary Tract Model for Radiological Protection.” ICRP Publication 100, Annals of the ICRP, 36:1-2, Pergamon Press, New York.

Isochem, Inc. 1967. PUREX Plant Thorium Process Operation Report. ISO-419, Isochem, Inc, Richland, Washington. Available in the Declassified Document Retrieval System:

www.2.hanford.gov/declass/

Issued for implementation effective 01/01/2010 
Jackson RR and RL Walser. 1977. PUREX Process and Performance, 1970 Thoria Campaign. ARH-2127, Atlantic Richfield Hanford Company, Richland, Washington. Available in the Declassified Document Retrieval System: www.2.hanford.gov/declass/

Jech JJ. 1970. “Internal Deposition Surveillance - Enriched Uranium Work.” Letter to JH Soehnlein, Battelle Northwest Division, December 14, 1970. Available in the Hanford Internal Dosimetry Program records.

Just RA. 1984. Report on Toxicological Studies Concerning Exposures to UF ${ }_{6}$ and $U F_{6}$ Hydrolysis Products. DOE Report K/D-5573, Revision 1, U.S. Department of Energy, Washington, D.C.

Just RA and VS Emler. 1984. Generic Report on Health Effects for the U.S. Gaseous Diffusion Plants. DOE Report K/D-5050, Section VII, Part 1.

Kathren RL and RK Burklin. 2008a. “Acute chemical toxicity of uranium.” Health Phys. 94(2):170-179.

Kathren RL and RK Burklin. 2008b. "Proposed Standards for Acute Exposure to Low Enrichment Uranium for Compliance with 10 CFR 70.61.” Operation Radiation Safety, Supplement to Health Physics, 95(2):S122-S127.

Lane BB. 1961. Glossary to Hanford Technology. HW-68206, General Electric Hanford Atomic Products Operation, Richland, Washington. Available in the Declassified Document Retrieval System.

Leggett RW. 1989. “The behavior and chemical toxicity of U in the kidney: A reassessment." Health Phys. 57(3):365-383.

Leggett RW and JD Harrison. 1995. “Fractional absorption of ingested uranium in humans.” Health Phys. 68:484-498.

Long MP, EH Carbaugh, and NL Fairrow. 1994. Practical Issues in Discriminating Between Environmental and Occupational Sources in a Uranium Urinalysis Bioassay Program. PNL-SA-24340, Pacific Northwest National Laboratory, Richland, Washington.

Long MP and EH Carbaugh. 1995. Final Report - Natural Uranium Background Study. Letter Report to distribution, dated June 26, 1995. Personal correspondence. Permanent copy retained in Hanford Radiological Records Historical File (contact EH Carbaugh).

Lynch TP. 2007. In Vivo Project Manual. Pacific Northwest Laboratory, Richland, Washington.

MacLellan JA, EJ Wyse, and LP Scott. 1998. "Discrimination Between Occupational and Environmental Sources of Uranium Intakes.” Radiation Protection Management 15(3):56-64.

McGuire SA. 1991. Chemical Toxicity of Uranium Hexafluoride Compared to Acute Effects of Radiation. NUREG-1391, U.S. Nuclear Regulatory Commission, Washington, D.C.

Morrow PE, LJ Leach, FA Smith, RM Gelein, JB Scott, HD Beiter, FJ Amato, JJ Picano, CL Yuile, and TG Consler. 1982. Metabolic Fate and Evaluation of Injury in Rats and Dogs Following Exposure to the 
Hydrolysis Products of Uranium Hexaflouride. NUREG/CR-2268, U.S. Nuclear Regulatory Commission, Washington D.C.

National Council on Radiation Protection and Measurements (NCRP). 1980. Management of Persons Accidentally Contaminated with Radionuclides. NCRP Report No. 65, Bethesda, Maryland.

National Council on Radiation Protection and Measurements (NCRP). 1988. Exposure of the Population in the United States and Canada from Natural Background Radiation. NCRP Report No. 94, Bethesda, Maryland.

Parkhurst MA, EG Daxon, GM Lodde, F Szrom, RA Guilmette, LE Roszell, GA Falo, and CB McKee. 2005. Depleted Uranium Aerosol Doses and Risks, Summary of U.S. Assessments. Battelle Press, Columbus, Ohio.

Public Health Service (PHS). 1997. Toxicological Profile for Uranium. Draft for public comment, U.S. Department of Health \& Human Services, Public Health Service, Agency for Toxic Substances and Disease Registry, Atlanta, Georgia.

Rich BL, SL Hinnefeld, CR Lagerquist, WG Mansfield, LH Munson, and ER Wagner. 1988. Health Physics Manual of Good Practices for Uranium Facilities. EGG-2530, EG\&G Idaho, Inc., Idaho Falls, Idaho.

Rosman KJR and PDP Taylor. 1998. “Isotopic compositions of the elements - 1997.” Pure and Applied Chemistry 70:217-236.

Sula MJ, EH Carbaugh, and DE Bihl. 1989. Technical Basis for Internal Dosimetry at Hanford. PNL-6866, Pacific Northwest Laboratory, Richland, Washington.

Sula MJ, EH Carbaugh, and DE Bihl. 1991. Technical Basis for Internal Dosimetry at Hanford. PNL-6866, Revision 1, Pacific Northwest Laboratory, Richland, Washington.

Thompson RJ. 1986. Operating Specifications for the Uranium Oxide Plant. OSD-U-185-00001, Rockwell Hanford Operations, Richland, Washington.

United Nations Scientific Committee on the Effects of Atomic Radiation (UNSCEAR). 1988. Sources, Effects, and Risks of Ionizing Radiation. Report to the General Assembly, with annexes, United Nations Publications, New York.

U.S. Department of Energy-Richland Operations Office (DOE-RL). 2000. Recycled Uranium: The Flow and Characteristics of Recycled Uranium Throughout the DOE Complex, 1952-1999. Volume II: Part 1, Hanford Site. Site Assessment Team Report, DOE/EH-0617 and DOE/RL-2000-43, Richland, Washington.

U.S. Environmental Protection Agency. 2006. 2006 Edition of the Drinking Water Standards and Health Advisories, EPA 822-R-06-013, U.S. Environmental Protection Agency, Washington, D.C. Available at: www.epa.gov/waterscience/criteria/drinking/dwstandards.pdf 
Weast RC [editor]. 1985. Handbook of Chemistry and Physics, 66th Edition, CRC Press, Inc., Boca Raton, Florida.

Welford GA and R Baird. 1967. "Uranium levels in human diet and biological materials." Health Phys. 13(1321-1324).

Wittekind WD and DC Morey. 1985. “Uranium 236 Material Flow and Computer Model.” UNI-3570, UNC Nuclear Industries, Richland, Washington.

Wrenn ME, PW Durbin, B Howard, JL Lipzstein, JL Rundo, ET Sill, and DL Willis. 1985. "Metabolism of ingested U and Ra.” Health Phys. 48:601-603.

Wyse EJ, OT Farmer, JP Bramson, JA MacLellan, and DW Koppenaal. 1995. “Radioanalytical Applications of ICP/MS Using Enhanced Sensitivity Techniques" (poster). Abstract in the Proceedings of the Fortieth Annual Meeting of the Health Physics Society, Joint Meeting with the American Association of Physicists in Medicine, July 23-27, 1995, Boston, Massachusetts. Health Physics Journal, June Supplement 68(6s), McLean, Virginia.

Zhao S and F-Y Zhao. 1990. “Nephrotoxic limit and annual limit on intake for Natural U.” Health Phys. 58(5):619-623. 


\section{Methods and Models of the Hanford Internal Dosimetry Program \\ PNNL-MA-860}

\subsection{Plutonium}

Issued for implementation effective 01/01/2010

Supersedes: January 2003

Use Category: Not applicable

\section{Approval Signatures:}

Prepared by: $\frac{\text { Donald Bihl }}{\text { DE Bihl, Scientist }}$

Approved by:

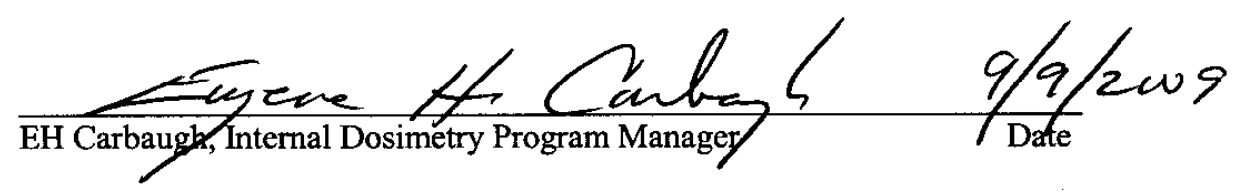

Reviewer Signatures:

Reviewed by:

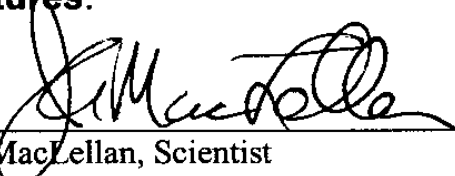

Approved by the Hanford Personnel Dosimetry Advisory Committee as recorded in the meeting minutes of March 10, 2009. 


\section{Contents}

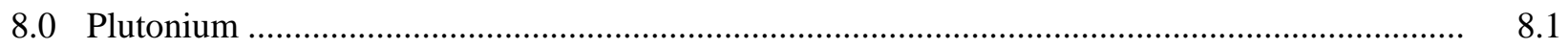

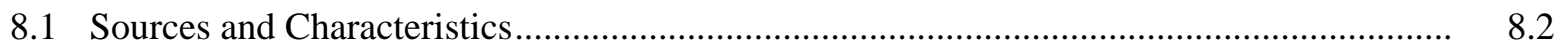

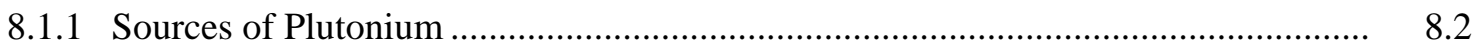

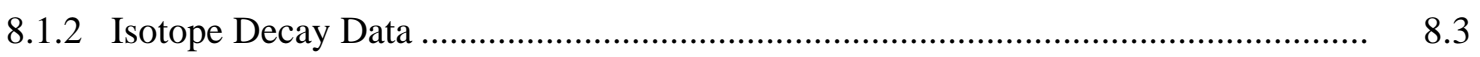

8.1.3 Reference Isotope Mixtures............................................................................. 8.3

8.2 Biokinetic Behavior................................................................................................ 8.5

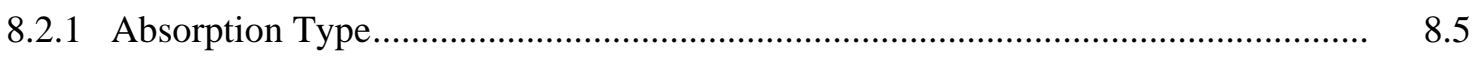

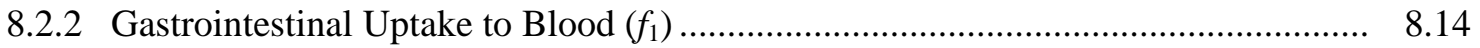

8.2.3 Distribution and Retention in Systemic Organs and Tissues ................................. 8.14

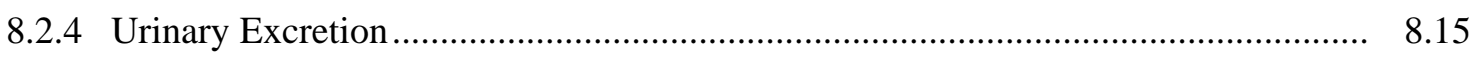

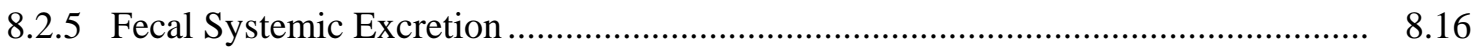

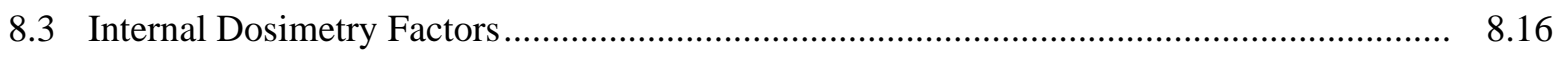

8.3.1 Intake Retention and Excretion Fractions ....................................................... 8.17

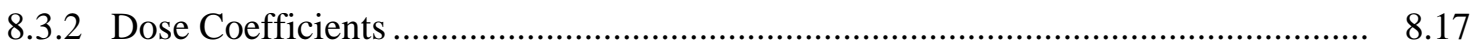

8.3.3 Cumulative Equivalent Doses .......................................................................... 8.30

8.3.4 Comparison with Published Dose Coefficients .................................................... 8.31

8.3.5 Derived Air Concentrations and Annual Limits on Intake...................................... 8.32

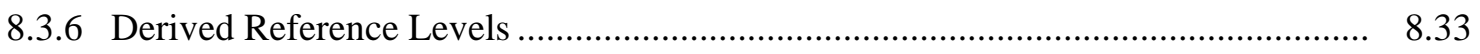

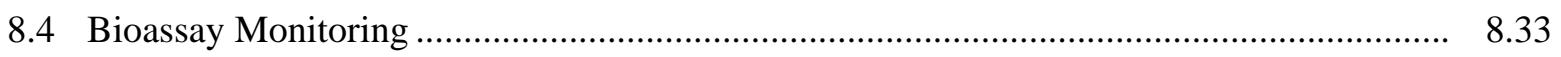

8.4.1 General Techniques and Applicability ........................................................... 8.33

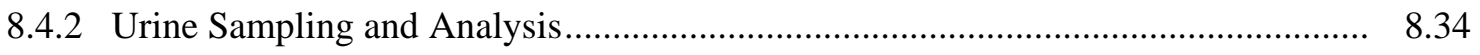

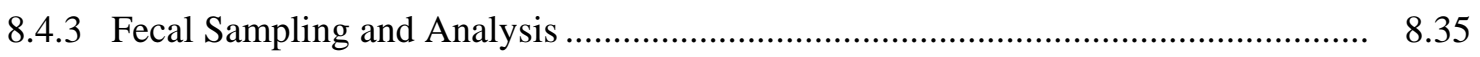

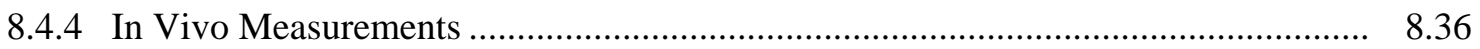

8.4.5 Bioassay Monitoring Capability ........................................................................ 8.38

8.4.6 Recommended Bioassay Monitoring Program.................................................. 8.71

8.4.7 Special Bioassay Monitoring........................................................................ 8.72

8.4.8 Bioassay Monitoring Capability for Workers with Known Plutonium
Depositions ........................................................................................... 8.74

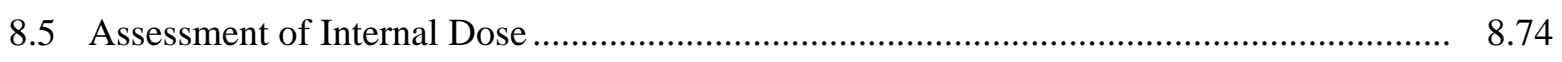

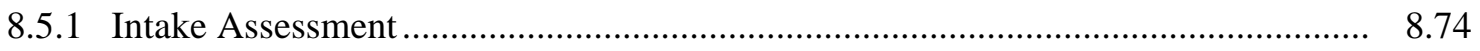

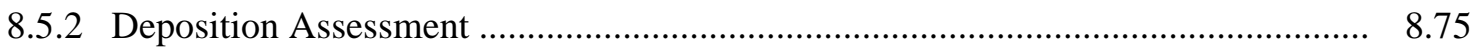

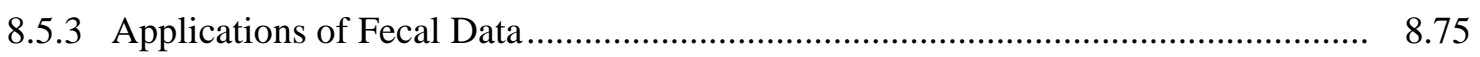

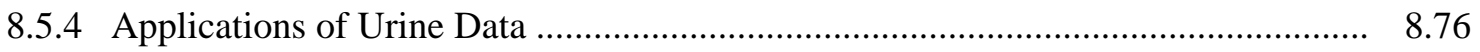

8.5.5 Applications of In Vivo Data ...................................................................... 8.76

8.5.6 Assessing Organ and Effective Doses.......................................................... 8.76 
8.6 Management of Internal Contamination Cases ............................................................ 8.77

8.6.1 Diagnostic Procedures ........................................................................................ 8.77

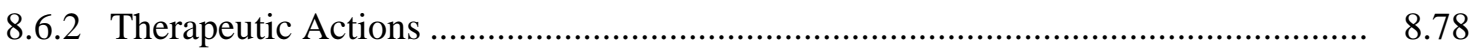

8.6.3 Long-Term Monitoring of Internal Depositions ............................................ 8.79

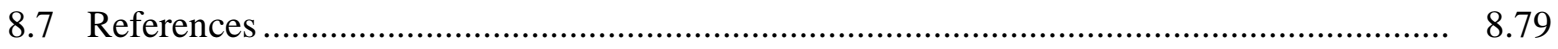

\section{Figures}

8.1 ${ }^{239+240} \mathrm{Pu} /{ }^{241} \mathrm{Am}$ Activity Ratio for Hanford Reference Plutonium Mixtures ............................ $\quad 8.9$

8.2 Total Alpha ${ }^{241}$ Am Activity Ratio for Hanford Reference Plutonium Mixtures........................ 8.9

8.3 Total Alpha $/{ }^{239+240} \mathrm{Pu}$ Activity Ratio for Hanford Reference Plutonium Mixtures ..................... 8.10

8.4 ${ }^{241}$ Am/Total Alpha Activity Ratio for Hanford Reference Plutonium Mixtures......................... 8.10

$8.5{ }^{239} \mathrm{Pu}$ Fractional Lung Retention ................................................................................... 8.19

8.6 ${ }^{241}$ Am Fractional Lung Retention Including Ingrowth from ${ }^{241} \mathrm{Pu} 5-\mu \mathrm{m}$-AMAD Particles ......... $\quad 8.21$

$8.7{ }^{239} \mathrm{Pu}$ Fractional Urinary Excretion, ICRP $67 \mathrm{Model}$............................................................ 8.23

$8.8{ }^{239} \mathrm{Pu}$ Urinary Excretion, Comparison of ICRP 30/Jones and ICRP 67 Models ......................... 8.23

$8.9{ }^{239}$ Pu Fractional Fecal Excretion, ICRP 67 Model ................................................................. 8.25

8.10 Feces-to-Urine Excretion Ratios for ${ }^{239} \mathrm{Pu}$ Intakes................................................................... 8.26

8.11 Minimum Detectable Committed Effective Doses for 20-Year-Aged Weapons-Grade Plutonium Based on Detection of $0.02 \mathrm{dpm} / \mathrm{d}{ }^{239} \mathrm{Pu}$ in Urine ................................................. 8.40

8.12 Minimum Detectable Committed Effective Doses for 50-Year-Aged Weapons-Grade Plutonium Based on Detection of $0.02 \mathrm{dpm} / \mathrm{d}{ }^{239} \mathrm{Pu}$ in Urine ................................................. 8.41

8.13 Minimum Detectable Committed Effective Doses for 20-Year-Aged Fuel-Grade Plutonium Based on Detection of $0.02 \mathrm{dpm} / \mathrm{d}{ }^{239} \mathrm{Pu}$ in Urine ................................................. 8.42

8.14 Minimum Detectable Committed Effective Doses for 50-Year-Aged Fuel-Grade Plutonium Based on Detection of $0.02 \mathrm{dpm} / \mathrm{d}{ }^{239} \mathrm{Pu}$ in Urine ................................................... 8.43

8.15 Minimum Detectable Bone Surface Doses for 20-Year-Aged Weapons-Grade Plutonium Based on Detection of $0.02 \mathrm{dpm} / \mathrm{d}^{239} \mathrm{Pu}$ in Urine ................................................ 8.44

8.16 Minimum Detectable Bone Surface Doses for 50-Year-Aged Weapons-Grade Plutonium

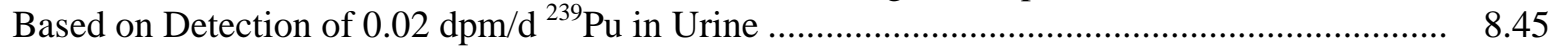

8.17 Minimum Detectable Bone Surface Doses for 20-Year-Aged Fuel-Grade Plutonium Based on Detection of $0.02 \mathrm{dpm} / \mathrm{d}^{239} \mathrm{Pu}$ in Urine ........................................................... 8.46

8.18 Minimum Detectable Bone Surface Doses for 50-Year-Aged Fuel-Grade Plutonium Based on Detection of $0.02 \mathrm{dpm} / \mathrm{d}{ }^{239} \mathrm{Pu}$ in Urine

8.19 Minimum Detectable Doses to Extrathoracic Tissues and the Lung from Inhalation of Type Super S Weapons-Grade Plutonium Based on Detection of $0.02 \mathrm{dpm} / \mathrm{d}{ }^{239} \mathrm{Pu}$ in Urine .

8.20 Minimum Detectable Doses to Extrathoracic Tissues and the Lung from Inhalation of Type Super S Fuel-Grade Plutonium Based on Detection of $0.02 \mathrm{dpm} / \mathrm{d}{ }^{239} \mathrm{Pu}$ in Urine 
8.21 Minimum Detectable Committed Effective Doses for 20-Year-Aged Weapons-Grade Plutonium Based on Detection of $0.16 \mathrm{nCi}^{241} \mathrm{Am}$ in the Lungs.

8.22 Minimum Detectable Committed Effective Doses for 50-Year-Aged Weapons-Grade Plutonium Based on Detection of $0.16 \mathrm{nCi}^{241} \mathrm{Am}$ in the Lungs.

8.23 Minimum Detectable Committed Effective Doses for 20-Year-Aged Fuel-Grade Plutonium Based on Detection of $0.16 \mathrm{nCi}^{241} \mathrm{Am}$ in the Lungs.

8.24 Minimum Detectable Committed Effective Doses for 50-Year-Aged Fuel-Grade Plutonium Based on Detection of $0.16 \mathrm{nCi}^{241} \mathrm{Am}$ in the Lungs.

8.25 Minimum Detectable Bone Surface Committed Equivalent Doses for 20-Year-Aged Weapons-Grade Plutonium Based on Detection of $0.16 \mathrm{nCi}^{241} \mathrm{Am}$ in the Lungs.....

8.26 Minimum Detectable Bone Surface Committed Equivalent Doses for 50-Year-Aged Weapons-Grade Plutonium Based on Detection of $0.16 \mathrm{nCi}^{241} \mathrm{Am}$ in the Lungs.

8.27 Minimum Detectable Bone Surface Committed Equivalent Doses for 20-Year-Aged Fuel-Grade Plutonium Based on Detection of $0.16 \mathrm{nCi}^{241} \mathrm{Am}$ in the Lungs......

8.28 Minimum Detectable Bone Surface Committed Equivalent Doses for 50-Year-Aged Fuel-Grade Plutonium Based on Detection of $0.16 \mathrm{nCi}^{241} \mathrm{Am}$ in the Lungs..

8.29 Minimum Detectable Committed Equivalent Doses for Extrathoracic Tissues and the Lung for Inhalation of Type Super S Weapons-Grade Plutonium Based on Detection of $0.16 \mathrm{nCi}^{241} \mathrm{Am}$ in the Lungs.

8.30 Minimum Detectable Committed Equivalent Doses for Extrathoracic Tissues and the Lung for Inhalation of Type Super S Fuel-Grade Plutonium Based on Detection of $0.16 \mathrm{nCi}^{241} \mathrm{Am}$ in the Lungs.

8.31 Minimum Detectable Committed Effective Doses for 20-Year-Aged Weapons-Grade Plutonium Based on Detection of $0.2 \mathrm{dpm} / \mathrm{d}{ }^{239} \mathrm{Pu}$ in Feces

8.32 Minimum Detectable Committed Effective Doses for 50-Year-Aged Weapons-Grade Plutonium Based on Detection of $0.2 \mathrm{dpm} / \mathrm{d}{ }^{239} \mathrm{Pu}$ in Feces.

8.33 Minimum Detectable Committed Effective Doses for 20-Year-Aged Fuel-Grade Plutonium Based on Detection of $0.2 \mathrm{dpm} / \mathrm{d}{ }^{239} \mathrm{Pu}$ in Feces

8.34 Minimum Detectable Committed Effective Doses for 50-Year-Aged Fuel-Grade Plutonium Based on Detection of $0.2 \mathrm{dpm} / \mathrm{d}{ }^{239} \mathrm{Pu}$ in Feces...

8.35 Minimum Detectable Bone Surface Committed Equivalent Doses for 20-Year-Aged Weapons-Grade Plutonium Based on Detection of $0.2 \mathrm{dpm} / \mathrm{d}{ }^{239} \mathrm{Pu}$ in Feces.

8.36 Minimum Detectable Bone Surface Committed Equivalent Doses for 50-Year-Aged Weapons-Grade Plutonium Based on Detection of $0.2 \mathrm{dpm} / \mathrm{d}{ }^{239} \mathrm{Pu}$ in Feces

8.37 Minimum Detectable Bone Surface Committed Equivalent Doses for 20-Year-Aged Fuel-Grade Plutonium Based on Detection of $0.2 \mathrm{dpm} / \mathrm{d}{ }^{239} \mathrm{Pu}$ in Feces.

8.38 Minimum Detectable Bone Surface Committed Equivalent Doses for 50-Year-Aged Fuel-Grade Plutonium Based on Detection of $0.2 \mathrm{dpm} / \mathrm{d}{ }^{239} \mathrm{Pu}$ in Feces.

8.39 Minimum Detectable Doses to Extrathoracic Tissues and the Lung from Inhalation of Type Super S Weapons-Grade Plutonium Based on Detection of $0.2 \mathrm{dpm} / \mathrm{d}$ ${ }^{239} \mathrm{Pu}$ in Feces....

8.40 Minimum Detectable Doses to Extra Thoracic Tissues and the Lung from Inhalation of Type Super S Fuel-Grade Plutonium Based on Detection of $0.2 \mathrm{dpm} / \mathrm{d}{ }^{239} \mathrm{Pu}$ in Feces. 
8.41 Minimum Detectable Intakes of Total Alpha for Type S Material Comparing Urine Sampling Versus Chest Counting for Two Bounding Mixture Types....

8.42 Minimum Detectable Intakes of Inhalation Type M, 20-Year-Aged Weapons-Grade and 50-Year-Aged Fuel-Grade Plutonium Mixtures from Fecal Sampling, Urine Sampling, and Chest Counting

8.43 Minimum Detectable Intakes of Inhalation Type S, 20-Year-Aged Weapons-Grade and 50-Year-Aged Fuel-Grade Plutonium Mixtures from Fecal Sampling, Urine Sampling, and Chest Counting ......

\section{Tables}

8.1 Plutonium and Americium Decay Data ............................................................................

8.2 Reference Hanford Plutonium Mixtures Prior to Aging....................................................... 8.4

8.3 Activity Composition of Hanford Reference Weapons-Grade Plutonium Mixture.................... 8.6

8.4 Activity Composition of Hanford Reference Fuel-Grade Plutonium Mixture .......................... 8.7

8.5 Activity Composition of Hanford Reference Commercial Power-Grade Plutonium

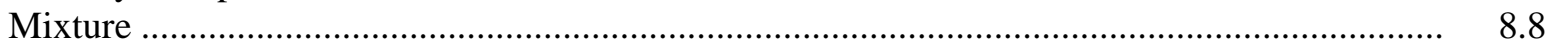

8.6 Solubility Parameter Comparison for SRS 498 ................................................................ 8.12

8.7 Parameters of the Type Super S Absorption Model ......................................................... 8.13

8.8 GI Uptake to Blood Factors (f1) for Hanford Pu Intakes .................................................... 8.14

8.9 Transfer Rates Between Compartments in the Plutonium Systemic Model of the

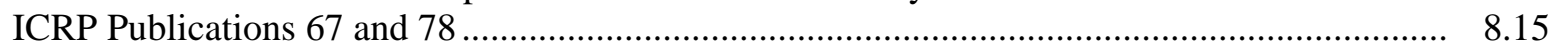

8.10 Lung Retention for 5- $\mu$ m-AMAD Particles Plutonium Acute Inhalation Intake....................... 8.18

8.11 Lung Retention of ${ }^{241} \mathrm{Am}$ per Unit Acute Intake of ${ }^{241} \mathrm{Am}$ with Ingrowth from ${ }^{241} \mathrm{Pu}$ for 5- $\mu \mathrm{m}$-AMAD Particles, Weapons-Grade Plutonium …....................................................... 8.20

$8.12{ }^{239} \mathrm{Pu}$ Urine Excretion Fractions for Instantaneous Uptake, Inhalation, and Ingestion Intakes.

$8.13{ }^{239} \mathrm{Pu}$ Fecal Excretion Fractions for Instantaneous Uptake, Inhalation, and Ingestion Intakes

8.14 Fecal-to-Urine Ratios for ${ }^{239}$ Pu Intakes ......................................................................... 8.26

8.15 Committed Dose Coefficients for Acute Intakes of ${ }^{238} \mathrm{Pu}$..................................................... 8.27

8.16 Committed Dose Coefficients for Acute Intakes of ${ }^{239} \mathrm{Pu}$ or ${ }^{240} \mathrm{Pu}$....................................... 8.27

8.1 Committed Dose Coefficients for Acute Intakes of ${ }^{241} \mathrm{Pu}$................................................... 8.28

8.18 Committed Dose Coefficients for Acute Intakes of ${ }^{241} \mathrm{Am}$ in a Plutonium Matrix.................... 8.28

8.19 Committed Dose Coefficients for Acute Intakes of Hanford Weapons-Grade Plutonium Mixtures

8.20 Committed Dose Coefficients for Acute Intakes of Hanford Fuel-Grade Plutonium Mixtures.

8.21 Cumulative Effective Dose and Equivalent Dose for ${ }^{239} \mathrm{Pu}$ Intakes....................................... 8.31

8.22 Comparison of Effective Dose Coefficients, Sv/Bq ............................................................ 8.32 
8.23 DACs, DALIs, and SALIs ....

8.24 Detection Limits for Routine Hanford Analyses of Plutonium in Urine .

8.25 Minimum Detectable Intakes of ${ }^{239} \mathrm{Pu}$ Based on Detection of $0.02 \mathrm{dpm} / \mathrm{d}$ in Urine.

8.26 Minimum Detectable Committed Effective Doses for 20-Year-Aged Weapons-Grade Plutonium Based on Detection of $0.02 \mathrm{dpm} / \mathrm{d}{ }^{239} \mathrm{Pu}$ in Urine.

8.27 Minimum Detectable Committed Effective Doses for 50-Year-Aged Weapons-Grade Plutonium Based on Detection of $0.02 \mathrm{dpm} / \mathrm{d}^{239} \mathrm{Pu}$ in Urine.

8.28 Minimum Detectable Committed Effective Doses for 20-Year-Aged Fuel-Grade Plutonium Based on Detection of $0.02 \mathrm{dpm} / \mathrm{d}{ }^{239} \mathrm{Pu}$ in Urine.

8.29 Minimum Detectable Committed Effective Doses for 50-Year- Aged Fuel-Grade Plutonium Based on Detection of $0.02 \mathrm{dpm} / \mathrm{d}^{239} \mathrm{Pu}$ in Urine.

8.30 Minimum Detectable Bone Surface Committed Equivalent Doses for 20-Year-Aged Weapons-Grade Plutonium Based on Detection of $0.02 \mathrm{dpm} / \mathrm{d}{ }^{239} \mathrm{Pu}$ in Urine.

8.31 Minimum Detectable Bone Surface Committed Equivalent Doses for 50-Year-Aged Weapons-Grade Plutonium Based on Detection of $0.02 \mathrm{dpm} / \mathrm{d}{ }^{239} \mathrm{Pu}$ in Urine

8.32 Minimum Detectable Bone Surface Committed Equivalent Doses for 20-Year-Aged Fuel-Grade Plutonium Based on Detection of $0.02 \mathrm{dpm} / \mathrm{d}{ }^{239} \mathrm{Pu}$ in Urine.....

8.33 Minimum Detectable Bone Surface Committed Equivalent Doses for 50-Year-Aged FuelGrade Plutonium Based on Detection of $0.02 \mathrm{dpm} / \mathrm{d}{ }^{239} \mathrm{Pu}$ in Urine....

8.34 Minimum Detectable Committed Equivalent Doses for Extrathoracic Tissues and the Lung for Inhalation of Type Super S Weapons-Grade Plutonium Based on Detection of $0.02 \mathrm{dpm} / \mathrm{d}{ }^{239} \mathrm{Pu}$ in Urine.

8.35 Minimum Detectable Committed Equivalent Doses for Extra Thoracic Tissues and the Lung for Inhalation of Type Super S Fuel-Grade Plutonium Based on Detection of $0.02 \mathrm{dpm} / \mathrm{d}{ }^{239} \mathrm{Pu}$ in Urine

8.36 Minimum Detectable Committed Effective Doses for 20-Year-Aged Weapons-Grade Plutonium Based on Detection of $0.16 \mathrm{nCi}^{241} \mathrm{Am}$ in the Lungs.

8.37 Minimum Detectable Committed Effective Doses for 50-Year-Aged Weapons-Grade Plutonium Based on Detection of $0.16 \mathrm{nCi}^{241} \mathrm{Am}$ in the Lungs.

8.38 Minimum Detectable Committed Effective Doses for 20-Year-Aged Fuel-Grade Plutonium Based on Detection of $0.16 \mathrm{nCi}^{241} \mathrm{Am}$ in the Lungs.

8.39 Minimum Detectable Committed Effective Doses for 50-Year-Aged Fuel-Grade Plutonium Based on Detection of $0.16 \mathrm{nCi}^{241} \mathrm{Am}$ in the Lungs.

8.40 Minimum Detectable Bone Surface Committed Equivalent Doses for 20-Year-Aged Weapons-Grade Plutonium Based on Detection of $0.16 \mathrm{nCi}^{241} \mathrm{Am}$ in the Lungs.

8.41 Minimum Detectable Bone Surface Committed Equivalent Doses for 50-Year-Aged Weapons-Grade Plutonium Based on Detection of $0.16 \mathrm{nCi}^{241} \mathrm{Am}$ in the Lungs.

8.42 Minimum Detectable Bone Surface Committed Equivalent Doses for 20-Year-Aged FuelGrade Plutonium Based on Detection of $0.16 \mathrm{nCi}^{241} \mathrm{Am}$ in the Lungs.

8.43 Minimum Detectable Bone Surface Committed Equivalent Doses for 50-Year-Aged FuelGrade Plutonium Based on Detection of $0.16 \mathrm{nCi}^{241} \mathrm{Am}$ in the Lungs ....

8.44 Minimum Detectable Committed Equivalent Doses for Extrathoracic Tissues and the Lung for Inhalation of Type Super S Weapons-Grade Plutonium Based on Detection of $0.16 \mathrm{nCi}^{241} \mathrm{Am}$ in the Lungs. 
8.45 Minimum Detectable Committed Equivalent Doses for Extrathoracic Tissues and the Lung for Inhalation of Type Super S Fuel-Grade Plutonium Based on Detection of $0.16 \mathrm{nCi}^{241} \mathrm{Am}$ in the Lungs.

8.46 Minimum Detectable Intakes of ${ }^{239} \mathrm{Pu}$ Based on Detection of $0.2 \mathrm{dpm} / \mathrm{d}$ in Feces......

8.47 Minimum Detectable Committed Effective Doses for 20-Year-Aged Weapons-Grade Plutonium Based on Detection of $0.2 \mathrm{dpm} / \mathrm{d}{ }^{239} \mathrm{Pu}$ in Feces

8.48 Minimum Detectable Committed Effective Doses for 50-Year-Aged Weapons-Grade Plutonium Based on Detection of $0.2 \mathrm{dpm} / \mathrm{d}{ }^{239} \mathrm{Pu}$ in Feces.

8.49 Minimum Detectable Committed Effective Doses for 20-Year-Aged Fuel-Grade Plutonium Based on Detection of $0.2 \mathrm{dpm} / \mathrm{d}{ }^{239} \mathrm{Pu}$ in Feces .

8.50 Minimum Detectable Committed Effective Doses for 50-Year-Aged Fuel-Grade Plutonium Based on Detection of $0.2 \mathrm{dpm} / \mathrm{d}{ }^{239} \mathrm{Pu}$ in Feces.

8.51 Minimum Detectable Bone Surface Committed Equivalent Doses for 20-Year-Aged Weapons-Grade Plutonium Based on Detection of $0.2 \mathrm{dpm} / \mathrm{d}{ }^{239} \mathrm{Pu}$ in Feces

8.52 Minimum Detectable Bone Surface Committed Equivalent Doses for 50-Year-Aged Weapons-Grade Plutonium Based on Detection of $0.2 \mathrm{dpm} / \mathrm{d}{ }^{239} \mathrm{Pu}$ in Feces .

8.53 Minimum Detectable Bone Surface Committed Equivalent Doses for 20-Year Aged FuelGrade Plutonium Based on Detection of $0.2 \mathrm{dpm} / \mathrm{d}{ }^{239} \mathrm{Pu}$ in Feces

8.54 Minimum Detectable Bone Surface Committed Equivalent Doses for 50-Year-Aged FuelGrade Plutonium Based on Detection of $0.2 \mathrm{dpm} / \mathrm{d}{ }^{239} \mathrm{Pu}$ in Feces 



\subsection{Plutonium}

This chapter provides information about the sources, characteristics, and biokinetics of plutonium and ingrown americium and summarizes the technical basis for their internal dosimetry at Hanford.

Prior to 1989, the general approach to plutonium internal dosimetry at Hanford was to evaluate the systemic deposition based on urine data, and compare the result with a referenced maximum permissible body burden (MPBB) such as those contained in Publication 2 of the International Commission on Radiological Protection (ICRP 1959). The assessed systemic deposition was a "committed" systemic deposition, i.e., an estimate of the total amount of activity that would eventually reach systemic compartments. The calculated depositions did not address the time post intake at which the maximum systemic deposition might be expected, nor the amount of activity that might be retained in the body at various times post intake. Once the committed systemic deposition was calculated, its value was assumed to remain constant for the worker's life. The percentage of the MPBB was used to indicate the degree of compliance (or noncompliance) with Atomic Energy Commission, Energy Research and Development Agency, and U.S. Department of Energy (DOE) standards for radiation protection. Initially, systemic depositions below 5\% MPBB were not reported as confirmed depositions. This cutoff for recording and reporting was lowered to $1 \%$ MPBB in the 1970 s.

Lung dose equivalents were assessed prior to 1989 in cases where in vivo measurements had observed activity in the lung. The approach used for assessment was documented on a case-by-case basis in each specific case evaluation. Generally, the approach was to use the best available information regarding isotope ratios and estimates of lung clearance rates based on ${ }^{241} \mathrm{Am}$ in vivo measurements, urine data, and fecal data when they were available. Lacking such data, default assumptions were used and documented in evaluations. The techniques for calculating dose were similar to those used in ICRP 2 (1959) and ICRP 10 (1969) and applied a quality factor of 10 for alpha particle emissions. The results of those lung dose estimates were compared with the long-standing 15-rem/y limit of ICRP 2.

In late 1988, the technical approach to plutonium dosimetry at Hanford changed to the dosimetry approach of ICRP 26/30 (1977/1979), incorporating the concepts of organ and tissue weighting factors to give an effective dose equivalent from specific organ doses. The alpha particle quality factor was also changed from 10 to 20, and the concepts of stochastic and deterministic (nonstochastic) dose limits were adopted. In addition, advances in measurement technology and modeling improved the capabilities for plutonium dosimetry. The concept of "presystemic deposition” was introduced by Sula et al. (1989) for the purpose of simulating biokinetic behavior in estimating internal doses. The presystemic deposition was defined as the component(s) of an initial deposition that would ultimately translocate to the blood, regardless of the time required to translocate. A transfer rate from the initial deposition into the systemic compartment was linked with each component of the presystemic deposition. Once material from the presystemic deposition reached the systemic compartment, it was assumed to behave in accordance with the applicable biokinetic model. The presystemic deposition specifically excluded material permanently retained at the entry site or in lymphatic tissues.

A further shift in internal dosimetry for plutonium occurred in 1992 with requirements to report intake magnitude in addition to dose equivalents (DOE 1992). This resulted in a shift away from presystemic deposition assessments (which ignored intake fractions not retained, such as the material exhaled 
immediately following inhalation) to the total intake assessment. The adoption of the CINDY internal dosimetry computer code (Strenge et al. 1992) as the principal calculational tool for Hanford internal dosimetry facilitated this shift to intake assessment.

This revision to internal dosimetry for plutonium implements the ICRP lung model presented in Publication 66 (ICRP 1994b) and the biokinetic model for plutonium presented in ICRP 67, Appendix B (ICRP 1993), ICRP 68 (1994a), ICRP 71 (1995), and ICRP 78 (1997). For those parameters with agespecific differences, the parameters for 'adult' are used. The ICRP 30 gastrointestinal (GI) model is still used (ICRP 1979) except that uptake factors from the gut to the blood, $f_{1}$, have been updated as presented in ICRP 68 (1994a). For dose calculations, tissues and tissue weighting factors introduced in ICRP 60 (1991) and adopted in the June 2007 revision of Title 10 of the Code of Federal Regulations Part 835 (10 CFR 835) are used. All excretion, retention, and dose coefficients were calculated using the IMBA Professional Plus internal (IMBA) dosimetry computer code (James et al. 2004). ${ }^{1}$

\subsection{Sources and Characteristics}

This section provides general information on the isotopes, mixtures, and forms of plutonium that are commonly found at Hanford. The physical data were taken directly from, or calculated based on, information in ICRP 30 (1979) and ICRP 38 (1983) and are consistent with the values used in IMBA and ICRP 78 (1997).

\subsubsection{Sources of Plutonium}

Production of plutonium was the original mission for Hanford. It was produced by irradiation of uranium fuel elements in reactors in the 100 Areas, then separated and purified in the 200 Area chemical processing facilities. After purification, it underwent conversion to final metallic form at the Plutonium Finishing Plant (234-5Z Building) in the 200 West Area, where it was stored until it was shipped to other DOE sites for component fabrication. Plutonium-contaminated waste is buried or stored in a variety of waste management facilities. Trace plutonium and americium levels can be found in some of the highlevel waste storage facilities (e.g., 100-K Spent Fuel Storage Basins, 200 Area tank farms and associated facilities).

Plutonium can also be found at Hanford as a result of research projects that involved spent fuel associated with nuclear power plants, breeder reactor applications, and radioisotope applications. Many of these research projects were in 300 Area facilities. Analytical chemistry laboratories may contain plutonium standard solutions.

Plutonium has also been distributed in the worldwide environment at very low levels as a result of atmospheric testing of nuclear devices. Wrenn et al. (1994) indicated that persons living in the northern hemisphere have accumulated about $3 \mathrm{pCi}$ of ${ }^{239+240} \mathrm{Pu}$ from fallout from the weapons tests of the 1950s, and reported a background mean urine excretion of 3 to $8 \times 10^{-5} \mathrm{dpm} /$ day resulting from that body burden. Similar levels of body burden have been reported by McInroy et al. (1979); McInroy et al. (1981); and Nelson et al. (1993). Ibrahim et al. (1999) reported a mean ${ }^{239} \mathrm{Pu}$ urine excretion rate of

\footnotetext{
${ }^{1}$ IMBA Professional Plus, which includes the current version of the user manual, is available from Health Protection Agency (HPA), Radiation Protection Division, Chilton, Didicot, Oxon., OX11 ORQ UK and from http://www.imbaprofessional.com/
}

PNNL-MA-860 Chapter 8.0

Page 8.2

Issued: HPDAC Ballot, January 23, 2009

Superseded: January 31, 2003 
$1.1 \mu \mathrm{Bq} / \mathrm{d}\left(9.2 \times 10^{-5} \mathrm{dpm} / \mathrm{d}\right)$ in a group of long-term residents near the Rocky Flats Site. These body burdens and the urine results suggest that normal background urinary excretion levels of plutonium are far below the nominal 0.02-dpm minimum detectable activity routinely available for Hanford urine bioassay measurements.

\subsubsection{Isotope Decay Data}

The plutonium and plutonium decay product isotopes of concern at Hanford and selected decay data are listed in Table 8.1. The radiological constants given in Table 8.1 are taken or calculated from data in ICRP 30 and 38.

Table 8.1. Plutonium and Americium Decay Data

\begin{tabular}{lcccccc}
\hline & \multirow{2}{*}{ Decay } & \multicolumn{2}{c}{ Half-Life } & \multicolumn{2}{c}{ Decay Constant } & Specific Activity \\
\cline { 3 - 7 } Isotope & Mode & Years & Days & Year-1 & Day-1 & Ci/g \\
\hline${ }^{238} \mathrm{Pu}$ & Alpha & 87.7 & $3.20 \mathrm{E}+04$ & $7.90 \mathrm{E}-03$ & $2.16 \mathrm{E}-05$ & $1.71 \mathrm{E}+01$ \\
${ }^{239} \mathrm{Pu}$ & Alpha & 24,065 & $8.78 \mathrm{E}+06$ & $2.88 \mathrm{E}-05$ & $7.89 \mathrm{E}-08$ & $6.21 \mathrm{E}-02$ \\
${ }^{240} \mathrm{Pu}$ & Alpha & 6,537 & $2.39 \mathrm{E}+06$ & $1.06 \mathrm{E}-04$ & $2.90 \mathrm{E}-07$ & $2.27 \mathrm{E}-01$ \\
${ }^{241} \mathrm{Pu}$ & Beta & 14.4 & $5.26 \mathrm{E}+03$ & $4.81 \mathrm{E}-02$ & $1.32 \mathrm{E}-04$ & $1.03 \mathrm{E}+02$ \\
${ }^{242} \mathrm{Pu}$ & Alpha & 376,300 & $1.37 \mathrm{E}+08$ & $1.84 \mathrm{E}-06$ & $5.05 \mathrm{E}-09$ & $3.92 \mathrm{E}-03$ \\
${ }^{241} \mathrm{Am}$ & Alpha & 432.2 & $1.58 \mathrm{E}+05$ & $1.60 \mathrm{E}-03$ & $4.39 \mathrm{E}-06$ & $3.43 \mathrm{E}+00$ \\
\hline
\end{tabular}

\subsubsection{Reference Isotope Mixtures}

Pure isotopes of plutonium are seldom encountered at Hanford facilities. Instead, plutonium is usually encountered as a mixture of isotopes. For specific exposure situations where the isotopic composition of a mixture is known, that composition should be used for dosimetry purposes. In situations where mixtures are unknown, or for bioassay planning purposes, assumptions regarding the mixture should be made.

The isotopic composition of a plutonium mixture is related to several variables, including the following:

- the length of time fuel was irradiated (fuel exposure or burn-up time)

- the time since irradiation (cooling time)

- the time since processing of fuel or purification of plutonium.

Typically, plutonium at Hanford falls into one of two generic mixtures. These mixtures are defined by the weight percent (wt\%) of ${ }^{240} \mathrm{Pu}$. Thus, $6 \%$ plutonium has a nominal ${ }^{240} \mathrm{Pu}$ content of $6 \mathrm{wt} \%$ and $12 \%$ plutonium has a nominal ${ }^{240} \mathrm{Pu}$ content of $12 \mathrm{wt} \%$. The $6 \%$ plutonium mixture is commonly referred to as "weapons grade" because that was the nominal target mixture for nuclear weapons components. Weapons-grade plutonium had a relatively short reactor exposure time. The $12 \%$ plutonium mixture is commonly referred to at Hanford as "fuel grade," and resulted from lengthier reactor exposure for research or power production purposes. 
Plutonium mixtures are also associated with the much longer fuel cycle of large-scale power production reactors. The spent fuel from the power reactor fuel cycle demonstrates a significant buildup of ${ }^{240} \mathrm{Pu}$, e.g., $25 \mathrm{wt} \%$ would not be an unusual number. This form of plutonium can be associated with Hanford research projects involving commercial fuel, such as the Nuclear Waste Vitrification Project (NWVP), circa 1970s.

Other isotopic compositions may be encountered and should be addressed as needed. In a discussion of the manufacture of plutonium, the DOE Standard, Guide of Good Practices for Occupational Radiological Protection in Plutonium Facilities (DOE 1998), identified isotopic mixtures for heat-source, weapons-grade and reactor-grade plutonium mixtures. The weapons-grade mixture is similar to the Hanford weapons-grade mixture, and the reactor-grade mixture is similar to the NWVP mixture described above. In the internal dosimetry section of the standard, the Hanford weapons-grade and fuel-grade mixtures are specifically listed as example mixtures. The heat-source mixture refers to material used for radioisotope thermal generators, which are primarily ${ }^{238} \mathrm{Pu}$. Heat-source plutonium is not a typical Hanford mixture, although some heat-source plutonium was handled in the 300 Area in the 1960s. The Plutonium Finishing Plant also handled unusual isotopic mixtures at times (Hoyt and Teal 2004), including $18 \%$ to $25 \%{ }^{240} \mathrm{Pu}$ in the 1960 s and early 1970 s, and processed plutonium from Shippingport spent fuel with about $24 \%{ }^{240} \mathrm{Pu}$ in the mid-1960s.

Reference Hanford plutonium mixtures, prior to any ${ }^{241}$ Am ingrowth, are listed in Table 8.2. These reference mixtures are approximations based on the isotopic composition of a number of batches of freshly processed plutonium and are not intended to represent any specific batch. Actual exposures may or may not reflect these compositions. When the actual composition of a mixture to which a worker has been exposed can be obtained, such data should be used.

Table 8.2. Reference Hanford Plutonium Mixtures Prior to Aging (wt\%)

\begin{tabular}{cccc}
\hline Isotope & Weapons Grade & Fuels Grade & Commercial Power Grade \\
\hline${ }^{238} \mathrm{Pu}$ & 0.05 & 0.10 & 1 \\
${ }^{239} \mathrm{Pu}$ & 93.1 & 84.8 & 55 \\
${ }^{240} \mathrm{Pu}$ & 6.0 & 12.0 & 26 \\
${ }^{241} \mathrm{Pu}$ & 0.8 & 3.0 & 13 \\
${ }^{242} \mathrm{Pu}$ & 0.05 & 0.1 & 5 \\
${ }^{241} \mathrm{Am}$ & 0.0 & 0.0 & 0.0 \\
\hline
\end{tabular}

Other nominal mixture compositions can be determined from the following relationships (in weight percent) (Kinderman et al. 1953):

$$
\begin{gathered}
{ }^{238} \mathrm{Pu}=0.001832\left({ }^{240} \mathrm{Pu}\right) \\
{ }^{239} \mathrm{Pu}=100.1-1.094\left({ }^{240} \mathrm{Pu}\right) \\
{ }^{240} \mathrm{Pu}=8.252\left({ }^{241} \mathrm{Pu}\right)^{1 / 2}
\end{gathered}
$$

In the typical plutonium mixture, the plutonium-alpha activity is relatively constant over time due to the long decay half-life of the alpha emitters. The plutonium-beta activity $\left({ }^{241} \mathrm{Pu}\right)$ decays with a 14 -year 
half-life into ${ }^{241} \mathrm{Am}$. Thus, over a period of years, plutonium-beta activity in a mixture will decrease while at the same time the ${ }^{241} \mathrm{Am}$ activity and the total alpha activity of the mixture will increase. Serial decay relationships can be used to estimate the activity of each isotope for any decay time. A handcalculator program developed at Hanford by Rittman (1984) and written into a computer utility for personal computers ${ }^{1}$ is used to solve these decay relationships, which can also be solved using computer spreadsheet application software. Tables 8.3, 8.4, and 8.5 provide the specific activities of each isotope in the reference mixtures and isotope ratios relative to ${ }^{239+240} \mathrm{Pu}$ and ${ }^{241} \mathrm{Am}$. These tables clearly show that ${ }^{242} \mathrm{Pu}$ is an insignificant contributor to the specific activity of the reference mixtures, and may be ignored for purposes of dosimetry.

For each reference mixture, a family of curves can be developed to describe the changing activity relationships between isotopes (see Figures 8.1 through 8.4). These curves can then be used to identify, for dosimetry purposes, the plutonium mixture and its approximate age after processing or purification. When information about isotopic composition or activity ratios is lacking, assumptions must be made for dose assessment. Hanford internal dosimetry applications of these curves were developed by Sula et al. (1989, 1991) for freshly separated and 5-year-aged conditions of 6\% Pu and 12\% Pu. Since that time, production of plutonium at Hanford has ceased and mixtures have continued to age. Thus, presentations of such relationships for freshly irradiated or separated plutonium mixtures are no longer needed, while the need for data about additional mixture ages has arisen. Consequently, this manual now uses, as the basis for bioassay program design and interpretation, reference mixtures of 20-, and 50-year-old weaponsand fuel-grade plutonium. The primary use for these reference mixtures is in the planning of bioassay monitoring frequencies and methods, and for defining the capability of the internal dosimetry program.

\subsection{Biokinetic Behavior}

The following sections discuss the inhalation absorption type, internal distribution and retention, and the urinary and fecal excretion of plutonium.

\subsubsection{Absorption Type}

In the ICRP 66 (1994b) respiratory tract model, deposition of particles into the respiratory tract and particle transport from various regions of the respiratory tract are assumed to be the same for all materials. Absorption of deposited material into the blood depends on the physical and chemical form of the material, but default values are given only for chemical forms. Absorption types are identified for particulates as Types $\mathrm{F}$ (for fast), $\mathrm{M}$ (for moderate), and S (for slow). Details and additional discussion on the respiratory tract model are provided in Appendix C.

ICRP 68 (1994a) assigned insoluble plutonium oxides to absorption Type $\mathrm{S}$ and all other plutonium compounds to Type M. No plutonium compounds were assigned to Type F. These default absorption types are adequate for program design; however, caution should be used in applying these categorizations to actual intakes because significant variations have been observed, as discussed below.

\footnotetext{
${ }^{1}$ Personal correspondence between PD Rittman and EH Carbaugh, 1993, Pacific Northwest National Laboratory.
} 


\begin{tabular}{|c|c|c|c|c|c|c|c|c|c|}
\hline Mixture Designation: & Fresh & 5-Year & 10-Year & 15-Year & 20-Year & 25-Year & 30-Year & 40-Year & 50-Year \\
\hline Years of Aging: & 0 & 5 & 10 & 15 & 20 & 25 & 30 & 40 & 50 \\
\hline \multicolumn{10}{|c|}{ Specific Activity in Mixture (Ci/g) } \\
\hline${ }^{238} \mathrm{Pu}$ & $8.56 \mathrm{E}-03$ & 8.23E-03 & 7.91E-03 & 7.60E-03 & 7.31E-03 & 7.03E-03 & $6.75 \mathrm{E}-03$ & $6.24 \mathrm{E}-03$ & 5.77E-03 \\
\hline${ }^{239} \mathrm{Pu}$ & 5.77E-02 & 5.77E-02 & 5.77E-02 & 5.77E-02 & 5.77E-02 & 5.77E-02 & 5.77E-02 & 5.76E-02 & 5.79E-02 \\
\hline${ }^{240} \mathrm{Pu}$ & $1.36 \mathrm{E}-02$ & $1.36 \mathrm{E}-02$ & $1.36 \mathrm{E}-02$ & $1.36 \mathrm{E}-02$ & 1.36E-02 & 1.36E-02 & $1.36 \mathrm{E}-02$ & $1.35 \mathrm{E}-02$ & 1.35E-02 \\
\hline${ }^{241} \mathrm{Pu}$ & 8.24E-01 & 6.48E-01 & 5.09E-01 & 4.00E-01 & 3.15E-01 & $2.48 \mathrm{E}-01$ & $1.95 \mathrm{E}-01$ & $1.20 \mathrm{E}-01$ & 7.44E-02 \\
\hline${ }^{242} \mathrm{Pu}$ & $1.97 \mathrm{E}-06$ & $1.97 \mathrm{E}-06$ & $1.97 \mathrm{E}-06$ & $1.97 \mathrm{E}-06$ & $1.97 \mathrm{E}-06$ & $1.97 \mathrm{E}-06$ & $1.97 \mathrm{E}-06$ & $1.97 \mathrm{E}-06$ & 1.97E-06 \\
\hline${ }^{241} \mathrm{Am}$ & $0.00 \mathrm{E}+00$ & 5.83E-03 & $1.04 \mathrm{E}-02$ & $1.39 \mathrm{E}-02$ & $1.66 \mathrm{E}-02$ & $1.87 \mathrm{E}-02$ & 2.03E-02 & 2.25E-02 & 2.36E-02 \\
\hline${ }^{239 / 240} \mathrm{Pu}$ & 7.13E-02 & 7.13E-02 & 7.13E-02 & 7.13E-02 & 7.13E-02 & 7.13E-02 & 7.13E-02 & 7.11E-02 & 7.14E-02 \\
\hline Pu-alpha & 7.99E-02 & 7.95E-02 & 7.92E-02 & 7.89E-02 & $7.86 \mathrm{E}-02$ & 7.83E-02 & 7.81E-02 & 7.73E-02 & 7.72E-02 \\
\hline Total alpha & 7.99E-02 & $8.54 \mathrm{E}-02$ & 8.96E-02 & $9.28 \mathrm{E}-02$ & $9.52 \mathrm{E}-02$ & $9.70 \mathrm{E}-02$ & $9.84 \mathrm{E}-02$ & $9.98 \mathrm{E}-02$ & $1.01 \mathrm{E}-01$ \\
\hline \multicolumn{10}{|c|}{ Activity Ratios } \\
\hline${ }^{239 / 240} \mathrm{Pu}:{ }^{241} \mathrm{Am}:$ & NA & $1.22 \mathrm{E}+01$ & $6.87 \mathrm{E}+00$ & $5.13 \mathrm{E}+00$ & $4.28 \mathrm{E}+00$ & $3.80 \mathrm{E}+00$ & $3.50 \mathrm{E}+00$ & $3.17 \mathrm{E}+00$ & $3.01 \mathrm{E}+00$ \\
\hline${ }^{241} \mathrm{Am}:{ }^{238} \mathrm{Pu}$ & NA & 7.09E-01 & $1.31 \mathrm{E}+00$ & $1.83 \mathrm{E}+00$ & $2.27 \mathrm{E}+00$ & $2.66 \mathrm{E}+00$ & $3.01 \mathrm{E}+00$ & $3.60 \mathrm{E}+00$ & $4.09 \mathrm{E}+00$ \\
\hline${ }^{241} \mathrm{Pu}:{ }^{239 / 240} \mathrm{Pu}$ & $1.16 \mathrm{E}+01$ & $9.09 \mathrm{E}+00$ & $7.15 \mathrm{E}+00$ & $5.62 \mathrm{E}+00$ & $4.42 \mathrm{E}+00$ & $3.48 \mathrm{E}+00$ & $2.73 \mathrm{E}+00$ & $1.69 \mathrm{E}+00$ & $1.05 \mathrm{E}+00$ \\
\hline Total alpha: ${ }^{239 / 240} \mathrm{Pu}$ & $1.12 \mathrm{E}+00$ & $1.20 \mathrm{E}+00$ & $1.26 \mathrm{E}+00$ & $1.30 \mathrm{E}+00$ & $1.34 \mathrm{E}+00$ & $1.36 \mathrm{E}+00$ & $1.38 \mathrm{E}+00$ & $1.40 \mathrm{E}+00$ & $1.41 \mathrm{E}+00$ \\
\hline Total alpha: ${ }^{241} \mathrm{Am}$ & NA & $1.46 \mathrm{E}+01$ & $8.63 \mathrm{E}+00$ & $6.67 \mathrm{E}+00$ & $5.72 \mathrm{E}+00$ & $5.18 \mathrm{E}+00$ & $4.84 \mathrm{E}+00$ & $4.45 \mathrm{E}+00$ & $4.26 \mathrm{E}+00$ \\
\hline \multicolumn{10}{|c|}{ IMBA-Associated Radionuclide Inputs $\left(\%\right.$ of $\left.{ }^{239} \mathrm{Pu}\right)$} \\
\hline${ }^{238} \mathrm{Pu}:{ }^{239 / 240} \mathrm{Pu}^{(\mathrm{a})}$ & $12.0 \%$ & $11.5 \%$ & $11.1 \%$ & $10.7 \%$ & $10.3 \%$ & $9.86 \%$ & $9.47 \%$ & $8.78 \%$ & $8.08 \%$ \\
\hline${ }^{241} \mathrm{Pu}:{ }^{239 / 240} \mathrm{Pu}^{(\mathrm{a})}$ & $1160 \%$ & $909 \%$ & $714 \%$ & $561 \%$ & $442 \%$ & $348 \%$ & $273 \%$ & $169 \%$ & $104 \%$ \\
\hline${ }^{242} \mathrm{Pu}:{ }^{239 / 240} \mathrm{Pu}$ & $0.00276 \%$ & $0.00276 \%$ & $0.00276 \%$ & $0.00276 \%$ & $0.00276 \%$ & $0.00276 \%$ & $0.00276 \%$ & $0.00277 \%$ & $0.00276 \%$ \\
\hline${ }^{241} \mathrm{Am}^{.239 / 240} \mathrm{Pu}^{(\mathrm{a})}$ & $0 \%$ & $8.18 \%$ & $14.6 \%$ & $19.5 \%$ & $23.3 \%$ & $26.2 \%$ & $28.5 \%$ & $31.6 \%$ & $33.1 \%$ \\
\hline \multicolumn{10}{|c|}{$\begin{array}{l}\text { (a) }{ }^{239} \mathrm{Pu} \text { and }{ }^{240} \mathrm{Pu} \text { summed and modeled as }{ }^{239} \mathrm{Pu} \text { in IMBA. } \\
\text { NA = not applicable. }\end{array}$} \\
\hline
\end{tabular}


Table 8.4. Activity Composition of Hanford Reference Fuel-Grade Plutonium Mixture

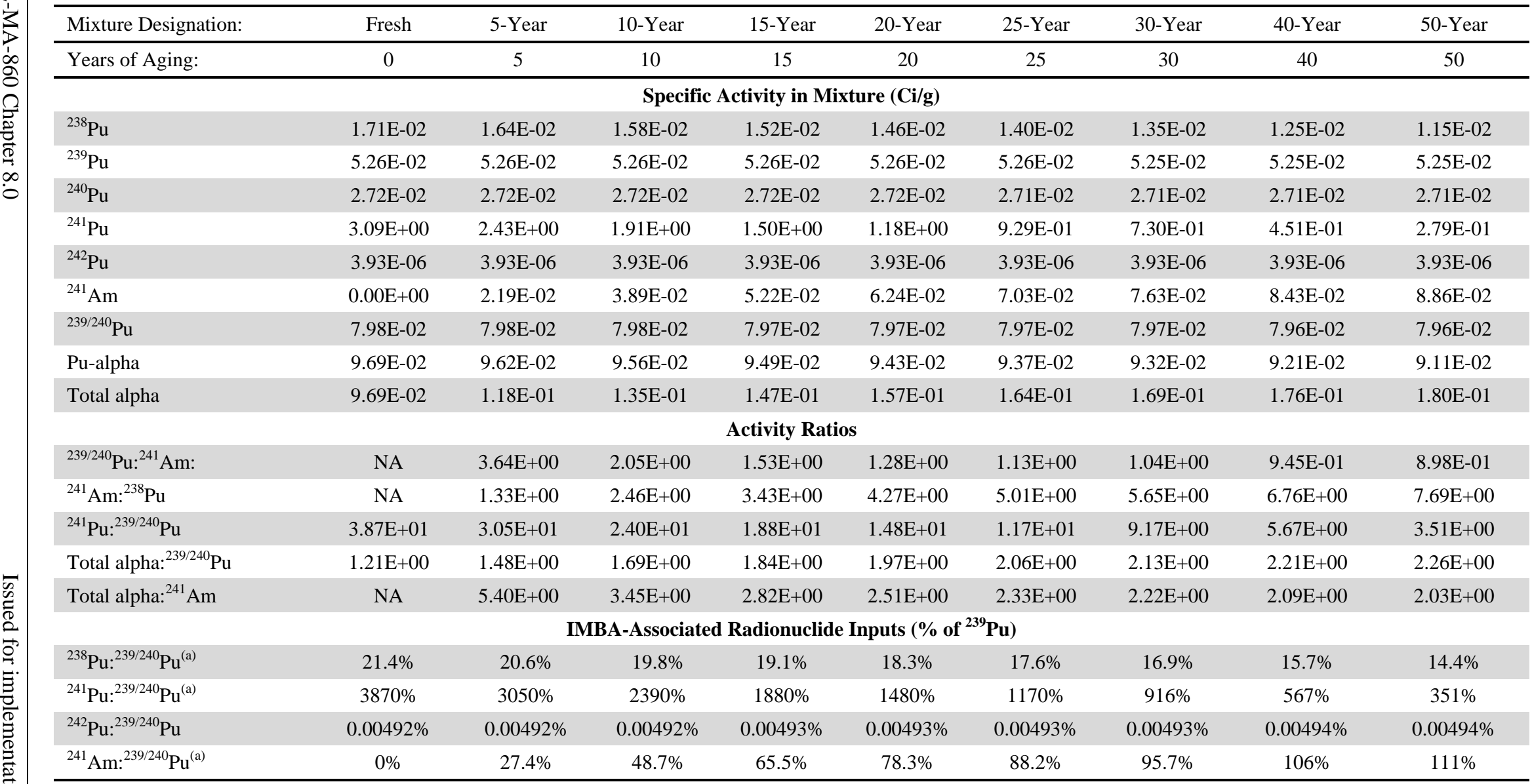

(a) ${ }^{239} \mathrm{Pu}$ and ${ }^{240} \mathrm{Pu}$ summed and modeled as ${ }^{239} \mathrm{Pu}$ in IMBA.

NA = not applicable. 
Table 8.5. Activity Composition of Hanford Reference Commercial Power-Grade Plutonium Mixture

\begin{tabular}{|c|c|c|c|c|c|c|c|c|c|}
\hline Mixture Designation: & Fresh & 5-Year & 10-Year & 15-Year & 20-Year & 25-Year & 30-Year & 40-Year & 50-Year \\
\hline Years of Aging: & 0 & 5 & 10 & 15 & 20 & 25 & 30 & 40 & 50 \\
\hline \multicolumn{10}{|c|}{ Specific Activity in Mixture (Ci/g) } \\
\hline${ }^{238} \mathrm{Pu}$ & $1.71 \mathrm{E}-01$ & $1.65 \mathrm{E}-01$ & $1.58 \mathrm{E}-01$ & $1.52 \mathrm{E}-01$ & $1.46 \mathrm{E}-01$ & $1.41 \mathrm{E}-01$ & 1.35E-01 & $1.25 \mathrm{E}-01$ & $1.15 \mathrm{E}-01$ \\
\hline${ }^{239} \mathrm{Pu}$ & $3.41 \mathrm{E}-02$ & $3.41 \mathrm{E}-02$ & $3.41 \mathrm{E}-02$ & $3.41 \mathrm{E}-02$ & $3.41 \mathrm{E}-02$ & $3.41 \mathrm{E}-02$ & $3.41 \mathrm{E}-02$ & $3.41 \mathrm{E}-02$ & 3.41E-02 \\
\hline${ }^{240} \mathrm{Pu}$ & 5.90E-02 & 5.89E-02 & 5.89E-02 & 5.89E-02 & 5.89E-02 & 5.88E-02 & 5.88E-02 & 5.87E-02 & 5.87E-02 \\
\hline${ }^{241} \mathrm{Pu}$ & $1.34 \mathrm{E}+01$ & $1.05 \mathrm{E}+01$ & $8.28 \mathrm{E}+00$ & $6.51 \mathrm{E}+00$ & $5.12 \mathrm{E}+00$ & $4.03 E+00$ & $3.17 E+00$ & $1.96 \mathrm{E}+00$ & $1.21 \mathrm{E}+00$ \\
\hline${ }^{242} \mathrm{Pu}$ & $1.97 \mathrm{E}-04$ & $1.97 \mathrm{E}-04$ & 1.97E-04 & $1.97 \mathrm{E}-04$ & 1.97E-04 & $1.97 \mathrm{E}-04$ & 1.97E-04 & $1.97 \mathrm{E}-04$ & 1.97E-04 \\
\hline${ }^{241} \mathrm{Am}$ & $0.00 \mathrm{E}+00$ & $9.49 \mathrm{E}-02$ & $1.69 \mathrm{E}-01$ & $2.26 \mathrm{E}-01$ & $2.70 \mathrm{E}-01$ & 3.04E-01 & 3.31E-01 & 3.65E-01 & 3.84E-01 \\
\hline${ }^{239 / 240} \mathrm{Pu}$ & 9.31E-02 & $9.31 \mathrm{E}-02$ & $9.30 \mathrm{E}-02$ & 9.30E-02 & $9.29 \mathrm{E}-02$ & 9.29E-02 & 9.29E-02 & $9.28 \mathrm{E}-02$ & $9.27 \mathrm{E}-02$ \\
\hline Pu-alpha & 2.65E-01 & $2.58 \mathrm{E}-01$ & $2.52 \mathrm{E}-01$ & $2.45 \mathrm{E}-01$ & 2.39E-01 & 2.34E-01 & $2.28 \mathrm{E}-01$ & 2.18E-01 & 2.08E-01 \\
\hline Total alpha & $2.65 \mathrm{E}-01$ & 3.53E-01 & 4.20E-01 & 4.71E-01 & 5.10E-01 & 5.38E-01 & 5.59E-01 & 5.83E-01 & 5.92E-01 \\
\hline \multicolumn{10}{|c|}{ Activity Ratios } \\
\hline${ }^{239 / 240} \mathrm{Pu}:{ }^{.241} \mathrm{Am}:$ & NA & $9.81 \mathrm{E}-01$ & $5.51 \mathrm{E}-01$ & 4.11E-01 & $3.44 \mathrm{E}-01$ & 3.05E-01 & $2.81 \mathrm{E}-01$ & $2.54 \mathrm{E}-01$ & $2.41 \mathrm{E}-01$ \\
\hline${ }^{241} \mathrm{Am}:{ }^{238} \mathrm{Pu}$ & NA & $5.76 \mathrm{E}-01$ & $1.07 \mathrm{E}+00$ & $1.49 \mathrm{E}+00$ & $1.85 \mathrm{E}+00$ & $2.17 \mathrm{E}+00$ & $2.45 \mathrm{E}+00$ & $2.92 \mathrm{E}+00$ & $3.33 \mathrm{E}+00$ \\
\hline${ }^{241} \mathrm{Pu}:{ }^{239 / 240} \mathrm{Pu}$ & $1.44 \mathrm{E}+02$ & $1.13 \mathrm{E}+02$ & $8.91 \mathrm{E}+01$ & $7.00 \mathrm{E}+01$ & $5.51 \mathrm{E}+01$ & $4.33 \mathrm{E}+01$ & $3.41 \mathrm{E}+01$ & $2.11 \mathrm{E}+01$ & $1.30 \mathrm{E}+01$ \\
\hline Total alpha: ${ }^{239 / 240} \mathrm{Pu}$ & $2.84 \mathrm{E}+00$ & $3.79 \mathrm{E}+00$ & $4.52 \mathrm{E}+00$ & $5.07 \mathrm{E}+00$ & $5.48 \mathrm{E}+00$ & $5.79 \mathrm{E}+00$ & $6.05 \mathrm{E}+00$ & $6.28 \mathrm{E}+00$ & $6.39 \mathrm{E}+00$ \\
\hline Total alpha: ${ }^{241} \mathrm{Am}$ & NA & $3.72 \mathrm{E}+00$ & $2.49 \mathrm{E}+00$ & $2.09 \mathrm{E}+00$ & $1.89 \mathrm{E}+00$ & $1.77 \mathrm{E}+00$ & $1.69 \mathrm{E}+00$ & $1.60 \mathrm{E}+00$ & $1.54 \mathrm{E}+00$ \\
\hline \multicolumn{10}{|c|}{ IMBA-Associated Radionuclide Inputs (\% of $\left.{ }^{239} \mathrm{Pu}\right)$} \\
\hline${ }^{238} \mathrm{Pu}:{ }^{239 / 240} \mathrm{Pu}^{(\mathrm{a})}$ & $184 \%$ & $177 \%$ & $170 \%$ & $163 \%$ & $157 \%$ & $152 \%$ & $145 \%$ & $135 \%$ & $124 \%$ \\
\hline${ }^{241} \mathrm{Pu}:{ }^{239 / 240} \mathrm{Pu}^{(\mathrm{a})}$ & $14400 \%$ & $11300 \%$ & $8900 \%$ & $7000 \%$ & $5510 \%$ & $4340 \%$ & $3410 \%$ & $2110 \%$ & $1310 \%$ \\
\hline${ }^{242} \mathrm{Pu}:{ }^{239 / 240} \mathrm{Pu}$ & $0.212 \%$ & $0.212 \%$ & $0.212 \%$ & $0.212 \%$ & $0.212 \%$ & $0.212 \%$ & $0.212 \%$ & $0.212 \%$ & $0.213 \%$ \\
\hline${ }^{241} \mathrm{Am}:{ }^{.39 / 240} \mathrm{Pu}^{(\mathrm{a})}$ & $0 \%$ & $102 \%$ & $182 \%$ & $243 \%$ & $291 \%$ & $327 \%$ & $356 \%$ & $393 \%$ & $414 \%$ \\
\hline \multicolumn{10}{|c|}{$\begin{array}{l}\text { (a) }{ }^{239} \mathrm{Pu} \text { and }{ }^{240} \mathrm{Pu} \text { summed and modeled as }{ }^{239} \mathrm{Pu} \text { in IMBA. } \\
\text { NA = not applicable. }\end{array}$} \\
\hline & & & & & & & & & \\
\hline
\end{tabular}




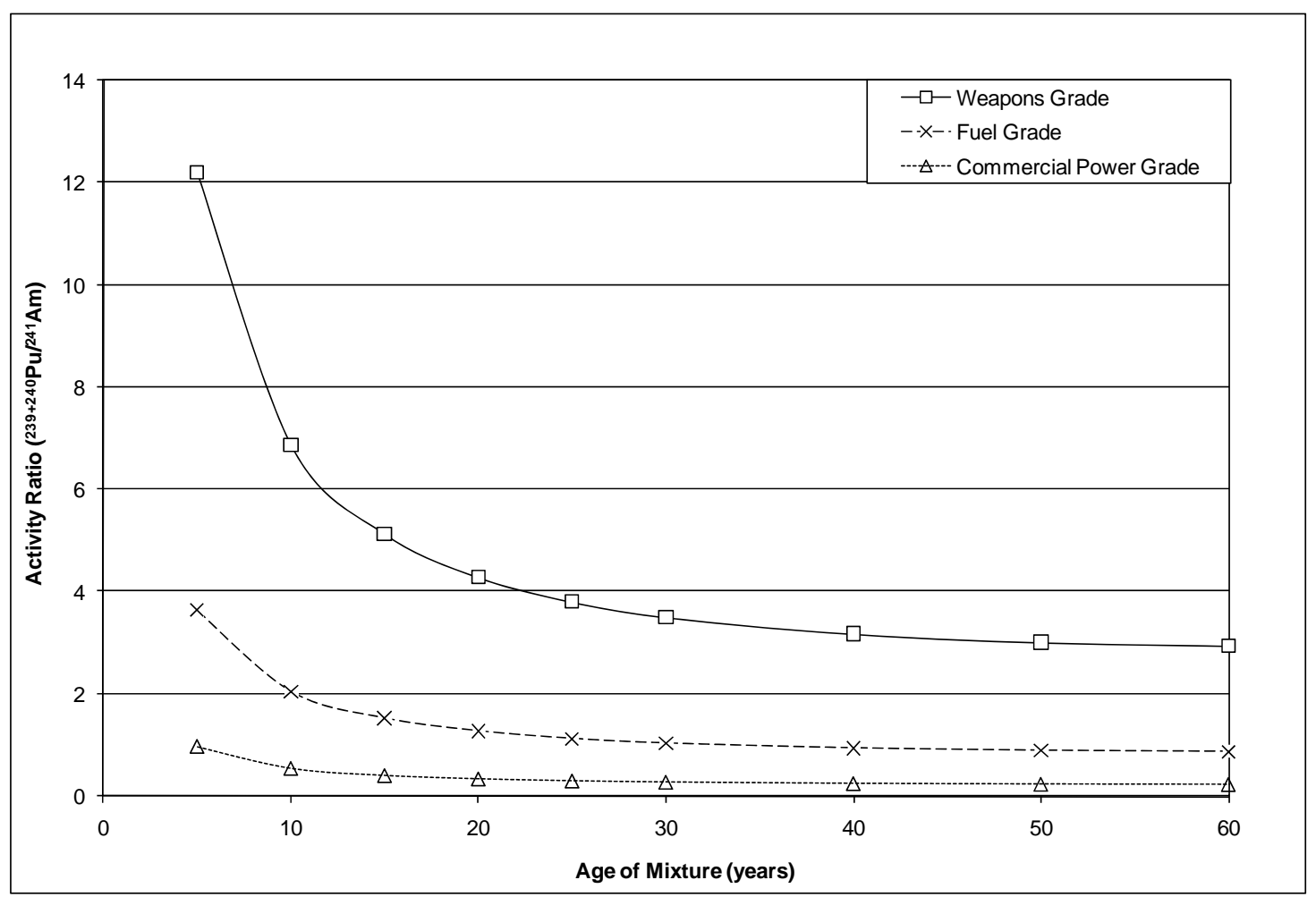

Figure 8.1. ${ }^{239+240} \mathrm{Pu} /{ }^{241} \mathrm{Am}$ Activity Ratio for Hanford Reference Plutonium Mixtures

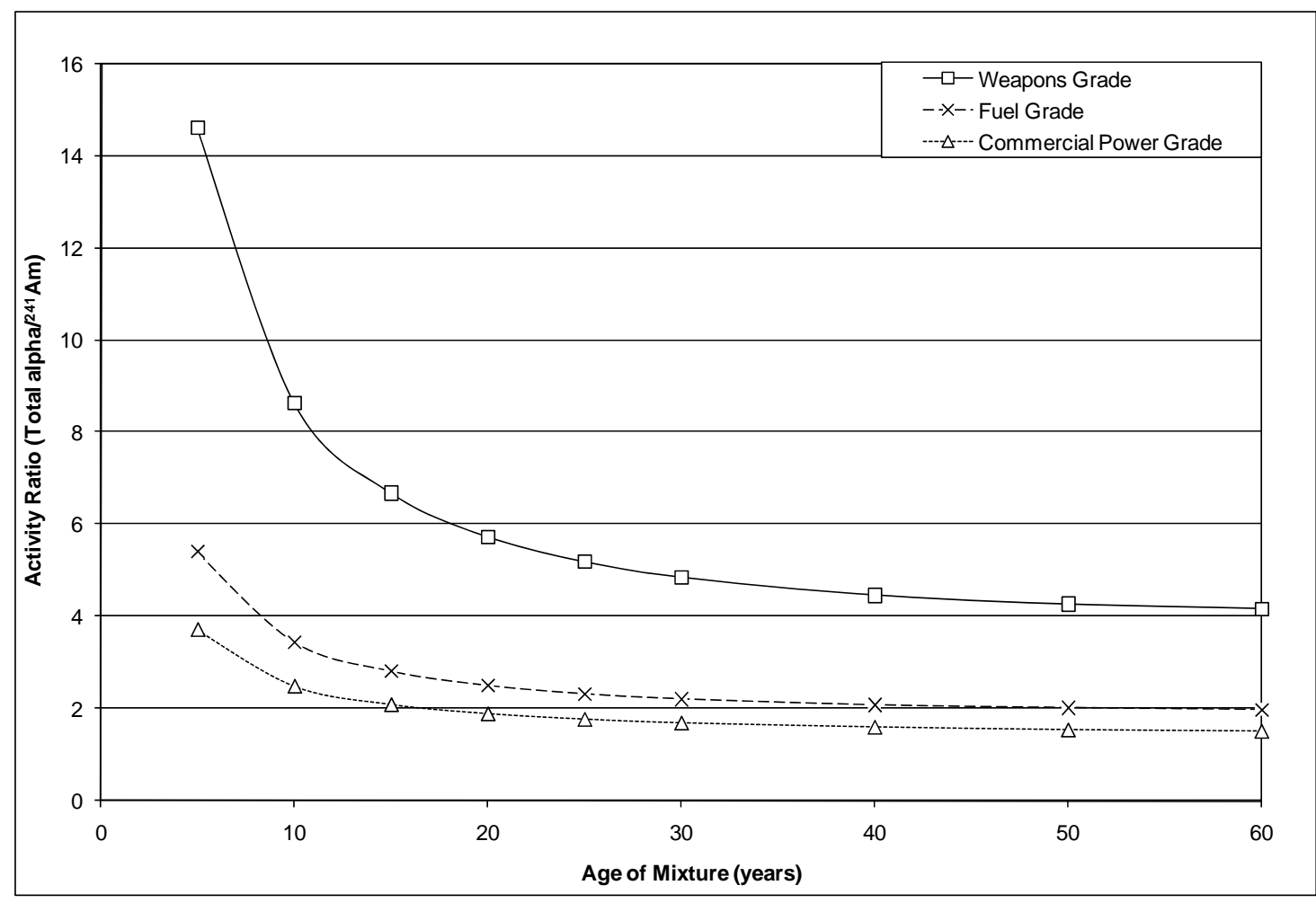

Figure 8.2. Total Alpha/ ${ }^{241}$ Am Activity Ratio for Hanford Reference Plutonium Mixtures 


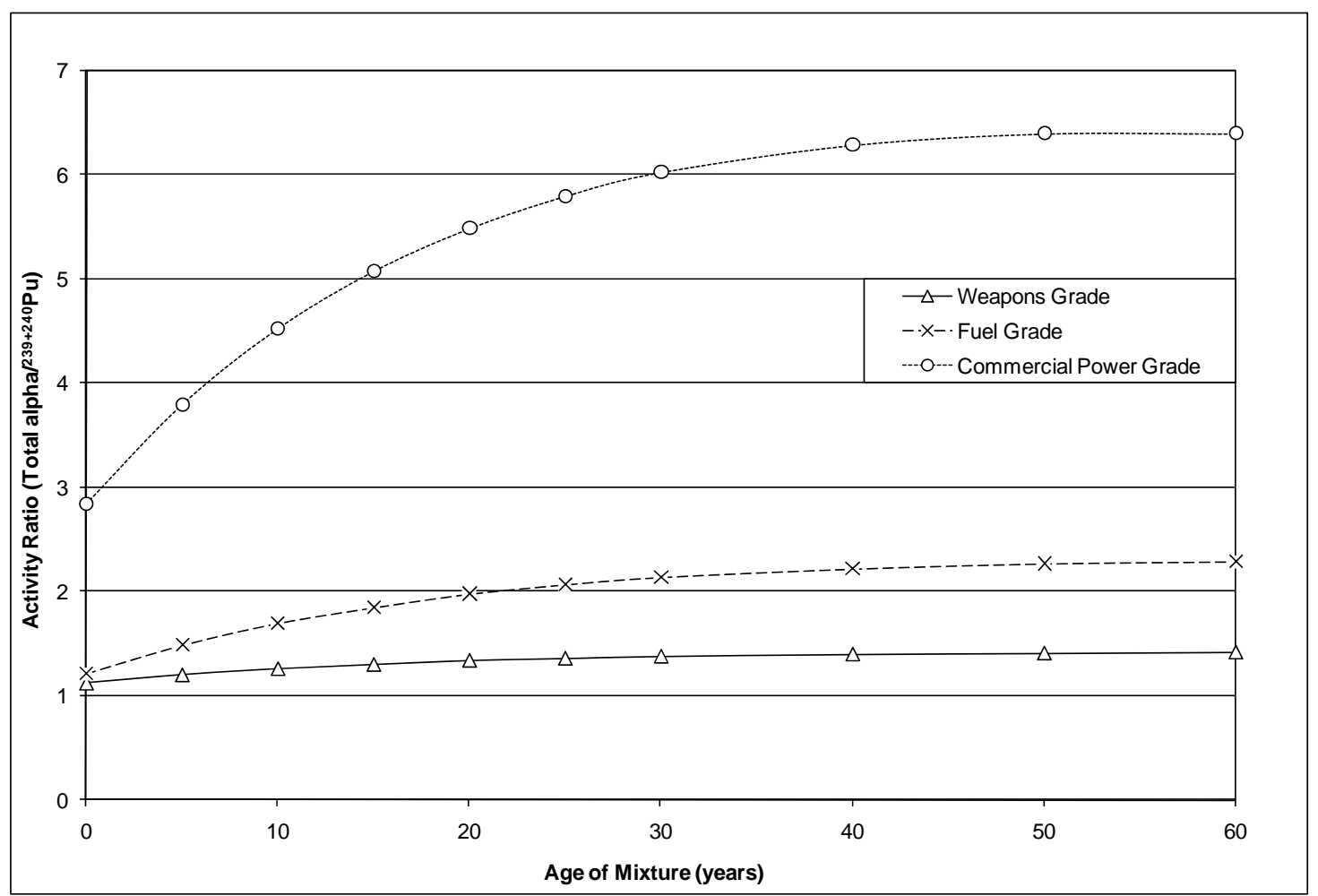

Figure 8.3. Total Alpha ${ }^{239+240} \mathrm{Pu}$ Activity Ratio for Hanford Reference Plutonium Mixtures

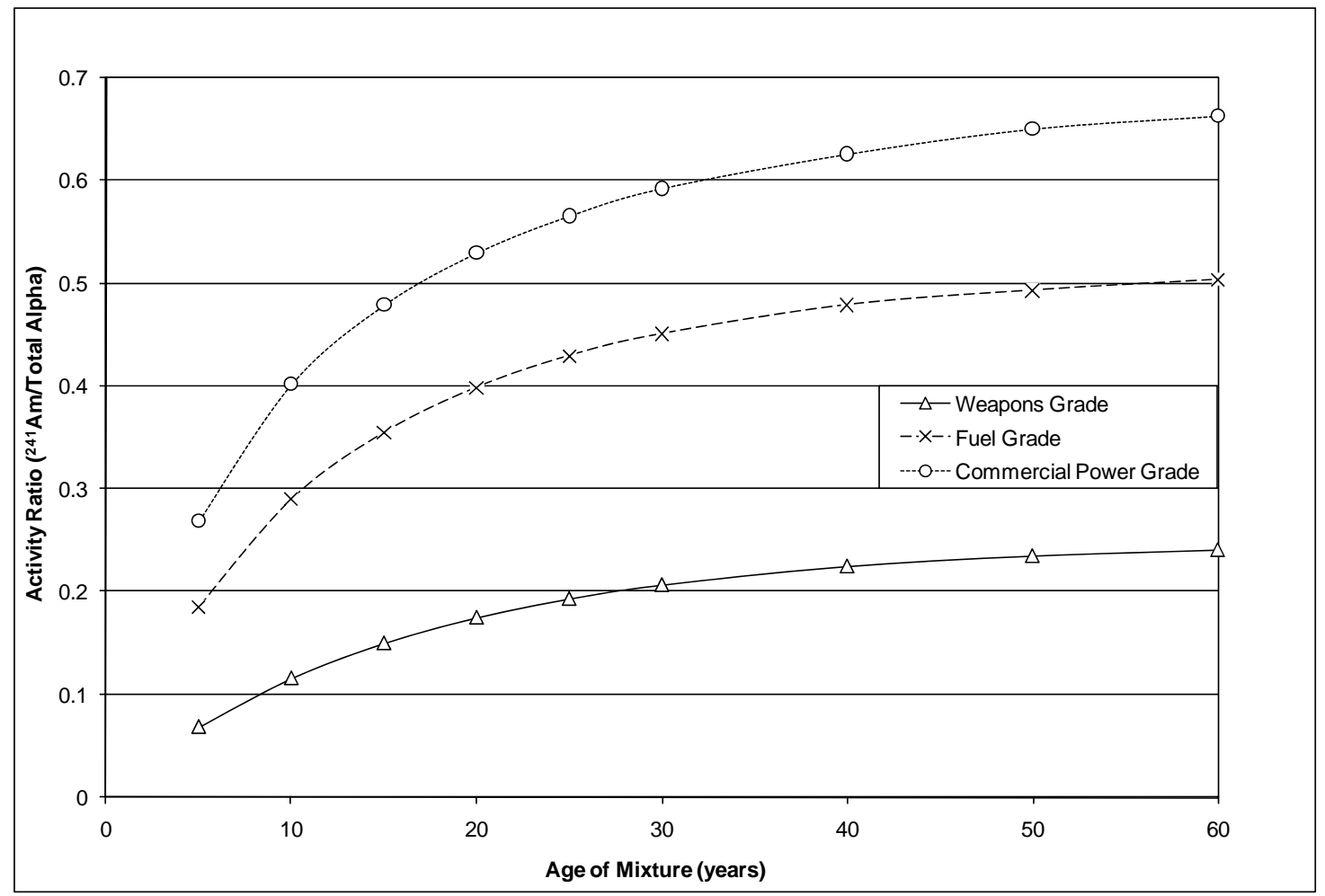

Figure 8.4. ${ }^{241} \mathrm{Am} /$ Total Alpha Activity Ratio for Hanford Reference Plutonium Mixtures 
Plutonium nitrate, as might be found in chemistry lab solutions and the early phases of plutonium finishing, was identified by ICRP 30 as Class W. However, work by Moody et al. (1994) concluded that plutonium nitrate behavior was something between Class W and Y, with aged nitrate residues being very similar to Class Y. The authors also compared their materials to the ICRP 66 classifications and concluded that aged plutonium nitrate residues dissolved at rates between Type $\mathrm{M}$ and $\mathrm{S}$ with the longer component being 3 to 15 times faster than Type S.

Stradling and Stather (1989) indicated that residual plutonium that has been subject to air oxidation for several years at normal room temperature and humidity may best be characterized as Class Y material. Stradling and Stather studied the behavior of two dusts in rat lungs. One dust was a plutonium dioxide corrosion product of plutonium metal oxidized in air under ambient conditions $\left(20^{\circ} \mathrm{C}\right.$ to $25^{\circ} \mathrm{C}$ and relative humidity of $60 \%$ to $70 \%$ ) over a period of about 15 years. The second dust was a dry powder, process line residue consisting of an atmospherically degraded mixture of plutonium and uranium nitrates (originally $1.2 \mathrm{M} \mathrm{HNO}_{3}$ ) intimately mixed and highly diluted with inactive debris, resulting from the corrosion of an experimental rig over 15 years (i.e., rust). The plutonium oxide powder was found to exhibit very definite Class $\mathrm{Y}$ behavior characteristics. The translocation rate for plutonium in the nitrate-bearing residues was about 3 times faster than for a Class Y compound, but about 10 times slower than for a Class W compound; i.e., the nitrate-bearing residue came closer to being Class Y than Class W in behavior. These findings imply that dry, residual plutonium contamination within facilities and gloveboxes should be treated as Class Y material regardless of its original chemical form. Designation of plutonium as a Class W material should be limited to current processes generating nitrates or residuals from recent runs of such processes. Because ICRP 66 absorption Type $S$ is modeled as a bit less soluble than ICRP 30 Class Y, this study also leads to the conclusion that old, air-oxidized plutonium contamination may be treated as Type $\mathrm{S}$ for design purposes but will likely demonstrate faster absorption in actual cases.

La Bone et al. (1992) identified a circumstance in which a ${ }^{238} \mathrm{Pu}$-oxide inhalation case appeared to exhibit biokinetic behavior more characteristic of a Class D material. This characteristic for ${ }^{238} \mathrm{Pu}$ has been informally discussed among internal dosimetrists and radiation protection staff for years. One explanation for it is that the alpha particle recoil from decay of the very high specific activity ${ }^{238} \mathrm{Pu}$ may serve to break down the matrix to forms that are readily absorbed by blood.

The possibility of a type of plutonium retained in the lung for a very long time has been identified (previously referred to as super Class Y and now referred to as Super S). Super S was defined by the Hanford Internal Dosimetry Program (HIDP) in 1988 to describe highly nontransportable forms of plutonium based on some actual observed cases at Hanford (Bihl et al. 1988; Carbaugh et al. 1991; Carbaugh and La Bone 2003). A similar case at the Savannah River Site (SRS) has been documented by La Bone and Findley (1999) and Carbaugh and La Bone (2003), and a case in the United Kingdom was reported by Foster (1991). The Rocky Flats Site had at least nine cases that demonstrated clearance much slower than regular Type S, although only one of these cases has been published (Mann and Kirchner 1967). The U.S. Transuranium and Uranium Registry also has found plutonium activity in the lungs of some donors that exceeded expectations for regular Type S (Filipy 2004; Kathren and McInroy 1991; McInroy et al. 1989). More recently a study of workers exposed to plutonium at the Mayak Production Association in Russia has also provided evidence of long-term retention in the lung (Romanov et al. 2003; Hahn et al. 2004). The Hanford and Rocky Flats cases involved known or suspected exposure to 
plutonium oxide that had been heated (burned or calcined). The material in the Savannah River case (referred to as SRS 498), on the other hand, was plutonium metal that had been exposed to air at ambient temperatures for only a year.

What causes some, but perhaps not all, plutonium oxide to behave with retention that exceeds the defaults for Type $\mathrm{S}$, or exactly what the default absorption rates should be has not been agreed upon by the scientific community. The Mayak study provides evidence of fibrosis of lung tissues associated with the plutonium particles (Romanov et al. 2003). Newman et al. (2005) present a case for micro fibrosis in lung tissue of Rocky Flats plutonium workers as well. An in vitro lung solubility analysis was performed on the material in the Savannah River case. Table 8.6 shows the results of the in vitro analysis as well as rate constants inferred from the urinalysis data compared to default Type S rate constants in the ICRP 66 lung model. The table shows that there was good agreement for the slow solubility rate parameter, $S_{s}$ between the in vitro dissolution study of the plutonium and the fit to the bioassay data.

Table 8.6. Solubility Parameter Comparison for SRS $498^{(a)}$

\begin{tabular}{lccc}
\hline \multicolumn{1}{c}{ Type } & $\begin{array}{c}\text { Fraction Rapidly } \\
\text { Dissolved, } f_{r}\end{array}$ & $\begin{array}{c}\text { Rapid Solubility } \\
\text { Rate, } s_{r}\left(\mathrm{~d}^{-1}\right)\end{array}$ & $\begin{array}{c}\text { Slow Solubility Rate, } \\
s_{s}\left(\mathrm{~d}^{-1}\right)\end{array}$ \\
\hline $\begin{array}{l}\text { In vitro study of } \\
\text { plutonium oxide } \\
\text { from air sample }\end{array}$ & 0.0007 & 1.56 & $1.3 \times 10^{-5}$ \\
$\begin{array}{l}\text { Parameters inferred } \\
\text { from bioassay }\end{array}$ & 0.002 & 9.9 & $9.7 \times 10^{-6}$ \\
$\begin{array}{l}\text { Standard ICRP 66 } \\
\text { Type S parameters }\end{array}$ & 0.001 & 100 & $1.0 \times 10^{-4}$ \\
\hline (a) From Carbaugh and La Bone (2003). & & \\
\hline
\end{tabular}

However, for the well-documented Hanford-1 (HAN-1) case and most of the Rocky Flats cases, changing absorption rates was not sufficient to fit the bioassay data well. Particle clearance rates had to be reduced as well. The ICRP 66 lung model applies the same parameters for the particle clearance mechanisms for all particles regardless of which element or chemical the particles are composed. An exception is presented for smoking, which may impair the mucociliary pathway from the deep lung to the GI tract (ICRP 1994b, p. 78). The smoking status of HAN-1 and the Rocky Flats cases was not documented. Hence, the apparent need to slow the particle transport rates to fit HAN-1 and the Rocky Flats cases might have been due to individual-specific impairment of the particle clearance mechanisms rather than an effect of the plutonium oxide per se. Or as the Mayak cases might indicate, the plutonium oxide particle does impair particle clearance mechanism through fibrosis of surrounding tissue. Whether plutonium oxide somehow impedes the particle clearance mechanisms is an open question; but, for now, there does not seem to be enough evidence to justify a Super S model that involves changes to particle clearance parameters.

Hence, the Super S model is predicated on the assumption that the material is highly insoluble and only absorption parameters are different from regular Type S. Using the "alternative representation" of the ICRP 66 absorption model, the Super S model is as shown in Table 8.7. That SRS 498 had an in vitro dissolution study on the source material and that the slow dissolution rate agreed well with the bioassay 
data made it the best study on which to base the model. The material in SRS 498 was oxidized for only a year at ambient temperature, whereas other cases involved heated plutonium oxide, either by fire or by calcining. It is possible that the latter cases would be less soluble than the SRS 498 material; however, Morgan et al (1988) did not find a difference in lung retention in mice of ${ }^{239} \mathrm{Pu}$ oxide fired at $550^{\circ} \mathrm{C}$, $750^{\circ} \mathrm{C}, 1000^{\circ} \mathrm{C}$, and $1250^{\circ} \mathrm{C}$. So the slow dissolution rate of $1 \times 10^{-5} \mathrm{~d}^{-1}$ from SRS 498 was assumed. Because the cases show little fast clearance to the blood (and hence to urine), the fraction of the deposition that dissolves quickly, $f_{\mathrm{r}}$, was reduced from $1 \times 10^{-3}$ to $2 \times 10^{-4}$. And a final change for consistency affected the GI tract model, not the lung model; because the material is less soluble, the uptake factor from the GI tract to the blood, $f_{1}$, was decreased by a factor of 10 . The Super $S$ model in Table 8.7 is purely conjecture without scientific consensus; its use is strictly for program design purposes; it should not be used for evaluation of actual worker intakes.

Table 8.7. Parameters of the Type Super S Absorption Model

\begin{tabular}{ccc}
\hline Parameter & Value & Relative to Type S \\
\hline$f_{\mathrm{r}}$ & $2 \mathrm{E}-04$ & Decreased \\
$s_{\mathrm{s}}$ & $1 \mathrm{E}-5 \mathrm{~d}^{-1}$ & Decreased \\
$f_{1}$ & $1 \mathrm{E}-06$ & Decreased \\
$f_{b}$ & 0 & Unchanged \\
$s_{\mathrm{r}}$ & $1.001 \mathrm{E}+02 \mathrm{~d}^{-1}$ & Unchanged \\
\hline
\end{tabular}

When combinations of absorption types may exist in a matrix, the absorption of the mixture is assumed to be that of the predominant material. For example, in a plutonium oxide matrix containing americium oxide as an ingrown impurity, the absorption of the americium oxide is assumed to be the same as that of the major mass constituent of the matrix (Eidson 1980). Thus, the americium is assumed to exhibit the Type $\mathrm{S}$ behavior of the host matrix (plutonium oxide), rather than the Type $\mathrm{M}$ behavior normally expected of americium oxide. The above-described behavior would not be the case if the mixture were merely a blend of the two oxide powders. In this latter case, each element would be expected to exhibit its own characteristic behavior. These assumptions are also consistent with the observations of Stradling and Stather (1989).

The wide range of transportability for plutonium compounds, and its variability from the standard ICRP recommendations, emphasizes the importance of addressing the uniqueness of individual workers and exposure circumstances when dealing with known intakes. When limited information is available, the Hanford practice is to use Type $\mathrm{M}$ for exposure to plutonium nitrate solutions (e.g., wet solutions, trace contaminants in high-level waste tanks) and Type S for oxides involving either heating or room temperature oxidation processes. However, Super S may be used as a conservative model in program design for exposure to heated oxidized plutonium. If nothing else, it serves as a reminder of the importance of chest counting as a part of routine monitoring for plutonium oxide. Based on personal communication with a Hanford soil chemist, ${ }^{1}$ plutonium in soil is assumed to be Type $\mathrm{S}$ unless the plutonium came from a recent release of plutonium nitrate (Type $\mathrm{M}$ ). Plutonium nitrate converts to the hydroxide form in the soil and oxides of plutonium are stable unless the soil is acidified $(\mathrm{pH}<5)$.

\footnotetext{
${ }^{1}$ Conversation between DA Cataldo and DE Bihl, 1995.
} 


\subsubsection{Gastrointestinal Uptake to Blood $\left(f_{1}\right)$}

The uptake of plutonium from the GI tract is quite small and is dependent on its chemical form. The latest GI tract model was issued by the ICRP (ICRP 2006), but it has not been incorporated into IMBA so it is not used by the HIDP at present. In the ICRP 30 model, the fraction of material taken up by the blood from the total in the GI tract is called the $f_{1}$ factor. In ICRP 30 Part 4 (1988), the ICRP recommended that $10^{-5}$ be used for oxides of plutonium, $10^{-4}$ for nitrates, and $10^{-3}$ for other compounds. In ICRP 56 (1989), the $10^{-3}$ value was used for adult members of the public. Based on additional published studies, ICRP 67 (1993) recommended a value of $5 \times 10^{-4}$ for unknown forms. This recommendation was adopted in ICRP 68 (1994a) for occupational exposures to all other compounds of plutonium except nitrate $\left(10^{-4}\right)$ and oxide $\left(10^{-5}\right)$. However, the tabulated plutonium dose coefficients in ICRP 68 showed the use of $5 \times 10^{-4}$ for Type M, rather than the nitrate value. For application to worker monitoring programs, ICRP 78 (1997) retained the ICRP 68 values for ingestion, and used $10^{-5}$ for inhalation of Type S compounds (insoluble oxides) and used $5 \times 10^{-4}$ for inhalation of Type M compounds (unspecified compounds). No $f_{1}$ factor was specifically identified for inhalation of nitrates. For Type Super $\mathrm{S}$, an $f_{1}$ factor of $10^{-6}$ is recommended. For Hanford plutonium internal dose applications, the $f_{1}$ factors of ICRP 78 are preferred, unless otherwise specified, as summarized in Table 8.8.

Table 8.8. GI Uptake to Blood Factors $\left(f_{1}\right)$ for Hanford Pu Intakes

\begin{tabular}{cccc}
\hline \multirow{2}{*}{$\begin{array}{c}\text { Absorption } \\
\text { Type }\end{array}$} & Compound & Inhalation & Ingestion \\
\cline { 3 - 4 } $\mathrm{M}$ & unspecified & $5 \times 10^{-4}$ & \\
$\mathrm{~S}$ & insoluble oxides & $1 \times 10^{-5}$ & \\
& unspecified & & $5 \times 10^{-4}$ \\
& nitrates & & $1 \times 10^{-4}$ \\
& insoluble oxides & & $1 \times 10^{-5}$ \\
Super S & very insoluble oxides & $1 \times 10^{-6}$ & \\
\hline
\end{tabular}

The term "instantaneous uptake" is used in this technical basis to refer to the material that is essentially immediately taken up by the transfer compartment upon intake, and is typically applied to wound scenarios in lieu of an ICRP- or NCRP-approved wound model.

\subsubsection{Distribution and Retention in Systemic Organs and Tissues}

The ICRP systemic model presented in ICRP 67 (1993) and ICRP 78 (1997) is used to calculate the distribution and retention of plutonium in the body. The basic model is described in Appendix C. The main sites of retention are the liver and the skeleton. Flow of plutonium from blood to organs, within organ compartments, and back to blood and to excretion is determined entirely by transfer rates, which are listed in Table 8.9. Because the transfer rates to the testes and ovaries differ, a small difference in dose between these organs can occur; IMBA assigns gonadal dose as the higher of the dose to either the testes or the ovaries. For systemic plutonium, the testicular committed equivalent dose exceeds the ovarian committed equivalent dose by less than $2 \%$. 
Table 8.9. Transfer Rates Between Compartments in the Plutonium Systemic Model of the ICRP Publications 67 and 78

\begin{tabular}{lc}
\hline \multicolumn{1}{c}{ Route } & Transfer Rate $\left(\mathrm{d}^{-1}\right)$ \\
\hline ST0 to blood & \\
ST1 to blood & $6.93 \mathrm{E}-01$ \\
ST2 to blood & $4.75 \mathrm{E}-04$ \\
Trabecular marrow to blood & $1.90 \mathrm{E}-05$ \\
Cortical marrow to blood & $7.60 \mathrm{E}-03$ \\
Kidneys (tissue) to blood & $7.60 \mathrm{E}-03$ \\
Liver2 to blood & $1.39 \mathrm{E}-03$ \\
Testes to blood & $2.11 \mathrm{E}-04$ \\
Ovaries to blood & $1.90 \mathrm{E}-04$ \\
Blood to ST0 & $1.90 \mathrm{E}-04$ \\
Blood to ST1 & $2.77 \mathrm{E}-01$ \\
ST1 to bladder (urinary excretion) & $8.06 \mathrm{E}-02$ \\
Blood to ST2 & $4.75 \mathrm{E}-04$ \\
Blood to trabecular surface & $1.29 \mathrm{E}-02$ \\
Trabecular surface to trabecular volume & $1.94 \mathrm{E}-01$ \\
Trabecular surface to trabecular marrow & $2.47 \mathrm{E}-04$ \\
Trabecular volume to trabecular marrow & $4.93 \mathrm{E}-04$ \\
Blood to cortical surface & $4.93 \mathrm{E}-04$ \\
Cortical surface to cortical volume & $1.29 \mathrm{E}-01$ \\
Cortical surface to cortical marrow & $4.11 \mathrm{E}-05$ \\
Cortical volume to cortical marrow & $8.21 \mathrm{E}-05$ \\
Blood to kidneys (tissue) & $8.21 \mathrm{E}-05$ \\
Blood to Liver1 & $3.23 \mathrm{E}-03$ \\
Liver1 to Liver2 & $1.94 \mathrm{E}-01$ \\
Liver1 to small intestine (fecal excretion) & $1.77 \mathrm{E}-03$ \\
Blood to upper large intestine (fecal excretion) & $1.33 \mathrm{E}-04$ \\
Blood to testes & $1.29 \mathrm{E}-02$ \\
Blood to ovaries & $2.30 \mathrm{E}-04$ \\
Blood to kidneys (urinary excretion) & $7.10 \mathrm{E}-05$ \\
Kidneys to bladder (urinary excretion) & $6.47 \mathrm{E}-03$ \\
Blood to bladder (urinary excretion) & $1.39 \mathrm{E}-02$ \\
\hline (a) ST = soft tissue (numbers indicate compartment numbers). & $1.29 \mathrm{E}-02$ \\
\hline
\end{tabular}

\subsubsection{Urinary Excretion}

Prior to implementation of the ICRP 67 systemic models, the HIDP used plutonium models presented in ICRP 30 and ICRP 48 (1986). The latter models, of themselves, did not provide accurate predictions of urinary excretion so the Jones function (Jones 1985) was used to relate the urinary excretion of plutonium to systemic uptake. 
The ICRP 67 systemic model predicts urinary excretion from uptake to blood using physiologically based transfer rates to the urinary pathway rather than an add-on empirical formula, such as the Jones function. Hence, instantaneous urinary excretion rates are predicted directly from the physiology built into the model and the Jones function is no longer used. The Jones function was used from November 1986 until the issuance of this revision and is described in previous versions of this manual; see, for instance, the January 31, 2003 version or the letter report to file by Carbaugh and Sula. ${ }^{1}$ The urinary excretion curves using the ICRP 30 systemic model and the Jones function for instantaneous uptake and 5 - $\mu \mathrm{m}$ Class $\mathrm{W}$ and 5- $\mu \mathrm{m}$ Class Y inhalation modes of intake are included in Figure 8.8 for comparison with the excretion predicted by ICRP 67 model. For historical note, the Jones excretion function described above replaced the Langham and Healy (Healy 1957) functions for evaluating plutonium depositions at Hanford. The referenced documents that provide details on the excretion functions historically used at Hanford can be found in the Hanford Radiation Protection Historical Files of the Radiation Records Library or HIDP files.

ICRP 67 models urinary excretion by transferring plutonium from the soft tissue (ST) compartment 1 directly to the urinary bladder contents, from the blood directly to the urinary bladder contents, and from blood to the kidneys (passing into the urine not kidney tissue) to the bladder contents. Transfer rates for these compartments are listed in Table 8.9, labeled as "urinary excretion" to distinguish them from the pathway from blood to kidney tissue.

\subsubsection{Fecal Systemic Excretion}

The excretion of bile to the GI tract provides a pathway for systemic excretion of plutonium from the liver to feces. In application of the ICRP 30 model in the HIDP, it was usually assumed that an equal amount was excreted from the systemic compartment by way of feces and urine. Similar to urinary excretion, ICRP 67 models transfer of systemic plutonium to the GI tract using physiologically based transfer rates via two pathways. One pathway is from blood to the liver compartment 1 and from liver compartment 1 to the small intestine (representing biliary secretion). The second pathway is directly from the blood to the upper large intestine, and the rate was set to be consistent with observed fecal excretion of plutonium in the Langham et al. (1950) studies shortly after uptake.

\subsection{Internal Dosimetry Factors}

This section contains factors that are useful in making internal dosimetry calculations. The factors included in this section are derived from IMBA and incorporate the models and assumptions described in the preceding section. Their application is intended for those circumstances where such assumptions are appropriate or more specific information is lacking. Variation from these factors is appropriate if sufficient data are available.

\footnotetext{
${ }^{1}$ Carbaugh EH and MJ Sula. 1986. Proposed Change to Plutonium Excretion Function Used for Hanford Internal Dosimetry. Letter Report to the Hanford Radiation Protection Historical Files, December 11, 1986, Pacific Northwest Laboratory, Richland, Washington.
} 


\subsubsection{Intake Retention and Excretion Fractions}

The intake retention (or excretion) fraction expresses the fraction of intake retained in a particular compartment or excreted by a particular pathway (urine or feces) at a given time post intake. Although excretion implies elimination rather than retention, conventional models include excretion compartments under the general term retention and use the term "intake retention fraction" (IRF) to describe both. The IRFs for various times post intake are tabulated as described below for ${ }^{239} \mathrm{Pu}$. These values are also suitable for other isotopes of plutonium, with appropriate correction for different radiological half-lives.

Lung retention fractions for absorption Types M, S, and Super S acute inhalations of 5- $\mu$ m-AMAD (activity median aerodynamic diameter) particles of ${ }^{239} \mathrm{Pu}$ are tabulated in Table 8.10 and plotted in Figure 8.5. Because under most circumstances chest counting measures the activity of ${ }^{241} \mathrm{Am}$ in the lung that is associated with the plutonium mixture, Table 8.11 and Figure 8.6 provide the fractions of ${ }^{241} \mathrm{Am}$ in the lung per unit intake of ${ }^{241} \mathrm{Am}$ for two weapons-grade plutonium mixtures (20 and 50 years after purification of the plutonium). The mixture ages refer to the age at time of intake. Ingrowth of ${ }^{241} \mathrm{Am}$ from ${ }^{241} \mathrm{Pu}$ based on the ratio at the time of intake is included in the calculations under the assumption that the plutonium and americium behave the same in the lung. These values are for illustrative purposes only; for a given intake, the retained quantity of ${ }^{241} \mathrm{Am}$ in the lung should be calculated from the actual isotopic ratios in the source of the inhaled material. However, the table and figure show that for the first several years after the intake the lung retained quantity is sensitive to the absorption type but not to the age of the mixture.

Urine excretion fractions for instantaneous uptakes, acute inhalations, and acute ingestions of ${ }^{239} \mathrm{Pu}$ are listed in Table 8.12 and plotted in Figure 8.7. Urinary excretion curves for the ICRP 30 and ICRP 66+67 models for injection and inhalation Class W, Type M, Class Y, Type S modes (5- $\mu$ m AMAD) are shown in Figure 8.8 for comparison. Fecal excretion fractions for an instantaneous uptake, acute inhalations, and acute ingestions are listed in Table 8.13 and plotted in Figure 8.9. Values for days other than those tabulated here can be obtained by interpolation between the tabulated data, or by obtaining the values directly from IMBA. The ratio of fecal-to-urinary excretion is shown for these same intakes in Table 8.14 and Figure 8.10. The latter table may be useful for identifying the appropriate type of intake for unknown circumstances, if sufficient data are obtained.

\subsubsection{Dose Coefficients}

Dose coefficients, expressed as committed effective or equivalent dose per unit activity of intake (rem per nanocurie of acute intake or rem per nanocurie per day of chronic intake), are a convenient shortcut to estimating doses based on standard assumptions when the magnitude of an intake is known or assumed. Acute intake dose coefficients have been tabulated in this section for instantaneous uptake; Types M, S, and Super S inhalations for 5- $\mu \mathrm{m}$-AMAD particle sizes; and for ingestion. These dose coefficients were all derived using IMBA. The organ referred to as "others" is representative of the organs not specifically listed in the table, almost all of which have the same or nearly the same dose coefficient. 
Table 8.10. Lung Retention for 5- $\mu$ m-AMAD Particles of Plutonium Following an Acute Inhalation Intake (fraction of intake)

\begin{tabular}{|c|c|c|c|}
\hline Days Post Intake & Type M & Type S & Type Super S \\
\hline 0 & $8.20 \mathrm{E}-02$ & $8.20 \mathrm{E}-02$ & $8.20 \mathrm{E}-02$ \\
\hline 1 & 5.76E-02 & 6.43E-02 & 6.43E-02 \\
\hline 2 & 5.59E-02 & 6.27E-02 & 6.28E-02 \\
\hline 3 & 5.50E-02 & 6.19E-02 & 6.20E-02 \\
\hline 4 & 5.42E-02 & 6.13E-02 & 6.14E-02 \\
\hline 5 & 5.34E-02 & 6.07E-02 & $6.08 \mathrm{E}-02$ \\
\hline 6 & 5.26E-02 & 6.01E-02 & 6.02E-02 \\
\hline 7 & 5.18E-02 & 5.95E-02 & 5.96E-02 \\
\hline 8 & 5.11E-02 & $5.90 \mathrm{E}-02$ & 5.91E-02 \\
\hline 9 & 5.04E-02 & 5.84E-02 & 5.85E-02 \\
\hline 10 & 4.97E-02 & 5.79E-02 & $5.80 \mathrm{E}-02$ \\
\hline 12 & 4.83E-02 & 5.68E-02 & $5.70 \mathrm{E}-02$ \\
\hline 14 & 4.70E-02 & 5.59E-02 & $5.60 \mathrm{E}-02$ \\
\hline 16 & 4.57E-02 & 5.49E-02 & 5.50E-02 \\
\hline 18 & 4.45E-02 & 5.40E-02 & $5.41 \mathrm{E}-02$ \\
\hline 20 & 4.34E-02 & 5.31E-02 & 5.33E-02 \\
\hline 25 & 4.08E-02 & 5.11E-02 & 5.13E-02 \\
\hline 30 & 3.84E-02 & 4.94E-02 & 4.95E-02 \\
\hline 40 & 3.43E-02 & 4.63E-02 & 4.65E-02 \\
\hline 50 & 3.09E-02 & 4.39E-02 & 4.41E-02 \\
\hline 60 & 2.81E-02 & 4.18E-02 & 4.21E-02 \\
\hline 70 & 2.57E-02 & 4.02E-02 & 4.05E-02 \\
\hline 80 & 2.36E-02 & 3.88E-02 & 3.91E-02 \\
\hline 90 & $2.18 \mathrm{E}-02$ & 3.76E-02 & 3.80E-02 \\
\hline 100 & 2.02E-02 & 3.67E-02 & 3.70E-02 \\
\hline 180 & 1.19E-02 & 3.20E-02 & 3.25E-02 \\
\hline 200 & $1.06 \mathrm{E}-02$ & 3.12E-02 & $3.18 \mathrm{E}-02$ \\
\hline 300 & 5.84E-03 & 2.82E-02 & $2.90 \mathrm{E}-02$ \\
\hline 365 & 3.99E-03 & 2.65E-02 & 2.74E-02 \\
\hline 400 & $3.26 \mathrm{E}-03$ & 2.57E-02 & 2.66E-02 \\
\hline 500 & 1.82E-03 & 2.34E-02 & 2.45E-02 \\
\hline 600 & 1.02E-03 & 2.14E-02 & 2.26E-02 \\
\hline 700 & 5.71E-04 & 1.96E-02 & 2.09E-02 \\
\hline $2 \mathrm{y}$ & 4.80E-04 & $1.91 \mathrm{E}-02$ & 2.04E-02 \\
\hline 800 & $3.21 \mathrm{E}-04$ & 1.79E-02 & 1.93E-02 \\
\hline 900 & $1.80 \mathrm{E}-04$ & 1.65E-02 & 1.79E-02 \\
\hline 1,000 & 1.02E-04 & 1.52E-02 & 1.66E-02 \\
\hline $3 y$ & 5.91E-05 & $1.40 \mathrm{E}-02$ & 1.55E-02 \\
\hline $5 y$ & $9.55 \mathrm{E}-07$ & 8.15E-03 & $9.61 \mathrm{E}-03$ \\
\hline 2,000 & 3.64E-07 & 7.28E-03 & 8.72E-03 \\
\hline
\end{tabular}


Table 8.10. (contd)

\begin{tabular}{cccc}
\hline Days Post Intake & Type M & Type S & Type Super S \\
\hline 3,000 & $1.59 \mathrm{E}-09$ & $4.27 \mathrm{E}-03$ & $5.60 \mathrm{E}-03$ \\
$10 \mathrm{y}$ & $5.05 \mathrm{E}-11$ & $3.31 \mathrm{E}-03$ & $4.60 \mathrm{E}-03$ \\
4,000 & $8.19 \mathrm{E}-12$ & $2.96 \mathrm{E}-03$ & $4.24 \mathrm{E}-03$ \\
5,000 & $4.67 \mathrm{E}-14$ & $2.26 \mathrm{E}-03$ & $3.55 \mathrm{E}-03$ \\
6,000 & $2.80 \mathrm{E}-16$ & $1.82 \mathrm{E}-03$ & $3.13 \mathrm{E}-03$ \\
7,000 & $1.72 \mathrm{E}-18$ & $1.50 \mathrm{E}-03$ & $2.82 \mathrm{E}-03$ \\
$20 \mathrm{y}$ & $3.65 \mathrm{E}-19$ & $1.42 \mathrm{E}-03$ & $2.74 \mathrm{E}-03$ \\
8,000 & insignificant & $1.25 \mathrm{E}-03$ & $2.58 \mathrm{E}-03$ \\
9,000 & insignificant & $1.05 \mathrm{E}-03$ & $2.37 \mathrm{E}-03$ \\
10,000 & insignificant & $8.90 \mathrm{E}-04$ & $2.19 \mathrm{E}-03$ \\
$50 \mathrm{y}$ & insignificant & $2.54 \mathrm{E}-04$ & $1.32 \mathrm{E}-03$ \\
\hline
\end{tabular}

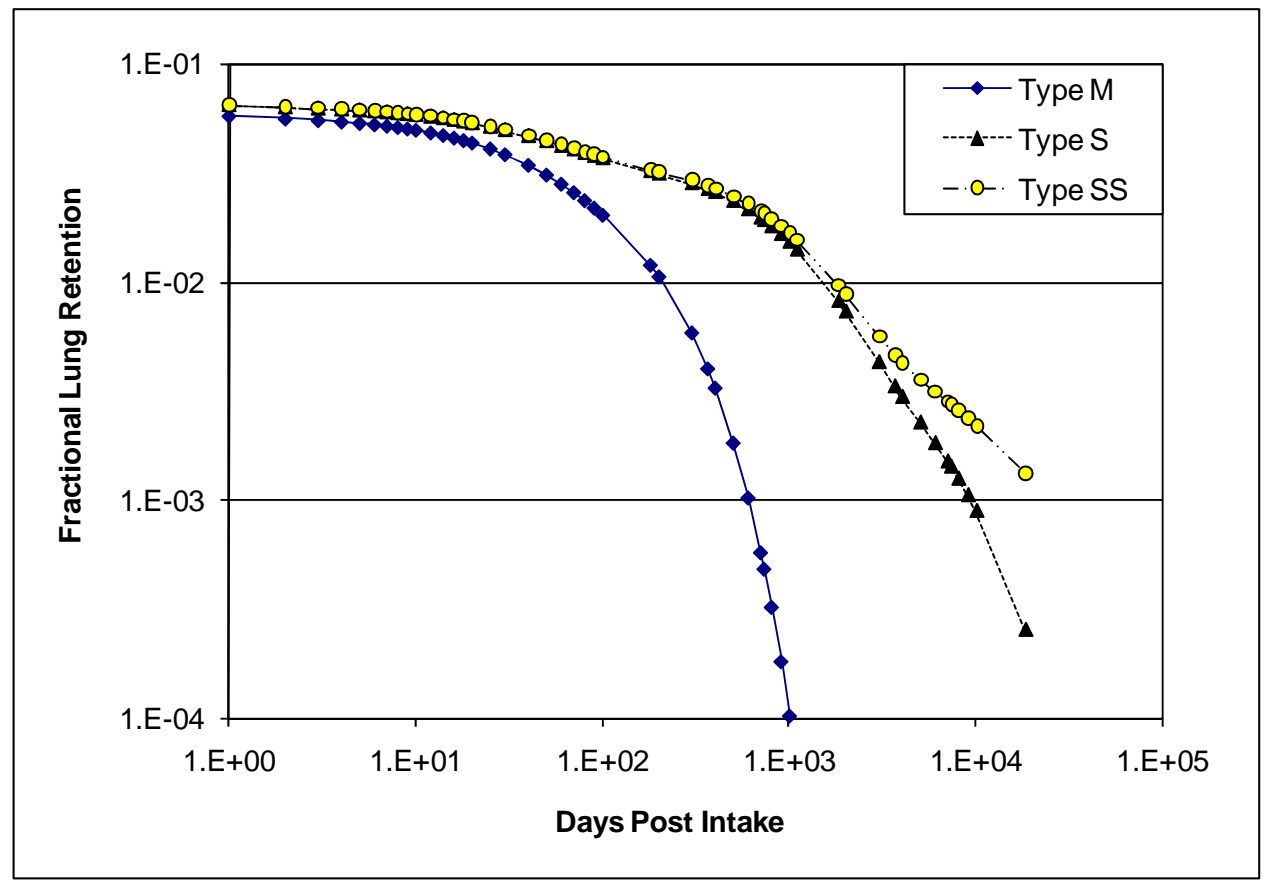

Figure 8.5. ${ }^{239} \mathrm{Pu}$ Fractional Lung Retention 
Table 8.11. Lung Retention of ${ }^{241}$ Am per Unit Acute Intake of ${ }^{241} \mathrm{Am}$ with Ingrowth from ${ }^{241} \mathrm{Pu}$ for 5- $\mu \mathrm{m}$-AMAD Particles, Weapons-Grade Plutonium

\begin{tabular}{|c|c|c|c|c|c|c|}
\hline \multirow{2}{*}{$\begin{array}{l}\text { Days Post } \\
\text { Intake }\end{array}$} & \multicolumn{3}{|c|}{$\begin{array}{c}\text { 20-Year Aged Weapons-Grade } \\
\text { Plutonium Mix }\end{array}$} & \multicolumn{3}{|c|}{$\begin{array}{l}\text { 50-Year Aged Weapons-Grade } \\
\text { Plutonium Mix }\end{array}$} \\
\hline & Type M & Type S & Type SS & Type $\mathrm{M}$ & Type S & Type SS \\
\hline 0.5 & $5.98 \mathrm{E}-02$ & $6.65 \mathrm{E}-02$ & $6.66 \mathrm{E}-02$ & $5.98 \mathrm{E}-02$ & $6.65 \mathrm{E}-02$ & $6.66 \mathrm{E}-02$ \\
\hline 1 & $5.76 \mathrm{E}-02$ & $6.43 \mathrm{E}-02$ & $6.43 \mathrm{E}-02$ & $5.76 \mathrm{E}-02$ & 6.43E-02 & 6.43E-02 \\
\hline 2 & 5.59E-02 & 6.27E-02 & $6.28 \mathrm{E}-02$ & 5.59E-02 & 6.27E-02 & $6.28 \mathrm{E}-02$ \\
\hline 3 & 5.50E-02 & $6.20 \mathrm{E}-02$ & $6.20 \mathrm{E}-02$ & 5.50E-02 & 6.19E-02 & $6.20 \mathrm{E}-02$ \\
\hline 4 & 5.42E-02 & 6.13E-02 & $6.14 \mathrm{E}-02$ & $5.42 \mathrm{E}-02$ & 6.13E-02 & 6.14E-02 \\
\hline 5 & 5.34E-02 & 6.07E-02 & 6.08E-02 & 5.34E-02 & 6.07E-02 & $6.08 \mathrm{E}-02$ \\
\hline 6 & 5.26E-02 & 6.01E-02 & 6.02E-02 & $5.26 \mathrm{E}-02$ & 6.01E-02 & 6.02E-02 \\
\hline 7 & 5.19E-02 & $5.96 \mathrm{E}-02$ & 5.97E-02 & 5.18E-02 & 5.95E-02 & $5.96 \mathrm{E}-02$ \\
\hline 8 & 5.11E-02 & 5.90E-02 & 5.91E-02 & 5.11E-02 & $5.90 \mathrm{E}-02$ & 5.91E-02 \\
\hline 9 & 5.04E-02 & 5.85E-02 & 5.86E-02 & $5.04 \mathrm{E}-02$ & 5.84E-02 & 5.85E-02 \\
\hline 10 & 4.97E-02 & 5.79E-02 & $5.80 \mathrm{E}-02$ & 4.97E-02 & 5.79E-02 & $5.80 \mathrm{E}-02$ \\
\hline 12 & 4.83E-02 & 5.69E-02 & 5.70E-02 & 4.83E-02 & 5.69E-02 & $5.70 \mathrm{E}-02$ \\
\hline 14 & 4.70E-02 & 5.59E-02 & 5.60E-02 & 4.70E-02 & 5.59E-02 & $5.60 \mathrm{E}-02$ \\
\hline 16 & 4.58E-02 & 5.50E-02 & 5.51E-02 & 4.57E-02 & 5.49E-02 & $5.50 \mathrm{E}-02$ \\
\hline 18 & 4.46E-02 & $5.41 \mathrm{E}-02$ & 5.42E-02 & 4.46E-02 & $5.40 \mathrm{E}-02$ & $5.41 \mathrm{E}-02$ \\
\hline 20 & 4.35E-02 & 5.32E-02 & 5.34E-02 & 4.34E-02 & 5.32E-02 & 5.33E-02 \\
\hline 25 & 4.08E-02 & 5.12E-02 & 5.14E-02 & 4.08E-02 & 5.12E-02 & 5.13E-02 \\
\hline 30 & 3.85E-02 & 4.95E-02 & 4.96E-02 & 3.84E-02 & 4.94E-02 & 4.95E-02 \\
\hline 40 & $3.44 \mathrm{E}-02$ & 4.65E-02 & 4.67E-02 & 3.43E-02 & 4.63E-02 & 4.65E-02 \\
\hline 50 & 3.10E-02 & 4.40E-02 & 4.43E-02 & 3.09E-02 & 4.39E-02 & 4.41E-02 \\
\hline 60 & 2.82E-02 & $4.20 \mathrm{E}-02$ & 4.23E-02 & 2.81E-02 & 4.19E-02 & $4.21 \mathrm{E}-02$ \\
\hline 70 & $2.58 \mathrm{E}-02$ & $4.04 \mathrm{E}-02$ & 4.07E-02 & 2.57E-02 & $4.02 \mathrm{E}-02$ & 4.05E-02 \\
\hline 80 & $2.38 \mathrm{E}-02$ & $3.90 \mathrm{E}-02$ & 3.94E-02 & $2.36 \mathrm{E}-02$ & 3.88E-02 & $3.91 \mathrm{E}-02$ \\
\hline 90 & 2.20E-02 & 3.79E-02 & 3.83E-02 & 2.18E-02 & 3.77E-02 & $3.80 \mathrm{E}-02$ \\
\hline 100 & 2.04E-02 & 3.69E-02 & 3.73E-02 & 2.03E-02 & 3.67E-02 & 3.71E-02 \\
\hline 180 & $1.21 \mathrm{E}-02$ & $3.24 \mathrm{E}-02$ & 3.30E-02 & $1.19 \mathrm{E}-02$ & $3.20 \mathrm{E}-02$ & $3.26 \mathrm{E}-02$ \\
\hline 200 & $1.07 \mathrm{E}-02$ & 3.17E-02 & 3.23E-02 & $1.06 \mathrm{E}-02$ & 3.13E-02 & 3.19E-02 \\
\hline 300 & 5.97E-03 & $2.88 \mathrm{E}-02$ & $2.96 \mathrm{E}-02$ & 5.85E-03 & 2.83E-02 & $2.91 \mathrm{E}-02$ \\
\hline 365 & $4.10 \mathrm{E}-03$ & 2.72E-02 & $2.82 \mathrm{E}-02$ & $4.01 \mathrm{E}-03$ & $2.66 \mathrm{E}-02$ & $2.75 \mathrm{E}-02$ \\
\hline 400 & 3.36E-03 & 2.64E-02 & $2.74 \mathrm{E}-02$ & $3.27 E-03$ & 2.57E-02 & 2.67E-02 \\
\hline 500 & $1.89 \mathrm{E}-03$ & 2.43E-02 & 2.54E-02 & 1.83E-03 & 2.35E-02 & $2.46 \mathrm{E}-02$ \\
\hline 600 & 1.07E-03 & 2.24E-02 & 2.36E-02 & $1.02 \mathrm{E}-03$ & 2.15E-02 & 2.27E-02 \\
\hline 700 & $6.01 \mathrm{E}-04$ & $2.06 \mathrm{E}-02$ & $2.20 \mathrm{E}-02$ & 5.75E-04 & 1.97E-02 & $2.10 \mathrm{E}-02$ \\
\hline $2 y$ & 5.07E-04 & $2.01 \mathrm{E}-02$ & 2.15E-02 & 4.84E-04 & $1.92 \mathrm{E}-02$ & 2.05E-02 \\
\hline 800 & $3.40 \mathrm{E}-04$ & $1.90 \mathrm{E}-02$ & 2.05E-02 & 3.23E-04 & $1.81 \mathrm{E}-02$ & $1.94 \mathrm{E}-02$ \\
\hline 900 & 1.93E-04 & $1.76 \mathrm{E}-02$ & $1.91 \mathrm{E}-02$ & $1.82 \mathrm{E}-04$ & $1.66 \mathrm{E}-02$ & $1.80 \mathrm{E}-02$ \\
\hline 1000 & 1.09E-04 & 1.63E-02 & 1.78E-02 & $1.03 \mathrm{E}-04$ & 1.53E-02 & 1.67E-02 \\
\hline $3 y$ & 6.38E-05 & $1.51 \mathrm{E}-02$ & 1.67E-02 & 5.96E-05 & $1.42 \mathrm{E}-02$ & $1.56 \mathrm{E}-02$ \\
\hline $5 y$ & $1.08 \mathrm{E}-06$ & $9.18 \mathrm{E}-03$ & $1.08 \mathrm{E}-02$ & $9.69 \mathrm{E}-07$ & 8.27E-03 & $9.75 \mathrm{E}-03$ \\
\hline 2000 & 4.13E-07 & 8.28E-03 & 9.92E-03 & 3.69E-07 & 7.39E-03 & 8.85E-03 \\
\hline 3000 & 1.89E-09 & 5.09E-03 & 6.68E-03 & 1.62E-09 & 4.36E-03 & 5.72E-03 \\
\hline $10 \mathrm{y}$ & $6.18 \mathrm{E}-11$ & 4.05E-03 & $5.64 \mathrm{E}-03$ & $5.17 \mathrm{E}-11$ & 3.39E-03 & $4.71 \mathrm{E}-03$ \\
\hline 4000 & $1.02 \mathrm{E}-11$ & 3.67E-03 & $5.26 \mathrm{E}-03$ & $8.40 \mathrm{E}-12$ & 3.03E-03 & 4.35E-03 \\
\hline 5000 & 5.98E-14 & $2.90 \mathrm{E}-03$ & 4.55E-03 & $4.80 \mathrm{E}-14$ & 2.33E-03 & 3.65E-03 \\
\hline 6000 & 3.68E-16 & $2.40 \mathrm{E}-03$ & 4.12E-03 & $2.89 \mathrm{E}-16$ & $1.88 \mathrm{E}-03$ & $3.23 \mathrm{E}-03$ \\
\hline
\end{tabular}




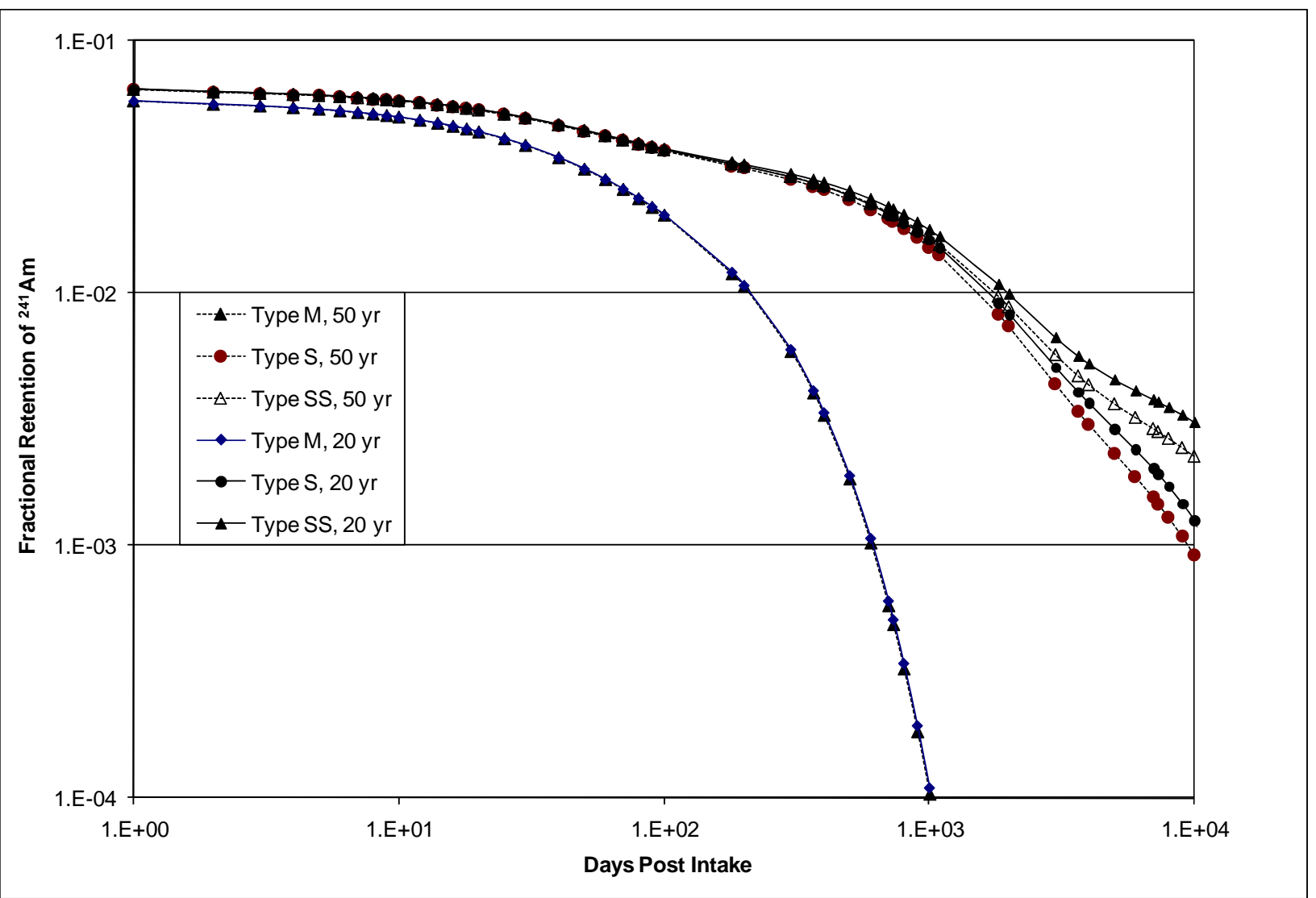

Figure 8.6. ${ }^{241} \mathrm{Am}$ Fractional Lung Retention Including Ingrowth from ${ }^{241} \mathrm{Pu} 5$ - $\mu \mathrm{m}-\mathrm{AMAD}$ Particles 
Table 8.12. ${ }^{239} \mathrm{Pu}$ Urine Excretion Fractions for Instantaneous Uptake, Inhalation (5 $\left.\mu \mathrm{m}\right)$, and Ingestion Intakes

\begin{tabular}{|c|c|c|c|c|c|c|}
\hline \multirow{2}{*}{$\begin{array}{l}\text { Days Post } \\
\text { Intake }\end{array}$} & \multirow{2}{*}{$\begin{array}{l}\text { Instantaneous } \\
\text { Uptake }\end{array}$} & \multirow{2}{*}{$\begin{array}{c}\text { Type M } \\
\text { Inhalation }\end{array}$} & \multirow{2}{*}{$\begin{array}{c}\text { Type S } \\
\text { Inhalation }\end{array}$} & \multirow{2}{*}{$\begin{array}{l}\text { Type SS } \\
\text { Inhalation }\end{array}$} & \multicolumn{2}{|c|}{ Ingestion } \\
\hline & & & & & $f_{1}=5 \mathrm{E}-04$ & $f_{1}=1 \mathrm{E}-05^{(\mathrm{a})}$ \\
\hline 0.5 & $4.47 \mathrm{E}-03$ & $1.25 \mathrm{E}-04$ & $1.26 \mathrm{E}-06$ & $2.50 \mathrm{E}-07$ & $1.30 \mathrm{E}-06$ & $2.59 \mathrm{E}-08$ \\
\hline 1 & 8.18E-03 & 2.32E-04 & 2.35E-06 & 4.64E-07 & 3.37E-06 & $6.73 \mathrm{E}-08$ \\
\hline 2 & 4.48E-03 & $1.31 \mathrm{E}-04$ & 1.36E-06 & 2.62E-07 & 2.59E-06 & 5.17E-08 \\
\hline 3 & 2.60E-03 & 7.78E-05 & 8.34E-07 & $1.57 \mathrm{E}-07$ & $1.45 \mathrm{E}-06$ & 2.89E-08 \\
\hline 4 & $1.71 \mathrm{E}-03$ & 5.30E-05 & 5.91E-07 & $1.07 \mathrm{E}-07$ & $9.28 \mathrm{E}-07$ & $1.86 \mathrm{E}-08$ \\
\hline 5 & $1.20 \mathrm{E}-03$ & 3.91E-05 & 4.55E-07 & 7.95E-08 & 6.47E-07 & 1.29E-08 \\
\hline 6 & 8.87E-04 & 3.03E-05 & 3.69E-07 & 6.20E-08 & 4.72E-07 & 9.45E-09 \\
\hline 7 & 6.74E-04 & $2.44 \mathrm{E}-05$ & 3.12E-07 & 5.02E-08 & 3.57E-07 & 7.13E-09 \\
\hline 8 & $5.27 \mathrm{E}-04$ & 2.03E-05 & 2.72E-07 & $4.21 \mathrm{E}-08$ & 2.77E-07 & 5.54E-09 \\
\hline 9 & $4.24 \mathrm{E}-04$ & $1.74 \mathrm{E}-05$ & 2.45E-07 & 3.64E-08 & $2.21 \mathrm{E}-07$ & 4.43E-09 \\
\hline 10 & 3.51E-04 & $1.54 \mathrm{E}-05$ & 2.25E-07 & $3.24 \mathrm{E}-08$ & $1.82 \mathrm{E}-07$ & 3.65E-09 \\
\hline 12 & 2.64E-04 & 1.29E-05 & 2.01E-07 & $2.76 \mathrm{E}-08$ & 1.35E-07 & 2.70E-09 \\
\hline 14 & 2.19E-04 & 1.16E-05 & 1.89E-07 & 2.51E-08 & $1.11 \mathrm{E}-07$ & 2.22E-09 \\
\hline 16 & $1.95 \mathrm{E}-04$ & 1.09E-05 & 1.83E-07 & 2.38E-08 & $9.86 \mathrm{E}-08$ & 1.97E-09 \\
\hline 18 & $1.82 \mathrm{E}-04$ & 1.05E-05 & 1.79E-07 & 2.31E-08 & 9.16E-08 & 1.83E-09 \\
\hline 20 & $1.74 \mathrm{E}-04$ & $1.02 \mathrm{E}-05$ & $1.77 \mathrm{E}-07$ & 2.27E-08 & 8.74E-08 & $1.75 \mathrm{E}-09$ \\
\hline 25 & $1.63 \mathrm{E}-04$ & $9.82 \mathrm{E}-06$ & $1.74 \mathrm{E}-07$ & 2.20E-08 & $8.16 \mathrm{E}-08$ & 1.63E-09 \\
\hline 30 & $1.55 \mathrm{E}-04$ & 9.51E-06 & 1.72E-07 & 2.16E-08 & 7.77E-08 & $1.55 \mathrm{E}-09$ \\
\hline 40 & 1.43E-04 & 8.98E-06 & 1.69E-07 & 2.10E-08 & 7.14E-08 & 1.43E-09 \\
\hline 50 & 1.32E-04 & 8.52E-06 & 1.67E-07 & 2.04E-08 & 6.59E-08 & 1.32E-09 \\
\hline 60 & $1.22 \mathrm{E}-04$ & 8.11E-06 & 1.65E-07 & $2.00 \mathrm{E}-08$ & $6.12 \mathrm{E}-08$ & $1.22 \mathrm{E}-09$ \\
\hline 70 & $1.14 \mathrm{E}-04$ & 7.74E-06 & 1.63E-07 & $1.96 \mathrm{E}-08$ & 5.70E-08 & 1.14E-09 \\
\hline 80 & $1.07 \mathrm{E}-04$ & 7.42E-06 & 1.62E-07 & 1.93E-08 & 5.34E-08 & $1.07 \mathrm{E}-09$ \\
\hline 90 & $1.00 \mathrm{E}-04$ & 7.12E-06 & $1.61 \mathrm{E}-07$ & $1.90 \mathrm{E}-08$ & 5.02E-08 & $1.00 \mathrm{E}-09$ \\
\hline 100 & $9.47 \mathrm{E}-05$ & 6.86E-06 & $1.60 \mathrm{E}-07$ & $1.88 \mathrm{E}-08$ & 4.74E-08 & $9.48 \mathrm{E}-10$ \\
\hline 180 & 6.87E-05 & 5.38E-06 & $1.60 \mathrm{E}-07$ & 1.81E-08 & 3.44E-08 & 6.87E-10 \\
\hline 200 & 6.53E-05 & 5.13E-06 & $1.61 \mathrm{E}-07$ & $1.81 \mathrm{E}-08$ & 3.27E-08 & $6.53 \mathrm{E}-10$ \\
\hline 300 & 5.58E-05 & 4.24E-06 & 1.65E-07 & $1.84 \mathrm{E}-08$ & 2.79E-08 & 5.58E-10 \\
\hline 365 & 5.27E-05 & 3.87E-06 & $1.68 \mathrm{E}-07$ & 1.87E-08 & 2.63E-08 & 5.27E-10 \\
\hline 400 & 5.14E-05 & $3.70 \mathrm{E}-06$ & 1.69E-07 & $1.88 \mathrm{E}-08$ & 2.57E-08 & $5.14 \mathrm{E}-10$ \\
\hline 500 & 4.83E-05 & 3.35E-06 & 1.73E-07 & $1.92 \mathrm{E}-08$ & 2.42E-08 & 4.83E-10 \\
\hline 600 & $4.58 \mathrm{E}-05$ & 3.08E-06 & $1.75 \mathrm{E}-07$ & $1.94 \mathrm{E}-08$ & 2.29E-08 & $4.58 \mathrm{E}-10$ \\
\hline 700 & 4.35E-05 & $2.88 \mathrm{E}-06$ & $1.77 \mathrm{E}-07$ & $1.96 \mathrm{E}-08$ & 2.18E-08 & 4.35E-10 \\
\hline $2 \mathrm{y}$ & 4.29E-05 & 2.82E-06 & 1.77E-07 & $1.96 \mathrm{E}-08$ & 2.14E-08 & 4.29E-10 \\
\hline 800 & 4.14E-05 & 2.71E-06 & 1.78E-07 & $1.97 \mathrm{E}-08$ & 2.07E-08 & 4.14E-10 \\
\hline 900 & 3.95E-05 & 2.56E-06 & 1.78E-07 & $1.97 \mathrm{E}-08$ & $1.98 \mathrm{E}-08$ & 3.95E-10 \\
\hline 1000 & 3.77E-05 & 2.44E-06 & 1.77E-07 & $1.97 \mathrm{E}-08$ & 1.89E-08 & 3.77E-10 \\
\hline $3 y$ & 3.32E-05 & 2.33E-06 & $1.76 \mathrm{E}-07$ & 1.96E-08 & 1.81E-08 & $3.62 \mathrm{E}-10$ \\
\hline $5 y$ & 2.73E-05 & 1.73E-06 & 1.62E-07 & $1.84 \mathrm{E}-08$ & 1.36E-08 & $2.73 \mathrm{E}-10$ \\
\hline 3000 & $2.00 \mathrm{E}-05$ & $1.26 \mathrm{E}-06$ & 1.36E-07 & 1.59E-08 & $1.00 \mathrm{E}-08$ & $2.00 \mathrm{E}-10$ \\
\hline $10 \mathrm{y}$ & $1.78 \mathrm{E}-05$ & 1.11E-06 & $1.24 \mathrm{E}-07$ & 1.49E-08 & 8.92E-09 & $1.78 \mathrm{E}-10$ \\
\hline $20 \mathrm{y}$ & $1.27 \mathrm{E}-05$ & 7.86E-07 & 9.35E-08 & $1.24 \mathrm{E}-08$ & 6.35E-09 & $1.27 \mathrm{E}-10$ \\
\hline
\end{tabular}

(a) Multiply values by 10 for $f_{1}=0.0001$. 


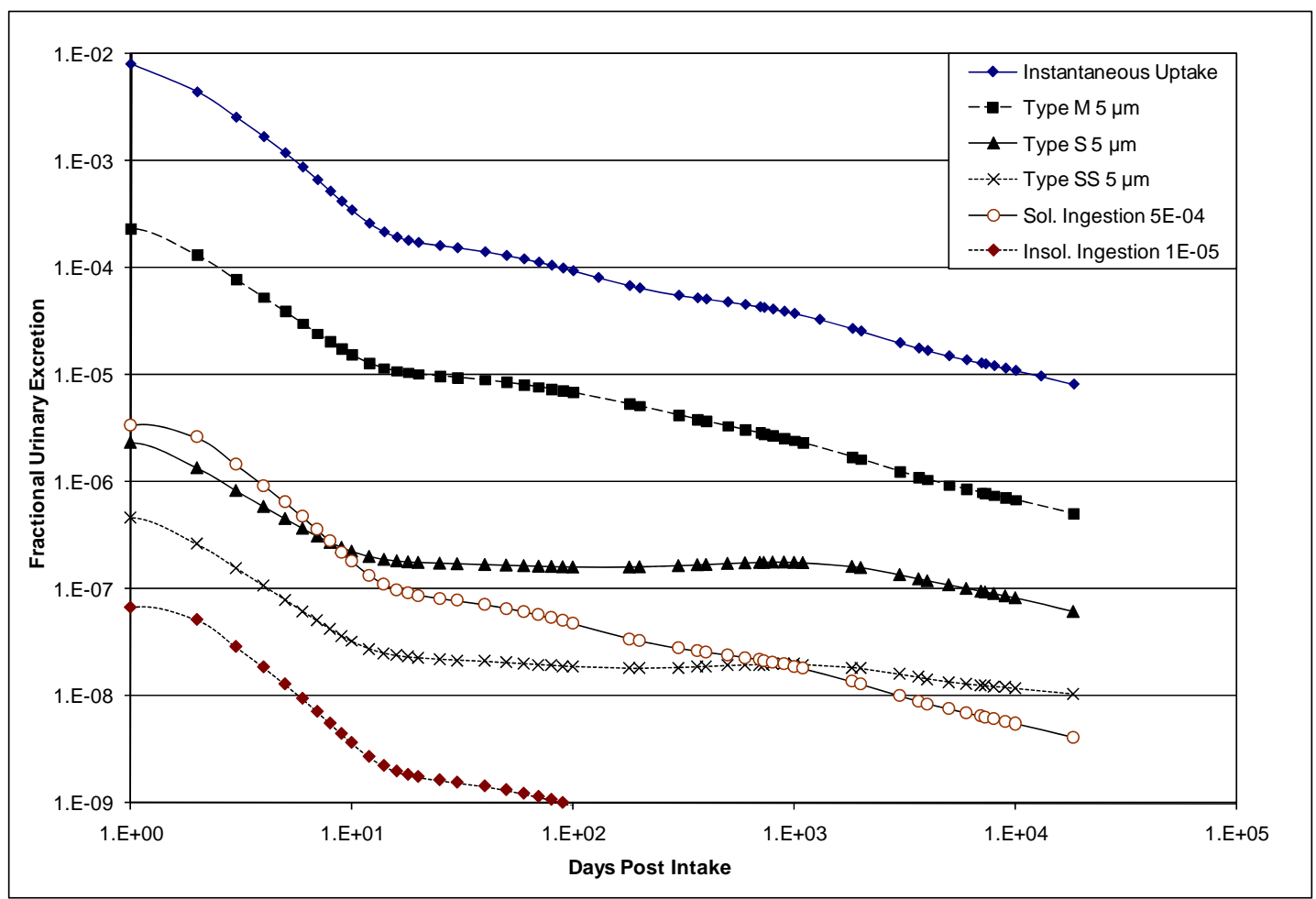

Figure 8.7. ${ }^{239} \mathrm{Pu}$ Fractional Urinary Excretion, ICRP 67 Model

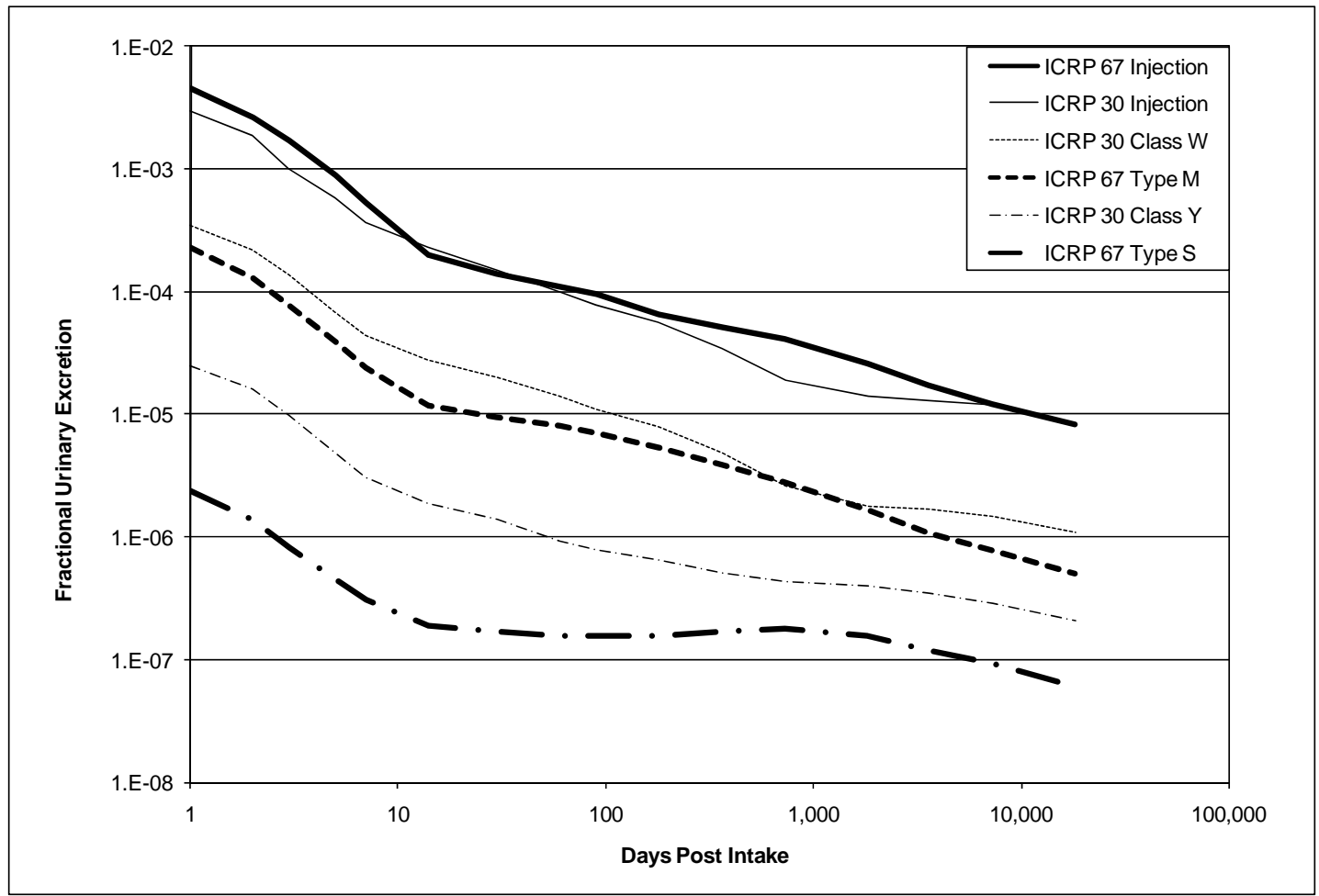

Figure 8.8. ${ }^{239} \mathrm{Pu}$ Urinary Excretion, Comparison of ICRP 30/Jones and ICRP 67 Models (ICRP 67 excretion curves are shown as heavier lines. The inhalation curves are for 5 - $\mu \mathrm{m}-\mathrm{AMAD}$ particles.) 
Table 8.13. ${ }^{239} \mathrm{Pu}$ Fecal Excretion Fractions for Instantaneous Uptake, Inhalation, and Ingestion Intakes

\begin{tabular}{|c|c|c|c|c|c|c|c|}
\hline \multirow{2}{*}{$\begin{array}{l}\text { Days Post } \\
\text { Intake }\end{array}$} & \multirow{2}{*}{$\begin{array}{c}\text { Instantaneous } \\
\text { Uptake }\end{array}$} & \multirow{2}{*}{$\begin{array}{c}\text { Type M } \\
\text { Inhalation }\end{array}$} & \multirow{2}{*}{$\begin{array}{c}\text { Type S } \\
\text { Inhalation }\end{array}$} & \multirow{2}{*}{$\begin{array}{c}\text { Type SS } \\
\text { Inhalation }\end{array}$} & \multicolumn{3}{|c|}{ Ingestion } \\
\hline & & & & & $f_{1}=5 \mathrm{E}-4$ & $f_{1}=1 \mathrm{E}-4$ & $f_{1}=1 \mathrm{E}-5$ \\
\hline 0.5 & 3.08E-04 & $2.60 \mathrm{E}-02$ & $2.73 E-02$ & 2.73E-02 & 7.03E-02 & 7.04E-02 & $7.04 \mathrm{E}-02$ \\
\hline 1 & $1.61 \mathrm{E}-03$ & 1.08E-01 & 1.14E-01 & 1.14E-01 & 2.82E-01 & 2.82E-01 & 2.82E-01 \\
\hline 2 & $4.30 \mathrm{E}-03$ & $1.55 \mathrm{E}-01$ & 1.63E-01 & 1.63E-01 & 3.89E-01 & 3.89E-01 & 3.89E-01 \\
\hline 3 & 4.19E-03 & 7.97E-02 & 8.41E-02 & 8.41E-02 & 1.97E-01 & $1.97 \mathrm{E}-01$ & 1.97E-01 \\
\hline 4 & 3.13E-03 & 3.35E-02 & 3.53E-02 & 3.54E-02 & 8.13E-02 & 8.14E-02 & 8.14E-02 \\
\hline 5 & $2.16 \mathrm{E}-03$ & 1.33E-02 & $1.41 \mathrm{E}-02$ & $1.41 \mathrm{E}-02$ & $3.14 \mathrm{E}-02$ & 3.14E-02 & $3.14 \mathrm{E}-02$ \\
\hline 6 & $1.48 \mathrm{E}-03$ & 5.37E-03 & 5.67E-03 & 5.67E-03 & 1.18E-02 & $1.18 \mathrm{E}-02$ & $1.18 \mathrm{E}-02$ \\
\hline 7 & $1.02 \mathrm{E}-03$ & 2.34E-03 & 2.47E-03 & 2.48E-03 & 4.38E-03 & 4.38E-03 & 4.38E-03 \\
\hline 8 & 7.09E-04 & 1.19E-03 & $1.28 \mathrm{E}-03$ & $1.28 \mathrm{E}-03$ & 1.62E-03 & $1.62 \mathrm{E}-03$ & $1.62 \mathrm{E}-03$ \\
\hline 9 & 5.02E-04 & 7.56E-04 & 8.23E-04 & 8.24E-04 & $5.96 \mathrm{E}-04$ & 5.97E-04 & 5.97E-04 \\
\hline 10 & 3.62E-04 & 5.85E-04 & $6.48 \mathrm{E}-04$ & 6.49E-04 & 2.20E-04 & 2.20E-04 & $2.20 \mathrm{E}-04$ \\
\hline 12 & 1.97E-04 & 4.77E-04 & 5.41E-04 & 5.42E-04 & 2.98E-05 & 2.98E-05 & 2.97E-05 \\
\hline 14 & $1.18 \mathrm{E}-04$ & 4.39E-04 & $5.06 \mathrm{E}-04$ & 5.07E-04 & 4.08E-06 & 4.04E-06 & 4.03E-06 \\
\hline 16 & 7.84E-05 & 4.13E-04 & 4.82E-04 & 4.83E-04 & 5.85E-07 & 5.53E-07 & $5.46 \mathrm{E}-07$ \\
\hline 18 & $5.90 \mathrm{E}-05$ & $3.90 \mathrm{E}-04$ & 4.60E-04 & $4.61 \mathrm{E}-04$ & $1.04 \mathrm{E}-07$ & 7.98E-08 & 7.43E-08 \\
\hline 20 & 4.95E-05 & 3.69E-04 & 4.39E-04 & 4.40E-04 & 3.51E-08 & $1.50 \mathrm{E}-08$ & $1.05 \mathrm{E}-08$ \\
\hline 25 & 4.16E-05 & 3.22E-04 & 3.92E-04 & 3.93E-04 & 2.09E-08 & 4.24E-09 & $4.85 \mathrm{E}-10$ \\
\hline 30 & 4.01E-05 & 2.81E-04 & 3.51E-04 & 3.52E-04 & 2.01E-08 & 4.01E-09 & $4.02 \mathrm{E}-10$ \\
\hline 40 & $3.94 \mathrm{E}-05$ & $2.16 \mathrm{E}-04$ & $2.82 \mathrm{E}-04$ & 2.83E-04 & 1.97E-08 & $3.94 \mathrm{E}-09$ & $3.94 \mathrm{E}-10$ \\
\hline 50 & $3.90 \mathrm{E}-05$ & 1.67E-04 & 2.28E-04 & 2.29E-04 & 1.95E-08 & $3.90 \mathrm{E}-09$ & $3.90 \mathrm{E}-10$ \\
\hline 60 & $3.86 \mathrm{E}-05$ & $1.31 \mathrm{E}-04$ & $1.86 \mathrm{E}-04$ & $1.87 \mathrm{E}-04$ & 1.93E-08 & 3.86E-09 & $3.86 \mathrm{E}-10$ \\
\hline 70 & 3.81E-05 & 1.03E-04 & $1.53 \mathrm{E}-04$ & $1.54 \mathrm{E}-04$ & $1.91 \mathrm{E}-08$ & 3.81E-09 & $3.81 \mathrm{E}-10$ \\
\hline 80 & 3.77E-05 & 8.24E-05 & $1.27 \mathrm{E}-04$ & $1.28 \mathrm{E}-04$ & 1.88E-08 & 3.77E-09 & 3.77E-10 \\
\hline 90 & 3.72E-05 & 6.65E-05 & $1.07 \mathrm{E}-04$ & $1.08 \mathrm{E}-04$ & 1.86E-08 & 3.72E-09 & 3.72E-10 \\
\hline 100 & 3.68E-05 & $5.44 \mathrm{E}-05$ & $9.09 \mathrm{E}-05$ & 9.17E-05 & 1.84E-08 & 3.68E-09 & $3.68 \mathrm{E}-10$ \\
\hline 180 & 3.32E-05 & 1.70E-05 & 3.74E-05 & 3.79E-05 & $1.66 \mathrm{E}-08$ & 3.32E-09 & 3.32E-10 \\
\hline 200 & 3.24E-05 & $1.41 \mathrm{E}-05$ & 3.31E-05 & 3.37E-05 & 1.62E-08 & 3.24E-09 & $3.24 \mathrm{E}-10$ \\
\hline 300 & 2.86E-05 & 7.42E-06 & $2.44 \mathrm{E}-05$ & 2.50E-05 & $1.43 \mathrm{E}-08$ & 2.86E-09 & $2.86 \mathrm{E}-10$ \\
\hline 365 & 2.64E-05 & 5.43E-06 & 2.22E-05 & 2.29E-05 & $1.32 \mathrm{E}-08$ & 2.64E-09 & $2.64 \mathrm{E}-10$ \\
\hline 400 & 2.53E-05 & 4.66E-06 & 2.13E-05 & 2.20E-05 & $1.27 \mathrm{E}-08$ & 2.53E-09 & $2.53 \mathrm{E}-10$ \\
\hline 500 & $2.26 \mathrm{E}-05$ & 3.16E-06 & $1.90 \mathrm{E}-05$ & 1.98E-05 & 1.13E-08 & 2.26E-09 & $2.26 \mathrm{E}-10$ \\
\hline 600 & 2.03E-05 & 2.27E-06 & $1.71 \mathrm{E}-05$ & 1.80E-05 & $1.02 \mathrm{E}-08$ & 2.03E-09 & 2.03E-10 \\
\hline 700 & $1.84 \mathrm{E}-05$ & $1.74 \mathrm{E}-06$ & $1.54 \mathrm{E}-05$ & 1.63E-05 & $9.21 \mathrm{E}-09$ & 1.84E-09 & $1.84 \mathrm{E}-10$ \\
\hline $2 \mathrm{y}$ & 1.79E-05 & $1.62 \mathrm{E}-06$ & $1.49 \mathrm{E}-05$ & $1.58 \mathrm{E}-05$ & 8.95E-09 & 1.79E-09 & $1.79 \mathrm{E}-10$ \\
\hline 800 & $1.68 \mathrm{E}-05$ & 1.41E-06 & 1.38E-05 & $1.48 \mathrm{E}-05$ & 8.40E-09 & 1.68E-09 & $1.68 \mathrm{E}-10$ \\
\hline 900 & $1.54 \mathrm{E}-05$ & 1.19E-06 & $1.24 \mathrm{E}-05$ & 1.34E-05 & 7.72E-09 & 1.54E-09 & $1.54 \mathrm{E}-10$ \\
\hline 1,000 & $1.43 \mathrm{E}-05$ & $1.04 \mathrm{E}-06$ & 1.12E-05 & $1.21 \mathrm{E}-05$ & 7.15E-09 & 1.43E-09 & $1.43 \mathrm{E}-10$ \\
\hline $3 y$ & $1.34 \mathrm{E}-05$ & 9.34E-07 & $1.01 \mathrm{E}-05$ & 1.11E-05 & 6.69E-09 & 1.34E-09 & $1.34 \mathrm{E}-10$ \\
\hline $5 y$ & 9.47E-06 & 6.04E-07 & 4.72E-06 & 5.49E-06 & 4.74E-09 & $9.47 \mathrm{E}-10$ & $9.47 \mathrm{E}-11$ \\
\hline 2,000 & $9.01 \mathrm{E}-06$ & 5.71E-07 & 3.95E-06 & 4.66E-06 & 4.51E-09 & $9.01 \mathrm{E}-10$ & $9.01 \mathrm{E}-11$ \\
\hline 3,000 & 7.55E-06 & 4.70E-07 & $1.51 \mathrm{E}-06$ & 1.91E-06 & 3.77E-09 & $7.55 \mathrm{E}-10$ & $7.55 \mathrm{E}-11$ \\
\hline $10 \mathrm{y}$ & 7.04E-06 & 4.37E-07 & 8.65E-07 & 1.14E-06 & 3.52E-09 & 7.04E-10 & $7.04 \mathrm{E}-11$ \\
\hline 5,000 & 6.29E-06 & $3.90 \mathrm{E}-07$ & 3.53E-07 & 4.88E-07 & 3.15E-09 & $6.30 \mathrm{E}-10$ & $6.30 \mathrm{E}-11$ \\
\hline 7,000 & 5.53E-06 & 3.43E-07 & 1.69E-07 & 2.47E-07 & 2.77E-07 & 5.53E-07 & 5.53E-11 \\
\hline $20 \mathrm{y}$ & $5.44 \mathrm{E}-06$ & 3.37E-07 & $1.57 \mathrm{E}-07$ & 2.31E-07 & 2.72E-09 & $5.44 \mathrm{E}-10$ & $5.44 \mathrm{E}-11$ \\
\hline 10,000 & 4.78E-06 & 2.95E-07 & $9.52 \mathrm{E}-08$ & 1.57E-07 & 2.39E-09 & $4.78 \mathrm{E}-10$ & 4.78E-11 \\
\hline $50 y$ & 3.60E-06 & 2.22E-07 & 3.64E-08 & $5.40 \mathrm{E}-08$ & 1.80E-09 & $3.60 \mathrm{E}-10$ & $3.60 \mathrm{E}-11$ \\
\hline
\end{tabular}




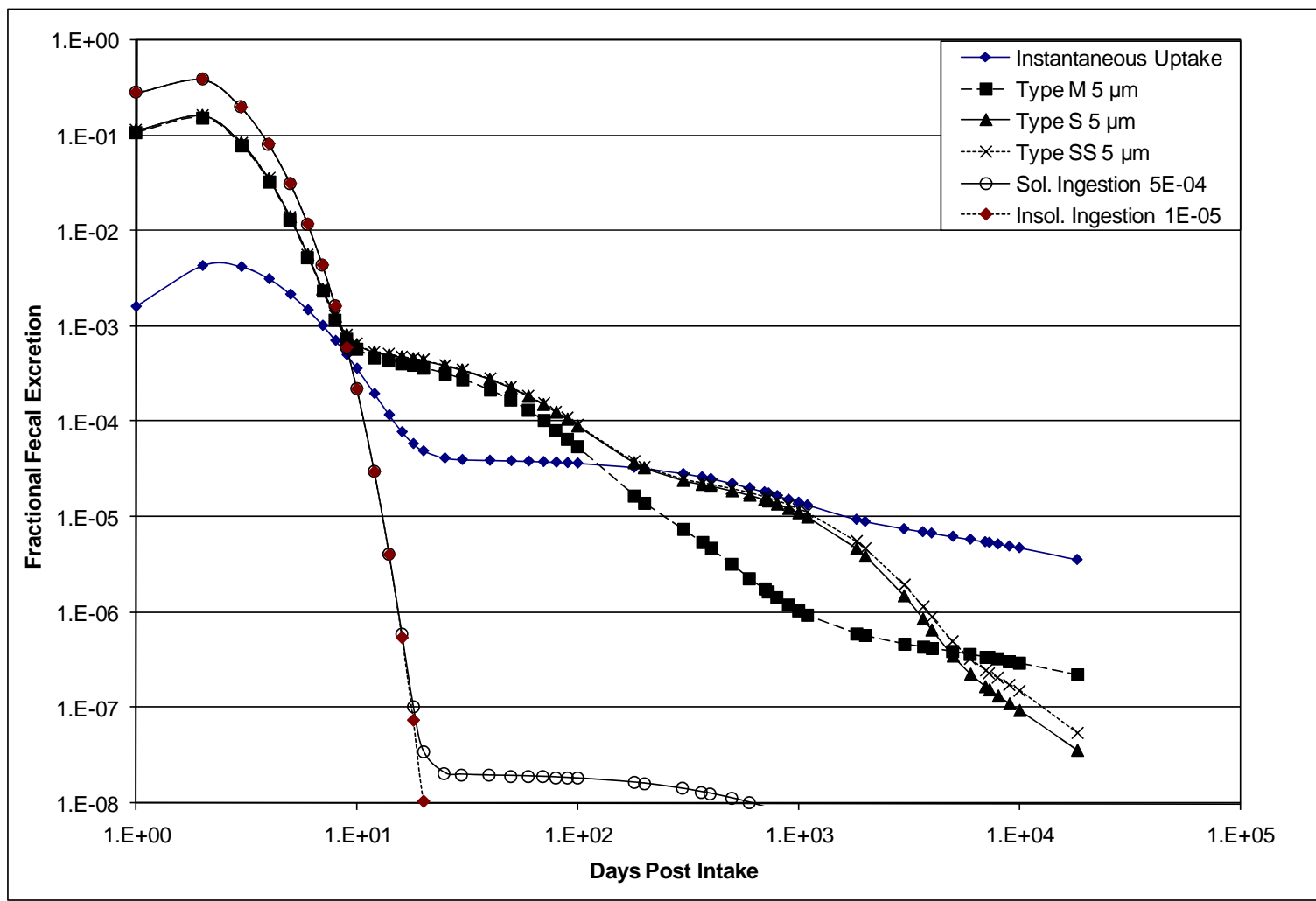

Figure 8.9. ${ }^{239} \mathrm{Pu}$ Fractional Fecal Excretion, ICRP 67 Model 
Table 8.14. Fecal-to-Urine Ratios for ${ }^{239} \mathrm{Pu}$ Intakes

\begin{tabular}{ccccccc}
\hline & & Type M & Type $S$ & Type SS & \multicolumn{2}{c}{ Ingestion } \\
\cline { 5 - 7 } $\begin{array}{c}\text { Days Post } \\
\text { Intake }\end{array}$ & $\begin{array}{c}\text { Instantaneous } \\
\text { Uptake }\end{array}$ & $\begin{array}{c}\text { Inhalation } \\
(5 \mu \mathrm{m})\end{array}$ & $\begin{array}{c}\text { Inhalation } \\
(5 \mu \mathrm{m})\end{array}$ & $\begin{array}{c}\text { Inhalation } \\
(5 \mu \mathrm{m})\end{array}$ & $f_{1}=5 \mathrm{E}-4$ & $f_{1}=1 \mathrm{E}-5$ \\
\hline 1 & $1.97 \mathrm{E}-01$ & $4.66 \mathrm{E}+02$ & $4.85 \mathrm{E}+04$ & $2.46 \mathrm{E}+05$ & $8.37 \mathrm{E}+04$ & $4.19 \mathrm{E}+06$ \\
2 & $9.60 \mathrm{E}-01$ & $1.18 \mathrm{E}+03$ & $1.20 \mathrm{E}+05$ & $6.22 \mathrm{E}+05$ & $1.50 \mathrm{E}+05$ & $7.52 \mathrm{E}+06$ \\
3 & $1.61 \mathrm{E}+00$ & $1.02 \mathrm{E}+03$ & $1.01 \mathrm{E}+05$ & $5.36 \mathrm{E}+05$ & $1.36 \mathrm{E}+05$ & $6.82 \mathrm{E}+06$ \\
5 & $1.79 \mathrm{E}+00$ & $3.40 \mathrm{E}+02$ & $3.10 \mathrm{E}+04$ & $1.77 \mathrm{E}+05$ & $4.85 \mathrm{E}+04$ & $2.43 \mathrm{E}+06$ \\
7 & $1.51 \mathrm{E}+00$ & $9.59 \mathrm{E}+01$ & $7.92 \mathrm{E}+03$ & $4.94 \mathrm{E}+04$ & $1.23 \mathrm{E}+04$ & $6.14 \mathrm{E}+05$ \\
8 & $1.35 \mathrm{E}+00$ & $5.86 \mathrm{E}+01$ & $4.71 \mathrm{E}+03$ & $3.04 \mathrm{E}+04$ & $5.85 \mathrm{E}+03$ & $2.92 \mathrm{E}+05$ \\
10 & $1.03 \mathrm{E}+00$ & $3.80 \mathrm{E}+01$ & $2.88 \mathrm{E}+03$ & $2.00 \mathrm{E}+04$ & $1.21 \mathrm{E}+03$ & $6.03 \mathrm{E}+04$ \\
12 & $7.47 \mathrm{E}-01$ & $3.70 \mathrm{E}+01$ & $2.69 \mathrm{E}+03$ & $1.96 \mathrm{E}+04$ & $2.21 \mathrm{E}+02$ & $1.10 \mathrm{E}+04$ \\
14 & $5.39 \mathrm{E}-01$ & $3.78 \mathrm{E}+01$ & $2.68 \mathrm{E}+03$ & $2.02 \mathrm{E}+04$ & $3.68 \mathrm{E}+01$ & $1.82 \mathrm{E}+03$ \\
20 & $2.84 \mathrm{E}-01$ & $3.62 \mathrm{E}+01$ & $2.48 \mathrm{E}+03$ & $1.94 \mathrm{E}+04$ & $4.02 \mathrm{E}-01$ & $6.00 \mathrm{E}+00$ \\
30 & $2.58 \mathrm{E}-01$ & $2.95 \mathrm{E}+01$ & $2.04 \mathrm{E}+03$ & $1.63 \mathrm{E}+04$ & $2.59 \mathrm{E}-01$ & $2.59 \mathrm{E}-01$ \\
60 & $3.16 \mathrm{E}-01$ & $1.62 \mathrm{E}+01$ & $1.13 \mathrm{E}+03$ & $9.35 \mathrm{E}+03$ & $3.15 \mathrm{E}-01$ & $3.16 \mathrm{E}-01$ \\
90 & $3.71 \mathrm{E}-01$ & $9.34 \mathrm{E}+00$ & $6.65 \mathrm{E}+02$ & $5.68 \mathrm{E}+03$ & $3.71 \mathrm{E}-01$ & $3.72 \mathrm{E}-01$ \\
180 & $4.83 \mathrm{E}-01$ & $3.16 \mathrm{E}+00$ & $2.34 \mathrm{E}+02$ & $2.09 \mathrm{E}+03$ & $4.83 \mathrm{E}-01$ & $4.83 \mathrm{E}-01$ \\
365 & $5.01 \mathrm{E}-01$ & $1.40 \mathrm{E}+00$ & $1.32 \mathrm{E}+02$ & $1.22 \mathrm{E}+03$ & $5.02 \mathrm{E}-01$ & $5.01 \mathrm{E}-01$ \\
$2 \mathrm{y}$ & $4.18 \mathrm{E}-01$ & $5.74 \mathrm{E}-01$ & $8.42 \mathrm{E}+01$ & $8.06 \mathrm{E}+02$ & $4.18 \mathrm{E}-01$ & $4.17 \mathrm{E}-01$ \\
$5 \mathrm{y}$ & $3.47 \mathrm{E}-01$ & $3.49 \mathrm{E}-01$ & $2.91 \mathrm{E}+01$ & $2.98 \mathrm{E}+02$ & $3.49 \mathrm{E}-01$ & $3.47 \mathrm{E}-01$ \\
$10 \mathrm{y}$ & $3.95 \mathrm{E}-01$ & $3.94 \mathrm{E}-01$ & $6.98 \mathrm{E}+00$ & $7.65 \mathrm{E}+01$ & $3.95 \mathrm{E}-01$ & $3.96 \mathrm{E}-01$ \\
$20 \mathrm{y}$ & $4.28 \mathrm{E}-01$ & $4.29 \mathrm{E}-01$ & $1.68 \mathrm{E}+00$ & $1.86 \mathrm{E}+01$ & $4.28 \mathrm{E}-01$ & $4.28 \mathrm{E}-01$ \\
$50 \mathrm{y}$ & $4.89 \mathrm{E}-01$ & $4.37 \mathrm{E}-01$ & $5.94 \mathrm{E}-01$ & $5.19 \mathrm{E}+00$ & $4.38 \mathrm{E}-01$ & $4.38 \mathrm{E}-01$ \\
\hline
\end{tabular}

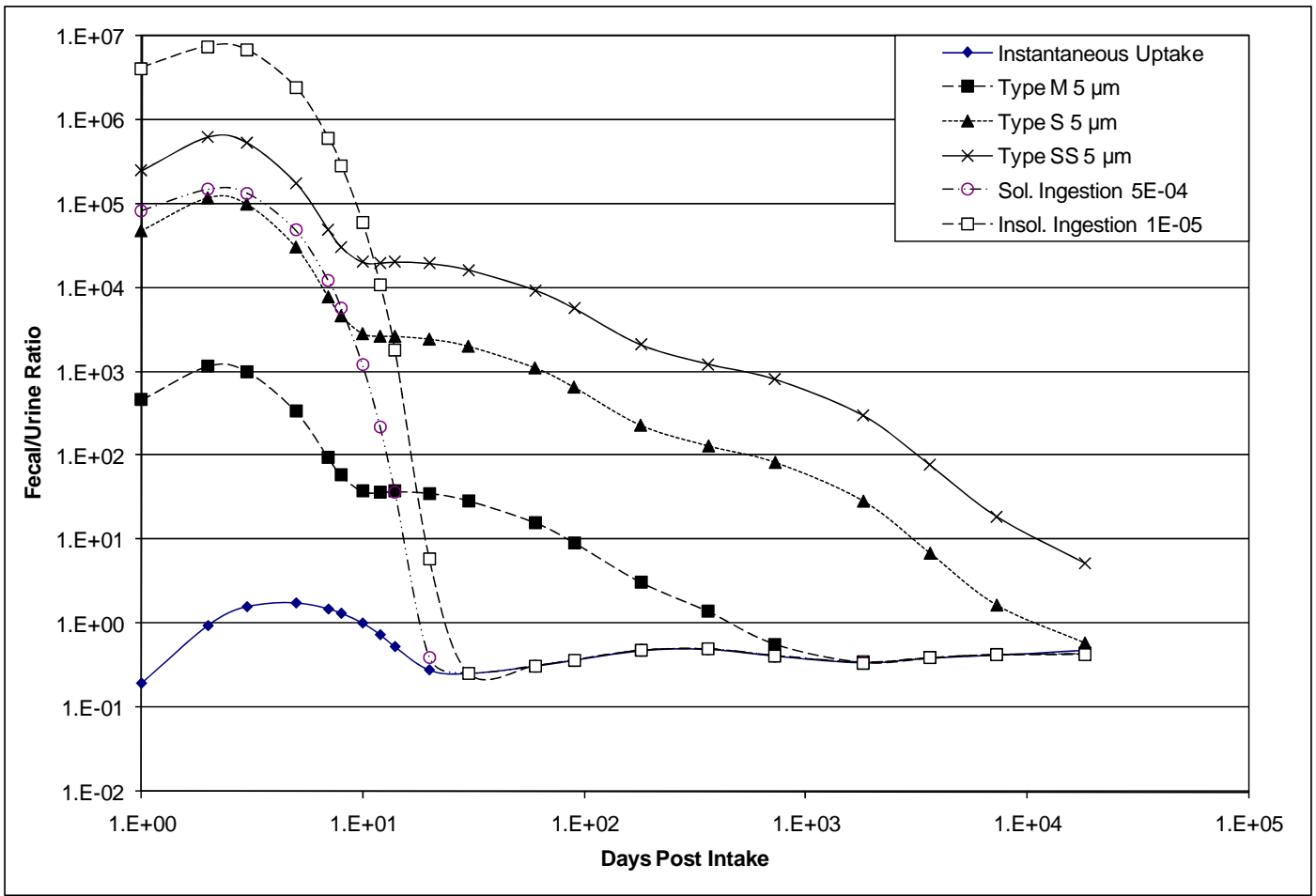

Figure 8.10. Feces-to-Urine Excretion Ratios for ${ }^{239} \mathrm{Pu}$ Intakes 
Dose coefficients for single isotopes are shown in Tables 8.15 through 8.18 . In the case of ${ }^{241} \mathrm{Pu}$, the ${ }^{241} \mathrm{Am}$ ingrown from the time of intake is included in Table 8.17. The ${ }^{241} \mathrm{Am}$ values listed in Table 8.18 assume that behavior is characteristic of plutonium; i.e., the plutonium respiratory and GI tract models are used for americium because the americium is considered trapped in a plutonium matrix, which limits its behavior to that of the predominant matrix.

Table 8.15. Committed Dose Coefficients for Acute Intakes of ${ }^{238} \mathrm{Pu}(\mathrm{rem} / \mathrm{nCi})$

\begin{tabular}{|c|c|c|c|c|c|c|}
\hline \multirow[b]{2}{*}{ Organ or Tissue } & \multirow{2}{*}{$\begin{array}{c}\text { Instantaneous } \\
\text { Uptake }\end{array}$} & \multirow{2}{*}{$\begin{array}{c}\text { Type M } \\
\text { Inhalation } \\
(5 \mu \mathrm{m})\end{array}$} & \multirow{2}{*}{$\begin{array}{c}\text { Type S } \\
\text { Inhalation } \\
(5 \mu \mathrm{m})\end{array}$} & \multirow{2}{*}{$\begin{array}{c}\text { Type SS } \\
\text { Inhalation } \\
(5 \mu \mathrm{m})\end{array}$} & \multicolumn{2}{|c|}{ Ingestion } \\
\hline & & & & & $f_{1}=5 \mathrm{E}-04$ & $f_{1}=1 \mathrm{E}-05$ \\
\hline Effective & $1.65 \mathrm{E}+00$ & $1.11 \mathrm{E}-01$ & 3.92E-02 & 3.54E-02 & 8.43E-04 & 3.29E-05 \\
\hline Bone Surface & $5.47 \mathrm{E}+01$ & $3.35 \mathrm{E}+00$ & 2.94E-01 & 3.78E-02 & 2.73E-02 & 5.47E-04 \\
\hline Liver & $1.15 \mathrm{E}+01$ & 7.08E-01 & 6.27E-02 & 8.06E-03 & 5.77E-03 & 1.15E-04 \\
\hline Red Marrow & $2.70 \mathrm{E}+00$ & $1.66 \mathrm{E}-01$ & $1.51 \mathrm{E}-02$ & $1.97 \mathrm{E}-03$ & $1.35 \mathrm{E}-03$ & 2.70E-05 \\
\hline Lungs & $9.54 \mathrm{E}-02$ & 8.71E-02 & 1.90E-01 & 2.17E-01 & 4.77E-05 & $9.54 \mathrm{E}-07$ \\
\hline $\mathrm{ET}$ & $9.54 \mathrm{E}-02$ & 5.61E-02 & 3.00E-01 & 3.27E-01 & 4.77E-05 & $9.54 \mathrm{E}-07$ \\
\hline Gonads & 7.32E-01 & 4.49E-02 & 3.96E-03 & $1.27 \mathrm{E}-04$ & 3.66E-04 & 7.32E-06 \\
\hline Kidneys & 2.37E-01 & $1.45 \mathrm{E}-02$ & 1.33E-03 & $1.75 \mathrm{E}-04$ & 1.18E-04 & 2.37E-06 \\
\hline Lower Large Intestine & $9.54 \mathrm{E}-02$ & 5.93E-03 & $6.04 \mathrm{E}-04$ & $1.64 \mathrm{E}-04$ & 2.57E-04 & 2.11E-04 \\
\hline Colon & $9.54 \mathrm{E}-02$ & $5.90 \mathrm{E}-03$ & $5.67 \mathrm{E}-04$ & 1.27E-04 & 1.79E-04 & 1.32E-04 \\
\hline Upper Large Intestine & $9.54 \mathrm{E}-02$ & 5.87E-03 & 5.38E-04 & 9.87E-05 & 1.19E-04 & 7.25E-05 \\
\hline Small Intestine & $9.54 \mathrm{E}-02$ & 5.85E-03 & $5.10 \mathrm{E}-04$ & 7.01E-05 & 5.95E-05 & $1.28 \mathrm{E}-05$ \\
\hline Stomach & $9.54 \mathrm{E}-02$ & 5.85E-03 & $5.06 \mathrm{E}-04$ & $6.68 \mathrm{E}-05$ & $5.24 \mathrm{E}-05$ & 5.68E-06 \\
\hline Others & $9.54 \mathrm{E}-02$ & $5.84 \mathrm{E}-03$ & $5.04 \mathrm{E}-04$ & $6.45 \mathrm{E}-05$ & 4.77E-05 & $9.54 \mathrm{E}-07$ \\
\hline
\end{tabular}

Table 8.16. Committed Dose Coefficients for Acute Intakes of ${ }^{239} \mathrm{Pu}$ or ${ }^{240} \mathrm{Pu}(\mathrm{rem} / \mathrm{nCi})^{(\mathrm{a})}$

\begin{tabular}{|c|c|c|c|c|c|c|}
\hline \multirow[b]{2}{*}{ Organ or Tissue } & \multirow{2}{*}{$\begin{array}{l}\text { Instantaneous } \\
\text { Uptake }\end{array}$} & \multirow{2}{*}{$\begin{array}{c}\text { Type M } \\
\text { Inhalation } \\
(5 \mu \mathrm{m})\end{array}$} & \multirow{2}{*}{$\begin{array}{c}\text { Type S } \\
\text { Inhalation } \\
(5 \mu \mathrm{m})\end{array}$} & \multirow{2}{*}{$\begin{array}{c}\text { Type SS } \\
\text { Inhalation } \\
(5 \mu \mathrm{m})\end{array}$} & \multicolumn{2}{|c|}{ Ingestion } \\
\hline & & & & & $f_{1}=5 \mathrm{E}-04$ & $f_{1}=1 \mathrm{E}-05$ \\
\hline Effective & $1.82 \mathrm{E}+00$ & $1.20 \mathrm{E}-01$ & 3.10E-02 & 3.38E-02 & $9.28 \mathrm{E}-04$ & 3.35E-05 \\
\hline Bone Surface & $6.08 \mathrm{E}+01$ & $3.73 \mathrm{E}+00$ & 3.36E-01 & 4.35E-02 & 3.04E-02 & $6.08 \mathrm{E}-04$ \\
\hline Liver & $1.28 \mathrm{E}-01$ & 7.85E-01 & 7.13E-02 & $9.27 \mathrm{E}-03$ & 6.39E-03 & $1.28 \mathrm{E}-04$ \\
\hline Red Marrow & $2.90 \mathrm{E}+00$ & $1.78 \mathrm{E}-01$ & $1.66 \mathrm{E}-02$ & 2.21E-03 & $1.45 \mathrm{E}-03$ & 2.90E-05 \\
\hline Lungs & $1.07 \mathrm{E}-01$ & 7.69E-02 & $1.74 \mathrm{E}-01$ & 2.03E-01 & 5.37E-05 & 1.07E-06 \\
\hline ET & 1.07E-01 & 5.53E-02 & 2.95E-01 & 3.21E-01 & 5.37E-05 & 1.07E-06 \\
\hline Gonads & 8.14E-01 & 5.00E-02 & 4.52E-03 & 5.86E-04 & 4.07E-04 & 8.14E-06 \\
\hline Kidneys & 2.50E-01 & $1.54 \mathrm{E}-02$ & $1.45 \mathrm{E}-03$ & 1.94E-04 & $1.25 \mathrm{E}-04$ & $2.50 \mathrm{E}-06$ \\
\hline Lower Large Intestine & $1.07 \mathrm{E}-01$ & 6.66E-03 & 6.73E-04 & 1.69E-04 & 2.50E-04 & 1.97E-04 \\
\hline Colon & $1.07 \mathrm{E}-01$ & 6.63E-03 & $6.38 \mathrm{E}-04$ & $1.34 \mathrm{E}-04$ & $1.76 \mathrm{E}-04$ & $1.24 \mathrm{E}-04$ \\
\hline Upper Large Intestine & 1.07E-01 & 6.61E-03 & 6.11E-04 & $1.07 \mathrm{E}-04$ & $1.21 \mathrm{E}-04$ & 6.79E-05 \\
\hline Small Intestine & 1.07E-01 & $6.58 \mathrm{E}-03$ & 5.85E-04 & 8.00E-05 & $6.47 \mathrm{E}-05$ & $1.21 \mathrm{E}-05$ \\
\hline Stomach & 1.07E-01 & $6.58 \mathrm{E}-03$ & 5.82E-04 & 7.68E-05 & 5.81E-05 & 5.49E-06 \\
\hline Others & $1.07 \mathrm{E}-01$ & $6.58 \mathrm{E}-03$ & $5.80 \mathrm{E}-04$ & 7.47E-05 & 5.37E-05 & 1.07E-06 \\
\hline
\end{tabular}


Table 8.17. Committed Dose Coefficients(a) for Acute Intakes of 241Pu (rem/nCi)

\begin{tabular}{|c|c|c|c|c|c|c|}
\hline \multirow[b]{2}{*}{ Organ or Tissue } & \multirow{2}{*}{$\begin{array}{c}\text { Instantaneous } \\
\text { Uptake }\end{array}$} & \multirow{2}{*}{$\begin{array}{c}\text { Type } \mathrm{M} \\
\text { Inhalation } \\
(5 \mu \mathrm{m})\end{array}$} & \multirow{2}{*}{$\begin{array}{c}\text { Type S } \\
\text { Inhalation } \\
(5 \mu \mathrm{m})\end{array}$} & \multirow{2}{*}{$\begin{array}{c}\text { Type SS } \\
\text { Inhalation } \\
(5 \mu \mathrm{m})\end{array}$} & \multicolumn{2}{|c|}{ Ingestion } \\
\hline & & & & & $f_{1}=5 \mathrm{E}-04$ & $f_{1}=1 \mathrm{E}-05$ \\
\hline Effective & 3.48E-02 & $2.16 \mathrm{E}-03$ & 3.13E-04 & $1.94 \mathrm{E}-04$ & $1.75 \mathrm{E}-05$ & $4.26 \mathrm{E}-07$ \\
\hline Bone Surface & $1.21+00$ & 7.44E-02 & 7.40E-03 & $9.85 \mathrm{E}-04$ & 6.03E-04 & $1.21 \mathrm{E}-05$ \\
\hline Liver & 2.50E-01 & $1.55 \mathrm{E}-02$ & $1.56 \mathrm{E}-03$ & 2.09E-04 & $1.25 \mathrm{E}-04$ & $2.50 \mathrm{E}-06$ \\
\hline Red Marrow & 4.73E-02 & 2.94E-03 & $3.25 \mathrm{E}-04$ & 4.53E-05 & 2.37E-05 & 4.73E-07 \\
\hline Lungs & 2.19E-03 & $1.54 \mathrm{E}-04$ & 7.93E-04 & $1.37 \mathrm{E}-03$ & 1.09E-06 & 2.19E-08 \\
\hline $\mathrm{ET}$ & 2.19E-03 & $1.72 \mathrm{E}-04$ & $1.11 \mathrm{E}-03$ & $1.31 \mathrm{E}-03$ & 1.09E-06 & 2.19E-08 \\
\hline Gonads & 1.62E-02 & $9.98 \mathrm{E}-04$ & 9.99E-05 & 1.33E-05 & 8.08E-06 & $1.62 \mathrm{E}-07$ \\
\hline Kidneys & $3.68 \mathrm{E}-03$ & 2.29E-04 & 2.65E-05 & 3.78E-06 & $1.84 \mathrm{E}-06$ & 3.68E-08 \\
\hline Lower Large Intestine & 2.19E-03 & 1.35E-04 & $1.34 \mathrm{E}-05$ & 2.22E-06 & 2.09E-06 & $1.02 \mathrm{E}-06$ \\
\hline Colon & 2.19E-03 & 1.35E-04 & 1.32E-05 & 2.03E-06 & 1.72E-06 & $6.46 \mathrm{E}-07$ \\
\hline Upper Large Intestine & 2.19E-03 & 1.35E-04 & $1.31 \mathrm{E}-05$ & 1.88E-06 & 1.43E-06 & 3.62E-07 \\
\hline Small Intestine & 2.19E-03 & 1.35E-04 & $1.30 \mathrm{E}-05$ & $1.74 \mathrm{E}-06$ & 1.15E-06 & 7.80E-08 \\
\hline Stomach & 2.19E-03 & 1.35E-04 & 1.29E-05 & 1.73E-06 & 1.12E-06 & 4.43E-08 \\
\hline Others & 2.19E-03 & $1.35 \mathrm{E}-04$ & $1.29 \mathrm{E}-05$ & $1.72 \mathrm{E}-06$ & $1.10 \mathrm{E}-06$ & 2.19E-08 \\
\hline
\end{tabular}

Table 8.18. Committed Dose Coefficients for Acute Intakes of ${ }^{241} \mathrm{Am}$ in a Plutonium Matrix (rem/nCi)

\begin{tabular}{lcccccc}
\hline & Instantaneous & Type $M$ & Type $S$ & Type SS & & Ingestion \\
\cline { 5 - 7 } \multicolumn{1}{c}{ Organ or Tissue } & Uptake & $(5 \mu \mathrm{m})$ & $(5 \mu \mathrm{m})$ & $(5 \mu \mathrm{m})$ & $f_{1}=5 \mathrm{E}-04$ & $f_{1}=1 \mathrm{E}-05$ \\
\hline Effective & $1.88 \mathrm{E}+00$ & $1.00 \mathrm{E}-01$ & $3.15 \mathrm{E}-02$ & $3.63 \mathrm{E}-2$ & $7.54 \mathrm{E}-04$ & $3.18 \mathrm{E}-05$ \\
Bone Surface & $6.25 \mathrm{E}+01$ & $4.10 \mathrm{E}+00$ & $3.71 \mathrm{E}-01$ & $4.81 \mathrm{E}-02$ & $3.34 \mathrm{E}-02$ & $6.67 \mathrm{E}-04$ \\
Liver & $1.32 \mathrm{E}+01$ & $2.52 \mathrm{E}-01$ & $2.41 \mathrm{E}-02$ & $3.25 \mathrm{E}-03$ & $2.05 \mathrm{E}-03$ & $4.10 \mathrm{E}-05$ \\
Red Marrow & $3.00 \mathrm{E}+00$ & $1.40 \mathrm{E}-01$ & $1.32 \mathrm{E}-02$ & $1.77 \mathrm{E}-03$ & $1.14 \mathrm{E}-03$ & $2.27 \mathrm{E}-05$ \\
Lungs & $1.10 \mathrm{E}-01$ & $8.80 \mathrm{E}-02$ & $1.93 \mathrm{E}-01$ & $2.25 \mathrm{E}-01$ & $5.67 \mathrm{E}-05$ & $1.14 \mathrm{E}-06$ \\
ET & $1.10 \mathrm{E}-01$ & $5.74 \mathrm{E}-02$ & $3.05 \mathrm{E}-01$ & $3.32 \mathrm{E}-01$ & $5.67 \mathrm{E}-05$ & $1.13 \mathrm{E}-06$ \\
Gonads & $8.37 \mathrm{E}-01$ & $7.97 \mathrm{E}-02$ & $7.29 \mathrm{E}-03$ & $9.49 \mathrm{E}-04$ & $6.49 \mathrm{E}-04$ & $1.32 \mathrm{E}-05$ \\
Kidneys & $2.60 \mathrm{E}-01$ & $2.10 \mathrm{E}-02$ & $2.01 \mathrm{E}-03$ & $2.71 \mathrm{E}-04$ & $1.71 \mathrm{E}-04$ & $3.44 \mathrm{E}-06$ \\
Lower Large Intestine & $1.10 \mathrm{E}-01$ & $7.04 \mathrm{E}-03$ & $6.97 \mathrm{E}-04$ & $1.79 \mathrm{E}-04$ & $2.75 \mathrm{E}-04$ & $2.19 \mathrm{E}-04$ \\
Colon & $1.10 \mathrm{E}-01$ & $7.00 \mathrm{E}-03$ & $6.58 \mathrm{E}-04$ & $1.40 \mathrm{E}-04$ & $1.93 \mathrm{E}-04$ & $1.38 \mathrm{E}-04$ \\
Upper Large Intestine & $1.10 \mathrm{E}-01$ & $6.98 \mathrm{E}-03$ & $6.28 \mathrm{E}-04$ & $1.11 \mathrm{E}-04$ & $1.31 \mathrm{E}-04$ & $7.56 \mathrm{E}-05$ \\
Small Intestine & $1.10 \mathrm{E}-01$ & $6.95 \mathrm{E}-03$ & $5.99 \mathrm{E}-04$ & $8.10 \mathrm{E}-05$ & $6.91 \mathrm{E}-05$ & $1.36 \mathrm{E}-05$ \\
Stomach & $1.10 \mathrm{E}-01$ & $6.95 \mathrm{E}-03$ & $5.96 \mathrm{E}-04$ & $7.81 \mathrm{E}-05$ & $6.16 \mathrm{E}-05$ & $6.08 \mathrm{E}-06$ \\
Others & $1.10 \mathrm{E}-01$ & $6.95 \mathrm{E}-03$ & $5.94 \mathrm{E}-04$ & $7.64 \mathrm{E}-05$ & $5.67 \mathrm{E}-05$ & $1.18 \mathrm{E}-06$ \\
\hline ET = extrathoracic. & & & & & &
\end{tabular}

Dose coefficients have been derived for intakes of some mixtures representing the types of plutonium most typically encountered at Hanford. The dose coefficients are listed in Table 8.19 for weapons-grade plutonium and in Table 8.20 for fuel-grade plutonium for instantaneous uptake, and Type M, S, and Super $\mathrm{S}$ inhalations for 5 - $\mu \mathrm{m}$-AMAD particles. The mixtures are weapons-grade and fuel-grade plutonium aged 20 years and 50 years. In general the dose coefficients only vary from $5 \%$ to $15 \%$ between these age categories and would vary less for years in between. Previous HIDP documentation provided dose coefficients for fresh and 5-year aged weapons and fuel-grade mixtures (Sula et al. 1989, 1991) and 
10-year aged mixtures (Carbaugh 2003b) (in the ICRP 30 methodology) but the younger mixtures are no longer relevant at Hanford. As discussed in Section 8.2.1, the retention model used for the Type Super S form is speculative. The Super $\mathrm{S}$ dose coefficients are intended for comparison with other more widely accepted models, rather than confident dosimetry. Reference mixture dose coefficients have not been provided for ingestion intakes, because ingestion has not historically been considered a significant mode of occupational dose, due to extremely low uptake of plutonium by the GI tract. If an ingestion intake occurs, the dose to significant organs can be calculated using IMBA or the individual nuclide dose coefficients for ingestion listed in Tables 8.15 through 8.18.

Table 8.19. Committed Dose Coefficients for Acute Intakes of Hanford Weapons-Grade Plutonium Mixtures (rem/nCi of total alpha)

\begin{tabular}{lcccc}
\hline \multicolumn{1}{c}{ Organ or Tissue } & $\begin{array}{c}\text { Instantaneous } \\
\text { Uptake }\end{array}$ & $\begin{array}{c}\text { Type M Inhalation } \\
(5 \mu \mathrm{m})\end{array}$ & $\begin{array}{c}\text { Type S Inhalation } \\
(5 \mu \mathrm{m})\end{array}$ & $\begin{array}{c}\text { Super S Inhalation } \\
(5 \mu \mathrm{m})\end{array}$ \\
\hline & $\mathbf{2 0}-$ Year-Aged Weapons-Grade Mixture & \\
Effective & $1.93 \mathrm{E}+00$ & $1.23 \mathrm{E}-01$ & $3.28 \mathrm{E}-02$ & $3.42 \mathrm{E}-02$ \\
Bone Surface & $6.46 \mathrm{E}+01$ & $4.01 \mathrm{E}+00$ & $3.63 \mathrm{E}-01$ & $1.03 \mathrm{E}-01$ \\
Liver & $4.11 \mathrm{E}+00$ & $7.38 \mathrm{E}-01$ & $6.76 \mathrm{E}-02$ & $1.25 \mathrm{E}-02$ \\
Red Marrow & $3.06 \mathrm{E}+00$ & $1.80 \mathrm{E}-01$ & $1.70 \mathrm{E}-02$ & $4.26 \mathrm{E}-03$ \\
Lungs & $1.14 \mathrm{E}-01$ & $8.01 \mathrm{E}-02$ & $1.81 \mathrm{E}-01$ & $2.07 \mathrm{E}-01$ \\
ET & $1.14 \mathrm{E}-01$ & $5.62 \mathrm{E}-02$ & $3.01 \mathrm{E}-01$ & $3.24 \mathrm{E}-01$ \\
Gonads & $8.65 \mathrm{E}-01$ & $5.81 \mathrm{E}-02$ & $5.29 \mathrm{E}-03$ & $1.76 \mathrm{E}-03$ \\
Kidneys & $2.63 \mathrm{E}-01$ & $1.71 \mathrm{E}-02$ & $1.63 \mathrm{E}-03$ & $5.22 \mathrm{E}-04$ \\
Lower Large & & & & \\
Intestine & $1.14 \mathrm{E}-01$ & $7.12 \mathrm{E}-03$ & $7.16 \mathrm{E}-04$ & $2.68 \mathrm{E}-04$ \\
Colon & $1.14 \mathrm{E}-01$ & $7.09 \mathrm{E}-03$ & $6.80 \mathrm{E}-04$ & $2.32 \mathrm{E}-04$ \\
Upper Large Intestine & $1.14 \mathrm{E}-01$ & $7.07 \mathrm{E}-03$ & $6.52 \mathrm{E}-04$ & $2.03 \mathrm{E}-04$ \\
Small Intestine & $1.14 \mathrm{E}-01$ & $7.04 \mathrm{E}-03$ & $6.25 \mathrm{E}-04$ & $1.76 \mathrm{E}-04$ \\
Stomach & $1.14 \mathrm{E}-01$ & $7.04 \mathrm{E}-03$ & $6.21 \mathrm{E}-04$ & $1.72 \mathrm{E}-04$ \\
Others & $1.14 \mathrm{E}-01$ & $7.04 \mathrm{E}-03$ & $6.19 \mathrm{E}-04$ & $1.70 \mathrm{E}-04$ \\
& $50-Y e a r-A g e d$ & Weapons-Grade & \\
Effective & $1.84 \mathrm{E}+00$ & $1.16 \mathrm{E}-01$ & $3.17 \mathrm{E}-02$ & $3.33 \mathrm{E}-02$ \\
Bone Surface & $6.14 \mathrm{E}+01$ & $3.83 \mathrm{E}+00$ & $3.45 \mathrm{E}-01$ & $1.20 \mathrm{E}-01$ \\
Liver & $4.02 \mathrm{E}+00$ & $6.63 \mathrm{E}-01$ & $6.06 \mathrm{E}-02$ & $1.28 \mathrm{E}-02$ \\
Red Marrow & $2.93 \mathrm{E}+00$ & $1.70 \mathrm{E}-01$ & $1.59 \mathrm{E}-02$ & $4.79 \mathrm{E}-03$ \\
Lungs & $1.08 \mathrm{E}-01$ & $7.98 \mathrm{E}-02$ & $1.79 \mathrm{E}-01$ & $2.01 \mathrm{E}-01$ \\
ET & $1.08 \mathrm{E}-01$ & $5.56 \mathrm{E}-02$ & $2.97 \mathrm{E}-01$ & $3.18 \mathrm{E}-01$ \\
Gonads & $8.22 \mathrm{E}-01$ & $5.71 \mathrm{E}-02$ & $5.19 \mathrm{E}-03$ & $2.13 \mathrm{E}-03$ \\
Kidneys & $2.53 \mathrm{E}-01$ & $1.67 \mathrm{E}-02$ & $1.59 \mathrm{E}-03$ & $6.19 \mathrm{E}-04$ \\
Lower Large & & & & \\
Intestine & $1.08 \mathrm{E}-01$ & $6.77 \mathrm{E}-03$ & $6.81 \mathrm{E}-04$ & $2.93 \mathrm{E}-04$ \\
Colon & $1.08 \mathrm{E}-01$ & $6.74 \mathrm{E}-03$ & $6.45 \mathrm{E}-04$ & $2.57 \mathrm{E}-04$ \\
Upper Large Intestine & $1.08 \mathrm{E}-01$ & $6.72 \mathrm{E}-03$ & $6.17 \mathrm{E}-04$ & $2.29 \mathrm{E}-04$ \\
Small Intestine & $1.08 \mathrm{E}-01$ & $6.69 \mathrm{E}-03$ & $5.90 \mathrm{E}-04$ & $2.02 \mathrm{E}-04$ \\
Stomach & $1.08 \mathrm{E}-01$ & $6.69 \mathrm{E}-03$ & $5.87 \mathrm{E}-04$ & $1.98 \mathrm{E}-04$ \\
Others & $1.08 \mathrm{E}-01$ & $6.69 \mathrm{E}-03$ & $5.85 \mathrm{E}-04$ & $1.96 \mathrm{E}-04$ \\
\hline ET = extrathoracic. & & & \\
\hline & & & & \\
\hline
\end{tabular}


Table 8.20. Committed Dose Coefficients for Acute Intakes of Hanford Fuel-Grade Plutonium Mixtures (rem/nCi of total alpha)

\begin{tabular}{|c|c|c|c|c|}
\hline Organ or Tissue & $\begin{array}{c}\text { Instantaneous } \\
\text { Uptake }\end{array}$ & $\begin{array}{l}\text { Type M Inhalation } \\
(5 \mu \mathrm{m})\end{array}$ & $\begin{array}{l}\text { Type S Inhalation } \\
(5 \mu \mathrm{m})\end{array}$ & $\begin{array}{l}\text { Super S Inhalation } \\
\qquad(5 \mu \mathrm{m})\end{array}$ \\
\hline \multicolumn{5}{|c|}{ 20-Year-Aged Fuel-Grade Mixture } \\
\hline Effective & $2.09 \mathrm{E}+00$ & 1.27E-01 & 3.43E-02 & 3.44E-02 \\
\hline Bone Surface & $6.99 \mathrm{E}+01$ & $4.40 \mathrm{E}+00$ & 4.01E-01 & $1.80 \mathrm{E}-01$ \\
\hline Liver & $8.26 \mathrm{E}+00$ & 6.81E-01 & 6.34E-02 & $1.66 \mathrm{E}-02$ \\
\hline Red Marrow & $3.27 \mathrm{E}+00$ & $1.84 \mathrm{E}-01$ & $1.75 \mathrm{E}-02$ & 6.89E-03 \\
\hline Lungs & 1.23E-01 & 8.33E-02 & 1.89E-01 & $2.10 \mathrm{E}-01$ \\
\hline $\mathrm{ET}$ & 1.23E-01 & 5.74E-02 & 3.07E-01 & $3.25 \mathrm{E}-01$ \\
\hline Gonads & $9.36 \mathrm{E}-01$ & $6.88 \mathrm{E}-02$ & $6.31 \mathrm{E}-03$ & 3.31E-03 \\
\hline Kidneys & 2.80E-01 & 1.92E-02 & $1.86 \mathrm{E}-03$ & $9.42 \mathrm{E}-04$ \\
\hline Lower Large Intestine & $1.23 \mathrm{E}-01$ & 7.75E-03 & 7.76E-04 & 3.95E-04 \\
\hline Colon & $1.23 \mathrm{E}-01$ & 7.72E-03 & 7.38E-04 & 3.57E-04 \\
\hline Upper Large Intestine & 1.23E-01 & 7.69E-03 & 7.09E-04 & 3.27E-04 \\
\hline Small Intestine & 1.23E-01 & 7.67E-03 & $6.81 \mathrm{E}-04$ & 2.98E-04 \\
\hline Stomach & 1.23E-01 & 7.67E-03 & 6.77E-04 & 2.95E-04 \\
\hline Others & $1.23 \mathrm{E}-01$ & 7.66E-03 & 6.75E-04 & 2.93E-04 \\
\hline \multicolumn{5}{|c|}{ 50-Year-Aged Fuel-Grade Mixture } \\
\hline Effective & $1.89 \mathrm{E}+00$ & 1.13E-01 & 3.22E-02 & 3.30E-02 \\
\hline Bone Surface & $6.30 \mathrm{E}+01$ & $4.00 \mathrm{E}+00$ & 3.61E-01 & $2.06 \mathrm{E}-01$ \\
\hline Liver & $7.68 \mathrm{E}+00$ & $5.40 \mathrm{E}-01$ & 4.98E-02 & $1.68 \mathrm{E}-02$ \\
\hline Red Marrow & $3.00 \mathrm{E}+00$ & 1.63E-01 & 1.53E-02 & 7.67E-03 \\
\hline Lungs & $1.11 \mathrm{E}-01$ & 8.31E-02 & 1.85E-01 & 2.01E-01 \\
\hline ET & $1.11 \mathrm{E}-01$ & $5.65 \mathrm{E}-02$ & 3.01E-01 & 3.15E-01 \\
\hline Gonads & 8.44E-01 & 6.58E-02 & 5.99E-03 & 3.88E-03 \\
\hline Kidneys & 2.59E-01 & $1.84 \mathrm{E}-02$ & $1.76 \mathrm{E}-03$ & 1.09E-03 \\
\hline Lower Large Intestine & $1.11 \mathrm{E}-01$ & 7.00E-03 & 7.00E-04 & 4.32E-04 \\
\hline Colon & $1.11 \mathrm{E}-01$ & $6.96 \mathrm{E}-03$ & 6.63E-04 & $3.94 \mathrm{E}-04$ \\
\hline Upper Large Intestine & $1.11 \mathrm{E}-01$ & $6.94 \mathrm{E}-03$ & $6.34 \mathrm{E}-04$ & 3.66E-04 \\
\hline Small Intestine & $1.11 \mathrm{E}-01$ & $6.91 \mathrm{E}-03$ & 6.06E-04 & 3.37E-04 \\
\hline Stomach & $1.11 \mathrm{E}-01$ & $6.91 \mathrm{E}-03$ & 6.03E-04 & 3.34E-04 \\
\hline Others & $1.11 \mathrm{E}-01$ & 6.91E-03 & $6.01 \mathrm{E}-04$ & 3.32E-04 \\
\hline
\end{tabular}

\subsubsection{Cumulative Equivalent Doses}

The cumulative equivalent dose from an intake through various times post intake is sometimes of interest with regard to tenaciously retained radionuclides. The most commonly referenced cumulative dose for occupational exposure is the committed equivalent dose through a 50-year period following an intake. The cumulative effective dose and equivalent dose for critical organs for other time periods (expressed as a percentage of the 50-year committed effective dose or equivalent dose) are shown in Table 8.21 for ${ }^{239} \mathrm{Pu}$ instantaneous uptake, and Type M, S, and Super S inhalation intakes of 5- $\mu \mathrm{m}-$ AMAD particles. Cumulative doses are of principal interest with regard to potential biological effects 
because they represent the dose received through a particular time interval of interest, e.g., from intake to end of life or to manifestation of cancer or other biological endpoint. Committed doses are for 50 years from intake regardless of the age of the person at time of intake and regardless if the total committed dose would be expected to be actually received.

Table 8.21. Cumulative Effective Dose and Equivalent Dose for ${ }^{239} \mathrm{Pu}$ Intakes (as a percentage of $50-\mathrm{y}$ cumulative dose)

\begin{tabular}{|c|c|c|c|c|c|}
\hline Organ & $\begin{array}{l}\text { Years After } \\
\text { Intake }\end{array}$ & $\begin{array}{l}\text { Instantaneous } \\
\text { Uptake }\end{array}$ & Tyре M & Type S & Super S \\
\hline \multirow[t]{6}{*}{ Effective } & 1 & 3.5 & 9.5 & 38.6 & 42.8 \\
\hline & 2 & 6.9 & 12.7 & 44.7 & 53.4 \\
\hline & 5 & 15.9 & 21.2 & 55.8 & 70.6 \\
\hline & 10 & 28.8 & 33.3 & 65.4 & 81.1 \\
\hline & 20 & 50.7 & 53.4 & 77.2 & 89.0 \\
\hline & 50 & 100 & 100 & 100 & 100 \\
\hline \multirow[t]{7}{*}{ Lung } & 0.5 & 2.2 & 86.5 & 51.0 & 43.7 \\
\hline & 1 & 4.1 & 89.9 & 57.1 & 49.1 \\
\hline & 2 & 7.4 & 91.8 & 65.5 & 56.6 \\
\hline & 5 & 15.0 & 92.8 & 79.3 & 69.8 \\
\hline & 10 & 24.8 & 93.3 & 88.3 & 79.4 \\
\hline & 20 & 42.8 & 95.2 & 94.9 & 88.5 \\
\hline & 50 & 100 & 100 & 100 & 100 \\
\hline \multirow[t]{7}{*}{ Bone surface } & 0.5 & 1.6 & 1.1 & 0.2 & 0.2 \\
\hline & 1 & 3.1 & 2.5 & 0.6 & 0.6 \\
\hline & 2 & 6.1 & 5.4 & 1.7 & 1.5 \\
\hline & 5 & 14.0 & 13.5 & 6.6 & 5.8 \\
\hline & 10 & 25.9 & 25.3 & 16.5 & 14.6 \\
\hline & 20 & 47.2 & 46.7 & 37.9 & 34.3 \\
\hline & 50 & 100 & 100 & 100 & 100 \\
\hline
\end{tabular}

\subsubsection{Comparison with Published Dose Coefficients}

A comparison of effective dose coefficients between IMBA-derived coefficients and those published in ICRP 68 (ICRP 1994a) is provided in Table 8.22. IMBA provides dose coefficients with three figures whereas the ICRP 68 values are listed with only two figures. Taking the rounding of numbers into account, the differences are minor. 
Table 8.22. Comparison of Effective Dose Coefficients, $\mathrm{Sv} / \mathrm{Bq}^{(\mathrm{a})}$

\begin{tabular}{lcc}
\hline \multicolumn{1}{c}{$\begin{array}{c}\text { Radionuclide and } \\
\text { Intake Mode }\end{array}$} & $\begin{array}{c}\text { IMBA Effective Dose } \\
\text { Coefficient }\end{array}$ & $\begin{array}{c}\text { ICRP 68 Effective } \\
\text { Dose Coefficient }\end{array}$ \\
\hline${ }^{238} \mathrm{Pu}$, Type $\mathrm{M}$ & $3.01 \mathrm{E}-05$ & $3.0 \mathrm{E}-05$ \\
${ }^{238} \mathrm{Pu}$, Type $\mathrm{S}$ & $1.06 \mathrm{E}-05$ & $1.1 \mathrm{E}-05$ \\
${ }^{238} \mathrm{Pu}$, ingestion & & \\
$\mathrm{f}_{1}=4 \mathrm{E}-04$ & $2.28 \mathrm{E}-07$ & $2.3 \mathrm{E}-07$ \\
${ }^{238} \mathrm{Pu}$, ingestion & & \\
$\mathrm{f}_{1}=1 \mathrm{E}-05$ & $8.89 \mathrm{E}-09$ & $8.8 \mathrm{E}-09$ \\
${ }^{239} \mathrm{Pu}$, Type $\mathrm{M}$ & $3.26 \mathrm{E}-05$ & $3.2 \mathrm{E}-05$ \\
${ }^{239} \mathrm{Pu}$, Type $\mathrm{S}$ & $8.37 \mathrm{E}-06$ & $8.3 \mathrm{E}+06$ \\
${ }^{239} \mathrm{Pu}$, ingestion & & \\
$\mathrm{f}_{1}=4 \mathrm{E}-04$ & $2.51 \mathrm{E}-07$ & $2.5 \mathrm{E}-07$ \\
${ }^{239} \mathrm{Pu}$, ingestion & & \\
$\mathrm{f}_{1}=1 \mathrm{E}-05$ & $9.06 \mathrm{E}-09$ & $9.0 \mathrm{E}-09$ \\
${ }^{241} \mathrm{Pu}$, Type $\mathrm{M}$ & $5.83 \mathrm{E}-07$ & $5.8 \mathrm{E}-07$ \\
${ }^{241} \mathrm{Pu}$, Type $\mathrm{S}$ & $8.45 \mathrm{E}-08$ & $8.4 \mathrm{E}-08$ \\
${ }^{241} \mathrm{Pu}$, ingestion & & \\
$\mathrm{f}_{1}=4 \mathrm{E}-04$ & $4.73 \mathrm{E}-09$ & $4.7 \mathrm{E}-09$ \\
${ }^{241} \mathrm{Pu}$, ingestion & & \\
$\mathrm{f}_{1}=1 \mathrm{E}-05$ & $1.15 \mathrm{E}-10$ & \\
\hline (a) For 5- $\mu \mathrm{Em}-\mathrm{AMAD}$ particles. & & \\
\hline
\end{tabular}

\subsubsection{Derived Air Concentrations and Annual Limits on Intake}

10 CFR 835 (DOE 2007) provides derived air concentrations (DACs) assuming 5- $\mu$ m-AMAD particles and the light worker breathing rate $\left(2,400 \mathrm{~m}^{3} / \mathrm{y}\right)$. The DACs for plutonium isotopes of concern at Hanford are deterministic DACs, meaning that the 50-rem equivalent dose to the critical organ was more limiting than the 5-rem effective dose. The annual limits on intake (ALIs) can be derived from the DACs as follows:

$$
\mathrm{ALI}(\mathrm{nCi})=(\mathrm{DAC} \mu \mathrm{Ci} / \mathrm{ml})\left(2400 \mathrm{~m}^{3}\right)\left(1 \mathrm{E} 6 \mathrm{ml} / \mathrm{m}^{3}\right)(1 \mathrm{E} 3 \mathrm{nCi} / \mu \mathrm{Ci}),
$$

which gives a deterministic ALI, sometimes referred to as a DALI. Sometimes it is informative to know the stochastic ALI, or SALI, which is based on a 5-rem effective dose. DALIs can also be calculated using the highest organ dose coefficient from Tables 8.15 through 8.17 and the 50-rem organ limit as follows:

$$
\mathrm{DALI}=50 \mathrm{rem} / \text { organ dose coefficient in rem/nCi. }
$$

Likewise the SALI can be calculated using the effective dose coefficient from Tables 8.15 through 8.17 and the 5-rem effective dose limit as follows:

$$
\text { SALI }=5 \text { rem/effective dose coefficient in rem/nCi. }
$$

Table 8.23 provides the 10 CFR 835 DACs and DALIs and SALIs for 5- $\mu$ m-AMAD particles. 
Table 8.23. DACs, DALIs, and SALIs

\begin{tabular}{lccc}
\hline Radionuclide and & DACs from & & \\
Absorption Type & 10 CFR 835 $(\mu \mathrm{Ci} / \mathrm{ml})$ & DALI $(\mathrm{nCi})^{(\mathrm{a})}$ & SALI $(\mathrm{nCi})^{(\mathrm{a})}$ \\
\hline${ }^{238} \mathrm{Pu}$, Type M & $6 \mathrm{E}-12$ & $14.9^{(\mathrm{b})}$ & 45.0 \\
${ }^{238} \mathrm{Pu}$, Type S & $5 \mathrm{E}-11$ & $167^{(\mathrm{c})}$ & 128 \\
${ }^{239} \mathrm{Pu}$, Type M & $5 \mathrm{E}-12$ & $13.4^{(\mathrm{b})}$ & 41.7 \\
${ }^{239} \mathrm{Pu}$, Type S & $6 \mathrm{E}-11$ & $149^{(\mathrm{b})}$ & 161 \\
${ }^{241} \mathrm{Pu}$, Type M & $2 \mathrm{E}-10$ & $672^{(\mathrm{b})}$ & 2,310 \\
${ }^{241} \mathrm{Pu}$, Type S & $2 \mathrm{E}-09$ & $6,760^{(\mathrm{b})}$ & 16,000 \\
\hline
\end{tabular}

(a) Using IMBA dose coefficients from Tables 8.15 through 8.17 .

(b) Bone surface is the limiting organ.

(c) Extrathoracic tissue is the limiting organ.

\subsubsection{Derived Reference Levels}

Unlike other radionuclides, such as ${ }^{137} \mathrm{Cs}$ or ${ }^{90} \mathrm{Sr}$, derived bioassay reference levels are of little value for routine plutonium bioassay (urinalysis or chest counting). The 20-year weapons-grade intake that would correspond to a 10-mrem screening level is only $0.081 \mathrm{nCi}$ total alpha for a Type M, 5- $\mu \mathrm{m}$-AMAD inhalation, which would produce only $0.0005 \mathrm{dpm}{ }^{239} \mathrm{Pu}$ in an annual 24-hour urine sample. The 100 -mrem investigation level intake of the same material might be detected some of the time $(<50 \%)$ in an annual urine sample with a $0.005 \mathrm{dpm}$ decision level (especially if the intake occurred more recently than 365 days). Annual chest counting is less sensitive. Even for special follow-up samples, the 10-mrem screening level could not be met for a Type S inhalation using urinalysis. Medical referral criteria have been established based on workplace indicators of potential intake, and are contained in Chapter 7 of the Hanford Internal Dosimetry Program Manual (EH Carbaugh, et al. 2009). The criteria were established based on historical Hanford experience as a good practice and not based on a rigid set of technical conditions or models.

The Hanford practice is to investigate all routine (periodic) urine or in vivo measurements that show indications of potential plutonium intake and to calculate doses for any confirmed intake. Thus, the derived screening and investigation level concepts of calculated bioassay results against which actual measurements are compared are not applicable.

\subsection{Bioassay Monitoring}

This section discusses the general techniques and applicability of bioassay monitoring and describes the capabilities of excreta sample bioassay and in vivo measurements. General recommendations are also provided for routine bioassay monitoring for plutonium.

\subsubsection{General Techniques and Applicability}

Bioassay monitoring for plutonium can be provided by both radiochemistry analysis of excreta and direct in vivo measurements. The application of these techniques and the interpretation of the resulting data are highly dependent upon the type of plutonium to which a worker may be exposed. 
Bioassay guidance has been developed for instantaneous uptake, Type M, S, and Super S compounds. The instantaneous uptake form is assumed to behave as a direct injection of plutonium into the transfer compartment. The Type M and S forms are described in Appendix C. The Super S form is discussed in Section 8.2.1 and key parameters are listed in Table 8.7.

\subsubsection{Urine Sampling and Analysis}

Urine sample analysis is the standard technique for confirming and evaluating the magnitude of systemic uptakes. Uptake is required for material to be excreted by the urine pathway. Urine sample analysis can also be used for estimating inhalation intakes; however, for plutonium it is best to use in combination with fecal samples and with in vivo measurements if ${ }^{241} \mathrm{Am}$ is also present. To reach the urine, plutonium must first reach the transfer compartment (blood) in a soluble (dissolved) form, from which it can then be removed by the kidneys through normal metabolic processes. Insoluble material in the transfer compartment is assumed to not be excreted by the urine pathway until it has been dissolved.

In reviewing urine sample results, anomalous results could be indicative of urine contamination from external sources (hands, sample container, and clothing). Caution needs to be exercised when samples are obtained from workers who have recently had external contamination. The extreme sensitivity of urine sample analysis lends itself to the possibility of the sample being contaminated by trace particles well below the level that can be observed by standard personal survey and workplace control practices. This was one of the reasons why at-home sampling was originally selected for the Hanford Site in lieu of obtaining a sample at work.

The typical urine sampling practice is to collect a urine sample over a specified time interval and perform a chemical separation for plutonium. This technique is followed by electroplating and quantitative alpha spectrometry. The final results are reported as ${ }^{238} \mathrm{Pu}$ and ${ }^{239} \mathrm{Pu}$. The reported ${ }^{239} \mathrm{Pu}$ result is actually the sum of the measured ${ }^{239+240} \mathrm{Pu}$, because alpha spectrometry systems do not have the capability to differentiate between the alpha energies for ${ }^{239} \mathrm{Pu}$ and ${ }^{240} \mathrm{Pu}$ decay emissions. This does not pose a significant problem because the dosimetry for the two isotopes is essentially the same. When considering the total plutonium-alpha activity of a sample, it is important to combine the ${ }^{238} \mathrm{Pu}$ with the ${ }^{239} \mathrm{Pu}$ results.

Prior to October 1983, the Hanford radiochemistry bioassay laboratory used an autoradiography procedure instead of the electroplating/alpha spectrometry procedure. This autoradiography procedure actually measured the total plutonium-alpha activity, which was reported as ${ }^{239} \mathrm{Pu}$. This point should be remembered when comparing sample results analyzed by autoradiography with sample results obtained from alpha spectrometry, and may help account for potential shifts in long-term data trends.

The reported detection levels for historical urine sample analysis procedures at various times are listed in Table 8.24. The method used to define the detection level has changed over time, so the values in Table 8.24 are not strictly comparable with each other.

Special rapid analytical procedures are available for special circumstances. These procedures can be executed and results obtained in substantially shorter times than the routine procedure, but they are less sensitive. Their use is primarily for diagnostic bioassay of suspected internal contamination related to unplanned exposures (incidents). The decision to use such procedures involves considering the probability and potential magnitude of the exposure. The contractual detection limit for plutonium in urine can be found in the radiochemistry bioassay laboratory statement of work that is available from the HIDP and in the Hanford Internal Dosimetry Program Manual (PNL-MA-552; EH Carbaugh, et al. 2009). 
Table 8.24. Detection Limits for Routine Hanford Analyses of Plutonium in Urine

\begin{tabular}{lc}
\hline \multicolumn{1}{c}{ Time Period } & $\begin{array}{c}\text { Detection Limit } \\
\text { (dpm/routine sample) }\end{array}$ \\
\hline Prior to June 1949 & $0.66^{(\mathrm{a})}$ \\
June 1949 to Dec. 1952 & 0.33 \\
Dec. 1952 to $01 / 28 / 53$ & 0.18 \\
$01 / 28 / 53$ to $03 / 27 / 53$ & 0.15 \\
$03 / 27 / 53$ to $11 / 07 / 53$ & 0.05 \\
$11 / 07 / 53$ to $12 / 04 / 53$ & 0.07 \\
$12 / 53$ to $04 / 55$ & 0.057 \\
$05 / 55$ to $08 / 55$ & $0.027^{(\mathrm{b})}$ \\
$09 / 55$ to $10 / 55$ & $0.04^{(\mathrm{b})}$ \\
$11 / 55$ to $9 / 30 / 83$ & $0.05^{(\mathrm{c})}$ \\
$10 / 01 / 83$ to $12 / 31 / 83$ & 0.035 \\
$1 / 02 / 84$ to $05 / 90$ & 0.02 \\
$06 / 90$ to $11 / 91$ & 0.03 \\
$11 / 91$ to present & 0.02 \\
\hline
\end{tabular}
(a) Closer to a decision level. The minimum detectable activity by present standards was closer to 0.96 (Healy 1948).
(b) Probably closer to a decision level.
(c) During part of this period, results that were less than the detection limit were reported as 0.025 .

\subsubsection{Fecal Sampling and Analysis}

Fecal samples are useful for confirming and evaluating suspected inhalation and ingestion exposures, especially at times shortly after the suspected intake. The sample results can be used with the models to estimate the magnitudes of intakes and initial lung depositions as a basis for lung dose assessment. They can also be used as checks on urine- or in vivo-based estimates of intake. In addition, alpha spectrometry of fecal samples can provide radionuclide identification data and isotope ratios. In this regard they are preferred to urine samples. Fecal samples are of primary value immediately following a suspected intake, when material is rapidly clearing the respiratory and GI tracts. Long-term sampling following intake can be useful for differentiating ingestion from inhalation and Type $\mathrm{M}$ from Type $\mathrm{S}$ inhalation, provided there is no chance of new ingestion intakes. It may also be of value at long times post intake as an aid to estimating residual lung burdens and isotope ratios; however, substantial uncertainties exist for such applications.

Most fecal excretion following an intake occurs shortly after the intake. Approximately $41 \%$ of an intake of Type S plutonium (5- $\mu$ m-AMAD particle size) would be excreted in the first 5 days following intake (39\% for Type M) (see Tables C67 and D34 in Potter 2002).

Some fecal excretion comes from systemic uptakes via the biliary pathway. In fact the ratio of fecalto-urinary daily excretion from systemically deposited plutonium is near or greater than 1 for 2 to 14 days after intake, as shown in Table 8.14. Generally, however, fecal sampling would not be used to document 
direct intakes to the blood, e.g., via a wound, because urinalysis and wound counting are more sensitive and fecal samples would be subject to interference from any possible ingestion or inhalation that might also have occurred.

The complications of interpreting long-term fecal excretions do not rule out their potential value, particularly if certain conditions can be met regarding their collection; notably, lack of potential additional exposure immediately prior to collection of the sample and collection of more than one sample.

Multiple fecal samples are recommended if the data are critical for an evaluation. Normal daily fecal excretion rates vary greatly from the 150 -g/d male or 135-g/d female averages established in ICRP 89 (2002). This variability can be offset to some extent by collecting consecutive samples and averaging the results. Also see Appendix C, Section C.4, for more details concerning fecal sampling.

The laboratory plutonium analysis procedure for fecal samples involves wet ashing and dry ashing to destroy organic elements, additional dissolution with hydrofluoric acid, redissolution to a standard volume using nitric acid, extraction of an aliquot of the sample, chemical separation of plutonium, followed by electroplating or co-precipitation, then counting by alpha spectrometry. $\mathrm{A}^{242} \mathrm{Pu}$ tracer is typically used for determining chemical yields.

The contractual detection limit for plutonium in feces can be found in the radiochemistry bioassay laboratory statement of work available from the HIDP and in the Hanford Internal Dosimetry Program Manual (EH Carbaugh, et al. 2009).

\subsubsection{In Vivo Measurements}

In vivo measurement techniques suitable for plutonium applications and routinely performed at the Hanford In Vivo Radioassay and Research Facility (IVRRF) include chest counting, skeleton measurement by head counting, liver counting, and wound counting. Less common measurements include upper extremity lymph node counting (e.g., axillary lymph nodes), and a scanning lung count to identify the likelihood of a nonuniform distribution of activity in the lung (e.g., a hot particle). Most of these procedures involve measurement of the $60-\mathrm{keV}$ photons from the ${ }^{241} \mathrm{Am}$ present as an ingrown impurity in a plutonium mixture. Direct measurement of the $17-\mathrm{keV}$ plutonium L x-rays is possible, but the sensitivity of the measurement is not adequate to detect most internal organ depositions. Direct measurement of plutonium in wounds can also be performed. Minimum detectable activities for these measurements are described in the In Vivo Monitoring Program Manual (PNL-MA-574; TP Lynch. 2007) and the Hanford Internal Dosimetry Program Manual (EH Carbaugh, et al. 2009).

Because of the relative insensitivity of direct in vivo plutonium measurement techniques at low levels (other than for wounds), the presence of plutonium is often inferred by detection of ${ }^{241} \mathrm{Am}$. Estimation of the amount of plutonium must be made using known or assumed isotope ratios. Such ratios may be obtained from workplace data (smear samples, air samples, etc.), inferred from fecal data (the difference in fecal excretion between Type $\mathrm{M}^{241} \mathrm{Am}$ and Type $\mathrm{S}$ plutonium is less than $10 \%$ over the first 5 days after intake), or from assumptions regarding material composition based on the facility and process involved. 
The types of in vivo measurements available at the Hanford IVRRF are listed here. Further discussion of these measurement techniques can be found in the In Vivo Monitoring Program Manual (PNL-MA-574; TP Lynch. 2007).

- Chest counting is a standard measurement technique used for monitoring plutonium workers. A count is performed by placing planar germanium detectors over the subject's chest. Because of the potential impact of chest wall thickness on measurement sensitivity, measurement corrections are made on all workers based on a height-to-weight ratio. In addition, measurements on workers with known depositions will usually be corrected based on direct measurement of chest wall thickness using ultrasound techniques. Chest measurement results may not represent actual lung burdens unless they have been corrected for interference from activity deposited in other organs (notably the skeleton and, to a lesser extent, the liver). When such a correction has been made the result is more correctly referred to as a lung burden estimate rather than a chest count result. Lacking such corrections, chest measurement results may conservatively be assumed to represent lung burdens, especially at short times after intake.

- Head counts (also called skull counts) will usually be performed when chest counts confirm detectable activity to determine if modification for skeleton activity is needed. The results of the head count are extrapolated to an estimate of the total quantity retained in the skeleton using a human skeleton calibration phantom. Head counts can also be used as an approximate check on urine-based systemic deposition estimates, recognizing that ionic americium in the blood may not behave the same as plutonium.

- Liver counts provide a direct estimate of activity in the liver based on the Livermore calibration phantom (Griffith et al. 1978). These counts are used to correct chest counts for interference from activity deposited in the liver and are primarily used for long-term follow-up and as an approximate check on urine-based systemic deposition estimates. They can also provide a check on the assumptions used in the computer codes for calculating committed doses.

- Wound counts using a single planar germanium detector can directly measure plutonium and americium. Wound counts can be performed either at the IVRRF or elsewhere, using a mobile counter, if there is access to electrical power and the background is low. The ${ }^{239} \mathrm{Pu}$ results (based on the 17-keV L x-rays) can be significantly underestimated if the activity is deeply embedded in tissue.

- Upper extremity lymph node counts are used to identify potential deposition sites for nontransportable or slowly transportable material deposited in extremity wounds. These nodes include the supratracular lymph nodes located near the elbow and the axillary lymph nodes located near the armpit. The nodes are counted by placing planar germanium detectors in the lymph node region. Activity deposited in the axillary lymph nodes has the potential to interfere with chest count results. Precise calibrations for these counts are not available.

- Scanning lung counts are used to determine the distribution of activity deposited in the lung. By a series of counts, the extent to which activity is deposited in the bronchial region (including the lymph nodes) and the left and right pulmonary regions can be reasonably determined. The results of these counts are not likely to affect lung dose estimates, except to the extent that they shed light on the nature of the retention and potential lung dynamics. Results may be expressed as the percentage of total lung activity in a given counting region. 


\subsubsection{Bioassay Monitoring Capability}

The bioassay monitoring capability for plutonium can be discribed as the minimum detectable intake (MDI) or minimum detectable dose (MDD) associated with a bioassay measurement at the minimum detectable activity (MDA) at some time post intake. Analyses of the MDIs and MDDs (committed effective dose, committed bone surface equivalent dose, committed lung equivalent dose, and committed equivalent dose to the extrathoracic (ET) tissues for cases where the organ dose was more limiting than the effective dose) have been performed for three bioassay methods $\left({ }^{239} \mathrm{Pu}\right.$ in urine, ${ }^{239} \mathrm{Pu}$ in feces, and in vivo ${ }^{241} \mathrm{Am}$ lung counting). These analyses included instant uptake and Type $\mathrm{M}, \mathrm{S}$, and Super S inhalations (5- $\mu$ m-AMAD particles) for both weapons-grade and fuel-grade reference plutonium mixtures, aged 20 and 50 years. The analyses assumed that the MDAs for the bioassay measurements were slightly higher than those that have been observed for most Hanford bioassay measurements. Thus, the stated MDIs and MDDs in the following tables are slightly higher than those expected to be achieved by routine worker monitoring.

To determine the capability of bioassay of plutonium by urine analysis, the intakes of ${ }^{239} \mathrm{Pu}$ associated with minimum detectable urine analysis results were calculated for transportable injection and Type M, S, and Super $\mathrm{S}$ inhalations. These intakes are given in Table 8.25. Based on the activity ratios described in Section 8.1, the total-alpha intake was calculated for the mixtures, and the committed effective doses and equivalent doses for bone surface, ET, and lung were calculated using the dose coefficients of Tables 8.19 and 8.20. The results are summarized in Tables 8.26 through 8.35 and graphically presented in Figures 8.11 through 8.20. For all mixtures, the bone surface was the critical organ for transportable injection and Type M and S inhalations. ET was the critical set of tissues for Type Super S inhalation with doses to the lung being just slightly less. The differences in effective and bone surface MDDs between 20-year-aged mixtures and 50-year-aged mixtures were small, $<11 \%$, for all intakes modes for all times out to 30 years after intake. The same was true for ET and lung MDDs for Super S inhalation. Urinalysis is able to detect intakes with resulting MDDs at or below the 5-rem limit for effective dose for transportable injection and Type $\mathrm{M}$ inhalations for up to 30 years after intake. The same is true for Type $\mathrm{S}$ inhalations for nearly 10 years after intake. Urinalysis is able to detect intakes with resulting MDDs at or below the 50-rem limit for any organ for transportable injection and Type $\mathrm{M}$ and S inhalations for 10 years after intake. Urinalysis is not effective for monitoring intakes of Type Super S plutonium except within the first couple of days after an intake.

The minimum detectable committed doses associated with ${ }^{241}$ Am detection by chest counting are listed in Tables 8.36 through 8.45 and plotted in Figures 8.21 through 8.30. Chest counting is able to detect intakes with resulting MDDs at or below the 5-rem limit for effective dose for at least 1 year after intake for Type $\mathrm{M}$ inhalation and at least 5 years for Type $\mathrm{S}$ and Super $\mathrm{S}$ inhalations. Chest counting can detect intakes with resulting MDDs at or below the 50-rem limit for bone surfaces for at least 5 years after 
intake for Type S inhalation. The same is true for ET tissues for Type Super S inhalation for at least 5 years (weapons grade) and 30 years (fuel grade) after intake. Type Super S MDDs for the lung are slightly less than for ET tissues.

The capability for plutonium fecal bioassay is addressed in a similar manner, with the ${ }^{239} \mathrm{Pu}$ intakes compiled in Table 8.46. The corresponding minimum detectable committed effective doses and equivalent doses for bone surface, ET tissues, and lung are listed in Tables 8.47 through 8.56 and in Figures 8.31 through 8.40. Fecal sampling is generally used for special bioassay taken promptly after a suspected intake; however, it is able to detect intakes with resulting MDDs at or below the 5-rem limit for effective dose for at least 1 year after intake. Fecal sampling can detect an intake resulting in a 50-rem equivalent dose to the bone surfaces up to about 90 days after an intake. The same is true for ET tissues for Type Super S inhalation for nearly 10 years (weapons grade) and more than 5 years (fuel grade) after intake. Type Super S MDDs for the lung are slightly less than for the ET tissues.

Table 8.25. Minimum Detectable Intakes (nCi) of ${ }^{239} \mathrm{Pu}$ Based on Detection of $0.02 \mathrm{dpm} / \mathrm{d}$ in Urine

\begin{tabular}{ccccc}
\hline Days Post Intake & $\begin{array}{c}\text { Instantaneous } \\
\text { Uptake }\end{array}$ & $\begin{array}{c}\text { Type M } \\
\text { Inhalation }\end{array}$ & $\begin{array}{c}\text { Type S } \\
\text { Inhalation }\end{array}$ & $\begin{array}{c}\text { Type Super S } \\
\text { Inhalation }\end{array}$ \\
\hline 1 & $1.10 \mathrm{E}-03$ & $3.89 \mathrm{E}-02$ & $3.84 \mathrm{E}+00$ & $1.94 \mathrm{E}+01$ \\
2 & $2.01 \mathrm{E}-03$ & $6.89 \mathrm{E}-02$ & $6.64 \mathrm{E}+00$ & $3.43 \mathrm{E}+01$ \\
5 & $7.48 \mathrm{E}-03$ & $2.30 \mathrm{E}-01$ & $1.98 \mathrm{E}+01$ & $1.13 \mathrm{E}+02$ \\
7 & $1.34 \mathrm{E}-02$ & $3.70 \mathrm{E}-01$ & $2.89 \mathrm{E}+01$ & $1.79 \mathrm{E}+02$ \\
14 & $4.12 \mathrm{E}-02$ & $7.75 \mathrm{E}-01$ & $4.76 \mathrm{E}+01$ & $3.59 \mathrm{E}+02$ \\
30 & $5.80 \mathrm{E}-02$ & $9.47 \mathrm{E}-01$ & $5.23 \mathrm{E}+01$ & $4.17 \mathrm{E}+02$ \\
60 & $7.37 \mathrm{E}-02$ & $1.11 \mathrm{E}+00$ & $5.47 \mathrm{E}+01$ & $4.51 \mathrm{E}+02$ \\
90 & $8.99 \mathrm{E}-02$ & $1.26 \mathrm{E}+00$ & $5.60 \mathrm{E}+01$ & $4.74 \mathrm{E}+02$ \\
180 & $1.31 \mathrm{E}-01$ & $1.68 \mathrm{E}+00$ & $5.63 \mathrm{E}+01$ & $4.98 \mathrm{E}+02$ \\
365 & $1.71 \mathrm{E}-01$ & $2.33 \mathrm{E}+00$ & $5.36 \mathrm{E}+01$ & $4.83 \mathrm{E}+02$ \\
730 & $2.10 \mathrm{E}-01$ & $3.19 \mathrm{E}+00$ & $5.09 \mathrm{E}+01$ & $4.59 \mathrm{E}+02$ \\
1,826 & $3.30 \mathrm{E}-01$ & $5.19 \mathrm{E}+00$ & $5.57 \mathrm{E}+01$ & $4.90 \mathrm{E}+02$ \\
3,652 & $5.05 \mathrm{E}-01$ & $8.09 \mathrm{E}+00$ & $7.24 \mathrm{E}+01$ & $6.05 \mathrm{E}+02$ \\
7,305 & $7.09 \mathrm{E}-01$ & $1.15 \mathrm{E}+01$ & $9.63 \mathrm{E}+01$ & $7.25 \mathrm{E}+02$ \\
10,957 & $8.51 \mathrm{E}-01$ & $1.38 \mathrm{E}+01$ & $1.14 \mathrm{E}+02$ & $7.80 \mathrm{E}+02$ \\
\hline
\end{tabular}


Table 8.26. Minimum Detectable Committed Effective Doses (rem) for 20-Year-Aged Weapons-Grade Plutonium Based on Detection of $0.02 \mathrm{dpm} / \mathrm{d}{ }^{239} \mathrm{Pu}$ in Urine

\begin{tabular}{rcccc}
\hline $\begin{array}{c}\text { Days Post } \\
\text { Intake }\end{array}$ & $\begin{array}{c}\text { Instantaneous } \\
\text { Uptake }\end{array}$ & $\begin{array}{c}\text { Type M } \\
\text { Inhalation }\end{array}$ & $\begin{array}{c}\text { Type S } \\
\text { Inhalation }\end{array}$ & $\begin{array}{c}\text { Type Super S } \\
\text { Inhalation }\end{array}$ \\
\hline 1 & $2.84 \mathrm{E}-03$ & $6.40 \mathrm{E}-03$ & $1.68 \mathrm{E}-01$ & $8.88 \mathrm{E}-01$ \\
2 & $5.19 \mathrm{E}-03$ & $1.13 \mathrm{E}-02$ & $2.91 \mathrm{E}-01$ & $1.57 \mathrm{E}+00$ \\
5 & $1.93 \mathrm{E}-02$ & $3.79 \mathrm{E}-02$ & $8.69 \mathrm{E}-01$ & $5.18 \mathrm{E}+00$ \\
7 & $3.45 \mathrm{E}-02$ & $6.08 \mathrm{E}-02$ & $1.27 \mathrm{E}+00$ & $8.20 \mathrm{E}+00$ \\
14 & $1.06 \mathrm{E}-01$ & $1.27 \mathrm{E}-01$ & $2.09 \mathrm{E}+00$ & $1.64 \mathrm{E}+01$ \\
30 & $1.50 \mathrm{E}-01$ & $1.56 \mathrm{E}-01$ & $2.30 \mathrm{E}+00$ & $1.91 \mathrm{E}+01$ \\
60 & $1.90 \mathrm{E}-01$ & $1.83 \mathrm{E}-01$ & $2.40 \mathrm{E}+00$ & $2.06 \mathrm{E}+01$ \\
90 & $2.32 \mathrm{E}-01$ & $2.08 \mathrm{E}-01$ & $2.45 \mathrm{E}+00$ & $2.17 \mathrm{E}+01$ \\
180 & $3.39 \mathrm{E}-01$ & $2.76 \mathrm{E}-01$ & $2.47 \mathrm{E}+00$ & $2.28 \mathrm{E}+01$ \\
365 & $4.42 \mathrm{E}-01$ & $3.83 \mathrm{E}-01$ & $2.35 \mathrm{E}+00$ & $2.21 \mathrm{E}+01$ \\
730 & $5.42 \mathrm{E}-01$ & $5.25 \mathrm{E}-01$ & $2.23 \mathrm{E}+00$ & $2.10 \mathrm{E}+01$ \\
1,826 & $8.52 \mathrm{E}-01$ & $8.54 \mathrm{E}-01$ & $2.44 \mathrm{E}+00$ & $2.24 \mathrm{E}+01$ \\
3,652 & $1.30 \mathrm{E}+00$ & $1.33 \mathrm{E}+00$ & $3.18 \mathrm{E}+00$ & $2.77 \mathrm{E}+01$ \\
7,305 & $1.83 \mathrm{E}+00$ & $1.88 \mathrm{E}+00$ & $4.22 \mathrm{E}+00$ & $3.32 \mathrm{E}+01$ \\
10,957 & $2.20 \mathrm{E}+00$ & $2.26 \mathrm{E}+00$ & $4.99 \mathrm{E}+00$ & $3.57 \mathrm{E}+01$ \\
\hline
\end{tabular}

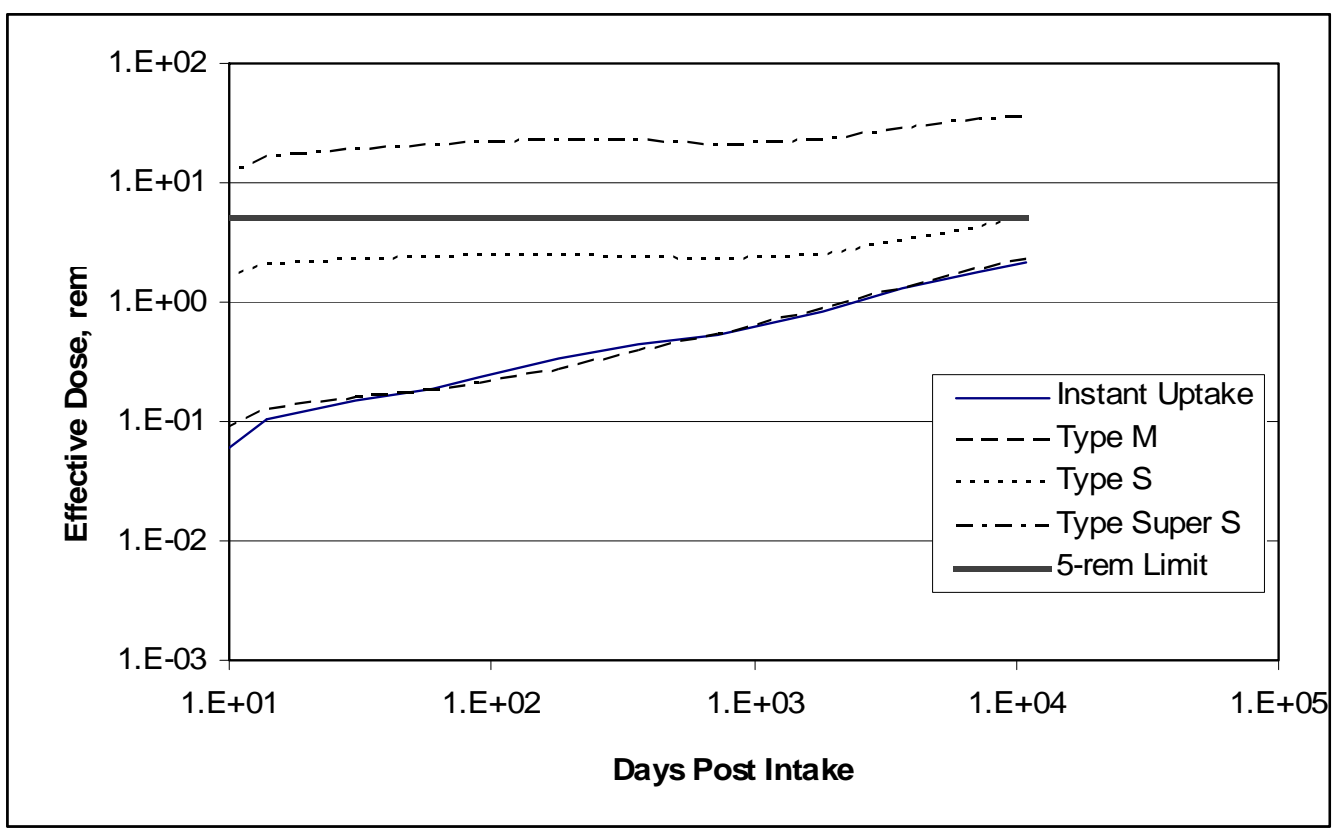

Figure 8.11. Minimum Detectable Committed Effective Doses for 20-Year-Aged Weapons-Grade Plutonium Based on Detection of $0.02 \mathrm{dpm} / \mathrm{d}{ }^{239} \mathrm{Pu}$ in Urine 
Table 8.27. Minimum Detectable Committed Effective Doses (rem) for 50-Year-Aged Weapons-Grade Plutonium Based on Detection of $0.02 \mathrm{dpm} / \mathrm{d}{ }^{239} \mathrm{Pu}$ in Urine

\begin{tabular}{rcccc}
\hline $\begin{array}{c}\text { Days Post } \\
\text { Intake }\end{array}$ & $\begin{array}{c}\text { Instantaneous } \\
\text { Uptake }\end{array}$ & $\begin{array}{c}\text { Type M } \\
\text { Inhalation }\end{array}$ & $\begin{array}{c}\text { Type S } \\
\text { Inhalation }\end{array}$ & $\begin{array}{c}\text { Type Super S } \\
\text { Inhalation }\end{array}$ \\
\hline 1 & $2.88 \mathrm{E}-03$ & $6.41 \mathrm{E}-03$ & $1.73 \mathrm{E}-01$ & $9.18 \mathrm{E}-01$ \\
2 & $5.26 \mathrm{E}-03$ & $1.14 \mathrm{E}-02$ & $2.99 \mathrm{E}-01$ & $1.62 \mathrm{E}+00$ \\
5 & $1.95 \mathrm{E}-02$ & $3.80 \mathrm{E}-02$ & $8.92 \mathrm{E}-01$ & $5.36 \mathrm{E}+00$ \\
7 & $3.49 \mathrm{E}-02$ & $6.09 \mathrm{E}-02$ & $1.30 \mathrm{E}+00$ & $8.49 \mathrm{E}+00$ \\
14 & $1.08 \mathrm{E}-01$ & $1.28 \mathrm{E}-01$ & $2.14 \mathrm{E}+00$ & $1.70 \mathrm{E}+01$ \\
30 & $1.52 \mathrm{E}-01$ & $1.56 \mathrm{E}-01$ & $2.36 \mathrm{E}+00$ & $1.97 \mathrm{E}+01$ \\
60 & $1.93 \mathrm{E}-01$ & $1.83 \mathrm{E}-01$ & $2.46 \mathrm{E}+00$ & $2.13 \mathrm{E}+01$ \\
90 & $2.35 \mathrm{E}-01$ & $2.08 \mathrm{E}-01$ & $2.52 \mathrm{E}+00$ & $2.24 \mathrm{E}+01$ \\
180 & $3.43 \mathrm{E}-01$ & $2.76 \mathrm{E}-01$ & $2.54 \mathrm{E}+00$ & $2.35 \mathrm{E}+01$ \\
365 & $4.47 \mathrm{E}-01$ & $3.84 \mathrm{E}-01$ & $2.41 \mathrm{E}+00$ & $2.28 \mathrm{E}+01$ \\
730 & $5.49 \mathrm{E}-01$ & $5.26 \mathrm{E}-01$ & $2.29 \mathrm{E}+00$ & $2.17 \mathrm{E}+01$ \\
1,826 & $8.63 \mathrm{E}-01$ & $8.56 \mathrm{E}-01$ & $2.51 \mathrm{E}+00$ & $2.32 \mathrm{E}+01$ \\
3,652 & $1.32 \mathrm{E}+00$ & $1.33 \mathrm{E}+00$ & $3.26 \mathrm{E}+00$ & $2.86 \mathrm{E}+01$ \\
7,305 & $1.85 \mathrm{E}+00$ & $1.89 \mathrm{E}+00$ & $4.34 \mathrm{E}+00$ & $3.43 \mathrm{E}+01$ \\
10,957 & $2.22 \mathrm{E}+00$ & $2.27 \mathrm{E}+00$ & $5.12 \mathrm{E}+00$ & $3.69 \mathrm{E}+01$ \\
\hline
\end{tabular}

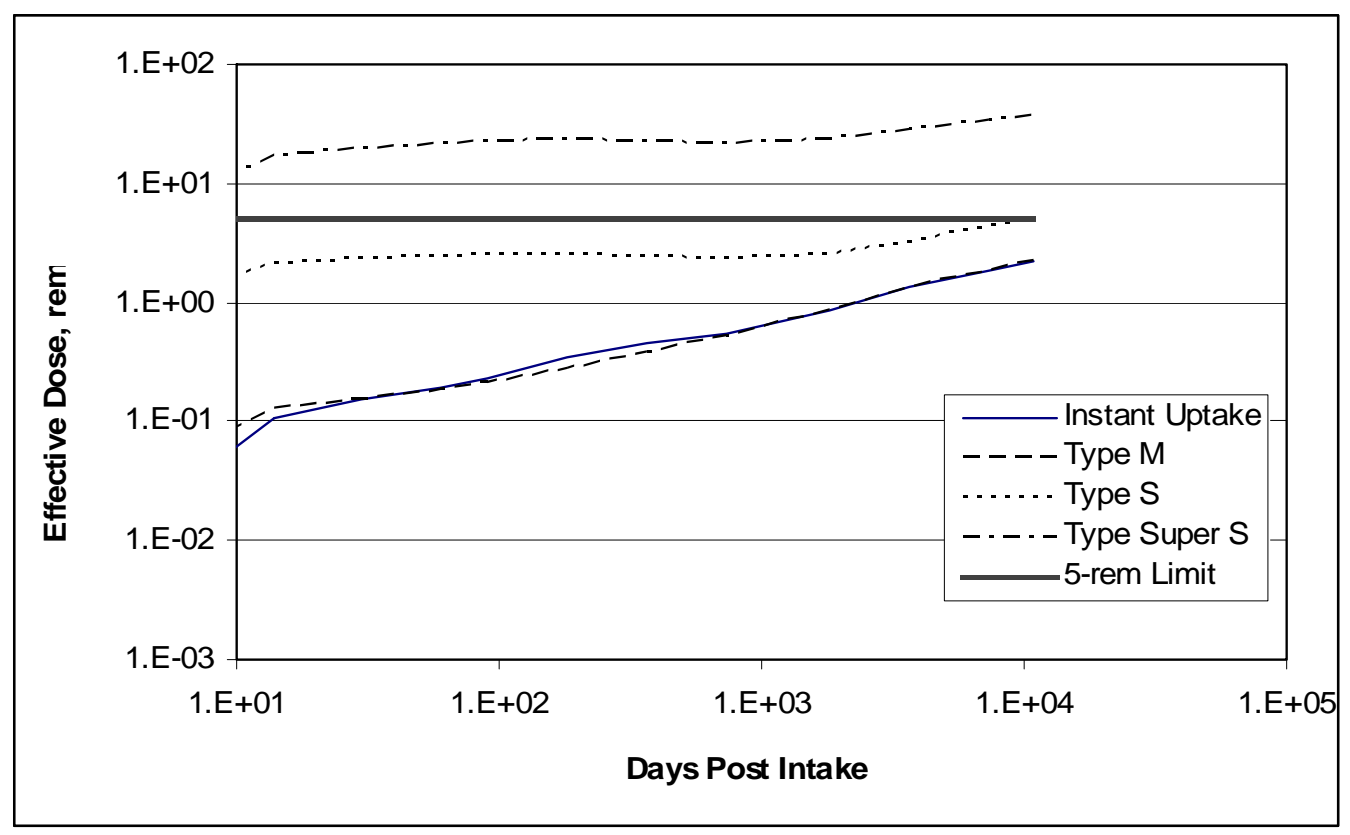

Figure 8.12. Minimum Detectable Committed Effective Doses for 50-Year-Aged Weapons-Grade Plutonium Based on Detection of $0.02 \mathrm{dpm} / \mathrm{d}^{239} \mathrm{Pu}$ in Urine 
Table 8.28. Minimum Detectable Committed Effective Doses (rem) for 20-Year-Aged Fuel-Grade Plutonium Based on Detection of $0.02 \mathrm{dpm} / \mathrm{d}{ }^{239} \mathrm{Pu}$ in Urine

\begin{tabular}{rcccc}
\hline $\begin{array}{c}\text { Days Post } \\
\text { Intake }\end{array}$ & $\begin{array}{c}\text { Instantaneous } \\
\text { Uptake }\end{array}$ & $\begin{array}{c}\text { Type M } \\
\text { Inhalation }\end{array}$ & $\begin{array}{c}\text { Type S } \\
\text { Inhalation }\end{array}$ & $\begin{array}{c}\text { Type Super S } \\
\text { Inhalation }\end{array}$ \\
\hline 1 & $4.53 \mathrm{E}-03$ & $9.73 \mathrm{E}-03$ & $2.60 \mathrm{E}-01$ & $1.32 \mathrm{E}+00$ \\
2 & $8.28 \mathrm{E}-03$ & $1.72 \mathrm{E}-02$ & $4.49 \mathrm{E}-01$ & $2.33 \mathrm{E}+00$ \\
5 & $3.08 \mathrm{E}-02$ & $5.77 \mathrm{E}-02$ & $1.34 \mathrm{E}+00$ & $7.68 \mathrm{E}+00$ \\
7 & $5.50 \mathrm{E}-02$ & $9.25 \mathrm{E}-02$ & $1.95 \mathrm{E}+00$ & $1.22 \mathrm{E}+01$ \\
14 & $1.69 \mathrm{E}-01$ & $1.94 \mathrm{E}-01$ & $3.21 \mathrm{E}+00$ & $2.43 \mathrm{E}+01$ \\
30 & $2.39 \mathrm{E}-01$ & $2.37 \mathrm{E}-01$ & $3.54 \mathrm{E}+00$ & $2.82 \mathrm{E}+01$ \\
60 & $3.04 \mathrm{E}-01$ & $2.78 \mathrm{E}-01$ & $3.70 \mathrm{E}+00$ & $3.06 \mathrm{E}+01$ \\
90 & $3.70 \mathrm{E}-01$ & $3.16 \mathrm{E}-01$ & $3.78 \mathrm{E}+00$ & $3.21 \mathrm{E}+01$ \\
180 & $5.40 \mathrm{E}-01$ & $4.19 \mathrm{E}-01$ & $3.81 \mathrm{E}+00$ & $3.37 \mathrm{E}+01$ \\
365 & $7.04 \mathrm{E}-01$ & $5.83 \mathrm{E}-01$ & $3.62 \mathrm{E}+00$ & $3.27 \mathrm{E}+01$ \\
730 & $8.65 \mathrm{E}-01$ & $7.98 \mathrm{E}-01$ & $3.44 \mathrm{E}+00$ & $3.11 \mathrm{E}+01$ \\
1,826 & $1.36 \mathrm{E}+00$ & $1.30 \mathrm{E}+00$ & $3.76 \mathrm{E}+00$ & $3.32 \mathrm{E}+01$ \\
3,652 & $2.08 \mathrm{E}+00$ & $2.02 \mathrm{E}+00$ & $4.89 \mathrm{E}+00$ & $4.10 \mathrm{E}+01$ \\
7,305 & $2.92 \mathrm{E}+00$ & $2.87 \mathrm{E}+00$ & $6.51 \mathrm{E}+00$ & $4.91 \mathrm{E}+01$ \\
10,957 & $3.50 \mathrm{E}+00$ & $3.44 \mathrm{E}+00$ & $7.68 \mathrm{E}+00$ & $5.29 \mathrm{E}+01$ \\
\hline
\end{tabular}

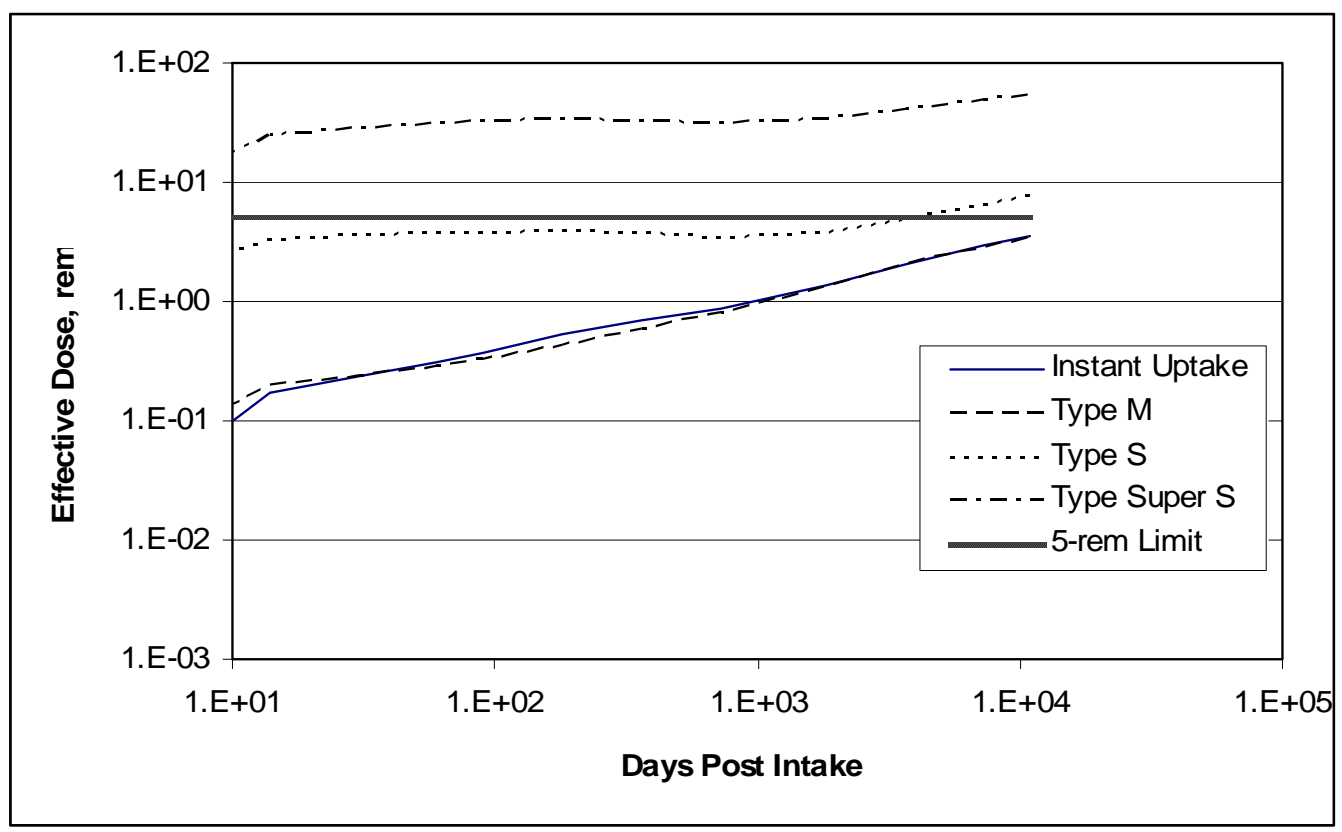

Figure 8.13. Minimum Detectable Committed Effective Doses for 20-Year-Aged Fuel-Grade Plutonium Based on Detection of $0.02 \mathrm{dpm} / \mathrm{d}{ }^{239} \mathrm{Pu}$ in Urine 
Table 8.29. Minimum Detectable Committed Effective Doses (rem) for 50-Year- Aged Fuel-Grade Plutonium Based on Detection of $0.02 \mathrm{dpm} / \mathrm{d}{ }^{239} \mathrm{Pu}$ in Urine

\begin{tabular}{rcccc}
\hline $\begin{array}{c}\text { Days Post } \\
\text { Intake }\end{array}$ & $\begin{array}{c}\text { Instantaneous } \\
\text { Uptake }\end{array}$ & $\begin{array}{c}\text { Type M } \\
\text { Inhalation }\end{array}$ & $\begin{array}{c}\text { Type S } \\
\text { Inhalation }\end{array}$ & $\begin{array}{c}\text { Type Super S } \\
\text { Inhalation }\end{array}$ \\
\hline 1 & $4.71 \mathrm{E}-03$ & $9.94 \mathrm{E}-03$ & $2.80 \mathrm{E}-01$ & $1.45 \mathrm{E}+00$ \\
2 & $8.59 \mathrm{E}-03$ & $1.76 \mathrm{E}-02$ & $4.84 \mathrm{E}-01$ & $2.56 \mathrm{E}+00$ \\
5 & $3.20 \mathrm{E}-02$ & $5.89 \mathrm{E}-02$ & $1.44 \mathrm{E}+00$ & $8.46 \mathrm{E}+00$ \\
7 & $5.71 \mathrm{E}-02$ & $9.45 \mathrm{E}-02$ & $2.10 \mathrm{E}+00$ & $1.34 \mathrm{E}+01$ \\
14 & $1.76 \mathrm{E}-01$ & $1.98 \mathrm{E}-01$ & $3.46 \mathrm{E}+00$ & $2.68 \mathrm{E}+01$ \\
30 & $2.48 \mathrm{E}-01$ & $2.42 \mathrm{E}-01$ & $3.81 \mathrm{E}+00$ & $3.11 \mathrm{E}+01$ \\
60 & $3.15 \mathrm{E}-01$ & $2.84 \mathrm{E}-01$ & $3.98 \mathrm{E}+00$ & $3.37 \mathrm{E}+01$ \\
90 & $3.84 \mathrm{E}-01$ & $3.23 \mathrm{E}-01$ & $4.08 \mathrm{E}+00$ & $3.54 \mathrm{E}+01$ \\
180 & $5.61 \mathrm{E}-01$ & $4.28 \mathrm{E}-01$ & $4.10 \mathrm{E}+00$ & $3.71 \mathrm{E}+01$ \\
365 & $7.31 \mathrm{E}-01$ & $5.96 \mathrm{E}-01$ & $3.90 \mathrm{E}+00$ & $3.60 \mathrm{E}+01$ \\
730 & $8.98 \mathrm{E}-01$ & $8.15 \mathrm{E}-01$ & $3.70 \mathrm{E}+00$ & $3.42 \mathrm{E}+01$ \\
1,826 & $1.41 \mathrm{E}+00$ & $1.33 \mathrm{E}+00$ & $4.05 \mathrm{E}+00$ & $3.66 \mathrm{E}+01$ \\
3,652 & $2.16 \mathrm{E}+00$ & $2.07 \mathrm{E}+00$ & $5.27 \mathrm{E}+00$ & $4.52 \mathrm{E}+01$ \\
7,305 & $3.03 \mathrm{E}+00$ & $2.93 \mathrm{E}+00$ & $7.01 \mathrm{E}+00$ & $5.41 \mathrm{E}+01$ \\
10,957 & $3.64 \mathrm{E}+00$ & $3.52 \mathrm{E}+00$ & $8.28 \mathrm{E}+00$ & $5.82 \mathrm{E}+01$ \\
\hline
\end{tabular}

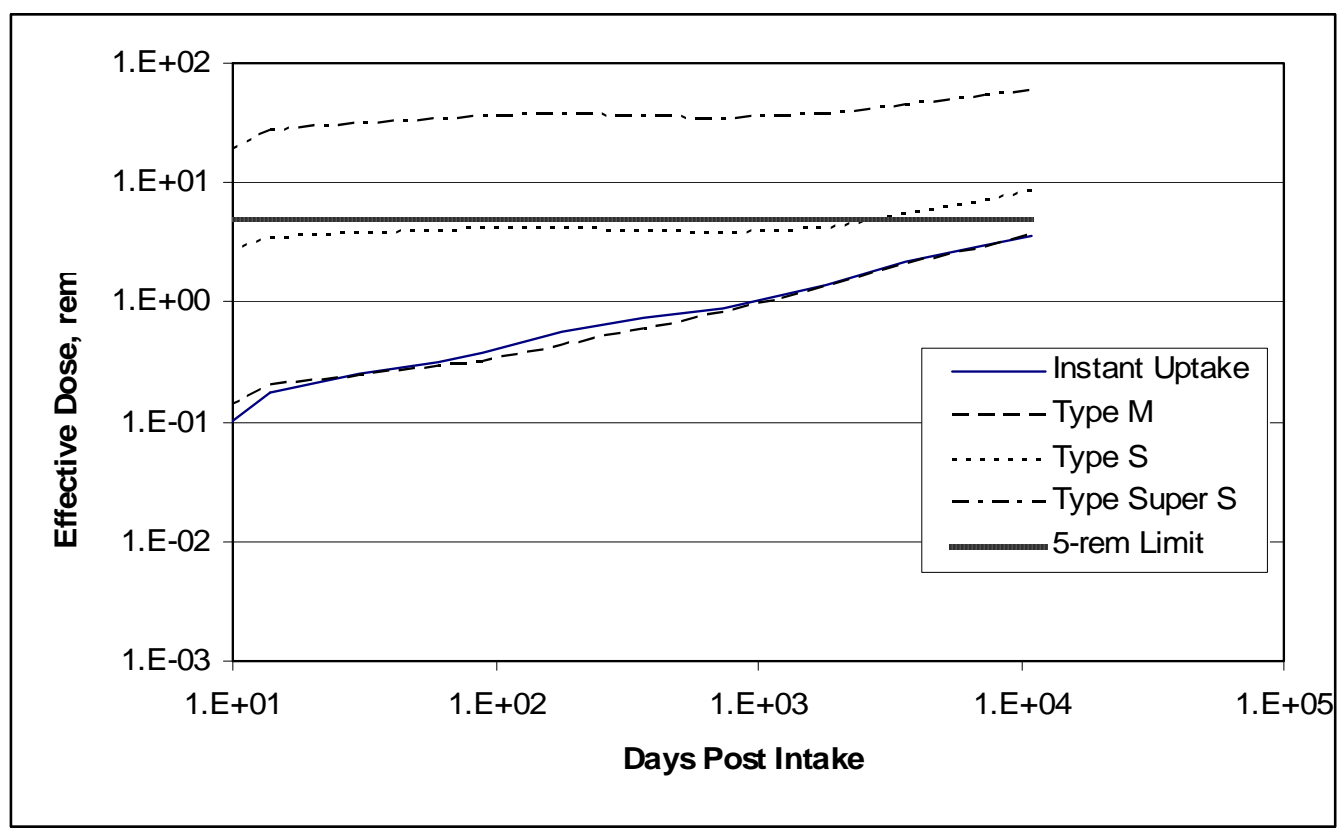

Figure 8.14. Minimum Detectable Committed Effective Doses for 50-Year-Aged Fuel-Grade Plutonium Based on Detection of $0.02 \mathrm{dpm} / \mathrm{d}{ }^{239} \mathrm{Pu}$ in Urine 
Table 8.30. Minimum Detectable Bone Surface Committed Equivalent Doses (rem) for 20-Year-Aged Weapons-Grade Plutonium Based on Detection of $0.02 \mathrm{dpm} / \mathrm{d}{ }^{239} \mathrm{Pu}$ in Urine

\begin{tabular}{rccc}
\hline Days Post Intake & $\begin{array}{c}\text { Instantaneous } \\
\text { Uptake }\end{array}$ & Type M Inhalation & Type S Inhalation \\
\hline 1 & $9.51 \mathrm{E}-02$ & $2.09 \mathrm{E}-01$ & $1.86 \mathrm{E}+00$ \\
2 & $1.74 \mathrm{E}-01$ & $3.70 \mathrm{E}-01$ & $3.22 \mathrm{E}+00$ \\
5 & $6.46 \mathrm{E}-01$ & $1.24 \mathrm{E}+00$ & $9.61 \mathrm{E}+00$ \\
7 & $1.15 \mathrm{E}+00$ & $1.98 \mathrm{E}+00$ & $1.40 \mathrm{E}+01$ \\
14 & $3.56 \mathrm{E}+00$ & $4.16 \mathrm{E}+00$ & $2.31 \mathrm{E}+01$ \\
30 & $5.01 \mathrm{E}+00$ & $5.08 \mathrm{E}+00$ & $2.54 \mathrm{E}+01$ \\
60 & $6.37 \mathrm{E}+00$ & $5.96 \mathrm{E}+00$ & $2.66 \mathrm{E}+01$ \\
90 & $7.76 \mathrm{E}+00$ & $6.78 \mathrm{E}+00$ & $2.72 \mathrm{E}+01$ \\
180 & $1.13 \mathrm{E}+01$ & $8.98 \mathrm{E}+00$ & $2.73 \mathrm{E}+01$ \\
365 & $1.48 \mathrm{E}+01$ & $1.25 \mathrm{E}+01$ & $2.60 \mathrm{E}+01$ \\
730 & $1.82 \mathrm{E}+01$ & $1.71 \mathrm{E}+01$ & $2.47 \mathrm{E}+01$ \\
1,826 & $2.85 \mathrm{E}+01$ & $2.78 \mathrm{E}+01$ & $2.70 \mathrm{E}+01$ \\
3,652 & $4.36 \mathrm{E}+01$ & $4.34 \mathrm{E}+01$ & $3.52 \mathrm{E}+01$ \\
7,305 & $6.13 \mathrm{E}+01$ & $6.14 \mathrm{E}+01$ & $4.68 \mathrm{E}+01$ \\
10,957 & $7.35 \mathrm{E}+01$ & $7.38 \mathrm{E}+01$ & $5.52 \mathrm{E}+01$ \\
\hline
\end{tabular}

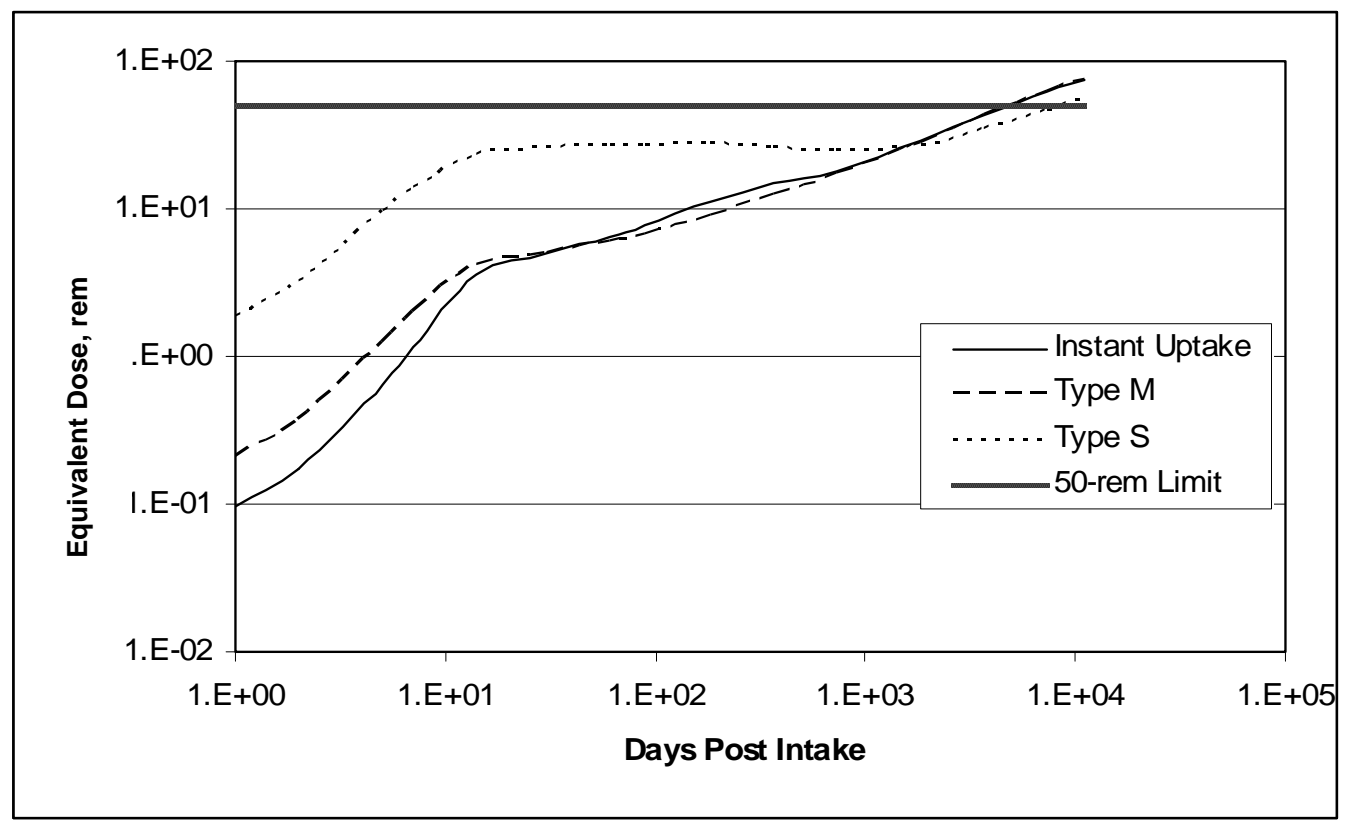

Figure 8.15. Minimum Detectable Bone Surface Doses for 20-Year-Aged Weapons-Grade Plutonium Based on Detection of $0.02 \mathrm{dpm} / \mathrm{d}{ }^{239} \mathrm{Pu}$ in Urine 
Table 8.31. Minimum Detectable Bone Surface Committed Equivalent Doses (rem) for 50-Year-Aged Weapons-Grade Plutonium Based on Detection of $0.02 \mathrm{dpm} / \mathrm{d}{ }^{239} \mathrm{Pu}$ in Urine

\begin{tabular}{cccc}
\hline Days Post Intake & $\begin{array}{c}\text { Instantaneous } \\
\text { Uptake }\end{array}$ & Type M Inhalation & Type S Inhalation \\
\hline 1 & $9.60 \mathrm{E}-02$ & $2.12 \mathrm{E}-01$ & $1.88 \mathrm{E}+00$ \\
2 & $1.75 \mathrm{E}-01$ & $3.75 \mathrm{E}-01$ & $3.25 \mathrm{E}+00$ \\
5 & $6.52 \mathrm{E}-01$ & $1.25 \mathrm{E}+00$ & $9.71 \mathrm{E}+00$ \\
7 & $1.17 \mathrm{E}+00$ & $2.01 \mathrm{E}+00$ & $1.42 \mathrm{E}+01$ \\
14 & $3.59 \mathrm{E}+00$ & $4.22 \mathrm{E}+00$ & $2.33 \mathrm{E}+01$ \\
30 & $5.06 \mathrm{E}+00$ & $5.15 \mathrm{E}+00$ & $2.57 \mathrm{E}+01$ \\
60 & $6.43 \mathrm{E}+00$ & $6.05 \mathrm{E}+00$ & $2.68 \mathrm{E}+01$ \\
90 & $7.84 \mathrm{E}+00$ & $6.88 \mathrm{E}+00$ & $2.74 \mathrm{E}+01$ \\
180 & $1.14 \mathrm{E}+01$ & $9.11 \mathrm{E}+00$ & $2.76 \mathrm{E}+01$ \\
365 & $1.49 \mathrm{E}+01$ & $1.27 \mathrm{E}+01$ & $2.63 \mathrm{E}+01$ \\
730 & $1.83 \mathrm{E}+01$ & $1.74 \mathrm{E}+01$ & $2.49 \mathrm{E}+01$ \\
1,826 & $2.88 \mathrm{E}+01$ & $2.83 \mathrm{E}+01$ & $2.73 \mathrm{E}+01$ \\
3,652 & $4.41 \mathrm{E}+01$ & $4.40 \mathrm{E}+01$ & $3.55 \mathrm{E}+01$ \\
7,305 & $6.19 \mathrm{E}+01$ & $6.23 \mathrm{E}+01$ & $4.72 \mathrm{E}+01$ \\
10,957 & $7.42 \mathrm{E}+01$ & $7.49 \mathrm{E}+01$ & $5.57 \mathrm{E}+01$ \\
\hline
\end{tabular}

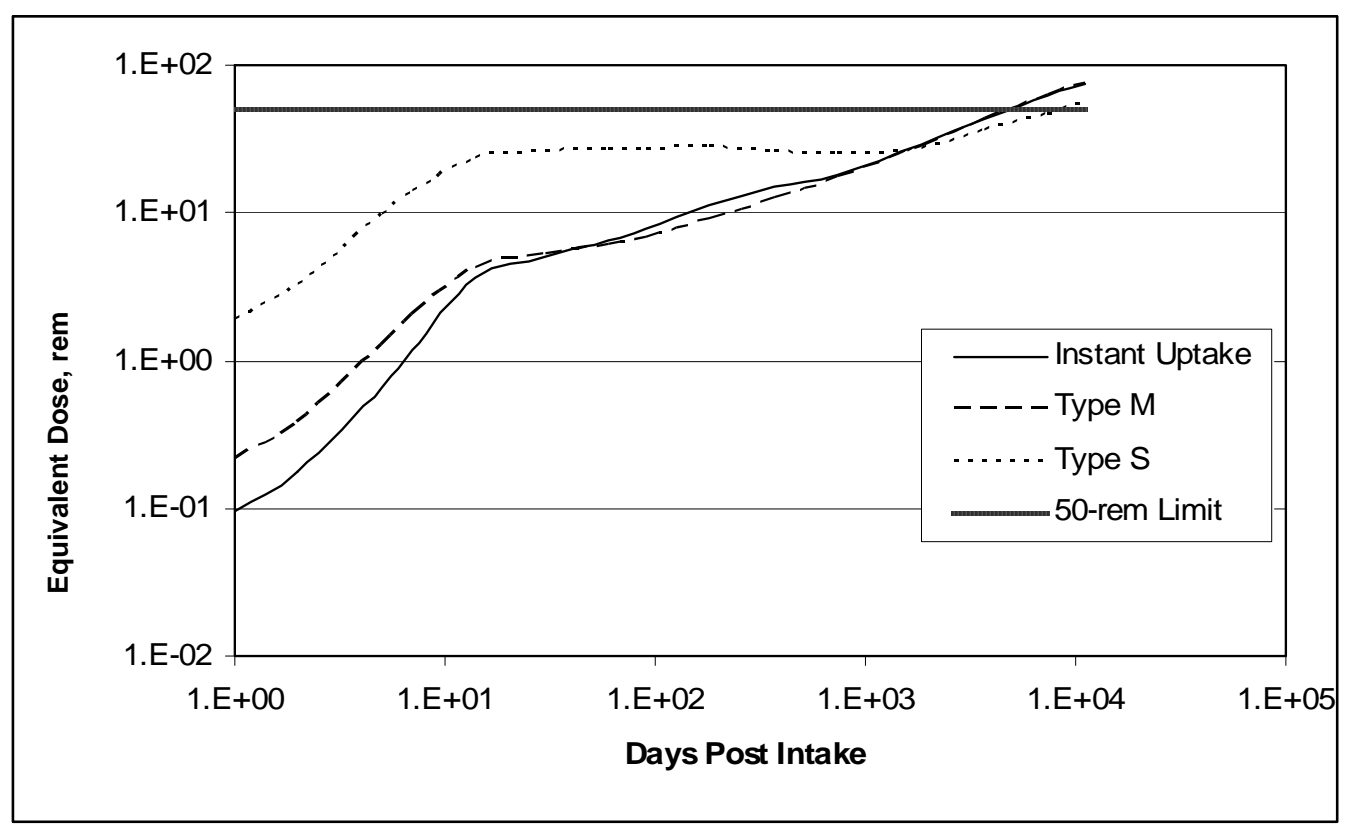

Figure 8.16. Minimum Detectable Bone Surface Doses for 50 -Year-Aged Weapons-Grade Plutonium Based on Detection of $0.02 \mathrm{dpm} / \mathrm{d}{ }^{239} \mathrm{Pu}$ in Urine 
Table 8.32. Minimum Detectable Bone Surface Committed Equivalent Doses (rem) for 20-Year-Aged Fuel-Grade Plutonium Based on Detection of $0.02 \mathrm{dpm} / \mathrm{d}{ }^{239} \mathrm{Pu}$ in Urine

\begin{tabular}{cccc}
\hline Days Post Intake & $\begin{array}{c}\text { Instantaneous } \\
\text { Uptake }\end{array}$ & Type M Inhalation & Type S Inhalation \\
\hline 1 & $1.52 \mathrm{E}-01$ & $3.37 \mathrm{E}-01$ & $3.03 \mathrm{E}+00$ \\
2 & $2.77 \mathrm{E}-01$ & $5.98 \mathrm{E}-01$ & $5.25 \mathrm{E}+00$ \\
5 & $1.03 \mathrm{E}+00$ & $2.00 \mathrm{E}+00$ & $1.56 \mathrm{E}+01$ \\
7 & $1.84 \mathrm{E}+00$ & $3.20 \mathrm{E}+00$ & $2.28 \mathrm{E}+01$ \\
14 & $5.67 \mathrm{E}+00$ & $6.72 \mathrm{E}+00$ & $3.76 \mathrm{E}+01$ \\
30 & $7.99 \mathrm{E}+00$ & $8.21 \mathrm{E}+00$ & $4.13 \mathrm{E}+01$ \\
60 & $1.02 \mathrm{E}+01$ & $9.63 \mathrm{E}+00$ & $4.32 \mathrm{E}+01$ \\
90 & $1.24 \mathrm{E}+01$ & $1.10 \mathrm{E}+01$ & $4.42 \mathrm{E}+01$ \\
180 & $1.81 \mathrm{E}+01$ & $1.45 \mathrm{E}+01$ & $4.45 \mathrm{E}+01$ \\
365 & $2.36 \mathrm{E}+01$ & $2.02 \mathrm{E}+01$ & $4.24 \mathrm{E}+01$ \\
730 & $2.89 \mathrm{E}+01$ & $2.76 \mathrm{E}+01$ & $4.02 \mathrm{E}+01$ \\
1,826 & $4.55 \mathrm{E}+01$ & $4.50 \mathrm{E}+01$ & $4.40 \mathrm{E}+01$ \\
3,652 & $6.96 \mathrm{E}+01$ & $7.01 \mathrm{E}+01$ & $5.72 \mathrm{E}+01$ \\
7,305 & $9.77 \mathrm{E}+01$ & $9.93 \mathrm{E}+01$ & $7.61 \mathrm{E}+01$ \\
10,957 & $1.17 \mathrm{E}+02$ & $1.19 \mathrm{E}+02$ & $8.98 \mathrm{E}+01$ \\
\hline
\end{tabular}

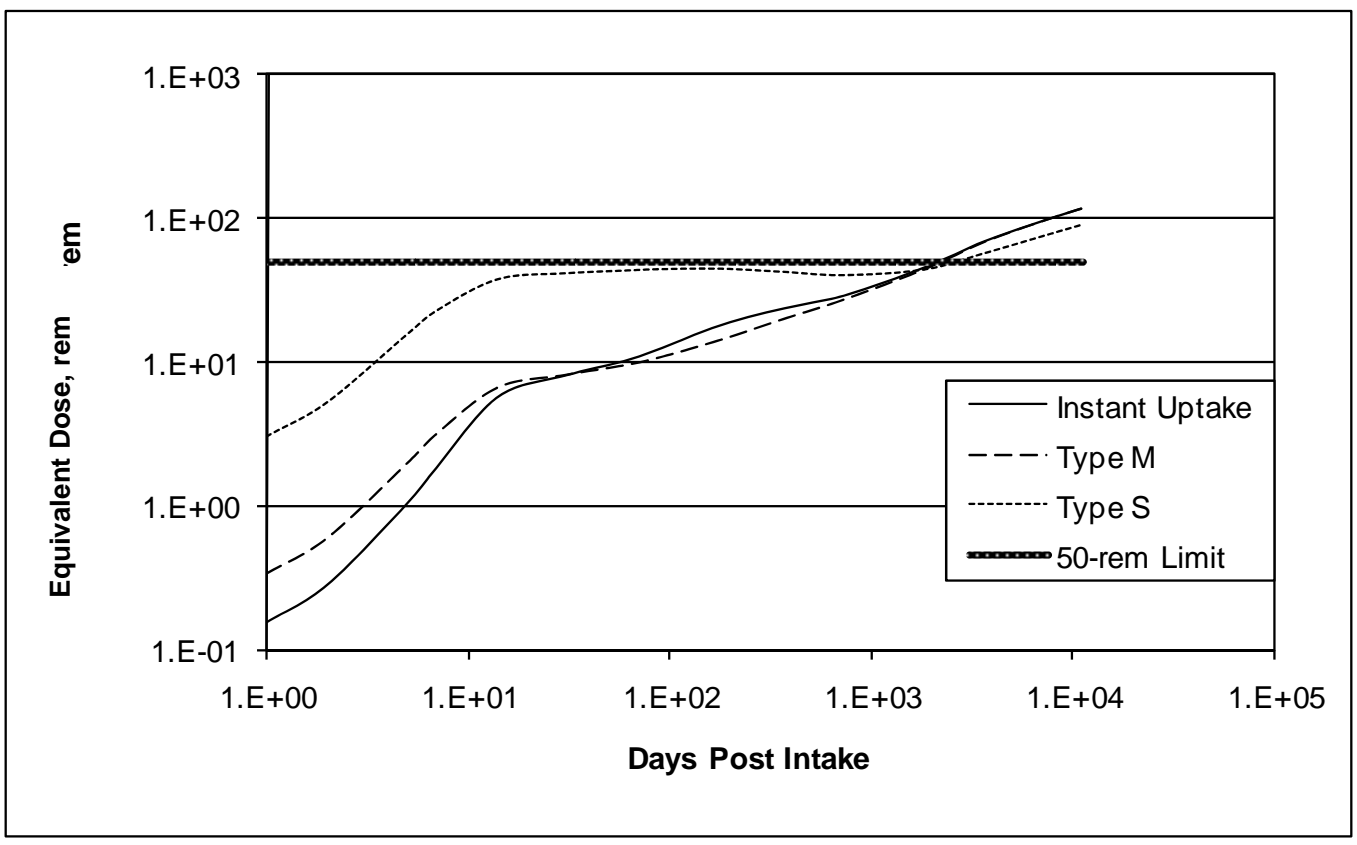

Figure 8.17. Minimum Detectable Bone Surface Doses for 20-Year-Aged Fuel-Grade Plutonium Based on Detection of $0.02 \mathrm{dpm} / \mathrm{d}{ }^{239} \mathrm{Pu}$ in Urine 
Table 8.33. Minimum Detectable Bone Surface Committed Equivalent Doses (rem) for 50-Year-Aged Fuel-Grade Plutonium Based on Detection of $0.02 \mathrm{dpm} / \mathrm{d}{ }^{239} \mathrm{Pu}$ in Urine

\begin{tabular}{cccc}
\hline Days Post Intake & $\begin{array}{c}\text { Instantaneous } \\
\text { Uptake }\end{array}$ & Type M Inhalation & Type S Inhalation \\
\hline 1 & $1.57 \mathrm{E}-01$ & $3.52 \mathrm{E}-01$ & $3.14 \mathrm{E}+00$ \\
2 & $2.86 \mathrm{E}-01$ & $6.24 \mathrm{E}-01$ & $5.42 \mathrm{E}+00$ \\
5 & $1.07 \mathrm{E}+00$ & $2.08 \mathrm{E}+00$ & $1.62 \mathrm{E}+01$ \\
7 & $1.90 \mathrm{E}+00$ & $3.34 \mathrm{E}+00$ & $2.36 \mathrm{E}+01$ \\
14 & $5.86 \mathrm{E}+00$ & $7.01 \mathrm{E}+00$ & $3.88 \mathrm{E}+01$ \\
30 & $8.27 \mathrm{E}+00$ & $8.57 \mathrm{E}+00$ & $4.27 \mathrm{E}+01$ \\
60 & $1.05 \mathrm{E}+01$ & $1.01 \mathrm{E}+01$ & $4.47 \mathrm{E}+01$ \\
90 & $1.28 \mathrm{E}+01$ & $1.14 \mathrm{E}+01$ & $4.57 \mathrm{E}+01$ \\
180 & $1.87 \mathrm{E}+01$ & $1.52 \mathrm{E}+01$ & $4.60 \mathrm{E}+01$ \\
365 & $2.44 \mathrm{E}+01$ & $2.11 \mathrm{E}+01$ & $4.38 \mathrm{E}+01$ \\
730 & $2.99 \mathrm{E}+01$ & $2.89 \mathrm{E}+01$ & $4.15 \mathrm{E}+01$ \\
1,826 & $4.70 \mathrm{E}+01$ & $4.70 \mathrm{E}+01$ & $4.54 \mathrm{E}+01$ \\
3,652 & $7.20 \mathrm{E}+01$ & $7.31 \mathrm{E}+01$ & $5.91 \mathrm{E}+01$ \\
7,305 & $1.01 \mathrm{E}+02$ & $1.04 \mathrm{E}+02$ & $7.86 \mathrm{E}+01$ \\
10,957 & $1.21 \mathrm{E}+02$ & $1.25 \mathrm{E}+02$ & $9.28 \mathrm{E}+01$ \\
\hline
\end{tabular}

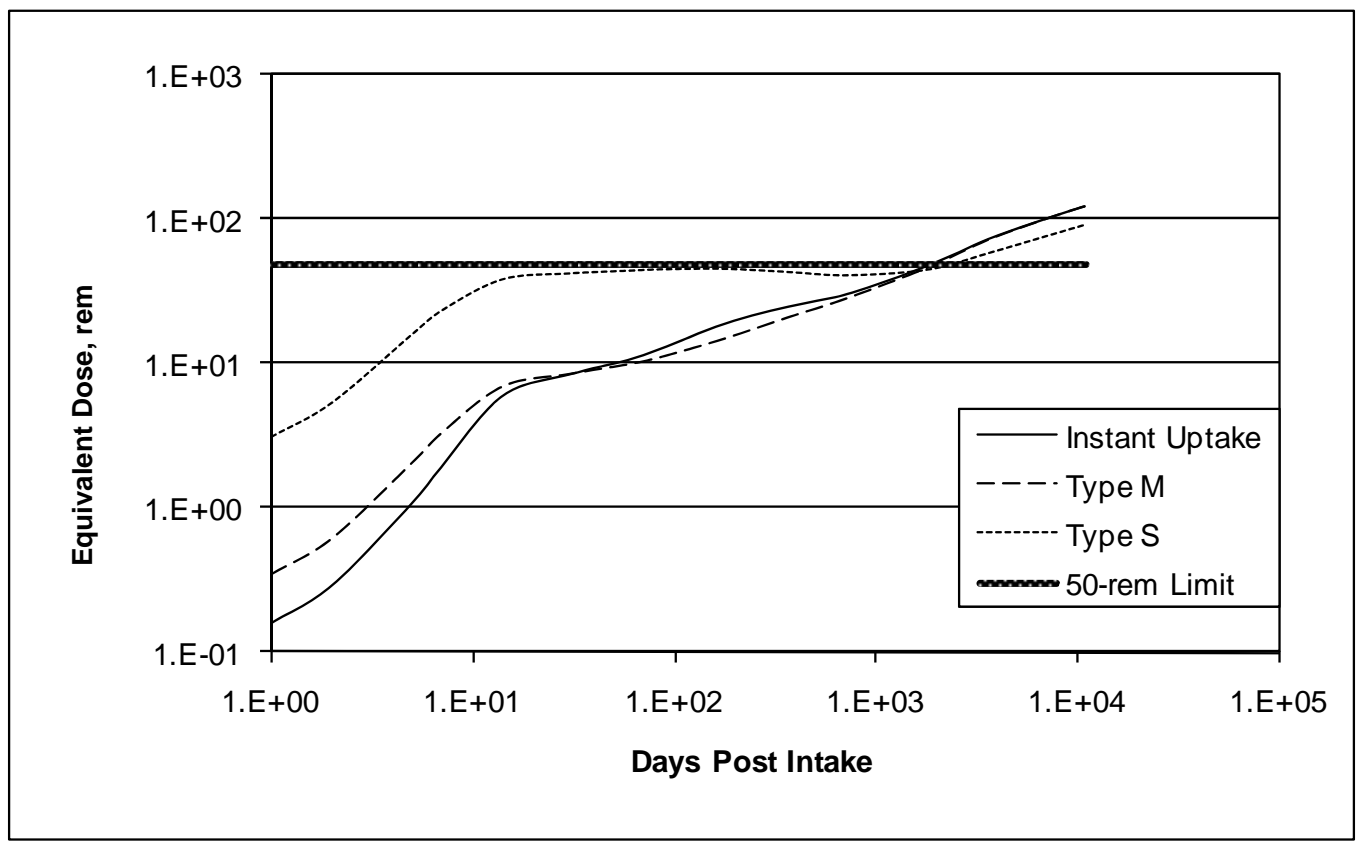

Figure 8.18. Minimum Detectable Bone Surface Doses for 50-Year-Aged Fuel-Grade Plutonium Based on Detection of $0.02 \mathrm{dpm} / \mathrm{d}{ }^{239} \mathrm{Pu}$ in Urine 
Table 8.34. Minimum Detectable Committed Equivalent Doses (rem) for Extrathoracic Tissues and the Lung (rem) for Inhalation of Type Super S Weapons-Grade Plutonium Based on Detection of $0.02 \mathrm{dpm} / \mathrm{d}{ }^{239} \mathrm{Pu}$ in Urine

\begin{tabular}{rcccc}
\hline & \multicolumn{2}{c}{ Extrathoracic Tissue } & \multicolumn{2}{c}{ Lung } \\
\cline { 2 - 5 } Days Post Intake & $\begin{array}{c}\text { 20-Year Weapons- } \\
\text { Grade Plutonium }\end{array}$ & $\begin{array}{c}50 \text {-Year Weapons- } \\
\text { Grade Plutonium }\end{array}$ & $\begin{array}{c}20 \text {-Year Weapons- } \\
\text { Grade Plutonium }\end{array}$ & $\begin{array}{c}50 \text {-Year Weapons- } \\
\text { Grade Plutonium }\end{array}$ \\
\hline 1 & $8.41 \mathrm{E}+00$ & $8.77 \mathrm{E}+00$ & $5.37 \mathrm{E}+00$ & $5.54 \mathrm{E}+00$ \\
2 & $1.49 \mathrm{E}+01$ & $1.55 \mathrm{E}+01$ & $9.50 \mathrm{E}+00$ & $9.80 \mathrm{E}+00$ \\
5 & $4.91 \mathrm{E}+01$ & $5.12 \mathrm{E}+01$ & $3.14 \mathrm{E}+01$ & $3.24 \mathrm{E}+01$ \\
7 & $7.77 \mathrm{E}+01$ & $8.10 \mathrm{E}+01$ & $4.97 \mathrm{E}+01$ & $5.12 \mathrm{E}+01$ \\
14 & $1.55 \mathrm{E}+02$ & $1.62 \mathrm{E}+02$ & $9.92 \mathrm{E}+01$ & $1.02 \mathrm{E}+02$ \\
30 & $1.80 \mathrm{E}+02$ & $1.88 \mathrm{E}+02$ & $1.15 \mathrm{E}+02$ & $1.19 \mathrm{E}+02$ \\
60 & $1.95 \mathrm{E}+02$ & $2.04 \mathrm{E}+02$ & $1.25 \mathrm{E}+02$ & $1.29 \mathrm{E}+02$ \\
90 & $2.05 \mathrm{E}+02$ & $2.14 \mathrm{E}+02$ & $1.31 \mathrm{E}+02$ & $1.35 \mathrm{E}+02$ \\
180 & $2.16 \mathrm{E}+02$ & $2.25 \mathrm{E}+02$ & $1.38 \mathrm{E}+02$ & $1.42 \mathrm{E}+02$ \\
365 & $2.09 \mathrm{E}+02$ & $2.18 \mathrm{E}+02$ & $1.34 \mathrm{E}+02$ & $1.38 \mathrm{E}+02$ \\
730 & $1.99 \mathrm{E}+02$ & $2.07 \mathrm{E}+02$ & $1.27 \mathrm{E}+02$ & $1.31 \mathrm{E}+02$ \\
1,826 & $2.12 \mathrm{E}+02$ & $2.22 \mathrm{E}+02$ & $1.36 \mathrm{E}+02$ & $1.40 \mathrm{E}+02$ \\
3,652 & $2.62 \mathrm{E}+02$ & $2.73 \mathrm{E}+02$ & $1.68 \mathrm{E}+02$ & $1.73 \mathrm{E}+02$ \\
7,305 & $3.14 \mathrm{E}+02$ & $3.28 \mathrm{E}+02$ & $2.01 \mathrm{E}+02$ & $2.07 \mathrm{E}+02$ \\
10,957 & $3.38 \mathrm{E}+02$ & $3.52 \mathrm{E}+02$ & $2.16 \mathrm{E}+02$ & $2.23 \mathrm{E}+02$ \\
\hline
\end{tabular}

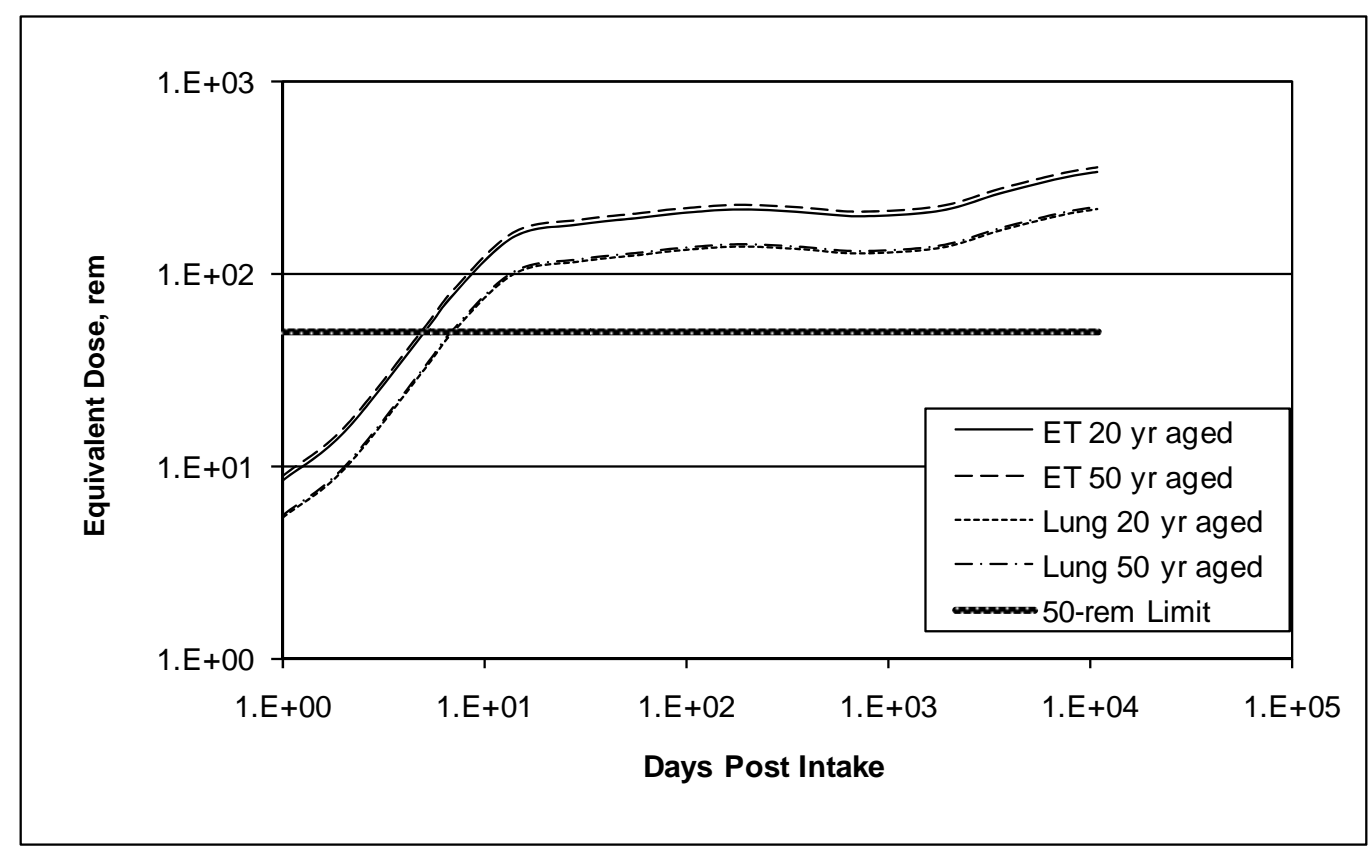

Figure 8.19. Minimum Detectable Doses to Extrathoracic Tissues and the Lung from Inhalation of Type Super S Weapons-Grade Plutonium Based on Detection of $0.02 \mathrm{dpm} / \mathrm{d}{ }^{239} \mathrm{Pu}$ in Urine 
Table 8.35. Minimum Detectable Committed Equivalent Doses (rem) for Extra Thoracic Tissues and the Lung (rem) for Inhalation of Type Super S Fuel-Grade Plutonium Based on Detection of $0.02 \mathrm{dpm} / \mathrm{d}{ }^{239} \mathrm{Pu}$ in Urine

\begin{tabular}{ccccc}
\hline & \multicolumn{2}{c}{ Extrathoracic Tissue } & \multicolumn{2}{c}{ Lung } \\
\cline { 2 - 5 } Days Post Intake & $\begin{array}{c}\text { 20-Year Fuel-Grade } \\
\text { Plutonium }\end{array}$ & $\begin{array}{c}50 \text {-Year Fuel- } \\
\text { Grade Plutonium }\end{array}$ & $\begin{array}{c}\text { 20-Year Fuel- } \\
\text { Grade Plutonium }\end{array}$ & $\begin{array}{c}50 \text {-Year Fuel- } \\
\text { Grade Plutonium }\end{array}$ \\
\hline 1 & $1.24 \mathrm{E}+01$ & $1.38 \mathrm{E}+01$ & $8.03 \mathrm{E}+00$ & $8.83 \mathrm{E}+00$ \\
2 & $2.20 \mathrm{E}+01$ & $2.45 \mathrm{E}+01$ & $1.42 \mathrm{E}+01$ & $1.56 \mathrm{E}+01$ \\
5 & $7.25 \mathrm{E}+01$ & $8.07 \mathrm{E}+01$ & $4.69 \mathrm{E}+01$ & $5.15 \mathrm{E}+01$ \\
7 & $1.15 \mathrm{E}+02$ & $1.28 \mathrm{E}+02$ & $7.42 \mathrm{E}+01$ & $8.16 \mathrm{E}+01$ \\
14 & $2.30 \mathrm{E}+02$ & $2.55 \mathrm{E}+02$ & $1.48 \mathrm{E}+02$ & $1.63 \mathrm{E}+02$ \\
30 & $2.67 \mathrm{E}+02$ & $2.97 \mathrm{E}+02$ & $1.72 \mathrm{E}+02$ & $1.89 \mathrm{E}+02$ \\
60 & $2.89 \mathrm{E}+02$ & $3.21 \mathrm{E}+02$ & $1.87 \mathrm{E}+02$ & $2.05 \mathrm{E}+02$ \\
90 & $3.03 \mathrm{E}+02$ & $3.37 \mathrm{E}+02$ & $1.96 \mathrm{E}+02$ & $2.15 \mathrm{E}+02$ \\
180 & $3.19 \mathrm{E}+02$ & $3.54 \mathrm{E}+02$ & $2.06 \mathrm{E}+02$ & $2.26 \mathrm{E}+02$ \\
365 & $3.09 \mathrm{E}+02$ & $3.44 \mathrm{E}+02$ & $2.00 \mathrm{E}+02$ & $2.20 \mathrm{E}+02$ \\
730 & $2.94 \mathrm{E}+02$ & $3.27 \mathrm{E}+02$ & $1.90 \mathrm{E}+02$ & $2.08 \mathrm{E}+02$ \\
1,826 & $3.14 \mathrm{E}+02$ & $3.49 \mathrm{E}+02$ & $2.03 \mathrm{E}+02$ & $2.23 \mathrm{E}+02$ \\
3,652 & $3.87 \mathrm{E}+02$ & $4.31 \mathrm{E}+02$ & $2.50 \mathrm{E}+02$ & $2.75 \mathrm{E}+02$ \\
7,305 & $4.64 \mathrm{E}+02$ & $5.16 \mathrm{E}+02$ & $3.00 \mathrm{E}+02$ & $3.30 \mathrm{E}+02$ \\
10,957 & $4.99 \mathrm{E}+02$ & $5.56 \mathrm{E}+02$ & $3.23 \mathrm{E}+02$ & $3.55 \mathrm{E}+02$ \\
\hline
\end{tabular}

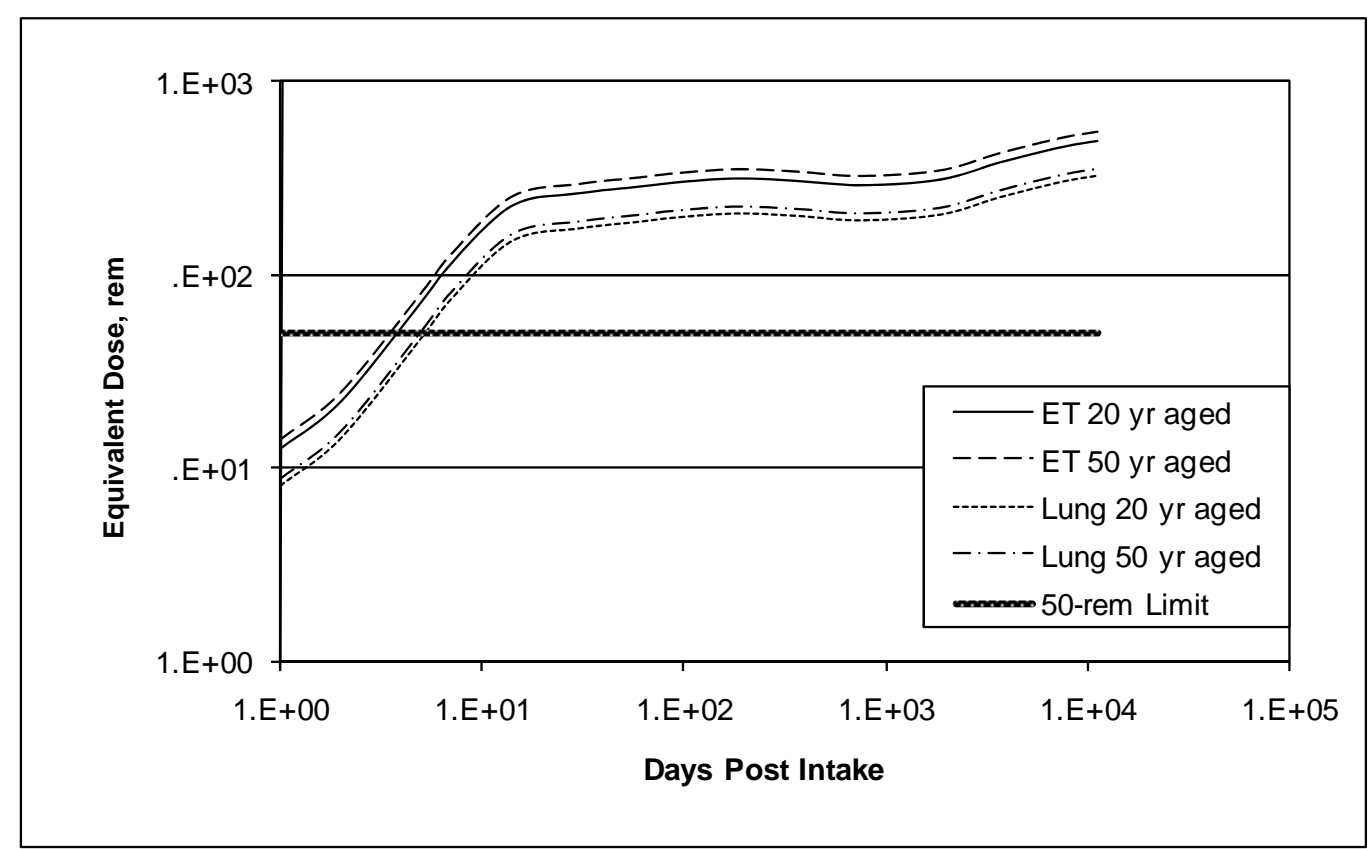

Figure 8.20. Minimum Detectable Doses to Extrathoracic Tissues and the Lung from Inhalation of Type Super S Fuel-Grade Plutonium Based on Detection of $0.02 \mathrm{dpm} / \mathrm{d}^{239} \mathrm{Pu}$ in Urine 
Table 8.36. Minimum Detectable Committed Effective Doses (rem) for 20-Year-Aged Weapons-Grade Plutonium Based on Detection of $0.16 \mathrm{nCi}^{241} \mathrm{Am}$ in the Lungs

\begin{tabular}{rccc}
\hline Days Post Intake & Type M Inhalation & Type S Inhalation & Type Super S Inhalation \\
\hline 0.5 & $1.89 \mathrm{E}+00$ & $4.52 \mathrm{E}-01$ & $4.71 \mathrm{E}-01$ \\
1 & $1.96 \mathrm{E}+00$ & $4.68 \mathrm{E}-01$ & $4.88 \mathrm{E}-01$ \\
2 & $2.02 \mathrm{E}+00$ & $4.80 \mathrm{E}-01$ & $5.00 \mathrm{E}-01$ \\
5 & $2.11 \mathrm{E}+00$ & $4.96 \mathrm{E}-01$ & $5.16 \mathrm{E}-01$ \\
7 & $2.18 \mathrm{E}+00$ & $5.05 \mathrm{E}-01$ & $5.26 \mathrm{E}-01$ \\
14 & $2.40 \mathrm{E}+00$ & $5.38 \mathrm{E}-01$ & $5.60 \mathrm{E}-01$ \\
30 & $2.93 \mathrm{E}+00$ & $6.08 \mathrm{E}-01$ & $6.32 \mathrm{E}-01$ \\
60 & $4.00 \mathrm{E}+00$ & $7.16 \mathrm{E}-01$ & $7.42 \mathrm{E}-01$ \\
90 & $5.14 \mathrm{E}+00$ & $7.94 \mathrm{E}-01$ & $8.20 \mathrm{E}-01$ \\
180 & $9.33 \mathrm{E}+00$ & $9.28 \mathrm{E}-01$ & $9.52 \mathrm{E}-01$ \\
365 & $2.75 \mathrm{E}+01$ & $1.10 \mathrm{E}+00$ & $1.11 \mathrm{E}+00$ \\
730 & not meaningful & $1.50 \mathrm{E}+00$ & $1.46 \mathrm{E}+00$ \\
1,826 & not meaningful & $3.28 \mathrm{E}+00$ & $2.90 \mathrm{E}+00$ \\
3,652 & not meaningful & $7.43 \mathrm{E}+00$ & $5.57 \mathrm{E}+00$ \\
7,305 & not meaningful & $1.57 \mathrm{E}+01$ & $8.45 \mathrm{E}+00$ \\
10,957 & not meaningful & $2.78 \mathrm{E}+01$ & $1.08 \mathrm{E}+01$ \\
\hline
\end{tabular}

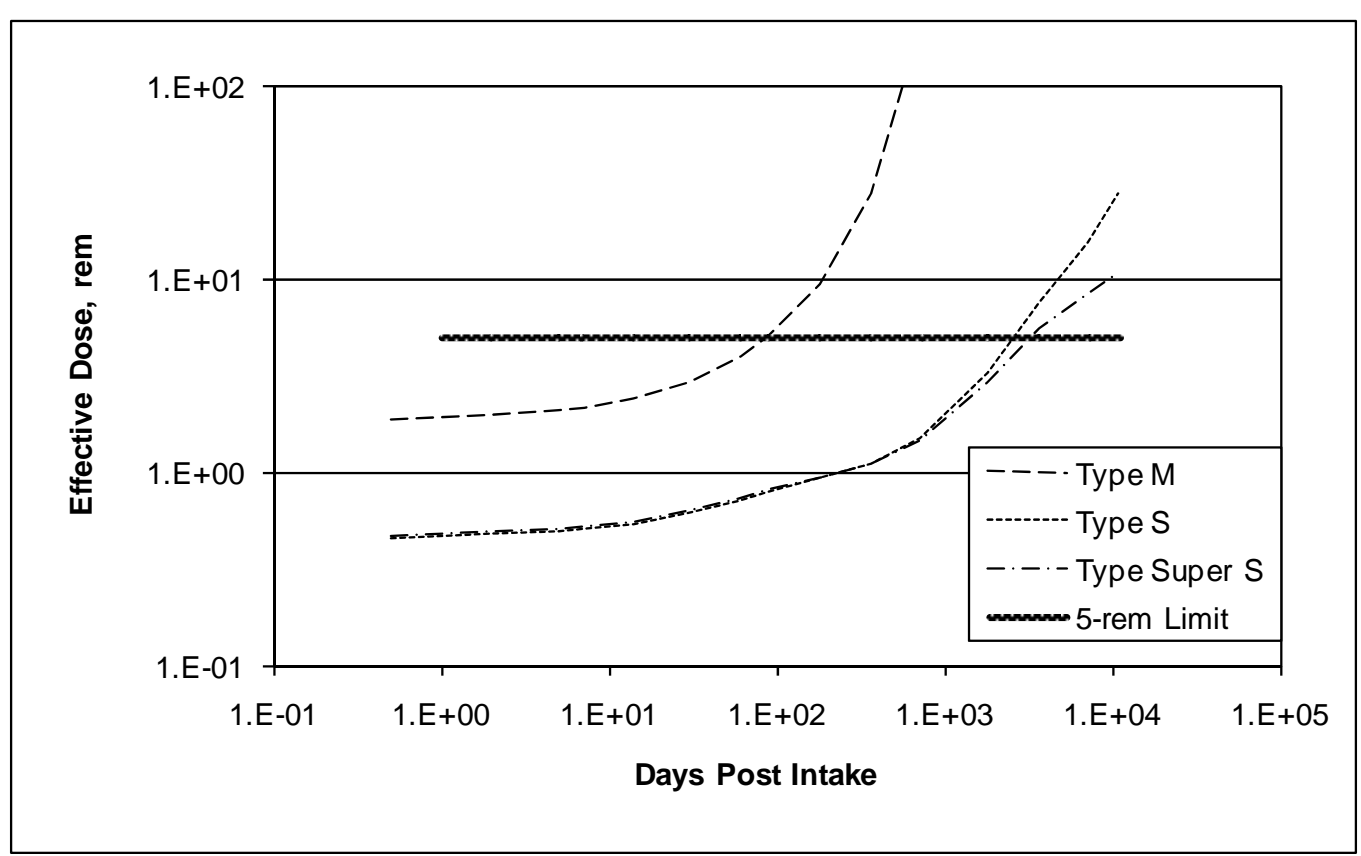

Figure 8.21. Minimum Detectable Committed Effective Doses for 20-Year-Aged Weapons-Grade Plutonium Based on Detection of $0.16 \mathrm{nCi}^{241} \mathrm{Am}$ in the Lungs 
Table 8.37. Minimum Detectable Committed Effective Doses (rem) for 50-Year-Aged Weapons-Grade Plutonium Based on Detection of $0.16 \mathrm{nCi}^{241} \mathrm{Am}$ in the Lungs

\begin{tabular}{rccc}
\hline Days Post Intake & Type M Inhalation & Type S Inhalation & Type Super S Inhalation \\
\hline 0.5 & $1.33 \mathrm{E}+00$ & $3.26 \mathrm{E}-01$ & $3.42 \mathrm{E}-01$ \\
1 & $1.38 \mathrm{E}+00$ & $3.38 \mathrm{E}-01$ & $3.54 \mathrm{E}-01$ \\
2 & $1.42 \mathrm{E}+00$ & $3.46 \mathrm{E}-01$ & $3.63 \mathrm{E}-01$ \\
5 & $1.49 \mathrm{E}+00$ & $3.58 \mathrm{E}-01$ & $3.75 \mathrm{E}-01$ \\
7 & $1.53 \mathrm{E}+00$ & $3.65 \mathrm{E}-01$ & $3.82 \mathrm{E}-01$ \\
14 & $1.69 \mathrm{E}+00$ & $3.89 \mathrm{E}-01$ & $4.07 \mathrm{E}-01$ \\
30 & $2.07 \mathrm{E}+00$ & $4.40 \mathrm{E}-01$ & $4.60 \mathrm{E}-01$ \\
60 & $2.83 \mathrm{E}+00$ & $5.19 \mathrm{E}-01$ & $5.41 \mathrm{E}-01$ \\
90 & $3.64 \mathrm{E}+00$ & $5.76 \mathrm{E}-01$ & $6.00 \mathrm{E}-01$ \\
180 & $6.65 \mathrm{E}+00$ & $6.78 \mathrm{E}-01$ & $7.00 \mathrm{E}-01$ \\
365 & $1.98 \mathrm{E}+01$ & $8.16 \mathrm{E}-01$ & $8.29 \mathrm{E}-01$ \\
730 & not meaningful & $1.13 \mathrm{E}+00$ & $1.11 \mathrm{E}+00$ \\
1,826 & not meaningful & $2.63 \mathrm{E}+00$ & $2.34 \mathrm{E}+00$ \\
3,652 & not meaningful & $6.40 \mathrm{E}+00$ & $4.84 \mathrm{E}+00$ \\
7,305 & not meaningful & $1.48 \mathrm{E}+01$ & $8.05 \mathrm{E}+00$ \\
10,957 & not meaningful & $2.77 \mathrm{E}+01$ & $1.08 \mathrm{E}+01$ \\
\hline
\end{tabular}

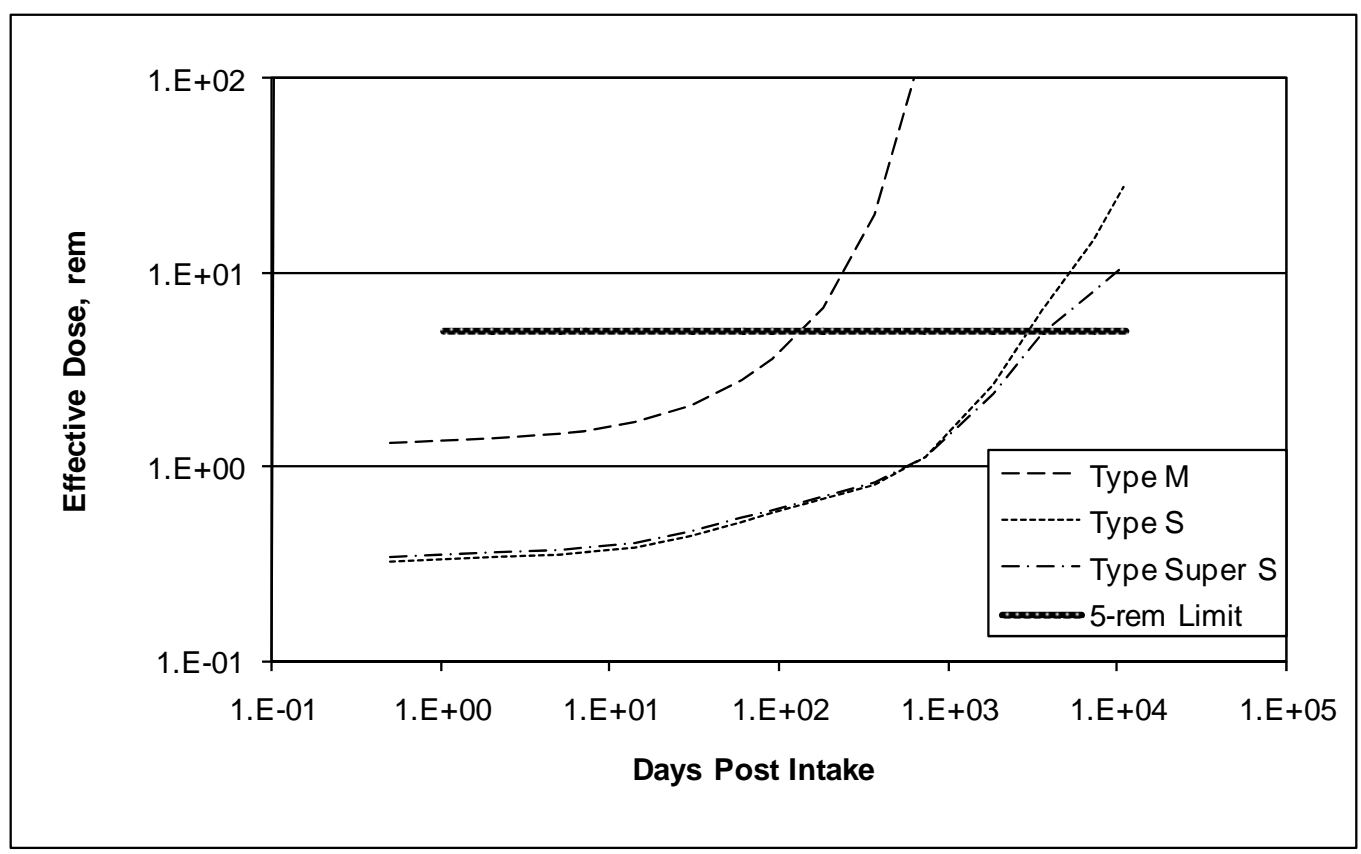

Figure 8.22. Minimum Detectable Committed Effective Doses for 50 -Year-Aged Weapons-Grade Plutonium Based on Detection of $0.16 \mathrm{nCi}{ }^{241} \mathrm{Am}$ in the Lungs 
Table 8.38. Minimum Detectable Committed Effective Doses (rem) for 20-Year-Aged Fuel-Grade Plutonium Based on Detection of $0.16 \mathrm{nCi}^{241} \mathrm{Am}$ in the Lungs

\begin{tabular}{rccc}
\hline Days Post Intake & Type M Inhalation & Type S Inhalation & Type Super S Inhalation \\
\hline 0.5 & $8.55 \mathrm{E}-01$ & $2.08 \mathrm{E}-01$ & $2.08 \mathrm{E}-01$ \\
1 & $8.87 \mathrm{E}-01$ & $2.15 \mathrm{E}-01$ & $2.15 \mathrm{E}-01$ \\
2 & $9.14 \mathrm{E}-01$ & $2.20 \mathrm{E}-01$ & $2.21 \mathrm{E}-01$ \\
5 & $9.58 \mathrm{E}-01$ & $2.27 \mathrm{E}-01$ & $2.28 \mathrm{E}-01$ \\
7 & $9.86 \mathrm{E}-01$ & $2.32 \mathrm{E}-01$ & $2.32 \mathrm{E}-01$ \\
14 & $1.09 \mathrm{E}+00$ & $2.47 \mathrm{E}-01$ & $2.47 \mathrm{E}-01$ \\
30 & $1.33 \mathrm{E}+00$ & $2.79 \mathrm{E}-01$ & $2.79 \mathrm{E}-01$ \\
60 & $1.81 \mathrm{E}+00$ & $3.28 \mathrm{E}-01$ & $3.27 \mathrm{E}-01$ \\
90 & $2.33 \mathrm{E}+00$ & $3.64 \mathrm{E}-01$ & $3.62 \mathrm{E}-01$ \\
180 & $4.23 \mathrm{E}+00$ & $4.26 \mathrm{E}-01$ & $4.20 \mathrm{E}-01$ \\
365 & $1.25 \mathrm{E}+01$ & $5.07 \mathrm{E}-01$ & $4.92 \mathrm{E}-01$ \\
730 & $1.01 \mathrm{E}+02$ & $6.86 \mathrm{E}-01$ & $6.44 \mathrm{E}-01$ \\
1,826 & not meaningful & $1.50 \mathrm{E}+00$ & $1.28 \mathrm{E}+00$ \\
3,652 & not meaningful & $3.41 \mathrm{E}+00$ & $2.46 \mathrm{E}+00$ \\
7,305 & not meaningful & $7.19 \mathrm{E}+00$ & $3.73 \mathrm{E}+00$ \\
10,957 & not meaningful & $1.28 \mathrm{E}+01$ & $4.77 \mathrm{E}+00$ \\
\hline
\end{tabular}

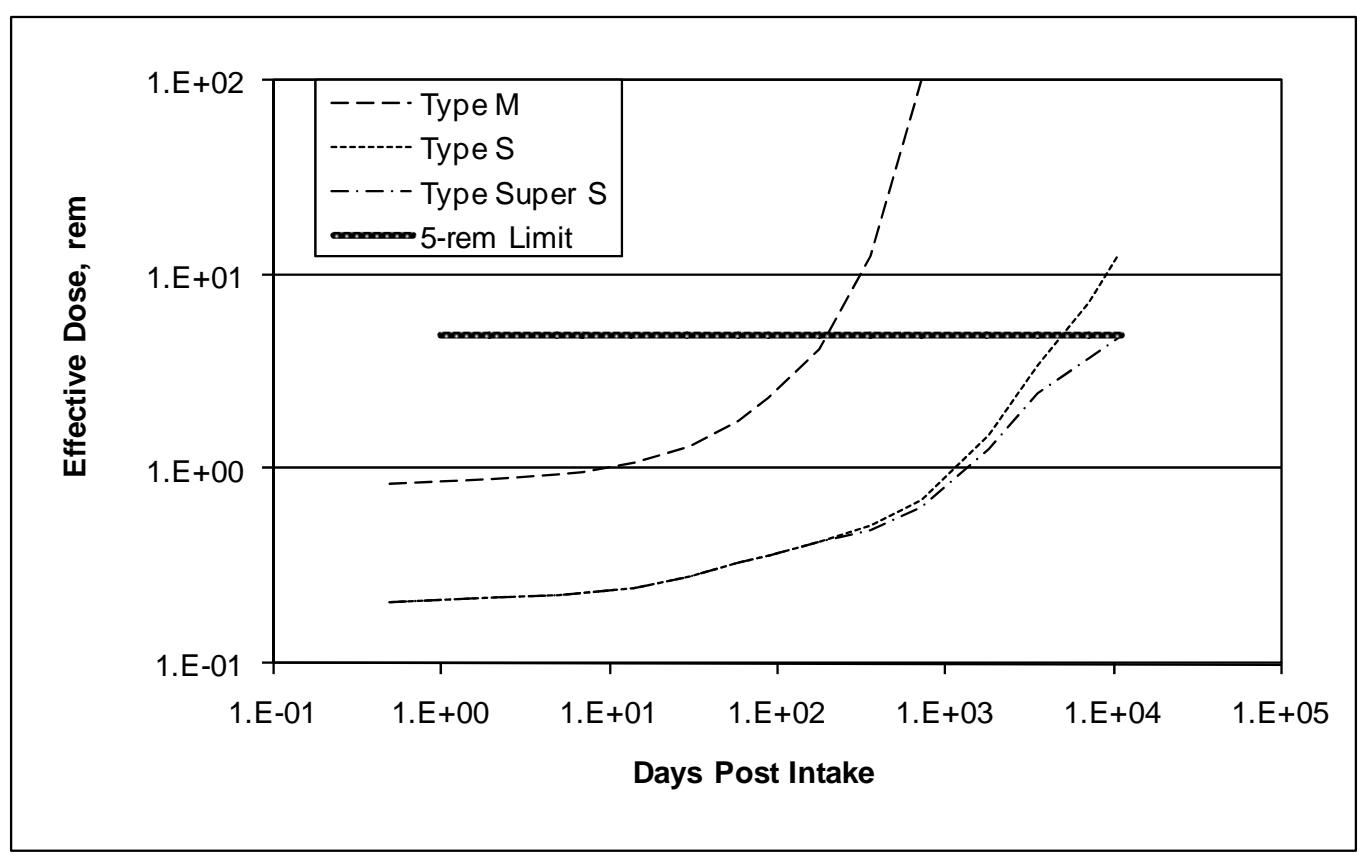

Figure 8.23. Minimum Detectable Committed Effective Doses for 20-Year-Aged Fuel-Grade Plutonium Based on Detection of $0.16 \mathrm{nCi}{ }^{241} \mathrm{Am}$ in the Lungs 
Table 8.39. Minimum Detectable Committed Effective Doses (rem) for 50-Year-Aged Fuel-Grade Plutonium Based on Detection of $0.16 \mathrm{nCi}^{241} \mathrm{Am}$ in the Lungs

\begin{tabular}{rccc}
\hline Days Post Intake & Type M Inhalation & Type S Inhalation & Type Super S Inhalation \\
\hline 0.5 & $6.14 \mathrm{E}-01$ & $1.57 \mathrm{E}-01$ & $1.61 \mathrm{E}-01$ \\
1 & $6.37 \mathrm{E}-01$ & $1.63 \mathrm{E}-01$ & $1.67 \mathrm{E}-01$ \\
2 & $6.57 \mathrm{E}-01$ & $1.67 \mathrm{E}-01$ & $1.71 \mathrm{E}-01$ \\
5 & $6.88 \mathrm{E}-01$ & $1.72 \mathrm{E}-01$ & $1.77 \mathrm{E}-01$ \\
7 & $7.09 \mathrm{E}-01$ & $1.76 \mathrm{E}-01$ & $1.80 \mathrm{E}-01$ \\
14 & $7.82 \mathrm{E}-01$ & $1.87 \mathrm{E}-01$ & $1.92 \mathrm{E}-01$ \\
30 & $9.57 \mathrm{E}-01$ & $2.12 \mathrm{E}-01$ & $2.17 \mathrm{E}-01$ \\
60 & $1.31 \mathrm{E}+00$ & $2.50 \mathrm{E}-01$ & $2.55 \mathrm{E}-01$ \\
90 & $1.68 \mathrm{E}+00$ & $2.78 \mathrm{E}-01$ & $2.82 \mathrm{E}-01$ \\
180 & $3.08 \mathrm{E}+00$ & $3.27 \mathrm{E}-01$ & $3.29 \mathrm{E}-01$ \\
365 & $9.17 \mathrm{E}+00$ & $3.94 \mathrm{E}-01$ & $3.90 \mathrm{E}-01$ \\
730 & $7.60 \mathrm{E}+01$ & $5.45 \mathrm{E}-01$ & $5.23 \mathrm{E}-01$ \\
1,826 & not meaningful & $1.27 \mathrm{E}+00$ & $1.10 \mathrm{E}+00$ \\
3,652 & not meaningful & $3.09 \mathrm{E}+00$ & $2.28 \mathrm{E}+00$ \\
7,305 & not meaningful & $7.13 \mathrm{E}+00$ & $3.79 \mathrm{E}+00$ \\
10,957 & not meaningful & $1.33 \mathrm{E}+01$ & $5.10 \mathrm{E}+00$ \\
\hline
\end{tabular}

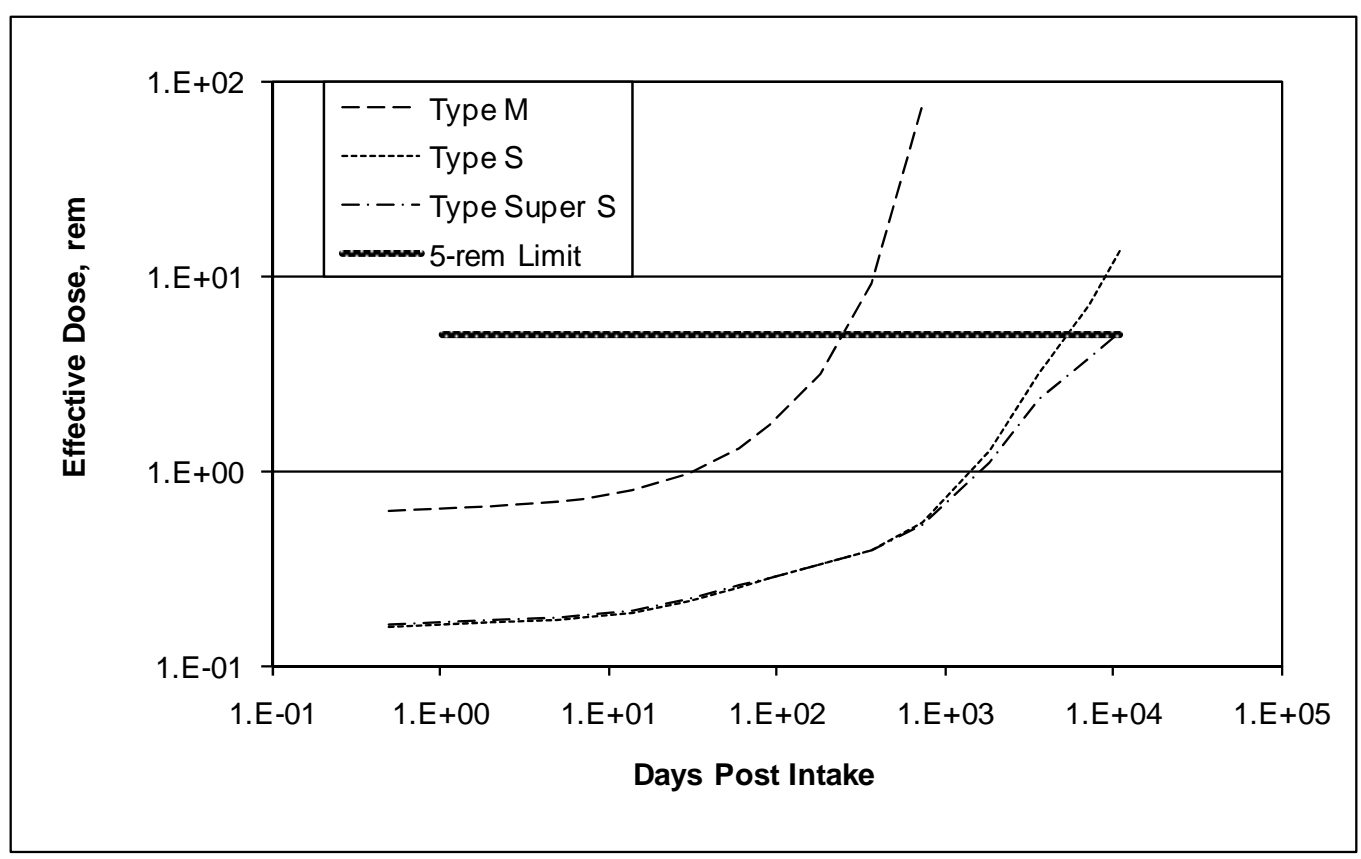

Figure 8.24. Minimum Detectable Committed Effective Doses for 50 -Year-Aged Fuel-Grade Plutonium Based on Detection of $0.16 \mathrm{nCi}^{241} \mathrm{Am}$ in the Lungs 
Table 8.40. Minimum Detectable Bone Surface Committed Equivalent Doses (rem) for 20-Year-Aged Weapons-Grade Plutonium Based on Detection of $0.16 \mathrm{nCi}^{241} \mathrm{Am}$ in the Lungs

\begin{tabular}{rrr}
\hline Days Post Intake & Type M Inhalation & Type S Inhalation \\
\hline 0.5 & $6.15 \mathrm{E}+01$ & $5.01 \mathrm{E}+00$ \\
1 & $6.38 \mathrm{E}+01$ & $5.18 \mathrm{E}+00$ \\
2 & $6.58 \mathrm{E}+01$ & $5.31 \mathrm{E}+00$ \\
5 & $6.89 \mathrm{E}+01$ & $5.49 \mathrm{E}+00$ \\
7 & $7.10 \mathrm{E}+01$ & $5.59 \mathrm{E}+00$ \\
14 & $7.82 \mathrm{E}+01$ & $5.96 \mathrm{E}+00$ \\
30 & $9.56 \mathrm{E}+01$ & $6.73 \mathrm{E}+00$ \\
60 & $1.30 \mathrm{E}+02$ & $7.92 \mathrm{E}+00$ \\
90 & $1.67 \mathrm{E}+02$ & $8.79 \mathrm{E}+00$ \\
180 & $3.04 \mathrm{E}+02$ & $1.03 \mathrm{E}+01$ \\
365 & $8.97 \mathrm{E}+02$ & $1.22 \mathrm{E}+01$ \\
730 & not meaningful & $1.66 \mathrm{E}+01$ \\
1,826 & not meaningful & $3.63 \mathrm{E}+01$ \\
3,652 & not meaningful & $8.22 \mathrm{E}+01$ \\
7,305 & not meaningful & $1.73 \mathrm{E}+02$ \\
10,957 & not meaningful & $3.08 \mathrm{E}+02$ \\
\hline
\end{tabular}

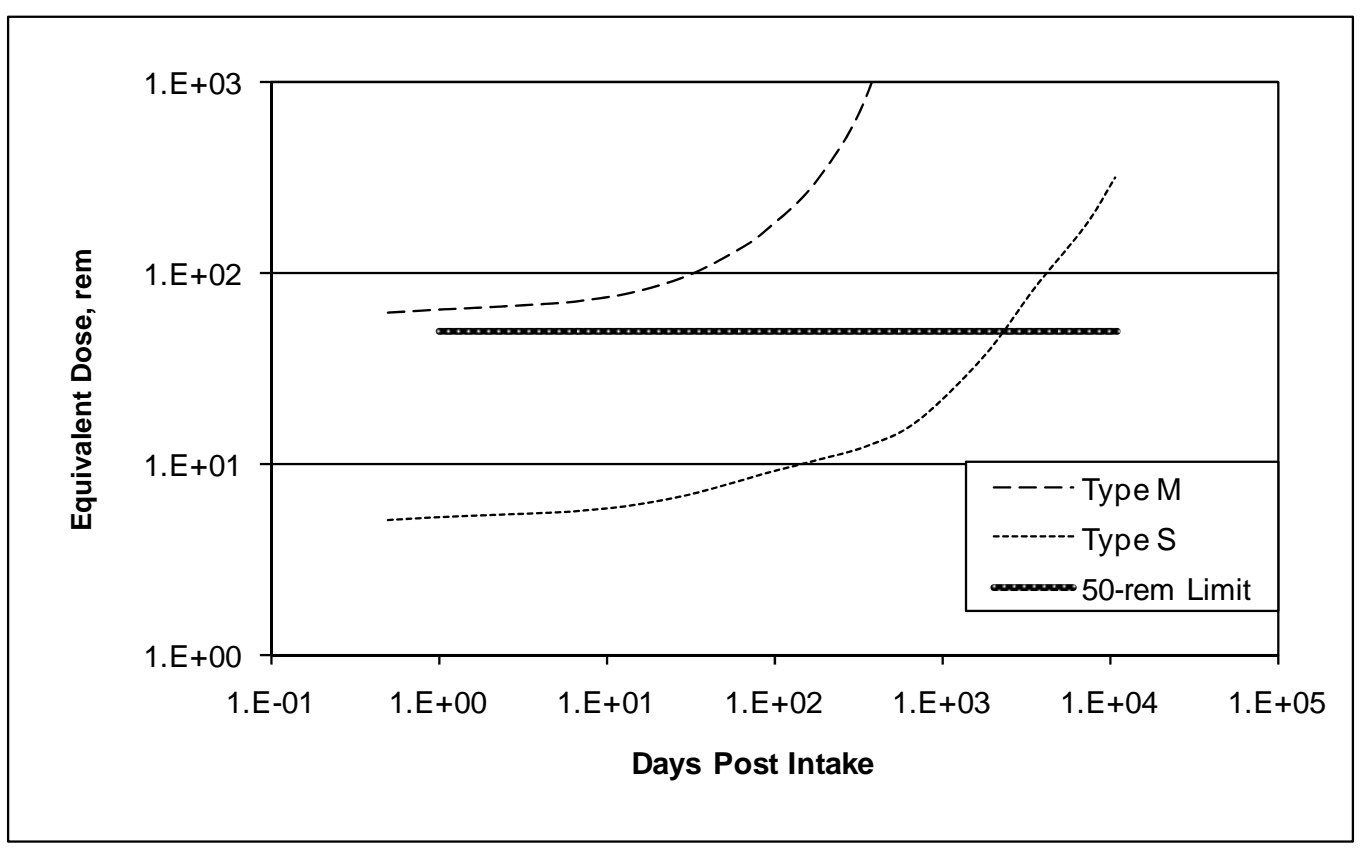

Figure 8.25. Minimum Detectable Bone Surface Committed Equivalent Doses for 20-Year-Aged Weapons-Grade Plutonium Based on Detection of $0.16 \mathrm{nCi}^{241} \mathrm{Am}$ in the Lungs 
Table 8.41. Minimum Detectable Bone Surface Committed Equivalent Doses (rem) for 50-Year-Aged Weapons-Grade Plutonium Based on Detection of $0.16 \mathrm{nCi}^{241} \mathrm{Am}$ in the Lungs

\begin{tabular}{ccc}
\hline Days Post Intake & Type M Inhalation & Type S Inhalation \\
\hline 0.5 & $4.39 \mathrm{E}+01$ & $3.55 \mathrm{E}+00$ \\
1 & $4.55 \mathrm{E}+01$ & $3.68 \mathrm{E}+00$ \\
2 & $4.69 \mathrm{E}+01$ & $3.77 \mathrm{E}+00$ \\
5 & $4.91 \mathrm{E}+01$ & $3.89 \mathrm{E}+00$ \\
7 & $5.06 \mathrm{E}+01$ & $3.97 \mathrm{E}+00$ \\
14 & $5.58 \mathrm{E}+01$ & $4.23 \mathrm{E}+00$ \\
30 & $6.83 \mathrm{E}+01$ & $4.79 \mathrm{E}+00$ \\
60 & $9.33 \mathrm{E}+01$ & $5.64 \mathrm{E}+00$ \\
90 & $1.20 \mathrm{E}+02$ & $6.27 \mathrm{E}+00$ \\
180 & $2.20 \mathrm{E}+02$ & $7.38 \mathrm{E}+00$ \\
365 & $6.55 \mathrm{E}+02$ & $8.89 \mathrm{E}+00$ \\
730 & not meaningful & $1.23 \mathrm{E}+01$ \\
1,826 & not meaningful & $2.86 \mathrm{E}+01$ \\
3,652 & not meaningful & $6.97 \mathrm{E}+01$ \\
7,305 & not meaningful & $1.61 \mathrm{E}+02$ \\
10,957 & not meaningful & $3.01 \mathrm{E}+02$ \\
\hline
\end{tabular}

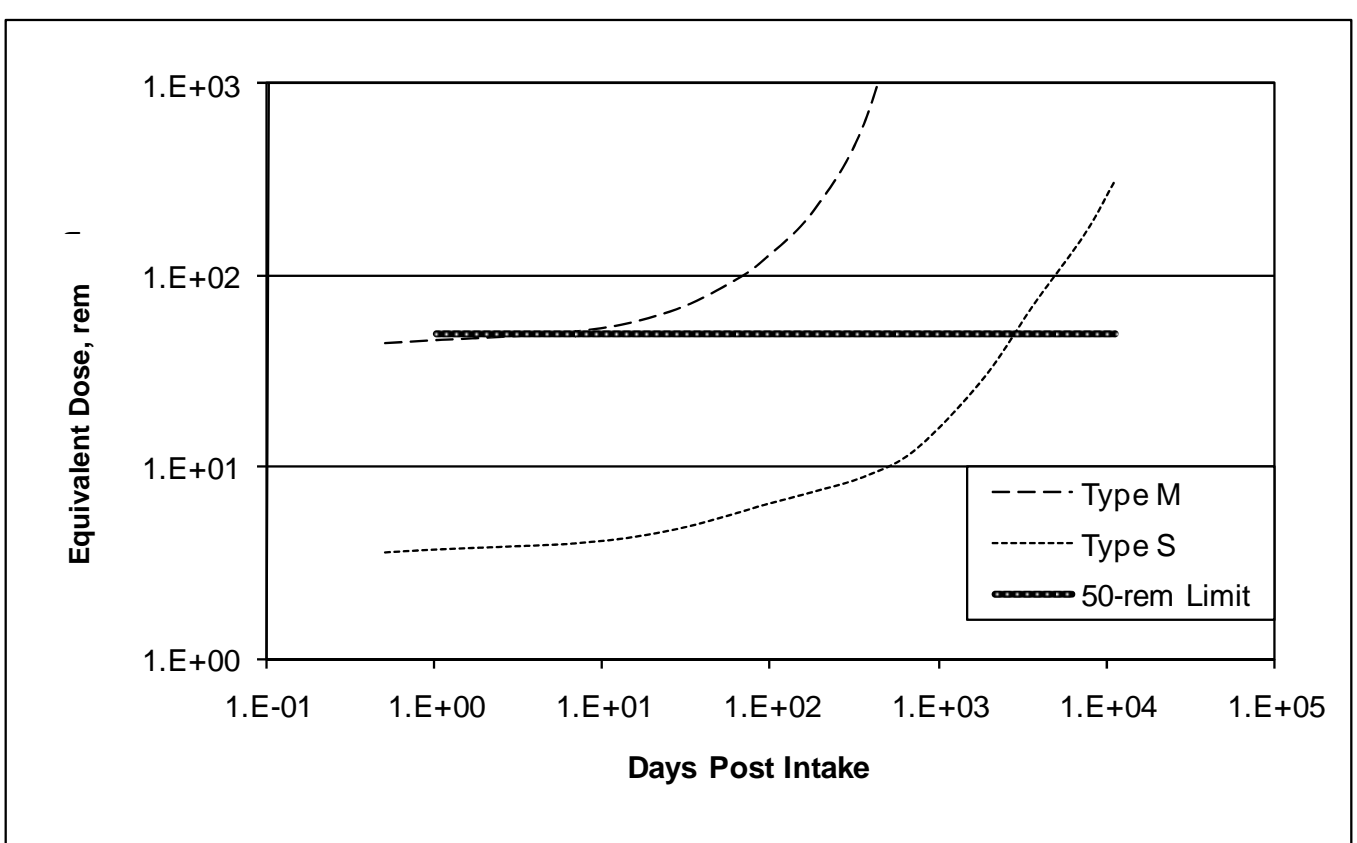

Figure 8.26. Minimum Detectable Bone Surface Committed Equivalent Doses (rem) for 50-Year-Aged Weapons-Grade Plutonium Based on Detection of $0.16 \mathrm{nCi}^{241} \mathrm{Am}$ in the Lungs 
Table 8.42. Minimum Detectable Bone Surface Committed Equivalent Doses (rem) for 20-Year-Aged Fuel-Grade Plutonium Based on Detection of $0.16 \mathrm{nCi}^{241} \mathrm{Am}$ in the Lungs

\begin{tabular}{rcc}
\hline Days Post Intake & Type M Inhalation & Type S Inhalation \\
\hline 0.5 & $2.96 \mathrm{E}+01$ & $2.43 \mathrm{E}+00$ \\
1 & $3.07 \mathrm{E}+01$ & $2.51 \mathrm{E}+00$ \\
2 & $3.17 \mathrm{E}+01$ & $2.57 \mathrm{E}+00$ \\
5 & $3.32 \mathrm{E}+01$ & $2.66 \mathrm{E}+00$ \\
7 & $3.42 \mathrm{E}+01$ & $2.71 \mathrm{E}+00$ \\
14 & $3.77 \mathrm{E}+01$ & $2.89 \mathrm{E}+00$ \\
30 & $4.60 \mathrm{E}+01$ & $3.26 \mathrm{E}+00$ \\
60 & $6.28 \mathrm{E}+01$ & $3.84 \mathrm{E}+00$ \\
90 & $8.06 \mathrm{E}+01$ & $4.26 \mathrm{E}+00$ \\
180 & $1.46 \mathrm{E}+02$ & $4.98 \mathrm{E}+00$ \\
365 & $4.32 \mathrm{E}+02$ & $5.93 \mathrm{E}+00$ \\
730 & not meaningful & $8.03 \mathrm{E}+00$ \\
1,826 & not meaningful & $1.76 \mathrm{E}+01$ \\
3,652 & not meaningful & $3.99 \mathrm{E}+01$ \\
7,305 & not meaningful & $8.41 \mathrm{E}+01$ \\
10,957 & not meaningful & $1.49 \mathrm{E}+02$ \\
\hline
\end{tabular}

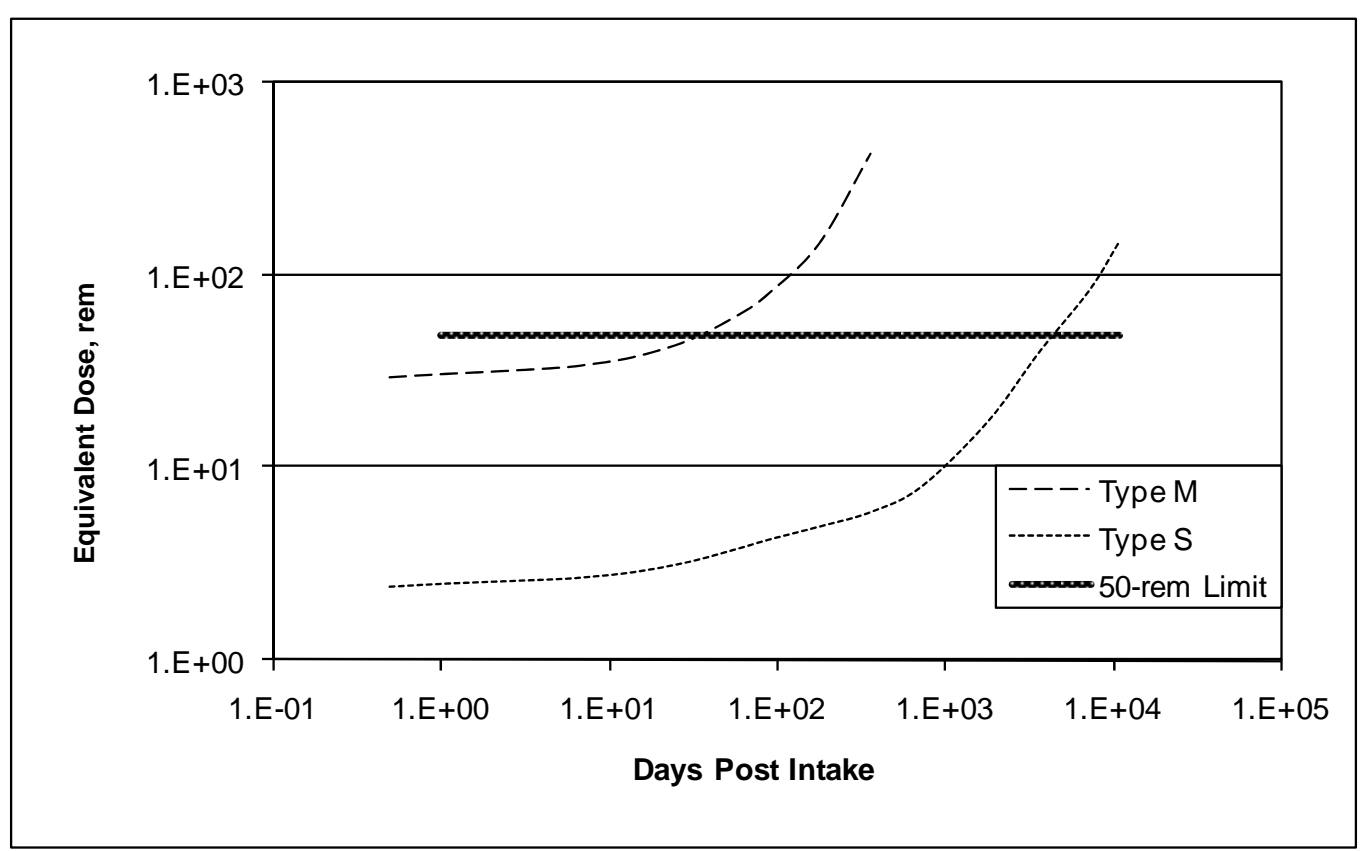

Figure 8.27. Minimum Detectable Bone Surface Committed Equivalent Doses for 20-Year-Aged FuelGrade Plutonium Based on Detection of $0.16 \mathrm{nCi}^{241} \mathrm{Am}$ in the Lungs 
Table 8.43. Minimum Detectable Bone Surface Committed Equivalent Doses (rem) for 50-Year-Aged Fuel-Grade Plutonium Based on Detection of $0.16 \mathrm{nCi}^{241} \mathrm{Am}$ in the Lungs

\begin{tabular}{rrr}
\hline Days Post Intake & Type M Inhalation & Type S Inhalation \\
\hline 0.5 & $2.17 \mathrm{E}+01$ & $1.76 \mathrm{E}+00$ \\
1 & $2.26 \mathrm{E}+01$ & $1.83 \mathrm{E}+00$ \\
2 & $2.32 \mathrm{E}+01$ & $1.87 \mathrm{E}+00$ \\
5 & $2.44 \mathrm{E}+01$ & $1.93 \mathrm{E}+00$ \\
7 & $2.51 \mathrm{E}+01$ & $1.97 \mathrm{E}+00$ \\
14 & $2.77 \mathrm{E}+01$ & $2.10 \mathrm{E}+00$ \\
30 & $3.39 \mathrm{E}+01$ & $2.38 \mathrm{E}+00$ \\
60 & $4.63 \mathrm{E}+01$ & $2.80 \mathrm{E}+00$ \\
90 & $5.95 \mathrm{E}+01$ & $3.12 \mathrm{E}+00$ \\
180 & $1.09 \mathrm{E}+02$ & $3.66 \mathrm{E}+00$ \\
365 & $3.25 \mathrm{E}+02$ & $4.41 \mathrm{E}+00$ \\
730 & not meaningful & $6.11 \mathrm{E}+00$ \\
1,826 & not meaningful & $1.42 \mathrm{E}+01$ \\
3,652 & not meaningful & $3.46 \mathrm{E}+01$ \\
7,305 & not meaningful & $8.00 \mathrm{E}+01$ \\
10,957 & not meaningful & $1.50 \mathrm{E}+02$ \\
\hline
\end{tabular}

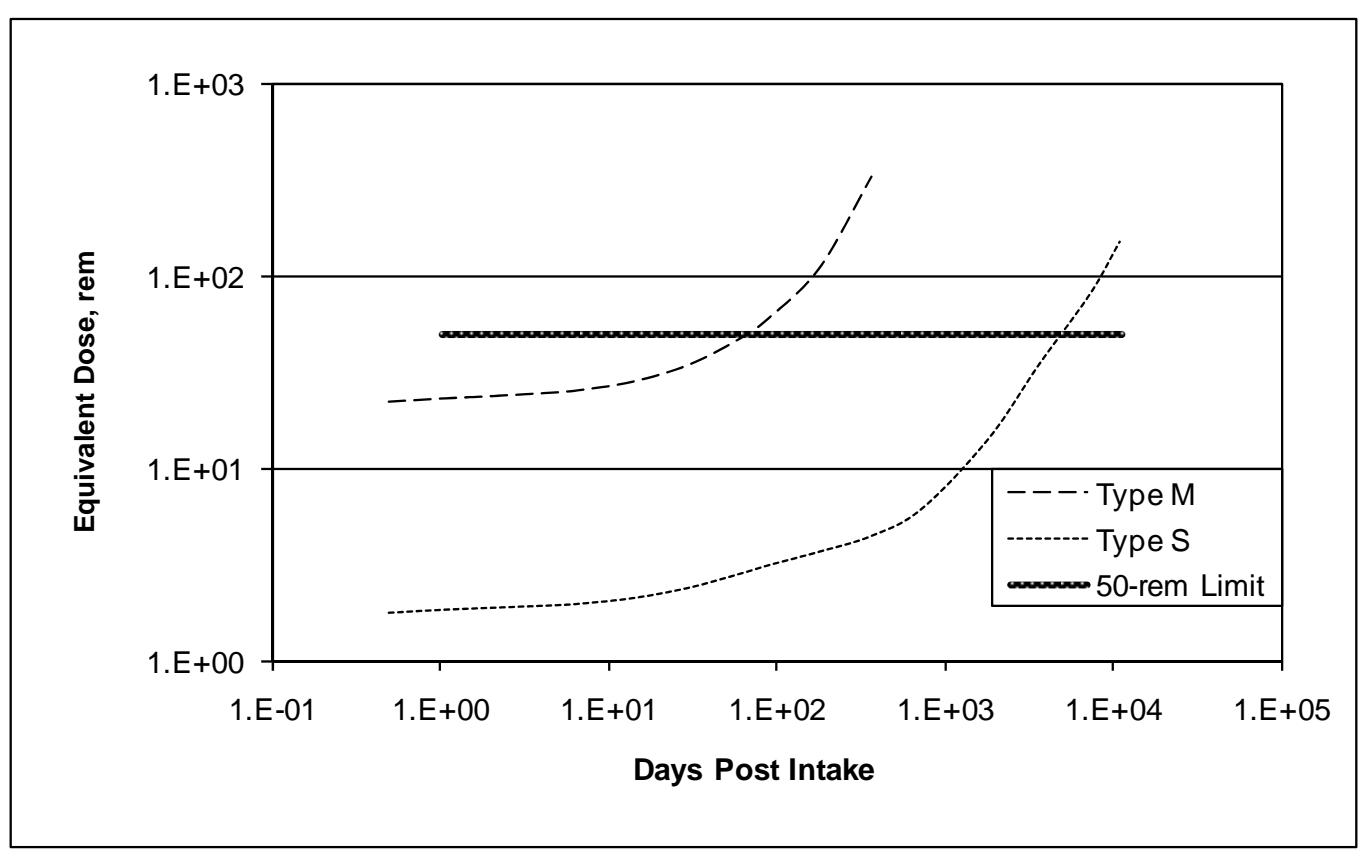

Figure 8.28. Minimum Detectable Bone Surface Committed Equivalent Doses for 50-Year-Aged FuelGrade Plutonium Based on Detection of $0.16 \mathrm{nCi}^{241} \mathrm{Am}$ in the Lungs 
Table 8.44. Minimum Detectable Committed Equivalent Doses (rem) for Extrathoracic Tissues and the Lung (rem) for Inhalation of Type Super S Weapons-Grade Plutonium Based on Detection of $0.16 \mathrm{nCi}^{241} \mathrm{Am}$ in the Lungs

\begin{tabular}{ccccc}
\hline & \multicolumn{2}{c}{ Extrathoracic Tissue } & \multicolumn{2}{c}{ Lung } \\
\cline { 2 - 5 } Days Post Intake & $\begin{array}{c}\text { 20-Year Weapons- } \\
\text { Grade Plutonium }\end{array}$ & $\begin{array}{c}50 \text {-Year Weapons- } \\
\text { Grade Plutonium }\end{array}$ & $\begin{array}{c}\text { 20-Year Weapons- } \\
\text { Grade Plutonium }\end{array}$ & $\begin{array}{c}\text { 50-Year Weapons- } \\
\text { Grade Plutonium }\end{array}$ \\
\hline 0.5 & $4.46 \mathrm{E}+00$ & $3.27 \mathrm{E}+00$ & $2.85 \mathrm{E}+00$ & $2.07 \mathrm{E}+00$ \\
1 & $4.62 \mathrm{E}+00$ & $3.38 \mathrm{E}+00$ & $2.95 \mathrm{E}+00$ & $2.14 \mathrm{E}+00$ \\
2 & $4.74 \mathrm{E}+00$ & $3.47 \mathrm{E}+00$ & $3.03 \mathrm{E}+00$ & $2.19 \mathrm{E}+00$ \\
5 & $4.89 \mathrm{E}+00$ & $3.58 \mathrm{E}+00$ & $3.12 \mathrm{E}+00$ & $2.26 \mathrm{E}+00$ \\
7 & $4.98 \mathrm{E}+00$ & $3.65 \mathrm{E}+00$ & $3.18 \mathrm{E}+00$ & $2.31 \mathrm{E}+00$ \\
14 & $5.31 \mathrm{E}+00$ & $3.89 \mathrm{E}+00$ & $3.39 \mathrm{E}+00$ & $2.46 \mathrm{E}+00$ \\
30 & $5.99 \mathrm{E}+00$ & $4.40 \mathrm{E}+00$ & $3.83 \mathrm{E}+00$ & $2.78 \mathrm{E}+00$ \\
60 & $7.03 \mathrm{E}+00$ & $5.17 \mathrm{E}+00$ & $4.49 \mathrm{E}+00$ & $3.27 \mathrm{E}+00$ \\
90 & $7.77 \mathrm{E}+00$ & $5.73 \mathrm{E}+00$ & $4.97 \mathrm{E}+00$ & $3.62 \mathrm{E}+00$ \\
180 & $9.01 \mathrm{E}+00$ & $6.68 \mathrm{E}+00$ & $5.76 \mathrm{E}+00$ & $4.23 \mathrm{E}+00$ \\
365 & $1.06 \mathrm{E}+01$ & $7.92 \mathrm{E}+00$ & $6.74 \mathrm{E}+00$ & $5.01 \mathrm{E}+00$ \\
730 & $1.38 \mathrm{E}+01$ & $1.06 \mathrm{E}+01$ & $8.83 \mathrm{E}+00$ & $6.71 \mathrm{E}+00$ \\
1,826 & $2.74 \mathrm{E}+01$ & $2.23 \mathrm{E}+01$ & $1.75 \mathrm{E}+01$ & $1.41 \mathrm{E}+01$ \\
3,652 & $5.28 \mathrm{E}+01$ & $4.62 \mathrm{E}+01$ & $3.37 \mathrm{E}+01$ & $2.92 \mathrm{E}+01$ \\
7,305 & $8.01 \mathrm{E}+01$ & $7.68 \mathrm{E}+01$ & $5.12 \mathrm{E}+01$ & $4.86 \mathrm{E}+01$ \\
10,957 & $1.02 \mathrm{E}+02$ & $1.03 \mathrm{E}+02$ & $6.54 \mathrm{E}+01$ & $6.54 \mathrm{E}+01$ \\
\hline
\end{tabular}

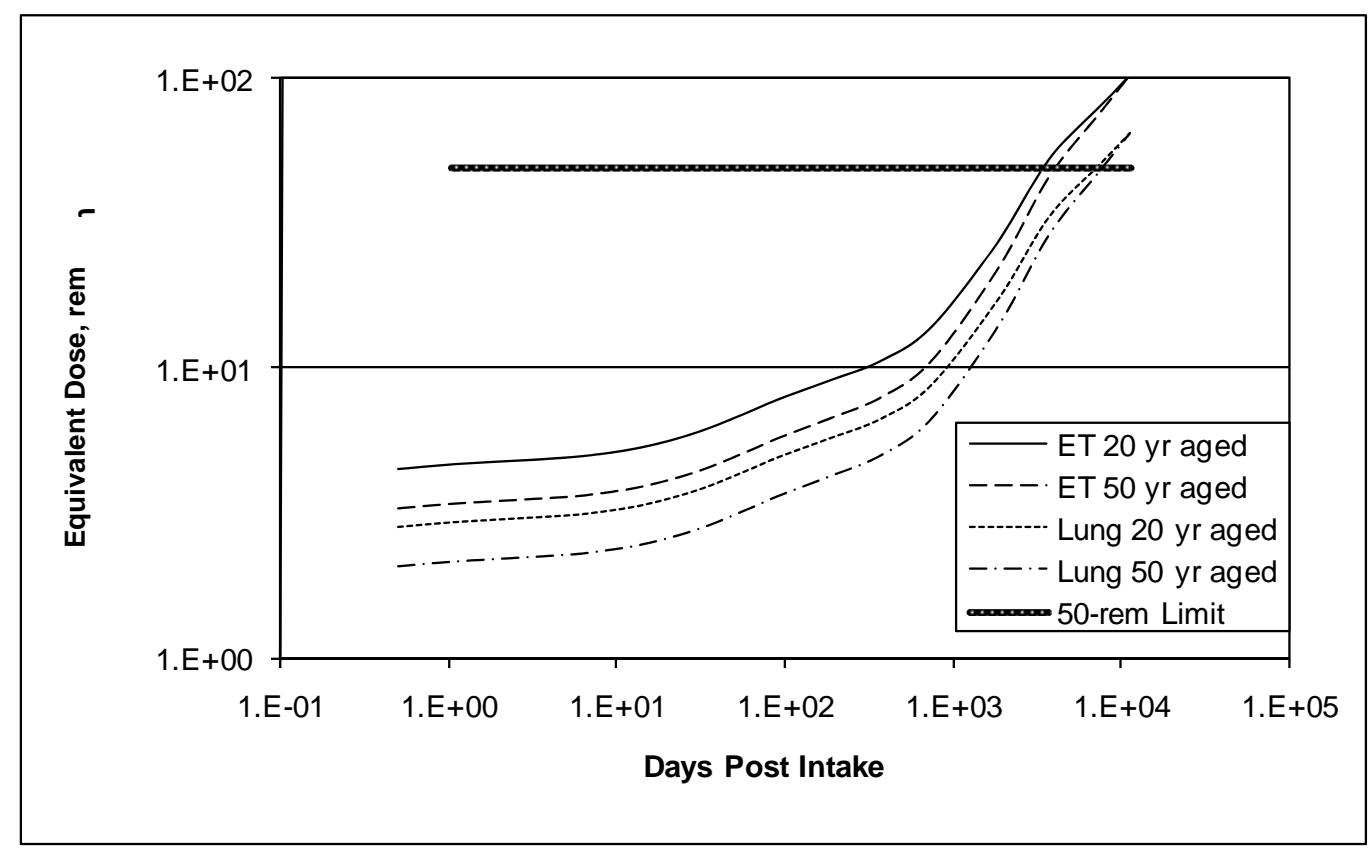

Figure 8.29. Minimum Detectable Committed Equivalent Doses (rem) for Extrathoracic Tissues and the Lung (rem) for Inhalation of Type Super S Weapons-Grade Plutonium Based on Detection of $0.16 \mathrm{nCi}^{241} \mathrm{Am}$ in the Lungs 
Table 8.45. Minimum Detectable Committed Equivalent Doses (rem) for Extrathoracic Tissues and the Lung (rem) for Inhalation of Type Super S Fuel-Grade Plutonium Based on Detection of $0.16 \mathrm{nCi}^{241} \mathrm{Am}$ in the Lungs

\begin{tabular}{ccccc}
\hline & \multicolumn{2}{c}{ Extrathoracic Tissues } & \multicolumn{2}{c}{ Lung } \\
\cline { 2 - 5 } Days Post Intake & $\begin{array}{c}\text { 20-Year Fuel- } \\
\text { Grade Plutonium }\end{array}$ & $\begin{array}{c}50 \text {-Year Fuel- } \\
\text { Grade Plutonium }\end{array}$ & $\begin{array}{c}20 \text {-Year Fuel- } \\
\text { Grade Plutonium }\end{array}$ & $\begin{array}{c}\text { 50-Year Fuel- } \\
\text { Grade Plutonium }\end{array}$ \\
\hline 0.5 & $1.96 \mathrm{E}+00$ & $1.54 \mathrm{E}+00$ & $1.27 \mathrm{E}+00$ & $9.81 \mathrm{E}-01$ \\
1 & $2.03 \mathrm{E}+00$ & $1.59 \mathrm{E}+00$ & $1.31 \mathrm{E}+00$ & $1.02 \mathrm{E}+00$ \\
2 & $2.08 \mathrm{E}+00$ & $1.63 \mathrm{E}+00$ & $1.35 \mathrm{E}+00$ & $1.04 \mathrm{E}+00$ \\
5 & $2.15 \mathrm{E}+00$ & $1.69 \mathrm{E}+00$ & $1.39 \mathrm{E}+00$ & $1.08 \mathrm{E}+00$ \\
7 & $2.19 \mathrm{E}+00$ & $1.72 \mathrm{E}+00$ & $1.42 \mathrm{E}+00$ & $1.10 \mathrm{E}+00$ \\
14 & $2.33 \mathrm{E}+00$ & $1.83 \mathrm{E}+00$ & $1.51 \mathrm{E}+00$ & $1.17 \mathrm{E}+00$ \\
30 & $2.64 \mathrm{E}+00$ & $2.07 \mathrm{E}+00$ & $1.70 \mathrm{E}+00$ & $1.32 \mathrm{E}+00$ \\
60 & $3.09 \mathrm{E}+00$ & $2.43 \mathrm{E}+00$ & $2.00 \mathrm{E}+00$ & $1.55 \mathrm{E}+00$ \\
90 & $3.42 \mathrm{E}+00$ & $2.69 \mathrm{E}+00$ & $2.21 \mathrm{E}+00$ & $1.72 \mathrm{E}+00$ \\
180 & $3.97 \mathrm{E}+00$ & $3.14 \mathrm{E}+00$ & $2.56 \mathrm{E}+00$ & $2.01 \mathrm{E}+00$ \\
365 & $4.64 \mathrm{E}+00$ & $3.72 \mathrm{E}+00$ & $3.00 \mathrm{E}+00$ & $2.38 \mathrm{E}+00$ \\
730 & $6.09 \mathrm{E}+00$ & $4.99 \mathrm{E}+00$ & $3.93 \mathrm{E}+00$ & $3.19 \mathrm{E}+00$ \\
1,826 & $1.21 \mathrm{E}+01$ & $1.05 \mathrm{E}+01$ & $7.81 \mathrm{E}+00$ & $6.70 \mathrm{E}+00$ \\
3,652 & $2.32 \mathrm{E}+01$ & $2.17 \mathrm{E}+01$ & $1.50 \mathrm{E}+01$ & $1.39 \mathrm{E}+01$ \\
7,305 & $3.53 \mathrm{E}+01$ & $3.61 \mathrm{E}+01$ & $2.28 \mathrm{E}+01$ & $2.31 \mathrm{E}+01$ \\
10,957 & $4.51 \mathrm{E}+01$ & $4.87 \mathrm{E}+01$ & $2.91 \mathrm{E}+01$ & $3.10 \mathrm{E}+01$ \\
\hline
\end{tabular}

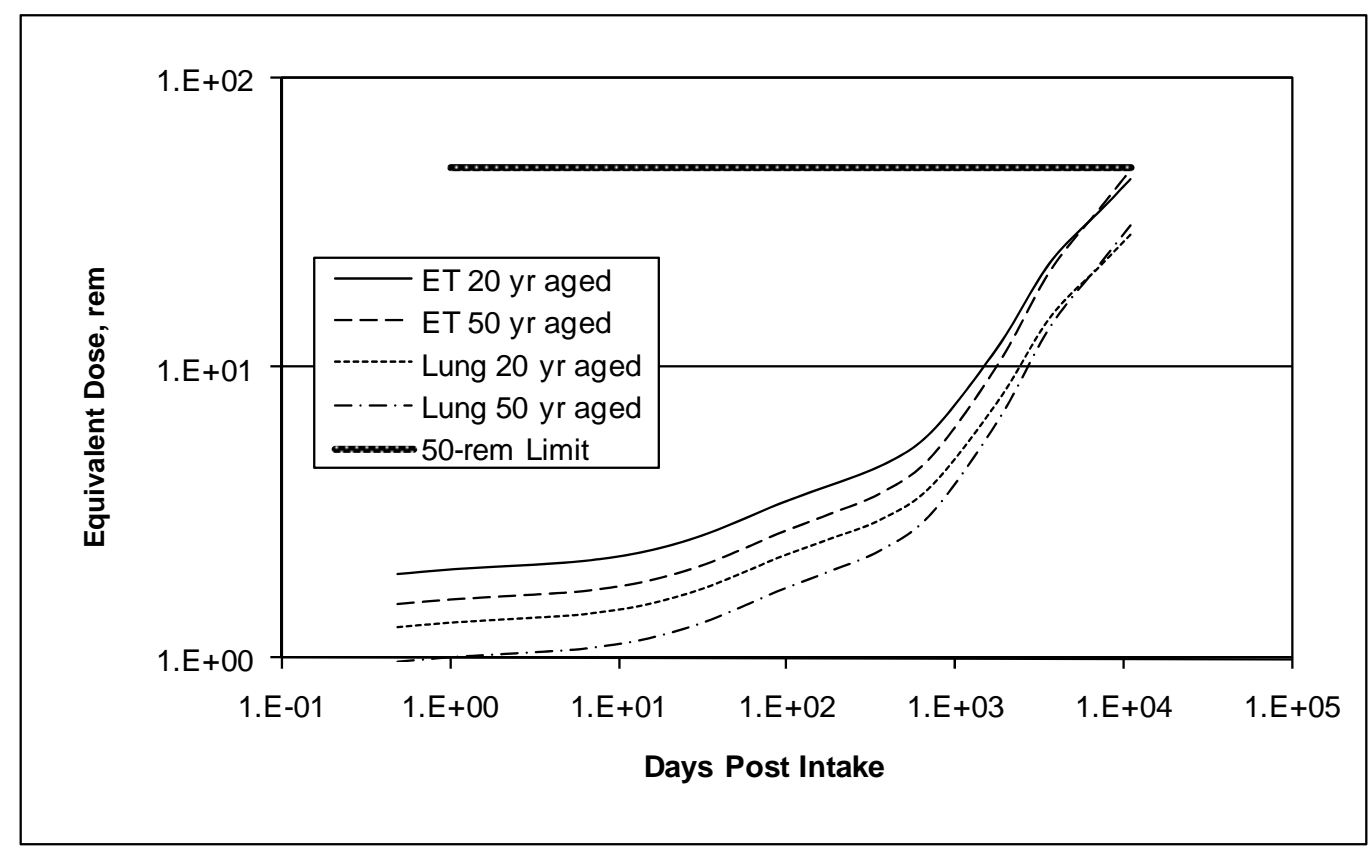

Figure 8.30. Minimum Detectable Committed Equivalent Doses (rem) for Extrathoracic Tissues and the Lung (rem) for Inhalation of Type Super S Fuel-Grade Plutonium Based on Detection of $0.16 \mathrm{nCi}^{241} \mathrm{Am}$ in the Lungs 
Table 8.46. Minimum Detectable Intakes (nCi) of ${ }^{239} \mathrm{Pu}$ Based on Detection of $0.2 \mathrm{dpm} / \mathrm{d}$ in Feces

\begin{tabular}{rrcc}
\hline Days Post Intake & Type M Inhalation & Type S Inhalation & Type SS Inhalation \\
\hline 1 & $8.32 \mathrm{E}-04$ & $7.90 \mathrm{E}-04$ & $7.89 \mathrm{E}-04$ \\
2 & $5.82 \mathrm{E}-04$ & $5.52 \mathrm{E}-04$ & $5.52 \mathrm{E}-04$ \\
5 & $6.75 \mathrm{E}-03$ & $6.41 \mathrm{E}-03$ & $6.40 \mathrm{E}-03$ \\
7 & $3.86 \mathrm{E}-02$ & $3.64 \mathrm{E}-02$ & $3.64 \mathrm{E}-02$ \\
14 & $2.05 \mathrm{E}-01$ & $1.78 \mathrm{E}-01$ & $1.78 \mathrm{E}-01$ \\
30 & $3.20 \mathrm{E}-01$ & $2.57 \mathrm{E}-01$ & $2.56 \mathrm{E}-01$ \\
60 & $6.89 \mathrm{E}-01$ & $4.84 \mathrm{E}-01$ & $4.81 \mathrm{E}-01$ \\
90 & $1.35 \mathrm{E}+00$ & $8.42 \mathrm{E}-01$ & $8.35 \mathrm{E}-01$ \\
180 & $5.28 \mathrm{E}+00$ & $2.41 \mathrm{E}+00$ & $2.38 \mathrm{E}+00$ \\
365 & $1.66 \mathrm{E}+01$ & $4.05 \mathrm{E}+00$ & $3.94 \mathrm{E}+00$ \\
730 & $5.55 \mathrm{E}+01$ & $6.06 \mathrm{E}+00$ & $5.70 \mathrm{E}+00$ \\
1,826 & $1.49 \mathrm{E}+02$ & $1.91 \mathrm{E}+01$ & $1.64 \mathrm{E}+01$ \\
3,652 & $2.06 \mathrm{E}+02$ & $1.04 \mathrm{E}+02$ & $7.92 \mathrm{E}+01$ \\
7,305 & $2.68 \mathrm{E}+02$ & $5.73 \mathrm{E}+02$ & $3.90 \mathrm{E}+02$ \\
10,957 & $3.17 \mathrm{E}+02$ & $1.09 \mathrm{E}+03$ & $6.75 \mathrm{E}+02$ \\
\hline
\end{tabular}


Table 8.47. Minimum Detectable Committed Effective Doses (rem) for 20-Year-Aged Weapons-Grade Plutonium Based on Detection of $0.2 \mathrm{dpm} / \mathrm{d}{ }^{239} \mathrm{Pu}$ in Feces

\begin{tabular}{rccc}
\hline Days Post Intake & Type M Inhalation & Type S Inhalation & $\begin{array}{c}\text { Type Super S } \\
\text { Inhalation }\end{array}$ \\
\hline 1 & $1.37 \mathrm{E}-04$ & $3.46 \mathrm{E}-05$ & $3.61 \mathrm{E}-05$ \\
2 & $9.57 \mathrm{E}-05$ & $2.42 \mathrm{E}-05$ & $2.52 \mathrm{E}-05$ \\
5 & $1.11 \mathrm{E}-03$ & $2.81 \mathrm{E}-04$ & $2.93 \mathrm{E}-04$ \\
7 & $6.34 \mathrm{E}-03$ & $1.60 \mathrm{E}-03$ & $1.66 \mathrm{E}-03$ \\
14 & $3.38 \mathrm{E}-02$ & $7.80 \mathrm{E}-03$ & $8.12 \mathrm{E}-03$ \\
30 & $5.27 \mathrm{E}-02$ & $1.13 \mathrm{E}-02$ & $1.17 \mathrm{E}-02$ \\
60 & $1.13 \mathrm{E}-01$ & $2.12 \mathrm{E}-02$ & $2.20 \mathrm{E}-02$ \\
90 & $2.23 \mathrm{E}-01$ & $3.69 \mathrm{E}-02$ & $3.82 \mathrm{E}-02$ \\
180 & $8.69 \mathrm{E}-01$ & $1.06 \mathrm{E}-01$ & $1.09 \mathrm{E}-01$ \\
365 & $2.73 \mathrm{E}+00$ & $1.78 \mathrm{E}-01$ & $1.80 \mathrm{E}-01$ \\
730 & $9.12 \mathrm{E}+00$ & $2.66 \mathrm{E}-01$ & $2.61 \mathrm{E}-01$ \\
1,826 & $2.45 \mathrm{E}+01$ & $8.37 \mathrm{E}-01$ & $7.51 \mathrm{E}-01$ \\
3,652 & $3.39 \mathrm{E}+01$ & $4.57 \mathrm{E}+00$ & $3.62 \mathrm{E}+00$ \\
7,305 & $4.40 \mathrm{E}+01$ & $2.51 \mathrm{E}+01$ & $1.78 \mathrm{E}+01$ \\
10,957 & $5.22 \mathrm{E}+01$ & $4.80 \mathrm{E}+01$ & $3.09 \mathrm{E}+01$ \\
\hline
\end{tabular}

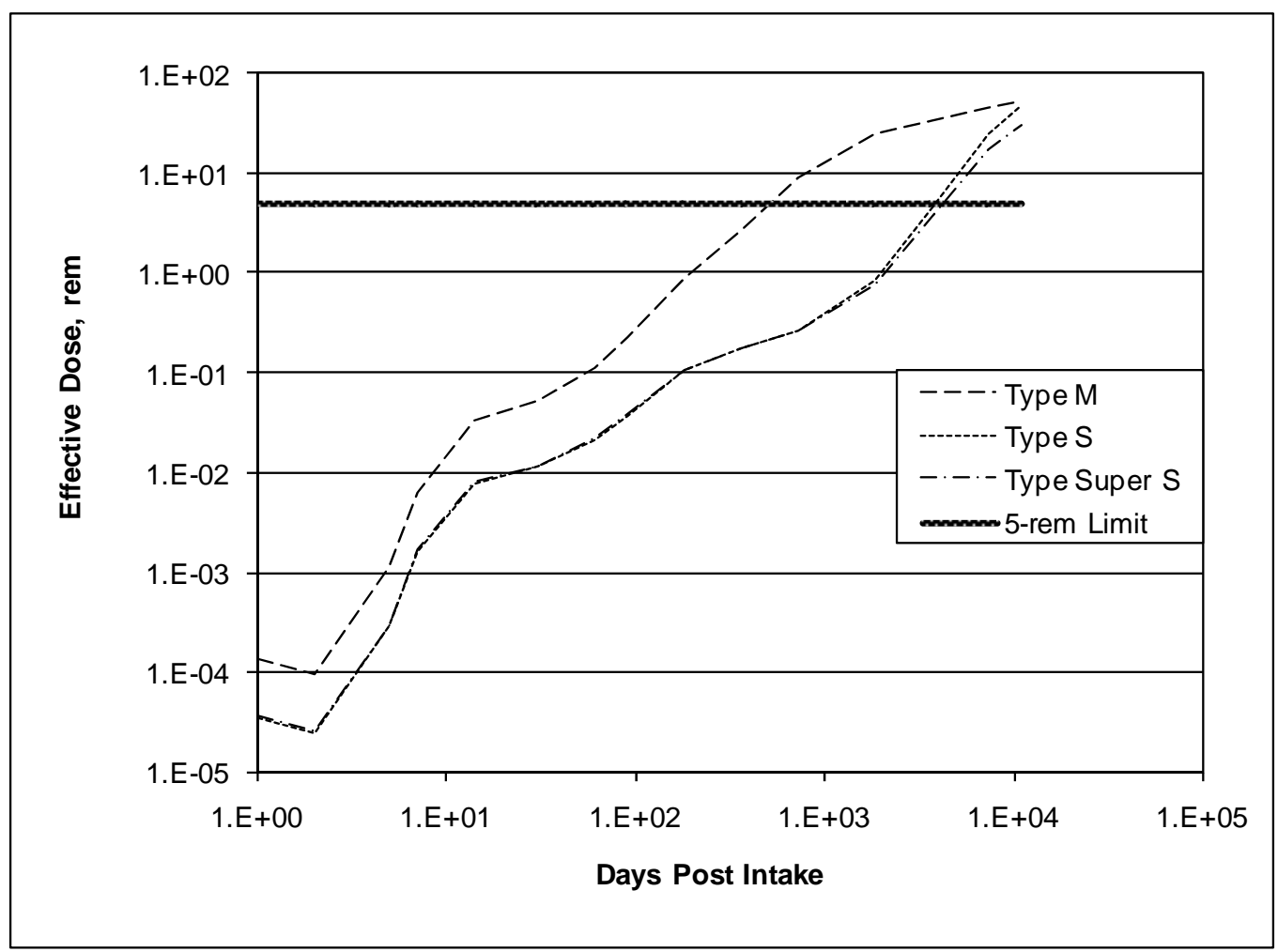

Figure 8.31. Minimum Detectable Committed Effective Doses for 20-Year-Aged Weapons-Grade Plutonium Based on Detection of $0.2 \mathrm{dpm} / \mathrm{d}{ }^{239} \mathrm{Pu}$ in Feces 
Table 8.48. Minimum Detectable Committed Effective Doses (rem) for 50-Year-Aged Weapons-Grade Plutonium Based on Detection of $0.2 \mathrm{dpm} / \mathrm{d}{ }^{239} \mathrm{Pu}$ in Feces

\begin{tabular}{rccc}
\hline Days Post Intake & Type M Inhalation & Type S Inhalation & $\begin{array}{c}\text { Type Super S } \\
\text { Inhalation }\end{array}$ \\
\hline 1 & $1.37 \mathrm{E}-04$ & $3.56 \mathrm{E}-05$ & $3.73 \mathrm{E}-05$ \\
2 & $9.60 \mathrm{E}-05$ & $2.49 \mathrm{E}-05$ & $2.61 \mathrm{E}-05$ \\
5 & $1.11 \mathrm{E}-03$ & $2.89 \mathrm{E}-04$ & $3.03 \mathrm{E}-04$ \\
7 & $6.36 \mathrm{E}-03$ & $1.64 \mathrm{E}-03$ & $1.72 \mathrm{E}-03$ \\
14 & $3.38 \mathrm{E}-02$ & $8.01 \mathrm{E}-03$ & $8.41 \mathrm{E}-03$ \\
30 & $5.28 \mathrm{E}-02$ & $1.16 \mathrm{E}-02$ & $1.21 \mathrm{E}-02$ \\
60 & $1.14 \mathrm{E}-01$ & $2.18 \mathrm{E}-02$ & $2.28 \mathrm{E}-02$ \\
90 & $2.23 \mathrm{E}-01$ & $3.79 \mathrm{E}-02$ & $3.95 \mathrm{E}-02$ \\
180 & $8.71 \mathrm{E}-01$ & $1.09 \mathrm{E}-01$ & $1.12 \mathrm{E}-01$ \\
365 & $2.73 \mathrm{E}+00$ & $1.83 \mathrm{E}-01$ & $1.86 \mathrm{E}-01$ \\
730 & $9.14 \mathrm{E}+00$ & $2.73 \mathrm{E}-01$ & $2.70 \mathrm{E}-01$ \\
1,826 & $2.46 \mathrm{E}+01$ & $8.60 \mathrm{E}-01$ & $7.77 \mathrm{E}-01$ \\
3,652 & $3.40 \mathrm{E}+01$ & $4.69 \mathrm{E}+00$ & $3.75 \mathrm{E}+00$ \\
7,305 & $4.41 \mathrm{E}+01$ & $2.58 \mathrm{E}+01$ & $1.84 \mathrm{E}+01$ \\
10,957 & $5.23 \mathrm{E}+01$ & $4.93 \mathrm{E}+01$ & $3.19 \mathrm{E}+01$ \\
\hline
\end{tabular}

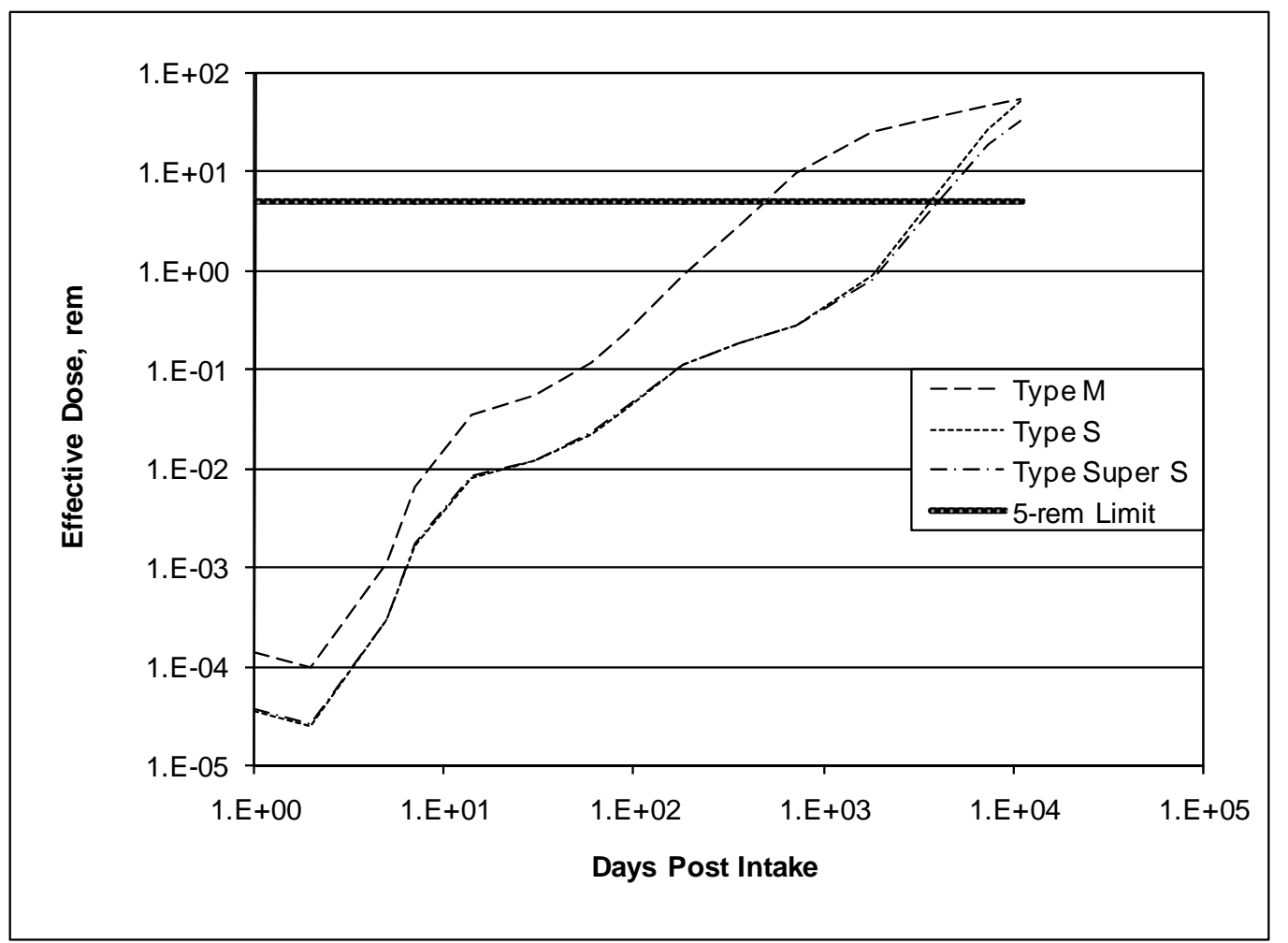

Figure 8.32. Minimum Detectable Committed Effective Doses for 50-Year-Aged Weapons-Grade Plutonium Based on Detection of $0.2 \mathrm{dpm} / \mathrm{d}{ }^{239} \mathrm{Pu}$ in Feces 
Table 8.49. Minimum Detectable Committed Effective Doses (rem) for 20-Year-Aged Fuel-Grade Plutonium Based on Detection of $0.2 \mathrm{dpm} / \mathrm{d}{ }^{239} \mathrm{Pu}$ in Feces

\begin{tabular}{rccc}
\hline Days Post Intake & Type M Inhalation & Type S Inhalation & $\begin{array}{c}\text { Type Super S } \\
\text { Inhalation }\end{array}$ \\
\hline 1 & $2.08 \mathrm{E}-04$ & $5.34 \mathrm{E}-05$ & $5.35 \mathrm{E}-05$ \\
2 & $1.46 \mathrm{E}-04$ & $3.73 \mathrm{E}-05$ & $3.74 \mathrm{E}-05$ \\
5 & $1.69 \mathrm{E}-03$ & $4.33 \mathrm{E}-04$ & $4.34 \mathrm{E}-04$ \\
7 & $9.65 \mathrm{E}-03$ & $2.46 \mathrm{E}-03$ & $2.47 \mathrm{E}-03$ \\
14 & $5.13 \mathrm{E}-02$ & $1.20 \mathrm{E}-02$ & $1.20 \mathrm{E}-02$ \\
30 & $8.02 \mathrm{E}-02$ & $1.74 \mathrm{E}-02$ & $1.74 \mathrm{E}-02$ \\
60 & $1.72 \mathrm{E}-01$ & $3.27 \mathrm{E}-02$ & $3.26 \mathrm{E}-02$ \\
90 & $3.39 \mathrm{E}-01$ & $5.69 \mathrm{E}-02$ & $5.66 \mathrm{E}-02$ \\
180 & $1.32 \mathrm{E}+00$ & $1.63 \mathrm{E}-01$ & $1.61 \mathrm{E}-01$ \\
365 & $4.15 \mathrm{E}+00$ & $2.74 \mathrm{E}-01$ & $2.67 \mathrm{E}-01$ \\
730 & $1.39 \mathrm{E}+01$ & $4.09 \mathrm{E}-01$ & $3.86 \mathrm{E}-01$ \\
1,826 & $3.73 \mathrm{E}+01$ & $1.29 \mathrm{E}+00$ & $1.11 \mathrm{E}+00$ \\
3,652 & $5.16 \mathrm{E}+01$ & $7.04 \mathrm{E}+00$ & $5.37 \mathrm{E}+00$ \\
7,305 & $6.69 \mathrm{E}+01$ & $3.87 \mathrm{E}+01$ & $2.64 \mathrm{E}+01$ \\
10,957 & $7.94 \mathrm{E}+01$ & $7.40 \mathrm{E}+01$ & $4.57 \mathrm{E}+01$ \\
\hline
\end{tabular}

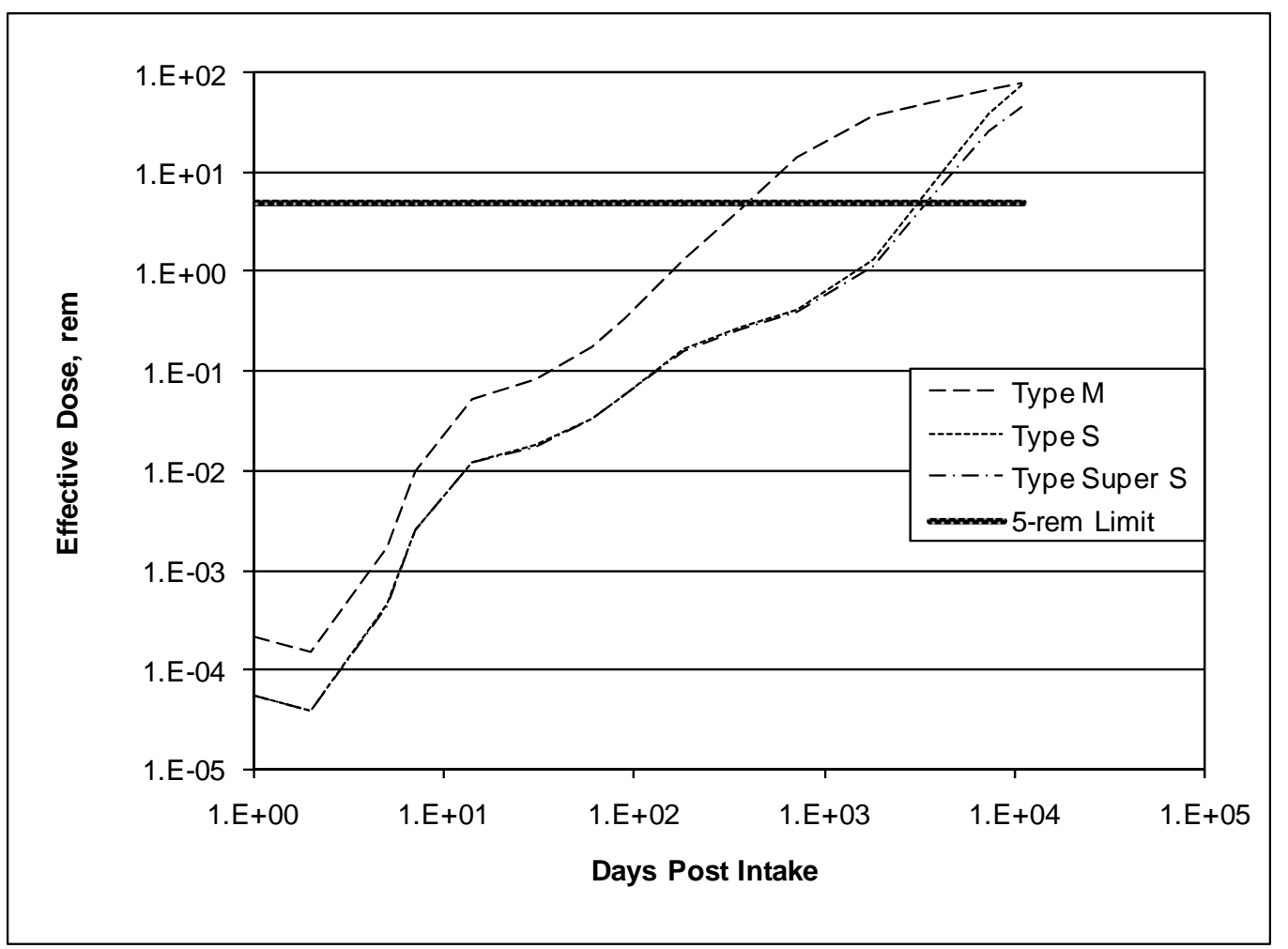

Figure 8.33. Minimum Detectable Committed Effective Doses for 20-Year-Aged Fuel-Grade Plutonium Based on Detection of $0.2 \mathrm{dpm} / \mathrm{d}{ }^{239} \mathrm{Pu}$ in Feces 
Table 8.50. Minimum Detectable Committed Effective Doses (rem) for 50-Year-Aged Fuel-Grade Plutonium Based on Detection of $0.2 \mathrm{dpm} / \mathrm{d}{ }^{239} \mathrm{Pu}$ in Feces

\begin{tabular}{rccc}
\hline Days Post Intake & Type M Inhalation & Type S Inhalation & $\begin{array}{c}\text { Type Super S } \\
\text { Inhalation }\end{array}$ \\
\hline 1 & $2.12 \mathrm{E}-04$ & $5.75 \mathrm{E}-05$ & $5.89 \mathrm{E}-05$ \\
2 & $1.49 \mathrm{E}-04$ & $4.02 \mathrm{E}-05$ & $4.12 \mathrm{E}-05$ \\
5 & $1.72 \mathrm{E}-03$ & $4.66 \mathrm{E}-04$ & $4.78 \mathrm{E}-04$ \\
7 & $9.85 \mathrm{E}-03$ & $2.65 \mathrm{E}-03$ & $2.72 \mathrm{E}-03$ \\
14 & $5.24 \mathrm{E}-02$ & $1.30 \mathrm{E}-02$ & $1.33 \mathrm{E}-02$ \\
30 & $8.19 \mathrm{E}-02$ & $1.87 \mathrm{E}-02$ & $1.91 \mathrm{E}-02$ \\
60 & $1.76 \mathrm{E}-01$ & $3.52 \mathrm{E}-02$ & $3.59 \mathrm{E}-02$ \\
90 & $3.46 \mathrm{E}-01$ & $6.13 \mathrm{E}-02$ & $6.23 \mathrm{E}-02$ \\
180 & $1.35 \mathrm{E}+00$ & $1.75 \mathrm{E}-01$ & $1.77 \mathrm{E}-01$ \\
365 & $4.24 \mathrm{E}+00$ & $2.95 \mathrm{E}-01$ & $2.94 \mathrm{E}-01$ \\
730 & $1.42 \mathrm{E}+01$ & $4.41 \mathrm{E}-01$ & $4.25 \mathrm{E}-01$ \\
1,826 & $3.81 \mathrm{E}+01$ & $1.39 \mathrm{E}+00$ & $1.22 \mathrm{E}+00$ \\
3,652 & $5.27 \mathrm{E}+01$ & $7.58 \mathrm{E}+00$ & $5.91 \mathrm{E}+00$ \\
7,305 & $6.84 \mathrm{E}+01$ & $4.17 \mathrm{E}+01$ & $2.91 \mathrm{E}+01$ \\
10,957 & $8.11 \mathrm{E}+01$ & $7.97 \mathrm{E}+01$ & $5.04 \mathrm{E}+01$ \\
\hline
\end{tabular}

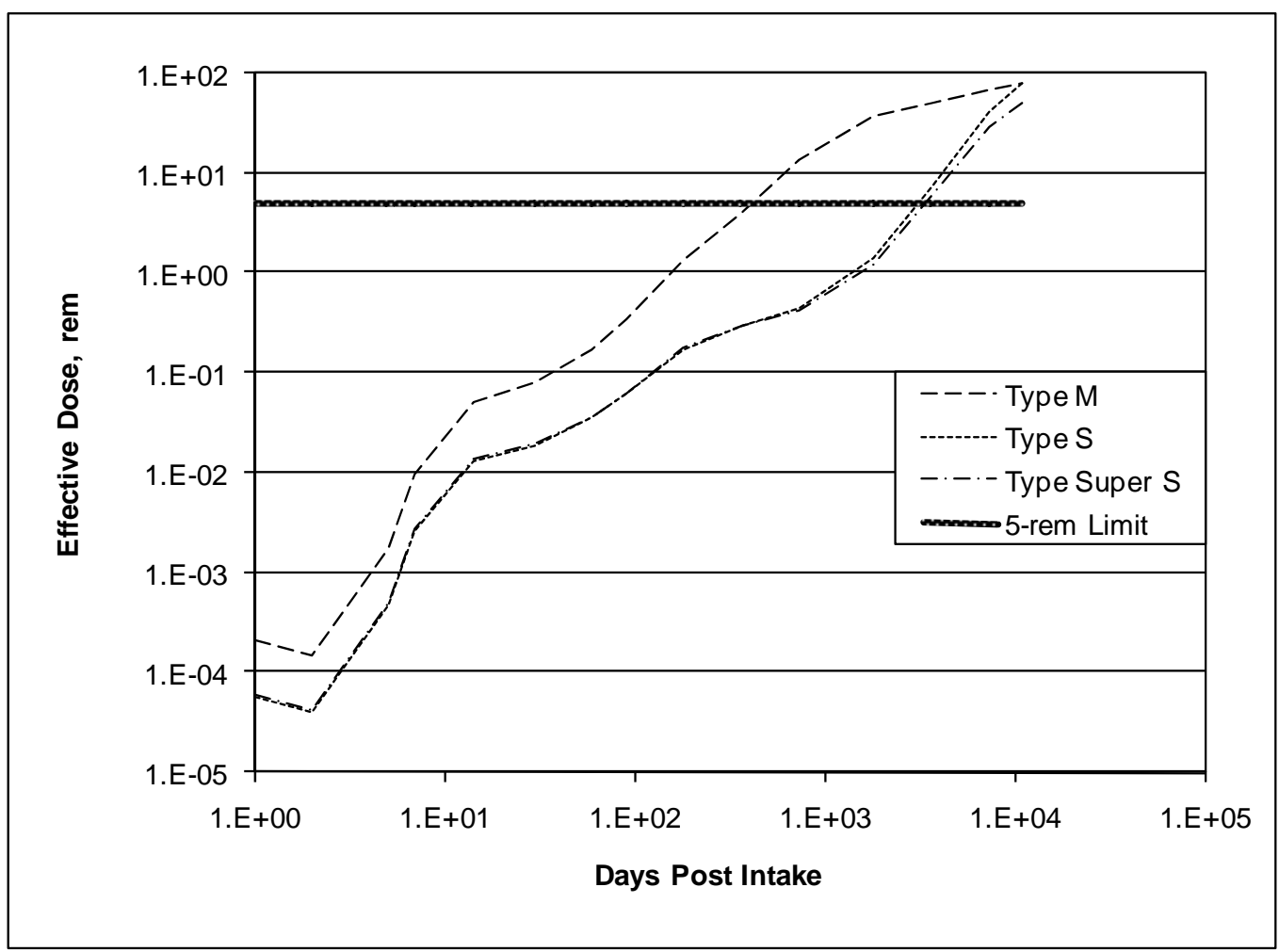

Figure 8.34. Minimum Detectable Committed Effective Doses for 50-Year-Aged Fuel-Grade Plutonium Based on Detection of $0.2 \mathrm{dpm} / \mathrm{d}{ }^{239} \mathrm{Pu}$ in Feces 
Table 8.51. Minimum Detectable Bone Surface Committed Equivalent Doses (rem) for 20-Year-Aged Weapons-Grade Plutonium Based on Detection of $0.2 \mathrm{dpm} / \mathrm{d}{ }^{239} \mathrm{Pu}$ in Feces

\begin{tabular}{rccc}
\hline Days Post Intake & Type M Inhalation & Type S Inhalation & $\begin{array}{c}\text { Type Super S } \\
\text { Inhalation }\end{array}$ \\
\hline 1 & $4.46 \mathrm{E}-03$ & $3.83 \mathrm{E}-04$ & $1.09 \mathrm{E}-04$ \\
2 & $3.12 \mathrm{E}-03$ & $2.68 \mathrm{E}-04$ & $7.60 \mathrm{E}-05$ \\
5 & $3.62 \mathrm{E}-02$ & $3.11 \mathrm{E}-03$ & $8.82 \mathrm{E}-04$ \\
7 & $2.07 \mathrm{E}-01$ & $1.77 \mathrm{E}-02$ & $5.01 \mathrm{E}-03$ \\
14 & $1.10 \mathrm{E}+00$ & $8.64 \mathrm{E}-02$ & $2.45 \mathrm{E}-02$ \\
30 & $1.72 \mathrm{E}+00$ & $1.25 \mathrm{E}-01$ & $3.53 \mathrm{E}-02$ \\
60 & $3.69 \mathrm{E}+00$ & $2.35 \mathrm{E}-01$ & $6.63 \mathrm{E}-02$ \\
90 & $7.26 \mathrm{E}+00$ & $4.09 \mathrm{E}-01$ & $1.15 \mathrm{E}-01$ \\
180 & $2.83 \mathrm{E}+01$ & $1.17 \mathrm{E}+00$ & $3.27 \mathrm{E}-01$ \\
365 & $8.90 \mathrm{E}+01$ & $1.97 \mathrm{E}+00$ & $5.42 \mathrm{E}-01$ \\
730 & $2.97 \mathrm{E}+02$ & $2.94 \mathrm{E}+00$ & $7.85 \mathrm{E}-01$ \\
1,826 & $7.99 \mathrm{E}+02$ & $9.27 \mathrm{E}+00$ & $2.26 \mathrm{E}+00$ \\
3,652 & $1.11 \mathrm{E}+03$ & $5.05 \mathrm{E}+01$ & $1.09 \mathrm{E}+01$ \\
7,305 & $1.43 \mathrm{E}+03$ & $2.78 \mathrm{E}+02$ & $5.37 \mathrm{E}+01$ \\
10,957 & $1.70 \mathrm{E}+03$ & $5.31 \mathrm{E}+02$ & $9.29 \mathrm{E}+01$ \\
\hline
\end{tabular}

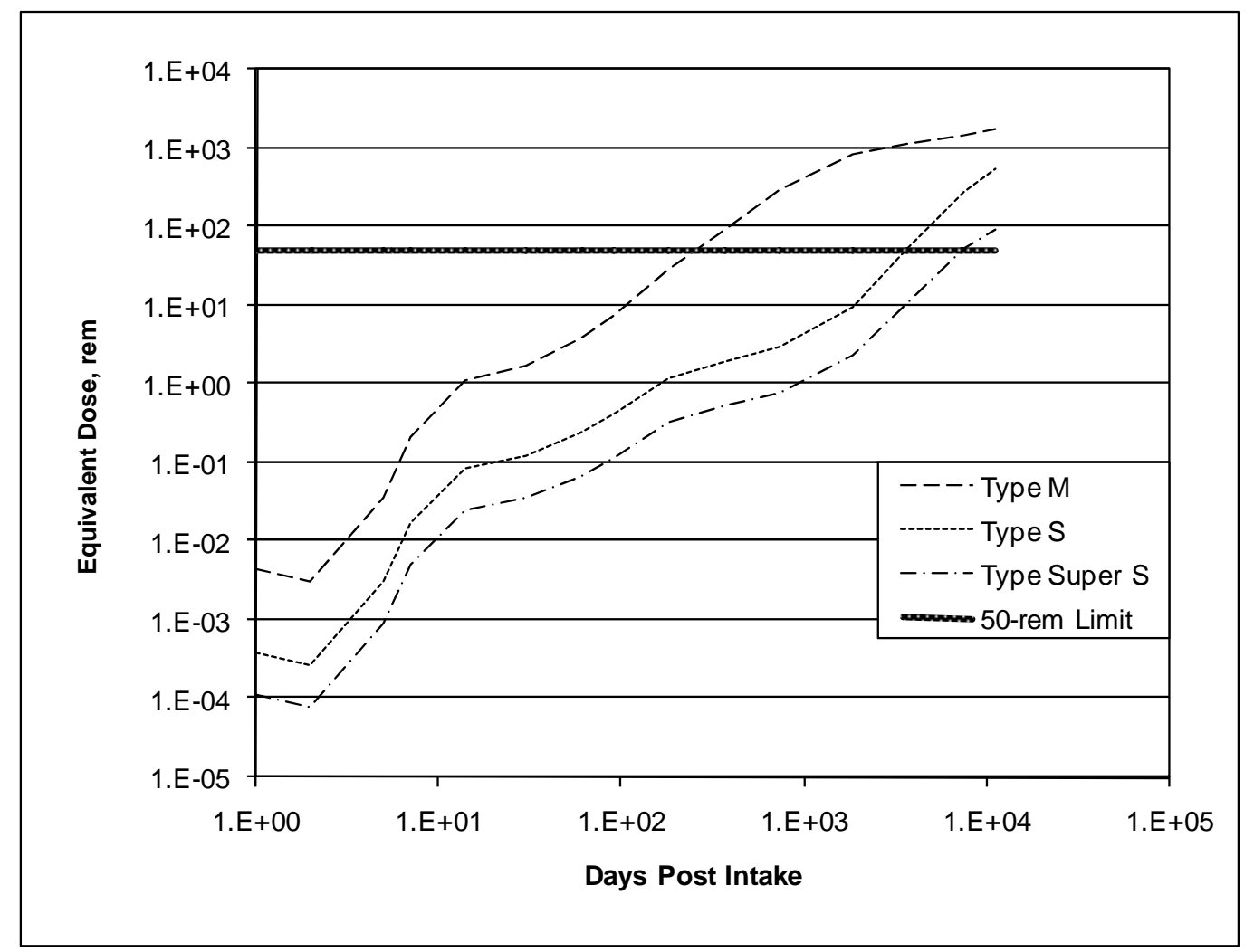

Figure 8.35. Minimum Detectable Bone Surface Committed Equivalent Doses for 20-Year-Aged Weapons-Grade Plutonium Based on Detection of $0.2 \mathrm{dpm} / \mathrm{d}{ }^{239} \mathrm{Pu}$ in Feces 
Table 8.52. Minimum Detectable Bone Surface Committed Equivalent Doses (rem) for 50-Year-Aged Weapons-Grade Plutonium Based on Detection of $0.2 \mathrm{dpm} / \mathrm{d}{ }^{239} \mathrm{Pu}$ in Feces

\begin{tabular}{rccc}
\hline Days Post Intake & Type M Inhalation & Type S Inhalation & $\begin{array}{c}\text { Type Super S } \\
\text { Inhalation }\end{array}$ \\
\hline 1 & $4.53 \mathrm{E}-03$ & $3.87 \mathrm{E}-04$ & $1.35 \mathrm{E}-04$ \\
2 & $3.17 \mathrm{E}-03$ & $2.71 \mathrm{E}-04$ & $9.41 \mathrm{E}-05$ \\
5 & $3.67 \mathrm{E}-02$ & $3.14 \mathrm{E}-03$ & $1.09 \mathrm{E}-03$ \\
7 & $2.10 \mathrm{E}-01$ & $1.78 \mathrm{E}-02$ & $6.20 \mathrm{E}-03$ \\
14 & $1.12 \mathrm{E}+00$ & $8.72 \mathrm{E}-02$ & $3.03 \mathrm{E}-02$ \\
30 & $1.74 \mathrm{E}+00$ & $1.26 \mathrm{E}-01$ & $4.37 \mathrm{E}-02$ \\
60 & $3.75 \mathrm{E}+00$ & $2.37 \mathrm{E}-01$ & $8.21 \mathrm{E}-02$ \\
90 & $7.37 \mathrm{E}+00$ & $4.13 \mathrm{E}-01$ & $1.42 \mathrm{E}-01$ \\
180 & $2.88 \mathrm{E}+01$ & $1.18 \mathrm{E}+00$ & $4.05 \mathrm{E}-01$ \\
365 & $9.03 \mathrm{E}+01$ & $1.99 \mathrm{E}+00$ & $6.71 \mathrm{E}-01$ \\
730 & $3.02 \mathrm{E}+02$ & $2.97 \mathrm{E}+00$ & $9.72 \mathrm{E}-01$ \\
1,826 & $8.11 \mathrm{E}+02$ & $9.36 \mathrm{E}+00$ & $2.80 \mathrm{E}+00$ \\
3,652 & $1.12 \mathrm{E}+03$ & $5.10 \mathrm{E}+01$ & $1.35 \mathrm{E}+01$ \\
7,305 & $1.46 \mathrm{E}+03$ & $2.81 \mathrm{E}+02$ & $6.65 \mathrm{E}+01$ \\
10,957 & $1.73 \mathrm{E}+03$ & $5.37 \mathrm{E}+02$ & $1.15 \mathrm{E}+02$ \\
\hline
\end{tabular}

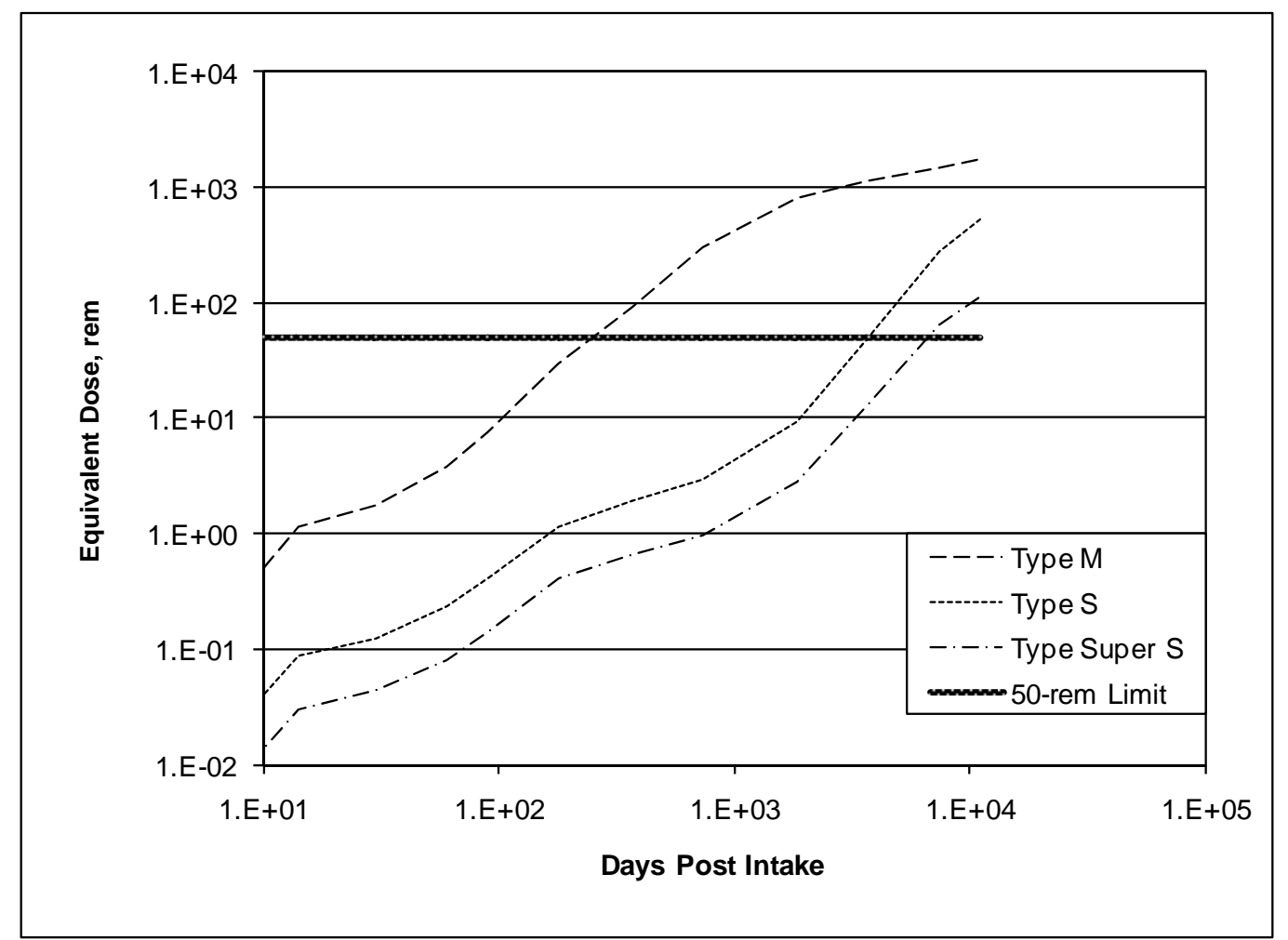

Figure 8.36. Minimum Detectable Bone Surface Committed Equivalent Doses for 50 -Year-Aged Weapons-Grade Plutonium Based on Detection of $0.2 \mathrm{dpm} / \mathrm{d}{ }^{239} \mathrm{Pu}$ in Feces 
Table 8.53. Minimum Detectable Bone Surface Committed Equivalent Doses (rem) for 20-Year Aged Fuel-Grade Plutonium Based on Detection of $0.2 \mathrm{dpm} / \mathrm{d}{ }^{239} \mathrm{Pu}$ in Feces

\begin{tabular}{rccc}
\hline Days Post Intake & Type M Inhalation & Type S Inhalation & $\begin{array}{c}\text { Type Super S } \\
\text { Inhalation }\end{array}$ \\
\hline 1 & $7.21 \mathrm{E}-03$ & $6.24 \mathrm{E}-04$ & $2.80 \mathrm{E}-04$ \\
2 & $5.05 \mathrm{E}-03$ & $4.36 \mathrm{E}-04$ & $1.96 \mathrm{E}-04$ \\
5 & $5.85 \mathrm{E}-02$ & $5.06 \mathrm{E}-03$ & $2.27 \mathrm{E}-03$ \\
7 & $3.34 \mathrm{E}-01$ & $2.88 \mathrm{E}-02$ & $1.29 \mathrm{E}-02$ \\
14 & $1.78 \mathrm{E}+00$ & $1.41 \mathrm{E}-01$ & $6.30 \mathrm{E}-02$ \\
30 & $2.78 \mathrm{E}+00$ & $2.03 \mathrm{E}-01$ & $9.08 \mathrm{E}-02$ \\
60 & $5.97 \mathrm{E}+00$ & $3.82 \mathrm{E}-01$ & $1.71 \mathrm{E}-01$ \\
90 & $1.17 \mathrm{E}+01$ & $6.65 \mathrm{E}-01$ & $2.96 \mathrm{E}-01$ \\
180 & $4.58 \mathrm{E}+01$ & $1.90 \mathrm{E}+00$ & $8.42 \mathrm{E}-01$ \\
365 & $1.44 \mathrm{E}+02$ & $3.20 \mathrm{E}+00$ & $1.40 \mathrm{E}+00$ \\
730 & $4.81 \mathrm{E}+02$ & $4.78 \mathrm{E}+00$ & $2.02 \mathrm{E}+00$ \\
1,826 & $1.29 \mathrm{E}+03$ & $1.51 \mathrm{E}+01$ & $5.82 \mathrm{E}+00$ \\
3,652 & $1.79 \mathrm{E}+03$ & $8.22 \mathrm{E}+01$ & $2.81 \mathrm{E}+01$ \\
7,305 & $2.32 \mathrm{E}+03$ & $4.53 \mathrm{E}+02$ & $1.38 \mathrm{E}+02$ \\
10,957 & $2.75 \mathrm{E}+03$ & $8.65 \mathrm{E}+02$ & $2.39 \mathrm{E}+02$ \\
\hline
\end{tabular}

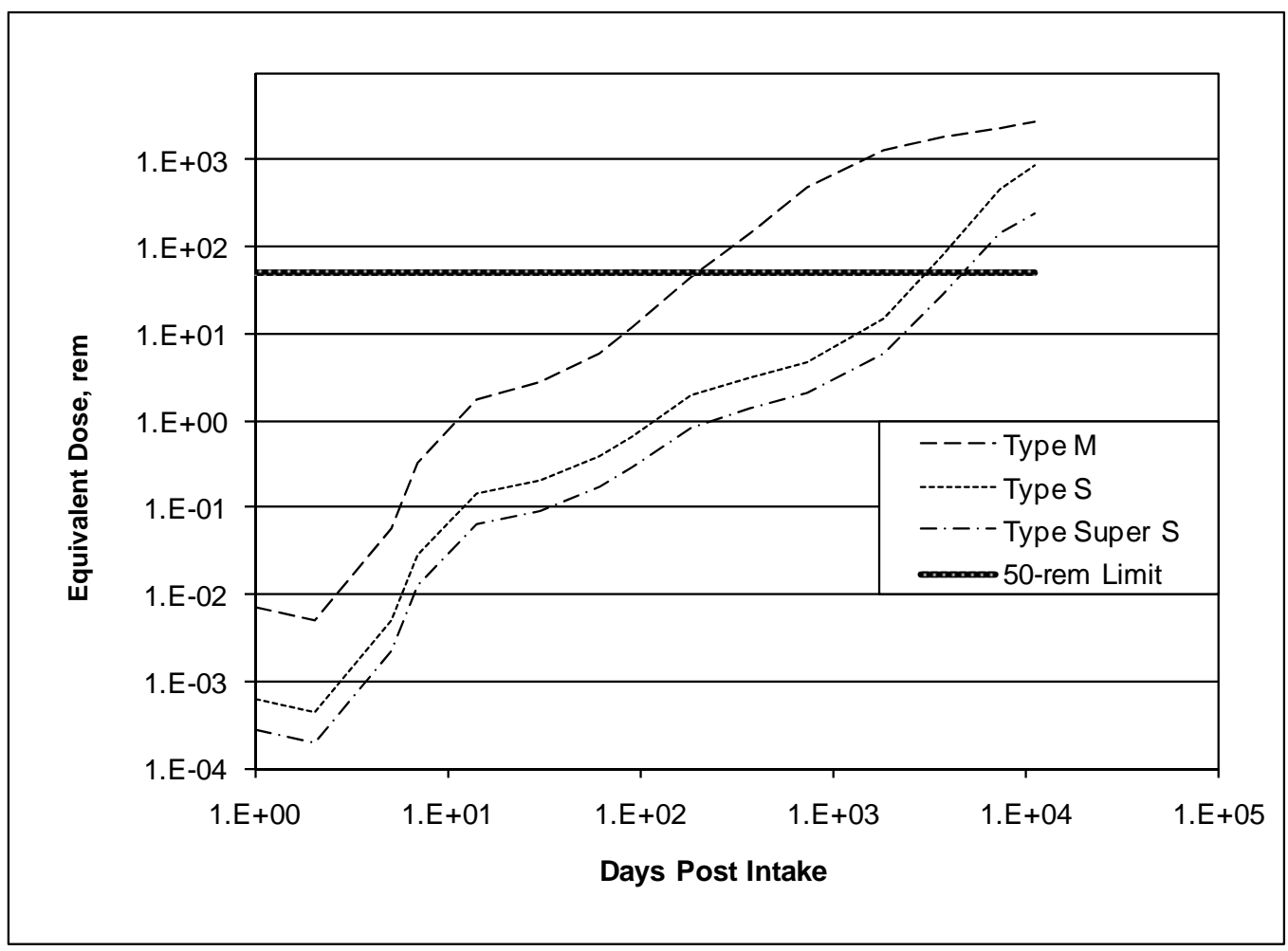

Figure 8.37. Minimum Detectable Bone Surface Committed Equivalent Doses for 20-Year-Aged FuelGrade Plutonium Based on Detection of $0.2 \mathrm{dpm} / \mathrm{d}{ }^{239} \mathrm{Pu}$ in Feces 
Table 8.54. Minimum Detectable Bone Surface Committed Equivalent Doses (rem) for 50-Year-Aged Fuel-Grade Plutonium Based on Detection of $0.2 \mathrm{dpm} / \mathrm{d}{ }^{239} \mathrm{Pu}$ in Feces

\begin{tabular}{rccc}
\hline Days Post Intake & Type M Inhalation & Type S Inhalation & $\begin{array}{c}\text { Type Super S } \\
\text { Inhalation }\end{array}$ \\
\hline 1 & $7.52 \mathrm{E}-03$ & $6.44 \mathrm{E}-04$ & $3.68 \mathrm{E}-04$ \\
2 & $5.26 \mathrm{E}-03$ & $4.51 \mathrm{E}-04$ & $2.57 \mathrm{E}-04$ \\
5 & $6.11 \mathrm{E}-02$ & $5.23 \mathrm{E}-03$ & $2.98 \mathrm{E}-03$ \\
7 & $3.49 \mathrm{E}-01$ & $2.97 \mathrm{E}-02$ & $1.69 \mathrm{E}-02$ \\
14 & $1.86 \mathrm{E}+00$ & $1.45 \mathrm{E}-01$ & $8.27 \mathrm{E}-02$ \\
30 & $2.90 \mathrm{E}+00$ & $2.10 \mathrm{E}-01$ & $1.19 \mathrm{E}-01$ \\
60 & $6.23 \mathrm{E}+00$ & $3.95 \mathrm{E}-01$ & $2.24 \mathrm{E}-01$ \\
90 & $1.22 \mathrm{E}+01$ & $6.87 \mathrm{E}-01$ & $3.89 \mathrm{E}-01$ \\
180 & $4.78 \mathrm{E}+01$ & $1.97 \mathrm{E}+00$ & $1.11 \mathrm{E}+00$ \\
365 & $1.50 \mathrm{E}+02$ & $3.31 \mathrm{E}+00$ & $1.83 \mathrm{E}+00$ \\
730 & $5.02 \mathrm{E}+02$ & $4.94 \mathrm{E}+00$ & $2.66 \mathrm{E}+00$ \\
1,826 & $1.35 \mathrm{E}+03$ & $1.56 \mathrm{E}+01$ & $7.65 \mathrm{E}+00$ \\
3,652 & $1.86 \mathrm{E}+03$ & $8.50 \mathrm{E}+01$ & $3.69 \mathrm{E}+01$ \\
7,305 & $2.42 \mathrm{E}+03$ & $4.68 \mathrm{E}+02$ & $1.82 \mathrm{E}+02$ \\
10,957 & $2.87 \mathrm{E}+03$ & $8.94 \mathrm{E}+02$ & $3.14 \mathrm{E}+02$ \\
\hline
\end{tabular}

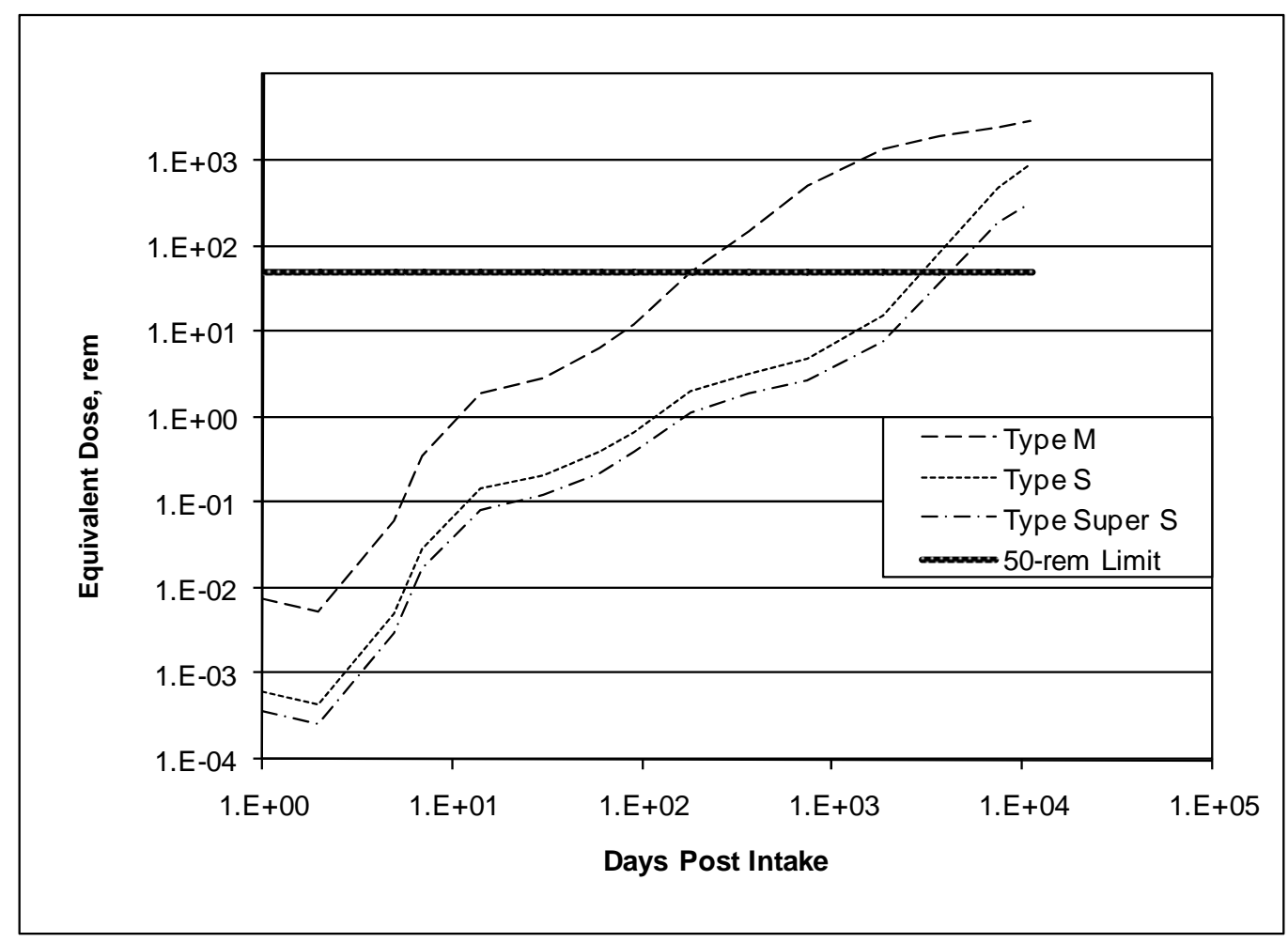

Figure 8.38. Minimum Detectable Bone Surface Committed Equivalent Doses for 50-Year-Aged FuelGrade Plutonium Based on Detection of $0.2 \mathrm{dpm} / \mathrm{d}^{239} \mathrm{Pu}$ in Feces 
Table 8.55. Minimum Detectable Committed Equivalent Doses (rem) for Extrathoracic Tissues and the Lung (rem) for Inhalation of Type Super S Weapons-Grade Plutonium Based on Detection of $0.2 \mathrm{dpm} / \mathrm{d}{ }^{239} \mathrm{Pu}$ in Feces

\begin{tabular}{rcccc}
\hline & \multicolumn{2}{c}{ Extrathoracic Tissues } & \multicolumn{2}{c}{ Lung } \\
\cline { 2 - 5 } Days Post Intake & $\begin{array}{c}20-\text { Year } \\
\text { Weapons-Grade } \\
\text { Plutonium }\end{array}$ & $\begin{array}{c}50 \text {-Year } \\
\text { Weapons-Grade } \\
\text { Plutonium }\end{array}$ & $\begin{array}{c}20-\text { Year } \\
\text { Weapons-Grade } \\
\text { Plutonium }\end{array}$ & $\begin{array}{c}50 \text {-Year } \\
\text { Weapons-Grade } \\
\text { Plutonium }\end{array}$ \\
\hline 1 & $3.42 \mathrm{E}-04$ & $3.57 \mathrm{E}-04$ & $2.18 \mathrm{E}-04$ & $2.25 \mathrm{E}-04$ \\
2 & $2.39 \mathrm{E}-04$ & $2.49 \mathrm{E}-04$ & $1.53 \mathrm{E}-04$ & $1.58 \mathrm{E}-04$ \\
5 & $2.77 \mathrm{E}-03$ & $2.89 \mathrm{E}-03$ & $1.77 \mathrm{E}-03$ & $1.83 \mathrm{E}-03$ \\
7 & $1.58 \mathrm{E}-02$ & $1.64 \mathrm{E}-02$ & $1.01 \mathrm{E}-02$ & $1.04 \mathrm{E}-02$ \\
14 & $7.70 \mathrm{E}-02$ & $8.03 \mathrm{E}-02$ & $4.92 \mathrm{E}-02$ & $5.07 \mathrm{E}-02$ \\
30 & $1.11 \mathrm{E}-01$ & $1.16 \mathrm{E}-01$ & $7.09 \mathrm{E}-02$ & $7.31 \mathrm{E}-02$ \\
60 & $2.08 \mathrm{E}-01$ & $2.17 \mathrm{E}-01$ & $1.33 \mathrm{E}-01$ & $1.37 \mathrm{E}-01$ \\
90 & $3.62 \mathrm{E}-01$ & $3.77 \mathrm{E}-01$ & $2.31 \mathrm{E}-01$ & $2.39 \mathrm{E}-01$ \\
180 & $1.03 \mathrm{E}+00$ & $1.07 \mathrm{E}+00$ & $6.57 \mathrm{E}-01$ & $6.78 \mathrm{E}-01$ \\
365 & $1.71 \mathrm{E}+00$ & $1.78 \mathrm{E}+00$ & $1.09 \mathrm{E}+00$ & $1.12 \mathrm{E}+00$ \\
730 & $2.47 \mathrm{E}+00$ & $2.58 \mathrm{E}+00$ & $1.58 \mathrm{E}+00$ & $1.63 \mathrm{E}+00$ \\
1,826 & $7.11 \mathrm{E}+00$ & $7.42 \mathrm{E}+00$ & $4.54 \mathrm{E}+00$ & $4.69 \mathrm{E}+00$ \\
3,652 & $3.43 \mathrm{E}+01$ & $3.58 \mathrm{E}+01$ & $2.19 \mathrm{E}+01$ & $2.26 \mathrm{E}+01$ \\
7,305 & $1.69 \mathrm{E}+02$ & $1.76 \mathrm{E}+02$ & $1.08 \mathrm{E}+02$ & $1.11 \mathrm{E}+02$ \\
10,957 & $2.92 \mathrm{E}+02$ & $3.05 \mathrm{E}+02$ & $1.87 \mathrm{E}+02$ & $1.93 \mathrm{E}+02$ \\
\hline
\end{tabular}

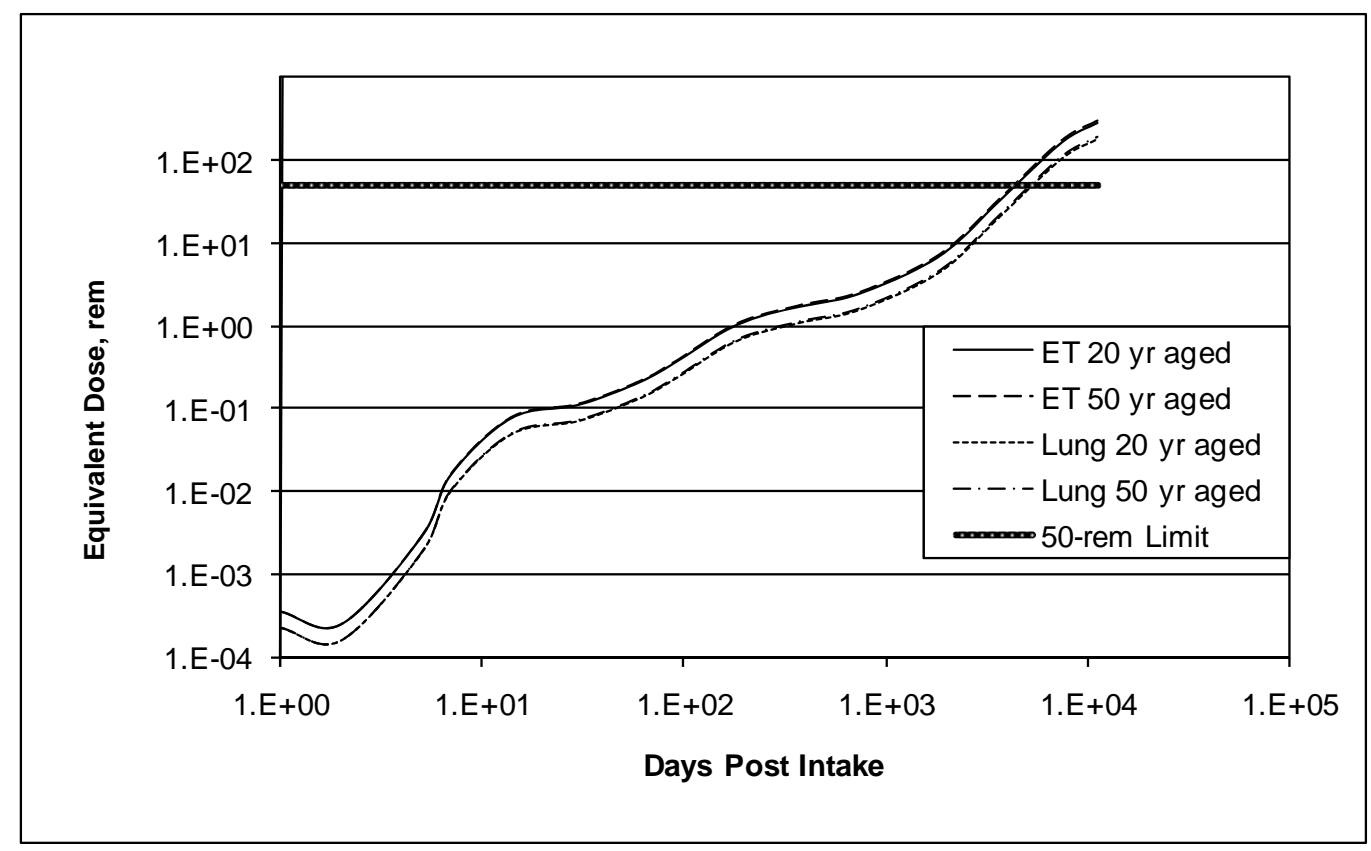

Figure 8.39. Minimum Detectable Doses to Extrathoracic Tissues and the Lung from Inhalation of Type Super S Weapons-Grade Plutonium Based on Detection of $0.2 \mathrm{dpm} / \mathrm{d}{ }^{239} \mathrm{Pu}$ in Feces 
Table 8.56. Minimum Detectable Committed Equivalent Doses (rem) for Extrathoracic Tissues and the Lung (rem) for Inhalation of Type Super S Fuel-Grade Plutonium Based on Detection of $0.2 \mathrm{dpm} / \mathrm{d}{ }^{239} \mathrm{Pu}$ in Feces

\begin{tabular}{|c|c|c|c|c|}
\hline \multirow[b]{2}{*}{ Days Post Intake } & \multicolumn{2}{|c|}{ Extrathoracic Tissues } & \multicolumn{2}{|c|}{ Lung } \\
\hline & $\begin{array}{l}\text { 20-Year } \\
\text { Fuel-Grade } \\
\text { Plutonium }\end{array}$ & $\begin{array}{c}50-\text { Year } \\
\text { Fuel-Grade } \\
\text { Plutonium }\end{array}$ & $\begin{array}{c}20-Y e a r \\
\text { Fuel-Grade } \\
\text { Plutonium }\end{array}$ & $\begin{array}{l}50-\text { Year } \\
\text { Fuel-Grade } \\
\text { Plutonium }\end{array}$ \\
\hline 1 & 5.05E-04 & $5.62 \mathrm{E}-04$ & $3.27 \mathrm{E}-04$ & $3.59 \mathrm{E}-04$ \\
\hline 2 & 3.53E-04 & 3.93E-04 & $2.28 \mathrm{E}-04$ & $2.51 \mathrm{E}-04$ \\
\hline 5 & 4.10E-03 & 4.56E-03 & 2.65E-03 & $2.91 \mathrm{E}-03$ \\
\hline 7 & 2.33E-02 & 2.59E-02 & $1.51 \mathrm{E}-02$ & $1.65 \mathrm{E}-02$ \\
\hline 14 & 1.14E-01 & $1.27 \mathrm{E}-01$ & 7.35E-02 & 8.07E-02 \\
\hline 30 & $1.64 \mathrm{E}-01$ & $1.82 \mathrm{E}-01$ & $1.06 \mathrm{E}-01$ & $1.16 \mathrm{E}-01$ \\
\hline 60 & 3.08E-01 & 3.43E-01 & $1.99 \mathrm{E}-01$ & 2.19E-01 \\
\hline 90 & 5.35E-01 & 5.95E-01 & 3.46E-01 & $3.80 \mathrm{E}-01$ \\
\hline 180 & $1.52 \mathrm{E}+00$ & $1.69 \mathrm{E}+00$ & 9.83E-01 & $1.08 \mathrm{E}+00$ \\
\hline 365 & $2.52 \mathrm{E}+00$ & $2.80 \mathrm{E}+00$ & $1.63 \mathrm{E}+00$ & $1.79 \mathrm{E}+00$ \\
\hline 730 & $3.65 \mathrm{E}+00$ & $4.06 \mathrm{E}+00$ & $2.36 \mathrm{E}+00$ & $2.59 \mathrm{E}+00$ \\
\hline 1,826 & $1.05 \mathrm{E}+01$ & $1.17 \mathrm{E}+01$ & $6.79 \mathrm{E}+00$ & $7.46 \mathrm{E}+00$ \\
\hline 3,652 & $5.07 \mathrm{E}+01$ & $5.64 \mathrm{E}+01$ & $3.28 \mathrm{E}+01$ & $3.60 \mathrm{E}+01$ \\
\hline 7,305 & $2.50 \mathrm{E}+02$ & $2.78 \mathrm{E}+02$ & $1.61 \mathrm{E}+02$ & $1.77 \mathrm{E}+02$ \\
\hline 10,957 & $4.32 \mathrm{E}+02$ & $4.81 \mathrm{E}+02$ & $2.79 \mathrm{E}+02$ & $3.07 \mathrm{E}+02$ \\
\hline
\end{tabular}

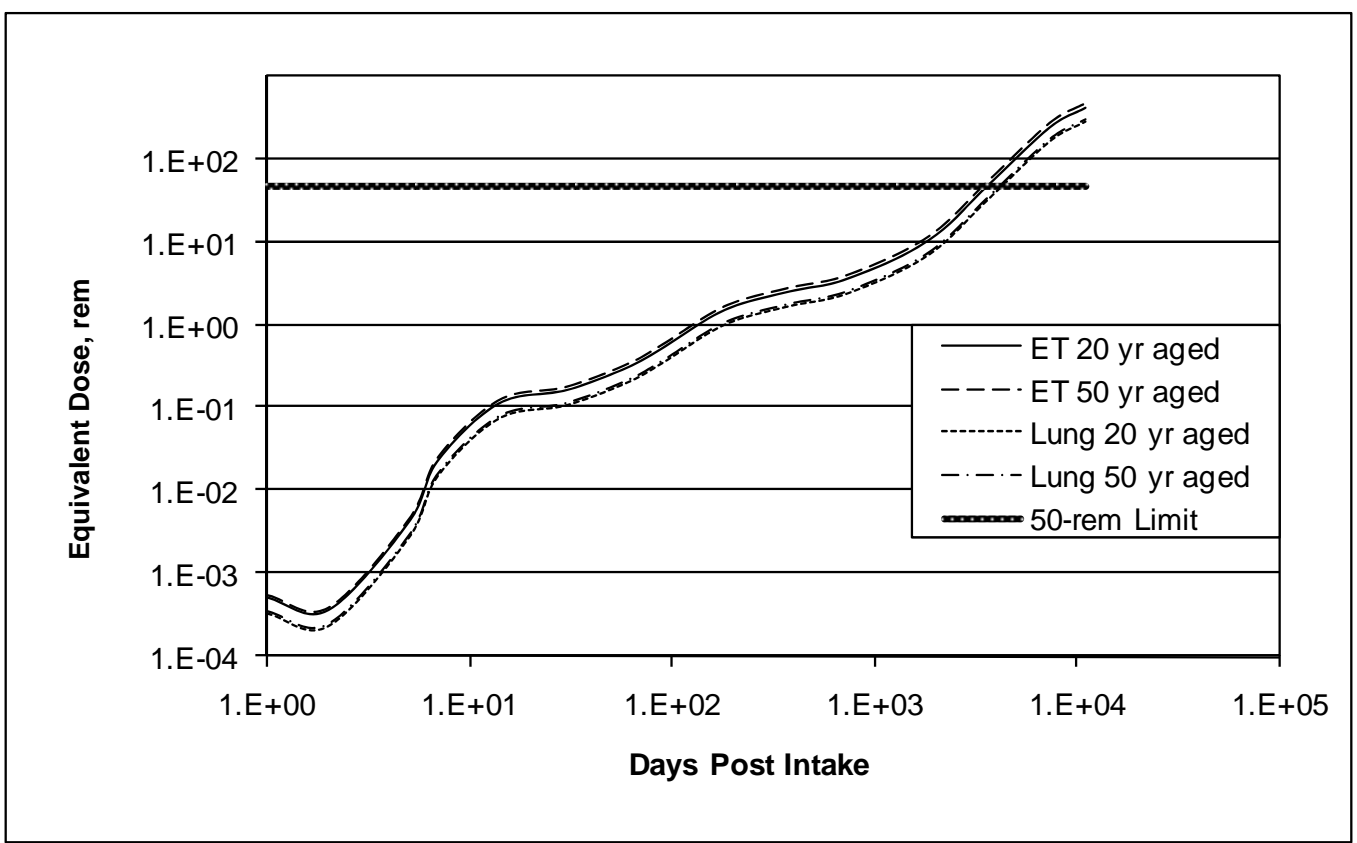

Figure 8.40. Minimum Detectable Doses to Extra Thoracic Tissues and the Lung from Inhalation of Type Super S Fuel-Grade Plutonium Based on Detection of $0.2 \mathrm{dpm} / \mathrm{d}{ }^{239} \mathrm{Pu}$ in Feces 


\subsubsection{Recommended Bioassay Monitoring Program}

The bone surface is the most limiting organ for instantaneous uptakes via wounds and for Type $\mathrm{M}$ and $S$ inhalations (5- $\mu \mathrm{m}$ AMAD). Annual urine sampling provides the capability of demonstrating compliance with the 50-rem deterministic limit for all of these intake modes for both weapons-grade and fuel-grade mixtures even with 50 years of ingrowth of ${ }^{241} \mathrm{Am}$. However, if the plutonium is more tenaciously retained in the lung than the default ICRP model for Type S, the dose to the ET tissues is greater than to the bone surface. Because of the difference in tissue weighting factors between ET tissues and bone surfaces, the 5-rem effective dose is slightly more limiting than the 50-rem equivalent dose to the ET tissues for Super S plutonium. In general, for Type S or Super S material, chest counting is the more sensitive monitoring method (i.e., has the smaller MDI); however, this depends on the time after the intake and the isotopic mixture. Figure 8.41 shows the total-alpha MDIs for inhalation of Type S plutonium comparing urine sampling versus chest counting for a 20 -year-aged weapons grade mixture and a 50-year-aged fuel-grade mixture. For the 20-year-aged weapons-grade mixture, chest counting is more sensitive from about 3 days to about 4 years after intake, with urine sampling being more sensitive at very early and very late times after intake. For the 50-year-aged fuel-grade mixture, chest counting is always more sensitive than urine sampling out to 20 years after intake.

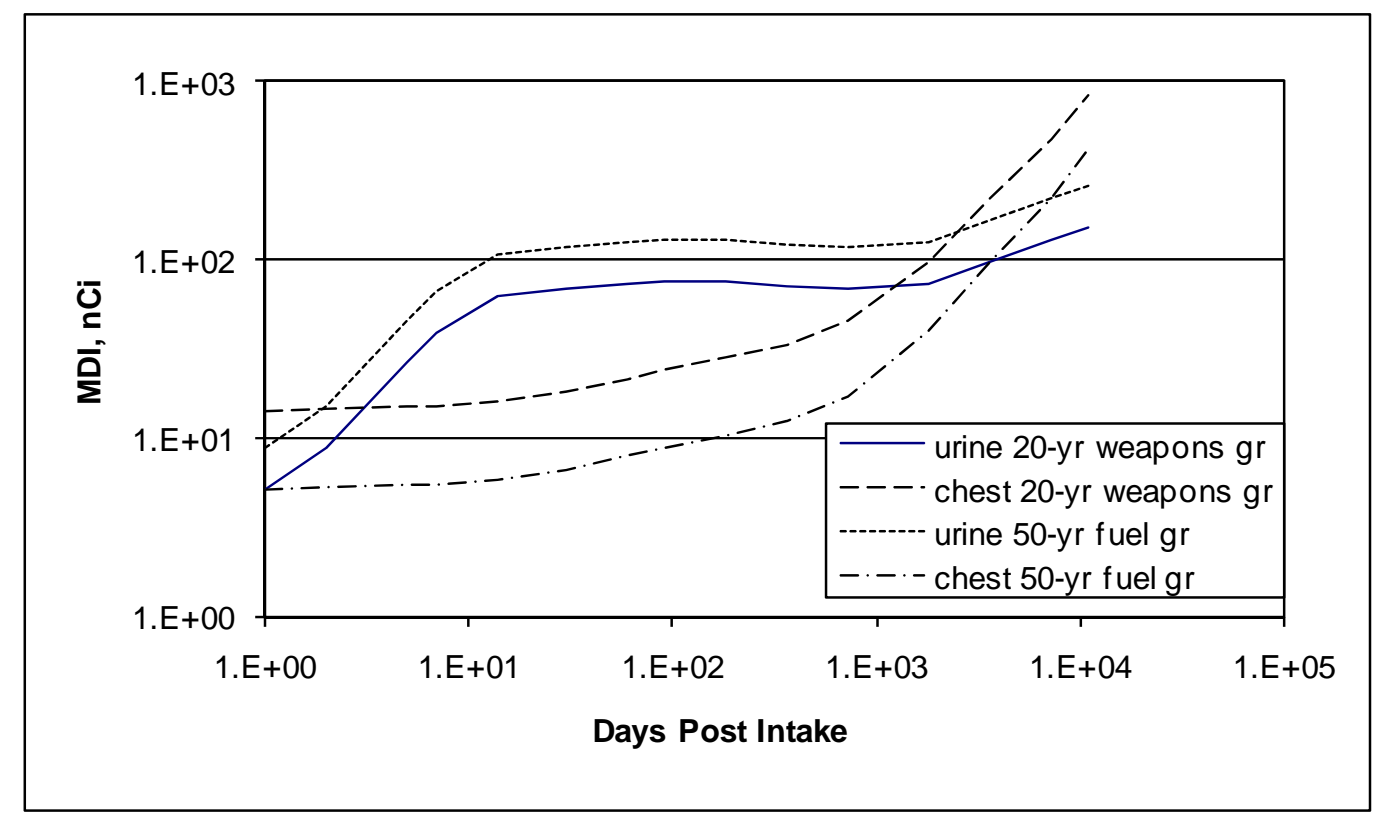

Figure 8.41. Minimum Detectable Intakes of Total Alpha for Type S Material Comparing Urine Sampling Versus Chest Counting for Two Bounding Mixture Types

The recommended periodic bioassay monitoring program for plutonium is to perform annual in vivo lung measurements and annual plutonium-in-urine assessments. Annual chest counts are more sensitive than annual urine samples for inhalations of Type S or Super S material, and annual urine samples are more sensitive for wounds or inhalations of Type M material. When both bioassay types are used annually, the appropriate dose limit (5-rem effective or 50-rem equivalent to the critical organ) is met for all modes of intake and all mixtures between 20-year-aged weapons-grade to 50-year-aged fuel-grade mixtures. More frequent chest counting is not particularly effective in lowering the MDD unless it is performed immediately after an intake. For instance, semiannual chest counting results in a $20 \%$ lower 
effective MDD versus annual chest counting for Type S material, and semiannual urine sampling can lower the bone surface MDD for Type M material by 39\%. However, these gains require twice the cost for each. Routine fecal sampling at annual or semiannual frequencies is less sensitive than urine sampling for instantaneous uptakes or Type M inhalations. For Type S inhalations, semiannual or annual fecal sampling is more sensitive than either chest counting or urine sampling; however, difficulties with collection (worker inconvenience and cooperation), analysis (a difficult matrix to analyze), and interpretation (potential interference from minor ingestion) suggest that fecal sampling is best applied to special investigations.

These recommendations do not provide the high degree of sensitivity for internal dose estimation available for fission products. The lack of sensitivity is due to the much higher dose per unit intake associated with tenaciously retained alpha-emitting radionuclides as compared with beta- and gammaemitting fission products.

Because of the lack of sensitivity of periodic bioassay, special bioassay monitoring as a supplement to the routine program should be promptly initiated when workplace indications of potential internal exposure to plutonium are noted. When adequate measurements are made promptly after a suspected intake, good sensitivity to potential dose can be obtained.

\subsubsection{Special Bioassay Monitoring}

If a potential intake of plutonium is suspected, special bioassay monitoring should be quickly initiated. Typically this monitoring should include same-day in vivo measurements, overnight or first-day urine collection, and early fecal sample collection. Fecal samples within the first 5 days after intake are orders of magnitude more sensitive than either urine samples or chest counts for 5 - $\mu \mathrm{m}$ AMAD particles for inhalation Types M, S, or Super S. Figure 8.42 compares the total-alpha MDIs for fecal sampling, urine sampling, and chest counting for 20-year-aged weapons-grade and 50-year-aged fuel-grade mixtures for Type M inhalations. Figure 8.43 provides the same comparisons for Type S inhalations. An early single voiding urine sample may also be warranted for determining the need for potential dose-reduction therapy. If DTPA (diethylene triamine pentaacetic acid) chelation therapy was administered, then a total urine sample collection is recommended to reduce any uncertainties associated with sample normalization. Total urine sample collection should be continued until the excretion pattern is established.

How many special bioassay measurements to obtain is a matter of professional judgment, factoring in the potential significance of the exposure, the appropriate types of measurements, worker inconvenience, cost, and the degree of confidence required in the assessment. Generally, if an initial chest count shows detectable lung activity, a next-day follow-up chest count should be performed to monitor early lung clearance. Additional counts are warranted if detection continues. Total fecal sample collections for the first week allow for complete observation of the early fecal clearance pattern and permit a higher degree of confidence in the intake estimate than does a single sample. Because the general early fecal clearance pattern is not significantly different for inhalation Types $M$ and $S$, the fecal-based intake estimate needs to be coupled with at least one early urine sample representing a period concurrent with at least one fecal sample to allow for a determination of inhalation type based on the ratio of fecal-to-urine excretion (see Table 8.14). The extent of this collection protocol can pose substantial inconvenience to the worker and can be costly. Such inconvenience and cost may be justified when doses are considered relatively high (e.g., greater than 500- to 1000-mrem committed effective dose). At lower doses, reliance on more 
limited measurements (e.g., one or two fecal samples and a urine sample) and standard assumptions about the source material and ICRP Reference Man biokinetic behavior may be appropriate.

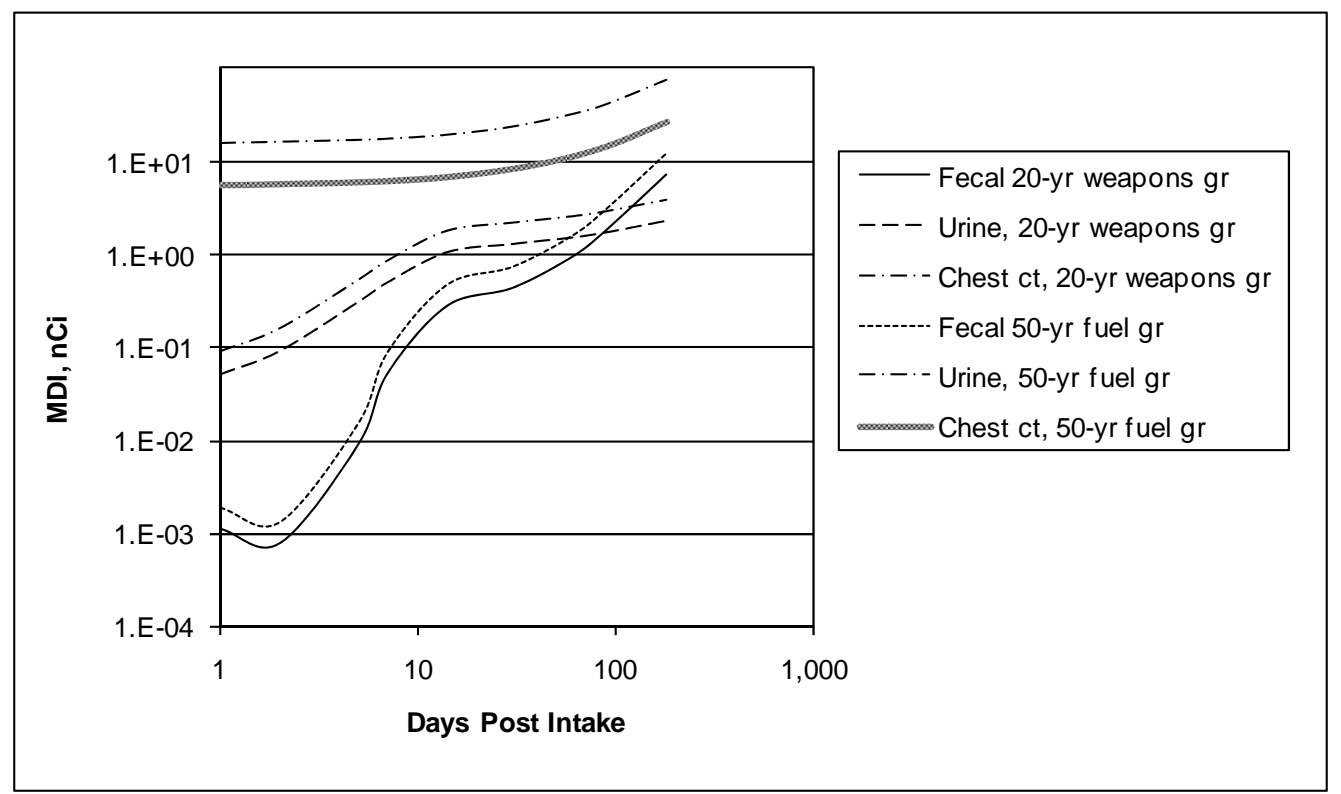

Figure 8.42. Minimum Detectable Intakes of Inhalation Type M, 20-Year-Aged Weapons-Grade and 50-Year-Aged Fuel-Grade Plutonium Mixtures from Fecal Sampling, Urine Sampling, and Chest Counting (nCi total alpha of mixture)

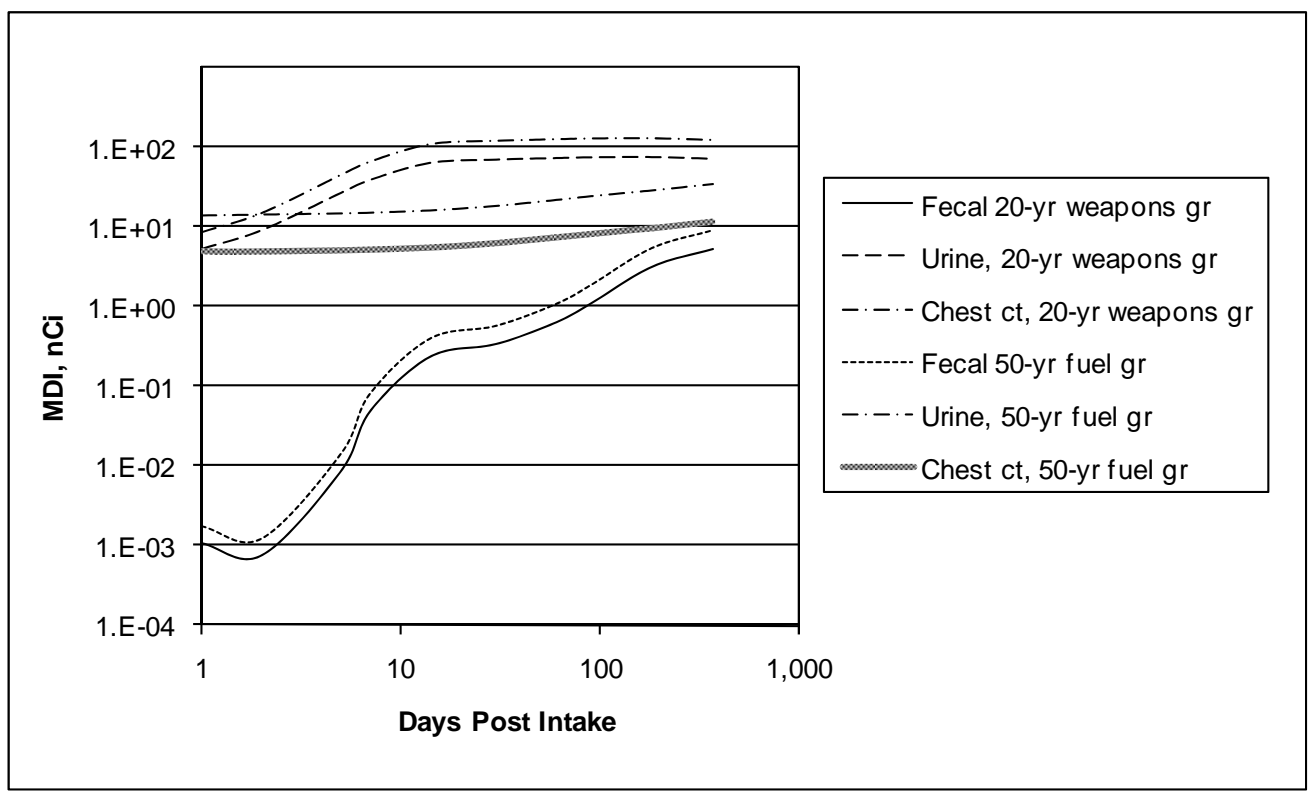

Figure 8.43. Minimum Detectable Intakes of Inhalation Type $S, 20$-Year-Aged Weapons-Grade and 50-Year-Aged Fuel-Grade Plutonium Mixtures from Fecal Sampling, Urine Sampling, and Chest Counting (nCi total alpha of mixture) 


\subsubsection{Bioassay Monitoring Capability for Workers with Known Plutonium Depositions}

The capability of a bioassay program is directly dependent upon the magnitude of an identifiable increase in a bioassay measurement. When a worker has a positive baseline bioassay level due to a previous intake, the ability to detect a subsequent increase in the bioassay level from an additional intake is more dependent on the variability of current bioassay levels and less dependent on analytical capability. In other words, to be detected, subsequent intakes must result in increases in bioassay measurements that exceed the baseline "noise" level. Guidance concerning the minimum detectable dose from potential additional intakes must be developed on a case-by-case basis. Appropriate adjustments to measurement frequencies can then be determined based on the potential undetected dose. As an approximate rule-ofthumb, a single bioassay measurement will probably have to be at least twice the baseline level to be readily recognized, due to the substantial variability in single bioassay measurements on individual people. For many situations, this may imply that a normally detectable intake may not be detectable on top of a pre-existing internal plutonium deposition. Like most rules-of-thumb, this is only a rough suggestion; cases of significance must be addressed individually.

\subsection{Assessment of Internal Dose}

The following sections discuss two general approaches to internal dosimetry and highlight some applications and caveats associated with different types of bioassay data. The most typical method used for plutonium internal dosimetry is intake assessment using fecal, urine, and in vivo data, as available. This method has been used for most Hanford assessments since the early 1990s. Prior to then the predominant method was a deposition assessment based primarily on urine data. It is a good practice to compare estimates based on different bioassay data sets for the same intake.

\subsubsection{Intake Assessment}

An intake of plutonium can be estimated by fitting the bioassay data to the appropriate retention or excretion function, using manual or computerized techniques. For a single data point, the intake can be estimated by dividing the measured excretion by the value of the retention function for the appropriate day after intake represented by the sample in a manner similar to Equation (2.5) in Chapter 2.0. Values for the retention function can be obtained from those tabulated in this chapter, or directly by running IMBA for times not given in the tables. For multiple data points, IMBA will determine the best intake using the maximum likelihood fitting technique. If parameters such as particle size or inhalation type are not known, these can be adjusted in IMBA to help determine the best fit. Once the intake is calculated, appropriate internal doses may be calculated by applying the dose coefficients of this chapter to Equation (2.10) or (2.11) in Chapter 2.0, if default model parameters have been used to determine the intake. IMBA may also be used to directly calculate internal doses, and its use is essential if model parameters have been modified.

In addition to their use for dose calculations, intakes calculated by the above techniques may also be compared with intake estimates based on air sample results. When bioassay data are not available or not sufficiently sensitive, air sample results may be the basis for estimating intake. 


\subsubsection{Deposition Assessment}

Deposition assessment involves determining the amount of material deposited in a body or tissue compartment of interest. Whereas the term intake includes all material taken into the body regardless of its subsequent fate, deposition is a more limited quantity that excludes material not retained (e.g., that immediately exhaled) and material not systemically absorbed (e.g., material cleared to the GI tract and excreted in feces without absorption). The HIDP coined the term presystemic deposition in the mid1980s to precisely define what was being evaluated and avoid terms that had developed generic, nebulous, or varied meanings (e.g., deposition, uptake, burden). In addition, the term deposition was gaining preference in the field of internal dosimetry as a process term associated with the respiratory tract, rather than a retained quantity. The HIDP defined presystemic deposition as the total radioactivity that will ultimately translocate into the transfer compartment from a metabolically isolated pool; in other words, the activity ultimately reaching the blood. Historically at Hanford, this was the quantity compared with the MPBB of $0.04 \mu \mathrm{Ci}\left({ }^{239} \mathrm{Pu}\right)$ listed in National Bureau of Standards Handbook 69 (NBS 1959), NCRP 22 (1959), and ICRP 2 (1959). It was related to, but significantly different from intake, lung deposition, long-term lung burden, and instantaneous body burden (or retained quantity).

Activity is deposited in presystemic compartments at the time of intake. From there, systemic uptake may be essentially instantaneous (as with a readily transportable wound intake), or it may occur gradually over an extended period of time (as in the case of an inhalation of Type S material). Transfer from the presystemic compartment into systemic circulation was assumed to be governed by linear first-order kinetics, and was described in terms of a transfer rate constant.

The computer program PUCALC was written to evaluate alternate values of the transfer rate and presystemic deposition, based on the urinary excretion data. The program described the urinary excretion of plutonium for user-selected values for the transfer rate and presystemic deposition. The code was retired in 2006. Additional information about PUCALC is available from the HIDP and the Hanford Radiation Records Historical File.

\subsubsection{Applications of Fecal Data}

Fecal data can be used in two ways for plutonium assessments. First, it can provide isotopic composition information for use with other bioassay and monitoring data. Secondly, it can be used in conjunction with a biokinetic model to estimate intake or initial depositions in various compartments of the respiratory tract. Caution must be exercised in interpreting fecal data, because a slight ingestion intake can significantly bias inhalation intake estimates. There is no way to differentiate inhalation from ingestion intakes by early fecal data. Follow-up fecal samples somewhat removed in time from the intake (2 to 4 weeks or more) may be helpful in determining if observed fecal activity is from lung clearance or ingestion clearance. Fecal excretion is also highly dependent on particle size, with larger sizes being more readily excreted in feces. Early fecal sampling is typically the most sensitive bioassay indicator of plutonium intake. Experience with Hanford cases suggests that the first fecal sample following an intake is likely to bias inhalation intake estimates high due to possible concurrent ingestion of large, nonrespirable particles. Undue emphasis should not be placed on the first fecal sample when other data appear to contradict it. For this reason, collection of the first fecal sample after a plutonium intake is not considered as important as collection of fecal samples provided in subsequent days. Because fecal excretion is usually not as homogeneous as it is projected to be by models, collection of multiple fecal samples from 
days 2 through 5 post intake is an excellent practice to reduce uncertainty in the fit. However, for small intakes of limited dose consequence, one or two fecal samples may be the only bioassay needed.

\subsubsection{Applications of Urine Data}

Urine sampling is the simplest and most accepted excreta sampling method by workers, however it is not particularly sensitive to low-level intakes. It is most appropriate for instantaneous uptake (wound) and Type $\mathrm{M}$ inhalations, and as a tool to compare with fecal samples to determine the inhalation type of an intake.

\subsubsection{Applications of In Vivo Data}

Chest counting data for plutonium is subject to some significant interpretation pitfalls, especially when the data show ${ }^{241} \mathrm{Am}$ detection over very long periods. Evaluations of chest count data must consider the potential for interference from activity deposited in other organs (particularly the skeleton and liver), as well as the specific chest-wall thickness of the individual. However, all of these complications are addressed by the In Vivo Counting Program so high chest count results will be corrected for interference and chest wall thickness. When chest count activity is near the detection limit, activity is often not detectable in skeleton and liver counts so interference correction is often not possible. The chest wall thickness correction using ultrasound is made for any detected activity. Another complication is the ingrowth of ${ }^{241} \mathrm{Am}$ over time. However, IMBA has the capability of determining the intake of ${ }^{241} \mathrm{Pu}$ from the ${ }^{241} \mathrm{Am}$ in the chest count taking ingrowth into account. The HIDP has also developed the AMERIN computer code to assist with case evaluations as a tool to identify a ${ }^{241} \mathrm{Am}$ biological clearance rate consistent with observed ingrowth in a single compartment. This tool was used prior to the development of IMBA.

Perhaps the most important complication is whether ${ }^{241} \mathrm{Am}$ in a plutonium mixture can be used to track clearance of plutonium from the lung. When ${ }^{241} \mathrm{Am}$ is a minor constituent by mass of the plutonium/americium mix, which is true for weapons-, fuel-, and commercial-grade mixtures as defined in Section 8.1.3, it is assumed that ${ }^{241} \mathrm{Am}$ does track with the plutonium in the lung. Laboratory animal research data have indicated that early clearance of plutonium mixtures from the lung may be enriched in ${ }^{241} \mathrm{Am}$ relative to the intake composition. This has been attributed to a more rapidly clearing component of the ${ }^{241} \mathrm{Am}$ that is initially deposited in the lung along with the plutonium. Once this initially soluble ${ }^{241} \mathrm{Am}$ has been cleared, the observed clearance rate for the remaining ${ }^{241} \mathrm{Am}$ will be similar to that of the host matrix material, i.e., plutonium (Eidson 1980). Because of the possibility for ${ }^{241} \mathrm{Am}$ to not track exactly with the plutonium over the first few days after intake, intake estimates should give more weight to later in vivo measurements as well as, of course, to urine and fecal sample results.

Lung measurement results are especially useful as a prompt (e.g., same day) upper-bound estimate for medical decisions while excreta samples are being collected and analyzed.

\subsubsection{Assessing Organ and Effective Doses}

The organs of primary interest for plutonium dose evaluations are the bone surface, red marrow, liver, and gonads. The ET tissues and lung are also important organs/tissues of interest for inhalations. Other organs or tissues may be of interest depending on the nature of an intake. For example, the dose to a 
specific lymph node or small volume of tissue may be of academic interest as the result of a wound intake of slowly transportable materials, even though doses to such tissues are not considered doses of record for compliance purposes. Such cases can be dealt with as they arise and are beyond the general scope of this technical basis.

Normally, IMBA or Tables 8.15 through 8.20 are used to calculate organ equivalent doses or effective dose. Because plutonium cannot be effectively measured in the systemic organs, and because plutonium and americium may not behave similarly after reaching the systemic organs, caution must be exercised in using measurements of americium in systemic organs for plutonium dose calculations based on the isotope ratios existing at the time of intake. Isotope ratios can change in the body over time due to the different solubility rates and retention characteristics of plutonium and americium. However, americium measurements can be used for americium dose calculations.

\subsection{Management of Internal Contamination Cases}

This section discusses the diagnostic procedures, therapeutic actions, and long-term monitoring of internal depositions.

\subsubsection{Diagnostic Procedures}

The diagnosis of an intake involves a combination of workplace monitoring to identify on-the-job potential intakes and bioassay measurements to confirm and quantify internal contamination.

The primary method of identifying potential intakes is by workplace monitoring, such as personal contamination surveys, nasal smear analyses, air sample results, or workers' identifications of unusual conditions. These techniques provide qualitative screening to alert radiation protection staff to potential internal exposure, rather than absolute confirmation that exposure has or has not occurred. For example, activity detected on nasal smears is usually an indication of an inhalation intake; however, the absence of activity does not necessarily mean that an intake did not occur. The absence of nasal smear activity following an inhalation intake can be explained by a sufficient delay between the time of intake and the collection of nasal smears to allow for complete clearance of activity from the nares. Additionally, some individuals are mouth-breathers, whose noses are partially or completely bypassed in the respiratory process, hence no activity may be deposited in the nares, despite the occurrence of an inhalation intake. Particle size can also significantly affect nasal deposition and clearance.

Once a worker has been identified as having incurred a potential intake, the initial diagnostic measurements are arranged. These may include a chest count, wound count, single voiding (spot) urine sample analysis, first-day fecal sampling, and overnight urine sampling. The purpose of these initial procedures is to provide an order-of-magnitude estimate of the potential internal exposure and dose. Initial diagnostic measurements are usually sufficient for final evaluations only when all results collectively rule out the possibility of an intake. In reality, initial measurements are not generally expected to do this, and follow-up measurements are necessary.

Follow-up diagnostic measurements may include additional urine and fecal samples, chest counts, liver counts, head counts, and lymph node counts. These analyses aid in determining the magnitude, location, and retention characteristics of the deposited material. In some cases, tissue specimens may also 
be appropriate and, rarely, blood samples. In addition, workplace or clothing contamination analyses, air sample analyses, particle size analyses, and/or solubility analyses may be performed to more clearly define the physical and radiological characteristics of the material to which the worker was exposed.

It is the responsibility of the exposure evaluator, working closely with contractor radiation protection staff, to determine the appropriate diagnostic protocols. Scheduling of follow-up measurements is done by HIDP with concurrence from the appropriate contractor radiation protection staff.

\subsubsection{Therapeutic Actions}

Therapeutic actions for potential internal contamination include the use of decorporation agents, catharsis, and surgical excision. For the purposes of this discussion, the normal skin decontamination procedures of Hanford contractors are not considered therapeutic actions, although it is acknowledged that these procedures can be quite effective in preventing the intake of radioactivity. The decision to undertake one or more of these therapeutic actions is the responsibility of the participating occupational medicine care provider with the concurrence of the patient. The exposure evaluator will provide advice and consultation to the physician and patient regarding the potential dose implications and efficacy of alternative actions. Guidance for the methods of therapy can be found in NCRP Report 65 (1980) and in the "Guidebook for the treatment of accidental internal radionuclide contamination of workers" (Bhattacharyya et al. 1992). Guidance for circumstances under which therapy may be warranted is contained in the Hanford Internal Dosimetry Program Manual (PNL-MA-552; EH Carbaugh, et al. 2009), but was established as a good practice based on experience rather than a detailed technical analysis.

Decorporation therapy, also referred to as chelation therapy, involves the chemical removal of radioactivity from the bloodstream through drug administration. The drug DTPA has U.S. Food and Drug Administration approval for use in removing plutonium and other heavy metals from the body. The Hanford occupational medicine contractor requires the patient to sign an informed consent form before the drug is administered. Other drugs are also available to Occupational Medicine, but none has demonstrated the efficacy of DTPA for plutonium chelation. The decision to administer DTPA is usually made based on workplace indicators suggesting the likelihood of a significant uptake. Urinalysis is required to determine the actual efficacy of treatment. When the need for DTPA therapy is indicated, special emergency processing of a single void urine sample should be performed to determine if additional (i.e., extended) therapy might be warranted. Professional judgment is required on the part of the medical and exposure evaluator staff to determine if continued therapy is warranted. DTPA chelation therapy can enhance urine excretion of plutonium by up to a factor of 100 or more for highly soluble forms of plutonium. For insoluble forms, it is relatively ineffective. Because of this wide range of effectiveness, dosimetric interpretation of the urine data of a person undergoing chelation therapy is problematic. Bihl (1994) has suggested a dose-averted method for interpreting urine data, however, the guidance values in that analysis were based on ICRP 30 methodology. The historical practice at Hanford was to base final dosimetry on urine samples obtained long after the excretion enhancement effect of DTPA had passed (typically 30 to 100 days after therapy).

Catharsis involves accelerating the passage of material through the GI tract by means of laxative drugs or physical means such as an enema. Catharsis has potential value in reducing the absorption of material into the blood stream from the GI tract and in reducing the dose to the GI tract organs from material passing through the GI tract. These measures are not generally considered for occupational exposures to plutonium, because the GI tract absorption of plutonium is so slight, and the dose to the GI tract organs is usually an insignificant fraction of the total effective dose.

PNNL-MA-860 Chapter 8.0

Page 8.78
Issued for implementation effective 01/01/2010

Superseded: January 31, 2003 
Surgical excision of wounds can be extremely effective in reducing the ultimate uptake, particularly when coupled with decorporation therapy. Excisions may be performed by the Occupational Medicine staff, or by emergency room doctors at local hospitals, depending on the location of the contaminated individual. Assistance with excision decisions, activity in excised material or residual at the wound site, and contamination control are provided by PNNL exposure evaluation and radiation protection personnel.

\subsubsection{Long-Term Monitoring of Internal Depositions}

Once an internal dosimetry evaluation has been completed, it may be recommended that the worker be placed on a specialized long-term bioassay monitoring schedule. The reasons for this are twofold: first, long-term follow-up monitoring results that are consistent with the projected results verify the conclusions of the evaluation. Second, if long-term results are projected to be detectable, and the worker returns to plutonium work, then the capability of a routine bioassay monitoring program to detect an additional intake may be affected. This latter point is addressed in greater detail in Section 8.4.8.

Specialized bioassay monitoring programs may be required for workers with known internal depositions of plutonium. These programs may include head counts, liver counts, periodic chest counts, and urine samples. In some cases fecal sampling may also be desired. It is the responsibility of the HIDP to recommend appropriate long-term bioassay monitoring to the contractor dosimetry or radiation protection organization that has the responsibility for acting on these recommendations.

\subsection{References}

10 CFR 835. 2007. “Occupation Radiation Protection.” Code of Federal Regulations. U.S. Department of Energy. Available at: http://www.access.gpo.gov

Bhattacharyya MH, BD Breitenstein, H Metivier, BA Muggenburg, GN Stradling, and V Volf. 1992. "Guidebook for the treatment of accidental internal radionuclide contamination of workers." Rad. Prot. Dosim. 41:1.

Bihl DE. 1994. “A dose-averted approach to intervention levels for intakes of plutonium.” Health Phys. 66(Supplement):S72.

Bihl DE, TP Lynch, EH Carbaugh, and MJ Sula. 1988. Methods to Improve Routine Bioassay Monitoring for Freshly Separated, Poorly Transported Plutonium. PNL-6695, Pacific Northwest Laboratory, Richland, Washington.

Carbaugh EH, DE Bihl, and MJ Sula. 1991. "Long-term follow-up of HAN-1, an acute plutonium oxide inhalation case.” Rad. Prot. Dosim. 38(1/3):99-104.

Carbaugh EH and TR La Bone. 2003. "Two case studies of highly insoluble plutonium inhalation with implications for bioassay.” Rad. Prot. Dosim. 105(1/4):133-138.

Carbaugh EH. 2003a. "Minimum detectable dose as a measure of bioassay programme capability.” Rad. Prot. Dosim. 105(1/4):391-394. 
Carbaugh EH, DE Bihl, JA MacLellan. 2009. Hanford Internal Dosimetry Programt Manual. PNL-MA-552, PNNL-15613, Pacific Northwest National Laboratory, Richland, Washington. (Internal manual.) A copy of this manual is maintained in the HIDP files and available from the HIDP Manager or online by searching, PNNL-15613 @ http://www.pnl.gov/publications/.

Eidson AF. 1980. Comparison of Physical Chemical Properties of Powders and Respirable Aerosols of Industrial Mixed Uranium and Plutonium Oxide Fuels. NUREG/CR-1736, U.S. Nuclear Regulatory Commission, Washington, D.C.

Filipy RE. 2004. "Applying the International Commission on Radiological Protection (ICRP) Biokinetic Models.” U.S. Transuranium and Uranium Registries Annual Report, February 1, 2003 - January 31, 2004. USTR-0197-04, Eds. SM Ehrhart, RE Filipy, Washington State University - Tri-Cities, Richland, Washington.

Foster PP. 1991. "Study of a plutonium oxide fuel inhalation case.” Rad. Prot. Dosim. 38(1-3):141-146.

Griffith RV, PN Dean, AL Anderson, and JC Fisher. 1978. "Fabrication of a Tissue-Equivalent Torso Phantom for Intercalibration of In-Vivo Transuranic-Nuclide Counting Facilities.” In Advances in Radiation Monitoring, Proceedings of an International Atomic Energy Agency Conference. International Atomic Energy Agency, Vienna, Austria.

Hahn FF, SA Romanov, RA Guilmette, AP Nifatov, JH Diel, and Y Zaytseva, 2004, "Plutonium Microdistribution in the Lungs of Mayak Workers.” Radiation Research, Vol. 161, pp. 568-581.

Healy JW. 1948. “Bioassay at Hanford.” HW-10522, Hanford Works, Richland, Washington, (available in the Hanford Declassified Documents Retrieval System) Available at:

http://www2.hanford.gov/declass/

Healy JW. 1957. "Estimation of plutonium lung burden by urine analysis.” Am. Ind. Hyg. Assoc. Qrtrly 18(3):261-266.

Hoyt RC and JA Teal. 2004. Plutonium Finishing Plant Operations Overview (1949 - 2004): Contamination Events and Plutonium Isotope Distributions of Legacy Holdup Material in Process Systems. HNF-22064, Fluor Hanford, Richland, Washington.

Ibrahim SA, FW Whicker, SK Reuss, RD Whicker, PL Chapman, and MP Krahenbuhl. 1999. "Plutonium excretion in urine of residents living near the Rocky Flats Environmental Technology Site." Health Phys. 76(4)368-379.

International Commission on Radiological Protection (ICRP). 1959. Report of Committee II on Permissible Dose for Internal Radiation. ICRP Publication 2. Pergamon Press, New York.

International Commission on Radiological Protection (ICRP). 1969. Evaluation of Radiation Doses to Body Tissues from Internal Contamination due to Occupational Exposure. ICRP Publication 10. Pergamon Press, New York. 
International Commission on Radiological Protection (ICRP). 1977. "Recommendations of the international commission on radiological protection.” ICRP Publication 26. Annals of the ICRP, 1:3. Pergamon Press, New York.

International Commission on Radiological Protection (ICRP). 1979. "Limits for Intakes of Radionuclides by Workers.” ICRP Publication 30, Part 1 and Supplements, Annals of the ICRP, 2:3-4 and 3:1-4, Pergamon Press, New York.

International Commission on Radiological Protection (ICRP). 1983. "Radionuclide Transformations: Energy and Intensity of Emissions.” ICRP Publication 38, Annals of the ICRP, Volumes 11-13, Pergamon Press, New York.

International Commission on Radiological Protection (ICRP). 1986. "The Metabolism of Plutonium and Related Elements.” ICRP Publication 48, Annals of the ICRP, 16:2-3, Pergamon Press, New York.

International Commission on Radiological Protection (ICRP). 1988. "Limits for Intakes of Radionuclides by Workers: An Addendum.” ICRP Publication 30, Part 4, Annals of the ICRP, 19:4, Pergamon Press, New York.

International Commission on Radiological Protection (ICRP). 1989. “Age-dependent Doses to Members of the Public from Intake of Radionuclides: Part 1.” ICRP Publication 56, Annals of the ICRP, 20:2, Pergamon Press, New York.

International Commission on Radiological Protection (ICRP). 1991. "1990 Recommendations of the International Commission on Radiological Protection.” ICRP Publication 60, Annals of the ICRP, 21:1-3, Pergamon Press, New York.

International Commission on Radiological Protection (ICRP). 1993. "Age-dependent Doses to Members of the Public from Intake of Radionuclides: Part 2 Ingestion Dose Coefficients.” ICRP Publication 67, Annals of the ICRP, 23:3-4. Pergamon Press, New York.

International Commission on Radiological Protection (ICRP). 1994a. "Dose Coefficients for Intakes of Radionuclides by Workers.” ICRP Publication 68, Annals of the ICRP, 24:4, Pergamon Press, New York.

International Commission on Radiological Protection (ICRP). 1994b. "Human Respiratory Tract Model for Radiological Protection.” ICRP Publication 66, Annals of the ICRP, 24:1-3, Pergamon Press, New York.

International Commission on Radiological Protection (ICRP). 1995. “Age-dependent Doses to Members of the Public from Intake of Radionuclides: Part 4 Inhalation Dose Coefficients.” ICRP Publication 71, Annals of the ICRP, 25:3-4, Pergamon Press, New York.

International Commission on Radiological Protection (ICRP). 1997. "Individual Monitoring for Internal Exposure of Workers.” ICRP Publication 78, Annals of the ICRP, 27:3-4, Pergamon Press, New York.

International Commission on Radiological Protection (ICRP). 2002. "Basic Anatomical and Physiological Data for Use in Radiological Protection: Reference Values.” ICRP Publication 89, Ed. J Valentin, Annals of the ICRP, 32:3-4, Pergamon Press, New York. 
International Commission on Radiological Protection (ICRP). 2006. "Human Alimentary Tract Model for Radiological Protection.” ICRP Publication 100, Annals of the ICRP, 36:1-2.

James AC, A Birchall, JW Marsh, and M Puncher. 2004 or current version. User Manual for IMBA Expert, USDOE-Edition (Phase II). ACJ \& Associates, Richland, Washington. (Current version is available electronically as part of the IMBA Professional Plus software code.)

Jones SR. 1985. "Derivation and validation of a urinary excretion function for plutonium applicable over tens of years post intake.” Rad. Prot. Dosim. 11(1):19-27.

Kathren RL and JF McInroy. 1991. "Comparison of Systemic Plutonium Deposition Estimates from Urinalysis and Autopsy Data in Five Whole-Body Donors.” Health Physics, 60(4) 481-488.

Kinderman EM, HR Schmidt, GJ Alkive, A Chetham-Strode, and R Ko. 1953. The Isotopic Content and Specific Activity of Pile-Produced Plutonium. HW-26584, Hanford Atomic Products Operation, Richland, Washington.

La Bone TR, EH Carbaugh, WC Griffith, RA Guilmette, and KW Skrable. 1992. Evaluation of Savannah River Site Internal Dosimetry Registry Case 665(U). ESH-HPT-920178, Westinghouse Savannah River Company, Aiken, South Carolina.

La Bone TR and WM Findley. 1999. Evaluation of Savannah River Site Internal Dosimetry Registry Case 498 (U). ESH-HPT-99-0244, Westinghouse Savannah River Company, Aiken, South Carolina.

Langham WH, SH Basset, PS Harris, and RE Carter. 1950. "Distribution and excretion of plutonium administered to man.” LA-1151, Los Alamos Scientific Laboratory, Los Alamos, New Mexico. Reprinted in Health Phys. 38:1031-1060.

Lynch TP. 2007. In Vivo Project Manual. Pacific Northwest Laboratory, Richland, Washington.

Mann JR and RA Kirchner. 1967. "Evaluation of Lung Burden Following Acute Inhalation Exposure to Highly Insoluble $\mathrm{PuO}_{2}$.” Health Physics 13:877-882.

McInroy JF, EE Campbell, WD Moss, GL Tietjen, BC Eutsler, and HA. Boyd. 1979 "Plutonium in autopsy tissue: A revision and updating of data reported in LA-4875.” Health Phys. 37(1):1-136.

McInroy JF, HA Boyd, and BC Eutsler. 1981. "Deposition and retention of plutonium in the United States general population.” In Actinides in Man and Animals, Ed. M. Wrenn, pp. 161-181, R. D. Press, Salt Lake City, Utah.

McInroy JF, RL Kathren, and MJ Swint. 1989. "Distribution of plutonium and americium in whole bodies donated to the United States Transuranium Registry.” Rad. Prot Dosim. 26(151-158).

Moody JC, GN Stradling, and AR Britcher. 1994. "Biokinetics of three industrial plutonium nitrate materials: Implications for human exposure.” Rad. Prot. Dosim. 53:1-4(169-172). 
Morgan A, A Black, D Knight, and SR Moores. 1988. "The Effect of Firing Temperature on the Lung Retention and Translocation of Pu Following the Inhalation of ${ }^{238} \mathrm{PuO}_{2}$ and ${ }^{239} \mathrm{PuO}_{2}$ by CBA/H Mice." Health Physics 54(3):301-310.

National Bureau of Standards (NBS). 1959. Maximum Permissible Body Burdens and Maximum Permissible Concentrations of Radionuclides in Air and Water for Occupational Exposure. Handbook 69, U.S. Department of Commerce, Washington, D.C.

National Council on Radiation Protection and Measurements (NCRP). 1959. Maximum Permissible Body Burdens and Maximum Permissible Concentrations of Radionuclides in Air and in Water for Occupational Exposure. NCRP Report No. 22, Bethesda, Maryland.

National Council on Radiation Protection and Measurements (NCRP). 1980. Management of Persons Accidentally Contaminated with Radionuclides. NCRP Report No. 65, Bethesda, Maryland.

Nelson IC, VW Thomas, Jr, and RL Kathren. 1993. "Plutonium in South-Central Washington State autopsy tissue samples - 1970-1975.” Health Phys. 65(4):422-428.

Newman LS, MM Mroz, A Ruttenber, and A James. 2005. "Lung Fibrosis in Plutonium Workers.” Radiation Research 164(2):123-131.

Potter CA. 2002. "Intake Retention Fractions Developed from Models Used in the Determination of Dose Coefficients Developed for ICRP Publication 68 - Particulate Inhalation.” Health Physics 83(5):594-789.

Rittman PD. 1984. Seven Health Physics Calculator Programs for the HP-41CV. RHO-HS-ST-5 P, Rockwell Hanford Operations, Richland, Washington.

Romanov SA, RA Guilmette, FF Hahn, AP Nifatov, YV Zaytseva, and YV Lyovkina. 2003. "Modifying the ICRP 66 Dosimetry Model Based on Results Obtained from Mayak Plutonium Workers.” Radiation Protection Dosimetry 105(1/4):85-90.

Stradling GN and JW Stather. 1989. "The use of animal experiments for assessing annual limits on intake and interpreting chest-monitoring data for workers exposed to industrial actinide-bearing dusts.” Health Phys. 57:Supplement 1:221-228.

Strenge DL, RA Kennedy, MJ Sula, and JR Johnson. 1992. Code for Internal Dosimetry (Cindy Version 1.2), Part 1: Conceptual Representation. PNL-7493 Pt. 1, Rev. 1, Pacific Northwest National Laboratory, Richland, Washington.

Sula MJ, EH Carbaugh, and DE Bihl. 1989. Technical Basis for Internal Dosimetry at Hanford. PNL-6866, Pacific Northwest Laboratory, Richland, Washington.

Sula MJ, EH Carbaugh, and DE Bihl. 1991. Technical Basis for Internal Dosimetry at Hanford. PNL-6866 Revision 1, Pacific Northwest National Laboratory, Richland, Washington.

U.S. Department of Energy (DOE). 1992. Radiological Control Manual. DOE/EH-0256T, Washington, D.C. 
U.S. Department of Energy (DOE). 1998. Guide of Good Practices for Occupational Radiological Protection in Plutonium Facilities. DOE-STD-1128-98, Washington, D.C. Available at: http://www.hss.energy.gov/NuclearSafety/techstds/standard/std1128/doe-std-1128-98_cn2.pdf

Wrenn ME, NP Singh, and YH Xue. 1994. "Urinary excretion of ${ }^{239} \mathrm{Pu}$ by the general population: Measurement technique and results.” Rad. Prot. Dosim. 53:1-4(81-84). 


\section{Methods and Models of the Hanford Internal Dosimetry Program \\ PNNL-MA-860}

\subsection{Americium}

Issued for implementation effective 01/01/2010

Supersedes: January 2003

\section{Use Category: Not applicable}

\section{Approval Signatures:}

Prepared by:

EH Carbaugh, Internal Dosimetry Program Manfger

Approved by:

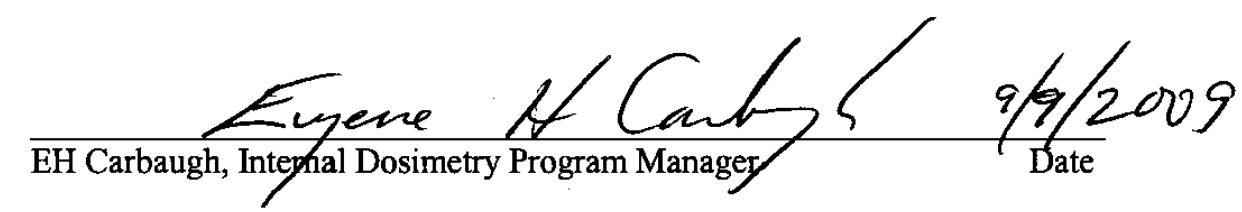

Reviewer Signatures:

Reviewed by:

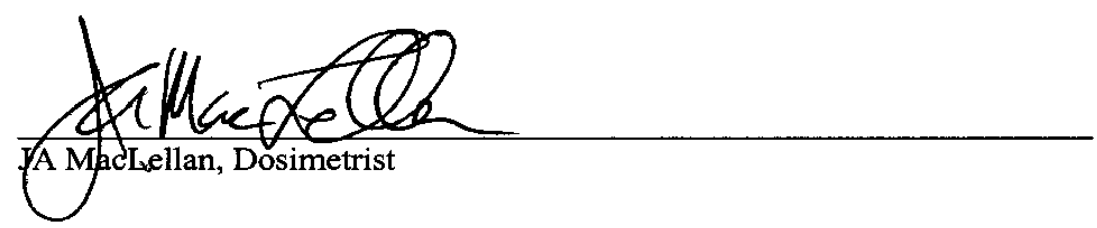

Approved by the Hanford Personnel Dosimetry Advisory Committee as recorded in the meeting minutes of October 14, 2008. 


\section{Contents}

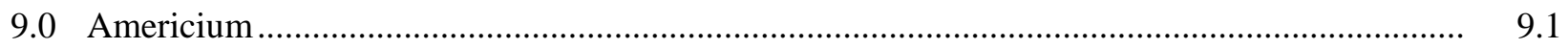

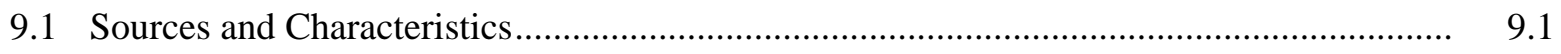

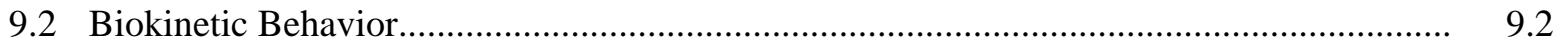

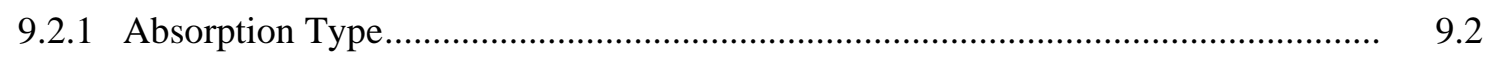

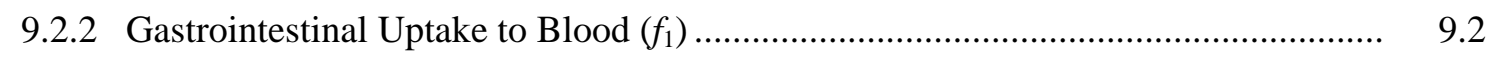

9.2.3 Distribution and Retention in Systemic Organs and Tissues ................................. 9.3

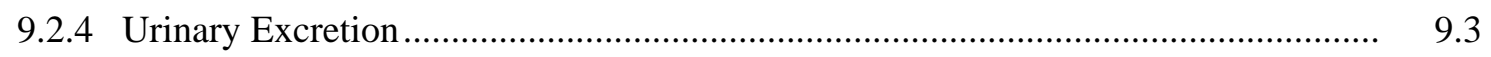

9.2.5 Fecal Systemic Excretion .............................................................................. 9.4

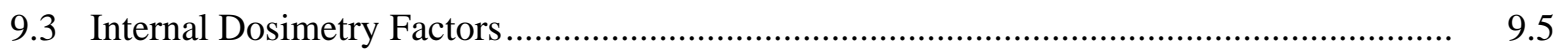

9.3.1 Intake Retention and Excretion Fractions ....................................................... 9.5

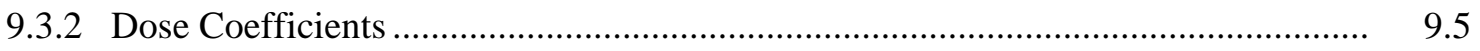

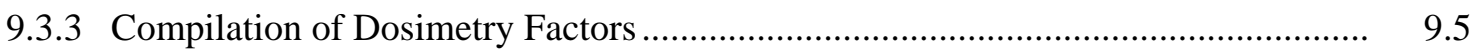

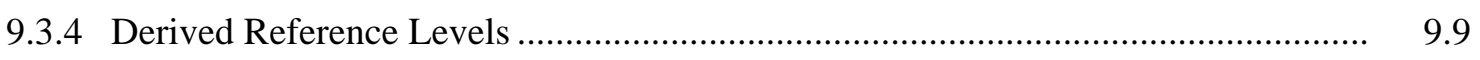

9.4 Bioassay for Americium........................................................................................... 9.9

9.4.1 Excreta Bioassay Techniques for Americium ...................................................... 9.9

9.4.2 In Vivo Bioassay Techniques for Americium ..................................................... 9.15

9.4.3 Recommended Periodic Bioassay Monitoring Protocol............................................ 9.18

9.4.4 Special Monitoring for Suspected Intakes........................................................... 9.19

9.4.5 Bioassay Monitoring Capability for Workers with Known Americium

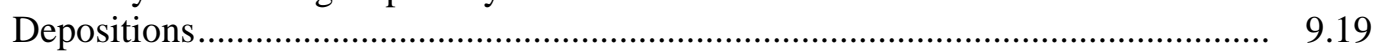

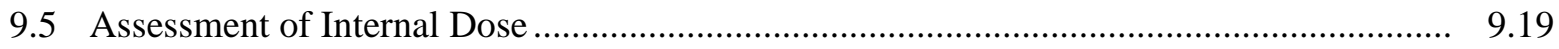

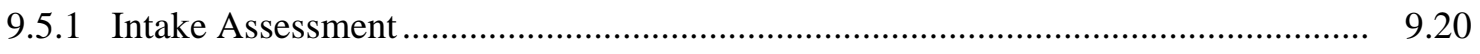

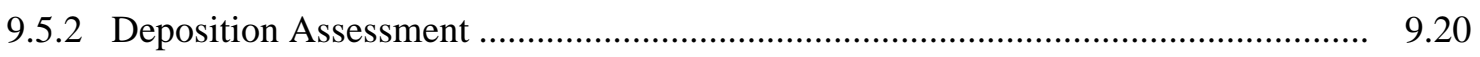

9.5.3 Assessing Organ and Effective Dose ................................................................ 9.20

9.6 Management of Internal Contamination Cases ............................................................. 9.21

9.6.1 Diagnostic Procedures...................................................................................... 9.21

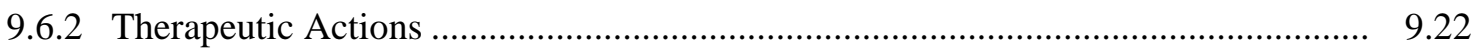

9.6.3 Long-Term Monitoring of Internal Depositions .................................................. 9.23

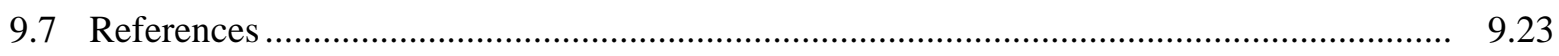

\section{Figures}

$9.1{ }^{241}$ Am Urine Excretion Fractions ................................................................................ 9.6

$9.2{ }^{241}$ Am Fecal Excretion Fractions................................................................................ 9.7

9.3 Lung Retention and Daily Excretion Fractions for 5- $\mu$ m Type $\mathrm{M}^{241} \mathrm{Am}$................................. 9.8

PNNL-MA-860 Chapter 9.0

Page 9.ii
Issued for implementation effective 01/01/2010

Supersedes: January 31, 2003 
9.4 Minimum Detectable Committed Effective Dose for ${ }^{241}$ Am Based on $0.02 \mathrm{dpm} / \mathrm{d}$ in Urine ....... 9.13

9.5 Minimum Detectable Committed Bone Surface Equivalent Dose for ${ }^{241} \mathrm{Am}$ Based on $0.02 \mathrm{dpm} / \mathrm{d}$ in Urine ........................................................................................................ 9.14

9.6 Minimum Detectable Committed Effective Dose for ${ }^{241} \mathrm{Am}$ Based on $0.8 \mathrm{dpm} / \mathrm{d}$ in Feces ........ 9. 9.16

9.7 Minimum Detectable Committed Bone Surface Equivalent Dose for ${ }^{241}$ Am Based on $0.8 \mathrm{dpm} / \mathrm{d}$ in Feces

9.8 Minimum Detectable Committed Doses for ${ }^{241}$ Am Type M 5- $\mu$ m-AMAD Acute Inhalation Based on $0.16 \mathrm{nCi}$ Detection in the Lung.....

\section{Tables}

9.1 Radiological Decay Data for Americium ...................................................................... 9.2

9.1 Transfer Rates Between Compartments in the Americium Systemic Model ............................ 9.4

9.3 Urine Excretion Fractions for ${ }^{241}$ Am Intakes .................................................................. 9.6

9.4 Fecal Excretion Fractions for ${ }^{241}$ Am Intakes ................................................................. 9.7

9.5 Lung Retention and Daily Excretion Fractions for Inhalation of 5- $\mu$ m-AMAD Type M ${ }^{241} \mathrm{Am}$ Fecal Excretion Fractions for ${ }^{241}$ Am Intakes.......................................................... 9.8

9.6 Committed Dose Coefficients for Intakes of ${ }^{241} \mathrm{Am}$........................................................... 9.9

9.7 Compilation of Selected Dosimetry Factors for ${ }^{241}$ Am......................................................... 9.10

9.2. ${ }^{241}$ Am Derived Reference Levels for Urine Excretion and Lung Burden for 5- $\mu$ m-AMAD Type M Acute Inhalation .................................................................................................... 9.11

9.9 Minimum Detectable Intakes for ${ }^{241} \mathrm{Am}$ Based on $0.02 \mathrm{dpm} / \mathrm{d}$ Detection of ${ }^{241} \mathrm{Am}$ in Urine..... 9.12

9.3 Minimum Detectable Committed Effective Dose for ${ }^{241} \mathrm{Am}$ Based on $0.02 \mathrm{dpm} / \mathrm{d}$ Detection of ${ }^{241} \mathrm{Am}$ in Urine ............................................................................................... 9.13

9.11 Minimum Detectable Committed Bone Surface Equivalent Dose for ${ }^{241}$ Am Based on $0.02 \mathrm{dpm} / \mathrm{d}$ Detection of ${ }^{241} \mathrm{Am}$ in Urine ........................................................................ 9.14

9.12 Minimum Detectable Intakes for ${ }^{241} \mathrm{Am}$ Based on $0.8 \mathrm{dpm} / \mathrm{d}$ Detection of ${ }^{241} \mathrm{Am}$ in Feces....... 9.15

9.13 Minimum Detectable Committed Effective Dose for ${ }^{241} \mathrm{Am}$ Based on $0.8 \mathrm{dpm} / \mathrm{d}$ Detection

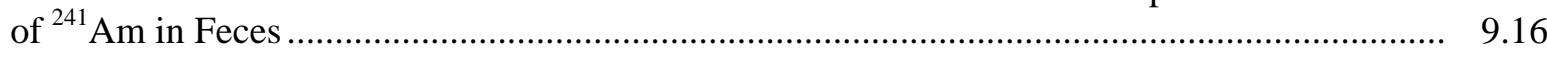

9.14 Minimum Detectable Committed Bone Surface Equivalent Dose for ${ }^{241}$ Am Based on $0.8 \mathrm{dpm} / \mathrm{d}$ Detection of ${ }^{241} \mathrm{Am}$ in Feces

9.15 Minimum Detectable Intakes and Committed Doses for Type M, 5- $\mu$ m-AMAD Acute Inhalation of ${ }^{241} \mathrm{Am}$ Based on $0.16 \mathrm{nCi}^{241} \mathrm{Am}$ Detection by Chest Counting 



\subsection{Americium}

This chapter provides technical information about the sources and characteristics of americium and summarizes the technical basis for its internal dosimetry at Hanford. Dosimetry methods used are based on the concepts of International Commission on Radiological Protection Publications 66 (ICRP 1994b) and 67 (ICRP 1993), as implemented using the Integrated Modules for Bioassay Analysis (IMBA) Professional Plus internal computer code (James et al. 2004). ${ }^{1}$

\subsection{Sources and Characteristics}

Americium at Hanford can be found as the ingrown ${ }^{241} \mathrm{Am}$ progeny of ${ }^{241} \mathrm{Pu}$ in a plutonium mixture or as a separated ${ }^{241} \mathrm{Am}$ isotope that exists singly or in combination with other separated isotopes in waste mixtures or laboratory facilities. In addition, ${ }^{243} \mathrm{Am}$ has been used in some Pacific Northwest National Laboratory (PNNL) facilities as a research isotope.

The ${ }^{241} \mathrm{Am}$ existing as an ingrown progeny in a plutonium mixture is typically a small fraction of the mass of the mixture. Consequently, it is assumed to be trapped in a plutonium matrix and exhibit the basic solubility and biokinetic characteristics of plutonium, rather than those of pure americium. Ingrown ${ }^{241} \mathrm{Am}$ is typically encountered at plutonium facilities such as most of the Plutonium Finishing Plant (PFP, 234-5Z Building), the Plutonium-Uranium Extraction (PUREX) Plant (202-A Building), or research facilities such as the former Critical Mass Laboratory (209-E Building).

Separated ${ }^{241} \mathrm{Am}$ can also be encountered at PFP because chemical separation of ${ }^{241} \mathrm{Am}$ from plutonium was a routine process at the Plutonium Reclamation Facility (236-Z Building) or the 242-Z facility and the ${ }^{241} \mathrm{Am}$ product was handled in PFP. The 242-Z facility was the site of the 1976 americium column explosion, which resulted in extensive contamination of the facility and its subsequent physical isolation from routine entry.

Separated ${ }^{241} \mathrm{Am}$ is also a trace contaminant in many of the 200-Area tank farm waste mixtures. During routine waste management activities, the trace americium was part of an intimately mixed waste slurry from the fuel processing facilities that was pumped into the waste tanks. With time, the slurry separated into a sludge at the bottom of the tanks and a supernate liquid above the sludge. The trace americium tended to be retained primarily in the supernate, along with ${ }^{137} \mathrm{Cs}$, while the sludge retained the majority of the trace plutonium and ${ }^{90} \mathrm{Sr}$. Subsequent supernate concentration activities produced salt cake that could also retain the trace ${ }^{241} \mathrm{Am}$. It is not likely that tank farm waste would contain separated ${ }^{241} \mathrm{Am}$ as a pure isotope; it can be anticipated that it would be accompanied by much larger quantities of fission product activity. However, there have been isolated discoveries of relatively pure ${ }^{241} \mathrm{Am}$ in tank farm related facilities.

\footnotetext{
${ }^{1}$ IMBA Professional Plus, which includes the current version of the user manual, is available from Health Protection Agency (HPA), Radiation Protection Division, Chilton, Didicot, Oxon., OX11 ORQ UK and from http://www.imbaprofessional.com/
} 
Pure isotopes of ${ }^{241} \mathrm{Am}$ and ${ }^{243} \mathrm{Am}$ can be found in analytical laboratory standard solutions and in pure isotope research applications.

The environmental levels of ${ }^{241} \mathrm{Am}$ from worldwide nuclear weapons testing fallout can be considered insignificant with regard to potential interferences with worker or workplace monitoring. The isotope has also found significant application as a sealed source for ionization in commercially manufactured smoke detectors, with the typical smoke detector containing about $1 \mu \mathrm{Ci}$ of ${ }^{241} \mathrm{Am}$, but there have been no indications that loss of containment has occurred with these sources.

Radiological decay data for ${ }^{241} \mathrm{Am}$ and ${ }^{243} \mathrm{Am}$ are listed in Table 9.1. The data were taken directly from, or calculated based on, information contained in ICRP 38 (1983).

Table 9.1. Radiological Decay Data for Americium

\begin{tabular}{|c|c|c|c|c|c|c|}
\hline \multirow[b]{2}{*}{ Isotope } & \multirow{2}{*}{$\begin{array}{l}\text { Principal Decay Mode, } \\
\text { Energy, and Yield }\end{array}$} & \multicolumn{2}{|c|}{ Physical Half-Life } & \multicolumn{2}{|c|}{ Decay Constant } & \multirow{2}{*}{$\begin{array}{c}\begin{array}{l}\text { Specific } \\
\text { Activity }\end{array} \\
\text { Ci/g }\end{array}$} \\
\hline & & Years & Days & Year $^{-1}$ & Day $^{-1}$ & \\
\hline${ }^{241} \mathrm{Am}$ & $\begin{array}{l}\text { Alpha 5.486 MeV, } 85.2 \% \\
\text { Gamma } \\
59.54 \mathrm{keV}, 35.7 \%\end{array}$ & 432.2 & $1.58 \mathrm{E}+05$ & $1.60 \mathrm{E}-03$ & 4.39E-06 & 3.43 \\
\hline${ }^{243} \mathrm{Am}$ & $\begin{array}{l}\text { Alpha } 5.276 \mathrm{MeV} \text {, } 87.9 \% \\
\text { Gamma } \\
74.67 \mathrm{keV}, 66.0 \%\end{array}$ & 7380 & $2.69 \mathrm{E}+06$ & 9.39E-05 & 2.57E-07 & 0.181 \\
\hline
\end{tabular}

\subsection{Biokinetic Behavior}

This section discusses the inhalation absorption type, internal distribution and retention, and the urinary and fecal excretion of americium. This discussion relates to pure ${ }^{241} \mathrm{Am}$ compounds or mixtures in which the ${ }^{241} \mathrm{Am}$ component represents a predominant fraction of the mixture mass (e.g., 50\% or more). Where americium is entrapped within a plutonium matrix as an ingrown progeny, it is assumed to behave characteristically with the plutonium matrix, and those properties are described in Chapter 8.0.

\subsubsection{Absorption Type}

The Human Respiratory Tract Model of ICRP 66 (1994b) assigned absorption Type M (for moderate rate of solubilization) to all forms of americium.

\subsubsection{Gastrointestinal Uptake to Blood $\left(f_{1}\right)$}

The fractional uptake to blood from the gastrointestinal (GI) tract is assumed to be $5 \times 10^{-4}$, as recommended in ICRP 67 (1993) and ICRP 78 (1997). This value was reduced from the $10^{-3}$ value used in earlier ICRP publications based on human studies discussed in ICRP 67, which became available in the late 1980s and early 1990s. The $5 \times 10^{-4}$ value applies to both inhalation and ingestion intakes. 


\subsubsection{Distribution and Retention in Systemic Organs and Tissues}

The systemic model presented in ICRP 67 (1993) and 78 (1997) is used to calculate the distribution and retention of americium in the body. The basic model is described in Appendix C. The main sites of retention are the liver and the skeleton. Flow of americium from blood to organs, within organ compartments, and back to blood and to excretion is determined entirely by transfer rates, which are listed in Table 9.2. Because the transfer rates to the testes and ovaries differ, a small difference in dose between these organs can occur; IMBA assigns gonadal dose as the higher of the dose to either the testes or the ovaries. For systemic americium, the testicular committed equivalent dose is about $1 \%$ less than the ovarian committed equivalent dose. Unlike the general model application to plutonium, the liver is treated as a single compartment (i.e., L1 and L2 are the same compartment of the liver, hence, no L1-toL2 transfer rate). Likewise, there is no direct soft tissue (ST1) to bladder (urinary excretion) pathway in the americium model. In Table 9.2 those two pathways are annotated as "not used" by the ICRP model for americium.

Historically, the Hanford Internal Dosimetry Program (HIDP) has used earlier ICRP models and a variant by the United States Transuranium Registry (USTR) for systemic distribution and retention of americium. The ICRP 2 (1959) critical organ model (with its associated maximum permissible body burden of $50 \mathrm{nCi}$ ) was used through 1987, when the ICRP 48 (1986) model was adopted. That model was superseded in 2000 with the adoption of the USTR model by Kathren (1994). The preceding models were formulated as simple first-order kinetics. The ICRP 67 model incorporates advanced physiologically based pharmaco kinetic modeling methods, including elemental recycling, and is implemented by this technical basis report, effective January 1, 2010.

\subsubsection{Urinary Excretion}

The ICRP 67 (1993) systemic model predicts urinary excretion from uptake to blood using physiologically based transfer rates to the urinary pathway rather than an empirical formula. ICRP 67 models urinary excretion by transferring americium from the blood directly to the urinary bladder contents, and from blood to the kidneys (passing into the urine rather than kidney tissue) to the bladder contents. Transfer rates for these compartments are listed in Table 9.2 and are labeled as "urinary excretion" to distinguish them from the pathway from blood to kidney tissue.

In ICRP 54 (1988), it was noted that there were few reports of americium excretion in humans, and for that publication, americium excretion was modeled the same as plutonium excretion. Based on that recommendation, the HIDP historically applied to americium the Jones excretion function for plutonium (Jones 1985). Jones' function was an empirical model that made no attempt to link the excretion process to specifically identifiable compartments. The Jones function was used from November 1986 until the issuance of this revision and is described in previous versions of this manual. For historical note, the Jones excretion function replaced the Rosen et al. (1972) model based on baboon data. That model was applied by Hanford dosimetrists to workers involved in the 1976 americium column explosion at the Hanford 242-Z facility, although only the most highly exposed worker was reported in the open literature (Robinson et al. 1983). The referenced documents that provide details about the excretion functions historically used at Hanford can be found in the Hanford Radiation Protection Historical Files of the Radiation Records Program or HIDP files.

Issued for implementation effective 01/01/2010

PNNL-MA-860 Chapter 9.0

Supersedes: January 31, 2003 
Table 9.2. Transfer Rates Between Compartments in the Americium Systemic Model

\begin{tabular}{lc}
\hline \multicolumn{1}{c}{ Route } & Transfer Rate $\left(\mathrm{d}^{-1}\right)$ \\
\hline ST0 to blood ${ }^{\text {(a) }}$ & $1.386 \mathrm{E}+00$ \\
ST1 to blood & $1.39 \mathrm{E}-02$ \\
ST2 to blood & $1.90 \mathrm{E}-05$ \\
Trabecular marrow to blood & $7.60 \mathrm{E}-03$ \\
Cortical marrow to blood & $7.60 \mathrm{E}-03$ \\
Kidneys (tissue) to blood & $1.39 \mathrm{E}-03$ \\
Liver 1 to blood & $1.85 \mathrm{E}-03$ \\
Testes to blood & $1.90 \mathrm{E}-04$ \\
Ovaries to blood & $1.90 \mathrm{E}-04$ \\
Blood to ST0 & $1.00 \mathrm{E}+01$ \\
Blood to ST1 & $1.67 \mathrm{E}+00$ \\
ST1 to bladder (urinary excretion) & Not used \\
Blood to ST2 & $4.66 \mathrm{E}-01$ \\
Blood to trabecular surface & $3.49 \mathrm{E}+00$ \\
Trabecular surface to trabecular volume & $2.47 \mathrm{E}-04$ \\
Trabecular surface to trabecular marrow & $4.93 \mathrm{E}-04$ \\
Trabecular volume to trabecular marrow & $4.93 \mathrm{E}-04$ \\
Blood to cortical surface & $3.49 \mathrm{E}+00$ \\
Cortical surface to cortical volume & $4.11 \mathrm{E}-05$ \\
Cortical surface to cortical marrow & $8.21 \mathrm{E}-05$ \\
Cortical volume to cortical marrow & $8.21 \mathrm{E}-05$ \\
Blood to kidneys (tissue) & $1.16 \mathrm{E}-01$ \\
Blood to Liver1 & $1.16 \mathrm{E}+01$ \\
Liver 1 to Liver 2 & Not used \\
Liver1 to small intestine (fecal excretion) & $4.90 \mathrm{E}-05$ \\
Blood to upper large intestine (fecal excretion) & $3.03 \mathrm{E}-01$ \\
Blood to testes & $8.20 \mathrm{E}-03$ \\
Blood to ovaries & $2.60 \mathrm{E}-03$ \\
Blood to kidneys (urinary excretion) & $4.66 \mathrm{E}-01$ \\
Kidneys to bladder (urinary excretion) & $9.90 \mathrm{E}-02$ \\
Blood to bladder (urinary excretion) & $1.63 \mathrm{E}+00$ \\
\hline (a) ST = soft tissue (the number indicates compartment number). \\
\hline
\end{tabular}

\subsubsection{Fecal Systemic Excretion}

The excretion of bile to the GI tract provides a pathway for systemic excretion of americium to feces from the liver. ICRP 67 models transfer of systemic americium to the GI tract using physiologically based transfer rates via two pathways. One pathway is from blood to the liver and from the liver to the small intestine (representing biliary secretion). The second pathway is directly from the blood to the upper large intestine. ICRP noted that half of the fecal excretion of systemic americium is assumed to come from the biliary pathway and the other half from intestinal secretion. Transfer rates, listed in 
Table 9.2, were established by ICRP based on human studies. For inhalation intakes, fecal excretion is dominated by clearance from the respiratory tract for the first year.

\subsection{Internal Dosimetry Factors}

This section contains factors that are useful in making internal dosimetry calculations. The factors included in this section are derived from IMBA and incorporate the models and assumptions described in the preceding section. Their application is intended for those circumstances where such assumptions are appropriate or more specific information is lacking. Variation from these factors is appropriate if sufficient data are available. The factors shown are for ${ }^{241} \mathrm{Am}$; however, the factors for ${ }^{243} \mathrm{Am}$ are only about $1 \%$ less than those for ${ }^{241} \mathrm{Am}$, thus the dosimetric difference is inconsequential.

\subsubsection{Intake Retention and Excretion Fractions}

The intake retention (or excretion) fraction expresses the fraction of intake retained in a particular compartment or excreted by a particular pathway (urine or feces) at a given time post intake. Although excretion implies elimination rather than retention, conventional models include excretion compartments under the general term retention and use the term "intake retention fraction" (IRF) to describe both. The IRFs for various times post intake are tabulated as described below for ${ }^{241} \mathrm{Am}$.

Urine excretion fractions for an instantaneous injection uptake, acute inhalation, and acute ingestion of ${ }^{241} \mathrm{Am}$ are listed in Table 9.3 and plotted in Figure 9.1. Corresponding values for fecal excretion are listed in Table 9.4 and plotted in Figure 9.2. Lung retention fractions for Type M inhalations of 5- $\mu \mathrm{m}-$ AMAD (activity median aerodynamic diameter) particles of ${ }^{241} \mathrm{Am}$ are listed in Table 9.5 and plotted in Figure 9.3. Values for days other than those tabulated here can be obtained by interpolation between the tabulated data, or by obtaining the values directly from IMBA.

\subsubsection{Dose Coefficients}

Dose coefficients, expressed as committed dose per unit activity of intake (rem per nanocurie of acute intake), are a convenient shortcut to estimating doses based on standard assumptions when the magnitude of an intake is known or assumed. Acute intake dose coefficients have been tabulated for instantaneous uptake, Type M inhalation of 5- $\mu$ m-AMAD particles, and for ingestion. The dose coefficients shown in Table 9.6 were derived by the IMBA computer code using the previously described models. The organ referred to as "others" is representative of the organs not specifically listed in the table, almost all of which have the same or nearly the same dose coefficient.

\subsubsection{Compilation of Dosimetry Factors}

A compilation of dosimetry factors, including dose coefficients, annual limits on intake (ALIs), and derived air concentrations (DACs), is provided in Table 9.7. For Hanford applications, the DAC values of Appendix A of Title 10 Part 835 of the Code of Federal Regulations (10 CFR 835) are typically used to control facility operations. 
Table 9.3. Urine Excretion Fractions for ${ }^{241}$ Am Intakes

\begin{tabular}{rccc}
\hline $\begin{array}{c}\text { Days Post } \\
\text { Intake }\end{array}$ & Instant Uptake & Ingestion & $\begin{array}{c}\text { Inhalation } \\
5-\mu m \text { Type M }\end{array}$ \\
\hline 0.5 & $5.55 \mathrm{E}-02$ & $2.25 \mathrm{E}-05$ & $1.57 \mathrm{E}-03$ \\
1 & $6.22 \mathrm{E}-02$ & $2.96 \mathrm{E}-05$ & $1.77 \mathrm{E}-03$ \\
2 & $7.46 \mathrm{E}-03$ & $4.59 \mathrm{E}-06$ & $2.32 \mathrm{E}-04$ \\
3 & $3.89 \mathrm{E}-03$ & $2.22 \mathrm{E}-06$ & $1.31 \mathrm{E}-04$ \\
4 & $2.43 \mathrm{E}-03$ & $1.33 \mathrm{E}-06$ & $8.97 \mathrm{E}-05$ \\
5 & $1.79 \mathrm{E}-03$ & $9.46 \mathrm{E}-07$ & $7.18 \mathrm{E}-05$ \\
7 & $1.29 \mathrm{E}-03$ & $6.60 \mathrm{E}-07$ & $5.77 \mathrm{E}-05$ \\
10 & $9.65 \mathrm{E}-04$ & $4.91 \mathrm{E}-07$ & $4.86 \mathrm{E}-05$ \\
14 & $6.99 \mathrm{E}-04$ & $3.55 \mathrm{E}-07$ & $4.08 \mathrm{E}-05$ \\
30 & $2.61 \mathrm{E}-04$ & $1.32 \mathrm{E}-07$ & $2.62 \mathrm{E}-05$ \\
60 & $1.38 \mathrm{E}-04$ & $6.93 \mathrm{E}-08$ & $1.88 \mathrm{E}-05$ \\
90 & $1.20 \mathrm{E}-04$ & $6.00 \mathrm{E}-08$ & $1.57 \mathrm{E}-05$ \\
180 & $9.87 \mathrm{E}-05$ & $4.94 \mathrm{E}-08$ & $1.10 \mathrm{E}-05$ \\
365 & $8.29 \mathrm{E}-05$ & $4.14 \mathrm{E}-08$ & $6.99 \mathrm{E}-06$ \\
730 & $6.68 \mathrm{E}-05$ & $3.34 \mathrm{E}-08$ & $4.52 \mathrm{E}-06$ \\
1,095 & $5.54 \mathrm{E}-05$ & $2.77 \mathrm{E}-08$ & $3.60 \mathrm{E}-06$ \\
1,825 & $4.06 \mathrm{E}-05$ & $2.03 \mathrm{E}-08$ & $2.59 \mathrm{E}-06$ \\
3,650 & $2.45 \mathrm{E}-05$ & $1.23 \mathrm{E}-08$ & $1.54 \mathrm{E}-06$ \\
7,300 & $1.69 \mathrm{E}-05$ & $7.31 \mathrm{E}-09$ & $9.08 \mathrm{E}-07$ \\
18,250 & $7.61 \mathrm{E}-06$ & $3.80 \mathrm{E}-09$ & $4.70 \mathrm{E}-07$ \\
\hline & & &
\end{tabular}

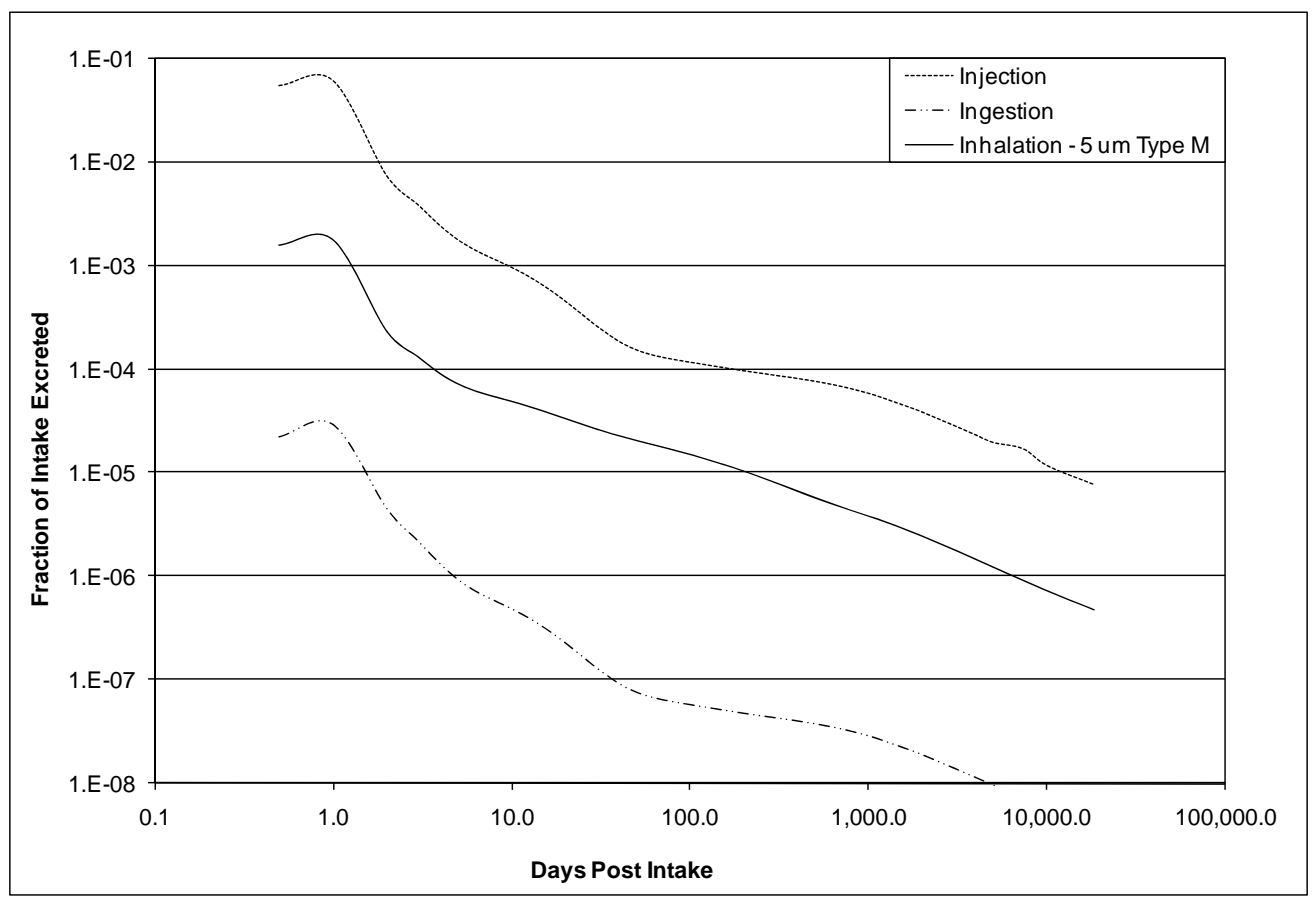

Figure 9.1. ${ }^{241} \mathrm{Am}$ Urine Excretion Fractions 
Table 9.4. Fecal Excretion Fractions for ${ }^{241}$ Am Intakes

\begin{tabular}{rccc}
\hline $\begin{array}{c}\text { Days Post } \\
\text { Intake }\end{array}$ & Instant Uptake & Ingestion & $\begin{array}{c}\text { Inhalation } \\
5-\mu \mathrm{m} \text { Type M }\end{array}$ \\
\hline 0.5 & $1.25 \mathrm{E}-03$ & $7.03 \mathrm{E}-02$ & $2.60 \mathrm{E}-02$ \\
1 & $3.74 \mathrm{E}-03$ & $2.82 \mathrm{E}-01$ & $1.08 \mathrm{E}-01$ \\
2 & $4.44 \mathrm{E}-03$ & $3.89 \mathrm{E}-01$ & $1.55 \mathrm{E}-01$ \\
3 & $2.60 \mathrm{E}-03$ & $1.97 \mathrm{E}-01$ & $7.97 \mathrm{E}-02$ \\
4 & $1.31 \mathrm{E}-03$ & $8.13 \mathrm{E}-02$ & $3.35 \mathrm{E}-02$ \\
5 & $6.34 \mathrm{E}-04$ & $3.14 \mathrm{E}-02$ & $1.33 \mathrm{E}-02$ \\
7 & $1.63 \mathrm{E}-04$ & $4.38 \mathrm{E}-03$ & $2.31 \mathrm{E}-03$ \\
10 & $5.67 \mathrm{E}-05$ & $2.20 \mathrm{E}-04$ & $5.75 \mathrm{E}-04$ \\
14 & $4.82 \mathrm{E}-05$ & $4.05 \mathrm{E}-06$ & $4.35 \mathrm{E}-04$ \\
30 & $4.62 \mathrm{E}-05$ & $2.31 \mathrm{E}-08$ & $2.80 \mathrm{E}-04$ \\
60 & $4.32 \mathrm{E}-05$ & $2.16 \mathrm{E}-08$ & $1.30 \mathrm{E}-04$ \\
90 & $4.10 \mathrm{E}-05$ & $2.05 \mathrm{E}-08$ & $6.59 \mathrm{E}-05$ \\
180 & $3.67 \mathrm{E}-05$ & $1.83 \mathrm{E}-08$ & $1.68 \mathrm{E}-05$ \\
365 & $3.15 \mathrm{E}-05$ & $1.58 \mathrm{E}-08$ & $5.56 \mathrm{E}-06$ \\
730 & $2.46 \mathrm{E}-05$ & $1.23 \mathrm{E}-08$ & $2.00 \mathrm{E}-06$ \\
1,095 & $1.98 \mathrm{E}-05$ & $9.89 \mathrm{E}-09$ & $1.33 \mathrm{E}-06$ \\
1,825 & $1.37 \mathrm{E}-05$ & $6.84 \mathrm{E}-09$ & $8.79 \mathrm{E}-07$ \\
3,650 & $7.58 \mathrm{E}-06$ & $3.79 \mathrm{E}-09$ & $4.77 \mathrm{E}-07$ \\
7,300 & $5.05 \mathrm{E}-06$ & $2.16 \mathrm{E}-09$ & $2.68 \mathrm{E}-07$ \\
18,250 & $2.21 \mathrm{E}-06$ & $1.10 \mathrm{E}-09$ & $1.36 \mathrm{E}-07$ \\
\hline
\end{tabular}

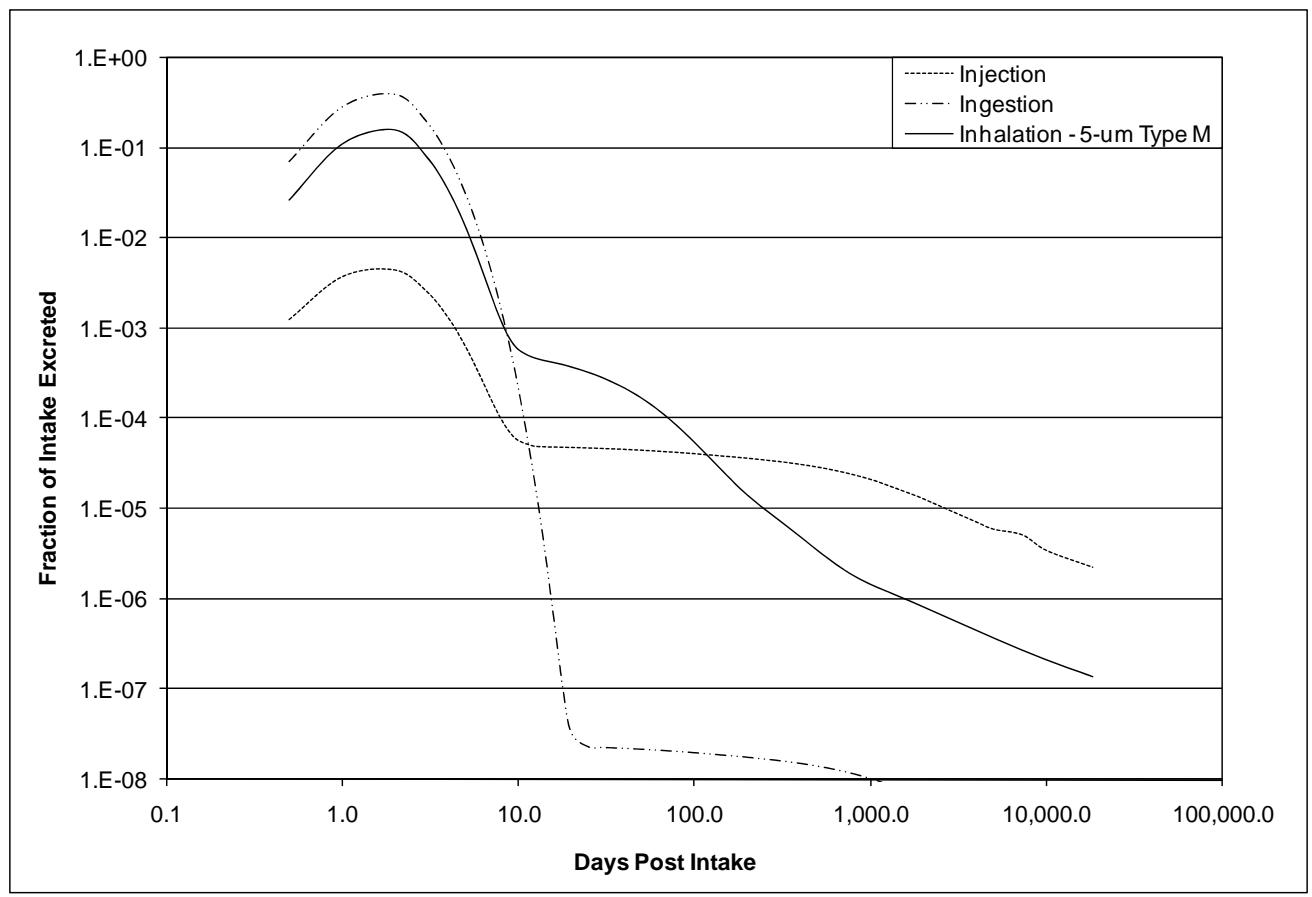

Figure 9.2. ${ }^{241} \mathrm{Am}$ Fecal Excretion Fractions 
Table 9.5. Lung Retention and Daily Excretion Fractions for Inhalation of 5- $\mu \mathrm{m}$-AMAD Type $\mathrm{M}^{241} \mathrm{Am}$ Fecal Excretion Fractions for ${ }^{241}$ Am Intakes

\begin{tabular}{rccc}
\hline $\begin{array}{c}\text { Days Post } \\
\text { Intake }\end{array}$ & $\begin{array}{c}\text { Lung } \\
\text { Retention }\end{array}$ & $\begin{array}{c}\text { Urine } \\
\text { Fraction }\end{array}$ & $\begin{array}{c}\text { Feces } \\
\text { Fraction }\end{array}$ \\
\hline 0.5 & $5.98 \mathrm{E}-02$ & $1.57 \mathrm{E}-03$ & $2.60 \mathrm{E}-02$ \\
1 & $5.76 \mathrm{E}-02$ & $1.77 \mathrm{E}-03$ & $1.08 \mathrm{E}-01$ \\
2 & $5.59 \mathrm{E}-02$ & $2.32 \mathrm{E}-04$ & $1.55 \mathrm{E}-01$ \\
3 & $5.50 \mathrm{E}-02$ & $1.31 \mathrm{E}-04$ & $7.97 \mathrm{E}-02$ \\
4 & $5.42 \mathrm{E}-02$ & $8.97 \mathrm{E}-05$ & $3.35 \mathrm{E}-02$ \\
5 & $5.34 \mathrm{E}-02$ & $7.18 \mathrm{E}-05$ & $1.33 \mathrm{E}-02$ \\
7 & $5.18 \mathrm{E}-02$ & $5.77 \mathrm{E}-05$ & $2.31 \mathrm{E}-03$ \\
10 & $4.97 \mathrm{E}-02$ & $4.86 \mathrm{E}-05$ & $5.75 \mathrm{E}-04$ \\
14 & $4.70 \mathrm{E}-02$ & $4.08 \mathrm{E}-05$ & $4.35 \mathrm{E}-04$ \\
30 & $3.84 \mathrm{E}-02$ & $2.62 \mathrm{E}-05$ & $2.80 \mathrm{E}-04$ \\
40 & $3.43 \mathrm{E}-02$ & $2.26 \mathrm{E}-05$ & $2.15 \mathrm{E}-04$ \\
50 & $3.09 \mathrm{E}-02$ & $2.03 \mathrm{E}-05$ & $1.66 \mathrm{E}-04$ \\
60 & $2.81 \mathrm{E}-02$ & $1.88 \mathrm{E}-05$ & $1.30 \mathrm{E}-04$ \\
90 & $2.18 \mathrm{E}-02$ & $1.57 \mathrm{E}-05$ & $6.59 \mathrm{E}-05$ \\
180 & $1.19 \mathrm{E}-02$ & $1.10 \mathrm{E}-05$ & $1.68 \mathrm{E}-05$ \\
365 & $3.99 \mathrm{E}-03$ & $6.99 \mathrm{E}-06$ & $5.56 \mathrm{E}-06$ \\
730 & $4.79 \mathrm{E}-04$ & $4.52 \mathrm{E}-06$ & $2.00 \mathrm{E}-06$ \\
1,095 & $5.88 \mathrm{E}-05$ & $3.60 \mathrm{E}-06$ & $1.33 \mathrm{E}-06$ \\
1,825 & $9.53 \mathrm{E}-07$ & $2.59 \mathrm{E}-06$ & $8.79 \mathrm{E}-07$ \\
3,650 & $5.02 \mathrm{E}-11$ & $1.54 \mathrm{E}-06$ & $4.77 \mathrm{E}-07$ \\
7,300 & $3.62 \mathrm{E}-19$ & $9.08 \mathrm{E}-07$ & $2.68 \mathrm{E}-07$ \\
18,250 & $3.09 \mathrm{E}-43$ & $4.70 \mathrm{E}-07$ & $1.36 \mathrm{E}-07$ \\
\hline
\end{tabular}

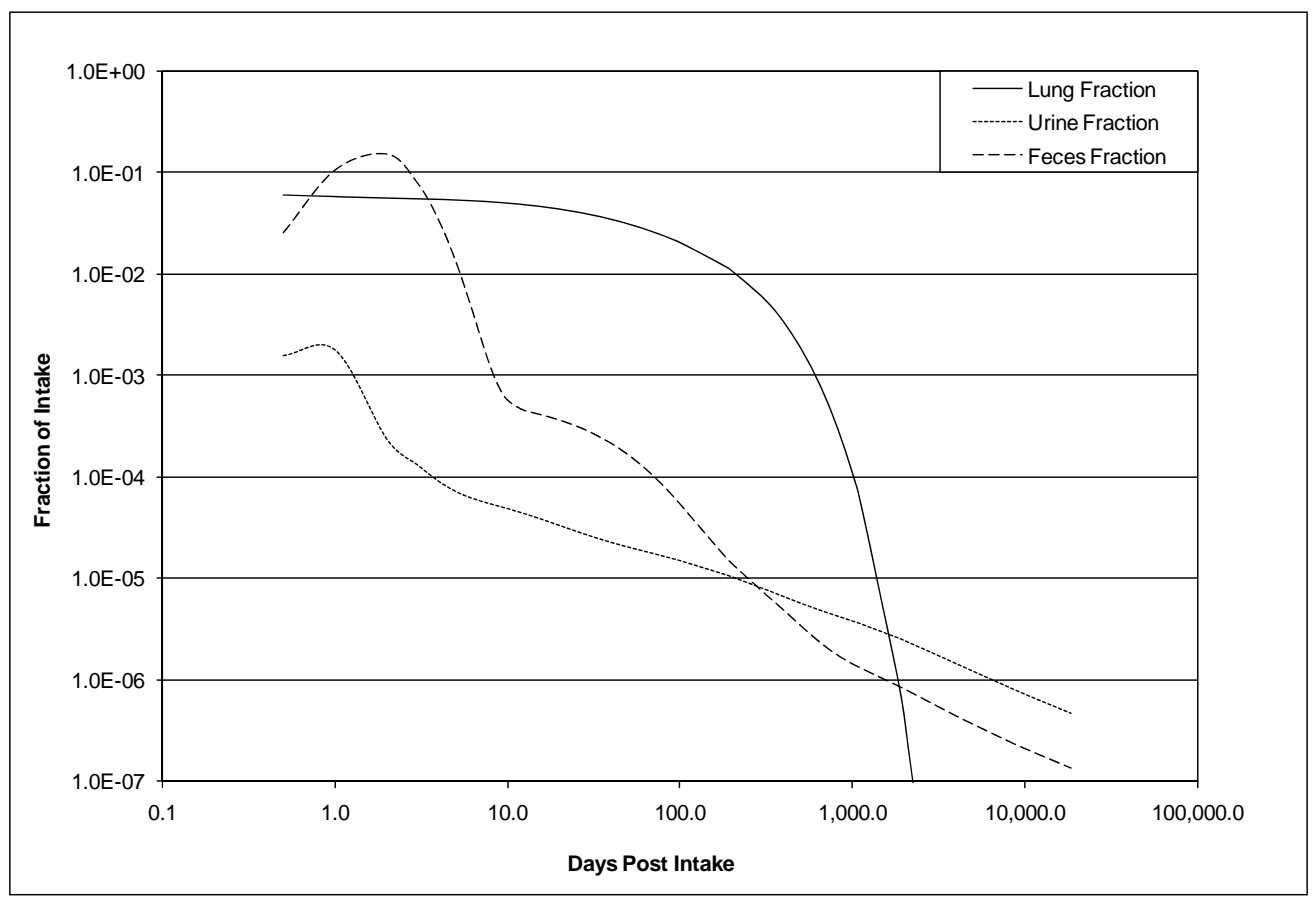

Figure 9.3. Lung Retention and Daily Excretion Fractions for 5- $\mu \mathrm{m}$ Type $\mathrm{M}^{241} \mathrm{Am}$ 
Table 9.6. Committed Dose Coefficients for Intakes of ${ }^{241} \mathrm{Am}$ (rem/nCi)

\begin{tabular}{lccc}
\hline \multicolumn{1}{c}{ Organ or Tissue } & $\begin{array}{c}\text { Instantaneous Uptake } \\
\text { (Injection) }\end{array}$ & $\begin{array}{c}\text { Inhalation, Type M } \\
\text { 5- } \mu \mathrm{m} \text { AMAD }\end{array}$ & $\begin{array}{c}\text { Ingestion } \\
f_{1}=5 \mathrm{E}-04\end{array}$ \\
\hline Effective & 1.47 & 0.100 & $7.54 \mathrm{E}-04$ \\
Bone Surface & 66.7 & 4.10 & $3.34 \mathrm{E}-02$ \\
Liver & 4.10 & 0.252 & $2.31 \mathrm{E}-03$ \\
Red Marrow & 2.27 & 0.140 & $1.14 \mathrm{E}-03$ \\
Lungs & 0.113 & 0.0880 & $5.67 \mathrm{E}-05$ \\
ET & 0.113 & 0.0574 & $5.67 \mathrm{E}-05$ \\
Gonads & 1.30 & 0.0797 & $6.49 \mathrm{E}-04$ \\
Kidneys & 0.324 & 0.0210 & $1.71 \mathrm{E}-04$ \\
Lower Large Intestine & 0.113 & 0.00704 & $2.75 \mathrm{E}-04$ \\
Colon & 0.113 & 0.00700 & $1.93 \mathrm{E}-04$ \\
Upper Large Intestine & 0.113 & 0.00698 & $1.31 \mathrm{E}-04$ \\
Small Intestine & 0.113 & 0.00695 & $6.91 \mathrm{E}-05$ \\
Stomach & 0.113 & 0.00695 & $6.16 \mathrm{E}-05$ \\
Others & 0.113 & 0.00711 & $5.81 \mathrm{E}-05$ \\
\hline ET = extrathoracic. & & & \\
\hline
\end{tabular}

\subsubsection{Derived Reference Levels}

Derived bioassay reference levels have been calculated for urine sampling and lung counting. The derived screening, investigation, and compliance levels (based on committed effective doses of 10-mrem and 100-mrem, and a committed bone surface equivalent dose of 50-rem, respectively) have been calculated for 5- $\mu \mathrm{m}$ Type $\mathrm{M}$ inhalations of pure ${ }^{241} \mathrm{Am}$ and are listed in Table 9.8. These levels are sufficiently low that, from a practical standpoint, any detected result is likely to result in investigation and dose assessment. This is particularly the case because ${ }^{241} \mathrm{Am}$ at Hanford is usually used as an indicator of potential plutonium intake.

\subsection{Bioassay for Americium}

This section discusses the general techniques and applicability of bioassay monitoring and describes the capabilities of excreta sample bioassay and in vivo measurements. General recommendations are also provided for routine bioassay monitoring for americium. Techniques are similar for both ${ }^{241} \mathrm{Am}$ and ${ }^{243} \mathrm{Am}$.

\subsubsection{Excreta Bioassay Techniques for Americium}

The typical urine sampling practice is to collect a urine sample over a specified time interval, ash the sample, dissolve the ash, and perform a chemical separation for americium using an added tracer to determine the chemical yield of the process. This technique is followed by coprecipitation or electroplating and quantitative alpha spectrometry. Where the analyte is ${ }^{241} \mathrm{Am}$, the tracer added to the chemical process is ${ }^{243} \mathrm{Am}$. If the analyte is ${ }^{243} \mathrm{Am}$, an ${ }^{241} \mathrm{Am}$ tracer is added. Because of the tracers used, if a worker is to be monitored for both ${ }^{241} \mathrm{Am}$ and ${ }^{243} \mathrm{Am}$, two samples will have to be collected and analyzed (or alternatively, a single sample must be split prior to adding the tracer and two different analyses performed.) 
Table 9.7. Compilation of Selected Dosimetry Factors for ${ }^{241} \mathrm{Am}$

\begin{tabular}{|c|c|c|c|}
\hline Reference Source & $\begin{array}{l}\text { Instantaneous Uptake } \\
\text { (Injection) }\end{array}$ & $\begin{array}{l}\text { Type M Inhalation } 5-\mu \mathrm{m} \\
\text { AMAD }\end{array}$ & $\begin{array}{c}\text { Soluble Ingestion } \\
f_{1}=5 \mathrm{E}-04\end{array}$ \\
\hline \multicolumn{4}{|c|}{ Dose Coefficients } \\
\hline IMBA $e(50)$ & $1.47 \mathrm{rem} / \mathrm{nCi}$ & $0.100 \mathrm{rem} / \mathrm{nCi}$ & 7.54E-04 rem/nCi \\
\hline $\begin{array}{l}\text { IMBA Bone surface as } \\
\text { maximal organ, } h(50)\end{array}$ & $66.7 \mathrm{rem} / \mathrm{nCi}$ & $4.10 \mathrm{rem} / \mathrm{nCi}$ & $0.0334 \mathrm{rem} / \mathrm{nCi}$ \\
\hline ICRP $68 e(50)$ & Not available & $\begin{array}{l}2.7 \mathrm{E}-05 \mathrm{~Sv} / \mathrm{Bq} \\
(0.10 \mathrm{rem} / \mathrm{nCi})\end{array}$ & $\begin{array}{c}2.0 \mathrm{E}-07 \mathrm{~Sv} / \mathrm{Bq} \\
(7.4 \mathrm{E}-04 \mathrm{rem} / \mathrm{nCi})\end{array}$ \\
\hline \multicolumn{4}{|c|}{ Annual Limit on Intake } \\
\hline $\begin{array}{l}\text { Calculated from IMBA } \\
h(50) \text { and } 50 \text { rem/y bone } \\
\text { surface limit }\end{array}$ & $0.75 \mathrm{nCi}$ & $12 \mathrm{nCi}$ & $1500 \mathrm{nCi}$ \\
\hline $\begin{array}{l}\text { Calculated from IMBA } \\
e(50) \text { and } 5 \mathrm{rem} / \mathrm{y} \\
\text { stochastic limit }\end{array}$ & $3.4 \mathrm{nCi}$ & $50 \mathrm{nCi}$ & $6600 \mathrm{nCi}$ \\
\hline \multicolumn{4}{|c|}{ Derived Air Concentration (DAC) } \\
\hline $\begin{array}{l}10 \text { CFR 835, App. A } \\
\text { Deterministic - based on } \\
\text { 50-rem bone surface } \\
H(50)\end{array}$ & Not applicable & $\begin{array}{l}5 \mathrm{E}-12 \mu \mathrm{Ci} / \mathrm{ml}^{3} \\
\left(1 \mathrm{E}-01 \mathrm{~Bq} / \mathrm{m}^{3}\right)\end{array}$ & Not applicable \\
\hline $\begin{array}{l}\text { Stochastic DAC based on } \\
\text { 5-rem } E(50)\end{array}$ & Not applicable & $2 \mathrm{E}-11 \mu \mathrm{Ci} / \mathrm{ml}$ & Not applicable \\
\hline $\begin{array}{l}10 \text { CFR } 20 \text { Table } 1 \text { DAC } \\
\text { (ICRP } 30 \text { based) }\end{array}$ & Not applicable & $3 \mathrm{E}-12 \mu \mathrm{Ci} / \mathrm{ml}$ & Not applicable \\
\hline
\end{tabular}

Fecal sample analysis follows a process similar to urine sample analysis, with a more complex ashing process.

Less sensitive, rapid analytical procedures are available for special circumstances. These procedures can be executed and results obtained in substantially shorter times than the routine procedure, but they are less sensitive. Their use is primarily for diagnostic bioassay of suspected internal contamination related to unplanned exposures (incidents). The decision to use such procedures involves considering the probability and potential magnitude of the exposure. Of particular interest as an alternative to the electroplating and alpha spectrometry procedure is direct counting of the low-energy ${ }^{241} \mathrm{Am}$ photon using a germanium detector. This protocol is substantially less sensitive than the alpha spectrometry, but is not subject to the difficulties associated with americium chemical separation. This analysis is an appropriate quickturnaround emergency analysis procedure that could be used as an indicator for a plutonium intake based on fecal sampling and reasonable knowledge of the americium-to-plutonium ratio. 
Table 9.8. ${ }^{241}$ Am Derived Reference Levels for Urine Excretion and Lung Burden for 5- $\mu \mathrm{m}-\mathrm{AMAD}$ Type M Acute Inhalation

\begin{tabular}{|c|c|c|c|c|c|c|}
\hline & \multicolumn{2}{|c|}{$\begin{array}{l}\text { 10-mrem } E(50) \\
\text { Screening Level }\end{array}$} & \multicolumn{2}{|c|}{$\begin{array}{l}\text { 100-mrem E(50) } \\
\text { Investigation Level }\end{array}$} & \multicolumn{2}{|c|}{$\begin{array}{c}\text { 50-rem } H(50) \\
\text { Compliance Level }\end{array}$} \\
\hline Intake: & \multicolumn{2}{|c|}{$0.100 \mathrm{nCi}$} & \multicolumn{2}{|c|}{$1.00 \mathrm{nCi}$} & \multicolumn{2}{|c|}{$12.2 \mathrm{nCi}$} \\
\hline Bioassay & \multicolumn{2}{|c|}{$\begin{array}{c}\text { Derived Screening } \\
\text { Level } \\
\end{array}$} & \multicolumn{2}{|c|}{$\begin{array}{c}\text { Derived Investigation } \\
\text { Level }\end{array}$} & \multicolumn{2}{|c|}{$\begin{array}{c}\text { Derived Compliance } \\
\text { Level } \\
\end{array}$} \\
\hline $\begin{array}{l}\text { Days Post } \\
\text { Intake }\end{array}$ & $\begin{array}{c}\text { Urine } \\
\text { (dpm/d) }\end{array}$ & $\begin{array}{l}\text { Lung } \\
(\mathrm{nCi})\end{array}$ & $\begin{array}{l}\text { Urine } \\
\text { (dpm/d) }\end{array}$ & $\begin{array}{l}\text { Lung } \\
(\mathrm{nCi})\end{array}$ & $\begin{array}{c}\text { Urine } \\
\text { (dpm/d) }\end{array}$ & $\begin{array}{l}\text { Lung } \\
(\mathrm{nCi})\end{array}$ \\
\hline 0.5 & $3.5 \mathrm{E}-01$ & $6.0 \mathrm{E}-03$ & $3.5 \mathrm{E}+00$ & $6.0 \mathrm{E}-02$ & $4.3 \mathrm{E}+01$ & 7.3E-01 \\
\hline 1 & 3.9E-01 & 5.8E-03 & $3.9 \mathrm{E}+00$ & $5.8 \mathrm{E}-02$ & $4.8 \mathrm{E}+01$ & 7.0E-01 \\
\hline 2 & $5.1 \mathrm{E}-02$ & $5.6 \mathrm{E}-03$ & $5.1 \mathrm{E}-01$ & $5.6 \mathrm{E}-02$ & $6.3 \mathrm{E}+00$ & 6.8E-01 \\
\hline 3 & 2.9E-02 & 5.5E-03 & 2.9E-01 & 5.5E-02 & $3.5 \mathrm{E}+00$ & 6.7E-01 \\
\hline 4 & 2.0E-02 & $5.4 \mathrm{E}-03$ & 2.0E-01 & $5.4 \mathrm{E}-02$ & $2.4 \mathrm{E}+00$ & 6.6E-01 \\
\hline 5 & 1.6E-02 & 5.3E-03 & $1.6 \mathrm{E}-01$ & 5.3E-02 & $1.9 \mathrm{E}+00$ & 6.5E-01 \\
\hline 7 & 1.3E-02 & 5.2E-03 & $1.3 \mathrm{E}-01$ & $5.2 \mathrm{E}-02$ & $1.6 \mathrm{E}+00$ & 6.3E-01 \\
\hline 14 & $9.1 \mathrm{E}-03$ & 4.7E-03 & $9.1 \mathrm{E}-02$ & 4.7E-02 & $1.1 \mathrm{E}+00$ & 5.7E-01 \\
\hline 30 & $5.8 \mathrm{E}-03$ & 3.8E-03 & $5.8 \mathrm{E}-02$ & 3.8E-02 & 7.1E-01 & 4.7E-01 \\
\hline 60 & $4.2 \mathrm{E}-03$ & 2.8E-03 & $4.2 \mathrm{E}-02$ & $2.8 \mathrm{E}-02$ & $5.1 \mathrm{E}-01$ & 3.4E-01 \\
\hline 90 & $3.5 \mathrm{E}-03$ & $2.2 \mathrm{E}-03$ & 3.5E-02 & 2.2E-02 & $4.2 \mathrm{E}-01$ & 2.7E-01 \\
\hline 180 & 2.4E-03 & $1.2 \mathrm{E}-03$ & 2.4E-02 & $1.2 \mathrm{E}-02$ & $3.0 \mathrm{E}-01$ & $1.5 \mathrm{E}-01$ \\
\hline 365 & $1.6 \mathrm{E}-03$ & 4.0E-04 & $1.6 \mathrm{E}-02$ & $4.0 \mathrm{E}-03$ & $1.9 \mathrm{E}-01$ & 4.9E-02 \\
\hline 730 & $1.0 \mathrm{E}-03$ & 4.8E-05 & $1.0 \mathrm{E}-02$ & 4.8E-04 & $1.2 \mathrm{E}-01$ & $5.8 \mathrm{E}-03$ \\
\hline 1,825 & $5.8 \mathrm{E}-04$ & $9.5 \mathrm{E}-08$ & $5.8 \mathrm{E}-03$ & $9.5 \mathrm{E}-07$ & 7.0E-02 & $1.2 \mathrm{E}-05$ \\
\hline 3,650 & 3.4E-04 & 5.0E-12 & 3.4E-03 & $5.0 \mathrm{E}-11$ & 4.2E-02 & $6.1 \mathrm{E}-10$ \\
\hline 7,300 & 2.0E-04 & $3.6 \mathrm{E}-20$ & 2.0E-03 & 3.6E-19 & 2.5E-02 & 4.4E-18 \\
\hline 18,250 & $1.0 \mathrm{E}-04$ & $3.1 \mathrm{E}-44$ & $1.0 \mathrm{E}-03$ & $3.1 \mathrm{E}-43$ & $1.3 \mathrm{E}-02$ & $3.8 \mathrm{E}-42$ \\
\hline
\end{tabular}

The contractual detection limits for americium in urine or feces can be found in the radiochemistry bioassay laboratory statement of work (available from the HIDP) and in the Hanford Internal Dosimetry Program Manual (PNL-MA-552; EH Carbaugh, et al. 2009).

The minimum detectable intakes based on a $0.02 \mathrm{dpm} / \mathrm{d}$ urinalysis sensitivity are listed in Table 9.9. The committed effective doses and bone surface equivalent doses associated with those intakes are shown in Tables 9.10 and 9.11, respectively. Figures 9.4 and 9.5 show graphical presentations of the minimum detectable doses. Corresponding data based on a $0.8 \mathrm{dpm} / \mathrm{d}$ fecal analysis sensitivity, are listed in Tables 9.12 through 9.14 and plotted in Figures 9.6 and 9.7. 
Table 9.9. Minimum Detectable Intakes (nCi) for ${ }^{241} \mathrm{Am}$ Based on $0.02 \mathrm{dpm} / \mathrm{d}$ Detection of ${ }^{241} \mathrm{Am}$ in Urine

\begin{tabular}{rccc}
\hline $\begin{array}{c}\text { Days Post } \\
\text { Intake }\end{array}$ & $\begin{array}{c}\text { Instant } \\
\text { Uptake }\end{array}$ & Ingestion & $\begin{array}{c}\text { Inhalation } \\
5-\mu \mathrm{m} \text {, Type M }\end{array}$ \\
\hline 1 & $1.4 \mathrm{E}-04$ & $3.0 \mathrm{E}-01$ & $5.1 \mathrm{E}-03$ \\
2 & $1.2 \mathrm{E}-03$ & $2.0 \mathrm{E}+00$ & $3.9 \mathrm{E}-02$ \\
5 & $5.0 \mathrm{E}-03$ & $9.5 \mathrm{E}+00$ & $1.3 \mathrm{E}-01$ \\
7 & $7.0 \mathrm{E}-03$ & $1.4 \mathrm{E}+01$ & $1.6 \mathrm{E}-01$ \\
14 & $1.3 \mathrm{E}-02$ & $2.5 \mathrm{E}+01$ & $2.2 \mathrm{E}-01$ \\
30 & $3.5 \mathrm{E}-02$ & $6.8 \mathrm{E}+01$ & $3.4 \mathrm{E}-01$ \\
60 & $6.5 \mathrm{E}-02$ & $1.3 \mathrm{E}+02$ & $4.8 \mathrm{E}-01$ \\
90 & $7.5 \mathrm{E}-02$ & $1.5 \mathrm{E}+02$ & $5.7 \mathrm{E}-01$ \\
180 & $9.1 \mathrm{E}-02$ & $1.8 \mathrm{E}+02$ & $8.2 \mathrm{E}-01$ \\
365 & $1.1 \mathrm{E}-01$ & $2.2 \mathrm{E}+02$ & $1.3 \mathrm{E}+00$ \\
730 & $1.3 \mathrm{E}-01$ & $2.7 \mathrm{E}+02$ & $2.0 \mathrm{E}+00$ \\
1,825 & $2.2 \mathrm{E}-01$ & $4.4 \mathrm{E}+02$ & $3.5 \mathrm{E}+00$ \\
3,650 & $3.7 \mathrm{E}-01$ & $7.3 \mathrm{E}+02$ & $5.9 \mathrm{E}+00$ \\
7,300 & $5.3 \mathrm{E}-01$ & $1.2 \mathrm{E}+03$ & $9.9 \mathrm{E}+00$ \\
18,250 & $1.2 \mathrm{E}+00$ & $2.4 \mathrm{E}+03$ & $1.9 \mathrm{E}+01$ \\
\hline
\end{tabular}


Table 9.10. Minimum Detectable Committed Effective Dose (rem) for ${ }^{241}$ Am Based on 0.02 dpm/d Detection of ${ }^{241} \mathrm{Am}$ in Urine

\begin{tabular}{rccc}
\hline $\begin{array}{c}\text { Days Post } \\
\text { Intake }\end{array}$ & $\begin{array}{c}\text { Instant } \\
\text { Uptake }\end{array}$ & Ingestion & $\begin{array}{c}\text { Inhalation } \\
\text { Type M 5- } \mu \mathrm{m}\end{array}$ \\
\hline 1 & $2.1 \mathrm{E}-04$ & $2.3 \mathrm{E}-04$ & $5.1 \mathrm{E}-04$ \\
2 & $1.8 \mathrm{E}-03$ & $1.5 \mathrm{E}-03$ & $3.9 \mathrm{E}-03$ \\
5 & $7.4 \mathrm{E}-03$ & $7.2 \mathrm{E}-03$ & $1.3 \mathrm{E}-02$ \\
7 & $1.0 \mathrm{E}-02$ & $1.0 \mathrm{E}-02$ & $1.6 \mathrm{E}-02$ \\
14 & $1.9 \mathrm{E}-02$ & $1.9 \mathrm{E}-02$ & $2.2 \mathrm{E}-02$ \\
30 & $5.1 \mathrm{E}-02$ & $5.2 \mathrm{E}-02$ & $3.4 \mathrm{E}-02$ \\
60 & $9.6 \mathrm{E}-02$ & $9.8 \mathrm{E}-02$ & $4.8 \mathrm{E}-02$ \\
90 & $1.1 \mathrm{E}-01$ & $1.1 \mathrm{E}-01$ & $5.7 \mathrm{E}-02$ \\
180 & $1.3 \mathrm{E}-01$ & $1.4 \mathrm{E}-01$ & $8.2 \mathrm{E}-02$ \\
365 & $1.6 \mathrm{E}-01$ & $1.6 \mathrm{E}-01$ & $1.3 \mathrm{E}-01$ \\
730 & $2.0 \mathrm{E}-01$ & $2.0 \mathrm{E}-01$ & $2.0 \mathrm{E}-01$ \\
1,825 & $3.3 \mathrm{E}-01$ & $3.3 \mathrm{E}-01$ & $3.5 \mathrm{E}-01$ \\
3,650 & $5.4 \mathrm{E}-01$ & $5.5 \mathrm{E}-01$ & $5.9 \mathrm{E}-01$ \\
7,300 & $7.8 \mathrm{E}-01$ & $9.3 \mathrm{E}-01$ & $9.9 \mathrm{E}-01$ \\
18,250 & $1.7 \mathrm{E}+00$ & $1.8 \mathrm{E}+00$ & $1.9 \mathrm{E}+00$ \\
\hline
\end{tabular}

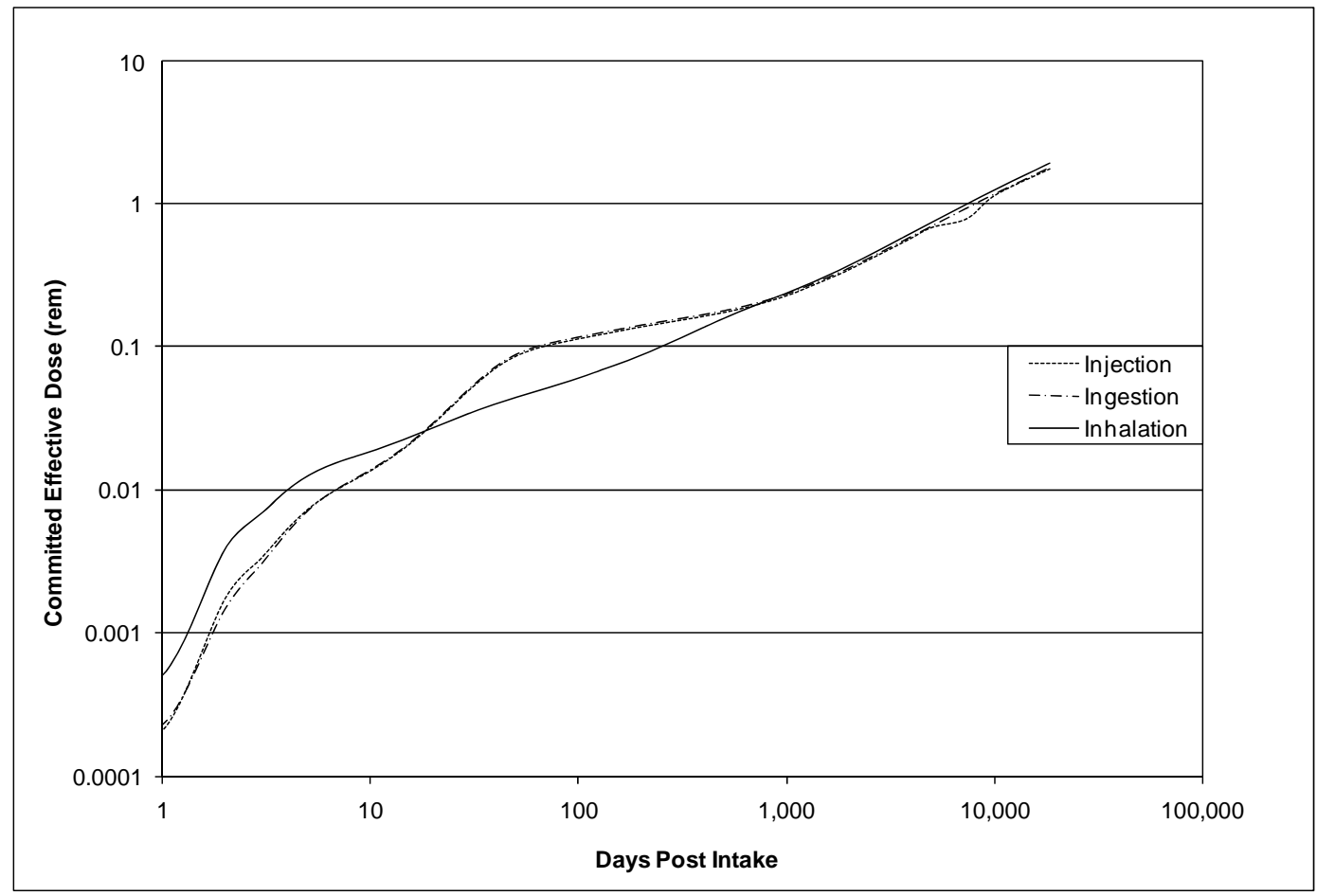

Figure 9.4. Minimum Detectable Committed Effective Dose for ${ }^{241}$ Am Based on $0.02 \mathrm{dpm} / \mathrm{d}$ in Urine 
Table 9.11. Minimum Detectable Committed Bone Surface Equivalent Dose (rem) for ${ }^{241}$ Am Based on $0.02 \mathrm{dpm} / \mathrm{d}$ Detection of ${ }^{241} \mathrm{Am}$ in Urine

\begin{tabular}{rccc}
\hline \multicolumn{1}{c}{$\begin{array}{c}\text { Days Post } \\
\text { Intake }\end{array}$} & $\begin{array}{c}\text { Instant } \\
\text { Uptake }\end{array}$ & Ingestion & $\begin{array}{c}\text { Inhalation } \\
5-\mu \mathrm{m} \text {, Type M }\end{array}$ \\
\hline 1 & $9.7 \mathrm{E}-03$ & $1.0 \mathrm{E}-02$ & $2.1 \mathrm{E}-02$ \\
2 & $8.1 \mathrm{E}-02$ & $6.6 \mathrm{E}-02$ & $1.6 \mathrm{E}-01$ \\
5 & $3.4 \mathrm{E}-01$ & $3.2 \mathrm{E}-01$ & $5.1 \mathrm{E}-01$ \\
7 & $4.7 \mathrm{E}-01$ & $4.6 \mathrm{E}-01$ & $6.4 \mathrm{E}-01$ \\
14 & $8.6 \mathrm{E}-01$ & $8.5 \mathrm{E}-01$ & $9.1 \mathrm{E}-01$ \\
30 & $2.3 \mathrm{E}+00$ & $2.3 \mathrm{E}+00$ & $1.4 \mathrm{E}+00$ \\
60 & $4.3 \mathrm{E}+00$ & $4.3 \mathrm{E}+00$ & $2.0 \mathrm{E}+00$ \\
90 & $5.0 \mathrm{E}+00$ & $5.0 \mathrm{E}+00$ & $2.4 \mathrm{E}+00$ \\
365 & $7.3 \mathrm{E}+00$ & $7.3 \mathrm{E}+00$ & $5.3 \mathrm{E}+00$ \\
730 & $9.0 \mathrm{E}+00$ & $9.0 \mathrm{E}+00$ & $8.2 \mathrm{E}+00$ \\
1,825 & $1.5 \mathrm{E}+01$ & $1.5 \mathrm{E}+01$ & $1.4 \mathrm{E}+01$ \\
3,650 & $2.5 \mathrm{E}+01$ & $2.5 \mathrm{E}+01$ & $2.4 \mathrm{E}+01$ \\
7,300 & $3.6 \mathrm{E}+01$ & $4.1 \mathrm{E}+01$ & $4.1 \mathrm{E}+01$ \\
18,250 & $7.9 \mathrm{E}+01$ & $7.9 \mathrm{E}+01$ & $7.9 \mathrm{E}+01$ \\
\hline
\end{tabular}

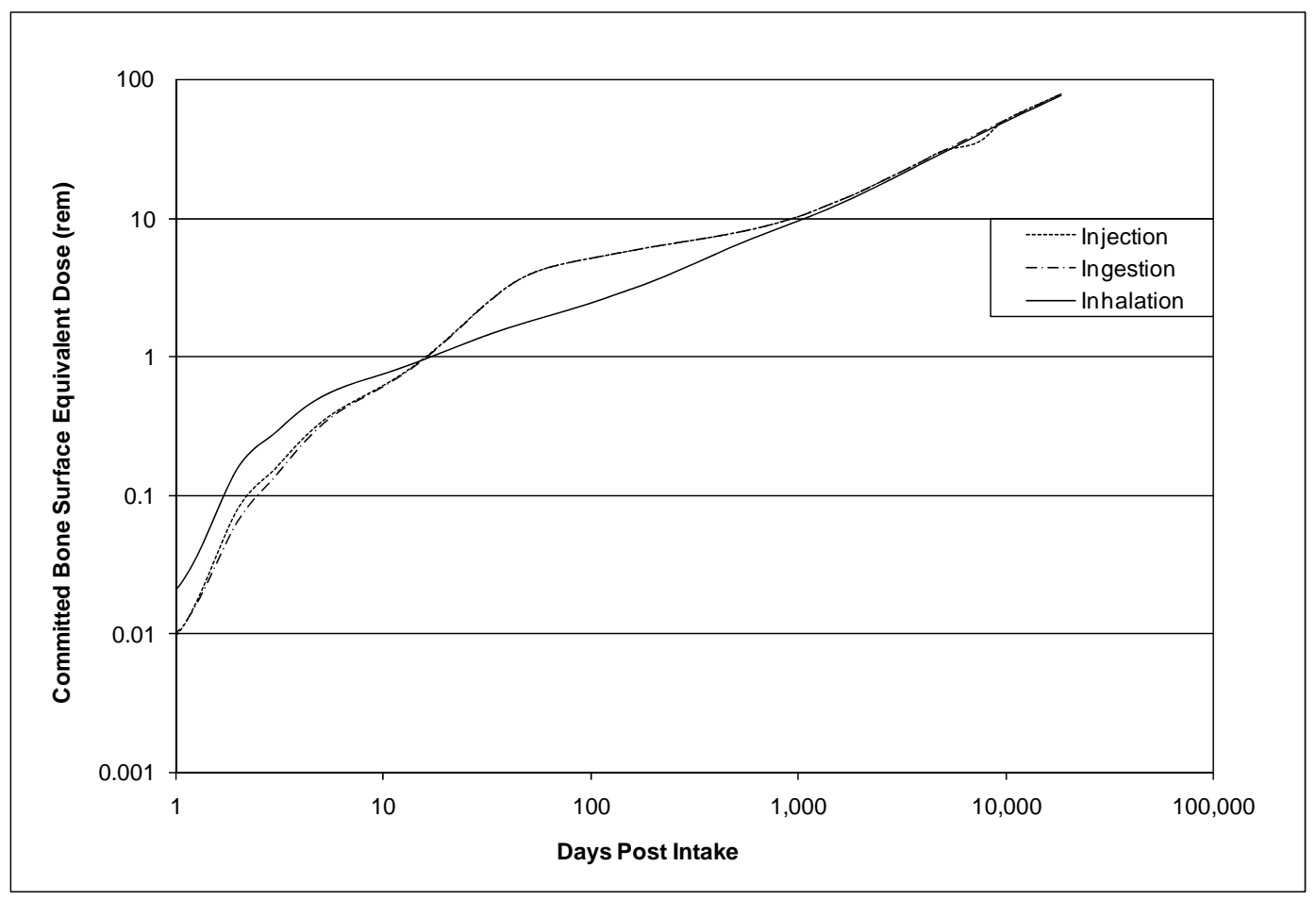

Figure 9.5. Minimum Detectable Committed Bone Surface Equivalent Dose for ${ }^{241} \mathrm{Am}$ Based on $0.02 \mathrm{dpm} / \mathrm{d}$ in Urine 
Table 9.12. Minimum Detectable Intakes (nCi) for ${ }^{241} \mathrm{Am}$ Based on $0.8 \mathrm{dpm} / \mathrm{d}$ Detection of ${ }^{241} \mathrm{Am}$ in Feces

\begin{tabular}{rccc}
\hline $\begin{array}{c}\text { Days Post } \\
\text { Intake }\end{array}$ & $\begin{array}{c}\text { Instant } \\
\text { Uptake }\end{array}$ & Ingestion & $\begin{array}{c}\text { Inhalation } \\
5-\mu \mathrm{m} \text {, Type M }\end{array}$ \\
\hline 1 & $9.6 \mathrm{E}-02$ & $1.3 \mathrm{E}-03$ & $3.3 \mathrm{E}-03$ \\
2 & $8.1 \mathrm{E}-02$ & $9.3 \mathrm{E}-04$ & $2.3 \mathrm{E}-03$ \\
5 & $5.7 \mathrm{E}-01$ & $1.1 \mathrm{E}-02$ & $2.7 \mathrm{E}-02$ \\
7 & $2.2 \mathrm{E}+00$ & $8.2 \mathrm{E}-02$ & $1.6 \mathrm{E}-01$ \\
14 & $7.5 \mathrm{E}+00$ & $8.9 \mathrm{E}+01$ & $8.3 \mathrm{E}-01$ \\
30 & $7.8 \mathrm{E}+00$ & $1.6 \mathrm{E}+04$ & $1.3 \mathrm{E}+00$ \\
60 & $8.3 \mathrm{E}+00$ & $1.7 \mathrm{E}+04$ & $2.8 \mathrm{E}+00$ \\
90 & $8.8 \mathrm{E}+00$ & $1.8 \mathrm{E}+04$ & $5.5 \mathrm{E}+00$ \\
180 & $9.8 \mathrm{E}+00$ & $2.0 \mathrm{E}+04$ & $2.1 \mathrm{E}+01$ \\
365 & $1.1 \mathrm{E}+01$ & $2.3 \mathrm{E}+04$ & $6.5 \mathrm{E}+01$ \\
730 & $1.5 \mathrm{E}+01$ & $2.9 \mathrm{E}+04$ & $1.8 \mathrm{E}+02$ \\
1,825 & $2.6 \mathrm{E}+01$ & $5.3 \mathrm{E}+04$ & $4.1 \mathrm{E}+02$ \\
3,650 & $4.8 \mathrm{E}+01$ & $9.5 \mathrm{E}+04$ & $7.6 \mathrm{E}+02$ \\
7,300 & $7.1 \mathrm{E}+01$ & $1.7 \mathrm{E}+05$ & $1.3 \mathrm{E}+03$ \\
18,250 & $1.6 \mathrm{E}+02$ & $3.3 \mathrm{E}+05$ & $2.6 \mathrm{E}+03$ \\
\hline
\end{tabular}

\subsubsection{In Vivo Bioassay Techniques for Americium}

In vivo measurement of americium is available for both ${ }^{241} \mathrm{Am}$ and ${ }^{243} \mathrm{Am}$, though it is not routinely performed for ${ }^{243} \mathrm{Am}$. Hanford in vivo measurements for americium include chest counts, skeleton measurements by head counting, liver counts, and wound counts. Minimum detectable activities for these measurements are described in the In Vivo Monitoring Program Manual (PNL-MA-574; TP Lynch. 2007) and the Hanford Internal Dosimetry Program Manual (PNL-MA-552; EH Carbaugh, et al. 2009).

The minimum detectable intakes of ${ }^{241} \mathrm{Am}$ and associated committed doses as determined by detection of $0.16 \mathrm{nCi}^{241} \mathrm{Am}$ by chest counting are described in Table 9.15 and illustrated in Figure 9.8. 
Table 9.13. Minimum Detectable Committed Effective Dose (rem) for ${ }^{241}$ Am Based on $0.8 \mathrm{dpm} / \mathrm{d}$ Detection of ${ }^{241} \mathrm{Am}$ in Feces

\begin{tabular}{rccc}
\hline $\begin{array}{c}\text { Days Post } \\
\text { Intake }\end{array}$ & $\begin{array}{c}\text { Instant } \\
\text { Uptake }\end{array}$ & $\begin{array}{c}\text { Ingestion } \\
\text { Inhalation } \\
5-\mu \mathrm{m} \text {, Type M }\end{array}$ \\
\hline 1 & $1.4 \mathrm{E}-01$ & $9.6 \mathrm{E}-07$ & $3.3 \mathrm{E}-04$ \\
2 & $1.2 \mathrm{E}-01$ & $7.0 \mathrm{E}-07$ & $2.3 \mathrm{E}-04$ \\
5 & $8.4 \mathrm{E}-01$ & $8.7 \mathrm{E}-06$ & $2.7 \mathrm{E}-03$ \\
7 & $3.3 \mathrm{E}+00$ & $6.2 \mathrm{E}-05$ & $1.6 \mathrm{E}-02$ \\
14 & $1.1 \mathrm{E}+01$ & $6.7 \mathrm{E}-02$ & $8.3 \mathrm{E}-02$ \\
30 & $1.1 \mathrm{E}+01$ & $1.2 \mathrm{E}+01$ & $1.3 \mathrm{E}-01$ \\
60 & $1.2 \mathrm{E}+01$ & $1.3 \mathrm{E}+01$ & $2.8 \mathrm{E}-01$ \\
90 & $1.3 \mathrm{E}+01$ & $1.3 \mathrm{E}+01$ & $5.5 \mathrm{E}-01$ \\
180 & $1.4 \mathrm{E}+01$ & $1.5 \mathrm{E}+01$ & $2.1 \mathrm{E}+00$ \\
365 & $1.7 \mathrm{E}+01$ & $1.7 \mathrm{E}+01$ & $6.5 \mathrm{E}+00$ \\
730 & $2.1 \mathrm{E}+01$ & $2.2 \mathrm{E}+01$ & $1.8 \mathrm{E}+01$ \\
1,825 & $3.9 \mathrm{E}+01$ & $4.0 \mathrm{E}+01$ & $4.1 \mathrm{E}+01$ \\
3,650 & $7.0 \mathrm{E}+01$ & $7.2 \mathrm{E}+01$ & $7.6 \mathrm{E}+01$ \\
7,300 & $1.0 \mathrm{E}+02$ & $1.3 \mathrm{E}+02$ & $1.3 \mathrm{E}+02$ \\
18,250 & $2.4 \mathrm{E}+02$ & $2.5 \mathrm{E}+02$ & $2.6 \mathrm{E}+02$ \\
\hline
\end{tabular}

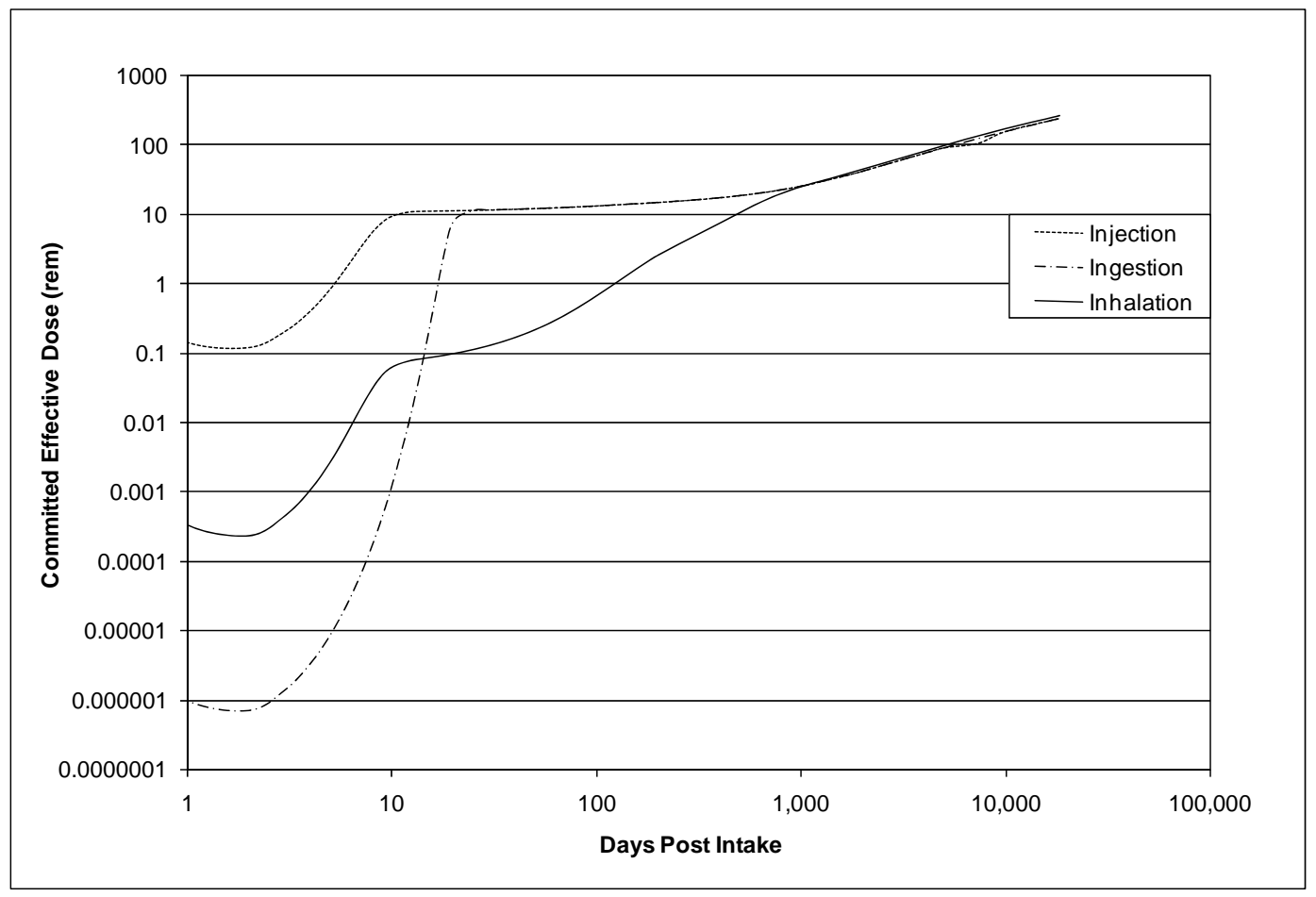

Figure 9.6. Minimum Detectable Committed Effective Dose for ${ }^{241} \mathrm{Am}$ Based on $0.8 \mathrm{dpm} / \mathrm{d}$ in Feces 
Table 9.14. Minimum Detectable Committed Bone Surface Equivalent Dose (rem) for ${ }^{241}$ Am Based on $0.8 \mathrm{dpm} / \mathrm{d}$ Detection of ${ }^{241} \mathrm{Am}$ in Feces

\begin{tabular}{rccc}
\hline $\begin{array}{c}\text { Days Post } \\
\text { Intake }\end{array}$ & $\begin{array}{c}\text { Instant } \\
\text { Uptake }\end{array}$ & Ingestion & $\begin{array}{c}\text { Inhalation } \\
5-\mu \mathrm{m} \text {, Type M }\end{array}$ \\
\hline 1 & $6.4 \mathrm{E}+00$ & $4.3 \mathrm{E}-05$ & $1.4 \mathrm{E}-02$ \\
2 & $5.4 \mathrm{E}+00$ & $3.1 \mathrm{E}-05$ & $9.5 \mathrm{E}-03$ \\
5 & $3.8 \mathrm{E}+01$ & $3.8 \mathrm{E}-04$ & $1.1 \mathrm{E}-01$ \\
7 & $1.5 \mathrm{E}+02$ & $2.7 \mathrm{E}-03$ & $6.4 \mathrm{E}-01$ \\
14 & $5.0 \mathrm{E}+02$ & $3.0 \mathrm{E}+00$ & $3.4 \mathrm{E}+00$ \\
30 & $5.2 \mathrm{E}+02$ & $5.2 \mathrm{E}+02$ & $5.3 \mathrm{E}+00$ \\
60 & $5.6 \mathrm{E}+02$ & $5.6 \mathrm{E}+02$ & $1.1 \mathrm{E}+01$ \\
90 & $5.9 \mathrm{E}+02$ & $5.9 \mathrm{E}+02$ & $2.2 \mathrm{E}+01$ \\
180 & $6.6 \mathrm{E}+02$ & $6.6 \mathrm{E}+02$ & $8.8 \mathrm{E}+01$ \\
365 & $7.6 \mathrm{E}+02$ & $7.6 \mathrm{E}+02$ & $2.7 \mathrm{E}+02$ \\
730 & $9.8 \mathrm{E}+02$ & $9.8 \mathrm{E}+02$ & $7.4 \mathrm{E}+02$ \\
1,825 & $1.8 \mathrm{E}+03$ & $1.8 \mathrm{E}+03$ & $1.7 \mathrm{E}+03$ \\
3,650 & $3.2 \mathrm{E}+03$ & $3.2 \mathrm{E}+03$ & $3.1 \mathrm{E}+03$ \\
7,300 & $4.8 \mathrm{E}+03$ & $5.6 \mathrm{E}+03$ & $5.5 \mathrm{E}+03$ \\
18,250 & $1.1 \mathrm{E}+04$ & $1.1 \mathrm{E}+04$ & $1.1 \mathrm{E}+04$ \\
\hline
\end{tabular}

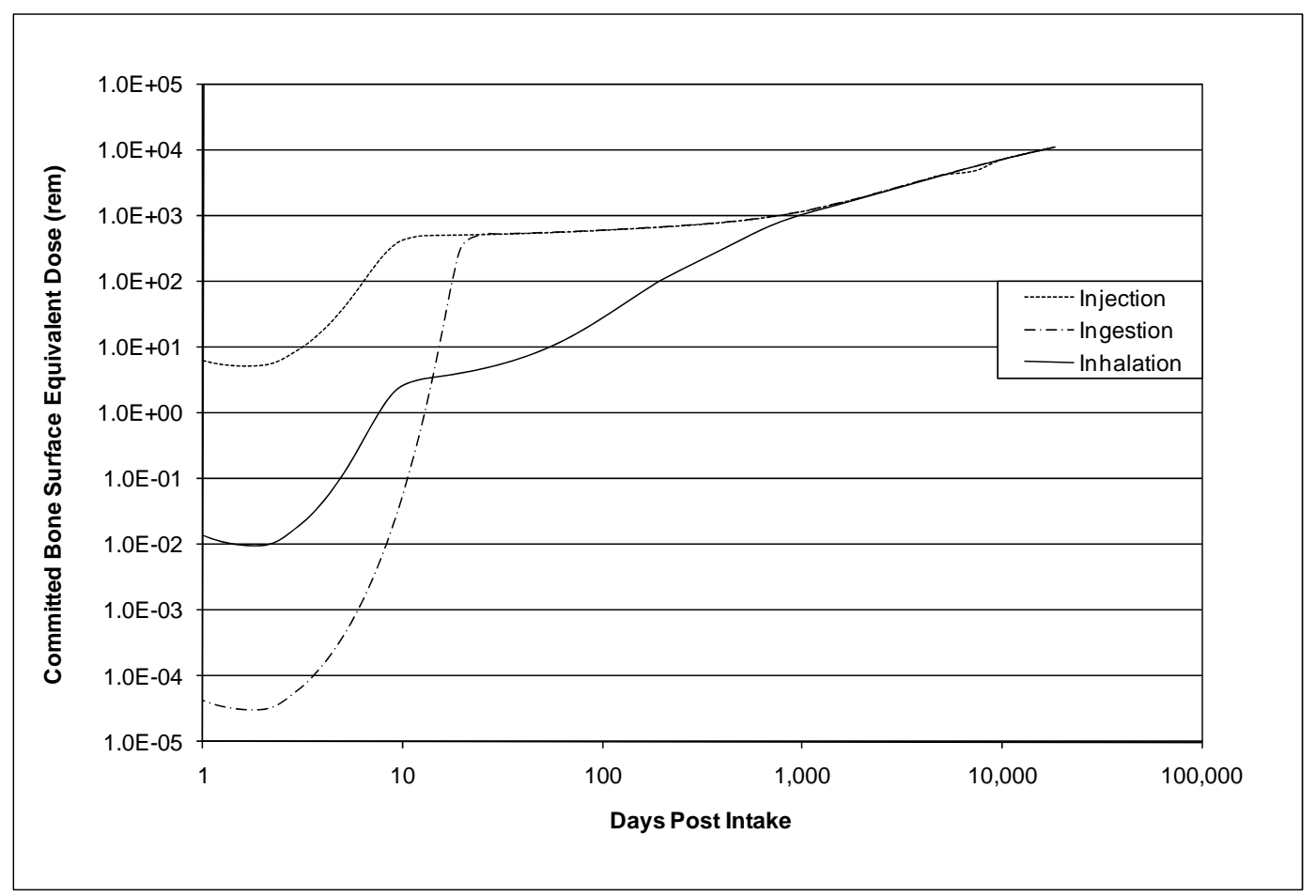

Figure 9.7. Minimum Detectable Committed Bone Surface Equivalent Dose for ${ }^{241} \mathrm{Am}$ Based on $0.8 \mathrm{dpm} / \mathrm{d}$ in Feces 
Table 9.15. Minimum Detectable Intakes and Committed Doses for Type M, 5- $\mu$ m-AMAD Acute Inhalation of ${ }^{241} \mathrm{Am}$ Based on $0.16 \mathrm{nCi}^{241} \mathrm{Am}$ Detection by Chest Counting

\begin{tabular}{rccc}
\hline $\begin{array}{c}\text { Days Post } \\
\text { Intake }\end{array}$ & $\begin{array}{c}\text { Intake } \\
(\mathrm{nCi})\end{array}$ & $\begin{array}{c}\text { Effective Dose } \\
(\text { rem })\end{array}$ & $\begin{array}{c}\text { Bone Surface } \\
\text { Dose (rem) }\end{array}$ \\
\hline 1 & $2.8 \mathrm{E}+00$ & $2.8 \mathrm{E}-01$ & $1.1 \mathrm{E}+01$ \\
2 & $2.9 \mathrm{E}+00$ & $2.9 \mathrm{E}-01$ & $1.2 \mathrm{E}+01$ \\
5 & $3.0 \mathrm{E}+00$ & $3.0 \mathrm{E}-01$ & $1.2 \mathrm{E}+01$ \\
7 & $3.1 \mathrm{E}+00$ & $3.1 \mathrm{E}-01$ & $1.3 \mathrm{E}+01$ \\
14 & $3.4 \mathrm{E}+00$ & $3.4 \mathrm{E}-01$ & $1.4 \mathrm{E}+01$ \\
30 & $4.2 \mathrm{E}+00$ & $4.2 \mathrm{E}-01$ & $1.7 \mathrm{E}+01$ \\
60 & $5.7 \mathrm{E}+00$ & $5.7 \mathrm{E}-01$ & $2.3 \mathrm{E}+01$ \\
90 & $7.3 \mathrm{E}+00$ & $7.3 \mathrm{E}-01$ & $3.0 \mathrm{E}+01$ \\
180 & $1.3 \mathrm{E}+01$ & $1.3 \mathrm{E}+00$ & $5.5 \mathrm{E}+01$ \\
365 & $4.0 \mathrm{E}+01$ & $4.0 \mathrm{E}+00$ & $1.6 \mathrm{E}+02$ \\
730 & $3.3 \mathrm{E}+02$ & $3.3 \mathrm{E}+01$ & $1.4 \mathrm{E}+03$ \\
1825 & $1.7 \mathrm{E}+05$ & $1.7 \mathrm{E}+04$ & $6.9 \mathrm{E}+05$ \\
\hline
\end{tabular}

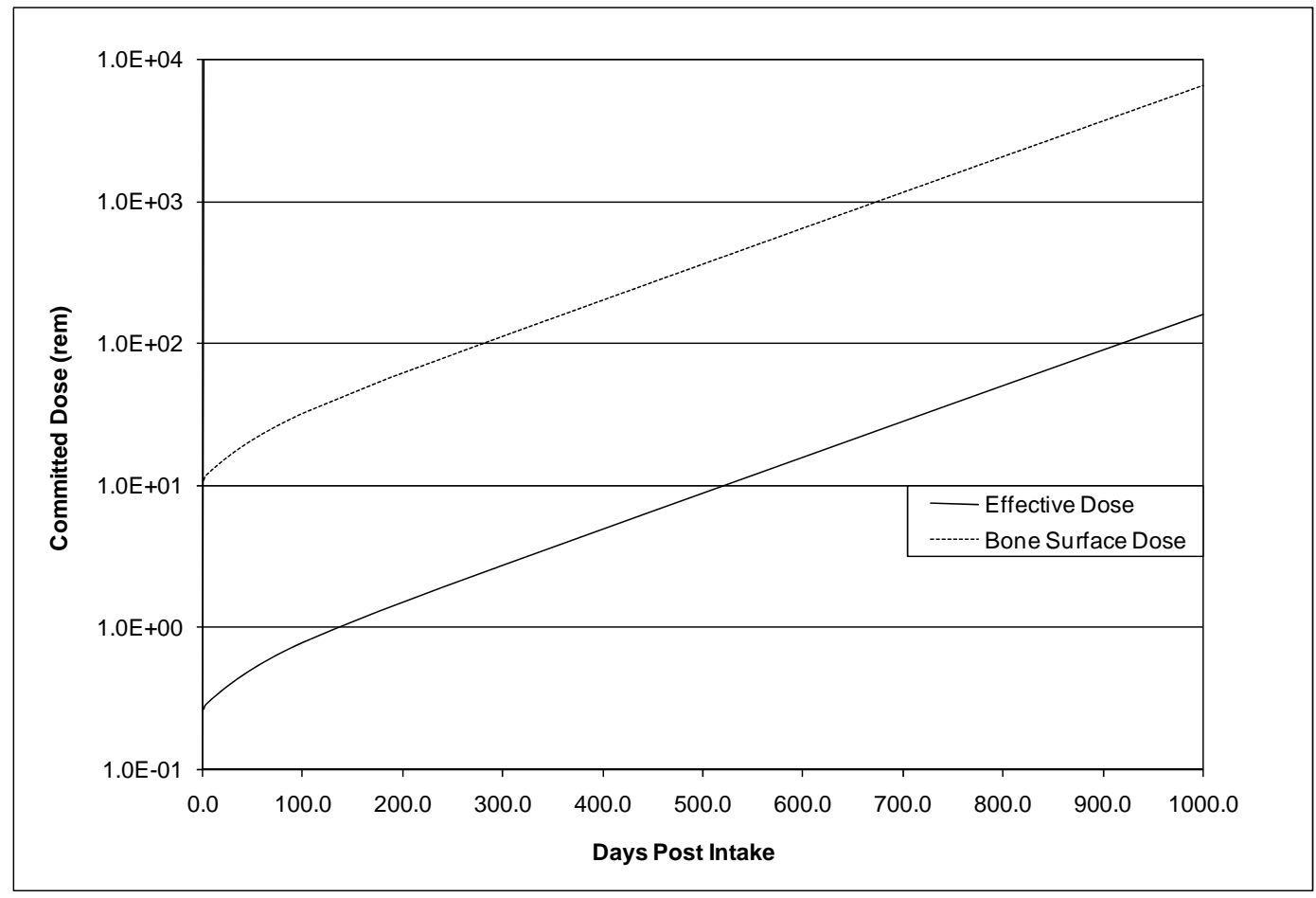

Figure 9.8. Minimum Detectable Committed Doses for ${ }^{241}$ Am Type M 5- $\mu m-A M A D$ Acute Inhalation Based on 0.16 nCi Detection in the Lung

\subsubsection{Recommended Periodic Bioassay Monitoring Protocol}

Based on Tables 9.10 and 9.11, an annual urine-sampling program is recommended for monitoring intakes of pure ${ }^{241} \mathrm{Am}$. Such a program is readily capable of demonstrating regulatory compliance with 
both stochastic and deterministic dose limits, and comes close to detecting doses at the monitoring threshold of 100-mrem committed effective dose. More frequent urinalysis can provide some improvement in sensitivity, including the ability to monitor a minimum detectable effective dose of less than 100 mrem, but with a corresponding increase in routine monitoring costs. Primary reliance must be placed on prompt detection of potential intakes by workplace indicators and special bioassay monitoring to provide low-level dosimetry.

Annual chest counting is appropriate as an augmentation, particularly when ${ }^{241} \mathrm{Am}$ is used as an indicator for plutonium.

\subsubsection{Special Monitoring for Suspected Intakes}

Special bioassay monitoring for suspected inhalation or ingestion intakes should include a chest count, urine sample, and at least one (preferably two or more) fecal samples. If these measurements are obtained within the first 3 to 5 days, committed effective doses in the range of a few millirem can be detected.

For potential wound intakes, special bioassay should consist of a wound count and a urine sample. Fecal sampling is not necessary for wound dosimetry; however, data on the fecal excretion following a wound can provide information that may be valuable for improving americium metabolic models.

\subsubsection{Bioassay Monitoring Capability for Workers with Known Americium Depositions}

The capability of a bioassay program is directly dependent upon the magnitude of an identifiable increase in a bioassay measurement. When a worker has a detectable baseline bioassay level due to a previous intake, the ability to detect a subsequent increase in the bioassay level from an additional intake is more dependent on the variability of current bioassay levels and less dependent on analytical capability. In other words, to be detected, subsequent intakes must result in increases in bioassay measurements that exceed the baseline or background "noise” level. Guidance concerning the potential dose from potentially undetected intakes must be developed on a case-by-case basis. Appropriate adjustments to measurement frequencies can then be determined based on the potential undetected dose. As an approximate rule-of-thumb, a single bioassay measurement will probably have to be at least twice the baseline level to be readily recognized, due to the substantial variability in single bioassay measurements on individual people. For many situations, this may imply that a normally detectable intake may not be detectable on top of a pre-existing internal americium deposition. Like most rules-of-thumb, this is only a rough suggestion; cases of significance must be addressed individually.

\subsection{Assessment of Internal Dose}

Assessments of internal dose for americium rely on evaluations of intake or deposition. Current practice for such evaluations is to perform an intake assessment. Prior to 1988, the common Hanford approach was a deposition assessment based on urine data. For significant cases, it may be possible to directly measure americium retention in the organ or tissue of interest using in vivo monitoring. In such cases, individual-specific retention parameters are appropriate for dosimetry. 


\subsubsection{Intake Assessment}

An americium intake can be estimated by fitting the bioassay data to the appropriate retention or excretion function, using manual or computerized techniques. For a single data point, the intake can be estimated by dividing the measured excretion by the value of the retention function for the appropriate day after intake represented by the sample in the manner described in Chapter 2.0, Equation (2.5). Values for the retention function can be obtained from those tabulated in this chapter, or directly from running the IMBA computer code. For multiple data points, the IMBA code provides a fitting routine, or a manually determined fit of the data to the expected function can be performed. Once the intake is calculated, appropriate internal doses may be calculated by applying the dose coefficients of this chapter to Equations (2.10) or (2.11) of Chapter 2.0. The IMBA computer code may also be used to directly calculate internal doses, and is particularly appropriate for complex cases.

\subsubsection{Deposition Assessment}

Deposition assessment involves determining the amount of material deposited in a body or tissue compartment of interest. Whereas the term "intake" includes all material taken into the body regardless of its subsequent fate, "deposition" is a more limited quantity that excludes material not retained (e.g., material that is immediately exhaled) and material not systemically absorbed (e.g., material cleared to the GI tract and excreted in feces without absorption). The HIDP coined the term "presystemic deposition" in the mid-1980s to precisely define what was being evaluated and avoid terms that had developed generic, ill-defined, or varied meanings (e.g., deposition, uptake, burden). In addition, the term "deposition" was gaining preference in the field of internal dosimetry as a process term associated with the respiratory tract, rather than a retained quantity. The HIDP defined presystemic deposition as the total radioactivity that will ultimately translocate into the transfer compartment from a metabolically isolated pool; in other words, the activity ultimately reaching the blood. Historically at Hanford, this was the quantity compared with the maximum permissible body burden (MPBB) of $0.05 \mu \mathrm{Ci}\left({ }^{241} \mathrm{Am}\right)$ as listed in ICRP 2 (1959). It is related to, but significantly different from intake, lung deposition, long-term lung burden, and instantaneous body burden (or retained quantity).

Activity is deposited in presystemic compartments at the time of intake. From there, systemic uptake may be essentially instantaneous or it may occur gradually over an extended period of time. Transfer from the presystemic compartment into systemic circulation is assumed to be governed by linear firstorder kinetics, and can be described in terms of a transfer rate constant. A urine excretion function such as that described in Section 9.2.4 is typically used to estimate the presystemic deposition.

\subsubsection{Assessing Organ and Effective Dose}

The organs of primary interest for americium dose evaluations are the bone surface, red marrow, liver, and gonads. The lung is also an organ of general interest for inhalations, even though its contribution to effective dose for Type $\mathrm{M}$ intakes is relatively insignificant. Other organs or tissues may be of interest depending on the nature of an intake. For example, the dose to a specific lymph node or small volume of tissue as the result of a wound intake of slowly transportable materials may be of academic interest, but is not a regulatory concern. Such cases can be dealt with as they arise and are beyond the general scope of this technical basis. 
Once the magnitude of an intake, presystemic deposition, or initial lung deposition has been determined, organ equivalent doses and the effective dose can be assessed using hand-calculation techniques or computer codes. The HIDP uses the IMBA computer code to aid in dose calculations. More detailed explanations and copies of the code are maintained in the HIDP records. The tabulated dose coefficients of Section 9.3 are useful for hand calculations.

\subsection{Management of Internal Contamination Cases}

This section discusses the diagnostic procedures, therapeutic actions, and long-term monitoring of internal depositions.

\subsubsection{Diagnostic Procedures}

The diagnosis of an intake involves a combination of workplace monitoring to identify on-the-job potential intakes and bioassay measurements to confirm and quantify internal contamination.

The primary method of identifying potential intakes is by workplace monitoring, such as personal contamination surveys, nasal smear analyses, air sample results, or worker identification of unusual conditions. These techniques provide qualitative screening to alert radiation protection staff about potential internal exposure, rather than providing absolute confirmation that exposure has or has not occurred. For example, activity detected on nasal smears is usually an indication of an inhalation intake; however, the absence of activity does not necessarily mean that an intake did not occur. The ICRP 66 model shows extrathoracic tissue compartment 1 (anterior nasal passages) clearing with a 17-hour halftime only by extrinsic means such as nose blowing and wiping. Allergies or a cold with significant mucous drainage could significantly alter this. Alternatively, some individuals are mouth-breathers, whose noses are partially or completely bypassed in the respiratory process, hence no activity may be deposited in the nares, despite the occurrence of an inhalation intake. Particle size can also significantly affect nasal deposition and clearance.

Once a worker has been identified as having incurred a potential intake, the initial diagnostic measurements are arranged. These may include a chest count, wound count, single voiding (spot) urine sample analysis, first-day fecal sampling, and overnight urine sampling. The purpose of these initial procedures is to provide an order-of-magnitude estimate of the potential internal exposure and dose. Initial diagnostic measurements are usually sufficient for final evaluations only when all results collectively rule out the possibility of an intake. In reality, initial measurements are not generally expected to do this, and follow-up measurements are necessary.

Follow-up diagnostic measurements may include additional urine and fecal samples, chest counts, liver counts, head counts, wound counts, and lymph node counts. These analyses aid in determining the magnitude, location, and retention characteristics of the deposited material. In some cases, blood samples or tissue specimens may also be appropriate. In addition, workplace or clothing contamination analyses, air sample analyses, particle size analyses, and/or dissolution rate analyses may be performed to more clearly define the physical and radiological characteristics of the material to which the worker was exposed. 
It is the responsibility of the exposure evaluator, working closely with contractor radiation protection staff, to determine the appropriate diagnostic protocols. Scheduling of follow-up measurements will normally be done by the appropriate contractor radiation protection staff.

\subsubsection{Therapeutic Actions}

Therapeutic actions for potential internal contamination include the use of decorporation agents, catharsis, and surgical excision. For the purposes of this discussion, the normal skin decontamination procedures of Hanford contractors are not considered therapeutic actions, although it is acknowledged that these procedures can be quite effective in preventing the intake of radioactivity. The decision to undertake one or more of these therapeutic actions is the responsibility of the participating Occupational Medicine care provider with the concurrence of the patient. The exposure evaluator will provide advice and consultation to the physician and patient regarding the potential dose implications and efficacy of alternative actions. Guidance for the methods of therapy can be found in National Council on Radiation Protection and Measurements Report No. 65 (NCRP 1980) and in the "Guidebook for the treatment of accidental internal radionuclide contamination of workers” (Bhattacharyya et al. 1992). Guidance for circumstances under which therapy may be warranted is contained in PNL-MA-552 (EH Carbaugh, et al. 2009), but was established as a good practice based on experience rather than a detailed technical analysis.

Decorporation therapy — also referred to as chelation therapy—involves the chemical removal of radioactivity from the bloodstream through drug administration. The drug diethylene triamine pentaacetic acid (DTPA) has U.S. Food and Drug Administration approval for use in removing americium. Decorporation therapy significantly enhances urinary excretion of americium, a point that must be considered when interpreting urine samples affected by therapy. ICRP 78 (1997) suggests that urinary excretion may be increased by as much as a factor of 50 .

After the 1976 americium column explosion at the 242-Z facility, the most exposed worker received extensive therapy using DTPA (Breitenstein 1983; Robinson et al. 1983). This therapy is generally recognized as having been life-saving, owing to the dose to the liver that was averted by the DTPA. Without the DTPA therapy it is generally considered that doses would have been sufficiently high as to ultimately result in liver failure. There was no evidence of liver disorder either during or after the DTPA therapy.

Catharsis involves accelerating the passage of material through the GI tract by means of laxative drugs or physical means such as an enema. Catharsis has potential value in reducing the adsorption of material into the bloodstream from the GI tract and in reducing the dose to the GI tract organs from material passing through the GI tract. These measures are not generally considered for occupational exposures to americium, because the GI tract adsorption of americium is slight, and the dose to the GI tract organs is an insignificant fraction of the total effective dose.

Surgical excision of wounds can be extremely effective in reducing the potential uptake, particularly when coupled with decorporation therapy. Minor excision may be performed at medical aid facilities by qualified medical personnel, assisted by PNNL exposure evaluator and radiation protection staff. 


\subsubsection{Long-Term Monitoring of Internal Depositions}

Once an internal dosimetry evaluation has been completed, it may be recommended that the worker be placed on a specialized long-term bioassay monitoring schedule. The reasons for this are twofold: first, long-term follow-up monitoring results that are consistent with the projected results verify the conclusions of the evaluation. Second, if long-term results are projected to be detectable, and the worker returns to americium work, then the capability of a routine bioassay monitoring program to detect an additional intake may be affected. This issue must be addressed on an individual-specific basis.

\subsection{References}

10 CFR 835. 2007. “Occupation Radiation Protection.” Code of Federal Regulations. U.S. Department of Energy. Available at: http://www.access.gpo.gov

Bhattacharyya MH, BD Breitenstein, H Metivier, BA Muggenburg, GN Stradling, and V Volf. 1992. "Guidebook for the treatment of accidental internal radionuclide contamination of workers." Rad. Prot. Dosim. 41:1.

Breitenstein BD. 1983. "1976 Hanford americium exposure incident: Medical management and chelation therapy.” Health Phys. 45:4(855-866).

Carbaugh EH, DE Bihl, JA MacLellan. 2009. Hanford Internal Dosimetry Program Manual. PNL-MA552, PNNL-15613, Pacific Northwest National Laboratory, Richland, Washington.(Internal manual.) A copy of this manual is maintained in the HIDP files and available from the HIDP Manager or online by searching, PNNL-15613 @ http://www.pnl.gov/publications/.

International Commission on Radiological Protection (ICRP). 1959. Report of Committee II on Permissible Dose for Internal Radiation. ICRP Publication 2, Pergamon Press, New York.

International Commission on Radiological Protection (ICRP). 1983. "Radionuclide Transformations: Energy and Intensity of Emissions.” ICRP Publication 38, Annals of the ICRP, 11-13, Pergamon Press, New York.

International Commission on Radiological Protection (ICRP). 1986. "The Metabolism of Plutonium and Related Elements.” ICRP Publication 48, Annals of the ICRP, 16:2-3, Pergamon Press, New York.

International Commission on Radiological Protection (ICRP). 1988. “Individual Monitoring for Intakes of Radionuclides by Workers: Design and Interpretation.” ICRP Publication 54, Annals of the ICRP, 19:1-3, Pergamon Press, New York.

International Commission on Radiological Protection (ICRP). 1993. “Age-dependent Doses to Members of the Public from Intake of Radionuclides: Part 2 Ingestion Dose Coefficients.” ICRP Publication 67, Annals of the ICRP, 23:3-4, Pergamon Press, New York.

International Commission on Radiological Protection (ICRP). 1994a. "Dose Coefficients for Intakes of Radionuclides by Workers.” ICRP Publication 68, Annals of the ICRP, 24:4, Pergamon Press, New York. 
International Commission on Radiological Protection (ICRP). 1994b. "Human Respiratory Tract Model for Radiological Protection.” ICRP Publication 66, Annals of the ICRP, 24:1-3, Pergamon Press, New York.

International Commission on Radiological Protection (ICRP). 1997. "Individual Monitoring for Internal Exposure of Workers.” ICRP Publication 78, Annals of the ICRP, 27:3-4, Pergamon Press, New York.

James AC, A Birchall, JW Marsh, and M Puncher. 2004 or current version. User Manual for IMBA Expert, USDOE-Edition (Phase II). ACJ \& Associates, Richland, Washington. (Current version is available electronically as part of the IMBA software code.)

Jones SR. 1985. "Derivation and validation of a urinary excretion function for plutonium applicable over tens of years post intake.” Rad. Prot. Dosim. 11(1):19-27.

Kathren RL. 1994. “Toward improved biokinetic models for actinides: The United States Transuranium and Uranium Registries, a twenty-five year report.” Rad. Prot. Dosim. 53:1-4(219-227).

National Council on Radiation Protection and Measurements (NCRP). 1980. Management of Persons Accidentally Contaminated with Radionuclides. NCRP Report No. 65, Bethesda, Maryland.

Pacific Northwest National Laboratory (PNNL). 2007. Hanford In Vivo Program Manual. PNL-MA574, Richland, Washington. (Internal manual.)

Robinson B, KR Heid, TL Aldridge, and RD Glenn. 1983. "1976 Hanford americium exposure incident: organ burden and radiation dose estimates.” Health Phys. 45:4(911-921).

Rosen J, N Cohen, and ME Wrenn. 1972. “Short-term metabolism of ${ }^{241} \mathrm{Am}$ in the adult baboon.” Health Phys. 22(621-626). 


\section{Methods and Models of the Hanford Internal Dosimetry Program \\ PNNL-MA-860}

\subsection{Neptunium}

Issued for implementation effective 01/01/2010

Supersedes: January 31, 2003

\section{Use Category: Not applicable}

\section{Approval Signatures:}

Prepared by: Donald Bihl

Approved by:

\section{Reviewer Signatures:}

Reviewed by:

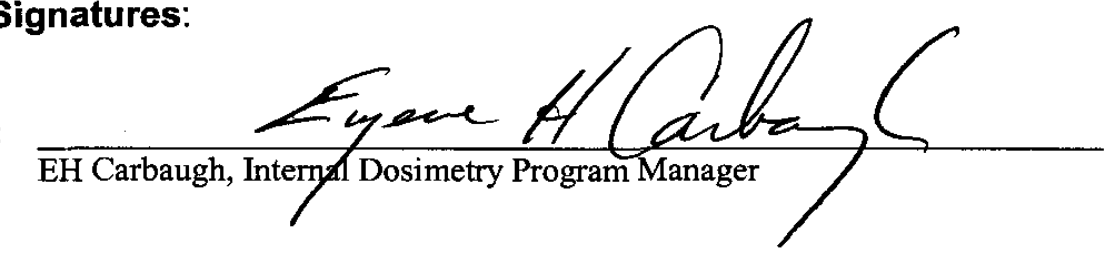

Approved by the Hanford Personnel Dosimetry Advisory Committee as recorded in the meeting minutes of March 10, 2009. 


\section{Contents}

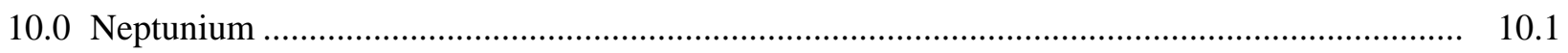

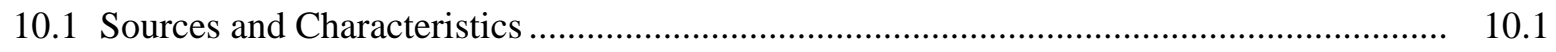

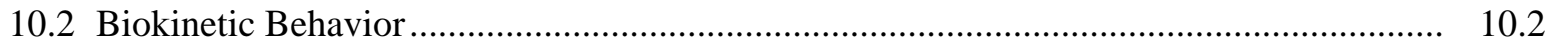

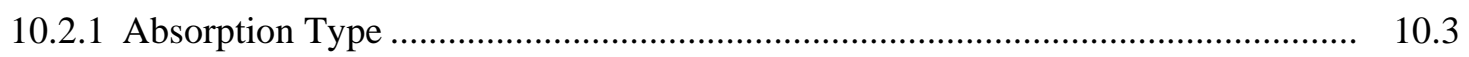

10.2.2 Gastrointestinal Uptake to Blood (f1) ............................................................... 10.3

10.2.3 Distribution and Retention in Systemic Organs and Tissues ................................ 10.3

10.2.4 Urinary and Fecal Excretion of Neptunium .................................................... 10.3

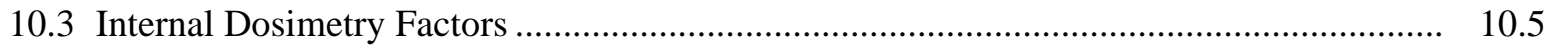

10.3.1 Intake Retention and Excretion Fractions ...................................................... 10.5

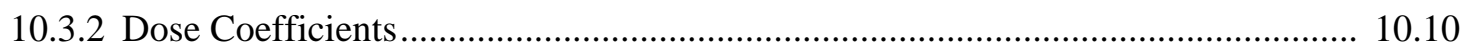

10.3.3 Comparison of Published Dosimetry Factors ..................................................... 10.11

10.3.4 Derived Air Concentrations and Annual Limits on Intake .................................. 10.11

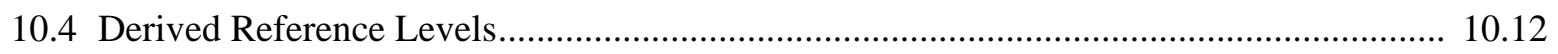

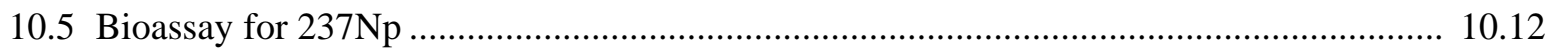

10.5.1 Excreta Bioassay Techniques for 237Np ....................................................... 10.12

10.5.2 In Vivo Bioassay Techniques for 237Np........................................................... 10.18

10.5.3 Recommended Periodic Bioassay Monitoring Protocol ...................................... 10.21

10.5.4 Special Monitoring for Suspected Intakes ....................................................... 10.22

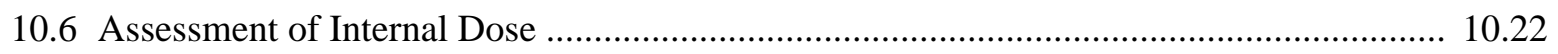

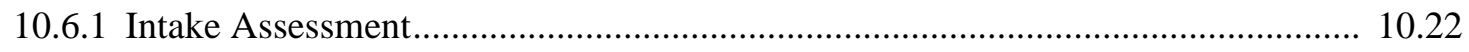

10.6.2 Assessing Organ and Effective Dose Equivalents ........................................... 10.22

10.7 Management of Internal Contamination Cases........................................................... 10.23

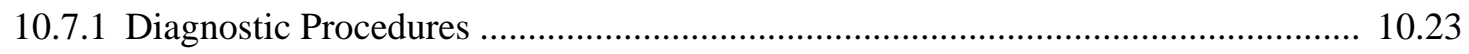

10.7.2 Therapeutic Actions ..................................................................................... 10.24

10.7.3 Long-Term Monitoring of Internal Depositions ............................................... 10.25

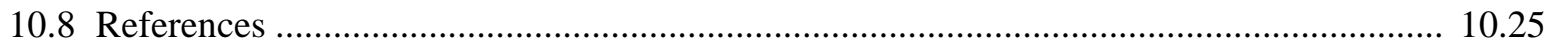

\section{Figures}

$10.1{ }^{237} \mathrm{~Np}$ Lung Retention from Acute Inhalation ................................................................ 10.6

$10.2{ }^{237} \mathrm{~Np}$ Whole Body Retention from Acute Intakes .......................................................... 10.7

$10.3{ }^{237} \mathrm{~Np}$ Urinary Excretion Fractions from Acute Intakes ......................................................... 10.8

$10.4{ }^{237} \mathrm{~Np}$ Fecal Excretion Fractions from Acute Intakes ........................................................ 10.9

$10.5{ }^{237} \mathrm{~Np}$ Fecal-to-Urine Ratios from Acute Intakes ............................................................ 10.10 
10.6 Minimum Detectable Committed Effective and Bone Surface Equivalent Doses for ${ }^{237} \mathrm{~Np}$ Based on Detection of $0.02 \mathrm{dpm} / \mathrm{d}$ in Urine

10.7 Minimum Detectable Committed Effective and Bone Surface Equivalent Doses for ${ }^{237} \mathrm{~Np}$ Based on Detection of $0.1 \mathrm{dpm} / \mathrm{d}$ in Feces

10.8 Minimum Detectable Committed Effective and Bone Surface Equivalent Doses for ${ }^{237} \mathrm{~Np}$ Based on Detection of $4.8 \mathrm{nCi}$ of ${ }^{233} \mathrm{~Pa}$ in a Whole Body Count

10.9 Minimum Detectable Committed Effective and Bone Surface Equivalent Doses for ${ }^{237} \mathrm{~Np}$ Based on Detection of $0.71 \mathrm{nCi}{ }^{237} \mathrm{~Np}$ in a Chest Count. 10.21

\section{Tables}

10.1 Radiological Decay Data for Neptunium

10.2

10.2 Transfer Rates Between Compartments in the Neptunium Systemic Model

10.4 Whole Body Retention Fractions for Acute ${ }^{237} \mathrm{~Np}$ Intakes.

10.5 Urine Excretion Fractions for Acute ${ }^{237} \mathrm{~Np}$ Intakes.

10.6 Fecal Excretion Fractions for Acute ${ }^{237} \mathrm{~Np}$ Intakes

10.7 Fecal-to-Urine Ratios for Acute ${ }^{237} \mathrm{~Np}$ Intakes.

10.8 Committed Dose Coefficients for Acute Intakes of ${ }^{237} \mathrm{~Np}$

10.9 Comparison of Effective Dose Coefficients, Sv/Bq, for ${ }^{237} \mathrm{~Np}$

10.10 DACs and DALIs for ${ }^{237} \mathrm{~Np}$ 10.12

$10.11{ }^{237} \mathrm{~Np}$ Urine and Fecal Excretion Reference Levels and Derived Reference Levels for Instantaneous Uptake and Type M Inhalation

$10.12{ }^{237} \mathrm{~Np}$ Chest Count and Whole Body Count Reference Levels and Derived Reference Levels for Instantaneous Uptake and Type M Inhalation

10.13 Minimum Detectable Intakes for ${ }^{237} \mathrm{~Np}$ Based on Detection of $0.02 \mathrm{dpm} / \mathrm{d}{ }^{237} \mathrm{~Np}$ in Urine 10.15

10.14 Minimum Detectable Committed Effective and Bone Surface Equivalent Dose for ${ }^{237} \mathrm{~Np}$ Based on Detection of $0.02 \mathrm{dpm} / \mathrm{d}^{237} \mathrm{~Np}$ in Urine

10.15 Minimum Detectable Intakes for ${ }^{237} \mathrm{~Np}$ Based on Detection of $0.1 \mathrm{dpm} / \mathrm{d}{ }^{237} \mathrm{~Np}$ in Feces

10.16 Minimum Detectable Committed Effective and Bone Surface Equivalent Dose for ${ }^{237} \mathrm{~Np}$ Based on Detection of $0.1 \mathrm{dpm} / \mathrm{d}{ }^{237} \mathrm{~Np}$ in Feces.

10.17 Minimum Detectable Intakes for ${ }^{237} \mathrm{~Np}$ Based on Detection of $4.8 \mathrm{nCi}$ of ${ }^{233} \mathrm{~Pa}$ in the Whole Body .....

10.18 Minimum Detectable Committed Effective and Bone Surface Equivalent Dose for ${ }^{237} \mathrm{~Np}$ Based on Detection of $4.8 \mathrm{nCi}{ }^{233} \mathrm{~Pa}$ in a Whole Body Count.

10.19 Minimum Detectable Intakes and Minimum Detectable Committed Effective and Bone Surface Equivalent Dose for ${ }^{237} \mathrm{~Np}$ Based on Detection of $0.71 \mathrm{nCi}^{237} \mathrm{~Np}$ in the Lung, Type M Inhalation. 


\subsection{Neptunium}

This revision to internal dosimetry for neptunium implements the International Commission on Radiological Protection (ICRP) lung model presented in Publication 66 (ICRP 1994b) and the biokinetic model for neptunium presented in ICRP 67, Appendix B (ICRP 1993), ICRP 68 (1994a), and ICRP 78 (1997). For parameters with age-specific differences, the parameters for 'adult' are used. The ICRP 30 gastrointestinal (GI) model (ICRP 1979) is still used except that uptake factors from the gut to the blood, $f_{1}$, have been updated as presented in ICRP 68 (1994a). For dose calculations, tissues, and tissue weighting factors introduced in ICRP 60 (1991) and adopted in the June 2007 revision of Title 10 Part 835 of the Code of Federal Regulations (10 CFR 835) are used. All excretion, retention, and dose coefficients were calculated using the Integrated Modules for Bioassay Analysis (IMBA) Professional Plus internal computer code, v. 4.0.43 (James et al. 2004). ${ }^{1}$

\subsection{Sources and Characteristics}

Neptunium played an important role at Hanford from 1958 until the Plutonium-Uranium Extraction Plant (PUREX) was placed into inactive status in 1972. As such this radionuclide may be encountered in decontamination operations. Neptunium-237 is the only isotope of neptunium likely to be present in dosimetrically significant activities.

Neptunium-237 was extracted from dissolved irradiated fuel, purified, and irradiated to produce ${ }^{238} \mathrm{Pu}$, which was a heat source for thermal generators. Most of the irradiation of the neptunium and extraction/ purification of the ${ }^{238} \mathrm{Pu}$ occurred at the Savannah River Site; however, some did occur at Hanford. There is evidence of small-scale extraction of crude ${ }^{237} \mathrm{~Np}$ and fume-hood level development of procedures (called flowsheets) as early as November 1956 (Sheppard and Becker 1957; Judson 1958; Ryan 1959).

However, production-scale extraction of neptunium-enriched nitrate solution started at PUREX in August 1958 and at the Reduction-Oxidation Plant (REDOX) in November 1959 (Briggs 2001; Travis 1958; Geier and Rathvon 1961). Purification of neptunium was performed in a special room at 222-S Building, called the 1-F Cubicle (Buckingham 1959, 1964). During this period, the material coming into 222-S was only crudely separated and actually had much more ${ }^{239-240} \mathrm{Pu}$ than ${ }^{237} \mathrm{~Np}$ by activity, according to data recorded in Buckingham's laboratory notebook and published articles (Buckingham 1959, 1961, 1963). After purification at 222-S, however, the neptunium product was quite pure, with batch activity ratios (neptunium to plutonium) ranging from 3 to nearly 100. According to personal communication with Mr. Buckingham, this material was usually sent to Oak Ridge National Laboratory or the Savannah River Site; but some of the material was sent to the 231-Z Building, where it was alloyed with aluminum, made into irradiation target elements, and then sent offsite (Beard and Judson 1959; Gifford 1959a, b).

Starting in 1963, the purification of the neptunium was transferred to PUREX in J Cell and Q Cell and purification at 222-S Building was stopped (Buckingham 1963; Briggs 2001). The product from Q Cell was equally as pure as the 222-S product. (This is mentioned because conventional wisdom at Hanford and the Savannah River Site was that neptunium intake sources were predominately plutonium

\footnotetext{
${ }^{1}$ IMBA Professional Plus, which includes the current version of the user manual, is available from Health Protection Agency (HPA), Radiation Protection Division, Chilton, Didicot, Oxon., OX11 ORQ UK and from http://www.imbaprofessional.com/
}

Issued for implementation effective 01/01/2010

Superseded: January 31, 2003

PNNL-MA-860 Chapter 10.0

Page 10.1 
by activity. This was true for the crudely separated material coming into 222-S or J Cell, but was not true for the material at 231-Z Building or the product of Q Cell.) Most of the material from Q Cell was shipped offsite, but some was sent to the Plutonium Chemistry Laboratory in the 234-5Z Building for conversion from nitrate to oxide, prior to shipping offsite.

Starting in 1965, a project was conducted whereby some of the PUREX neptunium was fabricated into target elements in the 308 Building and irradiated in the Hanford reactors, with separation of the ${ }^{238} \mathrm{Pu}$ from the unused neptunium in the 325 Building. Forty-four elements were fabricated and irradiated in N Reactor (Constable 1967). Even after separation of the ${ }^{238} \mathrm{Pu}$, the leftover neptunium was ${ }^{238} \mathrm{Pu}$ rich by activity, due to the large differences in specific activity, with ${ }^{238} \mathrm{Pu} /{ }^{237} \mathrm{~Np}$ ratios about 35 (Soine and Benedict 1968). A similar project was conducted in 1969 and 1970 involving decanning of the target elements in the 327 Building and separation in the 325 Building (Wheelwright 1970). The ${ }^{238} \mathrm{Pu} /{ }^{237} \mathrm{~Np}$ activity ratios in the leftover neptunium were similar. (This neptunium may have been the basis for the assumption that neptunium had high activities of plutonium.)

It is not clear what the isotopic activity composition might be of neptunium contamination or residual stored sources found during decontamination of old facilities; in the event of a possible intake detailed analysis of the source should be conducted. Facilities that might have residual neptunium contamination would be 222-S Building, REDOX, PUREX J and Q Cells, 231-Z Building, 325 Building hot cells, and burial grounds. The 308 and 327 Buildings have been scheduled for decontamination and demolition by 2010.

At various times, ${ }^{237} \mathrm{~Np}$ was referred to as birch, palm, brandy, or brandy wine. The overall project to extract ${ }^{237} \mathrm{~Np}$ and irradiate it to produce ${ }^{238} \mathrm{Pu}$ was called palmolive.

Radiological decay data for ${ }^{237} \mathrm{~Np}$ are shown in Table 10.1. The data were taken directly from, or calculated based on, information contained in ICRP 38 (1983).

Table 10.1. Radiological Decay Data for Neptunium

\begin{tabular}{ccccccc}
\hline & Principal Decay & \multicolumn{2}{c}{ Physical Half-Life } & \multicolumn{2}{c}{ Decay Constant } & Specific Activity \\
\cline { 3 - 6 } Isotope & Mode, Energy and & & & & \\
\cline { 3 - 6 } & Yield & Years & Days & Year $^{-1}$ & Day $^{-1}$ & Ci/g \\
\hline${ }^{237} \mathrm{~Np}$ & Alpha & $2.14 \mathrm{E}+06$ & $7.81 \mathrm{E}+08^{(\mathrm{a})}$ & $3.24 \mathrm{E}-07$ & $8.87 \mathrm{E}-10$ & $7.02 \mathrm{E}-04$ \\
& $4.772 \mathrm{MeV}, 25 \%$ & & & & & \\
& $4.789 \mathrm{MeV}, 47.1 \%$ & & & & & \\
Gamma & & & & & \\
& $86.5 \mathrm{keV}, 12.6 \%$ & & & & & \\
\hline
\end{tabular}

(a) IMBA also uses 7.811E+08 days; Kocher (1981) also lists 2.14E+06 years.

\subsection{Biokinetic Behavior}

This section discusses the inhalation absorption type, internal distribution and retention, and the urinary and fecal excretion of neptunium. 


\subsubsection{Absorption Type}

The ICRP 66 (1994b) respiratory tract model assigns absorption Type M (for moderate rate of solubilization) to all forms of neptunium which is consistent with the $\mathrm{W}$ transportability class (ICRP 1986) under the old model.

\subsubsection{Gastrointestinal Uptake to Blood $\left(f_{1}\right)$}

The fractional uptake to blood from the GI tract for both inhalation and ingestion intake modes is assumed to be $5 \times 10^{-4}$, as recommended in ICRP 68 Annexes E and F (1994a) and reiterated in ICRP 78 (1997). This value was reduced from the $10^{-3}$ value used in earlier ICRP publications based on recent human studies published by Popplewell et al. (1991) and discussed in ICRP 67, Appendix B (1993). The $5 \times 10^{-4}$ value was chosen to be slightly greater than the results of the human studies to accommodate uncertainty in the study results (ICRP 1993).

\subsubsection{Distribution and Retention in Systemic Organs and Tissues}

The systemic model presented in ICRP 67 Appendix B (1993) and ICRP 78 (1997) is used for calculating the distribution and retention of neptunium in the body and is incorporated by the IMBA computer code. The basic model is described in Appendix C. The main sites of retention are the liver and the skeleton, with $10 \%$ of the systemic circulation going to the liver and $45 \%$ to the skeleton. Thirty percent of the systemic circulation goes to soft tissue, but most is quickly turned over back to the blood (1 day half-time for soft tissue compartment 0 , longer for small amounts in soft tissue compartments 1 and 2). Flow of neptunium from blood to organs, within organ compartments, and back to blood and to excretion is determined entirely by transfer rates, which are listed in Table 10.2. Unlike the plutonium model, the neptunium model has no transfer between the soft tissue compartment 1 directly to urinary excretion. As with the plutonium model, the transfer rates from the blood to the testes and ovaries are different, resulting in a small difference in dose between these organs. IMBA assigns gonadal dose as the higher of the doses to either the testes or the ovaries. For systemic neptunium, the testicular committed equivalent dose exceeds the ovarian committed equivalent dose by less than $2 \%$.

The concept of retention half-time is somewhat lost with recycling models; however, an "externally viewed" or apparent half-time can be approximated for some applications. ICRP 67 suggested such a liver half-time of about 2 years, which is faster than that for plutonium and even a little faster than for americium. ICRP 67 does not provide an apparent skeleton half-time; however, the decrease in whole body retention between years 40 and 50 after an instantaneous uptake, which would reflect mostly skeletal retention, is consistent with a half-time of about 45 years. These modeling changes, combined with the new tissue weighting factors of ICRP 60 (1991), result in a much lower effective dose coefficient than the one derived using the ICRP 30 Part 4 (1988) and ICRP 48 (1986) models.

\subsubsection{Urinary and Fecal Excretion of Neptunium}

ICRP 67 models urinary excretion by transferring neptunium from the blood directly to the urinary bladder contents and from blood to the kidneys (passing into the urine not kidney tissue) to the bladder contents. Transfer rates for these compartments are listed in Table 10.2, labeled as "urinary excretion" to distinguish them from the pathway from blood to kidney tissue. As much as $32 \%$ of the neptunium in 
circulation in the blood is assumed to go directly to urinary excretion (ICRP 1993 Appendix B), which is a much higher percentage than for plutonium ( 2\%) or americium $(\sim 7 \%)$.

Table 10.2. Transfer Rates Between Compartments in the Neptunium Systemic Model ${ }^{(\mathrm{a})}$

\begin{tabular}{|c|c|}
\hline Route & Transfer Rate $\left(\mathrm{d}^{-1}\right)$ \\
\hline ST0 to blood ${ }^{(b)}$ & 6.93E-01 \\
\hline ST1 to blood & 6.93E-03 \\
\hline ST2 to blood & $1.90 \mathrm{E}-05$ \\
\hline Trabecular marrow to blood & 7.60E-03 \\
\hline Cortical marrow to blood & 7.60E-03 \\
\hline Kidneys (tissue) to blood & 1.39E-03 \\
\hline Liver2 to blood & $1.90 \mathrm{E}-03$ \\
\hline Testes to blood & $1.90 \mathrm{E}-04$ \\
\hline Ovaries to blood & $1.90 \mathrm{E}-04$ \\
\hline Blood to ST0 & 8.32E-01 \\
\hline Blood to ST1 & $1.611 \mathrm{E}-01$ \\
\hline Blood to ST2 & 3.88E-02 \\
\hline Blood to trabecular surface & 4.804E-01 \\
\hline Trabecular surface to trabecular volume & 2.47E-04 \\
\hline Trabecular surface to trabecular marrow & 4.93E-04 \\
\hline Trabecular volume to trabecular marrow & 4.93E-04 \\
\hline Blood to cortical surface & 3.93E-01 \\
\hline Cortical surface to cortical volume & 4.11E-05 \\
\hline Cortical surface to cortical marrow & 8.21E-05 \\
\hline Cortical volume to cortical marrow & 8.21E-05 \\
\hline Blood to kidneys (tissue) & $9.70 \mathrm{E}-03$ \\
\hline Blood to Liver1 & $1.941 \mathrm{E}-01$ \\
\hline Liver1 to Liver2 & 1.77E-03 \\
\hline Liver1 to small intestine (fecal excretion) & 1.33E-04 \\
\hline Blood to upper large intestine (fecal excretion) & 1.359E-02 \\
\hline Blood to testes & $6.80 \mathrm{E}-04$ \\
\hline Blood to ovaries & $2.10 \mathrm{E}-04$ \\
\hline Blood to kidneys (urinary excretion) & 2.91E-02 \\
\hline Kidneys to bladder (urinary excretion) & 4.95E-02 \\
\hline Blood to bladder (urinary excretion) & $6.211 \mathrm{E}-01$ \\
\hline
\end{tabular}

(a) From ICRP 78 (1997), as modeled in IMBA.

(b) ST = soft tissue; number indicates compartment number.

Previously, this manual recommended a 50-50 split for actinide material going from blood and systemic organs to urine and feces (Sula et al. 1989). The 2003 revision of this manual incorporated recommendations from ICRP 67 by recommending a 90-to-10 (urine-to-feces) split for neptunium. This assumption was necessary for use of the CINDY computer code. 
Similar to urinary excretion, ICRP 67 models transfer of systemic neptunium to the GI tract using physiologically based transfer rates via two pathways. One pathway is from blood to liver compartment 1 and from liver compartment 1 to the small intestine (representing biliary secretion). The second pathway is directly from the blood to the upper large intestine. These rates are set such that these two pathways remove essentially equal amounts of systemic neptunium, at about $0.7 \%$ each. Clearly, for systemic neptunium, the urinary pathway is far more dominant.

\subsection{Internal Dosimetry Factors}

This section contains factors that are useful in making internal dosimetry calculations. The factors included in this section are derived from the IMBA computer code (v. 4.0.43) and incorporate the models and assumptions described in the preceding section. Their application is intended for those circumstances where such assumptions are appropriate or more specific information is lacking. Variation from these factors is appropriate if sufficient data are available.

\subsubsection{Intake Retention and Excretion Fractions}

The intake retention (or excretion) fraction expresses the fraction of intake retained in a particular compartment or excreted by a particular pathway (urine or feces) at a given time post intake. Although excretion implies elimination rather than retention, conventional models include excretion compartments under the general term retention and use the term "intake retention fraction" (IRF) to describe both. IRFs for various times post intake are tabulated as described below for ${ }^{237} \mathrm{~Np}$.

Lung retention fractions for the acute inhalation of Type M 5- $\mu \mathrm{m}$ - activity median aerodynamic diameter (AMAD) particles of ${ }^{237} \mathrm{~Np}$, applicable to counting the $86.5-\mathrm{keV}$ photon , are tabulated in Table 10.3 and plotted in Figure 10.1. Whole body retention fractions for instantaneous uptake, Type M acute inhalation, and ingestion are listed in Table 10.4 and plotted in Figure 10.2. These would be applicable to counting the $312-\mathrm{keV}$ photon from ${ }^{233} \mathrm{~Pa}$, the first progeny of ${ }^{237} \mathrm{~Np}$ decay, assuming equilibrium. With its 27-day half-life, ${ }^{233} \mathrm{~Pa}$ would be in equilibrium for any sources at Hanford, except possibly small laboratory standards. If an intake of new ${ }^{237} \mathrm{~Np}$ occurred, whole body count results would have to be adjusted to account for the degree of disequilibrium between ${ }^{237} \mathrm{~Np}$ and ${ }^{233} \mathrm{~Pa}$. Urine excretion fractions for an instantaneous uptake, acute inhalation, and acute ingestions of ${ }^{237} \mathrm{~Np}$ are shown in Table 10.5 and plotted in Figure 10.3. Corresponding values for fecal excretion are also shown in Table 10.6 and plotted in Figure 10.4.

The ratio of fecal-to-urinary excretion is shown for these same intakes in Table 10.7 and Figure 10.5. The latter table may be useful for distinguishing between inhalation and ingestion intakes or combinations thereof, especially if samples are obtained shortly after intake and then at 20 or more days after intake. 
Table 10.3. Lung Retention Fractions for Acute Type M Inhalation of ${ }^{237} \mathrm{~Np}, 5-\mu \mathrm{m}-\mathrm{AMAD}$ Particles (fraction of intake)

\begin{tabular}{cc}
\hline Days Post Intake & Retention Fraction \\
\hline 0.5 & $5.98 \mathrm{E}-02$ \\
1 & $5.76 \mathrm{E}-02$ \\
2 & $5.59 \mathrm{E}-02$ \\
3 & $5.50 \mathrm{E}-02$ \\
5 & $5.34 \mathrm{E}-02$ \\
7 & $5.18 \mathrm{E}-02$ \\
14 & $4.70 \mathrm{E}-02$ \\
30 & $3.84 \mathrm{E}-02$ \\
60 & $2.81 \mathrm{E}-02$ \\
180 & $1.19 \mathrm{E}-02$ \\
365 & $3.99 \mathrm{E}-03$ \\
$2 \mathrm{y}$ & $4.80 \mathrm{E}-04$ \\
$3 \mathrm{y}$ & $5.91 \mathrm{E}-05$ \\
$5 \mathrm{y}$ & $9.55 \mathrm{E}-07$ \\
\hline
\end{tabular}

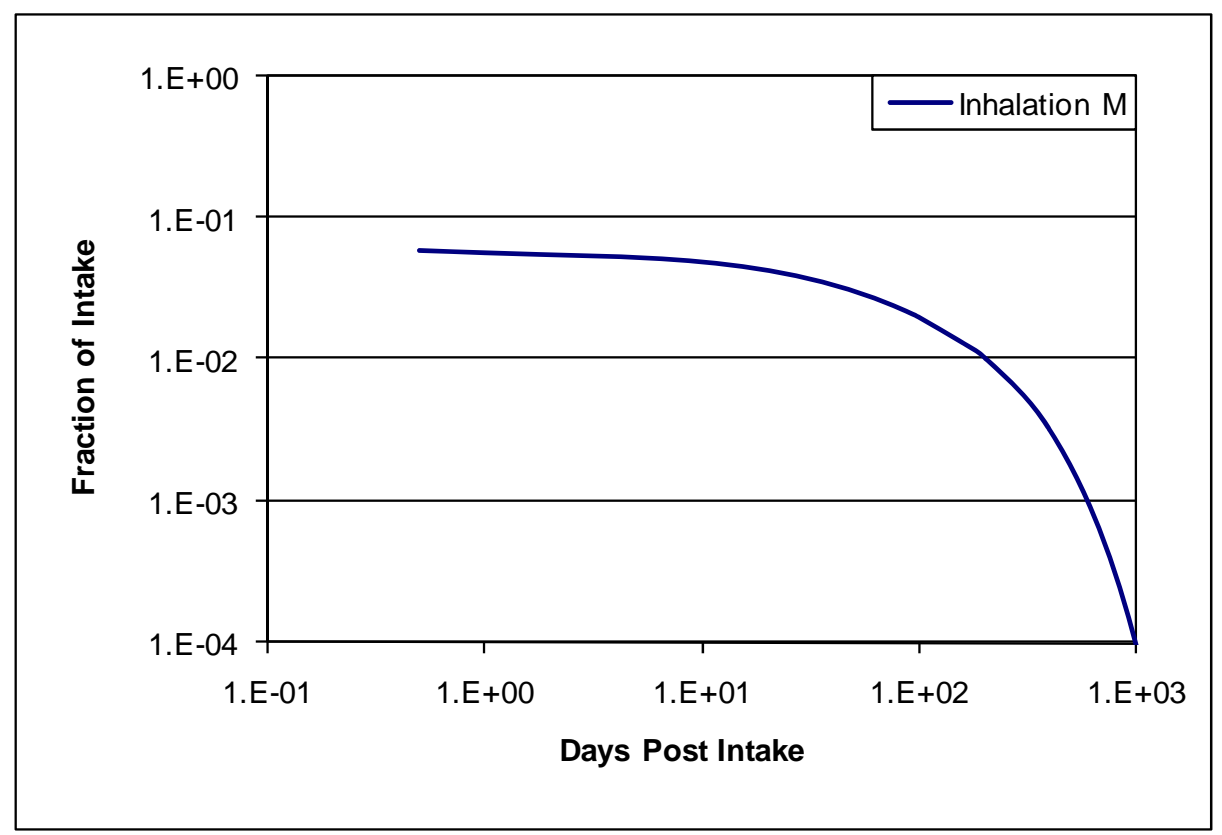

Figure 10.1. ${ }^{237} \mathrm{~Np}$ Lung Retention from Acute Inhalation 
Table 10.4. Whole Body Retention Fractions for Acute ${ }^{237} \mathrm{~Np}$ Intakes

\begin{tabular}{cccc}
\hline $\begin{array}{c}\text { Days Post } \\
\text { Intake }\end{array}$ & $\begin{array}{c}\text { Instant. } \\
\text { Uptake }\end{array}$ & Inhalation, Type M & Ingestion \\
\hline 0.5 & $8.46 \mathrm{E}-01$ & $6.56 \mathrm{E}-01$ & $9.30 \mathrm{E}-01$ \\
1 & $7.80 \mathrm{E}-01$ & $4.91 \mathrm{E}-01$ & $7.18 \mathrm{E}-01$ \\
2 & $7.34 \mathrm{E}-01$ & $2.56 \mathrm{E}-01$ & $3.29 \mathrm{E}-01$ \\
3 & $7.11 \mathrm{E}-01$ & $1.47 \mathrm{E}-01$ & $1.32 \mathrm{E}-01$ \\
5 & $6.86 \mathrm{E}-01$ & $8.49 \mathrm{E}-02$ & $1.91 \mathrm{E}-02$ \\
7 & $6.74 \mathrm{E}-01$ & $7.48 \mathrm{E}-02$ & $2.90 \mathrm{E}-03$ \\
14 & $6.64 \mathrm{E}-01$ & $6.92 \mathrm{E}-02$ & $3.34 \mathrm{E}-04$ \\
30 & $6.57 \mathrm{E}-01$ & $6.24 \mathrm{E}-02$ & $3.29 \mathrm{E}-04$ \\
60 & $6.48 \mathrm{E}-01$ & $5.48 \mathrm{E}-02$ & $3.24 \mathrm{E}-04$ \\
90 & $6.42 \mathrm{E}-01$ & $5.05 \mathrm{E}-02$ & $3.21 \mathrm{E}-04$ \\
180 & $6.29 \mathrm{E}-01$ & $4.46 \mathrm{E}-02$ & $3.14 \mathrm{E}-04$ \\
365 & $6.09 \mathrm{E}-01$ & $3.98 \mathrm{E}-02$ & $3.05 \mathrm{E}-04$ \\
$2 \mathrm{y}$ & $5.76 \mathrm{E}-01$ & $3.61 \mathrm{E}-02$ & $2.88 \mathrm{E}-04$ \\
$3 \mathrm{y}$ & $5.47 \mathrm{E}-01$ & $3.41 \mathrm{E}-02$ & $2.73 \mathrm{E}-04$ \\
$5 \mathrm{y}$ & $5.00 \mathrm{E}-01$ & $3.11 \mathrm{E}-02$ & $2.50 \mathrm{E}-04$ \\
$10 \mathrm{y}$ & $4.21 \mathrm{E}-01$ & $2.61 \mathrm{E}-02$ & $2.10 \mathrm{E}-04$ \\
$20 \mathrm{y}$ & $3.30 \mathrm{E}-01$ & $2.05 \mathrm{E}-02$ & $1.65 \mathrm{E}-04$ \\
$50 \mathrm{y}$ & $1.98 \mathrm{E}-01$ & $1.22 \mathrm{E}-02$ & $9.89 \mathrm{E}-05$ \\
\hline
\end{tabular}

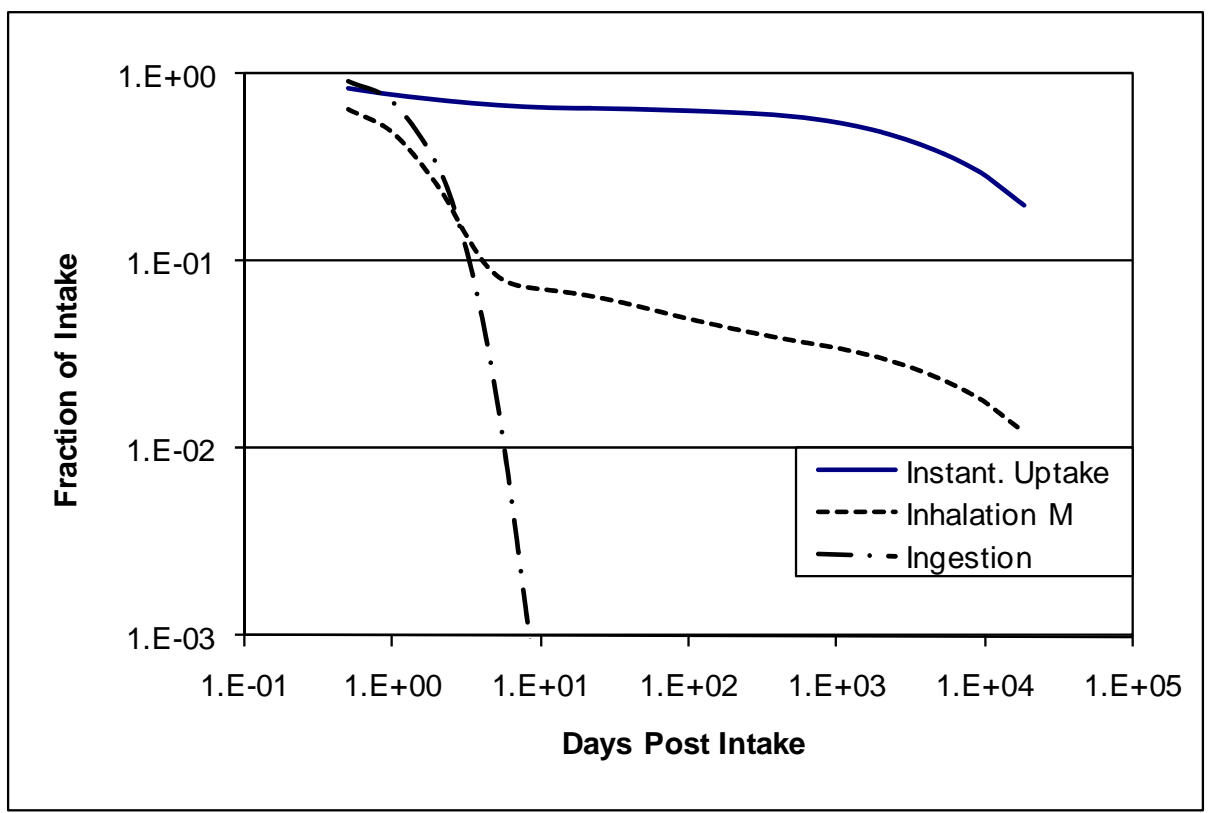

Figure 10.2. ${ }^{237} \mathrm{~Np}$ Whole Body Retention from Acute Intakes 
Table 10.5. Urine Excretion Fractions for Acute ${ }^{237} \mathrm{~Np}$ Intakes

\begin{tabular}{cccc}
\hline $\begin{array}{c}\text { Days Post } \\
\text { Intake }\end{array}$ & $\begin{array}{c}\text { Instant } \\
\text { Uptake }\end{array}$ & $\begin{array}{c}\text { Inhalation, Type M } \\
\text { Ingestion }\end{array}$ \\
\hline 0.5 & $1.54 \mathrm{E}-01$ & $4.32 \mathrm{E}-03$ & $4.85 \mathrm{E}-05$ \\
1 & $2.19 \mathrm{E}-01$ & $6.22 \mathrm{E}-03$ & $9.77 \mathrm{E}-05$ \\
2 & $4.42 \mathrm{E}-02$ & $1.34 \mathrm{E}-03$ & $3.05 \mathrm{E}-05$ \\
3 & $2.18 \mathrm{E}-02$ & $6.98 \mathrm{E}-04$ & $1.23 \mathrm{E}-05$ \\
5 & $9.17 \mathrm{E}-03$ & $3.44 \mathrm{E}-04$ & $5.01 \mathrm{E}-06$ \\
7 & $4.18 \mathrm{E}-03$ & $2.03 \mathrm{E}-04$ & $2.27 \mathrm{E}-06$ \\
14 & $7.39 \mathrm{E}-04$ & $1.00 \mathrm{E}-04$ & $3.79 \mathrm{E}-07$ \\
30 & $3.58 \mathrm{E}-04$ & $7.69 \mathrm{E}-05$ & $1.80 \mathrm{E}-07$ \\
60 & $2.00 \mathrm{E}-04$ & $5.60 \mathrm{E}-05$ & $1.00 \mathrm{E}-07$ \\
90 & $1.55 \mathrm{E}-04$ & $4.44 \mathrm{E}-05$ & $7.74 \mathrm{E}-08$ \\
180 & $1.16 \mathrm{E}-04$ & $2.69 \mathrm{E}-05$ & $5.82 \mathrm{E}-08$ \\
365 & $9.11 \mathrm{E}-05$ & $1.26 \mathrm{E}-05$ & $4.55 \mathrm{E}-08$ \\
$2 \mathrm{y}$ & $7.73 \mathrm{E}-05$ & $5.74 \mathrm{E}-06$ & $3.86 \mathrm{E}-08$ \\
$3 \mathrm{y}$ & $6.86 \mathrm{E}-05$ & $4.46 \mathrm{E}-06$ & $3.43 \mathrm{E}-08$ \\
$5 \mathrm{y}$ & $5.32 \mathrm{E}-05$ & $3.38 \mathrm{E}-06$ & $2.66 \mathrm{E}-08$ \\
$10 \mathrm{y}$ & $3.25 \mathrm{E}-05$ & $2.04 \mathrm{E}-06$ & $1.62 \mathrm{E}-08$ \\
$20 \mathrm{y}$ & $1.79 \mathrm{E}-05$ & $1.12 \mathrm{E}-06$ & $8.96 \mathrm{E}-09$ \\
$50 \mathrm{y}$ & $7.98 \mathrm{E}-06$ & $4.94 \mathrm{E}-07$ & $3.99 \mathrm{E}-09$ \\
\hline
\end{tabular}

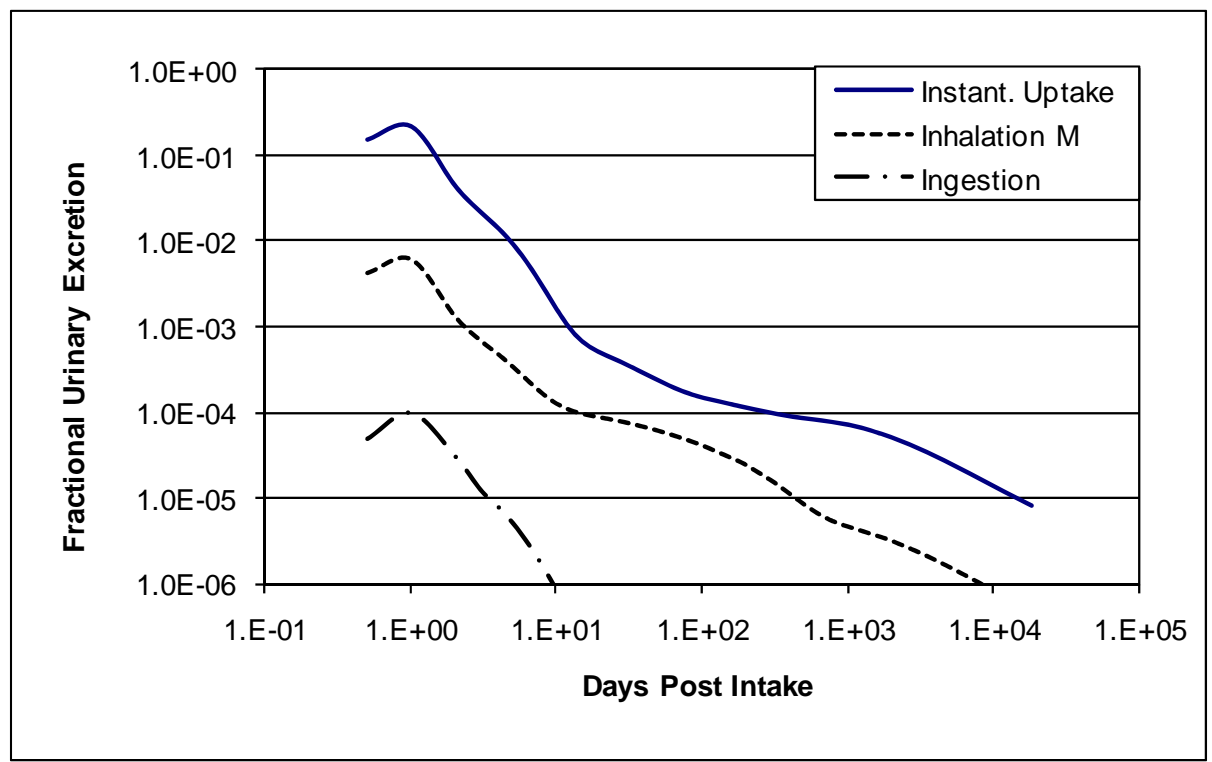

Figure 10.3. ${ }^{237} \mathrm{~Np}$ Urinary Excretion Fractions from Acute Intakes 
Table 10.6. Fecal Excretion Fractions for Acute ${ }^{237} \mathrm{~Np}$ Intakes

\begin{tabular}{cccc}
\hline $\begin{array}{c}\text { Days Post } \\
\text { Intake }\end{array}$ & $\begin{array}{c}\text { Instant } \\
\text { Uptake }\end{array}$ & Inhalation, Type M & Ingestion \\
\hline 0.5 & $2.62 \mathrm{E}-04$ & $2.60 \mathrm{E}-02$ & $7.03 \mathrm{E}-02$ \\
1 & $1.15 \mathrm{E}-03$ & $1.08 \mathrm{E}-01$ & $2.82 \mathrm{E}-01$ \\
2 & $2.14 \mathrm{E}-03$ & $1.55 \mathrm{E}-01$ & $3.89 \mathrm{E}-01$ \\
3 & $1.51 \mathrm{E}-03$ & $7.96 \mathrm{E}-02$ & $1.97 \mathrm{E}-01$ \\
5 & $5.27 \mathrm{E}-04$ & $1.33 \mathrm{E}-02$ & $3.14 \mathrm{E}-02$ \\
7 & $2.03 \mathrm{E}-04$ & $2.31 \mathrm{E}-03$ & $4.38 \mathrm{E}-03$ \\
14 & $2.46 \mathrm{E}-05$ & $4.33 \mathrm{E}-04$ & $4.04 \mathrm{E}-06$ \\
30 & $1.65 \mathrm{E}-05$ & $2.78 \mathrm{E}-04$ & $8.26 \mathrm{E}-09$ \\
60 & $1.56 \mathrm{E}-05$ & $1.28 \mathrm{E}-04$ & $7.83 \mathrm{E}-09$ \\
90 & $1.48 \mathrm{E}-05$ & $6.41 \mathrm{E}-05$ & $7.43 \mathrm{E}-09$ \\
180 & $1.28 \mathrm{E}-05$ & $1.52 \mathrm{E}-05$ & $6.40 \mathrm{E}-09$ \\
365 & $9.80 \mathrm{E}-06$ & $4.13 \mathrm{E}-06$ & $4.90 \mathrm{E}-09$ \\
$2 \mathrm{y}$ & $6.42 \mathrm{E}-06$ & $8.28 \mathrm{E}-07$ & $3.21 \mathrm{E}-09$ \\
$3 \mathrm{y}$ & $4.60 \mathrm{E}-06$ & $3.53 \mathrm{E}-07$ & $2.30 \mathrm{E}-09$ \\
$5 \mathrm{y}$ & $2.82 \mathrm{E}-06$ & $1.84 \mathrm{E}-07$ & $1.41 \mathrm{E}-09$ \\
$10 \mathrm{y}$ & $1.47 \mathrm{E}-06$ & $9.26 \mathrm{E}-08$ & $7.35 \mathrm{E}-10$ \\
$20 \mathrm{y}$ & $7.77 \mathrm{E}-07$ & $4.84 \mathrm{E}-08$ & $3.88 \mathrm{E}-10$ \\
$50 \mathrm{y}$ & $3.39 \mathrm{E}-07$ & $2.09 \mathrm{E}-08$ & $1.69 \mathrm{E}-10$ \\
\hline
\end{tabular}

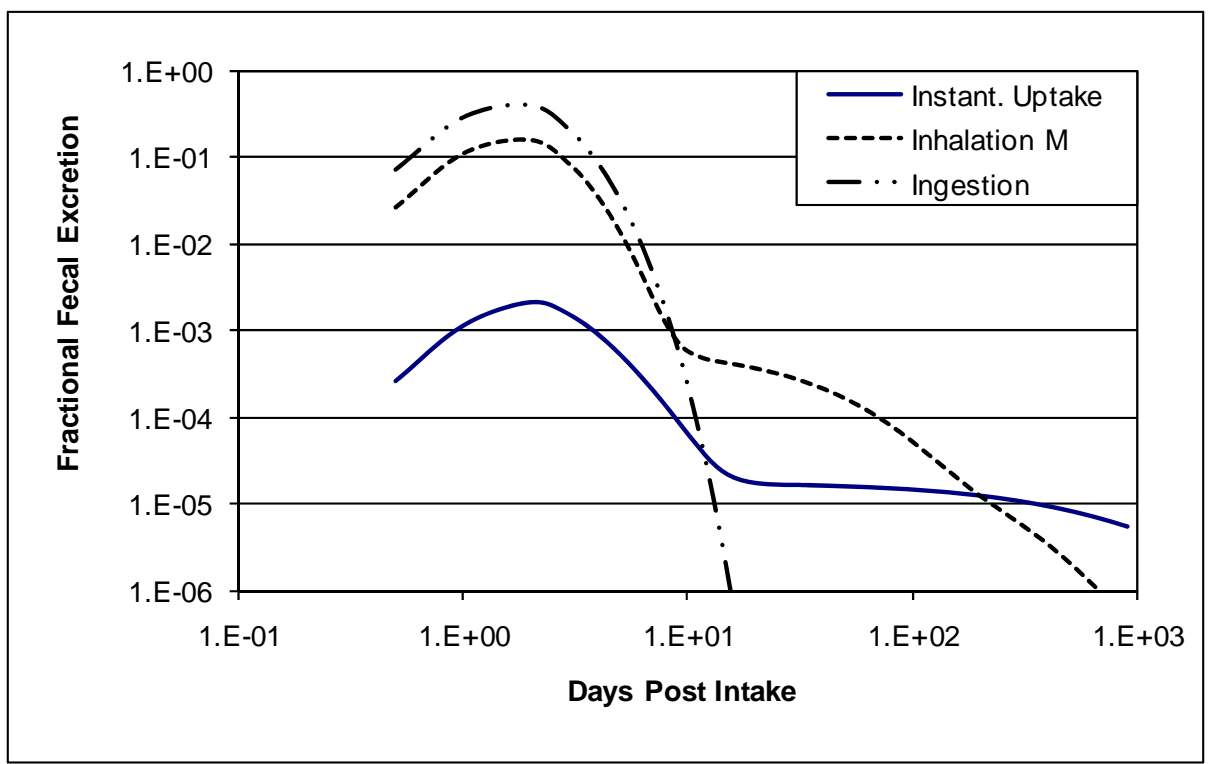

Figure 10.4. ${ }^{237} \mathrm{~Np}$ Fecal Excretion Fractions from Acute Intakes 
Table 10.7. Fecal-to-Urine Ratios for Acute ${ }^{237}$ Np Intakes

\begin{tabular}{cccc}
\hline $\begin{array}{c}\text { Days Post } \\
\text { Intake }\end{array}$ & $\begin{array}{c}\text { Instant } \\
\text { Uptake }\end{array}$ & Inhalation, Type M & Ingestion \\
\hline 0.5 & $1.70 \mathrm{E}-03$ & $6.01 \mathrm{E}+00$ & $1.45 \mathrm{E}+03$ \\
1 & $5.25 \mathrm{E}-03$ & $1.74 \mathrm{E}+01$ & $2.89 \mathrm{E}+03$ \\
2 & $4.84 \mathrm{E}-02$ & $1.16 \mathrm{E}+02$ & $1.27 \mathrm{E}+04$ \\
3 & $6.94 \mathrm{E}-02$ & $1.14 \mathrm{E}+02$ & $1.60 \mathrm{E}+04$ \\
5 & $5.75 \mathrm{E}-02$ & $3.87 \mathrm{E}+01$ & $6.27 \mathrm{E}+03$ \\
7 & $4.86 \mathrm{E}-02$ & $1.14 \mathrm{E}+01$ & $1.93 \mathrm{E}+03$ \\
14 & $3.33 \mathrm{E}-02$ & $4.31 \mathrm{E}+00$ & $1.06 \mathrm{E}+01$ \\
30 & $4.61 \mathrm{E}-02$ & $3.61 \mathrm{E}+00$ & $4.59 \mathrm{E}-02$ \\
60 & $7.81 \mathrm{E}-02$ & $2.28 \mathrm{E}+00$ & $7.79 \mathrm{E}-02$ \\
90 & $9.61 \mathrm{E}-02$ & $1.44 \mathrm{E}+00$ & $9.60 \mathrm{E}-02$ \\
180 & $1.10 \mathrm{E}-01$ & $5.64 \mathrm{E}-01$ & $1.10 \mathrm{E}-01$ \\
365 & $1.08 \mathrm{E}-01$ & $3.28 \mathrm{E}-01$ & $1.08 \mathrm{E}-01$ \\
730 & $8.30 \mathrm{E}-02$ & $1.44 \mathrm{E}-01$ & $8.30 \mathrm{E}-02$ \\
\hline
\end{tabular}

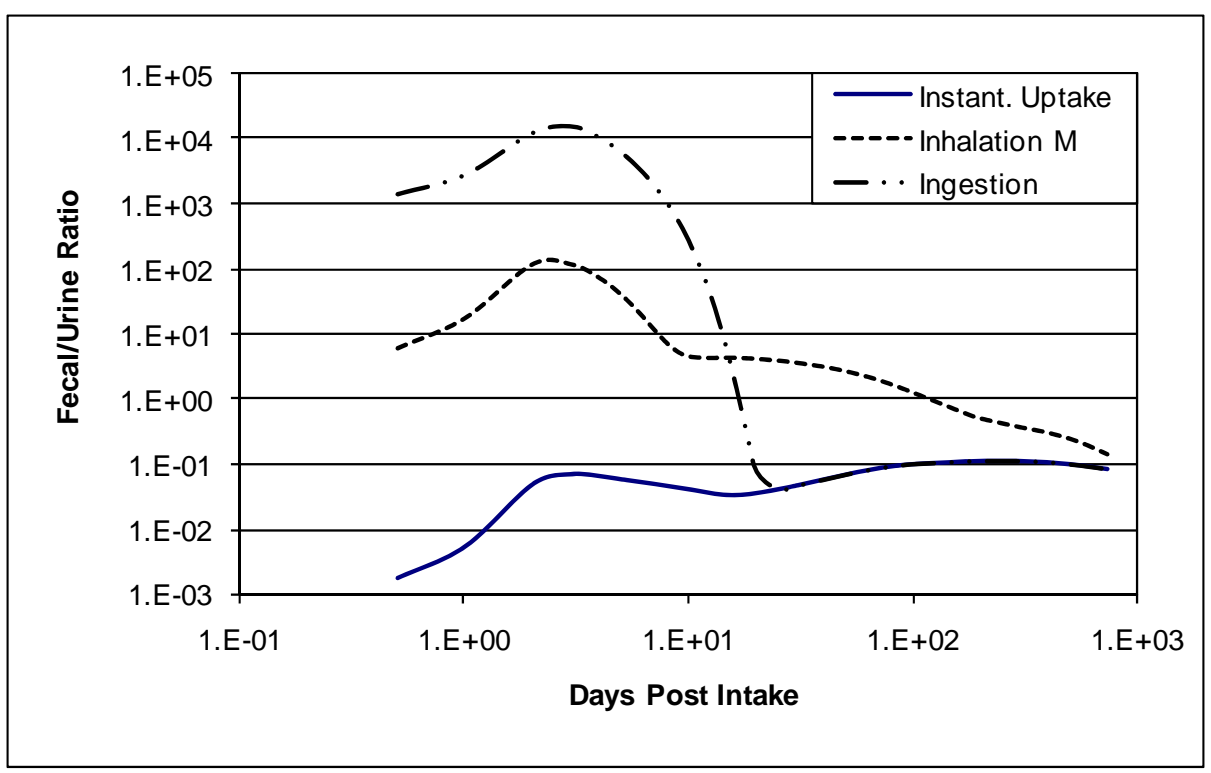

Figure 10.5. ${ }^{237} \mathrm{~Np}$ Fecal-to-Urine Ratios from Acute Intakes

\subsubsection{Dose Coefficients}

Dose coefficients, expressed as committed effective or equivalent dose per unit activity of intake (rem per nanocurie of acute intake or rem per nanocurie per day of chronic intake), are a convenient shortcut to estimating doses based on standard assumptions when the magnitude of an intake is known or assumed. Acute intake dose coefficients have been tabulated in this section, Table 10.8, for instantaneous uptake, Type M inhalation for 5- $\mu$ m-AMAD particle size, and for ingestion. Dose coefficients for organs that contribute at least $10 \%$ to the effective dose or have the highest organ dose coefficient are included in the table. For all three intake modes, the bone surface equivalent dose is more limiting relative to its 50-rem limit than the effective dose. 
These dose coefficients were all derived using the IMBA computer code. In dose calculations, IMBA super merges the first progeny, ${ }^{233} \mathrm{~Pa}$, meaning that the ${ }^{233} \mathrm{~Pa}$ is allowed to grow in over time from the ${ }^{237} \mathrm{~Np}$. However, dose from ${ }^{233} \mathrm{~Pa}$ present at the time of intake is not included. In terms of 50 -year committed doses, the additional dose from ${ }^{233} \mathrm{~Pa}$ at intake is negligible (the effective dose coefficient is approximately 5000 times smaller).

Table 10.8. Committed Dose Coefficients for Acute Intakes of ${ }^{237} \mathrm{~Np}(\mathrm{rem} / \mathrm{nCi})$

\begin{tabular}{lccc}
\hline \multicolumn{1}{c}{$\begin{array}{c}\text { Organ or } \\
\text { Tissue }\end{array}$} & $\begin{array}{c}\text { Instant } \\
\text { Uptake }\end{array}$ & $\begin{array}{c}\text { Inhalation, } \\
\text { Type M }\end{array}$ & Ingestion \\
\hline Effective & $7.60 \mathrm{E}-01$ & $5.40 \mathrm{E}-02$ & $3.95 \mathrm{E}-04$ \\
Bone Surface & $4.02 \mathrm{E}+01$ & $2.47 \mathrm{E}+00$ & $2.01 \mathrm{E}-02$ \\
Red Marrow & 1.54 & $9.45 \mathrm{E}-02$ & $7.68 \mathrm{E}-04$ \\
Lung & NA & $6.37 \mathrm{E}-02$ & NA \\
Gonads & 5.45E-01 & $3.35 \mathrm{E}-02$ & $2.73 \mathrm{E}-04$ \\
\hline
\end{tabular}

(a) Organ with highest dose or contributes $10 \%$ or more to effective dose.

Shaded cells indicate the organ with the highest dose coefficient for each intake mode.

\subsubsection{Comparison of Published Dosimetry Factors}

A comparison of effective dose coefficients between IMBA-derived coefficients and those published in ICRP 68 and 78 (ICRP 1994a, 1997) is provided in Table 10.9. IMBA provides dose coefficients with three digits whereas the ICRP values are listed with only two digits. Taking the rounding of numbers into account, there are no differences.

Table 10.9. Comparison of Effective Dose Coefficients, Sv/Bq, for ${ }^{237} \mathrm{~Np}$

\begin{tabular}{lcc}
\hline \multicolumn{1}{c}{ Intake Mode } & $\begin{array}{c}\text { IMBA Effective } \\
\text { Dose Coefficient }\end{array}$ & $\begin{array}{c}\text { ICRP 78 Effective } \\
\text { Dose Coefficient }\end{array}$ \\
\hline Inhalation Type M, $5 \mu \mathrm{m}$ & $1.46 \mathrm{E}-05$ & $1.5 \mathrm{E}-05$ \\
Ingestion, $f_{1}=5 \mathrm{E}-04$ & $1.07 \mathrm{E}-07$ & $1.1 \mathrm{E}-07$ \\
\hline
\end{tabular}

\subsubsection{Derived Air Concentrations and Annual Limits on Intake}

10 CFR 835 provides derived air concentrations (DACs) assuming 5- $\mu$ m-AMAD particles and the light worker breathing rate $\left(2,400 \mathrm{~m}^{3} / \mathrm{y}\right)$. The DAC for ${ }^{237} \mathrm{~Np}$ is shown in Table 10.10 . Because the bone surface equivalent dose is more limiting than the effective dose, the annual limit on intake (ALI) is a deterministic ALI, sometimes called a DALI. The stochastic ALI (SALI) is of potential use for determining bioassay requirement. The DALI and SALI can be determined from the dose coefficients per Equation 2.8 
Table 10.10. DAC and ALI for ${ }^{237} \mathrm{~Np}$

\begin{tabular}{ccc}
\hline DAC, $^{(a)}(\mu \mathrm{Ci} / \mathrm{ml})$ & DALI (nCi) & SALI (nCi) \\
\hline 8E-12 & 20 & 90 \\
\hline (a) From 10 CFR 835 Appendix A. & \\
\hline
\end{tabular}

\subsection{Derived Reference Levels}

Derived screening, investigation, and regulatory compliance levels (based on committed effective doses of 10 mrem, 100 mrem, and committed bone surface equivalent dose of 50,000 mrem, respectively) have been calculated for instantaneous uptake and 5- $\mu \mathrm{m}$ Type $\mathrm{M}$ inhalation of pure ${ }^{237} \mathrm{~Np}$. The urine and fecal excretion reference levels are shown in Table 10.11; chest count and whole body count reference levels are shown in Table 10.12. For in vivo counting, essentially anything detected should result in an investigation. Urine and fecal sampling are more sensitive, but anything detected on an annual urine sample should be investigated.

\subsection{Bioassay for ${ }^{237} \mathrm{~Np}$}

This section discusses the general techniques and applicability of bioassay monitoring and describes the capabilities of excreta sample bioassay and in vivo measurements. General recommendations are also provided for routine bioassay monitoring for ${ }^{237} \mathrm{~Np}$. Neptunium often, but not always, had contaminants, especially ${ }^{239} \mathrm{Pu}$ or ${ }^{238} \mathrm{Pu}$, so evidence of an intake of neptunium should result in obtaining bioassay for plutonium unless it is known for sure that the source material was pure.

\subsubsection{Excreta Bioassay Techniques for ${ }^{237} \mathrm{~Np}$}

The typical urine sampling practice is to collect a urine sample over a specified time interval and perform a chemical separation using an added tracer to determine the chemical yield of the process. This technique is followed by electroplating and quantitative alpha spectrometry. Fecal sample analysis follows a process similar to urine sample analysis.

Less sensitive, rapid analytical procedures are available for special circumstances. These procedures can be executed and results obtained in substantially shorter times than the routine procedure, but they are less sensitive. Their use is primarily for diagnostic bioassay of suspected intakes related to unplanned exposures (incidents). The decision to use such procedures involves considering the probability and potential magnitude of the exposure. 
Table 10.11. ${ }^{237} \mathrm{~Np}$ Urine and Fecal Excretion Reference Levels and Derived Reference Levels for Instantaneous Uptake and Type M Inhalation

\begin{tabular}{|c|c|c|c|c|c|c|}
\hline & \multicolumn{2}{|c|}{$\begin{array}{l}\text { 10-mrem Effective Reporting } \\
\text { Level }\end{array}$} & \multicolumn{2}{|c|}{$\begin{array}{l}\text { 100-mrem Effective } \\
\text { Investigation Level }\end{array}$} & \multicolumn{2}{|c|}{$\begin{array}{l}\text { 50-rem } \mathrm{H}_{\mathrm{T}}(50) \text { Compliance } \\
\text { Level }\end{array}$} \\
\hline & $\begin{array}{l}\text { Instantaneous } \\
\text { Uptake }\end{array}$ & $\begin{array}{c}5-\mu \mathrm{m} \\
\text { Type M } \\
\text { Inhalation }\end{array}$ & $\begin{array}{l}\text { Instantaneous } \\
\text { Uptake }\end{array}$ & $\begin{array}{c}5-\mu \mathrm{m} \\
\text { Type M } \\
\text { Inhalation }\end{array}$ & $\begin{array}{l}\text { Instantaneous } \\
\text { Uptake }\end{array}$ & $\begin{array}{c}5-\mu \mathrm{m} \\
\text { Type M } \\
\text { Inhalation }\end{array}$ \\
\hline $\begin{array}{l}\text { Intake } \\
(\mathrm{nCi})\end{array}$ & $1.32 \mathrm{E}-02$ & $1.85 \mathrm{E}-01$ & 1.32E-01 & $1.85 \mathrm{E}+00$ & $1.24-\mathrm{E}+00$ & $2.02 \mathrm{E}+01$ \\
\hline & $\begin{array}{l}\text { Derived } \\
\text { Screening } \\
\text { Level }\end{array}$ & $\begin{array}{l}\text { Derived } \\
\text { Screening } \\
\text { Level }\end{array}$ & $\begin{array}{c}\text { Derived } \\
\text { Investigation } \\
\text { Level }\end{array}$ & $\begin{array}{c}\text { Derived } \\
\text { Investigation } \\
\text { Level }\end{array}$ & $\begin{array}{c}\text { Derived } \\
\text { Compliance } \\
\text { Level }\end{array}$ & $\begin{array}{c}\text { Derived } \\
\text { Compliance } \\
\text { Level }\end{array}$ \\
\hline \multicolumn{7}{|c|}{ Urine Derived Reference Levels (dpm/d) } \\
\hline 0.5 & $4.49 \mathrm{E}+00$ & $1.78 \mathrm{E}+00$ & 4.49E+01 & $1.78 \mathrm{E}+01$ & $4.25 E+02$ & $1.94 \mathrm{E}+02$ \\
\hline 1 & $6.39 \mathrm{E}+00$ & $2.56 \mathrm{E}+00$ & $6.39 \mathrm{E}+01$ & $2.56 \mathrm{E}+01$ & $6.04 \mathrm{E}+02$ & $2.80 \mathrm{E}+02$ \\
\hline 2 & $1.29 \mathrm{E}+00$ & 5.49E-01 & $1.29 \mathrm{E}+01$ & $5.49 \mathrm{E}+00$ & $1.22 \mathrm{E}+02$ & $6.00 \mathrm{E}+01$ \\
\hline 3 & 6.37E-01 & 2.87E-01 & $6.37 \mathrm{E}+00$ & $2.87 \mathrm{E}+00$ & $6.02 \mathrm{E}+01$ & $3.14 \mathrm{E}+01$ \\
\hline 5 & 2.68E-01 & $1.41 \mathrm{E}-01$ & $2.68 \mathrm{E}+00$ & $1.41 \mathrm{E}+00$ & $2.53 \mathrm{E}+01$ & $1.54 \mathrm{E}+01$ \\
\hline 7 & $1.22 \mathrm{E}-01$ & 8.35E-02 & $1.22 \mathrm{E}+00$ & 8.35E-01 & $1.15 \mathrm{E}+01$ & $9.13 \mathrm{E}+00$ \\
\hline 14 & $2.16 \mathrm{E}-02$ & 4.13E-02 & $2.16 \mathrm{E}-01$ & 4.13E-01 & $2.04 \mathrm{E}+00$ & $4.52 \mathrm{E}+00$ \\
\hline 30 & 1.05E-02 & 3.16E-02 & $1.05 \mathrm{E}-01$ & 3.16E-01 & 9.89E-01 & $3.45 \mathrm{E}+00$ \\
\hline 60 & $5.86 \mathrm{E}-03$ & 2.30E-02 & 5.86E-02 & 2.30E-01 & 5.53E-01 & $2.52 \mathrm{E}+00$ \\
\hline 90 & 4.51E-03 & $1.83 \mathrm{E}-02$ & 4.51E-02 & 1.83E-01 & 4.27E-01 & $2.00 \mathrm{E}+00$ \\
\hline 180 & $3.40 \mathrm{E}-03$ & 1.11E-02 & $3.40 \mathrm{E}-02$ & 1.11E-01 & $3.22 \mathrm{E}-01$ & $1.21 \mathrm{E}+00$ \\
\hline 365 & 2.66E-03 & 5.19E-03 & 2.66E-02 & 5.19E-02 & 2.51E-01 & 5.67E-01 \\
\hline 730 & $2.26 \mathrm{E}-03$ & 2.36E-03 & 2.26E-02 & 2.36E-02 & 2.13E-01 & $2.58 \mathrm{E}-01$ \\
\hline $5 y$ & $1.55 \mathrm{E}-03$ & 1.39E-03 & $1.55 \mathrm{E}-02$ & 1.39E-02 & $1.47 \mathrm{E}-01$ & $1.52 \mathrm{E}-01$ \\
\hline $10 \mathrm{y}$ & $9.49 \mathrm{E}-04$ & 8.39E-04 & 9.49E-03 & 8.39E-03 & 8.97E-02 & 9.17E-02 \\
\hline \multicolumn{7}{|c|}{ Fecal Excretion Derived Reference Levels (dpm/d) } \\
\hline 0.5 & 7.66E-03 & $1.07 \mathrm{E}+01$ & 7.66E-02 & $1.07 \mathrm{E}+02$ & 7.24E-01 & $1.17 \mathrm{E}+03$ \\
\hline 1 & 3.36E-02 & $4.45 \mathrm{E}+01$ & 3.36E-01 & $4.45 \mathrm{E}+02$ & $3.18 \mathrm{E}+00$ & $4.87 \mathrm{E}+03$ \\
\hline 2 & $6.25 \mathrm{E}-02$ & $6.36 \mathrm{E}+01$ & $6.25 \mathrm{E}-01$ & $6.36 \mathrm{E}+02$ & $5.91 \mathrm{E}+00$ & $6.95 \mathrm{E}+03$ \\
\hline 3 & 4.42E-02 & $3.27 \mathrm{E}+01$ & 4.42E-01 & $3.27 \mathrm{E}+02$ & $4.18 \mathrm{E}+00$ & $3.58 \mathrm{E}+03$ \\
\hline 5 & $1.54 \mathrm{E}-02$ & $5.47 \mathrm{E}+00$ & $1.54 \mathrm{E}-01$ & $5.47 \mathrm{E}+01$ & $1.46 \mathrm{E}+00$ & $5.98 \mathrm{E}+02$ \\
\hline 7 & 5.94E-03 & $9.50 \mathrm{E}-01$ & 5.94E-02 & $9.50 \mathrm{E}+00$ & 5.61E-01 & $1.04 \mathrm{E}+02$ \\
\hline 14 & 7.18E-04 & $1.78 \mathrm{E}-01$ & 7.18E-03 & $1.78 \mathrm{E}+00$ & 6.79E-02 & $1.95 \mathrm{E}+01$ \\
\hline 30 & 4.83E-04 & $1.14 \mathrm{E}-01$ & 4.83E-03 & $1.14 \mathrm{E}+00$ & 4.56E-02 & $1.25 \mathrm{E}+01$ \\
\hline 60 & 4.57E-04 & 5.26E-02 & 4.57E-03 & 5.26E-01 & 4.32E-02 & $5.75 \mathrm{E}+00$ \\
\hline 90 & 4.34E-04 & 2.63E-02 & 4.34E-03 & 2.63E-01 & 4.10E-02 & $2.88 \mathrm{E}+00$ \\
\hline 180 & 3.74E-04 & $6.24 \mathrm{E}-03$ & 3.74E-03 & 6.24E-02 & 3.54E-02 & 6.82E-01 \\
\hline
\end{tabular}


Table 10.12. ${ }^{237} \mathrm{~Np}$ Chest Count and Whole Body Count Reference Levels and Derived Reference Levels for Instantaneous Uptake and Type M Inhalation

\begin{tabular}{|c|c|c|c|c|c|c|}
\hline & \multicolumn{2}{|c|}{$\begin{array}{l}\text { 10-mrem Effective Reporting } \\
\text { Level }\end{array}$} & \multicolumn{2}{|c|}{$\begin{array}{l}\text { 100-mrem Effective } \\
\text { Investigation Level }\end{array}$} & \multicolumn{2}{|c|}{$\begin{array}{c}\text { 50-rem } \mathrm{H}_{\mathrm{T}}(50) \text { Compliance } \\
\text { Level }\end{array}$} \\
\hline & $\begin{array}{l}\text { Instantaneous } \\
\text { Uptake }\end{array}$ & $\begin{array}{c}5-\mu \mathrm{m} \\
\text { Type M } \\
\text { Inhalation }\end{array}$ & $\begin{array}{l}\text { Instantaneous } \\
\text { Uptake }\end{array}$ & $\begin{array}{c}5-\mu \mathrm{m} \\
\text { Type } \mathrm{M} \\
\text { Inhalation }\end{array}$ & $\begin{array}{l}\text { Instantaneous } \\
\text { Uptake }\end{array}$ & $\begin{array}{c}5-\mu \mathrm{m} \\
\text { Type M } \\
\text { Inhalation }\end{array}$ \\
\hline $\begin{array}{l}\text { Intake } \\
(\mathrm{nCi})\end{array}$ & $1.32 \mathrm{E}-02$ & $1.85 \mathrm{E}-01$ & $1.32 \mathrm{E}-01$ & $1.85 \mathrm{E}+00$ & $1.24 \mathrm{E}+00$ & $2.02 \mathrm{E}+01$ \\
\hline & $\begin{array}{l}\text { Derived } \\
\text { Screening } \\
\text { Level }\end{array}$ & $\begin{array}{l}\text { Derived } \\
\text { Screening } \\
\text { Level }\end{array}$ & $\begin{array}{c}\text { Derived } \\
\text { Investigation } \\
\text { Level }\end{array}$ & $\begin{array}{c}\text { Derived } \\
\text { Investigation } \\
\text { Level }\end{array}$ & $\begin{array}{l}\text { Derived } \\
\text { Compliance } \\
\text { Level }\end{array}$ & $\begin{array}{c}\text { Derived } \\
\text { Compliance } \\
\text { Level }\end{array}$ \\
\hline \multicolumn{7}{|c|}{ Chest Count Derived Reference Levels (nCi) } \\
\hline 0.5 & NA & $1.11 \mathrm{E}-02$ & NA & $1.11 \mathrm{E}-01$ & NA & $1.21 \mathrm{E}+00$ \\
\hline 1 & NA & $1.07 \mathrm{E}-02$ & NA & $1.07 \mathrm{E}-01$ & NA & $1.17 \mathrm{E}+00$ \\
\hline 2 & NA & $1.04 \mathrm{E}-02$ & NA & $1.04 \mathrm{E}-01$ & NA & $1.13 E+00$ \\
\hline 3 & NA & $1.02 \mathrm{E}-02$ & NA & 1.02E-01 & NA & $1.11 \mathrm{E}+00$ \\
\hline 5 & NA & $9.88 \mathrm{E}-03$ & NA & $9.88 \mathrm{E}-02$ & NA & $1.08 \mathrm{E}+00$ \\
\hline 7 & NA & $9.60 \mathrm{E}-03$ & NA & $9.60 \mathrm{E}-02$ & NA & $1.05 \mathrm{E}+00$ \\
\hline 14 & NA & 8.70E-03 & NA & 8.70E-02 & NA & $9.51 \mathrm{E}-01$ \\
\hline 30 & NA & 7.11E-03 & NA & 7.11E-02 & NA & 7.77E-01 \\
\hline 60 & NA & $5.20 \mathrm{E}-03$ & NA & $5.20 \mathrm{E}-02$ & NA & 5.69E-01 \\
\hline 90 & NA & 4.04E-03 & NA & 4.04E-02 & NA & 4.42E-01 \\
\hline 180 & NA & $2.21 \mathrm{E}-03$ & NA & 2.21E-02 & NA & 2.41E-01 \\
\hline 365 & NA & 7.39E-04 & NA & 7.39E-03 & NA & 8.08E-02 \\
\hline \multicolumn{7}{|c|}{ Whole Body Count Derived Reference Levels (nCi) ${ }^{(a)}$} \\
\hline 0.5 & $1.11 \mathrm{E}-02$ & 1.22E-01 & $1.11 \mathrm{E}-01$ & $1.22 \mathrm{E}+00$ & $1.05 \mathrm{E}+00$ & $1.33 \mathrm{E}+01$ \\
\hline 1 & 1.03E-02 & 9.09E-02 & 1.03E-01 & 9.09E-01 & $9.70 \mathrm{E}-01$ & $9.94 \mathrm{E}+00$ \\
\hline 2 & 9.65E-03 & 4.75E-02 & 9.65E-02 & 4.75E-01 & 9.12E-01 & $5.19 \mathrm{E}+00$ \\
\hline 3 & 9.35E-03 & 2.72E-02 & 9.35E-02 & 2.72E-01 & 8.84E-01 & $2.98 \mathrm{E}+00$ \\
\hline 5 & $9.02 \mathrm{E}-03$ & $1.57 \mathrm{E}-02$ & $9.02 \mathrm{E}-02$ & $1.57 \mathrm{E}-01$ & 8.53E-01 & $1.72 \mathrm{E}+00$ \\
\hline 7 & 8.87E-03 & $1.38 \mathrm{E}-02$ & 8.87E-02 & $1.38 \mathrm{E}-01$ & 8.39E-01 & $1.51 \mathrm{E}+00$ \\
\hline 14 & 8.73E-03 & $1.28 \mathrm{E}-02$ & 8.73E-02 & $1.28 \mathrm{E}-01$ & 8.26E-01 & $1.40 \mathrm{E}+00$ \\
\hline 30 & 8.65E-03 & $1.16 \mathrm{E}-02$ & 8.65E-02 & 1.16E-01 & 8.17E-01 & $1.26 \mathrm{E}+00$ \\
\hline 60 & 8.53E-03 & $1.01 \mathrm{E}-02$ & 8.53E-02 & $1.01 \mathrm{E}-01$ & 8.06E-01 & $1.11 \mathrm{E}+00$ \\
\hline 90 & 8.45E-03 & 9.36E-03 & 8.45E-02 & 9.36E-02 & 7.98E-01 & $1.02 \mathrm{E}+00$ \\
\hline 180 & 8.27E-03 & 8.26E-03 & 8.27E-02 & 8.26E-02 & 7.82E-01 & $9.03 \mathrm{E}-01$ \\
\hline 365 & 8.01E-03 & 7.37E-03 & 8.01E-02 & 7.37E-02 & 7.58E-01 & 8.06E-01 \\
\hline
\end{tabular}


The contractual detection limits for ${ }^{237} \mathrm{~Np}$ in urine or feces can be found in the radiochemistry bioassay laboratory statement of work (available from the Hanford Internal Dosimetry Program) and in the Hanford Internal Dosimetry Program Manual (PNL-MA-552; EH Carbaugh, et al. 2009). ${ }^{1}$

The minimum detectable acute intakes based on a $0.02-\mathrm{dpm} / \mathrm{d}$ urinalysis sensitivity are listed in Table 10.13. The committed effective and bone surface equivalent doses associated with those intakes are shown in Table 10.14 and Figure 10.6 shows graphical presentations of the minimum detectable doses. Urinalysis can detect intakes at or better than the 100-mrem effective dose goal up to 2 years after an acute intake. Corresponding data based on a $0.1-\mathrm{dpm} / \mathrm{d}$ fecal analysis sensitivity are shown in Tables 10.15 and 10.16 and plotted in Figure 10.7. Fecal sampling after an acute inhalation intake can meet the 100-mrem effective dose goal for about 5 months after intake and can meet the bone surface regulatory limit for up to 1 year.

Table 10.13. Minimum Detectable Intakes (nCi) for ${ }^{237} \mathrm{~Np}$ Based on Detection of $0.02 \mathrm{dpm} / \mathrm{d}{ }^{237} \mathrm{~Np}$ in Urine

\begin{tabular}{cccc}
\hline $\begin{array}{c}\text { Days Post } \\
\text { Intake }\end{array}$ & $\begin{array}{c}\text { Instant. } \\
\text { Uptake }\end{array}$ & Type M Inhalation & Ingestion \\
\hline 1 & $4.12 \mathrm{E}-05$ & $1.45 \mathrm{E}-03$ & $9.22 \mathrm{E}-02$ \\
2 & $2.04 \mathrm{E}-04$ & $6.75 \mathrm{E}-03$ & $2.95 \mathrm{E}-01$ \\
5 & $9.83 \mathrm{E}-04$ & $2.62 \mathrm{E}-02$ & $1.80 \mathrm{E}+00$ \\
7 & $2.15 \mathrm{E}-03$ & $4.44 \mathrm{E}-02$ & $3.98 \mathrm{E}+00$ \\
14 & $1.22 \mathrm{E}-02$ & $8.97 \mathrm{E}-02$ & $2.38 \mathrm{E}+01$ \\
30 & $2.52 \mathrm{E}-02$ & $1.17 \mathrm{E}-01$ & $5.00 \mathrm{E}+01$ \\
60 & $4.49 \mathrm{E}-02$ & $1.61 \mathrm{E}-01$ & $8.97 \mathrm{E}+01$ \\
90 & $5.83 \mathrm{E}-02$ & $2.03 \mathrm{E}-01$ & $1.16 \mathrm{E}+02$ \\
180 & $7.74 \mathrm{E}-02$ & $3.35 \mathrm{E}-01$ & $1.55 \mathrm{E}+02$ \\
365 & $9.89 \mathrm{E}-02$ & $7.14 \mathrm{E}-01$ & $1.98 \mathrm{E}+02$ \\
$2 \mathrm{y}$ & $1.17 \mathrm{E}-01$ & $1.57 \mathrm{E}+00$ & $2.33 \mathrm{E}+02$ \\
$5 \mathrm{y}$ & $1.69 \mathrm{E}-01$ & $2.67 \mathrm{E}+00$ & $3.38 \mathrm{E}+02$ \\
$10 \mathrm{y}$ & $2.77 \mathrm{E}-01$ & $4.42 \mathrm{E}+00$ & $5.55 \mathrm{E}+02$ \\
$20 \mathrm{y}$ & $5.03 \mathrm{E}-01$ & $8.08 \mathrm{E}+00$ & $1.01 \mathrm{E}+03$ \\
$50 \mathrm{y}$ & $1.13 \mathrm{E}+00$ & $1.82 \mathrm{E}+01$ & $2.26 \mathrm{E}+03$ \\
\hline
\end{tabular}

\footnotetext{
${ }^{1}$ Pacific Northwest National Laboratory (PNNL). Hanford Internal Dosimetry Program Manual. PNL-MA-552, Richland, Washington. (Internal manual.) Available URL:

http://www.pnl.gov/main/publications/external/technical_reports/PNNL-15613.pdf
} 
Table 10.14. Minimum Detectable Committed Effective and Bone Surface Equivalent Dose for ${ }^{237} \mathrm{~Np}$ Based on Detection of $0.02 \mathrm{dpm} / \mathrm{d}{ }^{237} \mathrm{~Np}$ in Urine

\begin{tabular}{ccccccc}
\hline & \multicolumn{3}{c}{ Effective Dose (rem) } & \multicolumn{3}{c}{ Bone Surface Equivalent Dose (rem) } \\
\cline { 2 - 6 } $\begin{array}{c}\text { Days Post } \\
\text { Intake }\end{array}$ & $\begin{array}{c}\text { Instantaneous } \\
\text { Uptake }\end{array}$ & $\begin{array}{c}\text { Inhalation } \\
\text { Type M }\end{array}$ & Ingestion & $\begin{array}{c}\text { Instantaneous } \\
\text { Uptake }\end{array}$ & $\begin{array}{c}\text { Inhalation } \\
\text { Type M }\end{array}$ & Ingestion \\
\hline 1 & $3.13 \mathrm{E}-05$ & $7.82 \mathrm{E}-05$ & $3.64 \mathrm{E}-05$ & $1.65 \mathrm{E}-03$ & $3.58 \mathrm{E}-03$ & $1.85 \mathrm{E}-03$ \\
2 & $1.55 \mathrm{E}-04$ & $3.64 \mathrm{E}-04$ & $1.17 \mathrm{E}-04$ & $8.19 \mathrm{E}-03$ & $1.67 \mathrm{E}-02$ & $5.93 \mathrm{E}-03$ \\
5 & $7.47 \mathrm{E}-04$ & $1.42 \mathrm{E}-03$ & $7.11 \mathrm{E}-04$ & $3.95 \mathrm{E}-02$ & $6.47 \mathrm{E}-02$ & $3.62 \mathrm{E}-02$ \\
7 & $1.64 \mathrm{E}-03$ & $2.40 \mathrm{E}-03$ & $1.57 \mathrm{E}-03$ & $8.66 \mathrm{E}-02$ & $1.10 \mathrm{E}-01$ & $7.99 \mathrm{E}-02$ \\
14 & $9.27 \mathrm{E}-03$ & $4.84 \mathrm{E}-03$ & $9.39 \mathrm{E}-03$ & $4.90 \mathrm{E}-01$ & $2.21 \mathrm{E}-01$ & $4.78 \mathrm{E}-01$ \\
30 & $1.91 \mathrm{E}-02$ & $6.33 \mathrm{E}-03$ & $1.98 \mathrm{E}-02$ & $1.01 \mathrm{E}+00$ & $2.89 \mathrm{E}-01$ & $1.01 \mathrm{E}+00$ \\
60 & $3.42 \mathrm{E}-02$ & $8.68 \mathrm{E}-03$ & $3.54 \mathrm{E}-02$ & $1.81 \mathrm{E}+00$ & $3.97 \mathrm{E}-01$ & $1.80 \mathrm{E}+00$ \\
90 & $4.43 \mathrm{E}-02$ & $1.10 \mathrm{E}-02$ & $4.60 \mathrm{E}-02$ & $2.34 \mathrm{E}+00$ & $5.01 \mathrm{E}-01$ & $2.34 \mathrm{E}+00$ \\
180 & $5.88 \mathrm{E}-02$ & $1.81 \mathrm{E}-02$ & $6.11 \mathrm{E}-02$ & $3.11 \mathrm{E}+00$ & $8.27 \mathrm{E}-01$ & $3.11 \mathrm{E}+00$ \\
365 & $7.52 \mathrm{E}-02$ & $3.86 \mathrm{E}-02$ & $7.81 \mathrm{E}-02$ & $3.98 \mathrm{E}+00$ & $1.76 \mathrm{E}+00$ & $3.98 \mathrm{E}+00$ \\
$2 \mathrm{y}$ & $8.86 \mathrm{E}-02$ & $8.47 \mathrm{E}-02$ & $9.21 \mathrm{E}-02$ & $4.69 \mathrm{E}+00$ & $3.87 \mathrm{E}+00$ & $4.69 \mathrm{E}+00$ \\
$5 \mathrm{y}$ & $1.29 \mathrm{E}-01$ & $1.44 \mathrm{E}-01$ & $1.34 \mathrm{E}-01$ & $6.80 \mathrm{E}+00$ & $6.58 \mathrm{E}+00$ & $6.80 \mathrm{E}+00$ \\
$10 \mathrm{y}$ & $2.11 \mathrm{E}-01$ & $2.38 \mathrm{E}-01$ & $2.19 \mathrm{E}-01$ & $1.11 \mathrm{E}+01$ & $1.09 \mathrm{E}+01$ & $1.11 \mathrm{E}+01$ \\
$20 \mathrm{y}$ & $3.82 \mathrm{E}-01$ & $4.36 \mathrm{E}-01$ & $3.97 \mathrm{E}-01$ & $2.02 \mathrm{E}+01$ & $1.99 \mathrm{E}+01$ & $2.02 \mathrm{E}+01$ \\
$50 \mathrm{y}$ & $8.58 \mathrm{E}-01$ & $9.85 \mathrm{E}-01$ & $8.91 \mathrm{E}-01$ & $4.54 \mathrm{E}+01$ & $4.51 \mathrm{E}+01$ & $4.54 \mathrm{E}+01$ \\
\hline
\end{tabular}

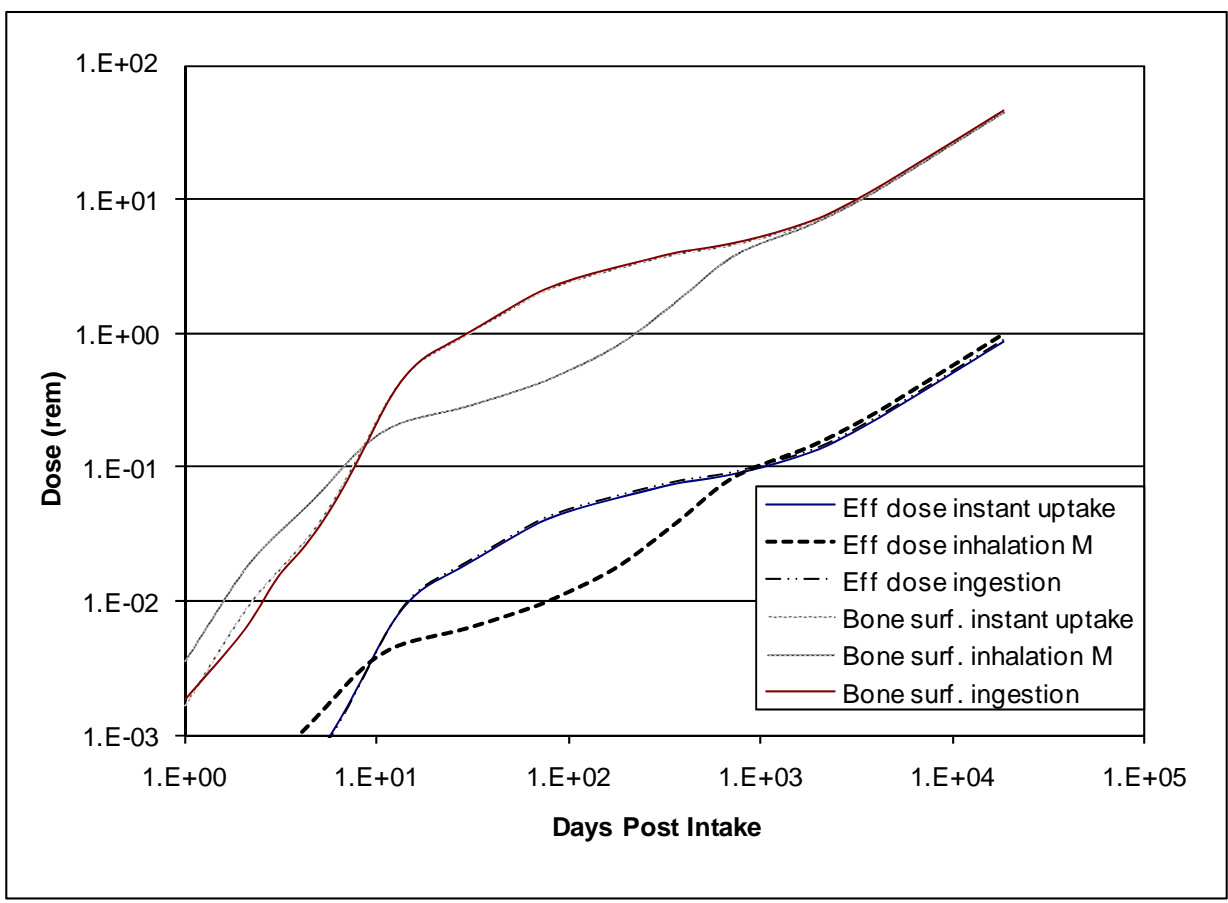

Figure 10.6. Minimum Detectable Committed Effective and Bone Surface Equivalent Doses for ${ }^{237} \mathrm{~Np}$ Based on Detection of $0.02 \mathrm{dpm} / \mathrm{d}$ in Urine. The instantaneous uptake and ingestion curves overlap. 
Table 10.15. Minimum Detectable Intakes (nCi) for ${ }^{237} \mathrm{~Np}$ Based on Detection of $0.1 \mathrm{dpm} / \mathrm{d}{ }^{237} \mathrm{~Np}$ in Feces

\begin{tabular}{ccc}
\hline $\begin{array}{c}\text { Days Post } \\
\text { Intake }\end{array}$ & Type M Inhalation & Ingestion \\
\hline 1 & $4.16 \mathrm{E}-04$ & $1.60 \mathrm{E}-04$ \\
2 & $2.91 \mathrm{E}-04$ & $1.16 \mathrm{E}-04$ \\
3 & $5.66 \mathrm{E}-04$ & $2.29 \mathrm{E}-04$ \\
5 & $3.39 \mathrm{E}-03$ & $1.43 \mathrm{E}-03$ \\
7 & $1.95 \mathrm{E}-02$ & $1.03 \mathrm{E}-02$ \\
10 & $7.86 \mathrm{E}-02$ & $2.05 \mathrm{E}-01$ \\
14 & $1.04 \mathrm{E}-01$ & $1.12 \mathrm{E}+01$ \\
20 & $1.23 \mathrm{E}-01$ & $2.41 \mathrm{E}+03$ \\
30 & $1.62 \mathrm{E}-01$ & NA \\
60 & $3.52 \mathrm{E}-01$ & NA \\
90 & $7.03 \mathrm{E}-01$ & NA \\
180 & $2.97 \mathrm{E}+00$ & NA \\
365 & $1.09 \mathrm{E}+01$ & NA \\
$2 \mathrm{y}$ & $5.44 \mathrm{E}+01$ & NA \\
\hline NA = not applicable & & \\
\hline
\end{tabular}

Table 10.16. Minimum Detectable Committed Effective and Bone Surface Equivalent Dose for ${ }^{237} \mathrm{~Np}$ Based on Detection of $0.1 \mathrm{dpm} / \mathrm{d}{ }^{237} \mathrm{~Np}$ in Feces

\begin{tabular}{ccccc}
\hline & \multicolumn{2}{c}{ Effective Dose (rem) } & \multicolumn{2}{c}{ Bone Surface Equivalent Dose (rem) } \\
\cline { 2 - 5 } Days Post Intake & Inhalation & & Inhalation & Type M \\
\hline 1 & Type M & Ingestion & $1.03 \mathrm{E}-03$ & Ingestion \\
\hline 2 & $2.25 \mathrm{E}-05$ & $6.30 \mathrm{E}-08$ & $7.19 \mathrm{E}-04$ & $2.33 \mathrm{E}-06$ \\
3 & $1.57 \mathrm{E}-05$ & $4.58 \mathrm{E}-08$ & $1.40 \mathrm{E}-03$ & $4.60 \mathrm{E}-06$ \\
5 & $3.05 \mathrm{E}-05$ & $9.04 \mathrm{E}-08$ & $8.37 \mathrm{E}-03$ & $2.88 \mathrm{E}-05$ \\
7 & $1.83 \mathrm{E}-04$ & $5.67 \mathrm{E}-07$ & $4.82 \mathrm{E}-02$ & $2.07 \mathrm{E}-04$ \\
10 & $1.05 \mathrm{E}-03$ & $4.06 \mathrm{E}-06$ & $1.94 \mathrm{E}-01$ & $4.12 \mathrm{E}-03$ \\
14 & $4.24 \mathrm{E}-03$ & $8.10 \mathrm{E}-05$ & $2.57 \mathrm{E}-01$ & $2.24 \mathrm{E}-01$ \\
20 & $5.62 \mathrm{E}-03$ & $4.41 \mathrm{E}-03$ & $3.05 \mathrm{E}-01$ & $4.85 \mathrm{E}+01$ \\
30 & $6.67 \mathrm{E}-03$ & $9.53 \mathrm{E}-01$ & $4.01 \mathrm{E}-01$ & NA \\
60 & $8.76 \mathrm{E}-03$ & NA & $8.70 \mathrm{E}-01$ & NA \\
90 & $1.90 \mathrm{E}-02$ & NA & $1.74 \mathrm{E}+00$ & NA \\
180 & $3.80 \mathrm{E}-02$ & NA & $7.33 \mathrm{E}+00$ & NA \\
365 & $1.60 \mathrm{E}-01$ & NA & $2.69 \mathrm{E}+01$ & NA \\
2 y & $5.88 \mathrm{E}-01$ & NA & $1.34 \mathrm{E}+02$ & NA \\
\hline NA = not applicable & $2.94 \mathrm{E}+00$ & NA & &
\end{tabular}




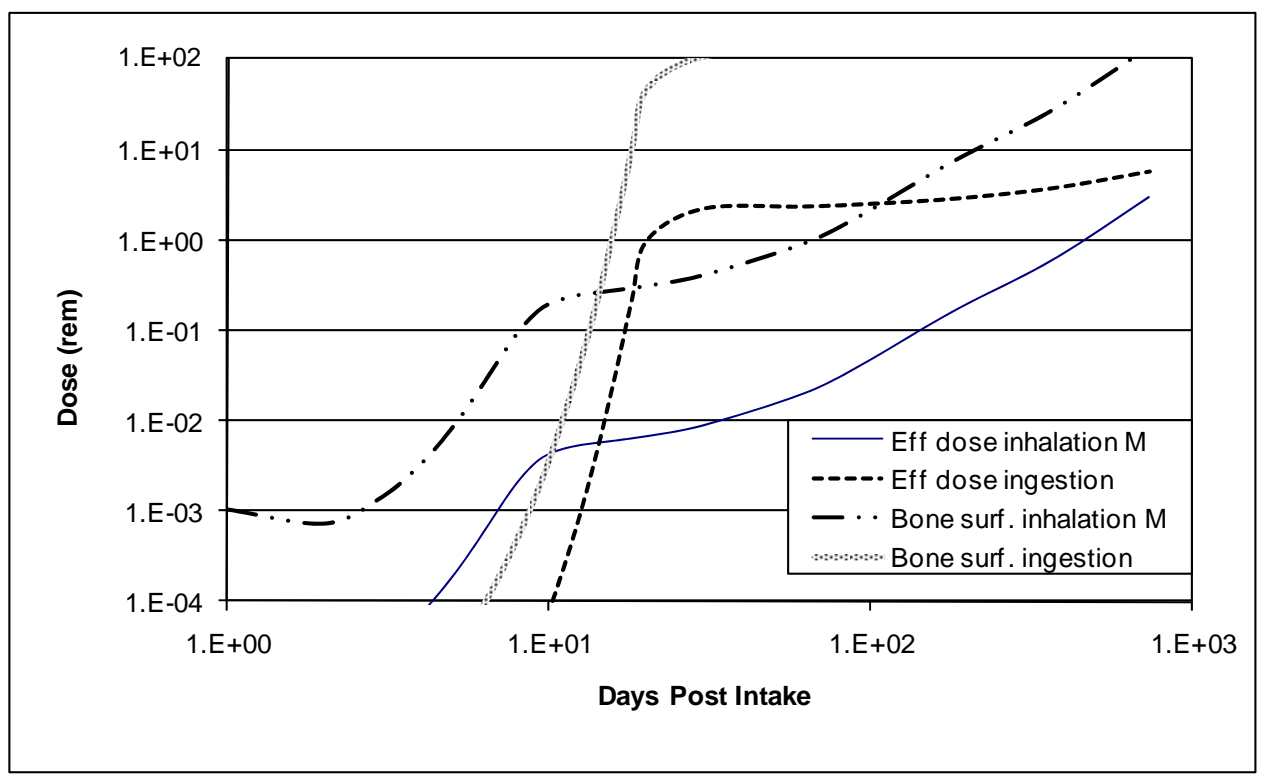

Figure 10.7. Minimum Detectable Committed Effective and Bone Surface Equivalent Doses for ${ }^{237} \mathrm{~Np}$ Based on Detection of $0.1 \mathrm{dpm} / \mathrm{d}$ in Feces

\subsubsection{In Vivo Bioassay Techniques for ${ }^{237} \mathrm{~Np}$}

In vivo whole body or chest counting can also be used to monitor for intakes of ${ }^{237} \mathrm{~Np}$, although in general neither method is as sensitive as urinalysis. Whole body counting can be accomplished using the 312-keV photon from ${ }^{233} \mathrm{~Pa}$ and chest counting can be accomplished using the $86-\mathrm{keV}$ photon from ${ }^{237} \mathrm{~Np}$. The minimum detectable acute intakes based on the 4.8-nCi minimum detectable activity (MDA) for a whole body count (standup counter) for ${ }^{233} \mathrm{~Pa}$ are shown in Table 10.17. The committed effective and bone surface equivalent doses associated with those intakes are shown in Table 10.18, and Figure 10.8 shows graphical presentations of the minimum detectable doses. The minimum detectable acute intakes based on the 0.71-nCi MDA for a chest count for ${ }^{237} \mathrm{~Np}$ are shown in Table 10.19. The committed effective and bone surface equivalent doses associated with those intakes are also shown in Table 10.19 and Figure 10.9 shows graphical presentations of the minimum detectable doses.

Except for ingestion intakes, whole body counting cannot detect the 100-mrem effective dose bioassay goal. The 50-rem regulatory limit for the bone surface cannot be met for an instantaneous uptake and can only be met within the first 3 days for an inhalation if the coaxial counter is used. Chest counting is slightly more sensitive than whole body counting for an inhalation intake, with the regulatory limit for the bone surface being met for somewhat over 30 days after an acute intake. 
Table 10.17. Minimum Detectable Intakes (nCi) for ${ }^{237} \mathrm{~Np}$ Based on Detection of $4.8 \mathrm{nCi}$ of ${ }^{233} \mathrm{~Pa}$ in the Whole Body ${ }^{\text {(a) }}$

\begin{tabular}{cccc}
\hline $\begin{array}{c}\text { Days Post } \\
\text { Intake }\end{array}$ & $\begin{array}{c}\text { Instant. } \\
\text { Uptake }\end{array}$ & $\begin{array}{c}\text { Type M } \\
\text { Inhalation }\end{array}$ & Ingestion \\
\hline 1 & $6.16 \mathrm{E}+00$ & $9.77 \mathrm{E}+00$ & $6.69 \mathrm{E}+00$ \\
2 & $6.54 \mathrm{E}+00$ & $1.87 \mathrm{E}+01$ & $1.46 \mathrm{E}+01$ \\
5 & $7.00 \mathrm{E}+00$ & $5.66 \mathrm{E}+01$ & $2.52 \mathrm{E}+02$ \\
7 & $7.12 \mathrm{E}+00$ & $6.42 \mathrm{E}+01$ & $1.66 \mathrm{E}+03$ \\
14 & $7.23 \mathrm{E}+00$ & $6.93 \mathrm{E}+01$ & $1.44 \mathrm{E}+04$ \\
30 & $7.31 \mathrm{E}+00$ & $7.69 \mathrm{E}+01$ & $1.46 \mathrm{E}+04$ \\
60 & $7.40 \mathrm{E}+00$ & $8.77 \mathrm{E}+01$ & $1.48 \mathrm{E}+04$ \\
90 & $7.48 \mathrm{E}+00$ & $9.50 \mathrm{E}+01$ & $1.50 \mathrm{E}+04$ \\
180 & $7.63 \mathrm{E}+00$ & $1.08 \mathrm{E}+02$ & $1.53 \mathrm{E}+04$ \\
365 & $7.88 \mathrm{E}+00$ & $1.21 \mathrm{E}+02$ & $1.58 \mathrm{E}+04$ \\
$2 \mathrm{y}$ & $8.34 \mathrm{E}+00$ & $1.33 \mathrm{E}+02$ & $1.67 \mathrm{E}+04$ \\
$5 \mathrm{y}$ & $9.60 \mathrm{E}+00$ & $1.54 \mathrm{E}+02$ & $1.92 \mathrm{E}+04$ \\
$10 \mathrm{y}$ & $1.14 \mathrm{E}+01$ & $1.84 \mathrm{E}+02$ & $2.28 \mathrm{E}+04$ \\
\hline
\end{tabular}

(a) The MDA for the coaxial counter is $3.5 \mathrm{nCi}$ so multiply the values above by 0.729 to obtain the minimum detectable intakes for the coaxial counter. 
Table 10.18. Minimum Detectable Committed Effective and Bone Surface Equivalent Dose for ${ }^{237} \mathrm{~Np}$ Based on Detection of $4.8 \mathrm{nCi}^{233} \mathrm{~Pa}$ in a Whole Body Count ${ }^{(\mathrm{a})}$

\begin{tabular}{ccccccc}
\hline & \multicolumn{3}{c}{ Effective Dose (rem) } & \multicolumn{3}{c}{ Bone Surface Equivalent Dose (rem) } \\
\cline { 2 - 7 } $\begin{array}{c}\text { Days Post } \\
\text { Intake }\end{array}$ & $\begin{array}{c}\text { Instantaneous } \\
\text { Uptake }\end{array}$ & $\begin{array}{c}\text { Inhalation } \\
\text { Type } M\end{array}$ & Ingestion & $\begin{array}{c}\text { Instantaneous } \\
\text { Uptake }\end{array}$ & $\begin{array}{c}\text { Inhalation } \\
\text { Type M }\end{array}$ & Ingestion \\
\hline 1 & $4.68 \mathrm{E}+00$ & $5.28 \mathrm{E}-01$ & $2.64 \mathrm{E}-03$ & $2.47 \mathrm{E}+02$ & $2.41 \mathrm{E}+01$ & $1.34 \mathrm{E}-01$ \\
2 & $4.97 \mathrm{E}+00$ & $1.01 \mathrm{E}+00$ & $5.77 \mathrm{E}-03$ & $2.63 \mathrm{E}+02$ & $4.63 \mathrm{E}+01$ & $2.94 \mathrm{E}-01$ \\
5 & $5.32 \mathrm{E}+00$ & $3.05 \mathrm{E}+00$ & $9.94 \mathrm{E}-02$ & $2.81 \mathrm{E}+02$ & $1.40 \mathrm{E}+02$ & $5.06 \mathrm{E}+00$ \\
7 & $5.41 \mathrm{E}+00$ & $3.47 \mathrm{E}+00$ & $6.54 \mathrm{E}-01$ & $2.86 \mathrm{E}+02$ & $1.59 \mathrm{E}+02$ & $3.33 \mathrm{E}+01$ \\
14 & $5.50 \mathrm{E}+00$ & $3.74 \mathrm{E}+00$ & $5.67 \mathrm{E}+00$ & $2.91 \mathrm{E}+02$ & $1.71 \mathrm{E}+02$ & $2.89 \mathrm{E}+02$ \\
30 & $5.55 \mathrm{E}+00$ & $4.15 \mathrm{E}+00$ & $5.77 \mathrm{E}+00$ & $2.94 \mathrm{E}+02$ & $1.90 \mathrm{E}+02$ & $2.94 \mathrm{E}+02$ \\
60 & $5.63 \mathrm{E}+00$ & $4.73 \mathrm{E}+00$ & $5.85 \mathrm{E}+00$ & $2.98 \mathrm{E}+02$ & $2.17 \mathrm{E}+02$ & $2.98 \mathrm{E}+02$ \\
90 & $5.68 \mathrm{E}+00$ & $5.13 \mathrm{E}+00$ & $5.91 \mathrm{E}+00$ & $3.01 \mathrm{E}+02$ & $2.35 \mathrm{E}+02$ & $3.01 \mathrm{E}+02$ \\
180 & $5.80 \mathrm{E}+00$ & $5.81 \mathrm{E}+00$ & $6.03 \mathrm{E}+00$ & $3.07 \mathrm{E}+02$ & $2.66 \mathrm{E}+02$ & $3.07 \mathrm{E}+02$ \\
365 & $5.99 \mathrm{E}+00$ & $6.51 \mathrm{E}+00$ & $6.23 \mathrm{E}+00$ & $3.17 \mathrm{E}+02$ & $2.98 \mathrm{E}+02$ & $3.17 \mathrm{E}+02$ \\
$2 \mathrm{y}$ & $6.34 \mathrm{E}+00$ & $7.17 \mathrm{E}+00$ & $6.59 \mathrm{E}+00$ & $3.35 \mathrm{E}+02$ & $3.28 \mathrm{E}+02$ & $3.35 \mathrm{E}+02$ \\
$5 \mathrm{y}$ & $7.29 \mathrm{E}+00$ & $8.33 \mathrm{E}+00$ & $7.58 \mathrm{E}+00$ & $3.86 \mathrm{E}+02$ & $3.81 \mathrm{E}+02$ & $3.86 \mathrm{E}+02$ \\
$10 \mathrm{y}$ & $8.67 \mathrm{E}+00$ & $9.93 \mathrm{E}+00$ & $9.01 \mathrm{E}+00$ & $4.59 \mathrm{E}+02$ & $4.54 \mathrm{E}+02$ & $4.59 \mathrm{E}+02$ \\
\hline
\end{tabular}

(a) The MDA for the coaxial counter is $3.5 \mathrm{nCi}$ so multiply the values above by 0.729 to obtain the minimum detectable intakes for the coaxial counter.

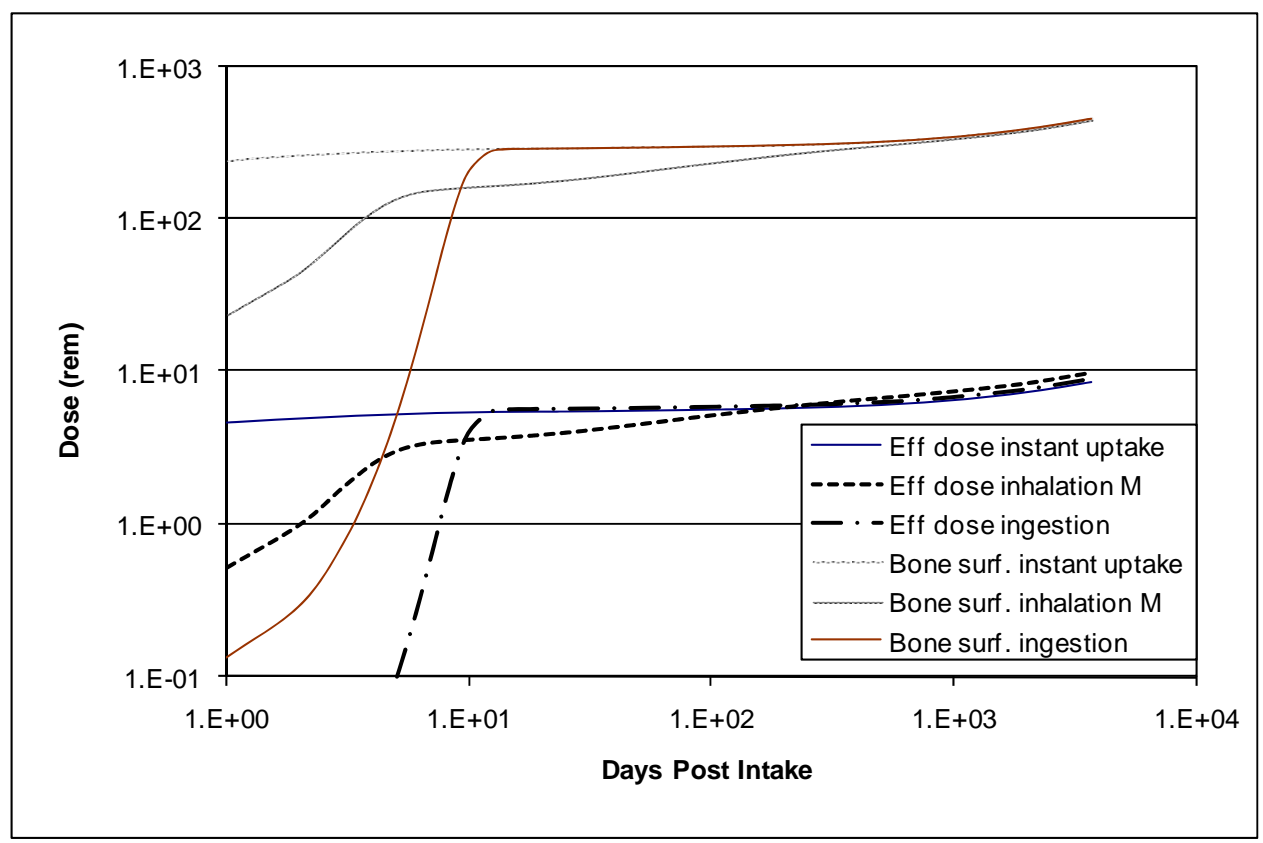

Figure 10.8. Minimum Detectable Committed Effective and Bone Surface Equivalent Doses for ${ }^{237} \mathrm{~Np}$ Based on Detection of $4.8 \mathrm{nCi}$ of ${ }^{233} \mathrm{~Pa}$ in a Whole Body Count 
Table 10.19. Minimum Detectable Intakes and Minimum Detectable Committed Effective and Bone Surface Equivalent Dose for ${ }^{237} \mathrm{~Np}$ Based on Detection of $0.71 \mathrm{nCi}{ }^{237} \mathrm{~Np}$ in the Lung, Type M Inhalation

\begin{tabular}{cccc}
\hline $\begin{array}{c}\text { Days Post } \\
\text { Intake }\end{array}$ & $\begin{array}{c}\text { Minimum Detectable } \\
\text { Intake (nCi) }\end{array}$ & $\begin{array}{c}\text { Minimum Detectable } \\
\text { Effective Dose (rem) }\end{array}$ & $\begin{array}{c}\text { Minimum Detectable } \\
\text { Bone Surface Equivalent } \\
\text { Dose (rem) }\end{array}$ \\
\hline 1 & $1.23 \mathrm{E}+01$ & $6.65 \mathrm{E}-01$ & $3.04 \mathrm{E}+01$ \\
2 & $1.27 \mathrm{E}+01$ & $6.85 \mathrm{E}-01$ & $3.14 \mathrm{E}+01$ \\
5 & $1.33 \mathrm{E}+01$ & $7.18 \mathrm{E}-01$ & $3.29 \mathrm{E}+01$ \\
7 & $1.37 \mathrm{E}+01$ & $7.40 \mathrm{E}-01$ & $3.38 \mathrm{E}+01$ \\
14 & $1.51 \mathrm{E}+01$ & $8.16 \mathrm{E}-01$ & $3.73 \mathrm{E}+01$ \\
30 & $1.85 \mathrm{E}+01$ & $9.99 \mathrm{E}-01$ & $4.57 \mathrm{E}+01$ \\
60 & $2.53 \mathrm{E}+01$ & $1.36 \mathrm{E}+00$ & $6.24 \mathrm{E}+01$ \\
90 & $3.25 \mathrm{E}+01$ & $1.76 \mathrm{E}+00$ & $8.04 \mathrm{E}+01$ \\
180 & $5.95 \mathrm{E}+01$ & $3.22 \mathrm{E}+00$ & $1.47 \mathrm{E}+02$ \\
365 & $1.78 \mathrm{E}+02$ & $9.60 \mathrm{E}+00$ & $4.39 \mathrm{E}+02$ \\
$2 \mathrm{y}$ & $1.48 \mathrm{E}+03$ & $7.98 \mathrm{E}+01$ & $3.65 \mathrm{E}+03$ \\
\hline
\end{tabular}

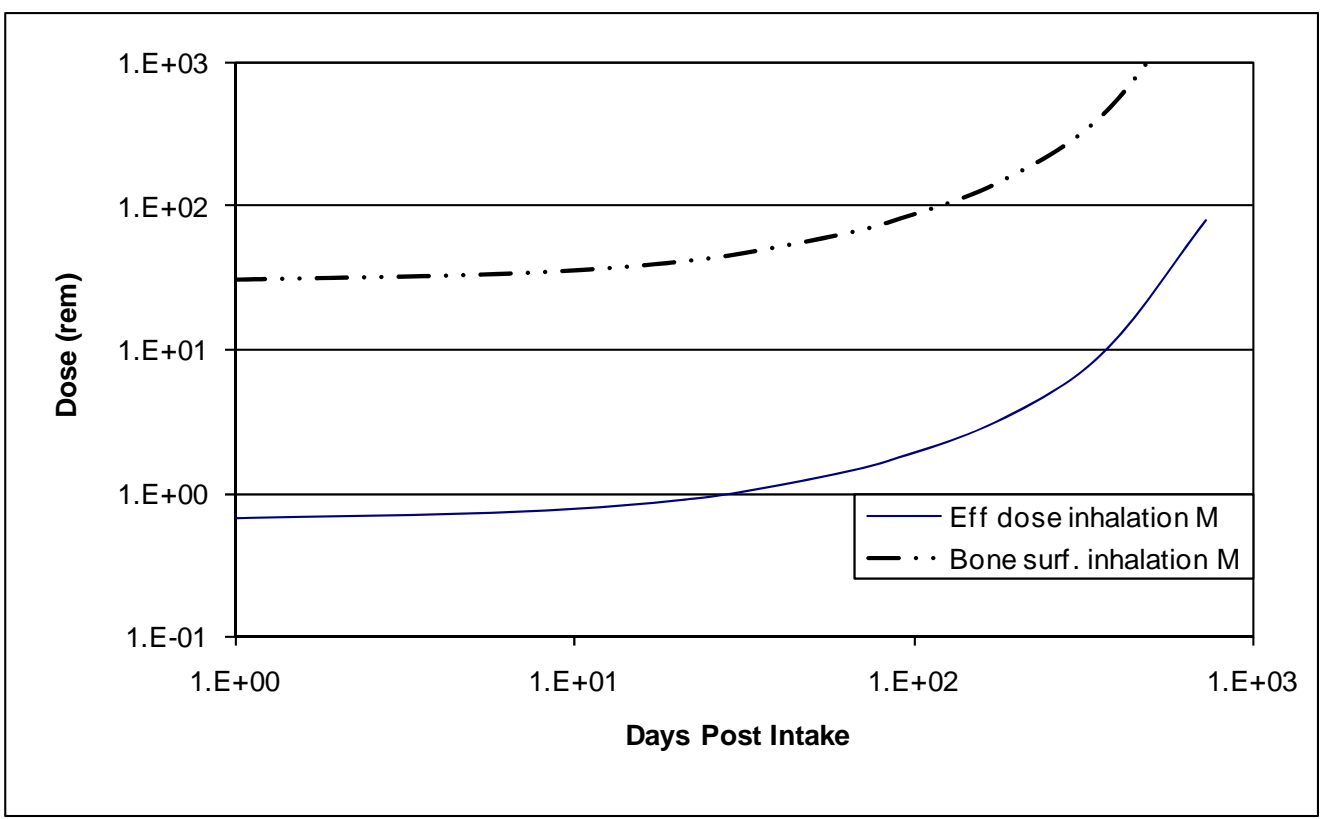

Figure 10.9. Minimum Detectable Committed Effective and Bone Surface Equivalent Doses for ${ }^{237} \mathrm{~Np}$ Based on Detection of $0.71 \mathrm{nCi}^{237} \mathrm{~Np}$ in a Chest Count

\subsubsection{Recommended Periodic Bioassay Monitoring Protocol}

Based on Table 10.14, an annual urine sampling program is recommended for monitoring intakes of pure ${ }^{237} \mathrm{~Np}$. Such a program is capable of demonstrating regulatory compliance with both stochastic and deterministic dose limits, and can detect intakes at the 100-mrem effective dose goal up to 2 years after an acute intake. Hence, unlike plutonium, no technology shortfall exists for pure ${ }^{237} \mathrm{~Np}$. Keep in mind, however, that plutonium may also be present in the intake mixture and it might add significantly to the dose. 


\subsubsection{Special Monitoring for Suspected Intakes}

Special bioassay monitoring for suspected inhalation, wounds, or ingestion intakes should include as a minimum a urine sample, and at least one (preferably two or more) fecal samples. Unless it is known that the intake material did not have any plutonium, the urine and fecal samples should also be analyzed for plutonium (isotopes 238 and 239+240). For inhalation intakes, both urine and fecal samples should be able to detect intakes resulting in committed effective doses in the range of a few millirem to tens of millirem up to three months after the intake. If an intake approaching a regulatory limit is suspected, one or more prompt chest counts should also be obtained. Resolution of contributions from both inhalation and ingestion can be made by obtaining urine and fecal samples shortly after intake and again at 20 or more days after intake and comparing the fecal-to-urine activity ratios to Table 10.7 values. For significant intakes, multiple urine and fecal samples obtained over several months is appropriate.

For potential wound intakes, special bioassay should consist of a wound count and a urine sample. If an intake approaching a regulatory limit is suspected, a whole body count with the wound shielded should also be obtained. Fecal sampling is not necessary for wound dosimetry; however, data about the fecal excretion following a wound can provide information which may be valuable to improving metabolic models.

\subsection{Assessment of Internal Dose}

Assessments of internal dose for neptunium rely on evaluations of intake based on urine, fecal, or in vivo data. For significant cases, it may be possible to directly measure neptunium retention in the liver or tissue of interest using in vivo monitoring. Head counting for bone retention would be of interest to track relative changes over time; however, there is no calibration for converting head activity to total bone activity at the present.

\subsubsection{Intake Assessment}

An intake can be estimated by fitting the bioassay data to the appropriate retention or excretion function, using manual or computerized techniques. For a single data point, the intake can be estimated by dividing the measured excretion by the value of the retention function for the appropriate day after intake represented by the sample in a manner similar to Equation (2.5) in Chapter 2.0. Values for the retention function can be obtained from those tabulated in this chapter or directly from running the IMBA computer code. For multiple data points, use of the IMBA computer code is preferred.

\subsubsection{Assessing Organ and Effective Dose Equivalents}

Once the intake is calculated, appropriate internal doses may be calculated by applying the dose coefficients of this chapter (Table 10.8) to Equations (2.10) or (2.11) in Chapter 2.0. The IMBA computer code may also be used to directly calculate internal doses and is strongly recommended if any model parameters have been changed from the default ICRP values. The IMBA code will also have to be used if doses from chronic intake should happen to be needed. The organs of primary interest for ${ }^{237} \mathrm{~Np}$ dose evaluations (contributing 10\% or more to the effective dose) are the bone surface, red marrow, and gonads for instantaneous uptake and ingestion. The lung is included in the list for inhalation. In all modes of intake, the bone surface receives the highest organ dose and is more limiting relative to regulatory limits 
than the effective dose. Other organs or tissues may be of interest depending on the nature of an intake. For example, the dose to a specific lymph node or small volume of tissue may be of academic interest as the result of a wound intake of slowly transportable materials, even though doses to such tissues are not of regulatory concern. Such cases can be dealt with as they arise and are beyond the general scope of this technical basis.

Intakes from contaminants in a neptunium mixture can be included if the activity ratios of the contaminants to the neptunium are determined from analysis of the source of the intake. Doses from contaminants can be determined from dose coefficients in the other chapters in this manual. Do not input contaminants as associated radionuclides in the IMBA code unless the absorption type is the same as for neptunium (Type M).

\subsection{Management of Internal Contamination Cases}

This section discusses the diagnostic procedures, therapeutic actions, and long-term monitoring of internal depositions.

\subsubsection{Diagnostic Procedures}

The diagnosis of an intake involves a combination of workplace monitoring to identify on-the-job potential intakes and bioassay measurements to confirm and quantify internal contamination.

The primary method of identifying potential intakes is by workplace monitoring, such as personal contamination surveys, nasal smear analyses, air sample results, or workers' identifications of unusual conditions. These techniques provide qualitative screening to alert radiation protection staff to potential intake, rather than absolute confirmation that an intake has or has not occurred. For example, activity detected on nasal smears is usually an indication of an inhalation intake; however, the absence of activity does not necessarily mean that an intake did not occur. The absence of nasal smear activity following an inhalation intake can be explained by a sufficient delay between the time of intake and the collection of nasal smears to allow for complete clearance of activity from the nares. Alternatively, some individuals are mouth-breathers, whose noses are partially or completely bypassed in the respiratory process, hence no activity may be deposited in the nares, despite the occurrence of an inhalation intake. Particle size can also significantly affect nasal deposition and clearance.

Once a worker has been identified as having incurred a potential intake, the initial diagnostic measurements are arranged. For neptunium, urine sampling is the primary bioassay for all modes of intake. Depending on the intake mode and suspected severity of the intake, diagnostic measurements may include a wound count, single voiding (spot) urine sample, first-day fecal sampling, overnight urine sampling and chest count. The purpose of these initial procedures is to provide an order-of-magnitude estimate of the potential intake and dose. Initial diagnostic measurements are usually sufficient for final evaluations only when all results collectively rule out the possibility of an intake or show that the intake was very small. In reality, initial measurements are not generally expected to do this, and follow-up measurements are necessary. Follow-up diagnostic measurements should include additional urine samples and may include additional fecal samples, chest counts, or wound counts. Whole body counts, liver counts, head counts, and lymph node counts may also be considered for very significant intakes. These analyses aid in 
determining the magnitude, location, and retention characteristics of the deposited material. In some cases, blood samples or tissue specimens may also be appropriate.

In addition, workplace or clothing contamination analyses, air sample analyses, particle size analyses, or solubility analyses may be performed to more clearly define the physical and radiological characteristics of the material to which the worker was exposed. Of these, samples that can be analyzed to quantify the activity of other radionuclides in the intake source are most important.

It is the responsibility of the exposure evaluator, working closely with contractor radiation protection staff, to determine the appropriate diagnostic protocols. Scheduling of follow-up measurements will normally be done by the appropriate contractor radiation protection staff.

\subsubsection{Therapeutic Actions}

Therapeutic actions for potential internal contamination include the use of decorporation agents, catharsis, and surgical excision. For the purposes of this discussion, the normal skin decontamination procedures of Hanford contractors are not considered therapeutic actions, although it is acknowledged that these procedures can be quite effective in preventing the intake of radioactivity. The decision to undertake one or more of these therapeutic actions is the responsibility of the participating Occupational Medicine care provider with the concurrence of the patient. The exposure evaluator will provide advice and consultation to the physician and patient regarding the potential dose implications and efficacy of alternative actions. Guidance for the methods of therapy can be found in National Council on Radiation Protection and Measurements Report 65 (NCRP 1980) and in the "Guidebook for the Treatment of Accidental Internal Radionuclide Contamination of Workers” (Bhattacharyya et al. 1992). Guidance for circumstances under which therapy may be warranted is contained in PNL-MA-552 (EH Carbaugh, et al. 2009), but was established as a good practice based on experience rather than a detailed technical analysis.

Decorporation therapy, also referred to as chelation therapy, involves the chemical removal of radioactivity from the bloodstream through drug administration. Both the "Guidebook for the Treatment of Accidental Internal Radionuclide Contamination of Workers” and NCRP 65 identify DTPA (diethylene triamine pentaacetic acid) as the principal therapeutic agent for neptunium; however, NCRP 65 cautions that it might not be effective. Decorporation therapy may significantly enhance urinary excretion of neptunium, a point that must be considered when interpreting urine samples affected by therapy. Human data for chelation enhancement factors for neptunium are not available; however, the caution regarding its effectiveness suggests that a factor somewhat less than the 50 used for americium would be appropriate.

Surgical excision following wounds can be extremely effective in reducing the potential internal uptake, particularly when coupled with decorporation therapy.

For ingestions, the "Guidebook for the treatment of accidental internal radionuclide contamination of workers" recommends antiacids and absorbents. Catharsis, involving accelerating the passage of material through the GI tract by means of laxative drugs or physical means such as an enema, also has potential value in reducing the adsorption of material into the bloodstream from the GI tract and in reducing the dose to the GI tract organs from material passing through the GI tract. However, these measures are not generally considered for occupational exposures to neptunium because the GI tract adsorption of 
neptunium is slight and the dose to the GI tract organs is an insignificant fraction of the total effective dose.

\subsubsection{Long-Term Monitoring of Internal Depositions}

Once an internal dosimetry evaluation has been completed, it may be recommended that the worker be placed on a specialized long-term bioassay monitoring schedule. The reasons for this are twofold: first, long-term follow-up monitoring results that are consistent with the projected results verify the conclusions of the evaluation. Second, if long-term results are projected to be detectable and the worker returns to neptunium work, then the capability of a routine bioassay monitoring program to detect an additional intake may be affected. This issue must be addressed on an individual-specific basis.

\subsection{References}

10 CFR 835. 2007. “Occupation Radiation Protection.” Code of Federal Regulations. U.S. Department of Energy. Available at: http://www.access.gpo.gov

Beard SJ and BF Judson. 1959. The Palmolive Cycle at Hanford. HW-60827, Hanford Atomic Products Operation, Richland, Washington.

Bhattacharyya MH, BD Breitenstein, H Metivier, BA Muggenburg, GN Stradling, and V Volf. 1992. "Guidebook for the Treatment of Accidental Internal Radionuclide Contamination of Workers.” Rad. Prot. Dosim. 41:1.

Briggs JD. 2001. Historical Time Line and Information about the Hanford Site, Richland, Washington. PNNL-13524, Pacific Northwest National Laboratory, Richland, Washington.

Buckingham JS. 1959. Palm Purification Run 12-58. HW-58999, Hanford Atomic Products Operation, Richland, Washington.

Buckingham JS. 1961. Purification of REDOX Brandy. HW-71723, Hanford Atomic Products Operation, Richland, Washington.

Buckingham JS. 1963. Measurements of REDOX Produced Neptunium. HW-77058, Hanford Atomic Products Operation, Richland, Washington.

Buckingham JS. 1964. "Ion Exchange Purification of Americium-241 in the 222-S Building I-F Cubicle.” HW-84352, Hanford Atomic Products Operation, Richland, Washington.

Carbaugh EH, DE Bihl, JA MacLellan. 2009. Hanford Internal Dosimetry Program Manual. PNL-MA552, PNNL-15613, Pacific Northwest National Laboratory, Richland, Washington. (Internal manual.) Available at: http://www.pnl.gov/main/publications/external/technical_reports/PNNL-15613.pdf

Constable DW. 1967. Final Report PT-68 Results of N Reactor Neptunium Irradiation. DUN-2913. Douglas United Nuclear, Inc., Richland, Washington. 
Geier RG and HC Rathvon. 1961. PUREX Plant Birch Isolation Run April 1961. HW-69517, Hanford Atomic Products Operation, Richland, Washington.

Gifford AT (USAEC Hanford Operations Office). 1959a. “Palm Element Program.” HAN-72264. Letter to HM Parker, Manager Hanford Laboratories Operation.

Gifford AT (USAEC Hanford Operations Office). 1959b. Palm Element Program. HAN-73101. Letter to HM Parker, Manager Hanford Laboratories Operation. August 21

International Commission on Radiological Protection (ICRP). 1979. "Limits for Intakes of Radionuclides by Workers.” ICRP Publication 30, Part 1, Annals of the ICRP, 2:3-4, Pergamon Press, New York.

International Commission on Radiological Protection (ICRP). 1983. "Radionuclide Transformations: Energy and Intensity of Emissions.” ICRP Publication 38, Annals of the ICRP, Volumes 11-13, Pergamon Press, New York.

International Commission on Radiological Protection (ICRP). 1986. "The Metabolism of Plutonium and Related Elements.” ICRP Publication 48, Annals of the ICRP, 16:2-3, Pergamon Press, New York.

International Commission on Radiological Protection (ICRP). 1988. "Limits for Intakes of Radionuclides by Workers: An Addendum.” ICRP Publication 30, Part 4, Annals of the ICRP, 19:4, Pergamon Press, New York.

International Commission on Radiological Protection (ICRP). 1991. "1990 Recommendations of the International Commission on Radiological Protection.” ICRP Publication 60, Annals of the ICRP, 21:1-3, Pergamon Press, New York.

International Commission on Radiological Protection (ICRP). 1993. “Age-dependent Doses to Members of the Public from Intake of Radionuclides: Part 2 Ingestion Dose Coefficients.” ICRP Publication 67, Annals of the ICRP, 23:3-4, Pergamon Press, New York.

International Commission on Radiological Protection (ICRP). 1994a. "Dose Coefficients for Intakes of Radionuclides by Workers.” ICRP Publication 68, Annals of the ICRP, 24:4, Pergamon Press, New York.

International Commission on Radiological Protection (ICRP). 1994b. "Human Respiratory Tract Model for Radiological Protection.” ICRP Publication 66, Annals of the ICRP, 24:1-3, Pergamon Press, New York.

International Commission on Radiological Protection (ICRP). 1997. "Individual Monitoring for Internal Exposure of Workers. ICRP Publication 78, Annals of the ICRP, 27:3-4, Pergamon Press, New York.

James AC, A Birchall, JW Marsh, and M Puncher. 2004 or current version. User Manual for IMBA Expert, USDOE-Edition (Phase II). ACJ \& Associates, Richland, Washington. (Current version is available electronically as part of the IMBA Professional Plus software code.)

Judson BF. 1958. The Recovery of Neptunium-237 and Production of Plutonium-238 at Hanford. HW-56556 DEL, Hanford Atomic Products Operation, Richland, Washington. 
Kocher DC. 1981. Radioactive Decay Data Tables, a Handbook of Decay Data for Application to Radiation Dosimetry and Radiological Assessments. DOE/TIC-11026, Technical Information Center, U.S. Department of Energy, Washington, D.C.

National Council on Radiation Protection and Measurements (NCRP). 1980. Management of Persons Accidentally Contaminated with Radionuclides. NCRP Report No. 65, Bethesda, Maryland.

Popplewell DS, JD Harrison, and GJ Ham. 1991. "Gastrointestinal absorption of neptunium and curium in humans.” Health Phys. 60(6)797-805.

Ryan JL. 1959. Concentration and Final Purification of Neptunium by Anion Exchange. HW-59193, Hanford Atomic Products Operation, Richland, Washington.

Sheppard JC and GW Becker. 1957. Palm Recovery Progress Report. HW-49825, Hanford Atomic Products Operation, Richland, Washington.

Soine TS and GE Benedict. 1968. Chemical Processing of Irradiated Targets from Hanford's Plutonium-238 Demonstration Program, Part I: N-Reactor Neptunium-Aluminum Alloy Elements. BNWL-CC-1762 1, Battelle Northwest, Richland, Washington.

Sula MJ, EH Carbaugh, and DE Bihl. 1989. Technical Basis for Internal Dosimetry at Hanford. PNL-6866, Pacific Northwest Laboratory, Richland, Washington.

Travis JE (USAEC Hanford Operations Office). 1958. "Status Report on the Palmolive Program September - December 1958.” HAN-70924, Letter to EJ Bloch, USAEC Washington, D.C., dated December 30.

Wheelwright EJ. 1970. Recovery and Purification of Plutonium and Neptunium from Irradiated $\mathrm{NpO}_{2}-$ Al and $\mathrm{NpO}_{2}-$ Graphite Targets. BNWL-B-6, Battelle Northwest Laboratory, Richland, Washington. 


\title{
Methods and Models of the Hanford Internal Dosimetry Program \\ PNNL-MA-860
}

\subsection{Cobalt-60 and Corrosion Products}

\author{
Issued for implementation effective 01/01/2010
}

Supersedes: September 12, 2000

\section{Use Category: Not applicable}

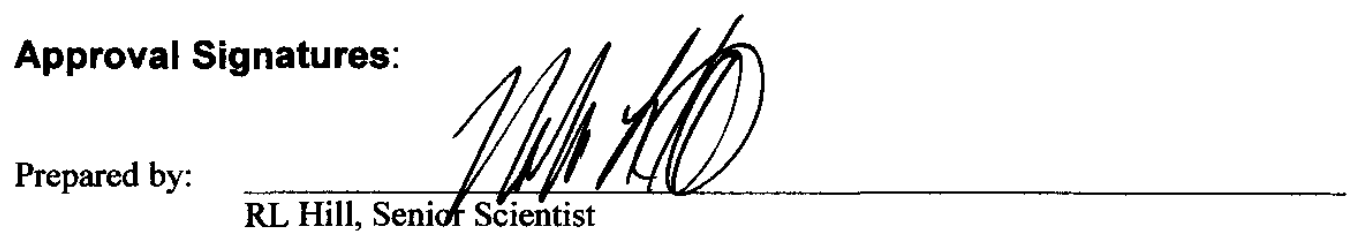

Approved by:

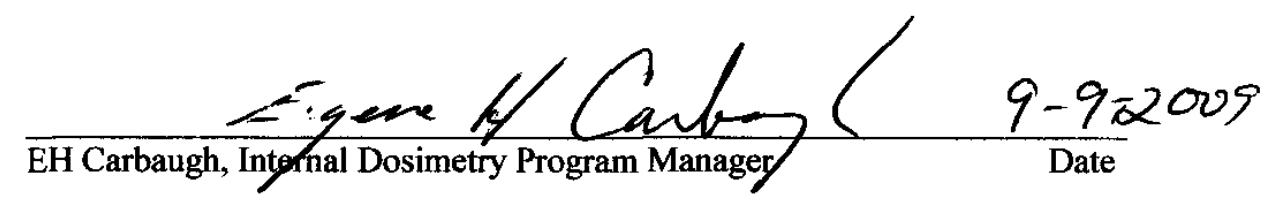

\section{Reviewer Signatures:}

Reviewed by:

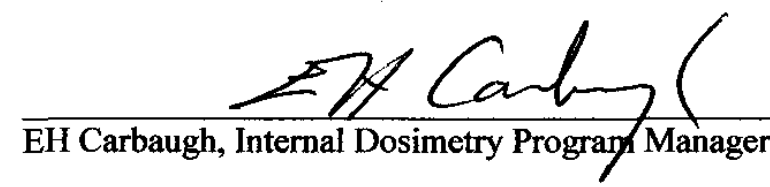

Approved by the Hanford Personnel Dosimetry Advisory Committee as recorded in the meeting minutes of March 10, 2009. 


\section{Contents}

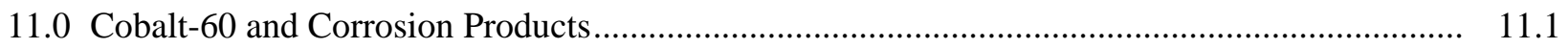

11.1 Sources and Characteristics of Corrosion Product Radionuclides.................................... 11.1

11.2 Biokinetic Behavior of Corrosion Product Radionuclides............................................... 11.2

11.2.1 Absorption Type .................................................................................... 11.2

11.2.2 Gastrointestinal Uptake to Blood (f1) .............................................................. 11.3

11.2.3 Biokinetic Models ............................................................................................. 11.3

11.3 Internal Dosimetry Factors for Cobalt ..................................................................... 11.3

11.3.1 Whole Body Retention for Cobalt ................................................................ 11.4

11.3.2 Dose Coefficients......................................................................................... 11.4

11.3.3 Comparison of Published Dosimetry Factors .................................................. 11.7

11.3.4 Derived Air Concentrations and Annual Limits on Intake .................................. 11.8

11.3.5 Derived Reference Levels............................................................................ 11.8

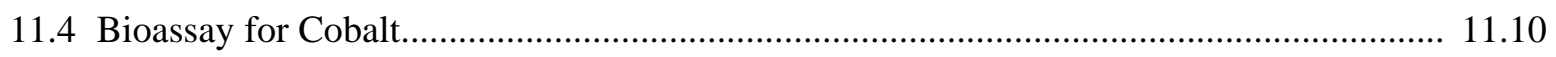

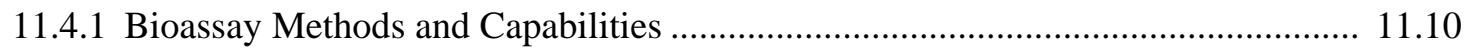

11.4.2 Routine Bioassay Monitoring Protocol............................................................. 11.11

11.4.3 Special Monitoring for Suspected Intakes ........................................................ 11.12

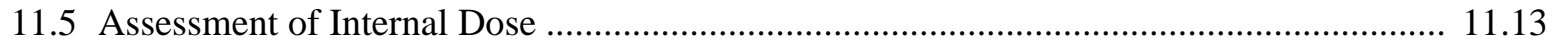

11.6 Management of Internal Contamination Cases............................................................ 11.14

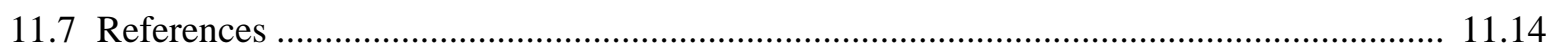

\section{Figures}

11.1 Retention of ${ }^{60} \mathrm{Co}$ in Whole Body as a Fraction of an Acute Inhalation Intake of 1- $\mu \mathrm{m}$ AMAD and 5- $\mu$ m-AMAD Particle Sizes .......................................................................... 11.5

11.2 Retention of ${ }^{60} \mathrm{Co}$ in Whole Body as a Fraction of Ingestion and Injection ............................ 11.6

\section{Tables}

11.1 Radiological Data for Common Corrosion Products ........................................................ 11.2

11.2 Lung Absorption and GI Uptake Factors for Cobalt ....................................................... 11.3

11.3 Biokinetic Model Parameters for Cobalt......................................................................... 11.4

11.4 Fractional Whole Body Retention from Inhalation of ${ }^{60} \mathrm{Co}$................................................... 11.5

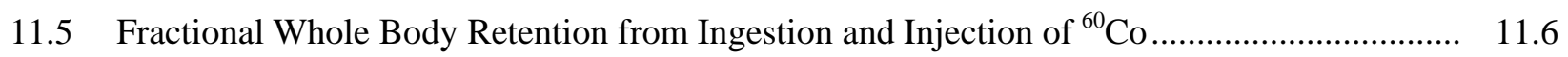


11.6 Committed Dose Coefficients for ${ }^{60}$ Cobalt, rem $/ \mathrm{nCi}$..................................................... 11.7

11.7 Comparison of ${ }^{60} \mathrm{Co}$ Committed Effective Dose Coefficients ............................................ 11.7

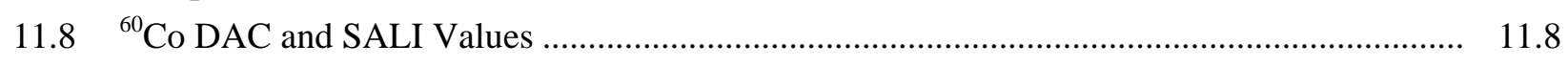

$11.9{ }^{60}$ Co Reference Values for Type M Inhalation....................................................................... 11.9

$11.10{ }^{60}$ Co Reference Values for Type S Inhalation ................................................................. 11.9

$11.1{ }^{60}$ Co Reference Values for Ingestion and Injection ............................................................ 11.10

11.12 Hanford In Vivo Measurement Detection Capability for ${ }^{60}$ Co............................................. 11.10

11.2 ${ }^{60}$ Co Minimum Detectable Intakes and Committed Effective Doses for Type M

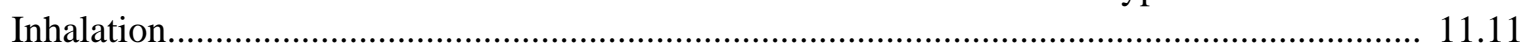

11.14 ${ }^{60}$ Co Minimum Detectable Intakes and Committed Effective Doses for Type S Inhalation.

11.15 ${ }^{60}$ Co Minimum Detectable Intakes and Committed Effective Doses for Ingestion and

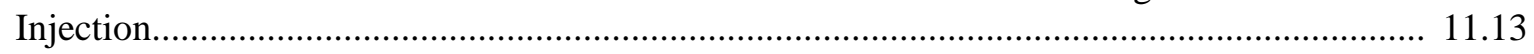





\subsection{Cobalt-60 and Corrosion Products}

This chapter provides background on the sources, characteristics, and biokinetic behavior of ${ }^{60} \mathrm{Co}$ and other corrosion product radionuclides and summarizes the technical basis used for their internal dosimetry at Hanford. This revision to the internal dosimetry approach for cobalt implements the International Commission on Radiological Protection lung model presented in its Publication 66 (ICRP 1994b) and the biokinetic model for cobalt presented in ICRP 30 Part 1 (1979), ICRP 68 (1994a), and ICRP 78 (1997). The ICRP 30 gastrointestinal (GI) model is still used (ICRP 1979) except that uptake factors from the gut to the blood, $f_{1}$, have been updated as presented in ICRP 68 (1994a). For dose calculations, tissues and tissue weighting factors introduced in ICRP 60 (1991) and adopted in the June 2007 revision of Title 10 of the Code of Federal Regulations Part 835 (10 CFR 835) are used. All excretion, retention, and dose coefficients were calculated using the Integrated Modules for Bioassay Analysis (IMBA) Professional Plus internal dosimetry computer code, v. 4.043 (James et al. 2004). ${ }^{1}$

\subsection{Sources and Characteristics of Corrosion Product Radionuclides}

Corrosion product radionuclides are created by neutron activation of reactor components such as piping or fuel element cladding. The principal sources of corrosion product radionuclides at Hanford are the old reactor facilities, such as N Reactor (operated until 1986); however, the Fast Flux Test Facility can also be a source. In addition, corrosion products can be found in workers who have had intakes at other nuclear facilities, notably nuclear power plants or naval shipyards servicing nuclear-powered vessels. Corrosion product radionuclides are generally high-energy gamma-emitters. Therefore, bioassay monitoring can be readily accomplished by whole body counting. Historically, fresh corrosion product radionuclides were usually a mixture of several radionuclides regardless of origin. The predominant radionuclides were ${ }^{60} \mathrm{Co}$, with ${ }^{58} \mathrm{Co},{ }^{54} \mathrm{Mn}$, and ${ }^{59} \mathrm{Fe}$ as the other significant constituents in a fresh mixture. Radiological decay data for the common corrosion products are shown in Table 11.1. Other radionuclides were often present in trace amounts, but they were generally of little dosimetric consequence. The relative abundance of the radionuclides varied from facility to facility. Given the time elapsed since operation of the reactors at Hanford, the short-lived corrosion products have decayed away, leaving ${ }^{60} \mathrm{Co}$ as the radionuclide of concern.

A detailed characterization of these corrosion products during $\mathrm{N}$ Reactor operations was performed by Weetman and DeHaven (1982a, 1982b). This work indicated that airborne particulates containing corrosion product radionuclides could be characterized by a lognormal distribution with an activity median aerodynamic diameter (AMAD) ranging from $0.5 \mu \mathrm{m}$ to $2.5 \mu \mathrm{m}$. With over 20 years of elapsed time since the reactor operations were shut down, and over 25 years since the characterization was performed, there has been ample time for particle growth by agglomeration, oxidation, and hygroscopy. Thus, larger particle sizes than originally indicated are considered most likely. The dosimetric significance of $1-\mu \mathrm{m}$ versus $5-\mu \mathrm{m}$ particles is around $10 \%$ or less for routine monitoring intervals of 0.5 to 2 years (typical interval is 1 year), as shown in Tables 11.13 and 11.14. Consequently, for purposes of

\footnotetext{
${ }^{1}$ IMBA Professional Plus, which includes the current version of the user manual, is available from Health Protection Agency (HPA), Radiation Protection Division, Chilton, Didicot, Oxon., OX11 ORQ UK and from http://www.imbaprofessional.com/
} 
program design and most occupational dose assessments, the ICRP 66 (1994b) recommendation to use a 5- $\mu \mathrm{m}-\mathrm{AMAD}$ particle size will be used as a default assumption.

Table 11.1. Radiological Data for Common Corrosion Products

\begin{tabular}{lccc}
\hline Isotope & Half-Life & Decay Constant & Specific Activity (Ci/g) \\
\hline${ }^{60} \mathrm{Co}$ & $5.27 \mathrm{y}$ & $1.32 \mathrm{E}-01 \mathrm{y}^{-1}$ & $1.13 \mathrm{E}+03$ \\
${ }^{58} \mathrm{Co}$ & $70.8 \mathrm{~d}$ & $9.79 \mathrm{E}-03 \mathrm{~d}^{-1}$ & $3.18 \mathrm{E}+04$ \\
${ }^{54} \mathrm{Mn}$ & $312.5 \mathrm{~d}^{\text {(a) }}$ & $2.22 \mathrm{E}-03 \mathrm{~d}^{-1}$ & $7.74 \mathrm{E}+03$ \\
${ }^{59} \mathrm{Fe}$ & $44.53 \mathrm{~d}^{\text {(b) }}$ & $1.56 \mathrm{E}-02 \mathrm{~d}^{-1}$ & $4.97 \mathrm{E}+04$ \\
\hline
\end{tabular}

(a) Half-life values are: 312.5 d (IMBA 2007), 312.7 d (Kocher 1981), and 312 d (ICRP 68 1994a).

(b) Half-life values are: 44.53 d (IMBA 2007), 44.63 d (Kocher 1981), and $44.5 \mathrm{~d}$ (ICRP 68 1994a).

For mixtures containing corrosion product radionuclides, the pulmonary retention of the individual radionuclides is probably influenced by the contaminant carrier matrix. Thus, pulmonary retention for all of the radionuclides within a single carrier matrix may be similar. Oxides characteristically represent the least transportable form of an element in the lung. For purposes of a priori calculations of expected dose from intake, the absorption type for the oxide form of the radionuclide is assumed. Nevertheless, retrospective assessment of internal dose following an intake should be based on actual observed retention in the lung.

\subsection{Biokinetic Behavior of Corrosion Product Radionuclides}

The biokinetic behavior of corrosion product radionuclides in the body is influenced by the physical and chemical properties of the host matrix as well as the individual elements composing the matrix. The actual behavior of the material following intake is dependent on numerous complex and competing factors. Although there have been numerous historical cases involving inhalation intakes of corrosion products at Hanford, the intakes involved have been too small to enable the specific radionuclide versus host matrix characteristics to be accurately described. The approach taken here is to assume that the radionuclide behaves according to the most insoluble form established for the element in ICRP 68 (1994a) unless sufficient in vivo data are available and the intake is of sufficient magnitude (e.g., potentially above $100 \mathrm{mrem}$ ) to warrant evaluation of individual-specific retention.

\subsubsection{Absorption Type}

ICRP 68 establishes default inhalation absorption types of Type M (for moderate rate of solubilization) and Type S (for slow) for cobalt. The IMBA computer code (James et al. 2004) implements the biokinetic models described in ICRP 30 for cobalt and is used to assess expected bioassay compartment quantities following intakes of the corrosion products. The biokinetic parameters of IMBA can also be modified to provide a better agreement between observed and expected bioassay compartment values. 
The ICRP 66 lung model (ICRP 1994b) introduced the concept of inhalation absorption type as a replacement for the ICRP 30 inhalation class. Table 11.2 shows the inhalation absorption type tabulated in ICRP 67 (1993), ICRP 68 (1994a), ICRP 69 (1995), and ICRP 78 (1997).

Table 11.2. Lung Absorption and GI Uptake Factors for Cobalt

\begin{tabular}{llcc}
\hline Isotope & \multicolumn{1}{c}{ Chemical Form } & $\begin{array}{c}\text { Inhalation } \\
\text { Absorption Type }\end{array}$ & GI Uptake, $f_{1}$ \\
\hline${ }^{60} \mathrm{Co}$ & $\begin{array}{l}\text { Oxides, hydroxides, } \\
\text { halides, nitrates } \\
\text { All other compounds }\end{array}$ & $\mathrm{S}$ & 0.05 \\
& $\mathrm{M}$ & 0.1 \\
\hline
\end{tabular}

Because corrosion products are typically oxides, the oxide form of these elements is assumed for Hanford internal dosimetry unless other information is available. Consequently, the default inhalation class for Hanford intakes of cobalt is absorption Type S.

\subsubsection{Gastrointestinal Uptake to Blood $\left(f_{1}\right)$}

The GI uptake $\left(f_{1}\right)$ factors for the corrosion products discussed in this section are shown in Table 11.2. No changes were made in the uptake factors for insoluble forms between ICRP 30 and ICRP 67 and ICRP 78. The uptake factor for moderately insoluble forms of cobalt is 0.1 for Type M and 0.05 for Type S.

\subsubsection{Biokinetic Models}

The ICRP 30 Part 1 (1979) model for cobalt is used for Hanford internal dosimetry. This model was also used in ICRP 68 and ICRP 78, as well as the IMBA computer code. Of the cobalt entering the blood stream, half (0.5) is excreted directly with a half-time of 0.5 days, with the remaining half $(0.5)$ distributed in the body. Of the amount distributed in the body, $10 \%$ is assumed to go to the liver and the remaining $90 \%$ is distributed throughout the rest of the body. The material deposited in body organs (other than lung) is removed from the organs at several rates. In the absence of retention data on a casespecific basis, the ICRP recommends that the fractional retention values of $0.6,0.2$, and 0.2 be used with respective biological half-lives of 6, 60, and 800 days for materials in the liver and rest of body. Because the retention characteristics are considered to be the same for the liver as for the rest of the body, the relative distribution can be assumed to be constant at $10 \%$ in the liver and $90 \%$ in all other body tissues (except lung). The biokinetic model parameters for cobalt are listed in Table 11.3.

One change was made in the model with respect to the urinary and fecal excretion rates. The urine to feces excretion ratio was changed to 6:1 in ICRP 67 and ICRP 78 from 7:1 in ICRP 54 (1988).

\subsection{Internal Dosimetry Factors for Cobalt}

This section contains factors that are useful in making internal dosimetry calculations. The factors included in this section are derived from the IMBA (v. 4.0.43) computer code and incorporate the models 
and assumptions of the preceding sections. Their application is intended for circumstances where such assumptions are appropriate or more specific information is lacking. Variation from these factors is appropriate if sufficient data are available.

Table 11.3. Biokinetic Model Parameters for Cobalt ${ }^{(a)}$

\begin{tabular}{lcc}
\hline \multicolumn{1}{c}{ Retention Compartment } & Fractional Uptake & Biological Half-Life (d) \\
\hline Transfer compartment (blood) & --- & 0.5 \\
Liver A & $3 \%$ & 6 \\
Liver B & $1 \%$ & 60 \\
Liver C & $1 \%$ & 800 \\
Soft Tissues A & $27 \%$ & 6 \\
Soft Tissues B & $9 \%$ & 60 \\
Soft Tissues C & $9 \%$ & 800 \\
Direct to Urinary bladder content & $(6 / 7) * 50 \%=43 \%$ & --- \\
Direct to Upper large intestine & $(1 / 7) * 50 \%=7 \%$ & --- \\
\hline (a) From James et al. 2004. & &
\end{tabular}

\subsubsection{Whole Body Retention for Cobalt}

The fractional whole body retention data for inhalation, ingestion, and injection ${ }^{1}$ of ${ }^{60} \mathrm{Co}$ are listed in Tables 11.4 and 11.5, and plotted in Figures 11.1 and 11.2. The fractions are based on inhalation of 1- $\mu \mathrm{m}$-AMAD and 5- $\mu \mathrm{m}$-AMAD particle sizes for Types $\mathrm{M}$ and Type $\mathrm{S}{ }^{60} \mathrm{Co}$. Excretion fractions have not been provided, because whole body counting data are typically used for these radionuclides and retention can be directly determined.

\subsubsection{Dose Coefficients}

Dose coefficients, expressed as committed equivalent dose per unit activity of intake (e.g., rem/nCi), are a convenient shortcut to estimating doses based on standard assumptions when the magnitude of an intake is known. Acute intake dose coefficients have been tabulated in Table 11.6 for selected exposure scenarios. The scenarios include acute inhalation of 1- $\mu \mathrm{m}$-AMAD and 5- $\mu \mathrm{m}-\mathrm{AMAD}$ particles as the Hanford default, ingestion, and injection. These dose coefficients were derived using the IMBA computer code. For all intake modes of ${ }^{60} \mathrm{Co}$, the most limiting dose coefficient is the committed effective dose.

\footnotetext{
${ }^{1}$ Also known as instantaneous uptake into the systemic circulation. 
Table 11.4. Fractional Whole Body Retention from Inhalation of ${ }^{60} \mathrm{Co}$

\begin{tabular}{ccccc}
\hline $\begin{array}{c}\text { Days Post } \\
\text { Intake }\end{array}$ & $\begin{array}{c}\text { Type M Inhalation } \\
1-\mu m \text { AMAD }\end{array}$ & $\begin{array}{c}\text { Type M Inhalation } \\
5-\mu \text { AMAD }\end{array}$ & $\begin{array}{c}\text { Type S Inhalation } \\
1-\mu m \text { AMAD }\end{array}$ & $\begin{array}{c}\text { Type S Inhalation } \\
5-\mu m \text { AMAD }\end{array}$ \\
\hline 0.5 & $4.27 \mathrm{E}-01$ & $6.52 \mathrm{E}-01$ & $4.32 \mathrm{E}-01$ & $6.57 \mathrm{E}-01$ \\
1 & $3.40 \mathrm{E}-01$ & $4.85 \mathrm{E}-01$ & $3.46 \mathrm{E}-01$ & $4.90 \mathrm{E}-01$ \\
2 & $2.19 \mathrm{E}-01$ & $2.57 \mathrm{E}-01$ & $2.21 \mathrm{E}-01$ & $2.53 \mathrm{E}-01$ \\
3 & $1.63 \mathrm{E}-01$ & $1.52 \mathrm{E}-01$ & $1.62 \mathrm{E}-01$ & $1.43 \mathrm{E}-01$ \\
4 & $1.38 \mathrm{E}-01$ & $1.09 \mathrm{E}-01$ & $1.38 \mathrm{E}-01$ & $9.79 \mathrm{E}-02$ \\
5 & $1.27 \mathrm{E}-01$ & $9.07 \mathrm{E}-02$ & $1.27 \mathrm{E}-01$ & $8.01 \mathrm{E}-02$ \\
6 & $1.22 \mathrm{E}-01$ & $8.27 \mathrm{E}-02$ & $1.23 \mathrm{E}-01$ & $7.27 \mathrm{E}-02$ \\
7 & $1.19 \mathrm{E}-01$ & $7.85 \mathrm{E}-02$ & $1.20 \mathrm{E}-01$ & $6.94 \mathrm{E}-02$ \\
8 & $1.16 \mathrm{E}-01$ & $7.58 \mathrm{E}-02$ & $1.18 \mathrm{E}-01$ & $6.75 \mathrm{E}-02$ \\
9 & $1.14 \mathrm{E}-01$ & $7.37 \mathrm{E}-02$ & $1.17 \mathrm{E}-01$ & $6.63 \mathrm{E}-02$ \\
10 & $1.12 \mathrm{E}-01$ & $7.19 \mathrm{E}-02$ & $1.16 \mathrm{E}-01$ & $6.53 \mathrm{E}-02$ \\
12 & $1.09 \mathrm{E}-01$ & $6.89 \mathrm{E}-02$ & $1.14 \mathrm{E}-01$ & $6.36 \mathrm{E}-02$ \\
14 & $1.06 \mathrm{E}-01$ & $6.63 \mathrm{E}-02$ & $1.12 \mathrm{E}-01$ & $6.21 \mathrm{E}-02$ \\
30 & $8.72 \mathrm{E}-02$ & $5.29 \mathrm{E}-02$ & $9.86 \mathrm{E}-02$ & $5.36 \mathrm{E}-02$ \\
60 & $6.66 \mathrm{E}-02$ & $4.03 \mathrm{E}-02$ & $8.36 \mathrm{E}-02$ & $4.47 \mathrm{E}-02$ \\
90 & $5.37 \mathrm{E}-02$ & $3.28 \mathrm{E}-02$ & $7.48 \mathrm{E}-02$ & $3.97 \mathrm{E}-02$ \\
180 & $3.27 \mathrm{E}-02$ & $2.06 \mathrm{E}-02$ & $6.17 \mathrm{E}-02$ & $3.24 \mathrm{E}-02$ \\
365 & $1.51 \mathrm{E}-02$ & $1.06 \mathrm{E}-02$ & $4.78 \mathrm{E}-02$ & $2.51 \mathrm{E}-02$ \\
$2 \mathrm{y}$ & $5.89 \mathrm{E}-03$ & $4.82 \mathrm{E}-03$ & $3.03 \mathrm{E}-02$ & $1.59 \mathrm{E}-02$ \\
$5 \mathrm{y}$ & $1.34 \mathrm{E}-03$ & $1.16 \mathrm{E}-03$ & $8.79 \mathrm{E}-03$ & $4.66 \mathrm{E}-03$ \\
$10 \mathrm{y}$ & $1.43 \mathrm{E}-04$ & $1.23 \mathrm{E}-04$ & $1.83 \mathrm{E}-03$ & $9.77 \mathrm{E}-04$ \\
$20 \mathrm{y}$ & $1.62 \mathrm{E}-06$ & $1.40 \mathrm{E}-06$ & $2.06 \mathrm{E}-04$ & $1.11 \mathrm{E}-04$ \\
$50 \mathrm{y}$ & $2.35 \mathrm{E}-12$ & $2.03 \mathrm{E}-12$ & $6.99 \mathrm{E}-07$ & $4.05 \mathrm{E}-07$ \\
\hline
\end{tabular}

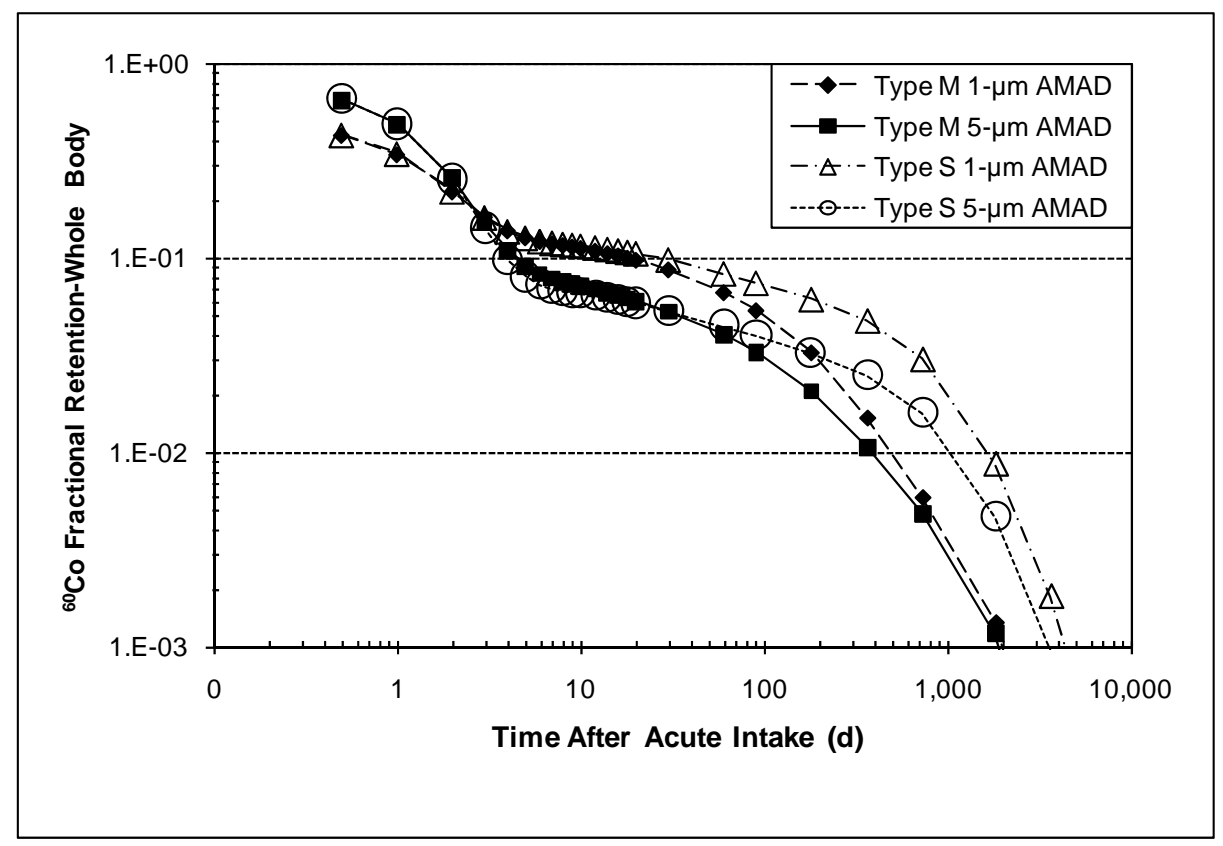

Figure 11.1. Retention of ${ }^{60} \mathrm{Co}$ in Whole Body as a Fraction of an Acute Inhalation Intake of 1- $\mu \mathrm{m}$ AMAD and 5- $\mu$ m-AMAD Particle Sizes 
Table 11.5. Fractional Whole Body Retention from Ingestion and Injection of ${ }^{60} \mathrm{Co}$

\begin{tabular}{cccc}
\hline Days Post Intake & $\begin{array}{c}\text { Soluble Ingestion } \\
\left(f_{1}=0.1\right)\end{array}$ & $\begin{array}{c}\text { Insoluble Ingestion } \\
\left(f_{1}=0.05\right)\end{array}$ & Injection \\
\hline 0.5 & $9.21 \mathrm{E}-01$ & $9.25 \mathrm{E}-01$ & $8.08 \mathrm{E}-01$ \\
1 & $7.11 \mathrm{E}-01$ & $7.14 \mathrm{E}-01$ & $6.69 \mathrm{E}-01$ \\
2 & $3.46 \mathrm{E}-01$ & $3.37 \mathrm{E}-01$ & $5.29 \mathrm{E}-01$ \\
3 & $1.63 \mathrm{E}-01$ & $1.47 \mathrm{E}-01$ & $4.60 \mathrm{E}-01$ \\
4 & $8.68 \mathrm{E}-02$ & $6.84 \mathrm{E}-02$ & $4.19 \mathrm{E}-01$ \\
5 & $5.59 \mathrm{E}-02$ & $3.73 \mathrm{E}-02$ & $3.88 \mathrm{E}-01$ \\
6 & $4.30 \mathrm{E}-02$ & $2.50 \mathrm{E}-02$ & $3.64 \mathrm{E}-01$ \\
7 & $3.70 \mathrm{E}-02$ & $1.98 \mathrm{E}-02$ & $3.44 \mathrm{E}-01$ \\
8 & $3.37 \mathrm{E}-02$ & $1.73 \mathrm{E}-02$ & $3.26 \mathrm{E}-01$ \\
9 & $3.16 \mathrm{E}-02$ & $1.60 \mathrm{E}-02$ & $3.10 \mathrm{E}-01$ \\
10 & $2.99 \mathrm{E}-02$ & $1.50 \mathrm{E}-02$ & $2.95 \mathrm{E}-01$ \\
12 & $2.73 \mathrm{E}-02$ & $1.37 \mathrm{E}-02$ & $2.71 \mathrm{E}-01$ \\
14 & $2.53 \mathrm{E}-02$ & $1.26 \mathrm{E}-02$ & $2.51 \mathrm{E}-01$ \\
16 & $2.36 \mathrm{E}-02$ & $1.18 \mathrm{E}-02$ & $2.35 \mathrm{E}-01$ \\
18 & $2.23 \mathrm{E}-02$ & $1.11 \mathrm{E}-02$ & $2.22 \mathrm{E}-01$ \\
20 & $2.12 \mathrm{E}-02$ & $1.06 \mathrm{E}-02$ & $2.11 \mathrm{E}-01$ \\
30 & $1.78 \mathrm{E}-02$ & $8.91 \mathrm{E}-03$ & $1.78 \mathrm{E}-01$ \\
60 & $1.43 \mathrm{E}-02$ & $7.15 \mathrm{E}-03$ & $1.43 \mathrm{E}-01$ \\
90 & $1.24 \mathrm{E}-02$ & $6.22 \mathrm{E}-03$ & $1.24 \mathrm{E}-01$ \\
180 & $9.22 \mathrm{E}-03$ & $4.61 \mathrm{E}-03$ & $9.21 \mathrm{E}-02$ \\
365 & $6.53 \mathrm{E}-03$ & $3.26 \mathrm{E}-03$ & $6.53 \mathrm{E}-02$ \\
$2 \mathrm{y}$ & $4.09 \mathrm{E}-03$ & $2.05 \mathrm{E}-03$ & $4.09 \mathrm{E}-02$ \\
$5 \mathrm{y}$ & $1.07 \mathrm{E}-03$ & $5.33 \mathrm{E}-04$ & $1.07 \mathrm{E}-02$ \\
$10 \mathrm{y}$ & $1.13 \mathrm{E}-04$ & $5.67 \mathrm{E}-05$ & $1.13 \mathrm{E}-03$ \\
$20 \mathrm{y}$ & $1.28 \mathrm{E}-06$ & $6.42 \mathrm{E}-07$ & $1.28 \mathrm{E}-05$ \\
$30 \mathrm{y}$ & $1.46 \mathrm{E}-08$ & $7.28 \mathrm{E}-09$ & $1.46 \mathrm{E}-07$ \\
$50 \mathrm{y}$ & $1.87 \mathrm{E}-12$ & $9.34 \mathrm{E}-13$ & $1.87 \mathrm{E}-11$ \\
\hline
\end{tabular}

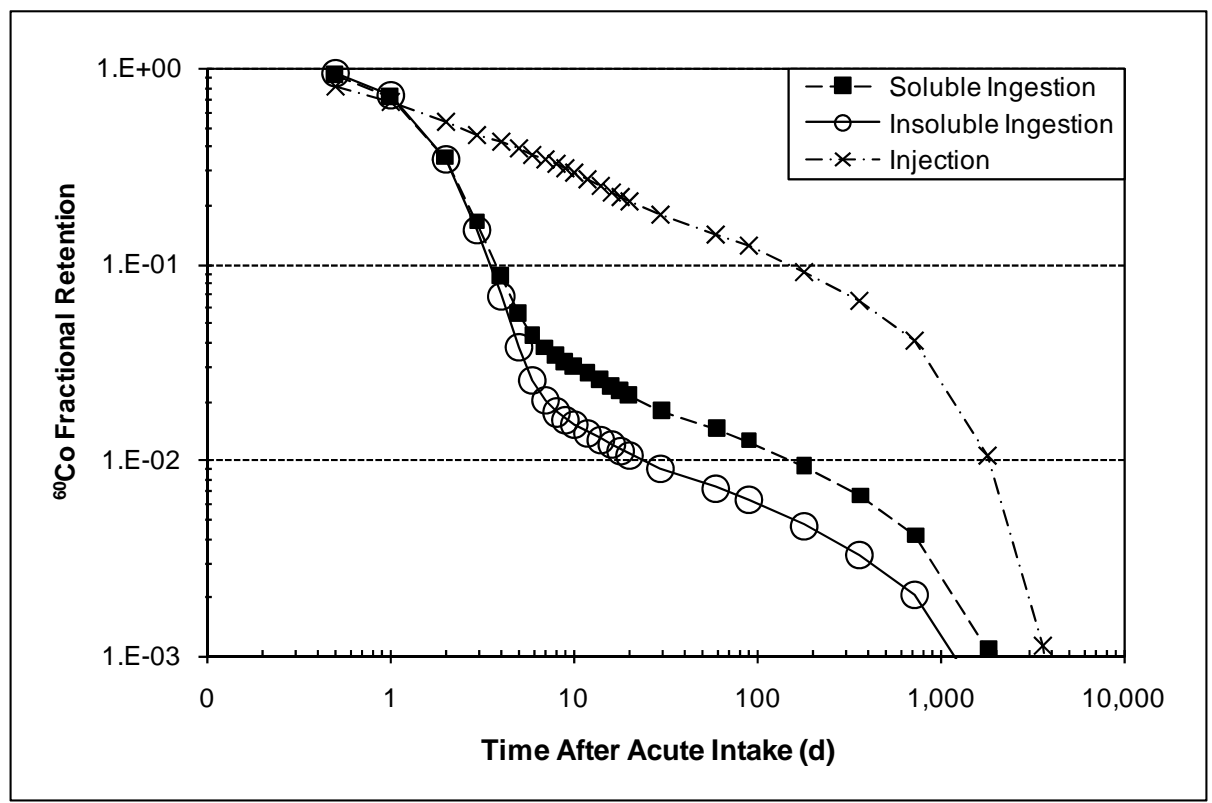

Figure 11.2. Retention of ${ }^{60} \mathrm{Co}$ in Whole Body as a Fraction of Ingestion and Injection 
Table 11.6. Committed Dose Coefficients for ${ }^{60}$ Cobalt, rem $/ \mathrm{nCi}$

\begin{tabular}{|c|c|c|c|c|c|c|c|}
\hline \multirow[b]{2}{*}{$\operatorname{Organ}^{(a)}$} & \multicolumn{2}{|c|}{ Type M Inhalation } & \multicolumn{2}{|c|}{ Type S Inhalation } & \multirow{2}{*}{$\begin{array}{c}\text { Soluble } \\
\text { Ingestion } \\
\left(f_{1}=0.1\right)\end{array}$} & \multirow{2}{*}{$\begin{array}{l}\text { Insoluble } \\
\text { Ingestion } \\
\left(f_{1}=0.05\right) \\
\end{array}$} & \multirow[b]{2}{*}{ Injection } \\
\hline & $\begin{array}{c}1-\mu m \\
\text { AMAD }\end{array}$ & $\begin{array}{c}5-\mu \mathrm{m} \\
\text { AMAD }\end{array}$ & $\begin{array}{c}1-\mu \mathrm{m} \\
\mathrm{AMAD}\end{array}$ & $\begin{array}{c}5-\mu m \\
\text { AMAD }\end{array}$ & & & \\
\hline Effective & $3.55 E-05$ & $2.63 E-05$ & $1.06 \mathrm{E}-04$ & $6.11 \mathrm{E}-05$ & $1.26 \mathrm{E}-05$ & $9.26 \mathrm{E}-06$ & $7.16 \mathrm{E}-05$ \\
\hline Lung & 1.81E-04 & $1.24 \mathrm{E}-04$ & $6.28 \mathrm{E}-04$ & 3.55E-04 & $6.56 \mathrm{E}-06$ & 3.38E-06 & 6.38E-05 \\
\hline Liver & 3.01E-05 & $2.26 \mathrm{E}-05$ & 6.94E-05 & 3.77E-05 & $1.64 \mathrm{E}-05$ & 8.65E-06 & $1.57 \mathrm{E}-04$ \\
\hline ULI & $1.44 \mathrm{E}-05$ & $1.55 \mathrm{E}-05$ & 1.69E-05 & $1.50 \mathrm{E}-05$ & $2.40 \mathrm{E}-05$ & 2.12E-05 & 7.46E-05 \\
\hline LLI & $1.81 \mathrm{E}-05$ & 2.27E-05 & 1.69E-05 & 2.11E-05 & 4.28E-05 & 4.10E-05 & 7.49E-05 \\
\hline SI & $1.21 \mathrm{E}-05$ & $1.18 \mathrm{E}-05$ & 1.33E-05 & $1.04 \mathrm{E}-05$ & $1.55 \mathrm{E}-05$ & $1.21 \mathrm{E}-05$ & 7.53E-05 \\
\hline Stomach & $1.60 \mathrm{E}-05$ & 1.19E-05 & 4.38E-05 & $2.40 \mathrm{E}-05$ & $9.43 \mathrm{E}-06$ & 6.17E-06 & $6.69 \mathrm{E}-05$ \\
\hline Colon & 1.60E-05 & $1.86 \mathrm{E}-05$ & 1.69E-05 & 1.77E-05 & 3.22E-05 & 2.98E-05 & 7.47E-05 \\
\hline $\mathrm{RBM}$ & $1.54 \mathrm{E}-05$ & 1.12E-05 & 4.30E-05 & 2.34E-05 & 7.92E-06 & 4.80E-06 & $6.41 \mathrm{E}-05$ \\
\hline Kidneys & $1.42 \mathrm{E}-05$ & $1.10 \mathrm{E}-05$ & 3.03E-05 & $1.69 \mathrm{E}-05$ & 8.78E-06 & 5.02E-06 & 7.65E-05 \\
\hline Bone Surface & $1.38 \mathrm{E}-05$ & $1.04 \mathrm{E}-05$ & 3.27E-05 & $1.81 \mathrm{E}-05$ & 7.56E-06 & 4.15E-06 & $6.90 \mathrm{E}-05$ \\
\hline Thyroid & $1.34 \mathrm{E}-05$ & 9.83E-06 & $3.46 \mathrm{E}-05$ & $1.89 \mathrm{E}-05$ & $6.29 \mathrm{E}-06$ & 3.16E-06 & $6.26 \mathrm{E}-05$ \\
\hline Gonads & $1.14 \mathrm{E}-05$ & $1.15 \mathrm{E}-05$ & 8.93E-06 & 8.34E-06 & $1.58 \mathrm{E}-05$ & $1.25 \mathrm{E}-05$ & 7.51E-05 \\
\hline
\end{tabular}

(a) ULI = upper large intestine; LLI = lower large intestine; SI = small intestine; and RBM = red bone marrow.

\subsubsection{Comparison of Published Dosimetry Factors}

A comparison of effective dose coefficients for ${ }^{60}$ Co between IBMA-derived values and those published in ICRP 68 (ICRP 1994a) is shown in Table 11.7. IMBA provides dose coefficients at three significant figures while ICRP 68 values are listed at only two significant figures. When rounding is taken into consideration, there are no differences between the IMBA and ICRP 68 values.

Similar comparisons with ${ }^{54} \mathrm{Mn}$ and ${ }^{59} \mathrm{Fe}$ have been omitted because of the lack of a Hanford source for these materials at this time. Their potential interest is mainly of a historical nature.

Table 11.7. Comparison of ${ }^{60}$ Co Committed Effective Dose Coefficients (Sv/Bq)

\begin{tabular}{|c|c|c|}
\hline Intake Mode & $\begin{array}{c}\text { IMBA } \\
\text { Effective Dose Coefficient }\end{array}$ & $\begin{array}{c}\text { ICRP } 68 \\
\text { Effective Dose Coefficient }\end{array}$ \\
\hline Tyре M 1- $\mu$ m AMAD & 9.59E-09 & $9.6 \mathrm{E}-09$ \\
\hline Tyре M 5- $\mu$ m AMAD & 7.11E-09 & 7.1E-09 \\
\hline Type S 1- $\mu$ m AMAD & 2.86E-08 & 2.9E-08 \\
\hline Type S 5- $\mu$ m AMAD & 1.65E-08 & $1.7 \mathrm{E}-08$ \\
\hline Soluble ingestion & 3.41E-09 & 3.4E-09 \\
\hline Insoluble ingestion & 2.50E-09 & 2.5E-09 \\
\hline Injection & 1.94E-08 & --- \\
\hline
\end{tabular}




\subsubsection{Derived Air Concentrations and Annual Limits on Intake}

10 CFR 835 provides derived air concentrations (DACs) at one significant figure, which are based on the assumptions of 5- $\mu \mathrm{m}$-AMAD particle size and 2,400 $\mathrm{m}^{3} / \mathrm{y}$ (ICRP 1994a) light worker breathing rate. While it is unlikely that ${ }^{60} \mathrm{Co}$ will be encountered as the sole radionuclide present for Hanford workers, its DAC value may be useful in determining a DAC value for a mixture of radionuclides using the sum of ratios methods for mixtures described in Appendix A of 10 CFR 835.

Annual limits on intake (ALIs) are not tabulated in 10 CFR 835, but can be calculated from fundamental principles. Because the effective dose is more limiting than organ dose for ${ }^{60} \mathrm{Co}$, the stochastic annual limit on intake (SALI) is appropriate to use.

The SALI is calculated using the AMAD inhalation effective dose coefficient from Table 11.6 and the 5-rem effective dose limit, as follows:

$$
S A L I(n C i)=\left(\frac{5 r e m}{e(50)\left(\frac{r e m}{n C i}\right)}\right),
$$

where $e(50)$ is the effective dose coefficient.

The 10 CFR 835 DAC and SALI, calculated using the effective dose coefficient given in Table 11.6, are presented in Table 11.8.

Table 11.8. ${ }^{60}$ Co DAC and SALI Values

\begin{tabular}{ccc}
\hline Radionuclide & $\mathrm{DAC}^{(\mathrm{a})}(\mu \mathrm{Ci} / \mathrm{ml})$ & $\mathrm{SALI}^{(\mathrm{b})}(\mathrm{nCi})$ \\
\hline${ }^{60}$ Co Type $\mathrm{M}$ & $7 \mathrm{E}-08$ & $1.9 \mathrm{E}+05$ \\
${ }^{60}$ Co Type S & $3 \mathrm{E}-08$ & $8.2 \mathrm{E}+04$ \\
\hline
\end{tabular}

(a) From 10 CFR 835 Appendix A.

(b) Derived from data in Table 11.6.

\subsubsection{Derived Reference Levels}

Derived reporting, investigation, and dose limit compliance levels (based on committed effective doses of 10 mrem, 100 mrem, and 5,000 mrem, respectively) have been calculated for ${ }^{60} \mathrm{Co}$ oxides. These levels are shown in Table 11.9 for Type $\mathrm{M}$ inhalation, Table 11.10 for Type $\mathrm{S}$ inhalation, and Table 11.11 for ingestion and injection. 
Table 11.9. ${ }^{60}$ Co Reference Values for Type M Inhalation

\begin{tabular}{|c|c|c|c|c|c|c|}
\hline \multirow[b]{2}{*}{ Intake (nCi): } & \multicolumn{3}{|c|}{ Type M 1- $\mu$ m AMAD } & \multicolumn{3}{|c|}{ Type M 5- $\mu$ m AMAD } \\
\hline & $2.82 \mathrm{E}+02$ & $2.82 \mathrm{E}+03$ & $1.41 \mathrm{E}+05$ & $3.80 \mathrm{E}+02$ & $3.80 \mathrm{E}+03$ & $1.90 \mathrm{E}+05$ \\
\hline $\begin{array}{l}\text { Days Post } \\
\text { Intake }\end{array}$ & $\begin{array}{c}\text { 10-mrem } \\
\text { Effective } \\
\text { Reporting } \\
\text { Level (nCi) }\end{array}$ & $\begin{array}{l}\text { 100-mrem } \\
\text { Effective } \\
\text { Investigation } \\
\text { Level (nCi) }\end{array}$ & $\begin{array}{c}\text { 5,000-mrem } \\
\text { Effective } \\
\text { Compliance } \\
\text { Level (nCi) }\end{array}$ & $\begin{array}{c}\text { 10-mrem } \\
\text { Effective } \\
\text { Reporting } \\
\text { Level (nCi) }\end{array}$ & $\begin{array}{l}\text { 100-mrem } \\
\text { Effective } \\
\text { Investigation } \\
\text { Level (nCi) }\end{array}$ & $\begin{array}{l}\text { 5,000-mrem } \\
\text { Effective } \\
\text { Compliance } \\
\text { Level (nCi) }\end{array}$ \\
\hline 0.5 & $1.20 \mathrm{E}+02$ & $1.20 \mathrm{E}+03$ & $6.02 \mathrm{E}+04$ & $2.48 \mathrm{E}+02$ & $2.48 \mathrm{E}+03$ & $1.24 \mathrm{E}+05$ \\
\hline 1 & $9.59 \mathrm{E}+01$ & $9.59 \mathrm{E}+02$ & $4.80 \mathrm{E}+04$ & $1.84 \mathrm{E}+02$ & $1.84 \mathrm{E}+03$ & $9.22 \mathrm{E}+04$ \\
\hline 2 & $6.18 \mathrm{E}+01$ & $6.18 \mathrm{E}+02$ & $3.09 \mathrm{E}+04$ & $9.77 \mathrm{E}+01$ & $9.77 \mathrm{E}+02$ & $4.88 \mathrm{E}+04$ \\
\hline 5 & $3.59 \mathrm{E}+01$ & $3.59 \mathrm{E}+02$ & $1.79 \mathrm{E}+04$ & $3.45 E+01$ & $3.45 E+02$ & $1.72 \mathrm{E}+04$ \\
\hline 7 & $3.34 \mathrm{E}+01$ & $3.34 \mathrm{E}+02$ & $1.67 \mathrm{E}+04$ & $2.98 \mathrm{E}+01$ & $2.98 \mathrm{E}+02$ & $1.49 \mathrm{E}+04$ \\
\hline 14 & $2.98 \mathrm{E}+01$ & $2.98 \mathrm{E}+02$ & $1.49 \mathrm{E}+04$ & $2.52 \mathrm{E}+01$ & $2.52 \mathrm{E}+02$ & $1.26 \mathrm{E}+04$ \\
\hline 30 & $2.46 \mathrm{E}+01$ & $2.46 \mathrm{E}+02$ & $1.23 \mathrm{E}+04$ & $2.01 \mathrm{E}+01$ & $2.01 \mathrm{E}+02$ & $1.01 \mathrm{E}+04$ \\
\hline 60 & $1.87 \mathrm{E}+01$ & $1.87 \mathrm{E}+02$ & $9.37 \mathrm{E}+03$ & $1.53 \mathrm{E}+01$ & $1.53 E+02$ & $7.66 \mathrm{E}+03$ \\
\hline 90 & $1.51 \mathrm{E}+01$ & $1.51 \mathrm{E}+02$ & $7.57 \mathrm{E}+03$ & $1.25 \mathrm{E}+01$ & $1.25 \mathrm{E}+02$ & $6.23 E+03$ \\
\hline 180 & $9.20 \mathrm{E}+00$ & $9.20 \mathrm{E}+01$ & $4.60 \mathrm{E}+03$ & $7.84 \mathrm{E}+00$ & $7.84 \mathrm{E}+01$ & $3.92 \mathrm{E}+03$ \\
\hline 365 & $4.26 \mathrm{E}+00$ & $4.26 \mathrm{E}+01$ & $2.13 \mathrm{E}+03$ & $4.02 \mathrm{E}+00$ & $4.02 \mathrm{E}+01$ & $2.01 \mathrm{E}+03$ \\
\hline $2 \mathrm{y}$ & $1.66 \mathrm{E}+00$ & $1.66 \mathrm{E}+01$ & $8.29 \mathrm{E}+02$ & $1.83 \mathrm{E}+00$ & $1.83 \mathrm{E}+01$ & $9.16 \mathrm{E}+02$ \\
\hline $5 \mathrm{y}$ & 3.78E-01 & $3.78 \mathrm{E}+00$ & $1.89 \mathrm{E}+02$ & 4.41E-01 & $4.41 \mathrm{E}+00$ & $2.20 \mathrm{E}+02$ \\
\hline $10 \mathrm{y}$ & 4.02E-02 & $4.02 \mathrm{E}-01$ & $2.01 \mathrm{E}+01$ & 4.69E-02 & 4.69E-01 & $2.34 \mathrm{E}+01$ \\
\hline $20 \mathrm{y}$ & 4.55E-04 & 4.55E-03 & 2.28E-01 & 5.31E-04 & 5.31E-03 & 2.65E-01 \\
\hline $50 \mathrm{y}$ & $6.62 \mathrm{E}-10$ & 6.62E-09 & 3.31E-07 & 7.72E-10 & 7.72E-09 & $3.86 \mathrm{E}-07$ \\
\hline
\end{tabular}

Table 11.10. ${ }^{60}$ Co Reference Values for Type S Inhalation

\begin{tabular}{|c|c|c|c|c|c|c|}
\hline \multirow[b]{2}{*}{ Intake (nCi): } & \multicolumn{3}{|c|}{ Type S 1- $\mu \mathrm{m}$ AMAD } & \multicolumn{3}{|c|}{ Type S 5- $\mu$ m AMAD } \\
\hline & $9.43 E+01$ & $9.43 \mathrm{E}+02$ & $4.72 \mathrm{E}+04$ & $1.64 \mathrm{E}+02$ & $1.64 \mathrm{E}+03$ & $8.18 \mathrm{E}+04$ \\
\hline \multirow{4}{*}{$\begin{array}{l}\text { Days Post } \\
\text { Intake }\end{array}$} & 10-mrem & 100-mrem & 5,000-mrem & 10-mrem & 100-mrem & 5,000-mrem \\
\hline & Effective & Effective & Effective & Effective & Effective & Effective \\
\hline & Reporting & Investigation & Compliance & Reporting & Investigation & Compliance \\
\hline & Level (nCi) & Level (nCi) & Level (nCi) & Level (nCi) & Level (nCi) & Level (nCi) \\
\hline 0.5 & $4.08 \mathrm{E}+01$ & $4.08 \mathrm{E}+02$ & $2.04 \mathrm{E}+04$ & $1.08 \mathrm{E}+02$ & $1.08 \mathrm{E}+03$ & $5.38 \mathrm{E}+04$ \\
\hline 1 & $3.26 \mathrm{E}+01$ & $3.26 \mathrm{E}+02$ & $1.63 \mathrm{E}+04$ & $8.02 \mathrm{E}+01$ & $8.02 \mathrm{E}+02$ & $4.01 \mathrm{E}+04$ \\
\hline 2 & $2.09 \mathrm{E}+01$ & $2.09 \mathrm{E}+02$ & $1.04 \mathrm{E}+04$ & $4.14 \mathrm{E}+01$ & $4.14 \mathrm{E}+02$ & $2.07 \mathrm{E}+04$ \\
\hline 5 & $1.20 \mathrm{E}+01$ & $1.20 \mathrm{E}+02$ & $6.01 \mathrm{E}+03$ & $1.31 \mathrm{E}+01$ & $1.31 \mathrm{E}+02$ & $6.55 \mathrm{E}+03$ \\
\hline 7 & $1.13 \mathrm{E}+01$ & $1.13 \mathrm{E}+02$ & $5.67 \mathrm{E}+03$ & $1.14 \mathrm{E}+01$ & $1.14 \mathrm{E}+02$ & $5.68 \mathrm{E}+03$ \\
\hline 14 & $1.05 \mathrm{E}+01$ & $1.05 \mathrm{E}+02$ & $5.27 \mathrm{E}+03$ & $1.02 \mathrm{E}+01$ & $1.02 \mathrm{E}+02$ & $5.08 \mathrm{E}+03$ \\
\hline 30 & $9.30 \mathrm{E}+00$ & $9.30 \mathrm{E}+01$ & $4.65 E+03$ & $8.77 \mathrm{E}+00$ & $8.77 \mathrm{E}+01$ & $4.39 E+03$ \\
\hline 60 & $7.89 \mathrm{E}+00$ & $7.89 \mathrm{E}+01$ & $3.94 \mathrm{E}+03$ & $7.32 \mathrm{E}+00$ & $7.32 \mathrm{E}+01$ & $3.66 \mathrm{E}+03$ \\
\hline 90 & $7.06 \mathrm{E}+00$ & $7.06 \mathrm{E}+01$ & $3.53 E+03$ & $6.50 \mathrm{E}+00$ & $6.50 \mathrm{E}+01$ & $3.25 E+03$ \\
\hline 180 & $5.82 \mathrm{E}+00$ & $5.82 \mathrm{E}+01$ & $2.91 \mathrm{E}+03$ & $5.31 \mathrm{E}+00$ & $5.31 \mathrm{E}+01$ & $2.65 E+03$ \\
\hline 365 & $4.51 \mathrm{E}+00$ & $4.51 \mathrm{E}+01$ & $2.26 \mathrm{E}+03$ & $4.10 \mathrm{E}+00$ & $4.10 \mathrm{E}+01$ & $2.05 E+03$ \\
\hline $2 \mathrm{y}$ & $2.86 \mathrm{E}+00$ & $2.86 \mathrm{E}+01$ & $1.43 E+03$ & $2.61 \mathrm{E}+00$ & $2.61 \mathrm{E}+01$ & $1.30 \mathrm{E}+03$ \\
\hline $5 \mathrm{y}$ & 8.29E-01 & $8.29 E+00$ & $4.15 \mathrm{E}+02$ & 7.62E-01 & $7.62 \mathrm{E}+00$ & $3.81 \mathrm{E}+02$ \\
\hline $10 \mathrm{y}$ & 1.73E-01 & $1.73 \mathrm{E}+00$ & $8.63 \mathrm{E}+01$ & $1.60 \mathrm{E}-01$ & $1.60 \mathrm{E}+00$ & $8.00 \mathrm{E}+01$ \\
\hline $20 \mathrm{y}$ & $1.94 \mathrm{E}-02$ & 1.94E-01 & $9.70 \mathrm{E}+00$ & $1.82 \mathrm{E}-02$ & 1.82E-01 & $9.12 \mathrm{E}+00$ \\
\hline $50 \mathrm{y}$ & $6.59 \mathrm{E}-05$ & 6.59E-04 & 3.30E-02 & 6.62E-05 & 6.62E-04 & 3.31E-02 \\
\hline
\end{tabular}


Table 11.11. ${ }^{60}$ Co Reference Values for Ingestion and Injection

\begin{tabular}{|c|c|c|c|c|c|c|c|c|c|}
\hline & \multicolumn{3}{|c|}{ Soluble Ingestion } & \multicolumn{3}{|c|}{ Insoluble Ingestion } & \multicolumn{3}{|c|}{ Injection } \\
\hline nCi: & $7.94 \mathrm{E}+02$ & $7.94 \mathrm{E}+03$ & $3.97 \mathrm{E}+05$ & $1.08 \mathrm{E}+03$ & $1.08 \mathrm{E}+04$ & $5.40 \mathrm{E}+05$ & $1.40 \mathrm{E}+02$ & $1.40 \mathrm{E}+03$ & $6.98 \mathrm{E}+04$ \\
\hline $\begin{array}{l}\text { Days } \\
\text { Post } \\
\text { Intake }\end{array}$ & $\begin{array}{l}\text { 10-mrem } \\
\text { Effective } \\
\text { Reporting } \\
\text { Level }\end{array}$ & $\begin{array}{c}\text { 100-mrem } \\
\text { Effective } \\
\text { Investigation } \\
\text { Level }\end{array}$ & $\begin{array}{c}\text { 5,000-mrem } \\
\text { Effective } \\
\text { Compliance } \\
\text { Level }\end{array}$ & $\begin{array}{c}\text { 10-mrem } \\
\text { Effective } \\
\text { Reporting } \\
\text { Level }\end{array}$ & $\begin{array}{l}\text { 100-mrem } \\
\text { Effective } \\
\text { Investigation } \\
\text { Level }\end{array}$ & $\begin{array}{c}\text { 5,000-mrem } \\
\text { Effective } \\
\text { Compliance } \\
\text { Level }\end{array}$ & $\begin{array}{c}\text { 10-mrem } \\
\text { Effective } \\
\text { Reporting } \\
\text { Level }\end{array}$ & $\begin{array}{c}\text { 100-mrem } \\
\text { Effective } \\
\text { Investigation } \\
\text { Level }\end{array}$ & $\begin{array}{c}\text { 5,000-mrem } \\
\text { Effective } \\
\text { Compliance } \\
\text { Level }\end{array}$ \\
\hline 0.5 & $7.31 \mathrm{E}+02$ & $7.31 \mathrm{E}+03$ & $3.66 \mathrm{E}+05$ & $9.99 \mathrm{E}+02$ & $9.99 \mathrm{E}+03$ & $5.00 \mathrm{E}+05$ & $1.13 \mathrm{E}+02$ & $1.13 \mathrm{E}+03$ & $5.64 \mathrm{E}+04$ \\
\hline 1 & $5.64 \mathrm{E}+02$ & $5.64 \mathrm{E}+03$ & $2.82 \mathrm{E}+05$ & $7.71 \mathrm{E}+02$ & $7.71 \mathrm{E}+03$ & $3.86 \mathrm{E}+05$ & $9.35 \mathrm{E}+01$ & $9.35 \mathrm{E}+02$ & $4.67 \mathrm{E}+04$ \\
\hline 2 & $2.74 \mathrm{E}+02$ & & & & $3.64 \mathrm{E}+03$ & & $7.38 \mathrm{E}+01$ & $7.38 \mathrm{E}+02$ & \\
\hline 5 & $4.44 \mathrm{E}+01$ & $4.44 \mathrm{E}+02$ & $2.22 \mathrm{E}+04$ & $4.03 \mathrm{E}+01$ & $4.03 E+02$ & $2.01 \mathrm{E}+04$ & $5.43 \mathrm{E}+01$ & $5.43 \mathrm{E}+02$ & $2.71 \mathrm{E}+04$ \\
\hline 7 & $2.94 \mathrm{E}+01$ & $2.94 \mathrm{E}+02$ & $1.47 \mathrm{E}+04$ & $2.14 \mathrm{E}+01$ & $2.14 \mathrm{E}+02$ & $1.07 \mathrm{E}+04$ & $4.80 \mathrm{E}+01$ & $4.80 \mathrm{E}+02$ & $2.40 \mathrm{E}+04$ \\
\hline 14 & $2.01 \mathrm{E}+01$ & $2.01 \mathrm{E}+02$ & $1.00 \mathrm{E}+04$ & $1.37 \mathrm{E}+01$ & $1.37 \mathrm{E}+02$ & $6.83 E+03$ & $3.51 \mathrm{E}+01$ & $3.51 E+02$ & $1.75 \mathrm{E}+04$ \\
\hline 30 & $1.41 \mathrm{E}+01$ & $1.41 \mathrm{E}+02$ & $7.07 \mathrm{E}+03$ & $9.62 \mathrm{E}+00$ & $9.62 \mathrm{E}+01$ & $4.81 \mathrm{E}+03$ & $2.48 \mathrm{E}+01$ & $2.48 \mathrm{E}+02$ & $1.24 \mathrm{E}+04$ \\
\hline 60 & $1.13 \mathrm{E}+01$ & $1.13 \mathrm{E}+02$ & $5.67 \mathrm{E}+03$ & $7.72 \mathrm{E}+00$ & $7.72 \mathrm{E}+01$ & $3.86 \mathrm{E}+03$ & $1.99 \mathrm{E}+01$ & $1.99 \mathrm{E}+02$ & $9.97 \mathrm{E}+03$ \\
\hline 90 & $9.87 \mathrm{E}+00$ & $9.87 \mathrm{E}+01$ & $4.93 \mathrm{E}+03$ & $6.72 \mathrm{E}+00$ & $6.72 \mathrm{E}+01$ & $3.36 \mathrm{E}+03$ & $1.74 \mathrm{E}+01$ & $1.74 \mathrm{E}+02$ & $8.68 \mathrm{E}+03$ \\
\hline 180 & $7.31 \mathrm{E}+00$ & $7.31 \mathrm{E}+01$ & $3.66 \mathrm{E}+03$ & $4.98 \mathrm{E}+00$ & $4.98 \mathrm{E}+01$ & $2.49 \mathrm{E}+03$ & $1.29 \mathrm{E}+01$ & $1.29 \mathrm{E}+02$ & $6.43 E+03$ \\
\hline 365 & $5.18 \mathrm{E}+00$ & $5.18 \mathrm{E}+01$ & $2.59 \mathrm{E}+03$ & $3.53 \mathrm{E}+00$ & $3.53 \mathrm{E}+01$ & $1.76 \mathrm{E}+03$ & $9.12 \mathrm{E}+00$ & $9.12 \mathrm{E}+01$ & $4.56 \mathrm{E}+03$ \\
\hline $2 y$ & $3.25 \mathrm{E}+00$ & $3.25 \mathrm{E}+01$ & $1.62 \mathrm{E}+03$ & $2.21 \mathrm{E}+00$ & $2.21 \mathrm{E}+01$ & $1.10 \mathrm{E}+03$ & $5.71 \mathrm{E}+00$ & $5.71 \mathrm{E}+01$ & $2.86 \mathrm{E}+03$ \\
\hline $5 y$ & 8.46E-01 & $8.46 \mathrm{E}+00$ & $4.23 \mathrm{E}+02$ & 5.75E-01 & $5.75 \mathrm{E}+00$ & $2.88 \mathrm{E}+02$ & $1.49 \mathrm{E}+00$ & $1.49 \mathrm{E}+01$ & $7.44 \mathrm{E}+02$ \\
\hline $10 \mathrm{y}$ & $9.00 \mathrm{E}-02$ & $9.00 \mathrm{E}-01$ & $4.50 \mathrm{E}+01$ & 6.13E-02 & 6.13E-01 & $3.06 \mathrm{E}+01$ & $1.58 \mathrm{E}-01$ & $1.58 \mathrm{E}+00$ & $7.92 \mathrm{E}+01$ \\
\hline $20 \mathrm{y}$ & $1.02 \mathrm{E}-03$ & $1.02 \mathrm{E}-02$ & 5.10E-01 & $6.94 \mathrm{E}-04$ & $6.94 \mathrm{E}-03$ & 3.47E-01 & $1.79 \mathrm{E}-03$ & 1.79E-02 & 8.97E-01 \\
\hline $50 y$ & 1.48E-09 & $1.48 \mathrm{E}-08$ & $7.41 \mathrm{E}-07$ & $1.01 \mathrm{E}-09$ & $1.01 \mathrm{E}-08$ & $5.04 \mathrm{E}-07$ & 2.61E-09 & 2.61E-08 & $1.30 \mathrm{E}-06$ \\
\hline
\end{tabular}

\subsection{Bioassay for Cobalt}

This section discusses the bioassay methods, capabilities, and protocols for ${ }^{60} \mathrm{Co}$.

\subsubsection{Bioassay Methods and Capabilities}

In vivo and excreta measurements are the bioassay methods used in monitoring for corrosion product radionuclides. However, ${ }^{60} \mathrm{Co}$ is a gamma-emitter and is readily measured by in vivo bioassay techniques, using either sodium-iodide (NaI) or coaxial germanium $(\mathrm{Ge})$ detectors. The minimum detectable activities for in vivo measurements are shown in Table 11.12

Table 11.12. Hanford In Vivo Measurement Detection Capability for ${ }^{60} \mathrm{Co}^{(\mathrm{a})}$

\begin{tabular}{lccc}
\hline \multicolumn{1}{c}{ Measurement Type } & Organ/Tissue & Decision Level (nCi) & MDA (nCi) \\
\hline $\begin{array}{l}\text { 3-Minute NaI } \\
\begin{array}{l}\text { Preview Count } \\
\text { 10-Minute Coaxial } \\
\text { Germanium Count }\end{array}\end{array}$ & Whole Body & 0.6 & 1.2 \\
\hline
\end{tabular}

(a) From the In Vivo Monitoring Program Manual, PNL-MA-574 (TP Lynch. 2007).

(b) The minimum detectable activity (MDA) values for the coaxial count can be higher by $30 \%$ or more for workers weighing more than 200 pounds. 
Because the radionuclides are easily detectable using in vivo measurement, excreta measurements are not required in most intake situations unless there is concern for other radionuclides such as strontium or plutonium, which are not readily measurable by in vivo techniques. Measurement of radionuclides in early fecal excretion can be used as a means for establishing the relative radionuclide distribution in a corrosion product mixture. However, analysis of a nasal or appropriate surface contamination smear sample is preferred if the elements present may exhibit different absorption characteristics in the GI tract.

Tables 11.13, 11.14, and 11.15 describe the nominal Hanford minimum detectable intakes and minimum detectable committed effective dose for Type $\mathrm{M}$ and Type $\mathrm{S}$ inhalation and ingestion, and injection of ${ }^{60} \mathrm{Co}$. It is important to note that the MDAs associated with the Hanford bioassay measurements are below those routinely used at many nuclear power plant facilities. Thus, it is possible that corrosion product activity detected by baseline Hanford measurements can be related to previously undetected intakes performed at facilities with less-sensitive MDAs.

Table 11.13. ${ }^{60}$ Co Minimum Detectable Intakes and Committed Effective Doses for Type M Inhalation

\begin{tabular}{|c|c|c|c|c|c|c|c|c|}
\hline \multirow{3}{*}{$\begin{array}{l}\text { Days } \\
\text { Post } \\
\text { Intake }\end{array}$} & \multicolumn{4}{|c|}{ Type M 1- $\mu$ m AMAD } & \multicolumn{4}{|c|}{ Type M 5- $\mu \mathrm{m}$ AMAD } \\
\hline & \multicolumn{2}{|c|}{$\begin{array}{c}\text { NaI System } \\
\text { Minimum Detectable }^{(a)}\end{array}$} & \multicolumn{2}{|c|}{$\begin{array}{c}\text { Coax Ge System } \\
\text { Minimum Detectable }^{(\mathrm{b})}\end{array}$} & \multicolumn{2}{|c|}{$\begin{array}{c}\text { NaI System } \\
\text { Minimum Detectable }^{(\mathrm{a})}\end{array}$} & \multicolumn{2}{|c|}{$\begin{array}{c}\text { Coax Ge System } \\
\text { Minimum Detectable } \\
\text { (b) }\end{array}$} \\
\hline & Intake (nCi) & $\begin{array}{c}\text { Dose } \\
\text { (mrem) }^{(\mathrm{c})}\end{array}$ & $\begin{array}{c}\text { Intake } \\
\text { (nCi) }\end{array}$ & $\begin{array}{c}\text { Dose } \\
\text { (mrem) }^{(\mathrm{c})}\end{array}$ & $\begin{array}{c}\text { Intake } \\
\text { (nCi) }\end{array}$ & $\begin{array}{c}\text { Dose } \\
(\mathrm{mrem})^{(\mathrm{c})}\end{array}$ & $\begin{array}{c}\text { Intake } \\
\text { (nCi) }\end{array}$ & $\begin{array}{c}\text { Dose } \\
(\mathrm{mrem})^{(\mathrm{c})}\end{array}$ \\
\hline 0.5 & 2.8 & 0.1 & 1.9 & 0.1 & 1.8 & 0.05 & 1.2 & 0.03 \\
\hline 1 & 3.5 & 0.1 & 2.3 & 0.1 & 2.5 & 0.1 & 1.6 & 0.04 \\
\hline 2 & 5.5 & 0.2 & 3.6 & 0.1 & 4.7 & 0.1 & 3.1 & 0.1 \\
\hline 5 & 9.4 & 0.3 & 6.3 & 0.2 & 13 & 0.3 & 8.8 & 0.2 \\
\hline 6 & 9.8 & 0.3 & 6.6 & 0.2 & 15 & 0.4 & 9.7 & 0.3 \\
\hline 7 & 10 & 0.4 & 6.7 & 0.2 & 15 & 0.4 & 10 & 0.3 \\
\hline 14 & 11 & 0.4 & 7.6 & 0.3 & 18 & 0.5 & 12 & 0.3 \\
\hline 30 & 14 & 0.5 & 9.2 & 0.3 & 23 & 0.6 & 15 & 0.4 \\
\hline 60 & 18 & 0.6 & 12 & 0.4 & 30 & 0.8 & 20 & 0.5 \\
\hline 90 & 22 & 0.8 & 15 & 0.5 & 37 & 1.0 & 24 & 0.6 \\
\hline 180 & 37 & 1.3 & 24 & 0.9 & 58 & 1.5 & 39 & 1.0 \\
\hline 365 & 79 & 2.8 & 53 & 1.9 & 114 & 3.0 & 76 & 2.0 \\
\hline $2 y$ & 204 & 7.2 & 136 & 5 & 249 & 6.5 & 166 & 4.4 \\
\hline $5 y$ & 894 & 32 & 596 & 21 & 1035 & 27 & 690 & 18.2 \\
\hline $10 \mathrm{y}$ & 8404 & 298 & 5,603 & 199 & 9729 & 255 & 6486 & 170.6 \\
\hline $\begin{array}{l}\text { (a) Bas } \\
\text { (b) Bas } \\
\text { (c) Dos }\end{array}$ & $\begin{array}{l}\mathrm{d} \text { on MDA of } \\
\mathrm{d} \text { on MDA of } \\
\text { values less th }\end{array}$ & $\begin{array}{l}.2 \mathrm{nCi} . \\
.8 \mathrm{nCi} . \\
\text { in } 1 \mathrm{mrem}\end{array}$ & ounded & signific & figure. & & & \\
\hline
\end{tabular}

\subsubsection{Routine Bioassay Monitoring Protocol}

Routine monitoring for gamma-emitting corrosion products is best accomplished by periodic whole body counting. With ${ }^{60} \mathrm{Co}$ as the predominant corrosion product at Hanford, Tables 11.13 through 11.15 show that minimum detectable doses of 10 mrem can be achieved with annual whole body counts having 
an MDA of $1.2 \mathrm{nCi}$. Such an MDA is readily achievable with the Hanford preview counter-a standup NaI detector system. Definitive measurements using the coaxial germanium detector system are preferred for identification and quantification of gamma-emitting nuclides due to the much higher resolution of that system and a lower MDA. Consequently, initial detection of a gamma-emitter such as ${ }^{60} \mathrm{Co}$ on the NaI system should be followed by a verification count on the coaxial germanium system, preferably immediately following the initial measurement while the subject is still at the In Vivo Radiobioassay and Research Facility.

Table 11.14. ${ }^{60}$ Co Minimum Detectable Intakes and Committed Effective Doses for Type S Inhalation

\begin{tabular}{|c|c|c|c|c|c|c|c|c|}
\hline \multirow{3}{*}{$\begin{array}{c}\text { Days } \\
\text { Post } \\
\text { Intake }\end{array}$} & \multicolumn{4}{|c|}{ Type S 1- $\mu$ m AMAD } & \multicolumn{4}{|c|}{ Type S 5- $\mu$ m AMAD } \\
\hline & \multicolumn{2}{|c|}{$\begin{array}{c}\text { NaI System } \\
\text { Minimum Detectable }^{(a)}\end{array}$} & \multicolumn{2}{|c|}{$\begin{array}{c}\text { Coax Ge System } \\
\text { Minimum Detectable }^{(\mathrm{b})}\end{array}$} & \multicolumn{2}{|c|}{$\begin{array}{c}\text { NaI System } \\
\text { Minimum Detectable }^{(\mathrm{a})}\end{array}$} & \multicolumn{2}{|c|}{$\begin{array}{c}\text { Coax Ge System } \\
\text { Minimum Detectable }^{(\mathrm{b})}\end{array}$} \\
\hline & $\begin{array}{c}\text { Intake } \\
(\mathrm{nCi})\end{array}$ & $\begin{array}{c}\text { Dose } \\
(\mathrm{mrem})^{(\mathrm{c})}\end{array}$ & $\begin{array}{l}\text { Intake } \\
(\mathrm{nCi})\end{array}$ & $\begin{array}{c}\text { Dose } \\
(\mathrm{mrem})^{(\mathrm{c})}\end{array}$ & $\begin{array}{l}\text { Intake } \\
(\mathrm{nCi})\end{array}$ & $\begin{array}{c}\text { Dose } \\
(\mathrm{mrem})^{(\mathrm{c})}\end{array}$ & $\begin{array}{l}\text { Intake } \\
(\mathrm{nCi})\end{array}$ & $\begin{array}{c}\text { Dose } \\
\left(\text { (mrem) }^{(\mathrm{c})}\right.\end{array}$ \\
\hline 0.5 & 2.8 & 0.3 & 1.9 & 0.2 & 1.8 & 0.1 & 1.2 & 0.07 \\
\hline 1 & 3.5 & 0.4 & 2.3 & 0.2 & 2.4 & 0.1 & 1.6 & 0.1 \\
\hline 2 & 5.4 & 0.6 & 3.6 & 0.4 & 4.7 & 0.3 & 3.2 & 0.2 \\
\hline 5 & 9.4 & 1.0 & 6.3 & 0.7 & 15 & 0.9 & 10 & 0.6 \\
\hline 7 & 10 & 1.1 & 6.7 & 0.7 & 17 & 1.1 & 12 & 0.7 \\
\hline 14 & 11 & 1.1 & 7.2 & 0.8 & 19 & 1.2 & 13 & 0.8 \\
\hline 30 & 12 & 1.3 & 8.1 & 0.9 & 22 & 1.4 & 15 & 0.9 \\
\hline 60 & 14 & 1.5 & 9.6 & 1.0 & 27 & 1.6 & 18 & 1.1 \\
\hline 90 & 16 & 1.7 & 11 & 1.1 & 30 & 1.8 & 20 & 1.2 \\
\hline 180 & 19 & 2.1 & 13 & 1.4 & 37 & 2.3 & 25 & 1.5 \\
\hline 365 & 25 & 2.7 & 17 & 1.8 & 48 & 2.9 & 32 & 1.9 \\
\hline $2 \mathrm{yr}$ & 40 & 4.2 & 26 & 2.8 & 75 & 4.6 & 50 & 3.1 \\
\hline $5 \mathrm{yr}$ & 137 & 14 & 91 & 9.6 & 258 & 16 & 172 & 10 \\
\hline $10 \mathrm{yr}$ & 656 & 69 & 437 & 46 & 1228 & 75 & 819 & 50 \\
\hline
\end{tabular}

(a) Based on an MDA of $1.2 \mathrm{nCi}$.

(b) Based on an MDA of $0.8 \mathrm{nCi}$.

(c) Dose values less than 1 mrem are rounded to one significant figure.

At very low indicated activities, if a follow-up measurement is not obtained or a contractor elects to waive the follow-up measurement, dose can be calculated based on the single initial count. Although the accuracy of a single count performed using the preview counter is somewhat less than that obtained using germanium detector systems, the higher uncertainty is not of much significance at low doses.

\subsubsection{Special Monitoring for Suspected Intakes}

An in vivo examination should be performed following any indication of an intake of ${ }^{60} \mathrm{Co}$ or other activated corrosion product radionuclides. Unless the intake appears to be of such a magnitude that medical treatment to aid removal of the material from the body is considered, the exam may be scheduled 
as convenient, within several days of the intake without significant loss of sensitivity to intake detection. All radionuclides potentially involved in the exposure should be considered during the follow-up investigation.

The interpretation of in vivo measurements shortly after intake may be complicated by early transport of material through the lung and GI tract. Measurements performed after about 5 days post intake are more appropriate for dose evaluation. Long-term follow-up bioassay measurements should be considered to monitor internal radioactivity levels and establish individual-specific retention characteristics.

Table 11.15. ${ }^{60}$ Co Minimum Detectable Intakes and Committed Effective Doses for Ingestion and Injection $^{(a)}$

\begin{tabular}{|c|c|c|c|c|c|c|c|c|c|c|c|c|}
\hline \multirow{3}{*}{$\begin{array}{l}\text { Days } \\
\text { Post } \\
\text { Intake }\end{array}$} & \multicolumn{4}{|c|}{ Soluble Ingestion $\left(f_{1}=0.1\right)$} & \multicolumn{4}{|c|}{ Insoluble Ingestion $\left(f_{1}=0.05\right)$} & \multicolumn{4}{|c|}{ Injection } \\
\hline & \multicolumn{2}{|c|}{$\begin{array}{l}\text { NaI System } \\
\text { Minimum } \\
\text { Detectable }^{(a)}\end{array}$} & \multicolumn{2}{|c|}{$\begin{array}{c}\text { Coax Ge System } \\
\text { Minimum } \\
\text { Detectable }^{(b)}\end{array}$} & \multicolumn{2}{|c|}{$\begin{array}{l}\text { NaI System } \\
\text { Minimum } \\
\text { Detectable }^{(a)}\end{array}$} & \multicolumn{2}{|c|}{$\begin{array}{l}\text { Coax Ge System } \\
\text { Minimum } \\
\text { Detectable }^{(b)}\end{array}$} & \multicolumn{2}{|c|}{$\begin{array}{l}\text { NaI System } \\
\text { Minimum } \\
\text { Detectable }^{(a)}\end{array}$} & \multicolumn{2}{|c|}{$\begin{array}{l}\text { Coax Ge System } \\
\text { Minimum } \\
\text { Detectable }^{(b)}\end{array}$} \\
\hline & $\begin{array}{l}\text { Intake } \\
\text { (nCi) }\end{array}$ & $\begin{array}{c}\text { Dose } \\
\text { (mrem) }^{(\mathrm{c})}\end{array}$ & $\begin{array}{l}\text { Intake } \\
(\mathrm{nCi})\end{array}$ & $\begin{array}{c}\text { Dose } \\
\text { (mrem) }^{(\mathrm{c})}\end{array}$ & $\begin{array}{l}\text { Intake } \\
(\mathrm{nCi})\end{array}$ & $\begin{array}{c}\text { Dose } \\
(\mathrm{mrem})^{(\mathrm{c})}\end{array}$ & $\begin{array}{l}\text { Intake } \\
(\mathrm{nCi})\end{array}$ & $\begin{array}{c}\text { Dose } \\
\text { (mrem) }^{(\mathrm{c})}\end{array}$ & $\begin{array}{l}\text { Intake } \\
\text { (nCi) }\end{array}$ & $\begin{array}{c}\text { Dose } \\
\left(\text { (mrem) }^{(\mathrm{c})}\right.\end{array}$ & $\begin{array}{c}\text { Intake } \\
\text { (nCi) }\end{array}$ & $\begin{array}{c}\text { Dose. } \\
\text { (mrem) })^{(\mathrm{c})}\end{array}$ \\
\hline 0.5 & 1.3 & 0.02 & 0.9 & 0.01 & 1.3 & 0.01 & 0.9 & 0.01 & 1.5 & 0.1 & 1.0 & 0.1 \\
\hline 1 & 1.7 & 0.02 & 1.1 & 0.01 & 1.7 & 0.02 & 1.1 & 0.01 & 1.8 & 0.1 & 1.2 & 0.1 \\
\hline 2 & 3.5 & 0.04 & 2.3 & 0.03 & 3.6 & 0.03 & 2.4 & 0.02 & 2.3 & 0.2 & 1.5 & 0.1 \\
\hline 5 & 21 & 0.3 & 14 & 0.2 & 32 & 0.3 & 21 & 0.20 & 3.1 & 0.2 & 2.1 & 0.1 \\
\hline 7 & 32 & 0.4 & 22 & 0.3 & 61 & 0.6 & 40 & 0.37 & 3.5 & 0.2 & 2.3 & 0.2 \\
\hline 14 & 47 & 0.6 & 32 & 0.4 & 95 & 0.9 & 63 & 0.59 & 4.8 & 0.3 & 3.2 & 0.2 \\
\hline 30 & 67 & 0.8 & 45 & 0.6 & 135 & 1.2 & 90 & 0.83 & 6.8 & 0.5 & 4.5 & 0.3 \\
\hline 60 & 84 & 1.1 & 56 & 0.7 & 168 & 1.6 & 112 & 1.0 & 8.4 & 0.6 & 5.6 & 0.4 \\
\hline 90 & 96 & 1.2 & 64 & 0.8 & 193 & 1.8 & 129 & 1.2 & 9.7 & 0.7 & 6.4 & 0.5 \\
\hline 180 & 130 & 1.6 & 87 & 1.1 & 260 & 2.4 & 174 & 1.6 & 13 & 0.9 & 8.7 & 0.6 \\
\hline 365 & 184 & 2.3 & 123 & 1.5 & 368 & 3.4 & 245 & 2.3 & 18 & 1.3 & 12 & 0.9 \\
\hline $2 y$ & 293 & 3.7 & 196 & 2.5 & 587 & 5.4 & 391 & 3.6 & 29 & 2.1 & 20 & 1.4 \\
\hline $5 y$ & 1,126 & 14 & 751 & 9.5 & 2,252 & 21 & 1,501 & 14 & 113 & 8.1 & 75 & 5.4 \\
\hline $10 \mathrm{y}$ & 10,576 & 133 & 7051 & 89 & 21,152 & 196 & 14,101 & 131 & 1058 & 76 & 705 & 50 \\
\hline
\end{tabular}

(a) Based on an MDA of $1.2 \mathrm{nCi}$.

(b) Based on an MDA of $0.8 \mathrm{nCi}$.

(c) Dose values less than 1 mrem are rounded to one significant figure.

\subsection{Assessment of Internal Dose}

The assessment of internal equivalent dose from corrosion products is accomplished by evaluating in vivo measurement results. While assessments of internal doses for intakes of mixtures of corrosion product radionuclides must consider the contribution of all radionuclides present in the mixture, ${ }^{60} \mathrm{Co}$ is the principal radionuclide of concern for corrosion products at Hanford.

The committed effective dose is calculated for any intake confirmed by special bioassay measurements, and for periodic measurements that exceed the screening levels contained in the Hanford Internal Dosimetry Program Manual (PNL-MA-552; EH Carbaugh, et al. 2009). Committed equivalent dose to specific organs and tissues is determined based on the criteria also presented in the Hanford Internal 
Dosimetry Program Manual. Several methods exist to evaluate in vivo results to assess the internal dose equivalent. The simplest method and the one recommended for initial evaluation of in vivo results as well as for final evaluations when doses are low, involves fitting the in vivo measurement data to the expected internal activity using the ${ }^{60} \mathrm{Co}$ biokinetic model prescribed by the ICRP 30 . This model is implemented using the IMBA computer code. Assumptions that are used for this evaluation are 1) that the material is in its most insoluble form (i.e., Type $S$ absorption); 2) that the intake date, if unknown, is assumed to be the midpoint of the period during which the intake could have occurred; and 3) that the intake consisted of inhalation of an aerosol with 5 - $\mu$ m-AMAD particles. Data fitting is performed using IMBA. Alternatively, a hand calculation can be performed using the factors tabulated in this chapter.

If the intake could potentially result in a committed effective dose exceeding 100 mrem or if a worker's retention seems to be significantly different from the default models, there are two recommendations: 1) investigate to determine the radionuclide composition of the involved corrosion product mixture and to assess the equivalent dose from all radionuclides present in the mixture; and 2) obtain a series of whole body counts over time and fit the in vivo measurement data using IMBA. The data analysis may include adjustments to biokinetic parameters to improve the agreement between the model and the observed in vivo measurement data. Any modifications to default model parameters must be documented in the internal dose assessment report. Adjustments to biokinetic parameter values are discouraged if the changes only result in minor improvements to the fit.

\subsection{Management of Internal Contamination Cases}

Historically, during reactor operations, activated corrosion product radionuclides were the most common type of internal exposure at Hanford. The exposures were minor and there is no known instance in which special therapeutic measures were applied for dose aversion. Various options exist for treatment to remove corrosion product radionuclides from the body (Bhattacharyya et al. 1992). These methods generally involve measures to minimize absorption into the blood and intestinal absorption, including stomach lavage and administration of purgatives, emetics, or phytates. Cobalt gluconate will aid in reducing absorption and enhancing excretion. Use of chelating agents may also be considered in significant exposure cases. The chelating agents to be used include Co-EDTA (cobalt salt of ethylenediaminetetraacetic acid), Zn-DTPA (zinc salt of diethylenetriaminepentaacetic acid), or penicillamine. A primary consideration for all mitigatory actions is prompt response because the effectiveness of treatment decreases rapidly with time post intake. The Occupational Medicine Provider should be notified immediately upon indication of a severe intake of corrosion product radionuclides.

\subsection{References}

10 CFR 835. 2007. “Occupation Radiation Protection.” Code of Federal Regulations. U.S. Department of Energy. Available at: http://www.access.gpo.gov

Bhattacharyya MH, BD Breitenstein, H Metivier, BA Muggenburg, GN Stradling, and V Volf. 1992. "Guidebook for the Treatment of Accidental Internal Radionuclide Contamination of Workers." Rad. Prot. Dosim. 41:1.

Carbaugh EH, DE Bihl, JA MacLellan. 2009. Hanford Internal Dosimetry Program Manual. PNL-MA552, PNNL-15613, Pacific Northwest National Laboratory, Richland, Washington. (Internal manual.) A 
copy of this manual is maintained in the HIDP files and available from the HIDP Manager or online by searching, PNNL-15613 @ http://www.pnl.gov/publications/.

International Atomic Energy Agency (IAEA). 1996. International Basic Safety Standards for Protection Against Ionizing Radiation and for the Safety of Radiation Sources. Safety Series No. 115, Vienna, Austria.

International Commission on Radiological Protection (ICRP). 1979. "Limits for Intakes of Radionuclides by Workers.” ICRP Publication 30, Part 1, Annals of the ICRP, 2:3-4, Pergamon Press, New York.

International Commission on Radiological Protection (ICRP). 1988. "Individual Monitoring for Intakes of Radionuclides by Workers: Design and Interpretation.” ICRP Publication 54, Annals of the ICRP, 19:1-3, Pergamon Press, New York.

International Commission on Radiological Protection (ICRP). 1993. “Age-dependent Doses to Members of the Public from Intake of Radionuclides: Part 2 Ingestion Dose Coefficients.” ICRP Publication 67, Annals of the ICRP, 23:3-4, Pergamon Press, New York.

International Commission on Radiological Protection (ICRP). 1994a. "Dose Coefficients for Intakes of Radionuclides by Workers.” ICRP Publication 68, Annals of the ICRP, 24:4, Pergamon Press, New York.

International Commission on Radiological Protection (ICRP). 1994b. "Human Respiratory Tract Model for Radiological Protection.” ICRP Publication 66, Annals of the ICRP, 24:1-3, Pergamon Press, New York.

International Commission on Radiological Protection (ICRP). 1995. "Age-dependent Doses to Members of the Public from Intake of Radionuclides: Part 3 Ingestion Dose Coefficients.” ICRP Publication 69, Annals of the ICRP, 25:13-23, Pergamon Press, New York.

International Commission on Radiological Protection (ICRP). 1997. “Individual Monitoring for Internal Exposure of Workers.” ICRP Publication 78, Annals of the ICRP, 27:3-4, Pergamon Press, New York.

James AC, JW Marsh, A Burchall, NS Jarvis, M Puncher, K Davis, and D King. 2004. User Manual for IMBA Expert USDOE-Edition, “Appendix A: Technical Basis.” ACJ \& Associates, Richland, Washington.

Kocher DC. 1981. Radioactive Decay Data Tables. DOE/TIC-11026, Technical Information Center, U.S. Department of Energy, Washington, D.C.

Weetman RA and HW DeHaven. 1982a. Characterization of Airborne Radionuclides in UNC Facilities. UNI-2164, UNC Nuclear Industries, Richland, Washington.

Weetman RA and HW DeHaven. 1982b. Characterization of Surface Contamination in UNC Facilities. UNI-2137, UNC Nuclear Industries, Richland, Washington. 


\title{
Methods and Models of the Hanford Internal Dosimetry Program \\ PNNL-MA-860
}

\section{0 lodine}

\author{
Issued for implementation effective 01/01/2010
}

Supersedes: September 12, 2000

\section{Use Category: Not applicable}

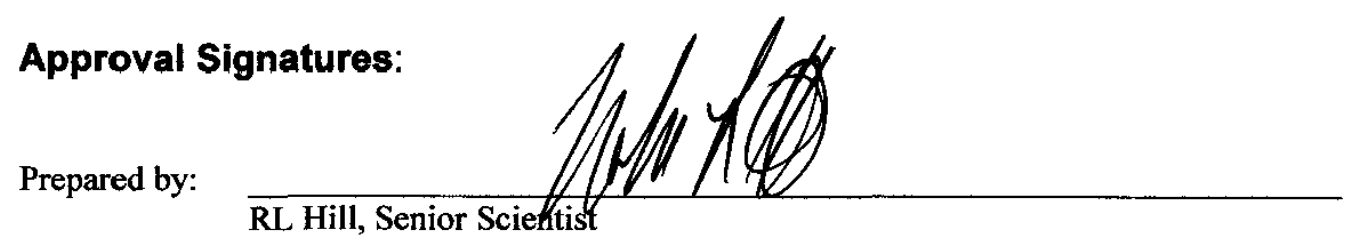

Approved by:

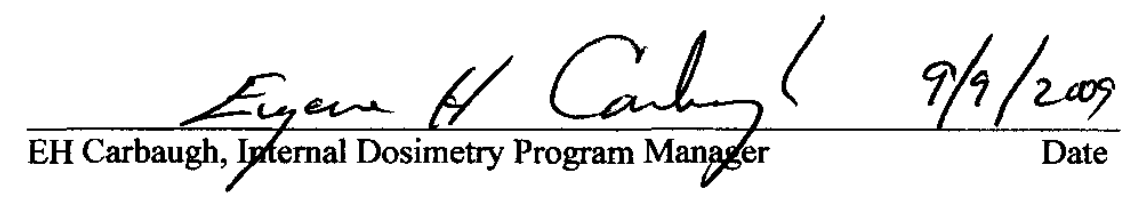

\section{Reviewer Signatures:}

Reviewed by:

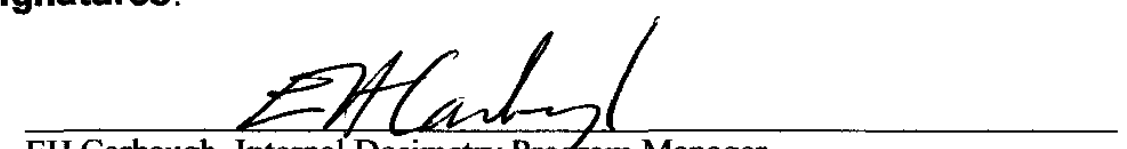

EH Carbaugh, Internal Dosimetry Program Manager

Approved by the Hanford Personnel Dosimetry Advisory Committee as recorded in the meeting minutes of March 10, 2009. 


\section{Contents}

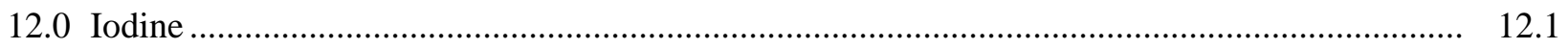

12.1 Sources and Characteristics of Radioiodine ............................................................... 12.1

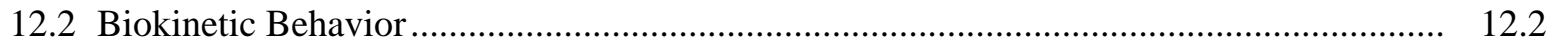

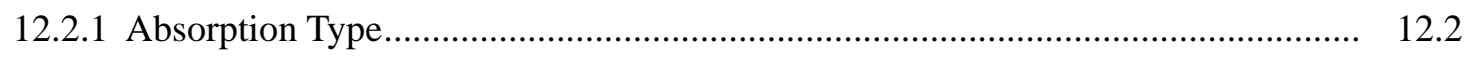

12.2.2 Gastrointestinal Uptake to Blood (f1) .............................................................. 12.3

12.2.3 Biokinetic Model ........................................................................................... 12.3

12.3 Internal Dosimetry Factors for Radioiodines............................................................ 12.4

12.3.1 Retention and Excretion of Radioiodine ........................................................... 12.5

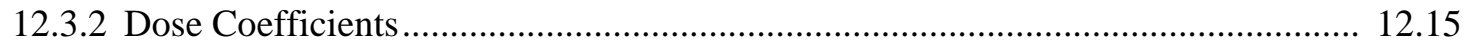

12.3.3 Comparison of Published Dosimetry Factors .................................................... 12.16

12.3.4 Derived Air Concentrations and Annual Limits on Intake .................................. 12.16

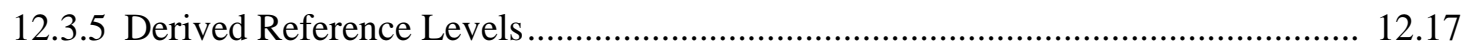

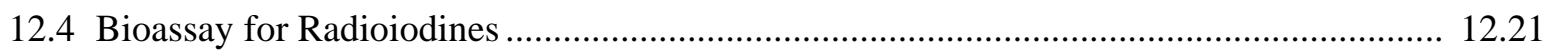

12.4.1 Bioassay Methods and Capabilities ................................................................. 12.21

12.4.2 Routine Bioassay Monitoring Protocol............................................................ 12.27

12.4.3 Special Monitoring for Suspected Intakes ....................................................... 12.27

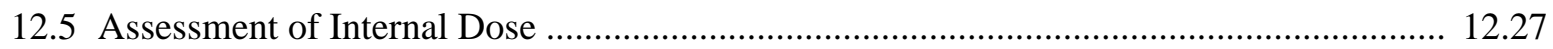

12.6 Management of Internal Contamination Cases.......................................................... 12.28

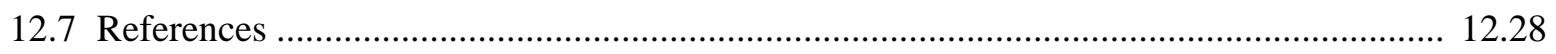

\section{Figures}

12.1 Biokinetic Model for Iodine.....

12.2 Retention of ${ }^{131} \mathrm{I}$ as a Fraction of an Acute Inhalation Intake of 5- $\mu \mathrm{m}$-AMAD Particle Sizes ......

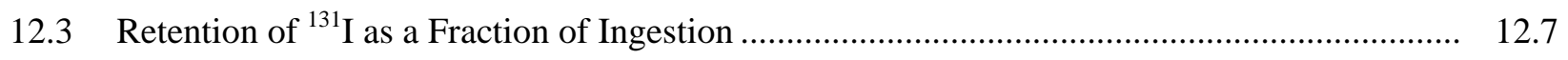

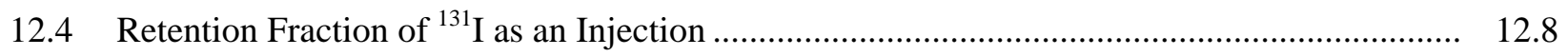

12.5 Retention of ${ }^{129} \mathrm{I}$ as a Fraction of an Acute Inhalation Intake of 5- $\mu$ m-AMAD Particle

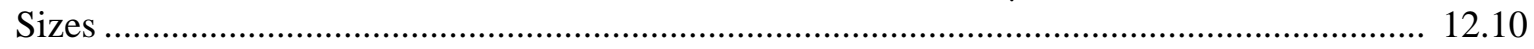

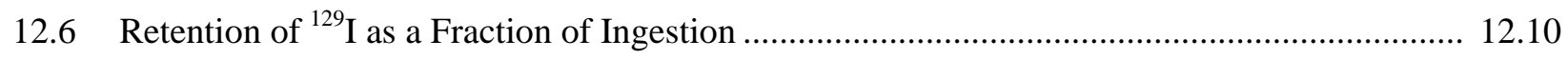

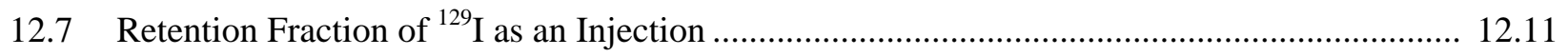

12.8 Retention of ${ }^{125} \mathrm{I}$ as a Fraction of an Acute Inhalation Intake of 5- $\mu \mathrm{m}$-AMAD Particle

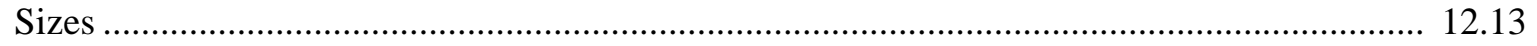

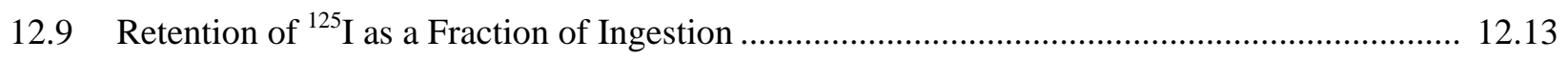

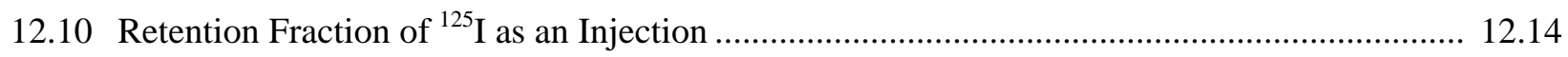


12.11 Comparison of Thyroid Retention Fraction and Urinary Excretion of ${ }^{131}$ I Following

Inhalation, Ingestion, or Injection .....

12.12 Comparison of Thyroid Retention Fraction and Urinary Excretion of ${ }^{125}$ I Following Inhalation, Ingestion, or Injection

12.13 Comparison of Thyroid Retention Fraction and Urinary Excretion of ${ }^{129}$ I Following Inhalation, Ingestion, or Injection .....

12.14 Minimum Detectable Thyroid Equivalent Dose Following Type F 5- $\mu \mathrm{m}-\mathrm{AMAD}$ Inhalation.

12.15 Minimum Detectable Thyroid Equivalent Dose for ${ }^{131}$ I Following Inhalation, Ingestion, and Injection for the Three Counting Systems (IG Thyroid Counting System)

12.16 Minimum Detectable Thyroid Equivalent Dose for ${ }^{131}$ I Following Inhalation, Ingestion, and Injection for the Three Counting Systems (Coaxial Whole Body Counting System)

12.17 Minimum Detectable Thyroid Equivalent Dose for ${ }^{131}$ I Following Inhalation, Ingestion, and Injection for the Three Counting Systems (NaI Preview Counting System) 12.26

\section{Tables}

12.1 Radiological Data for Radioiodines

12.2 Lung Absorption and GI Uptake Factors for Radioiodines.

12.3 Biokinetic Model Parameters for Iodine

12.4 Transfer Rates for the Iodine Biokinetic Model

12.5 Retention and Excretion Fractions for ${ }^{131} \mathrm{I}$

12.6 Retention and Excretion Fractions for ${ }^{129} \mathrm{I}$

12.7 Retention and Excretion Fractions for ${ }^{125} \mathrm{I}$ 12.12

12.8 Committed Dose Coefficients for Radioiodines .

12.9 Comparison of Effective Dose Coefficients for Radioiodines

Table 12.1. DACs and DALIs for Radioiodines..... 12.17

12.11 Reference Levels and Derived Reference Levels for ${ }^{131} \mathrm{I}$

12.12 Reference Levels and Derived Reference Levels for ${ }^{129} \mathrm{I}$

12.13 Reference Levels and Derived Reference Levels for ${ }^{125} \mathrm{I}$

12.14 Hanford In Vivo Measurement Detection Capability for ${ }^{131} \mathrm{I}$, ${ }^{129} \mathrm{I}$, and ${ }^{125} \mathrm{I}$

12.15 Minimum Detectable Intakes and Doses $E(50)$ and Thyroid $H_{\mathrm{T}}(50)$ for 5 - $\mu \mathrm{m}-\mathrm{AMAD}$ Type F Inhalation ....

12.16 Minimum Detectable Intakes and Doses $E(50)$ and Thyroid $H_{\mathrm{T}}(50)$ for Ingestion. 12.23

12.17 Minimum Detectable Intakes and Doses $E(50)$ and Thyroid $H_{\mathrm{T}}(50)$ for Injection 12.24 



\section{0 lodine}

Radioiodines generated or used at Hanford have included isotopes with half-lives ranging from minutes to millions of years in various physical and chemical forms. With the time that has elapsed since operation of Hanford production reactors and the Fast Flux Test Facility, the short-lived radioiodines have all decayed away, leaving only ${ }^{129}$ I as a waste contaminant. Laboratory use of short-lived radioiodines may still occur. This chapter provides information about the sources, characteristics, and biokinetics of radioiodine and summarizes the technical basis used for its internal dosimetry at Hanford.

This revision of the internal dosimetry approach for iodine implements the International Commission on Radiological Protection lung model presented in its Publication 66 (ICRP 1994b) and the biokinetic model for iodine presented in ICRP 56 (1989), ICRP 68 (1994a), and ICRP 78 (1997). For those parameters with age-specific differences, the parameters for "adult” are used. The ICRP 30 gastrointestinal (GI) model is still used (ICRP 1979), except that uptake factors from the gut to the blood, $f_{1}$, have been updated as given in ICRP 68 (1994a). For dose calculations, tissues and tissue weighting factors introduced in ICRP 60 (1991) and adopted in the June 2007 revision of Title 10 of the Code of Federal Regulations Part 835 (10 CFR 835) are used. All excretion, retention, and dose coefficients were calculated using the Integrated Modules for Bioassay Analysis (IMBA) Professional Plus internal computer code, v. 4.0.43 (James et. al. 2004), ${ }^{1}$ which implements the above-mentioned biokinetic models.

\subsection{Sources and Characteristics of Radioiodine}

At Hanford the radioiodines of principal interest are ${ }^{131} \mathrm{I}$, which is associated with reactor operations,

${ }^{129}$ I, which is associated with waste management and groundwater operations, and ${ }^{125}$ I, which is mainly associated with biological experimentation. Radiological decay data for these radioiodine nuclides are listed in Table 12.1.

Table 12.1. Radiological Data for Radioiodines ${ }^{(a)}$

\begin{tabular}{cccc}
\hline Isotope & Half-Life & Decay Constant & Specific Activity (Ci/g) \\
\hline${ }^{131} \mathrm{I}$ & $8.0 \mathrm{~d}$ & $8.7 \mathrm{E}-02 \mathrm{~d}^{-1}$ & $1.24 \mathrm{E}+05$ \\
${ }^{129} \mathrm{I}$ & $1.57 \mathrm{E}+07 \mathrm{y}$ & $4.4 \mathrm{E}-08 \mathrm{y}^{-1}$ & $1.77 \mathrm{E}-04$ \\
${ }^{125} \mathrm{I}$ & $60 \mathrm{~d}$ & $1.2 \mathrm{E}-02 \mathrm{~d}^{-1}$ & $1.74 \mathrm{E}+04$ \\
\hline
\end{tabular}

(a) Half-life values comparable between IMBA 2007 and ICRP 68 (1994a).

Historically, radioiodines were generated in large quantities during the operation of production and research reactors. However, with those reactors either permanently shut down or in long-term standby mode, the only current potential source of onsite fission product radioiodine at Hanford is from the Energy Northwest commercial nuclear power reactor, Columbia Generating Station. The most significant radioiodine from an internal exposure standpoint is considered to be ${ }^{131} \mathrm{I}$. Several other radioactive

\footnotetext{
${ }^{1}$ IMBA Professional Plus, which includes the current version of the user manual, is available from Health Protection Agency (HPA), Radiation Protection Division, Chilton, Didicot, Oxon., OX11 ORQ UK and from http://www.imbaprofessional.com/
} 
isotopes of iodine are generated by the fission process. However, with the exception of the long-lived ${ }^{129}$ I, the others are short-lived and of potential interest only during or within several days of reactor operation. Iodine-129 has, for practical purposes, an infinite half-life (i.e., 1.57E+07 years). It is contained in irradiated fuel, associated separations and waste management facilities, and may be encountered during some groundwater drilling operations on the Hanford Site. However, unless concentrated by some means (e.g., the Plutonium-Uranium Extraction Plant air treatment system), it is present in negligibly small quantities.

The vast majority of ${ }^{131}$ I measured in Hanford workers in recent years has been nonoccupational medical administrations for either diagnostic or therapeutic purposes. Patients receiving such administrations lose ${ }^{131}$ I by normal biological pathways including urine excretion and exhalation. The magnitude of medical administrations can easily result in small quantities of ${ }^{131} \mathrm{I}$ being absorbed by caregivers, family members, or those in close contact with patients, even after patients are released from a hospital.

Iodine-125 is not generated at Hanford, but it is purchased for use in various biological research experiments. Therefore, its use is generally limited to biology laboratories operated by Pacific Northwest National Laboratory. Quantities of the isotope in use at one time are generally limited to amounts that could not result in significant internal exposures. Just as for ${ }^{131} \mathrm{I},{ }^{125} \mathrm{I}$ is also encountered at Hanford as nonoccupational medical administrations for therapeutic purposes as brachytherapy sealed sources that are implanted in the individual. The activity in these permanently implanted ${ }^{125}$ I seeds may provide an interference with whole body counting.

\subsection{Biokinetic Behavior}

ICRP 68 (1994a) indicates that a revised biokinetic model based on a physiologically based recycling model is to be used for radioiodine. ICRP 56 (1989) describes the distribution and retention models that are used by the Hanford Internal Dosimetry Program to predict the uptake, retention, and resulting doses following an intake of a radioiodine.

\subsubsection{Absorption Type}

ICRP 78 (1997) establishes Type F (for fast rate of solubilization) as the default absorption type for the inhalation of radioiodines of concern at Hanford (i.e., ${ }^{131}$ I, ${ }^{129}$ I, ${ }^{125}$ I). ICRP 68 and 78 assign an absorption type of SR-1 (soluble or reactive) for elemental iodine vapor; however, this form of radioiodine is not currently part of the Hanford source term. Therefore, elemental iodine is not included in this chapter. IMBA v. 4.0.43 (James et. al. 2004) implements the biokinetic models for radioiodines described in ICRP 56, ICRP 68, and ICRP 78 and is used to assess expected bioassay compartment quantities following intakes of the radioiodines. The biokinetic parameters of IMBA can also be modified to provide a better agreement between observed and expected bioassay compartment values.

The ICRP 66 lung model (ICRP 1994b) introduced the concept of absorption type as a replacement for the ICRP 30 inhalation class. Table 12.2 shows the absorption type tabulated in ICRP 56, ICRP 68, and ICRP 78 for radioiodines. 
Table 12.2. Lung Absorption and GI Uptake Factors for Radioiodines ${ }^{(a)}$

\begin{tabular}{cccc}
\hline Isotope & Chemical Form & Absorption Type & GI Uptake $\left(f_{1}\right)$ \\
\hline${ }^{131} \mathrm{I}$ & All compounds $^{(\mathrm{b})}$ & $\mathrm{F}$ & 1.0 \\
${ }^{129} \mathrm{I}$ & All compounds $^{(\mathrm{b})}$ & $\mathrm{F}$ & 1.0 \\
${ }^{125} \mathrm{I}$ & All compounds $^{(\mathrm{b})}$ & $\mathrm{F}$ & 1.0 \\
\hline
\end{tabular}

(a) From ICRP 68 and 78.

(b) Includes all radioiodine compounds except iodine vapors/gases.

\subsubsection{Gastrointestinal Uptake to Blood $\left(f_{1}\right)$}

The GI uptake $\left(f_{1}\right)$ factor for all forms of iodine is 1.0. This $f_{1}$ value is consistent in ICRP 56, 67 (1993), 68, and 78.

\subsubsection{Biokinetic Model}

The ICRP 30 used a three-compartment model based on a model described by Riggs (1952) to describe the biokinetics of iodine in adults after its entry into the blood. This model, with modification for recycling, has been adopted by the ICRP in ICRP 56 for use after intakes of radioiodine. The ICRP 56 model allows recycling of iodine to the thyroid, which is necessary only for long-lived iodine isotopes such as those of interest at Hanford. Of the iodine entering the blood, $30 \%$ is assumed to be translocated to the thyroid, while the remainder (70\%) is assumed to go directly to urinary excretion. Iodine that is incorporated in thyroid hormones leaves the thyroid with a half-time of about 80 days. This iodine goes into the blood, where it is metabolized in tissues, retained with a half-time of about 12 days, and returns to the blood as inorganic iodine. Most of the iodine (80\%) subsequently released into the blood circulation will be recycled to the thyroid and urinary excretion, and about $20 \%$ will be excreted in feces (ICRP 78) either in a chemical form not subject to re-absorption or as input to a biokinetic compartment downstream of the GI tract absorption.

Table 12.3. Biokinetic Model Parameters for Iodine $\mathrm{a}^{(\mathrm{a})}$

\begin{tabular}{|c|c|c|c|c|c|c|}
\hline \multirow[b]{2}{*}{ Age } & \multicolumn{3}{|c|}{ Distribution (\%) } & \multicolumn{3}{|c|}{ Biological Half-Time (d) } \\
\hline & $\begin{array}{l}\text { Uptake by } \\
\text { Thyroid }\end{array}$ & $\begin{array}{l}\text { Prompt Urinary } \\
\text { Excretion } \\
\end{array}$ & $\begin{array}{c}\text { Fecal Excretion } \\
\text { from Rest of Body }\end{array}$ & Blood $\mathrm{T}_{\mathrm{a}}$ & $\begin{array}{c}\text { Thyroid } \\
\mathrm{T}_{\mathrm{b}} \\
\end{array}$ & $\begin{array}{l}\text { Rest of } \\
\text { Body } \mathrm{T}_{\mathrm{c}}\end{array}$ \\
\hline$\overline{\text { Adult }}$ & 30 & 70 & 20 & 0.25 & 80 & 12 \\
\hline
\end{tabular}

(a) The biokinetic data shown above refer to a recycling model (ICRP 56, 67, and 78).

A graphical representation of the recycling model for iodine (James et al. 2004) is shown in Figure 12.1. The model depicted shows the way in which the three-compartment model in ICRP 56 was adapted for implementation within IMBA. The transfer rates as used in IMBA are shown in Table 12.4. 


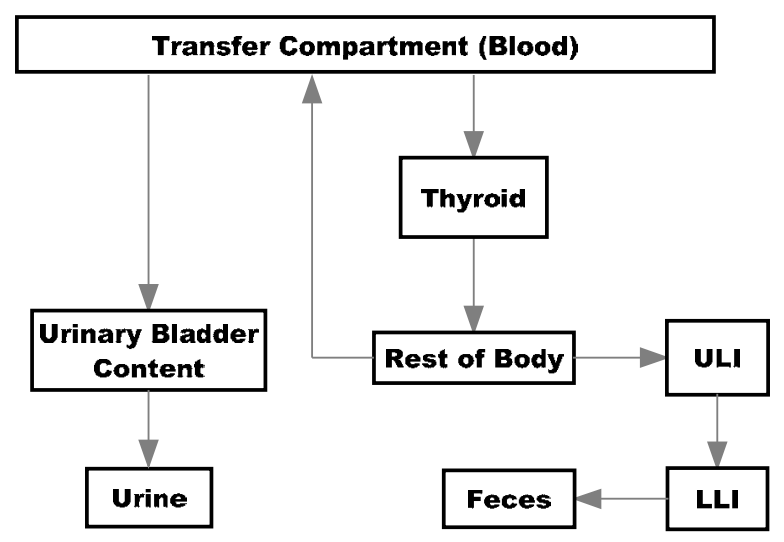

Figure 12.1. Biokinetic Model for Iodine (ULI = upper large intestine; LLI = lower large intestine)

Table 12.4. Transfer Rates for the Iodine Biokinetic Model ${ }^{(\mathrm{a})}$

\begin{tabular}{lc}
\hline \multicolumn{1}{c}{ Route of Transfer Between Compartments } & Transfer Rate $\left(\mathrm{d}^{-1}\right)$ \\
\hline Blood to Thyroid & 0.83178 \\
Blood to Urinary Bladder Content & 0.19408 \\
Thyroid to Rest of Body & 0.0086643 \\
Rest of Body to Blood & 0.04621 \\
Rest of Body to Upper Large Intestine Content & 0.01155 \\
\hline (a) From James et al. (2004). & \\
\hline
\end{tabular}

Because iodine is recycled through the thyroid, monitoring of the thyroid after an intake will not reveal a single exponential clearance. ICRP 56 describes the fractional retention $[R(t)]$ in the thyroid by the sum of two exponentials:

$$
R(t)=A e^{-0.693\left(\frac{t}{T_{1}}\right)}+(1-A) e^{-0.693\left(\frac{t}{T_{2}}\right)}
$$

where $T_{1}$ and $T_{2}$ are taken to be the observed half-times, to distinguish them from the biological halftimes. For isotopes with a short half-time like ${ }^{131} \mathrm{I}$, the retention in the thyroid is typically only followed for about 2 weeks, which is too short of a time to get the resolution of the two exponentials. As a result, many investigators report only a single exponential clearance from the thyroid, with " $\mathrm{T}$ " as the "apparent" half-time.

\subsection{Internal Dosimetry Factors for Radioiodines}

This section contains factors that are useful in making internal dosimetry calculations. The factors are derived from IMBA (v. 4.0.43) and incorporate the models and assumptions from the preceding sections. Their application is intended for circumstances where such assumptions are appropriate or more specific information is lacking. Variation from these factors is appropriate if sufficient data are available. 


\subsubsection{Retention and Excretion of Radioiodine}

The fractional retention factors for the whole body and the thyroid, and the urine and feces excretion fractions for acute inhalation, ingestion, and injection are listed in Table 12.5 and plotted in Figure 12.2 for ${ }^{131} \mathrm{I}$, Table 12.6 and Figure 12.3 for ${ }^{129} \mathrm{I}$, and Table 12.7 and Figure 12.4 for ${ }^{125} \mathrm{I}$. These fractions are calculated using IMBA v. 4.0.43 assuming a 5- $\mu$ m-activity median aerodynamic diameter (AMAD) particle size for ${ }^{131} \mathrm{I},{ }^{129} \mathrm{I}$, and ${ }^{125} \mathrm{I}$.

The data presented in Table 12.5 and Figure 12.2, show that the retention of ${ }^{131}$ I for the whole body and for the thyroid become essentially the same after about 5 days. After about 1 month, the retention in whole body and the thyroid drops off at a rapid pace. Urine excretion fraction drops off at a rapid pace for about the first 5 days, levels off somewhat for about 2 weeks, and then continues with a significant drop in the excretion fraction. Because fecal excretion is considered in the biokinetic model, the excretion fraction is shown for fecal excretion in Table 12.5 and Figure 12.2. The figure shows that virtually none of the original ${ }^{131}$ I that was from the intake is excreted into feces. The fecal excretion occurs mainly after the radioiodine has been recycled. Because of this and the fact that the fecal excretion rate is much less than for urine, this excretion pathway is omitted for the other iodine isotopes discussed in this chapter.

Figures $12.11,12.12$, and 12.13 provide a summary of the thyroid retentions and the urinary excretion patterns for ${ }^{131} \mathrm{I},{ }^{125} \mathrm{I}$, and ${ }^{129} \mathrm{I}$. The length of retention of the radioiodines in the thyroid is largely dependent on the physical half-life. The retention and excretion patterns for inhalation, ingestion, and injection pathways for each individual radioiodine appear to be very similar. For the thyroid, the ingestion and injection pathways have in essence the same retention fraction and the inhalation pathway has slightly less retention until approximately 2 weeks after intake when the retention fractions for all three pathways are essentially the same. For urinary excretion, the same pattern predominates where the excretion for ingestion and injection are basically the same and excretion for an inhalation is slightly less than for ingestion or injection until about 2 weeks after intake. Because the GI tract uptake factor is 1.0, the ingestion-based retention and excretion fractions may be used to approximate an injection (wound) intake. 
Table 12.5. Retention and Excretion Fractions for ${ }^{131} \mathrm{I}$

\begin{tabular}{|c|c|c|c|c|c|c|c|c|c|c|c|c|}
\hline \multirow[b]{2}{*}{$\begin{array}{l}\text { Time } \\
\text { (d) }\end{array}$} & \multicolumn{4}{|c|}{ Inhalation } & \multicolumn{4}{|c|}{ Ingestion } & \multicolumn{4}{|c|}{ Injection } \\
\hline & $\begin{array}{l}\text { Whole } \\
\text { Body }\end{array}$ & Thyroid & Urine & Feces & $\begin{array}{l}\text { Whole } \\
\text { Body }\end{array}$ & Thyroid & Urine & Feces & $\begin{array}{l}\text { Whole } \\
\text { Body }\end{array}$ & Thyroid & Urine & Feces \\
\hline 0.5 & 4.75E-01 & $9.02 \mathrm{E}-02$ & $1.83 \mathrm{E}-01$ & $7.42 \mathrm{E}-09$ & $6.70 \mathrm{E}-01$ & $1.52 \mathrm{E}-01$ & $2.88 \mathrm{E}-01$ & 5.86E-09 & 5.05E-01 & $2.15 \mathrm{E}-01$ & $4.53 \mathrm{E}-01$ & $2.38 \mathrm{E}-08$ \\
\hline 1 & 2.83E-01 & $1.20 \mathrm{E}-01$ & 2.73E-01 & $1.76 \mathrm{E}-07$ & 3.81E-01 & 2.39E-01 & 5.36E-01 & 2.23E-07 & $3.27 \mathrm{E}-01$ & 2.56E-01 & $5.90 \mathrm{E}-01$ & 4.82E-07 \\
\hline 2 & $1.62 \mathrm{E}-01$ & $1.19 \mathrm{E}-01$ & 3.13E-02 & $2.66 \mathrm{E}-06$ & 2.59E-01 & $2.47 \mathrm{E}-01$ & $9.11 \mathrm{E}-02$ & 4.50E-06 & $2.55 \mathrm{E}-01$ & $2.48 \mathrm{E}-01$ & 4.49E-02 & 6.36E-06 \\
\hline 3 & $1.24 \mathrm{E}-01$ & $1.09 \mathrm{E}-01$ & $1.88 \mathrm{E}-03$ & 8.47E-06 & 2.32E-01 & $2.27 \mathrm{E}-01$ & $5.49 \mathrm{E}-03$ & $1.59 \mathrm{E}-05$ & 2.32E-01 & 2.26E-01 & $2.68 \mathrm{E}-03$ & $1.90 \mathrm{E}-05$ \\
\hline 4 & 1.06E-01 & $9.92 \mathrm{E}-02$ & 1.73E-04 & $1.53 \mathrm{E}-05$ & 2.12E-01 & 2.06E-01 & 4.46E-04 & $3.00 \mathrm{E}-05$ & 2.12E-01 & 2.06E-01 & $2.94 \mathrm{E}-04$ & 3.34E-05 \\
\hline 5 & $9.50 \mathrm{E}-02$ & $9.03 \mathrm{E}-02$ & 8.99E-05 & $2.16 \mathrm{E}-05$ & 1.94E-01 & $1.88 \mathrm{E}-01$ & $1.87 \mathrm{E}-04$ & 4.30E-05 & $1.94 \mathrm{E}-01$ & $1.87 \mathrm{E}-01$ & $1.87 \mathrm{E}-04$ & 4.63E-05 \\
\hline 6 & $8.62 \mathrm{E}-02$ & $8.21 \mathrm{E}-02$ & $9.56 \mathrm{E}-05$ & $2.66 \mathrm{E}-05$ & 1.78E-01 & $1.71 \mathrm{E}-01$ & $1.95 \mathrm{E}-04$ & 5.36E-05 & $1.78 \mathrm{E}-01$ & $1.71 \mathrm{E}-01$ & 2.02E-04 & 5.65E-05 \\
\hline 7 & 7.86E-02 & 7.47E-02 & 1.03E-04 & 3.03E-05 & 1.63E-01 & $1.55 \mathrm{E}-01$ & 2.11E-04 & $6.16 \mathrm{E}-05$ & $1.63 \mathrm{E}-01$ & $1.55 \mathrm{E}-01$ & 2.17E-04 & $6.42 \mathrm{E}-05$ \\
\hline 8 & 7.19E-02 & $6.80 \mathrm{E}-02$ & $1.08 \mathrm{E}-04$ & 3.30E-05 & 1.49E-01 & $1.42 \mathrm{E}-01$ & $2.21 \mathrm{E}-04$ & $6.73 \mathrm{E}-05$ & 1.49E-01 & $1.41 \mathrm{E}-01$ & 2.27E-04 & 6.95E-05 \\
\hline 9 & 6.58E-02 & 6.19E-02 & $1.11 \mathrm{E}-04$ & 3.47E-05 & $1.37 \mathrm{E}-01$ & $1.29 \mathrm{E}-01$ & 2.27E-04 & 7.10E-05 & $1.37 \mathrm{E}-01$ & $1.29 \mathrm{E}-01$ & 2.32E-04 & 7.29E-05 \\
\hline 10 & $6.02 \mathrm{E}-02$ & 5.64E-02 & $1.11 \mathrm{E}-04$ & 3.56E-05 & 1.25E-01 & $1.17 \mathrm{E}-01$ & 2.29E-04 & 7.31E-05 & $1.25 \mathrm{E}-01$ & $1.17 \mathrm{E}-01$ & 2.33E-04 & 7.47E-05 \\
\hline 12 & $5.04 \mathrm{E}-02$ & 4.67E-02 & 1.09E-04 & 3.57E-05 & 1.05E-01 & $9.72 \mathrm{E}-02$ & 2.24E-04 & 7.36E-05 & $1.05 \mathrm{E}-01$ & $9.70 \mathrm{E}-02$ & 2.27E-04 & 7.47E-05 \\
\hline 14 & $4.21 \mathrm{E}-02$ & $3.87 \mathrm{E}-02$ & $1.02 \mathrm{E}-04$ & $3.42 \mathrm{E}-05$ & 8.76E-02 & 8.05E-02 & $2.11 \mathrm{E}-04$ & 7.07E-05 & 8.76E-02 & 8.04E-02 & 2.13E-04 & 7.16E-05 \\
\hline 16 & $3.52 \mathrm{E}-02$ & $3.21 \mathrm{E}-02$ & $9.38 \mathrm{E}-05$ & 3.19E-05 & 7.32E-02 & $6.68 \mathrm{E}-02$ & $1.94 \mathrm{E}-04$ & 6.59E-05 & 7.32E-02 & 6.67E-02 & $1.96 \mathrm{E}-04$ & $6.65 \mathrm{E}-05$ \\
\hline 18 & $2.94 \mathrm{E}-02$ & 2.66E-02 & 8.47E-05 & 2.90E-05 & 6.12E-02 & $5.54 \mathrm{E}-02$ & 1.75E-04 & $6.01 \mathrm{E}-05$ & $6.11 \mathrm{E}-02$ & 5.53E-02 & $1.76 \mathrm{E}-04$ & 6.06E-05 \\
\hline 20 & 2.46E-02 & $2.21 \mathrm{E}-02$ & 7.53E-05 & 2.60E-05 & 5.11E-02 & 4.59E-02 & $1.56 \mathrm{E}-04$ & 5.39E-05 & $5.10 \mathrm{E}-02$ & 4.59E-02 & $1.57 \mathrm{E}-04$ & 5.43E-05 \\
\hline 30 & $9.89 \mathrm{E}-03$ & 8.70E-03 & 3.71E-05 & $1.31 \mathrm{E}-05$ & 2.06E-02 & $1.81 \mathrm{E}-02$ & 7.70E-05 & 2.72E-05 & 2.06E-02 & $1.81 \mathrm{E}-02$ & 7.72E-05 & 2.72E-05 \\
\hline 60 & $6.28 \mathrm{E}-04$ & 5.38E-04 & 2.82E-06 & $1.01 \mathrm{E}-06$ & $1.31 \mathrm{E}-03$ & $1.12 \mathrm{E}-03$ & 5.86E-06 & $2.10 \mathrm{E}-06$ & $1.30 \mathrm{E}-03$ & $1.12 \mathrm{E}-03$ & 5.85E-06 & 2.10E-06 \\
\hline 90 & $3.92 \mathrm{E}-05$ & $3.34 \mathrm{E}-05$ & $1.82 \mathrm{E}-07$ & $6.53 \mathrm{E}-08$ & 8.16E-05 & 6.95E-05 & 3.78E-07 & $1.36 \mathrm{E}-07$ & 8.15E-05 & $6.95 \mathrm{E}-05$ & 3.77E-07 & $1.36 \mathrm{E}-07$ \\
\hline 180 & $9.48 \mathrm{E}-09$ & 8.07E-09 & 4.43E-11 & $1.59 \mathrm{E}-11$ & $1.97 \mathrm{E}-08$ & $1.68 \mathrm{E}-08$ & $9.20 \mathrm{E}-11$ & 3.31E-11 & $1.97 \mathrm{E}-08$ & $1.68 \mathrm{E}-08$ & $9.19 \mathrm{E}-11$ & 3.31E-11 \\
\hline 365 & 3.49E-16 & $2.97 \mathrm{E}-16$ & 1.63E-18 & $5.85 \mathrm{E}-19$ & 7.25E-16 & $6.17 \mathrm{E}-16$ & 3.38E-18 & $1.22 \mathrm{E}-18$ & 7.24E-16 & $6.16 \mathrm{E}-16$ & 3.38E-18 & $1.22 \mathrm{E}-18$ \\
\hline
\end{tabular}




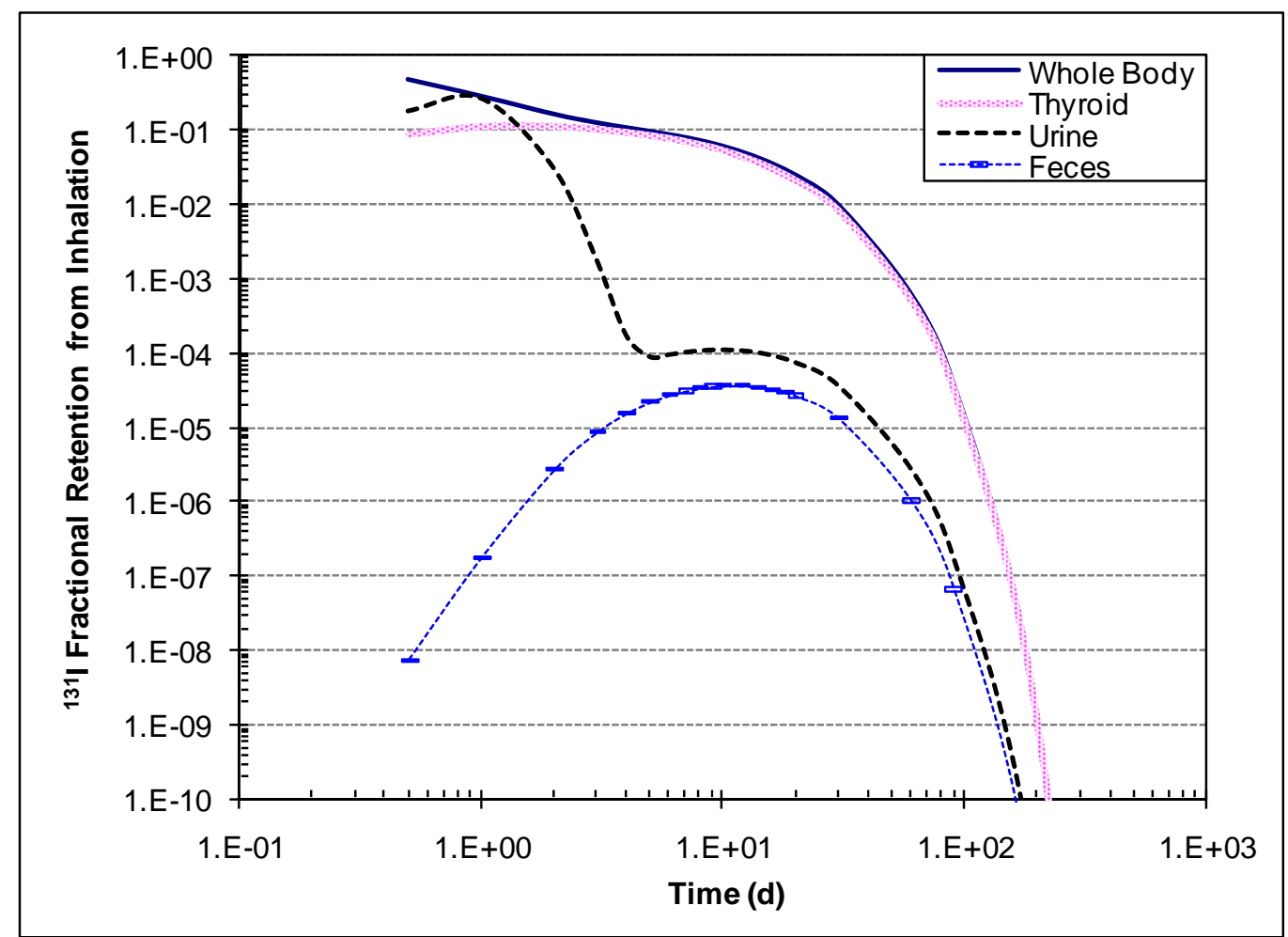

Figure 12.2. Retention of ${ }^{131} \mathrm{I}$ as a Fraction of an Acute Inhalation Intake of 5- $\mu \mathrm{m}$-AMAD Particle Sizes

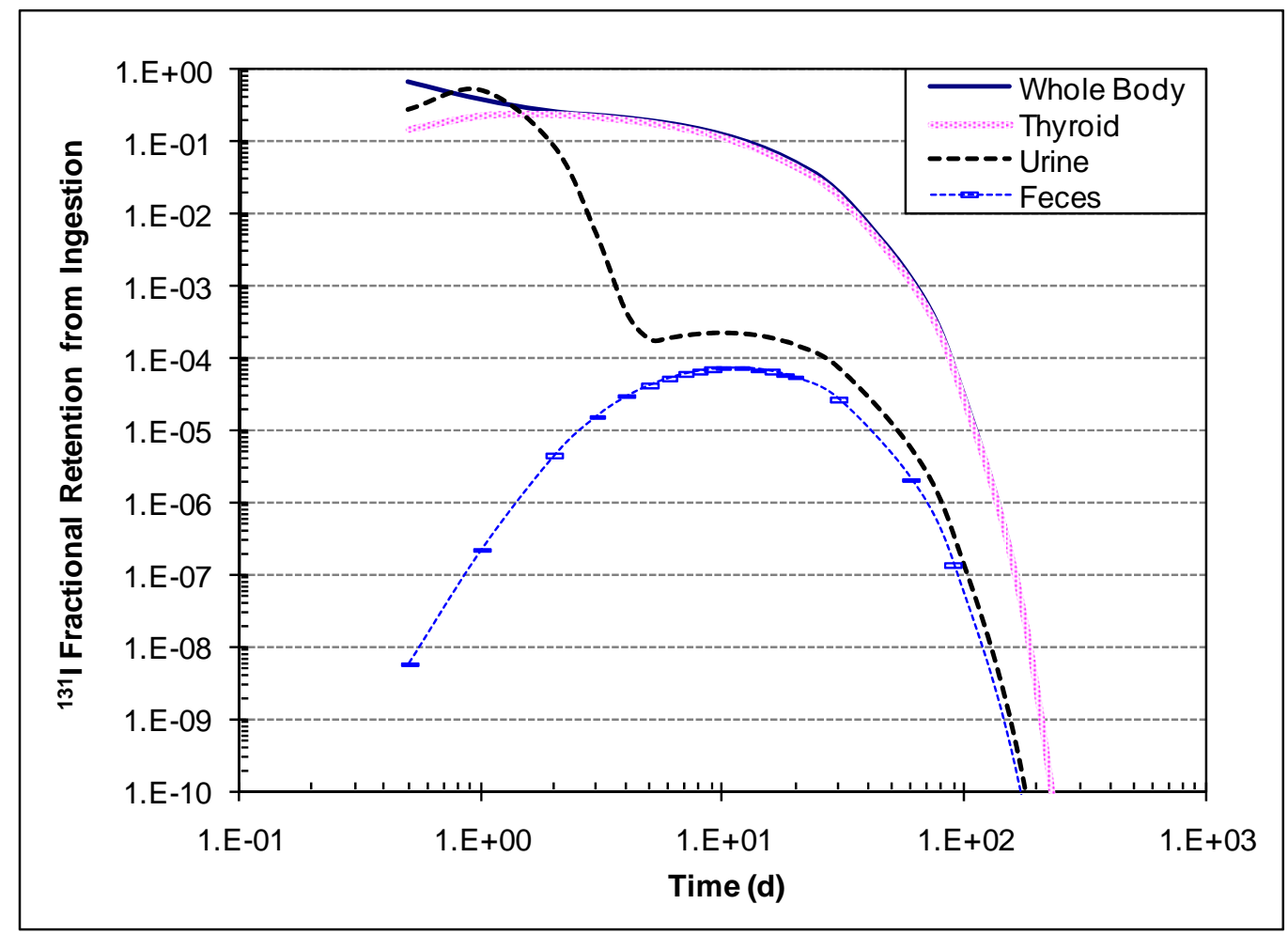

Figure 12.3. Retention of ${ }^{131} \mathrm{I}$ as a Fraction of Ingestion 


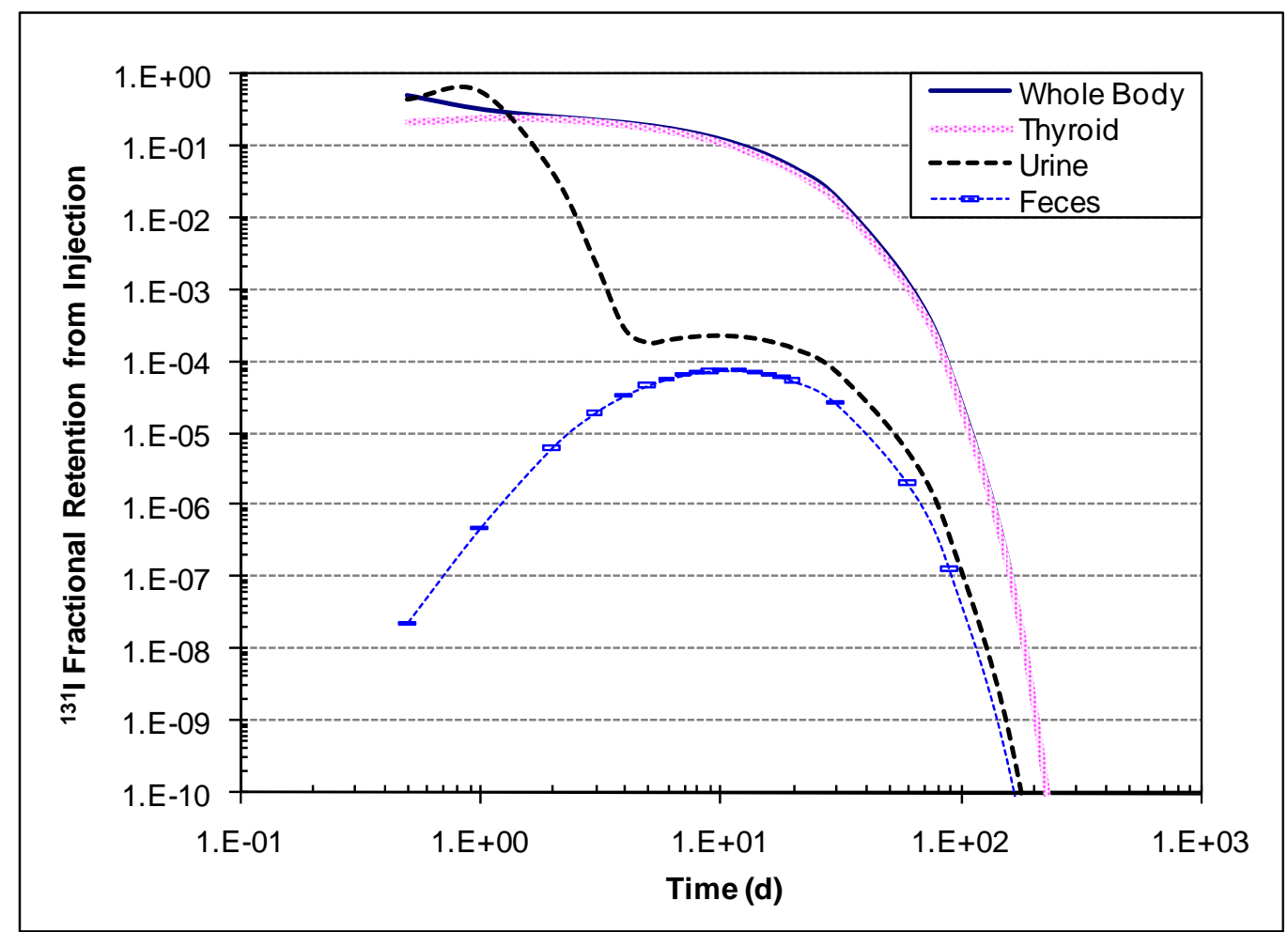

Figure 12.4. Retention Fraction of ${ }^{131} \mathrm{I}$ as an Injection 
Table 12.6. Retention and Excretion Fractions for ${ }^{129} \mathrm{I}$

\begin{tabular}{|c|c|c|c|c|c|c|c|c|c|}
\hline \multirow[b]{2}{*}{ Time (d) } & \multicolumn{3}{|c|}{ Inhalation } & \multicolumn{3}{|c|}{ Ingestion } & \multicolumn{3}{|c|}{ Injection } \\
\hline & $\begin{array}{l}\text { Whole } \\
\text { Body }\end{array}$ & Thyroid & Urine & Whole Body & Thyroid & Urine & Whole Body & Thyroid & Urine \\
\hline 0.5 & 4.95E-01 & 9.42E-02 & $1.91 \mathrm{E}-01$ & $7.00 \mathrm{E}-01$ & $1.59 \mathrm{E}-01$ & 3.00E-01 & 5.27E-01 & $2.24 \mathrm{E}-01$ & 4.73E-01 \\
\hline 1 & 3.09E-01 & 1.30E-01 & 2.97E-01 & 4.16E-01 & 2.60E-01 & 5.84E-01 & 3.57E-01 & 2.80E-01 & 6.43E-01 \\
\hline 2 & 1.93E-01 & $1.42 \mathrm{E}-01$ & 3.72E-02 & 3.07E-01 & 2.94E-01 & $1.08 \mathrm{E}-01$ & 3.03E-01 & 2.95E-01 & $5.34 \mathrm{E}-02$ \\
\hline 3 & $1.61 \mathrm{E}-01$ & $1.41 \mathrm{E}-01$ & 2.43E-03 & 3.00E-01 & 2.94E-01 & 7.12E-03 & 3.00E-01 & 2.93E-01 & $3.47 \mathrm{E}-03$ \\
\hline 4 & $1.50 \mathrm{E}-01$ & $1.40 \mathrm{E}-01$ & 2.45E-04 & $3.00 \mathrm{E}-01$ & 2.91E-01 & 6.30E-04 & $3.00 \mathrm{E}-01$ & 2.91E-01 & $4.15 \mathrm{E}-04$ \\
\hline 5 & $1.46 \mathrm{E}-01$ & 1.39E-01 & $1.38 \mathrm{E}-04$ & 2.99E-01 & 2.89E-01 & 2.88E-04 & 2.99E-01 & 2.88E-01 & 2.87E-04 \\
\hline 6 & $1.45 \mathrm{E}-01$ & 1.38E-01 & $1.60 \mathrm{E}-04$ & 2.99E-01 & 2.87E-01 & 3.27E-04 & 2.99E-01 & 2.86E-01 & 3.39E-04 \\
\hline 7 & $1.44 \mathrm{E}-01$ & 1.37E-01 & 1.89E-04 & 2.98E-01 & 2.84E-01 & 3.85E-04 & 2.98E-01 & 2.84E-01 & 3.97E-04 \\
\hline 8 & 1.43E-01 & 1.36E-01 & 2.15E-04 & 2.98E-01 & 2.82E-01 & 4.41E-04 & 2.98E-01 & 2.82E-01 & $4.52 \mathrm{E}-04$ \\
\hline 9 & 1.43E-01 & 1.35E-01 & 2.40E-04 & 2.97E-01 & $2.80 \mathrm{E}-01$ & 4.93E-04 & 2.97E-01 & 2.79E-01 & $5.04 \mathrm{E}-04$ \\
\hline 10 & 1.43E-01 & 1.33E-01 & 2.63E-04 & 2.96E-01 & 2.78E-01 & $5.42 \mathrm{E}-04$ & 2.96E-01 & 2.77E-01 & $5.52 \mathrm{E}-04$ \\
\hline 12 & $1.42 \mathrm{E}-01$ & $1.31 \mathrm{E}-01$ & 3.05E-04 & 2.95E-01 & 2.73E-01 & 6.30E-04 & 2.95E-01 & 2.73E-01 & $6.38 \mathrm{E}-04$ \\
\hline 14 & $1.41 \mathrm{E}-01$ & $1.29 \mathrm{E}-01$ & 3.42E-04 & 2.93E-01 & 2.69E-01 & 7.06E-04 & 2.93E-01 & 2.69E-01 & 7.13E-04 \\
\hline 16 & $1.40 \mathrm{E}-01$ & $1.28 \mathrm{E}-01$ & 3.73E-04 & 2.91E-01 & 2.65E-01 & 7.71E-04 & 2.91E-01 & 2.65E-01 & 7.78E-04 \\
\hline 18 & 1.39E-01 & $1.26 \mathrm{E}-01$ & $4.00 \mathrm{E}-04$ & 2.89E-01 & 2.61E-01 & $8.28 \mathrm{E}-04$ & 2.88E-01 & 2.61E-01 & 8.33E-04 \\
\hline 20 & $1.38 \mathrm{E}-01$ & $1.24 \mathrm{E}-01$ & 4.22E-04 & 2.86E-01 & $2.58 \mathrm{E}-01$ & 8.76E-04 & 2.86E-01 & 2.57E-01 & $8.80 \mathrm{E}-04$ \\
\hline 30 & $1.31 \mathrm{E}-01$ & $1.16 \mathrm{E}-01$ & 4.93E-04 & 2.73E-01 & $2.40 \mathrm{E}-01$ & $1.02 \mathrm{E}-03$ & 2.73E-01 & $2.40 \mathrm{E}-01$ & $1.02 \mathrm{E}-03$ \\
\hline 60 & $1.11 \mathrm{E}-01$ & $9.48 \mathrm{E}-02$ & 4.97E-04 & 2.30E-01 & 1.97E-01 & 1.03E-03 & 2.30E-01 & 1.97E-01 & $1.03 \mathrm{E}-03$ \\
\hline 90 & 9.19E-02 & 7.83E-02 & $4.25 \mathrm{E}-04$ & $1.91 \mathrm{E}-01$ & $1.63 \mathrm{E}-01$ & 8.85E-04 & $1.91 \mathrm{E}-01$ & $1.63 \mathrm{E}-01$ & $8.84 \mathrm{E}-04$ \\
\hline 180 & 5.21E-02 & 4.43E-02 & 2.43E-04 & 1.08E-01 & $9.22 \mathrm{E}-02$ & 5.05E-04 & 1.08E-01 & $9.21 \mathrm{E}-02$ & $5.05 \mathrm{E}-04$ \\
\hline 365 & $1.62 \mathrm{E}-02$ & $1.38 \mathrm{E}-02$ & 7.54E-05 & 3.36E-02 & 2.86E-02 & $1.57 \mathrm{E}-04$ & 3.36E-02 & 2.86E-02 & $1.57 \mathrm{E}-04$ \\
\hline
\end{tabular}




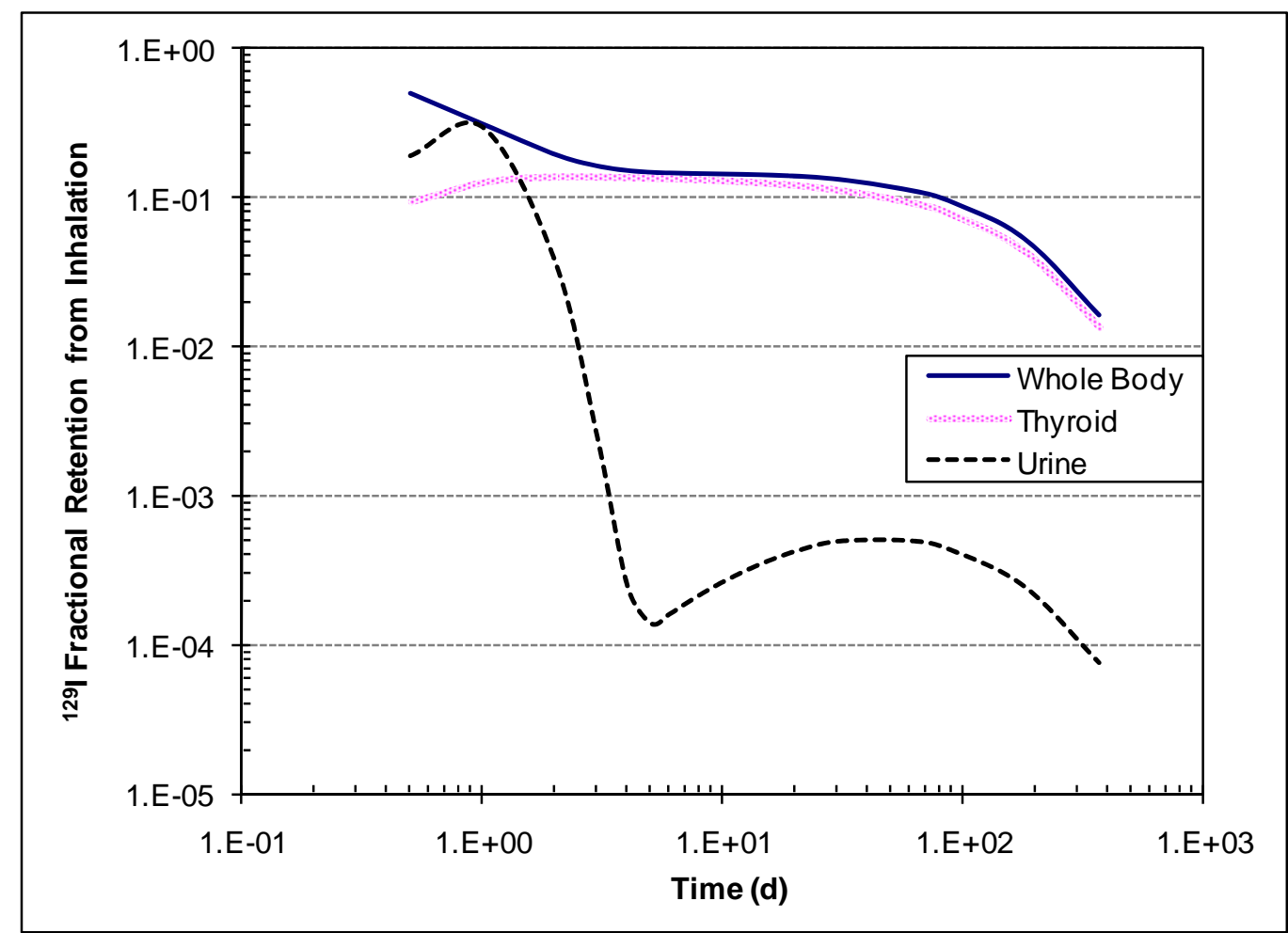

Figure 12.5. Retention of ${ }^{129} \mathrm{I}$ as a Fraction of an Acute Inhalation Intake of 5- $\mu \mathrm{m}$-AMAD Particle Sizes

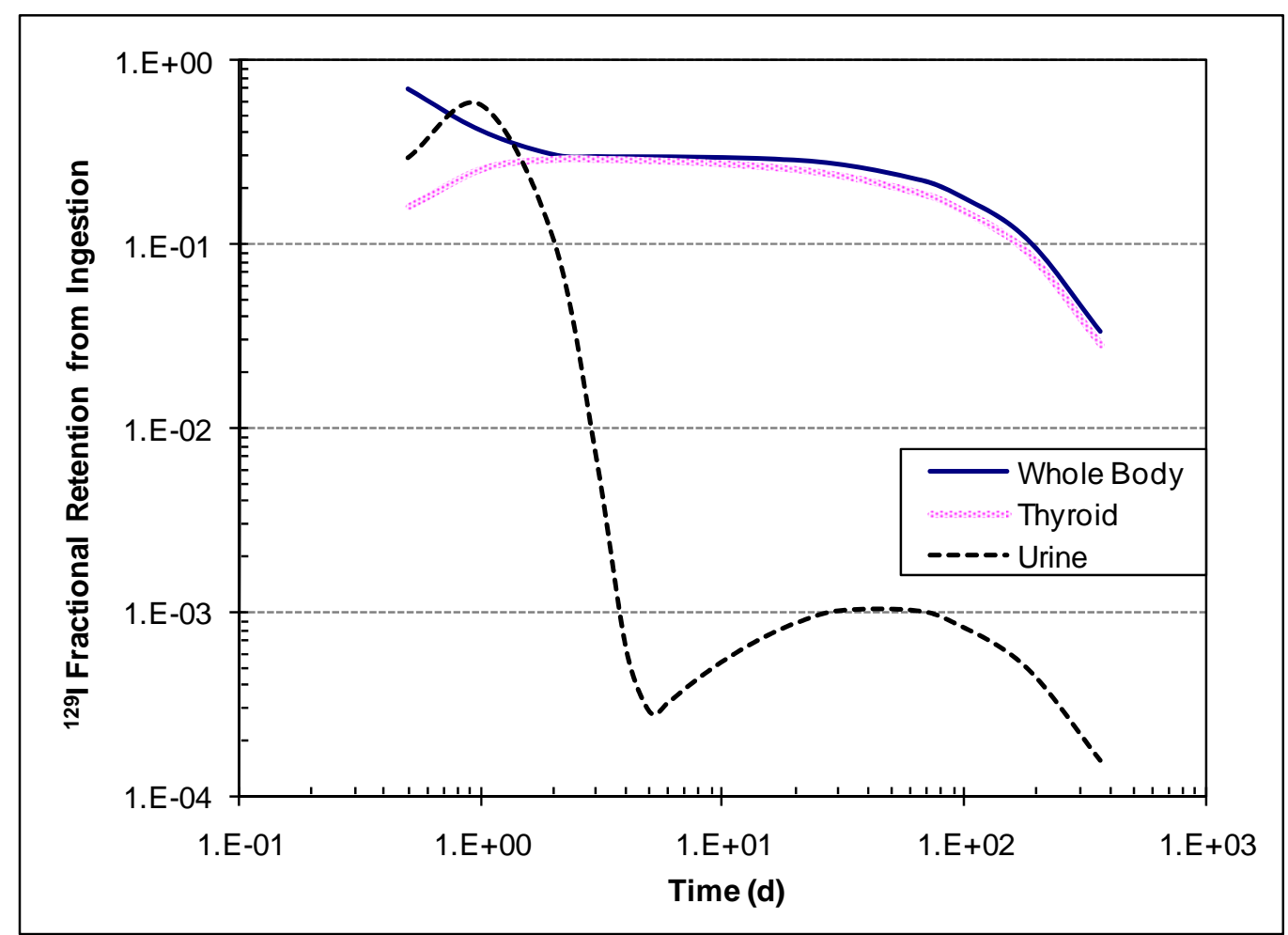

Figure 12.6. Retention of ${ }^{129} \mathrm{I}$ as a Fraction of Ingestion 


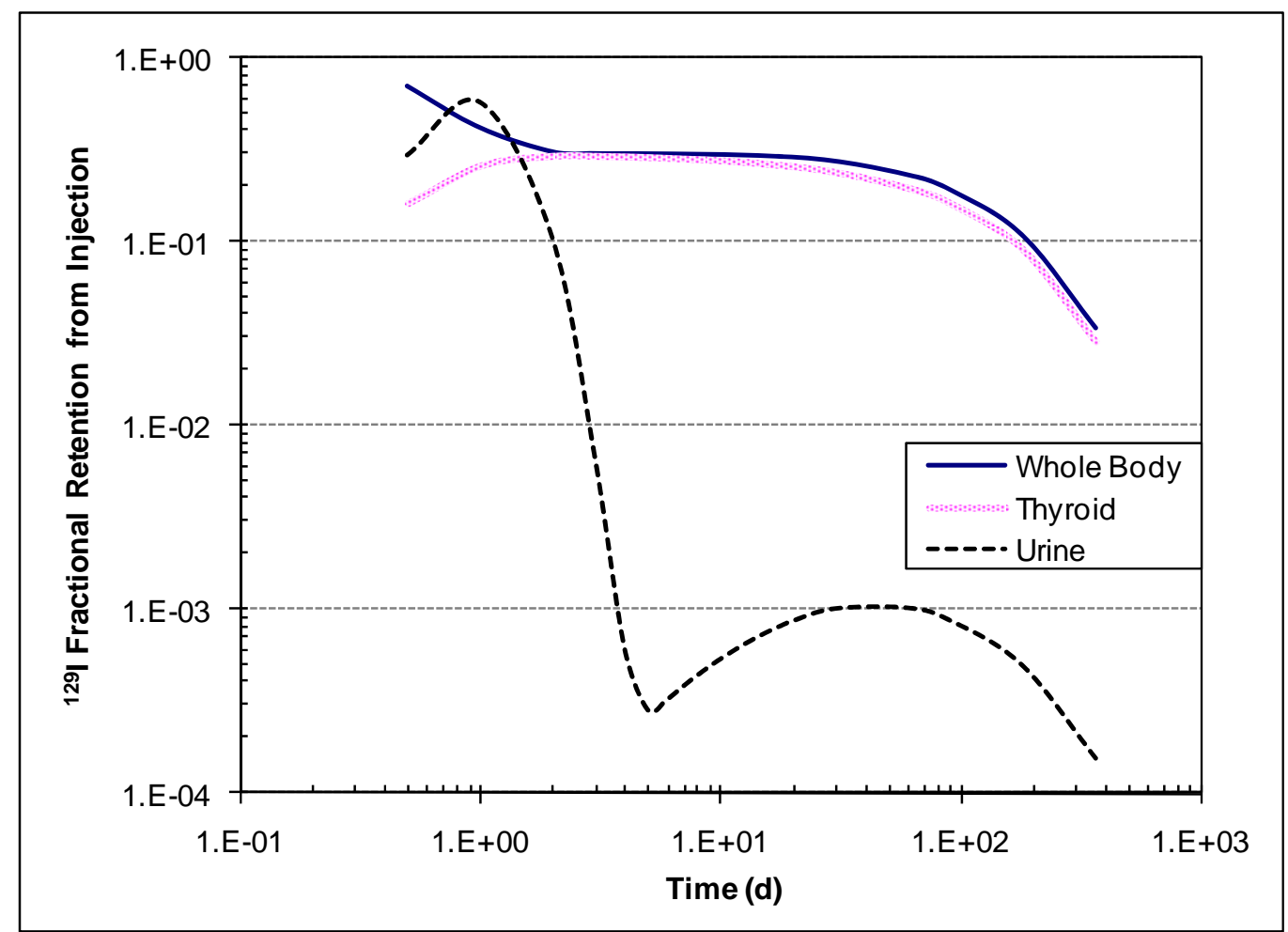

Figure 12.7. Retention Fraction of ${ }^{129} \mathrm{I}$ as an Injection 


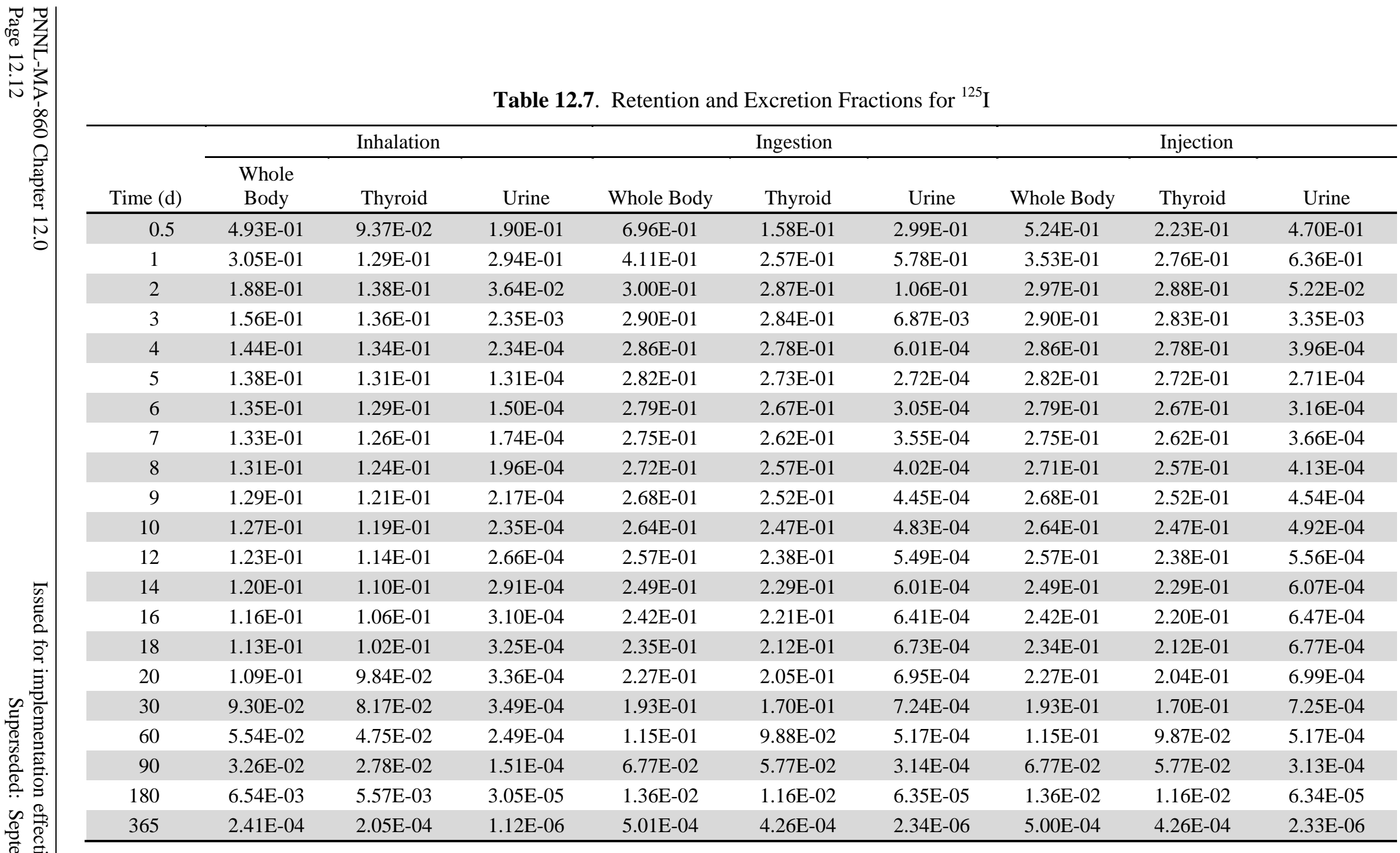




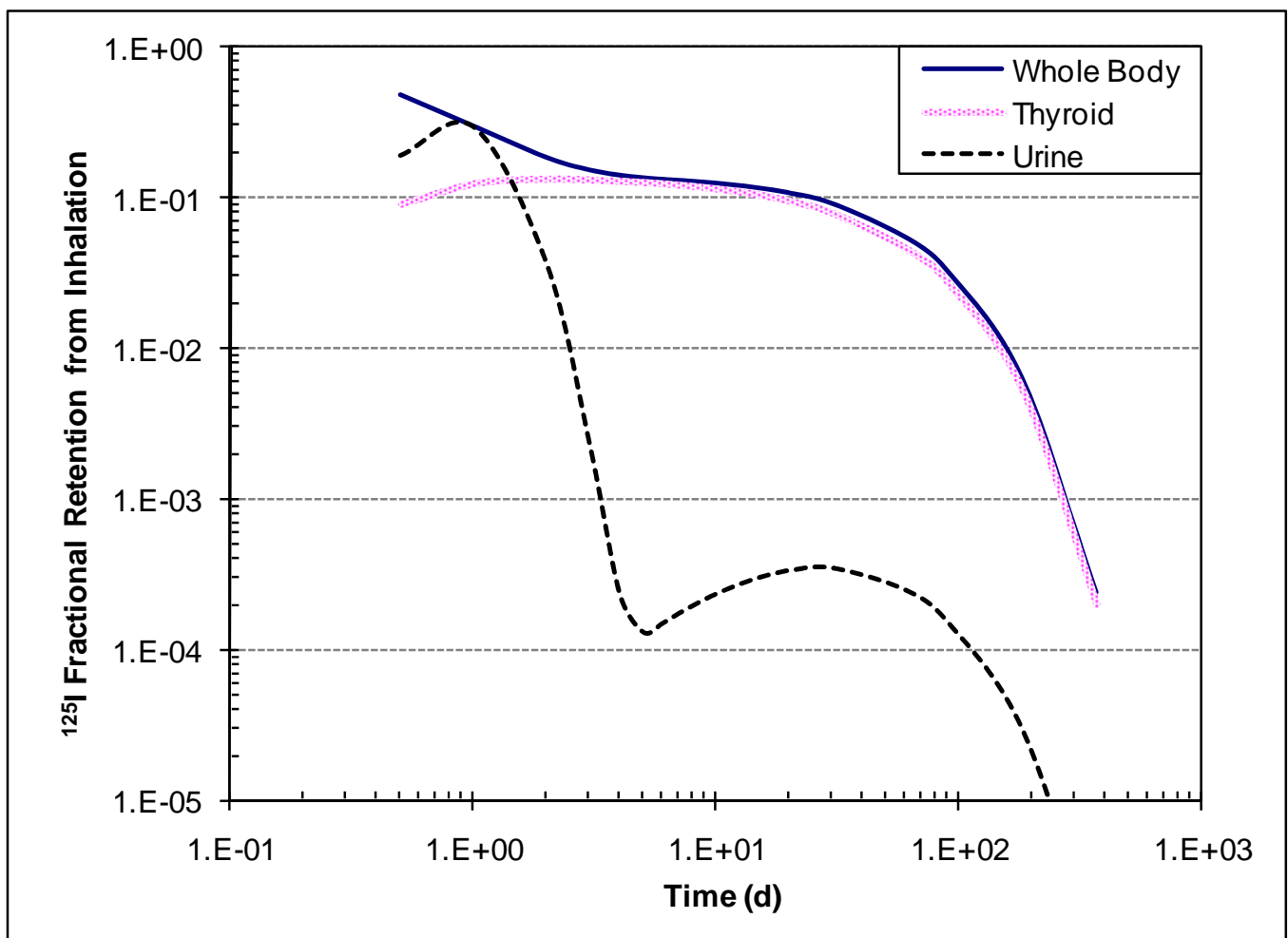

Figure 12.8. Retention of ${ }^{125} \mathrm{I}$ as a Fraction of an Acute Inhalation Intake of 5- $\mu \mathrm{m}$-AMAD Particle Sizes

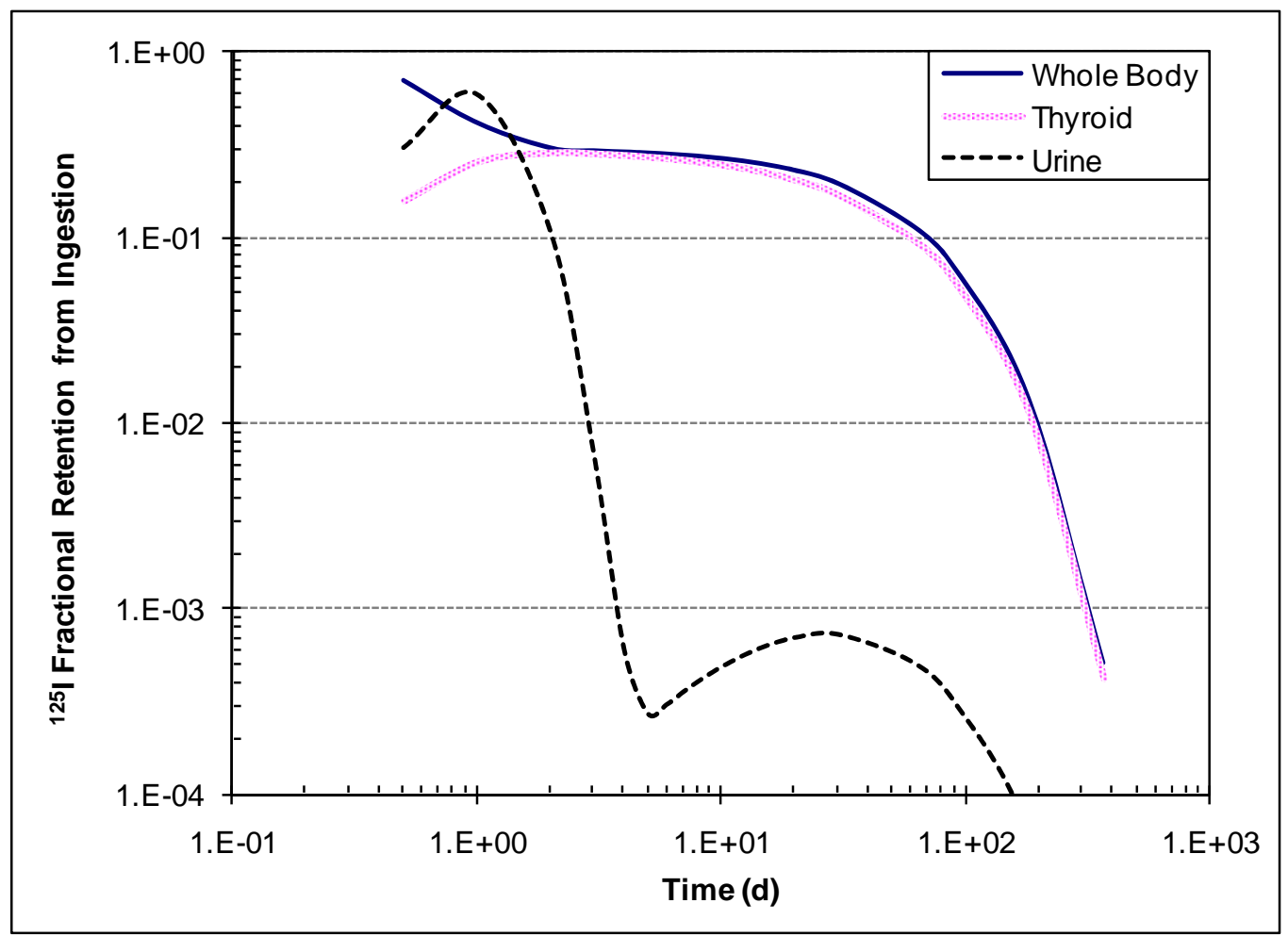

Figure 12.9. Retention of ${ }^{125} \mathrm{I}$ as a Fraction of Ingestion 


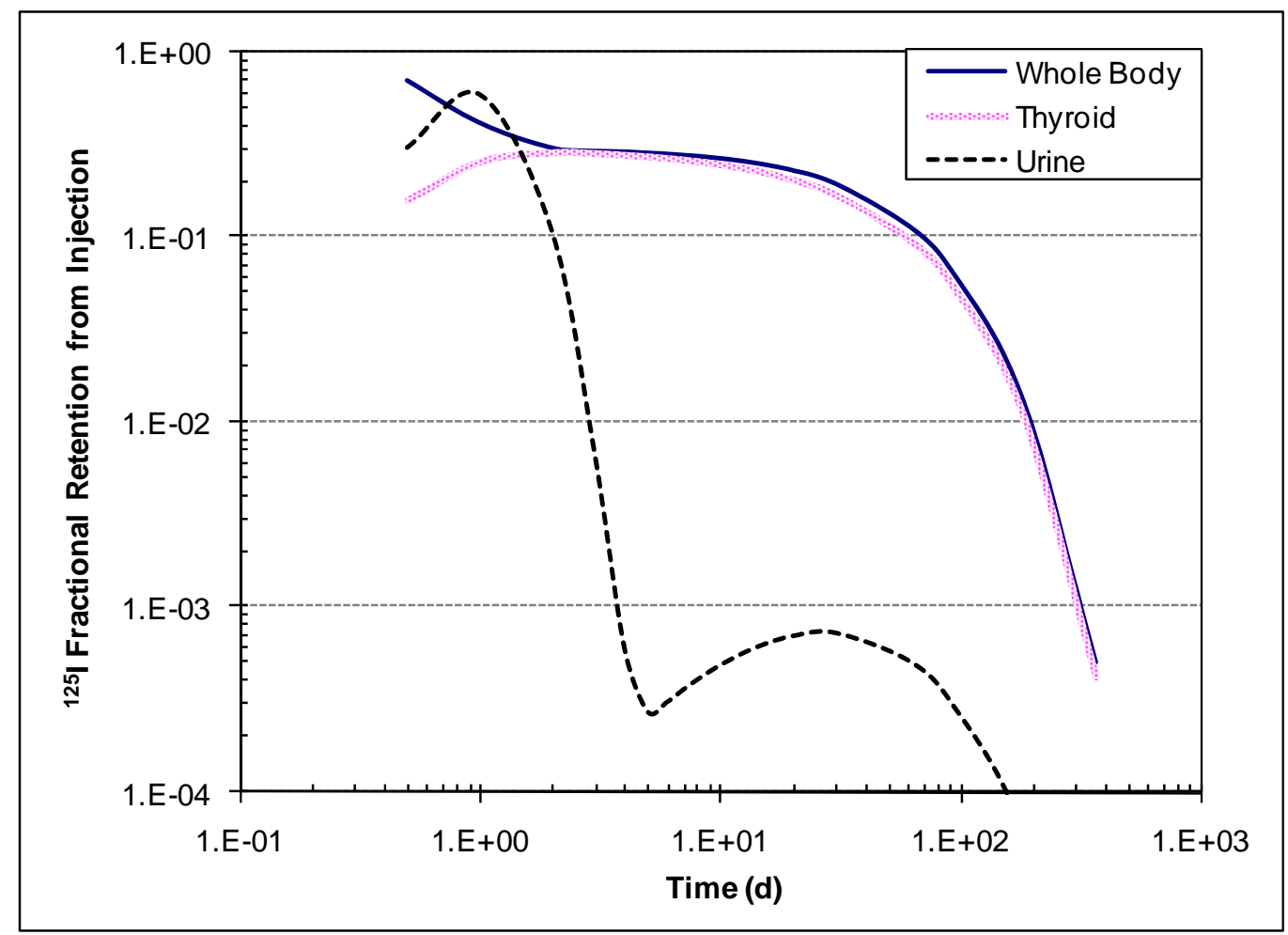

Figure 12.10. Retention Fraction of ${ }^{125} \mathrm{I}$ as an Injection

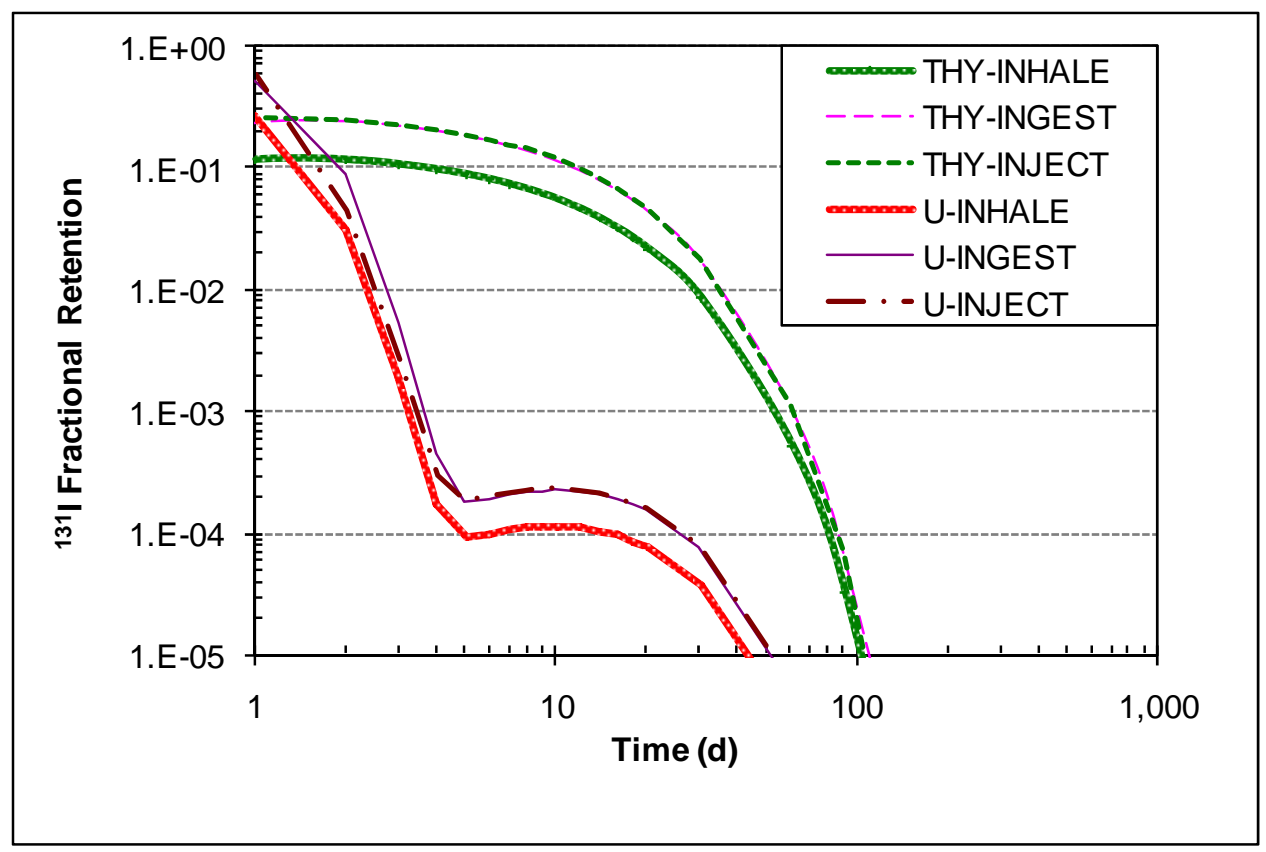

Figure 12.11. Comparison of Thyroid Retention Fraction and Urinary Excretion of ${ }^{131}$ I Following Inhalation, Ingestion, or Injection $\left({ }^{131}\right.$ I half-life $\left.=8.0 \mathrm{~d}\right)$ 


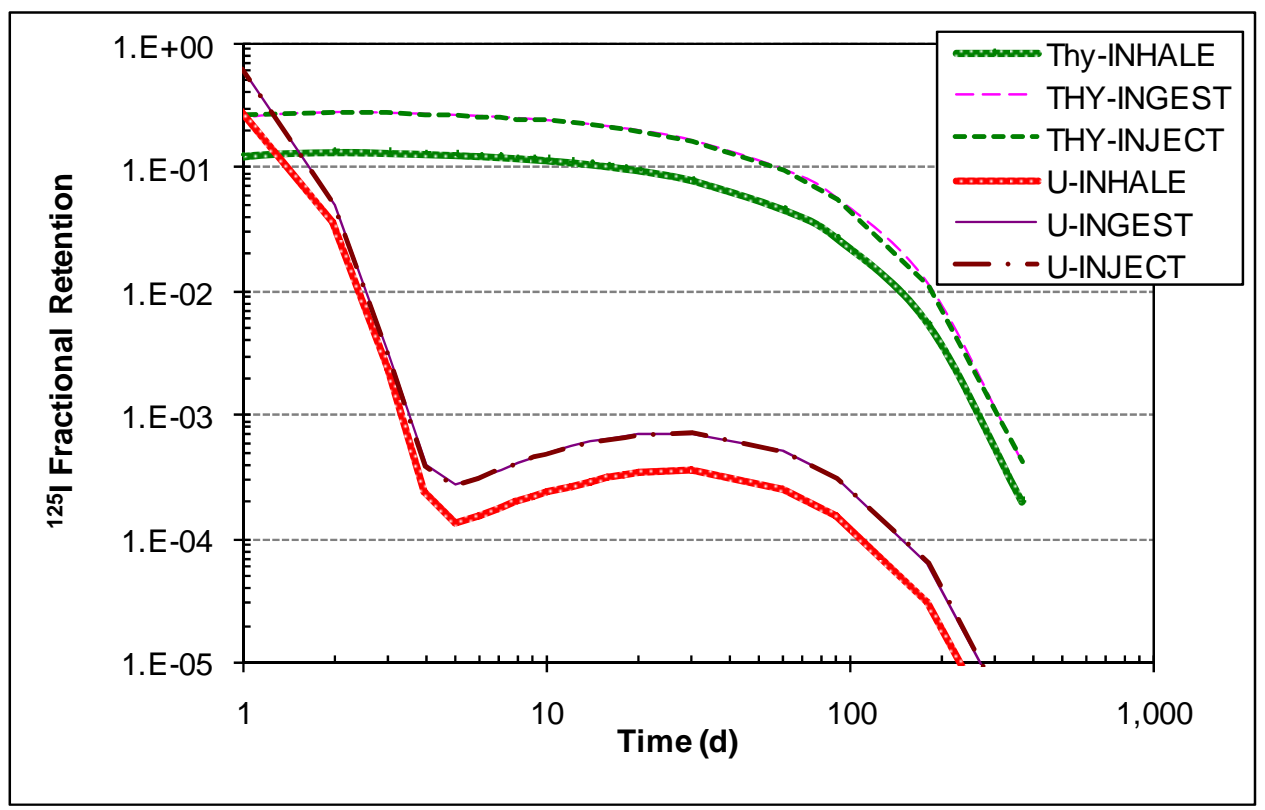

Figure 12.12. Comparison of Thyroid Retention Fraction and Urinary Excretion of ${ }^{125}$ I Following Inhalation, Ingestion, or Injection $\left({ }^{125}\right.$ I half-life $\left.=60 \mathrm{~d}\right)$

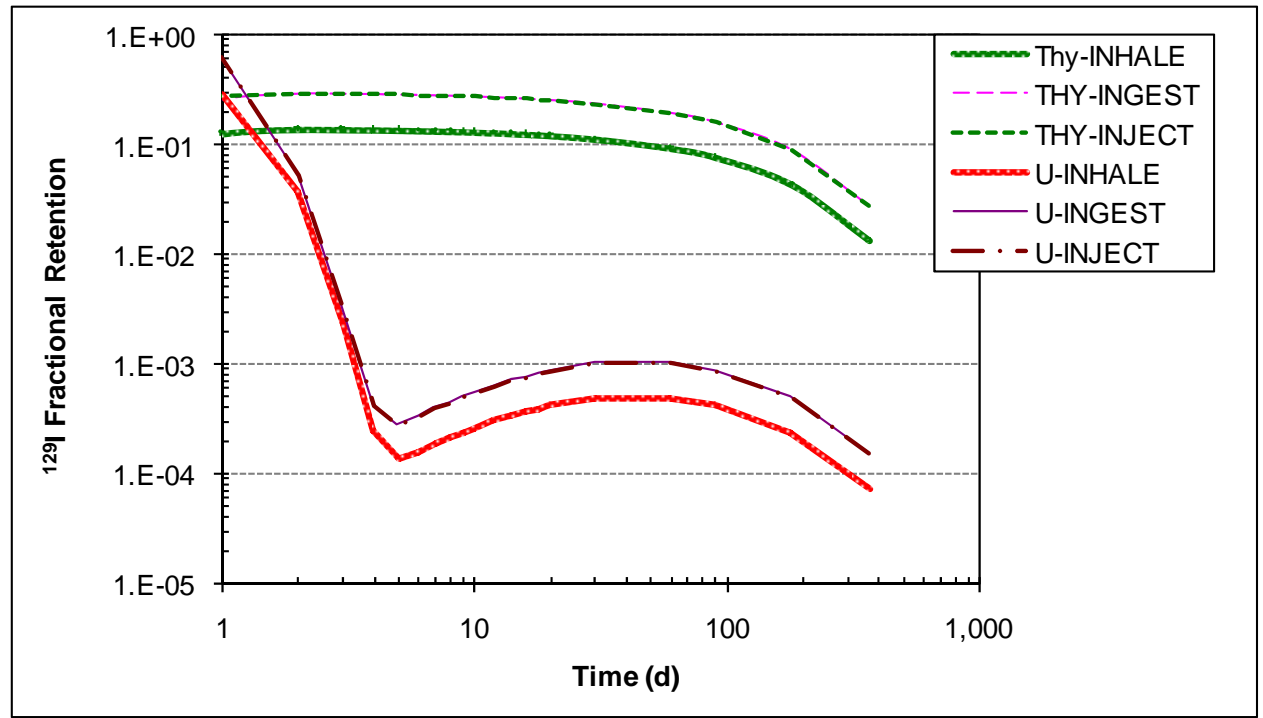

Figure 12.13. Comparison of Thyroid Retention Fraction and Urinary Excretion of ${ }^{129}$ I Following Inhalation, Ingestion, or Injection $\left({ }^{129}\right.$ I half-life $\left.=1.6 \mathrm{E} 7 \mathrm{y}\right)$

\subsubsection{Dose Coefficients}

Dose coefficients, expressed as committed equivalent or effective dose per unit activity of intake (e.g., rem/nCi), are a convenient shortcut for estimating doses based on standard assumptions when the magnitude of an intake is known. Acute intake dose coefficients have been calculated using IMBA and are tabulated for selected exposure scenarios in Table 12.8. 
Table 12.8. Committed Dose Coefficients for Radioiodines (rem/nCi)

\begin{tabular}{ccccc}
\hline \multirow{5}{*}{ Radionuclide } & Organ & $\begin{array}{c}\text { Type } F \\
\text { Inhalation, } \\
5-\mu m \text { AMAD }\end{array}$ & $\begin{array}{c}\text { Ingestion } \\
f_{1}=1\end{array}$ & Injection \\
\hline${ }^{131} \mathrm{I}$ & Effective & $3.89 \mathrm{E}-05$ & $8.01 \mathrm{E}-05$ & $8.13 \mathrm{E}-05$ \\
& Thyroid & $7.73 \mathrm{E}-04$ & $1.59 \mathrm{E}-03$ & $1.62 \mathrm{E}-03$ \\
${ }^{129} \mathrm{I}$ & Effective & $1.89 \mathrm{E}-04$ & $3.94 \mathrm{E}-04$ & $3.94 \mathrm{E}-04$ \\
& Thyroid & $3.78 \mathrm{E}-03$ & $7.86 \mathrm{E}-03$ & $7.86 \mathrm{E}-03$ \\
${ }^{125} \mathrm{I}$ & Effective & $2.71 \mathrm{E}-05$ & $5.62 \mathrm{E}-05$ & $5.63 \mathrm{E}-05$ \\
& Thyroid & $5.40 \mathrm{E}-04$ & $1.12 \mathrm{E}-03$ & $1.12 \mathrm{E}-03$ \\
\hline
\end{tabular}

The thyroid is the principally exposed organ following an intake of radioiodine and can be considered to be the only organ contributing to the effective dose for radioiodines. For all intake modes for the three radioiodine isotopes, the thyroid equivalent dose is more limiting than the effective dose relative to the regulatory dose limits.

\subsubsection{Comparison of Published Dosimetry Factors}

A comparison of the effective dose coefficients for ${ }^{131} \mathrm{I}$, ${ }^{125} \mathrm{I}$, and ${ }^{129} \mathrm{I}$ between IMBA-derived values and those published in ICRP 68 is shown in Table 12.9. IMBA provides dose coefficients with three digits while ICRP 68 provides the values using only two digits. The radioiodine values from IMBA were benchmarked against the effective dose coefficients using the mainframe PLEIADES code (which was used for ICRP calculations) and the differences were less than $0.1 \%$ (James et al. 2004, Appendix C). When rounding is taken into consideration, there are no differences between IMBA and ICRP 68 values.

\subsubsection{Derived Air Concentrations and Annual Limits on Intake}

Because the thyroid equivalent dose is more limiting than the effective dose, the annual limit on intake (ALI) is a deterministic ALI, or DALI.

Table 12.9. Comparison of Effective Dose Coefficients for Radioiodines (Sv/Bq)

\begin{tabular}{|c|c|c|c|}
\hline Radionuclide & Intake Mode & $\begin{array}{c}\text { IMBA } \\
\text { Effective Dose } \\
\text { Coefficient }\end{array}$ & $\begin{array}{c}\text { ICRP } 68 \\
\text { Effective Dose } \\
\text { Coefficient } \\
\end{array}$ \\
\hline \multirow[t]{3}{*}{${ }^{131} \mathrm{I}$} & 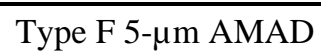 & $1.05 \mathrm{E}-08$ & $1.1 \mathrm{E}-08$ \\
\hline & Ingestion & $2.16 \mathrm{E}-08$ & $2.2 \mathrm{E}-08$ \\
\hline & Injection & 2.20E-08 & --- \\
\hline \multirow[t]{3}{*}{${ }^{129} \mathrm{I}$} & Type F 5- $\mu$ m AMAD & 5.12E-08 & $5.1 \mathrm{E}-08$ \\
\hline & Ingestion & $1.06 \mathrm{E}-07$ & $1.1 \mathrm{E}-07$ \\
\hline & Injection & 1.06E-07 & --- \\
\hline \multirow[t]{3}{*}{${ }^{125} \mathrm{I}$} & Type F 5- $\mu$ AMAD & 7.32E-09 & 7.3E-09 \\
\hline & Ingestion & $1.52 \mathrm{E}-08$ & $1.5 \mathrm{E}-08$ \\
\hline & Injection & 1.52E-08 & --- \\
\hline
\end{tabular}

PNNL-MA-860 Chapter 12.0

Page 12.16
Issued for implementation effective 01/01/2010

Superseded: September 12, 2000 
The DALI can be determined from the thyroid dose coefficient as follows:

$$
D A L I(n C i)=\left(\frac{50 \mathrm{rem}}{{ }_{T}(50)\left(\frac{r e m}{n C i}\right)}\right),
$$

Where ${ }^{\mathrm{h}}{ }_{\mathrm{T}}(50)=$ thyroid dose coefficient.

10 CFR 835 provides derived air concentrations (DACs) assuming 5- $\mu$ m-AMAD particles and the light worker breathing rate $\left(2,400 \mathrm{~m}^{3} / \mathrm{yr}\right)$. The DAC values for ${ }^{131} \mathrm{I},{ }^{125} \mathrm{I}$, and ${ }^{129} \mathrm{I}$ are listed in Table 12.10 .

Table 12.10. DACs and DALIs for Radioiodines

\begin{tabular}{ccc}
\hline Radionuclide & $\begin{array}{c}\text { DAC }(\mu \mathrm{Ci} / \mathrm{ml}) \\
\text { (from 10 CFR 835) }\end{array}$ & $\begin{array}{c}\text { DALI (nCi) } \\
\text { (from Table 12.8) }\end{array}$ \\
\hline${ }^{131} \mathrm{I}$ & $2 \mathrm{E}-08$ & $6.47 \mathrm{E}+04$ \\
${ }^{129} \mathrm{I}$ & $5 \mathrm{E}-09$ & $1.32 \mathrm{E}+04$ \\
${ }^{125} \mathrm{I}$ & $3 \mathrm{E}-08$ & $9.26 \mathrm{E}+04$ \\
\hline
\end{tabular}

\subsubsection{Derived Reference Levels}

Derived reporting and investigation levels (based on committed effective doses of 10 mrem and 100 mrem, respectively) and dose limit compliance levels (based on 50 rem to the thyroid) have been derived for inhalation of Type F 5- $\mu$ m-AMAD particles, ingestion, and injection. Tabulations are provided in Table 12.11 for ${ }^{131} \mathrm{I}$, Table 12.12 for ${ }^{129} \mathrm{I}$, and Table 12.13 for ${ }^{125} \mathrm{I}$. Examination of these tables shows that for each of the three nuclides, the value of each bioassay considered (whole body or thyroid) is similar after a few days, regardless of the type of intake. Thus, from a practical standpoint, the derived reference levels for a 5- $\mu$ m-AMAD inhalation, ingestion, and injection are sufficiently close to suggest that a single value can be used for any of them. For purposes of bioassay program design and data evaluation, the 5- $\mu \mathrm{m}$-AMAD inhalation-derived reference levels are used at Hanford as a standard with which routine monitoring data can be compared.

A point of interest regarding ${ }^{129} \mathrm{I}$ is that a compliance level intake of $1.32 \mathrm{E}+04 \mathrm{nCi}$ (i.e., the DALI) corresponds to $75 \mathrm{mg}$ of pure ${ }^{129} \mathrm{I}$, which is a level that greatly exceeds the nominal $13 \mathrm{mg}$ of iodine contained in the Reference Man total body and the nominal $12 \mathrm{mg}$ quantity of iodine that can be metabolically retained in the thyroid (ICRP 1975). Thus, it may be physiologically impossible for the thyroid to retain a sufficient uptake of ${ }^{129}$ I that would result in a dose exceeding the 50-rem thyroid dose limit. This does not hold true for the short half-life radioiodines. 
Table 12.11. Reference Levels and Derived Reference Levels for ${ }^{131} \mathrm{I}$

\begin{tabular}{|c|c|c|c|c|c|c|c|c|c|}
\hline \multirow[b]{2}{*}{$\begin{array}{l}\text { Days Post } \\
\text { Intake }\end{array}$} & \multicolumn{3}{|c|}{ 10-mrem E(50) Reporting Level } & \multicolumn{3}{|c|}{ 100-mrem $E(50)$ Investigation Level } & \multicolumn{3}{|c|}{ 50-rem $H_{\mathrm{T}}(50)$ Compliance Level } \\
\hline & 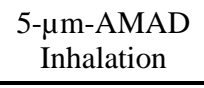 & Ingestion & Injection & 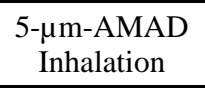 & Ingestion & Injection & 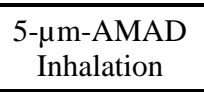 & Ingestion & Injection \\
\hline Intake (nCi) & $2.57 \mathrm{E}+02$ & $1.25 \mathrm{E}+02$ & $1.23 \mathrm{E}+02$ & $2.57 \mathrm{E}+03$ & $1.25 \mathrm{E}+03$ & $1.23 \mathrm{E}+03$ & $6.47 \mathrm{E}+04$ & $3.14 \mathrm{E}+04$ & $3.09 \mathrm{E}+04$ \\
\hline \multicolumn{10}{|c|}{ Whole Body Count Bioassay (nCi) } \\
\hline 0.5 & $1.22 \mathrm{E}+02$ & $8.37 \mathrm{E}+01$ & $6.21 \mathrm{E}+01$ & $1.22 \mathrm{E}+03$ & $8.37 \mathrm{E}+02$ & $6.21 \mathrm{E}+02$ & $3.07 \mathrm{E}+04$ & $2.11 \mathrm{E}+04$ & $1.56 \mathrm{E}+04$ \\
\hline 1 & $7.28 \mathrm{E}+01$ & $4.76 \mathrm{E}+01$ & $4.03 \mathrm{E}+01$ & $7.28 \mathrm{E}+02$ & $4.76 \mathrm{E}+02$ & $4.03 \mathrm{E}+02$ & $1.83 \mathrm{E}+04$ & $1.20 \mathrm{E}+04$ & $1.01 \mathrm{E}+04$ \\
\hline 2 & $4.17 \mathrm{E}+01$ & $3.23 \mathrm{E}+01$ & $3.14 \mathrm{E}+01$ & $4.17 \mathrm{E}+02$ & $3.23 \mathrm{E}+02$ & $3.14 \mathrm{E}+02$ & $1.05 E+04$ & $8.14 \mathrm{E}+03$ & $7.88 \mathrm{E}+03$ \\
\hline 3 & $3.20 \mathrm{E}+01$ & $2.89 \mathrm{E}+01$ & $2.85 \mathrm{E}+01$ & $3.20 \mathrm{E}+02$ & $2.89 \mathrm{E}+02$ & $2.85 E+02$ & $8.05 E+03$ & $7.29 \mathrm{E}+03$ & $7.15 \mathrm{E}+03$ \\
\hline 5 & $2.44 \mathrm{E}+01$ & $2.43 \mathrm{E}+01$ & $2.39 \mathrm{E}+01$ & $2.44 \mathrm{E}+02$ & $2.43 \mathrm{E}+02$ & $2.39 \mathrm{E}+02$ & $6.15 E+03$ & $6.12 \mathrm{E}+03$ & $6.00 \mathrm{E}+03$ \\
\hline 7 & $2.02 \mathrm{E}+01$ & $2.04 \mathrm{E}+01$ & $2.01 \mathrm{E}+01$ & $2.02 \mathrm{E}+02$ & $2.04 \mathrm{E}+02$ & $2.01 \mathrm{E}+02$ & $5.09 \mathrm{E}+03$ & $5.13 E+03$ & $5.03 E+03$ \\
\hline 14 & $1.08 \mathrm{E}+01$ & $1.09 \mathrm{E}+01$ & $1.08 \mathrm{E}+01$ & $1.08 \mathrm{E}+02$ & $1.09 \mathrm{E}+02$ & $1.08 \mathrm{E}+02$ & $2.73 \mathrm{E}+03$ & $2.76 \mathrm{E}+03$ & $2.70 \mathrm{E}+03$ \\
\hline 30 & $2.54 \mathrm{E}+00$ & $2.57 \mathrm{E}+00$ & $2.53 \mathrm{E}+00$ & $2.54 \mathrm{E}+01$ & $2.57 \mathrm{E}+01$ & $2.53 \mathrm{E}+01$ & $6.40 \mathrm{E}+02$ & $6.47 \mathrm{E}+02$ & $6.35 \mathrm{E}+02$ \\
\hline 60 & $1.61 \mathrm{E}-01$ & 1.63E-01 & $1.60 \mathrm{E}-01$ & $1.61 \mathrm{E}+00$ & $1.63 \mathrm{E}+00$ & $1.60 \mathrm{E}+00$ & $4.06 \mathrm{E}+01$ & $4.11 \mathrm{E}+01$ & $4.02 \mathrm{E}+01$ \\
\hline 90 & $1.01 \mathrm{E}-02$ & $1.02 \mathrm{E}-02$ & 1.00E-02 & $1.01 \mathrm{E}-01$ & 1.02E-01 & $1.00 \mathrm{E}-01$ & $2.54 \mathrm{E}+00$ & $2.57 \mathrm{E}+00$ & $2.52 \mathrm{E}+00$ \\
\hline 180 & 2.44E-06 & 2.46E-06 & 2.42E-06 & 2.44E-05 & 2.46E-05 & $2.42 \mathrm{E}-05$ & $6.13 \mathrm{E}-04$ & $6.20 \mathrm{E}-04$ & $6.08 \mathrm{E}-04$ \\
\hline 365 & 8.96E-14 & 9.05E-14 & 8.91E-14 & 8.96E-13 & $9.05 \mathrm{E}-13$ & 8.91E-13 & 2.25E-11 & $2.28 \mathrm{E}-11$ & 2.23E-11 \\
\hline \multicolumn{10}{|c|}{ Thyroid Count Bioassay (nCi) } \\
\hline 0.5 & $2.32 \mathrm{E}+01$ & $1.90 \mathrm{E}+01$ & $2.64 \mathrm{E}+01$ & $2.32 \mathrm{E}+02$ & $1.90 \mathrm{E}+02$ & $2.64 \mathrm{E}+02$ & $5.84 \mathrm{E}+03$ & $4.79 \mathrm{E}+03$ & $6.63 \mathrm{E}+03$ \\
\hline 1 & $3.08 \mathrm{E}+01$ & $2.98 \mathrm{E}+01$ & $3.15 \mathrm{E}+01$ & $3.08 \mathrm{E}+02$ & $2.98 \mathrm{E}+02$ & $3.15 E+02$ & $7.74 \mathrm{E}+03$ & $7.51 \mathrm{E}+03$ & $7.92 E+03$ \\
\hline 2 & $3.06 \mathrm{E}+01$ & $3.09 \mathrm{E}+01$ & $3.05 \mathrm{E}+01$ & $3.06 \mathrm{E}+02$ & $3.09 \mathrm{E}+02$ & $3.05 E+02$ & $7.71 \mathrm{E}+03$ & $7.78 \mathrm{E}+03$ & $7.65 \mathrm{E}+03$ \\
\hline 3 & $2.80 \mathrm{E}+01$ & $2.83 \mathrm{E}+01$ & $2.78 \mathrm{E}+01$ & $2.80 \mathrm{E}+02$ & $2.83 \mathrm{E}+02$ & $2.78 \mathrm{E}+02$ & $7.05 E+03$ & $7.13 E+03$ & $6.99 \mathrm{E}+03$ \\
\hline 5 & $2.32 \mathrm{E}+01$ & $2.34 \mathrm{E}+01$ & $2.31 \mathrm{E}+01$ & $2.32 \mathrm{E}+02$ & $2.34 \mathrm{E}+02$ & $2.31 \mathrm{E}+02$ & $5.84 \mathrm{E}+03$ & $5.91 \mathrm{E}+03$ & $5.79 \mathrm{E}+03$ \\
\hline 7 & $1.92 \mathrm{E}+01$ & $1.94 \mathrm{E}+01$ & $1.91 \mathrm{E}+01$ & $1.92 \mathrm{E}+02$ & $1.94 \mathrm{E}+02$ & $1.91 \mathrm{E}+02$ & $4.83 \mathrm{E}+03$ & $4.89 \mathrm{E}+03$ & $4.79 \mathrm{E}+03$ \\
\hline 14 & $9.95 E+00$ & $1.01 \mathrm{E}+01$ & $9.89 \mathrm{E}+00$ & $9.95 E+01$ & $1.01 \mathrm{E}+02$ & $9.89 \mathrm{E}+01$ & $2.50 \mathrm{E}+03$ & $2.53 \mathrm{E}+03$ & $2.48 \mathrm{E}+03$ \\
\hline 30 & $2.24 \mathrm{E}+00$ & $2.26 \mathrm{E}+00$ & $2.22 \mathrm{E}+00$ & $2.24 \mathrm{E}+01$ & $2.26 \mathrm{E}+01$ & $2.22 \mathrm{E}+01$ & $5.63 \mathrm{E}+02$ & $5.69 \mathrm{E}+02$ & $5.58 \mathrm{E}+02$ \\
\hline 60 & 1.38E-01 & 1.40E-01 & 1.37E-01 & $1.38 \mathrm{E}+00$ & $1.40 \mathrm{E}+00$ & $1.37 \mathrm{E}+00$ & $3.48 \mathrm{E}+01$ & $3.52 \mathrm{E}+01$ & $3.45 \mathrm{E}+01$ \\
\hline 90 & 8.59E-03 & $8.68 \mathrm{E}-03$ & 8.54E-03 & 8.59E-02 & 8.68E-02 & 8.54E-02 & $2.16 \mathrm{E}+00$ & $2.19 \mathrm{E}+00$ & $2.14 \mathrm{E}+00$ \\
\hline 180 & 2.08E-06 & 2.10E-06 & 2.06E-06 & 2.08E-05 & 2.10E-05 & $2.06 \mathrm{E}-05$ & $5.22 \mathrm{E}-04$ & $5.28 \mathrm{E}-04$ & $5.18 \mathrm{E}-04$ \\
\hline 365 & 7.63E-14 & 7.70E-14 & 7.58E-14 & 7.63E-13 & 7.70E-13 & $7.58 \mathrm{E}-13$ & $1.92 \mathrm{E}-11$ & $1.94 \mathrm{E}-11$ & $1.90 \mathrm{E}-11$ \\
\hline
\end{tabular}


Table 12.12. Reference Levels and Derived Reference Levels for ${ }^{129} \mathrm{I}$

\begin{tabular}{|c|c|c|c|c|c|c|c|c|c|}
\hline \multirow[b]{2}{*}{$\begin{array}{l}\text { Days Post } \\
\text { Intake }\end{array}$} & \multicolumn{3}{|c|}{ 10-mrem E(50) Reporting Level } & \multicolumn{3}{|c|}{ 100-mrem $E$ (50)Investigation Level } & \multicolumn{3}{|c|}{ 50-rem $H_{\mathrm{T}}(50)$ Compliance Level } \\
\hline & $\begin{array}{l}5-\mu m-A M A D \\
\text { Inhalation }\end{array}$ & Ingestion & Injection & $\begin{array}{c}5-\mu m-A M A D \\
\text { Inhalation }\end{array}$ & Ingestion & Injection & $\begin{array}{c}5-\mu \mathrm{m}-\mathrm{AMAD} \\
\text { Inhalation }\end{array}$ & Ingestion & Injection \\
\hline Intake (nCi) & $5.29 \mathrm{E}+01$ & $2.54 \mathrm{E}+01$ & $2.54 \mathrm{E}+01$ & $5.29 \mathrm{E}+02$ & $2.54 \mathrm{E}+02$ & $2.54 \mathrm{E}+02$ & $1.32 \mathrm{E}+04$ & $6.36 \mathrm{E}+03$ & $6.36 \mathrm{E}+03$ \\
\hline \multicolumn{10}{|c|}{ Whole Body Count Bioassay (nCi) } \\
\hline 0.5 & $2.62 \mathrm{E}+01$ & $1.78 \mathrm{E}+01$ & $1.34 \mathrm{E}+01$ & $2.62 \mathrm{E}+02$ & $1.78 \mathrm{E}+02$ & $1.34 \mathrm{E}+02$ & $6.55 \mathrm{E}+03$ & $4.45 \mathrm{E}+03$ & $3.35 \mathrm{E}+03$ \\
\hline 1 & $1.63 \mathrm{E}+01$ & $1.05 \mathrm{E}+01$ & $9.06 \mathrm{E}+00$ & $1.63 \mathrm{E}+02$ & $1.05 \mathrm{E}+02$ & $9.06 \mathrm{E}+01$ & $4.08 \mathrm{E}+03$ & $2.64 \mathrm{E}+03$ & $2.27 \mathrm{E}+03$ \\
\hline 2 & $1.02 \mathrm{E}+01$ & $7.80 \mathrm{E}+00$ & $7.70 \mathrm{E}+00$ & $1.02 \mathrm{E}+02$ & $7.80 \mathrm{E}+01$ & $7.70 \mathrm{E}+01$ & $2.55 E+03$ & $1.96 \mathrm{E}+03$ & $1.93 \mathrm{E}+03$ \\
\hline 3 & $8.53 \mathrm{E}+00$ & $7.62 \mathrm{E}+00$ & $7.61 \mathrm{E}+00$ & $8.53 \mathrm{E}+01$ & $7.62 \mathrm{E}+01$ & $7.61 \mathrm{E}+01$ & $2.13 \mathrm{E}+03$ & $1.91 \mathrm{E}+03$ & $1.91 \mathrm{E}+03$ \\
\hline 5 & $7.74 \mathrm{E}+00$ & $7.60 \mathrm{E}+00$ & $7.59 \mathrm{E}+00$ & $7.74 \mathrm{E}+01$ & $7.60 \mathrm{E}+01$ & $7.59 \mathrm{E}+01$ & $1.93 \mathrm{E}+03$ & $1.90 \mathrm{E}+03$ & $1.90 \mathrm{E}+03$ \\
\hline 7 & $7.61 \mathrm{E}+00$ & $7.57 \mathrm{E}+00$ & $7.57 \mathrm{E}+00$ & $7.61 \mathrm{E}+01$ & $7.57 \mathrm{E}+01$ & $7.57 \mathrm{E}+01$ & $1.90 \mathrm{E}+03$ & $1.90 \mathrm{E}+03$ & $1.90 \mathrm{E}+03$ \\
\hline 14 & $7.45 \mathrm{E}+00$ & $7.44 \mathrm{E}+00$ & $7.43 \mathrm{E}+00$ & $7.45 \mathrm{E}+01$ & $7.44 \mathrm{E}+01$ & $7.43 \mathrm{E}+01$ & $1.86 \mathrm{E}+03$ & $1.86 \mathrm{E}+03$ & $1.86 \mathrm{E}+03$ \\
\hline 30 & $6.95 \mathrm{E}+00$ & $6.94 \mathrm{E}+00$ & $6.93 \mathrm{E}+00$ & $6.95 \mathrm{E}+01$ & $6.94 \mathrm{E}+01$ & $6.93 \mathrm{E}+01$ & $1.74 \mathrm{E}+03$ & $1.74 \mathrm{E}+03$ & $1.74 \mathrm{E}+03$ \\
\hline 60 & $5.86 \mathrm{E}+00$ & $5.84 \mathrm{E}+00$ & $5.84 \mathrm{E}+00$ & $5.86 \mathrm{E}+01$ & $5.84 \mathrm{E}+01$ & $5.84 \mathrm{E}+01$ & $1.46 \mathrm{E}+03$ & $1.46 \mathrm{E}+03$ & $1.46 \mathrm{E}+03$ \\
\hline 90 & $4.86 \mathrm{E}+00$ & $4.85 \mathrm{E}+00$ & $4.85 \mathrm{E}+00$ & $4.86 \mathrm{E}+01$ & $4.85 \mathrm{E}+01$ & $4.85 E+01$ & $1.22 \mathrm{E}+03$ & $1.22 \mathrm{E}+03$ & $1.21 \mathrm{E}+03$ \\
\hline 180 & $2.75 E+00$ & $2.75 E+00$ & $2.74 \mathrm{E}+00$ & $2.75 E+01$ & $2.75 E+01$ & $2.74 \mathrm{E}+01$ & $6.89 \mathrm{E}+02$ & $6.89 \mathrm{E}+02$ & $6.88 \mathrm{E}+02$ \\
\hline 365 & 8.55E-01 & 8.53E-01 & 8.52E-01 & $8.55 \mathrm{E}+00$ & $8.53 \mathrm{E}+00$ & $8.52 \mathrm{E}+00$ & $2.14 \mathrm{E}+02$ & $2.14 \mathrm{E}+02$ & $2.14 \mathrm{E}+02$ \\
\hline \multicolumn{10}{|c|}{ Thyroid Count Bioassay (nCi) } \\
\hline 0.5 & $4.98 \mathrm{E}+00$ & $4.04 \mathrm{E}+00$ & $5.70 \mathrm{E}+00$ & 4.98E+01 & $4.04 \mathrm{E}+01$ & $5.70 \mathrm{E}+01$ & $1.25 \mathrm{E}+03$ & $1.01 \mathrm{E}+03$ & $1.43 \mathrm{E}+03$ \\
\hline 1 & $6.90 \mathrm{E}+00$ & $6.60 \mathrm{E}+00$ & $7.09 \mathrm{E}+00$ & $6.90 \mathrm{E}+01$ & $6.60 \mathrm{E}+01$ & $7.09 \mathrm{E}+01$ & $1.73 E+03$ & $1.66 \mathrm{E}+03$ & $1.78 \mathrm{E}+03$ \\
\hline 2 & $7.49 \mathrm{E}+00$ & $7.46 \mathrm{E}+00$ & $7.48 \mathrm{E}+00$ & $7.49 \mathrm{E}+01$ & $7.46 \mathrm{E}+01$ & $7.48 \mathrm{E}+01$ & $1.87 \mathrm{E}+03$ & $1.87 \mathrm{E}+03$ & $1.87 \mathrm{E}+03$ \\
\hline 3 & $7.47 \mathrm{E}+00$ & $7.45 \mathrm{E}+00$ & $7.44 \mathrm{E}+00$ & $7.47 \mathrm{E}+01$ & $7.45 \mathrm{E}+01$ & $7.44 \mathrm{E}+01$ & $1.87 \mathrm{E}+03$ & $1.87 \mathrm{E}+03$ & $1.87 \mathrm{E}+03$ \\
\hline 5 & $7.35 \mathrm{E}+00$ & $7.33 \mathrm{E}+00$ & $7.32 \mathrm{E}+00$ & $7.35 \mathrm{E}+01$ & $7.33 \mathrm{E}+01$ & $7.32 \mathrm{E}+01$ & $1.84 \mathrm{E}+03$ & $1.84 \mathrm{E}+03$ & $1.84 \mathrm{E}+03$ \\
\hline 7 & $7.23 \mathrm{E}+00$ & $7.22 \mathrm{E}+00$ & $7.20 \mathrm{E}+00$ & $7.23 \mathrm{E}+01$ & $7.22 \mathrm{E}+01$ & $7.20 \mathrm{E}+01$ & $1.81 \mathrm{E}+03$ & $1.81 \mathrm{E}+03$ & $1.81 \mathrm{E}+03$ \\
\hline 14 & $6.85 \mathrm{E}+00$ & $6.83 \mathrm{E}+00$ & $6.82 \mathrm{E}+00$ & $6.85 \mathrm{E}+01$ & $6.83 \mathrm{E}+01$ & $6.82 \mathrm{E}+01$ & $1.71 \mathrm{E}+03$ & $1.71 \mathrm{E}+03$ & $1.71 \mathrm{E}+03$ \\
\hline 30 & $6.11 \mathrm{E}+00$ & $6.10 \mathrm{E}+00$ & $6.09 \mathrm{E}+00$ & $6.11 \mathrm{E}+01$ & $6.10 \mathrm{E}+01$ & $6.09 \mathrm{E}+01$ & $1.53 \mathrm{E}+03$ & $1.53 \mathrm{E}+03$ & $1.53 \mathrm{E}+03$ \\
\hline 60 & $5.02 E+00$ & $5.01 \mathrm{E}+00$ & $5.00 \mathrm{E}+00$ & $5.02 E+01$ & $5.01 \mathrm{E}+01$ & $5.00 \mathrm{E}+01$ & $1.25 E+03$ & $1.25 E+03$ & $1.25 \mathrm{E}+03$ \\
\hline 90 & $4.14 \mathrm{E}+00$ & $4.14 \mathrm{E}+00$ & $4.13 E+00$ & 4.14E+01 & $4.14 \mathrm{E}+01$ & $4.13 E+01$ & $1.04 \mathrm{E}+03$ & $1.04 \mathrm{E}+03$ & $1.04 \mathrm{E}+03$ \\
\hline 180 & $2.34 \mathrm{E}+00$ & $2.34 \mathrm{E}+00$ & $2.34 \mathrm{E}+00$ & $2.34 \mathrm{E}+01$ & $2.34 \mathrm{E}+01$ & $2.34 \mathrm{E}+01$ & $5.86 \mathrm{E}+02$ & $5.86 \mathrm{E}+02$ & $5.86 \mathrm{E}+02$ \\
\hline 365 & 7.28E-01 & 7.26E-01 & 7.25E-01 & $7.28 \mathrm{E}+00$ & $7.26 \mathrm{E}+00$ & $7.25 \mathrm{E}+00$ & $1.82 \mathrm{E}+02$ & $1.82 \mathrm{E}+02$ & $1.82 \mathrm{E}+02$ \\
\hline
\end{tabular}


Table 12.13. Reference Levels and Derived Reference Levels for ${ }^{125} \mathrm{I}$

\begin{tabular}{|c|c|c|c|c|c|c|c|c|c|}
\hline \multirow[b]{2}{*}{$\begin{array}{l}\text { Days Post } \\
\text { Intake }\end{array}$} & \multicolumn{3}{|c|}{ 10-mrem E(50) Reporting Level } & \multicolumn{3}{|c|}{ 100-mrem $E(50)$ Investigation Level } & \multicolumn{3}{|c|}{ 50-rem $H_{\mathrm{T}}(50)$ Compliance Level } \\
\hline & $\begin{array}{c}5-\mu m-A M A D \\
\text { Inhalation }\end{array}$ & Ingestion & Injection & $\begin{array}{c}5-\mu \mathrm{m}-\mathrm{AMAD} \\
\text { Inhalation }\end{array}$ & Ingestion & Injection & $\begin{array}{c}5-\mu m-A M A D \\
\text { Inhalation }\end{array}$ & Ingestion & Injection \\
\hline Intake (nCi) & $3.69 \mathrm{E}+02$ & $1.78 \mathrm{E}+02$ & $1.78 \mathrm{E}+02$ & $3.69 \mathrm{E}+03$ & $1.78 \mathrm{E}+03$ & $1.78 \mathrm{E}+03$ & $9.26 \mathrm{E}+04$ & $4.46 \mathrm{E}+04$ & $4.46 \mathrm{E}+04$ \\
\hline \multicolumn{10}{|c|}{ Whole Body Count Bioassay (nCi) } \\
\hline 0.5 & $1.82 \mathrm{E}+02$ & $1.24 \mathrm{E}+02$ & $9.31 \mathrm{E}+01$ & $1.82 \mathrm{E}+03$ & $1.24 \mathrm{E}+03$ & $9.31 \mathrm{E}+02$ & $4.56 \mathrm{E}+04$ & $3.11 \mathrm{E}+04$ & $2.34 \mathrm{E}+04$ \\
\hline 1 & $1.13 \mathrm{E}+02$ & $7.31 \mathrm{E}+01$ & $6.27 \mathrm{E}+01$ & $1.13 \mathrm{E}+03$ & $7.31 \mathrm{E}+02$ & $6.27 \mathrm{E}+02$ & $2.82 E+04$ & $1.83 \mathrm{E}+04$ & $1.58 \mathrm{E}+04$ \\
\hline 2 & $6.95 \mathrm{E}+01$ & $5.35 \mathrm{E}+01$ & $5.27 \mathrm{E}+01$ & $6.95 \mathrm{E}+02$ & $5.35 \mathrm{E}+02$ & $5.27 \mathrm{E}+02$ & $1.74 \mathrm{E}+04$ & $1.34 \mathrm{E}+04$ & $1.32 \mathrm{E}+04$ \\
\hline 3 & $5.75 \mathrm{E}+01$ & $5.16 \mathrm{E}+01$ & $5.15 \mathrm{E}+01$ & $5.75 \mathrm{E}+02$ & $5.16 \mathrm{E}+02$ & $5.15 \mathrm{E}+02$ & $1.44 \mathrm{E}+04$ & $1.29 \mathrm{E}+04$ & $1.29 \mathrm{E}+04$ \\
\hline 5 & $5.09 \mathrm{E}+01$ & $5.03 \mathrm{E}+01$ & $5.02 \mathrm{E}+01$ & $5.09 \mathrm{E}+02$ & $5.03 \mathrm{E}+02$ & $5.02 \mathrm{E}+02$ & $1.28 \mathrm{E}+04$ & $1.26 \mathrm{E}+04$ & $1.26 \mathrm{E}+04$ \\
\hline 7 & $4.89 \mathrm{E}+01$ & $4.90 \mathrm{E}+01$ & $4.89 \mathrm{E}+01$ & $4.89 \mathrm{E}+02$ & $4.90 \mathrm{E}+02$ & $4.89 \mathrm{E}+02$ & $1.23 \mathrm{E}+04$ & $1.23 \mathrm{E}+04$ & $1.23 \mathrm{E}+04$ \\
\hline 14 & $4.42 \mathrm{E}+01$ & $4.44 \mathrm{E}+01$ & $4.42 \mathrm{E}+01$ & $4.42 \mathrm{E}+02$ & $4.44 \mathrm{E}+02$ & $4.42 \mathrm{E}+02$ & $1.11 \mathrm{E}+04$ & $1.11 \mathrm{E}+04$ & $1.11 \mathrm{E}+04$ \\
\hline 30 & $3.43 \mathrm{E}+01$ & $3.44 \mathrm{E}+01$ & $3.43 \mathrm{E}+01$ & $3.43 \mathrm{E}+02$ & $3.44 \mathrm{E}+02$ & $3.43 \mathrm{E}+02$ & $8.61 \mathrm{E}+03$ & $8.64 \mathrm{E}+03$ & $8.63 E+03$ \\
\hline 60 & $2.05 \mathrm{E}+01$ & $2.05 \mathrm{E}+01$ & $2.05 E+01$ & $2.05 E+02$ & $2.05 E+02$ & $2.05 E+02$ & $5.13 \mathrm{E}+03$ & $5.15 E+03$ & $5.14 \mathrm{E}+03$ \\
\hline 90 & $1.20 \mathrm{E}+01$ & $1.21 \mathrm{E}+01$ & $1.20 \mathrm{E}+01$ & $1.20 \mathrm{E}+02$ & $1.21 \mathrm{E}+02$ & $1.20 \mathrm{E}+02$ & $3.02 E+03$ & $3.02 E+03$ & $3.02 E+03$ \\
\hline 180 & $2.41 \mathrm{E}+00$ & $2.42 \mathrm{E}+00$ & $2.41 \mathrm{E}+00$ & $2.41 \mathrm{E}+01$ & $2.42 \mathrm{E}+01$ & $2.41 \mathrm{E}+01$ & $6.05 E+02$ & $6.07 \mathrm{E}+02$ & $6.06 \mathrm{E}+02$ \\
\hline 365 & 8.88E-02 & 8.91E-02 & 8.88E-02 & 8.88E-01 & 8.91E-01 & 8.88E-01 & $2.23 \mathrm{E}+01$ & $2.23 \mathrm{E}+01$ & $2.23 \mathrm{E}+01$ \\
\hline \multicolumn{10}{|c|}{ Thyroid Count Bioassay (nCi) } \\
\hline 0.5 & $3.46 \mathrm{E}+01$ & $2.82 \mathrm{E}+01$ & $3.96 \mathrm{E}+01$ & $3.46 \mathrm{E}+02$ & $2.82 \mathrm{E}+02$ & $3.96 \mathrm{E}+02$ & $8.67 \mathrm{E}+03$ & $7.07 \mathrm{E}+03$ & $9.96 \mathrm{E}+03$ \\
\hline 1 & $4.76 \mathrm{E}+01$ & $4.58 \mathrm{E}+01$ & $4.91 \mathrm{E}+01$ & $4.76 \mathrm{E}+02$ & $4.58 \mathrm{E}+02$ & $4.91 \mathrm{E}+02$ & $1.19 \mathrm{E}+04$ & $1.15 \mathrm{E}+04$ & $1.23 \mathrm{E}+04$ \\
\hline 2 & $5.11 \mathrm{E}+01$ & $5.11 \mathrm{E}+01$ & $5.11 \mathrm{E}+01$ & $5.11 \mathrm{E}+02$ & $5.11 \mathrm{E}+02$ & $5.11 \mathrm{E}+02$ & $1.28 \mathrm{E}+04$ & $1.28 \mathrm{E}+04$ & $1.29 \mathrm{E}+04$ \\
\hline 3 & $5.03 \mathrm{E}+01$ & $5.05 \mathrm{E}+01$ & $5.03 \mathrm{E}+01$ & $5.03 \mathrm{E}+02$ & $5.05 \mathrm{E}+02$ & $5.03 \mathrm{E}+02$ & $1.26 \mathrm{E}+04$ & $1.27 \mathrm{E}+04$ & $1.26 \mathrm{E}+04$ \\
\hline 5 & $4.84 \mathrm{E}+01$ & $4.85 \mathrm{E}+01$ & $4.84 \mathrm{E}+01$ & $4.84 \mathrm{E}+02$ & $4.85 \mathrm{E}+02$ & $4.84 \mathrm{E}+02$ & $1.21 \mathrm{E}+04$ & $1.22 \mathrm{E}+04$ & $1.22 \mathrm{E}+04$ \\
\hline 7 & $4.65 \mathrm{E}+01$ & $4.67 \mathrm{E}+01$ & $4.65 \mathrm{E}+01$ & $4.65 \mathrm{E}+02$ & $4.67 \mathrm{E}+02$ & $4.65 \mathrm{E}+02$ & $1.17 \mathrm{E}+04$ & $1.17 \mathrm{E}+04$ & $1.17 \mathrm{E}+04$ \\
\hline 14 & $4.06 \mathrm{E}+01$ & $4.08 \mathrm{E}+01$ & $4.06 \mathrm{E}+01$ & $4.06 \mathrm{E}+02$ & $4.08 \mathrm{E}+02$ & $4.06 \mathrm{E}+02$ & $1.02 \mathrm{E}+04$ & $1.02 \mathrm{E}+04$ & $1.02 \mathrm{E}+04$ \\
\hline 30 & $3.02 \mathrm{E}+01$ & $3.03 \mathrm{E}+01$ & $3.02 \mathrm{E}+01$ & $3.02 \mathrm{E}+02$ & $3.03 \mathrm{E}+02$ & $3.02 \mathrm{E}+02$ & $7.57 \mathrm{E}+03$ & $7.59 \mathrm{E}+03$ & $7.58 \mathrm{E}+03$ \\
\hline 60 & $1.75 \mathrm{E}+01$ & $1.76 \mathrm{E}+01$ & $1.75 E+01$ & $1.75 E+02$ & $1.76 \mathrm{E}+02$ & $1.75 E+02$ & $4.40 \mathrm{E}+03$ & $4.41 \mathrm{E}+03$ & $4.40 \mathrm{E}+03$ \\
\hline 90 & $1.02 \mathrm{E}+01$ & $1.03 \mathrm{E}+01$ & $1.02 \mathrm{E}+01$ & $1.02 \mathrm{E}+02$ & $1.03 \mathrm{E}+02$ & $1.02 \mathrm{E}+02$ & $2.57 \mathrm{E}+03$ & $2.58 \mathrm{E}+03$ & $2.57 \mathrm{E}+03$ \\
\hline 180 & $2.05 \mathrm{E}+00$ & $2.06 \mathrm{E}+00$ & $2.05 E+00$ & $2.05 E+01$ & $2.06 \mathrm{E}+01$ & $2.05 E+01$ & $5.15 \mathrm{E}+02$ & $5.17 \mathrm{E}+02$ & $5.16 \mathrm{E}+02$ \\
\hline 365 & 7.56E-02 & 7.58E-02 & 7.56E-02 & 7.56E-01 & 7.58E-01 & 7.56E-01 & $1.90 \mathrm{E}+01$ & $1.90 \mathrm{E}+01$ & $1.90 \mathrm{E}+01$ \\
\hline
\end{tabular}




\subsection{Bioassay for Radioiodines}

In vivo measurements and a routine monitoring program for radioiodine isotopes are the main bioassay considerations.

\subsubsection{Bioassay Methods and Capabilities}

Radioiodine isotopes can be easily detected by in vivo measurements. Iodine-131 can be readily detected using the sodium iodide (NaI)-detector preview counter or the coaxial germanium $(\mathrm{Ge})$ detector system. However, because the radioiodine nuclides are not in routine use at Hanford, they are not part of the standard library of nuclides for which in vivo measurement results are routinely calculated. The spectrum peak search routine, performed for each measurement, will find them if they are present above the peak search minimum detectable activity (MDA), which is less sensitive than the library search MDA. Because of their low-energy photon emissions, ${ }^{125} \mathrm{I}$ and ${ }^{129} \mathrm{I}$ can only be measured using the intrinsic germanium (IG) detector systems in the thyroid-counting configuration. The nominal ${ }^{131}$ I MDA values for the peak search routine and for thyroid counting are given in Table 12.14.

Table 12.14. Hanford In Vivo Measurement Detection Capability for ${ }^{131} \mathrm{I},{ }^{129} \mathrm{I}$, and ${ }^{125} \mathrm{I}^{\text {(a) }}$

\begin{tabular}{lcccc}
\hline & & \multicolumn{3}{c}{ MDA (nCi) } \\
\cline { 3 - 5 } \multicolumn{1}{c}{ Measurement Type } & Organ/Tissue & ${ }^{131} \mathrm{I}$ & ${ }^{129} \mathrm{I}$ & ${ }^{125} \mathrm{I}$ \\
\hline 3-Minute NaI Preview Counter & Whole Body & 15 & --- & --- \\
$\begin{array}{l}\text { 10-Minute Coaxial Germanium } \\
\text { Counter }\end{array}$ & Whole Body & 2 & --- & --- \\
$\begin{array}{l}\text { Intrinsic Germanium System in } \\
\text { Thyroid Counting Configuration }\end{array}$ & Thyroid & 0.26 & 0.2 & 0.1 \\
\hline (a) From In Vivo Monitoring Program Manual, PNL-MA-574 (TP Lynch. 2007). &
\end{tabular}

The minimum detectable intakes and associated minimum detectable doses (MDDs) based on the nominal MDAs are listed in Table 12.15 for inhalation, Table 12.16 for ingestion, and Table 12.17 for injection. Figure 12.14 shows the minimum equivalent dose in the thyroid from inhalation of ${ }^{131}$ I counted on the NaI preview counter, coaxial counter, and the IG thyroid counting system, and ${ }^{129}$ I and ${ }^{125}$ I when counted on the IG thyroid counting system. Figures 12.15 through 2.17 show the comparison of thyroid minimum equivalent doses for ${ }^{131}$ I inhalation, ingestion, and injection when counted on the three counting systems. For all of the counting systems, the three intake modes show essentially the same minimum doses after about 3 days post intake. Figures 12.15 through 2.17 also illustrate that the IG thyroid counting system produces the lowest MDD, followed by the coaxial counting system, with the NaI preview counting system having the highest MDD values.

Radioiodine bioassay programs at Hanford are based on in vivo measurements. Urine sample analysis using a gamma spectrum analysis protocol (Hanford MDA of $10 \mathrm{dpm} / \mathrm{L}$ ) can also be used for radioiodines. However, the ease and convenience of in vivo measurements at Hanford makes urinalysis the less preferred method. 
Table 12.15. Minimum Detectable Intakes and Doses $E(50)$ and Thyroid $H_{\mathrm{T}}(50)$ for 5- $\mu \mathrm{m}-\mathrm{AMAD}$ Type F Inhalation

\begin{tabular}{|c|c|c|c|c|c|c|c|c|c|c|c|c|c|c|c|}
\hline \multirow[b]{3}{*}{ Time (d) } & \multicolumn{9}{|c|}{${ }^{131} \mathrm{I}$} & \multirow{2}{*}{\multicolumn{3}{|c|}{$\begin{array}{l}{ }^{129} \mathrm{I} \\
\text { IG Thyroid Counter }^{(\mathrm{d})} \\
\text { Minimum Detectable }\end{array}$}} & \multirow{2}{*}{\multicolumn{3}{|c|}{$\begin{array}{c}{ }^{125} \mathrm{I} \\
\text { yroid Counter } \\
\text { num Detectable } \\
\text { num }\end{array}$}} \\
\hline & \multicolumn{3}{|c|}{$\begin{array}{c}\text { NaI System }{ }^{(\mathrm{a})} \\
\text { Minimum Detectable }\end{array}$} & \multicolumn{3}{|c|}{$\begin{array}{l}\text { Coaxial GE System }^{(\mathrm{b})} \\
\text { Minimum Detectable }\end{array}$} & \multicolumn{3}{|c|}{$\begin{array}{l}\text { IG Thyroid Counter }{ }^{(\mathrm{c})} \\
\text { Minimum Detectable }\end{array}$} & & & & & & \\
\hline & $\begin{array}{l}\text { WB } \\
\text { Intake } \\
(\mathrm{nCi})\end{array}$ & $\begin{array}{c}E(50) \\
\text { (mrem) }\end{array}$ & $\begin{array}{l}H_{\mathrm{T}}(50) \\
(\mathrm{mrem})\end{array}$ & $\begin{array}{l}\text { WB } \\
\text { Intake } \\
\text { (nCi) }\end{array}$ & $\begin{array}{l}E(50) \\
\text { (mrem) }\end{array}$ & $\begin{array}{l}H_{\mathrm{T}}(50) \\
(\mathrm{mrem})\end{array}$ & $\begin{array}{l}\text { Thyroid } \\
\text { Intake } \\
\text { (nCi) }\end{array}$ & $\begin{array}{l}E(50) \\
\text { (mrem) }\end{array}$ & $\begin{array}{l}H_{\mathrm{T}}(50) \\
(\mathrm{mrem})\end{array}$ & $\begin{array}{l}\text { Thyroid } \\
\text { Intake } \\
(\mathrm{nCi})\end{array}$ & $\begin{array}{l}E(50) \\
\text { (mrem) }\end{array}$ & $\begin{array}{l}H_{\mathrm{T}}(50) \\
(\mathrm{mrem})\end{array}$ & $\begin{array}{l}\text { Thyroid } \\
\text { Intake } \\
\text { (nCi) }\end{array}$ & $\begin{array}{c}E(50) \\
\text { (mrem) }\end{array}$ & $\begin{array}{l}H_{\mathrm{T}}(50) \\
(\mathrm{mrem})\end{array}$ \\
\hline 0.5 & $3.16 \mathrm{E}+01$ & $1.23 \mathrm{E}+00$ & $2.44 \mathrm{E}+01$ & $4.21 \mathrm{E}+00$ & $1.64 \mathrm{E}-01$ & $3.26 \mathrm{E}+00$ & $1.11 \mathrm{E}+00$ & $4.31 \mathrm{E}-02$ & 8.57E-01 & $8.49 \mathrm{E}+00$ & $1.61 \mathrm{E}+00$ & $3.21 \mathrm{E}+01$ & $8.54 \mathrm{E}+00$ & $2.31 \mathrm{E}-01$ & $4.61 \mathrm{E}+00$ \\
\hline 1 & $5.30 \mathrm{E}+01$ & $2.06 \mathrm{E}+00$ & $4.10 \mathrm{E}+01$ & $7.06 \mathrm{E}+00$ & 2.75E-01 & $5.46 \mathrm{E}+00$ & 8.36E-01 & 3.25E-02 & 6.46E-01 & $6.13 \mathrm{E}+00$ & $1.16 \mathrm{E}+00$ & $2.32 \mathrm{E}+01$ & $6.21 \mathrm{E}+00$ & $1.68 \mathrm{E}-01$ & $3.35 \mathrm{E}+00$ \\
\hline 2 & $9.25 \mathrm{E}+01$ & $3.60 \mathrm{E}+00$ & $7.15 \mathrm{E}+01$ & $1.23 \mathrm{E}+01$ & $4.80 \mathrm{E}-01$ & $9.54 \mathrm{E}+00$ & 8.39E-01 & $3.26 \mathrm{E}-02$ & $6.49 \mathrm{E}-01$ & $5.65 E+00$ & $1.07 \mathrm{E}+00$ & $2.14 \mathrm{E}+01$ & $5.78 \mathrm{E}+00$ & $1.57 \mathrm{E}-01$ & $3.12 \mathrm{E}+00$ \\
\hline 3 & $1.20 \mathrm{E}+02$ & $4.69 \mathrm{E}+00$ & $9.31 \mathrm{E}+01$ & $1.61 \mathrm{E}+01$ & $6.25 \mathrm{E}-01$ & $1.24 \mathrm{E}+01$ & $9.18 \mathrm{E}-01$ & 3.57E-02 & 7.09E-01 & $5.67 \mathrm{E}+00$ & $1.07 \mathrm{E}+00$ & $2.14 \mathrm{E}+01$ & $5.87 \mathrm{E}+00$ & 1.59E-01 & $3.17 \mathrm{E}+00$ \\
\hline 4 & $1.41 \mathrm{E}+02$ & $5.48 \mathrm{E}+00$ & $1.09 \mathrm{E}+02$ & $1.88 \mathrm{E}+01$ & 7.31E-01 & $1.45 \mathrm{E}+01$ & $1.01 \mathrm{E}+00$ & 3.92E-02 & 7.79E-01 & $5.71 \mathrm{E}+00$ & $1.08 \mathrm{E}+00$ & $2.16 \mathrm{E}+01$ & $5.98 \mathrm{E}+00$ & 1.62E-01 & $3.23 \mathrm{E}+00$ \\
\hline 5 & $1.58 \mathrm{E}+02$ & $6.14 \mathrm{E}+00$ & $1.22 \mathrm{E}+02$ & $2.10 \mathrm{E}+01$ & 8.19E-01 & $1.63 \mathrm{E}+01$ & $1.11 \mathrm{E}+00$ & 4.31E-02 & 8.57E-01 & $5.76 \mathrm{E}+00$ & $1.09 \mathrm{E}+00$ & $2.18 \mathrm{E}+01$ & $6.10 \mathrm{E}+00$ & 1.65E-01 & $3.29 \mathrm{E}+00$ \\
\hline 6 & $1.74 \mathrm{E}+02$ & $6.77 \mathrm{E}+00$ & $1.35 \mathrm{E}+02$ & $2.32 \mathrm{E}+01$ & $9.03 \mathrm{E}-01$ & $1.79 \mathrm{E}+01$ & $1.22 \mathrm{E}+00$ & 4.74E-02 & $9.41 \mathrm{E}-01$ & $5.81 \mathrm{E}+00$ & $1.10 \mathrm{E}+00$ & $2.20 \mathrm{E}+01$ & $6.22 \mathrm{E}+00$ & 1.69E-01 & $3.36 \mathrm{E}+00$ \\
\hline 7 & $1.91 \mathrm{E}+02$ & $7.42 \mathrm{E}+00$ & $1.47 \mathrm{E}+02$ & $2.54 \mathrm{E}+01$ & 9.89E-01 & $1.97 \mathrm{E}+01$ & $1.34 \mathrm{E}+00$ & $5.21 \mathrm{E}-02$ & $1.03 \mathrm{E}+00$ & $5.85 \mathrm{E}+00$ & $1.11 \mathrm{E}+00$ & $2.21 \mathrm{E}+01$ & $6.35 \mathrm{E}+00$ & 1.72E-01 & $3.43 \mathrm{E}+00$ \\
\hline 8 & $2.09 \mathrm{E}+02$ & $8.11 \mathrm{E}+00$ & $1.61 \mathrm{E}+02$ & $2.78 \mathrm{E}+01$ & $1.08 \mathrm{E}+00$ & $2.15 E+01$ & $1.47 \mathrm{E}+00$ & $5.72 \mathrm{E}-02$ & $1.14 \mathrm{E}+00$ & $5.90 \mathrm{E}+00$ & $1.12 \mathrm{E}+00$ & $2.23 \mathrm{E}+01$ & $6.47 \mathrm{E}+00$ & $1.75 \mathrm{E}-01$ & $3.49 \mathrm{E}+00$ \\
\hline 9 & $2.28 \mathrm{E}+02$ & $8.87 \mathrm{E}+00$ & $1.76 \mathrm{E}+02$ & $3.04 \mathrm{E}+01$ & $1.18 \mathrm{E}+00$ & $2.35 \mathrm{E}+01$ & $1.62 \mathrm{E}+00$ & $6.28 \mathrm{E}-02$ & $1.25 \mathrm{E}+00$ & $5.95 \mathrm{E}+00$ & $1.12 \mathrm{E}+00$ & $2.25 \mathrm{E}+01$ & $6.60 \mathrm{E}+00$ & 1.79E-01 & $3.56 \mathrm{E}+00$ \\
\hline 10 & $2.49 \mathrm{E}+02$ & $9.69 \mathrm{E}+00$ & $1.93 \mathrm{E}+02$ & $3.32 \mathrm{E}+01$ & $1.29 \mathrm{E}+00$ & $2.57 \mathrm{E}+01$ & $1.77 \mathrm{E}+00$ & $6.90 \mathrm{E}-02$ & $1.37 \mathrm{E}+00$ & $5.99 \mathrm{E}+00$ & $1.13 \mathrm{E}+00$ & $2.27 \mathrm{E}+01$ & $6.73 E+00$ & $1.82 \mathrm{E}-01$ & $3.63 \mathrm{E}+00$ \\
\hline 12 & $2.98 \mathrm{E}+02$ & $1.16 \mathrm{E}+01$ & $2.30 \mathrm{E}+02$ & $3.97 \mathrm{E}+01$ & $1.54 \mathrm{E}+00$ & $3.07 \mathrm{E}+01$ & $2.14 \mathrm{E}+00$ & 8.33E-02 & $1.66 \mathrm{E}+00$ & $6.09 \mathrm{E}+00$ & $1.15 \mathrm{E}+00$ & $2.30 \mathrm{E}+01$ & $6.99 \mathrm{E}+00$ & 1.89E-01 & $3.77 \mathrm{E}+00$ \\
\hline 14 & $3.56 \mathrm{E}+02$ & $1.38 \mathrm{E}+01$ & $2.75 \mathrm{E}+02$ & $4.75 \mathrm{E}+01$ & $1.85 \mathrm{E}+00$ & $3.67 \mathrm{E}+01$ & $2.58 \mathrm{E}+00$ & $1.00 \mathrm{E}-01$ & $2.00 \mathrm{E}+00$ & $6.18 \mathrm{E}+00$ & $1.17 \mathrm{E}+00$ & $2.34 \mathrm{E}+01$ & $7.26 \mathrm{E}+00$ & 1.97E-01 & $3.92 \mathrm{E}+00$ \\
\hline 16 & $4.26 \mathrm{E}+02$ & $1.66 \mathrm{E}+01$ & $3.29 \mathrm{E}+02$ & $5.68 \mathrm{E}+01$ & $2.21 \mathrm{E}+00$ & $4.39 \mathrm{E}+01$ & $3.12 \mathrm{E}+00$ & $1.21 \mathrm{E}-01$ & $2.41 \mathrm{E}+00$ & $6.27 \mathrm{E}+00$ & $1.19 \mathrm{E}+00$ & $2.37 \mathrm{E}+01$ & $7.54 \mathrm{E}+00$ & 2.04E-01 & $4.07 \mathrm{E}+00$ \\
\hline 18 & $5.10 \mathrm{E}+02$ & $1.98 \mathrm{E}+01$ & $3.94 \mathrm{E}+02$ & $6.80 \mathrm{E}+01$ & $2.64 \mathrm{E}+00$ & $5.26 \mathrm{E}+01$ & $3.76 \mathrm{E}+00$ & $1.46 \mathrm{E}-01$ & $2.90 \mathrm{E}+00$ & $6.37 \mathrm{E}+00$ & $1.20 \mathrm{E}+00$ & $2.41 \mathrm{E}+01$ & $7.83 \mathrm{E}+00$ & 2.12E-01 & $4.23 \mathrm{E}+00$ \\
\hline 20 & $6.11 \mathrm{E}+02$ & $2.38 \mathrm{E}+01$ & $4.72 \mathrm{E}+02$ & $8.14 \mathrm{E}+01$ & $3.17 \mathrm{E}+00$ & $6.30 \mathrm{E}+01$ & $4.53 \mathrm{E}+00$ & $1.76 \mathrm{E}-01$ & $3.50 \mathrm{E}+00$ & $6.46 \mathrm{E}+00$ & $1.22 \mathrm{E}+00$ & $2.44 \mathrm{E}+01$ & $8.13 \mathrm{E}+00$ & 2.20E-01 & $4.39 \mathrm{E}+00$ \\
\hline 30 & $1.52 \mathrm{E}+03$ & $5.90 \mathrm{E}+01$ & $1.17 \mathrm{E}+03$ & $2.02 \mathrm{E}+02$ & $7.86 \mathrm{E}+00$ & $1.56 \mathrm{E}+02$ & $1.15 \mathrm{E}+01$ & 4.47E-01 & $8.89 \mathrm{E}+00$ & $6.93 \mathrm{E}+00$ & $1.31 \mathrm{E}+00$ & $2.62 \mathrm{E}+01$ & $9.79 \mathrm{E}+00$ & 2.65E-01 & $5.29 \mathrm{E}+00$ \\
\hline 60 & $2.39 \mathrm{E}+04$ & $9.30 \mathrm{E}+02$ & $1.85 \mathrm{E}+04$ & $3.19 \mathrm{E}+03$ & $1.24 \mathrm{E}+02$ & $2.46 \mathrm{E}+03$ & $1.86 \mathrm{E}+02$ & $7.24 \mathrm{E}+00$ & $1.44 \mathrm{E}+02$ & $8.44 \mathrm{E}+00$ & $1.59 \mathrm{E}+00$ & $3.19 \mathrm{E}+01$ & $1.68 \mathrm{E}+01$ & 4.57E-01 & $9.10 \mathrm{E}+00$ \\
\hline 90 & $3.82 \mathrm{E}+05$ & $1.49 \mathrm{E}+04$ & $2.96 \mathrm{E}+05$ & $5.10 \mathrm{E}+04$ & $1.98 \mathrm{E}+03$ & $3.94 \mathrm{E}+04$ & $2.99 \mathrm{E}+03$ & $1.16 \mathrm{E}+02$ & $2.31 \mathrm{E}+03$ & $1.02 \mathrm{E}+01$ & $1.93 \mathrm{E}+00$ & $3.86 \mathrm{E}+01$ & $2.88 \mathrm{E}+01$ & 7.81E-01 & $1.56 \mathrm{E}+01$ \\
\hline 180 & $1.58 \mathrm{E}+09$ & $6.15 \mathrm{E}+07$ & $1.22 \mathrm{E}+09$ & $2.11 \mathrm{E}+08$ & $8.20 \mathrm{E}+06$ & $1.63 \mathrm{E}+08$ & $1.24 \mathrm{E}+07$ & $4.82 \mathrm{E}+05$ & $9.57 \mathrm{E}+06$ & $1.81 \mathrm{E}+01$ & $3.41 \mathrm{E}+00$ & $6.82 \mathrm{E}+01$ & $1.44 \mathrm{E}+02$ & $3.89 \mathrm{E}+00$ & $7.76 \mathrm{E}+01$ \\
\hline 365 & $4.30 \mathrm{E}+16$ & $1.67 \mathrm{E}+15$ & $3.33 \mathrm{E}+16$ & $5.74 \mathrm{E}+15$ & $2.23 \mathrm{E}+14$ & $4.44 \mathrm{E}+15$ & $3.37 \mathrm{E}+14$ & $1.31 \mathrm{E}+13$ & $2.61 \mathrm{E}+14$ & $5.82 \mathrm{E}+01$ & $1.10 \mathrm{E}+01$ & $2.20 \mathrm{E}+02$ & $3.91 \mathrm{E}+03$ & $1.06 \mathrm{E}+02$ & $2.11 \mathrm{E}+03$ \\
\hline $\begin{array}{ll}\text { (a) } & \mathrm{B} \\
\text { (b) } & \mathrm{B} \\
\text { (c) } & \mathrm{B} \\
\text { (d) } & \mathrm{B} \\
\text { (e) } & \mathrm{B}\end{array}$ & $\begin{array}{l}\mathrm{d} \text { on an MD } \\
\mathrm{d} \text { on an MD }\end{array}$ & $\begin{array}{l}\text { A of } 0.26 n \\
\text { A of } 0.2 n C \\
A \text { of } 0.1 n C\end{array}$ & $\begin{array}{l}\mathrm{Ci} \text {, thyroid ce } \\
\text { i, thyroid col } \\
\text { i, thyroid col }\end{array}$ & $\begin{array}{l}\text { y count. } \\
\text { count. } \\
\text { ount. } \\
\text { unt. } \\
\text { unt. }\end{array}$ & & & & & & & & & & & \\
\hline
\end{tabular}

PNNL-MA-860 Chapter 12.0

Page 12.22
Issued for implementation effective 01/01/2010

Superseded: September 12, 2000 
Table 12.16. Minimum Detectable Intakes and Doses $E(50)$ and Thyroid $H_{\mathrm{T}}(50)$ for Ingestion

\begin{tabular}{|c|c|c|c|c|c|c|c|c|c|c|c|c|c|c|c|c|}
\hline \multirow{4}{*}{\multicolumn{2}{|c|}{ 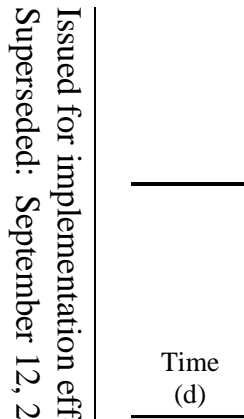 }} & \multicolumn{15}{|c|}{ Table 12.16. Minimum Detectable Intakes and Doses $E(50)$ and Thyroid $H_{\mathrm{T}}(50)$ for Ingestion } \\
\hline & & \multicolumn{9}{|c|}{${ }^{131} \mathrm{I}$} & \multicolumn{3}{|c|}{${ }^{129} \mathrm{I}$} & \multicolumn{3}{|c|}{${ }^{125} \mathrm{I}$} \\
\hline & & \multicolumn{3}{|c|}{$\begin{array}{c}\text { NaI System } \\
\text { Minimum Detectable }\end{array}$} & \multicolumn{3}{|c|}{$\begin{array}{l}\text { Coaxial GE System } \\
\text { Minimum Detectable }\end{array}$} & \multicolumn{3}{|c|}{$\begin{array}{l}\text { IG Thyroid Counter }{ }^{(c)} \\
\text { Minimum Detectable }\end{array}$} & \multicolumn{3}{|c|}{$\begin{array}{l}\text { IG Thyroid Counter }{ }^{(\mathrm{d})} \\
\text { Minimum Detectable }\end{array}$} & \multicolumn{3}{|c|}{$\begin{array}{l}\text { IG Thyroid Counter }{ }^{(\mathrm{e})} \\
\text { Minimum Detectable }\end{array}$} \\
\hline & & $\begin{array}{c}\text { WB } \\
\text { Intake } \\
(\mathrm{nCi}) \\
\end{array}$ & $\begin{array}{c}E(50) \\
\text { (mrem) }\end{array}$ & $\begin{array}{l}H_{\mathrm{T}}(50) \\
(\mathrm{mrem}) \\
\end{array}$ & $\begin{array}{c}\text { WB } \\
\text { Intake } \\
\text { (nCi) }\end{array}$ & $\begin{array}{c}E(50) \\
(\mathrm{mrem})\end{array}$ & $\begin{array}{l}H_{\mathrm{T}}(50) \\
(\mathrm{mrem}) \\
\end{array}$ & $\begin{array}{c}\text { Thyroid } \\
\text { Intake } \\
(\mathrm{nCi})\end{array}$ & $\begin{array}{c}E(50) \\
(\mathrm{mrem})\end{array}$ & $\begin{array}{l}H_{\mathrm{T}}(50) \\
(\mathrm{mrem})\end{array}$ & $\begin{array}{c}\text { Thyroid } \\
\text { Intake } \\
(\mathrm{nCi})\end{array}$ & $\begin{array}{c}E(50) \\
\text { (mrem) }\end{array}$ & $\begin{array}{l}H_{\mathrm{T}}(50) \\
\text { (mrem) } \\
\end{array}$ & $\begin{array}{c}\text { Thyroid } \\
\text { Intake } \\
(\mathrm{nCi})\end{array}$ & $\begin{array}{c}E(50) \\
\text { (mrem) }\end{array}$ & $\begin{array}{l}H_{\mathrm{T}}(50) \\
(\mathrm{mrem}) \\
\end{array}$ \\
\hline & 0.5 & $2.24 \mathrm{E}+01$ & $1.79 \mathrm{E}+00$ & $3.56 \mathrm{E}+01$ & $2.98 \mathrm{E}+00$ & 2.39E-01 & $4.75 \mathrm{E}+00$ & $6.56 \mathrm{E}-01$ & $5.25 \mathrm{E}-02$ & $1.04 \mathrm{E}+00$ & $5.03 E+00$ & $1.98 \mathrm{E}+00$ & $3.95 E+01$ & $5.05 E+00$ & 2.84E-01 & $5.66 \mathrm{E}+00$ \\
\hline 实 & 1 & $3.93 E+01$ & $3.15 E+00$ & $6.26 \mathrm{E}+01$ & $5.25 \mathrm{E}+00$ & $4.20 \mathrm{E}-01$ & $8.34 \mathrm{E}+00$ & 4.19E-01 & 3.36E-02 & 6.66E-01 & $3.07 \mathrm{E}+00$ & $1.21 \mathrm{E}+00$ & $2.42 \mathrm{E}+01$ & $3.11 \mathrm{E}+00$ & 1.75E-01 & $3.48 \mathrm{E}+00$ \\
\hline$\stackrel{\ominus}{\ominus}$ & 2 & $5.80 \mathrm{E}+01$ & $4.64 \mathrm{E}+00$ & $9.22 \mathrm{E}+01$ & $7.73 \mathrm{E}+00$ & $6.19 \mathrm{E}-01$ & $1.23 \mathrm{E}+01$ & 4.04E-01 & $3.24 \mathrm{E}-02$ & 6.43E-01 & $2.72 \mathrm{E}+00$ & $1.07 \mathrm{E}+00$ & $2.14 \mathrm{E}+01$ & $2.79 \mathrm{E}+00$ & $1.57 \mathrm{E}-01$ & $3.12 \mathrm{E}+00$ \\
\hline 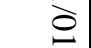 & 3 & $6.47 \mathrm{E}+01$ & $5.18 \mathrm{E}+00$ & $1.03 \mathrm{E}+02$ & $8.63 \mathrm{E}+00$ & 6.91E-01 & $1.37 \mathrm{E}+01$ & 4.41E-01 & 3.53E-02 & $7.01 \mathrm{E}-01$ & $2.72 \mathrm{E}+00$ & $1.07 \mathrm{E}+00$ & $2.14 \mathrm{E}+01$ & $2.82 \mathrm{E}+00$ & $1.58 \mathrm{E}-01$ & $3.16 \mathrm{E}+00$ \\
\hline N & 4 & $7.07 \mathrm{E}+01$ & $5.66 \mathrm{E}+00$ & $1.12 \mathrm{E}+02$ & $9.42 \mathrm{E}+00$ & 7.55E-01 & $1.50 \mathrm{E}+01$ & 4.85E-01 & $3.88 \mathrm{E}-02$ & 7.70E-01 & $2.75 E+00$ & $1.08 \mathrm{E}+00$ & $2.16 \mathrm{E}+01$ & $2.88 \mathrm{E}+00$ & $1.62 \mathrm{E}-01$ & $3.22 \mathrm{E}+00$ \\
\hline 总 & 5 & $7.71 \mathrm{E}+01$ & $6.18 \mathrm{E}+00$ & $1.23 \mathrm{E}+02$ & $1.03 \mathrm{E}+01$ & 8.24E-01 & $1.64 \mathrm{E}+01$ & 5.33E-01 & 4.27E-02 & 8.47E-01 & $2.77 \mathrm{E}+00$ & $1.09 \mathrm{E}+00$ & $2.18 \mathrm{E}+01$ & $2.93 \mathrm{E}+00$ & $1.65 \mathrm{E}-01$ & $3.28 \mathrm{E}+00$ \\
\hline & 6 & $8.42 E+01$ & $6.74 \mathrm{E}+00$ & $1.34 \mathrm{E}+02$ & $1.12 \mathrm{E}+01$ & 8.99E-01 & $1.79 \mathrm{E}+01$ & 5.85E-01 & 4.69E-02 & $9.31 \mathrm{E}-01$ & $2.79 \mathrm{E}+00$ & $1.10 \mathrm{E}+00$ & $2.19 \mathrm{E}+01$ & $2.99 \mathrm{E}+00$ & $1.68 \mathrm{E}-01$ & $3.35 \mathrm{E}+00$ \\
\hline & 7 & $9.19 \mathrm{E}+01$ & $7.36 \mathrm{E}+00$ & $1.46 \mathrm{E}+02$ & $1.23 \mathrm{E}+01$ & $9.82 \mathrm{E}-01$ & $1.95 \mathrm{E}+01$ & 6.43E-01 & 5.15E-02 & $1.02 \mathrm{E}+00$ & $2.81 \mathrm{E}+00$ & $1.11 \mathrm{E}+00$ & $2.21 \mathrm{E}+01$ & $3.05 \mathrm{E}+00$ & $1.71 \mathrm{E}-01$ & $3.42 \mathrm{E}+00$ \\
\hline & 8 & $1.00 \mathrm{E}+02$ & $8.04 \mathrm{E}+00$ & $1.60 \mathrm{E}+02$ & $1.34 \mathrm{E}+01$ & $1.07 \mathrm{E}+00$ & $2.13 \mathrm{E}+01$ & 7.07E-01 & $5.66 \mathrm{E}-02$ & $1.12 \mathrm{E}+00$ & $2.84 \mathrm{E}+00$ & $1.12 \mathrm{E}+00$ & $2.23 \mathrm{E}+01$ & $3.11 \mathrm{E}+00$ & 1.75E-01 & $3.48 \mathrm{E}+00$ \\
\hline & 9 & $1.10 \mathrm{E}+02$ & $8.79 \mathrm{E}+00$ & $1.74 \mathrm{E}+02$ & $1.46 \mathrm{E}+01$ & $1.17 \mathrm{E}+00$ & $2.33 \mathrm{E}+01$ & 7.76E-01 & $6.22 \mathrm{E}-02$ & $1.23 \mathrm{E}+00$ & $2.86 \mathrm{E}+00$ & $1.13 \mathrm{E}+00$ & $2.25 E+01$ & $3.17 \mathrm{E}+00$ & 1.78E-01 & $3.55 E+00$ \\
\hline & 10 & $1.20 \mathrm{E}+02$ & $9.60 \mathrm{E}+00$ & $1.91 \mathrm{E}+02$ & $1.60 \mathrm{E}+01$ & $1.28 \mathrm{E}+00$ & $2.54 \mathrm{E}+01$ & 8.53E-01 & 6.83E-02 & $1.36 \mathrm{E}+00$ & $2.88 \mathrm{E}+00$ & $1.14 \mathrm{E}+00$ & $2.26 \mathrm{E}+01$ & $3.23 \mathrm{E}+00$ & $1.82 \mathrm{E}-01$ & $3.62 \mathrm{E}+00$ \\
\hline & 12 & $1.43 \mathrm{E}+02$ & $1.15 \mathrm{E}+01$ & $2.28 \mathrm{E}+02$ & $1.91 \mathrm{E}+01$ & $1.53 \mathrm{E}+00$ & $3.04 \mathrm{E}+01$ & $1.03 \mathrm{E}+00$ & $8.24 \mathrm{E}-02$ & $1.64 \mathrm{E}+00$ & $2.93 \mathrm{E}+00$ & $1.15 \mathrm{E}+00$ & $2.30 \mathrm{E}+01$ & $3.36 \mathrm{E}+00$ & 1.89E-01 & $3.76 \mathrm{E}+00$ \\
\hline & 14 & $1.71 \mathrm{E}+02$ & $1.37 \mathrm{E}+01$ & $2.72 E+02$ & $2.28 \mathrm{E}+01$ & $1.83 \mathrm{E}+00$ & $3.63 \mathrm{E}+01$ & $1.24 \mathrm{E}+00$ & $9.94 \mathrm{E}-02$ & $1.97 \mathrm{E}+00$ & $2.97 \mathrm{E}+00$ & $1.17 \mathrm{E}+00$ & $2.34 \mathrm{E}+01$ & $3.49 \mathrm{E}+00$ & 1.96E-01 & $3.91 \mathrm{E}+00$ \\
\hline & 16 & $2.05 \mathrm{E}+02$ & $1.64 \mathrm{E}+01$ & $3.26 \mathrm{E}+02$ & $2.73 \mathrm{E}+01$ & $2.19 \mathrm{E}+00$ & $4.34 \mathrm{E}+01$ & $1.50 \mathrm{E}+00$ & $1.20 \mathrm{E}-01$ & $2.38 \mathrm{E}+00$ & $3.02 \mathrm{E}+00$ & $1.19 \mathrm{E}+00$ & $2.37 \mathrm{E}+01$ & $3.63 \mathrm{E}+00$ & 2.04E-01 & $4.06 \mathrm{E}+00$ \\
\hline & 18 & $2.45 \mathrm{E}+02$ & $1.96 \mathrm{E}+01$ & $3.90 \mathrm{E}+02$ & $3.27 \mathrm{E}+01$ & $2.62 \mathrm{E}+00$ & $5.20 \mathrm{E}+01$ & $1.81 \mathrm{E}+00$ & $1.45 \mathrm{E}-01$ & $2.87 \mathrm{E}+00$ & $3.06 \mathrm{E}+00$ & $1.21 \mathrm{E}+00$ & $2.41 \mathrm{E}+01$ & $3.77 \mathrm{E}+00$ & 2.12E-01 & $4.22 \mathrm{E}+00$ \\
\hline & 20 & $2.94 \mathrm{E}+02$ & $2.35 E+01$ & $4.67 \mathrm{E}+02$ & $3.92 \mathrm{E}+01$ & $3.14 \mathrm{E}+00$ & $6.23 \mathrm{E}+01$ & $2.18 \mathrm{E}+00$ & $1.74 \mathrm{E}-01$ & $3.46 \mathrm{E}+00$ & $3.10 \mathrm{E}+00$ & $1.22 \mathrm{E}+00$ & $2.44 \mathrm{E}+01$ & $3.91 \mathrm{E}+00$ & $2.20 \mathrm{E}-01$ & $4.38 \mathrm{E}+00$ \\
\hline & 30 & $7.29 \mathrm{E}+02$ & $5.84 \mathrm{E}+01$ & $1.16 \mathrm{E}+03$ & $9.72 \mathrm{E}+01$ & $7.78 \mathrm{E}+00$ & $1.55 \mathrm{E}+02$ & $5.53 \mathrm{E}+00$ & 4.43E-01 & $8.79 \mathrm{E}+00$ & $3.33 E+00$ & $1.31 \mathrm{E}+00$ & $2.62 \mathrm{E}+01$ & $4.70 \mathrm{E}+00$ & 2.64E-01 & $5.27 \mathrm{E}+00$ \\
\hline & 60 & $1.15 E+04$ & $9.20 \mathrm{E}+02$ & $1.83 \mathrm{E}+04$ & $1.53 \mathrm{E}+03$ & $1.23 \mathrm{E}+02$ & $2.44 \mathrm{E}+03$ & $8.94 \mathrm{E}+01$ & $7.16 \mathrm{E}+00$ & $1.42 \mathrm{E}+02$ & $4.06 \mathrm{E}+00$ & $1.60 \mathrm{E}+00$ & $3.19 \mathrm{E}+01$ & $8.10 \mathrm{E}+00$ & 4.55E-01 & $9.07 \mathrm{E}+00$ \\
\hline & 90 & $1.84 \mathrm{E}+05$ & $1.47 \mathrm{E}+04$ & $2.92 \mathrm{E}+05$ & $2.45 \mathrm{E}+04$ & $1.96 \mathrm{E}+03$ & $3.90 \mathrm{E}+04$ & $1.44 \mathrm{E}+03$ & $1.15 \mathrm{E}+02$ & $2.29 \mathrm{E}+03$ & $4.91 \mathrm{E}+00$ & $1.93 \mathrm{E}+00$ & $3.86 \mathrm{E}+01$ & $1.39 \mathrm{E}+01$ & 7.79E-01 & $1.55 \mathrm{E}+01$ \\
\hline$\nabla$ & 180 & $7.60 \mathrm{E}+08$ & $6.09 \mathrm{E}+07$ & $1.21 \mathrm{E}+09$ & $1.01 \mathrm{E}+08$ & $8.12 E+06$ & $1.61 \mathrm{E}+08$ & $5.95 E+06$ & $4.77 \mathrm{E}+05$ & $9.47 \mathrm{E}+06$ & $8.68 \mathrm{E}+00$ & $3.42 \mathrm{E}+00$ & $6.82 \mathrm{E}+01$ & $6.91 \mathrm{E}+01$ & $3.88 \mathrm{E}+00$ & $7.74 \mathrm{E}+01$ \\
\hline Z & 365 & $2.07 \mathrm{E}+16$ & $1.66 \mathrm{E}+15$ & $3.29 \mathrm{E}+16$ & $2.76 \mathrm{E}+15$ & $2.21 \mathrm{E}+14$ & $4.39 \mathrm{E}+15$ & $1.62 \mathrm{E}+14$ & $1.30 \mathrm{E}+13$ & $2.58 \mathrm{E}+14$ & $2.80 \mathrm{E}+01$ & $1.10 \mathrm{E}+01$ & $2.20 \mathrm{E}+02$ & $1.88 \mathrm{E}+03$ & $1.06 \mathrm{E}+02$ & $2.10 \mathrm{E}+03$ \\
\hline $\begin{array}{l}1 \\
3 \\
3 \\
0 \\
0 \\
0 \\
0\end{array}$ & $\begin{array}{ll}\text { (a) } & \mathrm{B} \\
\text { (b) } & \mathrm{B} \\
\text { (c) } & \mathrm{B} \\
\text { (d) } & \mathrm{B} \\
\text { (e) } & \mathrm{B}\end{array}$ & ed on an MD & $\begin{array}{l}\text { A of } 15 \mathrm{nCi} \\
\text { A of } 2 \mathrm{nCi} \text {, } \\
\text { A of } 0.26 \mathrm{n} \\
\text { A of } 0.2 \mathrm{nC} \\
\mathrm{A} \text { of } 0.1 \mathrm{nC}\end{array}$ & $\begin{array}{l}\text { i, whole bod } \\
\text { whole body } \\
\mathrm{Ci} \text {, thyroid c } \\
\mathrm{i} \text {, thyroid co } \\
\mathrm{i} \text {, thyroid co }\end{array}$ & $\begin{array}{l}\text { y count. } \\
\text { count. } \\
\text { count. } \\
\text { punt. } \\
\text { punt. }\end{array}$ & & & & & & & & & & & \\
\hline
\end{tabular}


Table 12.17. Minimum Detectable Intakes and Doses $E(50)$ and Thyroid $H_{\mathrm{T}}(50)$ for Injection

\begin{tabular}{|c|c|c|c|c|c|c|c|c|c|c|c|c|c|c|c|}
\hline \multirow[b]{3}{*}{$\begin{array}{l}\text { Time } \\
\text { (d) }\end{array}$} & \multicolumn{9}{|c|}{${ }^{131} \mathrm{I}$} & \multirow{2}{*}{\multicolumn{3}{|c|}{$\begin{array}{l}{ }^{129} \mathrm{I} \\
\text { IG Thyroid Counter }{ }^{(\mathrm{d})} \\
\text { Minimum Detectable }\end{array}$}} & \multirow{2}{*}{\multicolumn{3}{|c|}{$\begin{array}{l}{ }^{125} \mathrm{I} \\
\text { roid Counter } \\
\text { um Detectable }\end{array}$}} \\
\hline & \multicolumn{3}{|c|}{$\begin{array}{c}\text { NaI System }{ }^{(a)} \\
\text { Minimum Detectable }\end{array}$} & \multicolumn{3}{|c|}{$\begin{array}{l}\text { Coaxial GE System } \\
\text { Minimum Detectable }\end{array}$} & \multicolumn{3}{|c|}{$\begin{array}{l}\text { IG Thyroid Counter }{ }^{(\mathrm{c})} \\
\text { Minimum Detectable }\end{array}$} & & & & & & \\
\hline & $\begin{array}{l}\text { WB } \\
\text { Intake } \\
\text { (nCi) }\end{array}$ & $\begin{array}{c}E(50) \\
(\mathrm{mrem})\end{array}$ & $\begin{array}{l}H_{\mathrm{T}}(50) \\
(\mathrm{mrem})\end{array}$ & $\begin{array}{l}\text { WB } \\
\text { Intake } \\
\text { (nCi) }\end{array}$ & $\begin{array}{c}E(50) \\
\text { (mrem) }\end{array}$ & $\begin{array}{l}H_{\mathrm{T}}(50) \\
(\mathrm{mrem})\end{array}$ & $\begin{array}{l}\text { Thyroid } \\
\text { Intake } \\
\text { (nCi) }\end{array}$ & $\begin{array}{c}E(50) \\
\text { (mrem) }\end{array}$ & $\begin{array}{l}H_{\mathrm{T}}(50) \\
(\mathrm{mrem})\end{array}$ & $\begin{array}{l}\text { Thyroid } \\
\text { Intake } \\
\text { (nCi) }\end{array}$ & $\begin{array}{c}E(50) \\
\text { (mrem) }\end{array}$ & $\begin{array}{l}H_{\mathrm{T}}(50) \\
(\mathrm{mrem})\end{array}$ & $\begin{array}{l}\text { Thyroid } \\
\text { Intake } \\
\text { (nCi) }\end{array}$ & $\begin{array}{l}E(50) \\
(\mathrm{mrem})\end{array}$ & $\begin{array}{l}H_{\mathrm{T}}(50) \\
(\mathrm{mrem})\end{array}$ \\
\hline 0.5 & $2.97 \mathrm{E}+01$ & $2.42 \mathrm{E}+00$ & $4.81 \mathrm{E}+01$ & $3.96 \mathrm{E}+00$ & 3.22E-01 & $6.42 \mathrm{E}+00$ & 4.65E-01 & $3.78 \mathrm{E}-02$ & 7.54E-01 & $3.57 \mathrm{E}+00$ & $1.40 \mathrm{E}+00$ & $2.80 \mathrm{E}+01$ & $3.59 \mathrm{E}+00$ & $2.02 \mathrm{E}-01$ & $4.02 \mathrm{E}+00$ \\
\hline 1 & $4.58 \mathrm{E}+01$ & $3.72 \mathrm{E}+00$ & $7.42 \mathrm{E}+01$ & $6.11 \mathrm{E}+00$ & 4.97E-01 & $9.90 \mathrm{E}+00$ & 3.90E-01 & 3.17E-02 & 6.32E-01 & $2.86 \mathrm{E}+00$ & $1.13 \mathrm{E}+00$ & $2.25 E+01$ & $2.89 \mathrm{E}+00$ & 1.63E-01 & $3.24 \mathrm{E}+00$ \\
\hline 2 & $5.87 \mathrm{E}+01$ & $4.77 \mathrm{E}+00$ & $9.51 \mathrm{E}+01$ & $7.83 \mathrm{E}+00$ & 6.37E-01 & $1.27 \mathrm{E}+01$ & 4.03E-01 & $3.28 \mathrm{E}-02$ & 6.53E-01 & $2.72 \mathrm{E}+00$ & $1.07 \mathrm{E}+00$ & $2.13 \mathrm{E}+01$ & $2.78 \mathrm{E}+00$ & $1.56 \mathrm{E}-01$ & $3.11 \mathrm{E}+00$ \\
\hline 3 & $6.48 \mathrm{E}+01$ & $5.27 \mathrm{E}+00$ & $1.05 \mathrm{E}+02$ & $8.63 \mathrm{E}+00$ & 7.02E-01 & $1.40 \mathrm{E}+01$ & 4.42E-01 & 3.59E-02 & 7.16E-01 & $2.73 \mathrm{E}+00$ & $1.07 \mathrm{E}+00$ & $2.14 \mathrm{E}+01$ & $2.82 \mathrm{E}+00$ & 1.59E-01 & $3.16 \mathrm{E}+00$ \\
\hline 4 & $7.07 \mathrm{E}+01$ & $5.75 \mathrm{E}+00$ & $1.15 \mathrm{E}+02$ & $9.43 \mathrm{E}+00$ & 7.66E-01 & $1.53 \mathrm{E}+01$ & 4.85E-01 & 3.95E-02 & 7.86E-01 & $2.75 \mathrm{E}+00$ & $1.08 \mathrm{E}+00$ & $2.16 \mathrm{E}+01$ & $2.88 \mathrm{E}+00$ & 1.62E-01 & $3.23 \mathrm{E}+00$ \\
\hline 5 & $7.72 \mathrm{E}+01$ & $6.27 \mathrm{E}+00$ & $1.25 \mathrm{E}+02$ & $1.03 \mathrm{E}+01$ & 8.36E-01 & $1.67 \mathrm{E}+01$ & 5.33E-01 & 4.34E-02 & 8.64E-01 & $2.77 \mathrm{E}+00$ & $1.09 \mathrm{E}+00$ & $2.18 \mathrm{E}+01$ & $2.94 \mathrm{E}+00$ & 1.65E-01 & $3.29 \mathrm{E}+00$ \\
\hline 6 & $8.42 \mathrm{E}+01$ & $6.85 \mathrm{E}+00$ & $1.36 \mathrm{E}+02$ & $1.12 \mathrm{E}+01$ & 9.13E-01 & $1.82 \mathrm{E}+01$ & 5.86E-01 & 4.77E-02 & $9.50 \mathrm{E}-01$ & $2.80 \mathrm{E}+00$ & $1.10 \mathrm{E}+00$ & $2.20 \mathrm{E}+01$ & $3.00 \mathrm{E}+00$ & 1.69E-01 & $3.36 \mathrm{E}+00$ \\
\hline 7 & $9.20 \mathrm{E}+01$ & $7.48 \mathrm{E}+00$ & $1.49 \mathrm{E}+02$ & $1.23 \mathrm{E}+01$ & 9.97E-01 & $1.99 \mathrm{E}+01$ & $6.44 \mathrm{E}-01$ & 5.24E-02 & $1.04 \mathrm{E}+00$ & $2.82 \mathrm{E}+00$ & $1.11 \mathrm{E}+00$ & $2.22 \mathrm{E}+01$ & $3.06 \mathrm{E}+00$ & $1.72 \mathrm{E}-01$ & $3.42 \mathrm{E}+00$ \\
\hline 8 & $1.00 \mathrm{E}+02$ & $8.17 \mathrm{E}+00$ & $1.63 \mathrm{E}+02$ & $1.34 \mathrm{E}+01$ & $1.09 \mathrm{E}+00$ & $2.17 \mathrm{E}+01$ & 7.08E-01 & 5.75E-02 & $1.15 \mathrm{E}+00$ & $2.84 \mathrm{E}+00$ & $1.12 \mathrm{E}+00$ & $2.23 \mathrm{E}+01$ & $3.12 \mathrm{E}+00$ & $1.75 \mathrm{E}-01$ & $3.49 \mathrm{E}+00$ \\
\hline 9 & $1.10 \mathrm{E}+02$ & $8.92 \mathrm{E}+00$ & $1.78 \mathrm{E}+02$ & $1.46 \mathrm{E}+01$ & $1.19 \mathrm{E}+00$ & $2.37 \mathrm{E}+01$ & 7.78E-01 & 6.32E-02 & $1.26 \mathrm{E}+00$ & $2.86 \mathrm{E}+00$ & $1.13 \mathrm{E}+00$ & $2.25 \mathrm{E}+01$ & $3.18 \mathrm{E}+00$ & 1.79E-01 & $3.56 \mathrm{E}+00$ \\
\hline 10 & $1.20 \mathrm{E}+02$ & $9.75 \mathrm{E}+00$ & $1.94 \mathrm{E}+02$ & $1.60 \mathrm{E}+01$ & $1.30 \mathrm{E}+00$ & $2.59 \mathrm{E}+01$ & 8.54E-01 & 6.95E-02 & $1.38 \mathrm{E}+00$ & $2.89 \mathrm{E}+00$ & $1.14 \mathrm{E}+00$ & $2.27 \mathrm{E}+01$ & $3.24 \mathrm{E}+00$ & 1.82E-01 & $3.63 \mathrm{E}+00$ \\
\hline 12 & $1.43 \mathrm{E}+02$ & $1.16 \mathrm{E}+01$ & $2.32 \mathrm{E}+02$ & $1.91 \mathrm{E}+01$ & $1.55 \mathrm{E}+00$ & $3.09 \mathrm{E}+01$ & $1.03 \mathrm{E}+00$ & 8.38E-02 & $1.67 \mathrm{E}+00$ & $2.93 \mathrm{E}+00$ & $1.15 \mathrm{E}+00$ & $2.30 \mathrm{E}+01$ & $3.37 \mathrm{E}+00$ & 1.89E-01 & $3.77 \mathrm{E}+00$ \\
\hline 14 & $1.71 \mathrm{E}+02$ & $1.39 \mathrm{E}+01$ & $2.78 \mathrm{E}+02$ & $2.28 \mathrm{E}+01$ & $1.86 \mathrm{E}+00$ & $3.70 \mathrm{E}+01$ & $1.24 \mathrm{E}+00$ & $1.01 \mathrm{E}-01$ & $2.01 \mathrm{E}+00$ & $2.98 \mathrm{E}+00$ & $1.17 \mathrm{E}+00$ & $2.34 \mathrm{E}+01$ & $3.50 \mathrm{E}+00$ & 1.97E-01 & $3.92 \mathrm{E}+00$ \\
\hline 16 & $2.05 E+02$ & $1.67 \mathrm{E}+01$ & $3.32 \mathrm{E}+02$ & $2.73 E+01$ & $2.22 \mathrm{E}+00$ & $4.43 \mathrm{E}+01$ & $1.50 \mathrm{E}+00$ & $1.22 \mathrm{E}-01$ & $2.43 \mathrm{E}+00$ & $3.02 \mathrm{E}+00$ & $1.19 \mathrm{E}+00$ & $2.37 \mathrm{E}+01$ & $3.63 \mathrm{E}+00$ & 2.04E-01 & $4.07 \mathrm{E}+00$ \\
\hline 18 & $2.45 \mathrm{E}+02$ & $2.00 \mathrm{E}+01$ & $3.98 \mathrm{E}+02$ & $3.27 \mathrm{E}+01$ & $2.66 \mathrm{E}+00$ & $5.30 \mathrm{E}+01$ & $1.81 \mathrm{E}+00$ & 1.47E-01 & $2.93 \mathrm{E}+00$ & $3.06 \mathrm{E}+00$ & $1.21 \mathrm{E}+00$ & $2.41 \mathrm{E}+01$ & $3.77 \mathrm{E}+00$ & 2.12E-01 & $4.22 \mathrm{E}+00$ \\
\hline 20 & $2.94 \mathrm{E}+02$ & $2.39 \mathrm{E}+01$ & $4.76 \mathrm{E}+02$ & $3.92 \mathrm{E}+01$ & $3.19 \mathrm{E}+00$ & $6.35 \mathrm{E}+01$ & $2.18 \mathrm{E}+00$ & 1.77E-01 & $3.53 \mathrm{E}+00$ & $3.11 \mathrm{E}+00$ & $1.22 \mathrm{E}+00$ & $2.44 \mathrm{E}+01$ & $3.92 \mathrm{E}+00$ & 2.20E-01 & $4.39 \mathrm{E}+00$ \\
\hline 30 & $7.30 \mathrm{E}+02$ & $5.93 \mathrm{E}+01$ & $1.18 \mathrm{E}+03$ & $9.73 \mathrm{E}+01$ & $7.91 \mathrm{E}+00$ & $1.58 \mathrm{E}+02$ & $5.54 \mathrm{E}+00$ & 4.50E-01 & $8.97 \mathrm{E}+00$ & $3.33 \mathrm{E}+00$ & $1.31 \mathrm{E}+00$ & $2.62 \mathrm{E}+01$ & $4.71 \mathrm{E}+00$ & 2.65E-01 & $5.28 \mathrm{E}+00$ \\
\hline 60 & $1.15 E+04$ & $9.35 \mathrm{E}+02$ & $1.86 \mathrm{E}+04$ & $1.53 \mathrm{E}+03$ & $1.25 \mathrm{E}+02$ & $2.49 \mathrm{E}+03$ & $8.95 E+01$ & $7.28 \mathrm{E}+00$ & $1.45 \mathrm{E}+02$ & $4.06 \mathrm{E}+00$ & $1.60 \mathrm{E}+00$ & $3.19 \mathrm{E}+01$ & $8.11 \mathrm{E}+00$ & 4.57E-01 & $9.08 \mathrm{E}+00$ \\
\hline 90 & $1.84 \mathrm{E}+05$ & $1.50 \mathrm{E}+04$ & $2.98 \mathrm{E}+05$ & $2.45 E+04$ & $2.00 \mathrm{E}+03$ & $3.98 \mathrm{E}+04$ & $1.44 \mathrm{E}+03$ & $1.17 \mathrm{E}+02$ & $2.33 \mathrm{E}+03$ & $4.92 \mathrm{E}+00$ & $1.94 \mathrm{E}+00$ & $3.86 \mathrm{E}+01$ & $1.39 \mathrm{E}+01$ & 7.81E-01 & $1.55 \mathrm{E}+01$ \\
\hline 180 & $7.61 \mathrm{E}+08$ & $6.19 \mathrm{E}+07$ & $1.23 \mathrm{E}+09$ & $1.02 \mathrm{E}+08$ & $8.25 \mathrm{E}+06$ & $1.64 \mathrm{E}+08$ & $5.96 \mathrm{E}+06$ & $4.85 \mathrm{E}+05$ & $9.66 \mathrm{E}+06$ & $8.69 \mathrm{E}+00$ & $3.42 \mathrm{E}+00$ & $6.83 \mathrm{E}+01$ & $6.92 \mathrm{E}+01$ & $3.89 \mathrm{E}+00$ & $7.75 \mathrm{E}+01$ \\
\hline 365 & $2.07 \mathrm{E}+16$ & $1.68 \mathrm{E}+15$ & $3.36 \mathrm{E}+16$ & $2.76 \mathrm{E}+15$ & $2.25 \mathrm{E}+14$ & $4.47 \mathrm{E}+15$ & $1.62 \mathrm{E}+14$ & $1.32 \mathrm{E}+13$ & $2.63 \mathrm{E}+14$ & $2.80 \mathrm{E}+01$ & $1.10 \mathrm{E}+01$ & $2.20 \mathrm{E}+02$ & $1.88 \mathrm{E}+03$ & $1.06 \mathrm{E}+02$ & $2.11 \mathrm{E}+03$ \\
\hline $\begin{array}{l}\text { (b) } \\
\text { (c) } \\
\text { (d) } \\
\text { (e) }\end{array}$ & on $\mathrm{MD}$ & $0.1 \mathrm{nCi}$ & oid col & & & & & & & & & & & & \\
\hline
\end{tabular}




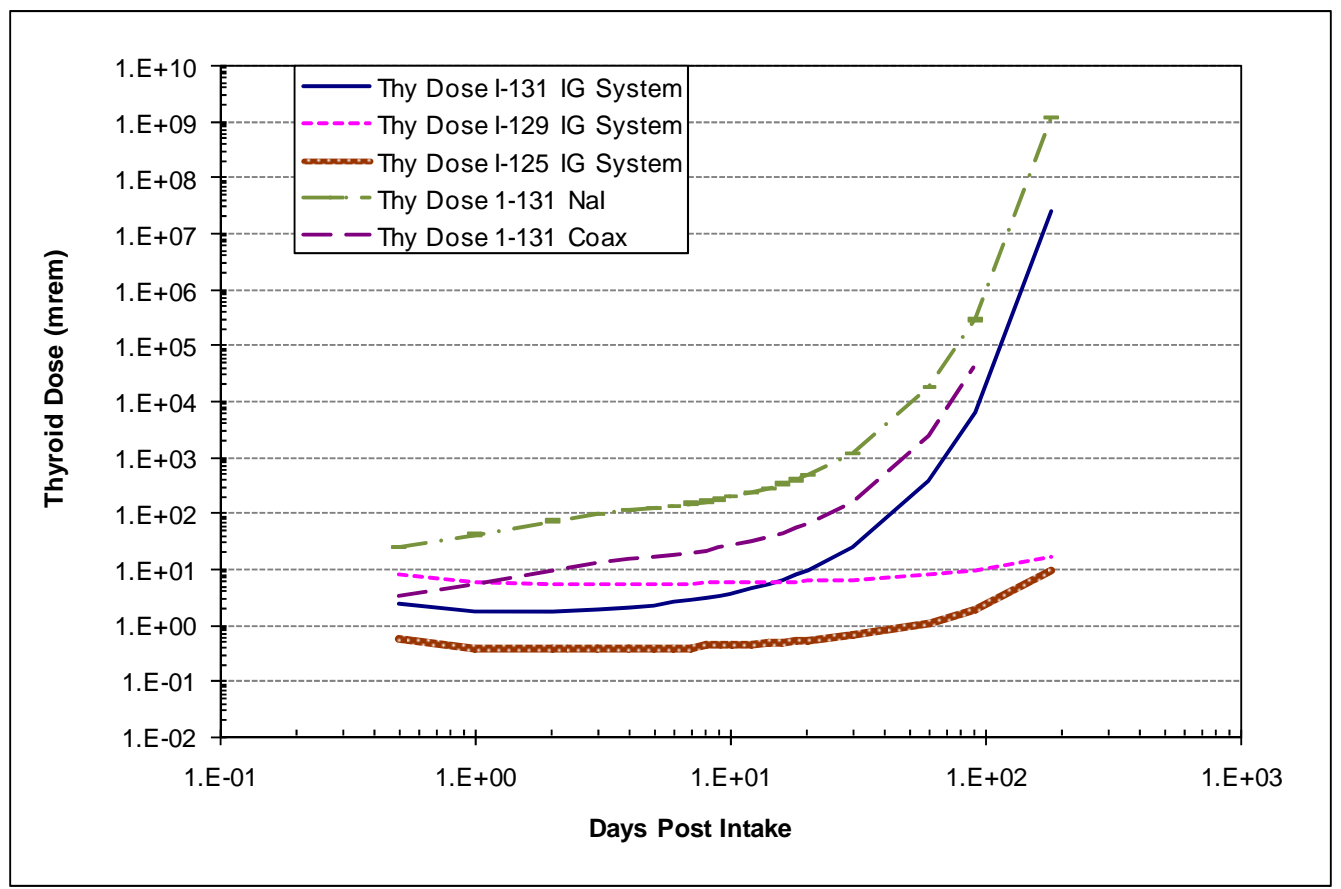

Figure 12.14. Minimum Detectable Thyroid Equivalent Dose Following Type F 5- $\mu$ m-AMAD Inhalation

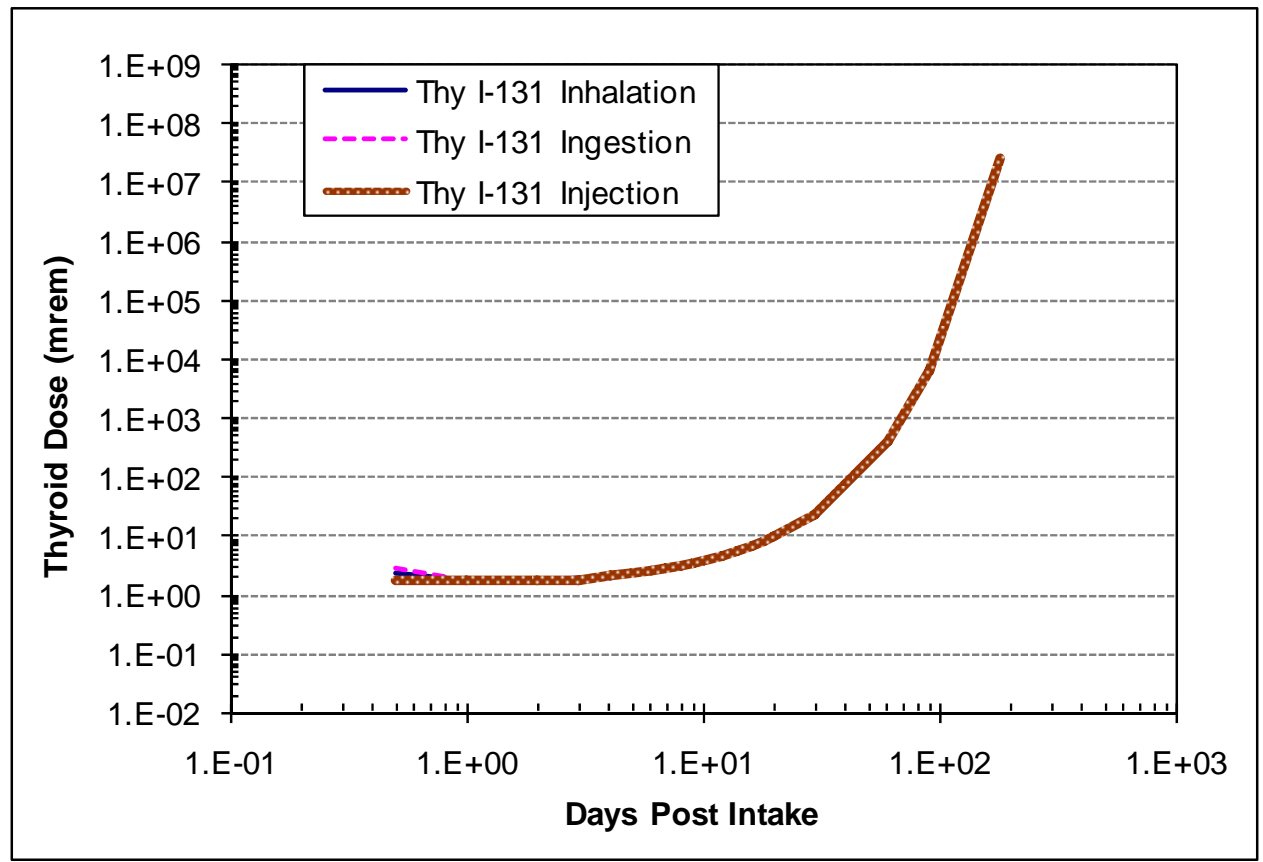

Figure 12.15. Minimum Detectable Thyroid Equivalent Dose for ${ }^{131}$ I Following Inhalation, Ingestion, and Injection for the Three Counting Systems (IG Thyroid Counting System) 


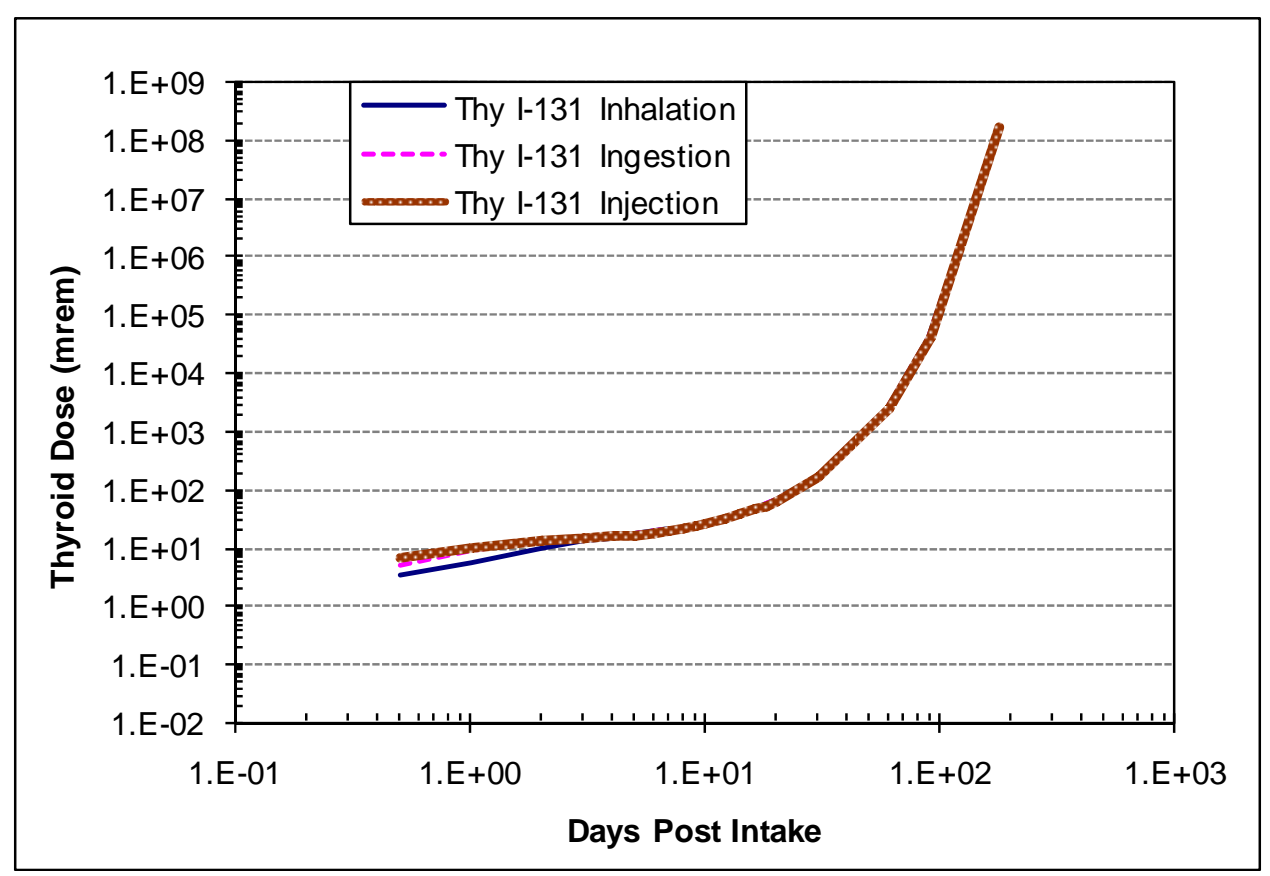

Figure 12.16. Minimum Detectable Thyroid Equivalent Dose for ${ }^{131}$ I Following Inhalation, Ingestion, and Injection for the Three Counting Systems (Coaxial Whole Body Counting System)

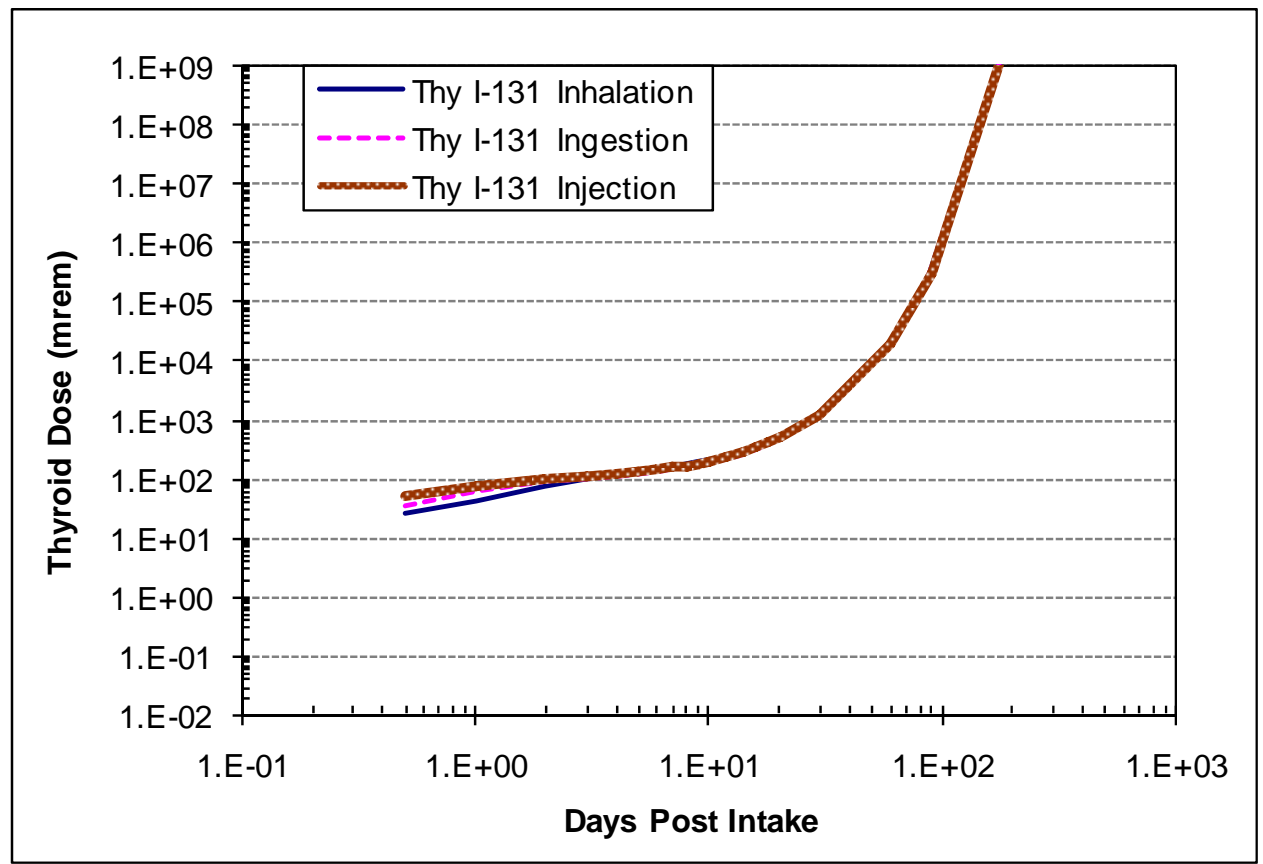

Figure 12.17. Minimum Detectable Thyroid Equivalent Dose for ${ }^{131}$ I Following Inhalation, Ingestion, and Injection for the Three Counting Systems (NaI Preview Counting System) 


\subsubsection{Routine Bioassay Monitoring Protocol}

It is recommended that routine bioassay measurements be performed at intervals not exceeding four to five effective half-lives of the radionuclide because of uncertainties associated with the assumed retention characteristics. Based on that recommendation and the minimum detectable doses listed in Tables 12.15, 12.16, and 12.17, the measurement frequency for the minimum recommended routine monitoring program for workers potentially exposed to ${ }^{131} \mathrm{I},{ }^{125} \mathrm{I}$, or ${ }^{129} \mathrm{I}$, is monthly, semiannually, and annually, respectively. If the coaxial germanium system is used for ${ }^{131} \mathrm{I}$ bioassay, bimonthly measurements (i.e., every 2 months) provide adequate sensitivity.

A supplemental approach to routine bioassay monitoring for radioiodines is to perform a workplace thyroid screening measurement shortly after completion of the iodine-related work. If there is any indication of radioiodine detection, then a more timely thyroid count can be performed using the highresolution systems.

If an iodine isotope is detected in a routine measurement, follow-up measurements to confirm the intake should be performed. The measurements should preferably be performed immediately following the initial measurement while the subject is at the in vivo monitoring counting facility. The use of the high-resolution germanium detectors for follow-up measurements is preferred to accurately quantify the thyroid deposition.

\subsubsection{Special Monitoring for Suspected Intakes}

Thyroid counts should be performed to assess the significance of an acute intake of radioiodine. The deposition of iodine in the thyroid following an acute intake is not instantaneous; rather, buildup of iodine in the thyroid will occur over a period of about 3 days after the intake. Results of thyroid counts obtained within a day or so of an intake may thus underestimate the maximum retained quantity that will be achieved after the exposure. Measurements made 2 to 3 days post intake will likely provide the best indication of the maximum retained quantity in the thyroid from the intake.

If significant quantities of short-lived radioiodines are possibly associated with an exposure, then in vivo measurements should be performed within a day of the intake. The measurements should be made using a germanium detector to achieve optimum resolution. Follow-up counts, if needed, should be performed. Data from facility monitoring may be used to identify the relative activities of the various radioiodines present at the time of intake. Caution should be exercised when analyzing in vivo data for short-lived iodine isotopes to ensure that activity within the thyroid (and not external contamination) is being measured.

\subsection{Assessment of Internal Dose}

Radioiodines can be detected and quantified in the thyroid using in vivo techniques. Measurement of ${ }^{125} \mathrm{I}$ and ${ }^{129} \mathrm{I}$ requires the use of the planar germanium counting system for thyroid counting. Thyroid counts are sufficiently sensitive to enable detection of activity in the thyroid at levels below that of any dosimetric consequence (see Tables 12.15 through 12.17). Thus, dose-based screening levels for thyroid 
assessments may be appropriate (e.g., a screening level based on 10-mrem committed effective dose provides assurance that significant doses do not go unassessed). Routine whole body counting or thyroid counting can be used for ${ }^{131} \mathrm{I}$.

Several methods exist for evaluating in vivo results to assess internal dose. The simplest method, and one that is recommended for initial evaluation of in vivo results as well as for final evaluations when doses are low, involves fitting the in vivo measurement data to the expected internal activity using the biokinetic model prescribed in this chapter. Data-fitting is performed using IMBA. Alternatively, a hand calculation can be performed using the factors tabulated in this chapter.

Assumptions that are used for this evaluation are that 1) the material is inhaled in Type F form, 2) the intake date, if unknown, is assumed to be the midpoint of the period during which the intake could have occurred, and 3) the intake consisted of the inhalation of an aerosol with an AMAD of $5 \mu \mathrm{m}$. Observed in vivo retention should be used in place of the ICRP biokinetic model for evaluations of internal doses that potentially exceed a 100-mrem committed effective dose when sufficient in vivo data are available for such an analysis.

\subsection{Management of Internal Contamination Cases}

In an accident exposure situation, iodine will likely be taken in by inhalation, ingestion, and absorption through the skin. If the iodine is very soluble, it will reach the thyroid relatively quickly; however, maximum thyroid activity may not occur until 2 or 3 days post intake. Thus, thyroid counts performed shortly after intake may underestimate the maximum deposition. Also of concern for in vivo measurements made shortly after intake are contributions to the count from radioiodine located outside the body or in other regions of the body. However, if thyroid measurements are made with a collimated germanium detector, these interferences can most likely be reduced to negligible levels.

The adult thyroid gland is considered to be a relatively radio resistant organ (with a tissue weighting factor of 0.05) with respect to the risk of fatal malignancies. However, thyroid nodules, cancer, and hypothyroidism are all associated with radiation exposure to the thyroid. The intervention therapy recommended by both National Council on Radiation Protection and Measurements Report 65 (NCRP 1980) and Bhattacharyya et al. (1992) is immediate administration of 300-mg potassium iodide (KI) or sodium iodide (NaI) tablets, regardless of the route of exposure, and daily administrations for 7 to 14 days (to prevent recycling back into the thyroid) as a mitigative action following a large intake. For individuals receiving greater than a 100-rem equivalent dose to the thyroid, an estimate of residual thyroid function should be made within 2 or 3 months after exposure (NCRP 1980). Occupational Medicine should be immediately notified of a potentially severe intake of radioiodine.

\subsection{References}

10 CFR 835. 2007. “Occupation Radiation Protection.” Code of Federal Regulations. U.S. Department of Energy. Available at: http://www.access.gpo.gov

Bhattacharyya MH, BD Breitenstein, H Metivier, BA Muggenburg, GN Stradling, and V Volf. 1992. "Guidebook for the treatment of accidental internal radionuclide contamination of workers." Rad. Prot. Dosim. 41:1. 
International Commission on Radiological Protection (ICRP). 1975. Report of Task Group on Reference Man. ICRP Publication 23, Pergamon Press, New York.

International Commission on Radiological Protection (ICRP). 1979. "Limits for intakes of radionuclides by workers.” ICRP Publication 30, Part 1 and Supplements, Annals of the ICRP, 2:3-4, Pergamon Press, New York.

International Commission on Radiological Protection (ICRP). 1989. "Age-dependent Doses to Members of the Public from Intake of Radionuclides: Part 1.” ICRP Publication 56, Annals of the ICRP, 20:2, Pergamon Press, New York.

International Commission on Radiological Protection (ICRP). 1991. "1990 Recommendations of the International Commission on Radiological Protection.” ICRP Publication 60, Annals of the ICRP, 21:1-3, Pergamon Press, New York.

International Commission on Radiological Protection (ICRP). 1993. “Age-dependent Doses to Members of the Public from Intake of Radionuclides: Part 2 Ingestion Dose Coefficients.” ICRP Publication 67, Annals of the ICRP, 23:3-4, Pergamon Press, New York.

International Commission on Radiological Protection (ICRP). 1994a. "Dose Coefficients for Intakes of Radionuclides by Workers.” ICRP Publication 68, Annals of the ICRP, 24:4, Pergamon Press, New York.

International Commission on Radiological Protection (ICRP). 1994b. "Human Respiratory Tract Model for Radiological Protection.” ICRP Publication 66, Annals of the ICRP, 24:1-3, Pergamon Press, New York.

International Commission on Radiological Protection (ICRP). 1997. "Individual Monitoring for Internal Exposure of Workers.” ICRP Publication 78, Annals of the ICRP, 27:3-4, Pergamon Press, New York.

James AC, Marsh, JW, Burchall, A, Jarvis, NS, Puncher, M, Davis K, King, D. 2004. User Manual for IMBA Expert USDOE-Edition, “Appendix A: Technical Basis.” ACJ \& Associates, Richland, Washington.

Lynch TP. 2007. In Vivo Monitoring Program Manual. PNL-MA-574, Pacific Northwest Laboratory, Richland, Washington. (Internal Manual.)

National Council on Radiation Protection and Measurements (NCRP). 1980. Management of Persons Accidentally Contaminated with Radionuclides. NCRP Report No. 65, Bethesda, Maryland.

Riggs DS. 1952. “Quantitative aspects of iodine metabolism in man.” Pharmacology Review $4: 284-370$. 


\section{Methods and Models of the Hanford Internal Dosimetry Program}

PNNL-MA-860

\subsection{Europium}

Issued for implementation effective 01/01/2010

Supersedes: September 12, 2000

\section{Use Category: Not applicable}

\section{Approval Signatures:}

Prepared by:

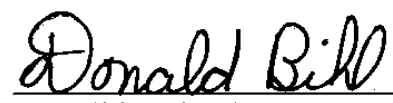

\section{DE Bihl, Scientist}

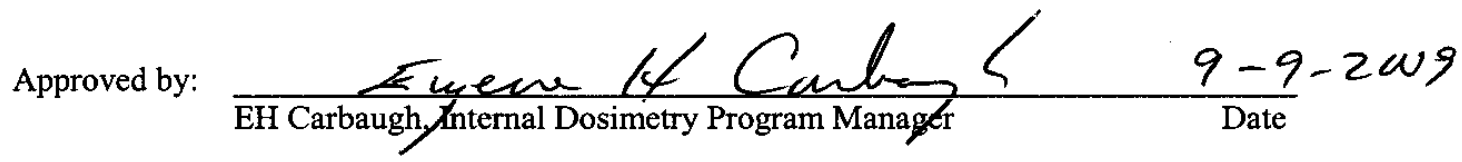

\section{Reviewer Signatures:}

Reviewed by:

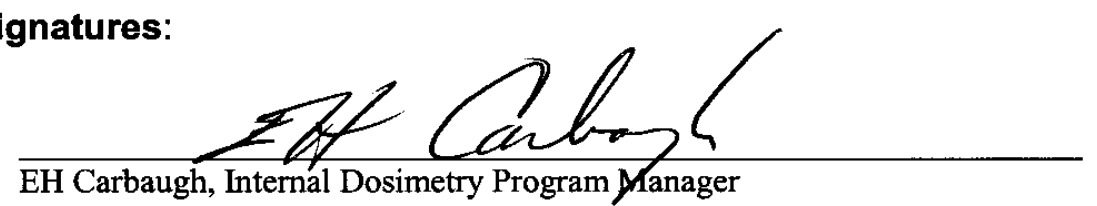

Approved by the Hanford Personnel Dosimetry Advisory Committee as recorded in the meeting minutes of March 10, 2009. 


\section{Contents}

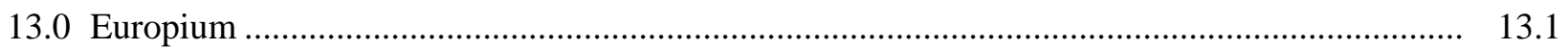

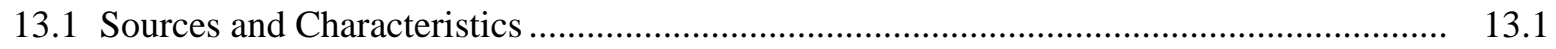

13.2 Biokinetic Behavior of Europium............................................................................. 13.3

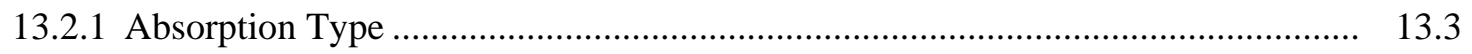

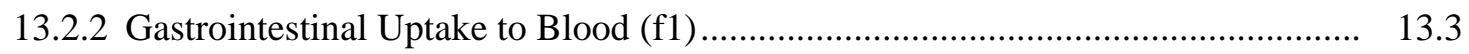

13.2.3 Distribution and Retention in Systemic Organs and Tissues ................................ 13.3

13.3 Internal Dosimetry Factors for Europium.............................................................. 13.4

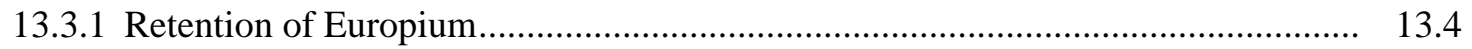

13.3.2 Dose Coefficients...................................................................................... 13.4

13.3.3 Derived Air Concentrations and Annual Limits on Intake ................................. 13.9

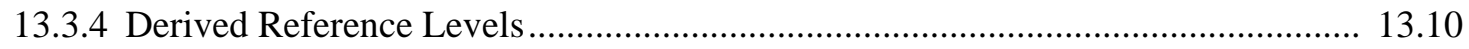

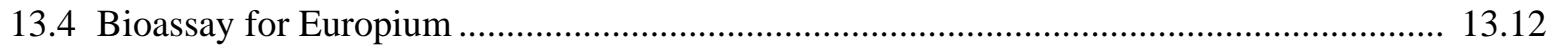

13.4.1 Bioassay Methods and Capabilities .................................................................. 13.12

13.4.2 Routine Bioassay Monitoring Protocol............................................................ 13.13

13.4.3 Special Bioassay for Suspected Intakes ......................................................... 13.17

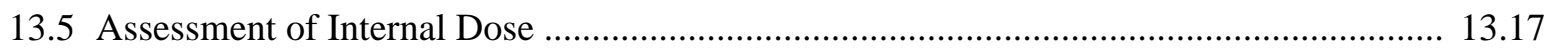

13.6 Management of Internal Contamination Cases............................................................ 13.18

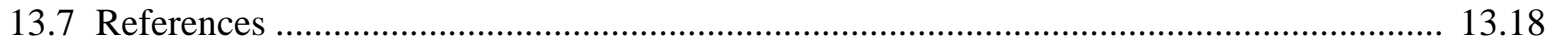

\section{Figures}

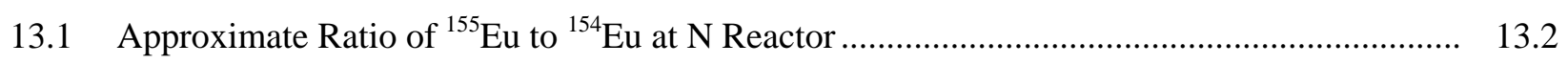

13.2 Approximate Ratios of ${ }^{155} \mathrm{Eu}$ and ${ }^{152} \mathrm{Eu}$ to ${ }^{154} \mathrm{Eu}$ in Tank Farms ......................................... 13.2

13.3 Retention of ${ }^{154} \mathrm{Eu}$ in the Whole Body, Lung, and Bone as a Fraction of Acute Type M Inhalation Intake for 0.5- $\mu \mathrm{m}-\mathrm{AMAD}$ and $5-\mu \mathrm{m}$-AMAD Particle Sizes

\section{Tables}

13.1 Radiological Data for Hanford Europium Isotopes............................................................ 13.2

13.2 ICRP 30 Biokinetic Model Parameters ......................................................................... 13.3

13.3 Fractional Retention of Inhalation Type M Europium, Acute Intake .................................... 13.5

13.4 Fractional Retention from Instantaneous Uptake and Ingested Europium.............................. 13.7

PNNL-MA-860 Chapter 13.0

Page 13.ii
Issued for implementation effective 01/01/2010

Superseded: September 12, 2000 
13.1 Committed Dose Coefficients for Europium............................................................... 13.8

13.6 Comparison of Effective Dose Coefficients, Sv/Bq....................................................... 13.9

13.7 Derived Air Concentration (DAC) and Annual Limits on Intake for Europium Isotopes ........ 13.9

13.8 Reference Levels and Derived Reference Levels for ${ }^{152}$ Eu.................................................. 13.10

13.9 Reference Levels and Derived Reference Levels for ${ }^{154}$ Eu................................................ 13.11

13.10 Reference Levels and Derived Reference Levels for ${ }^{155} \mathrm{Eu}$................................................ 13.12

13.11 Hanford In Vivo Measurement Detection Capability for ${ }^{152} \mathrm{Eu},{ }^{154} \mathrm{Eu}$, and ${ }^{155} \mathrm{Eu}, \mathrm{nCi}$............. 13.13

$13.12{ }^{152}$ Eu Minimum Detectable Intakes and Committed Effective Doses for 0.5- $\mu$ m-AMAD

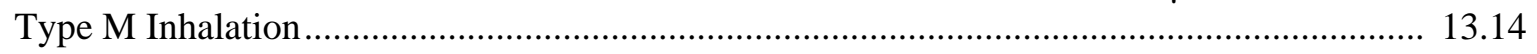

13.13 ${ }^{152}$ Eu Minimum Detectable Intakes and Committed Effective Doses for 5- $\mu m-A M A D$ Type M Inhalation......................................................................................................... 13.14

$13.14{ }^{152}$ Eu Minimum Detectable Intakes and Committed Effective Doses for Instantaneous

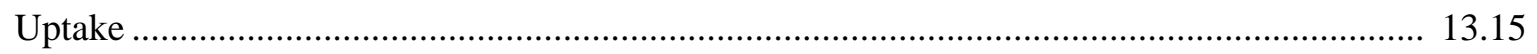

13.15 ${ }^{154}$ Eu Minimum Detectable Intakes and Committed Effective Doses for 0.5- $\mu$ m-AMAD

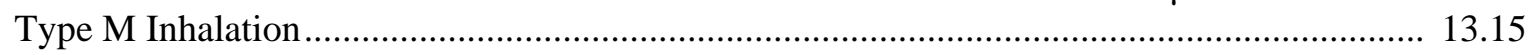

13.16 ${ }^{154} \mathrm{Eu}$ Minimum Detectable Intakes and Committed Effective Doses for 5- $\mu \mathrm{m}-\mathrm{AMAD}$

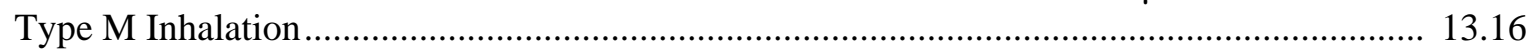

13.17 ${ }^{154}$ Eu Minimum Detectable Intakes and Committed Effective Doses for Instantaneous

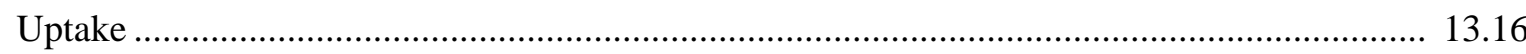





\subsection{Europium}

This chapter provides technical information about the sources, characteristics, biokinetics, and dosimetry of ${ }^{152} \mathrm{Eu},{ }^{154} \mathrm{Eu}$, and ${ }^{155} \mathrm{Eu}$, which are the principal europium radionuclides of concern for intakes at Hanford.

\subsection{Sources and Characteristics}

Europium-154 and ${ }^{155}$ Eu have been produced historically at Hanford by the reactors through neutron activation of samarium oxide marbles used in the reactor safety systems. The samarium oxide marbles were replaced in N Reactor in 1978 with marbles made of boron carbide; however, a few of the old samarium oxide marbles remained lodged in the graphite block moderator and continued to be activated during operation of the reactor until its shutdown in 1986 and short restart in 1987. During operation, the activity ratio of ${ }^{155} \mathrm{Eu}$ to ${ }^{154} \mathrm{Eu}$ was found to be approximately 0.5 (Sula et al. 1989).

Europium-152 has been found in coolant pipes of some of the old production reactors. Its exact source has not been determined, but it has been speculated that it might result from activation of stable ${ }^{151} \mathrm{Eu}$ from naturally occurring or fission-product sources. Europium-152 is a fission product, but its production in N Reactor fuel was orders of magnitude below production of the 154 and 155 isotopes.

Within the high-level waste tanks, the ratios of the three isotopes were 1:0.49:0.020 for ${ }^{154} \mathrm{Eu}:{ }^{155} \mathrm{Eu}:{ }^{152} \mathrm{Eu}$, based on the sum of activity in all tanks. Because the effective dates for the listed activities in the tanks vary by tank from 2004 to 2008, the ratios are just approximate. In the tank with the highest activity of europium, Tank AY-101, the ratios were 1:0.30:0.017 as of July 2008. However, there was about 600 times more ${ }^{90} \mathrm{Sr}$ activity in the tanks (300 times in Tank AY-101) than europium activity, a ratio that is increasing with time, so europium would not be expected to be a significant contributor to dose from an intake at the tank farms (DOE 2008).

The principal locations where exposures to europium radionuclides may occur are the reactors or perhaps buried waste from the reactors. In general when evaluating an intake of ${ }^{154} \mathrm{Eu}$, the contribution from ${ }^{152} \mathrm{Eu}$ can be ignored unless there is specific information to indicate that the ${ }^{152} \mathrm{Eu}$ comprises at least $10 \%$ of the activity.

Radiological decay data for these isotopes are given in Table 13.1. The change over time in the ratios of europium isotopes at $\mathrm{N}$ Reactor and the tank farms are shown in Figures 13.1 and 13.2. These ratios are good enough for planning purposes, but actual ratios should be used if possible in an actual intake event.

Based on numerous measurements made at various $\mathrm{N}$ Reactor locations (Weetman and DeHaven 1982), a particle size of 0.5- $\mu \mathrm{m}$ activity median aerodynamic diameter (AMAD) should be assumed for intakes in or around $\mathrm{N}$ Reactor, unless specific particle size data are available. This particle size is in contrast to the 5 - $\mu$ m-AMAD particle size recommended by the International Commission on Radiological Protection in Publication 66 (ICRP 1994b). 
Table 13.1. Radiological Data for Hanford Europium Isotopes

\begin{tabular}{cccc}
\hline Isotope & $\begin{array}{c}\text { Half-Life } \\
(\mathrm{y})\end{array}$ & $\begin{array}{c}\text { Decay Constant } \\
\left(\mathrm{y}^{-1}\right)\end{array}$ & $\begin{array}{c}\text { Specific } \\
\text { Activity (Ci/g) }\end{array}$ \\
\hline${ }^{152} \mathrm{Eu}$ & $13.3^{\text {(a) }}$ & 0.0521 & 176 \\
${ }^{154} \mathrm{Eu}$ & 8.80 & 0.0788 & 264 \\
${ }^{155} \mathrm{Eu}$ & 4.96 & 0.140 & 465 \\
\hline
\end{tabular}

(a) $13.6 \mathrm{y}$ in (Kocher 1981); $13.3 \mathrm{y}$ in IMBA internal dosimetry computer code 2007 and ICRP 68 (ICRP 1994a).

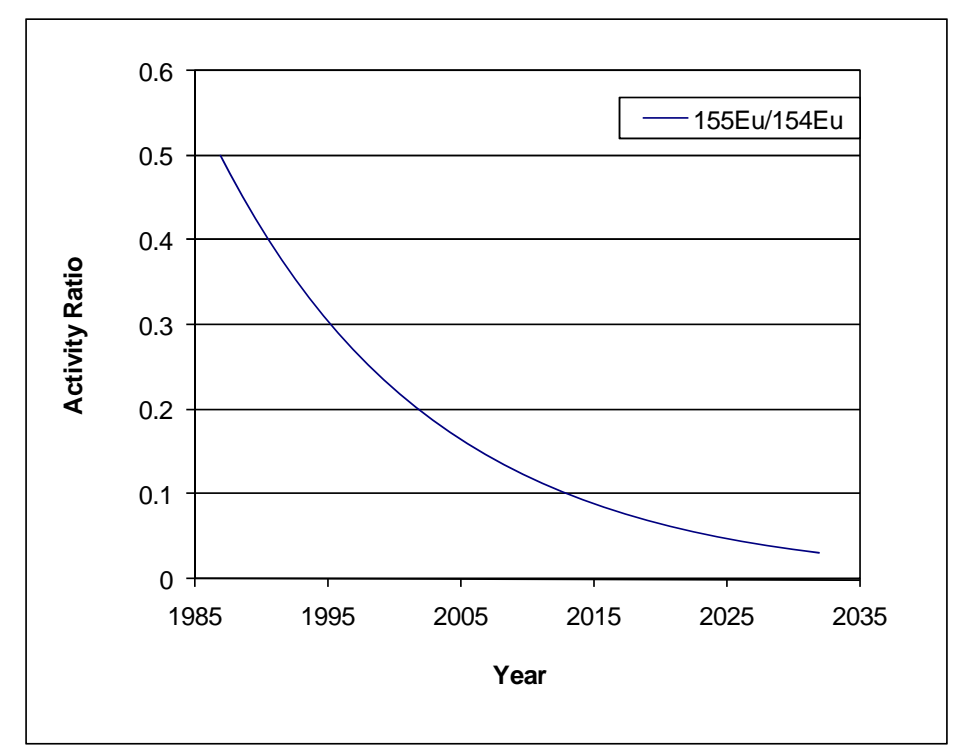

Figure 13.1. Approximate Ratio of ${ }^{155} \mathrm{Eu}$ to ${ }^{154} \mathrm{Eu}$ at $\mathrm{N}$ Reactor

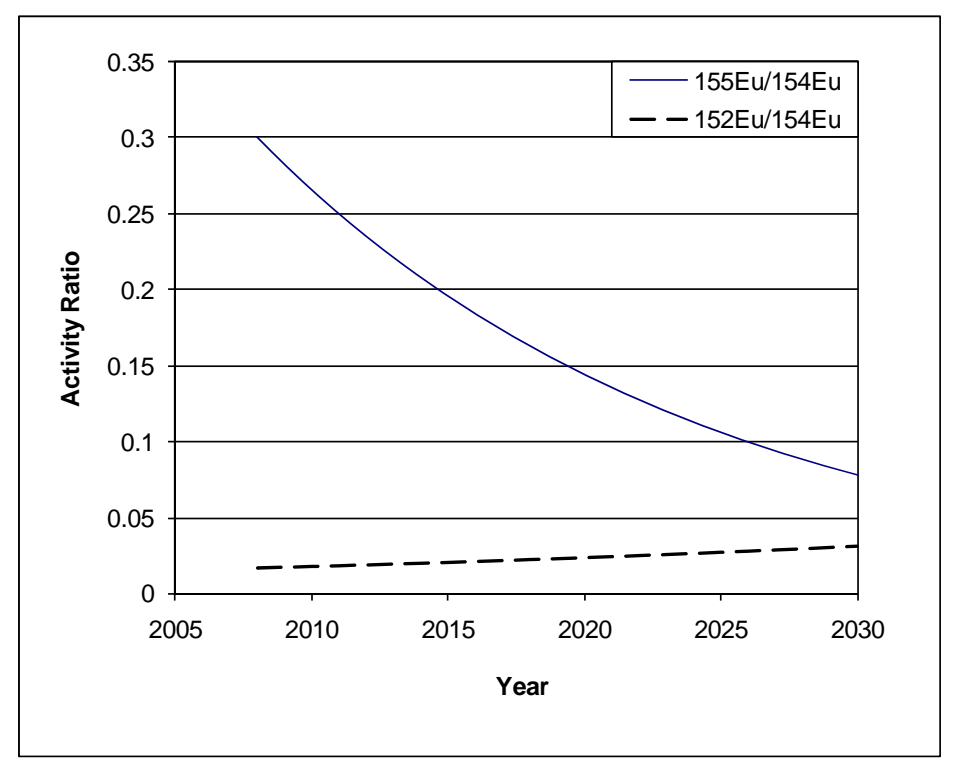

Figure 13.2. Approximate Ratios of ${ }^{155} \mathrm{Eu}$ and ${ }^{152} \mathrm{Eu}$ to ${ }^{154} \mathrm{Eu}$ in Tank Farms (based on Tank AY-101) 


\subsection{Biokinetic Behavior of Europium}

This section discusses the inhalation absorption type and internal distribution and retention of europium.

\subsubsection{Absorption Type}

ICRP 68 (1994a, Annex F) assigned all compounds of europium to absorption Type M (for moderate rate of solubilization), which is adopted as the default type for Hanford intakes.

\subsubsection{Gastrointestinal Uptake to Blood $\left(f_{1}\right)$}

ICRP 68 (1994a, Annexes E and F) assigned $5 \times 10^{-4}$ for the gastrointestinal (GI) uptake factor $\left(f_{1}\right)$ for europium for all compounds for both inhalation and ingestion modes of intake. This is a decrease from the previous value of $1 \times 10^{-3}$ recommended in ICRP 30 (1981) but is within the range of $2 \times 10^{-4}$ to $3 \mathrm{x}$ $10^{-3}$ presented in ICRP 30. The ICRP has not published a reason for the change; however, $5 \times 10^{-4}$ has been promulgated by the International Atomic Energy Agency in its Basic Safety Standards (IAEA 1996) and it appears to be the current scientific consensus. As such, it is adopted as the default $f_{1}$ factor for Hanford.

\subsubsection{Distribution and Retention in Systemic Organs and Tissues}

The ICRP has not updated the europium systemic model and, therefore, still uses the ICRP 30 Part 3 (1981) model; see, for instance, ICRP 72 (1996), Table 2. In the ICRP 30 model, europium entering the bloodstream is deposited and tenaciously retained mostly in the liver and on bone surfaces with a small fraction being briefly retained in the kidney. The distribution of europium entering the blood is given by ICRP 30 as shown in Table 13.2. This is the model used in the Integrated Modules for Bioassay Analysis (IMBA) Professional Plus internal dosimetry computer code (James et al. 2004). ${ }^{1}$

Table 13.2. ICRP 30 Biokinetic Model Parameters

\begin{tabular}{lcc}
\hline \multicolumn{1}{c}{ Organ/Tissue } & $\begin{array}{c}\text { Fraction } \\
\text { Retained }\end{array}$ & Biological Half-Life (d) \\
\hline Liver & 0.4 & 3500 \\
Bone Surfaces & 0.4 & 3500 \\
Kidney & 0.06 & 10 \\
Directly to Urinary & 0.07 & \\
Bladder (excretion) & & \\
$\begin{array}{l}\text { Directly to Upper } \\
\text { Large Intestine } \\
\text { (fecal excretion) }\end{array}$ & 0.07 & \\
\hline
\end{tabular}

\footnotetext{
${ }^{1}$ IMBA Professional Plus, which includes the current version of the user manual, is available from Health Protection Agency (HPA), Radiation Protection Division, Chilton, Didicot, Oxon., OX11 0RQ UK and from http://www.imbaprofessional.com/
} 


\subsection{Internal Dosimetry Factors for Europium}

This section contains factors that are useful in making internal dosimetry calculations. The factors included in this section are derived from the IMBA (v. 4.0.43) computer code and incorporate the models and assumptions described in the preceding section. Their application is intended for the circumstances for which such assumptions are appropriate or more specific information is lacking. Variation from these factors is appropriate if sufficient data are available.

\subsubsection{Retention of Europium}

Intake retention fractions for ${ }^{152} \mathrm{Eu},{ }^{154} \mathrm{Eu}$, and ${ }^{155} \mathrm{Eu}$ in the whole body, bone (same values as liver), and lung are listed in Table 13.3 for acute inhalation intakes for $0.5-\mu \mathrm{m}$-AMAD and $5-\mu \mathrm{m}-\mathrm{AMAD}$ particle size distributions. The organs and tissues selected for tabulation are those of greatest interest to routine and special bioassay measurements. Figure 13.3 shows the inhalation retention curves for ${ }^{154} \mathrm{Eu}$. The retention curves for the other isotopes are similar with a little more retention after 1 year for ${ }^{152} \mathrm{Eu}$ and a little less retention for ${ }^{155} \mathrm{Eu}$ due to the different radioactivity decay rates. Table 13.4 lists the intake retention fractions for instantaneous uptake into the blood and ingestion.

\subsubsection{Dose Coefficients}

Dose coefficients, expressed as committed effective dose or committed equivalent dose per unit activity of intake (rem per nanocurie of acute intake or rem per nanocurie per day of chronic intake), are a convenient shortcut to estimating doses based on standard assumptions when the magnitude of an intake is known or assumed. Acute intake dose coefficients have been tabulated in Table 13.5 for instantaneous uptake, Type M inhalation for 0.5- $\mu \mathrm{m}$-AMAD and 5- $\mu \mathrm{m}$-AMAD particle sizes, and for ingestion. These dose coefficients were all derived using the ICRP 30 models as implemented in the IMBA computer code. Dose coefficients for organs that contribute at least $10 \%$ to the effective dose or have the highest organ dose coefficient are included in the table. Although the bone surface is often the organ with the highest dose coefficient, it never contributes at the $10 \%$ or higher level toward the effective dose because of its small tissue weighting factor (0.01).

For ${ }^{152} \mathrm{Eu}$ and ${ }^{154} \mathrm{Eu}$, the most limiting dose coefficients (relative to the regulatory limits) are for the committed effective dose for all of the intake modes listed in Table 13.5. However, for ${ }^{155} \mathrm{Eu}$, the bone surface has the most limiting dose coefficients for the inhalations and the instantaneous uptake modes and the lower large intestine has the most limiting dose coefficient for the ingestion mode.

A comparison of effective dose coefficients between IMBA-derived coefficients and those published in ICRP 68 (ICRP 1994a) is provided in Table 13.6. IMBA provides dose coefficients to three significant figures, whereas the ICRP 68 values are listed with only two significant figures. Taking the rounding of numbers into account, there are no differences between the values. 
Table 13.3. Fractional Retention of Inhalation Type M Europium, Acute Intake

\begin{tabular}{|c|c|c|c|c|c|c|}
\hline \multirow[b]{2}{*}{$\begin{array}{l}\text { Days Post } \\
\text { Intake }\end{array}$} & \multicolumn{3}{|c|}{ 0.5- $\mu \mathrm{m}-\mathrm{AMAD}$ Particle Size } & \multicolumn{3}{|c|}{ 5- $\mu \mathrm{m}-\mathrm{AMAD}$ Particle Size } \\
\hline & $\begin{array}{c}{ }^{152} \mathrm{Eu} \\
\text { Whole Body }\end{array}$ & $\begin{array}{c}{ }^{152} \mathrm{Eu} \\
\text { Bone }^{(a)}\end{array}$ & $\begin{array}{l}{ }^{152} \mathrm{Eu} \\
\text { Lung }\end{array}$ & $\begin{array}{c}{ }^{152} \mathrm{Eu} \\
\text { Whole Body }\end{array}$ & $\begin{array}{c}{ }^{152} \mathrm{Eu} \\
\text { Bone }^{(\mathrm{a})}\end{array}$ & $\begin{array}{l}{ }^{152} \mathrm{Eu} \\
\text { Lung }\end{array}$ \\
\hline 0.5 & 3.05E-01 & $9.94 \mathrm{E}-03$ & $1.27 \mathrm{E}-01$ & 6.59E-01 & $1.36 \mathrm{E}-02$ & $5.98 \mathrm{E}-02$ \\
\hline 1 & 2.60E-01 & 1.34E-02 & 1.23E-01 & 4.95E-01 & $1.81 \mathrm{E}-02$ & $5.76 \mathrm{E}-02$ \\
\hline 2 & 1.93E-01 & 1.33E-02 & $1.20 \mathrm{E}-01$ & 2.61E-01 & $1.76 \mathrm{E}-02$ & 5.59E-02 \\
\hline 3 & $1.60 \mathrm{E}-01$ & $1.20 \mathrm{E}-02$ & $1.18 \mathrm{E}-01$ & $1.51 \mathrm{E}-01$ & $1.56 \mathrm{E}-02$ & $5.50 \mathrm{E}-02$ \\
\hline 5 & $1.40 \mathrm{E}-01$ & $1.08 \mathrm{E}-02$ & 1.15E-01 & 8.96E-02 & 1.35E-02 & 5.33E-02 \\
\hline 7 & $1.35 \mathrm{E}-01$ & 1.06E-02 & 1.12E-01 & 7.96E-02 & $1.28 \mathrm{E}-02$ & $5.18 \mathrm{E}-02$ \\
\hline 14 & $1.27 \mathrm{E}-01$ & 1.17E-02 & $1.02 \mathrm{E}-01$ & 7.42E-02 & $1.29 \mathrm{E}-02$ & 4.69E-02 \\
\hline 30 & $1.15 \mathrm{E}-01$ & 1.46E-02 & 8.44E-02 & 6.74E-02 & $1.42 \mathrm{E}-02$ & 3.82E-02 \\
\hline 60 & $1.00 \mathrm{E}-01$ & 1.87E-02 & 6.25E-02 & 6.01E-02 & $1.59 \mathrm{E}-02$ & 2.79E-02 \\
\hline 90 & $9.24 \mathrm{E}-02$ & 2.17E-02 & 4.87E-02 & 5.62E-02 & $1.72 \mathrm{E}-02$ & 2.15E-02 \\
\hline 180 & 8.13E-02 & $2.74 \mathrm{E}-02$ & 2.64E-02 & 5.07E-02 & $1.95 \mathrm{E}-02$ & $1.16 \mathrm{E}-02$ \\
\hline 365 & 7.13E-02 & 3.13E-02 & 8.62E-03 & 4.54E-02 & $2.08 \mathrm{E}-02$ & 3.79E-03 \\
\hline $2 \mathrm{yr}$ & $6.10 \mathrm{E}-02$ & $3.00 \mathrm{E}-02$ & $9.84 \mathrm{E}-04$ & 3.92E-02 & $1.94 \mathrm{E}-02$ & 4.33E-04 \\
\hline $5 \mathrm{yr}$ & 4.18E-02 & 2.09E-02 & $1.66 \mathrm{E}-06$ & 2.69E-02 & 1.35E-02 & 7.36E-07 \\
\hline $10 \mathrm{yr}$ & 2.24E-02 & 1.12E-02 & $<1 \mathrm{E}-10$ & 1.45E-02 & 7.23E-03 & $<1 \mathrm{E}-10$ \\
\hline $20 \mathrm{yr}$ & $6.47 \mathrm{E}-03$ & 3.23E-03 & $<1 \mathrm{E}-10$ & 4.17E-03 & 2.08E-03 & $<1 \mathrm{E}-10$ \\
\hline \multirow[t]{2}{*}{$50 \mathrm{yr}$} & 1.55E-04 & 7.75E-05 & $<1 \mathrm{E}-10$ & 9.99E-05 & 4.99E-05 & $<1 \mathrm{E}-10$ \\
\hline & \multicolumn{3}{|c|}{ 0.5- $\mu \mathrm{m}$-AMAD Particle Size } & \multicolumn{3}{|c|}{ 5- $\mu \mathrm{m}-\mathrm{AMAD}$ Particle Size } \\
\hline $\begin{array}{l}\text { Days Post } \\
\text { Intake }\end{array}$ & $\begin{array}{c}{ }^{154} \mathrm{Eu} \\
\text { Whole Body }\end{array}$ & $\begin{array}{c}{ }^{154} \mathrm{Eu} \\
\text { Bone }^{(a)}\end{array}$ & $\begin{array}{l}{ }^{154} \mathrm{Eu} \\
\text { Lung }\end{array}$ & $\begin{array}{c}{ }^{154} \mathrm{Eu} \\
\text { Whole Body }\end{array}$ & $\begin{array}{c}{ }^{154} \mathrm{Eu} \\
\text { Bone }^{(\mathrm{a})}\end{array}$ & $\begin{array}{l}{ }^{154} \mathrm{Eu} \\
\text { Lung }\end{array}$ \\
\hline 0.5 & 3.05E-01 & $9.94 \mathrm{E}-03$ & $1.27 \mathrm{E}-01$ & 6.59E-01 & $1.36 \mathrm{E}-02$ & $5.98 \mathrm{E}-02$ \\
\hline 1 & $2.60 \mathrm{E}-01$ & 1.34E-02 & 1.23E-01 & 4.95E-01 & $1.81 \mathrm{E}-02$ & 5.76E-02 \\
\hline 2 & 1.93E-01 & 1.33E-02 & $1.20 \mathrm{E}-01$ & 2.60E-01 & $1.76 \mathrm{E}-02$ & 5.59E-02 \\
\hline 3 & $1.60 \mathrm{E}-01$ & 1.20E-02 & $1.18 \mathrm{E}-01$ & $1.51 \mathrm{E}-01$ & $1.56 \mathrm{E}-02$ & $5.50 \mathrm{E}-02$ \\
\hline 5 & $1.40 \mathrm{E}-01$ & $1.08 \mathrm{E}-02$ & 1.15E-01 & 8.95E-02 & 1.35E-02 & 5.33E-02 \\
\hline 7 & 1.35E-01 & $1.06 \mathrm{E}-02$ & $1.12 \mathrm{E}-01$ & 7.96E-02 & $1.28 \mathrm{E}-02$ & $5.18 \mathrm{E}-02$ \\
\hline 14 & $1.27 \mathrm{E}-01$ & 1.17E-02 & $1.02 \mathrm{E}-01$ & 7.41E-02 & $1.29 \mathrm{E}-02$ & 4.68E-02 \\
\hline 60 & $9.98 \mathrm{E}-02$ & 1.86E-02 & 6.22E-02 & 5.98E-02 & 1.59E-02 & 2.77E-02 \\
\hline 90 & $9.18 \mathrm{E}-02$ & 2.16E-02 & 4.84E-02 & $5.58 \mathrm{E}-02$ & $1.71 \mathrm{E}-02$ & $2.14 \mathrm{E}-02$ \\
\hline 180 & 8.02E-02 & $2.70 \mathrm{E}-02$ & 2.61E-02 & $5.00 \mathrm{E}-02$ & $1.92 \mathrm{E}-02$ & $1.15 \mathrm{E}-02$ \\
\hline 365 & 6.94E-02 & 3.05E-02 & 8.39E-03 & 4.42E-02 & 2.02E-02 & $3.69 \mathrm{E}-03$ \\
\hline $2 \mathrm{yr}$ & $5.78 \mathrm{E}-02$ & 2.84E-02 & 9.33E-04 & 3.72E-02 & $1.84 \mathrm{E}-02$ & $4.10 \mathrm{E}-04$ \\
\hline $5 \mathrm{yr}$ & 3.66E-02 & 1.83E-02 & $1.45 \mathrm{E}-06$ & 2.35E-02 & $1.18 \mathrm{E}-02$ & $6.44 \mathrm{E}-07$ \\
\hline $10 \mathrm{yr}$ & $1.72 \mathrm{E}-02$ & 8.58E-03 & $<1 \mathrm{E}-10$ & $1.11 \mathrm{E}-02$ & 5.53E-03 & $<1 \mathrm{E}-10$ \\
\hline $20 \mathrm{yr}$ & 3.79E-03 & 1.89E-03 & $<1 \mathrm{E}-10$ & $2.44 \mathrm{E}-03$ & $1.22 \mathrm{E}-03$ & $<1 \mathrm{E}-10$ \\
\hline $50 \mathrm{yr}$ & 4.06E-05 & 2.03E-05 & $<1 \mathrm{E}-10$ & 2.62E-05 & $1.31 \mathrm{E}-05$ & $<1 \mathrm{E}-10$ \\
\hline
\end{tabular}


Table 13.3. (contd)

\begin{tabular}{|c|c|c|c|c|c|c|}
\hline \multirow[b]{2}{*}{$\begin{array}{l}\text { Days Post } \\
\text { Intake }\end{array}$} & \multicolumn{3}{|c|}{ 0.5- $\mu \mathrm{m}$-AMAD Particle Size } & \multicolumn{3}{|c|}{ 5- $\mu \mathrm{m}$-AMAD Particle Size } \\
\hline & $\begin{array}{l}{ }^{155} \mathrm{Eu} \\
\text { Whole Body }\end{array}$ & $\begin{array}{c}{ }^{155} \mathrm{Eu} \\
\text { Bone }^{(\mathrm{a})}\end{array}$ & $\begin{array}{l}{ }^{155} \mathrm{Eu} \\
\text { Lung }\end{array}$ & $\begin{array}{c}{ }^{155} \mathrm{Eu} \\
\text { Whole Body }\end{array}$ & $\begin{array}{c}{ }^{155} \mathrm{Eu} \\
\text { Bone }^{(a)}\end{array}$ & $\begin{array}{l}{ }^{155} \mathrm{Eu} \\
\text { Lung }\end{array}$ \\
\hline 0.5 & 3.05E-01 & $9.94 \mathrm{E}-03$ & 1.27E-01 & $6.59 \mathrm{E}-01$ & $1.36 \mathrm{E}-02$ & $5.98 \mathrm{E}-02$ \\
\hline 1 & 2.60E-01 & $1.34 \mathrm{E}-02$ & 1.23E-01 & 4.95E-01 & $1.81 \mathrm{E}-02$ & 5.76E-02 \\
\hline 2 & 1.93E-01 & 1.33E-02 & $1.20 \mathrm{E}-01$ & 2.60E-01 & $1.76 \mathrm{E}-02$ & 5.59E-02 \\
\hline 3 & $1.60 \mathrm{E}-01$ & $1.20 \mathrm{E}-02$ & 1.18E-01 & $1.51 \mathrm{E}-01$ & $1.56 \mathrm{E}-02$ & 5.49E-02 \\
\hline 5 & $1.40 \mathrm{E}-01$ & $1.08 \mathrm{E}-02$ & 1.15E-01 & 8.94E-02 & 1.35E-02 & 5.33E-02 \\
\hline 7 & 1.35E-01 & $1.06 \mathrm{E}-02$ & 1.12E-01 & 7.95E-02 & $1.28 \mathrm{E}-02$ & 5.17E-02 \\
\hline 14 & 1.27E-01 & 1.17E-02 & $1.02 \mathrm{E}-01$ & 7.39E-02 & $1.29 \mathrm{E}-02$ & 4.67E-02 \\
\hline 30 & 1.14E-01 & $1.45 \mathrm{E}-02$ & 8.38E-02 & 6.69E-02 & $1.41 \mathrm{E}-02$ & $3.80 \mathrm{E}-02$ \\
\hline 60 & 9.89E-02 & $1.84 \mathrm{E}-02$ & 6.16E-02 & 5.92E-02 & $1.57 \mathrm{E}-02$ & 2.75E-02 \\
\hline 90 & 9.04E-02 & 2.13E-02 & 4.77E-02 & 5.50E-02 & $1.69 \mathrm{E}-02$ & $2.11 \mathrm{E}-02$ \\
\hline 180 & 7.78E-02 & 2.62E-02 & 2.53E-02 & 4.86E-02 & 1.87E-02 & $1.11 \mathrm{E}-02$ \\
\hline 365 & 6.53E-02 & 2.87E-02 & 7.90E-03 & 4.16E-02 & $1.90 \mathrm{E}-02$ & 3.47E-03 \\
\hline $2 \mathrm{yr}$ & 5.12E-02 & $2.52 \mathrm{E}-02$ & 8.25E-04 & 3.29E-02 & 1.63E-02 & 3.63E-04 \\
\hline $5 \mathrm{yr}$ & 2.69E-02 & $1.35 \mathrm{E}-02$ & 1.07E-06 & $1.74 \mathrm{E}-02$ & 8.67E-03 & 4.75E-07 \\
\hline $10 \mathrm{yr}$ & 9.32E-03 & $4.66 \mathrm{E}-03$ & $<1 \mathrm{E}-10$ & $6.01 \mathrm{E}-03$ & 3.00E-03 & $<1 \mathrm{E}-10$ \\
\hline $20 \mathrm{yr}$ & 1.12E-03 & $5.58 \mathrm{E}-04$ & $<1 \mathrm{E}-10$ & 7.19E-04 & $3.60 \mathrm{E}-04$ & $<1 \mathrm{E}-10$ \\
\hline $50 \mathrm{yr}$ & $1.92 \mathrm{E}-06$ & $9.60 \mathrm{E}-07$ & $<1 \mathrm{E}-10$ & $1.24 \mathrm{E}-06$ & $6.18 \mathrm{E}-07$ & $<1 \mathrm{E}-10$ \\
\hline
\end{tabular}

(a) Fractional retention in the liver is the same as the fractional retention in the bone.

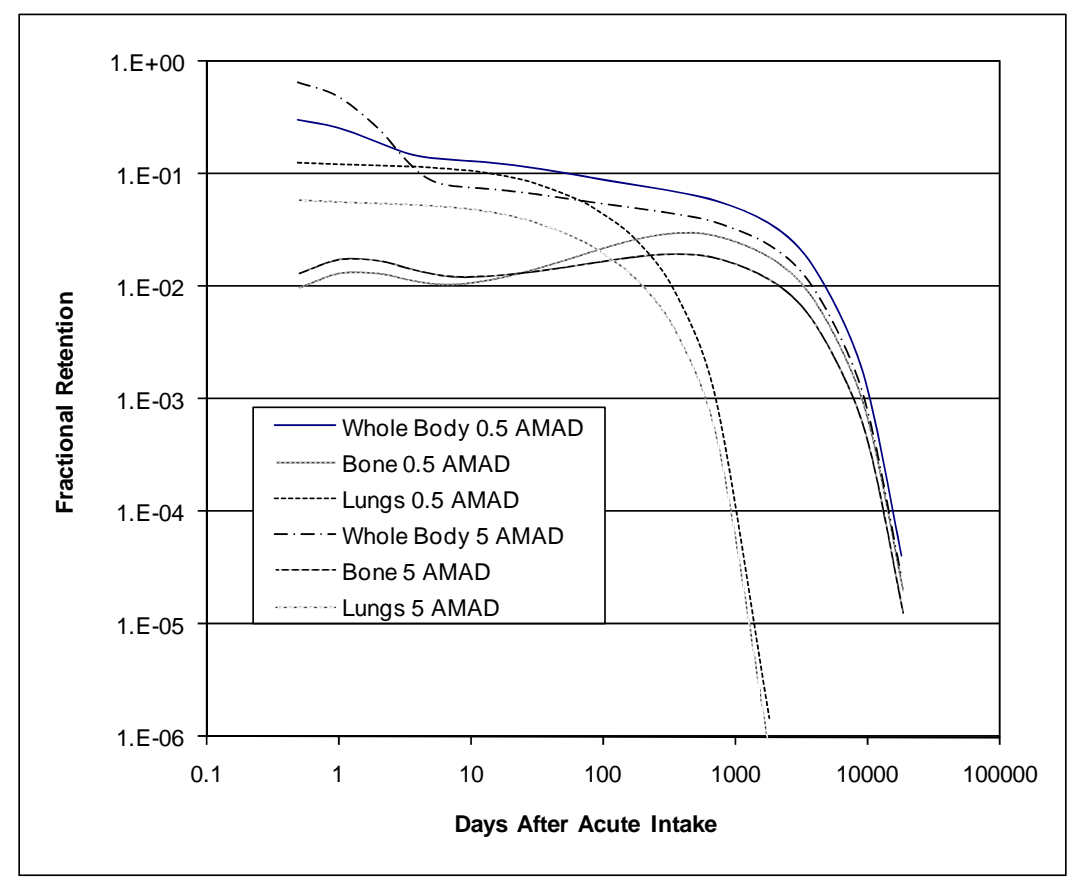

Figure 13.3. Retention of ${ }^{154} \mathrm{Eu}$ in the Whole Body, Lung, and Bone (Liver) as a Fraction of Acute Type M Inhalation Intake for 0.5- $\mu \mathrm{m}-\mathrm{AMAD}$ and 5- $\mu \mathrm{m}$-AMAD Particle Sizes 
Table 13.4. Fractional Retention from Instantaneous Uptake and Ingested Europium

\begin{tabular}{|c|c|c|c|c|c|c|}
\hline $\begin{array}{c}\text { Days Post } \\
\text { Intake }\end{array}$ & $\begin{array}{c}{ }^{152} \mathrm{Eu} \\
\text { Whole Body }\end{array}$ & $\begin{array}{l}{ }^{152} \mathrm{Eu} \\
\text { Bone }^{(a)}\end{array}$ & $\begin{array}{l}{ }^{154} \mathrm{Eu} \\
\text { Whole Body }\end{array}$ & $\begin{array}{l}{ }^{154} \mathrm{Eu} \\
\text { Bone } \mathrm{a}^{(\mathrm{a})}\end{array}$ & $\begin{array}{c}{ }^{155} \text { Eu Whole } \\
\text { Body }\end{array}$ & $\begin{array}{l}{ }^{155} \mathrm{Eu} \\
\text { Bone }{ }^{(a)}\end{array}$ \\
\hline \multicolumn{7}{|c|}{ Instantaneous Uptake } \\
\hline 0.5 & 9.49E-01 & 4.84E-01 & 9.49E-01 & 4.84E-01 & $9.48 \mathrm{E}-01$ & 4.84E-01 \\
\hline 1 & $9.18 \mathrm{E}-01$ & 6.37E-01 & $9.18 \mathrm{E}-01$ & 6.37E-01 & $9.18 \mathrm{E}-01$ & 6.37E-01 \\
\hline 2 & 8.83E-01 & 6.12E-01 & 8.83E-01 & $6.11 \mathrm{E}-01$ & 8.82E-01 & 6.11E-01 \\
\hline 3 & 8.63E-01 & 5.35E-01 & 8.63E-01 & 5.35E-01 & 8.63E-01 & 5.34E-01 \\
\hline 5 & 8.47E-01 & 4.49E-01 & 8.46E-01 & 4.49E-01 & 8.46E-01 & 4.49E-01 \\
\hline 7 & 8.39E-01 & 4.18E-01 & 8.38E-01 & 4.17E-01 & 8.37E-01 & 4.17E-01 \\
\hline 14 & 8.21E-01 & 3.99E-01 & 8.20E-01 & 3.98E-01 & 8.18E-01 & 3.97E-01 \\
\hline 30 & 8.00E-01 & 3.96E-01 & 7.98E-01 & 3.95E-01 & 7.94E-01 & 3.93E-01 \\
\hline 60 & 7.85E-01 & 3.92E-01 & 7.82E-01 & 3.90E-01 & 7.74E-01 & 3.86E-01 \\
\hline 90 & 7.76E-01 & 3.88E-01 & 7.71E-01 & 3.85E-01 & 7.60E-01 & 3.80E-01 \\
\hline 180 & 7.53E-01 & 3.76E-01 & 7.43E-01 & 3.71E-01 & 7.21E-01 & 3.60E-01 \\
\hline 365 & 7.07E-01 & 3.53E-01 & $6.88 \mathrm{E}-01$ & $3.44 \mathrm{E}-01$ & $6.47 \mathrm{E}-01$ & 3.24E-01 \\
\hline $2 \mathrm{y}$ & $6.24 \mathrm{E}-01$ & 3.12E-01 & 5.92E-01 & 2.96E-01 & 5.24E-01 & 2.62E-01 \\
\hline $5 \mathrm{y}$ & 4.30E-01 & 2.15E-01 & 3.76E-01 & $1.88 \mathrm{E}-01$ & 2.77E-01 & $1.38 \mathrm{E}-01$ \\
\hline $10 \mathrm{y}$ & 2.31E-01 & 1.15E-01 & 1.77E-01 & 8.83E-02 & 9.59E-02 & 4.79E-02 \\
\hline $20 \mathrm{y}$ & 6.65E-02 & 3.33E-02 & 3.89E-02 & 1.95E-02 & 1.15E-02 & $5.74 \mathrm{E}-03$ \\
\hline $50 \mathrm{y}$ & 1.59E-03 & 7.97E-04 & 4.18E-04 & 2.09E-04 & 1.97E-05 & 9.87E-06 \\
\hline \multicolumn{7}{|c|}{ Ingestion, $\boldsymbol{f}_{1}=\mathbf{0 . 0 0 0 5}$} \\
\hline 0.5 & $9.30 \mathrm{E}-01$ & $1.63 \mathrm{E}-04$ & 9.30E-01 & 1.63E-04 & $9.29 \mathrm{E}-01$ & $1.63 \mathrm{E}-04$ \\
\hline 1 & 7.18E-01 & 2.93E-04 & 7.18E-01 & 2.93E-04 & 7.17E-01 & 2.93E-04 \\
\hline 2 & 3.29E-01 & 3.13E-04 & 3.29E-01 & 3.13E-04 & 3.29E-01 & 3.13E-04 \\
\hline 3 & $1.32 \mathrm{E}-01$ & 2.75E-04 & 1.32E-01 & 2.75E-04 & 1.32E-01 & 2.74E-04 \\
\hline 5 & 1.91E-02 & 2.28E-04 & 1.91E-02 & 2.27E-04 & 1.91E-02 & 2.27E-04 \\
\hline 7 & $2.98 \mathrm{E}-03$ & $2.10 \mathrm{E}-04$ & 2.98E-03 & 2.10E-04 & 2.97E-03 & $2.09 \mathrm{E}-04$ \\
\hline 14 & 4.13E-04 & $1.99 \mathrm{E}-04$ & 4.13E-04 & 1.99E-04 & 4.12E-04 & $1.99 \mathrm{E}-04$ \\
\hline 30 & $4.00 \mathrm{E}-04$ & $1.98 \mathrm{E}-04$ & 3.99E-04 & $1.98 \mathrm{E}-04$ & 3.97E-04 & $1.97 \mathrm{E}-04$ \\
\hline 60 & 3.93E-04 & $1.96 \mathrm{E}-04$ & 3.91E-04 & 1.95E-04 & 3.87E-04 & $1.93 \mathrm{E}-04$ \\
\hline 90 & $3.88 \mathrm{E}-04$ & $1.94 \mathrm{E}-04$ & $3.86 \mathrm{E}-04$ & 1.93E-04 & $3.80 \mathrm{E}-04$ & $1.90 \mathrm{E}-04$ \\
\hline 180 & 3.76E-04 & $1.88 \mathrm{E}-04$ & $3.71 \mathrm{E}-04$ & 1.86E-04 & 3.60E-04 & $1.80 \mathrm{E}-04$ \\
\hline 365 & 3.53E-04 & 1.77E-04 & $3.44 \mathrm{E}-04$ & $1.72 \mathrm{E}-04$ & $3.24 \mathrm{E}-04$ & $1.62 \mathrm{E}-04$ \\
\hline $2 \mathrm{y}$ & 3.12E-04 & $1.56 \mathrm{E}-04$ & 2.96E-04 & $1.48 \mathrm{E}-04$ & 2.62E-04 & $1.31 \mathrm{E}-04$ \\
\hline $5 y$ & 2.15E-04 & 1.07E-04 & $1.88 \mathrm{E}-04$ & $9.40 \mathrm{E}-05$ & 1.39E-04 & $6.92 \mathrm{E}-05$ \\
\hline $10 \mathrm{y}$ & 1.15E-04 & 5.77E-05 & 8.83E-05 & 4.41E-05 & 4.79E-05 & $2.40 \mathrm{E}-05$ \\
\hline $20 \mathrm{y}$ & 3.33E-05 & $1.66 \mathrm{E}-05$ & $1.95 \mathrm{E}-05$ & $9.73 \mathrm{E}-06$ & 5.74E-06 & 2.87E-06 \\
\hline $50 \mathrm{y}$ & 7.97E-07 & 3.99E-07 & 2.09E-07 & $1.04 \mathrm{E}-07$ & 9.87E-09 & 4.93E-09 \\
\hline
\end{tabular}

(a) Fractional retention in the liver is the same as the fractional retention in the bone. 
Table 13.5. Committed Dose Coefficients for Europium (rem/nCi acute intake)

\begin{tabular}{|c|c|c|c|c|c|}
\hline \multirow[b]{2}{*}{ Isotope } & \multirow[b]{2}{*}{ Organ } & \multicolumn{2}{|c|}{ Type M Inhalation } & \multirow{2}{*}{$\begin{array}{l}\text { Instant. } \\
\text { Uptake }\end{array}$} & \multirow{2}{*}{$\begin{array}{c}\text { Ingestion } \\
f_{1}=5 \mathrm{E}-04\end{array}$} \\
\hline & & $0.5-\mu \mathrm{m}$ AMAD & 5- $\mu \mathrm{m}$ AMAD & & \\
\hline \multirow[t]{8}{*}{${ }^{152} \mathrm{Eu}$} & Effective & $1.53 \mathrm{E}-04$ & $1.01 \mathrm{E}-04$ & $1.42 \mathrm{E}-03$ & $5.02 \mathrm{E}-06$ \\
\hline & Bone Surface & 7.10E-04 & 4.63E-04 & 7.57-03 & 2.19E-06 \\
\hline & Liver & $1.02 \mathrm{E}-03^{(\mathrm{a})}$ & $6.61 \mathrm{E}-04$ & $1.08 \mathrm{E}-02$ & 5.81E-06 \\
\hline & Red Marrow & 2.61E-04 & 1.69E-04 & 2.74E-03 & 2.19E-06 \\
\hline & Lung & $2.20 \mathrm{E}-04$ & $1.46 \mathrm{E}-04$ & 8.67E-04 & 5.19E-07 \\
\hline & Lower Large Intestine & 5.31E-05 & 4.61E-05 & 5.01E-04 & $3.70 \mathrm{E}-05$ \\
\hline & Colon & 7.17E-05 & 5.43E-05 & 7.18E-04 & $2.48 \mathrm{E}-05$ \\
\hline & Gonads & $5.20 \mathrm{E}-05$ & 3.53E-05 & 5.45E-04 & 4.89E-06 \\
\hline \multirow[t]{8}{*}{${ }^{154} \mathrm{Eu}$} & Effective & 1.93E-04 & $1.29 \mathrm{E}-04$ & $1.68 \mathrm{E}-03$ & 7.52E-06 \\
\hline & Bone Surface & $1.52 \mathrm{E}-03$ & 9.91E-04 & 1.63E-02 & $8.58 \mathrm{E}-6$ \\
\hline & Liver & $1.24 \mathrm{E}-03$ & 8.11E-04 & 1.33E-02 & 7.11E-06 \\
\hline & Red Marrow & 3.37E-04 & 2.20E-04 & $3.60 \mathrm{E}-03$ & 2.67E-06 \\
\hline & Lung & $3.50 \mathrm{E}-04$ & $2.40 \mathrm{E}-04$ & 7.56E-04 & 4.71E-07 \\
\hline & Lower Large Intestine & 5.29E-05 & 5.52E-05 & 4.51E-04 & $6.64 \mathrm{E}-05$ \\
\hline & Colon & 6.69E-05 & 5.70E-05 & 6.39E-04 & 4.32E-05 \\
\hline & Gonads & 4.59E-05 & 3.14E-05 & 4.83E-04 & $5.08 \mathrm{E}-06$ \\
\hline \multirow[t]{8}{*}{${ }^{155} \mathrm{Eu}$} & Effective & $2.50 \mathrm{E}-05$ & 1.73E-05 & $1.90 \mathrm{E}-04$ & $1.20 \mathrm{E}-06$ \\
\hline & Bone Surface & 4.33E-04 & 2.85E-04 & $4.76 \mathrm{E}-03$ & 2.44E-06 \\
\hline & Liver & 1.37E-04 & $9.00 \mathrm{E}-05$ & $1.50 \mathrm{E}-03$ & 7.74E-07 \\
\hline & Red Marrow & 3.83E-05 & 2.52E-05 & 4.19E-04 & $2.60 \mathrm{E}-07$ \\
\hline & Lung & $6.46 \mathrm{E}-05$ & 4.71E-05 & 3.49E-05 & $2.02 \mathrm{E}-08$ \\
\hline & Lower Large Intestine & 3.85E-06 & 6.52E-06 & $1.94 \mathrm{E}-05$ & $1.28 \mathrm{E}-05$ \\
\hline & Colon & 3.81E-06 & 5.03E-06 & 2.72E-05 & 8.12E-06 \\
\hline & Gonads & $1.78 \mathrm{E}-06$ & $1.28 \mathrm{E}-06$ & 1.89E-05 & 3.53E-07 \\
\hline
\end{tabular}

(a) Shaded cells indicate the organ with the highest dose coefficient for each intake mode. 
Table 13.6. Comparison of Effective Dose Coefficients, Sv/Bq

\begin{tabular}{lcc}
\hline Radionuclide/Intake Mode & $\begin{array}{c}\text { IMBA Effective } \\
\text { Dose Coefficient }\end{array}$ & $\begin{array}{c}\text { ICRP 68 Effective } \\
\text { Dose Coefficient }\end{array}$ \\
\hline${ }^{152} \mathrm{Eu}$, Type M, $5 \mu \mathrm{m}$ & $2.72 \mathrm{E}-08$ & $2.7 \mathrm{E}-08$ \\
${ }^{152} \mathrm{Eu}$, ingestion & $1.36 \mathrm{E}-09$ & $1.4 \mathrm{E}-09$ \\
${ }^{154} \mathrm{Eu}$, Type M, $5 \mu \mathrm{m}$ & $3.50 \mathrm{E}-08$ & $3.5 \mathrm{E}-08$ \\
${ }^{154} \mathrm{Eu}$, ingestion & $2.03 \mathrm{E}-09$ & $2.0 \mathrm{E}-09$ \\
${ }^{155} \mathrm{Eu}$, Type M, $5 \mu \mathrm{m}$ & $4.68 \mathrm{E}-09$ & $4.7 \mathrm{E}-09$ \\
${ }^{155} \mathrm{Eu}$, ingestion & $3.32 \mathrm{E}-10$ & $3.2 \mathrm{E}-10$ \\
\hline
\end{tabular}

\subsubsection{Derived Air Concentrations and Annual Limits on Intake}

Title 10 of the Code of Federal Regulations Part 835 (10 CFR 835) provides derived air concentrations (DACs) assuming 5- $\mu \mathrm{m}$-AMAD particles and the light worker breathing rate $\left(2,400 \mathrm{~m}^{3} / \mathrm{y}\right)$. It is unlikely that workers at Hanford will encounter air contamination composed entirely of an isotope or isotopes of europium; however, europium DACs may be useful in determining a DAC for a mixture of radionuclides using the mixture rule. For ${ }^{152} \mathrm{Eu}$ and ${ }^{154} \mathrm{Eu}$, the effective dose is more limiting than any organ dose so the stochastic annual limit on intake (SALI) is appropriate.

The SALI can be calculated using the 5- $\mu$ m-AMAD inhalation effective dose coefficient from Table 13.5 and the 5-rem effective dose limit as follows:

$$
\mathrm{SALI}=5 \mathrm{rem} / \mathrm{effective} \text { dose coefficient in rem/nCi. }
$$

For ${ }^{155} \mathrm{Eu}$, the deterministic ALI (DALI) is more limiting. The DALI can also be calculated using the 5 - $\mu \mathrm{m}$-AMAD inhalation bone surface dose coefficient from Table 13.5 and the 50-rem organ dose limit as follows:

$$
\mathrm{DALI}=50 \mathrm{rem} / \text { bone surface dose coefficient in rem/nCi. }
$$

The 10 CFR 835 Appendix A DACs and the SALIs and DALIs from the equations above are listed in Table 13.7.

Table 13.7. Derived Air Concentration (DAC) and Annual Limits on Intake (ALI) for Europium Isotopes

\begin{tabular}{ccc}
\hline & DAC $(\mu \mathrm{Ci} / \mathrm{ml})$ & ALI (nCi) \\
& from 10 CFR 835 & from Table 13.5 \\
\hline${ }^{152} \mathrm{Eu}$ & $2 \mathrm{E}-08$ & $5.0 \mathrm{E}+04$ (SALI) \\
${ }^{154} \mathrm{Eu}$ & $1 \mathrm{E}-08$ & $3.9 \mathrm{E}+04$ (SALI) \\
${ }^{155} \mathrm{Eu}$ & $7 \mathrm{E}-08$ & $1.75 \mathrm{E}+05$ (bone surface DALI) \\
\hline
\end{tabular}




\subsubsection{Derived Reference Levels}

Derived reporting levels and investigation levels have been calculated for ${ }^{152} \mathrm{Eu},{ }^{154} \mathrm{Eu}$, and ${ }^{155} \mathrm{Eu}$, as pure isotopes, for whole body and skeleton bioassays (based on committed effective doses of 10 mrem and 100 mrem, respectively). Dose limit compliance levels are also provided based on the 5,000 mrem effective dose limit for ${ }^{152} \mathrm{Eu}$ and ${ }^{154} \mathrm{Eu}$ and on the 50,000 mrem bone surface equivalent dose for ${ }^{155} \mathrm{Eu}$. Derived levels for ${ }^{152} \mathrm{Eu}$ are listed in Table 13.8, for ${ }^{154} \mathrm{Eu}$ in Table 13.9, and for ${ }^{155} \mathrm{Eu}$ in Table 13.10. The reference levels for ${ }^{155} \mathrm{Eu}$ are for in vivo skeleton counting only because its principal gamma rays at 86 and $105 \mathrm{keV}$ are not readily detectable by whole body counting. Keep in mind that an intake of europium may not, and probably will not, involve a single isotope and that other, perhaps more limiting, fission/activation product radionuclides may also be present.

Table 13.8. Reference Levels and Derived Reference Levels for ${ }^{152} \mathrm{Eu}$

\begin{tabular}{|c|c|c|c|c|c|c|c|c|c|}
\hline \multirow[b]{2}{*}{$\begin{array}{c}\text { Days Post } \\
\text { Intake }\end{array}$} & \multicolumn{3}{|c|}{$\begin{array}{l}\text { 10-mrem } E(50) \\
\text { Reporting Level }\end{array}$} & \multicolumn{3}{|c|}{$\begin{array}{l}\text { 100-mrem E(50) } \\
\text { Investigation Level }\end{array}$} & \multicolumn{3}{|c|}{$\begin{array}{l}\text { 5,000-mrem } E(50) \\
\text { Compliance Level }\end{array}$} \\
\hline & $\begin{array}{c}0.5-\mu m \\
\text { Inhalation }\end{array}$ & $\begin{array}{c}5-\mu m \\
\text { Inhalation }\end{array}$ & $\begin{array}{l}\text { Instant. } \\
\text { Uptake }\end{array}$ & $\begin{array}{c}0.5-\mu m \\
\text { Inhalation }\end{array}$ & $\begin{array}{c}5-\mu m \\
\text { Inhalation }\end{array}$ & $\begin{array}{l}\text { Instant. } \\
\text { Uptake }\end{array}$ & $\begin{array}{c}0.5-\mu \mathrm{m} \\
\text { Inhalation }\end{array}$ & $\begin{array}{c}5-\mu m \\
\text { Inhalation }\end{array}$ & $\begin{array}{l}\text { Instant. } \\
\text { Uptake }\end{array}$ \\
\hline $\begin{array}{l}\text { Intake } \\
\text { (nCi): }\end{array}$ & $6.54 \mathrm{E}+01$ & $9.90 \mathrm{E}+01$ & $7.04 \mathrm{E}+00$ & $6.54 \mathrm{E}+02$ & $9.90 \mathrm{E}+02$ & $7.04 \mathrm{E}+01$ & $3.27 \mathrm{E}+04$ & $4.95 \mathrm{E}+04$ & $3.52 \mathrm{E}+03$ \\
\hline \multicolumn{10}{|c|}{ Whole Body Count Bioassay (nCi) } \\
\hline 0.5 & $1.99 \mathrm{E}+01$ & $6.52 \mathrm{E}+01$ & $6.68 \mathrm{E}+00$ & $1.99 \mathrm{E}+02$ & $6.52 \mathrm{E}+02$ & $6.68 \mathrm{E}+01$ & $9.97 \mathrm{E}+03$ & $3.26 \mathrm{E}+04$ & $3.34 \mathrm{E}+03$ \\
\hline 1 & $1.70 \mathrm{E}+01$ & $4.90 \mathrm{E}+01$ & $6.46 \mathrm{E}+00$ & $1.70 \mathrm{E}+02$ & $4.90 \mathrm{E}+02$ & $6.46 \mathrm{E}+01$ & $8.50 \mathrm{E}+03$ & $2.45 \mathrm{E}+04$ & $3.23 E+03$ \\
\hline 2 & $1.26 \mathrm{E}+01$ & $2.58 \mathrm{E}+01$ & $6.22 \mathrm{E}+00$ & $1.26 \mathrm{E}+02$ & $2.58 \mathrm{E}+02$ & $6.22 \mathrm{E}+01$ & $6.31 \mathrm{E}+03$ & $1.29 \mathrm{E}+04$ & $3.11 E+03$ \\
\hline 3 & $1.05 \mathrm{E}+01$ & $1.50 \mathrm{E}+01$ & $6.08 \mathrm{E}+00$ & $1.05 \mathrm{E}+02$ & $1.50 \mathrm{E}+02$ & $6.08 \mathrm{E}+01$ & $5.23 \mathrm{E}+03$ & $7.48 \mathrm{E}+03$ & $3.04 \mathrm{E}+03$ \\
\hline 4 & $9.54 \mathrm{E}+00$ & $1.06 \mathrm{E}+01$ & $6.01 \mathrm{E}+00$ & $9.54 \mathrm{E}+01$ & $1.06 \mathrm{E}+02$ & $6.01 \mathrm{E}+01$ & $4.77 \mathrm{E}+03$ & $5.30 \mathrm{E}+03$ & $3.00 \mathrm{E}+03$ \\
\hline 5 & $9.15 \mathrm{E}+00$ & $8.87 \mathrm{E}+00$ & $5.96 \mathrm{E}+00$ & $9.15 \mathrm{E}+01$ & $8.87 \mathrm{E}+01$ & $5.96 \mathrm{E}+01$ & $4.58 \mathrm{E}+03$ & $4.44 \mathrm{E}+03$ & $2.98 E+03$ \\
\hline 7 & $8.82 E+00$ & $7.88 \mathrm{E}+00$ & $5.91 \mathrm{E}+00$ & $8.82 E+01$ & $7.88 \mathrm{E}+01$ & $5.91 \mathrm{E}+01$ & $4.41 \mathrm{E}+03$ & $3.94 \mathrm{E}+03$ & $2.95 E+03$ \\
\hline 14 & $8.30 \mathrm{E}+00$ & $7.35 \mathrm{E}+00$ & $5.78 \mathrm{E}+00$ & $8.30 \mathrm{E}+01$ & $7.35 \mathrm{E}+01$ & $5.78 \mathrm{E}+01$ & $4.15 E+03$ & $3.67 \mathrm{E}+03$ & $2.89 E+03$ \\
\hline 30 & $7.52 \mathrm{E}+00$ & $6.67 \mathrm{E}+00$ & $5.63 \mathrm{E}+00$ & $7.52 \mathrm{E}+01$ & $6.67 \mathrm{E}+01$ & $5.63 \mathrm{E}+01$ & $3.76 \mathrm{E}+03$ & $3.34 \mathrm{E}+03$ & $2.82 E+03$ \\
\hline 60 & $6.54 \mathrm{E}+00$ & $5.95 \mathrm{E}+00$ & $5.53 \mathrm{E}+00$ & $6.54 \mathrm{E}+01$ & $5.95 \mathrm{E}+01$ & $5.53 \mathrm{E}+01$ & $3.27 \mathrm{E}+03$ & $2.98 \mathrm{E}+03$ & $2.76 \mathrm{E}+03$ \\
\hline 90 & $6.04 \mathrm{E}+00$ & $5.56 \mathrm{E}+00$ & $5.46 \mathrm{E}+00$ & $6.04 \mathrm{E}+01$ & $5.56 \mathrm{E}+01$ & $5.46 \mathrm{E}+01$ & $3.02 \mathrm{E}+03$ & $2.78 E+03$ & $2.73 E+03$ \\
\hline 180 & $5.31 \mathrm{E}+00$ & $5.02 \mathrm{E}+00$ & $5.30 \mathrm{E}+00$ & $5.31 \mathrm{E}+01$ & $5.02 \mathrm{E}+01$ & $5.30 \mathrm{E}+01$ & $2.66 \mathrm{E}+03$ & $2.51 \mathrm{E}+03$ & $2.65 E+03$ \\
\hline 365 & $4.66 \mathrm{E}+00$ & $4.50 \mathrm{E}+00$ & $4.98 \mathrm{E}+00$ & $4.66 \mathrm{E}+01$ & $4.50 \mathrm{E}+01$ & $4.98 \mathrm{E}+01$ & $2.33 E+03$ & $2.25 \mathrm{E}+03$ & $2.49 E+03$ \\
\hline 730 & $3.99 E+00$ & $3.88 \mathrm{E}+00$ & $4.39 \mathrm{E}+00$ & $3.99 \mathrm{E}+01$ & $3.88 \mathrm{E}+01$ & $4.39 \mathrm{E}+01$ & $1.99 \mathrm{E}+03$ & $1.94 \mathrm{E}+03$ & $2.20 \mathrm{E}+03$ \\
\hline 1826 & $2.73 \mathrm{E}+00$ & $2.66 \mathrm{E}+00$ & $3.03 E+00$ & $2.73 E+01$ & $2.66 \mathrm{E}+01$ & $3.03 E+01$ & $1.37 \mathrm{E}+03$ & $1.33 \mathrm{E}+03$ & $1.51 \mathrm{E}+03$ \\
\hline \multicolumn{10}{|c|}{ Skeleton Bioassay (nCi) } \\
\hline 0.5 & $6.50 \mathrm{E}-01$ & $1.35 \mathrm{E}+00$ & $3.41 \mathrm{E}+00$ & $6.50 \mathrm{E}+00$ & $1.35 \mathrm{E}+01$ & $3.41 \mathrm{E}+01$ & $3.25 E+02$ & $6.73 E+02$ & $1.70 \mathrm{E}+03$ \\
\hline 1 & 8.74E-01 & $1.79 \mathrm{E}+00$ & $4.49 \mathrm{E}+00$ & $8.74 \mathrm{E}+00$ & $1.79 \mathrm{E}+01$ & $4.49 \mathrm{E}+01$ & $4.37 \mathrm{E}+02$ & $8.96 \mathrm{E}+02$ & $2.24 \mathrm{E}+03$ \\
\hline 2 & 8.68E-01 & $1.74 \mathrm{E}+00$ & $4.31 \mathrm{E}+00$ & $8.68 \mathrm{E}+00$ & $1.74 \mathrm{E}+01$ & $4.31 \mathrm{E}+01$ & $4.34 \mathrm{E}+02$ & $8.71 \mathrm{E}+02$ & $2.15 \mathrm{E}+03$ \\
\hline 3 & 7.86E-01 & $1.54 \mathrm{E}+00$ & $3.77 \mathrm{E}+00$ & $7.86 \mathrm{E}+00$ & $1.54 \mathrm{E}+01$ & $3.77 \mathrm{E}+01$ & $3.93 \mathrm{E}+02$ & $7.72 \mathrm{E}+02$ & $1.88 \mathrm{E}+03$ \\
\hline 4 & 7.34E-01 & $1.42 \mathrm{E}+00$ & $3.39 E+00$ & $7.34 \mathrm{E}+00$ & $1.42 \mathrm{E}+01$ & $3.39 E+01$ & $3.67 \mathrm{E}+02$ & $7.08 \mathrm{E}+02$ & $1.70 \mathrm{E}+03$ \\
\hline 5 & 7.08E-01 & $1.34 \mathrm{E}+00$ & $3.16 \mathrm{E}+00$ & $7.08 \mathrm{E}+00$ & $1.34 \mathrm{E}+01$ & $3.16 \mathrm{E}+01$ & $3.54 \mathrm{E}+02$ & $6.68 \mathrm{E}+02$ & $1.58 \mathrm{E}+03$ \\
\hline 7 & 6.96E-01 & $1.27 \mathrm{E}+00$ & $2.94 \mathrm{E}+00$ & $6.96 \mathrm{E}+00$ & $1.27 \mathrm{E}+01$ & $2.94 \mathrm{E}+01$ & $3.48 \mathrm{E}+02$ & $6.34 \mathrm{E}+02$ & $1.47 \mathrm{E}+03$ \\
\hline 14 & 7.67E-01 & $1.28 \mathrm{E}+00$ & $2.81 \mathrm{E}+00$ & $7.67 \mathrm{E}+00$ & $1.28 \mathrm{E}+01$ & $2.81 \mathrm{E}+01$ & $3.84 \mathrm{E}+02$ & $6.39 \mathrm{E}+02$ & $1.40 \mathrm{E}+03$ \\
\hline 30 & $9.52 \mathrm{E}-01$ & $1.41 \mathrm{E}+00$ & $2.79 E+00$ & $9.52 E+00$ & $1.41 \mathrm{E}+01$ & $2.79 E+01$ & $4.76 \mathrm{E}+02$ & $7.03 \mathrm{E}+02$ & $1.39 \mathrm{E}+03$ \\
\hline 60 & $1.22 \mathrm{E}+00$ & $1.57 \mathrm{E}+00$ & $2.76 \mathrm{E}+00$ & $1.22 \mathrm{E}+01$ & $1.57 \mathrm{E}+01$ & $2.76 \mathrm{E}+01$ & $6.10 \mathrm{E}+02$ & $7.87 \mathrm{E}+02$ & $1.38 \mathrm{E}+03$ \\
\hline 90 & $1.42 \mathrm{E}+00$ & $1.70 \mathrm{E}+00$ & $2.73 E+00$ & $1.42 \mathrm{E}+01$ & $1.70 \mathrm{E}+01$ & $2.73 E+01$ & $7.10 \mathrm{E}+02$ & $8.51 \mathrm{E}+02$ & $1.37 \mathrm{E}+03$ \\
\hline 180 & $1.79 \mathrm{E}+00$ & $1.93 \mathrm{E}+00$ & $2.65 \mathrm{E}+00$ & $1.79 \mathrm{E}+01$ & $1.93 \mathrm{E}+01$ & $2.65 \mathrm{E}+01$ & $8.95 E+02$ & $9.65 E+02$ & $1.32 \mathrm{E}+03$ \\
\hline 365 & $2.05 \mathrm{E}+00$ & $2.06 \mathrm{E}+00$ & $2.49 \mathrm{E}+00$ & $2.05 \mathrm{E}+01$ & $2.06 \mathrm{E}+01$ & $2.49 \mathrm{E}+01$ & $1.02 \mathrm{E}+03$ & $1.03 \mathrm{E}+03$ & $1.24 \mathrm{E}+03$ \\
\hline 730 & $1.96 \mathrm{E}+00$ & $1.92 \mathrm{E}+00$ & $2.20 \mathrm{E}+00$ & $1.96 \mathrm{E}+01$ & $1.92 \mathrm{E}+01$ & $2.20 \mathrm{E}+01$ & $9.80 \mathrm{E}+02$ & $9.60 \mathrm{E}+02$ & $1.10 \mathrm{E}+03$ \\
\hline 1826 & $1.37 \mathrm{E}+00$ & $1.34 \mathrm{E}+00$ & $1.51 \mathrm{E}+00$ & $1.37 \mathrm{E}+01$ & $1.34 \mathrm{E}+01$ & $1.51 \mathrm{E}+01$ & $6.83 \mathrm{E}+02$ & $6.68 \mathrm{E}+02$ & $7.57 \mathrm{E}+02$ \\
\hline
\end{tabular}

PNNL-MA-860 Chapter 13.0 Page 13.10
Issued for implementation effective 01/01/2010 Superseded: September 12, 2000 
Table 13.9. Reference Levels and Derived Reference Levels for ${ }^{154} \mathrm{Eu}$

\begin{tabular}{|c|c|c|c|c|c|c|c|c|c|}
\hline \multirow[b]{2}{*}{$\begin{array}{l}\text { Days Post } \\
\text { Intake }\end{array}$} & \multicolumn{3}{|c|}{$\begin{array}{c}\text { 10-mrem } E(50) \\
\text { Reporting Level }\end{array}$} & \multicolumn{3}{|c|}{$\begin{array}{c}100 \text {-mrem } E(50) \\
\text { Investigation Level }\end{array}$} & \multicolumn{3}{|c|}{$\begin{array}{l}\text { 5,000-mrem } E(50) \\
\text { Compliance Level }\end{array}$} \\
\hline & $\begin{array}{c}0.5-\mu \mathrm{m} \\
\text { Inhalation }\end{array}$ & $\begin{array}{c}5-\mu m \\
\text { Inhalation }\end{array}$ & $\begin{array}{l}\text { Instant. } \\
\text { Uptake }\end{array}$ & $\begin{array}{c}0.5-\mu m \\
\text { Inhalation }\end{array}$ & $\begin{array}{c}5-\mu m \\
\text { Inhalation }\end{array}$ & Ingestion & $\begin{array}{c}0.5-\mu m \\
\text { Inhalation }\end{array}$ & $\begin{array}{c}5-\mu m \\
\text { Inhalation }\end{array}$ & $\begin{array}{l}\text { Instant. } \\
\text { Uptake }\end{array}$ \\
\hline $\begin{array}{l}\text { Intake } \\
\text { (nCi): }\end{array}$ & $5.18 \mathrm{E}+01$ & $7.75 \mathrm{E}+01$ & $5.95 \mathrm{E}+00$ & $5.18 \mathrm{E}+02$ & $7.75 \mathrm{E}+02$ & $5.95 \mathrm{E}+01$ & $2.59 \mathrm{E}+04$ & $3.88 \mathrm{E}+04$ & $2.98 \mathrm{E}+03$ \\
\hline \multicolumn{10}{|c|}{ Whole Body Count Bioassay (nCi) } \\
\hline 0.5 & $1.58 \mathrm{E}+01$ & $5.11 \mathrm{E}+01$ & $5.65 \mathrm{E}+00$ & $1.58 \mathrm{E}+02$ & $5.11 \mathrm{E}+02$ & $5.65 \mathrm{E}+01$ & $7.90 \mathrm{E}+03$ & $2.55 \mathrm{E}+04$ & $2.82 \mathrm{E}+03$ \\
\hline 1 & $1.35 \mathrm{E}+01$ & $3.84 \mathrm{E}+01$ & $5.46 \mathrm{E}+00$ & $1.35 \mathrm{E}+02$ & $3.84 \mathrm{E}+02$ & $5.46 \mathrm{E}+01$ & $6.74 \mathrm{E}+03$ & $1.92 \mathrm{E}+04$ & $2.73 E+03$ \\
\hline 2 & $1.00 \mathrm{E}+01$ & $2.02 \mathrm{E}+01$ & $5.26 \mathrm{E}+00$ & $1.00 \mathrm{E}+02$ & $2.02 \mathrm{E}+02$ & $5.26 \mathrm{E}+01$ & $5.00 \mathrm{E}+03$ & $1.01 \mathrm{E}+04$ & $2.63 \mathrm{E}+03$ \\
\hline 3 & $8.29 \mathrm{E}+00$ & $1.17 \mathrm{E}+01$ & $5.14 \mathrm{E}+00$ & $8.29 \mathrm{E}+01$ & $1.17 \mathrm{E}+02$ & $5.14 \mathrm{E}+01$ & $4.15 \mathrm{E}+03$ & $5.85 \mathrm{E}+03$ & $2.57 \mathrm{E}+03$ \\
\hline 4 & $7.56 \mathrm{E}+00$ & $8.29 \mathrm{E}+00$ & $5.08 \mathrm{E}+00$ & $7.56 \mathrm{E}+01$ & $8.29 \mathrm{E}+01$ & $5.08 \mathrm{E}+01$ & $3.78 \mathrm{E}+03$ & $4.15 E+03$ & $2.54 \mathrm{E}+03$ \\
\hline 5 & $7.25 \mathrm{E}+00$ & $6.94 \mathrm{E}+00$ & $5.04 \mathrm{E}+00$ & $7.25 \mathrm{E}+01$ & $6.94 \mathrm{E}+01$ & $5.04 \mathrm{E}+01$ & $3.63 \mathrm{E}+03$ & $3.47 \mathrm{E}+03$ & $2.52 E+03$ \\
\hline 7 & $6.99 E+00$ & $6.17 \mathrm{E}+00$ & $4.99 \mathrm{E}+00$ & $6.99 \mathrm{E}+01$ & $6.17 \mathrm{E}+01$ & $4.99 \mathrm{E}+01$ & $3.50 \mathrm{E}+03$ & $3.09 E+03$ & $2.49 E+03$ \\
\hline 14 & $6.58 \mathrm{E}+00$ & $5.74 \mathrm{E}+00$ & $4.88 \mathrm{E}+00$ & $6.58 \mathrm{E}+01$ & $5.74 \mathrm{E}+01$ & $4.88 \mathrm{E}+01$ & $3.29 E+03$ & $2.87 \mathrm{E}+03$ & $2.44 \mathrm{E}+03$ \\
\hline 30 & $5.91 \mathrm{E}+00$ & $5.21 \mathrm{E}+00$ & $4.75 \mathrm{E}+00$ & $5.91 \mathrm{E}+01$ & $5.21 \mathrm{E}+01$ & $4.75 \mathrm{E}+01$ & $2.95 E+03$ & $2.60 \mathrm{E}+03$ & $2.38 \mathrm{E}+03$ \\
\hline 60 & $5.17 \mathrm{E}+00$ & $4.64 \mathrm{E}+00$ & $4.65 \mathrm{E}+00$ & $5.17 \mathrm{E}+01$ & $4.64 \mathrm{E}+01$ & $4.65 E+01$ & $2.59 \mathrm{E}+03$ & $2.32 E+03$ & $2.33 E+03$ \\
\hline 90 & $4.76 \mathrm{E}+00$ & $4.33 \mathrm{E}+00$ & $4.59 \mathrm{E}+00$ & $4.76 \mathrm{E}+01$ & $4.33 \mathrm{E}+01$ & $4.59 \mathrm{E}+01$ & $2.38 \mathrm{E}+03$ & $2.16 \mathrm{E}+03$ & $2.29 \mathrm{E}+03$ \\
\hline 180 & $4.16 \mathrm{E}+00$ & $3.88 \mathrm{E}+00$ & $4.42 \mathrm{E}+00$ & $4.16 \mathrm{E}+01$ & $3.88 \mathrm{E}+01$ & $4.42 \mathrm{E}+01$ & $2.08 \mathrm{E}+03$ & $1.94 \mathrm{E}+03$ & $2.21 \mathrm{E}+03$ \\
\hline 365 & $3.60 \mathrm{E}+00$ & $3.43 \mathrm{E}+00$ & $4.10 \mathrm{E}+00$ & $3.60 \mathrm{E}+01$ & $3.43 E+01$ & $4.10 \mathrm{E}+01$ & $1.80 \mathrm{E}+03$ & $1.71 \mathrm{E}+03$ & $2.05 \mathrm{E}+03$ \\
\hline 730 & $2.99 \mathrm{E}+00$ & $2.88 \mathrm{E}+00$ & $3.52 \mathrm{E}+00$ & $2.99 \mathrm{E}+01$ & $2.88 \mathrm{E}+01$ & $3.52 \mathrm{E}+01$ & $1.50 \mathrm{E}+03$ & $1.44 \mathrm{E}+03$ & $1.76 \mathrm{E}+03$ \\
\hline 1826 & $1.90 \mathrm{E}+00$ & $1.82 \mathrm{E}+00$ & $2.24 \mathrm{E}+00$ & $1.90 \mathrm{E}+01$ & $1.82 \mathrm{E}+01$ & $2.24 \mathrm{E}+01$ & $9.48 \mathrm{E}+02$ & $9.11 \mathrm{E}+02$ & $1.12 \mathrm{E}+03$ \\
\hline \multicolumn{10}{|c|}{ Skeleton Bioassay (nCi) } \\
\hline 0.5 & 5.15E-01 & $1.05 \mathrm{E}+00$ & $2.88 \mathrm{E}+00$ & $5.15 \mathrm{E}+00$ & $1.05 \mathrm{E}+01$ & $2.88 \mathrm{E}+01$ & $2.57 \mathrm{E}+02$ & $5.27 \mathrm{E}+02$ & $1.44 \mathrm{E}+03$ \\
\hline 1 & 6.93E-01 & $1.40 \mathrm{E}+00$ & $3.79 \mathrm{E}+00$ & $6.93 \mathrm{E}+00$ & $1.40 \mathrm{E}+01$ & $3.79 \mathrm{E}+01$ & $3.46 \mathrm{E}+02$ & $7.02 \mathrm{E}+02$ & $1.90 \mathrm{E}+03$ \\
\hline 2 & $6.88 \mathrm{E}-01$ & $1.36 \mathrm{E}+00$ & $3.64 \mathrm{E}+00$ & $6.88 \mathrm{E}+00$ & $1.36 \mathrm{E}+01$ & $3.64 \mathrm{E}+01$ & $3.44 \mathrm{E}+02$ & $6.82 \mathrm{E}+02$ & $1.82 \mathrm{E}+03$ \\
\hline 3 & 6.23E-01 & $1.21 \mathrm{E}+00$ & $3.18 \mathrm{E}+00$ & $6.23 \mathrm{E}+00$ & $1.21 \mathrm{E}+01$ & $3.18 \mathrm{E}+01$ & $3.12 \mathrm{E}+02$ & $6.05 \mathrm{E}+02$ & $1.59 \mathrm{E}+03$ \\
\hline 4 & 5.82E-01 & $1.11 \mathrm{E}+00$ & $2.87 \mathrm{E}+00$ & $5.82 \mathrm{E}+00$ & $1.11 \mathrm{E}+01$ & $2.87 \mathrm{E}+01$ & $2.91 \mathrm{E}+02$ & $5.54 \mathrm{E}+02$ & $1.43 \mathrm{E}+03$ \\
\hline 5 & 5.61E-01 & $1.05 \mathrm{E}+00$ & $2.67 \mathrm{E}+00$ & $5.61 \mathrm{E}+00$ & $1.05 \mathrm{E}+01$ & $2.67 \mathrm{E}+01$ & $2.80 \mathrm{E}+02$ & $5.23 \mathrm{E}+02$ & $1.34 \mathrm{E}+03$ \\
\hline 7 & 5.52E-01 & 9.92E-01 & $2.48 \mathrm{E}+00$ & $5.52 \mathrm{E}+00$ & $9.92 \mathrm{E}+00$ & $2.48 \mathrm{E}+01$ & $2.76 \mathrm{E}+02$ & $4.96 \mathrm{E}+02$ & $1.24 \mathrm{E}+03$ \\
\hline 14 & $6.08 \mathrm{E}-01$ & $1.00 \mathrm{E}+00$ & $2.37 \mathrm{E}+00$ & $6.08 \mathrm{E}+00$ & $1.00 \mathrm{E}+01$ & $2.37 \mathrm{E}+01$ & $3.04 \mathrm{E}+02$ & $5.00 \mathrm{E}+02$ & $1.18 \mathrm{E}+03$ \\
\hline 30 & 7.53E-01 & $1.09 \mathrm{E}+00$ & $2.35 \mathrm{E}+00$ & $7.53 \mathrm{E}+00$ & $1.09 \mathrm{E}+01$ & $2.35 \mathrm{E}+01$ & $3.77 \mathrm{E}+02$ & $5.47 \mathrm{E}+02$ & $1.18 \mathrm{E}+03$ \\
\hline 60 & 9.63E-01 & $1.23 \mathrm{E}+00$ & $2.32 \mathrm{E}+00$ & $9.63 \mathrm{E}+00$ & $1.23 \mathrm{E}+01$ & $2.32 \mathrm{E}+01$ & $4.82 \mathrm{E}+02$ & $6.16 \mathrm{E}+02$ & $1.16 \mathrm{E}+03$ \\
\hline 90 & $1.12 \mathrm{E}+00$ & $1.33 \mathrm{E}+00$ & $2.29 \mathrm{E}+00$ & $1.12 \mathrm{E}+01$ & $1.33 \mathrm{E}+01$ & $2.29 \mathrm{E}+01$ & $5.59 \mathrm{E}+02$ & $6.63 \mathrm{E}+02$ & $1.15 \mathrm{E}+03$ \\
\hline 180 & $1.40 \mathrm{E}+00$ & $1.49 \mathrm{E}+00$ & $2.21 \mathrm{E}+00$ & $1.40 \mathrm{E}+01$ & $1.49 \mathrm{E}+01$ & $2.21 \mathrm{E}+01$ & $7.00 \mathrm{E}+02$ & $7.44 \mathrm{E}+02$ & $1.10 \mathrm{E}+03$ \\
\hline 365 & $1.58 \mathrm{E}+00$ & $1.57 \mathrm{E}+00$ & $2.05 E+00$ & $1.58 \mathrm{E}+01$ & $1.57 \mathrm{E}+01$ & $2.05 E+01$ & $7.90 \mathrm{E}+02$ & $7.83 \mathrm{E}+02$ & $1.02 \mathrm{E}+03$ \\
\hline 730 & $1.47 \mathrm{E}+00$ & $1.43 \mathrm{E}+00$ & $1.76 \mathrm{E}+00$ & $1.47 \mathrm{E}+01$ & $1.43 \mathrm{E}+01$ & $1.76 \mathrm{E}+01$ & $7.37 \mathrm{E}+02$ & $7.13 \mathrm{E}+02$ & $8.81 \mathrm{E}+02$ \\
\hline 1826 & 9.47E-01 & $9.15 \mathrm{E}-01$ & $1.12 \mathrm{E}+00$ & $9.47 \mathrm{E}+00$ & $9.15 E+00$ & $1.12 \mathrm{E}+01$ & $4.73 \mathrm{E}+02$ & $4.57 \mathrm{E}+02$ & $5.60 \mathrm{E}+02$ \\
\hline
\end{tabular}


Table 13.10. Reference Levels and Derived Reference Levels for ${ }^{155} \mathrm{Eu}$

\begin{tabular}{|c|c|c|c|c|c|c|c|c|c|}
\hline \multirow[b]{2}{*}{$\begin{array}{l}\text { Days Post } \\
\text { Intake }\end{array}$} & \multicolumn{3}{|c|}{$\begin{array}{l}\text { 10-mrem } E(50) \\
\text { Reporting Level }\end{array}$} & \multicolumn{3}{|c|}{$\begin{array}{c}100 \text {-mrem } E(50) \\
\text { Investigation Level }\end{array}$} & \multicolumn{3}{|c|}{$\begin{array}{l}\text { 50,000-mrem } H_{\mathrm{t}, 50} \\
\text { Compliance Level }\end{array}$} \\
\hline & $\begin{array}{l}0.5-\mu m \\
\text { Inhalation }\end{array}$ & $\begin{array}{c}5-\mu \mathrm{m} \\
\text { Inhalation }\end{array}$ & $\begin{array}{l}\text { Instant. } \\
\text { Uptake }\end{array}$ & $\begin{array}{l}0.5-\mu m \\
\text { Inhalation }\end{array}$ & $\begin{array}{l}5-\mu \mathrm{m} \\
\text { Inhalation }\end{array}$ & $\begin{array}{l}\text { Instant. } \\
\text { Uptake }\end{array}$ & $\begin{array}{l}0.5-\mu \mathrm{m} \\
\text { Inhalation }\end{array}$ & $\begin{array}{c}5-\mu \mathrm{m} \\
\text { Inhalation }\end{array}$ & $\begin{array}{l}\text { Instant. } \\
\text { Uptake }\end{array}$ \\
\hline $\begin{array}{l}\text { Intake } \\
(\mathrm{nCi}) \text { : }\end{array}$ & $4.00 \mathrm{E}+02$ & $5.78 \mathrm{E}+02$ & $5.26 \mathrm{E}+01$ & $4.00 \mathrm{E}+03$ & $5.78 \mathrm{E}+03$ & $5.26 \mathrm{E}+02$ & $1.15 \mathrm{E}+05$ & $1.75 \mathrm{E}+05$ & $1.05 \mathrm{E}+04$ \\
\hline \multicolumn{10}{|c|}{ Skeleton Bioassay (nCi) } \\
\hline 0.5 & $3.98 \mathrm{E}+00$ & $7.86 \mathrm{E}+00$ & $2.55 \mathrm{E}+01$ & $3.98 \mathrm{E}+01$ & $7.86 \mathrm{E}+01$ & $2.55 \mathrm{E}+02$ & $1.15 \mathrm{E}+03$ & $2.39 \mathrm{E}+03$ & $5.08 \mathrm{E}+03$ \\
\hline 1 & $5.35 \mathrm{E}+00$ & $1.05 \mathrm{E}+01$ & $3.35 \mathrm{E}+01$ & $5.35 \mathrm{E}+01$ & $1.05 \mathrm{E}+02$ & $3.35 \mathrm{E}+02$ & $1.54 \mathrm{E}+03$ & $3.18 \mathrm{E}+03$ & $6.69 E+03$ \\
\hline 2 & $5.31 \mathrm{E}+00$ & $1.02 \mathrm{E}+01$ & $3.22 \mathrm{E}+01$ & $5.31 \mathrm{E}+01$ & $1.02 \mathrm{E}+02$ & $3.22 \mathrm{E}+02$ & $1.53 \mathrm{E}+03$ & $3.09 \mathrm{E}+03$ & $6.42 \mathrm{E}+03$ \\
\hline 3 & $4.81 \mathrm{E}+00$ & $9.02 \mathrm{E}+00$ & $2.81 \mathrm{E}+01$ & $4.81 \mathrm{E}+01$ & $9.02 E+01$ & $2.81 \mathrm{E}+02$ & $1.39 \mathrm{E}+03$ & $2.74 \mathrm{E}+03$ & $5.61 \mathrm{E}+03$ \\
\hline 4 & $4.49 \mathrm{E}+00$ & $8.27 \mathrm{E}+00$ & $2.53 \mathrm{E}+01$ & $4.49 \mathrm{E}+01$ & $8.27 \mathrm{E}+01$ & $2.53 \mathrm{E}+02$ & $1.30 \mathrm{E}+03$ & $2.51 \mathrm{E}+03$ & $5.05 E+03$ \\
\hline 5 & $4.33 \mathrm{E}+00$ & $7.80 \mathrm{E}+00$ & $2.36 \mathrm{E}+01$ & 4.33E+01 & $7.80 \mathrm{E}+01$ & $2.36 \mathrm{E}+02$ & $1.25 \mathrm{E}+03$ & $2.37 \mathrm{E}+03$ & $4.72 E+03$ \\
\hline 7 & $4.25 \mathrm{E}+00$ & $7.40 \mathrm{E}+00$ & $2.19 \mathrm{E}+01$ & $4.25 \mathrm{E}+01$ & $7.40 \mathrm{E}+01$ & $2.19 \mathrm{E}+02$ & $1.23 E+03$ & $2.25 \mathrm{E}+03$ & $4.38 \mathrm{E}+03$ \\
\hline 14 & $4.68 \mathrm{E}+00$ & $7.46 \mathrm{E}+00$ & $2.09 \mathrm{E}+01$ & $4.68 \mathrm{E}+01$ & $7.46 \mathrm{E}+01$ & $2.09 \mathrm{E}+02$ & $1.35 \mathrm{E}+03$ & $2.26 \mathrm{E}+03$ & $4.17 E+03$ \\
\hline 30 & $5.78 \mathrm{E}+00$ & $8.15 E+00$ & $2.07 \mathrm{E}+01$ & $5.78 \mathrm{E}+01$ & $8.15 E+01$ & $2.07 \mathrm{E}+02$ & $1.67 \mathrm{E}+03$ & $2.47 \mathrm{E}+03$ & $4.13 E+03$ \\
\hline 60 & $7.36 \mathrm{E}+00$ & $9.08 \mathrm{E}+00$ & $2.03 \mathrm{E}+01$ & $7.36 \mathrm{E}+01$ & $9.08 \mathrm{E}+01$ & $2.03 E+02$ & $2.13 E+03$ & $2.75 E+03$ & $4.05 E+03$ \\
\hline 90 & $8.51 \mathrm{E}+00$ & $9.77 \mathrm{E}+00$ & $2.00 \mathrm{E}+01$ & $8.51 \mathrm{E}+01$ & $9.77 \mathrm{E}+01$ & $2.00 \mathrm{E}+02$ & $2.46 \mathrm{E}+03$ & $2.96 \mathrm{E}+03$ & $3.99 E+03$ \\
\hline 180 & $1.05 E+01$ & $1.08 \mathrm{E}+01$ & $1.89 \mathrm{E}+01$ & $1.05 \mathrm{E}+02$ & $1.08 \mathrm{E}+02$ & $1.89 \mathrm{E}+02$ & $3.03 E+03$ & $3.28 \mathrm{E}+03$ & $3.78 \mathrm{E}+03$ \\
\hline 365 & $1.15 \mathrm{E}+01$ & $1.10 \mathrm{E}+01$ & $1.71 \mathrm{E}+01$ & $1.15 \mathrm{E}+02$ & $1.10 \mathrm{E}+02$ & $1.71 \mathrm{E}+02$ & $3.31 \mathrm{E}+03$ & $3.33 \mathrm{E}+03$ & $3.40 \mathrm{E}+03$ \\
\hline 730 & $1.01 \mathrm{E}+01$ & $9.42 \mathrm{E}+00$ & $1.38 \mathrm{E}+01$ & $1.01 \mathrm{E}+02$ & $9.42 \mathrm{E}+01$ & $1.38 \mathrm{E}+02$ & $2.91 \mathrm{E}+03$ & $2.86 \mathrm{E}+03$ & $2.75 E+03$ \\
\hline 1826 & $5.39 \mathrm{E}+00$ & $5.01 \mathrm{E}+00$ & $7.26 \mathrm{E}+00$ & $5.39 \mathrm{E}+01$ & $5.01 \mathrm{E}+01$ & $7.26 \mathrm{E}+01$ & $1.56 \mathrm{E}+03$ & $1.52 \mathrm{E}+03$ & $1.45 \mathrm{E}+03$ \\
\hline
\end{tabular}

\subsection{Bioassay for Europium}

This section discusses bioassay methods, capabilities, and protocols for europium.

\subsubsection{Bioassay Methods and Capabilities}

The europium isotopes of concern at Hanford $\left({ }^{152} \mathrm{Eu},{ }^{154} \mathrm{Eu}\right.$, and $\left.{ }^{155} \mathrm{Eu}\right)$ are readily measured by in vivo bioassay techniques. Europium intakes can also be detected and assessed through collection and analysis of urine and fecal samples. However, because in vivo measurements provide a direct and sensitive method for assessing internal depositions of europium radionuclides, excreta measurements are generally not necessary. The recommended bioassay programs for europium are based on in vivo measurements. Nominal minimum detectable activities for in vivo measurements are shown in Table 13.11.

Europium-154 is the predominant long-lived europium radioisotope in europium mixtures at Hanford. During the operating lifetime of $\mathrm{N}$ Reactor, the ${ }^{154} \mathrm{Eu}:{ }^{155} \mathrm{Eu}$ activity ratio was about 2.0. Since the 1986 shutdown of $\mathrm{N}$ Reactor, this ratio should gradually increase due to the longer half-life of ${ }^{154} \mathrm{Eu}$ now that europium is no longer produced (see Figures 13.1 and 13.2). Because ${ }^{154} \mathrm{Eu}$ (1274-keV photon) is also more easily detectable in vivo than ${ }^{155} \mathrm{Eu}$, it is the best indicator of an intake of europium radionuclides. Whole body counting for ${ }^{154} \mathrm{Eu}$ is conveniently performed using the sodium iodide (NaI)-detector preview counter; however, the high-resolution large-volume coaxial germanium (Ge) detector system should be used for quantitative determinations if detection is indicated on the NaI system. 
Table 13.11. Hanford In Vivo Measurement Detection Capability for ${ }^{152} \mathrm{Eu},{ }^{154} \mathrm{Eu}$, and ${ }^{155} \mathrm{Eu}, \mathrm{nCi}$

\begin{tabular}{llccc}
\hline \multicolumn{1}{c}{ Measurement Type } & Organ/Tissue & ${ }^{152} \mathrm{Eu}$ & ${ }^{154} \mathrm{Eu}$ & ${ }^{155} \mathrm{Eu}$ \\
\hline NaI Preview Count & Whole Body & $20^{(\mathrm{a})}$ & $7^{(\mathrm{b})}$ & NA \\
Coaxial Germanium Count & Whole Body & $7^{(\mathrm{a})}$ & $2^{(\mathrm{b})}$ & NA \\
Chest Count & Lung & $0.4^{(\mathrm{a})}$ & $0.3^{(\mathrm{a})}$ & $0.6^{(\mathrm{a})}$ \\
Skull Count & Skeleton & $0.8^{(\mathrm{a})}$ & $0.5^{(\mathrm{a})}$ & $1.0^{(\mathrm{a})}$ \\
\hline
\end{tabular}

(a) Not part of routine library. Estimated based on peak search algorithm.

(b) From In Vivo Monitoring Program Manual, PNL-MA-574. (Lynch 2009)

NA = not applicable.

Europium-155 is more difficult to detect in vivo because its predominant gamma emission falls in the low-energy noise region of the standard whole body count. It can be detected in the skeleton or lungs (shortly after intake) using the low-energy planar germanium detector systems. The total body content of ${ }^{155} \mathrm{Eu}$ cannot be directly measured with the Hanford whole body counter. It can be estimated by establishing a ${ }^{155} \mathrm{Eu}:{ }^{154} \mathrm{Eu}$ ratio, using chest or skeleton counts, and then applying that ratio to the ${ }^{154} \mathrm{Eu}$ whole body count result. Skeleton counting would provide a more sensitive ratio for ${ }^{155} \mathrm{Eu}$ estimation.

Europium-152 (779-keV photon) can also be detected by whole body counting. Because it was probably formed in different locations in the reactors from different parent material, it is possible workers might encounter ${ }^{152} \mathrm{Eu}$ without the other isotopes. Europium-152 is not part of the routine whole body count library search algorithm, but is detectable by the peak search algorithm at whole body count levels of about $20 \mathrm{nCi}$.

Special measurements of lung, skeleton, or liver content may be desired to establish individualspecific patterns of distribution and retention. Because europium is a liver- and bone-seeking radionuclide, chest counts performed more than several weeks after intake may detect activity in the liver, the bones of the chest, and the lung, in any combination. Therefore, any quantification of lung activity should consider the contribution from the thoracic bones and the liver. Skeleton activity is estimated from a head count. A correction factor can then be derived for obtaining lung activity from a chest count. Likewise, a liver count should be made and used to correct the chest count for shine from the liver to get the true lung activity. These calculations are performed by the In Vivo Measurement Program staff.

Minimum detectable committed effective doses for ${ }^{152} \mathrm{Eu}$, based on whole body counting, are listed in

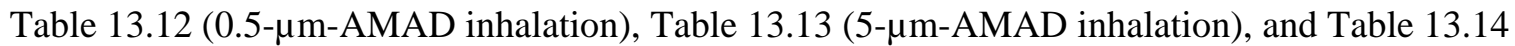
(instantaneous uptake). Corresponding values for ${ }^{154} \mathrm{Eu}$ are shown in Tables 13.15, 13.16, and 13.17. As stated previously, these values do not apply if the intake is a mixture of isotopes or other radionuclides.

\subsubsection{Routine Bioassay Monitoring Protocol}

Routine bioassay monitoring for europium at Hanford can be accomplished by whole body counting. From Tables 13.12 through 13.17, it is apparent that annual whole body counting for ${ }^{152} \mathrm{Eu}$ or ${ }^{154} \mathrm{Eu}$ using the NaI preview counter provides sufficient sensitivity for detecting inhalation intakes or instantaneous uptakes resulting in doses below the bioassay monitoring goal of 100-mrem effective dose. Although not shown in the tables, this is true even when ${ }^{155} \mathrm{Eu}$ is assumed to be present at the time of intake. 
Table 13.12. ${ }^{152}$ Eu Minimum Detectable Intakes and Committed Effective Doses for 0.5- $\mu$ m-AMAD Type M Inhalation

\begin{tabular}{|c|c|c|c|c|c|}
\hline & \multirow[b]{2}{*}{$\begin{array}{l}\text { Days Post } \\
\text { Intake }\end{array}$} & \multicolumn{2}{|c|}{$\begin{array}{c}\text { NaI System }^{(\mathrm{a})} \text { Minimum } \\
\text { Detectable }\end{array}$} & \multicolumn{2}{|c|}{$\begin{array}{c}\text { Coax Ge System }^{(\mathrm{b})} \\
\text { Minimum Detectable }\end{array}$} \\
\hline & & Intake (nCi) & $\begin{array}{c}\text { Dose } \\
(\mathrm{mrem})\end{array}$ & Intake (nCi) & $\begin{array}{c}\text { Dose } \\
\text { (mrem) }\end{array}$ \\
\hline & 0.5 & 66 & 10 & 23 & 4 \\
\hline & 1 & 77 & 12 & 27 & 4 \\
\hline & 2 & 104 & 16 & 36 & 6 \\
\hline & 5 & 143 & 22 & 50 & 8 \\
\hline & 7 & 148 & 23 & 52 & 8 \\
\hline & 14 & 157 & 24 & 55 & 8 \\
\hline & 30 & 174 & 27 & 61 & 9 \\
\hline & 60 & 200 & 31 & 70 & 11 \\
\hline & 90 & 216 & 33 & 76 & 12 \\
\hline & 180 & 246 & 38 & 86 & 13 \\
\hline & 365 & 281 & 43 & 98 & 15 \\
\hline & $2 \mathrm{y}$ & 328 & 50 & 115 & 18 \\
\hline & $5 y$ & 478 & 73 & 167 & 26 \\
\hline & $10 \mathrm{y}$ & 893 & 137 & 313 & 48 \\
\hline & $20 \mathrm{y}$ & 3090 & 473 & 1080 & 166 \\
\hline $\begin{array}{l}\text { (a) } \mathrm{B} \\
\text { (b) } \mathrm{B} \\
\end{array}$ & $\begin{array}{l}\text { 3ased on a } \\
\text { 3ased on a }\end{array}$ & $\begin{array}{l}\text { A of } 20 \mathrm{nCi} . \\
\text { A of } 7 \mathrm{nCi} .\end{array}$ & & & \\
\hline
\end{tabular}

Table 13.13. ${ }^{152}$ Eu Minimum Detectable Intakes and Committed Effective Doses for 5- $\mu$ m-AMAD Type M Inhalation

\begin{tabular}{|c|c|c|c|c|}
\hline \multirow[b]{2}{*}{ Days Post Intake } & \multicolumn{2}{|c|}{$\begin{array}{c}\text { NaI System }{ }^{(a)} \text { Minimum } \\
\text { Detectable }\end{array}$} & \multicolumn{2}{|c|}{$\begin{array}{c}\text { Coax Ge System }^{(\mathrm{b})} \\
\text { Minimum Detectable }\end{array}$} \\
\hline & Intake (nCi) & $\begin{array}{c}\text { Dose } \\
(\mathrm{mrem})\end{array}$ & Intake (nCi) & $\begin{array}{c}\text { Dose } \\
(\mathrm{mrem})\end{array}$ \\
\hline 0.5 & 30 & 3 & 11 & 1 \\
\hline 1 & 40 & 4 & 14 & 1 \\
\hline 2 & 77 & 8 & 27 & 3 \\
\hline 5 & 223 & 23 & 78 & 8 \\
\hline 7 & 251 & 25 & 88 & 9 \\
\hline 14 & 270 & 27 & 94 & 10 \\
\hline 30 & 297 & 30 & 104 & 10 \\
\hline 60 & 333 & 34 & 116 & 12 \\
\hline 90 & 356 & 36 & 125 & 13 \\
\hline 180 & 394 & 40 & 138 & 14 \\
\hline 365 & 441 & 44 & 154 & 16 \\
\hline $2 \mathrm{yr}$ & 510 & 52 & 179 & 18 \\
\hline $5 \mathrm{yr}$ & 743 & 75 & 260 & 26 \\
\hline $10 \mathrm{yr}$ & 1380 & 139 & 483 & 49 \\
\hline $20 \mathrm{yr}$ & 4800 & 484 & 1680 & 170 \\
\hline $\begin{array}{l}\text { (a) Based on MDA } \\
\text { (b) Based on MDA }\end{array}$ & $\begin{array}{l}20 \text { nCi. } \\
7 \text { nCi. }\end{array}$ & & & \\
\hline
\end{tabular}


Table 13.14. ${ }^{152}$ Eu Minimum Detectable Intakes and Committed Effective Doses for Instantaneous Uptake

\begin{tabular}{|c|c|c|c|c|c|}
\hline & \multirow[b]{2}{*}{$\begin{array}{l}\text { Days Post } \\
\text { Intake }\end{array}$} & \multicolumn{2}{|c|}{$\begin{array}{c}\text { NaI System }^{(\mathrm{a})} \text { Minimum } \\
\text { Detectable }\end{array}$} & \multicolumn{2}{|c|}{$\begin{array}{c}\text { Coax Ge System }^{(\mathrm{b})} \\
\text { Minimum Detectable }\end{array}$} \\
\hline & & Intake (nCi) & $\begin{array}{c}\text { Dose } \\
(\mathrm{mrem})\end{array}$ & Intake (nCi) & $\begin{array}{c}\text { Dose } \\
\text { (mrem) }\end{array}$ \\
\hline & 0.5 & 21 & 30 & 7 & 10 \\
\hline & 1 & 22 & 31 & 8 & 11 \\
\hline & 2 & 23 & 32 & 8 & 11 \\
\hline & 5 & 24 & 34 & 8 & 12 \\
\hline & 7 & 24 & 34 & 8 & 12 \\
\hline & 14 & 24 & 35 & 9 & 12 \\
\hline & 30 & 25 & 36 & 9 & 12 \\
\hline & 60 & 25 & 36 & 9 & 13 \\
\hline & 90 & 26 & 37 & 9 & 13 \\
\hline & 180 & 27 & 38 & 9 & 13 \\
\hline & 365 & 28 & 40 & 10 & 14 \\
\hline & $2 y$ & 32 & 46 & 11 & 16 \\
\hline & $5 y$ & 47 & 66 & 16 & 23 \\
\hline & $10 \mathrm{y}$ & 87 & 123 & 30 & 43 \\
\hline & $20 \mathrm{y}$ & 301 & 427 & 105 & 149 \\
\hline $\begin{array}{l}\text { (a) } \mathrm{B} \\
\text { (b) } \mathrm{B} \\
\end{array}$ & $\begin{array}{l}\text { 3ased on } \mathrm{N} \\
\text { Based on } \mathrm{P}\end{array}$ & $\begin{array}{l}\text { f } 20 \mathrm{nCi} . \\
\text { f } 7 \mathrm{nCi} .\end{array}$ & & & \\
\hline
\end{tabular}

Table 13.15. ${ }^{154} \mathrm{Eu}$ Minimum Detectable Intakes and Committed Effective Doses for 0.5- $\mu \mathrm{m}-\mathrm{AMAD}$ Type M Inhalation

\begin{tabular}{|c|c|c|c|c|c|}
\hline & \multirow[b]{2}{*}{$\begin{array}{l}\text { Days Post } \\
\text { Intake }\end{array}$} & \multicolumn{2}{|c|}{$\begin{array}{c}\text { NaI System }{ }^{(a)} \text { Minimum } \\
\text { Detectable }\end{array}$} & \multicolumn{2}{|c|}{$\begin{array}{c}\text { Coax Ge System }^{(\mathrm{b})} \\
\text { Minimum Detectable }\end{array}$} \\
\hline & & Intake (nCi) & $\begin{array}{c}\text { Dose } \\
(\mathrm{mrem})\end{array}$ & Intake (nCi) & $\begin{array}{c}\text { Dose } \\
\text { (mrem) }\end{array}$ \\
\hline & 0.5 & 23 & 4 & 7 & 1 \\
\hline & 1 & 27 & 5 & 8 & 1 \\
\hline & 2 & 36 & 7 & 10 & 2 \\
\hline & 5 & 50 & 10 & 14 & 3 \\
\hline & 7 & 52 & 10 & 15 & 3 \\
\hline & 14 & 55 & 11 & 16 & 3 \\
\hline & 30 & 61 & 12 & 18 & 3 \\
\hline & 60 & 70 & 14 & 20 & 4 \\
\hline & 90 & 76 & 15 & 22 & 4 \\
\hline & 180 & 87 & 17 & 25 & 5 \\
\hline & 365 & 101 & 19 & 29 & 6 \\
\hline & $2 \mathrm{yr}$ & 121 & 23 & 35 & 7 \\
\hline & $5 \mathrm{yr}$ & 191 & 37 & 55 & 11 \\
\hline & $10 \mathrm{yr}$ & 407 & 79 & 116 & 22 \\
\hline & $20 \mathrm{yr}$ & 1850 & 356 & 528 & 102 \\
\hline $\begin{array}{l}\text { (a) } \\
\text { (b) }\end{array}$ & $\begin{array}{l}\text { Based on } \\
\text { Based on }\end{array}$ & $\begin{array}{l}\text { of } 7 \mathrm{nCi} . \\
\text { of } 2 \mathrm{nCi} \text {. }\end{array}$ & & & \\
\hline
\end{tabular}


Table 13.16. ${ }^{154}$ Eu Minimum Detectable Intakes and Committed Effective Doses for 5- $\mu$ m-AMAD Type M Inhalation

\begin{tabular}{|c|c|c|c|c|c|}
\hline & \multirow[b]{2}{*}{$\begin{array}{l}\text { Days Post } \\
\text { Intake }\end{array}$} & \multicolumn{2}{|c|}{$\begin{array}{c}\text { NaI System }^{(\mathrm{a})} \text { Minimum } \\
\text { Detectable }\end{array}$} & \multicolumn{2}{|c|}{$\begin{array}{c}\text { Coax Ge System }^{(\mathrm{b})} \\
\text { Minimum Detectable }\end{array}$} \\
\hline & & Intake (nCi) & $\begin{array}{c}\text { Dose } \\
(\mathrm{mrem})\end{array}$ & Intake (nCi) & $\begin{array}{c}\text { Dose } \\
\text { (mrem) }\end{array}$ \\
\hline & 0.5 & 11 & 1 & 3 & $<1$ \\
\hline & 1 & 14 & 2 & 4 & $<1$ \\
\hline & 2 & 27 & 3 & 8 & $<1$ \\
\hline & 5 & 78 & 10 & 22 & 3 \\
\hline & 7 & 88 & 11 & 25 & 3 \\
\hline & 14 & 94 & 12 & 27 & 3 \\
\hline & 30 & 104 & 13 & 30 & 4 \\
\hline & 60 & 117 & 15 & 33 & 4 \\
\hline & 90 & 125 & 16 & 36 & 5 \\
\hline & 180 & 140 & 18 & 40 & 5 \\
\hline & 365 & 158 & 20 & 45 & 6 \\
\hline & $2 y$ & 188 & 24 & 54 & 7 \\
\hline & $5 y$ & 298 & 38 & 85 & 11 \\
\hline & $10 \mathrm{y}$ & 631 & 81 & 180 & 23 \\
\hline & $20 \mathrm{y}$ & 2870 & 370 & 820 & 106 \\
\hline $\begin{array}{l}\text { (a) } \mathrm{B} \\
\text { (b) } \mathrm{B}\end{array}$ & $\begin{array}{l}\text { 3ased on a } \\
\text { 3ased on a }\end{array}$ & $\begin{array}{l}\text { A of } 7 \mathrm{nCi} . \\
\text { A of } 2 \mathrm{nCi} \text {. }\end{array}$ & & & \\
\hline
\end{tabular}

Table 13.17. ${ }^{154} \mathrm{Eu}$ Minimum Detectable Intakes and Committed Effective Doses for Instantaneous Uptake

\begin{tabular}{ccccc}
\hline & \multicolumn{2}{c}{$\begin{array}{c}\text { NaI System } \\
\text { Detectable }\end{array}$} & \multicolumn{2}{c}{$\begin{array}{c}\text { Minimum Ge System } \\
\text { Minimum }\end{array}$} \\
$\begin{array}{c}\text { Days Postectable } \\
\text { Intake }\end{array}$ & Intake (nCi) & $\begin{array}{c}\text { Dose } \\
(\text { mrem) }\end{array}$ & Intake (nCi) & $\begin{array}{c}\text { Dose } \\
(\text { mrem) }\end{array}$ \\
\cline { 2 - 5 } & 7 & 12 & 2 & 4 \\
1 & 8 & 13 & 2 & 4 \\
2 & 8 & 13 & 2 & 4 \\
5 & 8 & 14 & 2 & 4 \\
7 & 8 & 14 & 2 & 4 \\
14 & 9 & 14 & 2 & 4 \\
30 & 9 & 15 & 3 & 4 \\
60 & 9 & 15 & 3 & 4 \\
90 & 9 & 15 & 3 & 4 \\
180 & 9 & 16 & 3 & 5 \\
365 & 10 & 17 & 3 & 5 \\
2 y & 12 & 20 & 3 & 6 \\
5 y & 19 & 31 & 5 & 9 \\
10 y & 40 & 66 & 11 & 19 \\
20 y & 180 & 302 & 51 & 86 \\
\hline
\end{tabular}

(a) Based on an MDA of $7 \mathrm{nCi}$.

(b) Based on an MDA of $2 \mathrm{nCi}$. 
The fact that the source of ${ }^{152} \mathrm{Eu}$ appears to be different from ${ }^{154,155} \mathrm{Eu}$ suggests that concurrent exposure to all three nuclides seems unlikely. Routine bioassay monitoring for ${ }^{155} \mathrm{Eu}$ is not required because its presence can be inferred from the detection of ${ }^{154} \mathrm{Eu}$, which is the predominant nuclide due to its longer radioactive half-life.

A supplemental skeleton count to establish the ${ }^{155} \mathrm{Eu}:{ }^{154} \mathrm{Eu}$ ratio would allow determination of the total body content of ${ }^{155} \mathrm{Eu}$. This measurement is warranted for an initial detection of ${ }^{154} \mathrm{Eu}$ on a whole body count, but need not be a routine bioassay.

Routine measurements in which a europium radionuclide is detected might exceed or at least will be close to the derived screening level; they should be confirmed by follow-up in vivo measurements and inquiry should be made about the possible presence of other radionuclides in the source term. The recommended protocol is to use high-resolution germanium detector whole body counting to confirm the identity and magnitude of activity indicated by the preview counter. Because of the adequate sensitivity of whole body counting, routine chest and skeleton measurements are not generally warranted for intake or dose assessment unless unusual retention or distribution is suspected.

\subsubsection{Special Bioassay for Suspected Intakes}

An in vivo whole body examination should be performed following a suspected intake. However, unless the exposure appears to be of such magnitude that actions to hasten the removal of the material from the body are considered, the initial examination can be at the earliest convenient time during normal working hours. A measurement of the chest or skeleton is warranted to establish the ${ }^{155} \mathrm{Eu}:{ }^{154} \mathrm{Eu}$ ratio if significant ${ }^{154} \mathrm{Eu}$ is found by the whole body count such that the total effective dose might approach the investigation level.

Because there is much movement of inhaled material in the body during the first hours after an inhalation intake, early in vivo measurements should be considered semi-quantitative. Where early measurements suggest that the committed effective dose might exceed $100 \mathrm{mrem}$, follow-up measurements should be performed after about 5 days to allow for early clearance of material via the GI tract. Likewise, specialized measurements to estimate clearance rates from specific organs (e.g., chest counts, skeleton counts) should also be delayed until early GI tract clearance is complete.

\subsection{Assessment of Internal Dose}

The assessment of internal dose from europium is accomplished by evaluating in vivo measurement results. Assessments must consider the contribution of all radionuclides present in the mixture. For mixtures of ${ }^{154} \mathrm{Eu}$ and ${ }^{155} \mathrm{Eu}$, the activity ratio should be established based on in vivo (e.g., skeleton) measurements of the two nuclides or determined from an isotopic analysis of a characteristic sample of the material. (However, for total effective dose estimates below the investigation level, a default ratio from Section 13.1 can be used. Be sure to take into account the presence or absence of other fission or activation product radionuclides.) If the intake occurred many years before the measurements, decay correction must be made to determine the ratios at the time of intake.

The committed effective dose is calculated for confirmed occupational intakes from incidents discovered promptly in the workplace. A 10-mrem screening level is applied to possible detections as part of routine 
bioassay monitoring. Committed equivalent doses to specific organs and tissues are determined based on the criteria presented in the Hanford Internal Dosimetry Program Manual (PNL-MA-552; et al. 2009).

The initial evaluation of in vivo results to assess the internal dose, as well as for final evaluations when doses are low, can be performed using the factors tabulated in this chapter. If the effective dose potentially exceeds 100 mrem or if a worker's retention seems to be significantly different from the default models, obtaining a series of whole body counts over time and fitting the in vivo measurement using IMBA is recommended. This may include changing respiratory tract or biokinetic parameters to improve the fit if such changes seem logical or are clearly indicated by the data. Adjustments to biokinetic parameters just to make minor improvements to the fit are discouraged. Modifications to default model parameters must be documented in the internal dose assessment report. All europium isotopes and other radionuclides in a mixture need be to be taken into account if the effective dose exceeds 100 mrem.

\subsection{Management of Internal Contamination Cases}

Although, historically, there have been intakes involving europium radionuclides at Hanford, in no case have the intakes resulted in significant internal doses relative to occupational exposure limits. Because europium radionuclides are no longer produced, the concentrations of europium radionuclides at Hanford are slowly diminishing.

In vivo measurements performed following a potential intake provide an initial indication of the significance of an intake, although external contamination and rapid translocation of the material through the body may interfere with the accuracy of the measurement. If a significant intake is indicated, then various mitigative actions are possible (NCRP 1980; Bhattacharyya et al. 1992). Purgatives or laxatives, as well as enemas or colonic irrigations, may reduce the residence time of the radionuclide in the GI tract, thereby reducing its absorption by the blood. Antacids may reduce the absorption rate from the GI tract. For europium that has reached the blood, diethylene triamine penta acetate (DTPA) may be considered as a chelating agent. All of these mitigative actions require prescription by medical authority. Occupational Medicine should be notified immediately upon indication of a severe intake potentially requiring mitigative action.

\subsection{References}

10 CFR 835. 2007. “Occupation Radiation Protection.” Code of Federal Regulations. U.S. Department of Energy. Available at: http://www.access.gpo.gov

Bhattacharyya MH., BD Breitenstein, H Metivier, BA Muggenburg, GN Stradling, and V Volf. 1992. "Guidebook for the treatment of accidental internal radionuclide contamination of workers." Rad. Prot. Dosim. 41:1.

Carbaugh EH, DE Bihl, JA MacLellan. 2009. Hanford Internal Dosimetry Program Manual. PNL-MA552, PNNL-15613, Pacific Northwest National Laboratory, Richland, Washington. (Internal manual.) A copy of this manual is maintained in the HIDP files and available from the HIDP Manager or online by searching, PNNL-15613 @ http://www.pnl.gov/publications/. 
Department of Energy (DOE) Office of River Protection. 2008. Tank Farm Inventory Network System. Available at: http://twins.pnl.gov (Accessed October 2008).

International Atomic Energy Agency (IAEA). 1996. International Basic Safety Standards for Protection Against Ionizing Radiation and for the Safety of Radiation Sources. Safety Series No. 115, Vienna, Austria.

International Commission on Radiological Protection (ICRP). 1981. "Limits for Intakes of Radionuclides by Workers.” ICRP Publication 30, Part 3, Annals of the ICRP, 6:2-3, Pergamon Press, New York.

International Commission on Radiological Protection (ICRP). 1994a. "Dose Coefficients for Intakes of Radionuclides by Workers.” ICRP Publication 68, Annals of the ICRP, 24:4, Pergamon Press, New York.

International Commission on Radiological Protection (ICRP). 1994b. "Human Respiratory Tract Model for Radiological Protection.” ICRP Publication 66, Annals of the ICRP, 24:1-3, Pergamon Press, New York.

International Commission on Radiological Protection (ICRP). 1996. “Age-dependent Doses to Members of the Public from Intake of Radionuclides: Part 5, Compilation of Ingestion and Inhalation Dose Coefficients.” ICRP Publication 72, Annals of the ICRP, 26:1, Pergamon Press, New York.

James AC, JW Marsh, A Birchall, NS Jarvis, M Puncher, K Davis, and D King. 2004. User Manual for IMBA Expert USDOE-Edition, “Appendix A: Technical Basis.” ACJ \& Associates, Richland, Washington.

Kocher DC. 1981. Radioactive Decay Data Tables. DOE/TIC-11026, Technical Information Center, U.S. Department of Energy, Washington, D.C.

Lynch TP. 2007. In Vivo Monitoring Program Manual. PNL-MA-574, Pacific Northwest Laboratory, Richland, Washington. (Internal Manual.)

National Council on Radiation Protection and Measurements (NCRP). 1980. Management of Persons Accidentally Contaminated with Radionuclides. NCRP Report No. 65, Bethesda, Maryland.

Sula MJ, EH Carbaugh, and DE Bihl. 1989. Technical Basis for Internal Dosimetry at Hanford. PNL-6866, Pacific Northwest Laboratory, Richland, Washington.

Weetman RA and HW DeHaven. 1982. Characterization of Airborne Radionuclides in UNC Facilities. UNI-2164, UNC Nuclear Industries, Richland, Washington. 


\title{
Methods and Models of the Hanford Internal Dosimetry Program \\ PNNL-MA-860
}

\author{
Appendix A, Glossary
}

Issued for implementation effective 01/01/2010

Supersedes: September 30, 2000

\section{Use Category: Not applicable}

\section{Approval Signatures:}

Prepared by:

EH Carbaugh, Internal Dosimetry Program Mapager

Approved by:

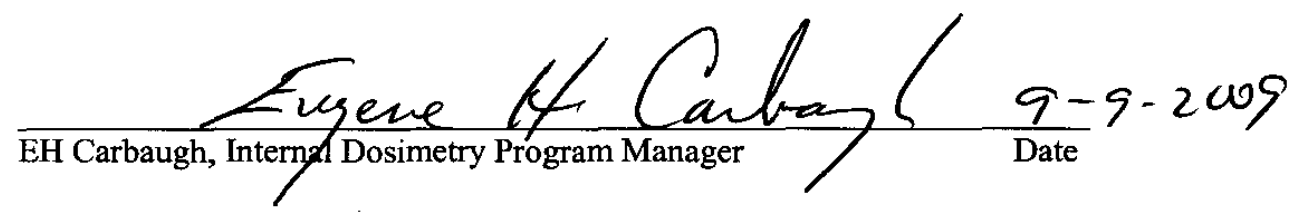

\section{Reviewer Signatures:}

Reviewed by:

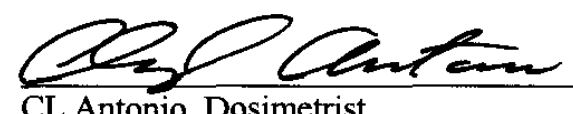

CL Antonio, Dosimetrist

Approved by the Hanford Personnel Dosimetry Advisory Committee as recorded in the meeting minutes of March 10, 2009. 


\section{Contents}

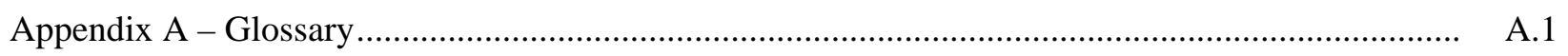




\section{Appendix A}

\section{Glossary}

This glossary is a limited compilation of specialized terms used in this manual that are pertinent to internal dosimetry and, in particular, the Hanford Internal Dosimetry Program. It is not intended to be a general glossary of health physics or internal dosimetry definitions. For more detailed compilations or cross references for health physics definitions, see Title 10 of the Code of Federal Regulations Part 835.2 (10 CFR 835.2), the U.S Department of Energy Radiation Protection Programs Guide (DOE 2008b), and the DOE Standard Internal Dosimetry (DOE 2008a). Most terms used in this manual are generally consistent with standard technical usage by the International Commission on Radiological Protection (ICRP), National Council on Radiation Protection and Measurements, Health Physics Society, DOE, and the Nuclear Regulatory Commission.

\section{absorption type}

bioassay

burden

committed equivalent dose, $\boldsymbol{H}_{\mathrm{T}}(\mathbf{5 0})$

committed effective dose, E(50)

\section{DAC-hours}

decision level, $D L$ or $L_{c}$
An ICRP 66 respiratory tract model concept describing the relative speed of dissolution and translocation to blood of material within the respiratory tract. It is related to the physical chemistry of the material. The ICRP 66 model defines three absorption types: Type F (fast solubilization), Type M (moderate rate of solubilization), and Type S (slow solubilization).

The determination of kinds, quantities, or concentrations, and, in some cases, locations of radioactive material in the human body, whether by direct (in vivo) measurement or by indirect analysis of material removed or excreted from the body.

The quantity of specific material in an organ or tissue of interest (e.g., lung, bone surfaces, whole body, wound site) at a specific point in time. Same as retained quantity.

Equivalent dose to an organ or tissue calculated for a 50-year period following an acute intake or onset of chronic intake. It does not include contributions from external dose.

The effective dose calculated for a 50-year period following an acute intake or onset of chronic intake. It does not include contributions from external dose.

The time- and concentration-integrated exposure to airborne radioactivity. Exposure to 1 DAC-hour implies the equivalent of one hour exposure to air at the DAC value.

The quantity of material in a measurement above which the analyte is interpreted as being present (i.e., analyte is detected). Also called the critical level of decision. See Appendix B for discussion. 


\section{decorporation}

deposition

derived reference levels

detection level

effective dose, $E$

equivalent dose, $H_{T}$

inhalation class

injection

instantaneous uptake
The chemical acceleration of the removal of radioactive atoms from the body using chelating agents, which bind the atoms and cause them to be excreted.

1) process of material being initially retained from an intake, 2) the material initially deposited at an entry site, 3) Hanford historical usage: the total quantity of radioactive material deposited in an organ or tissue over a specified period of time. See systemic deposition.

Bioassay measurement values corresponding to retention or excretion associated with an intake of the reference level. Derived reference levels are discussed in Section 2.12 of this manual and provided for nuclides in the respective chapters.

A general term relating to the smallest amount of material detectable as a function of the measurement method and instrument background. (The precise way that detection level has been used at Hanford has changed over the years. At times it has been defined as the minimum detectable activity, and at other times it has been defined as the decision level.)

The summation of the products of the equivalent doses $\left(H_{\mathrm{T}}\right)$ received by organs or tissues of the body and the appropriate tissue weighting factors $\left(w_{\mathrm{T}}\right)$.

The product of the average absorbed dose to an organ or tissue and the appropriate radiation weighting factor $\left(w_{R}\right)$ for the radiation causing the dose.

An ICRP 30 respiratory tract model concept describing the relative rate of clearance from the pulmonary region of the lungs. ICRP 30 defined three inhalation classes for materials, Class D (clearance halftime less than 10 days), Class W (10 to 100 days), and Class Y (greater than 100 days). Hanford has described a super-Y class as having a nominal clearance half-time of 10,000 days. Usage of inhalation class has been superseded by the concept of absorption type.

Any means whereby the radioactive material is placed in direct contact with the blood, excluding through the lung or gastrointestinal tract.

Material translocated from a point of intake to the blood with essentially no delay. In concept, a direct injection to the blood. 
intake

in vivo

minimum detectable activity, MDA

presystemic deposition

preview counter

reference level

retained quantity

retention
The amount of a radionuclide that enters the body. For inhalation, it is the material inhaled (including material that is subsequently exhaled). For material absorbed through the intact skin, it is the amount absorbed through the skin. For a wound or abraded skin, it is the amount absorbed through the skin; for practical purposes, it does not include material on the skin near the wound or material in the wound that is easily and promptly washed away. However, it does include material that is later removed by medical treatment if the time from deposition to treatment is deemed long enough to allow some material to reach the systemic circulation prior to treatment. Intake is independent of time.

Refers to measuring radioactivity directly in a living organism. In vivo is synonymous with the word "direct" when used in the phrase "direct bioassay."

The smallest activity of a radionuclide in a sample (or organ) that will be detected with a specified level of confidence. See Appendix B for details.

A mathematical or schematic component (or components) of the deposition at the entry site that is available for translocation to the blood. It excludes material that is permanently retained at the entry site or by the lymph system. This was a Hanford term used primarily before 1992.

A standup whole body counter consisting of five sodium iodide detectors. It is the principal counter used for routine whole body counts and incident screening counts, provided good resolution of photopeaks is not needed.

Hanford usage: a magnitude of intake used as a basis for some action (see derived reference level). Reference levels are discussed in Section 2.12 of this manual and provided for nuclides in the respective chapters.

Synonymous with burden.

The retained quantity (or burden) as a fraction of the uptake or intake. It can apply to any organ, tissue, system of tissues (e.g., gastrointestinal or respiratory tracts) or to the whole body. 
systemic deposition

transfer compartment

transportable

uptake
Hanford historical usage: activity retained for an extended period of time in all systemic organs and tissues. Differs from uptake in that activity that stays in the transfer compartment and is ultimately excreted without going to systemic organs (for instance, because of chelation) is included in the term uptake but not in the term systemic deposition.

A mathematical or schematic representation of the blood circulation system through which radioactive material is transported to organs, tissues, or excretion.

Material that is transferred from the site of initial deposition to the blood. As applied to material in the lung, readily transportable material would be considered Type F, whereas poorly transportable material would be considered Type S. It is generally equivalent to the term "soluble" as applied to human physiology, but it is not necessarily equivalent to chemical solubility in aqueous solutions.

Quantity of a radionuclide taken up by the systemic circulation or a specified organ or tissue via the blood. Uptake can occur by direct injection into the blood, by absorption from compartments in the respiratory or gastrointestinal tracts, or by absorption through the skin or through wounds in the skin.

\section{References}

10 CFR 835.2. 2008. “Occupational Radiation Protection, Definitions.” Code of Federal Regulations. U.S. Department of Energy. Available online at www.gpoaccess.gov. (Accessed December 19, 2008).

U.S. Department of Energy (DOE). 2008a. DOE Standard Internal Dosimetry. DOE-STD-1121-2008, Washington, D.C. Available online at www.standards.doe.gov. (Accessed December 19, 2008).

U.S. Department of Energy (DOE). 2008b. Radiation Protection Programs Guide for Use with Title 10, Code of Federal Regulations, Part 835, Occupational Radiation Protection. DOE G 441.1-1C, Washington, D.C. Available online at www.directives.doe.gov. (Accessed December 19, 2008). 


\title{
Methods and Models of the Hanford Internal Dosimetry Program
}

PNNL-MA-860

\section{Appendix B, Statistical Methods for Internal Dosimetry}

\author{
Issued for implementation effective 01/01/2010
}

Supersedes: September 30, 2000

\section{Use Category: Not applicable}

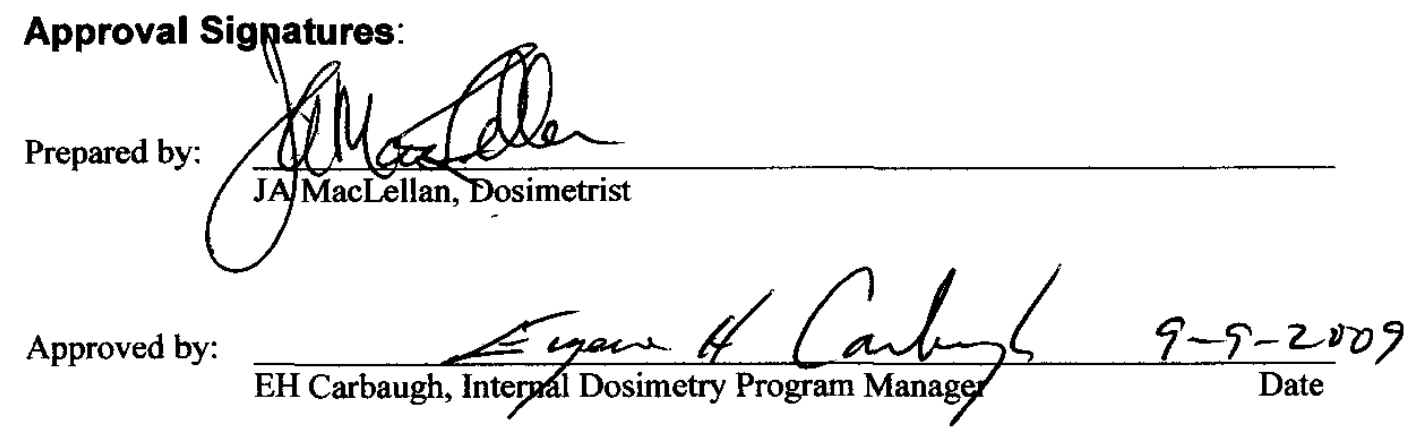

\section{Reviewer Signatures:}

Reviewed by:

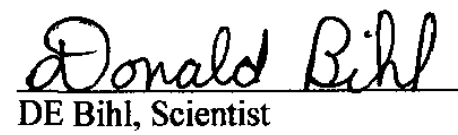

Approved by the Hanford Personnel Dosimetry Advisory Committee as recorded in the meeting minutes of March 10, 2009. 


\section{Contents}

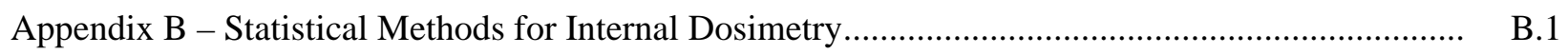

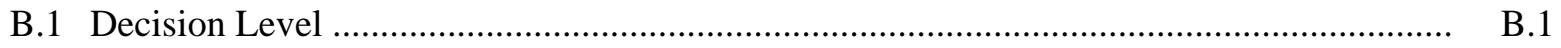

B.2 Minimum Detectable Amount................................................................................. B.2

B.3 Normalization of Excreta Bioassay Data ….................................................................. B. B

B.4 Treatment of Recounted Data Before Using It with Once-Counted Samples ..................... B. B.3

B.5 Uncertainty of Daily Excretion Estimate for Use in Intake Estimate Calculations.............. B.4

B.6 Curve-Fitting Techniques ....................................................................................... B. B

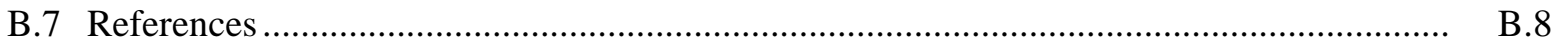




\section{Appendix B}

\section{Statistical Methods for Internal Dosimetry}

The Hanford Internal Dosimetry Program (HIDP) uses statistical methods to interpret bioassay data. Some of the principal statistical methods used by the HIDP are described in this appendix, including those used to 1) determine when a sample result indicates the presence of something (i.e., when the analyte is detected), 2) describe the overall capability of the bioassay method for continual assurance of detection of the analyte, 3) normalize data, and 4) fit data to retention or excretion functions to calculate intake. An additional issue is the determination that a detected analyte is significantly different from the normal presence of that analyte in a sample due to natural background. This latter item is particularly important for uranium in urine and is discussed in that context in Chapter 7.0.

The HIDP follows the concepts of critical level of decision, $\mathrm{L}_{c}$, (also called the decision level, DL) and minimum detectable amount (or activity) MDA (also called detection level, $\mathrm{L}_{\mathrm{d}}$, or lower limit of detection, LLD in various publications), as described by Currie $(1968,1984)$, the Health Physics Society (HPS 1996), and many others.

\section{B.1 Decision Level}

The $L_{c}$ is the parameter that is used to indicate that an analyte has been detected. The $L_{c}$ is dependent on the probability of obtaining false positive results (i.e., the probability of a type I error) that one is willing to accept. Decision levels for in vivo measurements are determined as described in the In Vivo Monitoring Project Manual. ${ }^{1}$ Decision levels for excreta samples are described below.

Until April 2000, the decision levels by which excreta samples containing elevated quantities of radioactive material were identified were all specified in the contract with the analytical laboratory as absolute activity values. The contract specified a contract limit (CL) as an upper bound for the MDA for each analysis and established the decision level at one-half of the CL. For most alpha spectrometry analyses the CL was $0.02 \mathrm{dpm}$ per sample. The decision level was applied to the activity result, rather than the count data. The detection criterion was therefore insensitive to sample-specific variables such as chemical yield and detector efficiency.

To select a better procedure, an investigation of the Health Physics Society American National Standard HPS N13.30 (HPS 1996) and other proposed decision level equations was initiated. The investigation concluded that the N13.30 equation significantly underestimates the number of false positive results (MacLellan 2000). The maximum number of false positive results peaks at about one background count during the counting period, but remains significant up to an expected 100 counts. The N13.30 equation answers the question, "How large a net count will be expected, less than 'alpha' percent of the time, for a given background count rate if there is no activity in the sample?” An equation proposed by Altshuler and Pasternack (1963) was found to be far superior:

\footnotetext{
${ }^{1}$ Pacific Northwest National Laboratory (PNNL). In Vivo Monitoring Program Manual. PNL-MA-574, Richland, Washington. (Internal manual.) 


$$
\Delta_{1}=\mathrm{k}_{\alpha} \sqrt{2 \mathrm{n}_{\mathrm{b}}}\left(\frac{\mathrm{k}_{\alpha}}{\sqrt{8 \mathrm{n}_{\mathrm{b}}}}+\sqrt{1+\frac{\mathrm{k}_{\alpha}^{2}}{8 \mathrm{n}_{\mathrm{b}}}}\right)
$$

where $\Delta$ is the decision level, $\mathrm{k}_{\alpha}$ is the false positive error term, and $\mathrm{n}_{\mathrm{b}}$ is the background count. That equation answers the question "How much activity can be in a sample, and the confidence interval for the net count still include zero?” The decision level obtained from the Altshuler and Pasternack equation remains unbiased down to an expected three counts during the counting period.

For alpha spectrometry analyses, the concept of the Altshuler and Pasternack equation was adopted for the Hanford bioassay program, but an additional simplification was incorporated. Although the form of the equation investigated previously calculates the decision level based only on the number of expected background counts, the original form of the equation used in the derivation equates the decision level with a multiple of the standard deviations estimate of a net count value $\left(\Delta_{1}\right)$. That is, the decision level is derived from the following equation:

$$
\Delta_{1}=\mathrm{k}_{\alpha} \sqrt{\mathrm{n}_{\mathrm{g}}+\mathrm{n}_{\mathrm{b}}}=\mathrm{k}_{\alpha} \sqrt{\Delta_{1}+2 \mathrm{n}_{\mathrm{b}}}
$$

where $\left(n_{g}+n_{b}\right)$ is used as the estimate of the net count variance, $n_{g}$ is the gross count, and $n_{b}$ is the background count. Equation (B.1) was derived by solving Equation (B.2) for $\Delta_{1}$. Hanford denotes the decision level by $\mathrm{L}_{\mathrm{c}}$ rather than the $\Delta_{1}$ used in Equations (B.1) and (B.2).

Equations (B.1) and (B.2) are based on counts; however, the Hanford bioassay contract requires an estimate of the combined standard uncertainty (CSU) for each result reported. (CSU was formerly referred to in HPS N13.30 (1996) as the total propagated uncertainty. CSU is now the technically preferred term.) A sample-specific decision level has been implemented based on the CSU. Rather than using Equation (B.1), Hanford alpha spectrometry decision levels are set from Equation (B.2), substituting the CSU for the radical. A $\mathrm{k}_{\alpha}$ value of 2 was chosen to maintain the average decision level near historic levels. The decision level, $\mathrm{L}_{\mathrm{c}}$, then takes the following simple form:

$$
L_{c}=2 \times C S U
$$

Any sample result that is equal to or greater than the $\mathrm{L}_{\mathrm{c}}$ is considered positive, i.e., the analyte has been detected. It is inherent in this method that when dealing with large numbers of samples some samples containing no activity will be declared positive. Using the above criteria, about $2 \%$ of the results are expected to be false positives assuming a normal distribution of the net count.

\section{B.2 Minimum Detectable Amount}

The minimum detectable amount (or activity) (MDA) provides a statement of the overall capability of the bioassay method to provide continual assurance of analyte detection. The MDA is a function of the probabilities of both false positive and false negative (type II error) results. For excreta bioassay results, the probability of each kind of error is set at 5\%. The MDA is determined annually from analysis of blank samples, using the methods of HPS N13.30 (1996). Annual MDAs are compared with values set by contract with the bioassay laboratory. (The MDAs must be less than contractual detection levels or 
corrective action is required.) It is the contractual detection levels that are referenced throughout this document because only the contractual detection levels are enforceable and are generally applicable over long periods of time. At any time though, actual MDAs are usually somewhat lower than the contractual detection levels quoted in this document.

Determinations of in vivo measurement MDAs are described in the In Vivo Monitoring Project Manual. (Lynch 2007)

\section{B.3 Normalization of Excreta Bioassay Data}

Excreta bioassay data may be normalized differently according to the sample type. Generally, urine data are normalized to total 24-hour excretion based on the sampling protocol. Total urine sampling for 24 hours does not require normalization; however, that protocol is generally not convenient for workers. Thus, an approximate 24-hour sample is generally used. The approximate 24-hour sample protocol (historically referred to as a "simulated 24-hour collection") involves collecting all urine voided between 0.5 to 1 hour before retiring at night through the first voiding after getting up in the morning; this is done for two consecutive nights. Provided that the sample is collected properly, a total or approximate 24-hour urine sample result is used as is; no further normalization is done. An overnight sample is considered to represent approximately 12 hours of urine collection and is normalized by doubling the result. Alternate normalization methods are described in Chapter 2.0 and may be used if they are more appropriate for the actual data.

\section{B.4 Treatment of Recounted Data Before Using It with Once-Counted Samples}

Results from samples that have been recounted should not be used directly with results from oncecounted samples in analysis programs. The best estimate of the mean value of the recounted sample and the best estimate of the uncertainty of the mean value need to be determined first so that each sample has

only one value. The mean value $\left(\mathrm{x}_{\text {avg }}\right)$ should be calculated in accordance with the formula for a weighted average:

$$
x_{\text {avg }}=\frac{\sum_{i=1}^{n} w_{i} x_{i}}{\sum_{i=1}^{n} w_{i}}
$$


where $\mathrm{x}_{\mathrm{i}}$ is each measurement result and $\mathrm{w}_{\mathrm{i}}$ is the associated weighting factor. The recommended weighting factor $\left(\mathrm{w}_{\mathrm{i}}\right)$ is the reciprocal of the variance of the measurement (i.e., the square of the combined standard uncertainty, $s_{i}^{2}$ ), and the mean value should be determined by the following formula:

$$
x_{\text {avg }}=\frac{\sum_{i=1}^{n} \frac{x_{i}}{s_{i}^{2}}}{\sum_{i=1}^{n} \frac{1}{s_{i}^{2}}}
$$

The best estimate of the uncertainty of the mean value should be determined by the following formula for a weighted uncertainty:

$$
\mathrm{s}_{\mathrm{avg}}=\sqrt{\frac{1}{\sum_{\mathrm{i}=1}^{\mathrm{n}} \frac{1}{\mathrm{~s}_{\mathrm{i}}^{2}}}}
$$

where $s_{i}$ is the combined standard uncertainty associated with each measurement.

This approach provides consistency in the way recounted sample data are used in dose assessments, and prevents recounted data from acquiring unwarranted weight relative to once-counted data for curvefitting purposes.

\section{B.5 Uncertainty of Daily Excretion Estimate for Use in Intake Estimate Calculations}

Other than hand-calculated intake estimates based on tabulated excretion or retention functions, the uncertainty of the bioassay result should be included in the intake estimate process. If an uncertainty estimate is not reported, an uncertainty estimate has to be assumed. The assumptions used to estimate the errors will have varying effects on the intake estimate. Consider the following when selecting a measurement error assumption:

- Selecting a Uniform Absolute assumption assigns a constant value to all included bioassay results regardless of the absolute values. Use of the Uniform Absolute assumption is not recommended.

- Selecting a Uniform Relative assumption assigns measurement errors equal to a constant times the measurement value. The Uniform Relative assumption should be used if the uncertainty of the sampling protocol predominates over the measurement uncertainty for the entire range of the bioassay data.

- Selecting the Square Root assumption assigns measurement errors equal to a constant times the square root of the measurement value, and should be used when counting statistics predominate.

For alpha spectrometry results less than $0.05 \mathrm{dpm}$, counting uncertainty predominates. If an uncertainty estimate is not provided with the result it should be estimated using the Square Root assumption. A multiplier of 0.35 for fecal bioassay results or 0.07 for urine bioassay results is recommended. For alpha 
spectrometry results greater than or equal to $0.05 \mathrm{dpm}$, the sampling uncertainty predominates and the Uniform Relative assumption is recommended. Use a multiplier of 0.55 for fecal results or 0.35 for urine results. For ${ }^{90} \mathrm{Sr}$ or total strontium results, the Square Root assumption with a multiplier of 1.0 is recommended for all results.

The uncertainty estimates reported with in vivo bioassay measurement may be considered the total uncertainty of the analysis, but the uncertainty estimates reported with excreta bioassay data do not include an important component of the daily excretion uncertainty, the collection period uncertainty. The distribution of the fraction of the daily excretion collected may be assumed to be normally distributed with a mean of 1 and standard deviation of 0.25 for urine samples and 0.5 for fecal samples.

The total uncertainty of the daily excretion value may then be found as follows when a normal distribution is assumed:

$$
\text { Daily Excretion Uncertainty }=A \sqrt{\frac{s_{A}^{2}}{A^{2}}+\frac{S_{S F}^{2}}{S F^{2}}}
$$

where A equals the analytical result, $\mathrm{s}_{\mathrm{A}}$ equals the combine standard uncertainty of the analytical result, SF equals the sample collection fraction (assumed to be 1), and $\mathrm{s}_{\mathrm{SF}}$ equals the standard deviation of the sample collection fraction.

\section{B.6 Curve-Fitting Techniques}

In all cases, outliers, or data that are not relevant to the equation being fit, should not be included in a fitting technique. Examples would include urine data influenced by diethylene triamine penta acetic acid (DTPA) therapy or a datum with a very high less-than result. The assessment should document which data are being ignored and why. As described in Section B.5 above, the uncertainty associated with excreta bioassay data should include the sample collection period uncertainty.

When multiple data are obtained following an intake, some kind of curve fit is performed to fit an appropriate retention or excretion function to the data. The weighted least-squares fit is appropriate when two results of the measurement process are known, i.e., the result itself (whether zero, negative, or positive), $x_{i}$, and its variance, $\sigma^{2}$, and when the variances are all determined in the same manner. The weighting factor is the inverse of the sum of the variances. The intake is given by

$$
I=\frac{\sum_{i=1}^{n} \frac{x_{i} r_{i}}{\sigma_{i}^{2}}}{\sum_{i=1}^{n} \frac{r_{i}^{2}}{\sigma_{i}^{2}}}
$$

where $r_{i}$ is the value of the fractional retention or excretion function at the same time after intake as the sample result $\mathrm{x}_{\mathrm{i}}$ (Bevington 1969). Use of the weighted least-squares fit avoids having the calculation of intake or uptake dominated by a few large data points that may have poor precision, such as a hastily analyzed urine sample collected shortly after an intake. 
If the variances are unknown, are known to be equal, or were determined differently (such as counting uncertainty versus total propagated uncertainty), then the unweighted (or uniform weighting) least-squares fit is appropriate for use. The unweighted least-squares fit is represented by Equation (B.8) when all variances are set equal to one, or as shown below:

$$
I=\frac{\sum_{i=1}^{n} x_{i} r_{i}}{\sum_{i=1}^{n} r_{i}^{2}}
$$

Data that are listed only as "less than" some value are difficult to use in a mathematical fitting technique. At times, the HIDP has arbitrarily set the value for the measurement as one-half of the less-than value for use in least-squares fitting techniques. This does not work well if too many of the data are lessthan values. If there are many less-than values and a few well-known data, then the dosimetrist may need to use only the well-known data in the least-squares fitting technique, making sure that the best fit does not seem unreasonable with regard to the many less-than data. The Integrated Modules for Bioassay Analysis (IMBA) Professional Plus internal dosimetry computer code is capable of using "less than" results directly.

An "eye-ball” fit consists of plotting a line through a data set and graphically extracting the required intercepts and slope. This approach involves subjective judgment by the dosimetrist and is not an objective statistical fit. Caution must be used in exercising eye-ball fits, because the quality of data obtained will vary depending on the type of axis (linear, logarithmic).

Because the Hanford Radiological Health and Safety Document (DOE RL 2001) defines dose assessment as the "process of determining radiation dose and uncertainty [emphasis added] included in the dose estimate ... ., it is recommended that IMBA be used to estimate the uncertainty in the intake estimate, which can be carried over to the dose estimate by assuming that the dose conversion factors have no uncertainty (i.e., are givens). If none of the bioassay quantities are "less than," the least squares fitting method will produce the same intake estimate as the maximum likelihood method to less than $1 \%$ difference. The least squares fitting method gives the standard error of the calculated intake, which is shown below the intake estimate. The least squares fitting method can only be used when

- you are fitting a single intake

- real uncertainties are given for each data point

- you are fitting only one bioassay quantity.

However, because of the limitations listed above for the least squares fitting method, it is usually preferable to use IMBA's maximum likelihood fitting method with the Bayesian approach for determining probability distribution functions.

The Bayesian approach requires the dosimetrist to select an assumed distribution for the probability of an intake (the Prior Probability Distribution). Regardless of the Prior Probability Distribution chosen, the range for the distribution must be large enough to include the estimated intake value. For example, if the uniform Prior Probability Distribution is chosen with a range 0 to $100 \mathrm{~Bq}$, then IMBA would not be 
able to predict an intake of $200 \mathrm{~Bq}$ because it lies outside the specified range. Outside the specified range, the probability is always zero. Consider the following when choosing a Prior Probability Distribution:

- A Uniform Prior Probability Distribution for an intake is used in cases where nothing is known about the amount of intake before a measurement is made. All values for an intake within a specified range are considered equally likely. If this Prior Probability Distribution is chosen, the minimum and maximum of the range of probable intakes are specified by the user.

- An Inverse Prior Probability Distribution is used when the probability of observing an intake between 10 and 100 is the same as observing an intake between 100 and 1000, or 1,000 and 10,000. The prior probability distribution of intake is then defined by $\mathrm{P}(\mathrm{I}) \mathrm{dI}=\mathrm{I}^{-1}$. If this Prior Probability Distribution is chosen, the minimum and maximum of the range of probable intakes are specified by the user.

- A Gaussian Prior Probability Distribution is used when it is believed the intake is likely to be distributed normally about a mean. If this Prior Probability Distribution is chosen, the mean and standard deviation of the Prior Probability Distribution are specified by the user.

- A Lognormal Prior Probability Distribution is used when the intake is likely to be distributed lognormally about a median (i.e., geometric mean). If this Prior Probability Distribution is chosen, the median and geometric standard deviation of the Prior Probability Distribution are specified by the user.

- The Alpha Prior Probability Distribution was developed at Los Alamos National Laboratory for applications where a routine bioassay monitoring program is in place, and experience has shown that substantial intakes are relatively rare (e.g., occurring on the order of 1 in 1,000 monitoring intervals). If this Prior Probability Distribution is chosen, the parameter values specified by the user are alphadelta $t$ (the product of the probability per unit time and a finite time interval), and Imax (the maximum probable intake).

Because HIDP procedures specify the calculation of intake estimates only for confirmed intakes, the Prior Probability Distribution selected should be appropriate for a non-routine scenario that has been investigated by HIDP. Generally, it should not reflect the probability of an intake for the general worker population. Therefore, the Alpha Prior Probability Distribution is not recommended. Rather, a Gaussian distributed excretion rate distribution assumption is recommended because it provides the best opportunity for weighting of individual measurement values. However, when multiple bioassay results are used for the intake estimate, the Prior Probability Distribution chosen has little effect on the Posterior Probability Distribution as long as the Prior Probability Distribution extends well beyond the intake estimate.

Early in the dose estimation process when there may be only a single bioassay result available, the IMBA Bayesian Analysis Tool can be used to predict a range of intake estimates and associated dose estimates. Such a range is often requested by Contractor personnel. The Uniform Prior Probability Distribution is recommended for this preliminary estimate. As additional bioassay data are obtained, the prediction range should be refined by rerunning the intake estimates and Posterior Probability Distribution prediction. If the preponderance of the evidence collected for the evaluation (e.g., bioassay, work place monitoring, etc.) supports the current intake estimates, the dosimetrist should consider alternate Prior Probability Distributions. The Gaussian Prior Probability Distribution with the mean set equal to the Intake Estimate and the standard deviation set at $40 \%$ relative uncertainty is suggested. 
The dose calculated from the intake estimate obtained using the maximum likelihood method should be used for compliance purposes. The Posterior Probability Distribution is only used to estimate the confidence interval of the intake estimate. The confidence interval of the dose may be obtained from the bounds of the confidence intervals for the intake regimes.

\section{B.7 References}

Altshuler B and B Pasternack. 1963. "Statistical measures of the lower limit of detection of a radioactivity counter.” Health Phys. 9:293-298.

Bevington PR. 1969. Data Reduction and Error Analysis for the Physical Sciences, pp. 69-73. McGraw-Hill Book Company, New York, New York.

Currie LA. 1968. "Limits for qualitative detection and quantitative determination." Analytical Chemistry 40(3):586-593.

Currie LA. 1984. Lower Limit of Detection: Definition and Elaboration of a Proposed Position for Radiological Effluent and Environmental Measurements. NUREG/CR-4007, U.S. Nuclear Regulatory Commission, Washington D.C.

DOD, DOE, EPA, DHS, FDA, USGS, NIST, and NRC. 2004. Multi-Agency Radiological Laboratory Analytical Protocols Manual (MARLAP), Revision 0, NUREG-1576, NTIS PB2004-105421, EPA 402-B04-001C: Part II: Chapters 18-20. Washington, D.C.

Health Physics Society (HPS). 1996. Performance Criteria for Radiobioassay. ANSI/HPS N13.301996, Health Physics Society, McLean, Virginia.

Lynch TP. 2007. In Vivo Monitoring Program Manual. PNL-MA-574, Pacific Northwest Laboratory, Richland, Washington. (Internal Manual.)

MacLellan JA. 2000. Hanford's Decision Level for Alpha Spectrometry Bioassay Analyses Based on the Sample Specific Total Propagated Uncertainty. PNNL-SA-33598, Pacific Northwest National Laboratory, Richland, Washington.

Strom DJ and JA MacLellan. 2001. "Evaluation of Eight Decision Rules for Low-Level Radioactivity Counting.” Health Physics 81(1):27-34.

U.S. Department of Energy Richland Operations Office (DOE-RL). 2001. Hanford Radiological Health and Safety Document. Richland, Washington. 


\title{
Methods and Models of the Hanford Internal Dosimetry Program
}

PNNL-MA-860

\author{
Appendix C, Biokinetic Models
}

Issued for implementation effective $01 / 01 / 2010$

Supersedes: January 2003

Use Category: Not applicable

Approval Signatures:

Prepared by: $\frac{\text { Dowald Bihl, Scientist }}{\text { BE Bikl }}$

Approved by:

Reviewer Signatures:

Reviewed by:

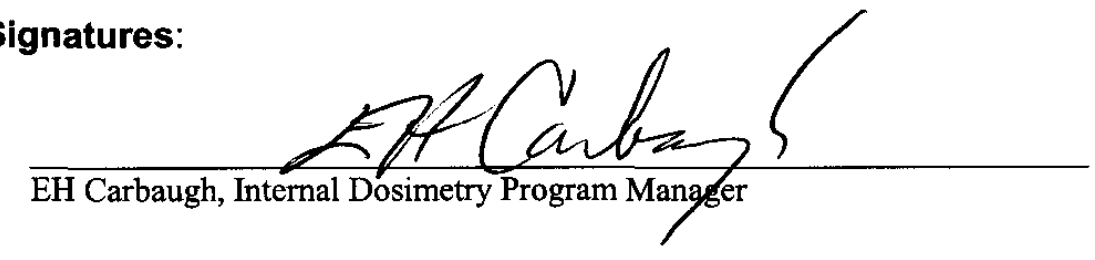

Approved by the Hanford Personnel Dosimetry Advisory Committee as recorded in the meeting minutes of June 10, 2008. 


\section{Contents}

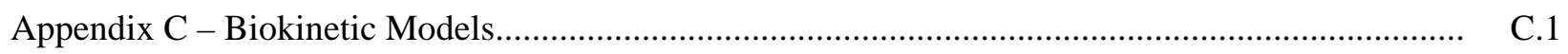

C.1 ICRP Respiratory Tract Model …............................................................................. C.1

C.1.1 HRTM Deposition Model..................................................................................... C.2

C.1.2 HRTM Particle Clearance Model..................................................................... C.5

C.1.3 HRTM Absorption into Blood …….................................................................... C.6

C.1.4 Modifying Factors for HRTM Parameters …...................................................... C.8

C.2 The Gastrointestinal Tract Model …........................................................................... C.8

C.3 Systemic Models .................................................................................................... C.9

C.4 Fecal Sampling Model ....................................................................................... C.12

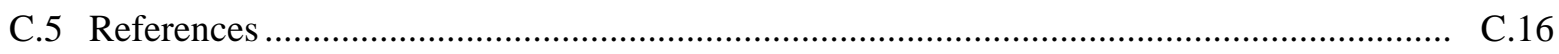

\section{Figures}

C.1 Major Regions of the Respiratory Tract Used in the Human Respiratory Tract Model .............. C.2

C.2 Compartment Model Representing Time-Dependent Particle Transport from Each Respiratory Tract Region

C.5

C.3 Standard Compartment Model Representing Time-Dependent Dissolution in the Respiratory Tract Followed by Instantaneous Uptake to Blood.

C.4 Alternate Compartment Model Representing Time-Dependent Dissolution in the Respiratory Tract Followed by Instantaneous Uptake to Blood ............................................ C.7

C.5 Biokinetic Model for the Gastrointestinal Tract ...................................................................... C.9

C.6 Systemic Model for Strontium and Radium ....................................................................... C... 10

C.7 Systemic Model for Thorium, Neptunium, Plutonium, Americium, and Curium ...................... C.11

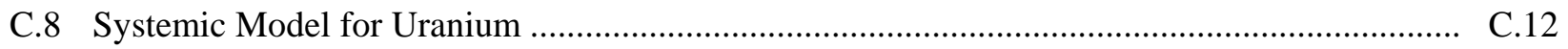

C.9 Comparison of Fecal Excretion Between 250 pCi Inhalation Type $\mathrm{M}^{239} \mathrm{Pu}, 100 \mathrm{pCi}$ Ingestion Moderately Soluble ${ }^{239} \mathrm{Pu}\left(f_{1}=5 \mathrm{E}-04\right), 250 \mathrm{pCi}$ Inhalation Type $\mathrm{S}^{239} \mathrm{Pu}$, and

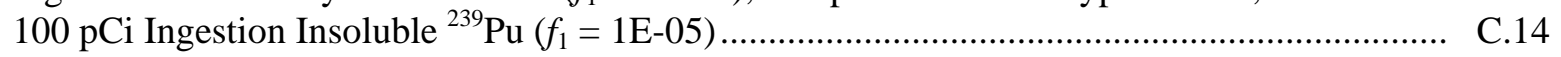

C.10 Effect of Particle Size on Fecal Excretion for Type $\mathrm{M}^{239} \mathrm{Pu}$............................................... C.. 15

\section{Tables}

C.1 Deposition of Inhaled Aerosols by an Adult, Nose-Breathing Male Undergoing Light Exercise.

C.2 Default Absorption Parameters for the Standard Representation of the Absorption Model ......... C.7

PNNL-MA-860 Appendix C

Page C.ii
Issued for implementation effective 01/01/2010

Supersedes: September 30, 2000 
C.3 Default Absorption Parameters for the Alternate Representation of the Absorption Model.........

C.4 Fraction of Intake Excreted via Feces Following an Acute Inhalation of Poorly Absorbed

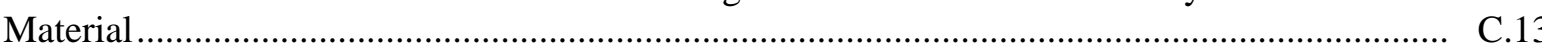





\section{Appendix C}

\section{Biokinetic Models}

Biokinetic models are used to describe the initial deposition, and subsequent movement and retention of material throughout the body. The Hanford Internal Dosimetry Program (HIDP) seeks to use realistic and generally accepted, peer-reviewed biokinetic models to the extent practicable. General models applicable to any element include the respiratory tract and gastrointestinal tract models that are described in this appendix. The International Commission on Radiological Protection (ICRP) introduced a physiologically based systemic model, also referred to as a recycling model, for a number of elements in a series of its publications including ICRP 56, 67, 68, 69, 71, 72, and 78 (1989, 1993, 1994a, 1995a, 1995b, 1996, 1997). The generic aspects of the physiologically based model are described in this appendix and element-specific factors are described in the element-specific chapters.

A computer code is typically required to implement these models for routine use. The HIDP has adopted the Integrated Modules for Bioassay Analysis (IMBA) Professional Plus internal dosimetry computer code. ${ }^{1}$ This appendix discusses how significant aspects of the general models are or can be implemented using IMBA. The radioelement specifics of the biokinetic models are addressed in the pertinent radioelement chapters of this manual. The biokinetic models are presented for stable elements; however, simple radiological decay information is incorporated into IMBA for radioactive isotopes.

\section{C.1 ICRP Respiratory Tract Model}

The HIDP uses the ICRP 66 (1994b) Human Respiratory Tract Model (HRTM). Additional guidance on use of the HRTM is found in "Guide for the Practical Application of the ICRP Human Respiratory Tract Model” (ICRP 2002b), also referred to as Supporting Guidance 3 document. The HRTM divides the respiratory tract into five regions as shown in Figure C.1. The extrathoracic (ET) airways in the head are divided into the front of the nasal passages, $\mathrm{ET}_{1}$, and the posterior nasal and oral passages, pharynx and larynx, $\mathrm{ET}_{2}$. The thoracic regions consist of the bronchial (generations 0-8), which includes the trachea and bronchi; the bronchiolar (generations 9-15), consisting of the bronchioles; and the alveolarinterstitial where the gas exchange occurs, which includes alveolar ducts and sacs with their alveoli and the interstitial connective tissue (James et al. 2004). The abbreviations for the three thoracic regions are $\mathrm{BB}, \mathrm{bb}$, and AI, respectively. Subscripts for these regions are used to designate specific components or clearance pathways. The $\mathrm{ET}_{2}, \mathrm{BB}$, bb, and $\mathrm{AI}$ have lymphatic tissue associated with them modeled as drainage from the extrathoracic region, $\mathrm{LN}_{\mathrm{ET}}$, and drainage from the three thoracic regions, $\mathrm{LN}_{\mathrm{TH}}$ (ICRP 1994b, 1997).

\footnotetext{
${ }^{1}$ IMBA Professional Plus, which includes the current version of the user manual, is available from Health Protection Agency (HPA), Radiation Protection Division, Chilton, Didicot, Oxon., OX11 ORQ UK and from http://www.imbaprofessional.com/
} 


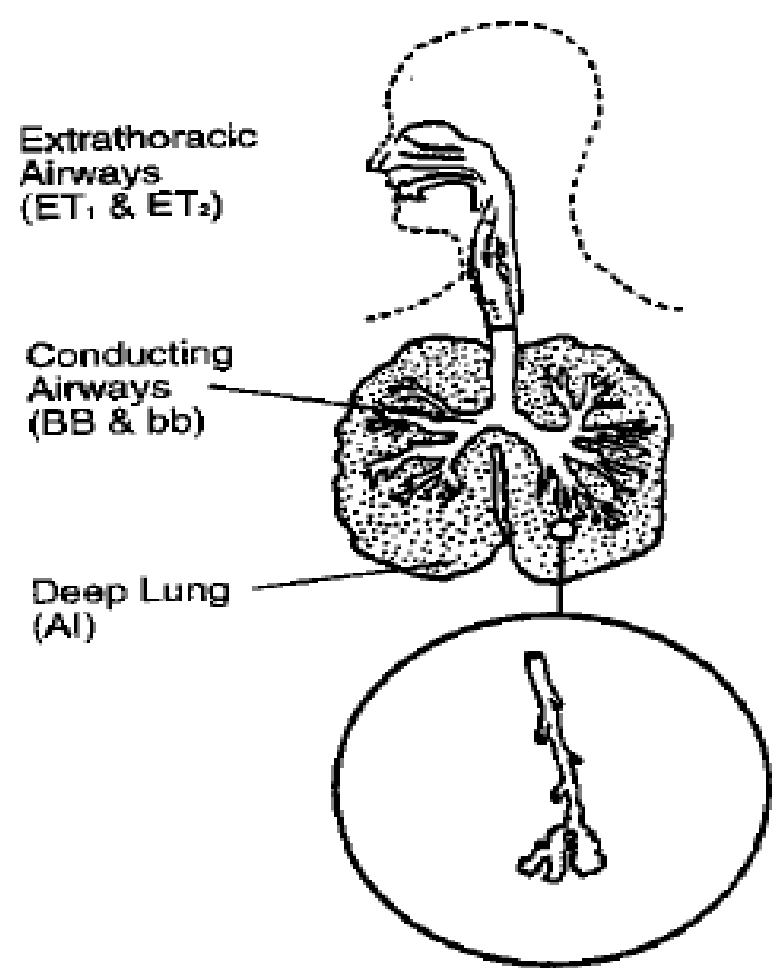

Figure Error! No text of specified style in document..1. Major Regions of the Respiratory Tract Used in the Human Respiratory Tract Model

The HRTM is comprised of three submodels: one that addresses inhalation of gases, vapors, and particles and deposition of particles into various regions of the respiratory tract; one that addresses movement of particles from the respiratory tract; and one that addresses dissolution of particles and absorption into body fluids.

\section{C.1.1 HRTM Deposition Model}

Detailed discussion of the deposition of particles in the respiratory tract can be found in ICRP 66 (1994b) and ICRP 78 (1997). The deposition model provides deposition of an aerosol in each of the five respiratory regions as a fraction of intake for particle sizes ranging from 0.0006 to $100 \mu \mathrm{m}$. For the ET regions, fractional deposition is related to particle size and airflow, and can be scaled by anatomical dimensions. For the thoracic airways, a theoretical model of gas transport and particle deposition is used to calculate deposition in the BB, bb, and AI regions, and to quantify the effects of the worker's lung size and breathing rate. To model particle deposition, the regions are treated as a series of filters, during both inhalation and exhalation. The efficiency of each is evaluated by considering aerodynamic and thermodynamic processes acting competitively. Aerodynamic processes are gravitational settling and inertial impaction and predominate for particle sizes greater than about $0.5 \mu \mathrm{m}$. The thermodynamic process is diffusion and predominates at particle sizes less than $0.5 \mu \mathrm{m}$. The respective terms applied to these particle sizes are the activity median aerodynamic diameter (AMAD) and the activity median thermodynamic diameter (AMTD), with the change in terminology occurring at nominally $0.5 \mu \mathrm{m}$. 
Regional deposition fractions are calculated for aerosols having lognormal particle size distributions, with geometric standard deviations, $\sigma_{\mathrm{g}}$, determined as a function of the median particle diameter, increasing from a value of 1.0 at $0.0006 \mu \mathrm{m}$ to 2.5 at $100 \mu \mathrm{m}$. ICRP recommends a default particle size of $5-\mu \mathrm{m}$ AMAD for radiation workers. Table C.1 shows the percent deposition relative to intake of 5- $\mu \mathrm{m}-$ AMAD particles in the five respiratory tract regions for an adult, nose-breathing male undergoing light exercise. Deposition of particles is not dependent on the elemental composition nor on the chemical compound per se, although these characteristics can affect the particle density. The geometric standard deviation for the 5- $\mu \mathrm{m}$ AMAD is 2.4977233. The geometric standard deviation is essentially 2.5 at three significant figures for particle sizes of $3 \mu \mathrm{m}$ and greater. The ICRP allows for use of workplace- or intake-specific particle size distributions, and IMBA allows the particle size to be changed from the default by the user. IMBA has a built-in calculator of the geometric standard deviation that should be used whenever the particle size is different than $5 \mu \mathrm{m}$. The HRTM also takes into account two other physical particle parameters: the density and the shape factor. The ICRP recommends a default density of $3 \mathrm{~g} / \mathrm{cm}^{3}$ and a default shape factor of 1.5 (ICRP 1994b, p.49). However, the ICRP offers little guidance on when or how to change these parameters.

Table Error! No text of specified style in document..1. Deposition of Inhaled Aerosols by an Adult, Nose-Breathing Male Undergoing Light Exercise (from ICRP 1997, Table 1)

\begin{tabular}{|c|c|}
\hline Region & $\begin{array}{c}\text { Deposition as \% of Intake for } \\
5-\mu \mathrm{m} \text {-AMAD Particles }\end{array}$ \\
\hline $\mathrm{ET}_{1}$ & 34 \\
\hline $\mathrm{ET}_{2}$ & 40 \\
\hline BB & 1.8 \\
\hline bb & 1.1 \\
\hline AI & 5.3 \\
\hline Total & 82 \\
\hline
\end{tabular}

The HRTM can be adjusted for breathing rate, size or gender, and whether the worker was a nasal breather or mouth breather at the time of the inhalation. Table 15 in ICRP 66 (ICRP 1994b) provides various anatomical and physiological parameters affecting regional deposition as a function of age, gender, and four breathing rates (characterized as sleeping, sitting, light exercise, and heavy exercise). The ICRP default worker is a nose breathing adult male undergoing light exercise. The ICRP defines ventilation rates for sleep $\left(0.45 \mathrm{~m}^{3} / \mathrm{h}\right)$, rest or sitting $\left(0.54 \mathrm{~m}^{3} / \mathrm{h}\right)$, light exercise $\left(1.5 \mathrm{~m}^{3} / \mathrm{h}\right)$ and heavy exercise $\left(3.0 \mathrm{~m}^{3} / \mathrm{h}\right)$. The rest, light exercise, and heavy exercise ventilation rates are used to define occupational work activities of light work $\left(9.6 \mathrm{~m}^{3}\right.$ per 8 -h day) and heavy work (13.5 $\mathrm{m}^{3}$ per 8-h day). The light worker is defined as performing $5.5 \mathrm{~h}$ of light exercise and $2.5 \mathrm{~h}$ of rest or sitting, averaging out to $1.2 \mathrm{~m}^{3} / \mathrm{h}$ for an 8 -h day. The heavy worker is defined as $7 \mathrm{~h}$ of light exercise and $1 \mathrm{~h}$ of heavy exercise, averaging out to $1.7 \mathrm{~m}^{3} / \mathrm{h}$ for an 8 -h day.

IMBA allows the user to choose between a "light worker" $\left(1.2 \mathrm{~m}^{3} / \mathrm{h}\right.$ average breathing rate) and a "heavy worker" $\left(1.7 \mathrm{~m}^{3} / \mathrm{h}\right.$ average breathing rate). For acute intakes when the intake period is approximately an hour or less, the dose assessment might be improved if the "heavy worker" option is used, which really means the worker was breathing at the light exercise rate for this short period of the intake. The impact on dose from the two breathing rate options was investigated. For inhalation of both Type M

Issued for implementation effective 01/01/2010 
(for moderate rate of solubilization) and Type S (for slow) plutonium, using reference worker parameters except for the breathing rate and a particle density ${ }^{1}$ of $15 \mathrm{~g} / \mathrm{cm}^{3}$, the lung committed equivalent doses for a unit excretion rate in urine at times after intake varying from 10 to 730 days showed significant differences between the breathing rates: $23 \%$ to $37 \%$ for Type $M$, and $45 \%$ to $57 \%$ for Type S. Other organ dose differences were less than $10 \%$ as were the differences for effective dose for Type M. However, for Type $\mathrm{S}$ the differences for effective dose varied between $13 \%$ to $26 \%$. Based on these examples, it is recommended that the heavy worker option be used for short acute intakes, unless it is known that the worker was resting (the ICRP also calls this "sitting") at the time of the intake. For chronic exposure or intakes occurring over a period of an hour or more, the light worker may better reflect the breathing pattern.

Breathing rates are especially critical when intakes are calculated from air concentrations and exposure times, and differences should definitely be taken into account for those calculations. It would be especially important to use the breathing rate for heavy exercise of $3.0 \mathrm{~m}^{3} / \mathrm{h}$ instead of the default $1.2 \mathrm{~m}^{3} / \mathrm{h}$ if heavy exercise was appropriate for the situation.

IMBA also allows the user to input different particle densities. The effect of using particle densities commonly associated with plutonium or uranium metals or compounds was investigated. Organ and effective doses using densities of 10,15 , and $19 \mathrm{~g} / \mathrm{cm}^{3}$ were compared to doses associated with the default $3 \mathrm{~g} / \mathrm{cm}^{3}$. Inhalation of Type $\mathrm{M}$ and $\mathrm{S}$ plutonium were used for the comparison, based on a unit excretion rate in urine at times after intake varying from 10 to 730 days. All other parameters were the default values. The differences in committed equivalent lung doses ranged from $20 \%$ to $25 \%$ for Type $\mathrm{M}$ and $10 \%$ to $14 \%$ for Type S. Differences for all other organs and effective dose were $<10 \%$. Logically, if the calculations were done based on a unit activity in the lung at various times after intake, the lung dose differences would be insignificant, but the dose differences for systemic organs might be significant. Relative to other sources of uncertainty in dose assessments, particle density appears to be marginal, especially if both lung and excretion data are used in the assessment. Figure 4.6 in ICRP Supporting Guidance 3 (2002b) shows that the effect of density on doses is greatest for particle sizes between 0.1- to 1.0- $\mu \mathrm{m}$ AMTD (AMAD); however, those graphs just compare dose coefficients, not doses resulting from unit bioassay measurements. Presumably, basing the comparison by starting from unit bioassay measurements should reduce the impact of the different densities.

In contrast to particles, for gases and vapors, deposition and especially absorption is dependent on the element or compound. The HRTM assigns gases and vapors to three classes of solubility or reactivity:

- Class SR-0 is comprised of gases that are insoluble and nonreactive, often called inert gases (e.g., $\mathrm{H}_{2}$, He, $\mathrm{N}_{2}$ ). For gases assigned to SR-0, it is assumed there is no deposition and no uptake of the gas into tissues or body fluids. This may not be completely true for all gases in this class, but the dose from the minor uptake is considered insignificant relative to dose from the contaminated air in the lung and external radiation from the gas cloud surrounding the worker.

- Class SR-2 is comprised of highly soluble and/or highly reactive gases (e.g., $\mathrm{SO}_{2}, \mathrm{HF}$ ). Gases assigned to class SR-2 are assumed to deposit $100 \%$ in the ET region. There is complete and instantaneous systemic uptake of the gas into body fluids. IMBA models deposition of an SR-2 gas as $100 \%$ in the $\mathrm{ET}_{2}$ region. Tritium as water vapor is assigned to SR-2 with an additional $50 \%$ of the

\footnotetext{
${ }^{1}$ The density of plutonium metal is $19.7 \mathrm{~g} / \mathrm{cm}^{3}$; plutonium nitrate is $14.4 \mathrm{~g} / \mathrm{cm}^{3}$; and $\mathrm{PuO}_{2}$ is $11.5 \mathrm{~g} / \mathrm{cm}^{3}$ (Handbook of Chemistry and Physics, 88th edition, 2007-2008). $15 \mathrm{~g} / \mathrm{cm}^{3}$ was used for illustration.
}

PNNL-MA-860 Appendix C Page C.4
Issued for implementation effective 01/01/2010 Supersedes: September 30, 2000 
uptake assigned to skin absorption (ICRP 1997). Another possibly important set of compounds in this class is carbon dioxide and all organic carbon compounds.

- Class SR-1 is comprised of a broad spectrum of gases with some solubility and/or some reactivity in various combinations that result in partial uptake by airway tissues. The ICRP (1994a, §A2) states that "in the absence of information 100\% deposition is assumed, with the following distribution: $10 \%$ $\mathrm{ET}_{1}, 20 \% \mathrm{ET}_{2}, 10 \% \mathrm{BB}, 20 \% \mathrm{bb}$, and $40 \% \mathrm{AI}$.” These are the default values in IMBA when the vapor intake mode/SR-1 is chosen. Elemental iodine vapor is assigned to this class with deposition of $10 \% \mathrm{ET}_{1}, 40 \% \mathrm{ET}_{2}$, and 50\% BB (ICRP 1994a, §A7).

\section{C.1.2 HRTM Particle Clearance Model}

(The following discussion is derived from ICRP 78 [1997] and Supporting Guidance 3 [2002b]). The compartment model for clearance of particles by means other than dissolution is shown in Figure C.2. Material deposited in $\mathrm{ET}_{1}$ is considered to not progress further into the body and is removed back out of the nose into the environment, such as by nose-blowing. In other regions overall clearance is competitive between movement of particles into the gastrointestinal (GI) tract or into the lymphatic system on one hand and dissolution of particles and absorption into the blood on the other hand. Removal rates associated with particle transport are independent of removal rates by dissolution and absorption. Removal rates associated with particle transport are the same for all materials and are independent of the age and sex of the worker. Default rates $\left(\mathrm{d}^{-1}\right)$ are shown in Figure C.2. IMBA allows the user to change any of the rates in the model.

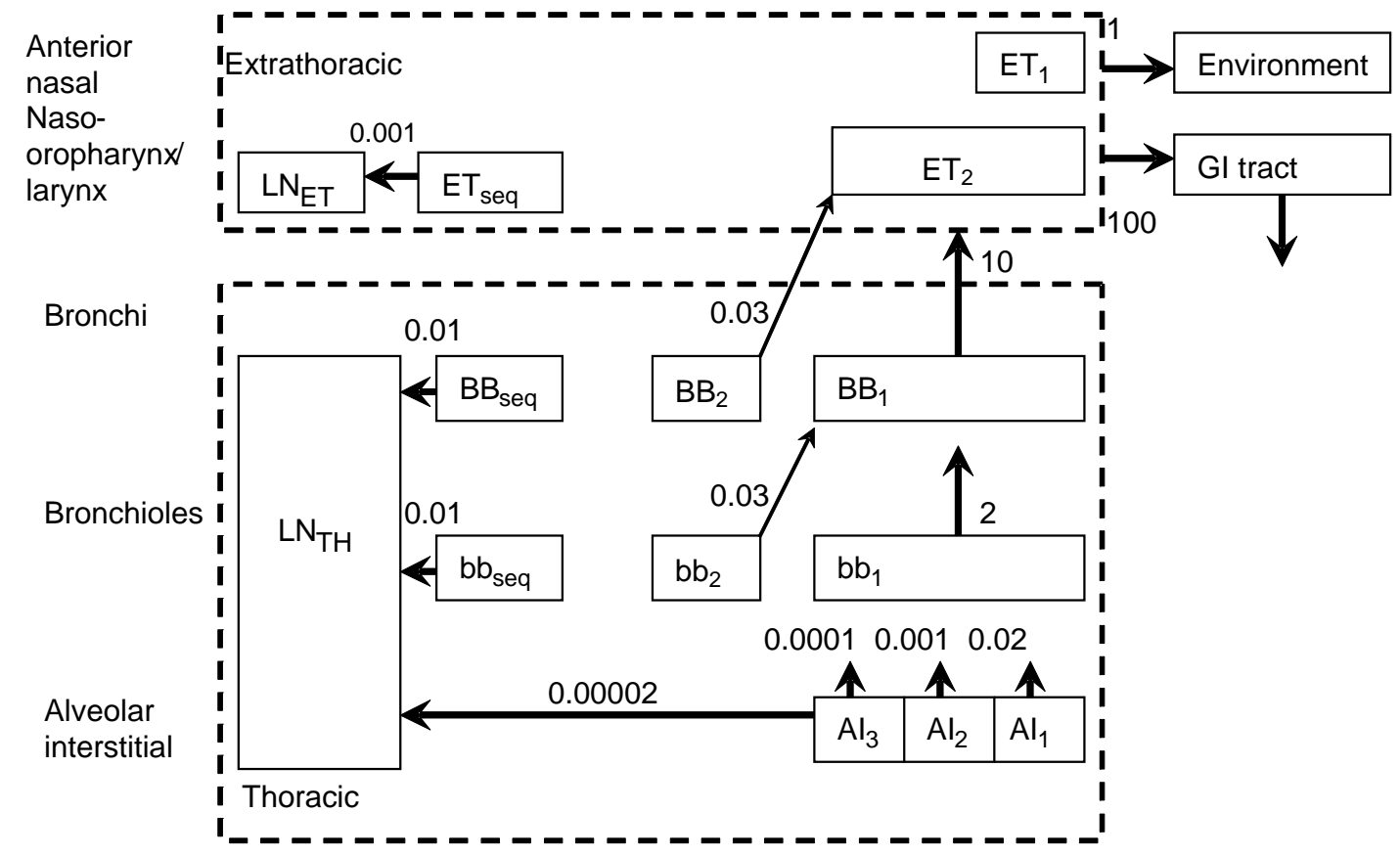

Figure Error! No text of specified style in document..2. Compartment Model Representing TimeDependent Particle Transport from Each Respiratory Tract Region. Rates shown alongside arrows are in units of $\mathrm{d}^{-1}$ (ICRP 1994b). 


\section{C.1.3 HRTM Absorption into Blood}

Movement of deposited material into the blood is modeled as a two-step process: 1) dissolution of the particles into material that can be absorbed, and 2) absorption into the blood of the soluble material. As mentioned, this process is occurring simultaneously with the particle transport process. Unlike the particle transport model, which has different rates for different locations in the respiratory tract, absorption rates are the same regardless of where a particle is deposited. The exception is $\mathrm{ET}_{1}$ from which no absorption occurs. Also in contrast to the particle transport model, absorption rates are dependent on the particle's element(s) and chemical form. Default parameters for the latter dependence are established in three categories: absorption Type F (for fast rate of solubilization), Type M, and Type $\mathrm{S}$. There is also a Type $\mathrm{V}$ for gases and vapors, which is described as $100 \%$ instantaneous absorption.

Two-compartment models have been developed to address dissolution and absorption. Both are available in IMBA. The standard representation is described in ICRP 66 (1994b) and ICRP 78 (1997) and shown in Figure C.3. The model provides a way to account for time-dependent dissolution. In this model, particles are initially deposited into a compartment labeled "initial state," from which some particles are dissolved rapidly and directly into blood at rate $\mathrm{s}_{\mathrm{p}}$ and some are transferred to a "transformed state." Material in the transformed state dissolves at a slower rate, $\mathrm{s}_{\mathrm{t}}$. The "bound state" is shown in Figure C.3 and is programmed into IMBA in the "standard representation;" however, the default parameters for absorption Types F, M, and S do not actually use the bound state $\left(f_{\mathrm{b}}=0\right)$ and the bound state is not shown in the ICRP 78 (1997) nor the Supporting Guidance 3 (ICRP 2002b). The physical phenomena modeled by the bound state are not well explained. Table C.2 gives the default parameter values for the standard representation. Particle transport operates on particles in both the initial state and the transformed state but not the bound state. Figure 24 in ICRP 66 (1994b) shows the combined clearance model (both particle transport and absorption).

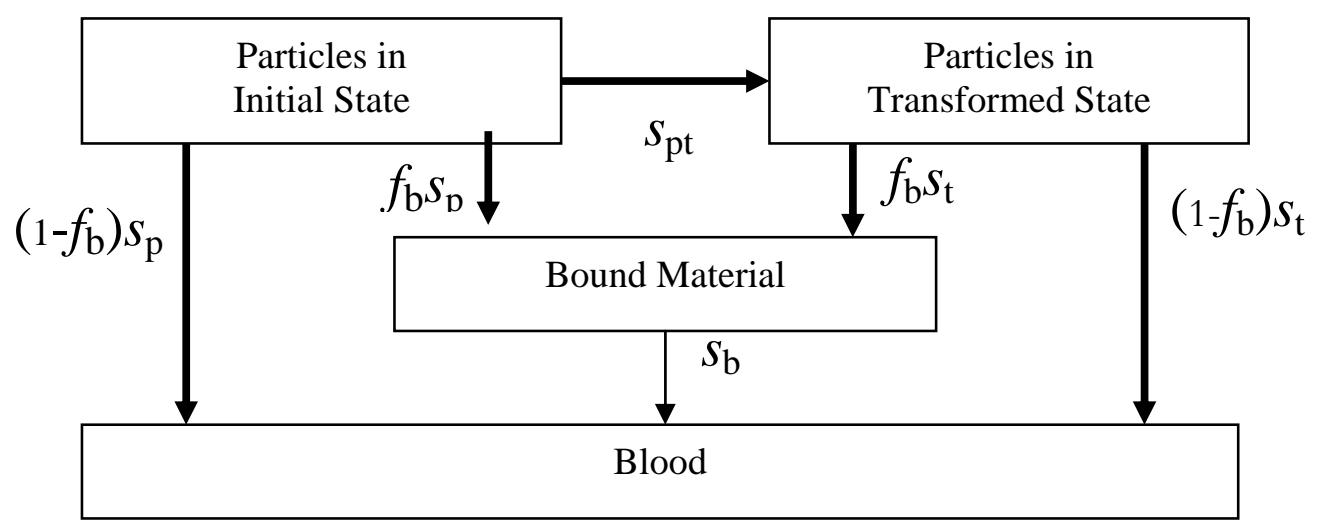

Figure Error! No text of specified style in document..3. Standard Compartment Model Representing Time-Dependent Dissolution in the Respiratory Tract Followed by Instantaneous Uptake to Blood (ICRP 1994b) 
Table Error! No text of specified style in document..2. Default Absorption Parameters for the Standard Representation of the Absorption Model

\begin{tabular}{lccc}
\hline \multicolumn{1}{c}{ Parameter } & Type $\mathrm{F}$ & Type $\mathrm{M}$ & Type S \\
\hline Initial dissolution rate, $\mathrm{s}_{\mathrm{p}},\left(\mathrm{d}^{-1}\right)$ & 100 & 10 & 0.1 \\
Transformation rate, $\mathrm{s}_{\mathrm{p}},\left(\mathrm{d}^{-1}\right)$ & 0 & 90 & 100 \\
Final dissolution rate, $\mathrm{s}_{\mathrm{t}},\left(\mathrm{d}^{-1}\right)$ & NA & 0.005 & 0.0001 \\
Fraction to bound state, $\mathrm{f}_{\mathrm{b}}$ & 0 & 0 & 0 \\
Uptake rate from bound state, $\mathrm{s}_{\mathrm{b}},\left(\mathrm{d}^{-1}\right)$ & not defined & not defined & not defined \\
\hline
\end{tabular}

Another representation of the same model is given in ICRP 66 (1994b) and Supporting Guidance 3 (2002b) and is available in IMBA under a tab called "alternative representation.” The IMBA alternative representation includes the bound state but the Supporting Guidance 3 leaves it out. This model is shown in Figure C.4 and the default parameters are provided in Table C.3.

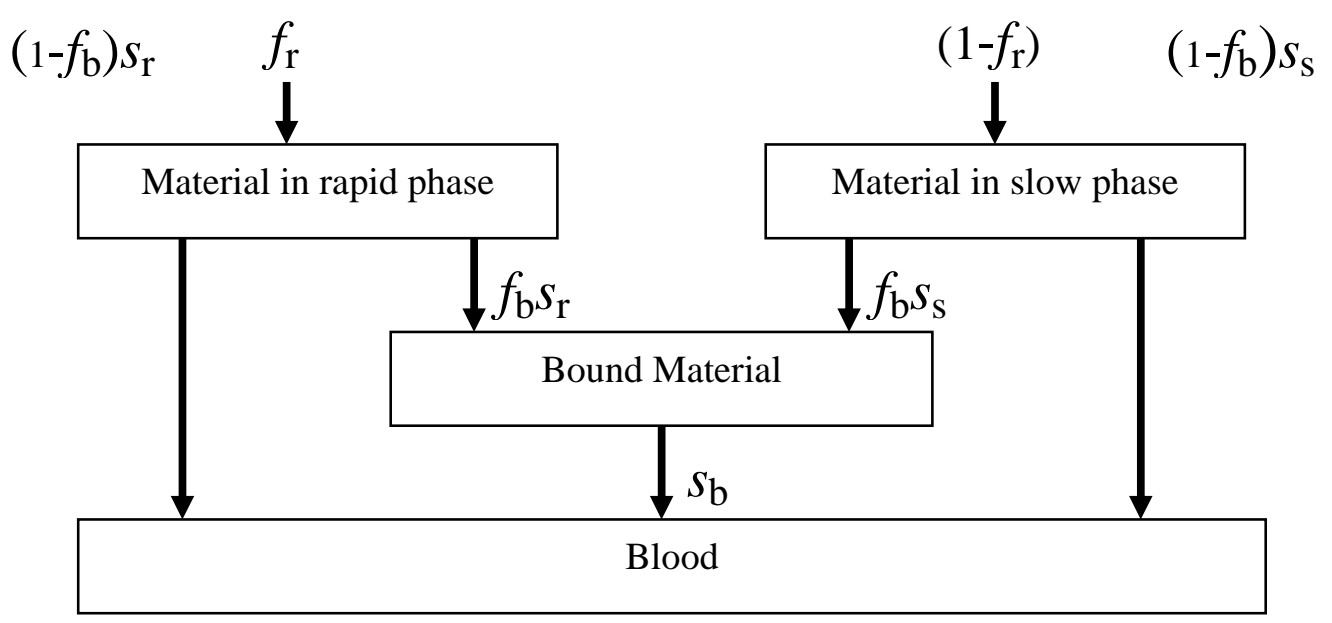

Figure Error! No text of specified style in document..4. Alternate Compartment Model Representing Time-Dependent Dissolution in the Respiratory Tract Followed by Instantaneous Uptake to Blood (ICRP 1994b)

Table Error! No text of specified style in document..3. Default Absorption Parameters for the Alternate Representation of the Absorption Model

\begin{tabular}{lccc}
\hline \multicolumn{1}{c}{ Parameter } & Type $\mathrm{F}$ & Type $\mathrm{M}$ & Type S \\
\hline Fraction dissolved rapidly, $\mathrm{f}_{\mathrm{r}}$, & 1 & $0.1^{(\mathrm{a})}$ & $0.001^{(\mathrm{b})}$ \\
Rapid dissolution rate, $\mathrm{s}_{\mathrm{r}},\left(\mathrm{d}^{-1}\right)$ & 100 & 100 & $100^{(\mathrm{c})}$ \\
Slow dissolution rate, $\mathrm{s}_{\mathrm{s}},\left(\mathrm{d}^{-1}\right)$ & $\mathrm{NA}$ & 0.005 & 0.0001 \\
Fraction to bound state, $\mathrm{f}_{\mathrm{b}}$ & 0 & 0 & 0 \\
Uptake rate from bound state, $\mathrm{s}_{\mathrm{b}},\left(\mathrm{d}^{-1}\right)$ & not defined & not defined & not defined \\
\hline
\end{tabular}

(a) IMBA uses 0.099955 .

(b) IMBA uses 0.000998 .

(c) IMBA uses 100.1. 
ICRP provides the following summary of the treatment of the default absorption types (ICRP 2002b):

- Type V: 100\% absorbed instantaneously. Regional deposition does not need to be assessed for such materials, because in dose calculations they can be treated as if they were injected directly into body fluids.

- Type F: $100 \%$ absorbed with a half-time of 10 minutes. There is rapid absorption of almost all material deposited in BB, bb, and AI, and $50 \%$ of material deposited in $\mathrm{ET}_{2}$. The other $50 \%$ of material in $\mathrm{ET}_{2}$ is cleared to the GI tract.

- Type M: $10 \%$ absorbed with a half-time of 10 minutes and $90 \%$ with a half-time of 140 days. There is rapid absorption of about $10 \%$ of the deposit in the BB and bb; and $5 \%$ of material deposited in $\mathrm{ET}_{2}$. About $70 \%$ of the deposit in the AI eventually reaches body fluids.

- Type S: $0.1 \%$ absorbed with a half-time of 10 minutes and $99.9 \%$ with a half-time of 7000 days. There is little absorption from $\mathrm{ET}_{2}, \mathrm{BB}$, or bb, and about $10 \%$ of the deposit in AI eventually reaches body fluids.

Recommended absorption types for various elements and chemical forms are found in ICRP 68, Table F.1 (1994a) for workers. Similar, but not exactly the same, recommendations for members of the public are found in ICRP 71 (1995b).

\section{C.1.4 Modifying Factors for HRTM Parameters}

Almost all of the clearance parameters can be changed by the user of IMBA, but there are many of them and changing parameters simply to fit bioassay data without underlying scientific justification is discouraged. The ICRP provides for adjustments to some particle transport parameters for some specific causes, such as age, diseases, or cigarette smoking (ICRP 66, Table 19 [1994b] or Supporting Guidance 3, Table A14 [2002b]). The adjustments are in the form of a modifying factor that is multiplied with the default rate constant. For instance, for a cigarette smoker, the particle transport rate from the $\mathrm{BB}_{1}$ to the $\mathrm{ET}_{2}$ compartments would be multiplied by 0.5 , the rates from $\mathrm{AI}_{2}$ to $\mathrm{bb}_{1}$ and $\mathrm{AI}_{3}$ to $\mathrm{bb}_{1}$ would be multiplied by 0.7 , and the fraction of $\mathrm{AI}$ deposits that go to $\mathrm{AI}_{1}$ would be changed to 0.3 .

\section{C.2 The Gastrointestinal Tract Model}

The HIDP uses the ICRP 30 (1979) Gastrointestinal Tract Model shown in Figure C.5. The model is integral to IMBA. ICRP defines absorption in the GI tract as occurring in the small intestine and expresses it as a fraction between 0 and 1, typically based on absorption studies where the absorption was determined following a known intake. ICRP 68, Tables E.1 and F.1 (1994a) provide guidance on $f_{1}$ values for various elements and compounds. The GI Tract Model of Figure C.5 shows various transfer rates between the compartments of the GI tract and also the transfer (absorption) rate into body fluids (or blood). From that model, the absorption fraction $f_{1}$ is expressed mathematically as

$$
f_{1}=\frac{\lambda_{B}}{\lambda_{B}+\lambda_{S I}}
$$

PNNL-MA-860 Appendix C Page C.8
Issued for implementation effective 01/01/2010

Supersedes: September 30, 2000 


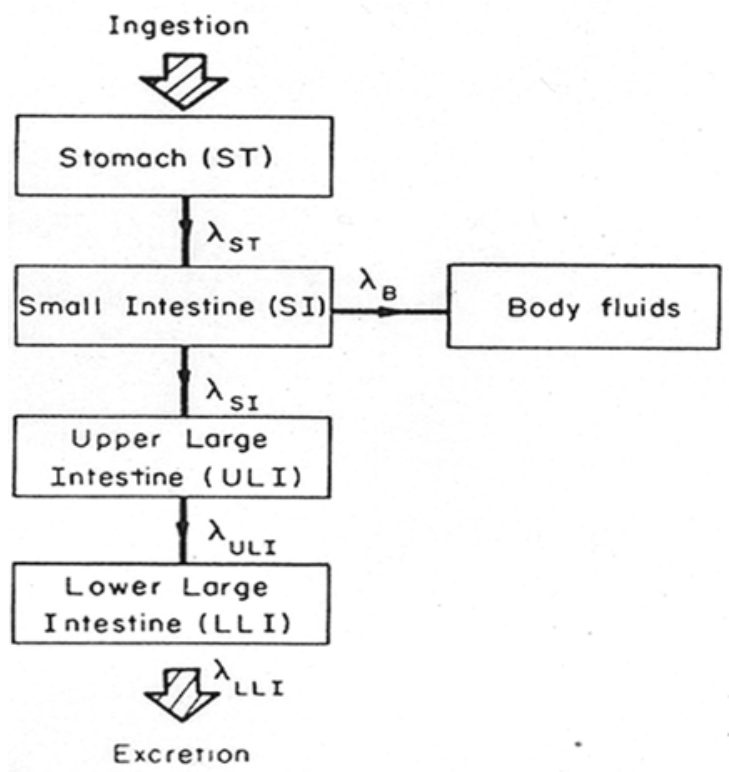

Figure Error! No text of specified style in document..5. Biokinetic Model for the Gastrointestinal Tract (from ICRP 30 [1979])

For computer modeling purposes, rate constants are required to express the differential equations describing biokinetics. Thus the $f_{1}$ fraction is converted to a blood absorption rate $\left(\lambda_{\mathrm{B}}\right)$ by the relationship, derived from Equation (C.1), the ICRP $f_{1}$ value, and the normal $\lambda_{\mathrm{SI}}$ value of $6 \mathrm{~d}^{-1}$ (or any other assumed $\lambda_{\mathrm{SI}}$ value) as follows:

$$
\lambda_{B}=\frac{f_{1} \lambda_{S I}}{1-f_{1}}
$$

The conversion of the absorption fraction to a rate constant by Equation (C.2) is problematic when $f_{1}=1$ because of division by zero. To prevent this, modelers may insert an arbitrarily small value to prevent the system from crashing. The codes used by ICRP in tabulating their published dose coefficients prevent this by using an actual $f_{1}$ value of 0.99 when the stated value is $1 .^{1}$ IMBA, however, does not make that automatic substitution, so for absorption fractions stated by ICRP to be equal to 1, the IMBA user needs to input 0.99 as the $f_{1}$ value to generate results comparable to ICRP. Inputting 1 into IMBA can result in day 1 urinary excretion rates somewhat different from those tabulated in ICRP 78 (1997), e.g., ${ }^{137} \mathrm{Cs}$, but has no significant impact on dose coefficients or assessments based on urine data subsequent to 1 day post intake.

\section{C.3 Systemic Models}

Biokinetic models are element specific. Generally, the ICRP presently uses three systemic models, which are incorporated into IMBA. The model for many elements is still the catenary compartment model of ICRP 30 (1979). However, since 1979, two physiologically based models incorporating

\footnotetext{
${ }^{1}$ Personal correspondence, e-mail from Keith Eckerman (Oak Ridge National Laboratory) to Eugene Carbaugh (Pacific Northwest National Laboratory), dated February 28, 2008.
} 
recycling of material from systemic organs back to blood and then redistribution back to systemic organs have been developed. The model shown in Figure C. 6 is the alkaline earth model used for strontium and radium. Activity entering the blood is distributed to bone or soft tissues or excreted in urine or feces. The urinary pathway is modeled separately from kidney tissue. Bone is divided into cortical and trabecular components, each of which is further divided into bone surface and bone volume, and bone volume is further divided into an exchangeable portion and a non-exchangeable portion. Rapidly exchanged activity is assumed to reside on the bone surface. The non-exchangeable compartment actually represents very slow turnover due to bone resorption.

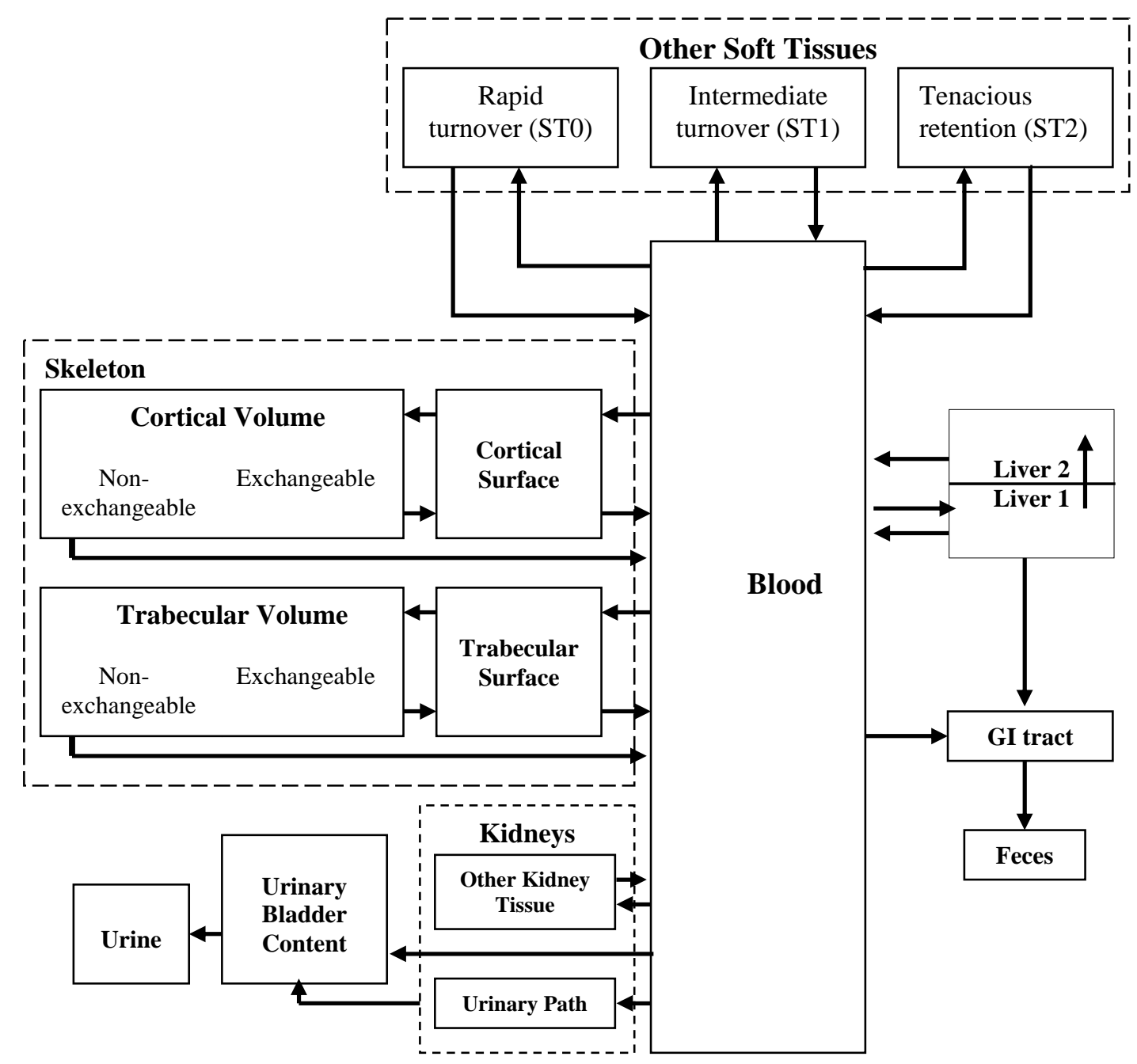

Figure Error! No text of specified style in document..6. Systemic Model for Strontium and Radium (ICRP 1997)

Figure C.7 shows the recycling model used for thorium, neptunium, plutonium, americium, and curium. The model is similar to the alkaline earth model except that the bone marrow is a specific compartment for both cortical and trabecular bone, and liver, gonads, and kidney are modeled separately from soft tissue. Activity entering the skeleton is initially assigned to bone surfaces and is subsequently transferred to bone marrow by bone resorption or to bone volume by bone formation. Activity in the 
bone marrow is returned to the blood over a period of months. Depending on the element, the liver is treated as a single compartment or two compartments. Liver 2 represents relatively tenacious retention (half-time $>1$ year). Plutonium uses the two liver compartments with Liver 1 having a relative short half-time and Liver 2 a half-time of many years. Americium and curium on the other hand are treated with a single liver compartment with a half-time of about 1 year.

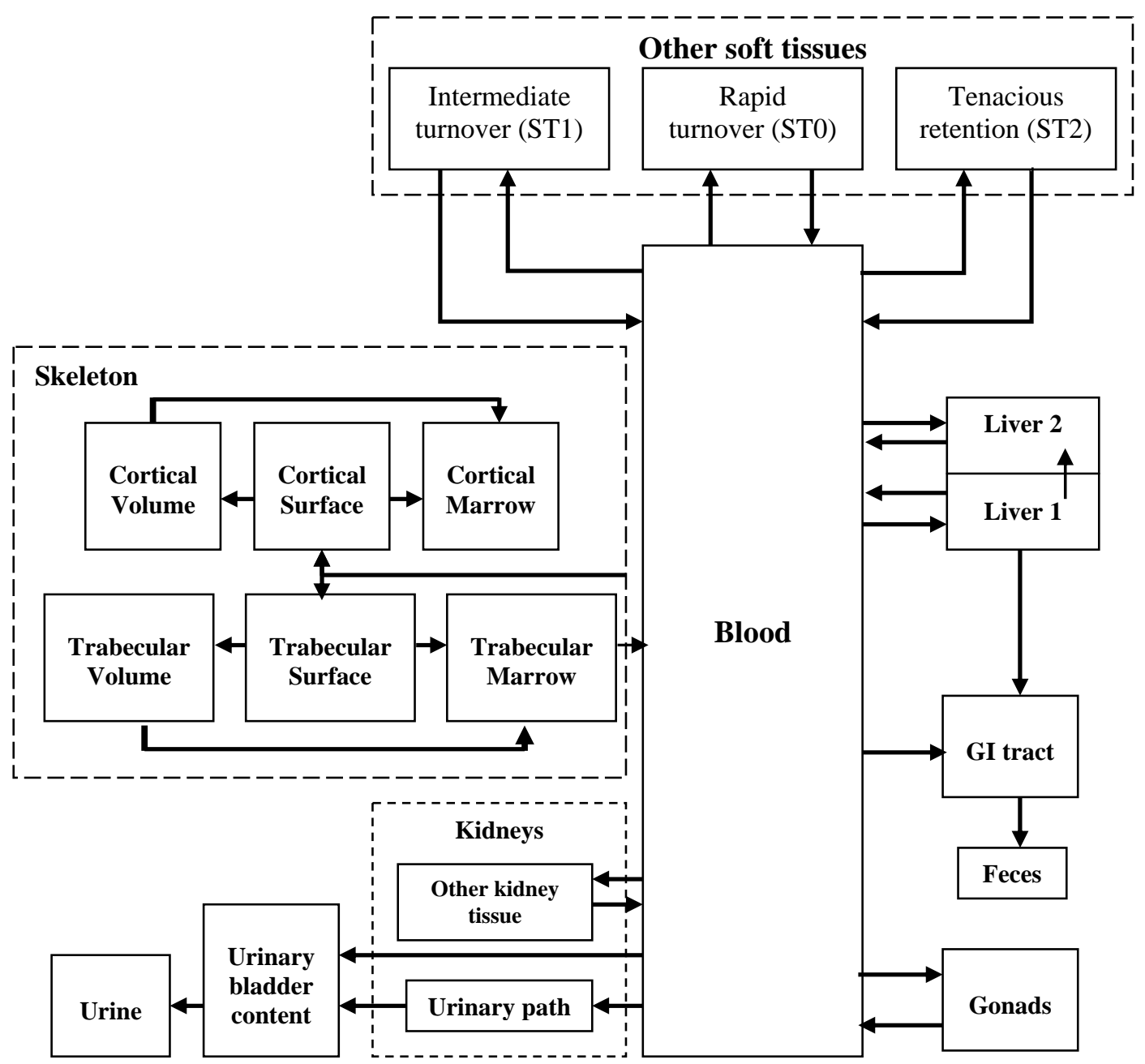

Figure Error! No text of specified style in document..7. Systemic Model for Thorium, Neptunium, Plutonium, Americium, and Curium (ICRP 1997)

Figure C.8 shows the uranium recycling model. It uses the alkaline earth model for the skeleton, the plutonium model for the kidneys, bladder, and liver, adds a red-blood cell compartment, but does not include the gonads as a compartment separate from soft tissue. The transfer from blood to liver is small and the half-times are shorter (7 days for Liver 1 to blood and 10 years for Liver 2 to blood).

Element-specific transfer rates between compartments of the models are provided in the elementspecific chapters. 


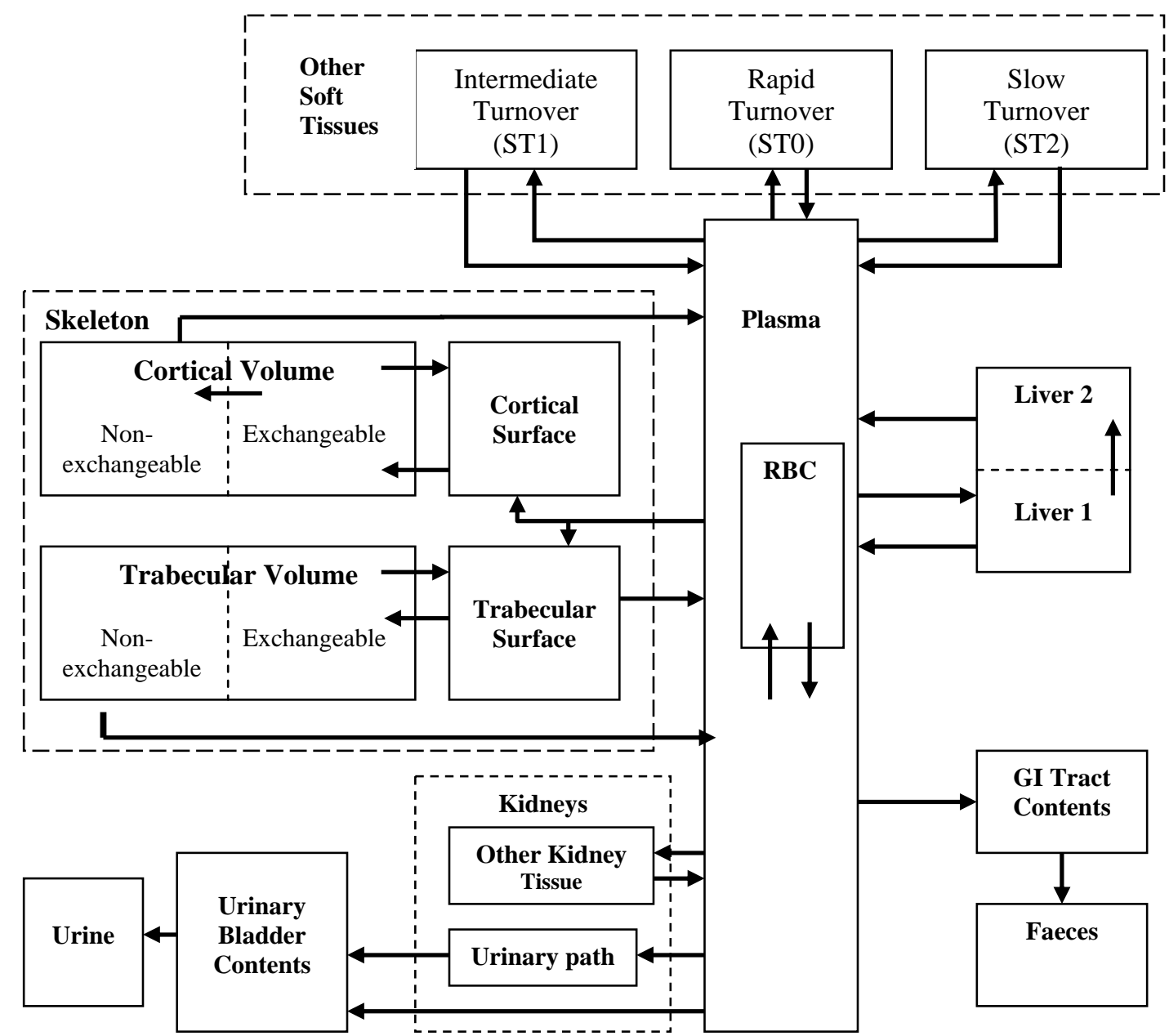

Figure Error! No text of specified style in document..8. Systemic Model for Uranium (ICRP 1995a)

\section{C.4 Fecal Sampling Model}

Fecal sampling can be a valuable aid for estimating the magnitude of an inhalation intake. For absorption Type $\mathrm{M}$ and $\mathrm{S}$ materials with poor uptake from the GI tract (small $f_{1}$ factors), e.g., plutonium, americium, thorium, and insoluble uranium, fecal sampling is often the most intake-sensitive type of sampling shortly after an acute intake. Fecal sampling may also be very helpful even at long times after intake if chelation therapy has been administered, because the therapy distorts the standard urinary excretion model.

IMBA provides the instantaneous fecal excretion rate. Because fecal excretion is more of a discontinuous, bolus phenomena rather than a more continuous phenomena like urinary excretion, the instantaneous excretion rate is not particularly appropriate for comparison to fecal sample results for times shortly after an acute intake for Type $\mathrm{M}$ and S insoluble materials. Cumulative excretion over fractions of a day to several days may be a more appropriate value to use with fecal results. 
Potter (2002) provided elemental intake retention/excretion fractions for inhalation of Type F, M, and S 5- $\mu$ m-AMAD particles for times ranging from 0.25 to 30,000 days. Potter's tables include the cumulative excretion. Table C. 4 shows Potter's cumulative fecal excretion per unit intake for several elements for which fecal sampling might be used at Hanford. Radioactive decay is not included in the excretion fractions, but is negligible for these short times. The values are identical for Type M plutonium, americium, and thorium, and, although not shown, are identical for Type M curium and neptunium as well.

Table Error! No text of specified style in document..4. Fraction of Intake Excreted via Feces Following an Acute Inhalation of Poorly Absorbed Material ${ }^{(\mathrm{a})}$

\begin{tabular}{|c|c|c|c|c|c|c|c|}
\hline \multirow[b]{3}{*}{$\begin{array}{l}\text { Days Post } \\
\text { Intake }\end{array}$} & \multicolumn{7}{|c|}{ Intake Fraction Excreted During Interval } \\
\hline & \multicolumn{2}{|c|}{ Plutonium } & \multirow{2}{*}{$\begin{array}{c}\text { Americium } \\
\text { Type M, } \\
f_{1}=5 \mathrm{E}-04\end{array}$} & \multicolumn{2}{|c|}{ Uranium } & \multicolumn{2}{|c|}{ Thorium } \\
\hline & $\begin{array}{c}\text { Type M, } \\
f_{1}=5 \mathrm{E}-04\end{array}$ & $\begin{array}{c}\text { Type S, } \\
f_{1}=1 \mathrm{E}-05\end{array}$ & & $\begin{array}{c}\text { Type M, } \\
f_{1}=2 \mathrm{E}-02\end{array}$ & $\begin{array}{l}\text { Type } S, f_{1} \\
=2 \mathrm{E}-03\end{array}$ & $\begin{array}{c}\text { Type M, } \\
f_{1}=5 \mathrm{E}-04\end{array}$ & $\begin{array}{c}\text { Type S, } \\
f_{1}=2 \mathrm{E}-04\end{array}$ \\
\hline $1(0-24 h)$ & 0.110 & 0.116 & 0.110 & 0.108 & 0.116 & 0.110 & 0.116 \\
\hline 2 (25-48 h) & 0.155 & 0.163 & 0.155 & 0.152 & 0.163 & 0.155 & 0.163 \\
\hline $3(49-72$ h) & 0.079 & 0.084 & 0.079 & 0.077 & 0.083 & 0.079 & 0.084 \\
\hline $4(73-96$ h) & 0.033 & 0.034 & 0.033 & 0.032 & 0.035 & 0.033 & 0.034 \\
\hline $5(97-120$ h) & 0.013 & 0.014 & 0.013 & 0.013 & 0.013 & 0.013 & 0.014 \\
\hline $0-2$ cumulative & 0.265 & 0.279 & 0.265 & 0.260 & 0.279 & 0.265 & 0.279 \\
\hline 0-3 cumulative & 0.344 & 0.363 & 0.344 & 0.337 & 0.362 & 0.344 & 0.363 \\
\hline 0-4 cumulative & 0.377 & 0.397 & 0.377 & 0.369 & 0.397 & 0.377 & 0.397 \\
\hline 0 -5 cumulative & 0.390 & 0.411 & 0.390 & 0.382 & 0.410 & 0.390 & 0.411 \\
\hline
\end{tabular}

(a) 5- $\mu$ m-AMAD particle size, and all other default parameters.

Ingestion can confound interpretation of fecal results taken shortly after an acute intake. Figure C.9 shows the fecal excretion curves for inhalation of $250 \mathrm{pCi}$ of Type M 5- $\mu \mathrm{m}$-AMAD plutonium, ingestion of $100 \mathrm{pCi}$ of moderately soluble plutonium, inhalation of $250 \mathrm{pCi}$ of Type S 5- $\mu \mathrm{m}$-AMAD plutonium, and ingestion of $100 \mathrm{pCi}$ of very insoluble plutonium. The figure makes three points: 1 ) ingestion has about 2.5 times more impact on fecal excretion during the first few days after intake relative to inhalation, but has no impact after about 10 days; 2) early fecal excretion provides little information about the inhalation type of the material nor the solubility of ingested material; 3) fecal excretion over the first several days cannot effectively distinguish between inhalation and ingestion intakes. Because of the impact of ingestion on early fecal excretion, it should be used in conjunction with urinalysis and chest counting unless the intake is small.

The extent of use of fecal sampling depends on the expected severity of the intake. For intakes that are estimated (based perhaps on workplace monitoring) to result in a committed effective dose of less than 100 mrem, or for situations where confirmation that an intake did not occur is desired, two fecal samples collected from 24 to 72 hours after the potential intake are recommended. Depending on other indicators, such as workplace data, it may suffice to analyze only one sample and hold the other in case there are problems with the first analysis. Feces are a difficult matrix to analyze, and there is a higher risk than for urine that the laboratory may not get valid results. Very insoluble plutonium particles are difficult to dissolve and the laboratory may need to use special techniques, e.g., HF, to ensure that all of 
the plutonium has been captured in the liquid phase. If the samples show significant detectable activity (e.g., implying a committed effective dose greater than 100-mrem), additional bioassay measurements should be obtained, including additional fecal samples collected from 20 to 100 days post intake, after early clearance to aid in distinguishing inhalation from ingestion. In some situations, these additional fecal samples may still be more sensitive to intake than other bioassay measurements, but special care is necessary to avoid further small intakes prior to collection of these additional samples. Fecal samples collected after 5 to 7 days post intake show a marked decrease in sensitivity to intake detection.

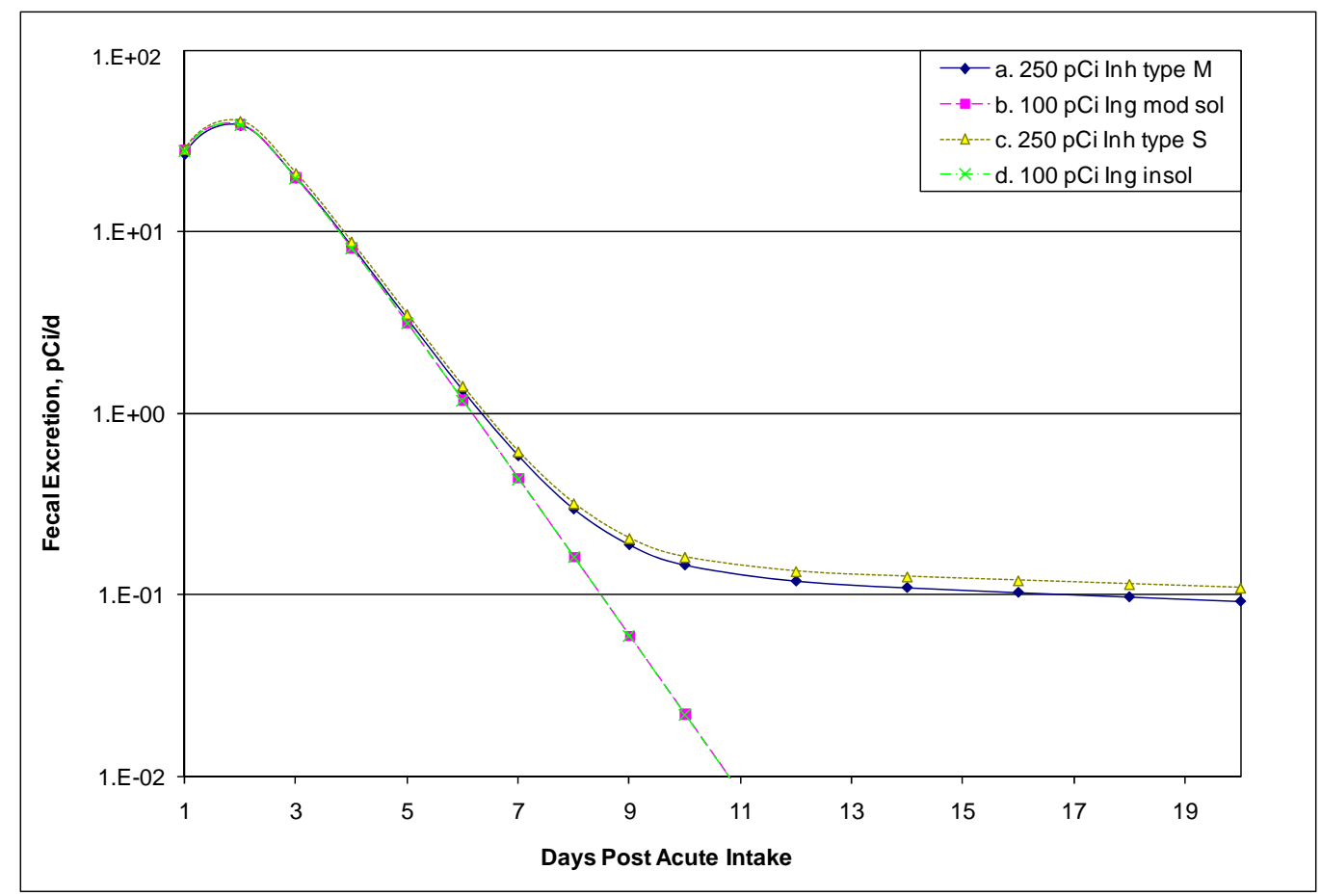

Figure Error! No text of specified style in document..9. Comparison of Fecal Excretion Between (a) 250 pCi Inhalation Type $\mathrm{M}^{239} \mathrm{Pu}$, (b) $100 \mathrm{pCi}$ Ingestion Moderately Soluble ${ }^{239} \mathrm{Pu}\left(f_{1}=5 \mathrm{E}-04\right)$, (c) $250 \mathrm{pCi}$ Inhalation Type $\mathrm{S}^{239} \mathrm{Pu}$, and (d) $100 \mathrm{pCi}$ Ingestion Insoluble ${ }^{239} \mathrm{Pu}\left(f_{1}=1 \mathrm{E}-05\right)$. Note that there is essentially no difference in the curves for the first 6 days.

If workplace monitoring results indicate a more serious intake, it is recommended to collect all fecal excretion from about 6 to 72 hours post intake or longer. The total result from all samples collected during this period is divided by the fractional accumulated excretion in Table C.4 to provide an estimate of intake, keeping in mind that the inhalation type will have to be determined another way. Reference Worker (ICRP 2002a) excretion for adults ranges from about $50 \mathrm{~g} / \mathrm{d}$ to nearly $500 \mathrm{~g} / \mathrm{d}$ depending on fiber intake, with a recommended average of $150 \mathrm{~g} / \mathrm{d}$ for an adult male and $120 \mathrm{~g} / \mathrm{d}$ for an adult female. Note that these values represent excretion "per day" not excretion "per bowel movement." When a single bowel movement is collected, it is generally interpreted as representing excretion for 1 day. If total accumulated excretion over a time period was requested and there is no apparent reason to suspect that total excretion was not provided, then all sample results should be used as is, without regard for the mass of individual samples. If excretions were missed during the time period, then normalization of the total mass to the total mass expected based on the reference values given above (or worker-specific values if available) should be used. 
There are problems with interpretation of fecal data for which the dosimetrist needs to stay alert. One is the possibility of interference by ingested material discussed previously. For sufficiently large intakes, this problem can be overcome by sampling during the slow clearance phase. Interpretation of fecal data is also sensitive to the size of the particles inhaled. For example, Figure C.10 shows fractional daily excretion for Type M plutonium for 0.5-, 1-, 5-, and 10- $\mu$ m-AMAD particles. In these cases collection of day 3 feces and assumption of 5- $\mu \mathrm{m}$-AMAD particles would result in overestimation of the intake by 1.7 and 3.2 for intakes actually involving Type M 1- and 0.5- $\mu$ m-AMAD particles, respectively; the difference between 5- $\mu \mathrm{m}$-AMAD and 10- $\mu \mathrm{m}$-AMAD particles is insignificant. Similar differences occur for Type S material.

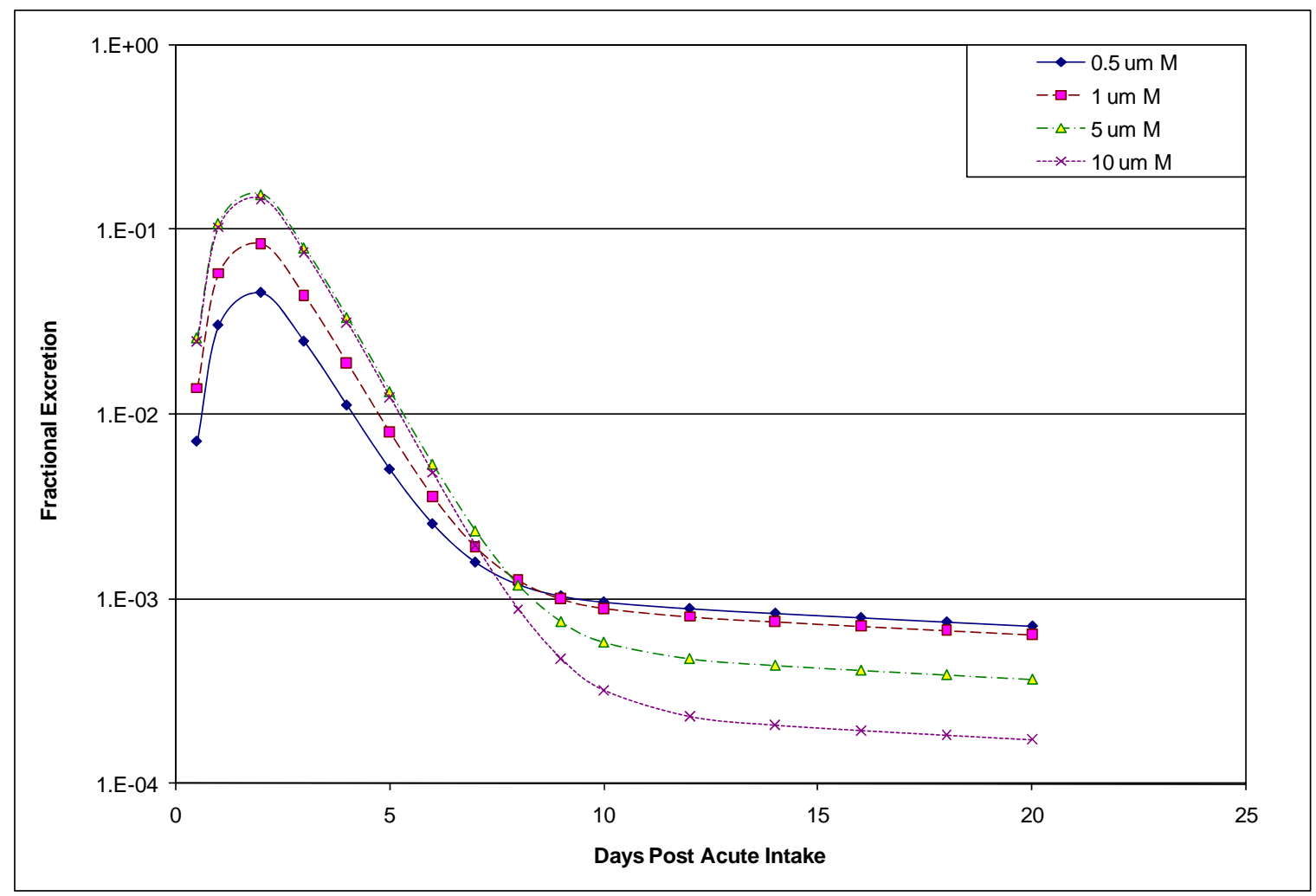

Figure Error! No text of specified style in document..10. Effect of Particle Size on Fecal Excretion for Type $\mathrm{M}^{239} \mathrm{Pu}$

Another difficulty arises from single-voiding samples. These are generally easier to obtain than total excretion over a specific period. But both inter- and intra-individual variation in the regularity of bowel movements can introduce large uncertainties if a single voiding is used to represent daily excretion. Normalization by mass can help reduce error when a single sample represents a fraction of a day's excretion, but it does not help when a single sample represents excretion for several days.

Contamination of a fecal sample by urine should be avoided, but generally will not introduce significant error if it occurs.

For uranium and thorium, natural daily ingestion needs to be taken into account. 


\section{C.5 References}

International Commission on Radiological Protection (ICRP). 1979. "Limits for Intakes of Radionuclides by Workers.” ICRP Publication 30, Part 1, Annals of the ICRP, 2:3/4, Pergamon Press, New York.

International Commission on Radiological Protection (ICRP). 1989. "Age-dependent Doses to the Members of the Public from Intake of Radionuclides: Part 1.” ICRP Publication 56, Annals of the ICRP, 20:2, Pergamon Press, New York.

International Commission on Radiological Protection (ICRP). 1993. "Age-dependent Doses to the Members of the Public from Intake of Radionuclides: Part 2 Ingestion Dose Coefficients.” ICRP Publication 67, Annals of the ICRP, 23:3-4, Pergamon Press, New York.

International Commission on Radiological Protection (ICRP). 1994a. "Dose Coefficients for Intakes of Radionuclides by Workers.” ICRP Publication 68, Annals of the ICRP, 24:4, Pergamon Press, New York.

International Commission on Radiological Protection (ICRP). 1994b. "Human Respiratory Tract Model for Radiological Protection.” ICRP Publication 66, Annals of the ICRP, 24:1-3, Pergamon Press, New York.

International Commission on Radiological Protection (ICRP). 1995a. "Age-dependent Doses to the Members of the Public from Intake of Radionuclides: Part 3 Ingestion Dose Coefficients.” ICRP Publication 69, Annals of the ICRP, 25:1, Pergamon Press, New York.

International Commission on Radiological Protection (ICRP). 1995b. “Age-dependent Doses to the Members of the Public from Intake of Radionuclides: Part 4 Inhalation Dose Coefficients.” ICRP Publication 71, Annals of the ICRP, 25:3-4, Pergamon Press, New York.

International Commission on Radiological Protection (ICRP). 1996. “Age-dependent Doses to the Members of the Public from Intake of Radionuclides: Part 5 Compilation of Ingestion and Inhalation Dose Coefficients.” ICRP Publication 72, Annals of the ICRP, 26:1, Pergamon Press, New York.

International Commission on Radiological Protection (ICRP). 1997. "Individual Monitoring for Internal Exposure of Workers.” ICRP Publication 78, Annals of the ICRP, 27:3-4, Pergamon Press, New York.

International Commission on Radiological Protection (ICRP). 2002a. "Basic Anatomical and Physiological Data for Use in Radiological Protection: Reference Values.” ICRP Publication 89, Ed. J Valentin, Annals of the ICRP, 32:3-4, Pergamon Press, New York.

International Commission on Radiological Protection (ICRP). 2002b. "Guide for the Practical Application of the ICRP Human Respiratory Tract Model.” Supporting Guidance 3, Annals of the ICRP, 32:1-2, Pergamon Press, New York.

James AC, A Birchall, JW Marsh, and M Puncher. 2004. User Manual for IMBA Expert, USDOEEdition (Phase II), ACJ \& Associates, Inc., Richland, Washington.

PNNL-MA-860 Appendix C

Page C.16
Issued for implementation effective 01/01/2010

Supersedes: September 30, 2000 
Potter CA. 2002. "Intake retention fractions developed from models used in the determination of dose coefficients developed for ICRP Publication 68 - particulate inhalation.” Health Physics 83(5):594-789. 


\section{Methods and Models of the Hanford Internal Dosimetry Program \\ PNNL-MA-860}

\section{Appendix D - Computer Codes}

Issued for implementation effective 01/01/2010

Supersedes: September 2000

\section{Use Category: Not applicable}

\section{Approval Signatures:}

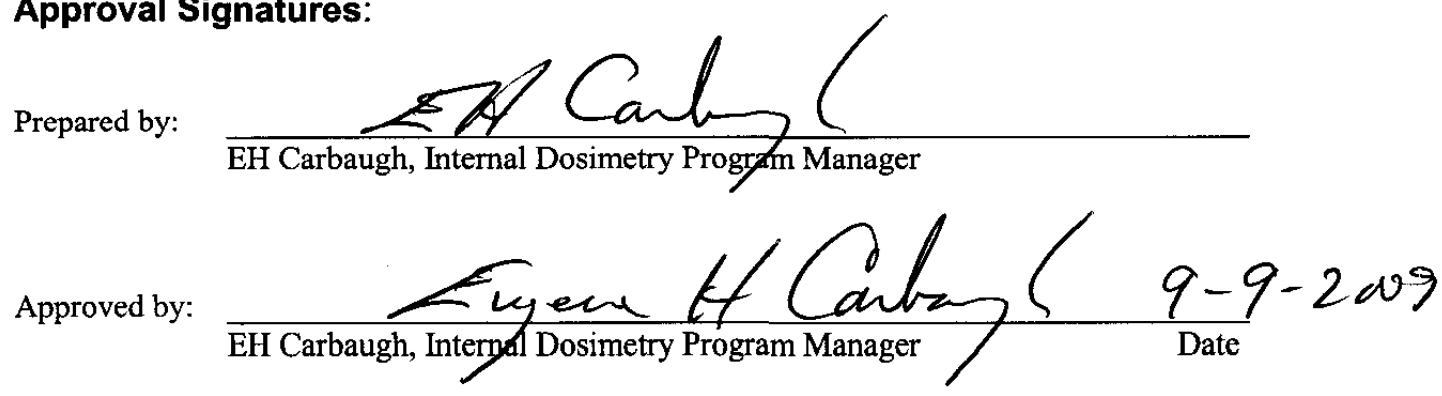

\section{Reviewer Signatures:}

Reviewed by:

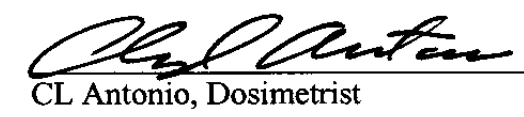

Approved by the Hanford Personnel Dosimetry Advisory Committee as recorded in the meeting minutes of May 13, 2008. 


\section{Contents}

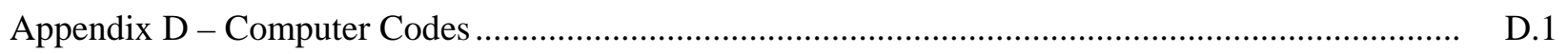

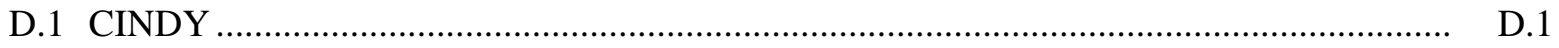

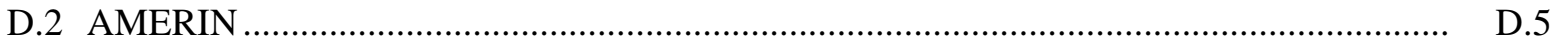

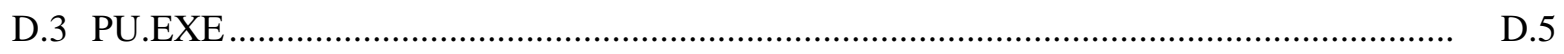

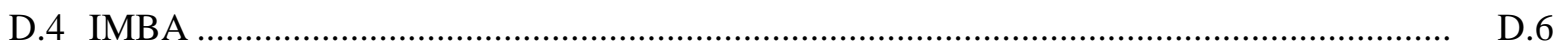

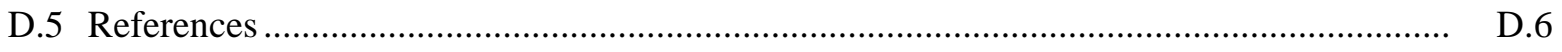

\section{Table}

D.1 CINDY Normalization Protocols for Bioassay Data ...................................................... D.. D 


\section{Appendix D}

\section{Computer Codes}

Computer codes are important to internal dosimetry because of the number and complexity of biokinetic models used for bioassay interpretation and dose assessment. The models have to factor in basic radiological decay parameters, intake parameters such as particle size and breathing rate, initial deposition within the body, subsequent distribution and translocation within body organs and tissues, excretion pathways, energy absorption in a target tissue from a radionuclide decay in a source tissue, and the various tissue weighting factors. An appropriate data-fitting routine is required for assessment of bioassay data and codes need various output routines to display data in useful formats such as reports and graphs. The Hanford Internal Dosimetry Program (HIDP) has several computer programs at its disposal to aid with internal dosimetry evaluations. These programs are listed below and discussed in the following sections:

- CINDY

- AMERIN

- PU.EXE

- IMBA

The HIDP maintains historical archives of computer codes used. This appendix only addresses codes in current use. In addition to the currently used codes, the HIDP may have codes that are undergoing consideration or testing but are not used for formal Hanford applications. Also, common commercially available spreadsheet and database software are not described here.

\section{D.1 CINDY}

The Code for INternal DosimetrY (CINDY) is the principal computer code used by the HIDP for dosimetry based on International Commission on Radiological Protection Publication 30 (ICRP 1979). The code can do intake calculations based on curve-fitting of bioassay data; calculate committed (or any specified interval) organ, tissue, and effective dose equivalents; and make bioassay projections. The wide range of radionuclides encompassed by the code library includes all of those addressed by this manual. A two-part manual details the conceptual models used by the code (Strenge et al. 1992a) and provides a user guide to loading and executing the code (Strenge et al. 1992b). The HIDP currently uses Version 1.4.

The code was developed at Pacific Northwest National Laboratory (PNNL) in the late 1980s and early 1990s under U.S. Department of Energy (DOE) funding specifically for implementing the dose provisions originally specified in DOE 5480.11 (1988). It is commercially available through Canberra Nuclear, Inc. ${ }^{1}$

\footnotetext{
${ }^{1}$ Canberra Nuclear, Inc., One State Street, Meriden, CT 06450. Phone (203) 238-2351.
} 
CINDY was originally designed for a DOS-based personal computer. It has been successfully used on WINDOWS 3.1, WINDOWS 95, WINDOWS 98, WINDOWS 2000, WINDOWS NT, and WINDOWS XP platforms; however, some problems were encountered in making it functional on more advanced platforms.

Canberra supplies users with a software key that inserts into a computer's parallel port slot. The software key allows full feature capability including saving files and printing. The HIDP has been unsuccessful in getting CINDY to print to a USB printer port.

\section{D.1.1 Models Included in CINDY}

CINDY incorporates the ICRP 30 (ICRP 1979) models for radionuclides, but permits modification of many parameters. Identification of some of the key adjustable parameters is discussed below.

The exposure scenario options permit inhalation, ingestion, and direct intake (which can be considered as either absorption through skin or wound injection). Inhalation and ingestion intakes use the ICRP 30 models. Inhalation permits use of Class D, W, or Y, or any combination thereof, and allows for specification of particle size. Ingestion may be of soluble or insoluble forms (with user-variable $f_{1}$ factors). Direct intake allows uptake to blood from one or more independent compartments, each exhibiting a user-defined clearance half-time to blood. Exposures may be either acute (instantaneous) intakes or chronic (continuous over a user-specified interval).

The respiratory tract model permits adjustment of both the compartment fraction and the clearance half-time for the individual compartments of the ICRP 30 model. Regional deposition fractions for the nasal-pharengeal, tracheobronchial, and pulmonary regions are set by the code based on the particle size specified.

The gastrointestinal (GI) tract model permits adjustment of the mean resident times (in hours) for the stomach, small intestine, upper large intestine, and lower large intestine. Absorption within the GI tract is established by setting the GI uptake $\left(f_{1}\right)$ factor for individual radionuclide biokinetic models.

Systemic distribution, retention, and excretion models are provided based on chemical elements. Typically, the parameters for distribution compartment fractions and clearance half-times are adjustable by the user. The default model used by CINDY for most elements is the ICRP 30 model; however, element-specific models are also provided for iodine, alkaline earths, radium/radon, tritium, carbon, tellurium/iodine, and uranium. The GI uptake $\left(f_{1}\right)$ factor is an element-specific variable. Detailed descriptions of the specific models are contained in Part 1 of the CINDY manual (Strenge et al. 1992a)

\section{D.1.2 Bioassay Data Input}

The excretion models used by CINDY are based on daily excretion rates. Because bioassay data are often provided using different formats, protocols for automatically manipulating data to give total daily bioassay values are incorporated into CINDY. The user must be aware of these protocols, otherwise biased conclusions can be reached by unanticipated, unrecognized, or unintended data adjustment. Table D.1 contains the CINDY bioassay data normalization protocols.

PNNL-MA-860 Appendix D

Page D.2
Issued for implementation effective 01/01/2010

Supersedes: September 30, 2000 
Table Error! No text of specified style in document..1. CINDY Normalization Protocols for Bioassay Data

\begin{tabular}{|c|c|c|c|}
\hline Input Data & $\begin{array}{c}\text { Sample } \\
\text { Period }\end{array}$ & $\begin{array}{l}\text { Sample } \\
\text { Volume }\end{array}$ & Manipulation for Daily Result Used in Curve Fitting \\
\hline Total activity units & $\begin{array}{l}\text { Unknown } \\
\text { (no input) }\end{array}$ & $\begin{array}{l}\text { Unknown } \\
\text { (no input) }\end{array}$ & $\begin{array}{l}\text { Sample is assumed to be 1-day excretion. No data } \\
\text { normalization. }\end{array}$ \\
\hline Total activity units & $\begin{array}{l}\text { Known } \\
\text { (input) }\end{array}$ & $\begin{array}{l}\text { Unknown } \\
\text { (no input) }\end{array}$ & Sample is normalized to 24-hour period. \\
\hline Total activity units & $\begin{array}{l}\text { Unknown } \\
\text { (no input) }\end{array}$ & $\begin{array}{l}\text { Known } \\
\text { (input) }\end{array}$ & Sample is normalized using reference daily volume. \\
\hline Total activity units & $\begin{array}{l}\text { Known } \\
\text { (input) }\end{array}$ & $\begin{array}{l}\text { Known } \\
\text { (input) }\end{array}$ & $\begin{array}{l}\text { Sample is normalized to } 24 \text {-hour period. Volume } \\
\text { ignored. }\end{array}$ \\
\hline Concentration units & $\begin{array}{l}\text { Unknown } \\
\text { (no input) }\end{array}$ & $\begin{array}{l}\text { Unknown } \\
\text { (no input) }\end{array}$ & $\begin{array}{l}\text { Concentration assumed for } 1 \text { day and daily result } \\
\text { calculated based on reference daily volume. }\end{array}$ \\
\hline Concentration units & $\begin{array}{l}\text { Known } \\
\text { (input) }\end{array}$ & $\begin{array}{l}\text { Unknown } \\
\text { (no input) }\end{array}$ & $\begin{array}{l}\text { Daily result is calculated based on reference daily } \\
\text { volume. Period ignored. }\end{array}$ \\
\hline Concentration units & $\begin{array}{l}\text { Unknown } \\
\text { (no input) }\end{array}$ & $\begin{array}{l}\text { Known } \\
\text { (input) }\end{array}$ & $\begin{array}{l}\text { Concentration assumed for } 1 \text { day and daily result } \\
\text { calculated based on reference daily volume. }\end{array}$ \\
\hline Concentration units & $\begin{array}{l}\text { Known } \\
\text { (input) }\end{array}$ & $\begin{array}{l}\text { Known } \\
\text { (input) }\end{array}$ & $\begin{array}{l}\text { Concentration multiplied by volume and normalized } \\
\text { by period to give daily result. }\end{array}$ \\
\hline
\end{tabular}

On the other hand, bioassay projection values, based on user-input intake values, are provided as instantaneous rates, so for the first few days after an intake, CINDY-generated excretion rates will not be exactly representative of total 24-hour excretion.

\section{D.1.3 Intake Assessment Curve-Fitting Routines}

Four methods for intake assessment by curve-fitting of bioassay data are included in CINDY. All are based on assumptions about the variance of the measurement value. Brief descriptions of the techniques are given below.

The unweighted least-squares (or uniform weighting) method assumes that weighting factors are constant and equal, implying that the variance is independent of the measurement magnitudes. This method is appropriate if all measured values are believed to have similar accuracy and are significantly above the detection limits of the measurement method.

The ratio of the means (or weighted least-squares) method assumes that data point weighting factors are inversely proportional to the expected value, implying that the variance is proportional to the magnitude of the expected value. This method avoids having the calculation dominated by a few large data points that may have poor precision.

The average of the slopes method assumes data point weighting factors are inversely proportional to the square of the expected value, implying that the variance is proportional to the square of the expected 
value. This method is appropriate when the variance is due primarily to biological factors rather than the detection precision of the measurement.

CINDY also has a user-defined weighting method in which the user supplies the estimate of variance for each measurement value. The weighting factors are calculated by CINDY as the inverse of the supplied variance.

\section{D.1.4 Dose Calculation}

CINDY calculates organ and tissue doses by determining the number of radionuclide transformations in a source organ or tissue over the time frame of interest (i.e., the time-integrated activity) and multiplying it by the specific effective energy (SEE) factor for the appropriate source-to-target combination contained in the code library. The library SEE factors were obtained from the Oak Ridge National Laboratory modeling group that developed them for ICRP 30.

\section{D.1.5 Acceptance Testing by the HIDP}

Prior to its initial adoption at Hanford in 1991, the CINDY code underwent extensive testing and benchmarking by the HIDP. It was compared with the standard Hanford code then being used (GENMOD) and was found to be in reasonable agreement. The 1995 revision to CINDY (Version 1.4) also underwent HIDP testing prior to acceptance.

\section{D.1.6 HIDP User Experience with CINDY}

After 16 years of using CINDY, the HIDP has identified a number of caveats and recommendations for its use. Among them are the following:

- Don’t mix intake units for different radionuclides in the same calculation. All units have to be the same.

- CINDY automatically uses three types of curve-fitting routines to determine intake from bioassay data, and it allows for the user to insert a fourth method. Experience has not shown that any one method is always best. The user should carefully review the plot of the various fits to the actual data before choosing an intake value. An average intake value may be acceptable if none of the fits appears to be the best choice. The intake assessment mode data-plotting routine plots only those data used in a "connect-the-dots" straight-line approach. The bioassay projection mode shows the actual retention pattern, but does not show the bioassay data points themselves.

- Using the user-defined inverse variance method for curve-fitting can result in the greatest weight being given to data that show no detectable activity, even though bracketed by data showing detectable activity. Caution is needed no matter which curve-fitting scheme is used.

- The end time for a chronic intake cannot be given as 12/31/xxxx 24:00 or as 01/01/xxxx 00:00 (the exact end or start of a year). The end time must be offset by at least one minute if the end time is the actual end of the year. Otherwise, the year of the specified end time will not be reported in the calendar year results and a 2-year period will be used in its place.

PNNL-MA-860 Appendix D

Page D.4
Issued for implementation effective 01/01/2010

Supersedes: September 30, 2000 
- The maximum number of report times allowed for a calculation is 70 (69 for continuous intakes). More data may be inputted, but some must then be flagged to reduce the total number of data points used in any given calculation to 70 .

- In the bioassay projection mode, including a report time of "0" can eliminate reporting of some organs that might be of interest (e.g., thyroid retention for iodines, bone surface for uranium, plutonium). If retention for a time immediately post intake is needed, 0.1 or 0.01 day can be used and will provide results for the full scope of organs and tissues included in the nuclide library.

- Bioassay projections for accumulated excretion values for early times post intake can be obtained by running the bioassay projection mode using increments of 0.1 day for the first few days of interest and summing the resulting instantaneous excretion rates over the period of interest.

- For tritium, the inhalation intake mode automatically factors in a skin absorption component equal to $50 \%$ of the inhalation. Thus, the total uptake from an inhalation is 1.5 times the inhalation intake.

- When two uranium isotopes are flagged as isotopes of concern, the intake assessment mode calculates the intake of the first correctly, but not the second. Run the uranium isotopes separately in the intake assessment mode.

- Ingrowth of ${ }^{241} \mathrm{Am}$ from ${ }^{241} \mathrm{Pu}$ is not accounted for in the intake assessment mode. Don't use longterm ${ }^{241} \mathrm{Am}$ in the lung to determine plutonium intakes if ${ }^{241} \mathrm{Am}$ ingrowth is a potential concern. Ingrowth is appropriately addressed in the bioassay projection mode.

- The error tolerance setting should be 1E-06 or 1E-07 when performing analyses using the Jones or Durbin excretion models. Instabilities can occur in the intake assessment or bioassay projection modes using the Jones or Durbin excretion models, usually at times following intake on the order of 1,000 to 10,000 days. The instabilities are easily observed in the display graphic results to screen mode. If instabilities are observed, rerun the case with a different error tolerance. Generally 1E-06 will provide acceptable results; be cautious of $1 \mathrm{E}-08$.

\section{D.2 AMERIN}

The AMERIN code is used for calculating the biological half-life and ingrowth for mixtures of ${ }^{241} \mathrm{Am}$ and ${ }^{241} \mathrm{Pu}$. The code is executable on a PC from a WINDOWS environment. It can calculate the biological clearance half-time from a single compartment using ${ }^{241} \mathrm{Pu}$ and ${ }^{241} \mathrm{Am}$ activities, or alternatively, calculate the activity of ${ }^{241} \mathrm{Am}$ at various times after intake when the biological half-time is given. The code was developed by the HIDP for use primarily with in vivo measurement data.

\section{D.3 PU.EXE}

PU.EXE is a plutonium utility developed at Hanford to calculate information about mixtures of plutonium isotopes. The HIDP uses it to show the isotopic composition of plutonium mixtures by weight, total mass, and total activity, and then age those mixtures and recompute the compositions. Heat generation rates, neutron production rates, and an inhalation dose factor are included in the utility but are not used by the HIDP. The utility was developed by Paul Rittmann, based on his earlier work (Rittmann 1984). 


\section{D.4 IMBA}

The HIDP has selected IMBA Professional Plus ${ }^{1}$ (IMBA) as the computer code for implementing the June 8, 2007 revision to Title 10 of the Code of Federal Regulations Part 835 (10 CFR 835). The name is derived from "Integrated Modules for Bioassay Analysis," a code developed by the United Kingdom Health Protection Agency to implement the ICRP 60 (1990) system of internal dosimetry, including the ICRP 66 (1994) Human Respiratory Tract Model, and advanced recycling biokinetic models. The U.S. Department of Energy provided funding to develop IMBA Expert USDOE Edition, specifically for DOE sites. That version included features for determining internal dose based on both ICRP 30 (1979) and ICRP 60 systems of dosimetry. In 2006, DOE advised its contractors that IMBA Expert USDOE Edition would be transitioned to IMBA Professional Plus, and the DOE Edition would no longer be supported. Hanford procured IMBA Professional Plus and the code is being used to revise the internal dosimetry technical basis documents to the advanced models and revised 10 CFR 835 methodology. Once fully implemented, IMBA will replace CINDY for routine internal dosimetry.

The HIDP program manager should be contacted for specific information regarding the status of IMBA implementation, including schedule, software quality assurance, procedure for use, and acceptance documents.

\section{D.5 References}

10 CFR 835. 2007. “Occupation Radiation Protection.” Code of Federal Regulations. U.S. Department of Energy. Available at: http://www.access.gpo.gov

International Commission on Radiological Protection (ICRP). 1994. "Human Respiratory Tract Model for Radiological Protection.” ICRP Publication 66, Annals of the ICRP, 24:1-3, Pergamon Press, New York.

International Commission on Radiological Protection (ICRP). 1990. "1990 Recommendations of the International Commission on Radiological Protection.” ICRP Publication 60, Annals of the ICRP, 21:1-3, Pergamon Press, New York.

International Commission on Radiological Protection (ICRP). 1979. "Limits for Intakes of Radionuclides by Workers.” ICRP Publication 30, Part 1, Annals of the ICRP, 2:3-4, Pergamon Press, New York.

Strenge DL, RA Kennedy, MJ Sula, and JR Johnson. 1992a. Code for Internal Dosimetry (CINDY Version 1.2) Part 1: Conceptual Representation. PNL-7493 Pt. 1, Rev. 1, Pacific Northwest Laboratory, Richland, Washington.

Strenge DL, RA Kennedy, MJ Sula, and JR Johnson. 1992b. Code for Internal Dosimetry (CINDY Version 1.2) Part 2: Users' Guide. PNL-7493 Pt. 2, Rev. 1, Pacific Northwest Laboratory, Richland, Washington.

\footnotetext{
${ }^{1}$ IMBA Professional Plus, which includes the current version of the user manual, is available from Health Protection Agency (HPA), Radiation Protection Division, Chilton, Didicot, Oxon., OX11 ORQ UK and from http://www.imbaprofessional.com/
}

PNNL-MA-860 Appendix D

Page D.6
Issued for implementation effective 01/01/2010

Supersedes: September 30, 2000 
Rittmann PD. 1984. Seven Health Physics Calculator Programs for the HP-41CV. RHO-HS-ST-5P, Rockwell Hanford Operations, Richland, Washington.

U.S. Department of Energy (DOE). 1988. Radiation Protection for Occupational Workers. DOE 5480.11, Washington, D.C. 


\section{Methods and Models of the Hanford Internal Dosimetry Program \\ PNNL-MA-860}

\section{Appendix E - Mixture and Tracer Radionuclides}

Issued for implementation effective 01/01/2010

Supersedes: September 30, 2000

\section{Use Category: Not applicable}

\section{Approval Signatures:}

Prepared by:

Approved by:

\section{Reviewer Signatures:}

Reviewed by:

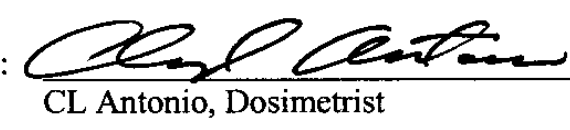

Approved by the Hanford Personnel Dosimetry Advisory Committee as recorded in the meeting minutes of March 10, 2009. 


\section{Contents}

Appendix E - Mixture and Tracer Radionuclides................................................................. E.1

E.1 Cesium-137 and Strontium-90 Mixtures .......................................................................... E.1

E.2 Cesium-137 and Plutonium Mixtures............................................................................... E.2

E.3 Strontium-90 and Plutonium Mixtures................................................................... E.6

\section{Figures}

E.1 Bioassay Capability Comparison for ${ }^{137} \mathrm{Cs}:{ }^{90} \mathrm{Sr}$ Mixtures Based on Preview Whole Body Count and ${ }^{90} \mathrm{Sr}$ Urinalysis

E.2 Bioassay Capability Comparison for ${ }^{137} \mathrm{Cs}:{ }^{90} \mathrm{Sr}$ Mixtures Based on Coaxial Whole Body Count and ${ }^{90} \mathrm{Sr}$ Urinalysis

E.3 Bioassay Capability Comparison for ${ }^{137} \mathrm{Cs}:{ }^{239} \mathrm{Pu}$ Mixtures Based on Preview Whole Body Count and ${ }^{239} \mathrm{Pu}$ Urinalysis

E.4 Bioassay Capability Comparison for ${ }^{137} \mathrm{Cs}:{ }^{239} \mathrm{Pu}$ Mixtures Based on Coaxial Whole Body Count and ${ }^{239} \mathrm{Pu}$ Urinalysis

E.5 Bioassay Capability Comparison for ${ }^{90} \mathrm{Sr}:{ }^{239} \mathrm{Pu}$ Mixtures Based on ${ }^{90} \mathrm{~S}$ Urinalysis and ${ }^{239} \mathrm{Pu}$ Urinalysis.

\section{Tables}

E.1 Minimum Detectable Dose, E(50) in mrem, for Mixtures of ${ }^{137} \mathrm{Cs}$ and ${ }^{90} \mathrm{Sr}$ Based on Tracer Nuclide Bioassay

E.2 Minimum Detectable Dose $E(50)$ in mrem for Mixtures of ${ }^{137} \mathrm{Cs}$ and ${ }^{239} \mathrm{Pu}$ Based on Tracer Nuclide Bioassay

E.3 Minimum Detectable Dose, E(50) in mrem, for Mixtures of ${ }^{90} \mathrm{Sr}$ and ${ }^{239} \mathrm{Pu}$ Based on Tracer Nuclide Bioassay 


\section{Appendix E}

\section{Mixtures and Tracer Radionuclides}

Mixtures of radionuclides at Hanford can be found in reactor facilities, former processing facilities, waste management facilities, and laboratories. The radionuclides most commonly encountered in mixtures include ${ }^{137} \mathrm{Cs},{ }^{90} \mathrm{Sr}$, and plutonium, although others are also possible. This appendix discusses the bioassay capability for mixtures of ${ }^{137} \mathrm{Cs}$ and ${ }^{90} \mathrm{Sr},{ }^{137} \mathrm{Cs}$ and plutonium, and ${ }^{90} \mathrm{Sr}$ and plutonium.

Where the composition of a mixture can be well-characterized, (e.g., a potential intake identified at the time by field indicators), then bioassay for a tracer radionuclide may provide optimum monitoring capability, with determination of nuclides not detectable by bioassay inferred by ratio using intake characterization information, such as a representative nasal or surface smear or an air sample. Depending upon the isotope ratios in the mixture, the tracer radionuclide may be important from a bioassay perspective, but may not be a dominant contributor to internal dose.

Bioassay for a tracer radionuclide can provide a reasonable indicator of potential intake as a costeffective alternative to multiple bioassays when the mixture is well-characterized. However, detection of the tracer radionuclide as a high routine measurement can lead to complicated assessments. For high routine bioassay measurements, there may not be any obvious specific material to which a worker was exposed. For many years an assumption of a $1: 1{ }^{137} \mathrm{Cs}:{ }^{90} \mathrm{Sr}$ activity ratio was used as a fission product mixture; however, the wide range of waste management practices that have occurred at Hanford do not provide assurance that the 1:1 ratio is valid. Thus, where one nuclide is used as an indicator for others, detection of that nuclide by routine measurement is most appropriately used as a trigger for supplemental bioassay for other, potentially significant, radionuclides. Once the bioassay analyses have been completed, intakes are confirmed only for those nuclides detected or those that can confidently be inferred from tracer nuclide detection and knowledge of the workplace mixture.

Bioassay capability (in terms of minimum detectable doses) has been evaluated for combinations of ${ }^{137} \mathrm{Cs}$ and ${ }^{90} \mathrm{Sr},{ }^{137} \mathrm{Cs}$ and plutonium, and ${ }^{90} \mathrm{Sr}$ and plutonium. For convenience, it is considered irrelevant as to whether the plutonium is ${ }^{239} \mathrm{Pu},{ }^{238} \mathrm{Pu}$, Pu-alpha, or ${ }^{241} \mathrm{Am}$, because the dose coefficients are reasonably close. The dose coefficients and retention fractions used for these analyses are taken from the chapters of this manual that address the specific radioisotopes.

\section{E.1 Cesium-137 and Strontium-90 Mixtures}

Mixtures of ${ }^{137} \mathrm{Cs}$ and ${ }^{90} \mathrm{Sr}$ are particularly common in waste management facilities and are especially prevalent in the 200 Area tank farms. It is assumed that both nuclides are absorption Type F (for fast rate of solubilization). Table E.1 and Figure E.1 show the minimum detectable doses associated with a preview whole body count and a ${ }^{90} \mathrm{Sr}$ urinalysis for several mixtures of ${ }^{137} \mathrm{Cs}$ and ${ }^{90} \mathrm{Sr}$. Collectively, these show that an annual whole body count using the sodium iodide preview counter meets the 100-mrem bioassay goal for minimum detectable committed effective dose for mixtures having ${ }^{137} \mathrm{Cs}:{ }^{90} \mathrm{Sr}$ activity ratios of up to approximately 1:30. Use of the germanium coaxial counter improves the ratio to about 1:40 for meeting the 100-mrem bioassay goal, as shown in Table E.1 and Figure E.2. The likelihood of 
potential exposure to a mixture having more ${ }^{90} \mathrm{Sr}$ than a nominal 1:30 activity ratio suggests that a worker on a periodic annual whole body count schedule should be considered for supplemental or periodic radiostrontium urinalysis.

Table Error! No text of specified style in document..1. Minimum Detectable Dose, $E(50)$ in mrem, for Mixtures ${ }^{(a)}$ of ${ }^{137} \mathrm{Cs}$ and ${ }^{90} \mathrm{Sr}$ Based on Tracer Nuclide Bioassay

\begin{tabular}{|c|c|c|c|c|c|c|c|c|c|}
\hline \multirow{2}{*}{$\begin{array}{l}\text { Days Post } \\
\text { Intake }\end{array}$} & Preview $^{(\mathrm{b})}$ & $\operatorname{Coax}^{(\mathrm{c})}$ & Urine $^{(\mathrm{d})}$ & Preview $^{(\mathrm{b})}$ & $\operatorname{Coax}^{(\mathrm{c})}$ & Urine $^{(\mathrm{d})}$ & Preview $^{(\mathrm{b})}$ & $\operatorname{Coax}^{(\mathrm{c})}$ & Urine $^{(\mathrm{d})}$ \\
\hline & \multicolumn{3}{|c|}{ 1:1 Cs:Sr } & \multicolumn{3}{|c|}{ 1:10 Cs:Sr } & \multicolumn{3}{|c|}{ 1:30 Cs:Sr } \\
\hline 1 & 0.30 & 0.23 & 0.01 & 2.5 & 1.9 & 0.01 & 7.4 & 5.7 & 0.01 \\
\hline 2 & 0.35 & 0.27 & 0.03 & 2.9 & 2.3 & 0.02 & 8.7 & 6.7 & 0.02 \\
\hline 7 & 0.42 & 0.33 & 0.10 & 3.5 & 2.7 & 0.08 & 10 & 8.0 & 0.08 \\
\hline 14 & 0.45 & 0.34 & 0.22 & 3.7 & 2.9 & 0.18 & 11 & 8.5 & 0.18 \\
\hline 30 & 0.50 & 0.38 & 0.64 & 4.2 & 3.2 & 0.54 & 12 & 9.5 & 0.53 \\
\hline 60 & 0.60 & 0.46 & 2.8 & 5.0 & 3.9 & 2.4 & 15 & 11 & 2.3 \\
\hline 90 & 0.73 & 0.56 & 5.6 & 6.1 & 4.7 & 4.7 & 18 & 14 & 4.6 \\
\hline 180 & 1.3 & 0.99 & 11 & 11 & 8.3 & 9.2 & 32 & 25 & 9.1 \\
\hline 365 & 4.2 & 3.2 & 29 & 35 & 27 & 25 & 100 & 80 & 24 \\
\hline \multirow[t]{2}{*}{730} & 43 & 33 & 77 & 360 & 280 & 64 & 1,100 & 810 & 63 \\
\hline & \multicolumn{3}{|c|}{ 1:40 Cs:Sr } & \multicolumn{3}{|c|}{ 1:100 Cs:Sr } & \multicolumn{3}{|c|}{ 1:1000 Cs:Sr } \\
\hline 1 & 10 & 7.5 & 0.01 & 24 & 19 & 0.01 & 240 & 190 & 0.01 \\
\hline 2 & 12 & 8.9 & 0.02 & 29 & 22 & 0.02 & 290 & 220 & 0.02 \\
\hline 7 & 14 & 11 & 0.08 & 35 & 27 & 0.08 & 350 & 270 & 0.08 \\
\hline 14 & 15 & 11 & 0.18 & 37 & 28 & 0.18 & 370 & 280 & 0.18 \\
\hline 30 & 16 & 13 & 0.53 & 41 & 31 & 0.53 & 410 & 310 & 0.53 \\
\hline 60 & 20 & 15 & 2.3 & 49 & 38 & 2.3 & 490 & 380 & 2.3 \\
\hline 90 & 24 & 18 & 4.6 & 60 & 46 & 4.6 & 600 & 460 & 4.6 \\
\hline 180 & 43 & 33 & 9.1 & 110 & 81 & 9.0 & 1100 & 810 & 9.0 \\
\hline 365 & 140 & 110 & 24 & 340 & 260 & 24 & 3,400 & 2,600 & 24 \\
\hline 730 & 1,400 & 1100 & 63 & 3,500 & 2,700 & 63 & 35,000 & 27,000 & 63 \\
\hline
\end{tabular}

(a) Assumes acute inhalation of Type F, 5- $\mu$ m-AMAD particles for both ${ }^{137} \mathrm{Cs}$ and ${ }^{90} \mathrm{Sr}$.

(b) Preview count MDA of $1.3 \mathrm{nCi}^{137} \mathrm{Cs}$.

(c) Coax count MDA of $1.0 \mathrm{nCi}{ }^{137} \mathrm{Cs}$.

(d) ${ }^{90} \mathrm{Sr}$ urinalysis MDA of $10 \mathrm{dpm} / \mathrm{d}$.

\section{E.2 Cesium-137 and Plutonium Mixtures}

Mixtures of ${ }^{137} \mathrm{Cs}$ and plutonium can be found primarily in facilities associated with spent fuel management and in wastes associated with such buildings. Examples include the spent fuel basins, fuel processing hot cells, and waste tank sludges. By radioactivity, these mixtures are likely to be mostly ${ }^{137} \mathrm{Cs}$, with ${ }^{137} \mathrm{Cs}$ :plutonium ratios ranging from perhaps 1000:1 to 1:1. Until the mid-1990s, little attention was given to trace amounts of plutonium in predominantly fission product contamination. However, recognition of the dosimetric importance of trace plutonium developed with the implementation of the committed dose system and as more detailed facility contamination characterization data became available. Determining whether the plutonium might be Type M (for moderate rate of solubilization) or Type $S$ (for slow) is problematic; if the plutonium contamination resulted from leaching out of fuel or 
residuals from processing of fuel, then a Type $\mathrm{M}$ assumption would be appropriate. If it resulted from corroded, unreprocessed fuel, then a Type S assumption would probably be more appropriate.

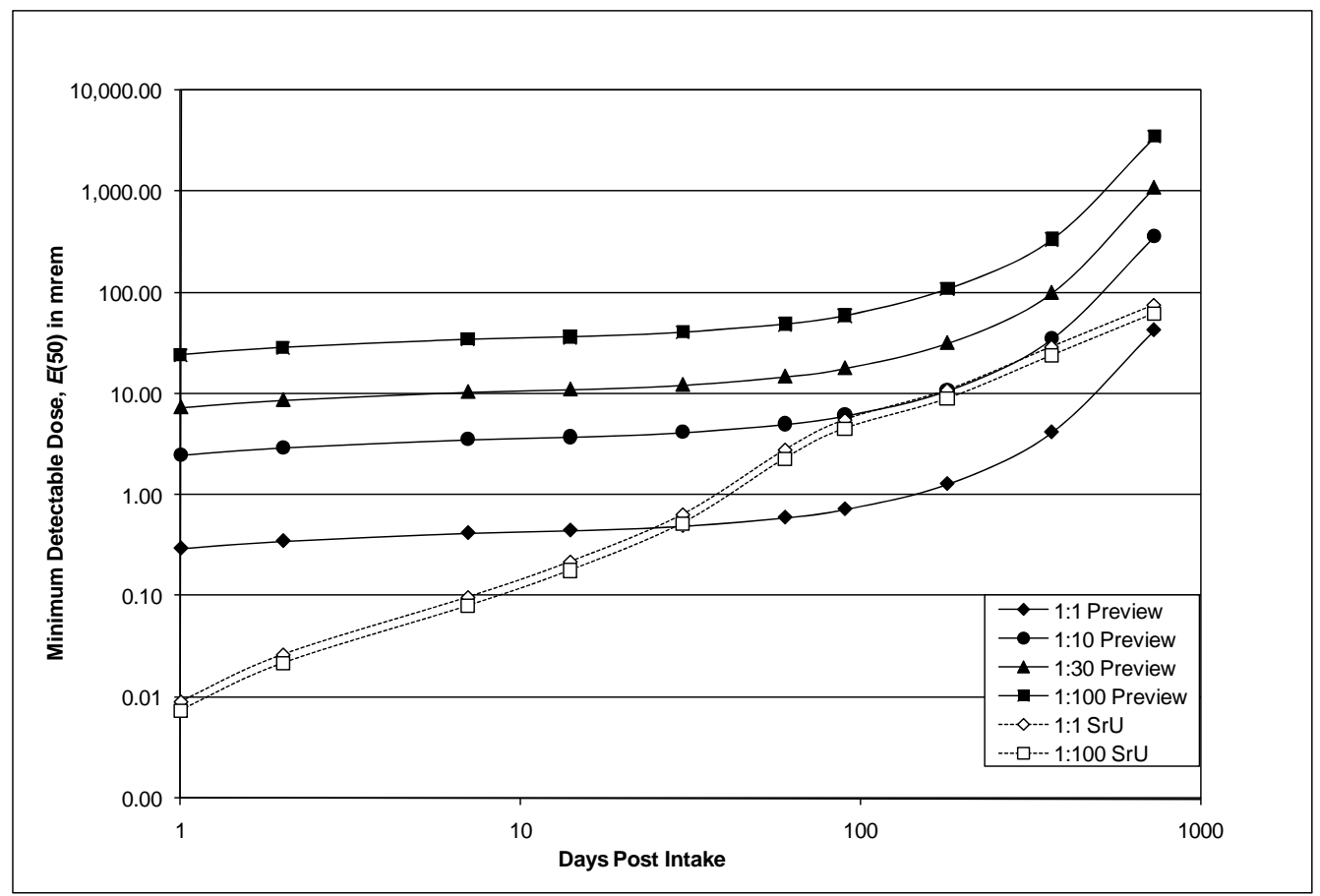

Figure Error! No text of specified style in document..1. Bioassay Capability Comparison for ${ }^{137} \mathrm{Cs}:{ }^{90} \mathrm{Sr}$ Mixtures Based on Preview Whole Body Count and ${ }^{90} \mathrm{Sr}$ Urinalysis (SrU)

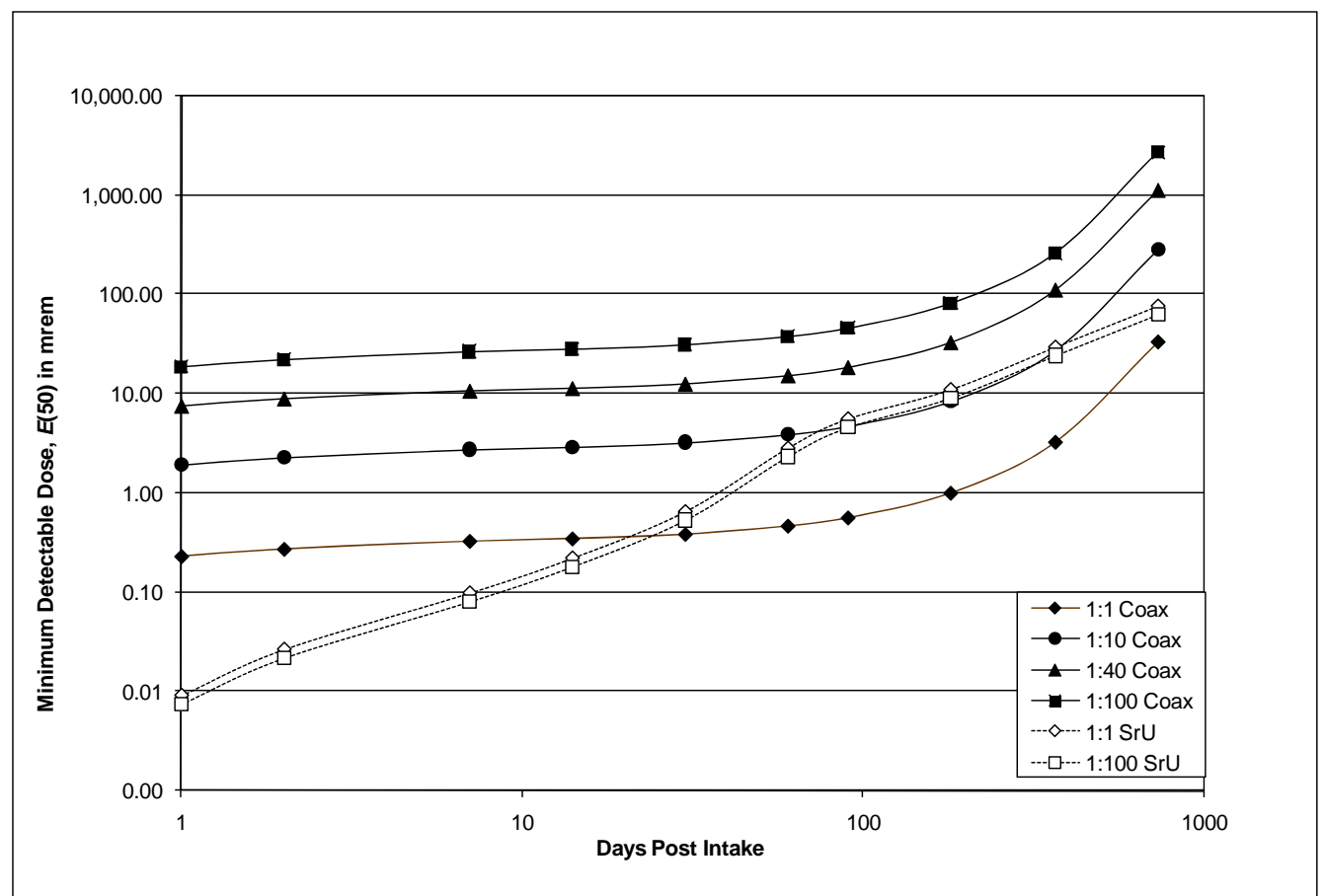

Figure Error! No text of specified style in document..2. Bioassay Capability Comparison for ${ }^{137} \mathrm{Cs}:{ }^{90} \mathrm{Sr}$ Mixtures Based on Coaxial Whole Body Count and ${ }^{90} \mathrm{Sr}$ Urinalysis (SrU) 
Bioassay program capabilities for ${ }^{137} \mathrm{Cs}$ and ${ }^{239} \mathrm{Pu}$ as tracer nuclides for several cesium-plutonium mixtures are listed in Table E.2 and plotted in Figures E.3 and E.4. The source material considered here is assumed to be Type $\mathrm{F}^{137} \mathrm{Cs}$ and Type $\mathrm{M}$ plutonium. This assumption provides a reasonably conservative estimate of minimum detectable dose (MDD) based on a whole body count and the assumed isotopic ratio. Doses associated with plutonium detection by urinalysis would be substantially higher if the plutonium was a Type S form.

Table Error! No text of specified style in document..2. Minimum Detectable Dose $E(50)$ in mrem for Mixtures ${ }^{(a)}$ of ${ }^{137} \mathrm{Cs}$ and ${ }^{239} \mathrm{Pu}$ Based on Tracer Nuclide Bioassay

\begin{tabular}{|c|c|c|c|c|c|c|c|c|c|}
\hline \multirow{2}{*}{$\begin{array}{l}\text { Days Post } \\
\text { Intake }\end{array}$} & Preview $^{(\mathrm{b})}$ & $\operatorname{Coax}^{(\mathrm{c})}$ & Urine $^{(\mathrm{d})}$ & Preview $^{(\mathrm{b})}$ & $\operatorname{Coax}^{(\mathrm{c})}$ & Urine $^{(\mathrm{d})}$ & Preview $^{(\mathrm{b})}$ & $\operatorname{Coax}^{(\mathrm{c})}$ & Urine $\mathrm{e}^{(\mathrm{d})}$ \\
\hline & \multicolumn{3}{|c|}{ 1000:1 Cs:Pu } & \multicolumn{3}{|c|}{ 100:1 Cs:Pu } & \multicolumn{3}{|c|}{ 40:1 Cs:Pu } \\
\hline 1 & 0.32 & 0.24 & 5.6 & 2.7 & 2.1 & 4.8 & 6.6 & 5.1 & 4.7 \\
\hline 2 & 0.37 & 0.29 & 10 & 3.2 & 2.4 & 8.4 & 7.8 & 6.0 & 8.3 \\
\hline 7 & 0.45 & 0.34 & 53 & 3.8 & 2.9 & 45 & 9.4 & 7.2 & 45 \\
\hline 14 & 0.47 & 0.36 & 110 & 4.0 & 3.1 & 95 & 10 & 7.6 & 94 \\
\hline 30 & 0.53 & 0.40 & 140 & 4.4 & 3.4 & 120 & 11 & 8.5 & 110 \\
\hline 60 & 0.64 & 0.49 & 160 & 5.4 & 4.1 & 140 & 13 & 10 & 130 \\
\hline 90 & 0.77 & 0.59 & 180 & 6.5 & 5.0 & 150 & 16 & 12 & 150 \\
\hline 180 & 1.4 & 1.1 & 240 & 12 & 8.9 & 210 & 29 & 22 & 200 \\
\hline 365 & 4.4 & 3.4 & 340 & 40 & 29 & 290 & 93 & 71 & 280 \\
\hline \multirow[t]{2}{*}{730} & 45 & 35 & 460 & 380 & 290 & 390 & 950 & 730 & 390 \\
\hline & \multicolumn{3}{|c|}{ 30:1 Cs:Pu } & \multicolumn{3}{|c|}{ 10:1 Cs:Pu } & \multicolumn{3}{|c|}{ 1:1 Cs:Pu } \\
\hline 1 & 9 & 7 & 4.7 & 26 & 20 & 4.7 & 260 & 200 & 4.7 \\
\hline 2 & 10 & 8 & 8.3 & 31 & 24 & 8.3 & 310 & 240 & 8.3 \\
\hline 7 & 12 & 10 & 45 & 37 & 29 & 44 & 370 & 290 & 44 \\
\hline 14 & 13 & 10 & 94 & 39 & 30 & 93 & 390 & 300 & 93 \\
\hline 30 & 15 & 11 & 110 & 44 & 34 & 110 & 440 & 340 & 110 \\
\hline 60 & 18 & 14 & 130 & 53 & 41 & 130 & 530 & 400 & 130 \\
\hline 90 & 21 & 16 & 150 & 64 & 49 & 150 & 640 & 490 & 150 \\
\hline 180 & 38 & 29 & 200 & 110 & 87 & 200 & 1100 & 870 & 200 \\
\hline 365 & 120 & 95 & 280 & 370 & 280 & 280 & 3700 & 2800 & 280 \\
\hline 730 & 1300 & 970 & 390 & 3800 & 2900 & 380 & 38,000 & 29,000 & 380 \\
\hline
\end{tabular}

(a) Assumes acute inhalation of Type F, 5- $\mu \mathrm{m}$-AMAD particles for ${ }^{137} \mathrm{Cs}$ and Type $\mathrm{M}$ for ${ }^{239} \mathrm{Pu}$.

(b) Preview count MDA of $1.3 \mathrm{nCi}^{137} \mathrm{Cs}$.

(c) Coax count MDA of $1.0 \mathrm{nCi}{ }^{137} \mathrm{Cs}$.

(d) ${ }^{239} \mathrm{Pu}$ urinalysis MDA of $0.02 \mathrm{dpm} / \mathrm{d}$.

Based on the data presented, an annual whole body count using the preview counter is capable of meeting the 100-mrem bioassay goal for mixtures greater than about a 40:1 ratio of ${ }^{137} \mathrm{Cs}$ :plutonium. Using the coaxial counter allows reduction to approximately 30:1. If the potential exists for exposure to material with ${ }^{137} \mathrm{Cs}$ :plutonium ratios lower than about 30:1, then the worker should be considered for routine plutonium bioassay as might be performed for a pure plutonium source. 


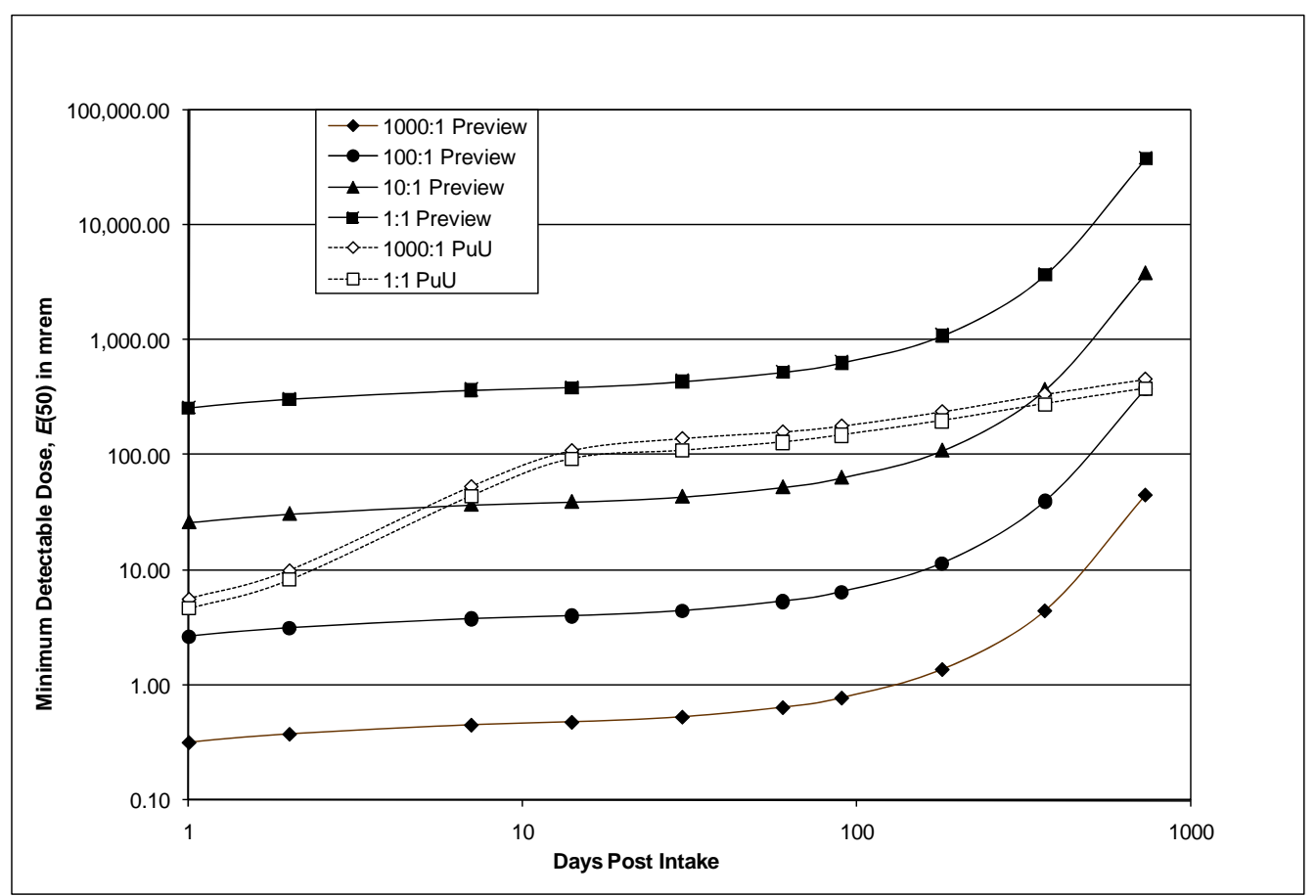

Figure Error! No text of specified style in document..3. Bioassay Capability Comparison for ${ }^{137} \mathrm{Cs}:{ }^{239} \mathrm{Pu}$ Mixtures Based on Preview Whole Body Count and ${ }^{239} \mathrm{Pu}$ Urinalysis (PuU)

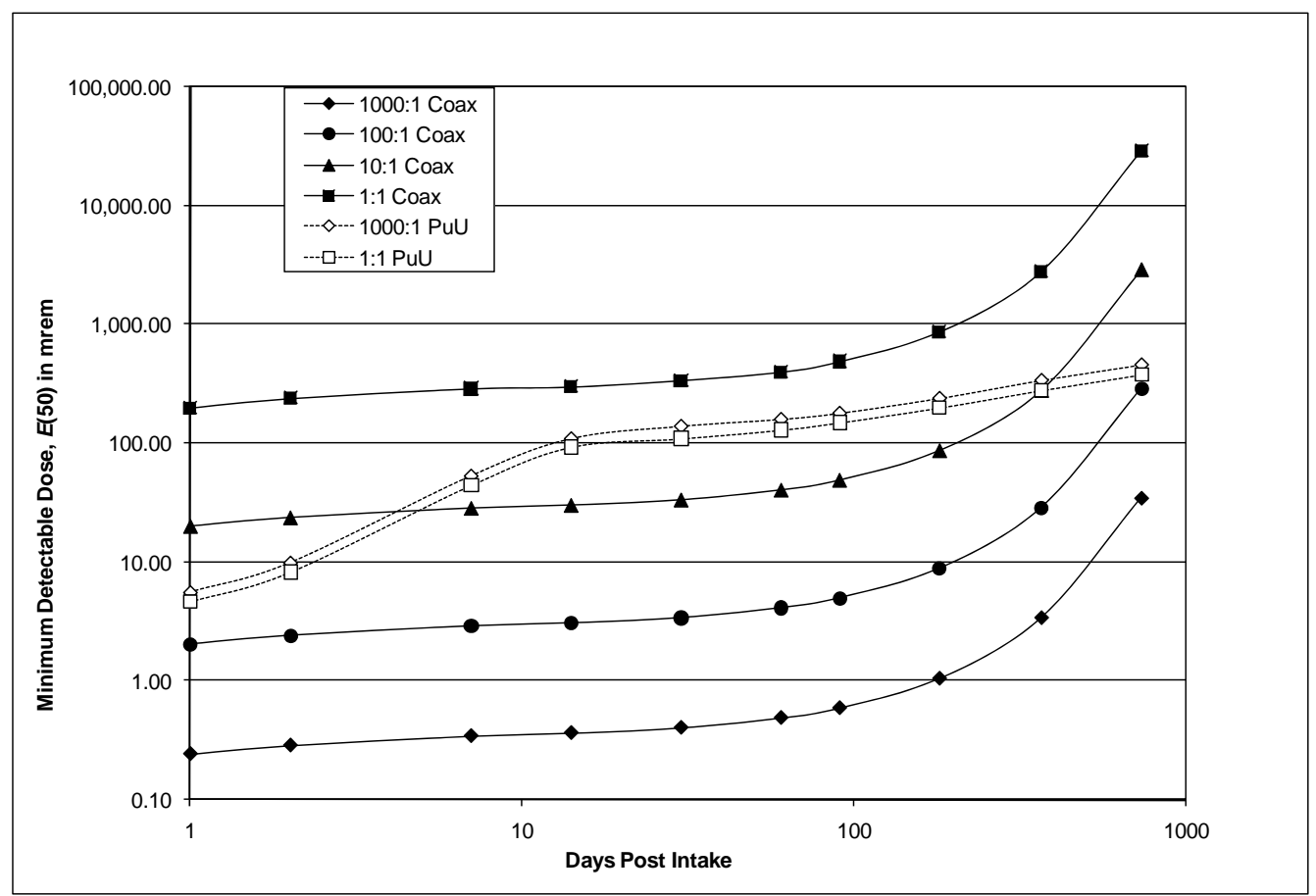

Figure Error! No text of specified style in document..4. Bioassay Capability Comparison for ${ }^{137} \mathrm{Cs}:{ }^{239} \mathrm{Pu}$ Mixtures Based on Coaxial Whole Body Count and ${ }^{239} \mathrm{Pu}$ Urinalysis (PuU) 


\section{E.3 Strontium-90 and Plutonium Mixtures}

Mixtures of ${ }^{90} \mathrm{Sr}$ and plutonium are considered most likely to occur in tank farm facilities, probably associated with contamination originating from waste tank sludges. The ${ }^{90} \mathrm{Sr}$ is assumed to be a Type $\mathrm{F}$ material and the plutonium a Type $\mathrm{M}$ material, consistent with the nitrate nature of most waste tank contents. It is possible that dry plutonium contamination exposed to dry air and a normal building/ outdoor temperature environment could undergo gradual oxidation over long time periods and approach a Type S material. However, the use of Type $\mathrm{M}$ dose coefficients for plutonium provides a conservative approach to the estimations of MDD based on ${ }^{90} \mathrm{Sr}$ as a tracer radionuclide.

Bioassay program capabilities for ${ }^{90} \mathrm{Sr}$ and ${ }^{239} \mathrm{Pu}$ as tracer nuclides for several strontium-plutonium mixtures are listed in Table E.3 and plotted in Figure E.5. The source material considered here is assumed to be Type $\mathrm{F}^{90} \mathrm{Sr}$ and Type $\mathrm{M}$ plutonium. This assumption provides a reasonably conservative estimate of MDD based on radiostrontium urinalysis and the assumed isotopic ratio. Doses associated with plutonium detection by urinalysis would be substantially higher if the plutonium was a Type $S$ form. Based on the data presented, an annual ${ }^{90} \mathrm{Sr}$ urinalysis is capable of meeting the 100-mrem bioassay goal for mixtures down to about a 340:1 ratio of ${ }^{90} \mathrm{Sr}$ :plutonium. The mixture for which an annual ${ }^{90} \mathrm{Sr}$ urinalysis would provide essentially equal MDD capability with an annual plutonium urinalysis for Type M plutonium was calculated to be 93:1, and the MDD was calculated to be 300 mrem. If the potential exists for exposure to material with ${ }^{90}$ Sr:plutonium ratios lower about 100:1, then the worker should be considered for routine plutonium bioassay as might be performed for a pure plutonium source.

Table Error! No text of specified style in document..3. Minimum Detectable Dose, $E(50)$ in mrem, for Mixtures ${ }^{(a)}$ of ${ }^{90} \mathrm{Sr}$ and ${ }^{239} \mathrm{Pu}$ Based on Tracer Nuclide Bioassay

\begin{tabular}{|c|c|c|c|c|c|c|c|c|}
\hline \multirow{2}{*}{$\begin{array}{c}\text { Days Post } \\
\text { Intake }\end{array}$} & \multicolumn{2}{|c|}{$1000: 1^{90} \mathrm{Sr}: \mathrm{Pu}$} & \multicolumn{2}{|c|}{$340: 1{ }^{90} \mathrm{Sr}: \mathrm{Pu}$} & \multicolumn{2}{|c|}{$100: 1^{90} \mathrm{Sr}: \mathrm{Pu}$} & \multicolumn{2}{|c|}{$10: 1^{90} \mathrm{Sr}: \mathrm{Pu}$} \\
\hline & ${ }^{90}$ Sr Urine ${ }^{(b)}$ & ${ }^{239} \mathrm{Pu}$ Urine ${ }^{(\mathrm{c})}$ & ${ }^{90}$ Sr Urine ${ }^{(b)}$ & ${ }^{239} \mathrm{Pu}$ Urine ${ }^{(\mathrm{c})}$ & ${ }^{90}$ Sr Urine ${ }^{(b)}$ & ${ }^{239} \mathrm{Pu}$ Urine ${ }^{(\mathrm{c})}$ & ${ }^{90}$ Sr Urine ${ }^{(b)}$ & ${ }^{239} \mathrm{Pu}$ Urine ${ }^{(\mathrm{c})}$ \\
\hline 1 & 0.02 & 9.0 & 0.03 & 6.1 & 0.09 & 5.1 & 0.80 & 4.7 \\
\hline 2 & 0.04 & 16 & 0.09 & 11 & 0.25 & 9.0 & 2.3 & 8.3 \\
\hline 7 & 0.17 & 86 & 0.33 & 58 & 0.94 & 48 & 8.6 & 45 \\
\hline 14 & 0.37 & 180 & 0.75 & 123 & 2.1 & 102 & 19 & 94 \\
\hline 30 & 1.1 & 220 & 2.2 & 150 & 6.2 & 120 & 57 & 110 \\
\hline 60 & 4.8 & 260 & 10 & 180 & 27 & 150 & 250 & 130 \\
\hline 90 & 9.4 & 290 & 19 & 200 & 53 & 170 & 490 & 150 \\
\hline 180 & 19 & 390 & 37 & 260 & 100 & 220 & 970 & 200 \\
\hline 365 & 50 & 540 & 100 & 370 & 280 & 300 & 2600 & 280 \\
\hline 730 & 130 & 740 & 260 & 500 & 730 & 420 & 6800 & 390 \\
\hline
\end{tabular}

(a) Assumes acute inhalation of Type F, 5- $\mu \mathrm{m}$-AMAD particles for ${ }^{90} \mathrm{Sr}$ and Type M, 5- $\mu \mathrm{m}$ particles for Pu.

(b) ${ }^{90} \mathrm{Sr}$ urinalysis MDA of $10 \mathrm{dpm} / \mathrm{d}$.

(c) ${ }^{239} \mathrm{Pu}$ urinalysis MDA of $0.02 \mathrm{dpm} / \mathrm{d}$.

PNNL-MA-860 Appendix E

Page E.6
Issued for implementation effective 01/01/2010

Supersedes: September 12, 2000 


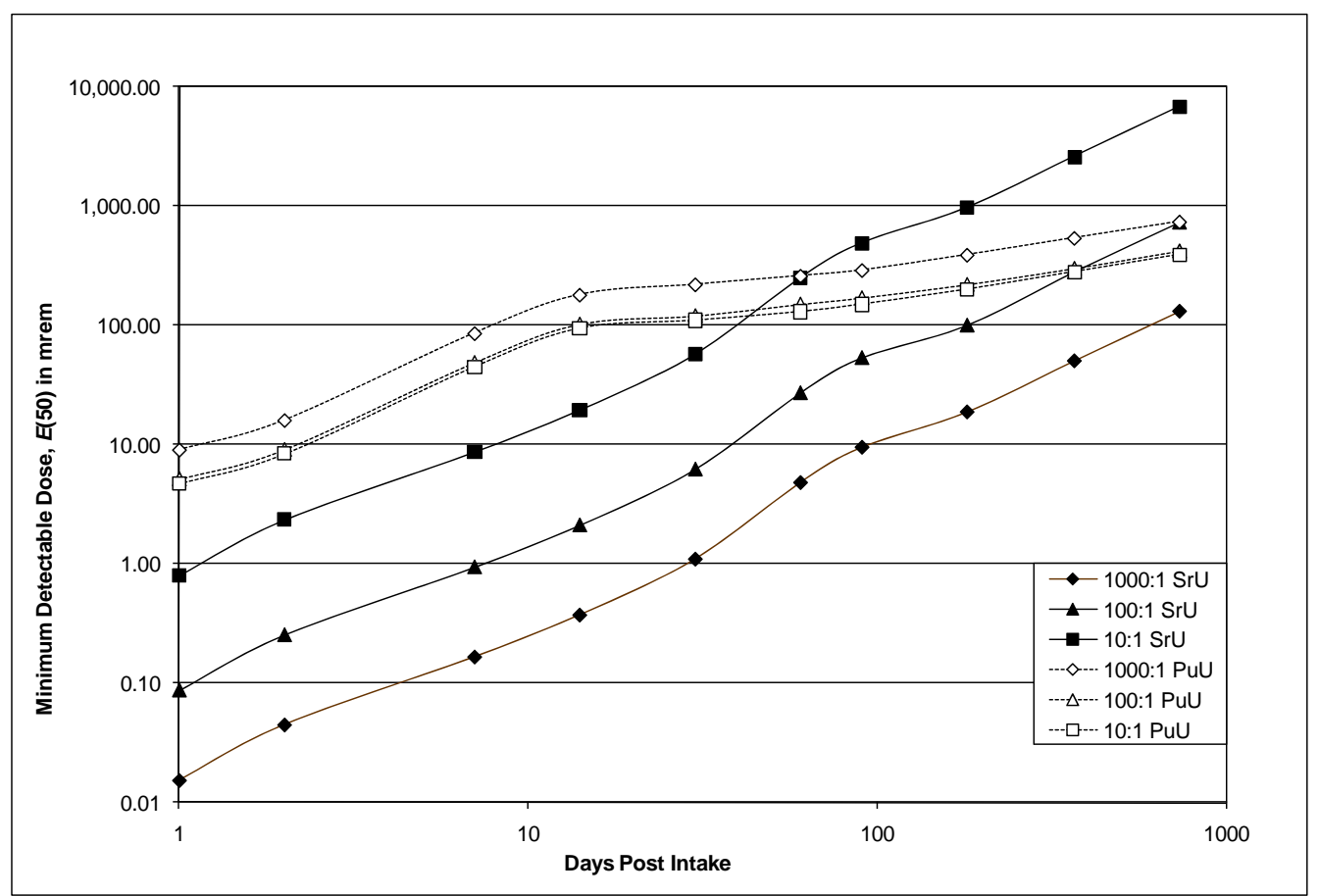

Figure Error! No text of specified style in document..5. Bioassay Capability Comparison for ${ }^{90} \mathrm{Sr}:{ }^{239} \mathrm{Pu}$ Mixtures Based on ${ }^{90} \mathrm{~S}$ Urinalysis (SrU) and ${ }^{239} \mathrm{Pu}$ Urinalysis (PuU) 